United States

Department of

Agriculture

Forest Service

Pacific Southwest Research Station

General Technical

Report PSW-GTR-152

遌

\title{
Ecology and Conservation of the
}

Marbled Murrelet

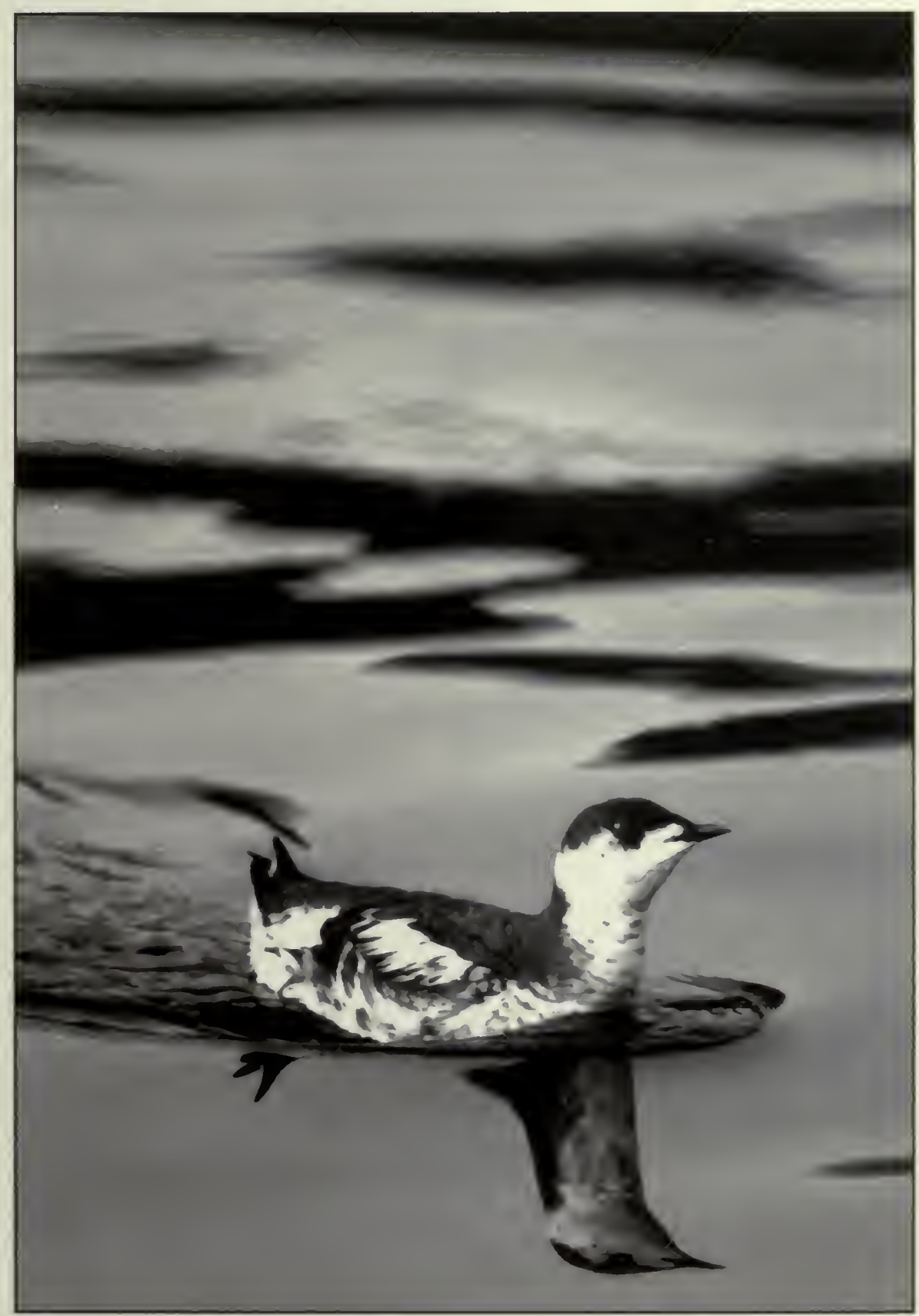




\section{Abstract:}

Ralph, C. John; Hunt, George L., Jr.; Raphael, Martin G.; Piatt, John F., Technical Editors. 1995. Ecology and conservation of the Marbled Murrelet. Gen. Tech. Rep. PSW-GTR-152. Albany, CA: Pacific Southwest Research Station, Forest Service, U.S. Department of Agriculture; 420 p.

This report on the Marbled Murrelet (Brachyramphus marmoratus) was compiled and editied by the interagency Marbled Murrelet Conservation Assessment Core Team. The 37 chapters cover both original studies and literature reviews of many aspects of the species' biology, ecology, and conservation needs. It includes new information on the forest habitat used for nesting, marine distribution, and demographic analyses; and describes past and potential effects of humans on the species' habitats. Future research needs and possible management strategies for both marine and forest habitats are suggested.

Retrieval Termis: Brachyramphus marnoratus, Marbled Murrelet, old-growth forests, habitat use, marine distribution, seabird.

\section{About This Report:}

\section{Technical Editors:}

- C. John Ralph, research wildlife biologist, Pacific Southwest Research Station, USDA Forest Service, 1700 Bayview Drive, Arcata, CA 95521

- George L. Hunt Jr., professor, Department of Ecology and Evolutionary Biology, 321 Steinhus Hall, University of California at Irvine, Irvine, CA 92717

- Martin G. Raphael, chief research wildlife biologist, Pacific Northwest Resesrch Station, USDA Forest Service, 3625-93rd Ave. S.W., Olympia, WA 98512

- John F. Piatt, research biologist, Alaska Science Center, U.S. Department of the Interior, National Biological Service, 1011 East Tudor Road, Anchorage, AK 99503

Cover: Late-winter-plumaged Marbled Murrelet, Auke Bay, Alaska -Photograph by Gus van Vliet

\section{Publisher:}

\section{Pacific Southwest Research Station Albany, California}

(Mailing address: P. O. Box 245, Berkeley, California 94701-0245

Telephone: 510-559-6300)

\section{February 1995}


From the collection of

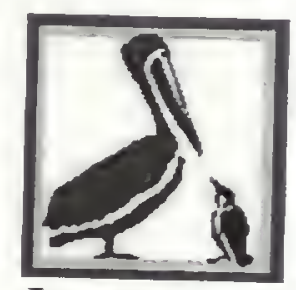

International

Bird Rescue

Research Center

Cordelia, California

in association with

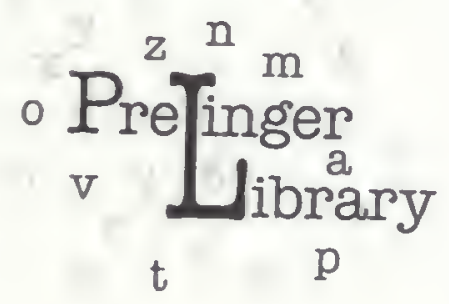

San Francisco, California

2006 


\section{Digitized by the Internet Archive in 2007 with funding from Microsoft Corporation}




\section{Ecology and Conservation of the Marbled Murrelet}

Technical Editors:

C. John Ralph George L. Hunt, Jr. Martin G. Raphael John F. Piatt

\section{Contents}

Preface vi

Part I: Introduction

Chapter 1

Ecology and Conservation of the Marbled Murrelet in North America: An Overview C. John Ralph, George L. Hunt, Jr., Martin G. Raphael, and John F. Piatt

Chapter 2

The Asian Race of the Marbled Murrelet

Nikolai B. Konyukhov and Alexander S. Kitaysky

Part II: Nesting Ecology, Biology, and Behavior

Chapter 3

Comparative Reproductive Ecology of the Auks (Family Alcidae)

with Emphasis on the Marbled Murrelet

Toni L. De Santo and S. Kim Nelson

Chapter 4

Nesting Chronology of the Marbled Murrelet

Thomas E. Hamer and S. Kim Nelson

Chapter 5

Nesting Biology and Behavior of the Marbled Murrelet

S. Kim Nelson and Thomas E. Hamer

Chapter 6

Characteristics of Marbled Murrelet Nest Trees and Nesting Stands Thomas E. Hamer and S. Kim Nelson 


\section{Contents}

Chapter 7

Breeding and Natal Dispersal, Nest Habitat Loss and Implications for

Marbled Murrelet Populations

George J. Divoky and Michael Horton

Chapter 8

Nest Success and the Effects of Predation on Marbled Murrelets

S. Kim Nelson and Thomas E. Hamer

Chapter 9

Molts and Plumages in the Annual Cycle of the Marbled Murrelet

Harry R. Carter and Janet L. Stein

\section{Part III: Terrestrial Environment}

\section{Section 1. Inland Patterns of Activity}

Chapter 10

Marbled Murrelet Inland Patterns of Activity: Defining Detections and Behavior

Peter W.C. Paton

Chapter 11

Patterns of Seasonal Variation of Activity of Marbled Murrelets in Forested Stands

Brian P. O'Donnell, Nancy L. Naslund, and C. John Ralph

Chapter 12

Daily Patterns of Marbled Murrelet Activity at Inland Sites

Nancy L. Naslund and Brian P. O'Donnell

Chapter 13

Interannual Differences in Detections of Marbled Murrelets in

Some Inland California Stands

C. John Ralph

Chapter 14

A Review of the Effects of Station Placement and Observer Bias in Detections of Marbled Murrelets in Forest Stands

Brian P. O'Donnell

\section{Section 2. Inland Habitat Use and Requirements}

Chapter 15

Inland Habitat Suitability for the Marbled Murrelet in Southcentral Alaska

Katherine J. Kuletz, Dennis K. Marks, Nancy L. Naslund, Nike J. Goodson, and Mary B. Cody

Chapter 16

Inland Habitat Associations of Marbled Murrelets in British Columbia

Alan E. Burger 


\section{Contents}

Chapter 17

Inland Habitat Associations of Marbled Murrelets in Western Washington

Thomas E. Hamer

Chapter 18

A Landscape-Level Analysis of Marbled Murrelet Habitat in Western Washington Martin G. Raphael, John A. Young, and Beth M. Galleher

Chapter 19

Marbled Murrelet Habitat Associations in Oregon

Jeffrey J. Grenier and S. Kim Nelson

Chapter 20

Relationship of Marbled Murrelets with Habitat Characteristics

at Inland Sites in California

Sherri L. Miller and C. John Ralph

\section{Part IV: The Marine Environment}

\section{Section 1. Marine Setting}

Chapter 21

Oceanographic Processes and Marine Productivity in Waters Offshore of

Marbled Murrelet Breeding Habitat

George L. Hunt, Jr.

Section 2. Foraging Biology

Chapter 22

Marbled Murrelet Food Habits and Prey Ecology

Esther E. Burkett

Chapter 23

Marbled Murrelet At-Sea and Foraging Behavior

Gary Strachan, Michael McAllister, and C. John Ralph

Chapter 24

Monospecific and Mixed Species Foraging Associations of Marbled Murrelets

George L. Hunt, Jr.

Chapter 25

Pollution and Fishing Threats to Marbled Murrelets

D. Michael Fry

Chapter 26

Mortality of Marbled Murrelets Due to Oil Pollution in North America

Harry R. Carter and Katherine J. Kuletz 


\section{Preface}

The Marbled Murrelet (Brachyramphus marmoratus) has long been regarded as a bird of mystery in the Pacific Northwest because its nesting habits have remained largely unknown to ornithologists, and its nearshore feeding habits made it difficult to survey. This small, dove-sized seabird inhabits coastal areas of North America from Alaska to central California. Throughout most of its range it nests in forests within about 25 to 50 miles of the coast, and feeds in nearshore marine waters on small fish and invertebrates. In contrast to most alcids, which nest colonially on rocky cliffs or relatively barren islands, the Marbled Murrelet nests inland throughout most of its range in solitary pairs (or perhaps loose associations), on the wide, upper branches of old, coniferous trees. This retiring habit delayed the discovery of its nest in North America until 1974, when one was found in central California (Binford and others 1975). Since then, despite many thousands of person-days of effort over the past decade, fewer than 60 nests have been located through the 1993 breeding season (Nelson and Hamer, this volume a).

In the 1980s, field biologists discovered evidence suggesting that many, if not most, individuals nest in unharvested coniferous old-growth forests. Further research, much of it presented for the first time in this volume, has provided additional information on habitat use, on their relatively low reproductive rates, and on the high predation they experience at the nest.

In at least some areas, evidence also began to accumulate that the Marbled Murrelet population has declined in recent years. This decline has been attributed to reduction and fragmentation of old-growth forests, increased predation, pollution (especially oil spills), and mortality from fishing nets. This potential decline heightened management sensitivity to assure the maintenance of healthy interacting populations throughout its range. At present, the murrelet is classified as threatened or endangered by the U.S. Fish and Wildlife Service in Washington, Oregon, and California, as well as by the State of California and the Province of British Columbia. For most land management agencies, these listings require inventories and analyses of potential impacts of proposed projects on the species. If adverse impact on murrelet habitat is found, it may result in mitigation measures, project modification, delays, and possible cancellation.

\section{Issues}

Several issues faced land management agencies in the United States and Canada in 1992 when the effort on this volume began.
Timber harvest-The legal status of the species was beginning to prevent or delay timber harvest activities throughout most of its range on the Pacific Coast of North America. No forest management standards and guidelines to maintain murrelet habitats existed, because documentation of the full range of the species' habitat was unknown.

Survey and monitoring efforts-Surveys to determine the species' presence or absence in forest stands throughout its range required substantial financial and personnel resources. Due to a lack of knowledge of its distribution and abundance, costly efforts often included surveys in areas that were unsuitable or of marginal value to the species.

Other resources-It seemed probable that the species occupied habitats containing large amounts of economically valuable timber.

These stands also functioned as reservoirs of biological diversity, and had great values as watersheds and as sources of a variety of wildlife and fishery resources. While at sea, the bird coexisted with large numbers of commercially important fish, especially salmon, the harvesting of which may result in significant murrelet mortality.

Consolidation of information-It was apparent that a need existed to consolidate available information, and to synthesize knowledge of population trends, distribution, habitat associations, and potential management alternatives. The U.S. Fish and Wildlife Service appointed a Marbled Murrelet Recovery Team early in 1993 to determine the status and mode of recovery of the species. They needed a rapid production of scientific background material for their deliberations.

\section{Goals of the Assessment}

To meet these issues, the USDA Forest Service began a "Marbled Murrelet Conservation Assessment" in late 1992 with the following mandate. The Assessment would consolidate the available information concerning Marbled Murrelet ecology and evaluate current habitat conditions to determine the likelihood of long-term persistence of healthy populations throughout its current range. The Assessment would include monitoring and research recommendations, be a primary source of information for the Recovery Team, and provide information that would enable agencies to make management plans.

This work would be accomplished by the following methods:

1. Identify patterns of habitat use in the forests and marine environments occupied by the murrelet, and develop an understanding of the spatial and temporal dynamics of these habitats and murrelet populations, by using a compilation of existing survey data.

2. Summarize and synthesize existing information from throughout the range about the life history, status, and trends of the murrelet and its utilized habitats, and provide the information gathered to all interested parties. 
3. Identify additional inventory needs and methodology to facilitate statistically meaningful long term monitoring of both the species and its habitats, thus providing the information needed to develop sound strategies to provide for their maintenance and management.

4. Identify additional research needs to fill information gaps preventing a full understanding of Marbled Murrelet ecology.

5. Provide suggestions to improve the compatibility of data bases maintained by various entities.

\section{Organization}

The Assessment effort was organized into a set of working groups as follows:

- Interagency Conservation Assessment Coordinating Group-The intent of this group was to coordinate and provide support to Conservation Assessment activities among the state, provincial, and federal agencies with Marbled Murrelet management responsibilities. These agencies and organizations were invited to participate by the two Group Leaders: Garland N. Mason, Pacific Southwest Research Station, Albany, California; and Hugh Black, Pacific Northwest Region, Portland, Oregon-both with the USDA Forest Service.

- Conservation Assessment Core Team-The Core Team was headed by a Team Leader (C.J. Ralph), provided by the Pacific Southwest Station, and three senior scientists with established expertise in various aspects of ecology who, drawing on the knowledge provided by the Technical Working Group, provided the scientific expertise to formulate the Conservation Assessment. The Team Leader provided the overall technical and administrative leadership for assessment development and ensured good communication between the Coordinating Group, the Core Team, and the Technical Working Group. The scientists in the Core Team became the technical editors of the final volume.

- Conservation Assessment Technical Working Group-This group was open to all persons with knowledge or abilities that could contribute to the formulation of the Conservation Assessment (see Appendix $A$ in this volume), and provided the following functions:

- Collected and provided technical information required by the Working Group.

- Wrote chapters of the Assessment, as appropriate.

- Provided assistance, advice, and input to other members of the Working Group as requested.

- Informed respective agencies, organizations, or regions as to progress and findings of the Conservation Assessment.

- Provided expertise to formulate inter-regional assessments.

- Identified and overcame obstacles to gathering information for the Assessment.
Members of the Working Group included:

- Marbled Murrelet specialists from universities, agencies, private industry, and conservation organizations.

- Regional representatives from USDA Forest Service Regions in Alaska, Washington, Oregon, and California.

- Agency Representatives from three U.S. Department of the Interior agencies - Fish and Wildlife Service, National Biological Service, National Park Serviceand Canadian Wildlife Service, among others.

- Representatives from state and provincial fish and wildlife agencies not represented above.

- Specialists from various disciplines useful to the process of the Assessment.

- Line officers.

Financial assistance was provided by various agencies and organizations, acknowledged in each chapter, and also by the Assessment itself that provided certain members of the Technical Working Group with funds to enable them to analyze their data in a more timely manner than would have been possible in the normal course of events.

\section{Working Environment}

Working sessions of the Core Team and the Working Group were open to all persons interested in the proceedings, with the Team Leader acting as chair.

Working Group members participated fully with the Core Team and participated in all decisions. The Core Team provided direction and strived for consensus among the Team and Group members. Minority reports were possible and encouraged. Wildlife Society standards for authorship were used. In the final stages of compilation of the volume, the technical editors met and reviewed chapters which were then sent to authors for final approval of all contents.

\section{Products}

The primary product of the Assessment is this volume. Each chapter in the volume was reviewed by numerous researchers and biologists in appropriate fields, as well as by the Core Team. In addition, the entire document was reviewed by four persons appointed by the Presidents of learned societies: The Wildlife Society (David Marshall), American Ornithologists Union (Peter Conners), Ecological Society of America (Frank A. Pitelka), and the Cooper Ornithological Society (Douglas Bell).

The report is organized into chapters addressing the various aspects of Marbled Murrelet biology and provide data and analyses. Some general management considerations are offered in the overview chapter, and are intended to 
supplement those offered by the Recovery Team, appointed by the USDI Fish and Wildlife Service.

\section{Acknowledgments}

We express our appreciation to all the reviewers, members of the Technical Working Group, and the authors, who worked so smoothly together to assemble this compendium of knowledge of the murrelet. Behind the scenes, employees of the Pacific Southwest Station's Redwood Sciences Laboratory did the lion's share of the work in first assembling the data, and preparing the manuscripts. Sherri Miller, Deborah Kristen, Ann Buell, Tina Menges, Jennifer Weeks, Brian Cannon, Robin Wachs, Kim Hollinger, Jim Dahl, Brian O'Donnell, and Michelle Kamprath worked tirelessly in the "Murrelet House" in downtown Arcata during 1993 to enable the authors to publish their data. John Young and Beth Galleher, Pacific Northwest Station, USDA Forest Service, Olympia, contributed to GIS data assembly and analysis. Garland
Mason, Mike Lennartz, and Barry Noon were very supportive of the entire effort, and we are grateful to them.

The final manuscripts were edited by technical publications editors B Shimon Schwarzschild, 'Sandra L. Young, and Laurie J. Dunn; and the layouts were designed and produced by visual information specialists Kathryn Stewart and Esther Kerkmann-all of the Pacific Southwest Research Station.

Finally, we acknowledge the herculean effort that Linda Long provided at all stages of the manuscript preparation, as she directed all of us towards producing an excellent product.

We hope that this effort will serve well the bird and the people charged with its management. Most importantly we dedicate this volume to the biologists who have spent so many cold, lonely, but exhilarating hours in pursuit of this sprightly, energetic bird, both on the ocean and in the forest, where it turns into a hurtling, small, dark shadow, as it enters the primeval forest in pursuit of its largely still mysterious habits.

Technical Editors:

\section{John Ralph \\ George L. Hunt, Jr. Martin G. Raphael \\ John F. Piatt}


少

Introduction 


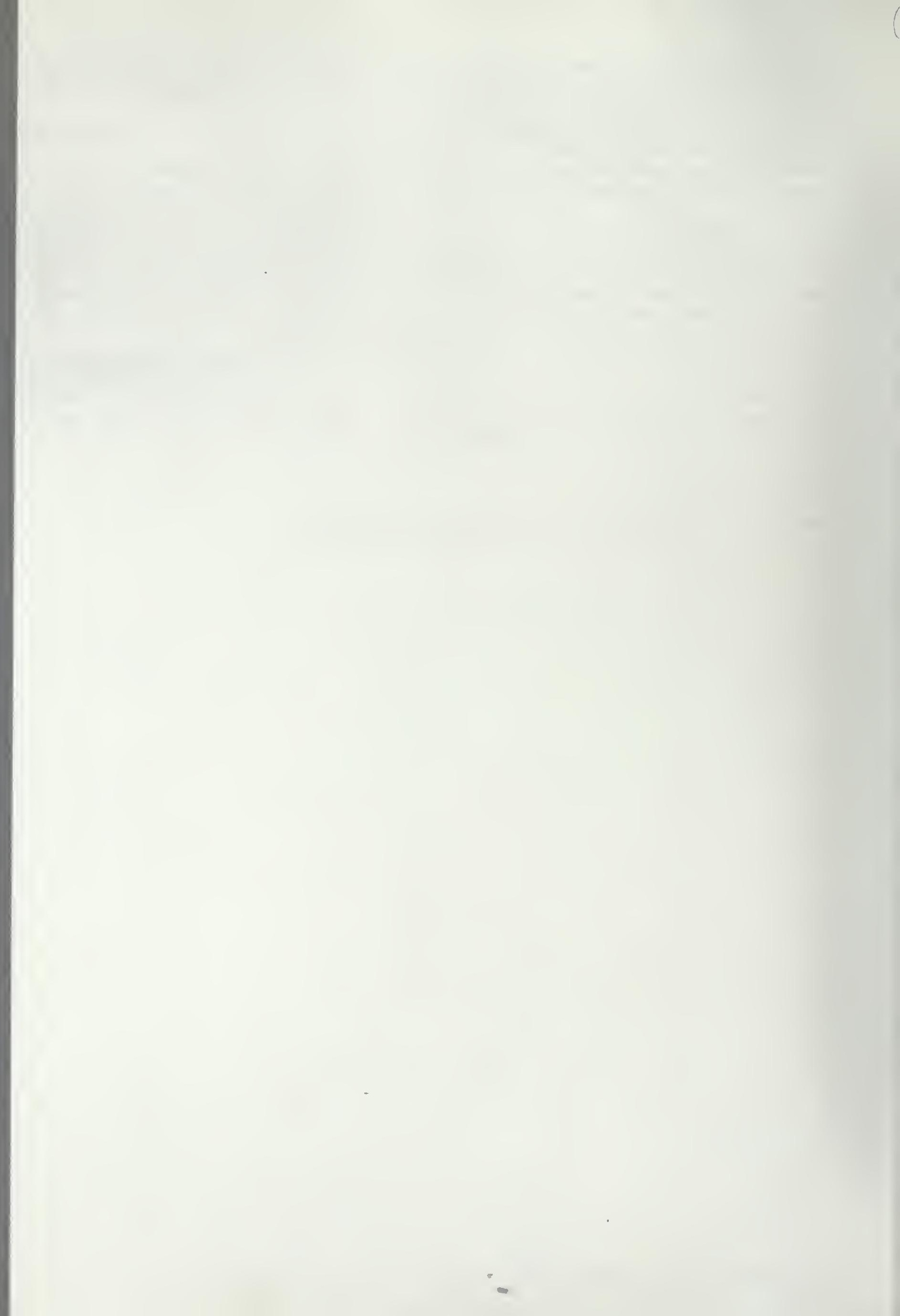




\section{Ecology and Conservation of the Marbled Murrelet in North America: an Overview}

C. John Ralph'

George L. Hunt, Jr. ${ }^{2}$
Martin G. Raphael ${ }^{3}$

John F. Piatte

\begin{abstract}
Over the past decade, the Marbled Murrelet has become a focus of much controversy. It was listed as threatened in Washington, Oregon, and California by the U.S. Fish and Wildlife Service in February I993. In order to aid the various agencies with management, the Marbled Murrelet Conservation Assessment was formed to bring together scientists, managers, and others to gather all the available data on this small seabird. This volume of research is the culmination of that effort. In this chapter, we integrate the results of the investigations and summaries on the past history, present status, and possible future of the species, based on the data presented in this volume and other published research. We also propose what we consider the most important research needs. Then, hased on the findings of this volume, we suggest actions for management to help ensure the survival of the species.
\end{abstract}

The recent decline and fragmentation of Marbled Murrelet (Brachyramphus marmoratus) populations in the southern portion of its range (California, Oregon, and Washington) resulted in an awareness that the species was in need of protection or it risked extirpation. In 1982 and 1986, the Pacific Seabird Group developed a set of resolutions that called attention to the Marbled Murrelet and the threats it faced. The Group requested that the appropriate agencies involved in management decisions consider research about the species. The response from the agencies was muted at best. On January 15, 1988, the National Audubon Society petitioned the U.S. Fish and Wildlife Service to list the California. Oregon, and Washington populations of the species as a threatened species. The Service's 90-day finding stated that the petition had presented substantial information to indicate that the requested action may be warranted. It was published in the Federal Register on October 17, 1988. Because of increased research efforts and the amount of new data available, several public comment periods were opened to receive additional information on the species and the potential threats to it. On the basis of the positive 90-day finding, the Marbled Murrelet was added to the Service's Notice of Review for Vertebrate Wildlife as a Category 2 Species for listing.

\footnotetext{
${ }^{1}$ Research Wildlife Biologist, Pacific Southwest Research Station, USDA Forest Service, Redwood Sciences Labratory, 1700 Bayview Drive, Arcata CA 95521

${ }^{2}$ Professor, Department of Ecology and Evolutionary Biology, University of California, Irvine, CA 92717

${ }^{3}$ Chief Research Wildlife Biologist, Pacific Northwest Research Station. USDA Forest Service, 3625 93rd Ave., Olympia, WA 98512-9193

4 Research Biologist. Alaska Science Center, U.S. Department of the Interior, National Biological Service, $10 t 1$ East Tudor Road, Anchorage, AK 99503
}

In 1990, the Marbled Murrelet was proposed as a threatened species by the British Columbia Ministry of Environment, Lands, and Parks to the Committee on the Status of Endangered Wildlife in Canada. The species was designated as nationally threatened in June 1990. A recovery team was established in September of that year and was unique to Canada because it included representatives of both the federal and provincial governments, the forest industry, environmental non-governmental organizations, and academia. The species was listed as threatened mainly because of loss of nesting habitat, but also because of fishing-net mortality and the threat of oil spills.

In 1991, the State of California listed the species as endangered because of the loss of older forests. On June 20, 1991, the U.S. Fish and Wildlife Service published a proposed rule in the Federal Register to designate it as a threatened species in Washington, Oregon, and California. The main reason for listing was the loss of older forest nesting habitat. Secondary threats included loss due to net fisheries and the potential threat of oil spills. In July 1992, the U.S. Fish and Wildlife Service published another notice in the Federal Register announcing a 6-month extension for determining the status of Marbled Murrelets. However, the Service was taken to court for not meeting the legal time frames provided for in the Endangered Species Act and, in September 1992, published a final rule in the Federal Register, listing the Marbled Murrelet as a threatened species in the three States. A recovery team was established in February 1993 and is now in the final stages of a recovery plan for the three-State area (U.S. Fish and Wildlife Service, in press).

The State of Washington is now reviewing a recommendation to classify the Marbled Murrelet as a threatened species. To date, the Marbled Murrelet has not been recommended for listing in Oregon.

This chapter reviews the results of published research and new investigations presented in this volume, discusses the likely future of the species and its habitat in North America, and outlines the actions considered necessary to maintain viable populations.

\section{Background and Assessment of Available Information}

\section{Distribution and Habitat}

Summary-Marbled Murrelets in North America occur from the Bering Sea to central Califormia. During the breeding season, the majority of murrelets are found offshore of late successional and old-growth forests, located mostly within 60 
$\mathrm{km}$ of the coast. In forests, most nest sites are on large diameter, often moss-covered, limbs. The small, relict populations at the limits of the range are particularly vulnerable to extirpation, and will require careful stewardship if they are to be preserved. At sea, foraging murrelets are usually found as widely spaced pairs. In some instances, murrelets join into flocks that are often associated with river plumes and currents. These flocks may contain sizable portions of local populations. Protection of foraging habitat and foraging murrelets will be necessary if adult mortality is to be minimized.

Marbled Murrelets are secretive on land, but spend most of their lives at sea, where they are relatively easily observed. Data obtained at sea are at present the best source of information about the distribution and abundance of the species. Patterns of distribution provide information on the murrelet's geographic range, terrestrial nesting habitats, and the oceanographic features of foraging areas.

Nest sites of the species were found only relatively recently. We can find no historical account that gives any credibility to the notion that the murrelet could nest in trees, although Dawson (1923) mentions (and then debunks) an apocryphal Indian account of them nesting inland in "hollow trees." Today, this seems easily interpretable as large, old trees containing hollows. In 1923, Joseph Grinnell (quoted in Carter and Erickson 1988) noted indirect evidence that the bird was associated with older forests. Since then, observers have noted links of the species with what has come to be called "old-growth" forests, that we define here for convenience as forests that have been largely unmodified by timber harvesting, and whose larger trees average over 200 years old. This definition of old-growth is in general agreement with the ideas of Franklin and others (1986). In some places in this chapter we refer to old-growth trees as those with a diameter of more than $81 \mathrm{~cm}$.

In the following chapters, various authors discuss how a shift from efforts to find nest sites to broader surveys monitoring the presence of murrelets in forested tracts, especially those slated for timber harvest, have increased the knowledge of the use of inland sites by murrelets. These efforts have resulted in a more complete picture on current distribution and abundance which may lead the way for management for this species.

Marine surveys remain the only method for estimating the size of Marbled Murrelet populations. These surveys have been carried out in a variety of intensities, and the most recent data are presented in the chapters to follow. Unfortunately, relatively little historical survey information is available. Early surveys were focused on species found in deeper waters, while the nearshore murrelet was generally ignored. Further, recent work has shown that to obtain useful data on murrelet distribution and abundance, surveys must be designed to focus on the nearshore waters where murrelets are found.

\section{Taxonomy and Range}

The species has been divided into two races, the North American (Brachyramphus marmoratus marmoratus) and the Asian (B. m. perdix). Recent evidence, not yet fully published in the literature (Friesen and others 1994a), strongly indicates that the North American race may be more distinct from the Asian race (referred to as the Long-billed Murrelet, $B$. perdix) than it is from the other North American Brachyramphus, the Kittlitz's Murrelet (B. brevirostris). Konyukhov and Kitaysky (this volume) contrast the Asian and North American races.

From California to Alaska, the Marbled Murrelet nests primarily in old-growth coniferous forests and may fly up to $70 \mathrm{~km}$ or more inland to nest. This is a radical departure from the breeding behavior of other alcids, but adaptation to old-growth conifers probably occurred early in its evolutionary history, perhaps in the mid-Miocene when enormous dawn redwoods (Metasequoia) blanketed the coast from California to the north slope of Alaska and Aleutian Islands. The other 21 extant species of the family Alcidae, known as auks or alcids, breed on the ground, mostly on predator-free islands. In Alaska, a very small proportion of the Marbled Murrelets breed on the ground, usually on barren, inland slopes and to the west of the major rain forests along the Alaskan gulf coast. Initial divergence of perdix and marmoratus occurred in the mid-Pliocene, perhaps as cooling temperatures eliminated coastal old-growth forests in the exposed Aleutian Islands, leading to a gap in east-west distribution of murrelets and isolated breeding stocks (Udvardy 1963). The divergence of Marbled and Kittlitz's murrelets occurred at the onset of the Pleistocene (Friesen and others 1994), and the present strong association of Kittlitz's Murrelet with glacial ice clearly indicates the importance of the glacial landscape in determining the northeasterly distribution of Kittlitz's Murrelet and ecological segregation of brevirostris and marmoratus into subarctic and boreal species.

\section{Geographic Range}

At the broad scale, the distribution of the Marbled Murrelet is fairly continuous from the Aleutian Islands to California. The present geographic center of the North American populations is found in the northern part of southeast Alaska (fig. I). Large populations are also found to the west around Prince William Sound and the Kodiak Island archipelago, and to the south along the British Columbia coast. In either direction, populations become more disjunct, with small, discrete sub-populations at the extreme ends of the range in the Santa Cruz Mountains of central California, and on Attu Island in the western Aleutians. In California, Oregon, and Washington, gaps in distribution between breeding populations may result largely from timber harvest practices. The disjunct distribution is a reflection of the remaining nesting habitat, primarily late-successional and old-growth forests on public land (Carter and Erickson 1992, Leschner and Cummins 1992a, Nelson and others 1992).

The small, relict populations of murrelets at the limits of the species' range are particularly vulnerable to extirpation. Particular care will need to be exercised if they are to be conserved. Murrelets range along 4,000 km of coastline and it is possible that some populations have distinct genetic 


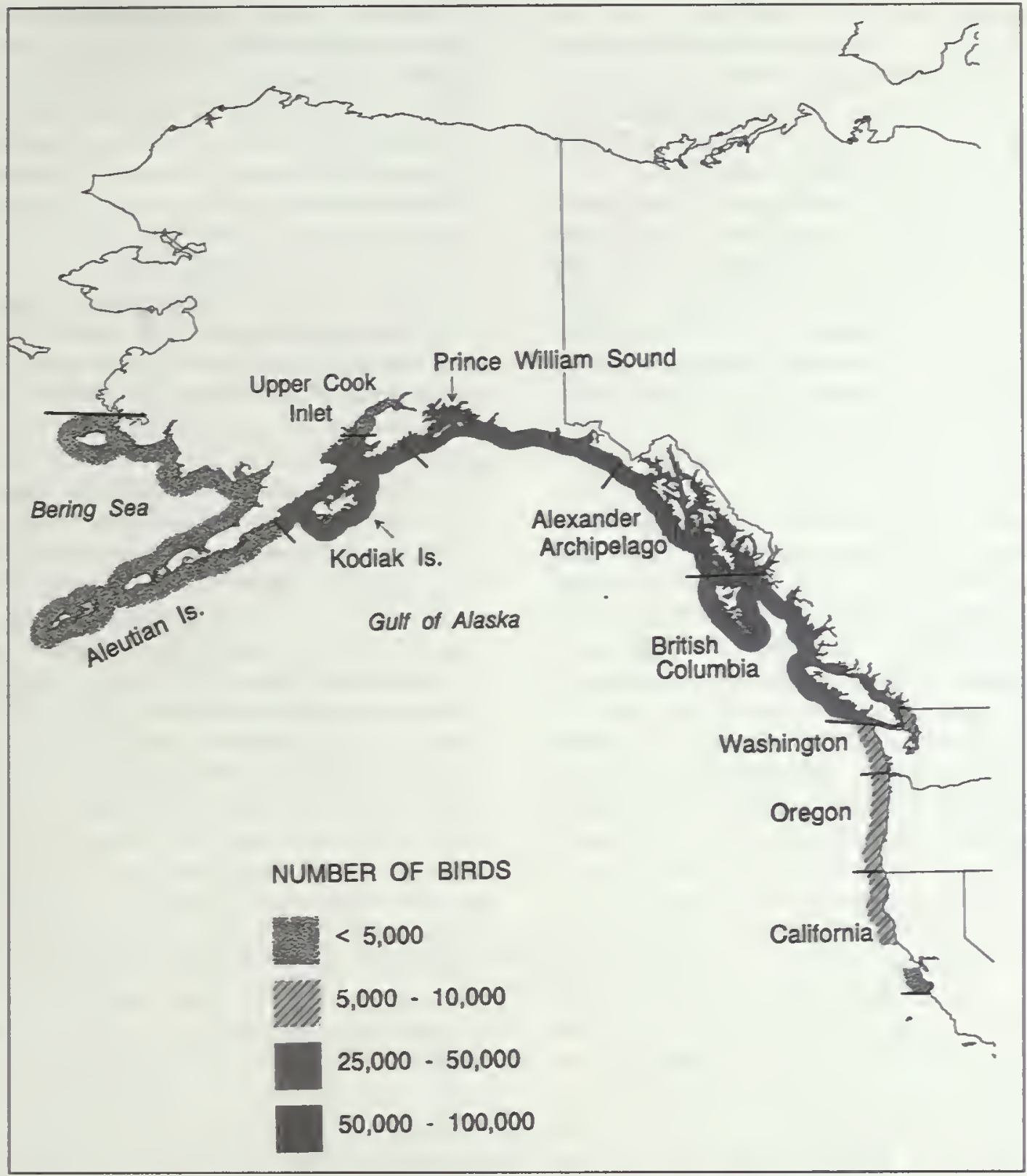

Figure 1-Range of the Marbled Murrelet, which stretches from central California to southern Alaska, and population size along sections of the coast. See table 2 for further details.

characteristics allowing for adaptation to variability in these environments. As an example, the waters between California and the Aleutian Islands are partitioned into several dramatically different regimes (Hunt, this volume a). The loss of these peripheral populations would likely reduce diversity in the population as a whole, and might reduce the capacity of the species to adapt to long-term environmental changes.

\section{Distribution in Relation to Nesting Habitat}

During the breeding season, the distribution of the Marbled Murrelet throughout its range is determined by the distribution and accessibility of old-growth and late-successional coniferous forests. Some evidence exists of a relationship between the estimates of Marbled Murrelet population size, based on at-sea surveys, and the amount of old-growth forest within a region. This relationship is most evident from California to southern Washington, a coastline that is relatively straight and contains disjunct pockets of old-growth forests. In this region, the largest concentrations of murrelets at sea during the breeding season are found along sections of coastal waters that are adjacent to inland breeding areas (Nelson and others 1992, Sowls and others 1980). Marine productivity is high along this entire coast during summer (Ainley and Boekelheide 1990), and access to suitable foraging areas does not appear to limit murrelet distribution. Circumstantial evidence is considerable that murrelet distribution is limited by nesting, rather than foraging, habitat. For example, murrelets concentrate offshore from old-growth areas during 
the breeding season (April-August), but move elsewhere when not breeding, presumably in response to food availability, which becomes more problematic during winter. Murrelets do, however, have the ability to fly long distances to reach suitable foraging habitat or areas with high productivity, even during the breeding season.

In northern Washington, British Columbia, and Alaska, the small-scale relationship between the at-sea distribution of murrelets and the presence of old-growth immediately adjacent to the coast is less clear. In this part of the murrelet's range, the coastline is much more complex. The numerous islands, bays, fjords, and sheltered inside waters, the greater abundance of contiguous stands of mature, old-growth forests, and the lack of survey effort, all have hindered assessment of fine-scale spatial associations between nesting and foraging habitat.

Inland, murrelets are detected almost exclusively in forest stands with old-growth characteristics (Burger, this volume a; Grenier and Nelson, this volume; Hamer, this volume; Kuletz and others, this volume; Paton and Ralph 1990; Rodway and others 1993b). All murrelet nests, south of Alaska, have been found in old-growth trees ( $>81 \mathrm{~cm} \mathrm{d.b.h.),} \mathrm{therefore} \mathrm{all}$ nests have been in stands with old-growth trees. To our knowledge, essentially all stands with birds flying below the canopy (termed "occupied behaviors") have also been in stands with old-growth trees. Grenier and Nelson (this volume) found all occupied sites had at least one old-growth tree per acre. There are reports of possibly occupied inland sites in Oregon without old-growth trees, but Nelson (pers. comm.) had not verified occupancy in most of these areas. By contrast, there is a high probability that a few murrelets are nesting in coastal stands without old-growth trees in the Sitka spruce/ western hemlock (Picea sitchensis/Tsuga heterophylla) forest type in Oregon (Nelson, pers. comm.). This forest type may provide nesting habitat at younger ages because trees grow fast in this area and smaller trees may also be used because mistletoe deformations are abundant in the hemlock trees. Young Douglas-fir (Pseudotsuga menziesii) forests do not provide the same opportunities.

Ground nesting by Marbled Murrelets has been documented in Alaska. Available information suggests that less than 5 percent of the total murrelet population in Alaska breeds on the ground in non-forested habitat in the western Gulf of Alaska and in the Aleutian Islands (Mendenhall 1992). There is also a small unknown percentage of the population that nests on the ground in old-growth forests; about five nests have been found to date (Kuletz, pers. comm.). It is important to recognize that despite these markedly different breeding habits, intermediate situations are generally not acceptable to murrelets. To our knowledge they do not breed in alpine forests, bog forests, scrub vegetation, scree slopes, and very rarely breed in second growth (e.g., trees $<81 \mathrm{~cm}$ d.b.h.) (Rodway and others 1993b). In the farthest northern portion of the range in Alaska (Kuletz and others, in press; Naslund and others, in press), and in the habitat of the Asian taxon of the murrelet (Konyukhov and Kitaysky, this volume), the nest trees become relatively short in stature, as compared to trees in forests farther south in North America. In these areas, murrelets appear to nest in the largest trees of the oldest forests. On the basis of all the information available, we conclude that throughout their range in North America, the great majority of murrelets are strongly associated with old-growth forests for breeding.

\section{Distribution in Relation to Distance from the Coast}

The maximum distance that murrelets can occur inland from coastal foraging areas may result from several factors, including suitability of climate, availability of nesting habitat, the maximum foraging range, and rates of predation. Average and maximum summer temperatures increase as a function of distance from the coast and the decreased influence of cool maritime breezes. For a well-insulated, oceanic species spending more than 95 percent of its time on the cold waters of the Pacific, inland temperatures in the south of its range could be too hot for nesting. Greater distances to the coast would also require longer foraging flights. For other species of alcids, typical one-way foraging ranges are 10-40 km, with maximum extremes of 100-150 km (Ainley and others 1990; Bradstreet and Brown 1985). For murrelets, studies of foraging range using radio-tagged birds have indicated that this species will fly up to $75 \mathrm{~km}$ from its nesting areas to forage, with most trips being considerably shorter (Burns and others 1994, Rodway and others, in press). The maximum distance inland at which murrelets have been found is about $100 \mathrm{~km}$ although most appear to nest less than $60 \mathrm{~km}$ inland (Hamer, this volume; Miller and Ralph, this volume). Records for maximum inland distance based on the discovery of grounded fledglings may be misleading because of the possibility of misdirected birds flying inland from their nest. Average distances of inland nesting cannot be firmly ascertained until the distribution of inland detections of murrelets is documented with a consistent survey effort. We do not know how the potential for nest site predation may vary with distance from the coast, but certainly longer flights between the nest sites and at-sea foraging areas increase the chance of being taken by aerial predators.

Although in some regions murrelets nest immediately adjacent to the coast, in most portions of their range studied the majority of nests are inland from the immediate coast. In Alaska, murrelets nest within $1 \mathrm{~km}$ of salt water (Kuletz and others, this volume; Naslund and others, in press), and in California the highest proportions of nesting stands are found within $10 \mathrm{~km}$ of the coast (Miller and Ralph, this volume). At least in the southern part of the range, we suspect that the readily-harvested trees on the coast were the first to be removed, leaving the more distant ones for future cutting and thereby influencing current patterns of murrelet nesting.

\section{Comparison of Habitat Correlates}

Several studies and surveys have documented behaviors at inland stands that are probably indicative of nesting (Nelson 
and Hamer, this volume a; Nelson and Peck, in press); see Paton (this volume) for details on the survey method and its caveats. We compared for each region (table 1), the site, stand, and tree attributes that have been shown to be correlated with nesting behavior. Among the most consistently observed of these attributes are the presence of large diameter conifer trees and associated nest platforms and covering limbs. The use or presence of large diameter conifers is pervasive throughout the studies in this volume. Occasional sites with only a few old-growth trees have been found in Oregon to have murrelets present (Nelson, pers. comm.). Further, as Grenier and Nelson (this volume) point out, stand structure is probably more important than stand age itself. However, as stands mature, they generally gain the characteristics necessary for nesting. These observations support the idea that it is the presence of adequate nesting platforms that defines suitable nesting habitat. The species of conifer is less important than its structural ability to support nest platforms (Burger, this volume a).

\section{Limiting Factors and Relative Importance in Old-Growth}

Several factors appear related to the preference for old-growth, including temperature, predation, stand and tree structure, and accessibility.

Temperatures in old-growth forests are lower than in open, second-growth areas. This may be very important for a thickly-feathered species primarily adapted for diving for food in cold ocean waters.

Old-growth stands may also provide more protection from inclement weather by providing greater cover around branches.

Predation apparently has a pervasive influence on murrelet reproductive success, as we detail below. Nelson and Hamer (this volume b) found that most studies of avian predator abundance or influence support the idea that modified forests have higher predator populations than older, undisturbed forests. In contrast, Rosenberg and Raphael (1986) found that predator populations were not greater in second growth, as compared to old-growth forests. Although more work needs to be done on this issue, it seems likely that predation could well be a principal limiting factor for selection of nesting habitat and reproductive success.

The presence of old-growth in an area does not assure sufficient substrate for nesting. Though old growth appears to be a necessary condition, some old-growth stands may have relatively few deformed or broad-limbed trees, possibly limiting the availability of nest sites. The physical condition of a tree appears to be the important factor in determining its suitability for nesting. Specifically, the murrelet, a bird with high wing loading, prefers high and broad platforms for landing and take-off, and surfaces which will support a nest cup (see Hamer and Nelson, this volume b). Accessibility of the stand,

Table I-Sire, stand, and tree attributes important to Marbled Murrelets

\begin{tabular}{|c|c|c|}
\hline Region & Important attributes & Source, this volume \\
\hline \multicolumn{3}{|l|}{ Nesting stands in: } \\
\hline Alaska & $\begin{array}{l}\text { Epiphyte cover, nesting platforms, } \\
\text { large diameter troes, old-growth forests. }\end{array}$ & Kuletz and others \\
\hline British Columbia & Old-growth forests, low elevation, large trees. & Burger (a) \\
\hline \multirow[t]{2}{*}{ Washington } & Old-growth forests, stand size, large sawtimber. & Raphael and others \\
\hline & $\begin{array}{l}\text { In old-growth forests: nest platforms, } \\
\text { moss cover, slopes, stem density, large } \\
\text { d.b.h., western hemlock, low elevation, } \\
\text { lack of lichen, low canopy cover. }\end{array}$ & Hamer \\
\hline Oregon & Older forests and large diameter trees. & Grenier and Nelson \\
\hline California & $\begin{array}{l}\text { Density of old-growth trees, lower } \\
\text { elevation, topography, redwood. }\end{array}$ & $\begin{array}{l}\text { Miller and Ralph } \\
\text { Paton and Ralph } 1990\end{array}$ \\
\hline \multicolumn{3}{|l|}{ Nest trees in: } \\
\hline All areas & $\begin{array}{l}\text { Large diameter, old-growth forests, and } \\
\text { decadent trees with mistletoe, deformations, } \\
\text { and moss on limbs. }\end{array}$ & Hamer and Nelson (b) \\
\hline
\end{tabular}


either as a function of the distance from the coast, or the thickness of growth limiting the ability of birds to fly into the stand, is also likely a factor involved in nest site selection.

Stand size has been suggested to be an important factor in the abundance of birds in a stand (Paton and Ralph 1990) and in the likelihood that a stand will be occupied (Raphael and others, this volume). Larger stands can contain more birds overall, but there is no evidence that density changes as a function of stand size (Miller and Ralph, this volume). Stand size, however, is probably importantly related to some of the other factors mentioned above, especially predation.

\section{Potential Biases in Determining Nest Sites}

Observers have usually chosen sites for nest search in areas with larger trees. Data from stratified samples for presence of birds in inland stands in California (Miller and Ralph, this volume), in Oregon (Nelson 1990), and in Alaska (Kuletz and others, this volume), as well as nests discovered from radio-tracking (Hamer and Nelson, this volume b), have probably been the most free of bias. Since these more randomly located sites have not differed markedly from the nest sites found in search areas that were potentially biased by the choice of area to be searched, we conclude that the documented nest sites described in most studies are representative of habitat selection by the species.

\section{Sources of Error in the Determination of Forest Use}

The most direct evidence of murrelet breeding is the finding of a nest, but nest detections are rare, due to the secretive nesting behavior of murrelets. Also, as Hamer and Nelson (this volume b) point out, locating nests is greatly dependent upon where observers have looked, making the habitat characteristics of nest sites subject to this bias. The majority of the conclusions about murrelet use of habitats relies upon detections of birds that have flown inland to presumed nesting areas (Naslund and O'Donnell, this volume; O'Donnell and others, this volume; Paton, this volume). Observations have been divided into two groups, those of birds flying over the canopy and those at or below the canopy level (Ralph and others 1993). It is suggested that the latter behavior (referred to as "occupied" behavior) is a strong indication that breeding is occurring in the stand, as this behavior is almost entirely restricted to the breeding season (O'Donnell, this volume).

We believe that the most objective method of determining habitat relationships is the detection of birds in the forest. Detections are usually within a 100-m-radius circle surrounding the observer, and provide a larger and less potentially biased sample than the location of nest trees. Below-canopy behavior has been observed in the vicinity of known nest trees. Despite the lack of data demonstrating that this behavior occurs only when a pair is nesting or prospecting, we suggest that the presence of this behavior is a strong indication that murrelets are nesting or intending to nest in a given stand. Stands where murrelets exhibit this behavior should be treated as if they contain nesting murrelets. Circling above the canopy is also thought to be associated with nesting murrelets (e.g., Nelson and Hamer, this volume; Nelson and Peck, in press). Other species of alcids often circle above the breeding grounds as part of their social interactions. However, as Divoky and Horton (this volume) argue, the possibility that non-breeding, dispersing young could be prospecting in marginal stands, thus distorting the value of these stands to the observers, cannot be dismissed.

Seasonality of the murrelets' visits may affect efforts to establish use of a stand. O'Donnell and others (this volume) describe the seasonal timing of forest visits, showing the peak of activity to be during the period of April through July, with peaks of activity in the more northern parts of the range occurring later in the summer. Naslund (1993) suggested that the winter visits of murrelets to stands, even though little or no below-canopy behavior is observed, might be a better indicator of nesting than those during the breeding season. However, we feel that until more compelling evidence is available, stand use during the breeding season should remain the criterion of breeding for management purposes, as suggested by Ralph and others (1993).

Many land managers depend upon the protocol developed by the Pacific Seabird Group (Paton and others 1990; Ralph and others 1993) to determine if murrelets are present in their forests. The basis of the timing and frequency of the surveys has depended upon a firm foundation of research as summarized in O'Donnell and others (this volume), Naslund and O'Donnell (this volume), and O'Donnell (this volume). Active research and statistical analyses are underway to validate the method and to determine the number of surveys necessary to establish birds as breeding in a stand, and how many years of survey are necessary. At issue is the possibility of interannual variation in occupancy of a site that requires protection. Ralph (this volume) found no significant differences among years in detection levels at three sites in California during years when there was a range of sea temperature conditions, with both El Niño (the periodic warming of ocean waters) and non-El Niño years during the study. However, Nelson (pers. comm.) suggests that her data show consistent differences among these same years in Oregon. Burger (this volume a) also found higher inland detection rates with normal sea temperatures, and lower detections with high sea temperatures. Additional work needs to be done to determine if differences in offshore conditions, resulting in changes in food abundance and perhaps breeding frequency, are reflected in inshore detections during the breeding season.

\section{Local Distribution at Sea and Foraging}

\section{Concentrations}

Patterns in the distribution of Marbled Murrelets at sea can be seen both at large scales (hundreds of kilometers) and at small scales of individual aggregations. The small-scale distribution of Marbled Murrelets at sea reflects their choice of foraging habitat. 
Although murrelets are often encountered as widely dispersed pairs, in some instances they gather into flocks that may contain a significant fraction of the local population (Strachan and others, this volume). Murrelets most often form flocks in the sheltered waters of Washington, British Columbia, and Alaska (Carter and Sealy 1990; Kaiser and others 1991; Piatt and Naslund, this volume; Prestash and others 1992), but they also occasionally aggregate along the open coasts of California (Ralph and Miller, this volume), and Oregon (Strong and others 1994). Information about where murrelets are likely to concentrate at sea is relevant to the prediction of where murrelet populations are likely to be particularly vulnerable to bycatch in gill nets, a local oil spill, other pollution event, or disturbance from good feeding areas by boat traffic (Kuletz 1994). Protection of these areas of aggregation may be important in reducing anthropogenic sources of adult mortality.

There are relatively few data on the distribution of murrelet aggregations or their frequency. Several authors have noted the correspondence between murrelet distribution and certain physical processes in the ocean. For instance, some observations indicate that along the open coasts, aggregations may be more frequent in the vicinity of river plumes (Strong and others, this volume; Varoujean and Williams, this volume), although old-growth stands may also be most numerous in river valleys, thus confounding the cause of the aggregations. In the bays and sounds of Washington, British Columbia, and Alaska, aggregations of murrelets are common, but little is known about the environmental conditions causing these concentrations. Piatt and Naslund (this volume) suggest that murrelets prefer stratified as opposed to well-mixed waters, but they also report that murrelets often concentrate near the outflows of large rivers and in rip tides. Burger (this volume b) reviewed the available data for British Columbia, and found equivocal evidence linking densities with water temperature. Kaiser and others (1991) found some correlations with temperature which they attributed to the effects of local tidal rips. Also there were instances where murrelets aggregated at some tidal rips and upwelling, but they were scarce or absent at other tidal rips where other species aggregated.

Murrelets have also been associated with particular marine habitats that are favored by prey, such as sand lance (Ammodytes hexapterus), and surf smelt (Hypomesus pretiosus). Burger (this volume b) suggested that murrelets aggregate in shallow bays of fjords, in estuaries, and off beaches because these locations are where prey such as sand lance might be common. In British Columbia, Carter (1984) found murrelets in waters over sand and gravel bottom, possibly because of the concentration of sand lance. Strong and others (1993) hypothesized that adjustments in local distribution off Oregon was in response to movements of surf smelt. Ainley and others (this volume) suggested that murrelets favor areas of upwelling, high productivity, and concentrations of prey along the more open coasts of
California, and that local movements here were also in response to food availability. We need considerably more information before we will be able to predict the types of locations where murrelets are likely to be concentrated. Our success in identifying the factors responsible for aggregations is likely to depend on concerted efforts to investigate the issue of prey distribution, and also on our sensitivity to the underlying spatial and temporal scales of the various mechanisms involved.

\section{Seasonal Movements}

In some, if not all, areas of their range, Marbled Murrelets exhibit seasonal redistributions of their populations (Klosiewski and Laing 1994; Kuletz 1994; Piatt and Naslund, this volume; Ralph and Miller, this volume; Strachan and others, this volume; Strong and others 1993). The studies of Burger (this volume $b$ ) and Speich and Wahl (this volume) provide important data showing that in winter murrelets move from the outer, exposed coasts of Vancouver lsland and the Straits of Juan de Fuca into the sheltered and productive waters of northern and eastern Puget Sound. Although the available data are sketchy, the possibility exists that a large portion of this murrelet population, which in summer is widely dispersed along remote coasts, is concentrated in winter in an area with beavy ship traffic, including the frequent movement of oil tankers to and from refineries. Less is known about seasonal movements along the outer coasts of Washington, Oregon, and California, but Speich and Wahl (this volume) suggest that birds from the outer coast of Washington move into Grays Harbor channel in winter. The potential for winter concentrations of murrelets to encounter industrial and oil pollution in the sheltered waters that they prefer is a conservation issue of considerable concern (Carter and Kuletz, this volume; Fry, this volume).

\section{Social Influences at Sea}

Association of murrelets in pairs, probably for foraging, is well documented (Strachan and others, this volume). The possible costs or benefits of interrelationships with other species, such as kleptoparasitism by gulls (Hunt, this volume b) or predation by Peregrine Falcons (Falco peregrinus) is more speculative. However, the possible effects of humancaused increases in gull populations may be of some concern.

\section{Estimates of Abundance and Historical Trends}

Summary-We estimate, based on information in this volume, that the total North American population of Marbled Murrelets is about 300,000 individuals. Approximately 85 percent of this population breeds along the coasts of the Gulf of Alaska and in Prince William Sound. There are few murrelets in the Aleutian Islands and Bering Sea. Murrelet populations in both Alaska and British Columbia have apparently declined substantially over the past 10 to 20 
years. In Washington, Oregon, and California, population trends are downward, but the magnitude of decline over the past few decades is unknown. As a result of the small size of remnant populations, the species has been listed by various authorities as threatened or endangered in parts of its range.

Counts of Marbled Murrelets at sea are currently the best method of estimating the size of regional populations. Nests are difficult to find, and although detections of calls at inland sites provide indices to local activity, numbers of detections can not be translated into absolute numbers of birds present. In contrast, surveys of birds at sea can be done from boats or airplanes, can cover large areas quickly, and can be standardized to provide repeatability. It is also possible to develop models for extrapolation of results from areas that have been surveyed thoroughly, and apply them to nearby areas that have received more cursory inspection (Ralph and Miller, this volume).

\section{Estimates of Population Size}

Based on the at-sea survey data, our best estimate of the Marbled Murrelet population in North America is on the order of 300,000 individuals (table 2). The major portion of this population is concentrated in northern Southeast Alaska and Prince William Sound.

Population size diminishes rapidly north and west of there. Populations are relatively small and fragmented throughout Washington, Oregon, and California.

The repeatability of survey results appears to vary considerably between location, methods, and researcher. In Alaska, overall population estimates were similar between summer and winter counts within the same decade (Piatt and Naslund, this volume). In contrast, population estimates for Prince William Sound varied considerably between those made in the 1970s and those made subsequent to the Exxon Valdez oil spill; the disparity is greater than can be explained by the oil spill alone, and probably is the result of different sampling methods in the 1970s or changes in food availability (Klosiewski and Laing 1994; Piatt and Naslund, this volume). In Washington, counts made from 1978 to 1985 (Speich and others 1992), were similar in magnitude to those made in 1993 (Varoujean and Williams, this volume), with perhaps 5,000 in the entire state. Likewise, along the Oregon coast, Varoujean and Williams (this volume), using an aerial survey, found murrelet numbers in 1993 to be in the same range as their estimates of population size in the

Table 2-Estimated size of Marbled Murrelet populations by geographic regions

\begin{tabular}{|c|c|c|}
\hline Regions & Estimated population' & Source \\
\hline \multicolumn{3}{|l|}{ Alaska } \\
\hline Bering Sea, Aleutians & 2,400 & Piatt and Naslund, this volume \\
\hline Gulf, Kodiak, AJaska Peninsula & 33,300 & Piatt and Naslund, this volume \\
\hline Prince William Sound & 89,000 & Klosiewski and Laing 1994 \\
\hline Alexander Archipelago & 96,200 & Piatt and Naslund, this volume \\
\hline State total & 220,900 & \\
\hline British Columbia & $45-50,000$ & Rodway and others 1992 \\
\hline \multicolumn{3}{|l|}{ Washington } \\
\hline Outer coast and Strait & 3,500 & Varoujean and Williams, this volume \\
\hline Oufer coast only & 2,400 & Speich and Wahl, this volume \\
\hline Puget Sound & 2,600 & Speich and Wahl, this volume \\
\hline State total & ca. 5,500 & \\
\hline Oregon & $\begin{array}{r}6,600 \\
15-20,000\end{array}$ & $\begin{array}{l}\text { Varoujean and Williams, this volume } \\
\text { Strong and others, this volume }\end{array}$ \\
\hline \multicolumn{3}{|l|}{ California } \\
\hline Northern California & 5,700 & Ralph and Miller, this volume \\
\hline Central California & 750 & Ralph and Miller, this volume \\
\hline Stale total & 6,450 & \\
\hline Total & ca. 287,00 to 300,000 & \\
\hline
\end{tabular}

${ }^{1}$ Midpoints are usually used where ranges were given in the source 
1980s. Their estimate is lower than the ship-based survey of Strong and others (this volume) by a factor of three, and the causes of this difference are probably due to differences in methodology, spatial coverage, assumptions, and survey and model errors.

\section{Sources of Error}

Although we believe that at-sea surveys for estimation of Marbled Murrelet population size is necessary, there is still need for validation of the methodology. Few seabird species have population estimates based on at-sea counts, and the accuracy (as opposed to precision) of these techniques is only now being established. Population estimates of murrelets based on at-sea counts are subject to several sources of error, and these sources and their magnitudes are likely to vary with location and season. Three aspects of surveys that can affect accuracy are the way in which counts of flying birds are made, observation conditions, and observer competence. The possibility exists for double counting birds that are flushed from the survey track and then settle on a portion of the track yet to be surveyed. This problem is more severe for ship-based than aerial surveys, because the speed of the plane is great relative to that of the birds. Even in aerial surveys, double counting may occur if adjacent survey lines are sufficiently close. Strong and others (this volume) suggest that double counting, even on ship-based surveys, may be only a minor problem, with an estimated 5 percent of counted birds being vulnerable to recounting. There is also the likelihood of not counting murrelets because they are underwater, either foraging or diving in response to a vessel or airplane (Strachan and others, this volume; Strong and others, this volume). This source of error is greatest for aerial surveys because a given area is in sight only for an instant. The ability of an observer on a boat or plane to see birds will vary with the speed of the survey platform, height of the observer, use of binoculars, the area for which each observer is responsible, and observer competence. To minimize these sources of error, or uncertainty, it is necessary to either limit observations to a narrow band (e.g., Varoujean and Williams, this volume), to correct for the diminishing visibility of birds at greater distances (Ralph and Miller, this volume), to calibrate aerial versus boat surveys, or to calibrate observers (i.e., use only a limited number of persons).

The patchy distribution of murrelets and their propensity for large daily shifts in distribution (Burger, this volume b; Rodway and others, in press; Speich and Wahl, this volume) further complicate the interpretation of survey data. Throughout their range, the largest numbers of Marbled Murrelets seen on the water are within a few kilometers, and often less than $500 \mathrm{~m}$, of shore. Data from British Columbia (Burger, this volume b; Morgan 1989; Sealy and Carter 1994; Vermeer and others 1983) suggest that along the outer, exposed coasts, murrelets may forage closer to shore (out to $500 \mathrm{~m}$ ) than they do in sheltered bays and fjords where birds are often 1 to 5 $\mathrm{km}$ offshore. Large-scale surveys by ship or airplane that fail to thoroughly survey this narrow, inshore strip are likely to underestimate local murrelet populations. Additionally, within this nearshore zone, murrelets are found concentrated in preferred foraging locales. A consequence of this small-scale patchiness is that surveys on different days must cover the same routes each time if they are to be comparable (they provide an index, not a sample), or they must be carefully stratified by foraging zone. In addition, variance of counts is large, so precise estimates of abundance require large samples (numbers of counts).

Temporal variation in the use of marine habitats by murrelets further complicates the assessment of annual or decade-long changes in numbers. Data from Washington (Speich and Wahl, this volume), British Columbia (Burger, this volume b; Rodway and others, in press) and Alaska (Kuletz and others 1994a; Piatt and Naslund, this volume) show that murrelets exhibit considerable seasonal and daily variation in their use of specific foraging areas. During the breeding season, the portion of the population attending nests will change with time. In order for surveys to be strictly comparable, care should be exercised to conduct surveys in similar seasons and at the same time of day, or to make appropriate corrections to account for these sources of variation. These sources of error apply to all surveys in table 2. More research is required to validate census techniques, to establish the accuracy of different survey methods, and to determine the time of year when the most comparable surveys should be done.

\section{Trends in Murrelet Populations}

Historical data for Marbled Murrelet populations are few, and no estimates can be made for populations before 1900. It is at least possible that the murrelet was an abundant bird, nesting in old-growth forests all along the Pacific Coast in numbers commensurate with the abundant nearshore small fish it preys upon, and not limited, as it is today, by the availability of remnant stands of old-growth forests in the southern portion of its range. Circumstantial evidence to support this argument is the existence of large numbers of murrelets in very high densities where old-growth is still abundant (i.e., the Gulf of Alaska), or where it is the most abundant seabird in summer (i.e., Prince William Sound) (Kuletz, pers. comm.).

Although the total population of Marbled Murrelets still appears large (table 2), there is reason for concern for the continued viability of this species in some regions. Numbers at the southern end of the range are small and concentrated geographically, thereby leaving subpopulations vulnerable to damage by stochastic events. More importantly, evidence is mounting that population trends are downward where they have been measured, even though short-term fluctuations in climate and longer-term variation in ocean currents can result in apparent or temporary increases.

In Alaska (Piatt and Naslund, this volume), and in Clayoquot Sound, British Columbia (Burger, this volume b; Kelson and others, in press), populations have apparently 
declined on the order of 50 percent in the last 10 to 20 years. Piatt and Naslund (this volume) based their conclusions on a decrease in the number of birds seen on small boat surveys of Prince William Sound in 1972-1973 compared to 1989-1991, as well as declines from Christmas Bird Counts during this period. Burger (this volume b) based his conclusions for Clayoquot Sound on density estimates from surveys made between 1979 and 1993. In Barkley Sound, British Columbia, Burger (this volume $b$ ) also found evidence of a decline from work in 1992 and 1993. However, in this area in the spring of 1994, he recorded 2-3 times as many murrelets, leading to the possibility that the low numbers in 1992 and 1993 were due to El Niño-like effects in those years.

The murrelet populations in Puget Sound, Washington, are apparently now lower than earlier this century. Few counts of offshore populations have been performed in the state, but Speich and Wahl (this volume) indicate some declines in recent decades. Both they, as well as Piatt and Naslund (this volume) in Alaska, suggest that some proportion of these declines may be linked to large-scale factors influencing the prey of marine bird populations over the past few decades, or that short-term environmental phenomena, such as El Niño events, may have caused local population declines or redistribution. They also identify a number of other factors that may have contributed to murrelet declines, including oil spills, gill netting, and timber harvest.

Although quantitative evidence concerning population trends is not available for Oregon and California, it is our judgment that the long-term trends have been downward in these states, as well as in Washington. Murrelets require forests with old-growth characteristics for nesting, and with the loss of their nesting habitat and incidental take in fishing nets and oil spills, Marbled Murrelet populations in the three states are almost certain to have decreased, as they have in Alaska and British Columbia. The declines in these latter two regions appear to have coincided with the cutting of a large fraction of the old-growth forests. The cumulative effects of oil pollution, gill netting, and natural changes in the marine environment have undoubtedly played a role as well. We are not able to separate these potential causes of decline at this point, but the declines, whatever their origin, are at least a cause for concern.

Beissinger (this volume) has estimated an annual decline of at least 4-6 percent throughout the species' range. These estimates are largely based on the observation of adult-to-young ratios at sea in the late summer, and inferences from other alcid species. However, the age ratio data are controversial, are from years when ocean conditions were warmer than usual, and may reflect a relatively temporary decline in reproduction. In addition, inferences from other species are fraught with danger. These estimates apply to past conditions and cannot be projected into the future, especially since implementation of the U.S. Government's Forest Plan would conserve most remaining nesting habitat on Federal lands of California, Oregon, and Washington.

\section{Demography of the Marbled Murrelet}

Summary-Based on the rate of successful fledging of young from observed nests, Marbled Murrelet populations in recent years have had one of the lowest reproductive rates of any alcid population thus far studied. For the population to be stable, these low rates of reproduction must be increased or balanced by higher than average rates of adult survival. Factors affecting these demographic parameters are the possible exclusion of a portion of the adult population from breeding due to lack of suitable nest sites, a decrease in the number of breeding attempts due to food limitation, loss of nest contents to avian predators, and mortality of adults from both avian predators and human activities, especially oil spills and entanglement in nearshore gill nets.

Long-term demographic data on adult survival, chick production, and chick survival, would be useful for determining whether murrelet populations are decreasing, stable, or increasing. These data would also help in evaluating the significance of threats to different components of the population, such as reduced productivity, and chick and adult mortality. For example, a 50 percent increase in juvenile predation might not be as serious as a 10 percent increase in adult mortality from gill-net losses, depending on what would be considered the normal range of these population parameters. Some species of alcids, such as Common Murres (Uria aalge), can recover from relatively large population losses because they have, for alcids, typically high levels of annual production, with $0.5-0.9$ chicks fledging per pair (Hudson 1985). For species with low rates of reproduction, high rates of adult survival are essential for a stable population.

It is exceptionally difficult to measure most of the critical population parameters for Marbled Murrelets. The traditional method of banding and resighting large numbers of seabirds at their colonies to estimate annual adult survival cannot be employed for murrelets because they are inaccessible. For example, a study of Common Murre breeding success at a single site in one year might include observations on hundreds of breeding pairs, and involve the banding of hundreds of chicks. At the end of the 1993 breeding season, after many years of dedicated effort, we have breeding success information on only 32 murrelet nests (Nelson and Hamer, this volume b). We do not know how representative these data are for the population as a whole. The only other source of demographic information is the ratio of juveniles to adults observed at sea during the post-breeding period (Ralph and Long, this volume; Varoujean and Williams, this volume). These are based on the identification of juveniles and adults on the water. As Carter and Stein (this volume) describe, this separation is fraught with difficulty. The extrapolation of these demographic data to longer time periods may be of limited value because many of the available data on juvenile:adult ratios were obtained in years when sea surface temperatures were unusually warm and prey availability 
may have been reduced. However, this type of demographic data provide perhaps our best hope of assessing this aspect of the species' life history.

\section{State of Knowledge of Marbled Murrelet Demography}

The rate of production of young by Marbled Murrelets appears to be one of the lowest of all alcids (De Santo and Nelson, this volume). Of the 32 nesting attempts for which we know the reproductive outcome, only 28 percent resulted in the fledging of young (Nelson and Hamer, this volume b). Data were gathered over several years throughout the murrelet's range from the Gulf of Alaska to California. In Washington, Oregon, and California, the success rate was somewhat higher, 36 percent of 22 nests fledged young. Most of the known causes of nest failure were related to predation of nest contents. Analysis of counts of young at sea in the early stages of the species' fledging period in relation to numbers of adults indicate that the reproductive rate in recent years has been less than that needed for a sustainable population (Beissinger, this volume).

The data used for determining productivity are based on a number of assumptions and may be biased. First, some of the data on nest success were gathered in years when ocean temperatures have been unusually high and prey availability may have been reduced. For most alcid species, breeding failures in warm water years are the result of adults forgoing breeding or chick starvation (Ainley and Boekelheide 1990). If warm water conditions during recent years depress the number of adults attempting to breed, the age ratio at sea would not be typical of years with high food availability. Secondly, the data on age ratios determined at sea are also based on assumptions about the ability of observers to separate adults from juveniles on the water (Carter and Stein, this volume). This can be further complicated later in the season when, as Hamer and Nelson (this volume a) indicate, young can be leaving the nest as late as September, and many adults have molted to a plumage indistinguishable from that of the young. Thus, the number of young may be underestimated. The data that Hamer and Nelson compiled can be used to correct for the proportion of young fledged at any given date (Beissinger, this volume; Ralph and Long, this volume), giving a more accurate picture of the proportion of young.

We think it unlikely that a reduction of murrelet prey, if such was the case during the recent studies, would be responsible in some way for the high rate of predation of nest contents. The ratios of juveniles to adults at sea would be influenced by the proportion of the adult population that bred, a proportion that is likely to be sensitive to prey availability. In contrast, nesting success may be depressed due to the possible attraction of nest predators to activities of researchers (see below).

Adult mortality rates are unknown. However, evidence is accumulating that fouling by oil and bycatch in gill nets may be locally significant (Carter and Kuletz, this volume; Carter and others, this volume; Fry, this volume).

\section{Inferences from Other Species}

In the absence of adequate data on most aspects of murrelet breeding, we must try to infer many of the population parameters of demography from more detailed studies of other alcids. We know that other small (150-500 g), fish-eating alcids (three Cepphus guillemot species and four Synthliboramphus murrelet species) naturally suffer high juvenile and adult losses from predation.

These species produce two eggs and often fledge two chicks. Thus, because they have high rates of reproduction, these species can experience high levels of adult mortality and still maintain stable populations (Hudson 1985). The larger (500-1000 g), fish-eating alcids (four puffin species [Fratercula sp.], two murre species, and the Razorbill Alca torda) produce only one egg, but under normal conditions have higher levels of chick production than most other alcids, due to low levels of juvenile and adult mortality and the long lifespans for some of these species (De Santo and Nelson, this volume).

The relatively small (ca. $230 \mathrm{~g}$ ) Marbled Murrelet differs from the other small fish-eating alcids by producing a single-egg clutch and having, at least in recent years, very low success in raising young to fledging. If these patterns of reproduction are typical, the Marbled Murrelet must have as high or higher levels of adult survival, compared to other alcids, if the murrelet populations are to be stable. The Marbled Murrelet may be more sensitive than other alcids to factors that increase adult mortality (Beissinger, this volume). In the absence of hard data, we must infer that murrelet demography is likely to be relatively more impacted than that of other alcids by adult losses to predation, oil pollution, gill nets, etc. Certainly, there is evidence of the pervasive influence of predation in shaping the breeding biology of the species (e.g., cryptic breeding plumage, crepuscular nest attendance, behavior at the nest, and nesting in trees) (Nelson and Hamer, this volume b; Ydenberg 1989).

\section{Factors Affecting Murrelet Demography}

The demography of Marbled Murrelets is influenced by age of first breeding, the proportion of the adult population that breeds, the rate of production of young that survive to breeding age, and adult and subadult mortality rates. In this section we evaluate these factors and their potential for influencing the population dynamics of Marbled Murrelets.

\section{Limits on the Proportion of Adults Breeding}

Limitation of Nesting Habitat-There is circumstantial evidence, including both distributional and observational data, that Marbled Murrelet populations are limited by the availability of suitable nesting habitat and that the habitat presently available is already occupied by breeding murrelets (at least south of Alaska). This evidence includes the following:

(a) Concentrations at sea near suitable nesting habitatMarine resources do not seem to determine the at-sea distribution of murrelets in the breeding season, at least in 
Washington, Oregon, and California. The observations that murrelets redistribute themselves after young have fledged indicate that food may be more abundant or accessible elsewhere. We thus conclude that the large-scale at-sea distribution and abundance of murrelets during the breeding season is not primarily related to the distribution and abundance of prey. It is possible, however, that the amount of prey offshore of old-growth influences the number of murrelets that breed there. Additionally, prey abundance may be influenced by oceanographic events that cause widespread, as well as local, reduction of productivity and prey availability.

(b) Winter visitation of nesting sites-Some murrelet populations continue to visit breeding areas during the winter (Naslund 1993), indicating that nest sites need to be defended year round. This is a behavior seen in other alcids when there is competition for nest sites (Ainley and Boekelheide 1990), and site retention may require sustained occupancy through the winter. Winter visitation by murrelets, however, was not apparent in British Columbia because the birds leave offshore areas near nesting sites in many parts of the Province (southwest Vancouver Island, and the Queen Charlotte Islands) (Burger, this volume b).

(c) Limitation of nest sites and habitat saturationSpacing of nesting pairs might lead to unused nest sites in some areas, but in others, high quality nest sites might be relatively infrequent, even in old-growth forest (Naslund, pers. comm.). The short stature of most Alaskan old-growth and the forms of some old-growth tree species at lower latitudes (for instance, redwoods have few large or deformed limbs) result in a potential scarcity of usable nest sites.

In areas where large amounts of habitat have been removed, it is likely that there is significant saturation of the habitat by murrelets. In Washington, Oregon, and California, approximately 85 percent of the historic old-growth has been removed. If the Marbled Murrelet was not limited by nesting habitat previously, certainly the chances of limitation have greatly increased today. If habitat is saturated, then the remaining stands in these three states should have maximum densities of murrelets. Data from Alaska suggest that murrelet density may be higher when the availability of suitable nesting habitat is restricted. For example, Kuletz and others (this volume) compared onshore dawn activity with offshore populations in the Kenai Fjords and in Prince William Sound. They found generally higher onshore populations in the Kenai than in the Sound, although the at-sea population in the Sound was much higher. They suggested the difference in numbers at sea was due to the relative abundance of good nesting habitat in the Sound, whereas the Kenai had relatively disjunct, smaller patches of large trees. We interpret the apparently higher number of detections on shore in the Kenai Fjords as a result of crowding into the limited number of sites available, rather than in a difference of the quality of the available nesting areas. More indirectly, evidence for packing into a habitat is found in an area of northwestern California, in the largest area of coastal old-growth forest that remains south of Puget Sound. That area, in the vicinity of Redwood National Park and Prairie Creek State Park, has the highest rate of murrelet detections of any area within the species' range, with detections often exceeding 200 per morning (Miller and Ralph, this volume). This may reflect packing into the remaining habitat, or it may reflect superior habitat that has always supported large numbers of birds, although we do not think the latter is the case. Even if nesting habitat is in general saturated, it is also probable that there will be years when suitable nest stands are unoccupied by murrelets. Absences could result from the temporary disappearance of inhabitants from the stand due to death or to irregular breeding, perhaps because of a temporary decline in prey resources. Under either of these circumstances, unoccupied stands would not necessarily indicate that, over a longer time scale, habitat was not limiting or that these stands were not part of the murrelet's habitat.

Behaviors-The behaviors that influence site fidelity and use, as well as the degree of coloniality, will affect the likelihood of occupying of new habitat, and both may influence the rate that birds displaced by habitat destruction will acquire new nesting grounds. Site fidelity is the propensity of breeding birds to return to the same nesting location year after year, whereas philopatry is the tendency of young birds to recruit to the area where they were raised. Coloniality, the clumping of nests in time and space, is a function of the number of nests likely to occur in a stand. Most seabirds show considerable site fidelity, and many individuals return to the same nest site annually (Divoky and Horton, this volume). The young of many alcid species recruit to their natal colonies, although the degree of philopatry can be as low as 50 percent. Previously unoccupied habitats are occupied and new colonies grow faster than can be accounted for by recruitment. As Divoky and Horton (this volume) discuss, from what we know of other seabirds, we can assume that Marbled Murrelets return to a stand once they have bred there and continue to use that stand at least as long as they breed successfully. Upon nest failure, they may change nest sites or mates, but they would be expected to remain in the stand. Thus, once a stand is occupied by murrelets, one would expect it to be used on a regular, if not annual, basis, so long as it is not modified.

Marbled Murrelets do not form dense colonies as is typical of most seabirds. However, limited evidence suggests that they may form loose colonies or clusters of nests in some cases. We would expect to find that the species maintains low nest densities, commensurate with available habitat. Coloniality evolves either as a means of protection against predation, or as an adaptation to exploit shared resources (nesting or foraging). We have no evidence that murrelets engage in group defense against predators, and their reliance upon cryptic coloration to avoid detection would argue for a wide spacing of nests to prevent predators from using area-restricted search, or from forming search images for murrelet nests. Marbled Murrelets have a number 
of aerial calls and displays (Nelson and Hamer, this volume a; Paton, this volume), the functions of which are not understood. If they have the same function as songs of songbirds, they could affect spacing. We doubt that murrelets exchange information about food resources while in the vicinity of the nest.

The possibility that murrelets may nest in loose colonies is supported by data from Naked Island, Prince William Sound, Alaska, where 2-3 pairs were found using a 3.6hectare stand, and 7-12 pairs used a 17.5-hectare stand (Naslund and others, in press). Two active Naked Island nests were $<20 \mathrm{~m}$ apart and two were $<300 \mathrm{~m}$ apart in 1991 . In 1994, three inland locations of radio-tagged birds were within $1 \mathrm{~km}$ or less of each other (two were definite nests, one was uncertain) (Kuletz, pers. comm.). As Ainley (pers. comm.) points out, if these internest distances are typical, they might characterize the murrelet as being loosely colonial, as in the Pigeon Guillemot (Cepphus columba) or Xantus' Murrelet (Synthliboramphus hypoleucus).

Food availability-Marbled Murrelets forage on a number of different species of small fish and macrozooplankton (Burkett, this volume). Several of these fish species are subject to commercial fishing. Although we suspect that food supplies do not limit murrelet populations at present, it is possible that the availability of fish to murrelets may be influenced by human fisheries activities. Fish species for which competition between fisheries and murrelets could occur include Pacific herring (Clupea harengus) (e.g., in Prince William Sound), rockfish (Sebastes sp.), and, more remotely, northern anchovy (Engraulis mordax). The stocks of both herring and rockfish are now depleted due to overfishing (Ainley and others 1994). Superimposed on any human-caused changes in food supply are short- and long-term natural fluctuations in marine productivity. El Niño events are well known to reduce food availability to seabirds (Ainley and Boekelheide 1990). Longer-term fluctuations in marine climate have apparently had major effects in the Bering Sea and on the reproductive performance of seabirds nesting on the Pribilof Islands (Decker and others 1994). Murrelets in central California generally forage in areas of upwelling (Ainley and others, this volume), and change their distribution in response to natural fluctuations in prey abundance, such as those ascribed to El Niño (Hunt, this volume $b$ ).

\section{Limitation of Reproduction by Predation}

Losses of eggs and chicks to avian predators were found to be the most important cause of nest failure in the 32 Marbled Murrelet nests for which the reproductive outcome was known (Nelson and Hamer, this volume b). Forty-three percent of these known nesting failures were ascribed to predation, a figure equivalent to 31 percent of all nests. The extent of site bias in these nests and the effect of observer influence are not known, but most nests have been found by investigators looking for them in or near openings in the forest where risk of predation may be higher.
The cryptic coloration and secretive, solitary (or loosely colonial) nesting behavior of Marbled Murrelets suggests that they have evolved under a regime of exposure to heavy predation. Only their ground-nesting congener, the Kittlitz's Murrelet, is equivalent in its cryptic coloration. Its nesting biology and behavior suggest that it is also subject to heavy predation. The apparently low levels of Marbled Murrelet reproductive success suggest that nest failure resulting from predation, if not higher than in the past, is certainly at present a significant factor in their demography (Nelson and Hamer, this volume b). It is therefore of interest to determine whether current forestry practices might be influencing the exposure of murrelet nests to predation.

Exposure to avian nest predators (i.e., jays and corvids) may be influenced by the size of a stand, and the placement of a nest relative to the edge of the stand. Paton (1994) reviewed literature on songbirds and found that artificial nests are subject to greater predation within $50 \mathrm{~m}$ of the edge of forest stands than in the center, although none of the studies were in western coniferous forests within the range of the murrelet. In British Columbia, Bryant (1994; Burger, this volume a) showed artificial nests of songbirds placed on or near the ground near the edge of a stand were more frequently preyed upon than those in the center of the stand. Bryant (pers. comm. in Burger, this volume a) also found corvids on Vancouver Island to be more common along the edges of forests than in their interior. Nelson and Hamer (this volume b), from a literature review, showed that (1) loss of nest contents to avian predators increases in some forested areas with habitat fragmentation and an increase in the ratio of forest edge to center habitat; (2) successful nests were further from edges (more than $55 \mathrm{~m}$ ) and were better concealed than unsuccessful nests; and (3) small stand size, fragmentation of forests, and the opening of roads and other clearings all increased the ratio of forest edge to center.

The failure rate for Marbled Murrelet nesting attempts may have increased due to an increase in the numbers of avian, especially corvid, predators and their foraging effectiveness (Nelson and Hamer, this volume b). Corvids are well known camp followers in parks and other outdoor recreation areas, and frequently follow or approach people in forested areas. Activity by researchers in the area of murrelet nests may attract corvids and increase the likelihood of murrelet nesting failure. Murrelets have nested successfully in the vicinity of campgrounds (Naslund 1993, Singer and others 1991), but it would be useful to test whether predators are more common where buman activity is present. It will also be important to review research procedures to ensure that predators are not gaining clues about the location of murrelet nests from researchers (see Nelson and Hamer, this volume a).

\section{Adult Mortality}

Mortality of adult Marbled Murrelets may occur from natural or human causes. Predation on adult murrelets by raptors occurs in transit to nest sites and at nest sites, but has 
not been documented at sea. Given the small number of nest sites that have been monitored, observations of the taking of adult murrelets by predators raises the possibility that this is not a rare event. In recently documented cases, a Sharp-shinned Hawk (Accipiter striatus) in Alaska attacked and killed a murrelet as it came to its nest (Marks and Naslund 1994), and a Peregrine Falcon was observed taking adults at Waddell Creek, California (Suddjian, pers. comm.). In Alaska, Marbled Murrelet wings were the most common prey remains found at coastal Peregrine Falcon nests (Jeff Hughes, pers. comm. to Kuletz), bones have been found at other Peregrine aeries (Campbell and others 1977), and the remains of unidentified alcids have also been found in goshawk nests (Iverson, pers. comm.). These anecdotal reports are primarily within the Gulf of Alaska region, where Ancient Murrelets were also found to form an important part of the Peregrine's diet (Gaston 1992). Therefore, it seems likely that Marbled Murrelets may also form a substantial part of the diet of avian predators.

Marbled Murrelets are vulnerable to discharge of pollution from point sources on land, to fouling by spilled oil, and to bycatch in gill nets (Carter and Kuletz, this volume; Carter and others, this volume; Fry, this volume; Kuletz 1994; Piatt and Naslund, this volume). Pollution discharged from point sources on land, particularly when it enters partially enclosed shallow bays, is a potential problem (Fry, this volume). For example, Miller and Ralph (unpubl. data) observed an increase in murrelet use of the coast immediately north of Humboldt Bay in 1993 after pulp mill effluent ceased to be discharged into the ocean. This was likely a response to increased prey (Ainley, pers. comm.). Oil spills are also of considerable concern, and have caused numerous losses of murrelets. In Alaska, the Exxon Valdez oil spill is estimated to have killed about 8,400 murrelets, approximately 3.4 percent of the Alaska population (Piatt and Naslund, this volume).

Nearshore gill-net fisheries are an important source of annual mortality in some regions. Murrelets are particularly vulnerable to entanglement in gill nets during the hours of darkness (Carter and others, this volume). Based on the compilation of DeGange and others (1993), an estimated 2,000 to 3,000 Marbled Murrelets are killed annually in Alaskan gill-net fisheries. In Barkley Sound, British Columbia, Carter and Sealy (1984) estimated that a gill-net fishery for salmon (Salmo sp.) in 1980 killed 7.8 percent of the projected fall population of murrelets. The location of that fishery was in an area where high densities of murrelets overlapped with an area that was intensively fished. That fishery has not opened in every year since 1980 (Carter, pers. comm. in DeGange and others 1993), and the 1980 value might not be typical of a long-term average mortality. In Puget Sound, Washington, Wilson (pers. comm.), estimated that as many as several hundred murrelets are killed in gill nets annually. These numbers, if correct, are a large proportion of the estimated murrelet population in the Sound. Few, if any, murrelets are killed in gill nets in Oregon or California, although, prior to the ban of shallow water gill netting in
California, murrelets were killed (DeGange and others 1993). The annual mortality rates of Marbled Murrelets projected for salmon gill-net fisheries of Washington, British Columbia, and Alaska are of a magnitude to cause concern because of overriding influence of adult survivorship on murrelet demographics (Beissinger, this volume).

\section{The Future Course of Habitat and Populations}

\section{Hahitat Trends}

We believe that the ultimate fate of the Marbled Murrelet is largely tied to the fate of its reproductive habitat, primarily old-growth forest or forest with an older tree component. It is clear that the amount of Marbled Murrelet nesting habitat has declined over the past 50 years, due primarily to timber cutting (Perry, this volume). Bolsinger and Waddell (1993) estimated that total acres of old-growth forest in California, Oregon, and Washington declined from nearly 33 million acres in the 1930s to about 10 million acres in 1992 (of a total forested area of 66 million acres), although their analysis was based on a broader region than the range of the Marbled Murrelet. Of the remaining 10 million acres of old-growth in this region, 85 percent is under federal ownership. Federal lands within the range of the northern race of the Spotted Owl (Strix occidentalis) in these three States contain an estimated 2.55 million acres of potential murrelet nesting habitat (U.S. Dep. Agric./U.S. Dep. Interior 1994). Some biologists, however, estimate that much of this land is too far inland and at too high an elevation to be used by murrelets (Hamer, pers. comm.). Assuming these federal lands represent about 85 percent of all murrelet nesting habitat on all lands, the future of current habitat heavily depends on management decisions on the federal lands.

The U.S. Government's Forest Plan is projected to conserve 89 percent of current murrelet nesting habitat within various categories of reserves on Federal lands in California, Oregon, and Washington. This amount of land represents approximately 75 percent of present murrelet nesting habitat in the three States. In addition, the plan calls for protection of nesting habitat within half-mile circles around all occupied sites. Therefore, in the short term, we expect little further loss of current habitat on Federal lands if the plan is implemented (although some occupied sites have been released to logging). Over the long term, we expect the amount of habitat on Federal lands to increase, as younger forest within these reserves matures.

In Alaska, about 90 percent of the coastal old-growth forests remain from Kodiak Island to northern Southeast Alaska. Approximately 93 percent of what is classified as productive (and of that, about 58 percent of the highly productive component) old-growth forests that represent Marbled Murrelet habitat remain on the Tongass National Forest in southeast Alaska (Perry, this volume). At this time there is no direct evidence that highly productive stands are 
used more than the lower volume productive stands in southeast Alaska. The results of Kuletz and others (in press, this volume) in Prince William Sound, Alaska, and Burger (this volume) in British Columbia do, however, suggest that stands with higher densities of old-growth trees have characteristics associated with high murrelet use. We cannot predict the trend of the remaining old-growth forests, as it will depend on the final outcome of National Forest land management plans. We expect further decline in area of murrelet nesting habitat in regions where terrestrial habitat loss continues, and we expect this decline to stabilize eventually. But when, and at what level, this stabilization will occur, is difficult to foresee. The apparent reduction of the species' population by 50 percent in Alaska must be viewed with concern. Similarly, in British Columbia, with only about 30 percent of original coastal old-growth forest remaining and a likelihood of further loss, we cannot predict when the amount of suitable habitat will stabilize.

On State lands, the status and trend of murrelet habitat depends on state forest practice regulations and implementation of take guidelines or Habitat Conservation Plans in cooperation with the U.S. Fish and Wildlife Service under the Endangered Species Act. In Washington, the State may seek an incidental take permit in exchange for delineating and protecting most currently occupied suitable habitat. Future management is difficult to predict, as new information may lead to revised definitions of suitable habitat and new management strategies. On tribal lands, we do not have information on likely management direction. On private lands, reduction of habitat with apparent breeding behavior is likely in the short term, but Habitat Conservation Plans may be undertaken by larger land owners. These plans may result in agreements to harvest some habitat in exchange for deferral of harvest of other habitat.

\section{Population Trends}

As we have suggested, available evidence indicates that the population of murrelets has declined over most of its range. As more nesting habitat is lost, coupled with the adult mortality in some areas from gill-net fisheries and occasional oil spills, we expect continued decline in the population of murrelets. The rate of future population decline may exceed the rate of habitat loss because of cumulative effects on adult survival. At-sea counts do not necessarily reflect breeding density, as some lag is expected between reduction in the nesting habitat and a decline in the at-sea population. Thus, effects may not appear in the form of a declining population for a decade or more. Murrelets are suspected to be long-lived, and adults may survive at sea even if nesting habitat is removed, perhaps leading to the low ratio of juveniles to adults found in at-sea counts in recent years (Beissinger, this volume). Reduction in prey, as might be occurring in recent warm-water years (1992-93), may also lead to a lower proportion of adults nesting and to lower reproductive success among those birds that do nest.
We do not have the necessary information to predict what proportion of the current population can be lost without irreversible consequences. The most prudent strategy for now is to conserve those forest stands (where the species is listed) that currently support murrelets within each physiographic region; between these conserved areas, additional areas should also be set aside to improve the likelihood of recolonization of unoccupied areas.

Some provision for catastrophic habitat loss and other unpredictable events is a necessary component of a conservation strategy. We cannot count on all areas of habitat to persist indefinitely. The forests within the range of the Marbled Murrelet are subject to periodic wildfire, to insect or disease outbreaks, to large scale windthrow, and other catastrophic losses. Managers will need to apply active management to reduce risk of loss in some regions. We recognize, however, that not all of these effects are bad, as some of these events result in creation of nesting habitat by stimulating formation of nesting platforms.

The following key points are clear:

(1) Murrelet population trends will vary by region, in relation to changes in the amount, distribution, protection, and ownership of remaining forest habitat, catastrophic loss of breeding habitat, prey abundance, and extent of mortality factors, such as oil spills, gill netting, and predation on adults and young.

(2) A need exists to establish the relative importance of nesting habitat versus other factors in causing population trends. We assume that the trend in amount and distribution of suitable nesting habitat is the most important determinant of the long-term population trends.

(3) Existing demographic methods do not permit analysis of population trends in relation to variation in quality of habitat (measured by amount and pattern of appropriate forest structure), because of the cost of gathering such data.

(4) Given current knowledge or demographic methods, we are unable to know the likelihood that any population of murrelets is approaching a demographic threshold from which recovery may not be possible.

(5) Net change in amount of habitat is a function of loss of current habitat versus succession of potential habitat. If other demographic characteristics prevent recovery as suitable habitat stabilizes or increases (that is, if murrelet populations continue to decline), then other factors are regulating the population.

(6) Populations are relatively large in Alaska and British Columbia, perhaps allowing more time to evaluate trends than in other parts of the range. However, large population declines in Alaska are, at least, cause for concern. Certainly, throughout the range, immediate management efforts should be directed towards maintenance of the North American population at or near present levels. In Alaska and British Columbia, we need an accelerated effort to better understand murrelet ecology and habitat relationships through research and surveys. These need to be initiated immediately, and a conservative habitat management approach needs be adopted in the interim. 
(7) The cumulative effects of further incremental loss of existing habitat, in addition to continued loss of adults at sea, must immediately be considered and dealt with by all relevant agencies. To this end, we strongly suggest that a prudent strategy would be to curtail further loss of occupied nesting habitat in at least Washington, Oregon, and California. Further, the sharp reduction, or preferably elimination, of night-time inshore gill netting at the earliest possible date, within the areas where murrelets are known to concentrate on the water, would greatly reduce the risk of adult mortality.

\section{Management}

The objectives of efforts to conserve the Marbled Murrelet should be to manage habitat and other factors to achieve a stable, well-distributed population of the species throughout its range. The U.S. Marbled Murrelet Recovery Plan (U.S. Fish and Wildlife Service, in press) has considered management alternatives, and most of our suggestions come from their findings. In some cases we further define potential management needs based on findings in this volume.

We agree with the U.S. Recovery Plan (U.S. Fish and Wildlife Service, in press) that the next 50 years will be the most critical period for murrelet conservation. Assuming that there has recently been a severe and critical loss of breeding habitat, the lag from the longevity of the species will result in continued population decline, resulting from birds dying without replacement over the next decade or two. Further, the loss of suitable habitat will continue, albeit at a reduced rate for the coming decade, at least. While efforts to stem adult mortality can be successful, they do not increase productivity. Only with increased suitable habitat, will the population again increase. Some areas, peripheral to present nest stands, could mature and become at least marginally suitable in 50 or, more likely, 100 years. We would expect that such succession, augmented by creative silvicultural practices to mimic older forests, could result in increases in the breeding population within 50 to 100 years. The sooner that habitat loss can be stopped and replacement of suitable habitat begun, the sooner the species can begin to recover substantially.

\section{Management of Current Nesting Habitat}

The overall objective of managing current nesting habitat should be to stabilize the amount of habitat as quickly as possible. This objective is expected to have the long-term effect of stabilizing or increasing the proportion of breeding adults and stabilizing or increasing juvenile recruitment.

\section{Identify Management Units at Various Scales}

Broad objectives by management agencies should be based on biological processes, not on political or administrative boundaries. The overall goal should be to maintain a well-dispersed Marbled Murrelet population, with each segment of the species' range managed to maintain a viable population. We suggest that management should be on a zonal basis and that nine Zones be designated. The U.S. Recovery Plan (U.S. Fish and Wildlife Service, in press) suggests six Conservation Zones for management in Washington, Oregon, and California as the basis for maintenance of the population. We would add additional zones to include all populations in North America. They are: (1) the Aleutian Islands Zone; (2) Southcentral Alaska Zone, including Prince William Sound, and 40 miles inland; (3) Southeast Alaska and Northern British Columbia Zone, from Yakutat Bay, Alaska and coastal British Columbia, south to Vancouver Island, and 40 miles inland; (4) Vancouver Island and Puget Sound Zone, including the Olympic Peninsula, and 40 miles inland; (5) the Southwest Washington Zone to 40 miles inland; (6) Oregon Coast Range Zone, south to Coos Bay and 35 miles inland; (7) the Siskiyou Coast Range Zone of southern Oregon and northern California to the Humbolt County line, south of Cape Mendocino, and 35 miles inland; (8) the Northcentral California Zone to include Mendocino, Sonoma, and Marin counties, and 25 miles inland; and (9) the Central California Zone south to Point Lobos in Monterey County, and 25 miles inland. These Zones are smaller to the south where populations are more fragmented and at greater risk. At the Zone level, broad objectives can be based on large-scale distribution of murrelet populations. Within each Zone, forest management could be planned on a scale that is relevant to the biology of the murrelet. We suggest that a relevant scale is at least 100-200 miles of coastline.

The rationale for this scale of analysis is that individual birds are known to travel as far as 60 miles in one direction, so a given offshore group could range over an area twice as wide (120 miles plus). It would be best to consider that the size of protected stands be a minimum of $500-1,000$ acres or more. This does not imply ignoring smaller occupied stands; this would not be desirable. Rather, these small stands could be included within larger units when possible. It is critical to avoid the incremental loss of small units that could lead to a small core population of murrelets lacking viability. Management units would be most effective if tied to existing land classification systems such as USGS hydrological basins. In Southeast Alaska, individual islands might be useful management units.

\section{Identify Highest Priority Sites Within Management Units}

Where available, we suggest the use of multi-year inland survey results to identify areas of high use, as Burger (this volume a) suggests for British Columbia. If these data are not available, then managers could use at-sea survey results to infer habitats that might support the highest numbers of murrelets within each management unit. This is usually only useful on a large scale; for example, no correlation has been found between activity at inland sites and immediately adjacent waters. On the other hand, the foraging area of the Waddell Creek population near Santa Cruz, California, appears to be closely tied to the nesting area (Ainley and others, this volume). 
We suggest that for areas where nesting and foraging locations have not been identified, inland sites of best remaining nesting habitat could be selected, using information from studies of habitat requirements. These areas would have the highest likelihood of supporting adequate numbers of nesting platforms and other structural elements correlated with nesting. This effort should be supported by inland surveys conducted to protocol standards to verify occupancy, but it is not practical to expect all potentially suitable habitat to be surveyed.

\section{Determine Current Management Status}

High-priority sites could then be evaluated to determine their likely level of long-term protection (usually likelihood of being reserved from timber cutting). That is, they could be evaluated as to whether they are under protection as late-successional reserves, or whether they are publicly or privately administered lands.

\section{Develop Management Strategy for Each Management Unit}

We suggest that a management strategy then be developed for each unit, based on the potential to support nesting and the role within a broader landscape (e.g., is this an area of special concern due to gaps in distribution, or lack of adjacent similar habitat?). The most effective and least risky technique to slow the current population decline is to conserve all current occupied sites or high quality habitat in areas where it is a listed species. If appropriate, especially on private lands and over the longer term, guidelines should be developed for removing murrelet habitat. For this effort, it will be necessary to determine the proportion of some specified land area around a site that can be cut without jeopardizing suitability of that site. For example, Raphael and others (this volume) found that, in Washington, $>35$ percent of the 200 hectares surrounding occupied sites was late-successional forest. Similar analyses should be conducted in other regions to test whether more general guidelines can be developed.

It is often an issue as to what effect the cutting of a tree or a partial harvest has on the birds. If nesting habitat is a limiting factor in an area, then the options for a bird to move to uncut habitat might be limited when a nesting stand or potential nest trees are removed. Although an individual might be able to move to an occupied stand, the increased risk of predation with increased density of nests could offset the advantages of this move. If evidence shows that nesting density is not at saturation, which would have prevented more pairs breeding, then this viewpoint could be changed. By the same logic, removal of non-nest trees could increase the risk of other factors, such as a resulting increase in predator populations (because of an increase in other prey populations), increased access of predators into the stand, and a decrease in hiding cover for murrelet nests. Such management activities could be interpreted as the biological equivalent of the removal of individuals from the reproductive population. For example, a tree hazard removal program in a state park could have the effect of removal of old-growth trees. If continued over the next 50 years, there certainly could be a significant reduction of murrelet habitat. As an example, tree hazard removal is occurring in most of the old-growth forests that have recreational facilities in California (Strachan, pers. comm.). We recommend that managers consider removal of developments, such as campgrounds, that are currently in old-growth.

\section{Evaluate Potential for Disturbance}

In the case of disturbance due to human activity in forest stands, the timing of disturbance can be adjusted to avoid disruption of murrelet activity, such as courtship, mating, or nesting. Risks to perpetuation of these sites from effects of fire, insects, disease, windthrow and other catastrophic events, should be evaluated. Actions to reduce such risk may be appropriate. We assume there will always be loss of habitat through natural processes, and management actions should allow for such losses. We need additional information about the likelihood that human activity near nests has any detrimental effects.

\section{Management for Buffer and Future Suitable Nesting Habitat}

The objective of managing for buffer and future suitable habitat is to provide additional structural cover to reduce fragmentation of nesting habitat, and to provide for replacement of habitat that might be lost from catastrophic events. This would provide a hedge against stochastic events and uncertainties in knowledge. This secondary habitat may also support additional nesting.

\section{Identify Habitat for Buffer Secondary Stands}

Identification of secondary habitat should be based on proximity to known nesting habitat and its potential to develop as nesting habitat within an appropriate time, perhaps 25 to 50 years. These secondary stands may serve as buffers around nesting stands to reduce risk of windthrow or other loss.

\section{Accelerate Habitat Development by Silviculture}

The potential (as yet untested and uncertain) exists to apply silvicultural techniques such as thinning and canopy modification that could accelerate the attainment of suitable habitat conditions in younger stands. These techniques need to be tested and fully evaluated in an adaptive management framework before being counted on to provide expected habitat conditions. If successful, such techniques might be used to produce trees with suitable nesting platforms and canopy characteristics.

\section{Managing At-Sea Habitats and Risks}

The management of marine habitats to reduce risks of mortality from human sources may be of equal importance to the management of terrestrial environments to maintain nesting habitats. It is essential for managers to identify at-sea areas where murrelets concentrate during both the breeding and non-breeding seasons. These areas should be designated as 
critical habitat and managed to reduce harm to murrelets. Threats to murrelets at sea include entanglement in fishing nets (particularly nearshore gill nets), oil spills, the presence of other pollutants (especially those that might affect the availability of prey organisms), and other factors causing loss of forage fish. However, we see the greatest challenges in the marine habitat to be the reduction of human-caused mortality of adult murrelets, rather than the enhancement of prey availability. Managing at-sea conditions will require overcoming jurisdictional problems involving overlapping responsibilities of multiple agencies (NOAA, U.S. Navy, U.S. Coast Guard, National Marine Fisheries Service, Environmental Protection Agency, U.S. Fish and Wildlife Service, USDA Forest Service, marine sanctuaries, tribal agencies and groups, and various state agencies, among others). Any solution will require close coordination and cooperation among all relevant agencies, and will be most effective if coordination is started at the highest political level (e.g., between Secretaries of relevant departments, and with coordination amoung appropriate state agencies and tribes).

There is also a need for international cooperation between the United States and Canada in marine management. Already in place is the British Columbia/Washington Environmental Cooperation Council with a Marine Science Panel, as well as the British Columbia-Alaska-Washington-OregonCalifornia Oil Spill Task Force.

\section{Research Needs}

We suggest a series of high-priority research needs for the species, as follows. We list these approximately in the order of what we consider their importance, although, in different regions, different priorities would apply.

\section{Inland Range of the Species}

The protection of nesting habitat requires defining the inland extent of murrelet habitat use. This has been based on observations of birds at inland sites. At some distance from the coast, the abundance of birds drops dramatically. Agencies have required that surveys be conducted at and beyond the farthest inland records of the species. We suggest that surveys to determine habitat use be concentrated at distances from the coast where the great majority of the population lives. We see little virtue in surveys conducted where murrelets only rarely explore. It is our opinion that these extremely peripheral areas can contribute very little to the species' survival. We also suggest that surveys be conducted at a distance from the coast in which more than 99.9 percent of the individuals in a region have been detected. The U.S. Recovery Plan (U.S. Fish and Wildlife Service, in press), defines "critical habitat" as being within 40 miles of salt water in Washington, 35 miles in Oregon and California north of Trinidad Head, and 25 miles for the remainder of California. With limited resources available for surveys, it seems prudent, from the standpoint of the conservation of the bird, to concentrate the majority of murrelet survey effort to these zones.

\section{Inland Habitat Association Surveys}

Habitat association patterns have received much attention, but a greater information-gathering effort needs to be made in most areas. Especially needed are surveys in forests of Alaska and British Columbia. Also needed are systematic surveys throughout actual and potential habitats to determine relative abundances (as estimated by activity level) according to the variables described in the various chapters, as well as along coastal-inland transects. Among the most important variables are the size of stands, their structure, and landscape configuration. While we have a good idea of the correlation of some variables with abundance of murrelets, knowledge is lacking of the actual way that these variables are important to the reproductive success of the species. We do not suggest, however, that large-scale manipulative experiments be launched with the idea of using this worthy method, especially from Washington south, where the potential negative effects of experimentation on already tenuous populations would be great. Rather, humans and nature have provided a range of natural conditions that can give a retrospective view of the habitat suitability. These effects include partial harvesting of timber, as well as thinning due to disease, fire, and windthrow.

Related to the above is the minimum stand size for occupancy. Part of the research involving stand size should include the gathering of data on the number of birds occupying a stand and the number of nests present. Using the number of detections in a stand (currently the only metric available), one could then estimate, at least in part, if bigger stands support more or fewer birds per unit area than smaller stands.

\section{Evaluate Importance of Human Causes of Mortality at Sea}

It is essential to obtain robust data on the take of murrelets in inshore gill nets and to relate that take to densities of murrelets in the area being fished, as well as the modes of fishing. Modifications of fishing techniques, such as limiting fishing to daylight hours or appropriate changes in mesh size, should be sought in areas where murrelets are killed, so as to reduce the bycatch. Gill-net fishing in inshore waters where murrelets are abundant should be prohibited at an early date, if less drastic measures are not successful. The concerns about loss to gill nets are particularly great in Washington and British Columbia, but apply throughout the species' range. Similar concerns apply to loss from oil spills and detailed knowledge of the distribution of murrelets could alert managers to potential areas of extreme risk to certain populations.

\section{Risk of Nest Predation Versus Forest Structures}

It is essential to determine the role of predation in populations by studying nesting success. We must also determine the influence of forest stand structure, and in particular the importance of the ratio of forest edge to interior area, on the number of predators present and how these factors affect the probability that a nest will be lost to predation. Surveys of the populations of potential predators in forest stands of 
varying types and degrees of fragmentation will provide the information on the direct effects of forest management on this source of mortality. Predation rates can be altered by forest types also, as the exposure of nests becomes greater with a more open forest. These data can be taken at the same sites as the surveys for murrelets described below.

\section{Population Size and Trends}

The sizes of populations in most of the range have only been approximated. Intensive surveys by air or sea can provide at a minimal cost a reliable index of population size. This is especially critical in Washington and Oregon, but is needed in most other areas of the range as well. Since definitive long-term trend data are lacking in virtually all populations, and are absolutely necessary for comparing the effects of management, succession, stochastic events, or the aging of the murrelet population, immediate efforts should be initiated to establish long-term studies. Calibration of at-sea survey techniques, including determination of the time of year when surveys are best done to determine population size, are needed. As part of this study, the hypothesized relationships between numbers of murrelets seen offshore, the number of detections during dawn watches, and the number of murrelets nesting in a stand should be tested. We recommend convening a workshop to evaluate at-sea sampling and data analysis methods.

\section{Demographic Information}

The methods of determining the demographic parameters of murrelets need to be expanded and refined. At present, observations of nests and the finding of young at sea provide the only clues about the demography of the species. These methods need to be continued and expanded, and new methods devised.

\section{Limitations of Fish Stocks}

We do not know if the availability of fish species important to murrelets has declined, because the relationship of the abundance and distribution of the several species taken by the bird and the interplay of the behavior and distribution of foraging birds is unknown. Use of bioacoustics could provide the data on fish abundance and distribution simultaneous with information on the birds' distribution, abundance, and foraging. We urge that these methods be implemented in at least two or three regions immediately. These methods would provide a basis for establishment of marine reserves to provide a source of abundant food fish for critical key areas of murrelet feeding, as well as providing a source of fish stocks for surrounding areas. Part of this research would include studies on the food habits of the murrelet.

\section{Genetic Structure of Populations}

Determinations should be made about the size of the various gene pools, the relative divergence of the populations, and the importance of gaps in distribution. We need genetic samples taken from throughout the range of the species.

\section{Coloniality and the Saturation of Nesting Sites}

The degree of clumping of murrelet nests should be determined on a stand, forest, and landscape basis, once sufficient data on nest locations are available. A determination should be made about the extent to which behavioral spacing mechanisms used by murrelets affect the density of birds in a stand and the potential for selective harvest of trees.

\section{Effects of Human Disturbance}

Both in forests and at sea, the effects of various types of human disturbance should be evaluated in controlled experiments. It is not necessary to conduct these experiments in areas where timber harvesting is being carried out, as the noise and traffic of such activities are easily simulated.

\section{Conclusions}

We conclude that the stabilization and recovery of murrelet populations will be aided by (I) provision of adequate nesting opportunities, (2) elimination of sources of adult mortality by human impact and development, and (3) management to minimize loss of nest contents to predators.

Specifically, we suggest the following steps be taken:

1. Maintain a well-dispersed Marbled Murrelet population, with each segment of the species' range managed to maintain a viable population. Nesting habitat appears to be a primary limiting factor in maintaining murrelet populations. We feel any futher reduction in nesting habitat or areas for the murrelet in Washington, Oregon, or California would severely hamper stabilization and recovery of those populations to viable levels. Occupied habitat should be maintained as reserves in large contiguous blocks and buffer habitat surrounding these sites should be enhanced.

Progress in attaining population stablization or enhancement can be measured by an increase in the productivity of the population, by increases in the total breeding population, an increase in the ratio of juveniles to adults in offshore population, and an increase in nesting success. It is critical that relevant agencies move quickly to put in place monitoring programs suggested above which can provide at least some of these data.

2. We suggest management for the murrelet on a regional basis, such as the Conservation Zones recommended by the U.S. Marbled Murrelet Recovery Team (U.S. Fish and Wildlife Service, in press). We strongly urge that objectives by management agencies be based on biological processes, not on political or administrative boundaries, as much as possible. The overall goal should be to maintain a well-dispersed Marbled Murrelet population, with each segment of the species' range managed to maintain a viable population.

3. Draft a landscape-based habitat conservation plan within each of the nine zones described above to ensure the maintenance of a viable population. As a result of this step, the suggested reserves would likely need to be augmented to 
promote conservation of the species. We feel that the reserves alone would be insufficient to reverse the decline and maintain a well-distributed population.

4. Adoption of the U.S. Recovery Plan's (U.S. Fish and Wildlife Service, in press) strategy that Late-Successional Reserves, as defined (U.S. Dep. Agric./U.S. Dep. Interior 1994), within the Conservation Zones of the murrelet in Washington, Oregon, and California, could be designated and serve as Marbled Murrelet Conservation Areas.

5. Conduct inland surveys in all suitable habitat within 55 miles of the coast. Most effort in surveys and research should be within the region of critical habitat defined by the U.S. Recovery Team (U.S. Fish and Wildlife Service, in press), within 40 miles of salt water in Washington, 35 miles in Oregon and California north of Trinidad Head, and 25 miles for the remainder of California, to help define the known habitat components of the species.

6. Accelerate efforts to better understand murrelet ecology and habitat relationships. Whereas the Alaskan and British Columbia populations are considered by many to be secure because of their large numbers, we have here reviewed evidence of a decline in populations in these regions and find that the evidence is sufficient to cause concern. Research efforts inland and at sea need to be started immediately, and a conservative habitat management approach be adopted in the interim. Otherwise, we believe that in Alaska and British Columbia, within the next 20 years, the species could well decline markedly, requiring similar habitat protection actions to those needed for the southern three states, where significant loss of old-growth forests has minimized management flexibility.

In British Columbia, the Canadian Marbled Murrelet Recovery Team has assembled guidelines for preservation of nesting habitat. Specifically, they have recommended preserving at least 10 percent of each watershed where logging is continuing, more if there is less habitat nearby, in minimum blocks of 200 ha. While this may be adequate, based on the experience in Washington, Oregon, and California, we do not believe that the literature is sufficient to support this level of harvesting.

7. It is useful to distinguish between the probable cause of the decline, and additional major threats to persistence and recovery. We have little doubt that the loss of suitable old-growth habitat has caused a marked decrease in the number of murrelets in most of their range. Where loss has been recent (within the last 15 years), we would expect to find there are a number of displaced adults who are no longer able to find breeding sites. In those areas, we should expect murrelet numbers to continue to fall until these displaced adults die off, as they will not be replacing themselves. Recovery of murrelet populations depends on the survival of breeding adults and their ability to produce young. The greatest threat to the recovery, therefore, is continued loss of habitat, adult mortality, and causes of breeding failure, in that order. We stress that it is critical to maintain and enhance habitat, reduce adult mortality rates due to at-sea risks and predation, and the reduce loss of nest site contents to predators. Better knowledge of how habitat structure influences predation risk would be a useful first step in setting priorities for development or protection of existing nesting habitat. What habitat features affect predator numbers and success remains uncertain.

We remain optimistic about the long-term survivablity of the species. The ability of the various agencies, organizations, members of the fishing and forestry industries, and others, to pull together in the survey and research efforts that are described in the chapters to follow, is strong evidence that many people of diverse opinions are interested in the maintenance of the Marbled Murrelet throughout its range.

\section{Acknowledgments}

Many people contributed insights into this chapter, including all of the authors of the other chapters in this volume. Gary S. Miller, of the U.S. Fish and Wildlife Service's Marbled Murrelet Recovery Team, was especially helpful and supportive, and provided the information on the listing process of the species. We thank Kelly Busse who created the range map. We also thank David Ainley, Alan E. Burger, Jack Capp, George Divoky, Ron Escaño, Jeffrey Grenier, Thomas Hamer, Chris Iverson, Kathy Kuletz, Linda Long, Garland Mason, Sherri Miller, Nancy Naslund, S. Kim Nelson, Jim Space, Steve Speich, and Craig Strong for helpful comments on the manuscript. We appreciate their insight and clear thinking. The conclusions of this paper represent, however, our collective conclusions, and differing viewpoints can be found among many biologists and in the pages of this volume. 


\section{The Asian Race of the Marbled Murrelet}

Nikolai B. Konyukhov'
Alexander S. Kitaysky²
Abstract: We present here an overview of the ecology, abundance, and distribution of the subspecies of the Marbled Murrelet inhabiting the coasts of Asia. In most regards, the species is similar to the North American race with respect to its feeding, breeding, molt, and habitat ecology. It is, however, a migratory species, moving into southern parts of its range in the Sea of Okhotsk during the winter. The population has not been censused, but may number in the tens of thousands. Populations in Asia are threatened by logging of breeding habitat, oil pollution, and gill nets.

During the last two decades, the attention of ornithologists has turned to the North American subspecies of the Marbled Murrelet, Brachyramphus marmoratus marmoratus (Gemlin), and they have gathered many data on the status and distribution of this poorly-known bird. On the other hand, relatively little information is available on the Asian subspecies of the Marbled Murrelet, B. m. perdix (Pallas). Recent work has suggested that this subspecies may actually be a separate species, the Long-billed Murrelet ( $B$. perdix)(Friesen and others 1994a, Piatt and others 1994). This paucity of data is due in large part to the difficulty in reaching the remote areas where the species breeds. This information gap could also be partially explained by the sparsity of marine ornithologists working within the large territory of the Far Eastern region of Asia. In virtually all areas where ornithological studies have been conducted, Marbled Murrelets have been recorded.

Most data on the species comes from work on Sakhalin Island, the Kamchatka Peninsula, and the Low Amur River region. In most coastal areas of the Sea of Okhotsk (except for some small areas), ornithological studies have never been carried out.

The broad outline of the breeding range can be designated quite clearly (fig. I), although the status of the species in the Koryak uplands is not clear. In the north part of its breeding range, most Marbled Murrelet records coincide with the borders of boreal coniferous forest, as establiched by Kistchinsky (1968b). The Asian subspecies, in contrast to the North American subspecies, is a migratory bird and leaves almost all of its breeding range in winter. It returns in early May to the southern parts of its breeding range (Nechaev 1986) and into northern parts at the end of May (Lobkov 1986).

${ }^{1}$ Research Fellow, Laboratory of Bird Ecology, Institute of Animal Evolutionary Morphology and Ecology, Leainsky pr.o, 33, Moscow 117071 , Russia

${ }^{2} \mathrm{Ph}$.D. Candidate, Ecology and Evolutionary Biology Department, University of California-Irvine, Irvine CA 92717

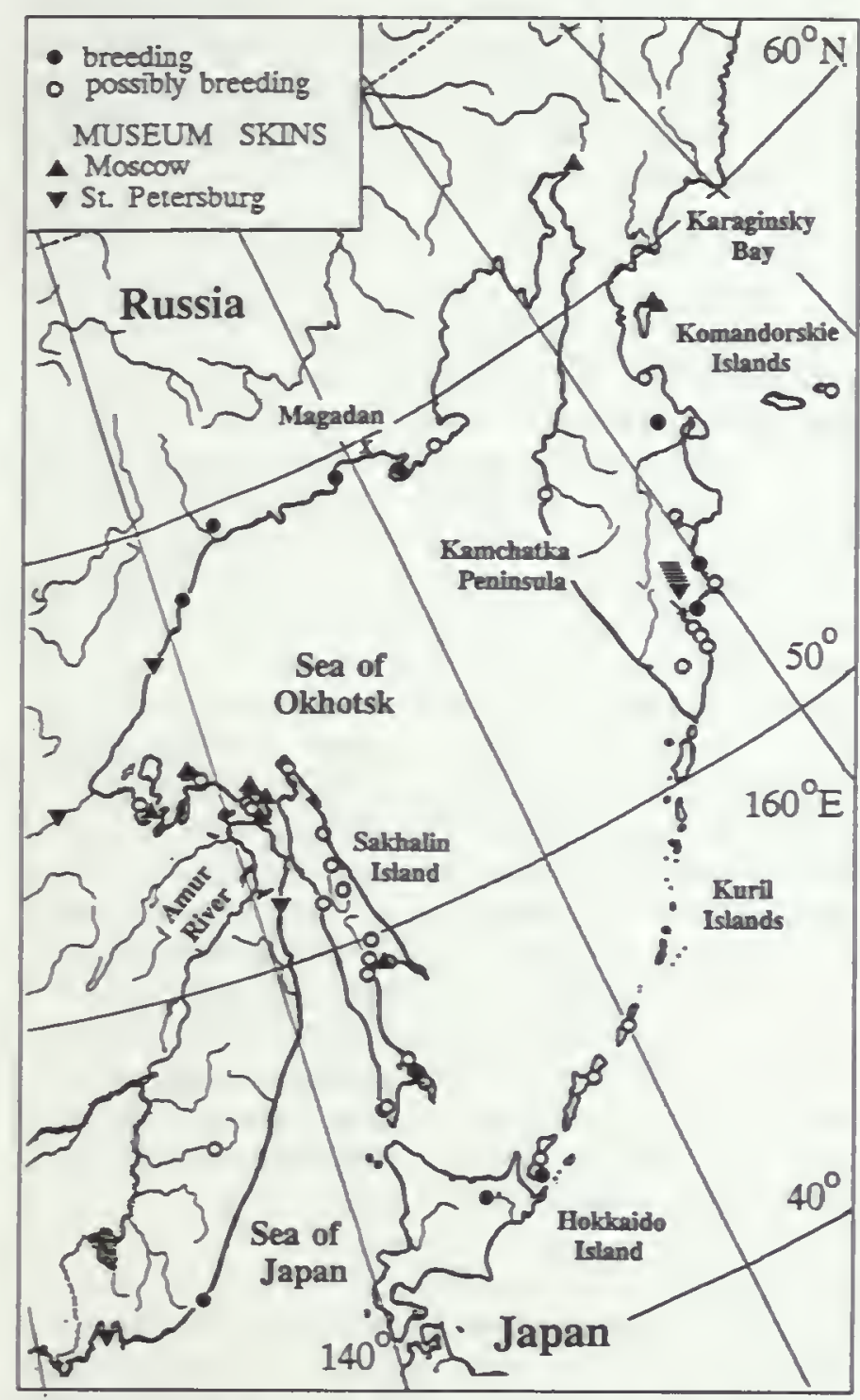

Figure 1-Distribution of the Asian race of the Marbled Murrelet (Brachyramphus mamoratus perdix) according to data obtained from literature and museum collections. Triangular symbols indicate collection locales of museum skins now in Moscow and SL. Petersburg.

\section{Methods}

In order to collect data on the distribution of the Marbled Murrelet in the Russian Far East, the senior author has examined 36 specimens in collections of Zoological Museums, both of Moscow University (ZMMU) and Zoological Institute, St. Petersburg (ZMZI). We also have investigated the biology of this species by examining all available literature, and through field observations in the Sea of Okhotsk. 


\section{Breeding Biology}

\section{Pre-Laying Period}

The wintering grounds of the Asian subspecies are thought to be situated around Hokkaido Island, Japan (excluding the shore of the Okhotsk Sea), and the northern part of Honshu Island (Brazil 1991). Although not identified with certainty as to subspecies, the Marbled Murrelet is rarely found in the waters of Kyushu, central Ryukyu, and the Amami Islands. Scattered birds have been noted inshore of the Korean Peninsula during the winter (Shibaev 1990).

\section{Timing of Breeding}

There are no direct observations of the length of the breeding season. The approximate time of hatching and fledging can be estimated from observations of fish-holding behavior by adults and of young birds at sea. Birds with fish were observed in the Amur River mouth in June (Shibaev 1990). A collected bird (ZMZI 168716/220-987) taken in July 1979 had a brood patch beginning to refeather.

Additionally, eggs and incubating birds have been found during June through the years (table 1). Specifically, eggs were found on 17 June 1961 and 23 June 1973 near the city of Okhotsk and to the south (Kuzyakin 1963, Yakhontov 1979), on 21 June 1984 in southern Primorye Region (Primorye), on 19 June 1976 on Northern Sakhalin Island (Labzyuk, cited in Shibaev 1990; Nechaev 1986), and on 15 June on Eastern Hokkaido Island (Brazil 1991). Using these data, Shibaev concluded (1990) that the breeding period is generally similar in different parts of the breeding range.

There is no information available about the duration of either incubation period or the chick-rearing period. According to Shibaev (1990), the chick-rearing period in southern parts of the breeding region is in June-July. In the northern part of the Sea of Okhotsk, we have observed murrelets carrying fish from early July until late August.

\section{Characteristics of the Egg and Nest}

Only six Marbled Murrelet eggs have been found over its vast breeding range in Russia, and three have been found on the island of Hokkaido. All of the eggs in Russia were found in the middle of June (table 1). Two of these eggs were taken from oviducts of females. One was collected on the northwestern coast of the Sea of Okhotsk $\left(58^{\circ} 30^{\prime} \mathrm{N}, 141^{\circ}\right.$ $20^{\prime} \mathrm{E}$ ) on 23 June 1977 (Yakhontov 1979), and the other on Semyachik Spit $\left(54^{\circ} 08^{\prime} \mathrm{N}, 160^{\circ} 02^{\prime} \mathrm{E}\right)$, Kamchatka Peninsula, on 13 June 1993 (Ladygin, pers. comm.). The ground color of most eggs is bluish-green or greenish-blue. Small markings of pale brown, brown, and dark-cream or brownish-gray, usually less than $2 \mathrm{~mm}$ in diameter, congregate near the blunt end of the egg (Kistchinsky 1968b, Nechaev 1986, Yakhontov 1979). The pointed end is free of any marks (Kuzyakin 1963, Nechaev 1986, Yakhontov 1979). Three measured eggs had the following sizes: $63.6 \times 39.3 \mathrm{~mm}$ and a weight of $48-50 \mathrm{~g}$ (Kuzyakin 1963); 63 x 38 (or 39) mm (Yakhontov 1979); $66.2 \times 39.0 \mathrm{~mm}$ and a weight of $53.7 \mathrm{~g}$ (Nechaev 1986). The murrelet lays only one egg (Kistchinsky 1968b).

All four nests in Russia were found in larch trees (Larix daurica). The nest in the Okhotsk and Kukuchtui rivers area (in the vicinity of the city of Okhotsk) was 6-7 km from the shore, $7 \mathrm{~m}$ up on a branch with a broad base formed by growth of several small limbs (Kuzyakin 1963). The egg was laid on a piece of lichen (Bryopodon). The nest in the Olga Bay area was in a tree, in a rocky coastal cliff area, and $2.5 \mathrm{~m}$ out on a branch similar to the above nest according to Labzyuk (Shibaev 1990). The nest on Sakhalin Island was 2 $\mathrm{km}$ from Chayvo Inlet and $5 \mathrm{~m}$ up on the broken top of the tree. The fourth nest was found in the Koni Peninsula near Magadan city. Izmailov observed that the nest was $12 \mathrm{~km}$ from the shore and $7 \mathrm{~m}$ up in the tree (Kondratyev and Nechaev 1989). In Japan, three murrelet eggs were found on the ground in mixed coniferous/broad-leaved forest on Mt. Mokoto, $24 \mathrm{~km}$ inland from the Okhotsk Sea coast on the island of Hokkaido on 15 June 1961 (Brazil 1991).

\section{Nest Attendance}

During the breeding season, murrelets often fly over the forest and mountain summits uttering sharp shrill whistles. In the morning, birds call from 0500 until 0700 , seldom as late as 0800 . In the evening they call less often, beginning about an hour prior to dusk (Nechaev 1986).

From Shibaev's observations (1990), adults visit the nest during the darker periods of the day in these high latitudes. But in the northern part of the Sea of Okhotsk, we have observed Marbled Murrelets carrying fish during both the morning period and at times during the day.

Table 1-Descriptions of Marbled Murrelet eggs found in Russia

\begin{tabular}{|c|c|c|c|c|c|c|c|}
\hline \multirow[b]{2}{*}{ Date } & \multicolumn{3}{|c|}{ Egg } & \multirow{2}{*}{$\begin{array}{l}\text { Location } \\
\text { found }\end{array}$} & \multirow{2}{*}{$\begin{array}{l}\text { Height from } \\
\text { ground } \\
\text { (m) }\end{array}$} & \multirow{2}{*}{$\begin{array}{c}\text { Distance } \\
\text { lo sea } \\
(\mathrm{km})\end{array}$} & \multirow[b]{2}{*}{ Source } \\
\hline & $\begin{array}{l}\text { Length } \\
(\mathrm{mm})\end{array}$ & $\begin{array}{c}\text { Breadth } \\
(\mathrm{mm})\end{array}$ & $\begin{array}{l}\text { Weight } \\
(\mathrm{g})\end{array}$ & & & & \\
\hline 17 June 1961 & 63.6 & 39.3 & 48.0 & larch tree & 6.8 & $6-7$ & Kuzyakin (1963) \\
\hline 23 June 1973 & 63.0 & 39.0 & - & oviduct & - & - & Yakhontov (1979) \\
\hline 19 June 1976 & 66.2 & 39.0 & 53.7 & larch tree & 5.0 & 2 & Nechaev (1986) \\
\hline 21 June 1984 & - & - & - & larch tree & 2.5 & 0 & Labzyuk (1987) \\
\hline- & - & - & - & larch tree & 7.0 & 12 & Kondratyev and Nechaev (1989) \\
\hline 13 June 1993 & 56.2 & 39.3 & - & oviducl & - & - & Ladygin (pers. comm.) \\
\hline
\end{tabular}




\section{Young Birds}

It is not clear how nestlings depart from the nest. As indicated earlier, nests can be situated close to or on the ground making it difficult for the young to take off. Some investigators believe that the young could use the nearest river or stream to reach the sea (Kistchinsky 1968a, Kuzyakin 1963).

There have been no descriptions of murrelet chicks in Asia. Young birds were found in late July 1976 on the fresh water Ozhabachye Lake on the Kamchatka Peninsula (Vyatkin 1981), in Mordvinov Bay, Sakhalin Island, on 6 August 1972 (Nechaev 1986), and in South Kuril Strait, Kunashir Island, on 8 August 1963 (Nechaev 1969). Two young birds were taken in Avacha Bay, Kamchatka Peninsula, on 9 and 18 August 1920 (Lobkov 1986). There are two skins of young birds in the Zoological Museum in St. Petersburg. These were taken from the Kamchatka Peninsula in the middle of August 1889 and in Aniva Bay, Sakhalin Island, on 23 September 1947. Four fledged young were collected close offshore near the foot of Mt. Mokoto, Hokkaido, in late August of 1982 (Brazil 1991).

\section{Foraging}

During the breeding period, the distribution of foraging Marbled Murrelets is linked to the estuarine ecosystems. They usually forage singly or in pairs, and rarely in groups of up to eight individuals. Near the southwest coast of the Sea of Okhotsk, birds fed from between $200-300 \mathrm{~m}$ to approximately $2-3 \mathrm{~km}$ offshore (Babenko and Poyarkov 1987). In Amur Lagoon they fed up to $5-10 \mathrm{~km}$ from the shore in brackish water (Shibaev 1990), the depth of which is $1-10 \mathrm{~m}$. In the Kamchatka Peninsula, birds congregate in bays, especially large ones (Lobkov 1986, Vyatkin 1981). Near the Kuril Islands, they have been observed opposite sandy beaches, very close to the shore (Velizhanin 1977). During observations in Tauy Liman area (in low-salinity water), birds foraged in shallow $(5-20 \mathrm{~m})$ inshore waters (Kitaysky, unpubl. data).

In addition to feeding at sea, murrelets forage in large freshwater lakes on the Kamchatka Peninsula. On Sakhalin Island, murrelets were found regularly on two brackish lagoons, Kronotzkoe Lake (20-30 pairs) and Kurilskoe Lake (15-20 pairs) (Lobkov 1986, Nechaev 1986).

Only the remains of invertebrates were detected in the stomachs of birds collected in late June (the beginning of the breeding season) (Yakhontov 1979). Adult birds feed their chicks on fish (Kistchinsky 1968b, Shibaev 1990), though the exact composition of the diet is not known. We have observed birds feeding on both capelin (Mallonus villosus) and sand lance (Ammodytes hexapterus) in the northern Sea of Okhotsk.

There are no direct reports on the availability of food resources, but according to indirect sources. they are ephemeral. For instance, near Baydukov Island, birds were absent on 26 July 1985, although during the previous day their density there was about 10 birds per kilometer of travel along the transect route (Babenko and Poyarkov 1987). High densities of murrelets in these areas are probably connected with aggregations of small fish, which are related to the complex dynamics of the oceanography in estuarine systems.

\section{Migration}

There is no information on visible observations of this murrelet's migration along the coastline. Birds disappear from the breeding range along the Kamchatka Peninsula in September (Lobkov 1986). In Ekaterina Bay, where they were common in summer, murrelets were gone by the end of October (Babenko and Poyarkov 1987). It is possible that a small number of birds reside in winter off Sakhalin Island (Nechaev 1986), but most of them migrate south to Japan (Brazil 1991, Shibaev 1990). It is possible that the species also winters in Alaskan waters based on a specimen (ZMZI 5033) taken on or near Kodiak Island in January 1845. It is more likely, however, that this bird was a vagrant. At least 13 specimens of this race of the Marbled Murrelet bave been collected at various inland locations in North America in recent years (Sealy and others 1982, 1991).

\section{Molt}

We have little information on the molt of the Asian race of the Marbled Murrelet. According to data taken from collected birds, primary and rectrix molt of adults takes place between late July, when all birds have old feathers, and late October, when birds are in new plumage. Some birds, taken in early September from Avacha Bay, Kamchatka Peninsula, had begun their primary molt, but others had not.

According to Koslova (1957), "A complete fall molt starts in cases with some adult murrelets in the first week of August. A female collected on 7 August in the Northern part of the Tatarskiy (Tartar) Strait (Taba Bay) had fresh feathers on the belly. Primaries, secondaries and tail feathers had not changed. Another female collected on 31 August in the Sea of Okhotsk had all its primaries, secondaries, and tail feathers fall out and the small feathers in the lower side were still in the tube [sheath] phase. Other adult individuals are delaying molt and have the full breeding plumage on the last week of August (date of collection: 18 August from the Litke Strait and on 24 August from the Ayan) without any signs of molt".

The sequence of molt is variable, and birds do not lose all their primaries at once. They can possibly fly during early stages of primary molt. The primary molt begins from the inner end of the primaries. It is likely that greater coverts of the primaries are lost earlier than the primaries themselves. Specimens show a variable amount of loss of flight feathers during molt. Individual specimens have lost between three (ZMZI 159931/425-974) and ten old primaries (ZMZI 159933/ 425-974) during molt. On the other hand, there was a specimen taken in the Sea of Okhotsk on 19 August 1845 which had lost all its primaries and secondaries (ZMZI 5047), and was obviously flightless. 
Rectrix molt begins just after the beginning of primary molt. They are lost outwards from the inner pair. Contour feathers likely begin to molt in September. Two birds taken in early September in Avacha Bay had definite alternate plumage, but their throats and cheeks were almost white. A very pale bird in alternate plumage was taken on Sakhalin Island on 20 March 1969. The ground color was almost white, and all dark colors were replaced by yellow-brown.

Shibaev (1990) describes a molting pattern in young birds as follows: "The change of nesting plumage into the first winter plumage takes place during September-October in young birds. The murrelets from the southern parts of the Far Eastern region of Asia, that had been collected in August, had a nesting plumage and had no signs of molt. The birds, collected in southern Primorye in the last week of October and in November, had changed from the nestling plumage into the first winter plumage already (excluding primaries, secondaries and tail feathers)."

\section{Body Measurements}

The Asian subspecies of the Marbled Murrelet is larger (lables 2 and 3 ) relative to the nominate race. This includes larger body mass (by about 50-70 g); larger culmen length (by about $5 \mathrm{~mm}$ ); and larger wing length (by about 5-6 $\mathrm{mm}$ ). See also Sealy and others (1982) and Piatt and others (1994) for discussion of body size characteristics.

Besides these mensural differences (Sealy and others 1982), these subspecies (or species) have differences in coloring of both their basic and alternate plumages. Jehl and Jehl (1981) noted that the North American Marbled Murrelet has a more rufous and darker alternate plumage than the Asian race, and has more pronounced spots near the eyes. In the basic plumage there is more contrast between the races (fig. 2). This can be seen by comparing pictures in field guides, for example Robbins and others (1983) and Wild Bird Society of Japan (1982). As with the basic

Table 2-Measurements of Brachyramphus marmoratus perdix, showing mean and range

\begin{tabular}{|c|c|c|c|}
\hline \multirow[b]{2}{*}{ Characteristic } & \multicolumn{2}{|c|}{ Shibaev 1990} & \multirow{2}{*}{$\frac{\text { Stepanjan } 1990}{\text { Both sexes }}$} \\
\hline & Male & Female & \\
\hline Wing length (mm) & $\begin{array}{c}141.2 \\
(136-147)\end{array}$ & $\begin{array}{c}138.3 \\
(130-145)\end{array}$ & $\begin{array}{c}143.5 \\
(133-150)\end{array}$ \\
\hline Bill length (mm) & $\begin{array}{c}20.2 \\
(18.9-22.2)\end{array}$ & $\begin{array}{c}19.0 \\
(18-21)\end{array}$ & - \\
\hline Tarsus length $(\mathrm{mm})$ & $\begin{array}{c}18.1 \\
(17-18.7)\end{array}$ & $\begin{array}{c}18.0 \\
(16.8-19.0)\end{array}$ & 一 \\
\hline Weight (g) & $\begin{array}{c}295.8 \\
(258-357)\end{array}$ & - & - \\
\hline
\end{tabular}

Table 3-Measurements of Brachyramphus marmoratus perdix fram museum specimens

\begin{tabular}{l|rrrrc}
\hline $\begin{array}{l}\text { Gender } \\
\text { Characleristic }\end{array}$ & Mean & $s . d$. & $n$ & Minimum & Maximum \\
\hline Male & & & & & \\
$\quad$ Wing (mm) & 147.2 & 3.7 & 5 & 141.0 & 150.0 \\
Tarsus (mm) & 18.2 & - & 1 & - & - \\
$\quad$ Bill (mm) & 20.0 & 1.4 & 6 & 19.1 & 22.8 \\
Female & & & & & \\
Wing (mm) & 145.0 & 7.2 & 10 & 130.0 & 156.0 \\
Tarsus (mm) & 18.8 & 0.6 & 3 & 18.4 & 19.5 \\
$\quad$ Bill (mm) & 20.3 & 1.3 & 7 & 19.0 & 22.2 \\
Pooled dala & & & & & \\
$\quad$ Weight (g) & 287.0 & 41.7 & 5 & 258.0 & 358.0 \\
Wing (mm) & 144.4 & 7.3 & 24 & 126.0 & 156.0 \\
Tarsus (mm) & 18.3 & 0.6 & 8 & 17.4 & 19.5 \\
Bill (mm) & 20.5 & 1.3 & 21 & 18.4 & 22.8 \\
\hline
\end{tabular}




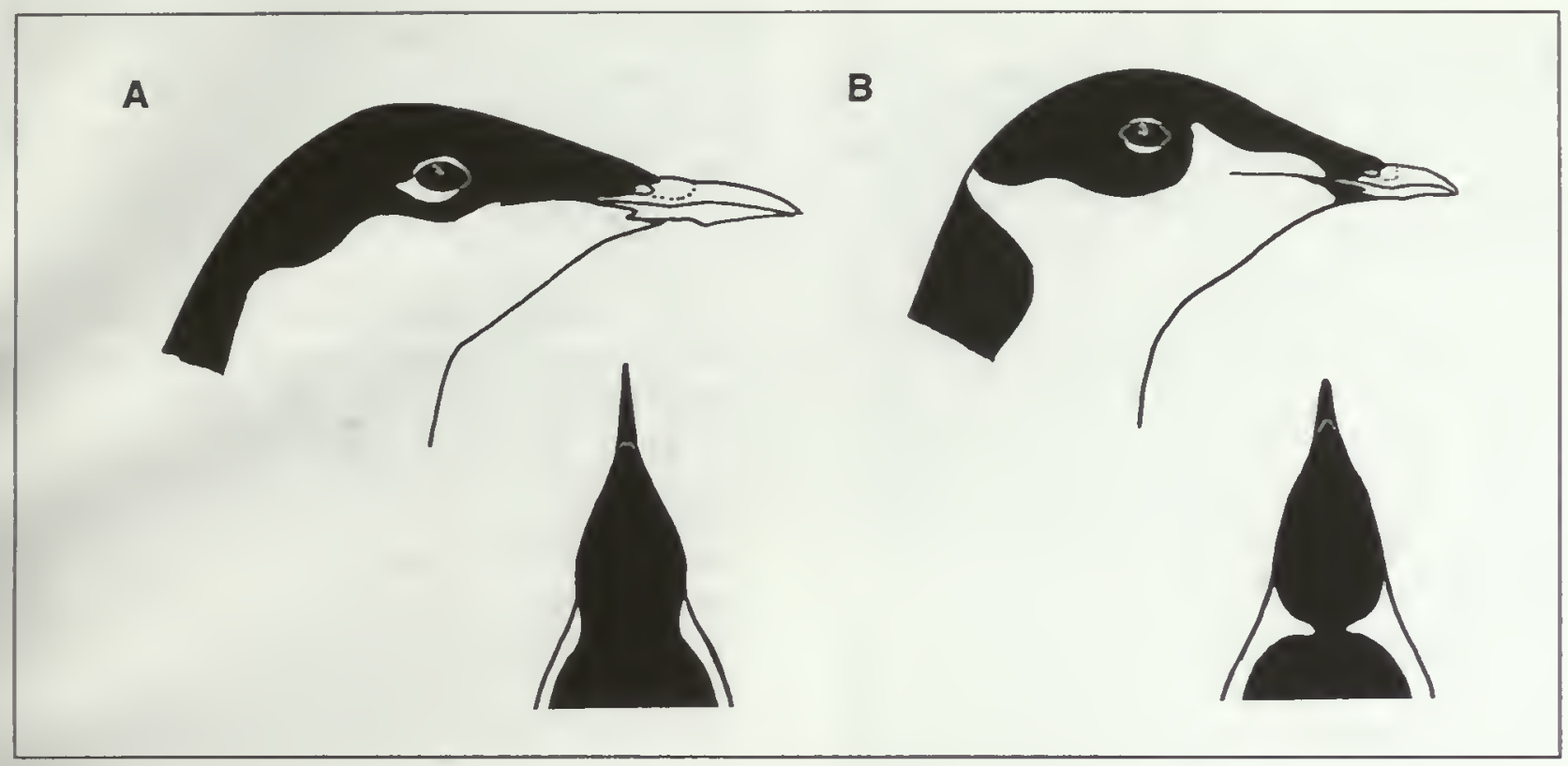

Figure 2-Basic plumage head patterns of the Marbled Murrelet subspecies: (A) Asian (or Long-billed) subspecies and (B) North American subspecies.

plumage, in the alternate plumage, the Asian race has more pronounced white eye spots. Also the border between white and dark brown on the head comes down to about the gape in the Asian race. Its upper mandible is dark and the lower is white. The chin is mainly white, but in some birds it is light gray.

In the North American race, some white is always present on its upper mandible. In different birds, white on the face extends up to before the eye, forming a crescent patch. The chin, in contrast to the Asian race, is always gray and more extensive.

The two races also differ in color of their tail feathers. In the Asian race, the outer vane of the outermost rectrix has a narrow, white marginal stripe. This stripe is especially pronounced in birds in fresh plumage. It might be absent in worn plumage because of abrasion. It is absent in the North American race.

There are also similar differences in the juvenal plumage. In the first winter, the young look like adults, but the border between dark and white coloring is not as sharp, and on the entire ventral side a slight wavy pattern is present (Carter and Stein, this volume).

\section{Breeding Distribution and Abundance}

The Asian subspecies is widely distributed around the Sea of Okhotsk, on the Pacific Coast of the Kamchatka Peninsula, and in the Kuril Islands (fig. 1). The southern limit for breeding is on the island of Hokkaido in northern Japan. It is rare in eastern Hokkaido during summer, and more common on the Sea of Okhotsk coast, especially near the Shiretoko Peninsula (Brazil 1991). Observations of the murrelet from April-August in the area led to the assumption that it breeds in the region. This was confirmed when an incubating female and three eggs were collected on Mt. Mokoto in 1961. In late August 1982, four fledged young were collected close to shore near the foot of Mt. Mokoto (Brazil 1991).

The southem limit of this species in Russia is in the southem Primorye Region where a bird was taken in Peter the Great Bay during the breeding period at the end of May (ZMZI 157639/6-971). Another location where murrelets have been taken at least twice is the middle reaches of the Bikin River (Gluschenko and others 1986). In the Primorye Region, a nest has been found in the forest on the shore of Olda Bay (Labzyuk 1987), and murrelets have been observed on the water there over many years. Birds, both single and in pairs, are found at sea there until the middle of June (Labzyuk 1975). According to these authors, the Marbled Murrelet is quite uncommon near the southem limit of its distribution.

At present, there are only a few areas where the Marbled Murrelet is considered common. One area is the lower Amur River area, on the southwestern coast of the Sea of Okhotsk. This coastline from Cape Lazarev to Aleksandra Bay was inventoried for seabirds in the summer months of 1980-1982 and 1984-1986 (Babenko and Poyarkov 1987; Poyarkov, pers. comm.; Poyarkov and Budris 1991). Densities of murrelets averaged $0.5-2.0$ birds per $\mathrm{km}$ of transect. Highest densities occurred between Baydukov Island and Aleksandra Bay. Lower densities were detected at the mouth of the Amur River and in Tatar Strait. The highest densities were found: (1) in Reynike Strait ( 300 birds on $2 \mathrm{~km}$ of transect) 
on 3 September; (2) near the western point of Baydukov Island ( 50 birds on $5 \mathrm{~km}$ on 25 July, and 89 birds on $18 \mathrm{~km}$ on 1 August); and (3) in Schastye Bay, where the species congregates in great numbers every fall. The observers did not detect any between-year differences in the number of birds. Shibaev (1990) described it as relatively common in the Amur Liman, though apparently not many birds are along the Primorye coast (Elsukov 1984) during the breeding season.

On Sakhalin Island, Marbled Murrelets breed in different areas of the island, but are very patchy in distribution. Overall, Nechaev $(1986,1987)$ considered the species to be uncommon here, but he also stated that during the breeding season it often flies over forest and mountain peaks. For example, on Shmidt Peninsula, during the peak of breeding season, voices of 1-2 birds could be heard frequently.

One bird was taken at least inland $60 \mathrm{~km}$ from the sea in the mouth of the Maya River (ca. $54^{\circ} 30^{\prime} \mathrm{N}, 134^{\circ} 20^{\prime} \mathrm{E}$ ), west of the Low Amur river area.

Despite the fact that Gizenko (1955) and Nechaev (1969) wrote that the murrelet is rare in the Kurils, later publications indicate differently. Marbled Murrelets at least breed on all of the forested Kuril Islands: Shikotan, Kunashir, Iturup, and Urup (Velizhanin 1977). Nechaev and Kurenkov (1986) said that calls have been heard from time to time all over Kunashir Island in June and July. Several pairs and separate birds were detected over the forest near Korotky Stream at dawn on Kunashir Island on 17 July 1983 (Gluschenko 1988). The species has not been recorded in the northern Kuril Islands (Podkovyrkin 1955). Since it also can nest in treeless areas (Hirsch and others 1981, Johnston and Carter 1985, Simons 1980), and breeds both on the southern Kurils and on Kamchatka Peninsula where it is common, we think that murrelets may nest on all the larger islands through the Kuril chain (fig. 1 ).

Near Magadan, this species is quite common in waters of Khmitievsky Peninsula, Tauyskaya Bay (Kondratyev and others 1992; Konyukhov, unpubl. data), and the Koni Peninsula (Leito and others 1991). The murrelet also is very common in Tauyskaya Bay in June through August. There we have found about 4 pairs per kilometer of coastline in June-July of 1991-1992. More than 200 birds were recorded in Nagaeva Bay (near Magadan) in June 1992 during a onehour vessel trip along shore. In contrast, their abundance is very low along the northern coast of the Sea of Okhotsk (Kistchinsky 1968a, Yakhontov 1979).

On the Kamchatka Peninsula the murrelets are quite common. It has been recorded within the inshore waters of the eastern coast, north to Karaginsky Bay, where they were more numerous in the larger bays. Eleven pairs were observed during a $50-\mathrm{km}$ transect from Zhupanovo village to the Zhupanovo River, at a distance of 1-2 km from shore, on 27 June 1973 (Lobkov 1986). Additional records are as follows: two in Asache Bay on 10 August 1972, four birds in Russian Bay on 13 August 1972; 52 birds in the southern half of Kronotzky Bay, from a ship over a 40-km transect on 16 June 1974; and two pairs were seen daily in Ukinskaya Bay during May and early June (Vyatkin 1981). Many specimens have been taken from Avacha Bay, near the city of Petropavlovsk-Kamchatskiy.

It is possible that the species nests on the Komandorskie (Commander) Islands. Dementiev and Glagkov (1951) and Kuzyakin (1963) have mentioned that Dybovsky had found an egg on Medny (Copper) Island, which has been ascribed to the Marbled Murrelet. The size of the egg $(62.5 \times 41.2$ $\mathrm{mm}$ ) was about the same as Marbled Murrelet eggs that have been described recently. One individual was also collected near that island in the spring. Later, Kartashev (1979) suspected that he had there a chick of the Ancient Murrelet (Synthliboramphus antiquus). He wrote: "The chick of the Ancient Murrelet, completely covered with down and with contour feathers beginning to erupt their sheaths, was found in a narrow crack of a cliff face near the southernmost tip of Medny (Copper) Island on 8 July 1960." One of us (Konyukhov 1990) had thought that this was a chick of the Kittlitz's Murrelet (Brachyramphus brevirostris), but because of the possibility of nesting Marbled Murrelets on land in crevices (Johnston and Carter 1985), and absence of records of enclosed Kittlitz's Murrelet nests, the senior author now thinks that the chick found by Kartashev was that of a Marbled Murrelet. Recent studies have shown presence of this species in that area during the breeding season. One bird was observed in Lisinskaya Bay, Bering Island, about $300 \mathrm{~m}$ from the shoreline on 17 June 1993 (Artyukhin, pers. comm.).

Besides the nests noted previously, a breeding male was collected in Tayozhneya Bay in northern Primorye (Elsukov 1984) and a female with a developing egg was collected 200 $\mathrm{km}$ to the southwest of Okhotsk City (Yakhontov 1979). Adult birds carrying fish were recorded in the Amur Liman by Shibaev (1990), in the Tauyskaya Bay, and in the Tauy Liman (Kitaysky, unpubl. data). A fledgling with remains of downy feathers on its back was also observed by Kitaysky (unpubl. data) inshore of Zavyalova Island, in the northern part of the Sea of Okhotsk. An unidentified murrelet fledgling (perhaps B. m. perdix) was observed near Talan Island (Kondratyev, pers. comm.).

\section{Forest Habitat}

On Sakhalin Island, the species breeds in coniferous and mixed forests, both on the plains and in the mountains as follows: in the interior of the island, Nechaev (1986) recorded birds in flocks of $2-3$, and sometimes four, in the upper reaches of the Onor River ( $30 \mathrm{~km}$ from the Sea of Japan) on 29 June 1977; near the foot of Lapatin Mountain (30-40 km from the Sea of Okhotsk, at 600-700 m elevation) on 16-17 July 1977; near the top of Krasnov Mountain (20-30 km from the Sea of Japan, at 500 m elevation) on 21-22 July 1987; and on the northern slopes of Nabil Mountain in the Shmidt Peninsula on 4-7 August.

In the lower Amur River area, where Marbled Murrelets are numerous, the seaward slopes of the mountains are covered with coniferous forests, while the boggy level shore is covered 
with larch forest (Babenko and Poyarkov 1987). It has been suggested (Kistchinsky 1968b) that the Marbled Murrelet breeding range is determined by taiga forest distribution in coastal areas of the region. Indeed, all nests and breeding birds observed to date have been in forested areas.

\section{Mortality and Population Trends}

Sources of mortality are rarely documented. There is one observation that Marbled.Murrelets are occasionally shot by hunters. This occurred on the southwest coast of the Sea of Okhotsk (Babenko and Poyarkov 1987). There have also been records of plumage contamination by oil (Kondratyev and Nechaev 1989).

Most authors have noted that the Marbled Murrelet is rare throughout its breeding areas. This may be a result of perspective, since the bird is small and relatively inconspicuous, as compared to other seabirds. No quantitative data exist, other than in small areas. Total population size is probably in the range of tens of thousands. No information exists to assess population trends.

\section{Conclusions}

Although Marbled Murrelets are widely distributed and relatively common in the Far Eastern region of Russia, to date we know little about the abundance, status, or main characteristics of the ecology of the Asian race of the species. Under these circumstances, it is impossible to say much about the murrelet's population status or to make recommendations for management of this subspecies in the Sea of Okhotsk.

Unfortunately, during the last few years the situation regarding the investigation and protection of wildlife in the former Soviet Union has taken a tum for the worse. It is important that Russia establish ecological control of natural resource exploitation, especially on the oceanic shelf. Intensive development of the oil industry on the Okhotsk and Bering Sea shelves is proceeding without appropriate control and is potentially threatening to shelf ecosystems in general. In particular, the overall breeding distribution of $B . m$. perdix matches the proposed areas for intensive oil development. It has long been suggested that increased murrelet mortality is quite possible because of oil pollution (Kondratyev and Nechaev 1989). Perhaps the greatest immediate threat to populations is from logging of forest habitats. Logging of prime old-growth forests has accelerated in recent years particularly on Sakhalin Island and the Kamchatka Peninsula, where companies have recently been granted logging rights over large tracts of virgin forest. This logging activity is apparently without regard to wildlife considerations. Ecological impacts of this industry are in need of investigation.

\section{Acknowledgments}

We thank John Piatt, Linda Long, and C. John Ralph for their hard work on the manuscript, including editing the final version into a coherent whole. 



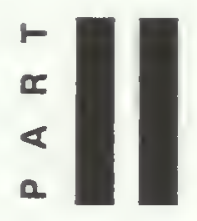

Nesting Ecology, Biology, and Behavior 


\title{
Comparative Reproductive Ecology of the Auks (Family Alcidae) with Emphasis on the Marbled Murrelet
}

\author{
Toni L. De Santo', $\quad$ S. Kim Nelson ${ }^{1}$
}

\begin{abstract}
Marbled Murrelets (Brachyramphus marmoratus) are comparable to most alcids with respect to many features of their reproductive ecology. Most of the 22 species of alcids are colonial in their nesting habits, most exhibit breeding site, nest site, and mate fidelity, over half lay one egg clutches, and all share duties of incubation and chick rearing with their males. Most alcids nest on rocky substrates, in earthen burrows, or in holes in sand, around logs, or roots. Marbled Murrelets are unique in choice of nesting habitat. In the northern part of their range, they nest on rocky substrate; elsewhere, they nest in the upper canopy of coastal coniferous forest trees. sometimes in what appear to be loose aggregations. Marbled Murrelet young are semi-precocial as are most alcids, yet they hatch from relatively large eggs (relative to adult body size) which are nearly as large as those of the precocial murrelets. They also share with precocial murrelets an early age of thermoregulation, as indicated by a short brooding period. Hatching success in monitored Marbled Murrelets nests was somewhat lower and fledging success was markedly lower than for other alcids. The lower rate of reproduction was attributed in part to egg and chick predation. Marbled Murrelet young raised in forest nests may incur additional mortality on their trips from inland nest sites to the ocean. El Niño effects may also decrease produclivity in this species. To document murrelet reproduction more fully, further study of individually marked, breeding Marbled Murrelets and their young conducted during periods without El Niño influences is needed.
\end{abstract}

The family Alcidae is composed of 22 living species of marine diving birds representing 12 genera (table 1). These birds, commonly referred to as auks, murres, guillemots, murrelets, auklets, and puffins, inhabit oceans of the Northern Hemisphere (Nettleship and Evans 1985; Udvardy 1963). Although seabird research is logistically difficult, much information has been gathered on the reproductive biology of alcids. Such research has been facilitated by the colonial nature of most species and by the accessibility of some breeding areas to scientists (Birkhead 1985). Thorough reviews have been published on nearly half of the species. For instance, Birkhead (1985), Gaston (1985), Harris and Birkhead (1985), Hudson (1985), and Nettleship and Evans (1985) present reviews of the reproductive biology of Atlantic alcids (Dovekie, Razorbill, Common Murre, Thick-billed Murre, Black Guillemot, Atlantic Puffin, and the extinct Great Auk [Plautus impennis]). Reviews of four auks that

\footnotetext{
${ }^{1}$ Research Wildlife Biologists, Oregon Cooperative Wildlife Research Unit, Oregon State University, Nash 104, Corvallis, OR 97331-3803

${ }^{2}$ Current address: Posidoctoral Research Associate, Pacific Northwesl Research Station, USDA Forest Service, 2770 Sherwood Lane, Suite 2A. Juneau, AK $99801-8545$
}

breed on the Farallon Islands in the Pacific Ocean (Common Murre, Pigeon Guillemot, Cassin's Auklet, Rhinoceros Auklet, and Tufted Puffin) are presented by Ainley (1990), Ainley and others (1990a, b, c) and Boekelheide and others (1990). Four inshore fish feeding alcids of the northern Pacific Ocean (Kittlitz's Murrelet, Pigeon Guillemot, Spectacled Guillemot, and Marbled Murrelet) are reviewed by Ewins and others (1993) (also see Marshall 1988a for a review of the Marbled Murrelet). The Ancient Murrelet, another inhabitant of the northern Pacific Ocean, has been reviewed by Gaston (1992).

Alcids that nest in small, loosely-aggregated colonies, as isolated pairs, or in areas less accessible to researchers, have not been well studied. For instance, the reproductive biology of Craveri's and Kittlitz's murrelets and Spectacled Guillemots is largely unknown. Although Marbled Murrelets have received considerable attention during the last two decades, the reproductive ecology of this species is not well understood. Unlike many other alcids, Marbled Murrelets do not nest in conspicuous colonies on cliffs, in rock crevices, or in burrows in the ground. Instead, this species nests on the alpine tundra or in the upper canopy of old-growth coniferous trees (Hamer and Nelson, this volume b; Marshall 1988a). Additionally, Marbled Murrelets are secretive around their nests and active during low light periods at dawn and dusk. Consequently, few nests have been located and observed, and few quantitative data have been collected.

This paper summarizes the reproductive ecology of the auk family and specifically compares Marbled Murrelets to the other alcids. Such a comparison may allow for a better understanding of the reproductive strategy of Marbled Murrelets and should provide useful information for conservation and management of this species.

\section{Nest Sites and Coloniality}

The nest sites of all alcids have been described, although few nests of some species have been located (e.g., Kittlitz's and Marbled murrelets). Murres and Razorbills nest primarily on cliff ledges or in crevices or caves. The nests of Common and Thick-billed murres are in the open whereas those of Razorbills are typically partially or fully enclosed (Byrd and others 1993; Harris and Birkhead 1985). Puffins and Rhinoceros Auklets nest in burrows they excavate. Additionally, nests of these species are found in rock crevices (Tufted and Homed, on the level ground of forested islands (Rhinoceros Auklet), and among boulders and rocks of islands lacking soft substrate for burrowing (Atlantic Puffin) (Byrd and others 1993; Hatch and Hatch 1983). The guillemots nest in cracks and crevices of cliffs, among stones or boulders, in 


\begin{tabular}{|c|c|}
\hline Common name(s) & Scientific name ${ }^{a}$ \\
\hline Dovekie (Litlle Aul & Alle alle \\
\hline Razorbill (Razorbil & - Alca torda \\
\hline Common Murre (C & Uria aalge \\
\hline Thick-billed Murre & . Uria lomvia \\
\hline Black Guillemot ... & Cepphus grylle \\
\hline Spectacled Guillem & Cepphus carbo \\
\hline Pigeon Guillemot .. & Cepphus columba \\
\hline Marbled Murrelet . & Brachyramphus marmoratus \\
\hline Kittlitz's Murrelet. & Brachyramphus brevirostris \\
\hline Xantus' Murrelet ... & Synthliboramphus hypoleucus \\
\hline Craveri's Murrelet . & Synthliboramphus craveri \\
\hline Ancient Murrelet ... & Synthliboramphus antiquus \\
\hline Japanese Murrelet ( & Synthliboramphus wumizusume \\
\hline Crested Auklet ....... & Aethia cristatella \\
\hline Least Auklet ......... & Aethia pusilla \\
\hline Whiskered Auklet .. & Aethia pygmaea \\
\hline Cassin's Auklet.... & Ptychoramphus aleuticus \\
\hline Parakeet Auklet ... & Cyclorrhynchus psittacula \\
\hline Rhinoceros Auklet ( & Cerorhinca monocerata \\
\hline Tufted Puffin ........ & Fratercula cirrhata \\
\hline Horned Puffin ....... & Fratercula corniculata \\
\hline Atlantic Puffin ..... & Fratercula arctica \\
\hline
\end{tabular}

aNomenclature according to American Ornithologists' Union (1983)

abandoned burrows, on covered ledges, or in self-excavated holes (Ewins and others 1993; Harris and Birkhead 1985). Nests of Dovekies are found most often in cracks in cliffs and among boulders (Harris and Birkhead 1985). Parakeet, Crested, Whiskered, and Least auklets nest under rocks in talus fields, whereas Cassin's Auklets excavate burrows in the soil (Springer and others 1993). The Synthliboramphus murrelets (Xantus', Craveri's, Ancient, and Japanese) nest in existing holes and hollows around tree roots, logs, or under rocks, or in crevices. Additionally, Japanese and Ancient murrelets may nest in self-excavated holes (Springer and others 1993). Kittlitz's Murrelets nest in the open on rocky ground. Marbled Murrelets nest in the open on rocky ground in the northern part of their range. In the southern part of their range, they nest on the large limbs of old-growth coniferous trees in forests up to $40 \mathrm{~km}$ from the ocean (Hamer and Nelson, this volume b; Marshall 1988a).

Alcids are highly social birds, and most species are colonial in their nesting habits (table 2). Nineteen of the 22 species can be found nesting in colonies consisting of 10 to several thousand pairs. Craveri's Murrelets probably nest in loose aggregations and as scattered pairs. The Kittlitz's Murrelet is the only species considered to be truly noncolonial (i.e., nesting only as isolated pairs).

Marbled Murrelets have been described as solitary (Gaston 1985) and loosely colonial (Divoky and Horton, this volume), and may nest solitarily in some areas, but in loose aggregations in others. Simons (1980) reported a ground nest that appeared to be a solitary nest. There is also strong indirect evidence that murrelets nest in loose aggregations. In Washington and Oregon, two concurrently active nests were located 100 and $30 \mathrm{~m}$ apart, respectively, within a forest stand (Hamer and Cummins 1991; Nelson, pers. obs.). In addition, in Oregon, multiple nests have been found in each of three trees located in different stands, and four trees within a small area (40-m radius) were found to contain nests (Nelson and others 1994). It is not known, however, if these nests were active concurrently.

\section{Breeding Site, Nest Site, and Mate Fidelity}

Studies of individually marked birds have provided information on the degree of breeding site and mate fidelity exhibited by alcids. Strong breeding site fidelity has been documented in the 15 species of alcids for which this aspect of reproductive ecology has been adequately investigated (Divoky and Horton, this volume) (table 2). For example, 96 percent of Common Murres at one colony returned to breed at the same colony site the following year, and 90 percent used the same nest site (Birkhead 1976 as cited by Hudson 1985). Similarly, Ashcroft (1979) as cited by Harris and Birkhead (1985) reported that 92 percent of Atlantic Puffins 
Table 2-Breeding site fidelity, mate fidelity, and degree of coloniality in the alcids

\begin{tabular}{|c|c|c|c|}
\hline Species & $\begin{array}{l}\text { Breeding site } \\
\text { fidelity }\end{array}$ & Mate fidelity & Degree of coloniality \\
\hline Dovekie & yes & yes & small to large colonies, scattered pairs \\
\hline Razorbill ${ }^{2}$ & yes & probably & small to large colonies \\
\hline Common Murre ${ }^{3}$ & yes & probably & small to large colonies \\
\hline Thick-billed Murre & probably & ? & small to large colonies \\
\hline Black Guillemot ${ }^{5}$ & yes & yes & small to large colonies, loose aggregations, scattered pairs \\
\hline Spectacled Guillemot ${ }^{6}$ & ? & ? & small to medium colonies, solitarily \\
\hline Pigeon Guillemot? & yes & probably & small, loose aggregations, medium colonies, isolated pairs \\
\hline Marbled Murrelet ${ }^{8}$ & probably & ? & probably in loose aggregations; probablysolitarily \\
\hline Kittlitz's Murrelet ${ }^{9}$ & possibly & $?$ & solitarily \\
\hline Xantus' Murrelet ${ }^{10}$ & yes & yes & small to large colonies \\
\hline Craveri's Murrelet "I & probably & probably & probably in loose aggregations and scattered pairs \\
\hline Ancient Murrelet ${ }^{12}$ & yes & possibly & small to large colonies \\
\hline Japanese Murrelet ${ }^{13}$ & ? & ? & small to medium colonies \\
\hline Crested Auklet $^{14}$ & yes & yes & small to large colonies \\
\hline Least Auklet ${ }^{15}$ & yes & yes & small to large colonies \\
\hline Whiskered Auklet ${ }^{16}$ & $?$ & $?$ & small to medium colonies \\
\hline Cassin's Auklet ${ }^{17}$ & yes & probably & small to large colonies \\
\hline Parakeet Auklet $^{18}$ & yes & ? & small, loose to large colonies \\
\hline Rhinoceros Auklet ${ }^{19}$ & yes & $?$ & small to large colonies, solitarily \\
\hline Tufted Puffin 20 & yes & $?$ & small to large colonies \\
\hline Homed Puffin ${ }^{21}$ & yes & $?$ & large colonies \\
\hline Atlantic Puffin ${ }^{22}$ & yes & yes & small to large colonies \\
\hline
\end{tabular}

${ }^{1}$ Reviewed by Birkhead (1985), Freethy (1987), Harris and Birkhead (1985), Nettleship and Evans (1985); Evans (1981), Norderhaug (1968)

${ }^{2}$ Reviewed by Birkhead (1985), Freethy (1987), Hudson (1985), Nettleship and Evans (1985); Lloyd (1976)

${ }^{3}$ Reviewed by Birkhead (1985), Freethy (1987), Harris and Birkhead (1985), Hudson (1985), Nettleship and Evans (1985); Sowls and others (1980), Speich and Wahl (1989)

${ }^{4}$ Reviewed by Birkhead (1985), Harris and Birkhead (1985), Hudson (1985), Nettleship and Evans (1985)

${ }^{5}$ Reviewed by Birkhead (1985), Freethy (1987), Harris and Birkhead (1985), Hudson (1985), Nettleship and Evans (1985)

${ }^{6}$ Reviewed by Birkhead (1985), Ewins and others (1993)

${ }^{7}$ Reviewed by Birkhead (1985). Emms and Verbeek (1989), Ewins (1993); Ainley and others (1990b), Sowls and others (1980), Speich and Wahl (1989)

${ }^{8}$ Reviewed by Birkhead (1985), Ewins and others (1993); Divoky and Horton (this volume), Nelson and others (1994), Simons (1980), Strong and others (in press)

${ }^{9}$ Reviewed by Birkhead (1985); Day and others (1983), Naslund and others (1994)

${ }^{10}$ Reviewed by Birkhead (1985); Carter and McChesney (1994), Murray and others (1983), Sowls and others (1980), Springer and others (1993)

${ }^{11}$ Reviewed by Birkhead (1985); DeWeese and Anderson (1976)

${ }^{12}$ Reviewed by Birkhead (1985), Gaston (1992); Gaston (1990), Springer and others (1993)

${ }^{13}$ Reviewed by Birkhead (1985); Springer and others (1993)

${ }^{14}$ Reviewed by Birkhead (1985), Freethy (1987); Bédard (1969b), Jones (1993a), Konyukhov (1990a), Sealy (1968), Springer and others (1993)

${ }^{15}$ Reviewed by Birkhead (1985); Bédard (1969b), Jones 1. (1992, 1993b), Jones and Montgomerie (1991), Roby and Brink (1986), Sealy (1968), Springer and others (1993)

16. Reviewed by Birkhead (1985); Byrd and Gibson (1980), Byrd and others (1993), Springer and others (1993)

${ }^{17}$ Revie wed by Birkhead (1985); Ainley and others (1990a), Emslie and others (1992), Sowls and others (1980), Speich and Manuwal (1974), Speich and Wahl (1989), Springer and others (1993), Vermeer and Lemon (1986)

${ }^{18}$ Reviewed by Birkhead (1985), Freethy (1987); Bédard (1969b), Sealy (1968), Springer and others (1993)

${ }^{19}$ Reviewed by Ainley and others (1990 c), Birkhead (1985); Byrd and others (1993), Sowls and others (1980), Speich and Wahl (1989), Weble (1980)

${ }^{20}$ Reviewed by Ainley and others (1990C), Birkhead (1985), Byrd and others (1993); Sowls and others (1980), Speich and Wahl (1989), Wehle (1980)

${ }^{21}$ Reviewed by Birkhead (1985), Byrd and others (1993); Wehle (1980)

${ }^{22}$ Reviewed by Birkhead (1985), Harris and Birkhead (1985), Nettleship and Evans (1985) 
returned to breed in the same burrow in consecutive years. Two studies reported at least 70 percent of Black Guillemots returned to use the same nest sites within the same nest colonies year after year (Asbirk [1979] and Petersen [1981], as cited by Harris and Birkhead 1985). Murray and others (1983) observed that 64 percent of Xantus' Murrelets retained the same nest sites for two years, and Roby and Brink (1986) found that 91 percent of Least Auklets used the same nest entrance in two consecutive years.

At least six alcids show mate fidelity (table 2 ). Divorce rates have been reported to be approximately 24 percent for Crested Auklets (Jones 1993a) and approximately 7 percent for Black Guillemots and Atlantic Puffins. These figures were confirmed by Harris and Birkhead (1985). Emslie and others (1992) have shown that mate retention has a positive influence on reproduction of Cassin's Auklets; both fledging and breeding success were higher for pairs that practiced mate retention.

No studies have been conducted on individually marked, breeding Marbled Murrelets, but indirect evidence suggests that they show both mate and breeding site fidelity. Murrelets are primarily observed in groups of two throughout the year, and many groups include a male and female (Carter 1984, Sealy 1975c). Strong and others (1993) observed at-sea groups of murrelets in spring and summer and reported that of 4918 groups, 55 percent consisted of pairs. The possibility exists that these twosomes were mated pairs, although without observations of marked birds this is speculative. Marbled Murrelet activity has been documented in the same forest stands for periods up to 18 years (Divoky and Horton, this volume), and murrelet nests have been found in the same trees (Nelson and others 1994; Nelson and Peck, in press; Singer and others, in press), and on the same general location of tundra (Simons 1980), in consecutive years. These observations suggest breeding site fidelity. Reuse of nests has recently been documented for the ground nesting Kittlitz's Murrelet, a close relative of the Marbled Murrelet (Naslund and others 1994).

\section{Adult Life History Characteristics}

Historically, the Great Auk, which became extinct in the $1800 \mathrm{~s}$, was the largest member of the Alcidae, ca. $5 \mathrm{~kg}$ (Harris and Birkhead 1985). At present, the murres are the largest alcids (ca. $1 \mathrm{~kg}$ ). Fifteen alcids are small by comparison, having body masses less than half that of the murres (table 3 ). The Marbled Murrelet has a mass of $220 \mathrm{~g}$, approximately 22 percent that of the murres.

Adult annual survival has been estimated for ten species (table 3). The lowest estimates of this population parameter are 75 percent reported for both the Least Auklet, the smallest alcid (ca. $85 \mathrm{~g}$ ), and 77 percent for the Ancient Murrelet, a relatively small alcid (ca. $200 \mathrm{~g}$ ), (fig. $1, r^{2}=0.45, P<0.05$ ). The larger alcids, Common and Thick-billed murres, Razorbills, and Atlantic Puffins (ca. 1004, 941, 620, and

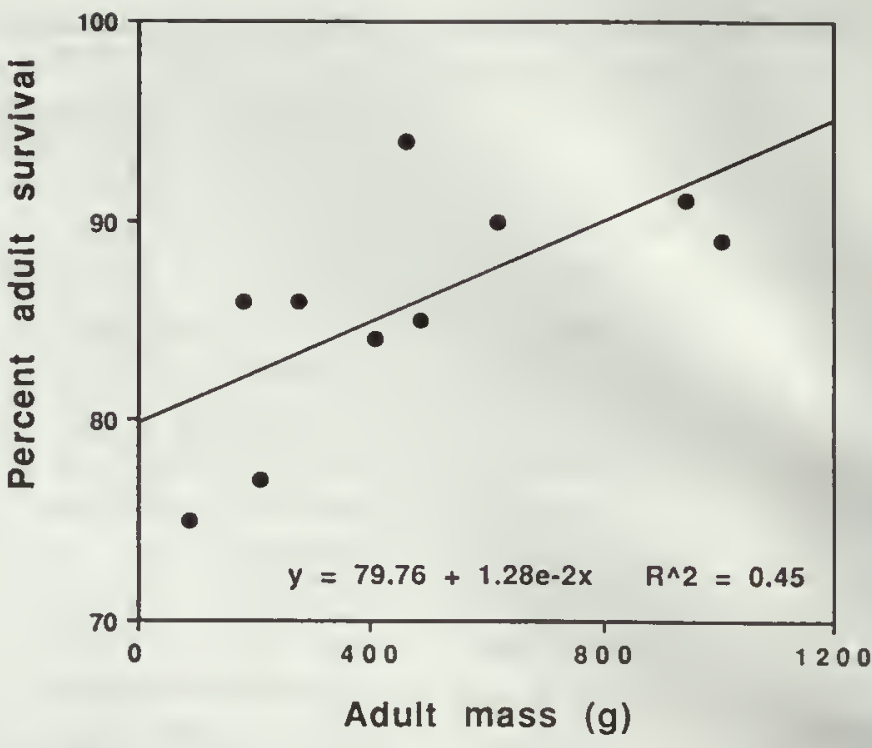

Figure 1-Relationship between mean adult body mass and percent annual adult survival for ten alcids (see table 3 for values).

$460 \mathrm{~g}$, respectively), have higher survival estimates ranging from 89 to 94 percent.

Adult annual survival has not been measured for Marbled Murrelets. However, based on the relationship between adult body mass and annual survival (fig. 1), Marbled Murrelets (ca. $220 \mathrm{~g}$ ) are predicted to have an annual adult survival of 83 percent, comparable to alcids of similar size (i.e., the Ancient Murrelet, ca. 206 g, 77 percent survival, or the Crested Auklet, $272 \mathrm{~g}, 86$ percent survival).

Alcids are considered long-lived although this life history aspect has not been well studied. Longevity of several individuals of several species has been documented from recovery of marked birds or their bands. Values range from 5 years for an Ancient Murrelet to 32 years for a Common Murre (table 3). Values determined from band returns may be indicative of band longevity, not bird longevity. These values should, therefore, be considered minimums (see Clapp and others 1982 for discussion). It is not known how long Marbled Murrelets live; no reports of recovered banded birds have been made.

Alcids exhibit deferred maturity with most species beginning to breed between 2 and 8 years of age (table 3 ). It is not known at what age Marbled Murrelets begin to breed, but an estimate of 2 to 4 years is reasonable based on information available for other alcids.

At least several alcid species breed annually once they reach sexual maturity (table 3 ). For example, over 80 percent of Least Auklets (Jones 1992) and 90 percent of Xantus' Murrelets (Murray and others 1983) bred in consecutive years. Cassin's Auklet is the only alcid known to lay a second clutch following the rearing of their first brood (Ainley 
Table 3-Sice, survival, longevity, age of first reproduction, and breeding frequency of adult alcids

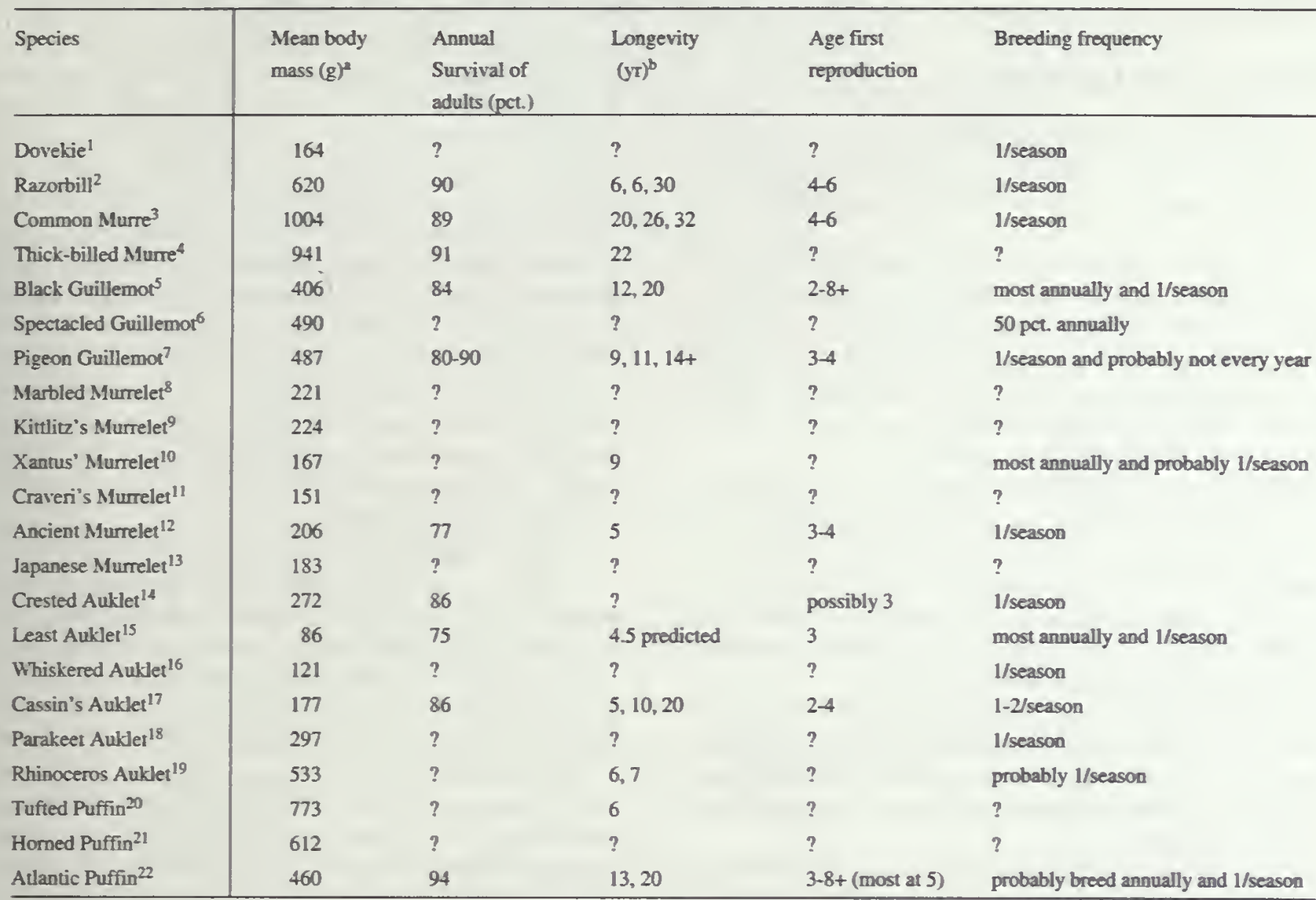

¿Adult mass prior to chick rearing used for Ancient Murrelet, Crested Auklet, Least Auklet, Cassin's Auklet, and Aulantic Puffin; includes both males and females

bobserved longevity of ringed or banded birds unless otherwise stated

${ }^{1}$ Reviewed by Harris and Birkhead (1985); Norderhaug (1980)

2Harris and Birkhead (1985), Hudson (1985); Clapp and others (1982), Freethy (1987), Klimkiewicz and Furcher (1989), Lloyd (1979)

${ }^{3}$ Reviewed by Harris and Birkhead (1985), Hudson (1985); Boeketheide and others (1990), Clapp and others (1982)

${ }^{4}$ Reviewed by Harris and Birkhead (1985), Hudson 1985); Clapp and others (1982)

5Reviewed by Hudson (1985); Ainley and others (1990b), Clapp and others (1982), Caims (1981, 1987), Divoky (1994, pers. comm.)

${ }^{6}$ Reviewed by Dunning (1992); Kitaysky (1994)

${ }^{7}$ Reviewed by Ewins (1993), Kuletz (1983); Ainley and others (1990b), Clapp and others (1982), Klimkiewicz and Futcher (1989), Nelson (1987), Ewins and others (1993)

${ }^{8}$ Sealy $(1975 \mathrm{a}, \mathrm{c})$

${ }^{9}$ Sealy (1975b)

${ }^{10}$ Klimkiewicz and Futcher (1989), Murray and others (1983)

${ }^{11}$ Reviewed by Dunning (1992)

${ }^{12}$ Clapp and others (1982), Gaston (1990), Gaston and Jones (1989), Jones (1990), Sealy (1975c, 1976), Vermeer and Lemon (1986)

${ }^{13}$ Kuroda (1967), Ono (1993)

${ }^{14}$ Bédard (1969b), Jones (1992, 1993a), Piatt and others (1990)

${ }^{15}$ Bédard (1969b), Jones (1992, 1993b, 1994), Piatt and others (1990), Roby and Brink (1986)

${ }^{16}$ Reviewed by Dunning (1992); Ainley and ochers (1990a), Knudtson and Byrd (1982)

${ }^{17}$ Ainley and others (1990a), Clapp and others (1982), Jones P. (1992), Gaston (1992), Klimkieuricz and Futcher (1989), Manuwal (1979), Speich and Manuwal (1974), Thorensen (1964), Vermeer and Cullen (1982)

${ }^{18}$ Ainley and others (1990a), Bédard (1969b), Sealy (1972)

${ }^{19}$ Ainley and others (1990c), Clapp and others (1982), Klimkiewicz and Futcher (1989)

${ }^{20}$ Klimkiewicz and Futcher (1989), Sealy (1972), Vermeet and Cullen (1979)

${ }^{21}$ Sealy (1973c)

${ }^{22}$ Reviewed by Harris and Birkhead (1985), Hudson (1985); Barrett and Rikardsen (1992), Clapp and others (1982), Harris and Hislop (1978), Klimbiewicz and Futcher (1989), Kress and Nettleship (1988), Nettleship (1972) 
and others 1990a; Manuwal 1979). Within and between year breeding frequencies for Marbled Murrelets are unknown.

\section{The Egg and Incubation}

Most alcids, including Marbled Murrelets, lay a clutch consisting of one egg (table 4). The guillemots and the Synthliboramphus murrelets typically have clutch sizes of two.

Alcid eggs range in size from less than $20 \mathrm{~g}$ to over 100 $\mathrm{g}$ (table 4) and vary in proportion to adult mass (fig. $2, r^{2}=$ $0.92, P<0.001)$. Alcid egg masses typically represent between 10 and 23 percent of the laying female's body mass (table 4) with the precocial species laying the heaviest eggs relative to adult body size. Marbled Murrelet eggs (ca. $35 \mathrm{~g}$ ) at 18 percent of adult body mass are also large.

The duties of incubation are shared by both members of the breeding pair (table 5). Incubation shifts can be as short as several hours (e.g., Pigeon and Black guillemots) or as lengthy as several days (e.g., Xantus', Ancient, and Japanese murrelets) (table 5). Incubation is completed within 27 and 45 days (table 5). Overall, there is no significant correlation between incubation period and egg mass (fig. $3, r^{2}=0.10, P$ $=0.21$ ). The eggs of four of the larger alcids (Rhinoceros Auklet and Tufted, Horned, and Atlantic puffins), however, require up to 45 days of incubation, while the small eggs of the Least Auklet are incubated for a much shorter period of time (ca. 30 days).

Nine species of alcids are known to leave their eggs unattended for periods of 1 to 19 days, particularly during the early stages of incubation (table 5). Egg neglect is common in Xantus' (Murray and others 1983) and Ancient murrelets (Gaston and Powell 1989) occurring at nearly half of the nests studied. Egg neglect can lengthen the period from laying to

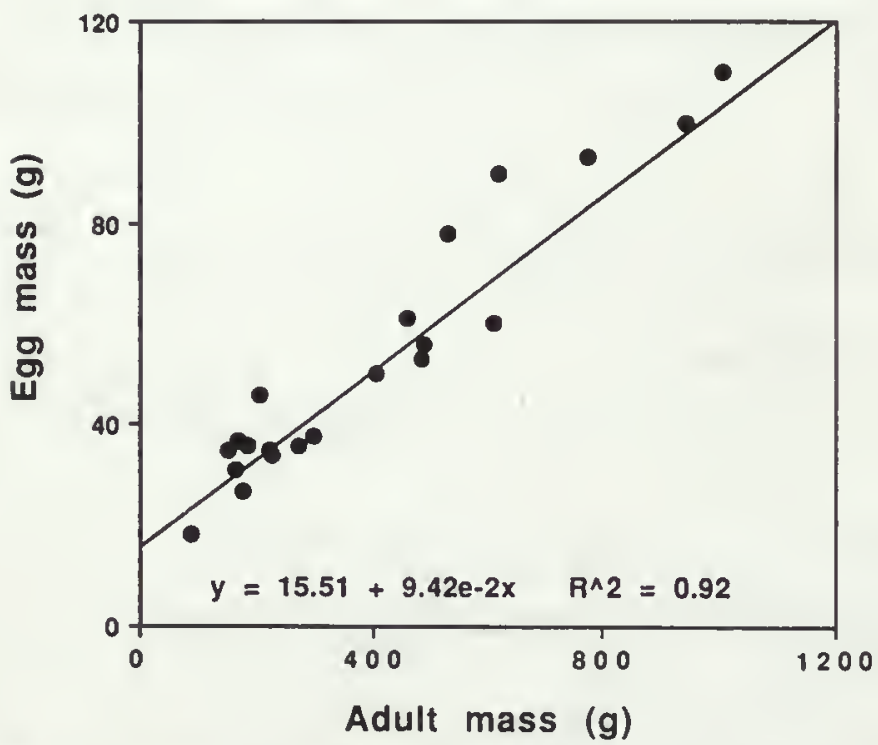

Flgure 2-Relationship between mean adult body mass and mean egg mass for 21 alcids (see tables 3 and 4 for values). hatching (Gaston and Powell 1989; Murray and others 1983; Sealy 1984), but can decrease the total number of days of actual incubation necessary (see Murray and others 1983).

Compared to other alcids, Marbled Murrelets have a short incubation period (ca. 27-30 days) (table 5). Parents exchange incubation duties every 24 hours (table 5), typically during pre-dawn hours (Naslund 1993a, Nelson and Hamer, this volume a; Nelson and Peck, in press; Simons 1980). Simons (1980) noted a one-day period of egg neglect early in incubation at an exposed ground nest of a Marbled Murrelet. Additionally, at three tree nests, eggs were left unattended for up to 4 hours during the day and evening (Naslund 1993a; Nelson and Hamer, this volume a; Nelson and Peck, in press). It is not known if egg neglect occurs commonly at Marbled Murrelet nests, but other alcid species which lay their eggs in open nests (e.g., Common and Thick-billed murres; see Gaston and Nettleship 1981) do not frequently leave their nests unattended.

Average hatching success exceeds 70 percent for over half of the 19 alcids for which this parameter has been measured (table 6 ). The lowest value (33 percent) was reported for Xantus' Murrelets nesting on islands with high rates of mouse predation (Murray and others 1983). Avian and mammalian predation have been cited as a cause for clutch loss in other studies as well (Birkhead and Nettleship 1981; Drent and others 1964; Emms and Verbeek 1989; Evans 1981; Ewins and others 1993; Gilchrist 1994; Harfenist 1994; Jones 1992; Piatt and others 1990; Sealy 1982; Thorensen 1964; Vermeer and Lemon 1986). Additional causes of hatching failure include infertility and embryo death (Evans 1981; Knudtson and Byrd 1982; Thorensen 1964), mechanical destruction of eggs or nests (Birkhead and Nettleship 1981; Thorensen 1964), and adverse weather (reviewed by Harris and Birkhead 1985).

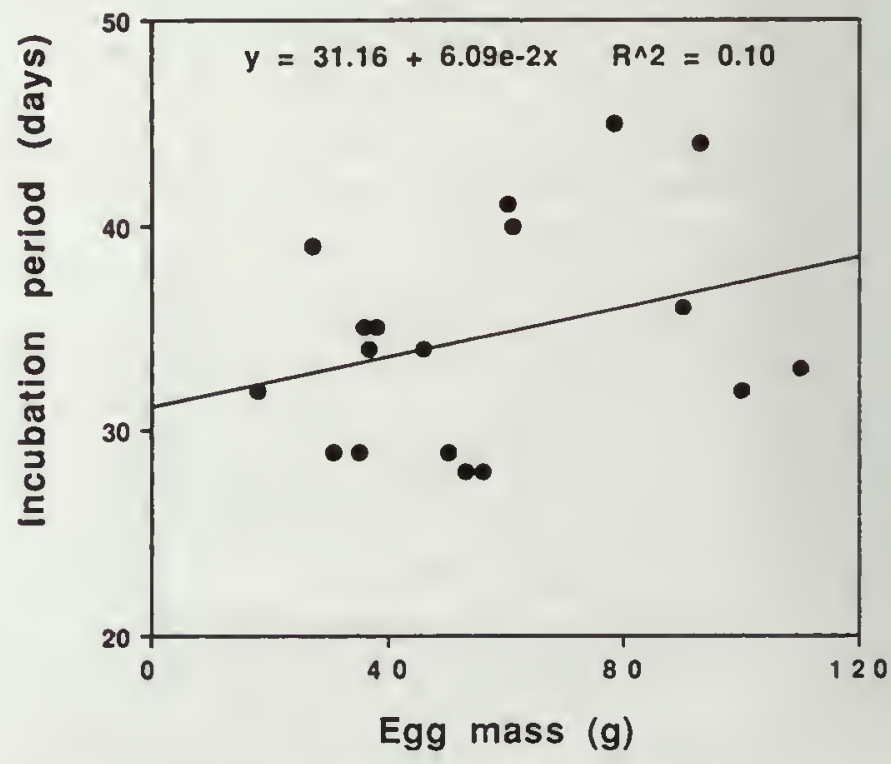

Figure 3-Relationship between mean egg mass and incubation period for 19 alcids (see tábles 4 and 5 for values). 
Table 4-Egg size, relationship of egg mass to adult body mass and clutch size of alcids

\begin{tabular}{|c|c|c|c|}
\hline Species & $\begin{array}{l}\text { Mean egg } \\
\text { mass }(g)\end{array}$ & $\begin{array}{l}\text { Egg mass as pct. } \\
\text { adult body mass }\end{array}$ & $\begin{array}{l}\text { Clutch size range } \\
\text { (average) }\end{array}$ \\
\hline Dovelie! & 31 (calculated) & 19 & 1 \\
\hline Razorbill $^{2}$ & 90 & 14 & 1 \\
\hline Common Murre ${ }^{3}$ & ca. 110 & 12 & 1 \\
\hline Thick-billed Murre & 100 & $10-12$ & 1 \\
\hline Black Guillemot 5 & 50 & $12-13$ & $1-2(1.83)$ \\
\hline Spectacled Guillemor ${ }^{6}$ & 56 & 11 & $1-2(1.60)$ \\
\hline Pigeon Guillemot? & 53 & 11 & $1-2(1.76)$ \\
\hline Marbled Murrelet ${ }^{8}$ & 35 & 18 & 1 \\
\hline Kittlitz's Murrelet ${ }^{9}$ & 34 & 15 & 1 \\
\hline Xantus' Murrelet ${ }^{10}$ & 37 & 22 & $1-2(1.70)$ \\
\hline Craveri's Murrelet ${ }^{11}$ & 35 & 23 & $1-2(1.88)$ \\
\hline Ancient Murrelet ${ }^{12}$ & 46 & 22 & $1-2(1.99)$ \\
\hline Japanese Murrelet $^{13}$ & 36 & 22 & $1-2(1.80)$ \\
\hline Crested Auklet $^{14}$ & 36 & 14 & 1 \\
\hline Least Auklet ${ }^{15}$ & 18 & 22 & 1 \\
\hline Whiskered Auklet ${ }^{16}$ & $?$ & $?$ & 1 \\
\hline Cassin's Auklet ${ }^{17}$ & 27 & 16 & 1 \\
\hline Parakeet Auklet ${ }^{18}$ & 38 & ca. 14 & 1 \\
\hline Rhinoceros Auklet ${ }^{19}$ & 78 & ca. 15 & 1 \\
\hline Tufted Puffin 20 & 93 & 12 & 1 \\
\hline Horned Puffin ${ }^{21}$ & ca. 60 & ca. 10 & 1 \\
\hline Atlantic Puffin 22 & 61 & ca. 13 & 1 \\
\hline
\end{tabular}

${ }^{1}$ Reviewed by Harris and Birkhead (1985), Evans (1981)

${ }^{2}$ Reviewed by Harris and Birkhead (1985)

${ }^{3}$ Reviewed by Harris and Birkhead (1985)

${ }^{4}$ Reviewed by Harris and Birkhead (1985)

${ }^{5}$ Reviewed by Harris and Birkhead (1985); Caims (1987), Divoky and others (1974)

${ }^{6}$ Reviewed by Ewins and others (1993); Kitaysky (1994), Thorensen (1984)

${ }^{7}$ Reviewed by Ewins (1993), Ewins and others (1993); Kuletz (1983), Nelson (1987)

${ }^{8}$ Hirsch and others (1981), Nelson and Hamer (this volume a), Sealy (1974, 1975b), Simons (1980)

${ }^{9}$ Reviewed by Day and others (1983); Sealy (1975b)

19Murray and others (1983)

${ }^{11}$ DeWeese and Anderson (1976), Schōnwetter (1963)

${ }^{12}$ Reviewed by Gaston (1992); Gaston (1990), Gaston and Jones (1989), Jones (1992), Sealy (1975b, 1976), Vermeer and Lemon (1986)

${ }^{13}$ Ono (1993), Ono and Nakamura (1993), Schōnwetter (1963)

${ }^{14}$ Reviewed by Jones (1993a); Bédard (1969b)

15 Jones (1993b), Piatt and others (1990), Roby and Brink (1986)

${ }^{16}$ Freethy (1987), Williams and others (1994)

${ }^{17}$ Ainley and others (1990a), Manuwal (1979), Vermeer and Lemon (1986)

${ }^{18}$ Sealy (1972), Bédard (1969b)

${ }^{19}$ Ainley and others (1990c), Freethy (1987), Sealy (1972), Wilson and Manuwal (1986)

${ }^{20}$ Reviewed by Boone (1986); Ainley and others (1990c), Sealy (1972)

${ }^{21}$ Freethy (1987), Sealy (1972)

${ }^{22}$ Reviewed by Harris and Birkhead (1985) 
Table 5-Incubation patterns of the alcids

\begin{tabular}{|c|c|c|c|c|}
\hline Species & $\begin{array}{c}\text { lncubating } \\
\text { parent }^{\mathrm{a}}\end{array}$ & $\begin{array}{l}\text { Incubation } \\
\text { shift (hours) }\end{array}$ & $\begin{array}{l}\text { Mean duration of } \\
\text { incubation (days) }\end{array}$ & Egg neglect \\
\hline Dovekie $^{1}$ & both & 12 & 29 & $?$ \\
\hline Razorbill ${ }^{2}$ & both & $12-24$ & 36 & $?$ \\
\hline Common Murre ${ }^{3}$ & both & $12-24$ & 33 & probably not \\
\hline Thick-billed Murre ${ }^{4}$ & both & $12-24$ & 32 & very infrequently \\
\hline Black Guillemot ${ }^{5}$ & both & ca. 1-3 & 29 & yes \\
\hline Spectacled Guillemot ${ }^{6}$ & $?$ & $?$ & ca. 28 & $?$ \\
\hline Pigeon Guillemot ${ }^{7}$ & both & $2-4$ but up to 17 & 28 & yes \\
\hline Marbled Murrelet $^{8}$ & both & ca. 24 & $27-30$ (probable range) & yes for several hrs to 1 day \\
\hline Kittlitz's Murrelet ${ }^{9}$ & $?$ & ? & $?$ & $?$ \\
\hline Xantus' Murrelet ${ }^{10}$ & both & $24-144$, most at 72 & 34 & yes for $1-19$ days \\
\hline Craveri's Murrelet $^{11}$ & both & $?$ & $?$ & $?$ \\
\hline Ancient Murrelet ${ }^{12}$ & both & $48-120$ & 34 & yes for $1-3$ days \\
\hline Japanese Murrelet ${ }^{13}$ & both & $24-72$ & ? & yes for 5 days \\
\hline Crested Auklet $^{14}$ & both & $?$ & 35 & possibly \\
\hline Least Auklet ${ }^{15}$ & both & 24 & 32 & yes \\
\hline Whiskered Auklet ${ }^{16}$ & both & 24 & ca. 35 & $?$ \\
\hline Cassin's Auklet ${ }^{17}$ & both & 24 & 39 & very infrequently \\
\hline Parakeet Auklet ${ }^{18}$ & both & ? & 35 & $?$ \\
\hline Rhinoceros Auklet ${ }^{19}$ & both & 24 & 45 & yes for $1-3$ days \\
\hline Tufted Puffin ${ }^{20}$ & both & $?$ & 44 & $?$ \\
\hline Horned Puffin ${ }^{21}$ & $?$ & $?$ & 41 & $?$ \\
\hline Atlantic Puffin ${ }^{22}$ & both & $2-50$ & range $35-45$ & yes frequently \\
\hline
\end{tabular}

ancubation refers to the period from clutch completion to egg hatching except for the Spectacled Guillemot for which this information was unavailable

${ }^{1}$ Reviewed by Harris and Birkhead (1985)

${ }^{2}$ Reviewed by Harris and Birkhead (1985)

${ }^{3}$ Reviewed by Harris and Birkhead (1985), Boekelheide and others (1990), Hatch and Hatch (1990a)

${ }^{4}$ Reviewed by Harris and Birkhead (1985), Hatch and Hatch (1990a)

${ }^{5}$ Reviewed by Harris and Birkhead (1985)

${ }^{6}$ Ritaysky (1994), Kondratyev (1994)

${ }^{7}$ Reviewed by Harris and Birkhead (1985), Ewins (1993); Ainley and others (1990b), Drent and others (1964)

${ }^{8}$ Carter (1984), Hirsch and others (1981), Naslund (1993a), Nelson and Hamer (this volume a), Nelson and Peck (in press), Sealy (1974, 1975a), Simons (1980), Singer and others (1991, in press)

${ }^{9}$ No information located

${ }^{10}$ Murray and others (1983)

${ }^{11}$ Reviewed by DeWeese and Anderson (1976)

${ }^{12}$ Reviewed by Gaston (1992); Gaston and Jones (1989), Gaston and Powell (1989), Sealy (1976, 1984)

${ }^{13}$ Ono and Nakamura (1993)

${ }^{14}$ Reviewed by Freethy (1987); Jones (1993a), Piatt and others (1990), Sealy (1984)

${ }^{15}$ Bédard (1969b), Knudtson and Byrd (1982), Piatt and others (1990), Roby and Brink (1986), Sealy (1984)

${ }^{16}$ Reviewed by Freethy (1987); Knudtson and Byrd (1982), Williams and others (1994)

${ }^{17}$ Reviewed by Manuwal and Thorensen (1993); Ainley and others (1990a), Manuwal $(1974,1979)$

${ }^{18}$ Bédard (1969b), Sealy and Bédard (1973)

${ }^{19}$ Leschner (1976), Wilson and Manuwal (1986)

${ }^{20}$ Reviewed by Freethy (1987); Ainley and others (1990c), Boone (1986)

${ }^{21}$ Ainley and others (1990c), Leshner and Burrell (1977), Sealy (1973c)

${ }^{22}$ Reviewed by Harris and Birkhead (1985) 
Table 6- Hatching and fledging success, number of young produced per breeding pair and juvenile survival for alcids

\begin{tabular}{|c|c|c|c|}
\hline Species & $\begin{array}{l}\text { Mean hatching } \\
\text { success }\end{array}$ & $\begin{array}{l}\text { Mean fledging } \\
\text { success }{ }^{2, b}\end{array}$ & $\begin{array}{l}\text { Juvenile } \\
\text { survival }\end{array}$ \\
\hline & & -percent- & \\
\hline Dovekie $^{1}$ & 65 & 77 & $?$ \\
\hline Razorbill $^{2}$ & 78 & 93 & 32 \\
\hline Common Murre ${ }^{3}$ & 79 & 88 & 30 \\
\hline Thick-billed Murre & 73 & 85 & 34 \\
\hline Black Guillemot ${ }^{5}$ & 66 & 68 & 27 \\
\hline Spectacied Guillemor 6 & $?$ & $?$ & $?$ \\
\hline Pigeon Guillemot ${ }^{7}$ & 70 & 67 & $?$ \\
\hline Marbled Murreler 8 & 67 & 45 & $?$ \\
\hline Kittliz's Murrelet9 & $?$ & $?$ & $?$ \\
\hline Xantus' Murrelet ${ }^{10}$ & 33 & $?$ & $?$ \\
\hline Craveri's Murrelet $^{11}$ & $?$ & $?$ & $?$ \\
\hline Ancient Murrelet ${ }^{12}$ & 91 & $>90$ & $\operatorname{cas} 50$ \\
\hline Japanese Murrelet $^{13}$ & 50 & 76 & $?$ \\
\hline Crested Auklet ${ }^{14}$ & 63 & 66 & $?$ \\
\hline Least Auklet ${ }^{15}$ & 82 & 81 & $?$ \\
\hline Whiskered Auklet ${ }^{16}$ & 86 & 100 & $?$ \\
\hline Cassin's Auklet ${ }^{17}$ & 75 & 80 & 65 \\
\hline Parakeet Aublet ${ }^{18}$ & 65 & $?$ & $?$ \\
\hline Rhinoceros Auklet ${ }^{19}$ & 81 & 69 & $?$ \\
\hline Tufted Puffin ${ }^{20}$ & 63 & 70 & $?$ \\
\hline Homed Puffin ${ }^{21}$ & 76 & 70 & $?$ \\
\hline \multirow[t]{2}{*}{ Atlantic Puffin ${ }^{22}$} & 72 & 73 & $0.4-13.3$ observed. \\
\hline & & & 15-36 calculated \\
\hline
\end{tabular}

"Includes replacement eggs for Common Murre, Razorbill, Thickbilled Murre, and Pigeon Guillemot, and possibly for Black Guillemot, and Atlantic and Horned puffins; does not include second broods

bFledging is defined as departure from the nest to the ocean

'Reviewed by Harris and Birlhead (1985); Evans (1981), Stempniewicz (1981)

${ }^{2}$ Reviewed by Harris and Birkhead (1985), Hudson (1985)

${ }^{3}$ Reviewed by Harris and Birkhead (1985), Hudson (1985); Ainley (1990), Boekelheide and others (1990), Murphy (1994); Hatch and Hatcb (1990b); also see Byrd and others (1993)

${ }^{4}$ Reviewed by Harris and Birkhead (1985), Hudson (1985); Hatcb and Hatch (1990b); also see Byrd and others (1993)

${ }^{5}$ Reviewed by Harris and Birkhead (1985), Hudson (1985); Caims (1981), Divoky (1994, pers. comm.)

'No information located

'Reviewed by Ewins and others (1993); Ainley and others (1990b), Kuletz (1983), Nelson (1987); also see summary by Ewins (1993)

${ }^{8}$ Nelson and Hamer (this volume b)

'No information located

10.Drost (1994), Murray and ochers (1983)

${ }^{11}$ No information located

${ }^{12}$ Gaston (1990, 1992), Rodway and others (1988), Vermeer and Lemon (1986)

${ }^{13}$ Ono (1993), Ono and Nakamura (1993)

${ }^{14}$ Knudtson and Byrd (1982), Piatt and others (1990), Sealy (1982); also see Jones (1993a)

15Jones (1992), Piatt and others (1990), Roby and Brink (1986), Sealy (1982); also see Jones (1993b)

${ }^{16}$ Knudtson and Byrd (1982), Williams and others (1994)

${ }^{17}$ Ainley and others (1990a), Manuwal (1979), Thorensen (1964), Vermeer and Cullen (1982), Vermeer and Lemon (1986)

${ }^{18}$ Sealy (1984)

${ }^{19}$ Vermeer and Cullen (1979), Watanuki (1987), Wilson and Manuwal (1986)

${ }^{20}$ Reviewed by Byrd and others (1993)

${ }^{21}$ Reviewed by Byrd and others (1993)

${ }^{22}$ Reviewed by Barrett and Rikardsen (1992), Harris and Birkhead (1985), Hudson (1985); Barrett and Rikardsen (1992), Nettleship (1972) 
There is some indication that hatching success of the Marbled Murrelet is low compared to other alcids (Nelson and Hamer, this volume b). Combining observations throughout the range of the Marbled Murrelet, 67 percent ( $n$ $=20$ ) of the eggs of 30 monitored nests successfully hatched. Egg predation was documented or strongly suspected to be the cause of failure for five of the 11 (45 percent) hatching failures (Nelson and Hamer, this volume b).

When the clutches of alcids are lost or fail to hatch, some species (e.g., Razorbills, Common and Thick-billed murres, Atlantic Puffins, and Black Guillemots [see Harris and Birkhead 1985 for review], Pigeon Guillemots [Ainley and others 1990b], Cassin's Auklets [Ainley and others 1990a; Manuwal 1979], Horned Puffins [Wehle 1983]) lay replacement eggs. Egg replacement in murres has been reported to be between 15 and 43 percent (reviewed by Boekelheide and others 1990; Byrd and others 1993). Ten percent of Cassin's Auklet pairs replaced naturally lost eggs, and 54. percent replaced eggs removed by researchers (Manuwal 1979). Hatching and fledging success of replacement clutches was often lower than first clutches (Ainley and others 1990a; Byrd and others 1993; Manuwal 1979; Murphy 1994). The incidence of egg replacement is low for Least and Crested auklets (Piatt and others 1990) and Xantus' Murrelets (Murray and others 1983) and apparently does not occur in Ancient Murrelets (Sealy 1976). Cassin's Auklet is the only alcid known to lay a second clutch following the rearing of their first brood (Ainley and others 1990a; Manuwal 1979). Hatching and fledging success of second clutches were usually lower than those of first clutches (Ainley and others 1990a). It is not known if Marbled Murrelets lay replacement eggs or if they attempt to raise more than one brood per season.

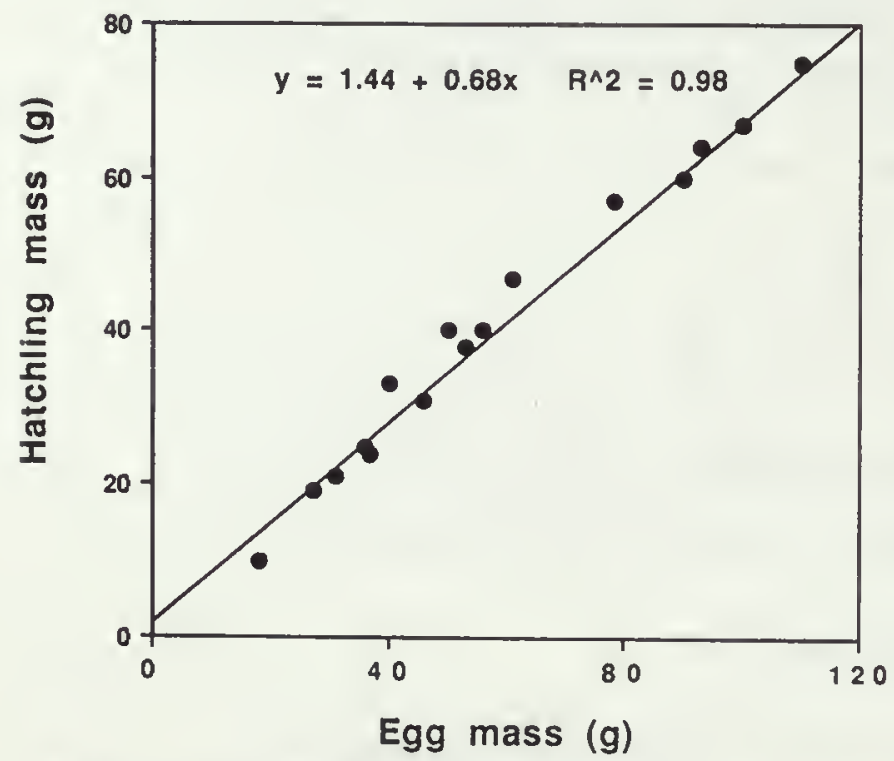

Flgure 4-Relationship between mean egg mass and mean hatchling mass for 18 alcids (see tables 4 and 7 for values).

\section{Development and Survival of the Young}

Newly hatched alcids are downy (table 7 ) and are brooded by their parents for 1 to 10 days (table 8 ) until homeothermy has been achieved (table 7). Body mass of hatchling alcids is proportional to egg mass (fig. $4, r^{2}=0.98, P<0.001$ ) and adult body mass (fig. $5, r^{2}=0.91, P<0.001$ ). Alcid chicks are between 6 and 15 percent adult size at hatching (table 7 ). Newly hatched Marbled Murrelet chicks at 15 percent adult body mass, are large in comparison to the other alcid chicks (tables 7-9).

Most alcid chicks are semi-precocial (table 7). Parents feed their semi-precocial young at the nest for 27-52 days until they reach at least 60 percent adult mass. Kittlitz's Murrelet may be an exception; the body mass of one fledgling was reported to be 40 percent that of an adult (Day and others 1983) (table 9). For most semi-precocial species, the young reach independence at the time of fledging (table 8 ).

The Synthliboramphus murrelets have precocial young. For up to 2 days after hatching, precocial alcid chicks are brooded but are not fed at the nest. Following this time, they depart the nest at only 12-14 percent adult size and accompany their parents to the sea where they receive additional care until reaching independence at approximately 4 weeks of age (tables 7, 8, and 9).

Murres and Razorbills are intermediate to these two patterns of development (Gaston 1985; table 7). Their young leave the nest at about 20 days of age, earlier than semi-precocial species, but much later than precocial species (table 9). At fledging, murre and Razorbill chicks are around 20 to 30 percent adult mass, lighter than semiprecocial young, yet heavier than precocial young (table 9). The chicks accompany their male parents to the sea

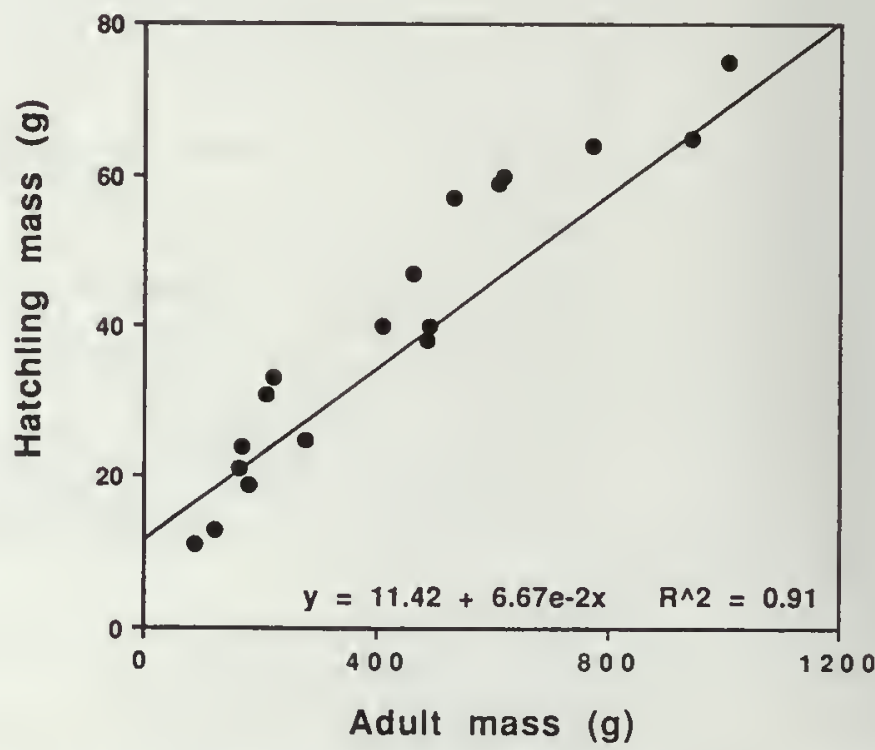

Figure 5-Relationship between mean adult mass and mean hatchling mass for 18 alcids (see tábles 3 and 7 for values). 
Table 7-Condition of alcid chicks at hatching and age at which homeothermy (uniform body temperature maintained nearly independent of environment) is achieved

\begin{tabular}{|c|c|c|c|c|c|}
\hline Species & $\begin{array}{l}\text { Developmental } \\
\text { stage at hatching }\end{array}$ & Plumage & $\begin{array}{l}\text { Mean body } \\
\text { mass (g) }\end{array}$ & $\begin{array}{l}\text { Pct. adult } \\
\text { mass at } \\
\text { hatching }\end{array}$ & $\begin{array}{l}\text { Age (days) of } \\
\text { homeothermy }\end{array}$ \\
\hline Dovekie $^{1}$ & semi-precocial & downy & 21 & 13 & $2-5$ \\
\hline Razorbill ${ }^{2}$ & intermediate & downy & ca. 60 & $9-10$ & $9-10$ \\
\hline Common Murre ${ }^{3}$ & intermediate & downy & 55-95 (range) & $6-10$ & 10 \\
\hline Thick-billed Murre 4 & intermediate & downy & ca. 65 & 7 & $9-10$ \\
\hline Black Guillemot ${ }^{5}$ & semi-precocial & downy & ca. 40 & ca. 10 & $1-4$ \\
\hline Spectacled Guillemot ${ }^{6}$ & semi-precocial & downy & $40(n=1)$ & 8 & $?$ \\
\hline Pigeon Guillemot $^{7}$ & semi-precocial & downy & 38 & 8 & 1 \\
\hline Marbled Murrelet $^{8}$ & semi-precocial & downy & 33 & 15 & probably $1-2$ \\
\hline Kittlitz's Murrelet ${ }^{9}$ & semi-precocial & downy & $?$ & $?$ & $?$ \\
\hline Xantus' Murrelet ${ }^{10}$ & precocial & downy & 24 & 15 & probably 1-2 \\
\hline Craveri's Murrelet"1 & precocial & downy & $?$ & $?$ & $?$ \\
\hline Ancient Murrelet ${ }^{12}$ & precocial & downy & 31 & 13 & 2 \\
\hline 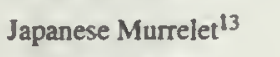 & precocial & downy & $?$ & $?$ & $?$ \\
\hline Crested Auklet ${ }^{14}$ & semi-precocial & downy & ca. 25 & 10 & probably 4-5 \\
\hline Least Auklet ${ }^{15}$ & semi-precocial & downy & 11 & $12-14$ & probably 5 \\
\hline Whiskered Auklet ${ }^{16}$ & semi-precocial & downy & 13 & 11 & probably by 7 \\
\hline Cassin's Aukdet ${ }^{17}$ & semi-precocial & downy & 19 & 11 & $3-4$ \\
\hline Parakeet Auklet ${ }^{18}$ & semi-precocial & downy & $?$ & $?$ & $?$ \\
\hline Rhinoceros Auklet ${ }^{19}$ & semi-precocial & downy & 57 & 10 & $?$ \\
\hline Tufted Puffin 20 & semi-precocial & downy & 64 & 8 & $?$ \\
\hline Horned Puffin 21 & semi-precocial & downy & 59 & 10 & $?$ \\
\hline Allantic Puffin ${ }^{22}$ & semi-precocial & downy & 47 & 11 & $6-7$ \\
\hline
\end{tabular}

${ }^{1}$ Reviewed by Gaston (1985), Harris and Birkhead (1985), Ydenberg (1989); Evans (1981), Konarzewski and others (1993), Norderhaug (1980)

${ }^{2}$ Reviewed by Gaston (1985), Harris and Birkhead (1985), Ydenberg (1989)

${ }^{3}$ Reviewed by Gaston (1985), Harris and Birkhead (1985), Ydenberg (1989); Birkhead (1976), Johnson and West (1975)

${ }^{4}$ Reviewed by Gaston (1985), Harris and Birkhead (1985), Ydenberg (1989); Birkhead and Nettleship (1981), Johnson and West (1975)

${ }^{5}$ Reviewed by Gaston (1985), Harris and Birkhead (1985), Ydenberg (1989); Cairns (1981, 1987)

${ }^{6}$ Kitaysky (1994), Thorensen (1984)

${ }^{7}$ Reviewed by Freethy (1987), Gaston (1985), Ydenberg (1989); Ainley and others (1990b), Drent (1965)

${ }^{8}$ Reviewed by Gaston (1985), Ydenberg (1989); Hirsch and others (1981), Sealy (1975c), Simons (1980)

${ }^{9}$ Reviewed by Freethy (1987), Ydenberg (1989)

${ }^{10}$ Reviewed by Freethy (1987), Gaston (1985), Y denberg (1989); Murray and others (1983)

${ }^{11}$ Reviewed by Gaston (1985), Ydenberg (1989); DeWeese and Anderson (1976)

${ }^{12}$ Reviewed by Gaston (1985, 1992), Y denberg (1989); Sealy (1976), Vermeer and Lemon (1986)

${ }^{13}$ Reviewed by Gaston (1985)

${ }^{14}$ Reviewed by Freethy (1987), Gaston (1985), Ydenberg (1989); Sealy (1968), Jones (1993a), Piatt and others (1990)

${ }^{15}$ Reviewed by Freethy (1987), Gaston (1985), Y denberg (1989); Jones (1993b), Piatt and others (1990), Roby and Brink (1986)

${ }^{16}$ Reviewed by Byrd and Williams (1993); Williams and others (1994)

${ }^{17}$ Reviewed by Gaston (1985), Ydenberg (1989); Ainley and others (1990a), Manuwal (1979), Thorensen (1964), Vermeer and Lemon (1986)

${ }^{18}$ Reviewed by Gaston (1985), Ydenberg (1989)

${ }^{19}$ Reviewed by Freethy (1987), Gaston (1985), Ydenberg (1989); Wilson and Manuwal (1986)

${ }^{20}$ Reviewed by Freethy (1987), Gaston (1985), Y denberg (1989); Boone (1986), Vermeer and others (1979)

${ }^{21}$ Reviewed by Freethy (1987), Gaston (1985), Y denberg (1989); Sealy (1973c)

${ }^{22}$ Reviewed by Gaston (1985), Harris and Birkhead (1985), Ydenberg (1989); Barrett and Rikardsen (1992) 
Table 8-Parental care in alcids

\begin{tabular}{|c|c|c|c|c|}
\hline Species & $\begin{array}{l}\text { Brooding } \\
\text { parent }\end{array}$ & $\begin{array}{l}\text { Period of } \\
\text { brooding (days) }\end{array}$ & Feeding parent & $\begin{array}{l}\text { Time at which young } \\
\text { reach independence }\end{array}$ \\
\hline Dovekie $^{1}$ & both & $2-7$ & both at nest; probably neither at sea & at fledging \\
\hline Razorbill ${ }^{2}$ & both & $5-10$ & both at nest; male at sea & several weeks following fledging \\
\hline Common Murre ${ }^{3}$ & both & until fledging & both at nest; male at sea & $70-85$ days \\
\hline Thick-billed Murre ${ }^{4}$ & both & until fledging & both at nest; male at sea & $?$ \\
\hline Black Guillemot $^{5}$ & both & $3-5$ & both at nest; neither at sea & at fledging \\
\hline Spectacled Guillemot ${ }^{6}$ & $?$ & $?$ & $?$ & $?$ \\
\hline Pigeon Guillemot ${ }^{7}$ & both & at least 3 & both at nest; neither at sea & at fledging \\
\hline Marbled Murrelet ${ }^{8}$ & both & $0.5-3.0$ & both at nest; probably neither at sea & at fledging \\
\hline Kittlitz's Murrelet? & $?$ & $?$ & both at nest & $?$ \\
\hline Xantus' Murrelet ${ }^{10}$ & both & $1-2$ & neither at nest; both at sea & ? \\
\hline Craveri's Murrelet $^{11}$ & $?$ & $?$ & both at sea & $?$ \\
\hline Ancient Murrelet ${ }^{12}$ & both & 2 & neither at nest; both at sea & $42-56$ days \\
\hline Japanese Murrelet ${ }^{13}$ & $?$ & $?$ & neither at nest; both at sea & $?$ \\
\hline Crested Auklet ${ }^{14}$ & both & 7 & both at nest; neither at sea & at fledging \\
\hline Least Auklet ${ }^{15}$ & both & 7 & both at nest; neither at sea & at fledging \\
\hline Whiskered Auklet ${ }^{16}$ & $?$ & probably 7 & both at nest & probably at fledging \\
\hline Cassin's Auklet ${ }^{17}$ & both & $3-5$ & both at nest; neither at sea & at fledging \\
\hline Parakeet Auklet $^{18}$ & both & $?$ & both at nest & $?$ \\
\hline Rhinoceros Auklet ${ }^{19}$ & both & 4 & both at nest & probably at fledging \\
\hline Tufted Puffin ${ }^{20}$ & $?$ & $?$ & $?$ & $?$ \\
\hline Homed Puffin ${ }^{21}$ & $?$ & $?$ & $?$ & $?$ \\
\hline Atlantic Puffin ${ }^{22}$ & both & 9 & both at nest; neither at sea & at fledging \\
\hline
\end{tabular}

${ }^{1}$ Reviewed by Gaston (1985), Harris and Birkhead (1985)

${ }^{2}$ Reviewed by Gaston (1985), Harris and Birkhead (1985)

${ }^{3}$ Reviewed by Gaston (1985), Harris and Birkhead (1985); Boekelheide and others (1990); also see Bayer and others (1991)

${ }^{4}$ Reviewed by Gaston (1985), Harris and Birkhead (1985)

${ }^{5}$ Reviewed by Gaston (1985), Hudson (1985)

${ }^{6}$ No information located

${ }^{7}$ Reviewed by Ewins (1993), Freethy (1987), Gaston (1985)

${ }^{8}$ Naslund (1993a), Nelson and Hamer (this volume a), Nelson and Hardin (1993a), Nelson and Peck (in press), Simons (1980), Singer and others (1992, in press)

9Naslund and others (1994)

${ }^{10}$ Reviewed by Freethy (1987); Murray and others (1983)

${ }^{11}$ DeWeese and Anderson (1976)

${ }^{12}$ Reviewed by Gaston (1990, 1992); Sealy (1976)

${ }^{13}$ Ono and Nakamura (1994)

${ }^{14}$ Reviewed by Freethy (1987), Gaston (1985); Jones (1993a), Piatt and others (1990)

${ }^{15}$ Reviewed by Gaston (1985); Jones (1993b), Piatt and others (1990), Roby and Brink (1986), Sealy (1973a)

${ }^{16}$ Reviewed by Byrd and Williams (1993), Freethy (1987)

${ }^{17}$ Ainley and others (1990a), Manuwal (1979), Vermeer (1981)

${ }^{18}$ Bédard (1969b)

${ }^{19}$ Reviewed by Vermeer and Cullen (1982); Wilson and Manuwal (1986)

${ }^{20,21}$ No information located

${ }^{22}$ Reviewed by Gaston (1985), Harris and Birkhead (1985) 
Table e-Condition of alcid young at time of fledging from the nest

\begin{tabular}{|c|c|c|c|}
\hline Species & $\begin{array}{l}\text { Mean fledging } \\
\text { age (days) }\end{array}$ & $\begin{array}{l}\text { Mean body mass } \\
\text { at fledging (g) }\end{array}$ & $\begin{array}{l}\text { Mean pct. } \\
\text { adult mass }\end{array}$ \\
\hline Dovekie ${ }^{1}$ & 27 & 120 & $67-80$ \\
\hline Razorbill $^{2}$ & 18 & ca. 170 & $20-30$ \\
\hline Common Murre ${ }^{3}$ & 21 & $170-270$ (range) & $18-28$ \\
\hline Thick-billed Murre & 22 & 180 & 19 \\
\hline Black Guillemot ${ }^{5}$ & 37 & 356 & 86 \\
\hline Spectacled Guillemot ${ }^{6}$ & $\cos 33$ & 545 (1 obs.) & 111 \\
\hline Pigeon Guillemor ${ }^{7}$ & 38 & 460 & 95 \\
\hline Marbled Murrelet ${ }^{8}$ & probably $27-40$ & 149 & 67 \\
\hline Kittliz's Murrelet? & 29 & possibly 90 (1 obs.) & possibly 40 \\
\hline Xantus' Murrele! ${ }^{10}$ & $1-2$ & 24 & 14 \\
\hline Craveri's Murrelet ${ }^{11}$ & 24 & $?$ & $?$ \\
\hline Ancient Murrelet ${ }^{12}$ & 2 & 26 & $12-13$ \\
\hline Japanese Murrelet $^{13}$ & $1-2$ & $?$ & $?$ \\
\hline Crested Auklet ${ }^{14}$ & 33 & ca. 245 & $80-100$ \\
\hline Least Auklet ${ }^{15}$ & 29 & 87 & 104 \\
\hline Whiskered Auklet ${ }^{16}$ & probably $39-42$ & 106 & 92 \\
\hline Cassin's Auklet' ${ }^{17}$ & 43 & 153 & 90 \\
\hline Parakeet Auklet ${ }^{18}$ & 35 & 235 & 79 \\
\hline Rhinoceros Auklet ${ }^{19}$ & 52 & 329 & 61 \\
\hline Tufted Puffin ${ }^{20}$ & 49 & 490 & 69 \\
\hline Homed Puffin 21 & 38 & 400 & 65 \\
\hline Atlantic Puffin 22 & 46 & 271 & 69 \\
\hline
\end{tabular}

${ }^{1}$ Reviewed by Gaston (1985), Harris and Birkhead (1985); Evans (1981)

${ }^{2}$ Reviewed by Gaston (1985), Harris and Birkhead (1985); Lloyd (1979)

${ }^{3}$ Reviewed by Gaston (1985), Harris and Birkhead (1985); Hatch and Hatch (1990a)

${ }^{4}$ Reviewed by Gaston (1985), Harris and Birichead (1985), Hudson (1985); Birkhead and Nettleship (1981), Hatch and Hacch (1990a)

${ }^{5}$ Reviewed by Gaston (1985), Harris and Birkhead (1985), Hudson (1985); Caims (1981, 1987)

${ }^{6}$ Kitaysky (1994), Kondratyev (1994), Thorensen (1984)

${ }^{7}$ Reviewed by Ewins (1993), Gaston (1985); Ainley and others (1990b), Drent and others (1964), Kuletz (1983)

${ }^{8}$ Reviewed by Gaston (1985); Hirsch and others (1981), Nelson and Hamer (this volume a). Nelson and Hardin (1993a), Nelson and Peck (in press), Sealy (1974, 1975a), Simons (1980), Singer and others (1992, in press)

9Day and others (1983), Naslund and others (1994)

${ }^{10}$ Reviewed by Gaston (1985); Murray and others (1983)

${ }^{11}$ Reviewed by DeWeese and Anderson (1976), Gaston (1985)

${ }^{12}$ Gaston (1992), Jones and Falls (1987), Sealy (1976), Vermeer and Lemon (1986)

${ }^{13}$ Reviewed by Gaston (1985), Ono and Nakamura (1993)

${ }^{14}$ Reviewed by Gaston (1985); Jones (1993a), Piatt and others (1990)

${ }^{15}$ Reviewed by Gaston (1985); Piart and others (1990), Roby and Brink (1986)

${ }^{16}$ Reviewed by Byrd and Williams (1993); Williams and others (1994)

${ }^{17}$ Reviewed by Gaston (1985); Ainley and others (1990a), Manuwal (1979), Thorensen (1964), Vermeer and Cullen (1982), Vermeer and Lemon (1986)

${ }^{18}$ Sealy and Bédard (1973)

${ }^{19}$ Reviewed by Byrd and others (1993), Gaston (1985); Ainley and others (1990c), Leschner (1976), Vermeer (1980), Vermeer and Cullen (1979), Wilson and Manuwal (1986); also see Berram (1988)

${ }^{20}$ Reviewed by Gaston (1985); Ainley and others (1990c), Boone (1986), Vermeer and Cullen (1979), Wehle (1980)

${ }^{21}$ Reviewed by Gaston (1985), Wehle (1983); Sealy (1973c)

${ }^{22}$ Reviewed by Gaston (1985), Harris and Birkhead (1985); Barrett and Rikardsen (1992), Harris and Hislop (1978), Nettleship (1972) 
where they receive additional care for several weeks until independent (table 8).

Marbled Murrelet chicks are semi-precocial and remain in the nest where they are cared for by both parents until fledging at 27 to 40 days of age (tables 7 and 8). The chick is apparently able to thermoregulate at an early age as continuous brooding by the parents ceases after 1-3 days (Naslund 1993a; Nelson and Hamer, this volume a; Nelson and Peck, in press; Simons 1980; S.W. Singer, pers. comm.). The period of continuous brooding is shorter than most alcids raised in the nest (semi-precocial and intermediate species) and is comparable to that of the precocial murrelets (table 7). Growth data have been collected for only four nestlings, the preliminary data suggest murrelets grow more rapidly than comparable alcids (Hamer and Cummins 1991; Hirsch and others 1981; Simons 1980).

The incubation and nestling periods of semi-precocial alcids are related (fig. $6, r^{2}=0.68, P<0.001$ ), however, the precocial and intermediate species do not fit this pattern. (The relationship between the incubation and the nestling period including the alcids with precocial and intermediate developmental modes is not significant $\left.\left[r^{2}=0.19, P<0.07\right]\right)$.

Lengthy incubation and nestling periods have been attributed to slow rates of development (Manuwal 1979). In contrast, Marbled Murrelets appear to have a relatively short incubation and nestling period indicating a rapid rate of development. However, the nestling stage of the Marbled Murrelet can vary between 27 and 40 days and the extended growth period may reflect parental difficulty in provisioning the nestling (Nelson and Hamer, this volume a; Nelson and Hardin 1993a). Barrett and Rikardsen (1992) reported lengthy nestling periods of Atlantic Puffins during years of food shortages when parents delivered less food to their young.

Estimates of mean fledging success range from 66 percent for Crested Auklets to over 90 percent for the Ancient Murrelets and Wiskered Auklet (table 6). Causes of prefledgling mortality include mammalian, avian, and reptilian predation (Emms and Verbeek 1989; Evans 1981; Ewins and others 1993; Gaston 1994; Jones 1992; Manuwal 1979; Sealy 1982; Thorensen 1964), food shortages or starvation (Ainley and Boekelheide 1990; Barrett and Rikardsen 1992; Manuwal 1979; Vermeer 1980), adverse weather (reviewed by Harris and Birkhead 1985), and injury inflicted by adult conspecifics (Birkhead and Nettleship 1981).

Fledging success of Marbled Murrelets has been estimated to be 45 percent, a value lower than those of other species (table 6). Chicks in 19 nests were, monitored in Alaska, California, Oregon, Washington, and British Columbia (Nelson and Hamer, this volume b). Nearly 25 percent of these young were documented or strongly suspected to have been taken by predators, three others fell from their nest trees, and one died of unknown causes.

Although juvenile survival is difficult to observe and measure, banding studies have provided estimates of survival for seven alcid species ranging from below 1 percent for Atlantic Puffins to a high of 65 percent for Cassin's Auklets

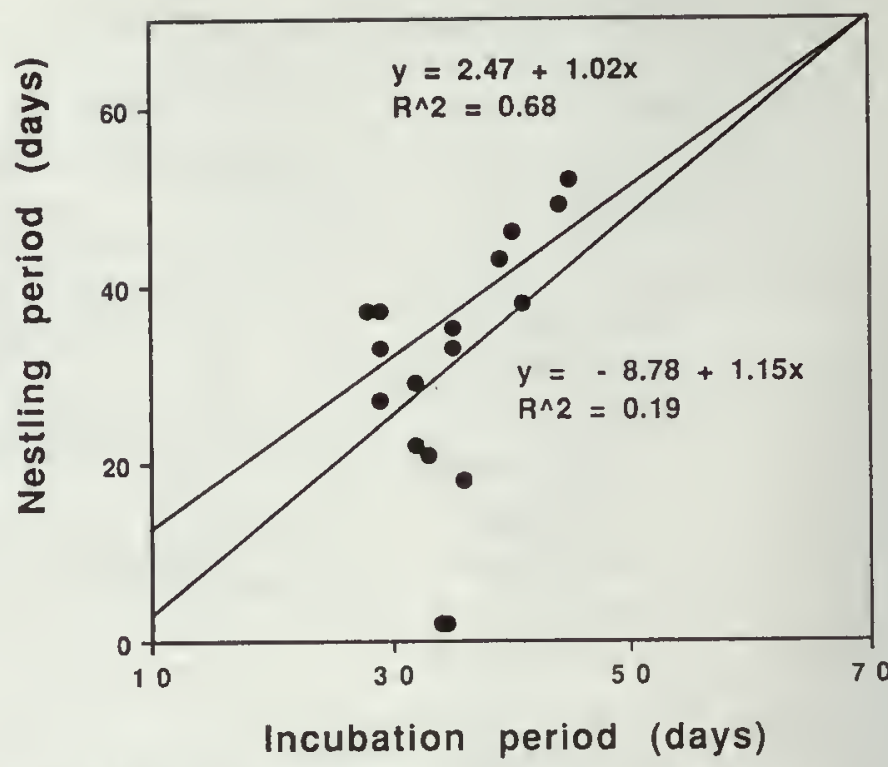

Flgure 6-Relationship between incubation and nestling periods for 19 alcids (see tables 5 and 9 for values).

(table 6). Juvenile survival has not been estimated for Marbled Murrelets. It is likely that recently fledged Marbled Murrelets experience some mortality on their trip from inland nest trees to the ocean. Forty-six juveniles in postfledging plumage have been found on the forest floor or in parking lots, presumably following unsuccessful attempts at fledging from inland nests (see Nelson and Hamer, this volume b). An indication of low fledgling success is also reflected in at-sea surveys conducted in California, Oregon, and Alaska in which only 1 to 5 percent of birds on the water were observed to be recently fledged young (Nelson and Hardin 1993a; Ralph and Long, this volume; Strong and others, in press; Strong and others, this volume; Varoujean and Williams, this volume).

Although the average number of young produced by alcid pairs can be high in some years, it is common for productivity to be variable among years, and extremely low reproductive rates are not uncommon. For example, over a 12-yr period on the South Farallon Islands, Common Murre pairs produced an average of 0.86 young per season, but values over this time fluctuated from a high of 0.9 to a low of 0.1 fledglings (Boekelheide and others 1990). Complete nesting failures have been documented as well (Bergman 1971).

Summarizing the available information on the reproduction of Marbled Murrelets, it appears that this alcid has a low reproductive rate. This species lays only one egg, has relatively low hatching success and fledgling survival, and a low rate of recruitment of young into the population. However, some of the Marbled Murrelet reproductive data were collected during El Niño periods (Ainley 1990). Because reproduction of other alcids has been documented to be low during such times (Boekelheide and others 1990), values reported for Marbled Murrelets may reflect a similar depression. Reproduction in "good" years may be higher. On the other 
hand, reproduction of the Marbled Murrelet is not likely to exceed that of other alcids with comparable reproductive traits. See Beissinger (this volume) for a discussion on the possible reproductive rates of Marbled Murrelets using general reproductive parameters.

If the Marbled Murrelet does have a low rate of reproduction, then it is quite possible that this species will have difficulty recovering from significant population declines, and steps should be taken to minimize the impact of human activity on the production of murrelet young. To completely address this issue, however, thorough study of the reproductive biology of this species is needed. Longterm studies of individually marked, nesting Marbled Murrelets and their young need are required. Effects of natural and human-induced perturbations on the reproductive ecology of this species can then be better understood.

\section{Acknowledgments}

George Divoky, Harry Carter, Steve Singer, Barney Dunning, and Scott Hatch assisted us in locating information and references for this review. We thank Bob Peck, Dave D'Amore, George Divoky, Jeff Grenier, Scott Hatch, and George Hunt for reviewing earlier drafts of this manuscript. Support for preparation of this manuscript was provided by the Oregon Department of Fish and Wildlife, USDA Forest Service, USDI Bureau of Land Management, and U.S. Fish and Wildlife Service. Support for preparation of this manuscript was provided by the Oregon Department of Fish and Wildlife, USDA Forest Service, USDI Bureau of Land Management, and U.S. Fish and Wildlife Service. This is Oregon State University Agricultural Experiment Station Technical Paper number 10,539. 



\author{
Thomas E. Hamer'
}

\section{S. Kim Nelson ${ }^{2}$}

\begin{abstract}
We compiled 86 breeding records of eggs, downy young, and fledgling Marbled Murrelets (Brachyramphus marmorarus) for which the fledging date could be estimated. Records were collected from California $(n=25)$, Oregon $(n=13)$, Washington $(n=13)$, British Columbia $(n=23)$, and Alaska $(n=12)$. The number of young fledging increased rapidly from 6 June to 19 July and peaked by the 10-day period beginning 19 July. A second peak in the number of young fledged was observed for the 10-day period beginning 18 August, with a rapid decrease in late August and early September. From these results, a gradual accumulation of fledglings on the ocean would be observed from 30 May until 16 September. By 27 August, only 84 percent of the juveniles in a given year would be expected to be counted at sea. In California and Oregon, it is likely that two distinct periods of breeding activity result from some proportion attempting to lay a second clutch, or pairs renesting after nesting failure. The breeding season appears to be much longer and less synchronous than that of many other members of the alcid family. We conclude that egg-laying and incubation spanned a long period, beginning $24 \mathrm{March}$ and ending 25 August, with the nestling period beginning 23 April and ending with a fledging record on 21 September, a breeding period of 182 days.
\end{abstract}

Detailed information on the breeding chronology of the Marbled Murrelet (Brachyramphus marmoratus) has been limited. More recently, a large amount of unpublished information has been collected from research projects being conducted throughout the range of the Marbled Murrelet. In this paper we review the nesting chronology of the Marbled Murrelet using data from four published studies that specifically addressed the topic ( $n=26$ records), additional published breeding records ( $n=26$ ), and unpublished breeding accounts ( $n=35$ ) of the Marbled Murrelet from Alaska, British Columbia, Washington, Oregon, and Califomia. This information was used to estimate the fledging dates for each record collected. We then summarized these fledging dates and used them to construct the timing of egg laying, incubation, and nestling period for each state and province to more accurately document the breeding chronology of the Marbled Murrelet.

An understanding of the breeding chronology of the Marbled Murrelet is important for several reasons. To learn more about the nesting ecology of this species, it is important to understand the timing and lengths of breeding activities and what factors affect this timing. To avoid disturbance to nesting colonies from land management activities, land

${ }^{1}$ Research Biologist, Hamer Environmental, 2001 Highway 9, Mt. Vernon, WA 98273

2 Research Wildlife Biologist, Oregon Cooperative Wildlife Research Unit, Oregon State University, Nash 104, Corvallis, OR 9733t-3803 managers will need to know the timing of the incubation and nestling periods for each geographic area. Biologists conducting nest searches and gathering information on nesting biology will want to know the optimum period to conduct these activities. In addition, biologists conducting marine surveys to collect information on the numbers of juveniles observed at sea, as an indication of reproductive success, will need nesting chronology data to determine the appropriate timing of these surveys.

Several studies have addressed the breeding chronology of the Marbled Murrelet. In British Columbia, Sealy (1974) collected female specimens at sea and examined the maturation of the ovarian follicles, the size of the brood patch, and the date juveniles were first observed on the ocean. Carter and Sealy (1987b) used 41 records of downy young and grounded fledglings to estimate the timing of breeding. Carter and Erickson (1992) used additional records of grounded chicks and fledglings to estimate the timing of egg laying, incubation, and chick rearing for murrelets in California. In addition, the breeding phenology of the murrelet in British Columbia was reviewed by Rodway and others (1992), adding some records to the previous work of Sealy (1974) and Carter and Sealy (1987b).

\section{Methods}

We compiled unpublished breeding records from intensive field work conducted on murrelets over the last five years, and from published observations of breeding records, downy young and fledgling Marbled Murrelets (table 1). Fledging dates were estimated using a 30-day incubation period and a 28 -day nestling period (Sealy 1974, Simons 1980, Hirsch and others 1981). For example, if a grounded chick was found and, from the description, was estimated to be 10 days old, we added 18 days to determine the approximate fledging date. Similarly, if an egg-laying date was available, but the egg was destroyed before hatching, we added 30 days for incubation and a 28-day nestling period to estimate the fledging date. The initiation of egg laying, incubation, and hatching were estimated for each record in the same manner. In some cases, where the size and plumage of a chick were not described completely, a subjective estimate of the age of the chick was made. These records were given a higher error estimate. Fledging dates were used for the analysis only if the date could be estimated with an error of $<8$ days so that the results would accurately describe the nesting chronology. Records were not used when a description of the plumage or size of the chick was not available. Records derived from juveniles first observed at sea were used only if the researcher was conducting weekly boat surveys within 
Table 1-Inland and at-sea records of eggs, downy young, and fledglings of Marbled Murrelets in North America ( $\mathrm{n}=$ 86) where the fledging date could be estimated. The term "grounded" under "Record type" refers to chicks or fledglings that were found on the ground

\begin{tabular}{|c|c|c|c|}
\hline Location & Sources & Record type & $\begin{array}{l}\text { Estimated } \\
\text { fledge date }\end{array}$ \\
\hline \multicolumn{4}{|l|}{ California } \\
\hline Big Basin State Park & Singer (pers. comm) & Grounded chick & $5 / 20 / 89$ \\
\hline Big Basin State Park & Binford and others (1975) & Grounded chick & $8 / 20 / 74$ \\
\hline Big Basin State Park & Carter and Erickson (1992) & Grounded fledgling & $6 / 12 / 76$ \\
\hline Big Basin State Park & Carter and Erickson (1992) & Grounded fledgling & $6 / 14 / 79$ \\
\hline Portola State Park & Anderson (1972) & Grounded fledgling & $6 / 15 / 57$ \\
\hline Big Basin State Park & Carter and Erickson (1992) & Grounded fledgling & $6 / 17 / 73$ \\
\hline Portola State Park & Desante and LeValley (1971) & Grounded fledgling & $6 / 27 / 71$ \\
\hline Gasquet Ranger District & Craig (pers. comm.) & Grounded fledgling & $6 / 30 / 92$ \\
\hline Big Basin State Park & Carter and Erickson (1992) & Grounded fledgling & $7 / 04 / 76$ \\
\hline Sequoia Park & Carter and Erickson (1992) & Grounded fledgling & $7 / 04 / 24$ \\
\hline Memorial County Park & Singer (pers. comm.) & Grounded fledgling & $7 / 19 / 88$ \\
\hline Big Basin State Park & Carter and Erickson (1992) & Grounded fledgling & $8 / 11 / 82$ \\
\hline Prairie Creek State Park & Carter and Erickson (1992) & Grounded fledgling & $8 / 13 / 84$ \\
\hline Big Basin State Park & Singer (pers. comm.) & Grounded fledgling & $8 / 15 / 90$ \\
\hline Big Basin State Park & Singer and Verado (1975) & Grounded fledgling & $8 / 18 / 60$ \\
\hline Big Basin State Park & Singer (pers. comm.) & Grounded fledgling & $8 / 25 / 92$ \\
\hline Big Basin State Park & Erickson and Morlan (1978) & Grounded fledgling & $8 / 31 / 77$ \\
\hline Loma Mar & Carter and Erickson (1992) & Grounded fledgling & $8 / 31 / 85$ \\
\hline Big Basin State Park & Singer (pers. comm.) & Grounded fledgling & $9 / 03 / 88$ \\
\hline Big Basin State Park & Singer (pers. comm.) & Grounded fledgling & $9 / 05 / 93$ \\
\hline Big Basin State Park & Singer and Verado (1975) & Grounded fledgling & $9 / 09 / 74$ \\
\hline Big Basin State Park & Singer (pers. comm.) & Grounded unknown & $5 / 18 / 84$ \\
\hline Big Basin State Park & Singer (pers. comm.) & Nest observed & $6 / 07 / 92$ \\
\hline Big Basin State Park & Singer (pers. comm.) & Nest observed & $7 / 03 / 91$ \\
\hline Elkhead Springs & Chinnici (pers. comm.) & Nest observed & $8 / 23 / 92$ \\
\hline Waddell Creek & Naslund (1993a) & Nest observed & $8 / 26 / 89$ \\
\hline \multicolumn{4}{|l|}{ Oregon } \\
\hline Five Rivers & Nelson and Peck (in press) & Grounded chick & $7 / 07 / 90$ \\
\hline God's Valley & Nelson and Peck (in press) & Grounded fledgling & $9 / 13 / 90$ \\
\hline Powers Ranger District & Nelson and Peck (in press) & Grounded fledgling & $7 / 26 / 92$ \\
\hline North Fork Siuslaw River & Jewett (1930) & Grounded fledgling & $9 / 08 / 18$ \\
\hline Siletz & Hein] (1988) & Grounded fledgling & $9 / 21 / 87$ \\
\hline Five Rivers & Nelson and Peck (in press) & Nest observed & $6 / 22 / 91$ \\
\hline Boulder and Warnicke Creeks & Nelson and Peck (in press) & Nest observed & $7 / 08 / 92$ \\
\hline Iron Mountain & Nelson and Peck (in press) & Nest observed & $7 / 09 / 92$ \\
\hline Cape Creek & Nelson and Peck (in press) & Nest observed & $7 / 20 / 91$ \\
\hline Siuslaw River & Nelson and Peck (in press) & Nest observed & $8 / 29 / 91$ \\
\hline Valley of The Giants & Nelson and Peck (in press) & Nest observed & $8 / 30 / 90$ \\
\hline Valley of The Giants & Nelson and Peck (in press) & Nest observed & $7 / 09 / 91$ \\
\hline Sinslaw River & Nelson and Peck (in press) & Nest observed & $9 / 09 / 91$ \\
\hline \multicolumn{4}{|l|}{ Washington } \\
\hline Rugged Ridge & Leschner and Cummins (1992a) & Grounded chick & $7 / 09 / 82$ \\
\hline Helena Creek & Reed and Wood(1991) & Grounded chick & $7 / 22 / 89$ \\
\hline Baker Lake & Hamer (pers. obs.) & Grounded chick & $7 / 24 / 90$ \\
\hline Heart of the Hills Trail & Hamer (pers. obs.) & Grounded chick & $8 / 07 / 91$ \\
\hline
\end{tabular}


Table I-continued

\begin{tabular}{|c|c|c|c|}
\hline Location & Sources & Record type & $\begin{array}{l}\text { Estimated } \\
\text { ledge date }\end{array}$ \\
\hline Aberdeen & Leschner and Cummins (1992a) & Grounded chick & $8 / 09 / 83$ \\
\hline Matheny Creek & Leschner and Cummins (1992a) & Grounded fledgling & $7 / 17 / 81$ \\
\hline North Fork Quinault & Leschner and Curnmins (1992a) & Grounded fledgling & $7 / 23 / 86$ \\
\hline Sedro Woolley & Hamer (pers. obs.) & Grounded fledgling & $7 / 24 / 90$ \\
\hline North Rosedale & Leschner and Cummins (1992a) & Grounded fledgling & $7 / 2471$ \\
\hline Federal Way & Leschner and Curmmins (1992a) & Grounded fledgling & $8 / 07 / 74$ \\
\hline Long Beach & Ritchie (pers. comm.) & Nest observed & $6 / 22 / 93$ \\
\hline Lake 22 & Hamer (pers. obs.) & Nest observed & $7 / 18 / 90$ \\
\hline Lake 22 & Hamer (pers. obs.) & Nest observed & $8 / 27 / 90$ \\
\hline \multicolumn{4}{|l|}{ British Columbia } \\
\hline Langara Island & Sealy (1974) & Egg development & $7 / 2071$ \\
\hline Langara Island & Sealy (1974) & Egg development & $7 / 26 / 71$ \\
\hline Langara Island & Sealy (1974) & Egg development & $7 / 3071$ \\
\hline Langara Island & Sealy (1974) & Egg development & $8 / 0270$ \\
\hline Langara Island & Sealy (1974) & Egg development & 80270 \\
\hline Langara Island & Sealy (1974) & Egg development & $8 / 0471$ \\
\hline Langara Island & Sealy (1974) & Egg development & $8 / 06 / 71$ \\
\hline Langara Island & Sealy (1974) & Egg development & 8,08770 \\
\hline Langara Island & Sealy (1974) & Egg development & $8 / 1970$ \\
\hline Langara Island & Sealy (1974) & Egg development & 83071 \\
\hline Vancouver Island & Harris (1971) & Grounded chick & $8 / 30 / 67$ \\
\hline Chilliwack & Rodway and others (1992) & Grounded fledgling & $7 / 07 / 87$ \\
\hline Hope Village & Rodway and others (1992) & Grounded fledgling & $7 / 12 / 47$ \\
\hline Queen Charbtte Island & Sealy (1974) & Grounded fledgling & $7 / 15 / 47$ \\
\hline Sayward & Rodway and others (1992) & Grounded fledgling & $7 / 15 / 86$ \\
\hline Karen Range & Paul Jones (pers. comm.) & Nest observed & $8 / 20 / 93$ \\
\hline Frederick Island & Drent and Guiguet (1961) & Sea observation & $6 / 28 / 61$ \\
\hline Frederick Island & Drent and Guiguet (1961) & Sea observation & $6 / 28 / 61$ \\
\hline Barclay Sound & Carter (1984) & Sea observation & $6 / 28 / 80$ \\
\hline Barclay Sound & Carter (1984) & Sea observation & $7 / 0479$ \\
\hline Langara Island & Sealy (1975a) & Sea observation & 7106770 \\
\hline Langara Island & Sealy (1975a) & Sea observation & $707 / 71$ \\
\hline Cox Island & Brooks (1926b) & Ses observation & $7 / 22 / 20$ \\
\hline \multicolumn{4}{|l|}{ Alaska } \\
\hline Montague Island & Mendenhall (1992) & Egg development & $8 / 1077$ \\
\hline Skagway & Mendenhall (1992) & Grounded fledgling & $7 / 18 / 87$ \\
\hline Afognak Island & Carter and Sealy (1987b) & Grounded fledgling & $8 / 18 / 76$ \\
\hline Cordova Airport & Carter and Sealy (1987b) & Grounded fledgling & $8 / 2078$ \\
\hline Port Chatham & Johnston and Carter (1985) & Nest observed & Unknown \\
\hline Naked Island & Naslund and others (in press) & Nest observed & $7 / 23 / 92$ \\
\hline Kodiak Island & Naslund and others (in press) & Nest observed & $7 / 24 / 92$ \\
\hline Kodiak Island & Naslund and others (in press) & Nest observed & $8 / 03 / 92$ \\
\hline Naked Island & Naslund and others (in press) & Nest observed & $8 / 13 / 91$ \\
\hline East Amamuli Island & Hirsch and others (1981) & Nest observed & $8 / 16 / 79$ \\
\hline East Amatuli Island & Simons (1980) & Nest observed & $8 / 27 / 78$ \\
\hline Auke Bay & Speckman (pers. comm.) & Sea observation & $7 / 10 \times 93$ \\
\hline Auke Bay & Speckman (pers. comm.) & Sea observation & $7 / 29 / 92$ \\
\hline
\end{tabular}


the same geographic area and surveys commenced before the fledging period of the breeding season. Therefore, only one datum was used for each boat survey in each year, indicating the first fledging date for that season. These observations made up a small portion of the records used.

Birds were assumed to be juveniles when a grounded juvenile was reported, and a plumage description was not provided. Fortunately, the use of the word "juvenile" to describe a young bird that had lost its downy plumage was consistent throughout the literature. We assumed that grounded juveniles were recently fledged individuals. The majority of records of grounded juveniles included descriptions of remaining down on the back and head and the presence of an egg tooth, confirming recent fledging.

Records of eggs collected or found and of incubating adults were not used because the development period of the embryo was unknown. But the presence of a postovulatory follicle, unshelled egg in the oviduct, or mature follicles from collected females indicated that egg laying would occur in 1-3 days (Sealy 1974). Therefore, egg-laying dates were estimated for these records by adding 2 days to the collection date and then estimating the fledging date by adding 58 days.

Sealy (1974) obtained 12 breeding records in British Columbia. He collected murrelet specimens in weekly intervals during the breeding season between 30 April and 10 August. He examined the size of the brood patch in male and females and the size and maturation of the largest follicle in each ovary of females to estimate the timing of egg laying, incubation, and chick rearing. Observations of adults carrying fish in their bills at dusk were used to estimate the hatching dates of eggs. The first fledglings observed on the water were used as an indication of the earliest fledging dates. For our summary, we used only records from Sealy in which the size and maturation of the ovarian follicles of females enabled an accurate estimate of the egg-laying date, and two cases in which juveniles were first observed at sea. Observations of brood patch development and fish-carrying behavior were not used because the accuracy of these methods in estimating the nesting stage of the Marbled Murrelet is unknown.

Carter and Erickson (1992) reviewed the breeding chronology of the murrelet in California by examining inland records of downy young and grounded juveniles, molt conditions of museum specimens, and records of juveniles observed at sea from 1892 to 1987. Carter and Erickson used 28 days for a nestling period and 30 days for an incubation period to estimate breeding chronology. In addition, 41 inland records of downy young and fledgling murrelets from 1918 to 1986 were summarized in North America by Carter and Sealy (1987b). Records of grounded nestlings and juveniles from these studies, in which an accurate fledging date could be estimated, were used in this analysis.

Fledgling dates were estimated using 86 breeding records from California $(n=25)$, Oregon $(n=13)$, Washington $(n=$ $13)$, British Columbia $(n=23)$, and Alaska $(n=12)$ (table
1). Records used for this analysis included observations of the presence of a postovulatory follicle $(n=9)$ or unshelled egg in the oviduct of collected females $(n=2)$, known egglaying dates $(n=2)$, known egg-hatching dates $(n=5)$, observations of young on nests $(n=4)$, grounded chicks ( $n=$ 9 ), grounded fledglings ( $n=35$ ), juveniles observed to fledge $(n=10)$, and dates that juveniles were first observed at sea from marine census studies $(n=9)$. Fledging dates for a large proportion of the records ( 67 percent) could be estimated accurately because the egg-laying date or the hatching date was known, the young were accurately aged on the nest, a grounded fledgling was recorded, or a nestling was actually observed to fledge $(n=56)$.

\section{Results}

Records of the earliest and latest breeding records of the Marbled Murrelet were all collected from California and Oregon. The earliest fledging record in North America was of a grounded downy chick discovered in Big Basin State Park in central California on 20 May 1989. The chick was estimated to be at least 2 weeks old (S.W. Singer, pers. comm.). The next fledging was a nestling observed to fledge on 7 June 1992 from a nest also in Big Basin State Park (S.W. Singer, pers. comm.) (fig. I). A record also exists of a grounded murrelet in Big Basin State Park on 18 May 1984, but it was not clear whether the bird was an adult or juvenile (S.W. Singer, pers. comm.). The next four earliest fledging dates, from 12 June to 17 June, were all from Big Basin and Portola State Parks in central California (Anderson 1972; Carter and Erickson 1992; S.W. Singer, pers. comm.).

The latest fledging date was a record of a fledging found on 21 September 1987 in a parking lot in the town of Siletz, Oregon (Heinl 1988, Nelson and Peck, in press). The next four latest fledging dates, from 30 August to 9 September, were all recorded from California and Oregon (Carter and Erickson 1992, Erickson and Morlan 1978, Jewett 1930, Nelson and others 1992, Singer and Verardo 1975).

The number of young observed or estimated to have fledged for all North American records was summarized for each 10-day period during the breeding season. Fledging rates increased rapidly from 6 June to 19 July, and peaked by the 10-day period beginning 19 July (fig. 1). A possible second peak in the number of young fledged was evident for the 10-day period beginning 18 August, with a rapid decrease in the number of young leaving nests in late August and early September. Egg laying and incubation began 24 March and ended 25 August, with the nestling period beginning 23 April and ending with a fledging record on 21 September, a breeding period of 182 days.

An analysis of the cumulative number of young fledged in North America for each 10-day period was used to predict the percentage of total juveniles that would be observed in the marine environment during different periods of the breeding season. This analysis also demonstrated the broad nesting chronology of the Marbled Murrelet (fig. 2). The 


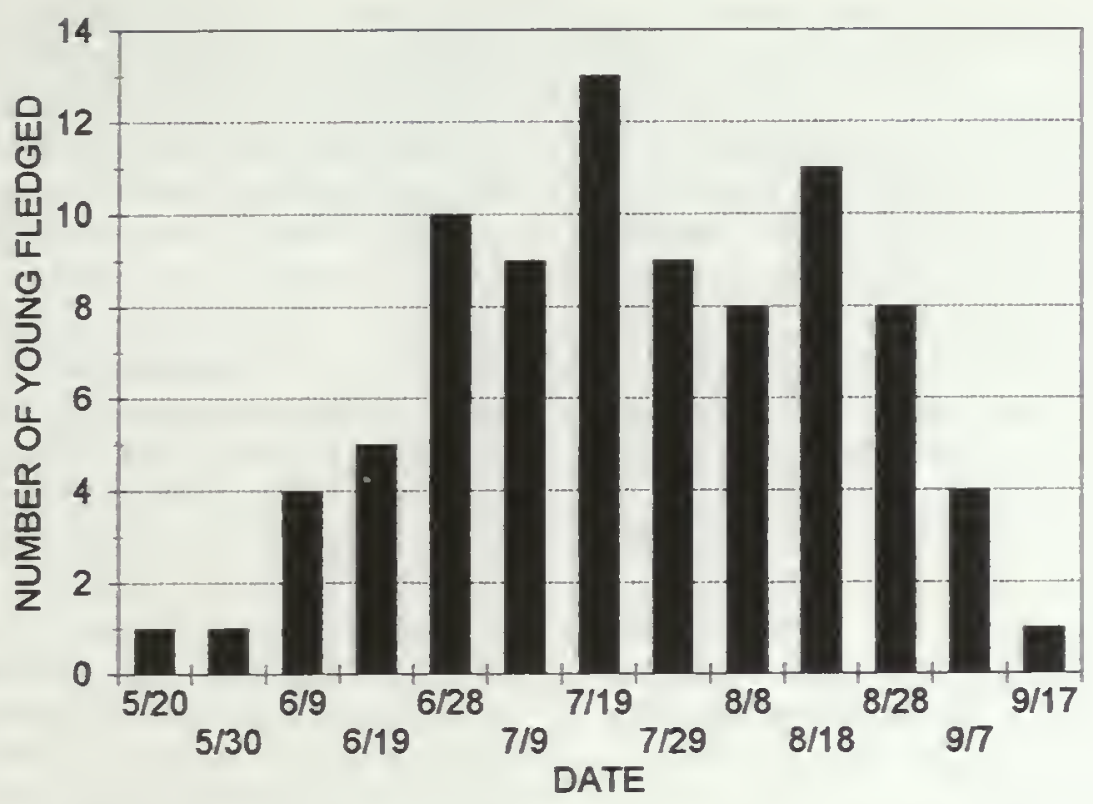

Figure 1-Fledging dates of Marbled Murrelet young from nests in North America $(n=86)$ in 10-day intervals. The date displayed for each histogram is the beginning of a 10-day period. Records were used only if the error in estimating the fledging date was $<8$ days.

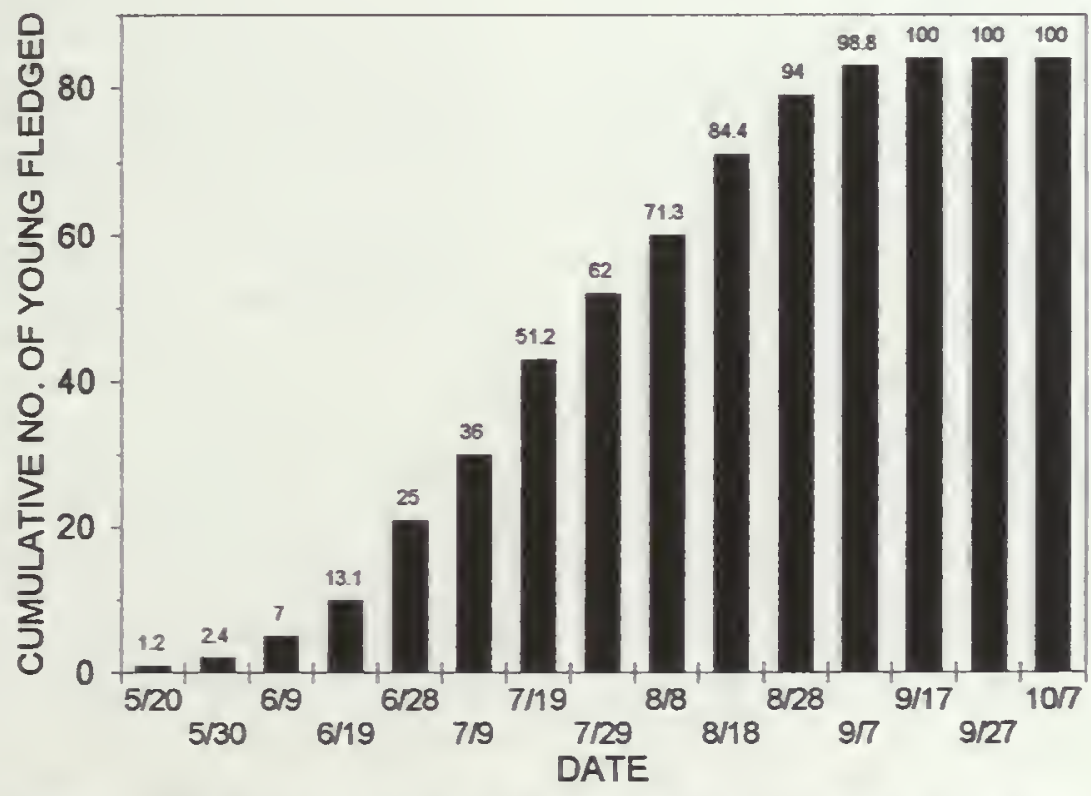

Figure 2-The cumulative number of Marbled Murrelet young fledged from nests in North America $(n=86)$ in 10-day intervals. The cumulative percentage of total young fledged in each 10-day interval is shown at the top of each histogram. The date displayed for each histogram is the beginning of a 10-day period. 
cumulative percentage change in the total number of young fledged from 20 May to 18 June was low, increasing only 1 6 percent between each 10-day period. A gradual accumulation of fledglings on the ocean would be predicted from 19 June until 27 August. During this period the cumulative percent change in the number of juveniles fledging between each 10 day period was very consistent, ranging from 9 to 15 percent. The latter part of the nesting season from 28 August to 26 September was similar to the beginning of the season, with the cumulative percent change in the number of young fledged ranging from 1 to 5 percent. For all states and provinces combined, the results show that by 27 August, only 84 percent of the juveniles in a given year would be expected to be counted at sea using marine census techniques. For California and Oregon, a census of all juveniles would not occur until the third week of September (fig. 3). In Washington, British Columbia, and Alaska, a full census of all juveniles would not occur until the third week of August (fig. 3).

\section{Discussion}

The breeding season of the Marbled Murrelet appears to be much longer than that of many other members of the alcid family. The long breeding period indicates that the synchronous nesting exhibited by many colonial and semicolonial nesting seabirds is likely not a characteristic of the breeding biology of the Marbled Murrelet. Few active nests have been found within the same stand to verify this. In one instance, two active nests were found only $100 \mathrm{~m}$ apart in the same forest stand in Washington. The first nest fledged a young murrelet on 18 July with the second nest fledging on 27 August, a 39-day difference (Hamer, pers. obs.). A trend toward a shorter breeding season in the northern range of the murrelet is apparent as one examines the fledging dates from California to Alaska (table 2, fig. 3). The longest breeding period was observed in California. Oregon had the next longest breeding period. The breeding season in Alaska was 64 days shorter than California.

For California and Oregon, a larger sample of breeding records is needed to further refine the breeding period and conduct statistical tests to determine whether two distinct breeding seasons exist. The fact that each breeding period was similar in total length supports the idea that there are two periods. When examined separately, the second breeding period was only 12 and 16 days shorter than the first breeding period for Oregon and California, respectively. The first breeding period in California (103 days) was similar to the total breeding season in Alaska (106 days).

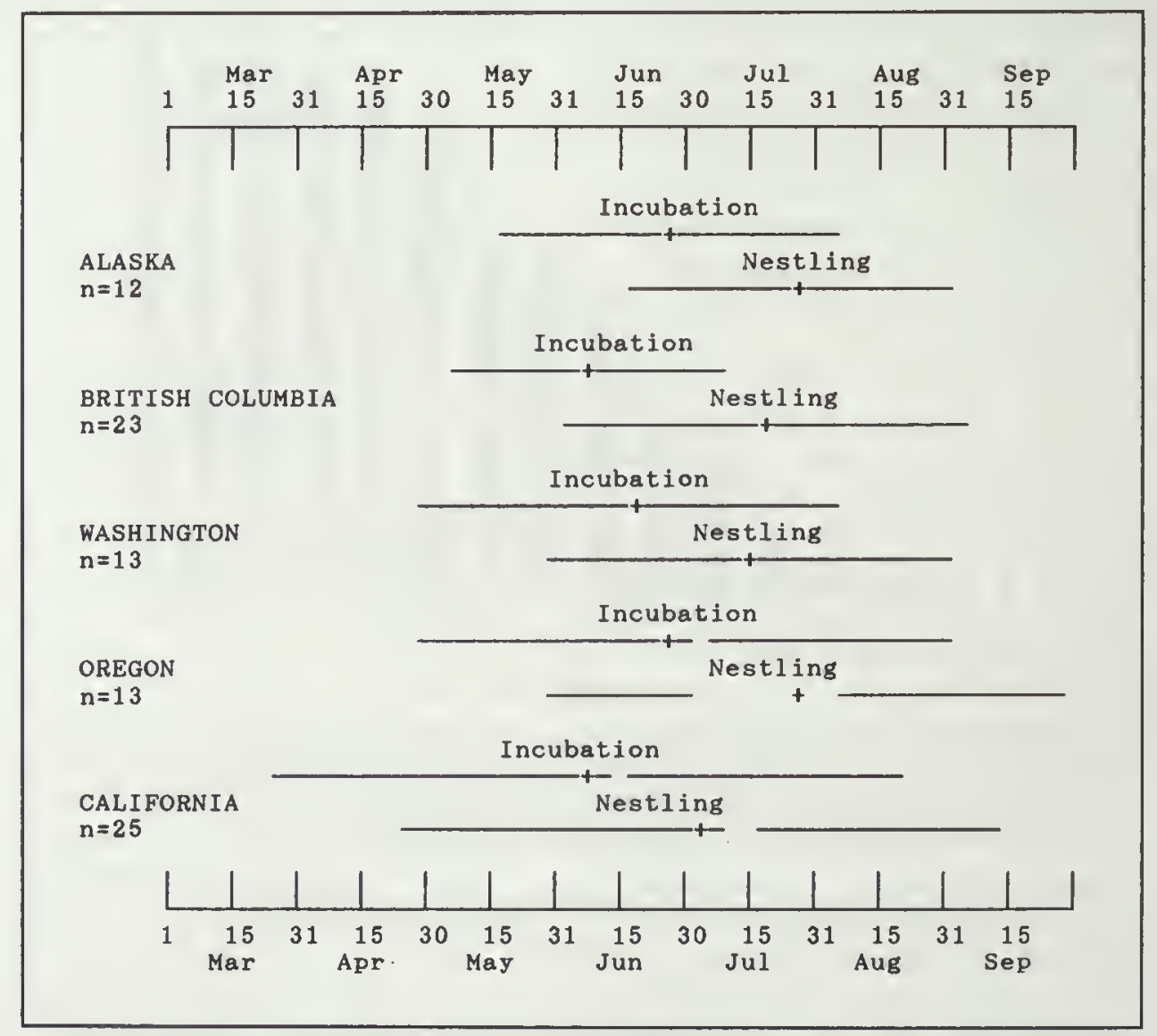

Figure 3 - Breeding phenology of the Marbled Murrelet in North America organized by state and province. The median for each incubation and nestling period is shown. 
Table 2-Number of Marbled Murrelt young observed and estimated to have fledged from nests in North America in 10-day intervals and listed by state and province. Records $(n=86)$ were used only if the error in estimating the fledging date was $<8$ days. The total length of the breeding period is listed under each state or province. The date displayed is the beginning of each 10-day period

\begin{tabular}{|c|c|c|c|c|c|c|c|c|c|c|c|c|c|c|}
\hline \multirow[t]{2}{*}{ State or province } & \multicolumn{14}{|c|}{ Number of birds observed in each 10-day interval } \\
\hline & $5 / 2$ & $5 / 30$ & $6 / 9$ & $6 / 19$ & $6 / 29$ & $7 / 9$ & $7 / 19$ & $7 / 29$ & $8 / 8$ & $8 / 18$ & $8 / 28$ & $9 \Pi$ & $9 / 17$ & $9 / 27$ \\
\hline \multicolumn{15}{|l|}{$\overline{\text { Alaska }}$} \\
\hline 106 days & & & & & & 2 & 2 & 2 & 3 & 3 & & & & \\
\hline \multicolumn{15}{|l|}{ British Columbia } \\
\hline 118 days & & & & 3 & 4 & 3 & 3 & 5 & 1 & 2 & 2 & & & \\
\hline \multicolumn{15}{|l|}{ Washington } \\
\hline 124 days & & ) & & 1 & & 3 & 5 & 2 & 1 & 1 & & & & \\
\hline \multicolumn{15}{|l|}{ Oregon } \\
\hline 149 days & & & & 1 & 3 & 1 & 2 & & & & 2 & 3 & 1 & \\
\hline \multicolumn{15}{|l|}{ California } \\
\hline 170 days & 1 & 1 & 4 & 1 & 4 & & 1 & & 3 & 5 & 4 & 1 & & \\
\hline
\end{tabular}

Explanations for the presence of two distinct breeding periods include: (1) small sample sizes, (2) variations in the timing of breeding of murrelets between years (as suggested by Carter and Erickson 1992), or (3) variation in oceanic and environmental conditions that promote breeding within these two distinct periods. Small sample sizes may not adequately explain this phenomenon, because it occurs only in the southern portions of the murrelet range, with sample sizes very similar to regions to the north. If the between-year variation in the timing of breeding was responsible for this trend, some young would have been expected to fledge over a period of years within the 1- to 2-week gap between breeding periods. A distinct proportion of the population nesting during each period is also possible. It is not clear what environmental or biological agents might cause this to occur. However, the most likely explanation is that some proportion of murrelets may attempt to lay a second clutch within the same breeding period. It is also possible that pairs with failed nests attempt to renest. The longer breeding season available for the murrelet in Oregon and California may make renesting more likely than in the northern regions of the range. The gap in breeding chronology may give females enough time to develop a new egg and select a different nest site. The shorter incubation and nestling period in the Marbled Murrelet, when compared to that of other species, such as the puffins and auklets, may make double brooding more feasible.

Egg replacement is a regular occurrence in ledge-nesting Alcids (Johnsgard 1987). Tuck (1960) estimated that 44 percent of Thick-billed Murres (Uria lomvia) pairs lost at least one egg during a 32-day period, with 30 percent of pairs laying one replacement egg; 11 percent laid two replacements, and the remaining 3 percent deserted or did not lay again. For higher arctic forms there are probably no opportunities to renest because of a short breeding season (Johnsgard 1987). The Xantus' Murrelet (Synthliboramphus hypoleucus) may lay two broods because egg laying has been observed until July, and Murray and others (1983) found evidence of occasional egg replacement in this species. Both Sealy (1975a) and Gaston (1992) found no evidence of replacement clutches in the Ancient Murrelet ( $S$. antiquus). If renesting and egg replacement does occur in the Marbled Murrelet, it will affect the interpretation of inland survey data and at-sea census results and population modeling for this species.

\section{Breeding Phenology Dates}

From the information presented above, we propose the following dates for the breeding phenology of the murrelet by state and province (fig. 3). In California, we estimated that the total breeding season lasted approximately 170 days. The first breeding period was 103 days long while a possible second period was 87 days long. The breeding periods were separated by 8-11 days. Incubation commenced 24 March and ended 13 August. The nestling period began 23 April and ended 9 September.

In Oregon, incubation was estimated to begin on 26 April and last until 25 August (fig. 3). The nestling period was estimated to begin 26 May and end on 21 September. The total breeding season length was 21 days shorter than that in California and was approximately 149 days long. The two possible periods of breeding activity were separated by only 6 days. The earliest recorded fledging date in Oregon is of a nestling observed to fledge from a nest on 22 June 1993 (Nelson, pers. obs.).

North of California and Oregon, the length of the breeding season was more restricted (fig. 3) (table 2). In Washington, the breeding season might appear shorter because of the smaller sample of breeding records used to predict fledging dates. However, it is probably similar to that found in British Columbia. Incubation was estimated to begin 26 April and end 30 July. The nestling period began 26 May and ended on 27 August. The total length of the breeding season was 124 days long, 25 days less than Oregon. The earliest fledging record is a nestling observed to fledge on 22 June 1993 (Ritchie, pers. comm.). The latest record is that of a nestling 
recorded on video tape fledging from a nest on 27 August 1990 (Hamer, pers. obs.).

In British Columbia, incubation was estimated to commence on 2 May and ended by 4 July (fig. 3). The nestling period began 1 June and ended by 30 August. The total breeding season was approximately 118 days. The earliest fledging date recorded was for a juvenile collected by Drent and Guiguet (1961) on 28 June 1961. The next five earliest records are of all juveniles observed or collected at sea. The first grounded fledging was not recorded until 7 July 1987 (Rodway and others 1992). The latest two fledging dates occurred on 30 August. One was of a chick that was discovered after a tree was felled (Harris 1971), and the second was a description of the follicle development of a female (Sealy 1974).

The length of the Alaska nesting season was greatly restricted and was estimated to be only 106 days. Incubation was estimated to begin on 14 May and end by 30 July. The nestling period ranged from 13 June to 27 August. The earliest fledging record was a juvenile observed at sea on 10 July 1993. The next earliest was a grounded fledging observed on 18 July 1987 (Mendenhall 1992). The latest estimated fledging date of 27 August 1978 was from an active groundnest observed by Simons (1980).

Sealy (1974) discovered that murrelets laid eggs in British Columbia over a 6- to 7-week period beginning 15 May and ending in late June or early July. Adults with fish in their bills were first observed on 16 June. Young birds were first observed on the water on 6 July 1970 and on 7 July 1971. Sealy concluded that the period of egg laying and incubation began around 15 May and lasted until 31 July. He estimated that the period of hatching and chick rearing started 15 June and ended around 15 August. Fledging began in the first week of July and continued to some time after 15 August (Sealy 1974). Sealy's study took place in the most northern portion of coastal British Columbia and thus may be more representative of Alaska than British Columbia. His breeding dates closely resemble the breeding chronology we report for Alaska (fig. 3). Rodway and others (1992) reached similar conclusions.

For North America, Carter and Sealy (1987b) calculated that egg-laying dates began between 15 and 22 April. The latest fledging dates reported were 8 and 9 September. Additional breeding records that we collected extend these dates by several weeks in California and Oregon. However, observations by Carter and Sealy of adults holding fish at sea as late as 17 September and records of several young still in downy plumage on 4 and 13 September led them to believe that the nestling period of the murrelet may extend into late September. Carter and Sealy concluded that murrelets may nest earlier and have a longer breeding season south of British Columbia. Carter (1984) speculated that the breeding season was protracted in southern British Columbia as compared to northern British Columbia.

Carter and Erickson (1992) estimated that egg-laying dates ranged from 15 April to 12 July in California, and hatching from 15 May to 10 August. New records that we examined extend these dates (fig. 3). Carter and Erickson found that fledging dates fell into two periods, 12 June to 4 July, and 11 August to 9 September. They believed the two different fledging periods in California were due either to low sample size, unknown factors affecting the grounding of fledglings, or variation between years in the timing of breeding. They concluded that egg laying begins earlier in California than farther north. An earlier breeding chronology was further supported by an examination of 45 museum specimens which showed an earlier timing of prealternate body molt for birds in California.

\section{Juvenile/Adult Ratios}

Adults molting into winter plumage can make it difficult to discriminate between adults and juveniles after 15 August (Carter and Stein, this volume). Because of this, for all provinces and states combined, 29 percent of the juvenile population produced in a given year may go uncounted if surveys after 15 August cannot accurately census young birds (fig. 2). It is impossible, at this time, with the small sample sizes to calculate the percent of young expected to be counted at sea during the breeding season for each state or province. When collected, this information would be valuable to researchers attempting to calculate juvenile/adult ratios or model population trends. A full census of juveniles would not be possible until after 16 September for California and Oregon, and after late August in Washington, British Columbia, and California. Sealy (1974) collected an adult female in British Columbia on 9 July 1971 that had already undergone a nearly complete body molt and was nearly in winter plumage. He suggested that this female may have undergone a premature body molt after an unsuccessful breeding effort. A complete census of juveniles may not be necessary for year-to-year comparisons of reproductive success. But, if complete censusing is not done, researchers should be careful of variations in the timing of breeding between years when conducting any annual comparisons. In addition, ratios of juveniles to adults observed at sea can be adjusted for birds that have not yet fledged (Beissinger, this volume) which may aid population modelling efforts and annual comparisons of reproductive success.

\section{Acknowledgments}

We are grateful for the unpublished accounts of nest observations, grounded chicks, and grounded fledglings provided to us by Nancy Naslund of the U.S. Fish and Wildlife Service, U.S. Department of Interior, Steve Singer of the Santa Cruz Mountains Murrelet Group, Bill Ritchie of the Washington Department of Wildlife, Paul Jones, Phyllis Reed, and Brenda Craig of the USDA Forest Service. Ray Miller and Sal Chinnici of the Pacific Lumber Company provided information from a nest in northern California. We thank Craig Strong, C.J. Ralph, Kathy Kuletz, and Susan Speckman for providing records of juveniles first observed at sea during marine survey efforts. Joanna Burger, Anthony Gaston, and Frank Pitelka provided helpful comments on early drafts of this manuscript. 


\title{
Nesting Biology and Behavior of the Marbled Murrelet
}

\author{
S. Kim Nelson ${ }^{1} \quad$ Thomas E. Hamer ${ }^{2}$
}

\begin{abstract}
We summarize courtship, incubation, feeding, fledging, and flight behavior of Marbled Murrelets (Brachyramphus marmoratus) using information collected at 24 nest sites in North America. Chick development, vocalizations given by adults and chicks at the nest, and predator avoidance behaviors are also described. Marbled Murrelets initiate nesting as early as March. Females lay a single egg and both adults participate in incubation, exchanging duties every 24 hours at dawn. Most incubation exchanges occur before sunrise. Chicks hatch after 27-30 days. Adults feed chicks single fish up to 8 times daily, but most feedings occur at dawn and dusk. Dawn feeding visits occur over a wider time period than incubation exchanges, with some occurring as late as 65 minutes after official sunrise. The timing of incubation exchanges and feeding visits are affected by weather and light conditions, and adults arrive later on cloudy or rainy days. To minimize the attraction of predators, visits to the nest are inconspicuous, with adults entering and exiting the nest during low light levels, and primarily without vocalizations. Because of this seabird's secretive behavior, our understanding of murrelet demography, nest site selection, and social interactions remain limited.
\end{abstract}

Marbled Murrelets (Brachyramphus marmoratus) are unique among seabirds in that they nest in older-aged coniferous forests throughout most of their range in North America. Little is known about their breeding biology because nest sites have only recently (1974) been discovered and described (Binford and others 1975; Hamer and Nelson, this volume b; Hirsch and others 1981; Nelson and Peck, in press; Quinlan and Hughes 1990; Simons 1980; Singer and others 1991). Marbled Murrelet behavior at the nest has been monitored at 24 of 52 ( 35 tree and 17 ground) active nests since 1980; however, only a few accounts have been published (Nelson and Peck, in press; Simons 1980; Singer and others 1991 , in press). In this paper, we provide a synthesis of information on murrelet behavior patterns, chick development, and vocalizations recorded at these 24 nest sites.

\section{Methods}

We compiled all known data on Marbled Murrelet behavior at active nests in North America and combined them with our own studies of murrelet nests. Data were summarized from two ground and five tree nests in Alaska (Hirsch and others 1981; Naslund, pers. comm.; Simons 1980), one tree nest in British Columbia ( $\mathrm{P}$. Jones, pers. comm.), two tree nests in Washington (Hamer and Cummins 1991; Ritchie, pers. comm.),

\footnotetext{
${ }^{1}$ Research Wildlife Biologist, Oregon Cooperative Wildlife Research Unit, Oregon State University, Nash 104, Corvallis, OR 97331-3803

2 Research Biologist, Hamer Environmental, 2001 Highway 9, Mt. Vernon, WA 98273
}

nine tree nests in Oregon (Nelson, unpubl. data; Nelson and Peck, in press), and five tree nests in California (Kerns, pers. comm.; Naslund 1993a; Singer and others 1991, in press; S.W. Singer, pers. comm.) (table I). Information on pair bonding and courtship are also summarized.

Active nests were located by observing murrelets land in trees, finding eggshells on the ground and subsequently locating the nest, using radio telemetry, or by incidental observations. Fifteen of the nests were found during the egg stage and 9 during the nestling stage. Some nests were intensively monitored, others only intermittently. Data recorded at many nests included time and duration of incubation exchanges and feeding visits, behavior of chicks and adults, flight behavior, and vocalizations. Weather conditions (percent clouds, precipitation, temperature, wind) were also recorded for comparison with the timing and duration of murrelet activity at the nest. Means, standard errors, and ranges were calculated for numerical data, such as the timing of incubation exchanges and feeding visits in relation to sunrise and sunset, and the length of these encounters at nests.

\section{Results}

\section{Pair Bonding and Courtship Behavior}

Little is known about when and how Marbled Murrelets pair. Murrelets are primarily observed in groups of two throughout the year, both in the forest and on the water. Many pairs on the water have included a male and female, and were assumed to be mated (Carter 1984; Carter and Stein, this volume; Sealy 1975a). Some of these "pairs" could also be composed of adults in a temporary social association; this is known to occur on the water, especially when birds are not feeding (Carter, pers. comm.). However, we believe that Marbled Murrelets remain paired throughout the year based on these year-round pair groups and data from other alcids (e.g., Harris and Birkhead 1985).

Courtship behavior has been observed on the water in early spring, when some adults are still in winter plumage, as well as throughout the summer. Participation in courtship behaviors while in winter plumage is expected because: (1) the monomorphic plumage in Marbled Murrelets in not a sexually selected trait; and (2) they probably maintain strong pair bonds throughout the year. During courtship, pairs join closely together $(<0.5 \mathrm{~m})$, point their bills in the air, partially lift their breasts out of the water, and swim rapidly forward (Byrd and others 1974; Nelson, unpubl. data; Van Vliet, pers. comm.). Pairs also dive synchronously and surface within 1-3 seconds next to one another, suggesting that they remain together under water (Van Vliet, pers. comm.). Preceding the dive or while swimming together in courship 
Table 1-Marbled Murrelet tree and ground nests by state or province, site, year, and number of days of observation

\begin{tabular}{|c|c|c|c|c|}
\hline \multirow{2}{*}{$\begin{array}{l}\text { State/province } \\
\text { Site/year }\end{array}$} & \multirow[t]{2}{*}{ Number of nests } & \multicolumn{2}{|c|}{ Number of observation days } & \multirow[t]{2}{*}{ Reference } \\
\hline & & lncubation & Nestling & \\
\hline \multicolumn{5}{|l|}{ Alaska } \\
\hline Barren Islands 1978/1979 & 2 & 33 & 56 & $\begin{array}{l}\text { Hirsch and others } 1981 \\
\text { Simons } 1980\end{array}$ \\
\hline Naked Island 1991/1992 & 5 & 14 & 0 & Naslund, pers. comm. \\
\hline \multicolumn{5}{|l|}{ British Columbia } \\
\hline Caren Range 1993 & 1 & 0 & 14 & P. Jones, pers. comm. \\
\hline \multicolumn{5}{|l|}{ Washington } \\
\hline Lake 221991 & 1 & 0 & 24 & Hamer and Cummins 1991 \\
\hline Nemah 1993 & 1 & 0 & 4 & Ritchie, pers. comm. \\
\hline \multicolumn{5}{|l|}{ Oregon } \\
\hline Five Rivers 1990/1991 & 2 & 17 & 14 & Nelson and Peck, in press \\
\hline Valley of Giants 1990/1991 & 2 & 26 & 6 & Nelson and Peck, in press \\
\hline Cape Creek 1991 & 1 & 9 & 0 & Nelson and Peck, in press \\
\hline Siuslaw River 1991 & 2 & 0 & 23 & Nelson and Peck, in press \\
\hline Boulder Wamicke 1992 & 1 & 0 & 8 & Nelson and Peck, in press \\
\hline Copper Iron 1992 & 1 & 0 & 13 & Nelson and Peck, in press \\
\hline \multicolumn{5}{|l|}{ California } \\
\hline Big Basin 1989 & 2 & 45 & 4 & $\begin{array}{l}\text { Naslund 1993a } \\
\text { Singer and others } 1991\end{array}$ \\
\hline Father 1991/1992 & 2 & 13 & 25 & Singer and others, in press \\
\hline Elkhead 1993 & 1 & 0 & 12 & Kerns, pers. comm. \\
\hline
\end{tabular}

dances, birds frequently give soft, synchronous nasal vocalizations. Pairs also chase one another in flights just above the water surface throughout the spring and summer, in what may be courtship behavior (see below about similar behaviors exhibited at inland nesting sites).

Copulation has rarely been observed. It is known to occur within trees ( $n=1$ observation in Alaska; Kuletz, pers. comm.) and on the water where it has been observed at least 15 times (Kuletz, pers. comm.; Naslund, pers. comm; Nelson, unpubl. data; Van Vliet, pers. comm.). Preceding and following copulation, the birds often vocalize with an emphatic, nasal "eeh-eeh" call (Van Vliet, pers. comm.). We expect that copulation primarily occurs at the nest based on observations from other alcids (Sealy 1975a).

Before they lay eggs, pairs probably visit the breeding grounds, not only to pair and copulate, but also to select nest sites. In Oregon, a pair was observed landing on a nest platform for 3 mornings in early May, two weeks prior to laying an egg at that site. Pre-laying visitation to nests, three to four weeks before egg-laying, has been observed in other alcids (Gaston 1992; Nettleship and Birkhead 1985).

\section{Egg-Laying and Incubation Behavior}

Marbled Murrelets start to lay eggs as early as March (Hamer and Nelson, this volume a). They lay a single egg weighing approximately $36-41 \mathrm{~g}$ (16-18.5 percent of adult weight) (Hirsch and others 1981; Sealy 1975a; Simons 1980). The egg is subelliptical in shape, and measures an average of $59.5 \times 37.4 \mathrm{~mm}(n=11 \mathrm{eggs})$ and $0.21 \mathrm{~mm}$ in thickness (Day and others 1983; Hirsch and others 1981; Kiff 1981; Sealy 1975a; Simons 1980). The egg has a pale-olive green to greenish-yellow background color, and is covered with irregular brown, black, and purple spots which are more prevalent at the larger end of the egg (Becking 1991; Binford and others 1975; Day and others 1983; Kiff 1981; Nelson 1991, 1993; Nelson, and Hardin 1993a; Reed and Wood 1991; Singer and others 1991).

After the female lays an egg, the pair begins 24-hour shifts of incubation duty; one adult broods the egg while the other forages at sea ( $n=12$ nests) (Naslund 1993a, pers. comm.; Nelson and Peck, in press; Simons 1980; Singer and others 1991). The incubating adults sit on the egg in a flattened posture and remain motionless on the nest more than 90 percent of the time ( $n=4$ nests) (Naslund 1993a; Nelson and Peck, in press; Simons 1980). Other behaviors observed during incubation at most nests include turning the egg, re-arranging nest material, and preening. At nests in California $(n=1)$ and Alaska $(n=5)$, the average occurrence of these behaviors were 11,8 , and 1 time(s) per day, respectively (Naslund 1993a, pers. comm.). 
At a given nest, the two adults appear to have distinct plumage colorations. A light brown and a dark chocolate brown adult (sex of each unknown) have been observed attending nests on 24-hour shifts, indicating possible sexual plumage dichromatism ( $n=8$ nests) (Fortna, pers. comm.; P. Jones, pers. comm.; Naslund 1993a; Nelson 1991,1992; Ritchie, pers. comm.; Singer and others 1991). In addition, the white patches on the nape of the neck and cheek have varied between adults at a single nest, and individuals at different nests ( $n=7$ nests) (Fortna, pers. comm.; Hamer and Cummins 1991; P. Jones, pers. comm.; Nelson 1991, 1992; Simons 1980). The variations in these nape and cheek patches may provide a means for identifying individuals.

Murrelets have been observed leaving their egg unattended for 3-4 hours during the morning, mid-day, and evening ( $n=$ 4 nests; Naslund 1993a, pers. comm.; Nelson and Peck, in press; Simons 1980). Seabirds often leave their eggs unattended to maximize foraging time and accumulate sufficient energy reserves for lengthy incubation shifts (Boersma and Wheelwright 1979, Gaston and Powell 1989, Murray and others 1983). Murray and others (1993) have hypothesized that the benefits of increased foraging time during egg neglect often outweigh the disadvantages of leaving the egg unattended. Disadvantages of egg neglect include predation, heat loss, and exposure to the elements. In Oregon, an egg was believed to have been taken by a corvid when adults left their nest unattended (Nelson and Hamer, this volume b).

\section{Timing of Incubation Exchanges}

Adults usually exchange incubation duties at dawn ( $n=$ 12 nests), although Simons (1980) believed exchanges may have taken place at dusk at a ground nest in Alaska. Incubation exchanges generally occur before official sunrise, and often correspond with the first auditory detections of murrelets each morning (Naslund 1993a; Nelson and Peck, in press;
S.W. Singer, pers. comm.) (table 2). The timing of exchanges were significantly affected by weather patterns and light levels; birds arrived later during overcast or rainy conditions (Naslund 1993a, pers. comm.; Nelson and Peck, in press). In addition, birds arrived earlier in areas of higher latitude likely because of longer periods of twilight. In Prince William Sound, Alaska, incubation exchanges occurred from 37-82 minutes prior to official sunrise ( $\bar{x}=-52$, s.e. $=3.1, n=14$ observations at 5 nests) (Naslund, pers. comm.). In Oregon and California, the timing of incubation exchanges ranged from 31 minutes before to 1 minute after official sunrise ( $\bar{x}$ $=-18.5$, s.e. $=0.7, n=85$ observations at 7 nests) (Naslund 1993a; Nelson and Peck, in press; Singer and others 1991; S.W. Singer, pers. comm.) (table 2). No nocturnal incubation exchanges were observed during intensive observations in California (Naslund 1993a, Singer and others 1991); nocturnal surveys have not been conducted elsewhere.

Incubating birds usually left immediately after the arrival of their mate. Most incubation exchanges lasted 3 to 60 seconds $(\bar{x}=26.0$ seconds, s.e. $=4.5, n=76$ observations at 7 nests), although at one nest in California one exchange lasted 3 minutes and 40 seconds (Naslund 1993a; Nelson and Peck, in press; S.W. Singer, pers. comm.) (table 3). The arriving adult often remained motionless on the nest limb before occupying the nest and commencement of incubation; this waiting period lasted 14 to 357 seconds in California and Oregon (Naslund 1993a; Nelson and Peck, in press).

\section{Egg-Hatching, Brooding Behavior, and Chick Development}

The single murrelet chick hatches after 27 to 30 days of incubation (Carter 1984; Hirsch and others 1981; Sealy 1974, 1975a; Simons 1980). Adults become active before the egg hatches, standing and turming more frequently than earlier in the incubation period (Naslund 1993a; Nelson and Peck, in

Table 2-Mean time of incubation exchanges in relation to official sunrise at Marbled Murrelet nests by stasel

\begin{tabular}{l|ccccc}
\hline State $^{2}$ & $\begin{array}{c}\text { Number } \\
\text { nests }\end{array}$ & $\begin{array}{c}\text { Number } \\
\text { observation days }\end{array}$ & $\begin{array}{c}\text { Mean time } \\
\text { before sunise } \\
\text { (min) }\end{array}$ & $\begin{array}{c}\text { Standard } \\
\text { error }\end{array}$ & Range \\
\hline Alaska & 5 & 14 & -52.3 & 3.1 & $-82,-37$ \\
Oregon & 4 & 49 & -18.5 & 0.8 & $-30,-8$ \\
California & 3 & 36 & -18.4 & 1.3 & $-31,+1$ \\
Total & 12 & 99 & -23.2 & 1.4 & $-82,+1$ \\
Oregon and California only & 7 & 85 & -18.5 & 0.7 & $-3 t,+1$ \\
\hline
\end{tabular}

\footnotetext{
${ }^{1}$ Data from Naslund, pers. comm.; Nelson and Peck, in press; S.W. Singer, pers. comm.

2 Incubation exchanges were not observed in British Columbia and Washington.
} 
Table 3-Mean length of incubation exchanges at Marbled Murrelet nests by state

\begin{tabular}{l|ccccc}
\hline State $^{2,3}$ & $\begin{array}{c}\text { Number } \\
\text { nests }\end{array}$ & $\begin{array}{c}\text { Number } \\
\text { observation days }\end{array}$ & $\begin{array}{c}\text { Mean } \\
\text { length } \\
(\mathrm{sec})\end{array}$ & $\begin{array}{c}\text { Standard } \\
\text { error }\end{array}$ & $\begin{array}{c}\text { Range } \\
(\mathrm{min}: \mathrm{sec})\end{array}$ \\
\hline Oregon & 4 & 42 & 16.3 & 2.8 & $0: 03-1: 07$ \\
California & 3 & 34 & 38.1 & 1.1 & $0: 02-3: 40$ \\
& 7 & 76 & 26.0 & 4.5 & $0: 02-3: 40$ \\
\hline
\end{tabular}

\footnotetext{
${ }^{1}$ Dala from Nelson and Peck, in press; S.W. Singer, pers. comm.

${ }^{2}$ Incubation exchanges were not observed in British Columbia and Washington.

${ }^{3}$ Data from Alaska were not available.
}

press; Simons 1980). Chicks are semi-precocial at hatching, and weigh approximately $32.0-34.5 \mathrm{~g}(n=2$ chicks) (Simons 1980, Hirsch and others 1981). They are covered with a dense yellowish down, sprinkled evenly with irregular dark spots (brown and black), except on the head where spots are concentrated in large patches, and on their bellies which are covered with a dense, pale grey down (Binford and others 1975, Simons 1980).

Adults usually brood the chick for 1 to 2 days after hatching ( $n=4$ nests) (Nelson and Peck, in press; Simons 1980; S.W. Singer, pers. comm.), possibly until the chick reaches homeothermy. However, Naslund (1993a) recorded intermittent brooding by adults after daytime and evening feedings at least 3 days after hatching. Naslund (1993a) suggested that the increased brooding may have occurred to protect the chick from predators in the vicinity of the nest. In addition, in British Columbia, Eisenhawer and Reimchen (1990) presented circumstantial evidence that adults returned at night to brood young chicks.

During brooding, adults are active and restless, regularly standing, turning, and repositioning themselves on the chick. Adults do not remove the eggshell from the nest cup, therefore pieces that do not fall out accidentally remain in the nest cup and often are crushed into the nest material by adult and chick activity.

During the first 6 days after hatching, droppings from the chick begin to accumulate around the perimeter of the nest cup (adults are not known to defecate at the nest). By the time the chick fledges, the fecal ring can be up to $51 \mathrm{~mm}$ thick. Odor (ammonia and fish) from fecal material can be detected by humans from up to $2 \mathrm{~m}$ away.

Murrelet chicks grow rapidly compared to most alcids, gaining 5-15 g per day during the first 9 days after hatching ( $n=2$ chicks) (Hirsch and others 1981; Simons 1980). As chicks age, the juvenal plumage begins to develop beneath the down; both feather types grow from the same sheath. By day 17, the wing coverts have emerged and down is missing from the forehead and around the mandibles $(n=5$ chicks). By day 21 , chicks lose most of their belly down, and by day 26 , up to 20 percent of body down disappears.
Twelve to 48 hours prior to fledging, the murrelet chick, by preening, scratching, and wing flapping, removes the remaining down, revealing their black and white juvenal plumage ( $n=10$ chicks) (Hamer and Cummins 1991; Hirsch and others 1981; P. Jones, pers. comm.; Nelson and Peck, in press; Simons 1980; Singer and others 1992, in press). This pattern of down loss and feather development is unique among alcids, except the closely related Kittlitz's Murrelet (Brachyramphus brevirostris).

Wing length increases rapidly in the last 4 days prior to fledging, and at fledging the chicks wings are 103-144 $\mathrm{mm}$ long (86 percent of adult wing length) (Hamer and Cummins 1991; Hirsch and others 1981; Sealy 1975a; Simons 1980). Chicks fledge at age 27-40 days (Hirsch and others 1981; Nelson and Peck, in press; Simons 1980). At this time they still possess an egg tooth, and weigh an average of $146.8-157.0 \mathrm{~g}$ (s.e. $=3.6-9.5, n=4-9)$, which is $63-70$ percent of adult ( $222 \mathrm{~g})$ weight (Hamer and Cummins 1991; Hirsch and others 1981; Sealy 1975a; Simons 1980). Fledging takes place at dusk, between 11 and $55+$ minutes after official sunset (Hamer and Cummins 1991; Hirsch and others 1981; P. Jones, pers. comm.; Nelson and Peck, in press; Singer and others, in press) (table 4).

Chicks are thought to fly directly from the nest to the ocean (Hamer and Cummins 1991; Quinlan and Hughes 1990; Sealy 1975a). Hamer and Cummins (1991) radiotagged a juvenile Marbled Murrelet on a nest in Washington, $37 \mathrm{~km}$ inland, and monitored its flight to the ocean. The chick fledged in the evening and was found 18 hours later, $100 \mathrm{~m}$ from shore and $2 \mathrm{~km}$ north of a direct east-west line between the nest and Puget Sound. The juvenile flew directly to the ocean and did not spend any time in the vicinity of the nest. However, several fledglings have been observed swimming in creeks in California and Washington (Hamer and Cummins 1991; Miller, pers. comm.). It is not known if these fledglings fell from nests, became grounded on their maiden flight to the ocean, or were actually trying to reach the ocean by swimming the creek. Numerous fledging birds in North America appear to have become grounded during flights to the Pacific (Nelson and Hamer, this volume b). 
Table -Dates and timing of observed Marbled Murrelet fledgings from nests by state and provincel

\begin{tabular}{l|cccc}
\hline State/province & $\begin{array}{c}\text { Number } \\
\text { nests }\end{array}$ & Date & $\begin{array}{c}\text { Fledging } \\
\text { time }\end{array}$ & $\begin{array}{c}\text { Minutes after } \\
\text { sunset }\end{array}$ \\
\hline Alaska & $t$ & $8 / 16 / 79$ & $>2200$ & +21 \\
British Columbia & $t$ & $8 / 20 / 93$ & 2051 & +30 \\
Washington & 3 & $6 / 22 / 93$ & 2124 & +14 \\
& & $8 / 07 / 91$ & 2046 & +11 \\
& & $8 / 27 / 90$ & 2020 & +20 \\
Oregon & 1 & $8 / 29 / 91$ & $>2050^{2}$ & +55 \\
California & & & & +18 \\
& 2 & $6 / 07 / 92$ & 2046 & +19 \\
\hline
\end{tabular}

${ }^{1}$ Data from Hamer and Cummins 1991; Hirsch and others 1981; P. Jones, pers. comm.; Nelson and Peck, in press; Singer and others, in press.

${ }^{2}$ Chick fledged between 2050 and 0700 hours.

Many of these grounded fledglings may be unable to take flight again or make it to the ocean by other means. Once juveniles reach the ocean they are thought to be independent and not attended either parent contrary to the suggestion of Ydenberg (1989).

\section{Chick Behavior}

Chicks remain motionless or sleep 80-94 percent of the time on the nest ( $n=8$ chicks) (Hamer and Cummins 1991; Naslund 1993a; Nelson and Peck, in press). Other behaviors include standing, turning, shifting position, preening, stretching, flapping, pecking at the nest substrate or the tree limb, food begging in the presence of adults, and snapping at insects. Behaviors such as wing flapping and preening increase markedly in the week prior to fledging.

On the two evenings prior to fledging, chicks are very active (Hamer and Cummins 1991; Ritchie, pers. comm.; Singer and others, in press). Behaviors during this time include continual rapid pacing on the nest platform, frequent vigorous flapping of the wings, repeated peering over the edge of the nest platform, rapid nervous head movements, and constant preening. After a vigorous session of wing flapping, young birds sometimes hold their wings outstretched and vibrate them rapidly, giving the appearance of shivering wings. These behaviors begin in late afternoon or minutes before sunset, and continue until dark or until the bird fledges.

Low light levels may induce fledging. After a captive reared chick fledged from an artificial nest platform in the dark, it was placed back on the platform and the room brightened by artificial light (Hamer and Cummins 1991). The chick immediately sat motionless and ceased all activity.
When the room was darkened again by turning off the light, the chick immediately began the pre-fledging behaviors described above and fledged a second time.

\section{Feeding Frequency, Behavior, and Prey Species}

Adults return to feed young up to eight times daily ( $\bar{x}=$ 3.2, s.e. $=0.4, n=10$ nests) (Hamer and Cummins 1991; Hirsch and others 1981; P. Jones, pers. comm.; Kerns, pers. comm.; Nelson and Peck, in press; Simons 1980; S.W. Singer, pers. comm.) (table 5). Chicks are usually fed at least once a day for the $27-40$ days they are on the nest, although the frequency is variable and sometimes decreases prior to fledging. The last feeding prior to fledging occurs between 5 minutes (Singer and others, in press) and 2.5 days (Hamer and Cummins 1991) before the young murrelet leaves the nest.

The timing of dawn feedings is more variable than incubation exchanges. First dawn feedings occur from 37 minutes before to 65 minutes after official sunrise $(\bar{x}=6.0$, s.e. $=3.7, n=68$ feedings at 13 nests) (Hamer and Cummins 1991; Kerns, pers. comm.; Naslund 1993a; Nelson and Peck, in press; S.W. Singer, pers. comm.) (fig. 1 , table 6). Similar to incubation exchanges, weather and light conditions influence the arrival times of the adults, and feedings often occur later on rainy or cloudy days (Naslund 1993a, Nelson and Peck, in press). Second morning feedings occur from 18 minutes before, to 225 minutes ( $1009 \mathrm{hrs})(\bar{x}=53.7$, s.e. $=$ 9.6, $n=40$ observations at 13 nests) after, official sunrise. Other feedings take place during the day between the hours of 1100 and 1700 (Hamer and Cummins 1991; P. Jones, pers. comm.; Kerns, pers. comm.; Naslund 1993a; Nelson and Peck, in press; Singer and others 1991)(fig. 1). Dusk 
Table 5-Mean number of feeding visits observed per day ${ }^{1}$ at Marbled Murrelet nests by state and province ${ }^{2}$

\begin{tabular}{l|cccccc}
\hline State/province $^{3}$ & $\begin{array}{c}\text { Number } \\
\text { nests }\end{array}$ & $\begin{array}{c}\text { Number } \\
\text { observation days }\end{array}$ & $\begin{array}{c}\text { Number } \\
\text { feedings }\end{array}$ & $\begin{array}{c}\text { Mean } \\
\text { per day }\end{array}$ & $\begin{array}{c}\text { Slandard } \\
\text { error }\end{array}$ & Range \\
\hline British Columbia & 1 & 11 & 44 & 4.0 & 0.8 & $1-8$ \\
Washingion & 1 & 8 & 23 & 2.9 & 0.4 & $2-5$ \\
Oregon $^{4}$ & 5 & 22 & 61 & 2.8 & 0.3 & $1-5$ \\
California $^{4}$ & 3 & 21 & 67 & 3.4 & 0.3 & $1-6$ \\
Overall & 10 & 62 & 195 & 3.2 & 0.4 & $1-8$ \\
\hline
\end{tabular}

\footnotetext{
${ }^{1}$ Not all nests were monitored during mid-day or at night, thus some feeding visits may have been missed. Data include only days where nests were monilored al dawn and dusk on all observation days.

${ }^{2}$ Data from Hamer and Cummins 1991; P. Jones, pers. comm.; Kerns, pers. comm.; Nelson and Peck, in press; S.W. Singer, pers. comm.

${ }^{3}$ No tree nests with chicks were observed in Alaska; data from 2 ground nests in Alaska were not available.

${ }^{4}$ Two nests in Oregon and 1 in California were not monitored at dawn and dusk on the same day.
}

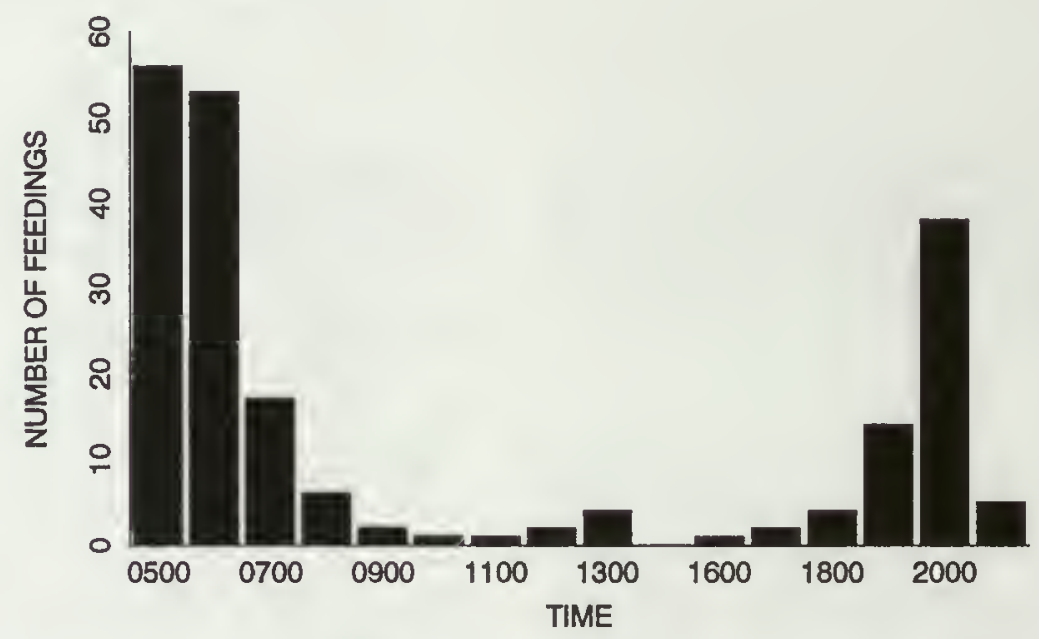

Figure 1-Number of feedings by time of day (0500-2100 hrs) at ten Marbled Murrelet nests in British Columbia, Washington, Oregon, and California $(n=$ 206 feedings).

feedings occur from 90 minutes before, to 71 minutes after, official sunset, with the last feeding visit occurring 40 minutes before, to 71 minutes after, official sunset $(\bar{x}=18.4$, s.e. $=$ $4.1, n=41$ feedings at 12 nests) (Hamer and Cummins 1991; Naslund 1993a; Nelson and Peck, in press; Singer and others, in press) (table 7). No nocturnal (after dusk) feeding visits were recorded during all-night observations in Washington and California ( $n=38$ nights at 3 nests) (Hamer and Cummins 1991; Naslund 1993a).

On several occasions ( $n=7$ of 68 visits at three nests), two adults arrived at the nest with fish at the same time (Kerns, pers. comm; P. Jones, pers. comm.; Nelson and Peck, in press). In Oregon, when this occurred, one adult flew away, and returned only after the other adult had left. In California and British Columbia, both adults left and returned individually at a later time, or both remained until the chick had eaten one of the fish.

Adults usually carry single fish in their bills, holding it crosswise at the mid-point of the fish's body, or just posterior to the operculum. On several occasions, adults were observed arriving with 2 fish at nests in California and Oregon $(n=$ 3)(Buchholz, pers. comm.; Kerns, pers. comm). When adults arrive at the nest with a fish, they often remain in a motionless posture on the landing pad for up to 11 minutes before approaching the nest ( $n=11$ nests) (Hamer and Cummins 1991; Kerns, pers. comm.; Naslund 1993a, pers. comm.; Nelson 
Table 6-Mean time of first morning feeding visits in relation to official sunrise at Marbled Murrelet nests by state ${ }^{l}$

\begin{tabular}{|c|c|c|c|c|c|}
\hline State 2,3 & $\begin{array}{c}\text { Number } \\
\text { nests }\end{array}$ & $\begin{array}{l}\text { Number } \\
\text { feedings }\end{array}$ & $\begin{array}{c}\text { Mean } \\
\text { time (min) }\end{array}$ & $\begin{array}{c}\text { Standard } \\
\text { error }\end{array}$ & Range \\
\hline Washington & 2 & 10 & -9.3 & 11.1 & $-37,+50$ \\
\hline Oregon ${ }^{4}$ & 7 & 32 & +7.9 & 5.1 & $-36,+65$ \\
\hline California . & 4 & 26 & +9.5 & 5.9 & $-31,+62$ \\
\hline Overall & 13 & 68 & +6.0 & 3.7 & $-37,+65$ \\
\hline
\end{tabular}

\footnotetext{
' Data from Hamer and Cummins 1991; Kems, pers. comm.; Nelson and Peck, in press; S.W. Singer, pers. comm.

${ }^{2}$ No tree nests with chicks were observed in Alaska; data from 2 ground nests in Alaska not available.

${ }^{3}$ Data from British Columbia were not available.

${ }^{4}$ Does not include one late observation (104 min), assumed to be a second feeding.
}

Table 7-Mean time of last evening feeding visits in relation to official sunset at Marbled Murrelet nests by state ${ }^{I}$

\begin{tabular}{l|ccccc}
\hline State & $\begin{array}{c}\text { Number } \\
\text { nests }\end{array}$ & $\begin{array}{c}\text { Number } \\
\text { feedings }\end{array}$ & $\begin{array}{c}\text { Mean } \\
\text { time (min) }\end{array}$ & $\begin{array}{c}\text { Standard } \\
\text { error }\end{array}$ & Range \\
\hline Washington & 2 & 4 & +9.3 & 22.3 & $-39,+69$ \\
Oregon & 7 & 17 & +15.3 & 5.7 & $-40,+62$ \\
California & 3 & 20 & +23.0 & 5.5 & $-15,+71$ \\
Overall & 12 & 41 & +18.4 & 4.1 & $-40,+71$ \\
\hline
\end{tabular}

\footnotetext{
'Data from Hamer and Cummins 1991; Kerns, pers. comm.; Nelson and Peck, in press; S.W. Singer, pers. comm.

${ }^{2}$ No tree nests with chicks were observed in Alaska; data from 2 ground nests in Alaska not available.

${ }^{3}$ Data from British Columbia were not available.
}

and Peck, in press; S.W. Singer, pers. comm.). At a nest in Washington, adults rested on the nest platform an average of 2.2 minutes before approaching the chick with food.

In Oregon and Washington, the chick sometimes gave begging calls just prior to the adults landing on the nest platform ( $\bar{x}=1.2$ minutes before adults arrived, $n=8$ observations at nest) and throughout the feeding visit (see vocalizations section) (Hamer and Cummins 1991; Nelson and Peck, in press). At a nest in Washington, the chick spent an average of 10.8 minutes begging during each feeding visit.

After approaching the chick, the adult stands motionless as the chick energetically strokes or nudges the throat and beak of the adult with its beak (Hamer and Cummins 1991;
Naslund 1993a; Nelson and Peck, in press). Adults at a nest in Washington held the fish over the chick for an average of 9.7 minutes (s.e. $=1.4, n=16$ observations) before the food transfer took place. The adults occasionally give soft whistle or grunt-like vocalizations until the nestling takes the fish (Hamer and Cummins 1991; Nelson and Peck, in press). The time adults spent at nests during feedings ranged from 13 seconds to 80 minutes $(\bar{x}=12.6 \mathrm{~min}$, s.e. $=0.7, n=16$ ) (Hamer and Cummins 1991; Hirsch and others 1981; P. Jones, pers. comm.; Kerns, pers. comm.; Naslund 1993a; Nelson and Peck, in press; Simons 1980) (table 8). Fifty percent of feedings lasted $>11$ (median) minutes. Chicks held the fish 5 seconds to 2 minutes before swallowing it 
Table 8-Mean length of feeding visits at Marbled Murrelet nests by state and province

\begin{tabular}{l|ccccc}
\hline State/province & $\begin{array}{c}\text { Number } \\
\text { nests }\end{array}$ & $\begin{array}{c}\text { Number } \\
\text { feedings }\end{array}$ & $\begin{array}{c}\text { Mean } \\
\text { time (min) }\end{array}$ & $\begin{array}{c}\text { Standard } \\
\text { error }\end{array}$ & Range \\
\hline Alaska & 2 & 5 & 5.0 & 1.7 & $1.43-10.0$ \\
British Columbia & 1 & 38 & 13.2 & 2.0 & $1.00-80.0$ \\
Washington & 2 & 24 & 10.4 & 1.2 & $0.30^{3}-20.0$ \\
Oregon & 7 & 61 & 16.7 & 1.3 & $0.18^{3}-46.0$ \\
California & 4 & 82 & 10.4 & 0.8 & $0.13^{3}-48.0$ \\
& & & & & 0.7 \\
Overall & 16 & 210 & 12.6 & $0.13^{3}-80.0$ \\
\hline
\end{tabular}

\footnotetext{
${ }^{1}$ Data from Hamer and Cummins 1991; Hirsch and others 1981; P. Jones, pers. comm.; Kerns, pers comm.; Nelson and Peck, in press; Ritchie, pers. comm.; Simons 1980; S.W. Singer, pers. comm.

${ }^{2}$ No tree nests with chicks were observed in Alaska.

${ }^{3}$ Adults may not have fed chicks fish on some of the shorter visits.
}

head first and whole ( $\bar{x}=1.4$ minutes at a nest in Washington, $n=4$ observations) (Hamer and Cummins 1991; Nelson and Peck, in press). Adults usually leave within 1 minute of the fish exchange.

To provide chicks with fish at dawn, adults probably forage at night, perhaps taking advantage of fish that forage near the water surface during darkness (Carter and Sealy 1987a, 1990). Fish species that have been fed to chicks at nests include Pacific sand lance (Ammodytes hexapterus), Pacific herring (Clupea harengus), and northern anchovy (Engraulis mordax) (P. Jones, pers. comm.; Nelson and Peck, in press). Other potential prey species that were not positively identified included capelin (Mallotus spp.), smelt (Osmeridae; probably whitebait [Allosmerus elongatus] or surf smelt [Hypomesus pretiosus]), and herring species (Clupeidae or Dussumieriidae) (Naslund 1993a; Nelson, unpubl. data; Simons 1980; but see Burkett, this volume).

\section{Flight Behavior}

Adult murrelets often use similar flight paths on approaches and departures from tree nests. Generally, they follow openings such as creeks, roads or other clearings that allow for direct approaches and departures from the nest (Kerns, pers. comm.; Nelson and Péck, in press; Singer and others 1991; Singer and others, in press). The directions that birds enter and leave nests appear to be related to openings in the canopy or forest around the nest tree, and gaps in the horizontal cover surrounding the nest limb (Naslund, pers. comm.; Nelson and Peck, in press; Singer and others 1991; Singer and others, in press). Birds approach nests below tree canopy at heights as low as $\mathbf{5}$, and usually ascend steeply to the nest in a "stall-out" fashion. Landings are sometimes hard and audible (Nelson and Peck, in press; S.W. Singer, pers. comm.). We have observed and heard murrelets crashing into tree limbs on some occasions during final approaches to nests (Nelson and Peck, in press). In addition, birds occasionally abandoned landings and circled around for second attempts. When leaving the nest, birds usually drop 5-30 m in height before ascending over the canopy to continue their departure flights. They have not been observed departing at nest height or flying upwards on take-off from the nest limb.

When landing on the nest branch, murrelets splay out their webbed feet, lean backwards, and use their wings to slow their forward motion. They land hard enough on the nest limb to create a landing pad, or area where the moss or duff becomes flattened, removed, and worn by repeated landings. Toe nail markings are evident at some landing pads. Landing pads are most often located on the nest limb within $1 \mathrm{~m}$ of the nest cup, however they have also been located on adjacent limbs. In the latter case, murrelets hop to the nest limb.

Subcanopy behaviors, including one or more birds flying through, into, or out of the tree canopy, and birds landing in trees, are flight behaviors indicative of nesting and have been noted in nest stands and around nest trees. Landings and departures from trees have been observed at nests, on other branches in nest trees, in trees adjacent to nest trees, and other trees in nest stands throughout the breeding season. These landings may indicate nesting, territorial behavior, searches for nest sites, or resting or roosting behavior (Naslund 1993a). Singer and others (1991), and Naslund (1993a) described an additional four flight patterns observed near nest trees: (1) fly-bys and stall-flights, including single birds or pairs flying by or stalling out next to a known nest tree, at nest branch height; (2) flying-in-tandem and tail-chases, where pairs of birds fly in close proximity to known nest trees; and 
(3) buzzing, which includes single birds flying through the canopy making continuous low-pitched buzzing wing sounds.

Several flight behaviors above the canopy are also indicative of nesting. Like other alcids, Marbled Murrelets are often observed circling singly or in groups above the nesting grounds (Gaston 1992). Nesting birds may join with others before returning to the ocean after incubation and feeding visits. Nonbreeders may also accompany nesting birds in these circling flights above the canopy. Murrelets also occasionally create a loud sound, like a jet, during a shallow or steep dive that often originates above the canopy and ends at or below canopy level (Nelson and Peck, in press; S.W. Singer, pers. comm.). In Oregon, this behavior has been observed most often ( 67 percent) associated with known nest trees. In California, the jet dive during encounters between two murrelets has been observed and may be an aggressive posture or territorial defense.

\section{Predator Avoidance Behavior}

The Marbled Murrelet's primary defense against predators at the nest is to avoid detection through their secretive behavior at or near the nest, morphological defense mechanisms, such as cryptic plumage, and location of nest sites in trees and stands with hiding cover. In direct response to calls, silhouettes, or the presence of predators, and other disturbances (e.g., airplanes) at nests, adults and chicks often flatten themselves against the tree branch, holding their backs and heads low and remaining motionless (Kerns, pers. comm.; Naslund 1993a; Nelson and Peck, in press; Quinlan and Hughes 1990; Simons 1980; Singer and others 1991). However, they may also attempt to defend themselves against predators that have located the nest. At a nest in California, a murrelet chick was observed to defeñd itself against a Steller's Jay (Cyanocitta stelleri) by standing erect, turning to face the intruder, and jabbing it with its slightly open bill (Naslund 1993a; S.W. Singer, pers. comm.). In addition, Naslund (1993a) noted that occasionally when a raven flew by a nest, the adult assumed an erect posture as if readying itself to take flight. S.A. Singer (pers. comm.) observed an incubating adult lunge with open bill at a raven as it approached the nest, causing it to veer off instead of landing.

\section{Vocalizations and Wingbeats}

Marbled Murrelets primarily give soft or muted calls from the nest limb that are not audible from the ground. They rarely give loud vocalizations from stationary locations or in close proximity to a nest. When loud vocalizations are given at or near a nest, they can be heard from the ground depending on weather conditions and the location of the observer. However, because loud calls are uncommon, using them as a means for locating nests is not feasible with our current understanding of murrelet vocalizations.

Below is a summary of the vocalizations heard from murrelet nests. Most of these vocalizations were heard with the aid of microphones and other recording equipment pointed directly at the nest branch.
Adults and chicks were heard giving soft vocalizations at most nests $(n=14)$, but loud vocalizations were heard at only seven nests. These calls were given during incubation exchanges and feeding visits. Soft vocalizations include groan or grunt calls (duck-like quacks; previously referred to as alternate calls), whistle calls, and faint peeps. Loud vocalizations consist of keer and groan calls (Nelson and Peck, in press).

During incubation exchanges in Alaska, Oregon, and California, vocalizations were primarily given at the nest as birds arrived or departed the nest limb or during the brief seconds when adults were on the nest limb together. However, an interesting long $(13.5 \mathrm{sec})$ vocal sequence was recorded at one nest in Oregon. First, the incubating adult made soft groans from the nest branch, and at the same time a second adult flying nearby gave short, loud whistle calls. The incubating adult then emitted additional groans, which became increasingly louder and more emphatic. As the flying adult joined the other on the nest limb, one of these two birds gave loud whistle calls.

The frequency of exchanges with vocalizations varied among nests. In Alaska, 10 of 11 incubation exchanges included soft groan and other (undescribed) calls; and adults gave 1-2 loud keer calls when arriving or departing during incubation exchanges on two of 12 mornings (Naslund, pers. comm.). In Oregon, only 10 percent of incubation exchanges included soft or loud vocalizations $(n=59)$. At a nest in California, adults gave loud, emphatic "keer" and groan calls just before leaving the nest branch on five of 17 incubation exchanges (Naslund 1993a; Singer and others 1991; S.W. Singer, pers. comm.). In addition, several soft grunt calls, sounding like "unh-unh-unh", were heard on one occasion after an adult landed on the nest branch.

During feeding visits in Oregon, Washington, and British Columbia, adults occasionally gave loud keer calls and soft groan and "eeeuh" or "eeea" whistle calls as they flew from the nest branch or while bringing food to a chick at the nest (Hamer, unpubl. data; P. Jones, pers. comm.; Nelson and Peck, in press). The latter calls sounded like a muffled honking that adults gave while holding fish during feeding visits. In addition, in California, a series of soft "chip" notes, duck-like quacks, or short, soft grunts were given after the adult bird arrived to feed the chick (Singer and others 1991; S.W. Singer, pers. comm.). In British Columbia, a one-note bleating call (soft groan) was usually made when two adults were at the nest simultaneously ( $n=4$ occasions at 1 nest).

Chicks emit a rapid, high pitched begging call during feeding sessions. This begging call was recorded from a captive chick, and heard or recorded from active nests in Oregon and Washington $(n=4)$. In addition, P. Jones (pers. comm.) described a soft peep or begging call (repeated "puli-puli") that may have been given by the chick during feedings at a nest in British Columbia. We believe begging calls occur during every food delivery, but this sound is not usually audible, especially without microphones placed at or near the nest. 
Calls and fly-bys that indicate the impending arrival of an adult may also be given at nest sites. On several occasions in Oregon and Washington, incubating adults or chicks became alert, and chicks gave begging calls, moments before the arrival of the (other) adult (Hamer and Cummins 1991; Nelson and Peck, in press). Naslund (1993a) and Eisenhawer and Reimchen (1990) also mentioned keer and groan vocalizations given by adults prior to incubation exchanges.

Wingbeats have been heard during landings and takeoffs from nest branches at all nests, and while murrelets were flying through the tree canopy. Murrelets appear to be able to purposely create the wing sounds, because they are not heard during all landings, take-offs, and flights through the canopy.

\section{Discussion}

Marbled Murrelet breeding biology, morphology, and behavior, like that of other alcids, is affected by distance of nest sites from food sources, risk of predation, and other physical and biological factors (Cody 1973; De Santo and Nelson, this volume; Vermeer and others 1987a; Ydenberg 1989). The risk of predation may be the most significant factor in the development of alcid behavior, especially for Marbled Murrelets in their forest nesting environment.

Exposure to predation has influenced the length of incubation shifts, chick feeding frequency, and fledging strategy of alcids (Ydenberg 1989). Predator avoidance may be the driving force behind the long incubation shifts of both the Marbled ( 24 hours) and the Ancient (48 to 120 hours) Murrelets (Synthliboramphus antiquus)(Gaston 1992), as frequent visits to a nest can increase the chances of being discovered by predators and endanger the parents and young. Because of this risk, some species of alcids only feed their chick once in a 24-hour period (nocturnal alcids with semiprecocial young), whereas others (Synthliboramphus spp.) produce precocial chicks that are not fed at the nest site. In addition, feeding frequency within a species can vary among nesting colonies, with young in safe sites receiving more food than those in unsafe sites (Ydenberg 1989). Young that receive multiple daily feedings grow faster and fledge earlier than those with lower provisioning rates (Gaston and Nettleship 1981). Early fledging helps to minimize nest mortality (Cody 1971).

Marbled Murrelets have optimized their survival strategies by laying a single egg, feeding their chick relatively frequently, and concentrating most of their activity in the low light levels of dawn and dusk. With multiple daily feedings, murrelet chicks grow relatively rapidly and generally fledge earlier compared with most semi-precocial alcids (De Santo and Nelson, this volume). Despite this earlier fledging, Marbled Murrelet chicks are vulnerable in their open nest sites for 27 to 40 days. Therefore, selection of safe nest sites (Hamer and Nelson, this volume b) and secretive behaviors to avoid predation are also necessary for their survival.
In response to pressures from predation at nesting sites, alcids have developed specific behavioral characteristics (flight behavior, nocturnal activity) and have selected nest sites in inaccessible areas (burrows and crevices). Whereas most alcids are diurnal, nine species, including Marbled Murrelets, are primarily nocturnal or crepuscular (Synthliboramphus murrelets, Cassin's [Ptychoramphus aleuticus] and Rhinoceros [Cerorhinca monocerata] Auklets, Kittlitz's Murrelet, Dovekie [Alle alle]). Activity during low light levels (or twilight hours in the high arctic) minimizes predation by diurnal avian predators like gulls and corvids (Ainley and Boekelheide 1990; Gaston 1992; Nettleship and Birkhead 1985). Most alcids nest in inaccessible areas (burrows, crevices) to hide from predators, however, some species nest in the open on rock ledges (Common Murre, Thick-billed Murre [Uria lomvia], and Razorbill [Alca torda]), and must protect their young by nesting in large colonies or by guarding them during the day (Nettleship and Birkhead 1985).

The Brachyramphus murrelets also nest in the open, but they generally nest solitarily. For protection from predation, these murrelets have developed a cryptic plumage and secretive behaviors that allow them to remain hidden. For example, Marbled Murrelets have developed a variety of morphological and behavioral characteristics as defense mechanisms, some of which are shared by Kittlitz's Murrelet and other alcids: (1) concentrating activities in forests during crepuscular periods when light levels are low (i.e., incubation exchanges and feeding visits at dawn and dusk); (2) cryptic coloration of the egg, chick, and adult (breeding plumage); (3) rapid flight into and away from the nest; (4) visiting the nest briefly during incubation and less so during feeding of young; (5) "freezing" behavior exhibited by adults after landing at the nest during incubation exchanges and feeding visits; (6) remaining relatively silent on the nest branch (vocalizations are muted); (7) low, motionless posture of the incubating adult; (8) well developed thermoregulatory capabilities of the chick shortly after hatching allowing for minimal parental care; (9) chick remaining motionless for long time periods; $(10)$ retention of down feathers by chick concealing bright juvenal plumage until just prior to fledging; (11) young fledging just after dusk; (12) long distance indirect flights through the forest canopy to access nests; (13) fly by inspections of nests and nesting area by adults before a nest visit; (14) flying in groups within and above the nesting grounds, which may provide protection from predators and serve as an important social function; and (15) selecting nest platforms with high levels of vertical or hiding cover (see Binford and others 1975; Hamer and Cummins 1991; Hamer and Nelson, this volume b; Naslund 1993a; Nelson and Peck, in press; Sealy 1974, 1975a; Singer and others 1991). The number and diversity of these adaptations suggests that predation has been a selective factor on Marbled Murrelets in the past. Given these predator avoidance strategies, one would expect predation at nests to be low. However, Marbled Murrelets are still vulnerable 
to seemingly high rates of predation (see Nelson and Hamer, this volume b). Predation rates on alcid nests are often higher in areas where predators have been introduced, habitat has been modified, or where birds are disturbed by humans (Gaston 1992; Murray and others 1983; Nettleship and Birkhead 1985).

Observations of Marbled Murrelet behavior at nest sites have provided us with a wealth of new information that was not available prior to 1980 . Their secretive behavior, rapid flights in low light levels, and the inaccessibility of many of their nests, however, has limited our opportunities to study many aspects of their biology. The paucity of information on some aspects of Marbled Murrelet breeding biology minimizes the accuracy with which land managers can maintain or create suitable habitat for this species. In addition, their secretive behaviors limit our ability to identify nesting sites, especially in stands that contain few birds. Continued research on the biology, demography, and habitat selection of this species should be conducted, in addition to determining the effects of different forest management strategies on nesting success of this unique seabird.

\section{Acknowledgments}

We are grateful to the biologists who kindly shared their data with us; special thanks go to Dave Buchholz, Dave Fortna, Paul Jones, Steve Kerns, Kathy Kuletz, Nancy Naslund, Bill Ritchie, and Steve and Stephanie Singer for their time and generosity. We also thank Dan Anderson, Toni De Santo, George Hunt, Robert Peck, and C. John Ralph for reviewing earlier drafts of this manuscript. Support for preparation of this manuscript was provided by the Oregon Department of Fish and Wildlife, USDA Forest Service, USDI Bureau of Land Management and U.S. Fish and Wildlife Service. This is Oregon State University Agricultural Experiment Station Technical Paper 10,536. 



\title{
Chapter 6 \\ Characteristics of Marbled Murrelet Nest Trees and Nesting Stands
}

\author{
Thomas E. Hamer $\quad$ S. Kim Nelson ${ }^{2}$
}

\begin{abstract}
We summarize the characteristics of 61 tree nests and nesting stands of the Marbled Murrelet (Brachyramphus marmoratus) located from 1974 to 1993 in Alaska, British Columbia, Washington, Oregon, and California. Evidence of breeding $30-60 \mathrm{~km}$ inland was common in Califomia, Oregon, and Washington. Nesting greater distances from the coast may have evolved to avoid nest predation by corvids and gulls which are more abundant in coastal areas. In Califomia, Oregon, Washington, and British Columbia, murrelets nested in low elevation old-growth and mature coniferous forests, with multi-layered canopies $(>2)$, a high composition of low elevation conifer trees $(\bar{x}=91$ percent) and, on the lower two-thirds of forested slopes, with moderate gradients ( $\bar{x}=23$ percent slope). Stand canopy closure was often low ( $\bar{x}=50$ percent), suggesting use of canopy openings for access to nest platforms. Nests in the Pacific Northwest were typically in the largest diameter old-growth trees available in a stand $(\bar{x}=211 \mathrm{~cm})$; many nest trees were in declining conditions and had multiple defects. It is likely that western hemlock and Sitka spruce constitute the most important nest trees, with Douglas-fir important south of British Columbia. Many processes contributed to creating the nesı platforms observed. Mistletoe blooms, unusual limb deformations, decadence, and tree damage, commonly observed in old-growth and mature stands, all appear to create nest platforms. Therefore, the stand structure and the processes within a stand may be more important than tree size alone in producing nesting platforms and suitable habitat. Moss cover was also an important indicator of suitable nesting habitat.
\end{abstract}

We summarize the characteristics of 61 tree nests and nesting stands of the Marbled Murrelet (Brachyramphus marmoratus) located from 1974 to 1993 in Alaska, British Columbia, Washington, Oregon, and California (table 1). The majority of the nest site information was unpublished and obtained directly from field biologists who were conducting inland studies on the murrelet. The preponderance of unpublished nest information is due to the recent discovery of most nest sites. The only other summary was completed by Day and others (1983), based on two tree nests and five ground nests of the Marbled Murrelet.

Because of the murrelet's small body size, dense forested nesting habitat, cryptic plumage, crepuscular activity, fast flight speed, and secretive behavior near nests, its nests have been extremely difficult to locate. The first tree nest

\footnotetext{
${ }^{1}$ Research Biologist, Hamer Environmental, 2001 Highway 9, Mt. Vernon, WA 98273

${ }^{2}$ Research Wildlife Biologist, Oregon Cooperative Wildlife Research Unit, Oregon State University, Nash 104, Corvallis, OR 97331-3803
}

was located only in 1974 (Binford and others 1975), despite decades of searching by ornithologists in North America. Although a significant amount of nesting habitat information has been collected over the past four years, the efficiency of locating active nests is still low. Experiences gained from nest search efforts have led to the development and refinement of methodologies for locating new nests (Naslund and Hamer 1994).

Fortunately, an increased understanding of murrelet nesting ecology has allowed biologists to locate nests that have not been used for several months or, in some cases, several years. This involves searching for old nest cup depressions, worn spots or "landing pads" created on mosscovered branches by visiting adults, old fecal rings, and habitat features commonly associated with suitable nesting platforms. In addition, biologists learned that eggshells could be located in the duff and litter of nest platforms unused for a year or more.

Intensive search efforts by biologists across the Pacific Northwest have led to the discovery of 65 tree nests since 1974, with 63 (95 percent) located since 1990. Although this is still a relatively small sample size considering the large geographic area these nests represent, the sample does allow a characterization of the tree nests and nesting stands.

The two species of murrelets in the genus Brachyramphus (Kittlitz's and Marbled) display a complete dichotomy in their choice of nesting habitat. The Kittlitz's (B. brevirostris) murrelet nests up to $30 \mathrm{~km}$ inland on the ground on exposed rocky scree slopes, often at higher elevations. The Marbled Murrelet is unique among Alcids in selecting almost exclusively to nest on large limbs of dominant trees, which can be located long distances from the marine environment.

Long considered a subspecies of the Marbled Murrelet, the Asian race of the Marbled Murrelet (B.m. perdix Pallas) is distributed from the Kamchatka Peninsula south to Japan. New genetic evidence (Friesen and others 1994a) indicates the it is most likely a distinct species from the Marbled Murrelet. From the little evidence collected to date, it may be an obligate tree nesting seabird (Konyukhov and Kitaysky, this volume), with its range coinciding closely with the coastal coniferous forests of Russia and Japan (Kuzyakin 1963).

At a few sites in Alaska and Russia, at or beyond the margin of Pacific Coastal coniferous forests, the Marbled Murrelet nests on the ground. From an examination of the summer distribution of the species, approximately 3 percent of the Alaskan murrelet population may nest on the ground (Piatt and Ford 1993). These nests have been found at 
Table 1-Records of nest trees and nest stands of the Marbled Murrelet found in North America from 1974 to 1993

\begin{tabular}{|c|c|c|c|}
\hline $\begin{array}{c}\text { State/province } \\
\text { Record no. }\end{array}$ & Location & Date found & Sources \\
\hline \multicolumn{4}{|l|}{ Californla } \\
\hline 1 & Big Basin Redwood State Park & 7 Aug. 1974 & Binford and others 1975 \\
\hline 2 & Big Basin Redwood State Park & 3 Jun. 1989 & S.W. Singer (pers. comm.) \\
\hline 3 & Big Basin Redwood State Park & 28 Jun. 1989 & S.W. Singer (pers. comm.) \\
\hline 4 & Big Basin Redwood State Park & 5 May 1991 & S.W. Singer (pers. comm.) \\
\hline 5 & Big Basin Redwood State Park & 24 May 1992 & S.W. Singer (pers. comm.) \\
\hline 6 & Jedediah Smith State Park & 9 Aug. 1993 & Hamer (pers. obs.) \\
\hline 7 & Prairie Creek State Park & 23 Jul. 1993 & Hamer (pers. obs.) \\
\hline 8 & Bell-Lawrence & 14 Oct. 1993 & Chinnici (pers. comm.) \\
\hline 9 & Elk Head Springs & 16 Sep. 1992 & Chinnici (pers. comm.) \\
\hline 10 & Shaw Creek & 30 Sep. 1992 & Chinnici (pers. comm.) \\
\hline \multicolumn{4}{|l|}{ Oregon } \\
\hline 11 & Boulder and Warnicke Creeks & 17 Jun. 1992 & Nelson (pers. obs.) \\
\hline 12 & Cape Creek & 23 May 1991 & Nelson (pers. obs.) \\
\hline 13 & Iron Mountain & 30 May 1992 & Nelson (pers. obs.) \\
\hline 14 & Five Mile Flume Creek & 28 Sep. 1993 & Nelson (pers. obs.) \\
\hline 15 & Five Rivers & 19 May 1990 & Nelson (pers. obs.) \\
\hline 16 & Five Rivers & 14 Jun. 1991 & Nelson (pers. obs.) \\
\hline 17 & Five Rivers & 23 Sep. 1993 & Nelson (pers. obs.) \\
\hline 18 & Green Mountain & 17 Jun. 1993 & Nelson (pers. obs.) \\
\hline 19 & Green Mountain & 22 Sep. 1993 & Nelson (pers. obs.) \\
\hline 20 & Siuslaw River & 13 Aug. 1991 & Nelson (pers. obs.) \\
\hline 21 & Siuslaw River & 30 Aug. 1991 & Nelson (pers. obs.) \\
\hline 22 & Valley of the Giants & 29 Jun. 1993 & Nelson (pers. obs.) \\
\hline 23 & Valley of the Giants & 29 Jun. 1993 & Nelson (pers. obs.) \\
\hline 24 & Valley of the Giants & 24 Aug. 1993 & Nelson (pers. obs.) \\
\hline 25 & Valley of the Giants & 24 Aug. 1993 & Nelson (pers. obs.) \\
\hline 26 & Valley of the Giants & 24 Aug. 1993 & Nelson (pers. obs.) \\
\hline 27 & Valley of the Giants & 21 Sep. 1993 & Nelson (pers. obs.) \\
\hline 28 & Valley of the Giants & 25 Aug. 1993 & Nelson (pers. obs.) \\
\hline 29 & Valley of the Giants & 21 Sep. 1993 & Nelson (pers. obs.) \\
\hline 30 & Valley of the Giants & 12 Jul. 1990 & Nelson (pers. obs.) \\
\hline 31 & Valley of the Giants & 14 May 1991 & Nelson (pers. obs.) \\
\hline 32 & Valley of the Giants & 14 Jul. 1992 & Nelson (pers. obs.) \\
\hline \multicolumn{4}{|l|}{ Washington } \\
\hline 33 & Nemah River & 7 May 1993 & Ritchie (pers. comm.) \\
\hline 34 & Lake 22 Creek & 9 Jul. 1990 & Hamer (pers. obs.) \\
\hline 35 & Lake 22 Creek & 2 Aug. 1990 & Hamer (pers. obs.) \\
\hline 36 & Dungeness River & 10 Sep. 1990 & Holtrop (pers. comm.) \\
\hline 37 & Heart of the Hills Trail & 26 Jul. 1991 & Hamer (pers. obs.) \\
\hline 38 & Jimmey Come Lately Creek & 24 Jul. 1991 & Holtrop (pers. comm.) \\
\hline
\end{tabular}




\begin{tabular}{|c|c|c|c|}
\hline $\begin{array}{c}\text { State/province } \\
\text { Record no. }\end{array}$ & Location & Date found & Sources \\
\hline \multicolumn{4}{|c|}{ British Columbia } \\
\hline 39 & August Creek, Vancouver Is. & 12 Sep. 1993 & Burger (pers. comm) \\
\hline 40 & Carmanah Creek, Vancouver Is. & 2 Oct. 1992 & Jordan and Hughes (in press) \\
\hline 41 & Walbran Creek, Vancouver Is. & 12 Oct 1992 & Jordan and Hughes (in press) \\
\hline 42 & Walbran Creek, Vancouver Is. & 3 Aug. 1990 & Manley and Kelson (in press) \\
\hline 43 & Walbran Creek, Vancouver ls. & 24 Ang. 1991 & Manley and Kelson (in press) \\
\hline 44 & Walbran Creek, Vancouver Is. & 25 Aug. 1992 & Jordan and Hughes (in press) \\
\hline 45 & Caren Range & 1 Aug. 1993 & P. Jones (pers. comm) \\
\hline 46 & Clayoquot River & 1993 & Kelson (pers. cornm.) \\
\hline 47 & Megin River & 1993 & Manley (pers. comm.) \\
\hline \multicolumn{4}{|l|}{ Alaska } \\
\hline 48 & Afognac Is. Alaska Peninsula & 26 Jul. 1992 & Naslund and others (in press) \\
\hline 49 & Afognac Is., Alaska Peninsula & 6 Aug. 1992 & Naslund and others (in press) \\
\hline 50 & Kodiak Is., Alaska Peninsula & 17 Aug 1992 & Naslund and others (in press) \\
\hline 51 & Kodiak Is., Alaska Peninsula & 17 Aug. 1992 & Naslund and others (in press) \\
\hline 52 & Naked Is., Prince William Sound & 13 Jun. 1991 & Naslund and others (in press) \\
\hline 53 & Naked Is., Prince William Sound & 25 Jun. 1991 & Naslund and others (in press) \\
\hline 54 & Naked Is., Prince William Sound & 6 Jul. 1991 & Naslund and others (in press) \\
\hline 55 & Naked Is., Prince William Sound & 26 Jul. 1991 & Naslund and others (in press) \\
\hline 56 & Naked Is., Prince William Sound & I Jul. 1991 & Naslund and others (in press) \\
\hline 57 & Naked Is., Prince William Sound & 25 May 1992 & Naslund and others (in press) \\
\hline 58 & Naked Is., Prince William Sound & $20 \mathrm{Jul} .1992$ & Naslund and others (in press) \\
\hline 59 & Naked Is., Prince William Sound & 5 Aug 1992 & Naslund and others (in press) \\
\hline 60 & Naked Is., Fince William Sound & 6 Aug. 1992 & Naslund and others (in press) \\
\hline 61 & Naked Is., Prince William Sound & 9 Jun. 1991 & Naslund and others (in press) \\
\hline
\end{tabular}

Augustine Island (Cook Inlet), Kodiak Island, the Barren Islands, and the Kenai Peninsula (Day and others 1983, Mendenhall 1992, Simons 1980). All of these nests were located in areas of talus where surrounding rocks formed a protected area for the nests, or in areas dominated by alder. The egg was laid on existing mat vegetation or bare soil. Whereas most of these sites were above the local tree line and had only low-lying mat vegetation, the Kenai site had a forested area on a nearby slope. An additional ground nest found on Prince of Wales Island in southeastern Alaska in 1993 was located on a platform of moss covering three intertwined roots of a western hemlock (Tsuga heterophylla) tree at the top of an 11-meter high cliff (Ford and Brown 1994). The nest had many of the characteristics of a tree nest when approached from downslope, but was similar to a ground nest when approached from up slope.

\section{Methods}

We compiled information from 61 nest stands and nest trees throughout the geographic range of the Marbled Murrelet in North America using published and unpublished information. Information from three additional tree nests in Alaska were not obtained for this review. We did not include data from ground nests in this summary. We summarized tree and stand characteristics from 14 tree nests in Alaska (Naslund and others, in press), nine nests in British Columbia (Burger, pers. comm.; P. Jones, pers. comm.; Jordan and others in press; Kelson, pers. comm.; Manley, pers. comm.; Manley and Kelson, in press), six nests in Washington (Hamer, unpubl. data; Holtrop, pers. comm.; Ritchie, pers. comm.), 22 nests in Oregon (Nelson, unpubl. data), and 10 nests in California (Binford and others, 1975; Chinnici, pers. comm.; Folliard, pers. comm.; Hamer, unpubl. data; S.W. Singer, pers. comm.; Singer and others, 1991) (table 1). 
The sample size for each nest characteristic varied because some variables were not measured at some nest sites, or the information was not available to us. A protocol that outlined a methodology for measuring the structure of nests was not available until 1993 (Hamer 1993), so some characteristics of earlier nests were not measured. Stands were delineated and stand sizes calculated generally by defining stands as a contiguous group of trees with no gaps larger than $100 \mathrm{~m}$. Stand ages were derived from stand information data bases of the landowners or by aging individual trees in the stand using increment bores. Limb diameters were generally reported with the moss cover on the limb included in the measurement. Nest platform lengths were measured as the length of the nest branch until it was judged to be too narrow to support a nest $(<10 \mathrm{~cm})$.

We calculated the range, mean, and standard deviation for each nest and stand characteristic for each state or province. In addition, we pooled the sample of nests for what we term the "Pacific Northwest", using data from nests located in California, Oregon, Washington, and British Columbia (tables 2 and 3). Nests located in Alaska were treated as a separate sample (tables 2 and 3).

We chose to segregate the data using state or provincial boundaries because different forest types generally occur within these boundaries. Forest types in California within the murrelet's breeding range were predominately coastal redwood (Sequoia sempervirens). Oregon had fire regenerated stands dominated by Douglas-fir (Pseudotsuga menziesii), and in Washington, mixed forests of western red cedar (Thuja plicata), western hemlock, Douglas-fir, and Sitka spruce (Picea sitchensis), created by the combined forces of fire and wind, covered the majority of the landscape. British Columbia was similar to Washington, with the addition of yellow cedar (Chamaecyparis nootkatensis), found in stands at higher elevations. Forest types in Alaska were very distinct, with many stands dominated by mountain hemlock (Tsuga mertensiana) which were small in stature and diameter.

\section{Results}

\section{Landscape Characteristics}

\section{Distance to Salt Water}

A sample of 45 nests in the Pacific Northwest were located a mean distance of $16.8 \mathrm{~km}$ inland (table 2, fig. I). Nests in California were found a mean distance of $13 \mathrm{~km}$ from salt water; the farthest inland nest in California was located $28.9 \mathrm{~km}$ inland (table 2). The farthest inland nest in Oregon was located $40 \mathrm{~km}$ from the sea. This coincides with a historical record of a downy young found on the ground 40 $\mathrm{km}$ inland on the South Fork of the Coos River in Coos County (Nelson and others 1992). In Washington, nests were located a mean distance of $16 \mathrm{~km}$ inland. Other information from Washington indicated nesting at stands further inland than known nest sites. A small downy chick was located by the senior author on the ground along a trail on the east shore of Baker Lake in 1991, $63 \mathrm{~km}$ from the ocean. Another downy chick was located $45 \mathrm{~km}$ inland in
Helena Creek, in Snohomish County (Reed and Wood 1991). Six additional records of eggs, downy young, and fledglings found $29-55 \mathrm{~km}$ inland in Washington were compiled by Leschner and Cummins (1992a), and Carter and Sealy (1987b).

In British Columbia, nest trees were located a mean distance of $11.5 \mathrm{~km}$ from the Pacific. In addition, there was a record of a fledgling found on the ground near Hope, British Columbia, $101 \mathrm{~km}$ from salt water (Rodway and others 1991). This is the farthest inland distance recorded for Marbled Murrelets in North America. Nest trees in Alaska were typically located close to the coast, with a mean distance of $0.5 \mathrm{~km}$ (table 2), corresponding to the closer inland distribution of suitable nesting habitat.

\section{Elevation}

The mean elevation of nest trees from a sample of 45 murrelet nests in the Pacific Northwest was $332 \mathrm{~m}$ (table 2). In Alaska nest trees were low in elevation with a mean of 96 $\mathrm{m}$ and a maximum of $260 \mathrm{~m}$ (table 2).

\section{Aspect}

Nest stands in the Pacific Northwest occur on a variety of aspects. Twenty-six percent of the stands had northeast aspects, 12 percent southeast, 28 percent southwest, 12 percent northwest, and 21 percent were on flat topography with no aspect (table 2). In Alaska, 93 percent of the nest stands had westerly aspects (NW, W, or SW), with the majority (50 percent) facing northwest.

Slope

Nests in the Pacific Northwest were located on slopes with moderate gradients, with a mean of 23 percent. Slope gradients for nests in Alaska were higher than nests for the Pacific Northwest with a mean slope of 69 percent.

The majority of nests in the Pacific Northwest ( 80 percent) were located on the lower one-third or middle one-third of the slope. Nest stands in Alaska were located low in elevation, but were usually located on the top one-third of the slope, unlike nests in the southern part of the range. Nest stands in Alaska have been described as being located on gradual or moderate slopes (Naslund and others, in press).

\section{Forest Characteristics}

Age

For a sample of 16 nests in the Pacific Northwest the mean stand age was 522 years with the youngest stand age reported as 180 years old (table 2 ). The oldest stand was 1,824 years old located on the mainland coast of British Columbia, and was dated using nearby stumps from a recent clear-cut. To date, all 61 tree nests found in North America have been found in stands described as old-growth or mature forests.

\section{Tree Size}

The mean d.b.h. of trees in nest stands was not reported for many sites. Nest stands in Washington and Oregon were characterized by large diameter trees $(\bar{x}=47.7 \mathrm{~cm})$, a mean density of large trees ( $>46 \mathrm{~cm}$ d.b.h.) of $93.8 / \mathrm{ha}$, an average 
Table 2-The mean, standard deviation, range, and sample size for the forest stand characteristics of Marbled Murrelet tree nests located in North America. The Pacific Northwest data include nests located in California, Oregon, Washington, and British Columbia. For some characteristics, either no data were available for that state or province, or the sample size was too small to calculate the mean and range. Sample sizes for each variable are shown in parenthesis

\begin{tabular}{|c|c|c|c|c|c|c|}
\hline Characteristics & $\begin{array}{c}\text { California } \\
n=10\end{array}$ & $\begin{array}{c}\text { Oregon } \\
n=20\end{array}$ & $\begin{array}{c}\text { Washington } \\
n=6\end{array}$ & $\begin{array}{c}\text { British } \\
\text { Columbia } \\
n=9\end{array}$ & $\begin{array}{c}\text { Pacific } \\
\text { Northwest } \\
n=45\end{array}$ & $\begin{array}{l}\text { Alaska } \\
n=14 \\
\end{array}$ \\
\hline \multirow[t]{3}{*}{ A.pect (") } & $210 \pm 122$ & $147 \pm 63$ & $180=121$ & - & $166 \pm 92$ & $267 \pm 66$ \\
\hline & $45-352$ & $48-253$ & $39-331$ & - & $35-39$ & $270-360$ \\
\hline & (7) & (19) & (5) & & (33) & (14) \\
\hline \multirow[t]{3}{*}{ Elevation $(m)$} & $286 \pm 125$ & $379 \pm 152$ & $348 \pm 176$ & $321 \pm 310$ & $332 \pm 206$ & $96 \pm 50$ \\
\hline & $45-46$ & $61-646$ & $15-610$ & $14-1097$ & $14-1097$ & $30-260$ \\
\hline & (10) & (10) & (6) & (9) & (35) & (14) \\
\hline \multirow[t]{3}{*}{ lope (pct) } & $18 \pm 14$ & $41 \pm 27$ & $21 \pm 13$ & $3 \pm 4$ & $23 \pm 23$ & $69 \pm 16$ \\
\hline & $0-41$ & $10-87$ & $0-39$ & $0-11$ & $0-87$ & $47-100$ \\
\hline & (7) & $(10)$ & (6) & (7) & (30) & (10) \\
\hline \multirow[t]{3}{*}{ Slope position ${ }^{1}$} & $1 \pm 0$ & $2.1 \pm 0.9$ & $1.3 \pm 0.5$ & $1.3 \pm 0.7$ & $1.5 \pm 0.8$ & - \\
\hline & $1-1$ & $1-3$ & $1-2$ & $1-3$ & $1-3$ & - \\
\hline & (7) & $(10)$ & $(6)$ & (7) & (30) & \\
\hline \multirow[t]{3}{*}{ Stand size (ha) } & $352 \pm 432$ & $80 \pm 49$ & $354 \pm 401$ & - & $206 \pm 351$ & $31 \pm 26$ \\
\hline & $100-1100$ & $3-149$ & $5-990$ & - & $3-1100$ & 463 \\
\hline & (4) & (9) & (5) & & (16) & (10) \\
\hline \multirow[t]{3}{*}{ Pct. composition low elevation trees ${ }^{2}$} & $100 \pm 0$ & $100 \pm 0$ & $90 \pm 9$ & $64 \pm 29$ & $91 \pm 19$ & $64 \pm 14$ \\
\hline & $100-100$ & $100-100$ & $78-100$ & $20-100$ & $20-100$ & $39-91$ \\
\hline & (10) & (10) & (5) & (6) & (31) & (8) \\
\hline \multirow[t]{3}{*}{ otal uree density (number/ha) } & $235 \pm 178$ & $120 \pm 72$ & $136 \pm 28$ & $297 \pm 136$ & $182 \pm 132$ & $575 \pm 270$ \\
\hline & $92-504$ & $48-282$ & $84-162$ & $148-530$ & $48-530$ & 295-978 \\
\hline & (5) & (10) & (5) & (5) & (25) & (8) \\
\hline \multirow[t]{3}{*}{ Canopy height (m) } & $88 \pm 0$ & $59 \pm 8$ & $54 \pm 5$ & - & $64 \pm 16$ & $23 \pm 4$ \\
\hline & $88-88$ & $48-75$ & $44-59$ & - & $38-88$ & $16-30$ \\
\hline & (5) & (9) & (5) & 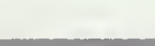 & (20) & (14) \\
\hline \multirow[t]{3}{*}{ Canupy layers (number) } & - & $2.2 \pm 0.4$ & $3.4 \pm 0.5$ & - & $2.5 \pm 0.7$ & 一 \\
\hline & - & $2-3$ & $3-4$ & - & $2-4$ & - \\
\hline & & $(10)$ & (4) & 6 & $(20)$ & \\
\hline \multirow[t]{3}{*}{ Canopy closure (pct) } & $39 \pm 6$ & $43 \pm 27$ & $69 \pm 18$ & - & $49 \pm 23$ & $62 \pm 15$ \\
\hline & $25-48$ & $12-99$ & $36-88$ & - & $12-99$ & $40-85$ \\
\hline & (7) & (8) & (5) & & (21) & (12) \\
\hline \multirow[t]{3}{*}{ Distance to coast (km) } & $13.1 \pm 8.3$ & $25.8 \pm 9.7$ & $15.9 \pm 13$ & $11.5 \pm 3.7$ & $16.8 \pm 10.6$ & $0.5 \pm 0.3$ \\
\hline & $4.9-28.9$ & $1.6-40.0$ & $4.1-34.2$ & $3.2-17.3$ & $1.6-40$ & $0.1-1.2$ \\
\hline & (10) & (10) & (6) & (9) & (35) & (14) \\
\hline \multirow[t]{3}{*}{ Distance to stream (m) } & $108 \pm 67$ & $280 \pm 312$ & $70 \pm 69$ & $100 \pm 165$ & $159 \pm 224$ & $109 \pm 108$ \\
\hline & $30-215$ & $8-1000$ & $14-200$ & $5-500$ & $5-1000$ & $2-325$ \\
\hline & (7) & (10) & (5) & (7) & (29) & (9) \\
\hline \multirow[t]{3}{*}{ Distance to nearest opening (m) } & - & $67 \pm 70$ & $65 \pm 33$ & - & $92 \pm 131$ & - \\
\hline & - & $15-300$ & $18-120$ & - & $15-700$ & - \\
\hline & & 20) & (5) & . & $(30)$ & 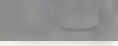 \\
\hline \multirow[t]{3}{*}{ Stand age (yrs) } & - & $209 \pm 48$ & $879 \pm 606$ & - & $522 \pm 570$ & - \\
\hline & - & $180-350$ & $450-1736$ & - & $180-1824$ & - \\
\hline & & $(10)$ & (3) & & (16) & \\
\hline
\end{tabular}

${ }^{1}$ Slope position codes: (1) lower $1 / 3,(2)$ middle $1 / 3$, and (3) upper $1 / 3$.

${ }^{2}$ Measure of the percent of western hemlock, Douglas-fir, western red cedar, Sitka spruce, and coastal redwood in a stand. 
Table 3-The mean, standard deviation, range, and sample size for platform and tree characteristics of Marbled Murrelet tree nests ( $\mathrm{n}=61$ ) located in North America. The Pacific Northwest data include nests located in California, Oregon, Washington, and British Columbia. For some characteristics, either no data were available for that state or province, or the sample size was too small to calculate the mean and range. Calculations were rounded to the nearest cm for all measurements except nest substrate depth. Sample sizes for each variable are shown in parenthesis.

\begin{tabular}{|c|c|c|c|c|c|c|}
\hline Characteristics & $\begin{array}{c}\text { California } \\
n=10\end{array}$ & $\begin{array}{l}\text { Oregon } \\
n=22\end{array}$ & $\begin{array}{c}\text { Washington } \\
\quad n=6\end{array}$ & $\begin{array}{c}\text { British } \\
\text { Columbia } \\
n=9\end{array}$ & $\begin{array}{c}\text { Pacific } \\
\text { Northwest } \\
n=47\end{array}$ & $\begin{array}{l}\text { Alaska } \\
n=14\end{array}$ \\
\hline \multicolumn{7}{|l|}{ Tree species } \\
\hline Sutka spruce & & 1 & & 6 & 7 & 5 \\
\hline Douglas-fir & 4 & 20 & 3 & & 27 & \\
\hline Western hemlock & 1 & 1 & 2 & 2 & 6 & \\
\hline Western red cedar & & & 1 & & 1 & \\
\hline Alaska yellow cedar & & & & 1 & 1 & \\
\hline Coastal redwood & 5 & & & & 5 & \\
\hline Mountaun hemlock & & & & & & 2 \\
\hline \multirow[t]{3}{*}{ Tree diameier $(\mathrm{cm})$} & $278 \pm 136$ & $192 \pm 47$ & $152 \pm 45$ & $212 \pm 84$ & $211 \pm 91$ & $63 \pm 18$ \\
\hline & $139-533$ & $127-279$ & $88-220$ & $90-370$ & $88-533$ & $30-104$ \\
\hline & (10) & 122) & (5) & (9) & (46) & 14 \\
\hline \multirow[t]{3}{*}{ Tree height $(\mathrm{m})$} & $73 \pm 8$ & $67 \pm 11$ & $57 \pm 7$ & $58 \pm 15$ & $66 \pm 13$ & $23 \pm 4$ \\
\hline & $61-86$ & $36-86$ & $45-65$ & $30-80$ & $30-86$ & $16-30$ \\
\hline & $(10)$ & $(22)$ & (5) & (9) & (46) & $(14)$ \\
\hline \multirow[t]{3}{*}{ Tree diameter at nest heıght $/ \mathrm{cm}$} & $105 \pm 48$ & $81 \pm 23$ & $72 \pm 21$ & $110 \pm 60$ & $88 \pm 39$ & - \\
\hline & $70-199$ & $36-122$ & $40-97$ & $50-209$ & $36-209$ & - \\
\hline & (5) & $(15)$ & (5) & (5) & (30) & \\
\hline \multirow[t]{3}{*}{ Branch height (m) } & $47 \pm 11$ & $51 \pm 12$ & $37 \pm 11$ & $33 \pm 8$ & $45 \pm 13$ & $13 \pm 2$ \\
\hline & $33-68$ & $18-73$ & $23-53$ & $18-44$ & $18-73$ & $10-17$ \\
\hline & (10) & $(21)$ & $(5)$ & (9) & $(45)$ & (14) \\
\hline \multirow[t]{3}{*}{ Branch diameter at trunk $(\mathrm{cm})$} & $35 \pm 13$ & $31 \pm 11$ & $36 \pm 12$ & $32 \pm 9$ & $32 \pm 11$ & $15 \pm 5$ \\
\hline & $21-61$ & $14-56$ & $14-49$ & $18-43$ & $14-61$ & $9-27$ \\
\hline & (8) & (19) & $(5)$ & (9) & (41) & (12) \\
\hline \multirow[t]{3}{*}{ Branch diameter at nest $(\mathrm{cm})$} & $34 \pm 13$ & $34 \pm 18$ & $29 \pm 13$ & $27 \pm 9$ & $32 \pm 16$ & $19 \pm 5$ \\
\hline & $16-61$ & $10-81$ & $11-46$ & $15-38$ & $10-81$ & $12-28$ \\
\hline & $(10)$ & $(20)$ & (4) & $(7)$ & $(41)$ & (11) \\
\hline \multirow[t]{3}{*}{ Branch crown position (pct) } & $64 \pm 13$ & $74 \pm 12$ & $63 \pm 15$ & $58 \pm 11$ & $68 \pm 14$ & $59 \pm 12$ \\
\hline & $50-91$ & $50-92$ & $41-81$ & $40-74$ & $40-92$ & $44-79$ \\
\hline & (10) & 121) & (5) & (9) & $(45)$ & (14) \\
\hline \multirow[t]{3}{*}{ Branch orientation $\left(^{\circ}\right)$} & $203 \pm 103$ & $173 \pm 87$ & $233 \pm 109$ & $187 \pm 90$ & $189 \pm 96$ & - \\
\hline & $45-360$ & $20-360$ & $110-342$ & $18-341$ & $18-360$ & - \\
\hline & $(10)$ & (20) & (4) & (9) & $(43)$ & \\
\hline \multirow[t]{3}{*}{ Distance trunk to nest $(\mathrm{cm})$} & $47 \pm 61$ & $101 \pm 160$ & $26 \pm 26$ & $134 \pm 122$ & $89 \pm 132$ & $62 \pm 66$ \\
\hline & $0-184$ & $1-762$ & $0-57$ & $0-340$ & $0-762$ & $0-224$ \\
\hline & 10 & (21) & 141 & 19) & 1441 & $|13|$ \\
\hline \multirow[t]{3}{*}{ Nest platform length $(\mathrm{cm})$} & $20 \pm 10$ & $41 \pm 17$ & $29 \pm 16$ & $21 \pm 13$ & $32 \pm 18$ & - \\
\hline & $8-40$ & $12-71$ & $10-57$ & $12-50$ & $8-71$ & - \\
\hline & $(10)$ & $(21)$ & (5) & (6) & $(42)$ & \\
\hline \multirow[t]{3}{*}{ Nest platform width $(\mathrm{cm})$} & $15 \pm 7$ & $28 \pm 12$ & $24 \pm 11$ & $12 \pm 3$ & $22 \pm 12$ & - \\
\hline & $6-23$ & $7-51$ & $10-39$ & $9-19$ & $7-51$ & - \\
\hline & $(10)$ & (21) & (5) & (6) & $(42)$ & \\
\hline \multirow[t]{3}{*}{ Nest platform moss depth $(\mathrm{cm})$} & $2.9 \pm 2.7$ & $5.1 \pm 2.5$ & $2.7 \pm 0.7$ & $4.8 \pm 1.4$ & $4.5 \pm 2.4$ & $3.9 \pm 1.3$ \\
\hline & $0.8-8.1$ & $0.6-12$ & $2.0-3.5$ & $2.7-7.0$ & $0.6-12$ & $2.0-6.0$ \\
\hline & (5) & $(17)$ & (2) & (9) & (33) & $(12)$ \\
\hline \multirow[t]{3}{*}{ Nesi platform duff and litter depth $(\mathrm{cm})$} & $7.4 \pm 7.3$ & $3.4 \pm 0.4$ & $2.9 \pm 0.7$ & - & $5.0 \pm 5.2$ & - \\
\hline & $2.5-20.0$ & $3.0-3.8$ & $2.0-3.8$ & - & $2.0-20.0$ & - \\
\hline & (4) & (2) & (3) & & (9) & \\
\hline \multirow[t]{3}{*}{ Cover above nest (pct) } & $90 \pm 28$ & $79 \pm 14$ & $90 \pm 10$ & $100 \pm 0$ & $85 \pm 20$ & $89 \pm 05$ \\
\hline & $5-100$ & $40-100$ & $70-100$ & $100-100$ & $5-100$ & $81-95$ \\
\hline & $(10)$ & (18) & (5) & (2) & $(35)$ & (8) \\
\hline
\end{tabular}




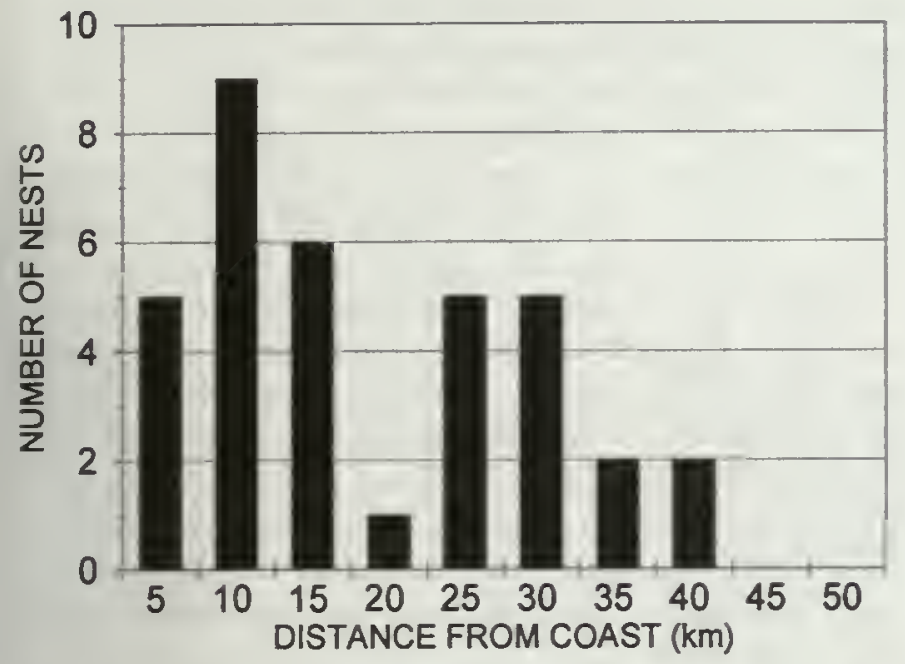

Figure 1-Distances from the Marbled Murrelet nest trees $(n=35)$ to the nearest salt water for nests found in the Pacific Northwest. The number of nests was listed in 5-km increments beginning with nests found $0-5 \mathrm{~km}$ inland.

total tree density ( $>10 \mathrm{~cm}$ d.b.h.) of 324/ha, multiple canopy layers (2-3), and the presence of snags ( $>10 \mathrm{~cm}$ d.b.h.) (mean density $=71 / \mathrm{ha}$ ) (Nelson and others, in press). In Alaska, most nest trees were located in forests with significantly larger tree size classes ( $\geq 23 \mathrm{~cm}$ d.b.h.) and higher volume classes $\left(1883-5649 \mathrm{~m}^{3} / \mathrm{ha}\right.$ ) than other forest types (Kuletz and others, in press).

\section{Tree Species Composition and Stem Density}

Conifer species that typically grow at higher elevations in the Pacific Northwest include mountain hemlock, silver fir (Abies amabilis), and yellow cedar. Conifer species most abundant at lower elevations include Douglas-fir, western red cedar, Sitka spruce, western hemlock, and coastal redwood. Nest stands in the Pacific Northwest were composed primarily of low elevation conifer species $(\bar{x}=$ 91 percent) (table 2). In Alaska, the composition of low elevation trees was much lower, with a mean of 64 percent. The total mean tree density for nest stands in the Pacific Northwest was 182 trees/ha; total density was about three times greater in Alaska (table 2).

All nest trees in the Pacific Northwest were recorded in stands characterized as old-growth and mature forest. These stands were dominated by either Douglas-fir, coast redwood, western hemlock, western red cedar, or Sitka spruce. The one exception was a higher elevation nest stand found in the Caren Range of British Columbia which was dominated by old-growth mountain hemlock ( 60 percent) with smaller percentages of yellow cedar ( 20 percent) and silver fir (20 percent). In California, nest stands were dominated by coast redwood and Douglas-fir, with a component of western hemlock and Sitka spruce in some nest stands. In both central and northern California, all nest sites had a higher percentage of redwood trees than Douglas-fir. Nest stands in Oregon were dominated by Douglas-fir and western hemlock, with one site dominated by Sitka spruce. Forest types in Washington included stands dominated by western hemlock, Douglas-fir, and Sitka spruce. These stands commonly had a large component of western red cedar. Silver fir made up a smaller component of some of the nest stands in Washington.

In British Columbia, six nest stands were dominated primarily by Sitka spruce and western hemlock, with four stands also having a component of silver fir, and one stand with western red cedar. One nest stand in the Caren Range was dominated by mountain hemlock. For a sample of eight nests located in Alaska, mountain hemlock was the dominant tree species at five nests, and western hemlock was the dominant species at three nest stands (Naslund and others, in press). Sitka spruce were reported as an important component at most of these nest sites.

\section{Canopy Characteristics}

Nest stands in the Pacific Northwest had a mean canopy height of $64 \mathrm{~m}$ with the redwood zone included in this sample (table 2). The mean canopy height for stands located in Oregon, Washington, and British Columbia was $61 \mathrm{~m}$. The canopy height of Alaska nest stands were lower $(\bar{x}=23 \mathrm{~m})$, reflecting the small stature of the trees in this geographic area.

For nest stands in the Pacific Northwest, the mean canopy closure was 49 percent, and all nest stands were reported to have 2-4 tree canopy layers where this variable was recorded (table 2). Canopy closures below 40 percent were reported for 40 percent of the nest stands (fig. 2). Mean canopy closures were especially low in California and Oregon. Canopy closures for a typical old-growth stand in Washington generally average 80 percent. Canopy closures reported from Alaska were similar to nest stands in the Pacific Northwest (table 2) with a mean of 62 percent.

The presence of dwarf mistletoe (Arceuthobium) in the nest stands or within the canopy of nest trees was not reported consistently enough to determine its importance to murrelets. Mistletoe was reported at 13 of 20 nest stands, where its occurrence was evaluated.

\section{Stand Size}

Mean nest stand size for the Pacific Northwest was 206 ha. Several nest stands were only 3,5 , and 15 ha in size. In Alaska, stands were naturally fragmented in many cases, and averaged 31 ha. Stand sizes were generally smaller in Alaska because of the naturally fragmented nature of the coastal forests in this region.

\section{Distance to Openings}

Distance of nest trees to streams for nests in the Pacific Northwest was variable, with a mean of $159 \mathrm{~m}$. Nest trees were located a mean distance of $92 \mathrm{~m}$ from natural or manmade openings (table 2). A combined analysis indicated that the mean distance to an opening or stream was $123 \mathrm{~m} \mathrm{(} n=$ $68, s . d .=177)$. Sixty-six percent of the nest trees were $\leq 100$ $\mathrm{m}$ from an opening (fig. 3). 


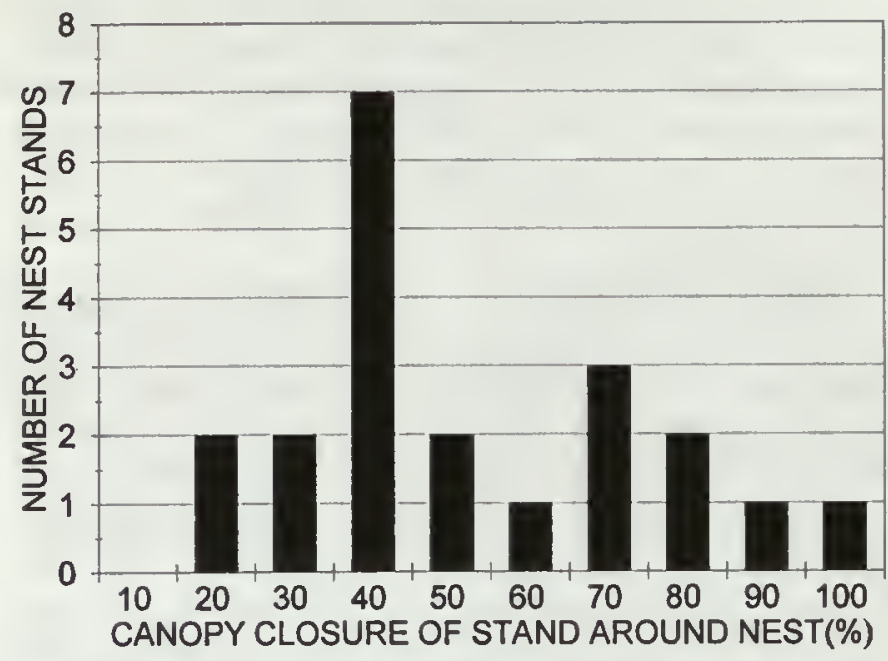

Flgure 2-Canopy closure of the stand surrounding the nest tree for 34 Marbled Murrelet nests found in North America. The number of nests was listed in 10-percent increments beginning with nests with 0-10 percent canopy closure.

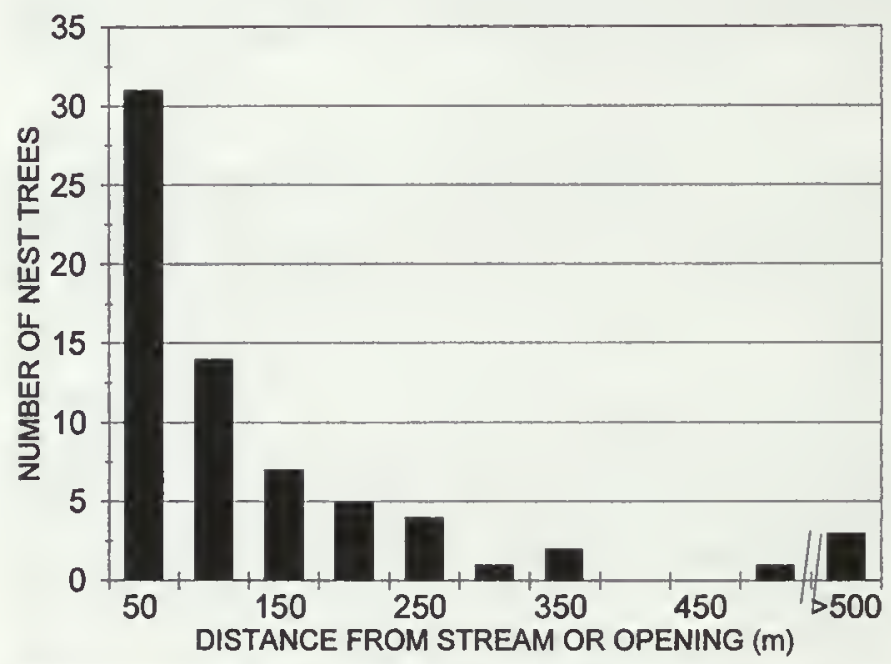

Figure 3-Distances from the Marbled Murrelet nest trees $(n=68)$ to the nearest stream, creek, or opening for nests found in North America. Some nests had two measurements, one to the nearest opening and one to the nearest stream.

\section{Tree Characteristics}

Nest trees used by murrelets in the Pacific Northwest included Douglas-fir (57 percent), Sitka spruce (15 percent), western hemlock ( 13 percent), coast redwood ( 11 percent), and western red cedar (2 percent) (table 3 ). In one exception, a nest in British Columbia was found in a yellow cedar (2 percent). Western hemlock was the only nest tree species reported used by Marbled Murrelets throughout their geographic range. Although Sitka spruce was only reported from Alaska, British Columbia, and Oregon, it is likely this species is also used throughout the range of the murrelet since it is common in coastal coniferous forests of Washington through California. Douglas-fir nest trees were only located in Washington, Oregon, and California. Nests in cedar trees were reported only from Washington and British Columbia, but this was probably due to a small sample size. Mountain hemlock nest trees were only reported from Alaska.

In the Pacific Northwest, the mean nest tree diameter was $211 \mathrm{~cm}$, with the smallest diameter nest tree reported from Washington, which was a western hemlock $88 \mathrm{~cm}$ in diameter (table 3). Nest tree diameters were normally distributed with a maximum number of trees found between 140 and $160 \mathrm{~cm}$, and 85 percent of the trees ranging between 120 and $280 \mathrm{~cm}$ (fig. 4). Nest tree diameters were much smaller in Alaska $(\bar{x}=63 \mathrm{~cm})$ due to the small stature of the trees in this region.

Mean nest tree heights were highest in California and Oregon where the majority of nest trees were in redwood and Douglas-fir trees which can grow to great heights. Mean tree heights were similar between Washington and British Columbia where more of the nest trees were in cedar, spruce, and hemlock. Mean tree heights in the Pacific Northwest were $66 \mathrm{~m}$ (table 3). Nest tree heights in Alaska were low, with a mean of $23 \mathrm{~m}$, with one nest tree measured at $16 \mathrm{~m}$.

The mean diameter of the tree trunk at nest height was $88 \mathrm{~cm}$ in the Pacific Northwest, with minimum trunk diameters of $36 \mathrm{~cm}$ and $40 \mathrm{~cm}$ reported for Oregon and Washington respectively. Trunk diameters at the nest height were not reported for nests in Alaska (table 3).

The condition of nest trees in the Pacific Northwest varied, with 64 percent recorded as alive/healthy and 36 percent as declining $(n=44)$. No nests were reported in snags. Nest trees with declining tops ( 8 percent), broken tops (37 percent) and dead tops ( 8 percent) were commonly reported, with only 47 percent of the nest tree tops recorded as alive/healthy. In Alaska $(n=14), 57$ percent of the nest trees were reported as declining, and one nest tree was recorded as dead.

In the Pacific Northwest, mean nest branch height was $45 \mathrm{~m}$ (table 3). Mean nest branch height was highest in California and Oregon, where the mean tree height was also the highest. Mean nest branch height was lowest in Alaska $(13 \mathrm{~m})$, with one nest located only $10 \mathrm{~m}$ above the ground.

The mean diameter of nest branches measured at the tree trunk and at the nest varied little between each state or Province for the Pacific Northwest (table 3). Mean nest branch diameters at the nest for each state or province ranged from $27-34 \mathrm{~cm}$ with a mean diameter of $32 \mathrm{~cm}$ for the Pacific Northwest. The distribution of limb diameters at the nest in the Pacific Northwest were normally distributed, with a maximum number ( 22 percent) of nests located on limbs 35 $40 \mathrm{~cm}$ in diameter (fig. 5). In Alaska, the smallest branch diameters at the nest were 12,14 , and $16 \mathrm{~cm}$, with a mean diameter of only $19 \mathrm{~cm}$. The length of the nest branches in the Pacific Northwest ranged from $1 \mathrm{~m}$ to $14 \mathrm{~m}$, with a mean length of $5.3 \mathrm{~m}(n=42)$. 


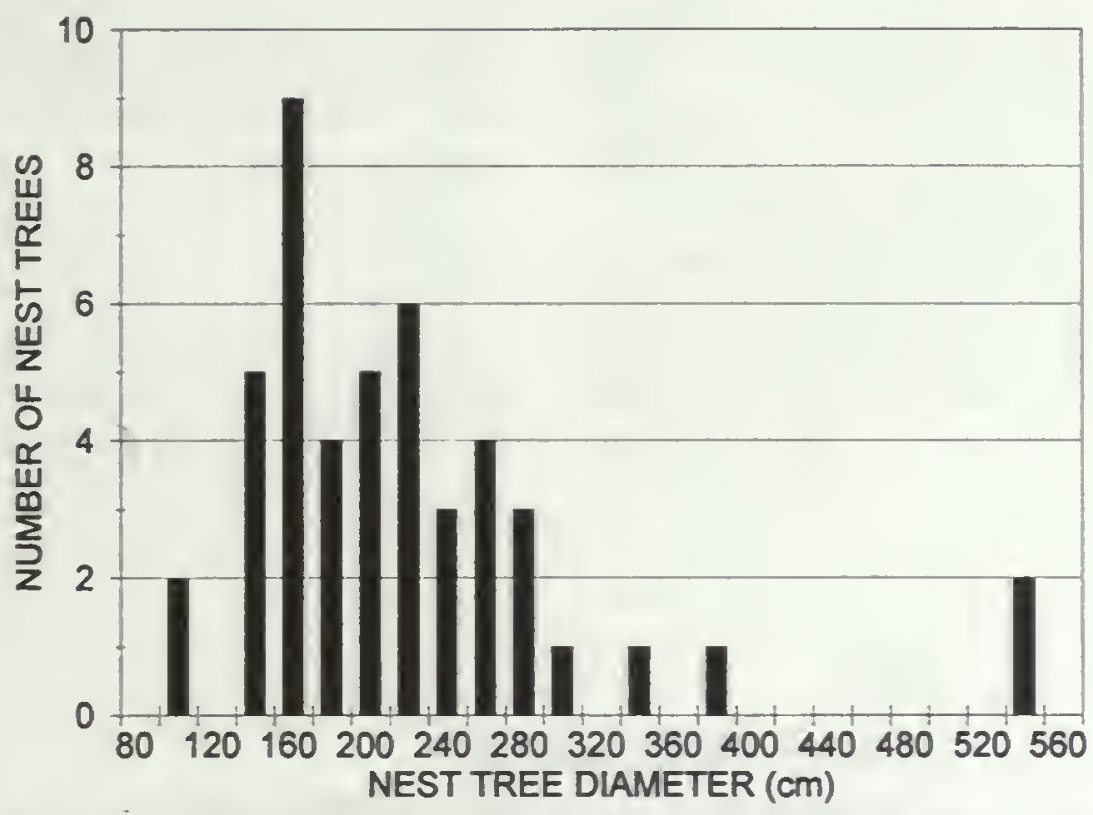

Figure 4-The diameter at breast height for 46 nest trees of the Marbled Murrelet found in Califor: Oregon, Washington, and British Columbia. The number of nest trees was listed i $120-\mathrm{cm}$ increments beginning with trees $70-80 \mathrm{~cm}$ in diameter.

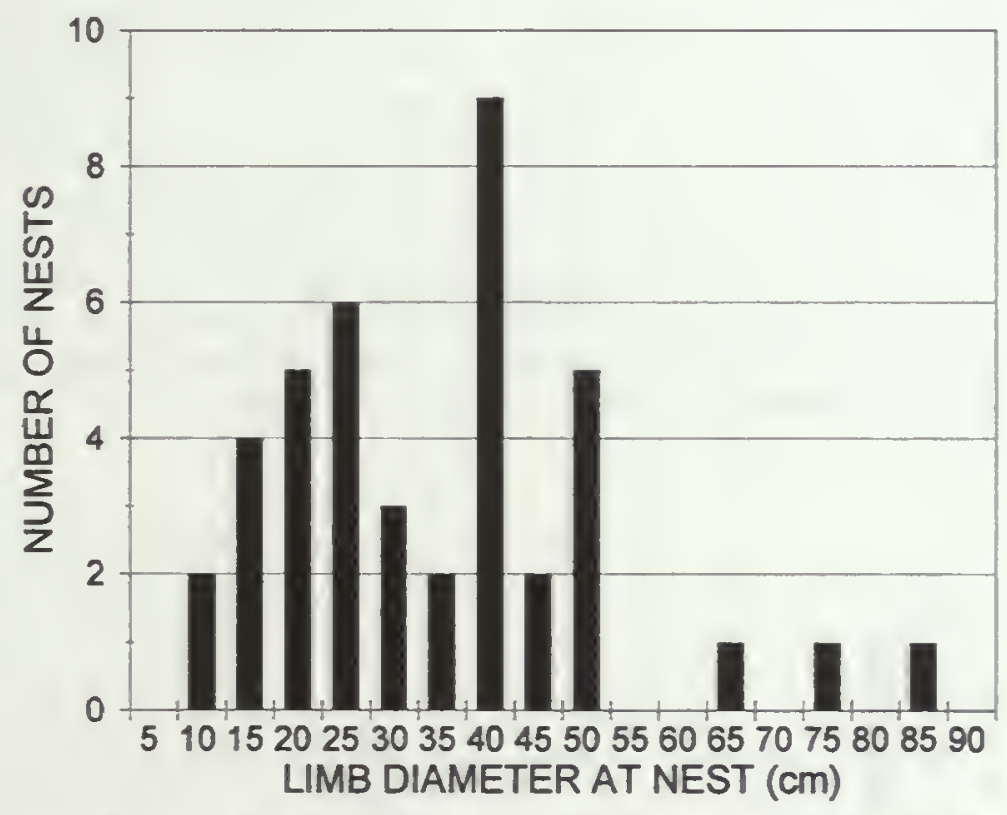

Figure 5- The diameter of the tree limbs under or next to 41 nests of the Marbled Murrelet found in California, Oregon, Washington, and British Columbia. The number of nests was listed in $5-\mathrm{cm}$ increments beginning with limbs $0-5 \mathrm{~cm}$ in diameter.

The condition of the nest branches for nests in the Pacific Northwest varied from healthy limbs (70 percent) to those reported as declining ( 27 percent) or dead ( 3 percent) $(n=37)$. Nest limbs with broken ends were reported in 16 percent of the records $(n=37)$. In Alaska, 50 percent of the nest branches were recorded as declining, 7 percent were reported with broken ends, with I nest located on a dead branch $(n=14)$.
The position of the nest on the tree bole was calculated by dividing the nest height by the total tree height. Nests in the Pacific Northwest were located an average of 68 percent up the bole of the nest tree (table 3). Fifty-nine percent of the nests were located in the top one-third of the tree bole, and 87 percent of the nests were located in the top one-half of the tree. No nests were located lower than 40 percent of the total 
tree bole height. Nests in Alaska were also located high up the tree bole with a mean of 59 percent. Positions of the nest on the tree bole for all nests throughout the range of the Marbled Murrelet showed that the top 10 percent of the tree was not utilized to any great degree, with a maximum number of nests located 70-80 percent up the tree bole (fig. 6).

The majority of nest limbs in the Pacific Northwest $(n=$ 44) were oriented toward the south or the north. Forty-four percent of the limbs faced a southerly direction ranging between 136 and 225 degrees (table 3). Another group of nests ( 26 percent) were oriented in a northerly direction ranging between 316 and 45 degrees. Nest limbs oriented toward the east or west consisted of 14 percent and 16 percent of the sample respectively.

\section{Nest Characteristics}

Nest cups were located a mean distance of $89 \mathrm{~cm}$ from the tree bole for nests in the Pacific Northwest (table 3). Here, a total of 71 percent of the nests were located within $1 \mathrm{~m}$ of the tree bole. This relationship was also true for nests located throughout the North American range (fig. 7), as 51 percent of the nests were located within $40 \mathrm{~cm}$ of the tree trunk.

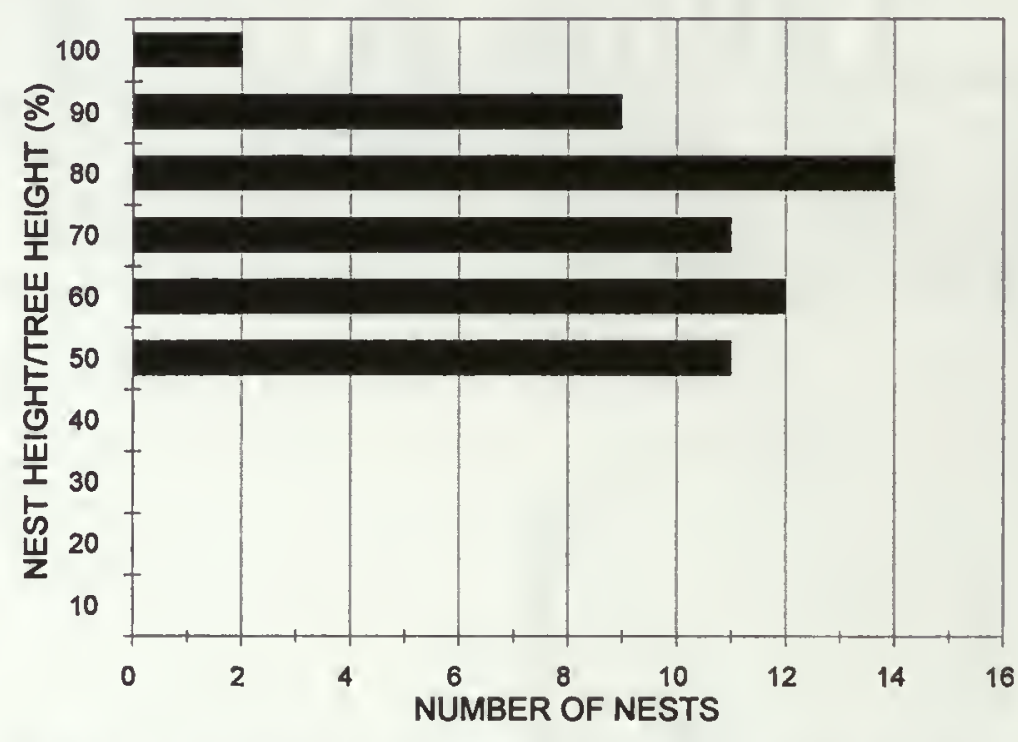

Figure 6-The relative vertical positions of Marbled Murrelet nests in relation to the heights of the tree bole for 59 tree nests found in North America.

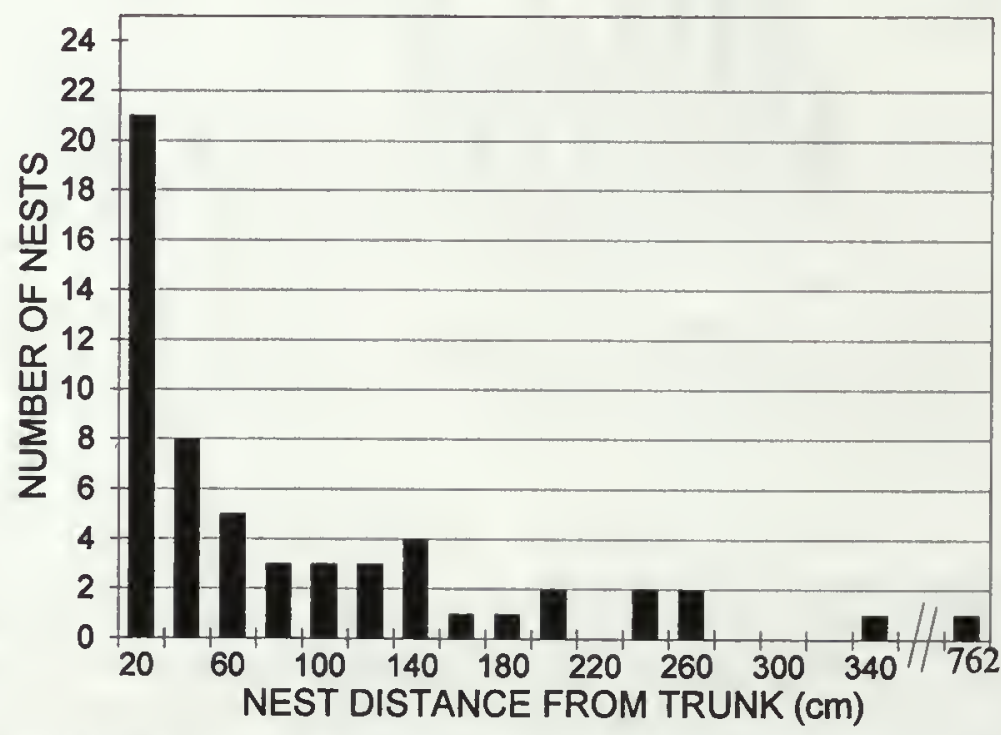

Figure 7-Nest distances from the tree trunk for 57 Marbled Murrelet nests found in North America. The number of nests was listed in $20-\mathrm{cm}$ increments beginning with nests found $0-20 \mathrm{~cm}$ from the tree trunk 
Nest platforms in the Pacific Northwest had a mean length of $32 \mathrm{~cm}$ and a mean width of $22 \mathrm{~cm}$. The mean total platform area was 842 square $\mathrm{cm}$ (table 3 ). In the Pacific Northwest, moss (Isothecium) formed the major proportion of the substrate for 67 percent of the nests. Litter, such as bark pieces, conifer needles, small twigs, and duff, was substrate in 33 percent of the nests. For nests found throughout North America, moss formed 49 percent of the substrate, moss mixed with lichen or litter formed 30 percent of the nests, and litter 21 percent $(n=37)$. All nests found in Alaska had moss as a component of the nest substrate.

Mean moss depth at, or directly adjacent to, the nest cup was $4.5 \mathrm{~cm}$ (table 3). Mean litter depth was $5 \mathrm{~cm}$ for nests in the Pacific Northwest. Mean moss depths in Alaska were 3.9 $\mathrm{cm}$. The majority ( 86 percent) of nests in North America ( $n$ $=52$ ) had substrates that were $>2 \mathrm{~cm}$ in depth with a large number of nests ( $n=16$ ) having substrate depths between 3.1 and $4.0 \mathrm{~cm}$ (fig. 8).

Nest platforms in the Pacific Northwest $(n=44)$ were created by large primary branches ial 32 percent of the cases. In addition, 23 percent of the rests were located on tree limbs where they became larger in diameter when a main limb forked into two secondary limbs, or a secondary limb branched off a main limb. In many instances, branches were also larger in diameter where they were attached to the tree bole. Locations where a limb formed a wider area where it grew from the trunk of a tree formed 18 percent of the nest platforms. Cases of dwarf mistletoe infected limbs (witches' broom) (9 percent), large secondary limbs ( 7 percent), natural depressions on a large limb (7 percent), limb damage ( 2 percent), and an old stick nest ( 2 percent) were also recorded as forming platforms. Multiple overlapping branches at the point where they exited the trunk of a tree were sometimes used as a nest platform. Many of the tree limbs creating nest platforms had grooves or deformations forming natural depressions on the surfaces of the limb.

Cover directly above the nest was high in almost all cases in the Pacific Northwest, with a mean of 85 percent. Eighty-seven percent of all nests had $>74$ percent overhead cover. Cover above the nest platforms in Alaska was similar to that in the Pacific Northwest (table 3).

\section{Discussion}

Marbled Murrelets have a limit on their inland breeding distribution because of the energetic requirements of flying inland to incubate eggs and feed young. They forage at sea, carrying single prey items to the nest and feed their young several times per day during the late stages of nesting. To some extent, the inland distance information presented here is biased towards lower values, because nest search and survey efforts have been more intensive closer to the coast in all regions, where higher murrelet detection rates make locating nests an easier task. Even with the potential problems of energetic expenditure, murrelets displayed a great tolerance for using nesting stands located long distances from the ocean. Evidence of breeding was common in California, Oregon, and Washington, in areas located 30-60 km inland. Unlike many other alcids, the Marbled Murrelet forages in near-coastal shallow water environments. The use of tree limbs as a nesting substrate may have developed because older-aged forests were the only habitats that were abundant and commonly available close to the foraging grounds of this seabird. Areas of brush-free open ground or rocky talus

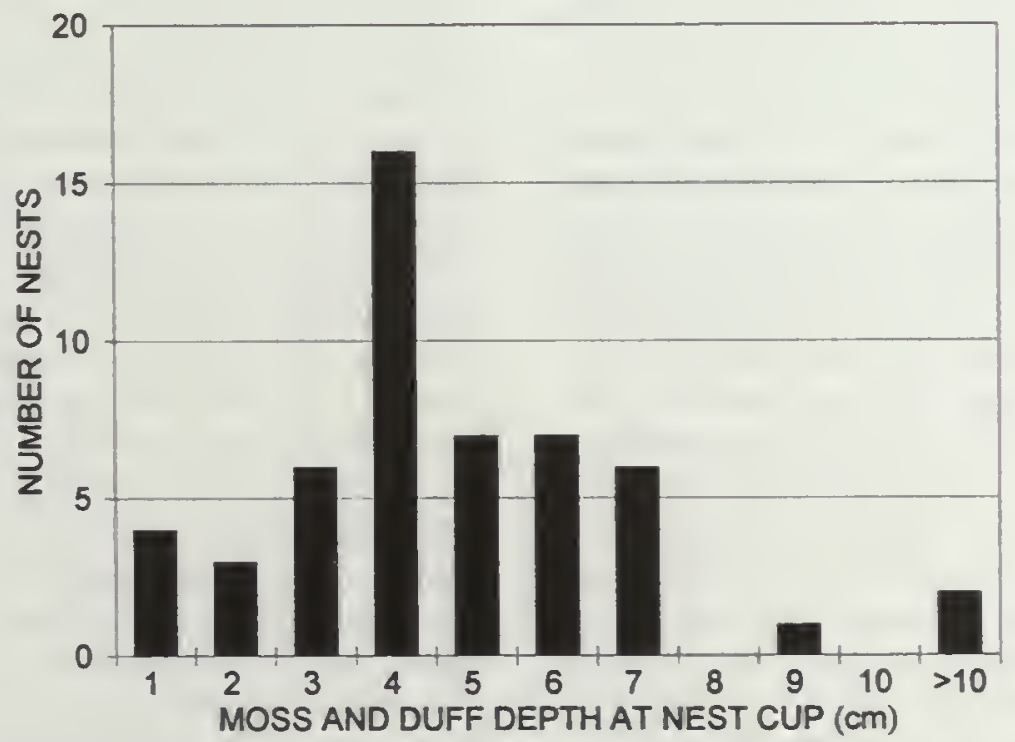

Figure 8 - The depth of moss and litter under or directly adjacent to the nest cup for 52 nests of the Marbled Murrelet in North America. 
slopes that are commonly used by other alcids as nesting habitat, are not commonly available along the forested coasts of the Pacific Northwest. Old-growth and mature forests also provided large nesting platforms on which to raise young. Nesting greater distances from the coast may have developed over time to avoid higher nest predation by corvids and gulls whose population numbers may be much higher in food-rich coastal areas. In addition, much of the near-coastal nesting habitat has been eliminated in the Pacific Northwest which may cause birds to nest further inland. Nest search efforts and surveys for the presence of murrelets should be conducted in areas farther inland in order to refine the abundance and distribution of this seabird away from the coast. We currently have no information to determine what proportion of the population nests in these inland areas, or any data to compare the reproductive success of far versus near-coastal nesting pairs.

In Washington, inland detection rates of Marbled Murrelets did not show declines until inland distances were $>63 \mathrm{~km}$ from salt water (Hamer, this volume). In Oregon, most detections occurred within $40 \mathrm{~km}$ of the ocean (Nelson, pers. obs.). In British Columbia, murrelet detection rates in Carmanah Creek on Vancouver Island decreased with increasing distance from the ocean (Manley and others 1992). Savard and Lemon (1992) found a significant negative correlation between detection frequency and distance to saltwater on Vancouver Island in only 1 of 3 months tested during the breeding season. Inland distances for all nests in Alaska were low because rock and icefields dominate the landscape a few kilometers from the coast in most regions.

We found that all nest trees throughout the geographic range were located in stands defined by the observers as oldgrowth and mature stands or stands with old-growth characteristics. The youngest age reported for a nesting stand was 180 years. Marbled Murrelet occupancy of stands, and the overall abundance of the species has been related to the proportion of old-growth forest available from studies conducted in California, Washington, and Alaska (Hamer, this volume; Kuletz, in press; Miller and Ralph, this volume; Raphael and others, this volume). Carter and Erickson (1988) reported that all records of grounded downy young and fledglings (young that have fallen from a nest or unsuccessfully fledged) $(n=17)$ that they compiled were associated with stands of old-growth forests in California. All records of nests, eggs, eggshell fragments, and downy chicks in Washington have been associated with old-growth forests ( $n$ = 17) (Hamer, this volume; Leschner and Cummins 1992a).

Marbled Murrelets consistently nested in low elevation ( $<945 \mathrm{~m}$ ) old-growth and mature forests. Tree species that are most abundant at lower elevations $(<945 \mathrm{~m})$ such as Douglas-fir, western hemlock, Sitka spruce, redwood, and cedar, may have a higher abundance of potential nest platforms than the higher elevation conifers such as silver fir and mountain hemlock.
Marbled Murrelets were found nesting in stands of very small size in some instances, although the reproductive success of these nests compared to stands of larger sizes was not known (but see Nelson and Hamer, this volume b). A wide range of canopy closures were reported for nest stands and around nest sites. A study conducted in Washington and Oregon compared random plots within a stand to plots surrounding the nest tree (Nelson and others, in press). They found that canopy closures were significantly lower around nest trees in Oregon compared to random plots adjacent to the nest tree, but the relationship was not significant in Washington. It is unknown how stand size and canopy closure affect nest success, but stands with lower canopy closures might have less visual screening to conceal adult visits to the nest tree (see Nelson and Hamer, this volume b). Therefore, it is possible that low canopy closures within a stand will make locating nests easier for visual predators such as corvids. In addition, smaller stands will have fewer nesting and hiding opportunities for Marbled Murrelets. They may be choosing lower canopy closures immediately around the nest to improve flight access, but select nest platforms with dense overhead cover for protection from predation, as indicated by the extremely high cover values found directly over the nest.

The majority of nests in the Pacific Northwest were located within $100 \mathrm{~m}$ of water, but a few nest sites were found at much longer distances (fig. 3). Small streams and creeks commonly bisect stands in the Pacific Northwest, creating larger openings and long travel corridors. Murrelets are often observed using these features to travel through a stand. This may be one reason nest sites were often in close proximity to streams. Many nests were also located near openings such as roads or clear-cuts, but there may be an observer bias to finding nests located in areas with better access and viewing conditions.

A variety of processes contributed to producing potential nest platforms within the forest including deformations and damage sustained by trees. This is probably why a measure of potential nest platforms, and not tree size, was the best predictor of stand occupancy by murrelets in Washington (Hamer, this volume), as larger diameter trees alone were often not responsible for the majority of available platforms within a stand. Mistletoe blooms, unusual limb deformations, decadence, and tree damage commonly observed in nest stands, all appear to create a large number of nest platforms. Therefore, the structure of a stand and the processes occurring within a stand may be more important than tree size alone in producing nesting platforms and suitable habitat for the Marbled Murrelet (see Grenier and Nelson, this volume).

It would still be desirable to know when trees, in general, begin producing potential nest platforms. In Washington, Hamer (this volume) measured potential nest platform abundance using a sample of 2,035 conifers, and found platforms were generally available when tree diameters exceeded $76 \mathrm{~cm}$. The mean number of platforms/tree was found to increase rapidly with an increase in tree diameter 
from $50-200 \mathrm{~cm}$. No increase in the mean number of platforms was evident for larger trees that ranged from $220-300 \mathrm{~cm}$ in diameter. These results explain why all the nest trees found in the Pacific Northwest were $\geq 88 \mathrm{~cm}$ in diameter, although mistletoe brooms on smaller trees may also provide habitat. In southcentral Alaska, the minimum d.b.h. associated with a tree having at least one platform ranged from $29-37 \mathrm{~cm}$ (Naslund and others, in press).

In a study completed in 1993, nest tree and stand characteristics in Washington and Oregon were compared between 15 murrelet nests and randomly located dominant trees and plots within the same nest stand (Nelson and others in press). Nest sites were similar to the forest stands in which they were located, except that a significantly higher number of potential nest platforms were recorded at nest trees, than at random trees. They also found that Marbled Murrelets selected trees at nest sites that had $\geq 4$ potential nest platforms, and trees with $\leq 3$ platforms were avoided. In Alaska (Naslund and others, in press), one study compared nest tree characteristics $(n=14)$ to a sample of random trees surrounding each nest tree, and found nest trees ' vere larger in diameter, had more potential nest platforms, and had greater epiphyte cover. This study also concluded that Sitka spruce appeared to be the most suitable tree for nesting when compared to western hemlock and mountain hemlock, because of its high number of platforms and greater epiphyte cover. They also found that nest and landing trees tended to be larger in diameter than surrounding trees, and nest trees were more likely to contain at least one potential nest platform with moderate to heavy epiphyte cover when compared to nearby trees. Stands with high potential nest platform densities may reduce competition for nest branches and provide a high diversity of nest site choices.

Nests located high in the canopy may provide better access by adults to the nest site in dense, old-growth stands. Nesting as high in the canopy as possible may also help in avoiding predation. Although positioning the nest as high off the ground as possible would likely reduce the incidence of mammalian predators, we have also observed that the Steller's Jays (Cyanocitta stelleri), predators of nestlings and eggs, often forage in the lower portions of the canopy. Better horizontal and vertical cover is available in the top portions of the tree crown which may help reduce predation. Data needs to be collected on the positioning of nests within the live crown of the tree, not just the tree bole, to determine if murrelets prefer certain areas of the tree crown foliage for nesting.

Murrelets may choose to place nests near the trunk of the tree for a variety of reasons. First, overhead and horizontal cover is higher around the nest cup due to the position of the tree crown directly overhead. Second, the tree trunk itself provides a large amount of cover and visual screening and branches are typically larger in diameter near the tree bole. Also, more duff and litter, which often form the nest substrate, is trapped near the tree bole, and the percent cover of moss on the limbs of trees is higher, often forms a more complete coverage, and forms a deeper layer near the tree bole. Some conifer species typically have little or no moss available on their limbs, so that platforms created by accumulations of duff and debris are the only nest choices available for murrelets in these forest types.

Murrelets nest on large limbs. The smallest limb used at the nest cup throughout the range of the murrelet was $10 \mathrm{~cm}$ in diameter, which is likely the smallest diameter branch that could support a successful nest. Nests located on smaller limbs would probably have a higher likelihood of losing chicks or eggs from accidental falls, an occurrence that is well documented (Hamer and Nelson, this volume a). Nests located on limbs $<16 \mathrm{~cm}$ diameter all had moss as a nest substrate, except in one instances where a $13 \mathrm{~cm}$ nest branch had litter and lichen as a substrate. Small limb diameters without a moss covering may be avoided by nesting birds because the hazards of raising eggs and young are increased without the moss to help stabilize and insulate the egg on the limb, increase the diameter of the nest limb/platform, and provide a substrate on which to create a nest cup (depression). In addition, moss and litter may help insulate eggs and chicks during cold weather and may help drain water from eggs and chicks helping thermoregulation (Naslund and others, in press). An abundance of mosses creates a multitude of nest platform choices by providing substrate on many locations throughout a single limb. In addition, the presence of dwarf mistletoe in stands can increase the number of nesting opportunities for murrelets and may be important in providing nest platforms in areas with low moss abundance and dryer conditions.

The nest site selection of the Marbled Murrelet may have evolved primarily to reduce predation. Selection of nest sites away from the coast, in dense old-growth and mature forests with multi-layered canopies, high in the forest canopy, on limbs with high overhead and horizontal cover, and near the tree bole where the tree bole itself provides a large degree of cover, may help reduce nest predation. Results from studies of murrelet habitat use to date have been derived from comparisons of stands occupied by murrelets to unoccupied stands, comparisons of stands receiving high use versus low use, or comparisons of nest trees and nest plots to random trees and plots. Although these can provide extremely useful descriptions and definitions of suitable habitat, they do not provide information on the habitat characteristics associated with successful nests. Information on the landscape and within-stand habitat characteristics that influence reproductive success is needed to fully understand murrelet nesting ecology and to model optimum habitat suitability for this species. Such studies may find that stand size analyzed in conjunction with the number of nesting and hiding opportunities within the stand (habitat quality), may greatly influence reproductive success because of predation pressures at the nest site. Habitat factors that could influence reproductive success may include stand fragmentation, stand canopy closure, and the amount of overhead and horizontal cover surrounding the nest. 


\section{Acknowledgments}

We would like to acknowledge the contributions of unpublished information made available to us by researchers and wildlife biologists throughout the range of the Marbled Murrelet. Their generous contributions of nest information made this summary possible. For the California data, we are extremely grateful to Steve Singer for the information he has collected over the last two decades. Additional information was kindly provided by Sal Chinnici of the Pacific Lumber Company in association with Dave Fortna and Steve Kerns. Lee Folliard of Arcata Redwood Company provided information from an additional 2 nests. We would like to thank Karen Holtrop for her efforts and successes in locating nests in Washington and her contributions of nest data. Stephanie Hughes, Kevin Jordan, Irene Manley, John Kelson, Paul Jones, and Alan Burger provided valuable nest information from British Columbia. We are also grateful to Nancy Naslund and Kathy Kuletz for contributing the majority of nest site information from Alaska. We thank Alan Burger, Martin Raphael, Nancy Naslund, Evelyn Bull, Kimberly Titus, and C. John Ralph for reviewing earlier drafts of this paper. 


\section{Chapter 7 \\ Breeding and Natal Dispersal, Nest Habitat Loss and Implications for Marbled Murrelet Populations}

\section{George J. Divoky' Michael Horton ${ }^{2}$}

Abstract: Evidence of breeding and natal dispersal in alcids is typically provided by the resightings of banded birds, the establishment of new colonies, and/or evidence of immigration to established colonies. The difficulties in banding, observing, and censusing Marbled Murrelets at nesting areas preclude using any of these methods for this species. Based on the limited number of nests observed in consecutive breeding seasons, breeding site fidelity (birds breeding in the same nest as the previous year) may be lower than most other alcids. This is likely due to low breeding success associated with high levels of nest predation. By contrast, annual use of nest stands suggests fidelity to a nesting area may be high. Natal dispersal, the breeding at locations away from their fledging site, is likely similar to that of other alcids. Loss or degradation of previously occupied nesting habitat will result in the displaced breeders prospecting for new nest sites. In areas with no unoccupied available habitat, this could result is birds being prevented from breeding, attempting breeding in suboptimal habitat, or increasing the distance dispersed from the previous breeding sites. Each of these is likely to result in a decrease in reproductive output. Dispersal patterns need 10 be considered when assessing the importance of stands and the status of populations. The small population size and fragmented nature of the remaining breeding babitat could increase the time required for prospecting birds to locate recenily matured old-growth forest, resulting in underestimating the importance of a stand. Additionally, birds could be dispersing from regions of high production of young to areas with low production but where recruitment opportunities are higher, partially hiding the low reproduction of the latter population.

The ability of Marbled Murrelets to disperse from natal sites, and their fidelity to breeding sites or stands, has important implications for the potential of the species to respond to habitat loss and colonize or reestablish breeding areas when habitat has been altered. With knowledge of these factors, we could more accurately assess the effects of habitat destruction on the viability of populations throughout the species' range. In the discussion below, we examine what is known about dispersal in other alcid species and the possible implications for the Marbled Murrelet.

Dispersal of birds can occur both by established breeders changing breeding sites (breeding dispersal) and by birds nesting away from their natal nesting area (natal dispersal) (Greenwood and Harvey 1982). The degree of nest-site fidelity by established breeders can be expected to be related to previous breeding success and the frequency of change in availability of suitable nest sites and prey resources. Nest

\footnotetext{
${ }^{1}$ Wildlife Biologist, Institute of Arctic Biology, University of Alaska, Fairbanks, AK 99705

${ }^{2}$ Wildlife Biologist, U.S. Fish and Wildlife Service, U.S. Department of Interior, 2800 Cottage Way, Room E1803, Sacramento, CA 95825
}

site availability can be decreased both through the destruction of nest sites and through chronic predation. An increased rate of natal dispersal should be related to the potential to be more successful in finding mates or nest sites away from the natal nest site or colony.

\section{Breeding Dispersal}

Breeding site fidelity in a long-lived species, which the Marbled Murrelet is presumed to be (Beissinger, this volume), can provide benefits in increased breeding success and lifetime fitness. Site fidelity can reduce potential reproductive effort by (1) increasing the chances of breeding with the previous year's mate, (2) eliminating or reducing the need to locate a suitable nest site, and (3) allowing the development of familiarity with the marine and terrestrial environment.

The rate of breeding dispersal is low for most alcid species that have been studied. Rates of nest-site fidelity of previously breeding alcids are: 91.5 percent Razorbills (Alca torda) (Lloyd 1976); 96 percent Common Murres (Uria aalge) (Birkhead 1977); 93.2 percent Atlantic Puffins (Fratercula arctica) (Ashcroft 1979), 57-95 percent Black Guillemots (Cepphus grylle) (Divoky, unpubl. data; Petersen 1981); 86 percent Pigeon Guillemots (C. columba) (Drent 1965); 78 percent Ancient Murrelet (Synthliboramphus antiquus) (Gaston 1992).

The degree of breeding dispersal displayed by an alcid should be related to the rate that nesting habitat is created and destroyed, the level of mortality of breeding birds, and the availability of nest sites. Species with a high probability of returning to a nest site destroyed over the winter would have fewer reasons to have evolved site tenacity. Harris and Birkhead (1985) suggested that the Thick-billed Murre (Uria lomvia) might show less site tenacity than other Atlantic alcids because rockfalls destroy or create nest sites in their colonies more frequently than for other species. Burrow nesting alcids could be expected to show higher rates of breeding dispersal than talus nesters due to the higher frequency of collapse of burrows.

Annual overwinter mortality could be expected to influence breeding site fidelity. High overwinter mortality would decrease the chances of a surviving bird being able to breed with the previous year's mate and, by creating more vacancies at established nest sites, increase the opportunities for dispersal for species that are nest site limited.

For those alcid species in which breeding site fidelity has been examined, and for birds in general (Greenwood and Harvey 1982), changes in nest site are more frequent after a breeding failure. For Black Guillemots, nest-site fidelity was 92 percent for successful pairs and 48 percent for failed 
pairs (Petersen 1981). For Ancient Murrelets, reoccupancy rates of burrows that supported successful breeding the preceding year was 80 percent, and only about 50 percent for unsuccessful burrows (Gaston 1992). Nest changes caused by simple breeding failure typically result in small scale movements (usually tens of meters) to nearby sites (Divoky, unpubl. data; Petersen 1981).

Chronic disturbance at the nest site can cause established breeders to move to a new breeding location thousands of meters away. A Pigeon Guillemot that experienced persistent disturbance at its nest site was found breeding on an island $7.7 \mathrm{~km}$ away 3 years later (Drent 1965). At a Black Guillemot colony where any movement of established breeders is typically to an adjacent nest site $(<10 \mathrm{~m})$, one bird moved approximately $1 \mathrm{~km}$ and another over $5 \mathrm{~km}$, after Horned Puffins (Fratercula corniculata) using the same nest site had repeatedly disrupted nesting (Divoky 1982 and unpubl. data).

Essentially all information on breeding dispersal in alcids has been obtained through the banding and resighting of individuals. The difficulty of capturing and observing Marbled Murrelets at the nest site has prevented the collection of similar information for this species. The old-growth nesting habitat of the Marbled Murrelet is relatively stable. Natural destruction of old growth forests through fire or wind storms is rare enough, and the degradation of nest trees is slow enough, that high site fidelity could have evolved.

Observations of murrelets engaging in "occupied behavior," strongly suggesting nesting (Ralph and others 1993), indicate that Marbled Murrelets, as a species, exhibit high fidelity to a nesting area. Marbled Murrelets have been recorded in the same forest stands for a minimum of 20 years in northern California (Strachan, pers. comm.; Miller, pers. comm.), 18 years in central California (S.W. Singer, pers. comm.), 7 years in Oregon (Nelson, pers. comm.), and 3 years in Washington (Hamer, pers. comm.). These results are in part a function of the duration of survey effort. While these observations indicate that the species exhibits high fidelity to forest stands, no direct information is available on stand or nest-site fidelity of individual birds.

For species having high annual survival and site fidelity, the occupation of the same nest site in consecutive years is strongly suggestive of individual nest-site fidelity. Reoccupation of the same nest site has occurred only once in the 13 instances where Marbled Murrelet nests have been examined in the breeding season following a year of known occupancy ( $\mathrm{P}$. Jones, pers. comm.) and nesting occurred in the same tree four times (P. Jones, pers. comm.; Naslund, pers. comm.; Nelson, pers. comm.; Singer, in press). Additional evidence of fidelity to a nest tree is provided by Nelson's (pers. comm.) finding of three nest cups on three platforms in a single tree, although we do not know if it was the same individuals. While the sample size is small, the observed fidelity to the same nest depression in consecutive years appears to be lower than for other alcids. This could be related to the high rate of predation recorded for murrelet nests (Nelson and Hamer, this volume b). It also indicates that while breeding habitat for this species is reduced (Perry, this volume), and may be limiting, the number of nest platforms apparently is not. If the high predation rate is a recent phenomenon, nest-site fidelity may have been higher in the past. As previously mentioned, breeding dispersal increases with increased rates of nesting failure (Greenwood and Harvey 1982). The high rates of observed nest failure (Nelson and Hamer, this volume b) may explain murrelets not reoccupying a nest site in subsequent years.

\section{Natal Dispersal}

The primary benefit that a bird derives from breeding at its natal colony may be that the natal area is a known location where conspecifics of a similar genetic background successfully bred in the past (Ashmole 1962). However if a breeding location is near those of related individuals, there is the possibility of kin selection occurring and a moderate level of inbreeding (Shields 1983).

Philopatry (chicks returning to their natal colony or nesting location to breed) is more difficult to study than the fidelity of breeders to a nest site. It had been assumed that the majority of alcids surviving to breeding are recruited into their natal nesting area (Hudson 1985). More recent information, however, shows that prospecting by prebreeders at non-natal colonies is a regular occurrence in Common Murres (Halley and Harris 1993) and Atlantic Puffins (Harris 1983, Kress and Nettleship 1988). Until recently, the instances of banded birds initiating breeding at a non-natal colony were limited (Asbirk 1979, Lloyd and Perrins 1977). However, recent information indicates that, at least in the Atlantic Puffin, half the chicks that survive to breeding emigrate to a new colony (Harris and Wanless 1991).

Other evidence of natal dispersal is provided by the establishment of new colonies and growth rate of existing colonies that could only be explained by immigration (Divoky, unpubl. data; Gaston 1992; Petersen 1981). The frequency with which new alcid colonies have formed on the west coast of North America in the short period that systematic censusing has been conducted (table 1) proves that natal dispersal is common in the alcidae.

The distance that birds will breed from their natal site can be great. Banding returns show that the distance dispersed can be as great as $420 \mathrm{~km}$ (by sea) for the Common Murre (Halley and Harris 1993) and over $450 \mathrm{~km}$ for the Atlantic Puffin (Harris and Wanless 1991). The rate of increase of some breeding populations, and the establishment of new colonies, indicates that Ancient Murrelets are being recruited into breeding populations at least $30 \mathrm{~km}$ from their natal site (Gaston 1992), Black Guillemots from over $500 \mathrm{~km}$, and Horned Puffins from over $200 \mathrm{~km}$ (Divoky, unpubl. data).

Because of the difficulties of marking and subsequently resighting Marbled Murrelets, any direct evidence of natal dispersal would have to come from observations of range expansion, occupation of previously unoccupied breeding 
Table I-Alcid species that have recently formed new colonies in western North America

\begin{tabular}{|c|c|c|c|c|c|}
\hline Species & Alaska & British Columbia & Washington & Oregon & Califomia \\
\hline Common Murre & & $\begin{array}{l}\text { Campbell and } \\
\text { others } 1975\end{array}$ & Speich and Wahl 1999 & $\begin{array}{l}\text { USFW'! unpubl. dala } \\
\text { Neupor. OR }\end{array}$ & $\begin{array}{l}\text { Sou is and ochers } 1980 \\
\text { Carter and others } 1992\end{array}$ \\
\hline Thick-billed Murre & $\begin{array}{l}\text { Sowls and others } \\
1982\end{array}$ & $\begin{array}{l}\text { Vallee and Cannings } \\
1983\end{array}$ & & & \\
\hline Pigeon Gu llemor & $\begin{array}{l}\text { Sou is and otbers } \\
1978 \\
\text { LSFW' unpubl dala, } \\
\text { Anchorage, AK }\end{array}$ & Campbell 1977 & Speich and $1 \mathrm{H}$ ahl 1959 & $\begin{array}{l}\text { USFW S, unpubl dala } \\
\text { Neapor. OR }\end{array}$ & $\begin{array}{l}\text { Sow Ls and others } 1980 \\
\text { Carter and others } 1992\end{array}$ \\
\hline Black Guillemot & $\begin{array}{l}\text { Divoly and others } \\
1974\end{array}$ & & & & \\
\hline Cassug's Aukler & & & & & Canler and others 1992 \\
\hline Rhinoceros Aullet & & $\begin{array}{l}\text { Campbell and } \\
\text { others } 1975\end{array}$ & Speich and Wahl 1989 & $\begin{array}{l}\text { USFWS, unpubl. data } \\
\text { Newport, OR } \\
\text { Scott and others } 1974\end{array}$ & $\begin{array}{l}\text { Sowls and others } 1980 \\
\text { Carter and others } 1992\end{array}$ \\
\hline Tuñed Puffin & Byrd and others 198 d & & & $\begin{array}{l}\text { USFI S, unpubi data } \\
\text { lewpor. OR }\end{array}$ & Sou is and eiber 1990 \\
\hline Homed Puffin & $\begin{array}{l}\text { Divoky } 1982 \\
\text { Divoky, unpubl. data }\end{array}$ & & & & \\
\hline
\end{tabular}

${ }^{1}$ USFWS - U.S. Fish and Wildlife Service

areas, or growth of local populations that could only be accounted for by immigration. The nesting habits of the species makes the detection of any of these difficult, as does the short period that the species has been the focus of research. In addition, the high rate of habitat destruction recently experienced (Perry, this volume) adds to these difficulties.

Natal dispersal can be expected to be high in Marbled Murrelets compared with other alcids for several reasons. The winter distribution is extensive, with the species wintering in the nearshore waters of the breeding range, as well as in areas where breeding does not occur. The distance that individual birds disperse from either their breeding or natal area can be great, as murrelets are regularly found in southern California some $300 \mathrm{~km}$ south of the closest known breeding area (Briggs and others 1987). Because murrelets attend inland breeding areas during the winter (Naslund 1993b), information on breeding areas is provided to prospecting nonbreeders at all times of the year. The prebreeding period for this species is probably between 2 and 5 years (Beissinger, this volume), allowing sufficient time to prospect for a suitable nesting area. Additionally, the area where Marbled Murrelets might discover suitable nesting habitat is a $60-\mathrm{km}$ band adjacent to the coast. This extensive area of potential breeding habitat may have selected for more extensive prospecting behavior than in other alcids where potential breeding sites are largely linearly distributed in a narrow shoreline band.

\section{Methods of Dispersal}

The manner in which alcids coalesce into breeding pairs can have implications for the level of breeding and natal dispersal. The vast majority of breeding dispersal in alcids consists of birds moving to sites either immediately adjacent, or close to, the previously occupied nest site (Divoky, unpubl. data). This occurs even when an established breeder initiates a new pair bond with another established breeder (Divoky, unpubl. data), indicating that pairing for most, if not all, alcids occurs near the breeding site. If pairing occurs on the water when birds are staging near the breeding location, one would expect to see almost random movement of the established breeders that lose or change mates. Additionally, if established breeders paired on the water, the pair would have affinities to two sites.

Because ownership of a quality nest site or territory is an important prerequisite for breeding, pairing at the nest site allows a bird to find out whether a prospective mate owns a site and to determine the quality of that site. Pairing 
with a bird that owns a nest site increases the chances that a bird will pair with an experienced breeder.

Nonbreeding birds, with no previous experience, also probably form pairs near the nest site. Observations of Black Guillemots in northern Alaska (Divoky, unpubl. data) show that nonbreeders are present at the colony throughout the breeding season, and many display a high level of mate and site fidelity. Although nonbreeders form pairs with each other, when one member of an established nest site owning pair dies, the vacancy is typically filled by a nonbreeder of the appropriate sex. Nonbreeding pairs can be recruited as a unit should a new site be created or should two vacancies occur at an established site. However, the low annual mortality rates of breeding alcids indicates that most recruitment occurs through a single vacancy in an established pair. With recruitment occurring at or near the nest site, the established breeder and the individual being recruited, can pair with a familiar bird. Recruitment in murrelets could occur in the same manner. Those birds prospecting new nesting areas could pair on the water before prospecting potential nest sites.

\section{Implications of Habitat Loss and Fragmentation of Populations}

The final rule listing Marbled Murrelets as threatened (U.S. Fish and Wildlife Service 1992) regards loss of older forests and associated nest sites as the main cause of decline in murrelet populations. When nest sites are limiting, the loss of nesting habitat has both immediate and long term impacts on the reproductive potential of a murrelet population. While alcid populations have been shown to recover in a relatively short period from episodic anthropogenic mortality events, such as gill net and oil spill mortality (Piatt and others 1991; Carter and others 1992), loss of nesting habitat directly affects the long term reproductive potential of a population. This is especially true for tree-nesting Marbled Murrelet populations where the creation of nesting habitat is extremely time-consuming, perhaps 200 years.

Fragmentation of old-growth also has the potential of reducing murrelet breeding success by increasing the densities of predator populations. Corvids are "edge species" that have been found to increase in numbers with increased forest fragmentation (Andren and others 1985, Wilcove 1985, Small and Hunter 1988). Similar findings have been reported in central Oregon regarding Great Horned Owls (Johnson 1992). In addition, corvid predation on small bird nests has been found to increase with increased forest fragmentation, decreased distance of nests from a forest edge or both (Gates and Gysel 1978, Andren and others 1985, Small and Hunter 1988, Yahner and Scott 1988). Factors that increase fragmentation, such as a wildfire or timber harvest, could reduce murrelet breeding success both through the reduction of cover and the increase in predator densities. This reduced breeding success could be expected to increase the rate, and possibly the distance, of breeding dispersal. The distances moved would probably relate to the level of disturbance and the threat that the predators pose to adult birds. The reduction and fragmentation of habitat would also act to increase the distance prospecting prebreeders would have to travel to find a suitable nest site.

Habitat loss could be expected to result in the displacement of breeding birds, while fragmentation could lead to both displacement and decreased breeding success. In cases where stands used for nesting are destroyed, the birds previously breeding in the stand would have to locate a new nesting area. If all available nest sites in adjacent habitats are occupied, the displaced birds could attempt to breed in suboptimal sites with a decreased chance of successful reproduction, prospect more distant areas, or not breed at all. There are no conclusive indications of higher densities of murrelet nesting in stands remaining after timber harvests (Ralph and others, this volume). The ease and rapidity with which displaced murrelets seek out new breeding areas could be expected to be related to how frequently murrelets normally change sites. If the level of individual nest-site fidelity is as low as observations indicate, then murrelets may be able to readily move at least short distances to new nest sites. The fidelity birds show to a previously used breeding area or site that no longer can support breeding, should be related to the rate and magnitude of habitat destruction. There is evidence of murrelets visiting remnants of newly harvested stands before disappearing from the area (Folliard, pers. comm.), thus indicating that murrelets might not immediately abandon the unsuitable nest stand. This is consistent with observations in other alcid species. Pairs have shown fidelity to previously occupied, and recently destroyed, nest sites for two years in the Black Guillemot (Divoky, unpubl. data), and a minimum of two years in the Least Auklet (Aethia pusilla) (1. Jones, pers. comm.). This type of nest loss would be similar to the loss of a previously used murrelet nest platform branch and not the removal of a nesting stand.

\section{Management Implications of Dispersal}

High levels and extensive distances of natal dispersal could result in source areas with high productivity producing young that will be incorporated into sink regions with low productivity, or high adult mortality, or both. This could result in populations in sink areas showing little change in numbers. Without monitoring breeding success, the inability of the sink population to produce enough young to balance adult mortality would not be evident. The maintenance of such a population would be dependent on the continued production of a surplus of young by the source population. The true reproductive status of the sink population would be masked until immigration declines. Such immigration could explain the ability of the central California murrelet population to lose an estimated 150 to 300 birds in the early $1980 \mathrm{~s}$ (Carter and Erickson 1988) and not show any signs of decline (Carter and others 1992). 
The secretive nature of murrelet nesting has precluded the determination of breeding areas solely by the discovery of nests, eggs or chicks. Biologists and managers have had to identify breeding areas based on the birds engaged in activities included in "occupied behavior" as strongly indicative of nesting (Ralph and others 1994). Relying on instances of occupied behavior as an indication of the importance of a stand to Marbled Murrelets has a number of potential weaknesses.

First, recently matured forests that are able to support nesting could not be expected to be immediately discovered and occupied by prospecting murrelets. The ability of alcids to occupy areas where suitable breeding habitat is made available is evident from the rapid colonization of islands in the Aleutian Islands where fox have been eliminated (Bailey and Kaiser 1993). The occupation of newly available suitable habitat by Marbled Murrelets in Washington, Oregon, and California may be delayed by the small stand size, high fragmentation and disjunct distribution of the old growth forest. The small size and apparently low breeding success (Nelson and Hamer, this volume b) of the population can be expected to further slow occupation ( f newly available habitats. Because almost all prospecting of currently unoccupied suitable habitat would occur through natal dispersal, low productivity would reduce the potential of a population to disperse. This would result in a lack of detections in stands that have the potential of supporting murrelet breeding, but have not yet been discovered by murrelets. The importance of this apparently suitable but currently unoccupied habitat to the future of the species needs to be recognized.

In regions where a large nonbreeding population is prevented from breeding by lack of nest sites, prospecting birds might investigate areas and habitats that do not support breeding. This could result in "occupied" behavior being recorded in areas where nesting is not occurring. Prospecting alcids can be present in apparently suitable habitat (Divoky 1982, unpubl. data; Kress and Nettleship 1988; Carter and others 1992), although no breeding is occurring. If loss of old-growth habitat has both increased the level of dispersal and limited potential nest sites, substantial numbers of murrelets could be displaying "occupied behavior" in habitats where breeding is not currently being attempted or where successful breeding could not occur. Such could be the case in central California where Carter and Erickson (1988) believed that all remaining nesting habitat is occupied and because the population is nest site limited, nonbreeding birds may be present over land and sea in a greater percentage than elsewhere. While this may result in overestimating the use of stands, it is unlikely that murrelets would be repeatedly encountered in stands that do not have some present or future potential for supporting successful breeding.

\section{Discussion}

The coastal old-growth forest utilized for breeding by Marbled Murrelets would have selected for relatively high rates of breeding and natal dispersal. Based on the behavior and cryptic coloration of the breeding adults and chicks, and the high rate of nest predation for observed nests (Nelson and Hamer, this volume b), the risk of nest predation appears to be higher than for other alcids. The assumed high rate of nest predation would have selected for frequent short distance movernents, while the extensive time required for old growth stands to be destroyed or degraded under natural conditions would have selected for individual fidelity to a nesting stand. There is no indication that the distance that breeding murrelets typically disperse would be any greater than the conservative movements (usually $<1 \mathrm{~km}$ ) that have been observed for other alcids.

Most dispersal in alcids is probably due to natal dispersal, and Marbled Murrelets appear to have the capacity for extensive natal dispersal given the extent of the breeding range, the overlap between the wintering and breeding areas, and the distance individuals are known to move from breeding areas in winter. It would not be unreasonable to assume the percentage of birds that initiate breeding at a non-natal locality (natal dispersal) is as high or higher than has been reported for other alcids (approximately 50 percent) (Harris and Wanless 1991). The ability to prospect for breeding localities should be well developed in Marbled Murrelets. Unlike the potential breeding area of most alcids, which is linearly distributed in a narrow band on the shoreline, murrelet nesting habitat is found in a wide (as much as $60 \mathrm{~km}$ ) band adjacent to the coast.

Breeding habitat fragmentation and loss can be expected to have affected the rate and extent of murrelet dispersal. In Washington, Oregon, and California, high predation rates apparently associated with fragmentation would select for increasing the rate and extent of breeding dispersal. However, the small size and highly fragmented and disjunct nature of the old-growth remaining in this area can be assumed to have decreased the potential distance for breeding dispersal (at least in areas where stand size is small). Natal dispersal rates and extent may have been increased as habitat in the natal locality was reduced and the distance to the location of suitable habitat is increased. These changes in dispersal may have the overall effect of depressing reproductive output.

\section{Acknowledgments}

We thank George Hunt, Linda Long, Phil Detreich, and Edward Murphy for helpful comments and work on this manuscript. 



\section{Chapter 8 \\ Nest Success and the Effects of Predation on Marbled Murrelets}

\section{S. Kim Nelson ${ }^{1} \quad$ Thomas E. Hamer ${ }^{2}$}

\begin{abstract}
We summarize available information on Marbled Murrelet (Brachyramphus marmoratus) productivity and sources of mortality compiled from known tree nests in North America. We found that 72 percent ( 23 of 32 ) of nests were unsuccessful. Known causes of nest failure included predation of eggs and chicks $(n=10)$, nest abandonment by adults $(n=4)$, chicks falling from nests $(n=3)$, and nestlings dying ( $n=1$ ). The major cause of nest failure was predation (56 percent; 10 of 18). Predators of murrelet nests included Common Ravens (Conus corax) and Steller's Jays (Cyanocitta stelleri); predation of a nest by a Great Homed Owl (Bubo virginianus) was also suspected. We believe that changes in the forested habitat, such as increased amounts of edge, are affecting murrelet productivity. Successful nests were significantly further from edges ( $\bar{x}=$ 155.4 versus $27.4 \mathrm{~m}$ ) and were better concealed ( $\bar{x}=87.2$ versus 67.5 percent cover) than unsuccessful nests. The rate of predation on Marbled Murrelet nests in this stud appear higher than for many seabirds and forest birds. If these prec ation rates are representative of rates throughout the murrelet's range, then the impacts on murrelet nesuing success will be significant. We hypothesize that because this seabird has a low reproductive rate (one egg clutch), small increases in predation will have deleterious effects on population viability. Rigorous studies, including testing the effects of various habitat features on recruitment and demography, should be developed to investigate the effects of predation on Marbled Murrelet nesuing success.
\end{abstract}

Nesting success in seabirds is influenced by a variety of physical and biological factors, including food availability, habitat quality, energetics, predation, and climatic conditions (Croxall 1987, Nettleship and Birkhead 1985, Vermeer and others 1993). Because the effects of these factors can vary spatially and temporally, seabird nesting success can be highly variable among years (Birkhead and Harris 1985; Boekelheide and others 1990; De Santo and Nelson, this volume). For example, in some years, anomalous warm oceanographic conditions ( $\mathrm{El}$ Niño) cause a decrease in prey availability, thus impacting nesting attempts and nest success (Ainley and Boekelheide 1990, Hodder and Greybill 1985, Vermeer and others 1979). In addition, disturbance to nesting habitat (e.g., habitat loss, modification) and associated cumulative impacts can affect the ability of seabirds to successfully reproduce (Evans and Nettleship 1985; Gaston 1992, Reville and others 1990).

\footnotetext{
${ }^{1}$ Research Wildlife Biologist, Oregon Cooperative Wildlife Research Uni, Oregon State University, Nash 104, Corvallis, OR 97331-3803

${ }^{2}$ Research Biologist, Hamer Environmental, 2001 Highway 9, Mt. Vernon, WA 98273
}

The influence of these biological and physical factors on the nesting success of Marbled Murrelets (Brachyramphus marmoratus) is not fully known. In order to completely address this issue, well designed studies investigating the conditions that directly influence murrelet reproduction are needed. However, data are available on murrelet nesting success from tree nests that have been located and monitored in North America. In this paper, we summarize this information on murrelet productivity and sources of mortality. In addition, because predation was the major cause of nest failure, we discuss the implications of predation on this threatened, forest-nesting seabird.

\section{Methods}

We compiled information on nest success and failure from published and unpublished records of 65 Marbled Murrelet tree nests found in North America between 1974 and 1993. The sample size of tree nests were distributed by state and province as follows: Alaska $(n=18)$, British Columbia $(n=9)$, Washington $(n=6)$, Oregon $(n=22)$, and California $(n=10)$ (table 1). Success and failure of nests were determined through intensive monitoring of nesting activity, or evidence collected at the nest. The outcomes of nests were compared between regions (Alaska versus British Columbia, the Pacific Northwest and northern California). Nests were considered to fail if: (1) the chick or egg disappeared, fell out of the nest, or was abandoned; (2) the chick died; (3) unfaded eggshell fragments were found during the breeding season in nest cups without fecal rings; or (4) predation was documented. Nests were considered or assumed to be destroyed by a predator based on one or more of the following: (1) predation was observed, (2) the egg or chick disappeared prematurely between nest observations and neither were located on the ground after a thorough search of the area, and (3) evidence, such as puncture marks on eggs, or albumen or blood on eggshell fragments, was discovered and predators were aware of the nest location or seen in the immediate area. In addition to data from active nests, information on eggs, nestlings, and hatch-year birds found on the ground were compiled from published and unpublished records between 1900 and the present.

We used a Mann-Whitney U-test to compare the characteristics of nests that were successful with those of nests that failed because of predation. Variables used in the analysis were those that could have an effect on nest exposure or concealment: distance to edge, canopy cover, stand size, percent cover above the nest cup, nest height, distance of the 
Table 1-Marbled Murrelet tree nests by state or province, site, year, and outcome.

\begin{tabular}{|c|c|c|c|c|c|}
\hline \multirow{2}{*}{$\begin{array}{l}\text { State or province } \\
\text { Nest site/year found }\end{array}$} & \multicolumn{3}{|c|}{ Nest outcome } & \multirow[t]{2}{*}{ Reason for failure ${ }^{1}$} & \multirow[t]{2}{*}{ Predator ${ }^{2}$} \\
\hline & Successful & Failed & Unknown & & \\
\hline \multicolumn{6}{|l|}{ Alaska } \\
\hline Kelp Bay $1984^{a}$ & - & 1 & - & Abandoned egg & - \\
\hline Naked Island 1991/92b & - & 7 & 3 & $\begin{array}{l}\text { ?Predation of egg }(n=1) \\
\text { Abandoned egg }(n=3) \\
\text { Unknown/egg stage }(n=2) \\
\text { Unknown/chick stage }(n=1)\end{array}$ & $\begin{array}{l}\text { ?Steller's Jay } \\
\text { ?Common Raven }{ }^{3} \\
- \\
-\end{array}$ \\
\hline Kodiak $1992^{\mathrm{b}}$ & - & - & 2 & - & - \\
\hline Chugach $1992^{b}$ & - & - & 1 & - & - \\
\hline Afognak $1992^{b}$ & - & - & 2 & - & - \\
\hline Prince of Wales $1992^{c}$ & - & - & 1 & - & - \\
\hline SE Alaska $1993^{d}$ & - & 1 & - & Predation of egg or chick & - \\
\hline \multicolumn{6}{|l|}{ British Columbia } \\
\hline Walbran $1990 / 91^{\mathrm{e}}$ & - & - & 2 & - & - \\
\hline Carmanah $1992^{f}$ & - & - & 1 & - & - \\
\hline Walbran $1992^{f}$ & - & - & 2 & - & - \\
\hline Clayoquot 19938 & - & - & 2 & - & 一 \\
\hline Carmanah 19938 & - & - & 1 & - & - \\
\hline Caren $1993^{b}$ & 1 & - & - & 一 & - \\
\hline \multicolumn{6}{|l|}{ Washington } \\
\hline Lake $221991^{\mathrm{i}}$ & 2 & - & - & - & - \\
\hline Jimmycomelately $1991^{i}$ & - & - & 1 & 一 & - \\
\hline Heart of Hills $1991^{i}$ & - & 1 & - & Chick fell out & - \\
\hline Olympic $1991^{i}$ & - & - & 1 & - & - \\
\hline Nemah 1993j & 1 & - & - & - & - \\
\hline \multicolumn{6}{|l|}{ Oregon } \\
\hline Five Rivers $1990^{k}$ & - & 1 & - & Chick fell out & - \\
\hline Valley of Giants $1990^{k}$ & - & 1 & - & Predation of chick & ?Great Horned Owl \\
\hline Five Rivers $1991^{k}$ & 1 & - & - & - & - \\
\hline Valley of Giants $1991^{k}$ & - & 1 & - & Predation of egg & ?Common Raven \\
\hline Cape Creek 1991k & - & 1 & - & Predation of egg & ?Common Raven \\
\hline Siuslaw \#1 1991k & 1 & - & - & - & - \\
\hline Siuslaw \#2 1991k & - & 1 & - & Predation of chick & ?Steller's Jay \\
\hline Boulder Warnike $1992^{k}$ & - & 1 & - & ?Predation of chick & $?$ \\
\hline Valley of Giants $1992^{k}$ & - & 1 & - & Predation of egg & ?Common Raven \\
\hline Copper Iron $1992^{k}$ & 1 & - & - & - & - \\
\hline Valley of Giants $1993^{1}$ & - & - & 8 & - & - \\
\hline Green Mountain 19931 & - & - & 2 & - & - \\
\hline Five Rivers $1993^{1}$ & - & - & 1 & - & - \\
\hline Five Mile Flume $1993^{1}$ & - & - & 1 & - & - \\
\hline \multicolumn{6}{|l|}{ California } \\
\hline "J" Camp 1974" & - & 1 & - & Chick fell out & - \\
\hline Waddell Creek 1989n & - & 1 & - & Predation of chick & Steller's Jay \\
\hline Opal Creek 1989n & - & 1 & - & Predation of egg & Common Raven \\
\hline Father 1991/92 ${ }^{\circ}$ & 2 & - & - & - & - \\
\hline Palco $1992^{p}$ & - & 1 & 2 & Chick died & - \\
\hline Prairie Creek State Park 1993i & - & 1 & - & Unknown & - \\
\hline Jedediah Smith State Park $1993^{i}$ & - & 1 & - & Unknown & 一 \\
\hline
\end{tabular}




\title{
Table 1-continued
}

\author{
1 ?Predation = predation known or suspected based on available evidence. \\ 2 ?Predator = suspected predator, species seen in vicinity of nest. \\ ${ }^{3}$ Common Raven flushed adult off one of these nests; this may have had an impact on its abandonment which occurred 2 days later. \\ - Quinlan and Hughes, 1990 \\ ' Naslund and others, in press \\ e Twelve Mile Arm nest; Brown, pers. comm. \\ ¿Unusual ground level nest located on tree roots above $11 \mathrm{~m}$ cliff in Log Jam Creek; Brown, pers. comm. \\ e Manley and Kelson, in press \\ Jordan and Hughes, in press \\ 8 Hughes, pers. comm. \\ "P. Jones, pers. comm. \\ ${ }^{\mathrm{i}}$ Hamer, unpublished data \\ j Ritchie, pers. comm. \\ ${ }^{k}$ Nelson, unpublished data; Nelson and Peck, in press \\ "Nelson, unpublished data \\ m Binford and others 1975. \\ - Singer and others 1991. \\ - Singer and others, in press. \\ P Kerns, pers. comm.
}

nest from the trunk, limb diajzeter at the nest, and nest substrate type (i.e., moss or diff). Edges were defined as unnatural openings, including, but not limited to, roads and clearcuts. Differences in the mean characteristics (ranks) were considered significant at $P<0.05$.

\section{Results and Discussion}

\section{Nest Success and Failure}

Nesting success or failure was documented at 49 percent (32 of 65) of the nests (table 2). Timing of discovery (after the nesting season), limited evidence, or inadequate monitoring prevented conclusions about the outcomes at the remainder of nests. Therefore we limit our discussion to these 32 tree nests.

Seventy-two percent ( 23 of 32 ) of the nests were unsuccessful (rables 1 and 2). Known causes of nest failure included predation of eggs and chicks, nest abandonment by adults, chicks falling from nests, and nestlings dying (tables $I$ and 3). Nesting success of 28 percent is lower than reported for 17 other alcid species ( $\bar{x}=57$ percent, range $=$ 33-86) (De Santo and Nelson, this volume), and for 11 species of sub-canopy and canopy nesting neotropical landbird migrants $(\bar{x}=51$ percent, range $=20-77$ ) (Martin 1992). However, some species of seabirds (e.g., Xantus' Murrelet [Synthliboramphus hypoleucus]) and forest nesting neotropical migrants (e.g., Western Kingbird [Tyrannus verticalis]), also experienced low nesting success (33 and 20 percent, respectively) in some years (Martin 1992; Murray and others 1983). Hatching and fledging success of Marbled Murrelet nests were 67 and 45 percent, respectively. Fledging success was also lower than reported for all other alcid species $(\bar{x}=78$ percent, range $=66-100, n=16$ ) (De Santo and Nelson, this volume).

For all nests, 52 percent of the failures occurred during the egg stage, whereas in Washington, Oregon, and California most ( 62 percent) failed during the chick stage (table 3 ). The difference in stage of failure between the southern portion of the murrelet's range and all known nests can be explained by greater abandonment of eggs at nests in Alaska (Naslund, pers. comm.). The high incidence of abandonment in eggs in Alaska between 1991 and 1994 may have been related to limited food resources (Kuletz, pers. comm.).

Failure during the egg stage was caused by abandonment and predation. Failure during the chick stage occurred because of predation, death from a burst aorta (Palco nest in California), and falling from the nest. Chicks may fall from nests because nests are located on small platforms, or in response to unfavorable weather conditions, such as high winds, or other natural and unnatural disturbances. In Oregon, a 6-day-old chick may have fallen from its ridgetop nest tree (Five Rivers) because of gusty winds that occurred during a midday storm. Chicks are also occasionally very active on the nest, picking at nesting material, changing positions, snapping at insects, exercising their wings, and pacing on the nest limb (see Nelson and Hamer, this volume a). They could easily fall from the nest platform during these times of activity. In addition, predator activity could cause chicks to fall from the nesting platform.

In addition to failure documented at active nests, nestlings, fledglings, and eggs have been found on the ground during the breeding season at numerous sites throughout North America (table 4). Chicks and eggs located on the ground probably fell from nests as indicated above. However, eggs could also be carried by predators and dropped in locations distant from nest sites.

Fledglings have been discovered on the ground at varying distances from the ocean during the breeding season (up to $101 \mathrm{~km}$ inland). Many of these birds still retained an egg tooth and small traces of down on their head and back, indicating recent fledging. Marbled Murrelet hatch-year birds 
Table 2-Summary of Marbled Murrelet nest success and failure by state and province

\begin{tabular}{l|ccc}
\hline \multirow{2}{*}{ State/province } & \multicolumn{3}{|c}{ Nest outcome } \\
\cline { 2 - 4 } & Successful & Failed & Unknown \\
\hline Alaska & 0 & 9 & 9 \\
British Columbia & 1 & 0 & 8 \\
Washington & 3 & 1 & 2 \\
Oregon & 3 & 7 & 12 \\
California & 2 & 6 & 2 \\
Overall total & 9 & 23 & 33 \\
& $(14$ pct.) & $(35$ pct. $)$ & $(51$ pct.) \\
Total for Washington, & & & 14 \\
Oregon, and California & 8 & 14 & $(39$ pct.) \\
& $(22$ pct.) & $(39$ pct. $)$ & \\
\end{tabular}

Table 3-Type and stage of Marbled Murrelet nest failure

\begin{tabular}{|c|c|c|c|}
\hline \multirow[t]{2}{*}{ Type of failure } & \multirow[t]{2}{*}{ Number (pct.) } & \multicolumn{2}{|c|}{ Stage of failure } \\
\hline & & Egg & Chick \\
\hline \multicolumn{4}{|l|}{ All nests } \\
\hline Predation & $10^{1} \quad(43)$ & $5(56)$ & $4(44)$ \\
\hline Unknown & $5^{1} \quad(22)$ & $2(50)$ & $2(50)$ \\
\hline Abandonment & $4 \quad(17)$ & $4(100)$ & 0 \\
\hline Chick fell out & 3 (13) & - & $3(100)$ \\
\hline Chick died & $1 \quad(4)$ & - & $1(100)$ \\
\hline Total & $23^{2}(100)$ & $11(52)$ & $10(48)$ \\
\hline \multicolumn{4}{|c|}{$\begin{array}{l}\text { Nests in Washington, } \\
\text { Oregon, and California }\end{array}$} \\
\hline Predation & $8 \quad(57)$ & $5(62)$ & $3(38)$ \\
\hline Unknown & $2^{t} \quad(14)$ & 0 & $1(100)$ \\
\hline Abandonment & 0 & 0 & 0 \\
\hline Chick fell out & 3 (21) & - & $3(100)$ \\
\hline Chick died & $1 \quad(7)$ & - & $1(100)$ \\
\hline Total & $14^{l}(100)$ & $5(38)$ & $8(62)$ \\
\hline
\end{tabular}

${ }^{1}$ One nest failed at unknown stage.

2 Two nests failed at unknown stage. 
Table 4-Marbled Murrelet chicks, eggs, and juveniles found on the ground by state and province - an indication of additional nest failurel

\begin{tabular}{l|ccc}
\hline State/province & $\begin{array}{c}\text { Number } \\
\text { grounded } \\
\text { chicks }\end{array}$ & $\begin{array}{c}\text { Number } \\
\text { whole } \\
\text { eggs }\end{array}$ & $\begin{array}{c}\text { Number } \\
\text { grounded } \\
\text { juveniles }\end{array}$ \\
\hline Alaska & 1 & 1 & 5 \\
British Columbia & 3 & 0 & 6 \\
Washington & 3 & 2 & 9 \\
Oregon & 2 & 1 & 4 \\
California & 3 & 0 & 22 \\
Overall & 12 & 4 & 46 \\
\hline
\end{tabular}

\footnotetext{
${ }^{1}$ Data from Atkinson, pers. comm.; Confer, pers. comm.; Carter and Erickson 1992; Carter and Sealy 1987b; Hamer, unpublished data; Kuletz, pers. comm.; Leschner and Cummins 1992b; Mendenhall 1992; Nelson, unpublished data; Nelson and others 1992; Rodway and others 1992; S.W. Singer, pers. comm.
}

are believed to fly directly from : nland nest sites to the ocean after fledging (Nelson and Hamer, this volume a; Quinlan and Hughes 1990). Their travel to the ocean may be unsuccessful, however, because of navigational problems or exhaustion. Unlike other alcids, hatch-year Marbled Murrelets .nust fly relatively long distances to reach the sea without the benefit of past flight experience, wing muscle development that comes with flight, or adult guidance. The large number of juveniles found on the ground while dispersing from nest sites raises questions about the relationship between murrelet energetics, location of the nest in relation to the ocean, and nesting success. Given that some hatch-year birds become grounded each year, and may be unable to take flight again, nest success may actually be much lower than our estimates from nest observations.

\section{Failure because of predation}

The major cause of nest failure was predation. Fortythree percent of all nests and 57 percent of nests in Washington, Oregon and California failed as a result of predation (table 3). Predation rates were higher (56 and 67 percent, respectively) when excluding unknown causes of failure, which could have included predation. Known predators of murrelet nests include Common Ravens (Corvus corax) and Steller's Jays (Cyanocitta stelleri) (Naslund 1993; Singer and others 1991) (table 1). Predation of a nest by a Great Horned Owl (Bubo virginianus) is also suspected. Other potential predators in forests include several species of forest owls, accipiters and American Crows (Corvus brachyrhynchos). No Marbled Murrelet nests are known to have been destroyed by mammalian predators, although raccoons (Procyon lotor), marten (Martes americana), fisher (Martes pennanti), and several species of rodents are potential predators.

Predation rates on murrelet nests appear higher than other alcids, perhaps with the exception of areas with introduced or high numbers of predators. For example, 44 percent of the eggs laid by a population of Xantus' Murrelets on Santa Barbara Island in California were taken by deer mice (Peromyscus spp.) during periods of egg neglect (Murray and others 1983). Rates of predation on murrelet nests also appear higher than those observed for many forest birds, with the exception of some species of sub-canopy and canopy nesting neotropical migrants (e.g., $\bar{x}=42$ percent, range $=$ 18-67 percent) (Martin 1992). However, the impacts of predation on the nesting success of species that lay clutches of two or more eggs (e.g., Xantus' Murrelets, Yellow-rumped Warbler [Dendroica coronata]) may be less than on species that lay only one egg, such as Marbled Murrelets.

Predation on Marbled Murrelet nests has been observed or documented during both the egg and nestling stages, but most (56 percent) occurred during the egg stage (table 3 ). Predation during the egg stage is most likely to occur if an incubating adult neglects or abandons the nest. Seabirds are known to completely abandon their nests during years in which prey availability is limited (i.e., during EI Niño events) (Ainley and Boekelheide 1990, Hodder and Greybill 1985, Vermeer and others 1979). In addition, seabirds may neglect their eggs for short periods to maximize foraging time and accumulate sufficient energy reserves for the lengthy incubation shifts (Boersma and Wheelwright 1979, Gaston and Powell 1989, Murray and others 1983). During this time, the eggs are subject to a variety of negative factors including predation, heat loss, and exposure to the elements.

Murrelets have been observed leaving their eggs unattended for short periods of time (2-3 hrs on several days) (Naslund 1993; Nelson and Peck, in press), and during such a time in Oregon (Cape Creek nest), an egg was taken by a predator (most likely a Common Raven). In addition, murrelets regularly left their egg unattended in the afternoon, evening, and early morning hours during a 5-day period at a 
nest in Alaska (Naked Island 1992), and the nest subsequently failed (Naslund and others, in press). Eggs were also abandoned when adults were flushed from the nest by a predator in California (Opal Creek) and Alaska (Naked Island) (Naslund 1993; Naslund and others, in press; Singer and others 1991). The eggs from these nests were later observed or believed to have been destroyed by a Common Raven and Steller's Jay, respectively.

In Oregon, additional egg predation was determined by finding blood and albumen on eggshell fragments. The egg disappeared from the 1991 Valley of the Giants nest after three weeks of incubation. Upon climbing the nest tree, a large eggshell fragment with blood stains was found in the nest cup. The suspected predator was a Common Raven that flew directly adjacent to the nest branch on its daily foraging forays. At the 1992 Valley of the Giants nest, eggshell fragments with blood and albumen were found at the base of a large Douglas-fir (Pseudotsuga menziesii) tree. An empty nest cup was subsequently discovered. The predator was most likely a Common Raven observed near the nest tree on several occasions.

In Oregon, chicks disappeared or were killed by predators at three nests during the 1991 and 1992 breeding seasons. A 3 -week-old chick at the Siuslaw \#2 nest was killed when its skull was pierced by a predator. Two species of corvids (Steller's Jay or Gray Jay [Perisoreus canadensis]) detected in the nest tree and adjacent area are the suspected predators. At the Boulder Warnicke nest, a 3-week-old chick disappeared from the nest. The predator could have been any one of the corvids that were present in the area or landed in the nest tree: Steller's Jays, Gray Jays, or Common Ravens. A 6-dayold chick disappeared at the Valley of Giants 1990 nest between 2100 and 0600 hrs on 6 August. A Great Horned Owl was heard calling from an adjacent tree (within $10 \mathrm{~m}$ ) during this time period, and is the suspected predator.

Marbled Murrelets have limited defenses and their primary protection against predation at the nest is to avoid detection (Nelson and Hamer, this volume a; Nelson and Peck, in press). Therefore, the nestling depends on its cryptic plumage and the location of the nest for safety. If a predator discovers the nest, the chick will attempt to defend itself with aggressive behaviors as witnessed by Naslund (1993) and Singer and others (1991), when a Steller's Jay attacked a 4-day-old chick at the Waddell Creek nest in California. The chick rotated its sitting position on the nest to constantly face the predator, reared up its body and head, opened its beak, and jabbed at the predator. The chick was unable to ward off the jay and was carried away.

Nesting attempts also may fail because adults have been killed on their way to or at nest sites. In forests of southeast and southcentral Alaska, Sharp-shinned Hawks (Accipiter striatus) and Northern Goshawks (Accipiter gentilis) are known to prey on adult murrelets (Marks and Naslund 1994; Naslund, pers. comm.). In addition, Peregrine Falcons (Falco peregrinus) and Common Ravens have been observed chasing Marbled Murrelets just above and within the forest canopy, respectively (Hamer, unpubl. data; Hunter, pers. comm.; Suddjian, pers. comm.). A Peregrine Falcon was successful in capturing a Marbled Murrelet at one such site in central California (Suddjian, pers. comm.).

Predation of adults at the nest site also can occur. There are two known records from California and Alaska. A Common Raven flushed an adult murrelet from a nest in California (Opal Creek), and was later seen carrying what appeared to be a partial carcass (Naslund 1993, Singer and others 1991). In Alaska, an adult was killed by a Sharpshinned Hawk seconds after it landed on a suspected nest limb (Naked Island) (Marks and Naslund 1994).

\section{Potential for Bias}

The Marbled Murrelet nests at which predation has been studied may not be an unbiased sample. The high predation rates recorded at these nests could be biased because many of the nests were located in fragmented areas and near forest edges (table 5) rather than in the centers of large, dense stands. Thus, there is the possibility that nest sites located by researchers are also those more easily located by predators (see below). At present we lack information to evaluate this source of potential bias.

In addition, it has been suggested that researchers studying these nests had an impact on their success (see Götmark 1992; Martin and Geupel 1993). We believe the disturbance to the nests was minimal, except at two. In southeast Alaska, researchers approached very close to an unusual murrelet nest located on tree roots near ground level (Brown, pers. comm.). The aduit was flushed or disturbed on five occasions, which may have contributed to its failure (egg or newly hatched chick disappeared). The "J" Camp nest in California also failed from direct human intervention (Binford and others 1975). No human impacts are suspected at nests where the chick fell out $(n=1$ in Oregon) or died ( $n=1$ in California), or where nests were found after they had failed ( $n=1$ each in Washington and Oregon, $n=2$ in California). At all other nests, human impacts were also limited because: (1) some nests were monitored infrequently ( $n=8$ in Alaska and $n=2$ in Oregon); (2) predators knew the location of the nest on day of and probably prior to discovery, and, additionally, precautions (e.g., limiting noises and number of observers near nest; see Martin and Geupel 1993) were implemented to minimize disturbance and predator attraction ( $n=1$ in Oregon, $n=2$ in California); and (3) nests were monitored from $>25 \mathrm{~m}$ horizontal distance from the nest and precautions (see above) were implemented ( $n=17)$. For (2) and (3) above, predators were occasionally attracted to the observer's location on the ground (especially Steller's Jays), but not to the nest site, $>18 \mathrm{~m}$ above the ground. In contrast, intensive disturbance occurred at three successful nests. In Oregon, the only nest tree that was climbed while active was successful, and in Washington, chicks at two nests fledged despite regular climbing (approximately once a day for 9-20 days) to collect nestling growth and development data. 
Table 5-Characteristics of successful Marbled Murrelet tree nests compared with those that failed because of predation

\begin{tabular}{|c|c|c|c|c|c|c|c|c|c|}
\hline $\begin{array}{l}\text { Statefprovince } \\
\text { Site/year }\end{array}$ & Outcome' & $\begin{array}{l}\text { Distance } \\
\text { to edge } \\
\text { (m) }\end{array}$ & $\begin{array}{l}\text { Canopy } \\
\text { cover } \\
\text { (pct) }\end{array}$ & $\begin{array}{l}\text { Stand } \\
\text { size } \\
\text { (ha) }\end{array}$ & $\begin{array}{c}\text { Nest } \\
\text { concealment } \\
(p c t)\end{array}$ & $\begin{array}{l}\text { Nest } \\
\text { height } \\
\text { (m) }\end{array}$ & $\begin{array}{l}\text { Limb } \\
\text { diameter } \\
\text { (cm) }\end{array}$ & $\begin{array}{l}\text { Distance } \\
\text { from } \\
\text { trunk }(\mathrm{cm})\end{array}$ & Substrate \\
\hline \multicolumn{10}{|l|}{ British Columbia } \\
\hline Caren 1993² & 1 & 700 & 70 & 800 & 100 & 18.0 & 20.0 & 0 & moss \\
\hline \multicolumn{10}{|l|}{ Washington } \\
\hline Lake $221991^{\mathrm{b}}$ & 1 & 55 & 58 & 405 & 70 & 31.4 & 10.7 & 45.6 & moss \\
\hline Lake $221991^{\mathrm{b}}$ & 1 & 65 & 74 & 405 & 95 & 27.7 & 36.5 & 57.0 & duff \\
\hline Nemah $1993^{\circ}$ & 1 & 10 & 65 & 142 & 80 &.$-^{3}$ & -- & $\cdots$ & moss \\
\hline \multicolumn{10}{|l|}{ Oregon } \\
\hline Valley of Giants $1990^{\circ}$ & 0 & 20 & 44 & 149 & 70 & 56.0 & 34.5 & 33.0 & moss \\
\hline Five Rivers $1991^{d}$ & 1 & 75 & 49 & 46 & 80 & 50.3 & 38.0 & 116.2 & moss \\
\hline Valley of Giants $1991^{\circ}$ & 0 & 28 & 50 & 149 & 80 & 50.3 & 41.0 & 17.1 & duff \\
\hline Cape Creek $1991^{d}$ & 0 & 16 & 65 & 138 & 95 & 44.2 & 10.0 & 7620 & moss \\
\hline Siuslaw $1991^{\circ}$ & 1 & 56 & 60 & 89 & 85 & 60.3 & 23.3 & 1520 & moss \\
\hline Siuslaw $\# 21991^{d}$ & 0 & 64 & 52 & 47 & 80 & 51.5 & 13.0 & 230.0 & duff \\
\hline Boulder Wamicke $1992^{\mathrm{d}}$ & 0 & 32 & 19 & 3 & 80 & 61.0 & 21.6 & 46.0 & moss \\
\hline Valley of Giants $1992^{\circ}$ & 0 & 15 & 66 & 149 & 70 & 52.0 & 47.0 & 35.0 & moss \\
\hline Copper Iron $1992^{d}$ & 1 & 300 & 93 & 542 & 75 & 49.0 & 34.0 & 1.0 & moss \\
\hline \multicolumn{10}{|l|}{ California } \\
\hline Waddell Creek $1989^{6}$ & 0 & 10 & 40 & 1700 & 25 & 38.5 & 36.3 & 61.0 & moss \\
\hline Opal Creek 1989 & 0 & 34 & 40 & 1700 & 40 & 43.7 & 47.7 & 1220 & moss \\
\hline Father $1991^{f}$ & 1 & 69 & 40 & 1700 & 100 & 41.1 & 61.0 & 0 & duff \\
\hline Father $1992^{f}$ & 1 & 69 & 40 & 1700 & 100 & 53.2 & 42.0 & $\mathbf{0}$ & duff \\
\hline
\end{tabular}

1 I successful, $0=$ failed.

2 Edge $=$ Distance to nearest unnatural edge (road or clearcut).

${ }^{3}$ Data not available.

a. Jones, pers. comm.

${ }^{b}$ Hamer, unpublished data.

c Ritchie, pers. comm.

Nelson, unpublished data; Nelson and Pock, in press.

e Singer and others 1991.

${ }^{r}$ Singer and others, in press.

\section{Habitat Characteristics and Predation of Nests}

The effect of predators on avian nesting success can vary significantly with geographic location, and is dependent upon the species of predators present, accessibility of nests, type and dimension of the habitat, topography, and vegetative complexity (vertical and horizontal diversity) (Chasko and Gates 1982; Martin 1992; Marzluff and Balda 1992; Paton 1994; Reese and Ratti 1988; Yahner 1988; Yahner and others 1989). For example, alcids nesting on islands relatively free of mammalian predalors, or on cliffs inaccessible to terrestrial predators, experience lower predation rates than species nesting in accessible sites and with abundant predators (Ainley and Boekelheide 1990; Hudson 1985). Because many species of birds have evolved in association with predators, the long term impacts of predation on avian nesting success are expected to be minimal in natural situations. However, rapid and unnatural changes, such as the introduction of mammalian predators (cats, goats, mice, pigs, raccoons, rats) and habitat modification, can have significant impacts on nesting success of seabirds (Bailey and Kaiser 1993; Ewins and others 1993; Gaston 1992; Murray and others 1983), and neotropical migrants (Chasko and Gates 1982; Martin 1992), respectively. In these cases, predation can be a major factor affecting avian population viability (Martin 1992).

Significant changes have occurred in the forested landscapes of the United States over the past century, including loss of late-successional forests, habitat fragmentation, and increases in the amount of edge (Hansen and others 1991; Harris 1984; Morrison 1988; Perry, this volume; Thomas and Raphael 1993). These changes have affected the abundance and distribution of many avian predators and forest nesting birds. For example, populations of corvids and 
Great Horned Owls are increasing in numbers throughout the western United States, especially in response to increases in habitat fragmentation and human disturbance (Johnson 1993; Marzluff 1994; Marzluff and Balda 1992; Robbins and others 1986; Rosenberg and Raphael 1986; Yahner and Scott 1988). In contrast, numerous neotropical migrant species are declining in numbers because they are unable to adjust to fragmentation and rapidly changing habitat conditions (Hagan and Johnson 1992; Hansen and others 1991, Hejl 1992, Martin 1992, Morrison and others 1992, Rosenberg and Raphael 1986). The Marbled Murrelet was listed as a threatened species in 1992 as changes in the forested landscape appear to be negatively impacting their populations (U.S. Fish and Wildlife Service 1992).

Although the relationship between predator numbers, habitat fragmentation, and predation on Marbled Murrelet nests has not been specifically studied, we believe, based on the following data, that changes in their habitat, such as increased amounts of edge, may significantly affect their nesting success. First, evidence from murrelet nests in this study suggests that distance to edge, stand size, canopy closure, percent cover above the nest cup (nest concealment), and distance of the nest from the tree trunk may be affecting predation rates (table 5). In a comparison of these habitat characteristics between successful nests $(n=9)$ and nests that failed because of predation ( $n=8$, excluding Alaska), we determined that successful nests were located significantly farther from edges ( $\mathrm{U}=2.9, n=16$ trees, $P<0.05)$ (table 5). All successful nests were located $>55 \mathrm{~m}(\bar{x}=166.3, n=8$ trees, s.e. $=82.3$ ) from an edge (road or clearcut), with the exception of the Nemah nest in Washington, which was located within $10 \mathrm{~m}$ of an old road near the center of a 142 ha forest. In contrast, all nests that failed because of predation were located within $64 \mathrm{~m}(\bar{x}=27.4$, s.e. $=6.0)$ of an edge. In a review of numerous artificial nest predation studies, Paton (1994) found evidence that predation of bird nests is higher within $50 \mathrm{~m}$ of edges. This result supports our hypothesis that murrelet nests near edges may be more vulnerable to predation than those located in the stand interior. In addition, nest concealment was significantly greater at successful nests $(\bar{x}=87.2$ percent, s.e. $=3.9)$ compared with nests that failed because of predation $(\bar{x}=67.5$ percent, s.e. $=8.2)(\mathrm{U}=2.3$, $n=17, P<0.05$ ) (table 5). Nest concealment has been shown to decrease predation rates (Chasko and Gates 1982; Marzluff and Balda 1992; Martin and Roper 1988). Stand size (532.0 versus 407.4 ha, $n=11$ stands) and canopy closure near nests ( 63.6 versus 47.0 percent, $n=16$ plots) were higher and nests located closer to the trunk ( 46.5 versus $163.3 \mathrm{~cm}$ ) at successful sites, but were not significantly different from nests that failed because of predation.

Second, it has been suggested that changes in forests where boundaries are contiguous with secondary succession may not create the same predation problems as those observed in static, simple forests in urban and agricultural areas that are defined by distinct boundaries (Rosenberg and Raphael 1986; Rudnicky and Hunter 1993). However, numerous studies in the eastern United States provide empirical evidence that edge effects in a forest dominated landscape (forest/ clearcut edge) are similar to those in forest/urban or agricultural settings. For example, in studies of eastern neotropical migrants, predation was lower in the forest interior (>50 $\mathrm{m}$ from the edge) compared with edge habitat (Chasko and Gates 1982; Yahner and Scott 1988). Predation was also lower in areas with high vegetative heterogeneity and concealing cover (Chasko and Gates 1982).

Evidence from artificial nest studies in forests of the Pacific Northwest also suggests that predation of birds' nests may be affected by habitat fragmentation and forest management. On Vancouver Island, British Columbia, Bryant (1994) demonstrated that artificial ground and shrub nests located along forest/clearcut edges (within $100 \mathrm{~m}$ ) were subject to higher predation rates than those in the forest interior (100-550 $\mathrm{m}$ from the edge). In the Oregon Coast Range, predation on artificial shrub nests was higher in clearcuts and shelterwood (20-30 green tress $>53 \mathrm{~cm}$ d.b.h./ha) stands than in stands with group selection cuts $(1 / 3$ volume removed in 0.2 ha openings) and unmanaged (control) stands (Chambers, pers. comm.). Additionally, in the Oregon Cascades, Vega (1994) found that predation on ground nests was significantly greater in clearcuts compared with retention stands ( 12 trees/ ha and 7.5 snags/ha), and predation on shrub nests was highest in retention stands compared to the other treatment types (clearcuts and mature stands). Steller's Jays, the suspected predator of the shrub nests, were more abundant in the retention stands, where they probably used the remnant trees for perching (see Wilcove 1985; Yahner and Wright 1985).

Third, despite differences in results among nest predation studies (e.g., Rudnicky and Hunter 1993 versus Yahner and Scott 1988), existing evidence strongly indicates that avian nesting success declines near edges (Paton 1994). In addition, regardless of the type of edge, fragmentation of forests often reduces structural complexity and heterogeneity of stands, and exposes remnant patches to edge effects (Hansen and others 1991; Harris 1984; Lehmkuhl and Ruggerio 1991). Because of increases in the amount of edge, productivity of interior forest species is generally impacted (Lehmkuhl and Ruggerio 1991; Reese and Ratti 1988; Yahner and others 1989), and generalist species, which benefit from the ecotone, usually increase in numbers (Yahner and Scott 1988). In addition, as vegetative complexity and canopy volume are reduced through fragmentation, bird nests (especially those located in shrubs or trees) may be more conspicuous and easier for avian predators to locate (Rudnicky and Hunter 1993; Vega 1994; Wilcove 1985; Yahner and Cypher 1987; Yahner and others 1989; Yahner and Scott 1988).

The rates of predation on Marbled Murrelet nests in this study appear higher than for many seabirds and forest birds. If the observed predation rates are representative of predation rates throughout the murrelet's range, then the impacts of predation on murrelet nesting success is significant and of concern (Wilcove 1985). Even if these high predation rates are localized to certain states or areas within states, the 
combination of low annual nesting success, low fecundity rates (Beissinger, this volume), and low or declining population sizes (Carter and Erickson 1992; Kelson and others, in press; Kuletz, 1994), could impact the survival and recovery of this threatened seabird.

\section{Conclusions}

Results from this study suggest that predation on murrelet nests may be relatively high compared with many alcids and forest nesting birds. Because Marbled Murrelets have no protection at nest sites other than the ability to remain hidden (Nelson and Hamer, this volume a), the availability of safe nest sites will be imperative to their survival. If logging and development (e.g., clearing land, creating patches of habitat, thinning stands) within the murrelet's range has resulted in increased numbers of predators or predation rates, and has made murrelet nests easier to locate because of increased amounts of edge and limited numbers of platforms with adequate hiding cover, then predation on murrelet nests could be significantly higher in such situations. In addition, areas heavily used by humans $\mathrm{fc}, \mathrm{recreational}$ activities (i.e., picnic and camping grounds) cál attract corvids (Marzluff and Balda 1992, Singer and others 1991) and may increase the chance of nest predation within these areas. Therefore, we hypothesize that because this seabird has low reproductive rates (one egg clutch), small increases in predation will have deleterious effects on murrelet population viability.
Rigorous studies should be developed to investigate the effects of predator numbers, predator species, predator foraging success, landscape patterns, habitat types, and forest structural characteristics on Marbled Murrelet nesting success. In implementation of these studies, hypotheses on the effects of various habitat features on fitness components (recruitment and demography) should be tested (Martin 1992, Paton 1994). At the same time, the effects of these hypotheses on coexisting species and the interacting effects these species have on one another should be evaluated (Martin 1992).

\section{Acknowledgments}

We are grateful to the biologists who kindly shared their data with us; special thanks go to Jim Atkinson, Alan Burger, Stephanie Hughes, John Hunter, Paul Jones, Kevin Jordan, John Kelson, Steve Kerns, Kathy Kuletz, Irene Manley, Ray Miller, Nancy Naslund, Bill Ritchie, Steve and Stephanie Singer, and David Suddjian for their time and generosity. We also thank Alan Burger, George Hunt, John Marzluff, Robert Peck, Steve Speich, and several anonymous reviewers for providing valuable comments on earlier drafts of this manuscript. Support for preparation of this manuscript was provided by the Oregon Department of Fish and Wildlife, USDA Forest Service, USDI Bureau of Land Management, and the U.S. Fish and Wildlife Service, U.S. Department of the Interior. This is Oregon State University Agricultural Experiment Station Technical Paper 10,540. 
8 . 


\title{
Chapter 9 \\ Molts and Plumages in the Annual Cycle of the Marbled Murrelet
}

\author{
Harry R. Carter' Janet L. Stein ${ }^{2}$
}

\begin{abstract}
Marbled Murrelets have distinct basic, alternate and juvenal plumages. In after-hatching-year (adult) birds, the incomplete pre-alternate molt occurs rapidly over a period of about one month per individual between late February and mid-May. The complete pre-basic molt occurs between mid-July and December. At this time, individuals are flightless for about two months. In late summer, it is difficult to distinguish adult birds undergoing prebasic molt from juveniles at sea. Field methods for separating these age categories at sea at this time of the year are presented. By early fall, older juveniles are not distinguishable in the field from after-hatching-year birds in basic plumage. The timing of prebasic and pre-alternate molts were closely related to the timing of breeding. movements and other aspects of the annual cycle of Marbled Murrelets in Barkley Sound, British Columbia.
\end{abstract}

Little has been published on the plumages and molts of the Marbled Murrelet (Brachyramphus marmoratus). Although the general pattern of molt and plumages has been documented, many details that are important for interpreting aspects of the biology of this enigmatic species have remained undescribed. Adults, also referred to as after-hatching-year birds (i.e., breeding adults and subadults, including firstyear birds in their second calendar year), have distinct alternate versus basic plumages that they wear during summer and winter periods, respectively. Subadults have not attained full maturity and have not yet bred. The mottled-brown alternate plumage is certainly responsible for the English name "Marbled" Murrelet. In addition, juveniles less than 6 months old, also known as hatching-year birds, wear a distinct juvenal plumage during late summer. Murrelets replace their alternate plumage with a basic plumage during a complete pre-basic molt (involving flight and body feathers) in the late summer and fall. Similarly, during an incomplete pre-alternate molt (involving only body feathers), they replace their basic plumage with the alternate plumage in spring. These general plumage stages and molts are similar for many other seabirds and birds in general (Welty and Baptista 1988). The juvenal, alternate, and basic plumages of the Marbled Murrelet are illustrated in many reputable bird identification field guides (e.g., Harrison 1983, National Geographic Society 1983).

Many past studies of Marbled Murrelets have not required a detailed knowledge of the stages of molts and plumages. Workers quantifying distribution and abundance of murrelets

1 Wildlife Biologist, National Biological Service, U.S. Deparment of Interior, Califomia Pacific Science Center, 6924 Tremonı Rd. Dixon, CA 95620

2 Wildlife Biologist, Washington Deparment of Fish and Wildlife, I6018 Mill Creek Blvd., Mill Creek, WA 98012 at sea have usually lumped all murrelets together regardless of plumage, or they conducted their studies in summer or winter when most or all birds were in the same plumage. Plumages of birds observed at inland nesting areas have not been distinguished because individuals fly high overhead under low light conditions or darkness during censuses. Interest in the relationship of plumage and molt to other aspects of the murrelet's life history has grown rapidly since 1992. Researchers in Alaska, British Columbia, Washington, Oregon, and California have recently attempted to census juveniles at sea in the late summer and early fall to indirectly determine breeding success. These efforts were prompted by concerns that the very low numbers of juveniles compared to adults ( $1-5$ percent) observed during recent surveys in Oregon and California represent very low breeding success (Nelson, pers. comm.; Hardin, pers. comm.; Ralph and others, this volume; Strong and others 1993). Such low levels of breeding success could indicate that murrelet populations in Washington, Oregon and California can no longer maintain themselves. However, surveys at this time of the year have difficulties that can lead to undercounting or overcounting juveniles in relation to adult birds from the same breeding population, including: (1) the degree that researchers can accurately separate the plumages of juveniles and adult birds in the field, even under adequate viewing conditions; (2) possible post-breeding season movements of adults, juveniles, or both into or out of the area studied; (3) differential use of at-sea habitats by various age classes and during different stages in the annual cycle; and (4) the timing and degree of natural and anthropogenic mortality of juveniles and adult birds. Thus, the adult:juvenile ratio is complex and must be interpreted with caution.

To address these difficulties, especially the first, we reviewed available information on plumages and molt from published and unpublished sources with three main objectives in mind. First, we summarized information on plumages and molt and identified gaps. Second, we summarized some other aspects of murrelet biology during the molt period that may be important for assessing the adult:juvenile ratio. Third, we developed field criteria for separating juveniles from adult birds at sea during the late summer and early fall. This method, based on current knowledge, will require modification as new results are obtained. Our goal has been to provide workers with sufficient information to gather more data to confirm and expand on known patterns. This summary is not complete and we refer the reader to other chapters in this volume for additional information on murrelet biology during the breeding and non-breeding seasons. 


\section{Methods}

We relied heavily on studies involving collected birds that allowed a close examination of plumages and molt condition. Sealy $(1972 ; 1974 ; 1975 a, b)$ studied breeding phenology, diet and body condition of murrelets at Langara Island, British Columbia, March-July 1970-1971. Carter (Carter 1984, Carter and Sealy 1990, Rodway and others 1992) studied at-sea distribution and foraging behavior of murrelets, as well as breeding phenology, diet and body condition, in Barkley Sound, British Columbia, May-October and December 1979-1980. Carter (unpubl. data) collected a complete series of birds undergoing pre-basic molt, as well as some juveniles, from July to October. These birds were preserved as study skins by Sealy and are housed at the University of Manitoba Zoology Museum, Winnipeg, Manitoba. In addition, Carter (unpubl. data) observed Marbled Murrelets off Victoria, British Columbia, during NovemberMarch 1978-1980 (see Gaston and others 1993). These studies were collated to present a general picture of murrelet plumages and molts throughout the year for southern Vancouver Island, British Columbia.

To confirm plumage and molt patterns identified from other studies, we examined a total of 106 specimens from the late summer and fall periods in the Royal British Columbia Museum (Victoria, British Columbia) and in the California Academy of Sciences (San Francisco, California). We examined total length, the ratio of dark:light coloration, ventral coloration and patterning, dorsal coloration, and primary wing molt. Total length was measured from 46 adult and 30 juvenile (including recently-fledged and older juvenal plumages) specimens that had been collected during June through September. The ratio of dark:light coloration was determined by placing a grid marked with 0.5 inch $\times 0.5$ inch quadrats over the dorsal, left and right sides of museum specimens and tallying the number of quadrats filled with mainly dark or mainly light plumage. Only the dorsal surface and sides of the specimens were examined in order to determine the dark:light ratio for the area of the bird most often seen when they are sitting on the water. Notes on the ventral coloration and patterning and dorsal coloration were also recorded for 67 adult and 35 juvenile specimens.

\section{Plumages}

\section{Basic and Alternate Plumages}

Kozlova (1957) provides good general descriptions of the basic and alternate plumages of the Marbled Murrelet. The following is a summary of Kozlova (1957) with a few added comments. In basic plumage, adults are dark brownish above, with bluish grey margins to the back feathers and largely white scapulars. The sides of the head and band around the neck, extending almost to the nape, are white. The underparts are white with some brown feathers still sprinkled on the flanks (figs. 1 and 2). In alternate plumage, the upper body parts are brownish black with rusty-buff margins to the back feathers. The sides of the head, front and

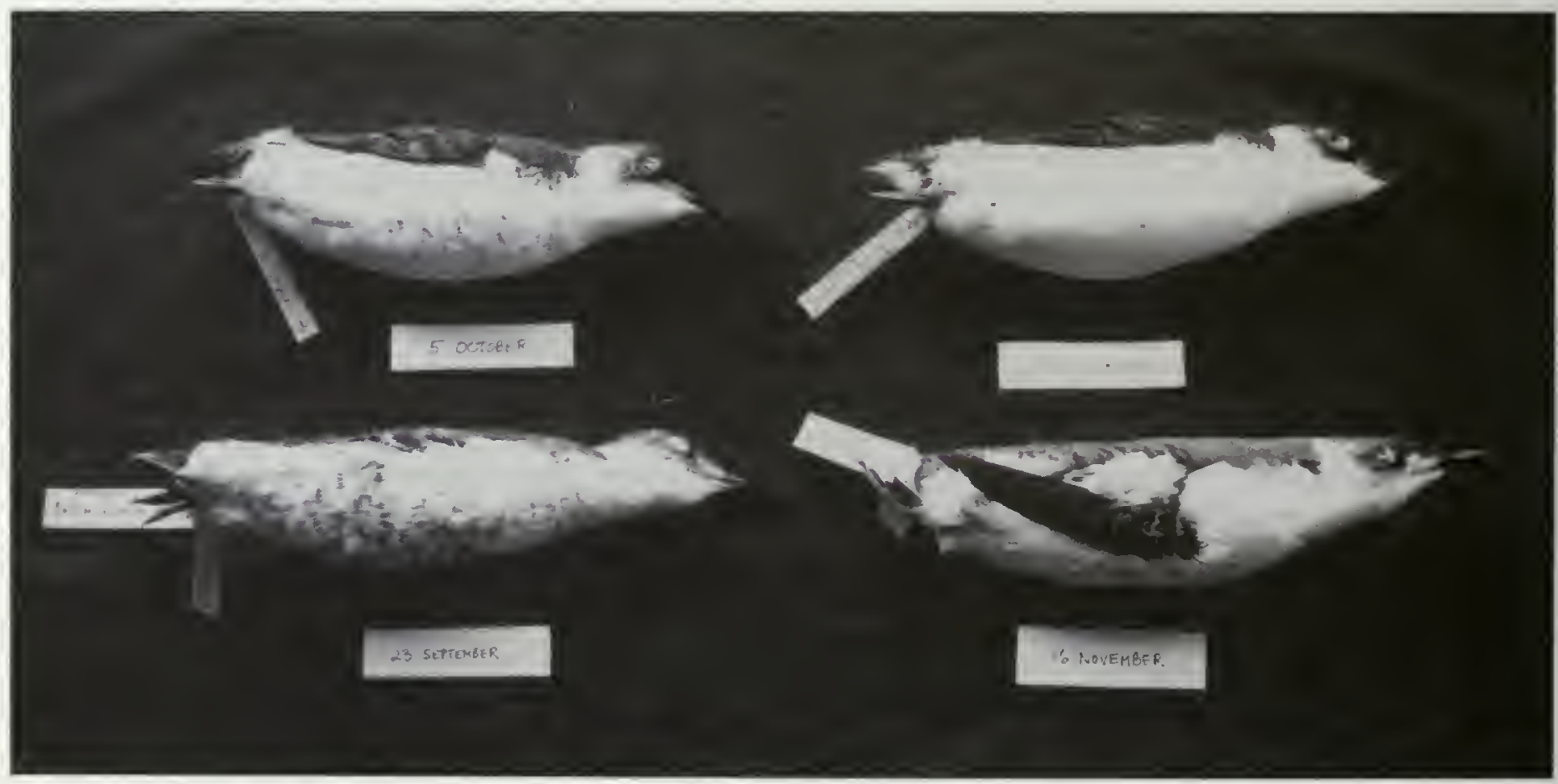

Figure 1-Plumage similarities during fall between older juvenile Marbled Murrelets (top) and adult birds (bottom). Collection dates of juveniles: 5 October 1907 (left), 8 November 1907 (right). Collection dates of adult birds: 23 September 1895 (left), 16 November 1895 (right). Specimens are housed at the California Academy of Sciences, San Francisco, California. Photo taken by H.R. Carter: 


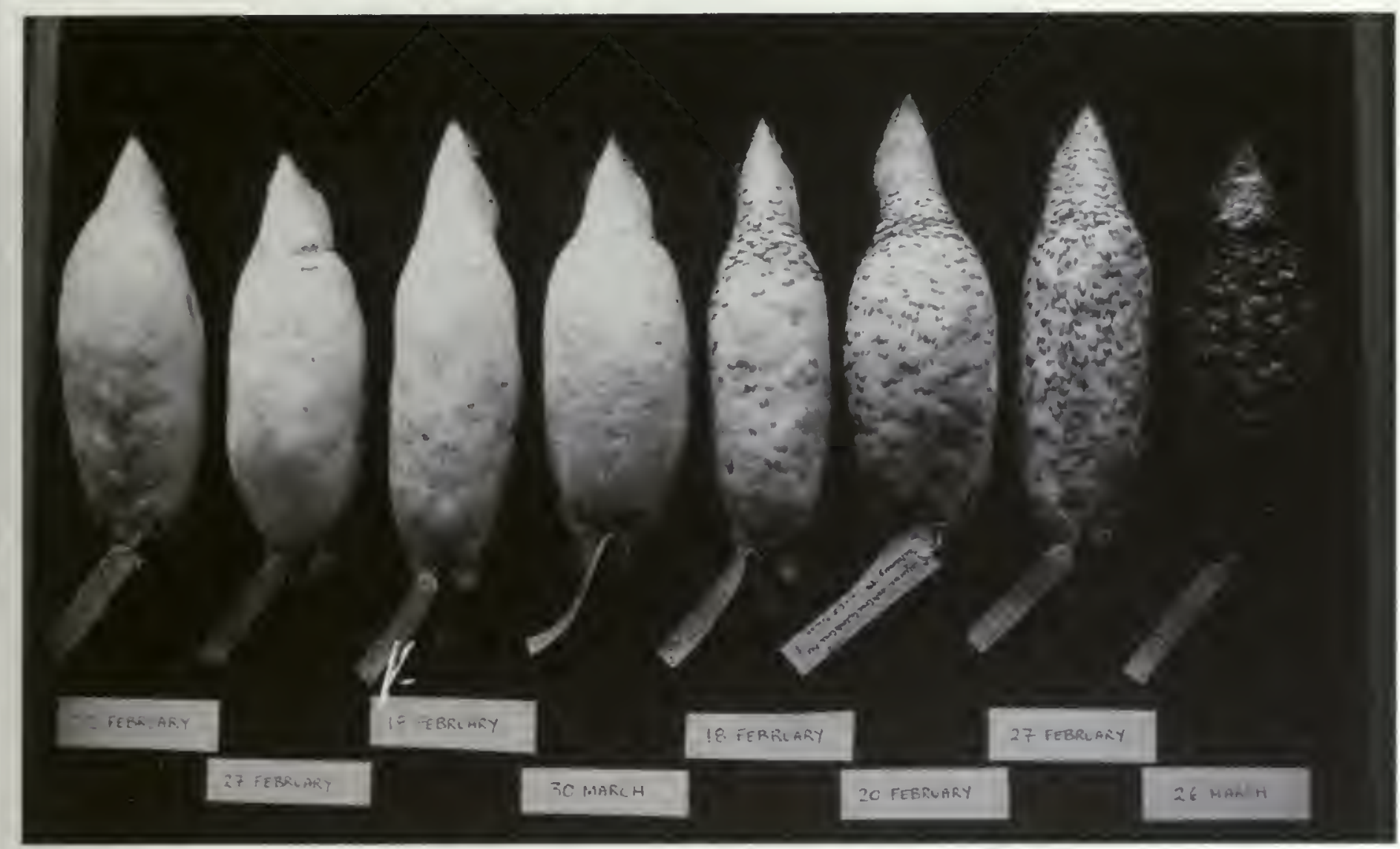

Flgure 2-Pre-alternate molt sequence in Marbled Murrelets. Museum specimens are ordered to reflect changes in ventral plumage during prealternate molt. The far left specimen is in basic plumage and the far right specimen is in alternate plumage. Collection dates of specimens from left to right: 22 February 1900, 27 February 1907, 18 February 1907, 30 March 1907, 18 February 1907, 20 February 1896, 27 February 1907, 26 March 1907. Specimens are housed at the California Academy of Sciences, San Francisco, Califomia. Photo taken by H.R. Carter.

sides of the neck, and underparts are covered with white feathers that are edged with broad dark-brown margins (fig. 2). These dark margins take up about half of each feather. The flanks are almost entirely dark brown, the upper wing coverts are dark brown with occasional narrow white edges, and the under wing coverts and axillaries are brownish grey. The rectrices are brownish black, occasionally with narrow white margins and brownish dots on the outer rectrices. There are no known differences in plumage appearance between sexes or ages of adult birds. However, in some European alcids, first-year birds may retain certain upperwing coverts, leading to a visible contrast between older, retained feathers against newer, replaced feathers (Pyle, pers. comm.). Such detailed examinations are required for the Marbled Murrelet to unveil such possible distinctions when examining birds in the hand.

Murrelets in basic plumage closely resemble the plumage of several other alcids, being "dark above" and "light below." The basic plumage is often considered closer to an older, ancestral plumage. The evolution of the cryptic alternate plumage is an obvious adaptation for nesting solitarily in old-growth forests (Binford and others 1975). It is likely that the Marbled Murrelet originally evolved its cryptic plumage by using similar nesting habitats as the closelyrelated Kittlitz's Murrelet (B. brevirostris). The latter species also attains a very cryptic alternate plumage for nesting solitarily on mountain scree slopes in Alaska and Russia up to $100 \mathrm{~km}$ inland from the ocean (Day and others 1983). However, the alternate plumage of the Marbled Murrelet is darker overall and, unlike the Kittlitz's Murrelet, the rusttipped back feathers of Marbled Murrelets closely match the bark of typical nest trees. While about 3 percent of the Alaskan population of Marbled Murrelets nests solitarily on the ground (Day and others 1983, Mendenhall 1992, Piatt and Ford 1993), it is unclear whether they represent remnant, ancestral ground-nesting behavior or a more recent redevelopment of such behavior. In any case, the cryptic alternate plumage was one preadaption that may have allowed Marbled Murrelets to originally colonize and nest in oldgrowth forests.

Distinctions between the plumages and other characteristics of the American Marbled Murrelet (B. $m$. marmoratus) and the Asian Marbled Murrelet (B. m. perdix) can be found in several papers (Erickson and others 1994; Kozlova 1957; Sealy and others 1982, 1991; Sibley 1993). Recent evidence indicates that the Asian Marbled Murrelet 
should be considered to be a separate species (Friesen and others 1994a, Piatt and others 1994).

\section{Nestling Plumage}

Binford and others (1975) described the downy chick in detail. Newly-hatched chicks are covered by a thick layer of natal down. Generally, the yellowish down is interspersed with irregular dark spots that cover the upper parts and are more prevalent on the head. A paler grey down covers the belly (Simons 1980). The down covers the developing juvenal plumage and is retained for a relatively long period of time, until just prior to fledging. At this time, the down appears to be preened or scratched off and may be ingested by the chick (Simons 1980). At fledging, juvenile birds fly to the ocean (Carter and Sealy 1987b, Hamer and Cummins 1991). Most juveniles arrive at sea in juvenal plumage, although some individuals may still retain some down, especially on the neck and crown (Sealy 1975a).

The cryptic downy nestling plumage of the Marbled Murrelet is also an obvious adaptation for nesting in oldgrowth forests (Binford and others 1975) or on mountainous scree slopes. Chicks of precocial alcids have more dense down coverings and resemble the adult plumage in pattern and coloration. Other semi-precocial alcid nestlings (like the Marbled Murrelet) have unmarked grey down. The late retention of this downy nestling plumage, in association with nest placement, tree bark or rock color, adult activities, and chick behavior, is probably important for reducing predation at the nest site.

\section{Juvenal Plumage}

Recently-fledged juveniles are uniformly dark brownish above with white scapulars. The underparts and sides of the head are white and speckled with blackish brown which does not fully conceal the white ground color of the feathers (fig. 3). The under wing coverts are brownish grey with some white. White bars are present on the outer rectrices and the inner vanes are pale brownish. Recently-fledged juveniles also retain the egg tooth for some time after fledging (Sealy 1970), although it is almost impossible to see the egg tooth in the field. The late retention of the egg tooth is probably related to the late retention of nestling down, early fledging (i.e. when less than fully grown), or both.

The juvenal plumage of recently-fledged juveniles differs from older juveniles that have been at sea for a longer period of time. Recently-fledged juveniles appear darker overall with most feathers on the sides of the head, neck, breast and abdomen edged with thin dark margins (fig. 3). This pattern gives juveniles a "speckled" appearance, especially on the breast and upper abdomen. Thicker dark margins occur on the side and flank feathers (similar to adults). Recentlyfledged juveniles often exhibit a neckband formed by a greater density of feathers with dark margins in the upper breast region. The plumage of recently-fledged juveniles is often referred to as the "juvenal plumage" in such field identification guides as the National Geographic Society guide (1983). Older juveniles appear to become whiter and lose any neck band and most or all of the dark margins that characterize typical juvenal plumage (fig. 1). This transition may occur as early as a few weeks after fledging. In addition, the uniform dark brown to black feathers on the upperparts of recently-fledged juveniles are replaced with feathers edged with thick grey margins in older juveniles (similar to adult birds). It is unclear how these plumage changes occur during this period (see below). Once older juveniles have completed this plumage transition, they are impossible to separate from adult birds in full basic plumage in the field (fig. 1). However, in the hand, remnant speckling of the juvenal plumage can be seen on the ventral parts of some birds as late as February.

One hypothesis that explains the plumage transition between recently-fledged and older juveniles is that murrelets have not achieved their full juvenal plumage at fledging. Chicks fledge at 70 percent adult weight (Sealy 1975a) and grow to attain full adult size at sea. For instance, recentlyfledged juveniles often still have sheathed outer primaries. The dark margins on recently-fledged juveniles may represent a stage of feather growth between the shedding of natal down and the full attainment of juvenal plumage when full adult size is reached. The dark-margined ventral feathers and/or the grey back feathers may be replaced near the end of the "nestling" growth period that occurs at sea. Alternatively, the thin and fragile dark margins of the ventral feathers may wear off quickly when exposed to salt water and swimming and diving activities. A second explanation for the plumage transition between recently-fledged and older juveniles is that a separate partial body molt occurs, causing loss and replacement of dark-margined ventral feathers and dark back feathers with completely white and greymargined feathers, respectively. Kozlova (1957) stated that the juvenal plumage is exchanged for the first winter plumage in the fall. She did not provide the basis for this statement, and it is unclear if actively molting feather tracts were observed on specimens examined. If such a molt did occur, it would probably occur some time well after fledging. We cannot currently determine which mechanism best explains this transition because the actual fledging dates of specimens examined is not known and could vary by several months due to protracted breeding. Some form of feather replacement could be supported by finding actively molting feather tracts on juveniles collected in late summer and early fall.

\section{Annual Cycle of Molts and Plumages}

Pre-alternate and pre-basic molts are controlled by levels of sex and other hormones, which change throughout the year. The pre-alternate molt precedes breeding and is associated with egg-laying and/or associated nesting behaviors. However, the onset and progression of molt probably also is modified by several environmental factors. Molt imposes high energetic demands within the annual cycle of the Marbled Murrelet. In particular, the replacement of flight and body feathers during the pre-basic molt requires significant changes 


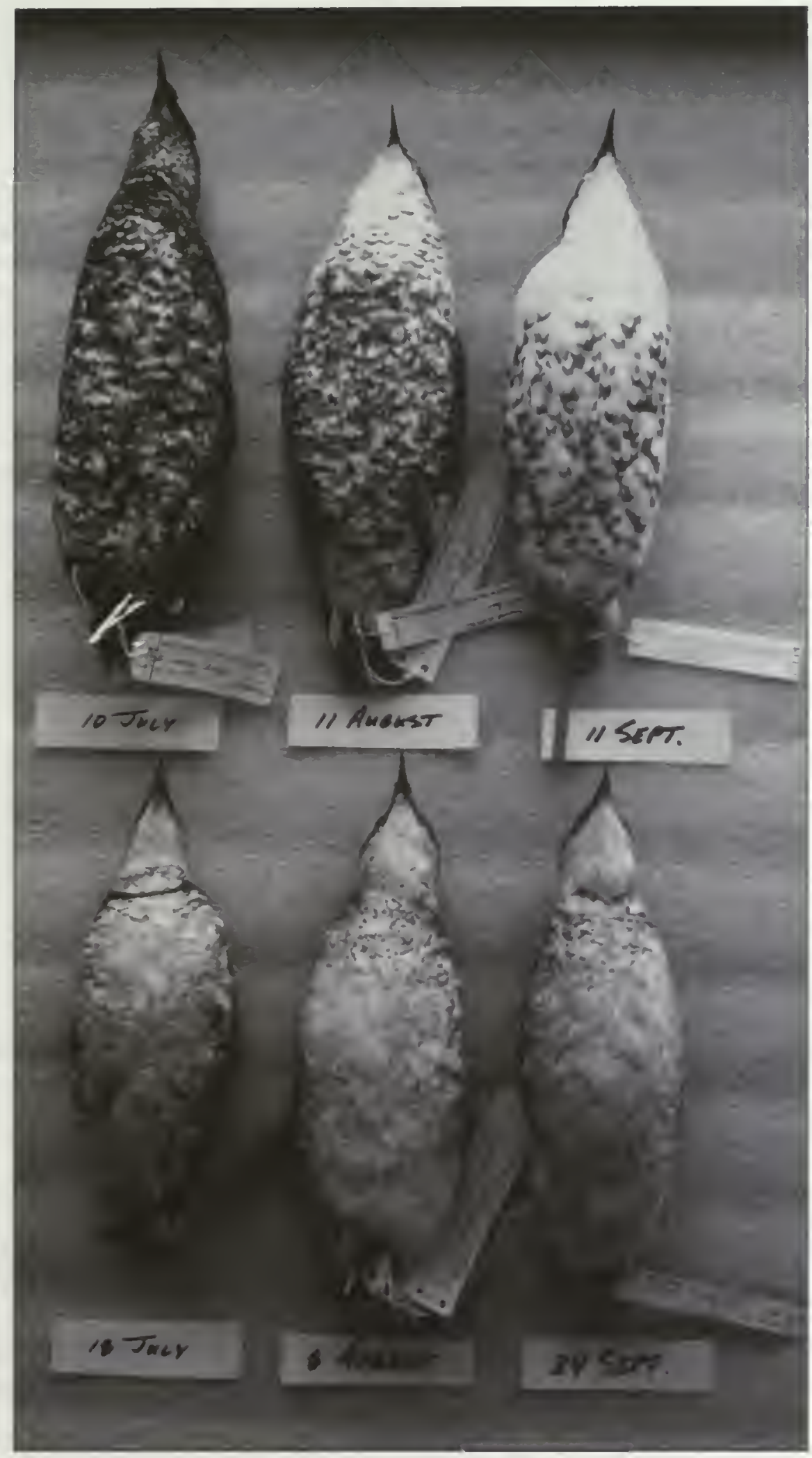

Flgure 3-Ventral plumage differences between adult Marbled Murrelets undergoing prebasic molt (top) and recently-fledged juveniles (bottom). Note the "blotchy" appearance of adult birds versus the "speckled" appearance of juveniles. Collection dates of adult specimens: 10 July 1965, 11 August 1964, 11 September 1969. Collection dates of juvenile specimens: 18 July 1920, 8 August 1961,24 September 1924. Specimens are housed at the Royal British Columbia Museum, Victoria, British Columbia. Photo taken by J.L. Stein. 
in behavior and biology. Flightless murrelets must select molting areas which provide adequate prey resources within swimming distance for about two months. Clearly, it is impossible for Marbled Murrelets to overlap breeding with the flightless pre-basic molt because they would be unable to fly to nests. In contrast, the gradually molting auklets retain flight during the pre-basic molt and do overlap pre-basic molt with breeding (Bédard and Sealy 1984, Emslie and others 1990, Payne 1965).

It is likely that the timing of molt varies between years and between different parts of the breeding range, in concert with variation in the timing of breeding and variation in local prey resources (Ewins 1988, Emslie and others 1990). It is clear that the hormonal integration of molt, breeding and other aspects of the annual cycle of the Marbled Murrelet is complex and our understanding of these processes is limited. In southern parts of the breeding range in North America where murrelets are largely resident, visitation of nesting areas does not occur during the flightless pre-basic molt, does occur during the winter period (when birds are in basic plumage), is reduced during pre-alternate molt (prior to egglaying), and then occurs throughout the breeding season by birds in alternate plumage (Carter and Sealy 1986, Naslund 1993b). Some birds that nest farther north in parts of British Columbia and Alaska appear to winter in different areas or habitats than where they breed. While a portion of the population may visit nesting areas for most of the year, a significant portion or the majority may visit nesting areas only during the breeding season (Rodway and others 1992). Such major differences in the annual cycles of differing populations undoubtedly results in complex patterns of molts and plumages in different geographic areas.

\section{Timing of Breeding and Pre-Basic Molt}

In Barkley Sound, British Columbia, Carter (1984) found that the asynchronous or protracted timing of breeding within this population of Marbled Murrelets appeared to lead to a protracted pre-basic molt period (fig. 4). Breeding occurred mainly from early April to the end of July, although it extended as late as mid-September. The first fledglings were observed on 4 July 1979 and 28 June 1980 and the last fledgling (a recently-fledged juvenile with an egg tooth) was collected on 5 October 1980. The last bird in alternate plumage was observed flying and carrying a fish on 17 September 1980.

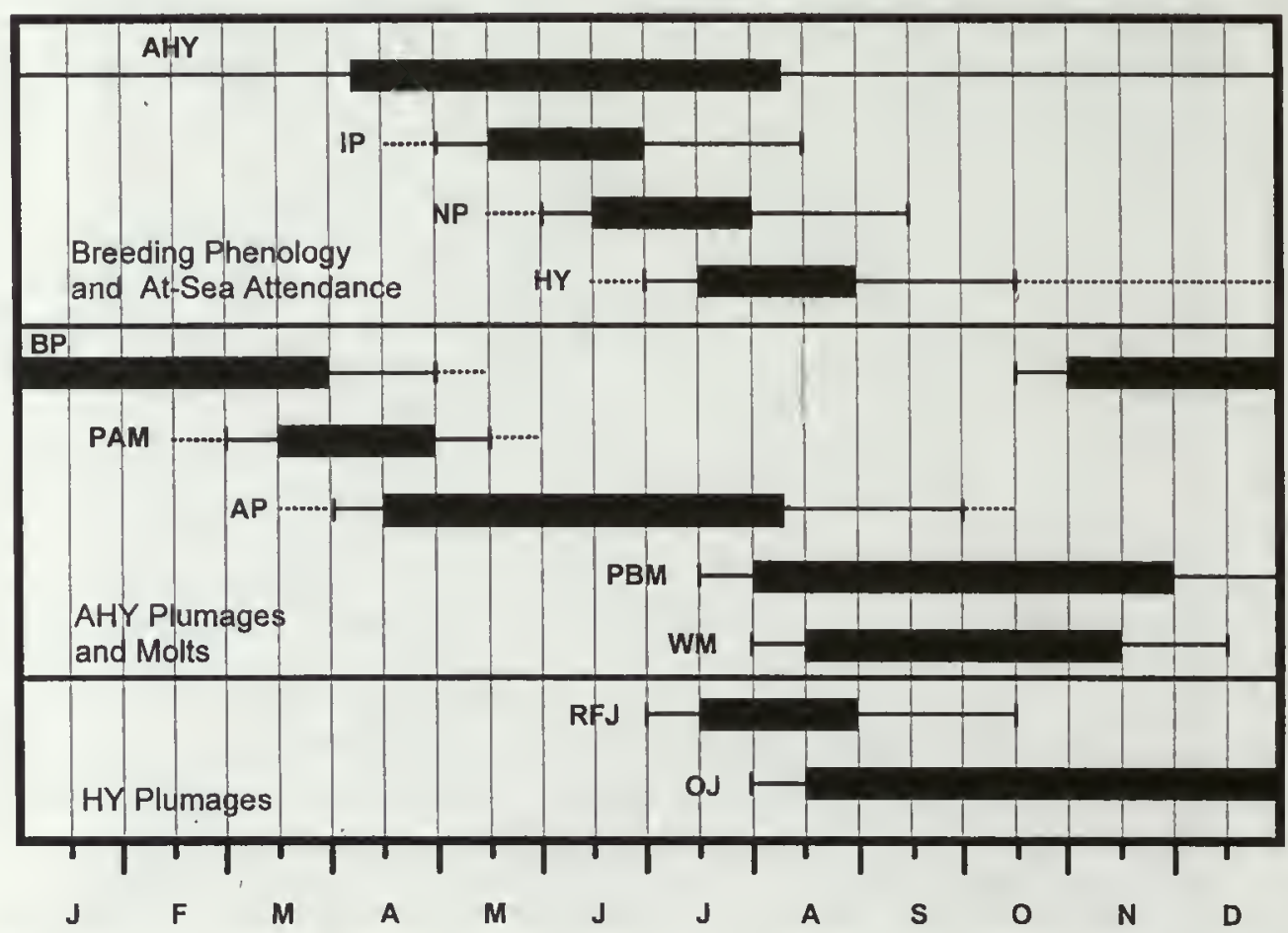

Figure 4-Annual cycle of molts, plumages, breeding phenology and attendance of at-sea feeding areas for Marbled Murrelets in southern Vancouver Island, British Columbia, in 1979-1980 (Carter 1984; Carter, unpubl. data; Sealy 1975b). Codes are: AHY (attendance by adult, after-hatching-year birds); IP (incubation period); NP (nestling period); HY (attendance by juvenile, hatching-year birds); BP (basic plumage); PAM (pre-alternate molt); AP (alternate plumage); PBM (pre-basic molt); WM (wing primary molt); RFJ (recently-fledged juvenile); and OJ (older juvenile). Thick portions of ranges indicate timing for a large proportion of the population. Thin lines indicate usual range. Dots indicate extremes. 
Most recently-fledged juveniles occurred at sea in July and August in Barkley Sound (Carter 1984, Guiguet 1971), although recently-fledged and older juveniles occurred there into early October when observations ceased (fig. 4).

To project possible timing of molt for other populations in relation to Barkley Sound, we have summarized the earliest and latest possible fledging dates for Marbled Murrelets in different areas from British Columbia to Califormia. Less is known about the average and latest fledging dates (but see Hamer and Nelson, this volume a). At Langara Island, British Columbia, Sealy $(1974,1975$ a) reported the first young on the water on 6 and 7 July in 1970 and 1971, respectively. In all of British Columbia, juveniles have been observed at sea between 28 May and 5 October (Rodway and others 1992). In Washington, the earliest known nest fledging date is 22 June 1993 (Ritchie, pers. comm.). A juvenile collected on 3 August 1950 in the San Juan Islands, Washington, still had an egg tooth (Leschner and Cummins 1992a). In Oregon, juveniles have been observed at sea as early as 15 June (Hardin, pers. comm; Nelson, pers. comm.; Strr.: $z$ and others 1993). Inland records of fledglings in Califo' nia occur from 12 June to late September whereas recently-fledged juveniles have been found at sea as early as 1 June (Carter and Erickson 1988, 1992; Carter and Sealy 1987b). In general, nesting appears to occur slightly earlier, but over the same general period from late April to September, in the southern part of its range. Thus, the timing of molt would not be expected to vary much throughout this area in relation to the timing observed at Barkley Sound, British Columbia, in 1979-1980 (fig. 4).

In Barkley Sound, British Columbia, pre-basic molt extended over a long period from miu-July to at least late November (fig. 4). The first bird undergoing pre-basic wing molt was collected on 24 July 1980 (Carter 1984). Whereas some collected birds had almost completed wing molt by mid-September, others that were still molting in early October would not have completed remigial molt until November (Carter, unpubl. data). Murrelets examined by Sealy (1975a) on 20 July at Langara Island had begun body molt on their capital and spinal tracts, but the remiges and rectrices had not begun to molt when observations ceased on 12 August. Kozlova (1957) stated that the complete molt of adult American Marbled Murrelets occurs in September and October and may extend into November, but she did not give the geographic locations of the specimens examined. She also noted that an Asian Marbled Murrelet collected in the Sea of Okhotsk on 31 August had already shed its flight and tail feathers but that other birds obtained in late August on the east coast of Kamchatka showed no traces of molt. Stresemann and Stresemann (1966) noted a rapid molt of the flight feathers that occurred between early August and late October, after examining specimens mainly from California. The closely related Kittlitz's Murrelet also undergoes a flightless pre-basic molt in Alaska between August and October (Sealy 1977). Only a few other references to molting Marbled Murrelets have been made. Smith (1959) noted a bird "in changing plumage" drowned in a fisherman's net at Cohoe
Beach, Alaska, on 22 August 1959. DeBenedictis and Chase (1963) noted one bird "in molt" on 27 July 1963 between Santa Cruz and Pigeon Point, California. Gill and others (1981) noted two flightless adults in Nelson Lagoon, Alaska, on 3 September 1977. On 1 September 1992, eight murrelets were collected in Mitrofania Bay, Alaska (Piatt, pers. comm.; Pitocchelli, pers. comm.): four birds were in alternate plumage (three with bare brood patches and one with a regressing brood patch), two birds were well into pre-basic molt and two birds were recently-fledged juveniles (with neck bands and egg teeth). In general, it appears that the timing of prebasic molt follows breeding phenology throughout their range in North America. Large numbers of molting birds occur in museum collections which still need to be summarized to confirm this generalization (Carter, unpubl. data; Becking, pers. comm.).

Failed breeders or stressed adult birds may initiate an unusually rapid body molt much earlier than the rest of the population. At Langara Island, British Columbia, Sealy (1975a) collected an adult female on 9 July 1971 with a fully developed brood patch and a flaccid ovary. This bird had already undergone a nearly complete body molt into basic plumage, without having yet started wing molt.

\section{Timing of Pre-Alternate Molt}

The timing of pre-alternate molt is more poorly known than for pre-basic molt and appears to vary between breeding adults and subadults. For the American Marbled Murrelet, Kozlova (1957) stated that the incomplete pre-alternate molt began in April and is completed by late May. Molt may be delayed until June in first-year birds. One male, collected on 31 May in the Diomede Islands, had many growing alternate plumage feathers (evident through active blood-filled papillae) on the upper parts, whereas most of the rest of the body was in basic plumage. This bird was collected north of the current breeding range for the species (Sealy and others 1982). It is possible that this bird was not molting in the usual pattern. Sealy (1975a) noted a slight delay in the pre-alternate molt in subadult murrelets at Langara Island, British Columbia. Both adults and subadults returned to Langara Island in late April. Most adults were in alternate plumage whereas subadults were still in basic plumage, although actively molting on their capital and spinal tracts. All subadults eventually achieved alternate plumage by late May (Sealy, pers. comm.). In Barkley Sound, British Columbia, two of 45 birds in alternate plumage were considered to be subadult non-breeders because they lacked brood patches and had small gonads in June and July (Carter 1984). No birds in basic plumage were observed in Barkley Sound from early May to late July (Carter, unpubl. data). Occasional summer sightings of murrelets in basic plumage have been reported to Carter from various areas along the west coast of North America but none have been confirmed with specimens or photographs. Museum specimens must be examined to further confirm that all adult birds (including first-year birds) attain the full alternate plumage during the breeding season. 


\section{Pre-Basic Molt Duration and Sequence}

The length of time required to complete the pre-basic molt is not well known because individuals have not been followed in captivity or in the wild throughout this period. In Barkley Sound, British Columbia, Carter (unpubl. data) determined that the relatively synchronous molt of the primaries, secondaries and rectrices in each individual required about 65 days but ranged between 45 and 75 days, based on a regression of molt scores and date (Pimm 1976). The entire pre-basic molt (body and remiges) probably requires about 2-3 months per individual. In adult birds, pre-basic molt occurs almost simultaneously in all body tracts. Body molt begins slightly before and ends slightly after remigial molt. In the field, body molt is visible first in the throat area, as the dark feathers are lost and replaced with white feathers. The completion of body molt proceeds from anterior to posterior in ventral feather tracts from the breast to the vent area. In some ventral areas, thick dark-margined feathers are not all lost simultaneously and some are retained for a period of time. Remnant feathers from the alternate plumage were visible mainly in abdominal areas on museum specimens we examined as late as December. The grey-edged, dark back feathers (typical of the basic plumage) gradually replace the rust-edged feathers as the molt progresses. Certain museum specimens that had not yet shed their primaries already showed some grey-edged back feathers, suggesting that molt starts earlier in this region.

During pre-basic molt, murrelets are flightless (Carter 1984), as is expected during a synchronous wing molt. Such molts are considered to be adaptive by shortening the period of feather replacement in birds with aerodynamically inefficient wings such as loons (Savile 1957, Woolfenden 1967), alcids, and diving petrels (Storer 1971, Stresemann and Stresemann 1966, Watson 1968). Stresemann and Stresemann (1966) considered the Marbled Murrelet to have an "accelerated" pre-basic molt where they incorrectly assumed that birds could barely fly during molt. Whereas murrelets are in fact flightless, they do have a less than synchronous pattern of primary replacement. Carter (unpubl. data) found that the first six primaries are lost in order and almost simultaneously; the outer four primaries are lost later. The order of feather loss and replacement is similar to gradual molting auklets and to most birds. The delay in the molt of the outer primaries also was evident in birds examined by Stresemann and Stresemann (1966). Eventually, all primaries are shed and growing at the same time. However, due to the delay in the shedding of the outer primaries, the growth of the inner primaries are completed first, leading to a rounded wing tip in birds later in the molt (fig. 5). Regardless of the delay in the outer primaries, pre-basic molt still occurs relatively rapidly. Molt duration is similar to Common Murres, Uria aalge (mean $=63$ days in nine captive birds; Birkhead and Taylor 1977) but takes longer than for ducks (e.g., 18-29 days; Bailey 1980, Balat 1970).

\section{Pre-Alternate Molt Duration and Sequence}

The duration and sequence of pre-alternate molt is even less well known. It is likely that this molt occurs more rapidly than the pre-basic molt. Carter and Erickson (1988, 1992) noted that museum specimens from California collected

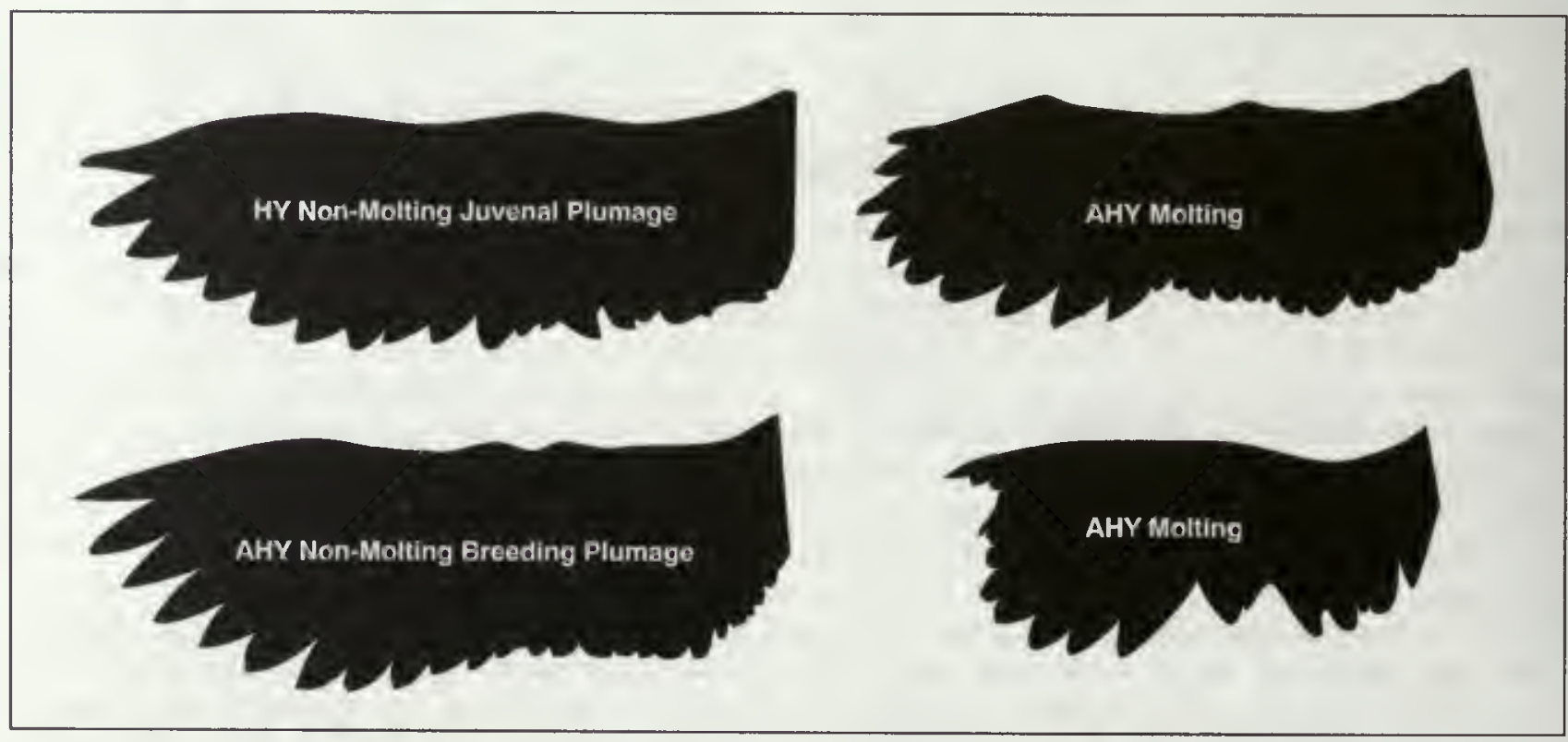

Figure 5-Wing tracings of juvenile, hatching-year (HY) and adult, after-hatching-year (AHY) Marbled Murrelets, illustrating differences between non-molting and molting birds. Molting adult birds have "stubby" wings (bottom right) if all primaries have been recently lost, or "paddle-shaped" wings (top right) as the new inner primaries grow out before the outer primaries. All birds were collected on 1 September 1992 in Mitrofania Bay, Alaska by J. Pitocchelli. Tracings by H.R. Carter. 
as early as 18 February already had some white body feathers with broad dark margins on their underparts (fig. 2). It is not likely that these represent remnant feathers that were not replaced during pre-basic molt because several specimens exhibited a similar pattern in late February. By March, many specimens were well into alternate plumage. The first bird in full alternate plumage was collected on 26 March, as were several birds on the same date. Without further information, pre-alternate molt appears to occur rapidly and requires about one month. Additional field work and examination of more specimens will better establish the full sequence of the pre-alternate body molt. However, the highest density of dark, thick-margined feathers were seen in the neck area on several spring specimens, suggesting that molt proceeds from anterior to posterior in the ventral tracts.

\section{Behavior and Diet of Murrelets During Pre-Basic Molt}

In Barkley Sound, British Co'sinbia, Carter (1984) noted that most adult birds departed $\mathrm{f}_{1}^{\prime}$ om the Sound after breeding in early August (fig. 4) and presumably underwent the prebasic molt elsewhere. However, the smaller numbers of adult birds that remained, moved into nearshore areas and underwent molt from late July to November. During this period, they occurred with juvenile birds which also did not appear to leave the Sound until at least early October. Even the smaller numbers of remaining adult and juvenile birds were mostly gone by late December 1979 (Carter, unpubl. data). Stresemann and Stresemann (1966) asserted that Marbled Murrelets molt after reaching tireir wintering areas. We presume that they reached this conclusion after examining molting birds from California where, at that time, murrelets were not known to breed. Undoubtedly, the proportion of birds that remain to molt near breeding areas rather than molt at wintering areas will depend on a variety of factors, including the timing of breeding, degree of winter residency, the timing of winter dispersal or migration, and other environmental parameters. McAllister (pers. comm.) reported that most adult birds remained in the general vicinity of summer feeding areas in southeastern Alaska but tended to occur in somewhat different areas and closer to shore during molt in September.

In Barkley Sound, flock sizes of adult birds during prebasic molt were difficult to obtain since few birds were present and it was difficult to separate molting and juvenile birds from a distance (Carter, unpubl. data). There were 30 flocks from which molting birds were collected in 19791980. Of these flocks, 10, 15, 2, 2 and 1 contained 1, 2, 3, 5 and 6 birds, respectively. The larger flocks also contained juveniles. McAllister (pers. comm.) noted the tendency for juveniles to occur very close to shore in southeastern Alaska, although he found juveniles in different areas than molting adults. Most molting and juvenile birds were observed very close to shore, usually within $200 \mathrm{~m}$, in Barkley Sound (Carter, unpubl. data). Most birds were observed in the Deer
Group islands (south of Fleming Island, mainly in Satellite Passage and near Seppings Island) and in the Broken Group islands (Sechart Channel, Coaster Channel and between Gibraltar and Nettle islands) (Carter, unpubl. data). In contrast, birds were found both in nearshore, inshore and offshore habitats in many parts of the Sound during the breeding season (Carter 1984, Sealy and Carter 1984). One adult bird that was collected on 24 July 1980 about $1.5 \mathrm{~km}$ SE of Cree Island was just beginning primary molt. Birds must swim into nearshore areas if they become flightless farther offshore.

Carter (unpubl. data) collected five pairs of molting Marbled Murrelets in Barkley Sound in the pre-basic molt period. All were male-female pairs and were probably mated. One pair had started body molt but not wing molt and the rest were all actively undergoing wing molt. All mates were almost synchronized and had very similar molt scores, despite the generally asynchronous timing of molt within the population.

During molt in Barkley Sound, adult and juvenile murrelets fed primarily on small fish of size classes II and III (fish length classes: I, $<30 \mathrm{~mm}$; II, 30-60 mm; and III, 60$90 \mathrm{~mm}$ ), primarily Pacific Herring (Clupea harengus), Pacific Sand lance (Ammodytes hexapterus) and Northern Anchovy (Engraulis mordax) (Carter 1984). On average, similar size classes (II and III) were eaten by wintering birds in December, but smaller size classes (I and II) of the same species were eaten by adults during the main breeding season.

\section{Guide for Differentiating Juvenile Murrelets from Adult Birds at Sea in Late Summer and Early Fall}

It is not difficult to differentiate a recently-fledged juvenile from an adult bird at sea in alternate or basic plumage, given adequate viewing conditions. Due to the protracted breeding season, however, many complete or partial plumages of both juveniles and adult murrelets may be encountered at sea during the late breeding and early post-breeding seasons. As mentioned previously, many factors affect counts of juveniles at sea during this time, including timing of fledging, at-sea mortality after fledging, timing of post-breeding dispersal and ocean habitats used. Highest counts will occur in suitable habitats in the post-breeding season when most or all juveniles have fledged but have not yet dispersed. However, during this period, confusion in identification occurs because adult birds undergoing pre-basic molt become difficult to separate from juveniles. In addition, older juveniles attain a first-winter plumage that is inseparable in the field from adult birds in basic plumage. Despite the difficulties of determining breeding success indirectly from surveys of juveniles at sea, such surveys are still one of the only measures of breeding success, unless larger numbers of nests can be located and monitored.

To help prevent misidentification of juveniles at sea, Stein and Carter (1994) examined museum specimens and reviewed literature and unpublished data from British Columbia, Washington, and California in order to evaluate 
five main criteria for use as an efficient, standardized method in identifying juveniles versus adult murrelets in the late breeding and early post-breeding season from June to November. The criteria examined included: (1) relative size; (2) dark:light coloration ratio; (3) ventral coloration and patterning; (4) dorsal coloration; and (5) primary molt and wing shape.

Recently-fledged juveniles are smaller than adult birds (70 percent adult mass at fledging) but become more similar to adult birds in size after foraging at sea during the first few months after fledging. Total length differed significantly between adult and juvenile birds $(t=7.52, P<0.001)$ but some juveniles collected in August and September were as long as adults collected during these months. In the field, size may be a useful criterion for differentiating juveniles from adults when mixed flocks are encountered early in the post-breeding season, but will be less useful during August and September when many juveniles have already grown at sea for at least a month.

Recently-fledged juveniles are lighter in color than adults in alternate plumage. In alternate plumage, a murrelet was estimated to have a 90:10 dark:light (D:L) ratio. In basic plumage, the ratio changed to $55: 45 \mathrm{D}: \mathrm{L}$. One molting adult collected on 19 June 1985 was 75:25 D:L. By August, more molting adults were found in the collections. Flightless adults collected on 11, 22, and 31 August measured 70:30, 65:35, and 79:21 D:L, respectively. By September, there was a larger range of color ratios. Some birds were close to completing the pre-basic molt while others were still in alternate plumage. Birds collected on 11, 16 (two specimens), 20 , and 30 September varied from 53:47, 99:1, 47:53, 85:15, and 52:48 D:L, respectively. Juvenile specimens were also examined. Generally, older juveniles appeared to be lighter overall than recently-fledged juveniles. The coloration ratio for juveniles with egg teeth averaged 65:35 D:L $(n=15)$, whereas juveniles without egg teeth averaged 58:42 D:L ( $n$ $=14$ ). Due to protracted breeding, juveniles varying in age by 2-3 months may be present on the water in August and September and be easily confused with molting adults that may have similar color ratios.

Recently-fledged juveniles possess a "speckled" appearance, resulting from many of the feathers on the sides of the head, neck, breast and abdomen being edged with thin dark margins (fig. 3). However, older juveniles without egg teeth appear lighter overall as many of the dark margins are lost. In contrast to the thin dark margins of juvenal feathers, the dark margins of the feathers of adult birds are much wider and have a "blotchy" appearance (fig. 3). As adult pre-basic molt progresses from anterior to posterior in ventral tracts, the density of blotchy feathers decreases. During boat survey work in Washington, "blotchy" feathers were often visible on the posterior ventral surface of molting adults as they dove in front of the boat (Stein, unpubl. data). This criterion was often helpful in separating adult birds that were more advanced in their pre-basic molt from juveniles. Remnant blotches or "speckled" feathers were noted on some specimens as late as November and December, but they probably would not have been noticeable in the field (fig. 1 ).

As pre-basic molt progresses in adult birds, the rustedged back feathers are gradually replaced by the greyedged, dark back feathers, typical of basic plumage. Some grey-tipped back feathers were observed on adult specimens collected as early as June although specimens in which all orange-tipped feathers had been replaced had not been collected until July. Although recently-fledged juveniles are uniformly dark brown to almost black above, the upperparts of older juveniles possess grey margins similar to adult birds. Grey-tipped feathers were not noted on juvenile specimens collected earlier than September, but were more common after this time. Dorsal surface coloration appears to be an unreliable criterion for separating older juveniles from adult birds during the pre-basic molt.

About 35 percent $(n=20)$ and 78 percent $(n=9)$ of adult birds collected in August and September, respectively, appeared flightless. Except for their flightless condition, these specimens were similar in appearance to juveniles. During August 1993 boat surveys in Washington, the condition of the molted primaries was the most reliable criterion for differentiating confusing birds (Stein, unpubl. data). Many adult birds were advanced in their pre-basic body molt by this time and could not be differentiated from older juveniles on the basis of the other four criteria mentioned above.

In summary, the number of criteria useful for differentiating juveniles from adult murrelets decreases as the post-breeding season progresses. Of the five criteria evaluated, the first four would be useful in June and July. Recently-fledged juveniles are smaller than adults ( 70 percent body weight at fledging), lighter overall, appear speckled on the throat, breast, abdomen, and are uniformly dark brown to black on the upper body parts. In comparison, most adults in June and July are still in their alternate plumage and are much darker overall with rust-edged back feathers still apparent. By August and September, most adult birds are undergoing pre-basic molt, have lost the dorsal rust coloration, have replaced many of the dark-edged ventral body feathers with totally white feathers, and appear much lighter overall. Many juveniles, which have grown at sea for at least a month by this time, lose many of the characteristic speckled feathers, either by wear or replacement. During these months, the most reliable criterion for differentiating juvenile from adult birds is the condition of the molted primaries that can be best assessed when birds flap their wings while sitting on the water. Molting adults have "stubby" wings, if all primaries have recently been lost. Later, wings appear more rounded and have a "paddle-shaped" appearance when the new inner primaries become fully grown before the outer primaries (fig. 5). Juveniles lack gaps and have more pointed wing tips than molting birds at all times. In October and November, it is not practical to separate juveniles from adult birds in the field (fig. 1), although some late breeders, late molters and late fledglings may still be encountered and differentiated on the basis of all criteria. 


\section{Acknowledgments}

Murrelet research by Carter in Barkley Sound, British Columbia, was conducted as part of a Master of Science degree at the University of Manitoba, under the supervision of Spencer G. Sealy. In particular, Sealy's encouragement, interest and involvement with regard 10 studying alcid molt patterns has made this paper possible. Funding was provided through Canadian Wildlife Service Scholarships to Carter and Natural Sciences and Engineering Research Council grants to Sealy. The Bamfield Marine Station provided facilities and support. The Washington Department of Fish and Wildlife and the
National Biological Service, U.S. Department of Interior, also provided support. We thank Michael McNall and Andrew Nieman of the Royal British Columbia Museum and Karen Cebra of the California Academy of Sciences for assistance with museum specimens. Deborah Jory Carter and Leigh K. Ochikubo assisted with the examination of museum specimens and Michael Casazza assisted with figure preparation. We are grateful for the comments provided on this manuscript by Rudolph Becking, John Kelson, Linda L. Long, Irene Manley, Michael L. McAllister, Sherri Miller, Jay Pitocchelli, Peter Pyle, C. John Ralph, Sievert Rohwer, Steven M. Speich, and especially for those by Spencer G. Sealy. 



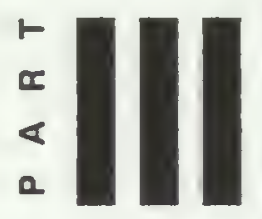

Terrestrial Environment 
$A$ 


\section{Marbled Murrelet Inland Patterns of Activity: Defining Detections and Behavior}

\author{
Peter W. C. Paton'
}

Abstract: This chapter summarizes terminology and methodology used by Marbled Murrelet (Brachyramphus marmorarus) biologists when surveying inland forests. Information is included on the types of behaviors used to determine if murrelets may be nesting in an area, and the various types of detections used to quantify murrelet use of forest stands. Problems with the methodology are also discussed.

Censusing Marbled Murrelets (Brachyramphus marmoratus) at inland forest sites presents a relatively unique problem to avian ecologists attempting to assess population trends, determine current population densities, or merely quantify the presence or absence of birds on a specific tract of land. In contrast to most avian species which tend to be relatively sedentary and territorial on their breeding grounds (see Ralph and Scott 1981), murrelets are considerably more difficult to detect near their nests (e.g., Naslund 1993a; Nelson and Hamer, this volume a; Singer and others 1991).

Murrelets tend to be detectable at inland forested sites only at dusk and dawn, and most observations are auditory detections of birds vocalizing while flying overhead (e.g., Naslund and O'Donnell, this volume; O'Donnell 1993; Rodway and others 1993b). In addition, murrelets are nonvocal near their nests (e.g., Naslund 1993a; Nelson and Hamer, this volume a; Singer and others 1991), suggesting that birds heard calling are often not near their own nest. Murrelets have been recorded as far inland as $84 \mathrm{~km}$, with downy chicks found up to $64 \mathrm{~km}$ inland (Hamer and Nelson, this volume b; Ralph and others 1994). Therefore, murrelets observed flying overhead may be great distances from their breeding stands. Finally, virtually nothing is known about what percentage of birds visiting inland sites is non-breeding birds; this can be greater than 25 percent at Ancient Murrelet (Synthliboramphus antiquus) colonies (Gaston 1990).

Detections provide a relative index to murrelet abundance, and presently have not been used to calculate density estimates. This is because individual murrelets will often circle over the forest canopy for long periods of time, vocalizing (Hamer and Cummins 1990, 1991; Naslund 1993a; Nelson 1989; Rodway and others 1993b). Therefore, a series of calls could represent a single bird or several birds. Unless a bird is under constant observation, it is usually extremely difficult to determine how many birds a series of detections actually represents.

' Biologist, Utah Cooperative Fish and Wildlife Unit, Utah State Universily, Logan, UT 84322
Although biologists have attempted to quantify murrelet use patterns on inland forested sites for about eight years, the biological significance of these data has yet to be determined. Only when an actual nest site is found can one be certain that murrelets are breeding in a particular forest stand. All other types of observations only suggest, with varying degrees of certainty, that murrelets may be nesting in a specific tract of land forest tract. There is no definitive evidence that Marbled Murrelet use inland sites for night roosts. Birds in some areas can be detected at inland sites virtually year-round (Naslund 1993b). Only within the past five years have detailed behavioral observations taken place at nest sites. This information may aid in pinpointing nest sites by determining if murrelets give any unique behavioral clues near nests sites (e.g., Naslund 1993a). Many of those data are summarized for the first time by Nelson and Hamer in this volume a.

The primary objective of this chapter is to give some sense of the types of data ornithologists have collected over the past eight years to quantify murrelet activity levels at inland forested sites. It is hoped that these data, specifically detection rates, can eventually be converted to a relative index to determine the approximate number of murrelets using a forest stand. Given the current state of the art concerning murrelet detection rates, comparisons between forest tracts are best done with data that were collected at the same time of year using similar methodology (e.g., fixedpoint count for the entire morning survey period). Given those criteria, areas that have an order of magnitude difference in detection rates (e.g., 10 detections versus 100 detections) probably have different numbers of birds using each area, but exactly how many birds a specific detection rate represents remains uncertain.

Given this brief summary of the problems with surveying murrelets at inland sites, the following summarizes the methodology used by most ornithologists to quantify murrelet activity levels at inland sites:

\section{Definition of Detection}

The primary method for censusing Marbled Murrelets at inland forested stands is surveying from fixed points for varying amounts of time: 10 minutes (Paton and Ralph 1990) to 2-3 hours (Naslund 1993a, O'Donnell 1993). The sampling unit of inland surveys is a Detection, defined as the sighting or hearing of one or more murrelets acting in a similar manner (Paton and others 1990, Ralph and others 1994). Therefore, only when the observer is certain that vocalizations are coming from the same bird or flock of 
birds, is the observation classified as a single detection. Two birds under observation simultaneously, but behaving differently, are categorized as two separate detections. Hamer and Cummins (1990) required a minimum time interval between call notes to classify an observation as two detections. The total number of birds in a detection represents the total group size. Therefore, biologists can quantify detection rates between study sites (e.g., Naslund 1993b), and also determine annual fluctuations in mean total group size at the same site (e.g., Rodway and others 1993b).

Rodway and others (1993) also suggested an alternative method to quantify murrelet activity patterns would be to count all vocalizations and visual detections, rather than keep track of total detections.

\section{Type of Detection}

Murrelet detections are generally classified into one of three categories: (1) the bird was only heard and not seen (i.e., an audio detection); (2) the bird was seen and not heard (a visual detection); or (3) the bird was both seen and heard (see Ralph and others 1994). Audio detections are usually subdivided into separate types of vocalizations and mechanical sounds, in the hope that future researchers will be able to determine the context when a specific vocalization is given. As far as I know, there is no unique vocalization given only at the nest that would aid researchers in finding nests (Nelson and Hamer, this volume a). Listed below are the current categories for types of vocalizations and visual detections.

\section{Types of Audio Detections}

(1) Keer calls-two-syllable, high-pitched vocalization, similar to the vocalizations of many gulls (Larus spp.) (O'Donnell 1993). When properly trained, there appears to be little observer bias in quantifying the number of keer calls given by murrelets (Rodway and others 1993b). During the summer months in northern California, 91.1 percent of the detected birds vocalized, compared to 98.7 percent during the winter months (O'Donnell 1993). In addition, O'Donnell (1993) found in the summer that murrelets flying above the canopy were significantly more likely $(P<.001)$ to vocalize than birds flying below the canopy. Rodway and others (1993) found the number of detections increased on cloudy days, but the number of calls per detection was not affected by weather.

(2) Non-keer calls-A low, two-part, guttural vocalization, which some researchers believe is associated with reproductive behavior. However, O'Donnell (1993) heard murrelets give non-keer vocalizations all months of the year, although at a reduced rate from December through February. In addition, O'Donnell (1993) found in his study of nine forest stands, that an average of 12 percent of murrelet detections had one or more non-keer vocalization (range = 7.5-21.9 percent). For further details, see Nelson and Hamer (this volume a) who have subdivided non-keer vocalizations into whistle- and groan-like calls.
(3) Stationary calls-Detections with three or more calls that are $100 \mathrm{~m}$ or less from the observer, where the observer believes the bird has not moved, are classified as a Stationary Detection (Ralph and others 1994).

(4) Wing beats-A tremulous, fluttering sound presumably generated by movement of a murrelet's wings through the air. Singer and others (1991) heard wing beats near active nest sites, and wing beats were also heard every morning near an active nest in northern California (Fortna, pers. comm.). Wing beats were heard on 0.5 percent of detections at nine sites in northwestern California (O'Donnell, pers. comm.).

(5) Jet dive-Little is known about the origin or function of the jet dive, or power dive, which makes a sound somewhat similar to the roar of a jet engine. It is heard rarely, comprising only 10 of 21,437 detections at nine sites in northwestern California (O'Donnell, pers. comm.). This sound is presumably a mechanical sound made by murrelet's feathers while in a steep dive above the forest canopy. Nelson and Hamer (this volume a) report in Oregon on the rare occasions when this sound is heard, it is usually near a nest tree.

\section{Visual Detections}

Rodway and others (1993) found significant variation between observers in the proportion of murrelets that were visually detected. This suggests that biologists doing field work should be screened and trained to insure that there is minimal observer bias (see also Ralph and others 1994 for training details). Categories for visual detections include:

(1) Birds flying above the canopy-This includes both straight-line flight and circling over a forest stand. This was the most frequently observed type of detection in a study of nine study areas in northwestern California, ranging from 8 to 33 percent of all detections (O'Donnell 1993). In British Columbia, 75-89 percent of all detections were birds flying over the canopy (Rodway and others 1993b).

(2) Birds flying below the canopy - This refers to murrelets both flying through a forest stand and adjacent to the stand. O'Donnell (1993) found that at Lost Man Creek in northern California, 25 percent of murrelet detections during the summer months (April-August) were birds flying below the canopy, compared to 0.4 percent during the winter months (September-March). Rodway and others (1993b) found that more birds flew below the forest canopy in June than during other times of the year.

(3) Landing and perching in a tree-O'Donnell (1993) found 0.4 percent of the total summer detections (AprilAugust) at Lost Man Creek were of birds landing in trees ( $n$ $=10,154$ ), although no nests were found in this area. At two active nests, Naslund (1993a) observed birds flying to the nest for incubation exchanges 31 minutes before sunrise to 3 minutes after sunrise (see also Nelson and Hamer, this volume a). Adults typically took predictable flight paths to the nest (Nelson and Hamer, this volume a). Murrelets incubate for 24-hour bouts (Naslund 1993a, Nelson and Hamer, this volume a, Singer and others 1991). Nest exchanges and feedings generally took place 17-24 minutes before sunrise, with two 
daytime feedings 82 and 150 minutes after sunrise (Naslund 1993a, see also Nelson and Hamer, this volume a).

Below are some relevant definitions useful to biologists studying Marbled Murrelets, based on Ralph and others (1994):

Potential Nesting Habitat-(1) mature or old-growth coniferous forests; mature forest can be with and without an old-growth component (see Ralph and others 1994, Raphael and others, this volume); (2) younger coniferous forests that have large, deformed trees or structures suitable for nesting.

Forest Stand-a group of trees that forms a continuous, relatively homogeneous, potential nesting hahitat with no gaps $>100 \mathrm{~m}$.

Survey-The process of determining the presence, absence, and occupancy of Marbled Murrelets in a forest stand. Surveys generally are conducted during the morning hours, when detection rates are greatest (Paton and others 1990; Ralph and others 1994; Rodway and others 1993b). In addition, surveys generally occur from May through July when detection rates peak (e.g., Rodway and others 1993b); however, murrelets are known to visit inland forest stands throughout the year (Naslund 1993b; O'Donnell 1993; O' Donnell and Naslund, this volume).

Intensive Survey-Designed to determine the probable presence, absence, or occupancy of Marbled Murrelets in a specific tract of land. When conducting an intensive survey, the observer surveys from one point for the entire morning survey period. Under most forest conditions, observers can see murrelets within $100 \mathrm{~m}$, and hear them within $200 \mathrm{~m}$ (Ralph and others 1994). Therefore, approximately 12 ha ( $\pi$ $\times[200 \mathrm{~m}]^{2}=12.6 \mathrm{ha}$ ) can be adequately surveyed from a single point for auditory detections, while only 3.14 ha can be monitored for visual detections. Under certain conditions, visual and auditory ranges are reduced (e.g., next to a stream or under a dense forest canopy). Surveys generally are conducted from 45 minutes before sunrise to 75 minutes after sunrise (Paton and others 1990, Ralph and others 1994), although surveys at northern latitudes start and end earlier (e.g., Kuletz and others, this volume; Rodway and others 1993b). The exact methodologies for Intensive and General Surveys are detailed in Ralph and others (1994).

General Survey-A survey designed to determine the geographic distribution of Marbled Murrelets over large tracts of land (e.g., states, counties, basins). General surveys are exploratory in nature and cannot be used to confirm murrelet absence from specific forest stands. These surveys consist of a transect of 8-10 stations surveyed during a 2hour period each morning. Stations are spaced 0.5-1.0 km apart, depending on terrain, with each station surveyed for 10 minutes.

Survey Area-the entire area being surveyed.

Survey Visit-a single morning's visit.

Survey Site-an area containing $\geq 1$ survey station.

Survey Station-the exact location where an observer stands to survey murrelets.

Occupied Stand-a forest stand, consisting of potential nesting habitat, where murrelets were observed exhibiting subcanopy behaviors associated with nesting. Quantitative information on murrelet behavior near nests is scarce; however, some data are available from Naslund (1993a), and Nelson and Hamer (this volume a). Data collected by Naslund (1993a) suggests that only 6-21 percent of the detections $\leq 100 \mathrm{~m}$ from known active nests represent "occupied behaviors" (see below), while most detections near nests were birds flying above the canopy. The proportion of detections which were categorized as occupied behaviors was not affected by weather conditions (i.e. cloud cover, ceiling), although the total number of detections increased significantly on cloudy days (Naslund 1993a, Rodway and others 1993b).

\section{Evidence for Nesting:}

Seven different categories are considered indicators of nesting. They are listed below with varying degrees of certainty that murrelets are nesting in a particular forest stand. Only categories 1-3 listed below provide confirmation of breeding, whereas categories 4-7 are occupied behaviors, which are behaviors that suggest that murrelets could be nesting in a specific forest stand.

\section{Confirmation of breeding:}

(1) Discovery of an active nest-either with an incubating adult, brooding adult and chick, or pre-fledged chick.

(2) Obvious signs of recent nesting activity - such as fecal rings surrounding the nest or eggshell fragments in a nest scrape.

(3) Discovery of a chick or eggshell fragments on the forest floor-see Becking 1991, and Ralph and others 1994 for detailed information on the characteristics of murrelet eggs.

\section{Occupied behaviors:}

(4) Birds flying below the top of the forest canopy (also called subcanopy behaviors; Ralph and others 1994)-This refers to murrelets either flying through the stand, into or out of the stand, or adjacent to a forest stand, the weakest evidence in this category (O'Donnell and Naslund, this volume; Rodway and others 1993b). Because tree heights can vary, a bird observed at or below the height of the top of the tallest tree visible to the observer would be classified as a subcanopy detection. Based on observations at active nests, only silent birds are probably near an active nest (Naslund 1993a, but see Nelson and Hamer, this volume a). This category includes birds flying over or along roads, young stands, or recently harvested areas adjoining potential nesting habitat. In these latter two instances, only the adjacent potential nesting habitat should be classified as occupied. Subcanopy behaviors are currently thought to be the strongest indirect evidence of nesting in a stand (Ralph and others 1994).

(5) Birds circling above the forest canopy at any radiiCircling is common flight behavior over occupied sites. However murrelets have also been observed circling over young or non-forested habitats (Hamer and Cummins 1990, 
1991; Nelson 1989, 1990a). In most instances, these areas of apparently unsuitable nesting habitat were near or adjacent to potential nesting habitat. Circling is currently believed to be fairly strong evidence that a stand is occupied (Ralph and others 1994).

(6) Birds seen perching, landing, or attempting to land on tree branches-There are a total of six flight behaviors recorded near known active nests (Naslund 1993a; Nelson and Hamer, this volume a; Singer and others 1991). Birds landing in trees could indicate nest sites, although I know of no evidence to suggest that murrelets commonly perch in trees near active nests. Therefore, perching is currently not definitive evidence there is a murrelet nest in the area. During observations of two nests in Big Basin State Park, California, Naslund (1993a) found that, during incubation exchanges, the adults always flew directly to the nest branch without vocalizing (with one exception), landed directly on the nest branch, and then walked to the nest (see also Nelson and Hamer, this volume a).

(7) Birds calling from a stationary location within the stand.-This category only applies to detections with $\geq 3$ calls heard and a bird $<100 \mathrm{~m}$ away. Adult and juvenile murrelets are generally quiet while on the nest limb (Nelson and Hamer, this volume a). Naslund (1993a) never heard adults give loud vocalizations from the nest while incubating or brooding. Because adults and juveniles tend to be relatively quiet on the nest, this category is probably weak evidence for an active nest in the area, at least for the murrelet giving the vocalizations. Further research is needed to quantify the types of behaviors given at active nests.

\section{Presence}

When murrelets are detected, but no occupied behaviors are observed, then observation is categorized simply as "presence".

\section{Discussion}

Most biologists conducting murrelet surveys use detections, defined as the sightings or hearing of individuals or flocks behaving similarly, as the independent sampling unit. The primary variable when comparing studies is the amount of time observers remain at survey stations, which can range from 10 minutes to 3 hours. Most inland surveys conducted to date have concentrated on the breeding season (April through August). However, a recent paper by Naslund (1993b) suggests that surveys during the winter months may be more useful for monitoring long-term population trends. This was because variability in detection rates is relatively low in the winter months compared to breeding season surveys. Currently, we have no basis to convert detection rates into density estimates, and it is unclear when ornithologists will be able to determine an accurate conversion factor. However, Ralph (pers. comm.) and Miller (pers. comm.) recently have been working on determining a conversion factor, using a combination of offshore survey data and intensive inland surveys. Data that have been gathered to date will provide baseline data for future researchers, and can be used for comparative purposes across studies to provide relative indices to murrelet activity patterns.

\section{Acknowledgments}

I thank Peter Connors, Steve Courtney, Dave Fortna, Anne Harfenist, Gary Kaiser, Brian O’Donnell, C.J. Ralph, Lynn Roberts, Michael Rodway, and Fred Sharpe for useful comments on earlier drafts of this paper. 


\section{Patterns of Seasonal Variation of Activity of Marbled Murrelets in Forested Stands}

\author{
Brian P. O'Donnell'
}

\author{
C. John Ralph ${ }^{3}$
}

\begin{abstract}
Determining the annual cycles of Marbled Murrelet (Brachyramphus marmoratus) behavior is crucial both for understanding the life history and for management of this species. In this paper we review available information on the annual patterns of behavior in forests throughout its range, with special emphasis on California. Data were derived from standardized forest surveys. Murrelet activity peaks during the summer (breeding season), is lower during the winter (non-breeding season), and absent or very low during transition periods (pre-alternate and pre-basic molts). Murrelets are regularly detected at some breeding stands even in the non-breeding season, however, birds are rarely observed flying through or below the forest canopy during this period. Vocalizations and flock size exhibit seasonal variation as well. While certain aspects of seasonal activity and behavior patterns conform with our limited understanding of its life history, much of the species' behavior within the forest remains a mystery. Current guidelines for monitoring the Marbled Murrelet at inland sites restrict surveys for management purposes to the breeding season.
\end{abstract}

Determining the annual cycles of Marbled Murrelet (Brachyramphus marmoratus) activity and behavior at inland sites is important for an understanding of this species' life history and its management. In order to assess the probable presence of nesting murrelets in a forest stand, we must first know how their behavior in the forest changes through the year, and what these seasonal changes tell us about its biology. With this information in hand, we can then determine how best to develop a survey protocol. In this chapter we review available information on the annual cycles of activity and behavior in the forest. We draw heavily from the results of two studies in California (Naslund 1993,b; O'Donnell 1993). Data in these studies were collected using intensive survey techniques (Paton, this volume; Paton and others 1990; Ralph and others 1994). Additional information, derived from general and intensive survey techniques, are reported from studies throughout the range of the species. As the measure of activity we use the "detection": the observation of one or more birds acting in a similar manner.

\footnotetext{
${ }^{1}$ Wildlife Biologist, Pacific Southwest Research Station, Redwood Sciences Laboratory, USDA Forest Service, 1700 Bayview Drive, Arcata, CA 95521

${ }^{2}$ Wildlife Biologist, U.S. Fish and Wildlife Service, U.S. Department of Interior, 1011 E. Tudor Road, Anchorage, AK 99503

${ }^{3}$ Research Biologist, Pacific Southwest Research Station, Redwood Sciences Laboratory, USDA Forest Service, 1700 Bayview Drive, Arcata, CA 95521
}

\section{Variation in Detection Levels}

Numbers of detections vary dramatically through the year, and in general, are greatest during the summer months. Detection levels were compared between months through the year in two studies in California. Naslund (1993a) compared detections at two sites in central California between three periods: (1) breeding season-April through July; (2) transition periods-March, and August through October; and (3) winter-November through February. She found detections were significantly greater during the summer period (table 1). O'Donnell (1993) also found significant differences between months at each of three sites in northwestern California. He found that mean numbers of detections per survey were greatest in July at all sites (fig. I). Mean numbers of detections per survey in April through June ranged from 28 to 62 percent of those in July, and mean detections per survey in May and June were always intermediate between those in April and July.

Murrelet detection levels also tended to peak during July and early August in most locations to the north of California. In Oregon, Nelson (1989) found the greatest detection levels from 12 July to 9 August at sites (fig. 2). She also noted an early period of high activity in late May and early June. The two activity peaks were detected during both dawn and evening surveys. During the 1990 breeding season in northwestern Washington, Hamer and Cummins (1990) noted 60 percent of all detections occurred between 25 June and 27 July (fig. 3). Numbers of detections per survey were greatest from mid-July through the end of the month. In the following summer, 77 percent of all detections were recorded between 8 July and 11 August, with the greatest numbers of detections per survey occurring in the week of 22 July (Hamer and Cummins 1991) (fig. 4). During 1990, weekly mean numbers of detections of murrelets peaked in the last week of July at two sites in the Queen Charlotte Islands, British Columbia (Rodway and others 1993b) (figs. 5, 6). However, detection levels at sites on Vancouver Island, British Columbia, reached their greatest levels in late June (Manley and others 1992) (fig.7). At a site on Mitkof Island, in southeastern Alaska, where Doerr and Walsh have conducted one to three morning surveys each month since December 1992, the numbers of detections peaked in July (Doerr, pers. comm.; Walsh, pers. comm.). Kuletz and others (1994c) found that seasonal peaks of murrelet activity in Prince William Sound, Alaska, were similar to those reported for the more southerly areas of the species' distribution (figs. $8,9)$. They also noted an early period of greater activity in 
Table 1-Variations in Marbled Murrelet detections by season at the Waddell Creek and Opal Creek nest sites. Results are given for each ANOVA comparing total detections, occupied detections, and percent of occupied detections between seasons

\begin{tabular}{|c|c|c|c|c|c|c|c|c|c|c|}
\hline \multirow[b]{2}{*}{ Variable } & \multirow[b]{2}{*}{$n$} & \multicolumn{3}{|c|}{ Total detections } & \multicolumn{3}{|c|}{ Occupied Detections } & \multicolumn{3}{|c|}{ Percent Occupied $^{\mathrm{a}}$} \\
\hline & & $\bar{x}$ & s.d. & (range) & $\bar{x}$ & s.d. & (range) & $\bar{x}$ & s.d. & (range) \\
\hline \multicolumn{11}{|c|}{ Waddell Creek } \\
\hline \multicolumn{11}{|l|}{ Season } \\
\hline Summer & 32 & 50 & 32.8 & $(18-176)$ & 5 & 8.6 & $(0-45)$ & 18.6 & 17.1 & $(0-55.6)$ \\
\hline Transition & 16 & 12 & 17.1 & $(0-49)$ & 0 & 0.6 & $(0-2)$ & 8.7 & 25.5 & $(0-100.0)$ \\
\hline Winter & 2 & 17 & 2.8 & $(15-19)$ & 1 & 0.7 & $(0-1)$ & 16.7 & 23.6 & $(0-33.3)$ \\
\hline ANOVA & & $F=14.6$ & $\mathrm{df}=2$ & $P=0.0001$ & $F=4.11$ & $d f=2$ & $P=0.0230$ & $F=2.79$ & $\mathrm{df}=2$ & $P=0.0723$ \\
\hline \multicolumn{11}{|l|}{ Opal Creek } \\
\hline \multicolumn{11}{|l|}{ Season } \\
\hline Summer & 18 & 100 & 28.5 & $(59-159)$ & 2 & 2.1 & $(0-7)$ & 6.3 & 6.1 & $(0-21.7)$ \\
\hline Transition & 11 & 25 & 41.5 & $(0-121)$ & 0 & 0.3 & $(0-2)$ & 0.2 & 0.7 & $(0-2.4)$ \\
\hline Winter & 2 & 80 & 22.6 & $(64-96)$ & 0 & 0.0 & & & & \\
\hline ANOVA & & $F=16.51$, & $\mathrm{df}=2$ & $P=0.0001$ & $F=2.51$ & $\mathrm{df}=2$ & $P=0.1019$ & $F=7.92$ & $\mathrm{df}=2$, & $P=0.0022$ \\
\hline
\end{tabular}

a Percent of detections $\leq 100 \mathrm{~m}$ from the observer

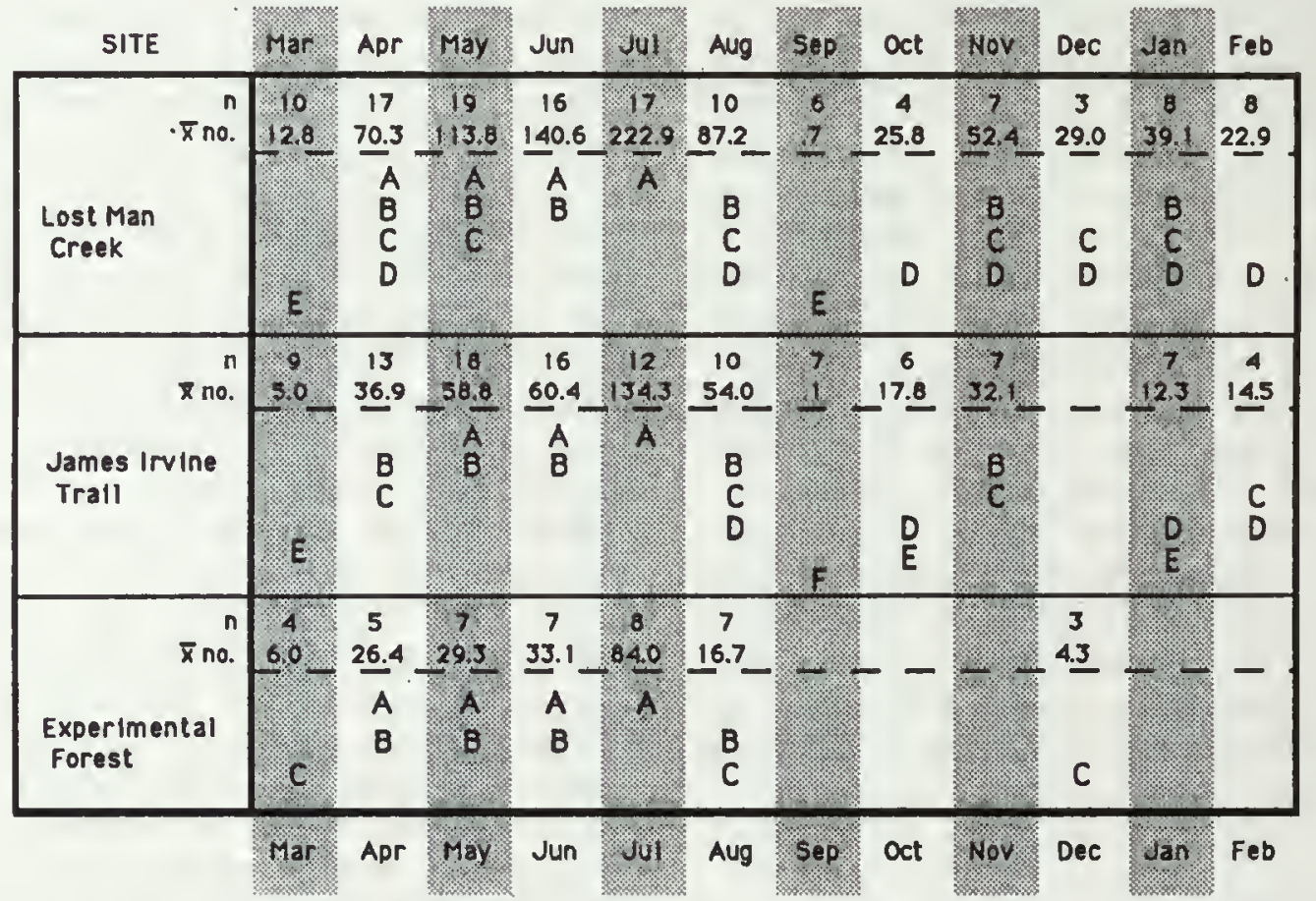

Flgure 1-Results of Ryan-Einot-Gabriel-Welsh multiple range test companing numbers of detections of Marbled Murrelets per survey between months at three sites in northwestem California, 1989-1991. Months with the same letter indicate that the mean numbers of detections were not significantly different from each other. " $n$ " indicates the number of surveys in the respective month and " $\bar{x}$ no." is the mean number of detections per survey. Means presented are untransformed values. Surveys from all years were combined for the analysis, and months with less than three surveys were not included in the analysis. From O'Donnell 1993. 


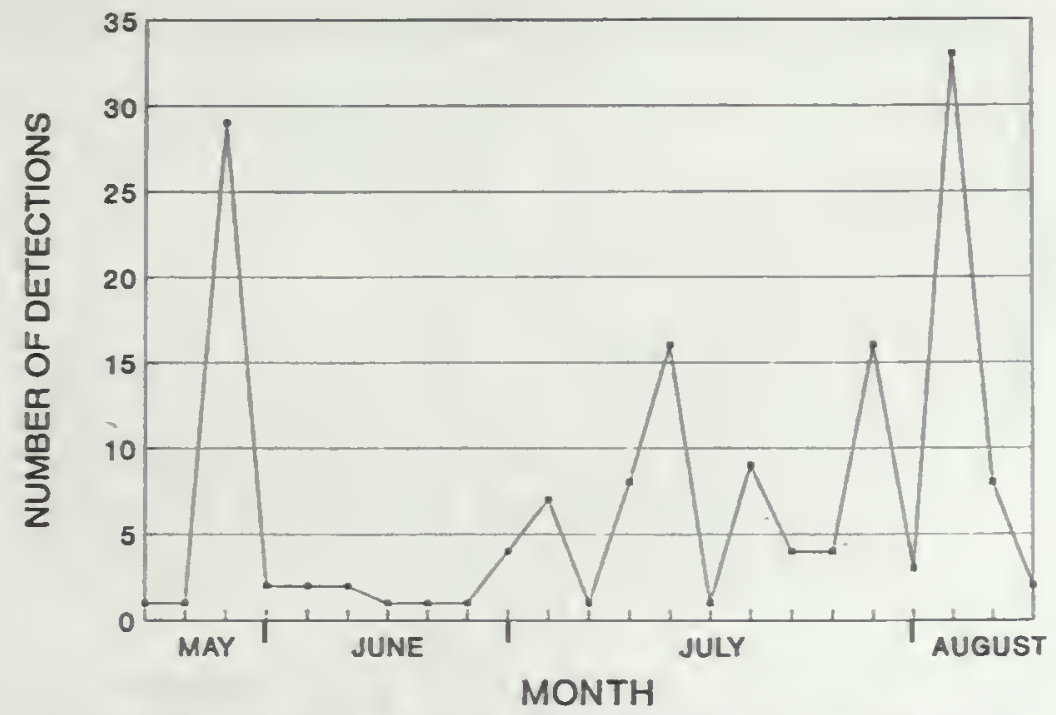

Figure 2-Number of detections of Marbled Murrelets by survey month on 20 general surveys (Paton, this volume) along roads, central Oregon Coast Range, 1988. From Nelson 1989.

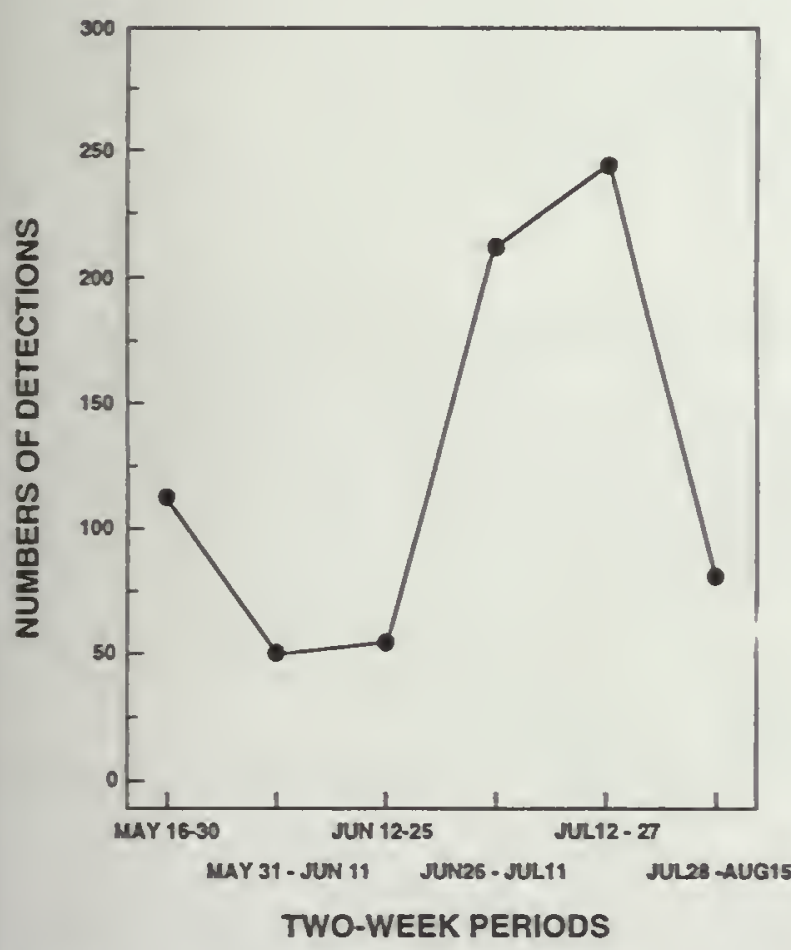

Figure 3-Total number of Marbled Murrelet detections for each two-week period from 16 May to 15 August, 1990, at 41 sites (245 survey mornings) in nortwwestern Washington. From Hamer and Cummins 1990.

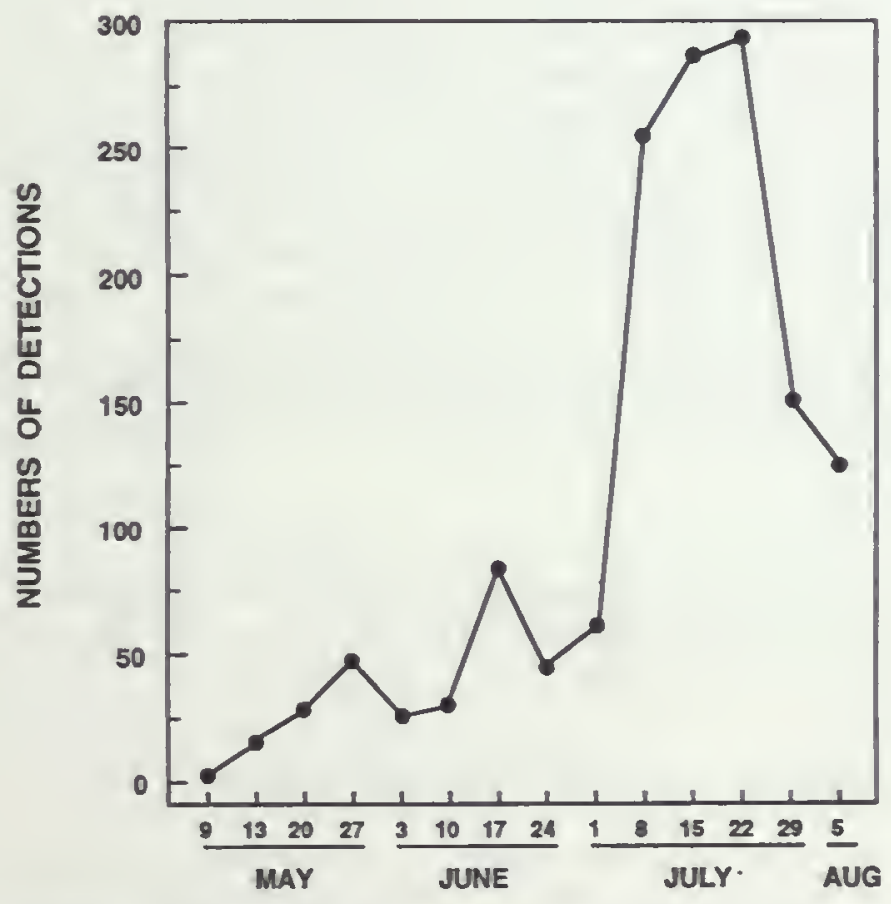

Figure 4-Total number of Marbled Murrelet detections for each oneweek period from 9 May to 9 August, 1991, at 75 sites (287 survey mornings) in northwestern Washington. From Hamer and Cummins 1991. 


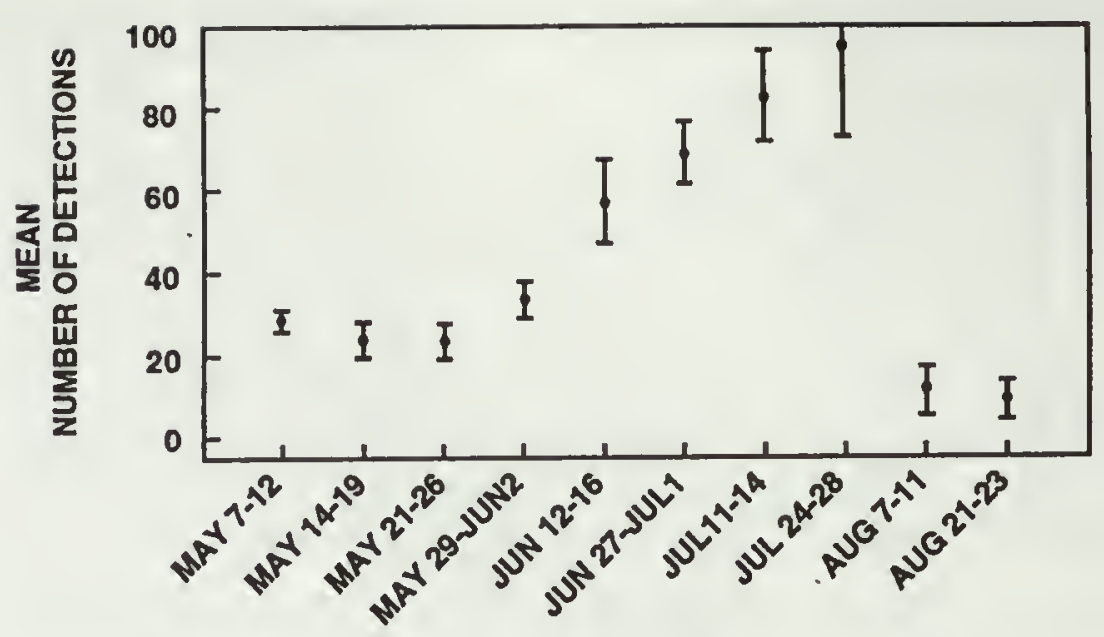

Figure 5-Weekly mean (t s.e.) numbers of Marbled Murrelet detections per survey at Phantom Creek, British Columbia, in 1990. A total of 49 morning surveys were conducted. From Rodway and others 1993b.

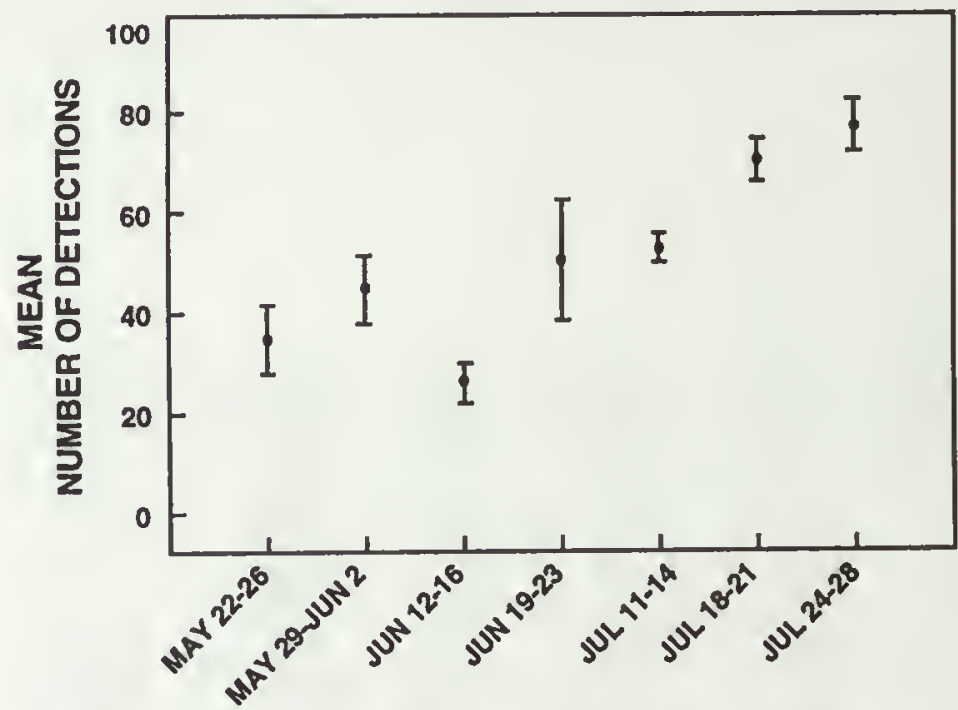

Figure 6-Weekly mean ( \pm s.e.) numbers of Marbled Murrelet detections per survey at Lagins Creek, British Columbia, in 1990. A total of 33 morning survey were conducted. From Rodway and others 1993b.

late May, similar to that reported by Nelson (1989). At two sites, detection levels during this period were approximately equal to or even exceeded those during July.

\section{Patterns of Detections in Winter}

Winter attendance at breeding stands is well documented for California (figs. 10, 11). For example, Sander (1987) detected murrelets on 66 percent of 53 mornings surveyed between January and mid-March at a site in northwestern California. Carter and Erickson (1988) also report on the detection of murrelets from January through March at Big Basin State Park (central California) over several years.
Murrelets have also been detected at forest stands during the winter in Oregon (Nelson, pers. comm.), Washington (Hamer, pers. comm.), and southeastern Alaska (Naslund, unpubl. data; Walsh, pers. comm.).

At the three sites in northwestern California, O'Donnell (1993) found that mean numbers of detections per survey during the winter months (November through February) ranged from nine to 24 percent of mean levels in July, with detection numbers in November consistently the greatest in this period. Naslund (1993b) found that mean numbers of detections for winter surveys ranged from 35 to 80 percent of mean summer detection levels for five sites in central California (fig. 12). Doerr and Walsh noted similar differences between winter 


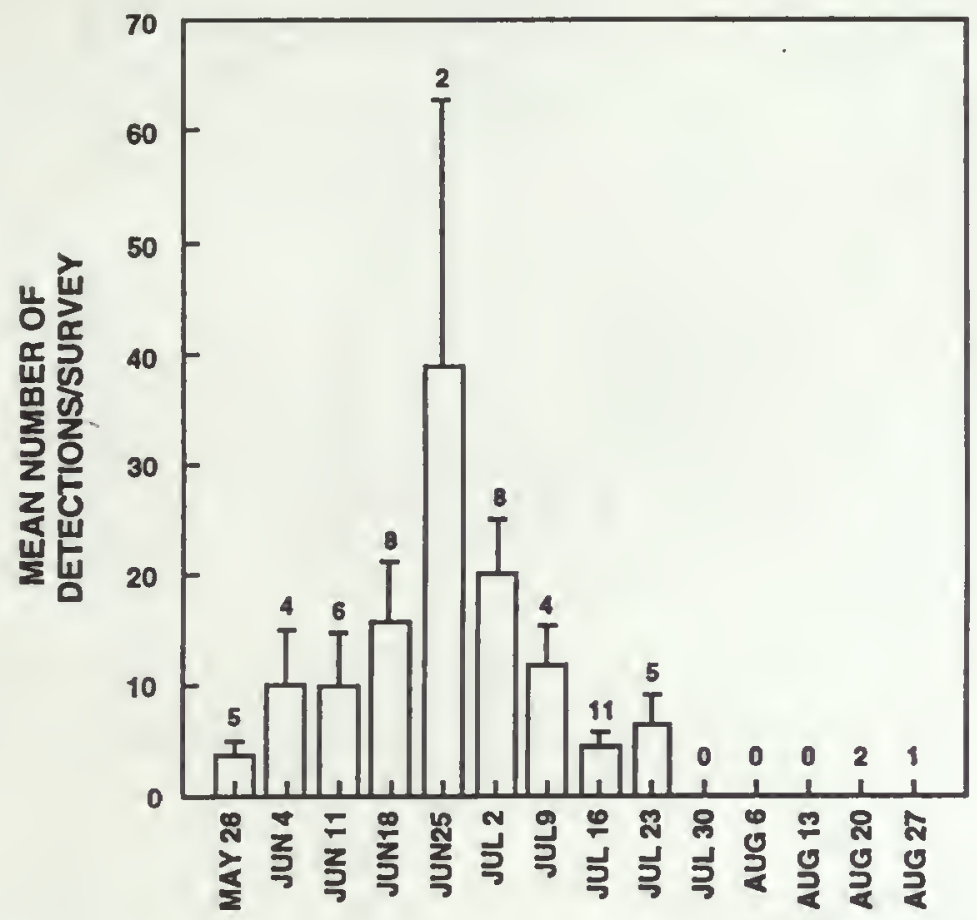

WEEK BEGINNING

Figure 7-Weekly mean numbers (bar segment) of Marbled Murrelet detections per survey per week along upper Carmanah Creek, British Columbia, 28 May to 27 August 1990. The standard error (line segment) and number of surveys in each week are also given. From Manley and others 1992.

and summer detection levels on Mitkof Island, Alaska (Doerr, pers. comm.; Walsh, pers. comm.).

The remaining two months, March and September, had low to no activity (Naslund 1993b, O'Donnell 1993). In northwestern California, detections in March ranged from four to seven percent of those in July, and September levels were less than one percent of July levels. Detection levels in March and September were usually significantly lower than all other months (O’Donnell 1993).

\section{Patterns of Absence from Stands}

Marbled Murrelets are most often absent, or in much reduced numbers, from breeding stands during the two transition periods: (1) March, and (2) mid-August through October (Naslund 1993b, O’Donnell 1993) (figs. 10, 11). Doerr and Walsh failed to detect murrelets from 27 August to 2 October 1992, at their study site on Mitkof Island, Alaska (Doerr, pers. comm.; Walsh, pers. comm.). In central California, from 1989 through 1991, the proportion of surveys in August through October with murrelets present was significantly lower than for surveys in summer, in winter, or in March (Naslund 1993a). Similarly, murrelets were observed on a significantly smaller proportion of surveys in March than during summer or winter (Naslund 1993a) (fig. 13). At nine sites in northwestern California from 1989 through 1991 , murrelets were not detected on 33 percent of 30 surveys conducted in March, nor on 31 percent of 80 surveys conducted in August through October (O'Donnell 1993). In addition, surveys with no detections occurred with significantly greater frequency from November through February than from April through July. Murrelets were not detected on 10 of 71 counts conducted from November through February, while birds were detected during all but one of 227 surveys from April through July (O’Donnell 1993).

\section{Variation in Frequency of Behaviors and Flock Sizes}

\section{Flight Altitude}

The behavior classes recorded during murrelet surveys differentiate between two classes of behaviors, those occurring above the forest canopy, and those at the top, below, and within the forest canopy. These latter behaviors occurring at or below the canopy we will refer to as "below canopy behaviors", and are considered most indicative of probable nesting (Ralph and others 1993). They have also been referred to as "occupied behaviors", that is, indicative of birds occupying a given stand for nesting. Studies in California (Naslund 1993b, O'Donnell 1993) found that the numbers of different behaviors, both above and below the canopy, differed significantly between months through the year (table 1). O'Donnell (1993) detected murrelets flying above the canopy throughout the year at three sites in northwestern California. The patterns of behaviors 

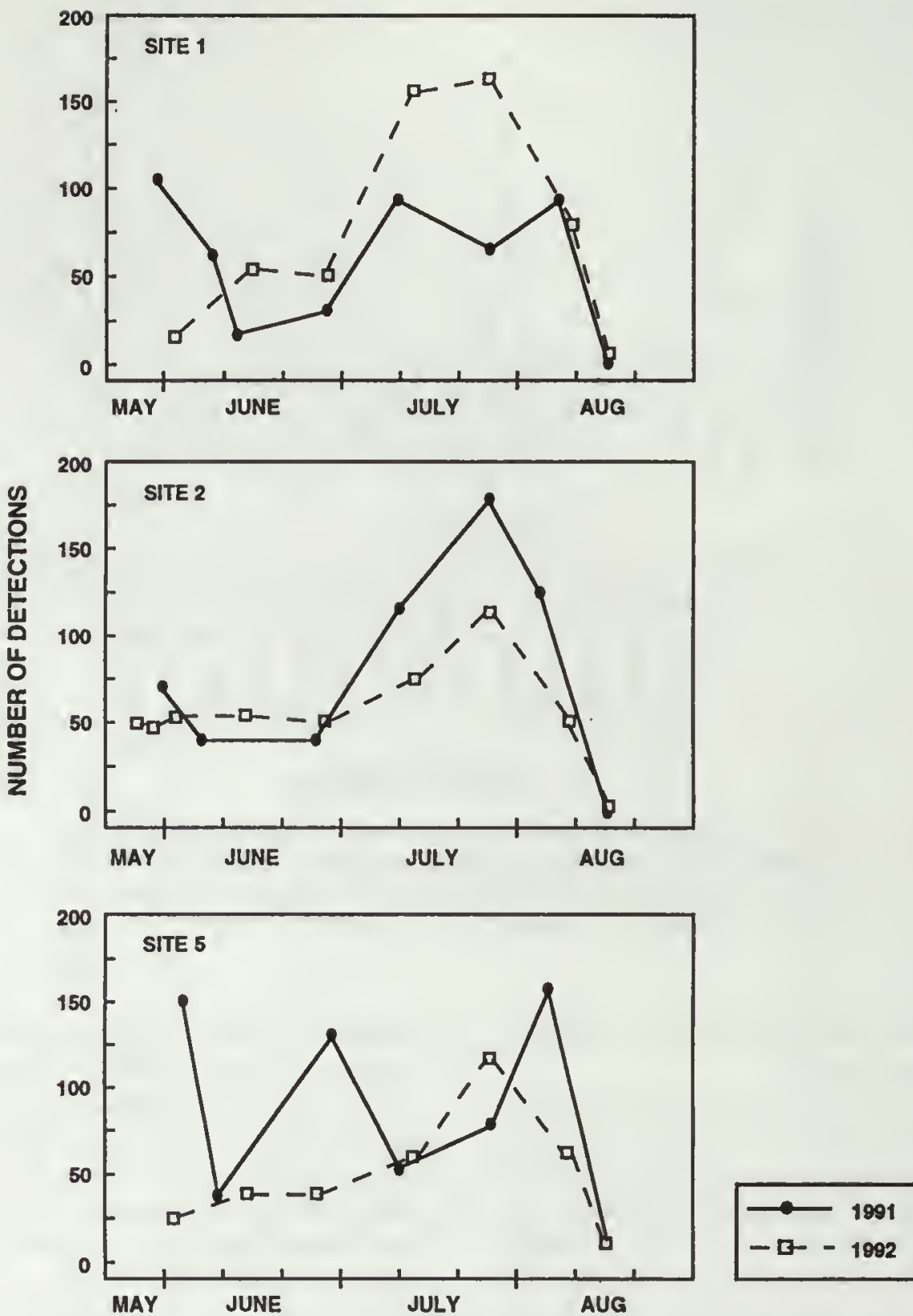

Figure 8-Numbers of detections of Marbled Murrelets per survey at three sites on Naked Island in Prince William Sound, Alaska, during the 1991 and 1992 breeding seasons. From Kuletz and others 1994c.

above the canopy at Lost Man Creek (fig. 14a) are representative of those at the two other sites. Numbers of these behaviors were greatest during the breeding season, reaching a peak in July, and lowest during the non-breeding season, with a small winter peak in November (fig. 14b).

Below canopy behaviors showed a more pronounced seasonality (fig. 14a) at Lost Man Creek and are representative of the two other sites. Naslund (1993a) found that only a small percentage of detections recorded near two nest trees during the winter, non-breeding season (October through March) consisted of below canopy behaviors (table 1). Similarly, at Lost Man Creek, below canopy behaviors made up 24.7 percent of detections from April through August, while from September through March, of 1,185 detections, only five were of murrelets flying below the canopy. Numbers of occupied behaviors were segregated by a multiple range test into three periods at Lost Man Creek (fig. 14b), reflecting peak levels in July, lower levels during the remainder of the breeding season, and their absence in the non-breeding season.

\section{Vocalizations}

O'Donnell (1993) examined seasonal differences in the number of calls per detection at two sites in northwestern California, Lost Man Creek and James Irvine Trail. Detections with greater then 9 calls were assigned a value of ten for the analysis. The number of calls per detection 


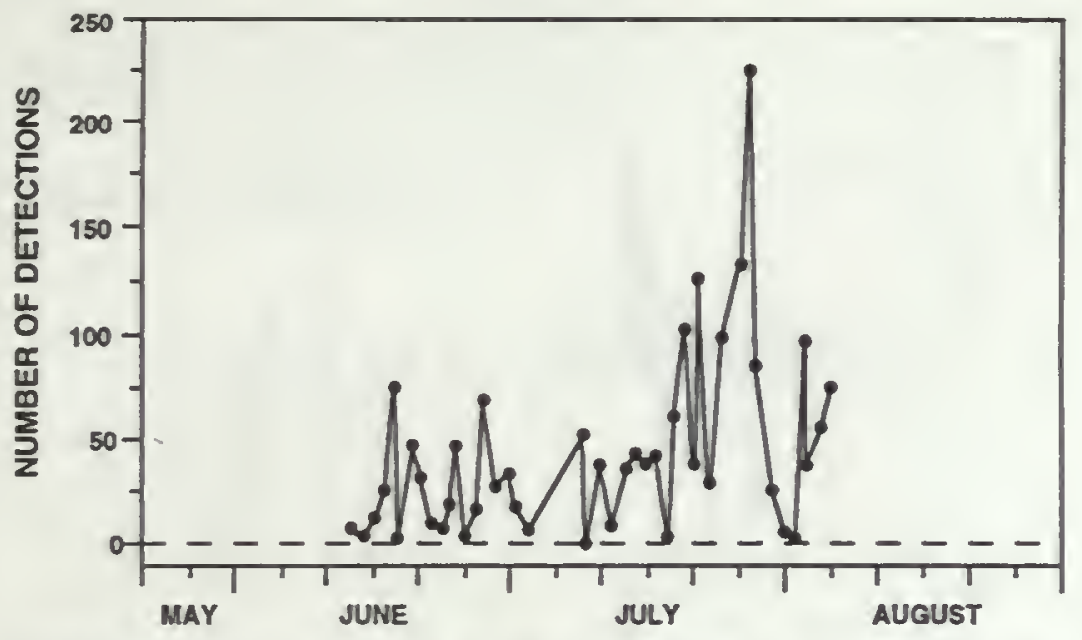

Figure 9-Numbers of detections of Marbled Murrelets throughout westem Prince William Sound, Alaska, during the 1992 breeding season. Data was collected at 67 randomly selected (boat-based) sites. From Kuletz and others 1994C.

was greater during the winter, from October through February, than from March through August at both sites. For instance, at Lost Man Creek the mean numbers of calls per detection ranged from 7.4 to 9.3 from October through February. From March through August mean calls per detection ranged from 3.7 to 6 .I at this site. Numbers of calls were significantly different between months only at Lost Man Creek.

Rodway and others (1993b) compared levels of vocalizations between months at two sites in the Queen Charlotte Islands, British Columbia. Months compared were May through July at the Lagins Creek site, and May through August at the Phantom Creek site. They examined changes in both the number of calls per detection (all calls counted), as well as number of calls per survey (detections with "multiple" calls assigned a value of 25). Number of calls per detection were similar in May, June, and July at both sites. At Phantom Creek, vocalization levels dropped significantly after July 24. Number of calls per survey increased through July, reaching peaks in the last week of July at both sites, and falling rapidly in the second week of August at Phantom Creek.

O'Donnell (1993) also looked at the occurrence of grunt or groan calls (previously referred to as alternate calls) for evidence of seasonal patterns (Paton, this colume; Nelson and Hamer, this volume a). He compared between months, for above and below canopy detections, the proportion of detections which included these calls, and found seasonality was not marked. Only at Lost Man Creek, where the sample was greatest, was there significant differences between months in the proportions of detections above the canopy with alternate calls. These calls occurred in lower proportions in December through February than in the remainder of the year. However, a subsequent multiple range test did not distinguish any significantly different months. The percentage of detections of murrelets giving grunt calls below the canopy also showed seasonality only at Lost
Man Creek, where they occurred in significantly greater proportions during July.

\section{Flock Size}

Changes in flock size through the breeding season have been noted in two studies (O'Donnell 1993, Rodway and others 1993b). O'Donnell (1993) found that both flocks observed above and below the canopy were smallest during May and June at each of three sites in California. Above canopy flocks at the Experimental Forest site had significantly fewer birds in June, and were also smaller in June at James Irvine Trail, though not significantly so (fig. 15). At Lost Man Creek, flocks above the canopy had significantly fewer murrelets in May, and significantly more birds in July. Reduction in the size of flocks below the canopy was especially marked at James Irvine Trail, where flock size was significantly less in May and June than during the remaining summer months (fig. 15). Below canopy flocks with the fewest numbers occurred in June at all three sites.

Rodway and others (1993b) similarly detected smaller flocks during May and June at their two sites in British Columbia. Single birds were observed most frequently in these two months, and flocks of two were most common in July at both sites.

\section{Discussion}

\section{Seasonal Patterns of Behavior and Activity}

Marbled Murrelets show consistent, seasonal patterns of activity and behavior. Throughout their range they exhibit the greatest levels of inland activity from April through August, with peak levels usually occurring from about the second week of July through early August. Hamer and Cummins (1990) suggested greater detection rates in late July may reflect increased food needs of nestling murrelets and the consequent increase in foraging trips by parent birds. Paton and Ralph 

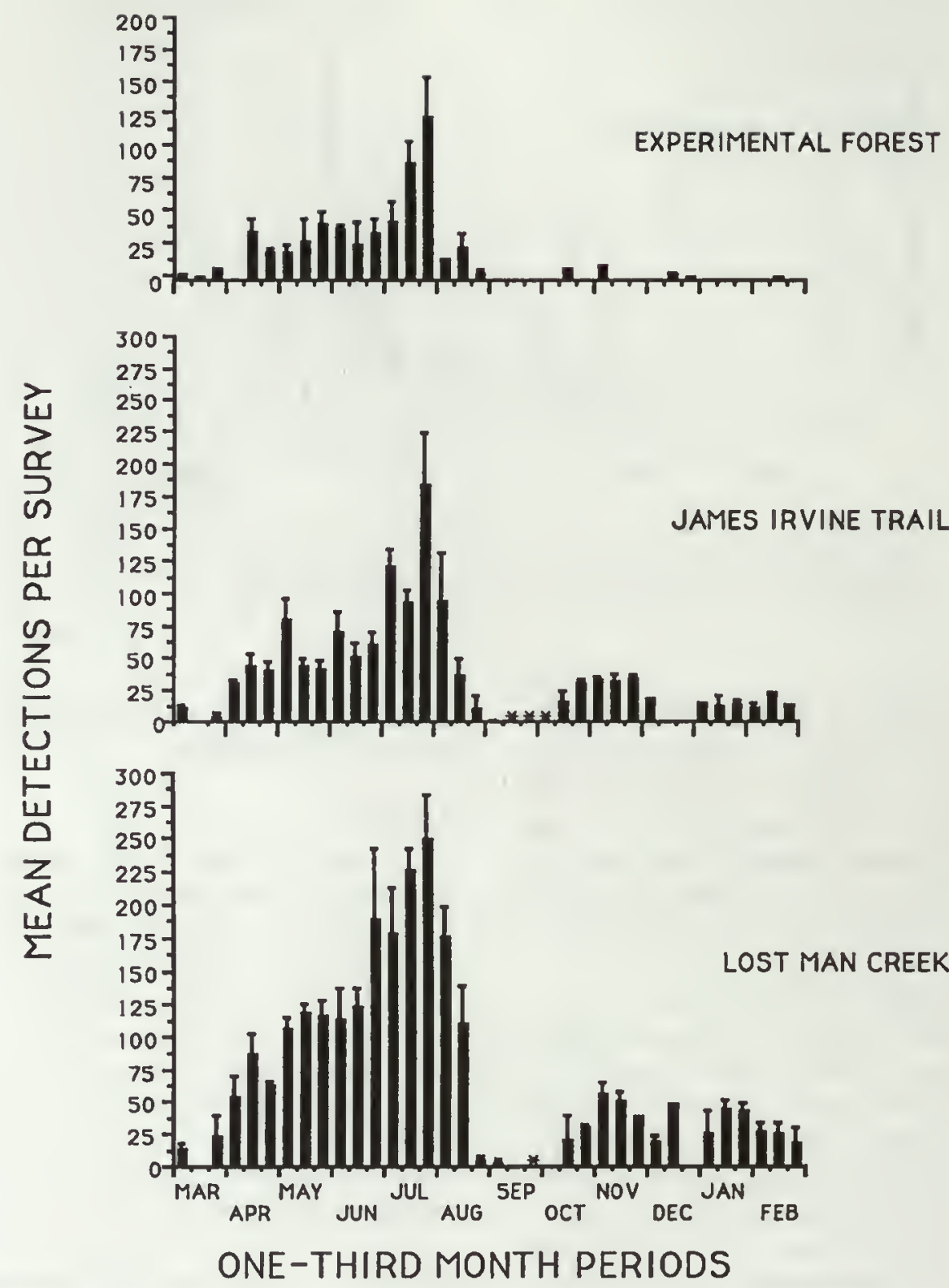

Figure 10-Mean numbers of detections of Marbled Murrelets per survey $( \pm$ s.e.) for one-thirdmonth periods at three sites in northwestern California, 1989-1991. Data from all years was combined for calculations. Asterisks $\left({ }^{*}\right)$ denotes periods in which no birds were detected during surveys; bars without standard error (vertical line segments) indicates only one survey was conducted during the period; ail other blank columns represent weeks in which no data was collected. From O'Donnell 1993.

$(1988,1990)$ felt the summer peak was likely the result of increased activity by breeding birds in the stand, perhaps in association with the fledging period, as opposed to an influx of non-breeding birds. However, many investigators have found that it is common among long-lived seabirds that defer sexual maturity for immatures to visit breeding sites later in the season in years prior to their first breeding attempt (Lack 1968, Sealy 1976, Gaston 1990). Sealy (1976) found increasing numbers of subadult Ancient Murrelets (Synthliboramphus antiquus) visiting nesting colonies later in the breeding season. He found that attendance by subadults peaked by about one month after 90 percent of adults and newly-hatched young had departed to sea. Increased activity at breeding stands in July by Marbled Murrelets may indeed involve non-breeders investigating potential breeding sites. An increased presence by non-breeding birds later in the breeding season might also contribute to the increase in flock size noted by both O'Donnell (1993) and Rodway and others (1993b).

In California, regular visitation at forest stands outside of the breeding season has been established. Fall and winter attendance has also been documented at several alcid colonies (e.g., Common Murre, Uria aalge, Razorbill, Alca torda, Black Guillemot, Cepphus grylle, Atlantic Puffin, Fratercula arctica, and Cassin's Auklet, Ptychoramphus aleuticus), 

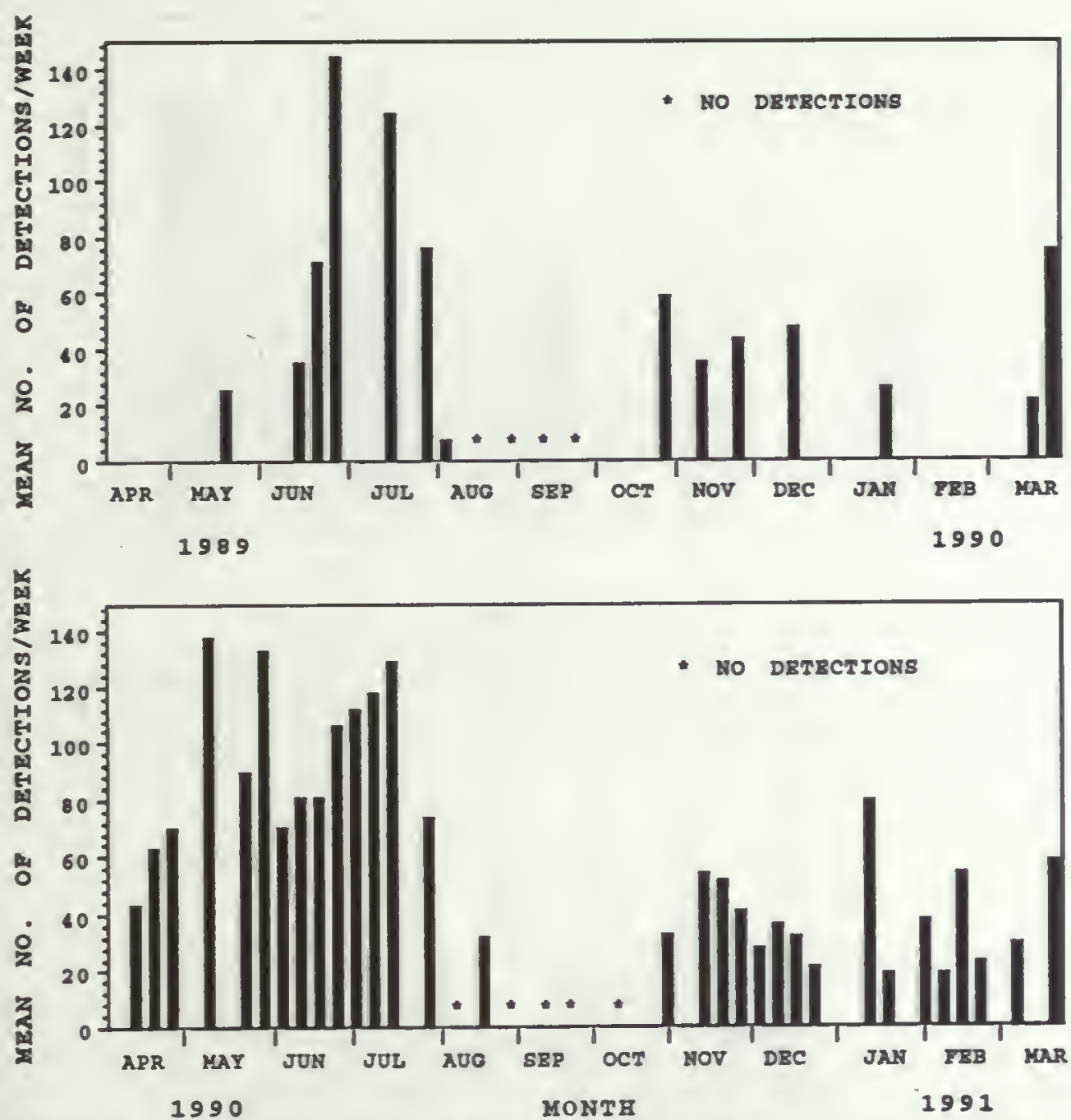

Figure 11-Mean number of Marbled Murrelet detections per week at Bloom's Creek Campground, California, in 1989-1990 (upper) and 1990-1991 (lower). Each weekly mean was calculated from 1-3 intensive dawn inventories. Asterisks (") indicate that a survey was conducted but no murrelets were detected; all other blank columns represent weeks in which no data was collected. From Naslund $1993 \mathrm{~b}$.

generally at the southern end of each species' range (Ainley and Boekelheide 1990, Greenwood 1987, Harris 1985, Harris and Wanless 1989, Taylor and Reid 1981, Sydeman 1993, Thoreson 1964). Harris and Wanless (1989) found a positive correlation between winter visitation and breeding success in the previous and following breeding season for a population of marked Common Murres. Winter attendance at breeding stands by murrelets may similarly relate to prior reproductive success, and might also enhance pair bond maintenance, facilitate earlier breeding (Carter and Erickson 1988), and reinforce familiarity with flight paths to the breeding stands.

Two periods of very low (or no) activity occurred during March and from mid-August through early October. The pre-alternate molt period in California may begin as early as mid-February and extend through March (Carter and Stein, this volume). The relatively low level of March detections levels probably reflects this molt. Although murrelets do not molt flight feathers at this time (Carter and Stein, this volume), the increased energetic demands of molting body feathers could limit inland visits. The second period, from mid-August through early October coincides with the cessation of nesting and the molt into basic plumage. The more extensive nature of this prebasic molt (full body and simultaneous wing molt of the adults) is reflected in the longer period of time murrelets are absent from the forest.

Numbers of above canopy behaviors closely mirror the patterns of total detection levels through the year, with the greatest levels occurring in the summer months and lower levels during the remainder of the year. Detections of birds below the canopy, however, coincide with the breeding season (April through September), and are largely absent outside of this period. Investigations of murrelet behavior around nest sites have consistently reported on observations of single birds and pairs flying below the canopy in the vicinity of nest trees (Nelson and Hamer, this 


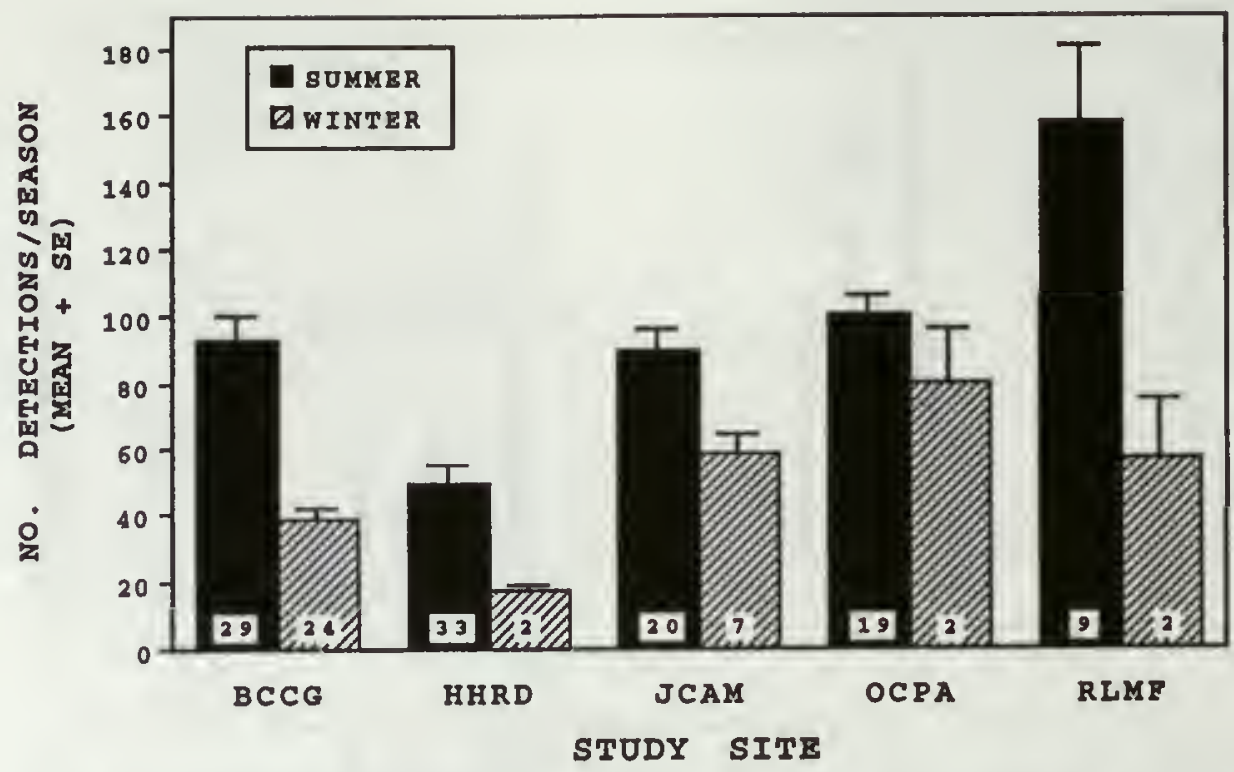

Figure 12-Mean number (histogram bar) and standard error (line segment) of Marbled Murrelet detections by season at five study sites in central California. "Summer" includes April-July and "winter" Includes November-February. Sample sizes (number of surveys) are indicated in histogram bars. From Naslund 1993b.

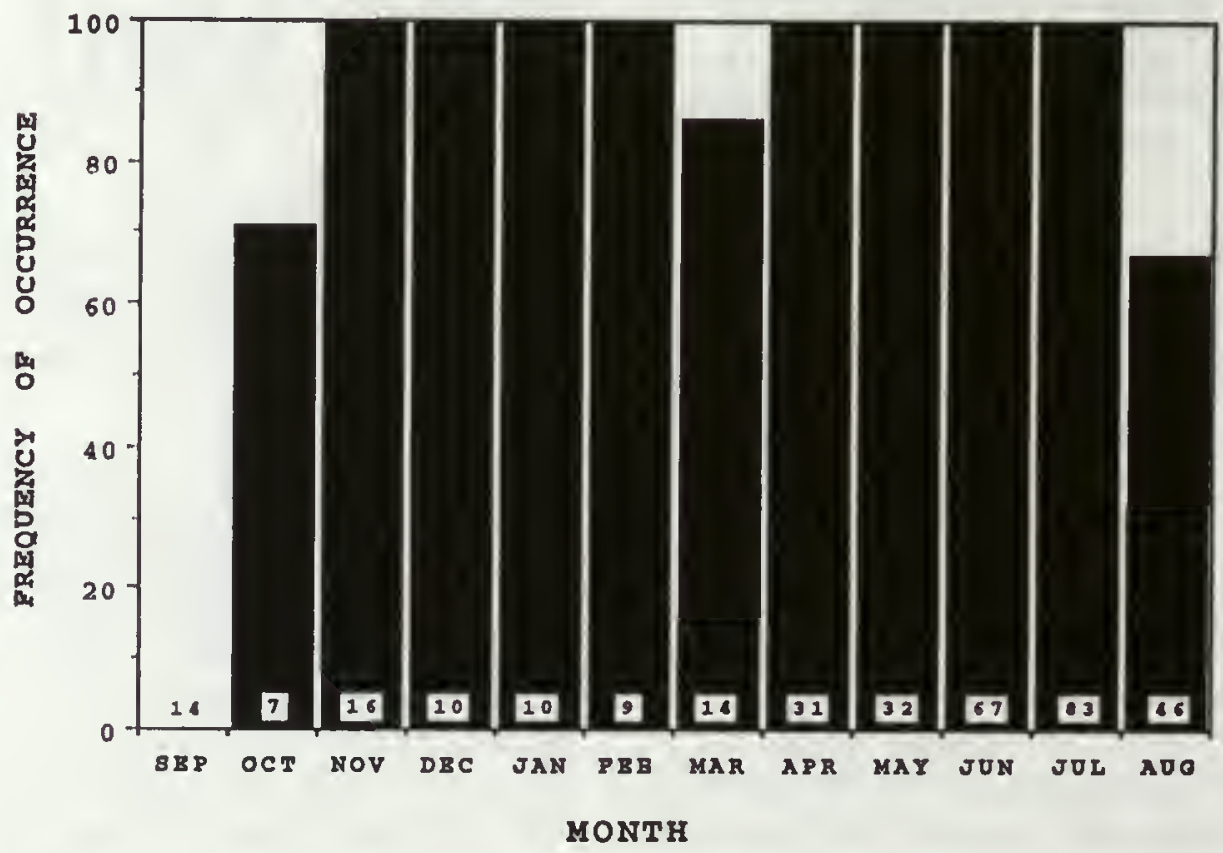

Figure 13-Percent of surveys with detections of Marbled Murrelets by month for five study sites in central California, 1989-1991. Surveys from all sites were pooled. Sample sizes (number of surveys) are indicated in the histogram bars. Missing histogram bar in September denotes that no murrelets were detected during 14 surveys. From Naslund 1993b. 


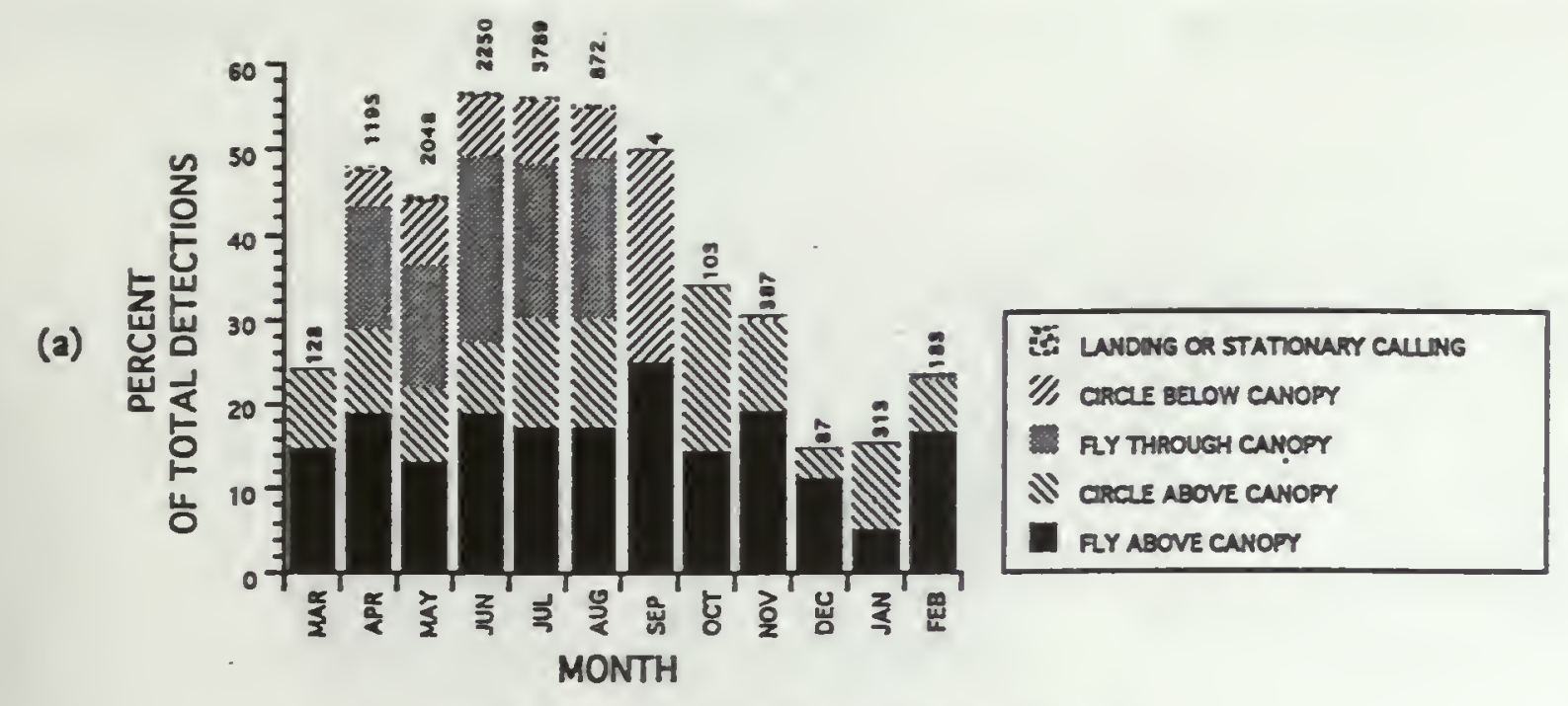

(b)

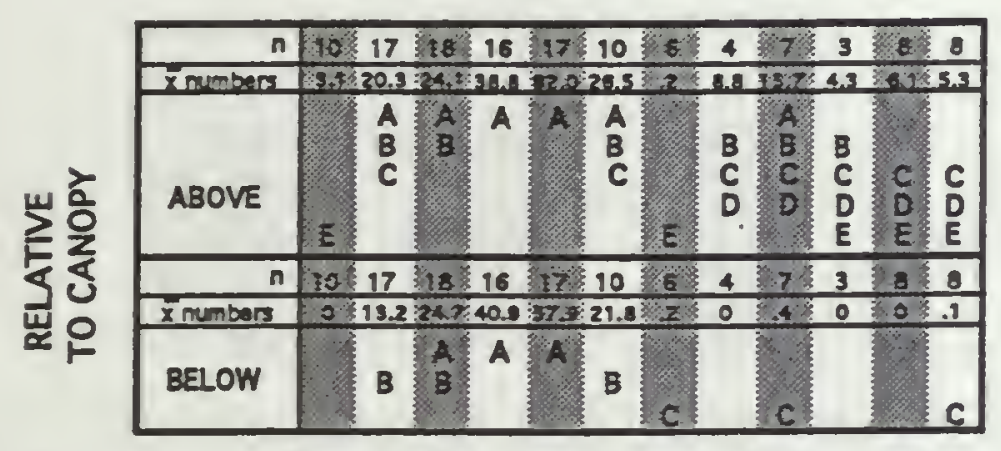

Flgure 14 - (a) Percent of detections of Marbled Murrelets in each month for five behaviors at Lost Man Creek, California, 1989 1991. The number of total detections in each month is shown above the bars, and the percent of "unknown" behaviors is not shown; (b) Results of Ryan-Einot-Gabriel-Welsh multiple range tests comparing numbers of above and below canopy behaviors by marbled murrelets between months. Months with the same letter indicate that the mean number of detections were not significantly different from each other. The term " $n$ " indicates the number of surveys in the respective month and " $\overline{\boldsymbol{X}}$ numbers" is the mean number of detections per survey. Means presented are untransformed values. Surveys from all years were combined for the analysis, and months with less than three surveys were not included in the analysis. From O'Donnell 1993.

volume a). Several studies (Naslund 1993a, Nelson and Hamer, this volume a; Nelson and Peck, in press; O'Donnell 1993, Rodway and others 1993b, Singer and others 1991) have also noted the tendency of birds below the canopy to fly silently without vocalizing. The sharp seasonality of below canopy behaviors, in conjunction with these behavioral observations gathered at nest sites, strongly reinforces the relationship between below canopy behaviors and breeding activity. It should be noted, however, that murrelets have on rare occasions been observed flying below the canopy in habitat not considered suitable for nesting (e.g., Habitat Restoration Group 1992; Keitt 1991; Singer and others 1991, 1992). These were usually in areas adjacent to suitable habitat.

\section{Monitoring}

Current guidelines, as recommended in Ralph and others (1993), restrict surveys for management purposes to the breeding season. The survey season in California begins on
15 April, in Oregon, Washington, and British Columbia on 1 May, and in Alaska on 15 May. The survey season ends on 5 August in all regions. The later start of the season at more northerly latitudes reflects a later breeding season in these areas (Kuletz and others 1994c; Hamer and Nelson, this volume a; Sealy 1974, 1975a). The timing of the survey season should of course maximize survey goals. Based on data collected in northwestern California (O’Donnell 1993), the recommended survey season for this state is a reasonable, if not slightly conservative, window for monitoring murrelets. Murrelets were detected during all surveys conducted at 9 sites in April ( 16 of which were conducted before 15 April) throughout the study. Mean detection levels were slightly higher, however, during the last two-thirds of the month. It has been clearly established that numbers of detections, as well as above and below canopy behaviors, usually reach peak levels during July throughout the range of the species. To minimize the likelihood of failing to detect murrelets when they are actually present, Ralph and others (1993) 
(a)

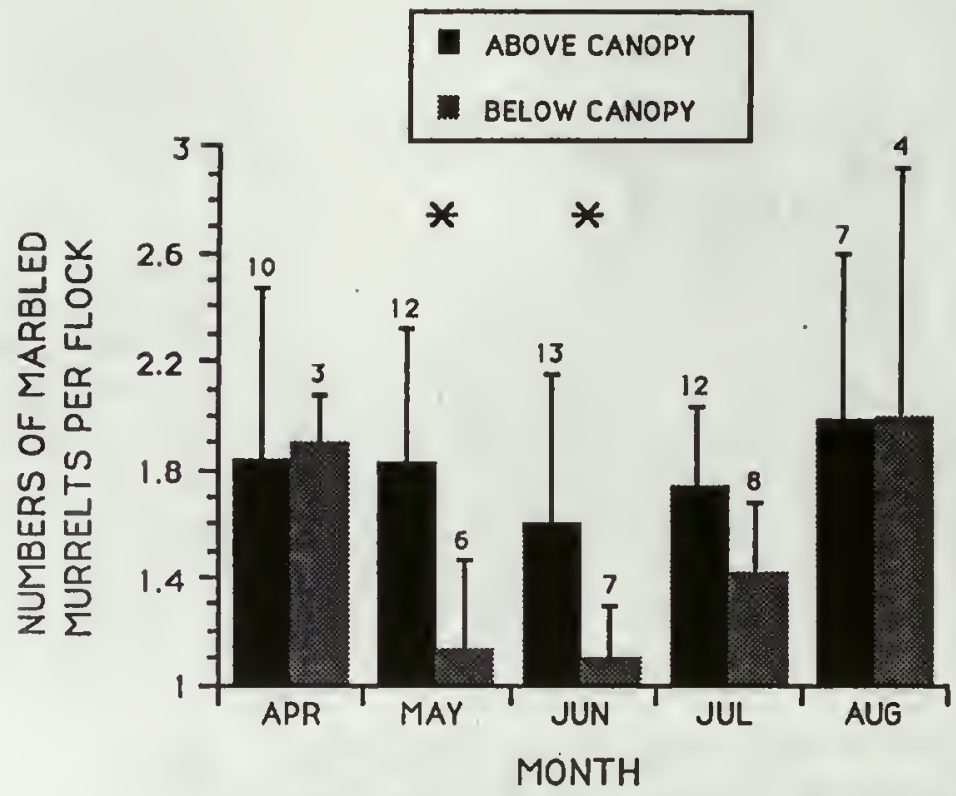

(b)

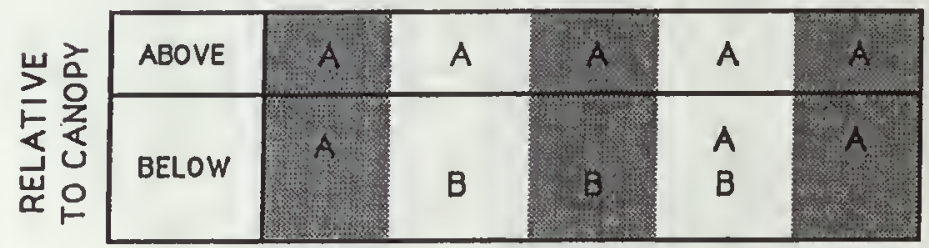

Flgure 15-(a) Mean size of Marbled Murrelet flocks observed above and below the canopy during the breeding season at James Irvine Trail, California, 1989-1991. Surveys from all years were combined. The numbers of surveys in each month are shown above the bars. An asterisk ( $\left.{ }^{*}\right)$ denotes a significant difference $(P=0.05)$ between above and below canopy flock sizes in the respective month; (b) Results of Ryan-Einot-Gabriel-Welsh multiple range tests comparing above and below canopy flock sizes between months. Months with the same letter indicate that the mean flock sizes were not significantly different from each other.

recommend that of four surveys conducted within a summer, two be conducted after 20 June, and at least one be conducted during the last three weeks of July. The earliest that birds were no longer detected at a stand in northwestern California was on 17 August (O’Donnell 1993). Detections of murrelets below the canopy, however, are absent earlier than this, and therefore 5 August is a reasonable termination date for the murrelet survey season in California.

Naslund (1993b) speculates that the population of birds visiting breeding stands during the winter may consist of a higher proportion of resident breeders than during the summer. Therefore, she suggests that surveys conducted during the winter may actually monitor, for management purposes, the most important segment of the population (i.e., breeding birds). Until the relevance of winter numbers is established, however, surveys should continue in the breeding season.

\section{Acknowledgments}

We thank Jim Baldwin, Ann Buell, Alan E. Burger, Peter Connors, George Hunt, Debbie Kristan, S. Kim Nelson, Lynn Roberts, Michael Rodway, Jean-Pierre Savard, Fred Sharpe, and Sherri Miller for helpful comments on this manuscript. 


\title{
Chapter 12 Daily Patterns of Marbled Murrelet Activity at Inland Sites
}

\author{
Nancy L. Naslund' Brian P. O'Donnell²
}

\begin{abstract}
Patterns in the daily activity of Marbled Murrelets (Brachyramphus marmorarus) at inland sites has been studied throughout their range from California to Alaska. Murrelets are most active at inland sites around dawn, and to a lesser degree, at dusk. Throughout their range, peak levels of activity (detections) occur in the hour around dawn, but detections begin progressively earlier as one moves from south to north, corresponding to changing daylight regimes (e.g., Califomia: 45 minutes before to 75 minutes after sunrise; Alaska: 90 minutes before to 40 minutes after sunrise). Timing of dawn detections also varies seasonally in relation 10 changing sunrise times. The duration of morning activity periods varies seasonally, being longest ( 2 hours) during summer and shortest ( $<1$ hour) in winter. In all areas, weather conditions affect the timing, duration, and level of murrelet activity. In general, activity tends to begin later, last longer, and reach peak levels on cloudy or foggy momings. The frequency of different behaviors varies throughout the morning period of activity. Murrelets tend to fly below the canopy more before sunrise than after, and group sizes become larger after sunrise. Early detections tend to include more silent birds, solitary calls, and wing sounds than later detections.
\end{abstract}

The relatively predictable changes in diumal activity of birds have been well documented. Patterns of daily activity and behavior can vary widely between species. Knowledge of these activity patterns helps us understand avian ecology, develop appropriate survey techniques, and ultimately to manage threatened or endangered species. Relevant research questions include: How do activity levels and behaviors change between different times of the day? What are reasonable interpretations of temporal variation in behaviors? How should factors influencing variation in daily activity be used to interpret survey results? In this chapter, we examine the daily patterns of Marbled Murrelet (Brachyramphus marmoratus) activity at inland sites and how they are influenced by season, geographic location, and environmental conditions. Where applicable, patterns of subcanopy behaviors (i.e., murrelets occurring below canopy level), thought to be indicative of nesting, are also examined (see Ralph and others 1994).

\section{Methods and Results}

Data were collected primarily using general and intensive survey techniques (see Paton and others 1990, Ralph and others 1994). During these surveys, each time one or more murrelets were seen or heard, the event was recorded as a

\footnotetext{
${ }^{1}$ Wildlife Biologist, U.S. Fish and Wildlife Service, U.S. Department of Interior, 1011 E. Tudor Road, Anchorage, AK 99503

2 Wildlife Biologist, Pacific Southwest Research Station, USDA Forest Service, Redwood Sciences Laboratory. 1700 Bayview Drive, Arcata, CA 95521
}

"detection" (see Paton and others 1990). Additional results from other research activities in murrelet nesting habitat (e.g., nest searches, observations at nests) are presented. For example, data from Alaska are from intensive surveys and from "stake-outs." During the latter, only those murrelet detections that occurred within $100 \mathrm{~m}$ of the observer were recorded (see Kuletz and others 1994c, Naslund and Hamer 1994). Only visual observations of murrelets were used in analyses of behavior (i.e., flying above or below canopy) and murrelet group size. All detections were used in other analyses.

\section{General Patterns of Daily Activity}

Murrelets are primarily active at inland sites around dawn and dusk. However, activity levels in the evening are lower and more sporadic than those during the morning. Nelson (1989) recorded that 12 percent of detections occurred at dusk and that murrelets were present on only 36 percent of dusk surveys in Oregon during the breeding season. In northern California, dawn activity was about five to six times greater than at dusk (Paton and Ralph 1988). Similar trends have been observed during the breeding season in British Columbia, Alaska, and at known nest sites in central California (Eisenhawer and Reimchen 1990, Kuletz 1991, Manley and others 1992, Naslund 1993a, Rodway and others 1993b). Anecdotal evidence for California and Alaska indicates that dusk activity also occurs during winter but may be less frequent than during the breeding season (Naslund, unpubl. data; Piatt, pers. comm.; Westphal, pers. comm.).

In central California, two murrelet nests were monitored using video equipment and night viewing devices. Murrelets were not observed visiting nests during the night (i.e., 1 hour after sunset through 1 hour before sunrise; Naslund 1993a). Radar studies on Vancouver Island found no detectable flight activity by murrelets through the middle of the night (Burger 1994, Burger and Dechesne 1994).

\section{Timing and Duration of Morning Activity}

In California and Oregon, murrelets were generally active between 45 minutes before and 75 minutes after official sunrise although most activity occurred during the hour around sunrise (Nelson 1989, Paton and Ralph 1988, Sander 1987). Murrelets occasionally were detected prior to 45 minutes before sunrise, but rarely more than an hour before (fig. I; Naslund 1993a, Nelson 1989, Paton and Ralph 1988). Activity in Washington probably began earlier and lasted later than activity further south, and the peak activity period also occurred slightly earlier (Hamer and Cummins 1990, Hamer and others 1991). Murrelets in British Columbia typically became active up to about 75 minutes before sunrise (fig. 1; Manley and others 1992, Rodway and others 1993b). In southeast Alaska, most murrelets were detected between 


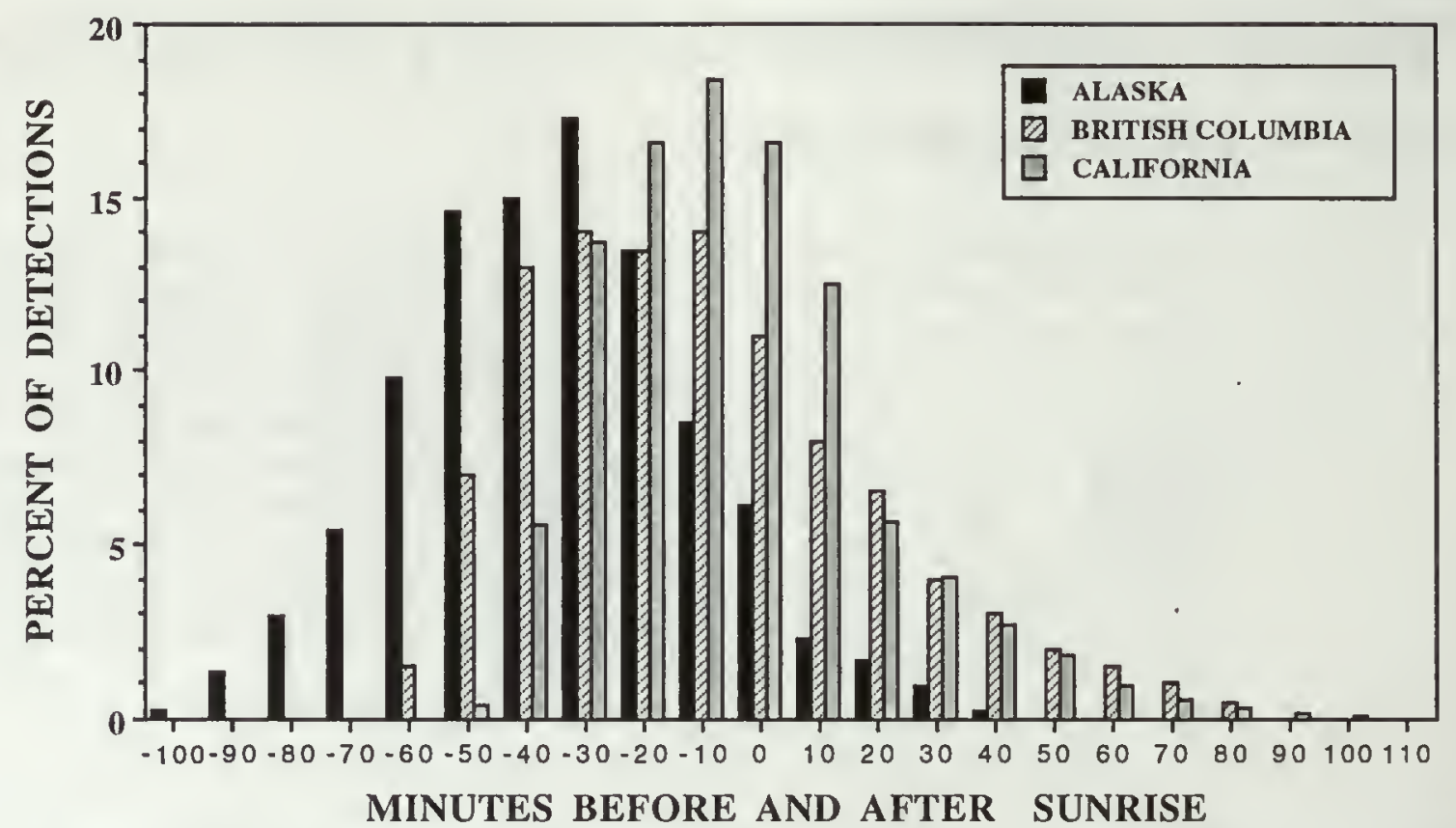

Flgure 1-Timing of Marbled Murrelet detections relative to sunrise in California $(n=9764 ;$ Big Basin Redwoods State Park, 1989-1991; Naslund, unpubl. data), British Columbia ( $n=2142$; Phantom Creek, May-August 1990; Rodway and others 1991), and Alaska ( $n=1649$; Naked Island, May-August 1991; Kuletz and others 1994C)

1 hour before and 1 hour after sunrise (Walsh, pers. comm.). In southcentral Alaska, murrelets were generally active between 90 minutes before and 40 minutes after sunrise, although the majority were detected during the 75 minutes before sunrise (fig. 1; Kuletz 1991, Kuletz and others 1994c). However, they sometimes were detected $120+$ minutes before sunrise (Kuletz 1991; Naslund, unpubl. data). In Alaska, the timing of first detections varied during the breeding season. Murrelets were active earliest around the beginning of summer (fig. 2; Kuletz and others 1994c).

In California, the duration of murrelet activity was longest during the breeding season (fig. 3; Naslund, unpubl. data; O'Donnell, unpubl. data). Conversely, their winter activity period was compressed and typically ended before sunrise (fig. 3). Murrelet activity occasionally began slightly earlier during winter than during summer (fig. 3). Murrelets tended to be active later in the morning and for shorter periods of time during August than in other summer months, in both California and Alaska (fig. 3; Kuletz, pers. comm.; Naslund, unpubl. data; O'Donnell, unpubl. data).

\section{Timing and Duration of Evening Activity}

In California and Oregon, most evening detections occurred from about 20-30 minutes (but up to 90 minutes) before, through about 20-30 minutes after, official sunset (Fortna, pers. comm.; Nelson 1989; Paton and Ralph 1988). Murrelets have been detected up to 45 minutes past sunset in Oregon, and were rarely heard during the middle of the night in California (Nelson 1989; Strachan, pers. comm.). Timing of evening activity in British Columbia was slightly later than that observed farther south, with 95 percent of detections occurring between sunset and 45 minutes after sunset (Rodway and others 1993b). Elsewhere in British Columbia, murrelets were most active $>45$ minutes after sunset in early June (Eisenhawer and Reimchen 1990). Virtually all evening activity in Alaska has been detected after sunset, and murrelets occasionally fly inland throughout the relatively bright nights around the summer solstice (Kuletz, pers. comm; Naslund, unpubl. data).

\section{Weather Effects on Timing and Levels of Activity}

Weather has been observed to affect the timing and duration of activity throughout the murrelet's range. Murrelet activity tends to begin later and last longer on cloudy or foggy mornings than on clear mornings (Kuletz, pers. comm; Manley and others 1992; Naslund, unpubl. data; Nelson 1989; Nelson and Hardin 1993a; Paton and Ralph 1988; Rodway and others 1993b; Sander 1987). However, Nelson (1989) noted that murrelet activity in Oregon also began earlier and lasted longer on clear mornings than on mornings with intermediate cloud cover, though not longer than on mornings with 100 percent cloud cover. In Alaska, activity several hours after sunrise was associated with heavy fog at ground level or mist (Kuletz 1991; Walsh, pers. comm.).

Environmental conditions can also affect levels of murrelet activity. At nest sites in central California, total numbers of detections and numbers of subcanopy behaviors tended to be higher when cloud cover was $>80$ percent, but was variable between sites (Naslund 1993a, unpubl. data). Rodway and others (1993b) also found that activity levels 


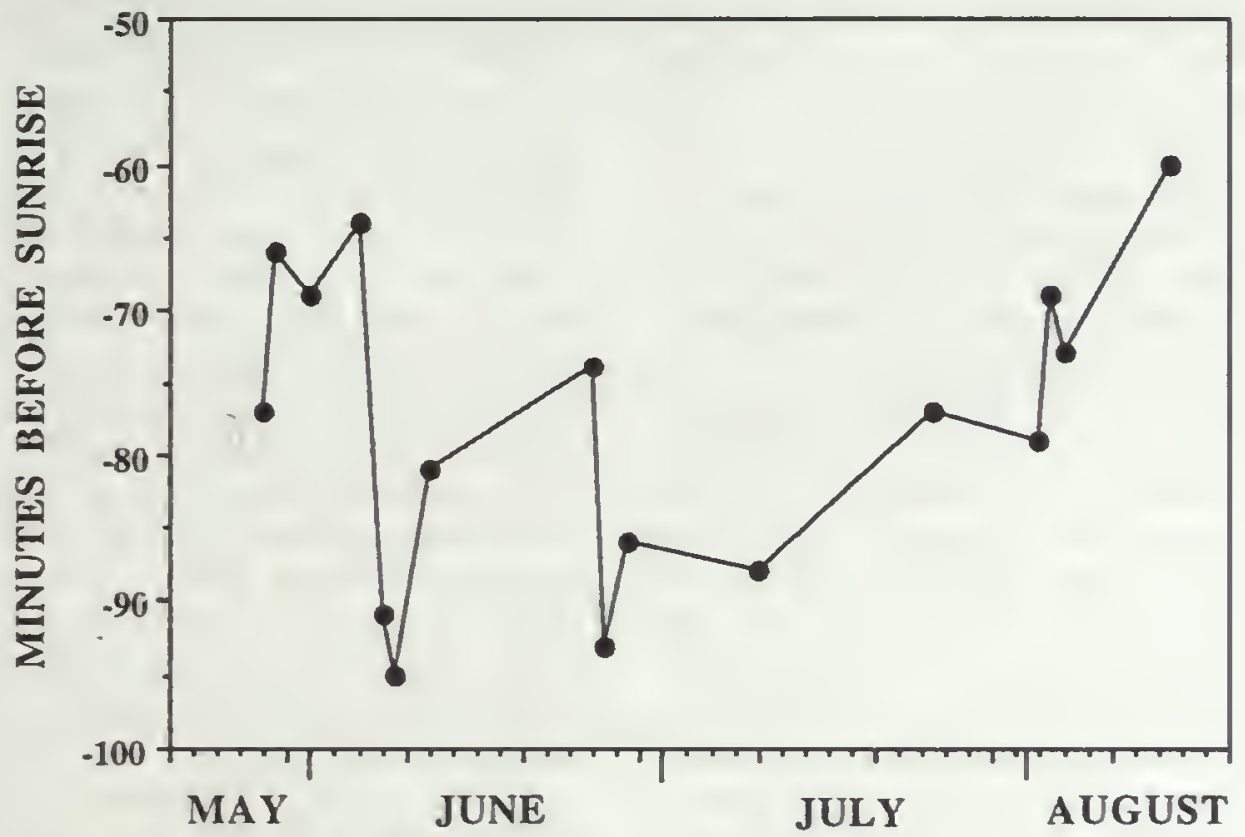

Figure 2-Timing of first Marbled Murrelet detections relative to official sunrise on Naked Island, Prince William Sound, Alaska, in May-August 1991 (Kuletz, pers. comm.)

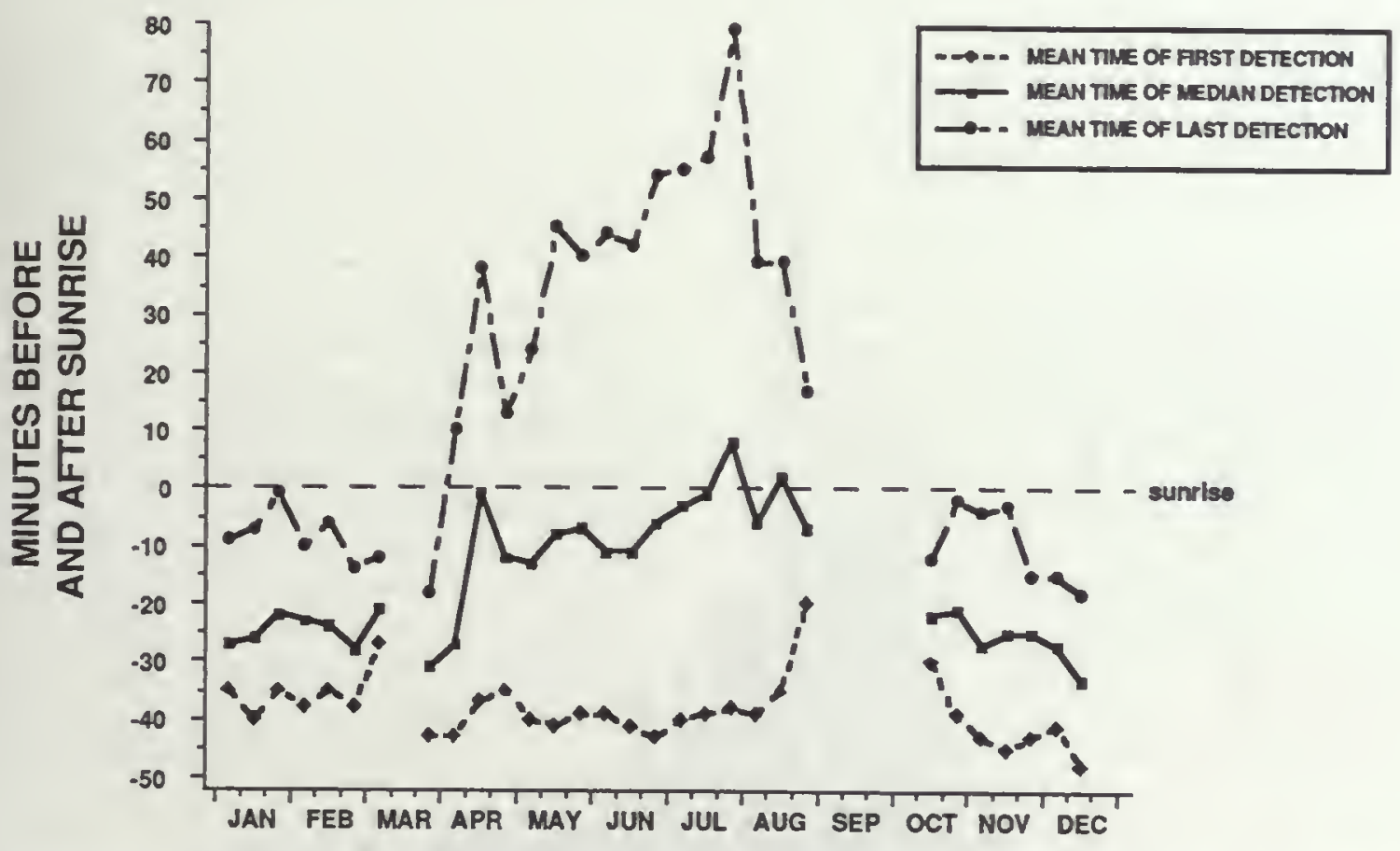

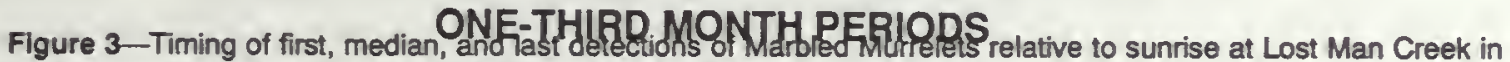
northwestern California, 1989-1991 (O'Donnell, unpubl. data) 
were higher on cloudy ( $\geq 80$ percent cloud cover) than on clear $(<80$ percent cloud cover) days in British Columbia. Conversely, highest activity levels and detection rates have been recorded during clear $(<25$ percent cloud cover) and mostly cloudy ( $>75$ percent cloud cover) mornings in Washington and Oregon (Hamer and Cummins 1990, Nelson 1989, Nelson and Hardin 1993a). However, Hamer and Cummins also noted that activity (mean number of detections) was greatest during conditions of light drizzle.

Other environmental factors also affect murrelet activity. Activity levels were high during periods of low cloud ceiling and decreased with increased wind speed and decreased temperatures during summer in Alaska (Kuletz and others 1994c). Mean detection rates were highest during conditions of poor visibility (i.e., low visibility ratings corresponded to days with low cloud ceilings) (Hamer and Cummins 1990). When examining weather effects in more detail, it was found that murrelets in Oregon were most active when it rained at the beginning of the survey, or when it was foggy at the end (Nelson and Hardin 1993a). In Alaska, murrelets sometimes exhibited high activity levels during snowstorms, when cloud ceilings were low and wind was negligible (Naslund, unpubl. data; Piatt, pers. comm.).

Weather may also influence the occurrence of activity around dusk. Although activity at dusk is infrequent in Alaska, murrelets were detected circling inland on two extremely foggy evenings (Kuletz 1991).

\section{Variation in Behaviors, Vocalizations, and Group Size During the Morning Activity Period}

Murrelet detections below canopy were more frequent than those above canopy, early in the morning activity period during the breeding season in northern California (fig. 4; O'Donnell, unpubl. data). The opposite was true after sunrise. It appears that this pattern remains intact throughout the year. The mean time that murrelets were seen in nest stands below canopy was significantly earlier than flight activity seen above canopy year-round in central California and during the breeding season in Alaska (table 1).

Group size of murrelets seen flying in forested stands varies with time of day. In central California and Alaska, the mean time at which different group sizes were observed varied throughout the morning during the breeding and nonbreeding (California only) seasons (table 1). Individuals occurred earliest, pairs somewhat later, and groups (i.e., $\geq 3$ ) latest. However, this trend was not apparent during the transitional period. Similar trends have been noted in British Columbia and Oregon. In these regions, most observations before 20 minutes before sunrise were single birds, whereas later detections included larger groups (Manley and others 1992, Nelson and Hardin 1993a).

Numbers of vocalizations made by murrelets also exhibit temporal variation during the morning activity period. Single calls were heard earlier than calls involving $\geq 6$ calls/detection, although this was only significant during the breeding season

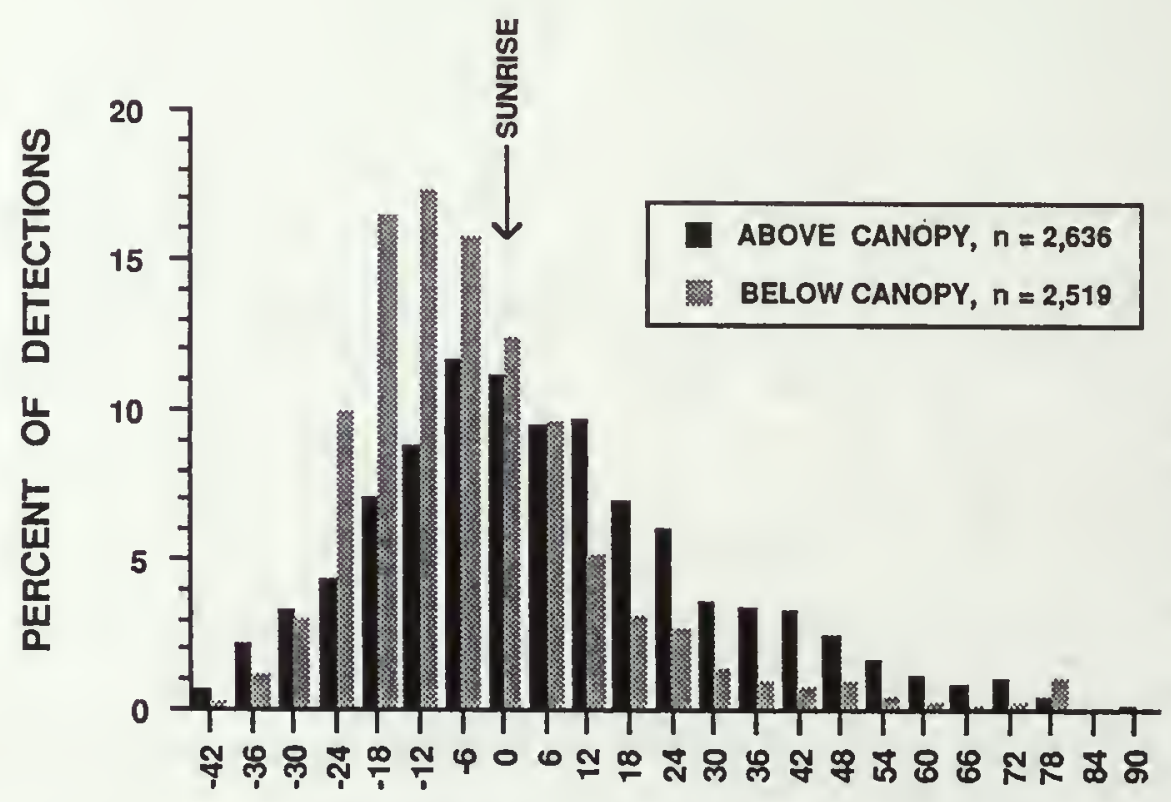

\section{MINUTES BEFORE AND AFTER SUNRISE}

Figure 4-Timing of detections of Marbled Murrelets above and below the canopy relative to sunrise. Data presented are from Lost Man Creek in northwestern California, 1989-1991. $n$ is the number of detections for each behavior class (O'Donnell, unpubl. data) 
Table 1-Mean detection times $(\bar{x})$ and their standard deviation (sd), in minutes, relative to sunrise of Marbled Murrelet detection categories at Big Basin Redwoods State Park, California from 1989-1991, and at Naked Island, Alaske during 1992. Results of Tukey-Kramer range tests are shown. Means with different letters (in parentheses) are significantly $(P<0.05)$ different from each other

\begin{tabular}{|c|c|c|c|c|c|c|c|c|c|c|c|c|}
\hline \multirow[b]{3}{*}{ Variable } & \multicolumn{6}{|c|}{ Breeding } & \multirow{2}{*}{\multicolumn{3}{|c|}{$\begin{array}{c}\text { Nonbreeding } \\
\text { California }\end{array}$}} & \multirow{2}{*}{\multicolumn{3}{|c|}{$\begin{array}{c}\text { Transitional } \\
\text { Califomia }\end{array}$}} \\
\hline & \multicolumn{3}{|c|}{ California $^{1}$} & \multicolumn{3}{|c|}{ Alaska $^{2}$} & & & & & & \\
\hline & $n$ & $\bar{x}$ & sd & $n$ & $\overline{\bar{x}}$ & $s d$ & $n$ & $\bar{x}$ & sd & $n$ & $\bar{x}$ & $s d$ \\
\hline \multicolumn{13}{|l|}{ Bird height } \\
\hline Below & 714 & $-4(a)$ & 19.9 & 252 & $-37(a)$ & 21.5 & 7 & $-28(a)$ & 8.0 & 63 & $-3(a)$ & 14. \\
\hline Above & 1251 & $8(b)$ & 20.4 & 297 & $-18(b)$ & 25.4 & 33 & $-17(b)$ & 10.1 & 100 & $3(b)$ & 15.1 \\
\hline \multicolumn{13}{|l|}{ Group size } \\
\hline 1 & 1005 & $-1(a)$ & 19.7 & 226 & $-34(a)$ & 22.3 & 16 & $-25(a)$ & 9.8 & 94 & $2(a)$ & 16.7 \\
\hline 2 & 737 & $6(b)$ & 22.5 & 258 & $-26(b)$ & 24.2 & 13 & $-19(a b)$ & 8.0 & 55 & $-1(a)$ & 12.4 \\
\hline$\geq 3$ & 259 & $10(c)$ & 18.2 & 68 & $-8(c)$ & 29.2 & 13 & $-13(b)$ & 11.2 & 17 & 1(a) & 12.4 \\
\hline \multicolumn{13}{|l|}{ No. calls } \\
\hline 0 & 1248 & $3(a)$ & 21.8 & 126 & $-38(a)$ & 18.9 & 9 & $-27(a)$ & 12.1 & 106 & 2(a) & 16.4 \\
\hline 1 & 1761 & $-4(b)$ & 23.6 & 231 & $-38(a)$ & 22.5 & 291 & $-27(a)$ & 15.4 & 299 & $-13(b)$ & 16.3 \\
\hline $2-5$ & 2376 & $-2(b c)$ & 23.5 & 490 & $-33(a b)$ & 25.6 & 332 & $-25(a)$ & 13.8 & 274 & $-10(b c)$ & 15.2 \\
\hline $6-9$ & 824 & $O(c)$ & 23.6 & 190 & $-29(b)$ & 27.0 & 148 & $-23(a)$ & 128 & 83 & $-8(c)$ & 15.4 \\
\hline$>9$ & 4171 & $O(c)$ & 22.6 & 1004 & $-29(b)$ & 24.5 & 859 & $-25(a)$ & 12.1 & 457 & $-10(b c)$ & 14.7 \\
\hline \multicolumn{13}{|l|}{ Type } \\
\hline Wings ${ }^{3}$ & 74 & $-13(a)$ & 14.2 & 36 & $-48(a)$ & 13.0 & 7 & $-32(a)$ & 7.0 & 7 & $-19(a)$ & 8.6 \\
\hline Heand & 8415 & -1 (b) & 23.4 & 944 & $-33(b)$ & 21.8 & 1602 & $-25(a b)$ & 13.2 & 1054 & $-12(a b)$ & 15.3 \\
\hline Both $^{5}$ & 751 & $4(b c)$ & 19.5 & 80 & $-18(c)$ & 26.6 & 31 & $-16(a b)$ & 8.9 & 60 & $-1(b c)$ & 11.8 \\
\hline Seen $^{6}$ & 1174 & $4(c)$ & 21.8 & 83 & $-32(b)$ & 17.5 & 2 & $-11(b)$ & 14.1 & 99 & $3(c)$ & 15.9 \\
\hline
\end{tabular}

${ }^{1}$ Naslund (unpubl. data)

${ }^{2}$ Kuletz (pers. comm.)

${ }^{3}$ Wings heard only, not seen

4 Heard calling, not seen

${ }^{5}$ Seen and heard calling

${ }^{6}$ Seen, nor calling

(table 1). In British Columbia, solitary calls were most frequent before sunrise (Manley 1992). Murrelets making only wing sounds were heard earlier than those heard vocalizing or those seen (lable 1). This pattern was consistent year-round but was significant only during the breeding seasons in California and Alaska. Silent murrelets were also seen relatively earlier in Alaska than in California. This may partially be a function of greater light levels before dawn in Alaska, thereby making murrelets easier for observers to see. In British Columbia, Manley (1992) found that the occurrence of silent murrelets (including both single birds and pairs) peaked 20 minutes before sunrise.

\section{Discussion}

\section{Daily Patterns of Activity and Behaviors}

Murrelets exhibit a primary period of inland activity around dawn and a secondary period around dusk. That murrelets are most active during the low light levels of dawn and dusk presumably reflects adaptation to predation pressures in the forest. Nesting murrelets and their chicks and eggs are vulnerable to a variety of avian predators including corvids and raptors (Brown, pers. comm.; Marks and Naslund 1994; Naslund and others, in press; Nelson and Hamer 1992, this volume b; Singer and others 1991). Crepuscular activity also allows for maximum diurnal foraging time.

Variation in activity levels during the day appears to mirror aspects of murrelet nesting biology. Murrelets exchange incubation duties and exhibit peak feeding rates of young chicks around dawn (Hamer and Cummins 1991; Naslund 1993a; Nelson and Hamer, this volume a; Nelson and Hardin 1993a; Nelson and Peck, in press; Singer-and others 1991, 1992). Murrelets also sometimes exhibit flight behaviors around nests and feed chicks around dusk. They visit nests with young chicks infrequently mid-day, though diurnal feedings increase when chicks get older (Fortna, pers. comm.; Hamer and others 1991; Naslund 1993a; Nelson and Hamer, this volume a; Singer and others 1991).

Low detection levels at dusk may result from temporal differences in the composition and behavior of murrelets at inland sites. Fewer nonbreeders may fly inland during the evening activity period. Murrelets appear to fly silently while 
carrying fish and are generally silent when visiting or flying around nests during the evening and are thus less easily detected (Naslund 1993a, unpubl. data).

Activity levels relative to sunrise are notably earlier at northern latitudes (i.e., British Columbia and Alaska) than at more southern latitudes. This difference in activity periods results from differing light regimes. Pre-dawn light levels are greater and occur earlier, relative to sunrise, in Alaska. In this region, the seasonal variation in timing of first murrelet detections appeared to track changes in light levels. Murrelets were heard earliest, and occasionally throughout the "night", around the summer solstice when light levels were greatest (Kuletz and others 1994c). As summer advanced and light levels decreased, murrelet activity occurred increasingly later. Similarly, early activity in Washington and British Columbia is thought to result from longer twilight periods (Eisenhawer and Reimchen 1990; Hamer and Cummins 1990; Rodway and others 1991, 1993b).

Cloudy or foggy weather results in lower light levels than clear mornings and may thus be affecting the timing of murrelet activity similar to changes in twilight regimes. In addition, murrelets may respond to periods of low fog or clouds, light rain, or snow by flying lower and calling more frequently and are thus detected more frequently under these conditions. However, on at least some occasions, murrelets fly above the fog, then drop below the fog just before entering the forest canopy (Kristan, pers. comm.). The influence of weather on murrelet activity is further evidenced by observations of murrelets exchanging incubation duties later on cloudy mornings and mornings with low cloud ceilings than on clear mornings, as well as changes in behaviors at nests with changes in weather conditions (Naslund 1993a, Nelson and Peck, in press).

Although weather conditions apparently affect many aspects of murrelet activity, murrelets exhibit variable responses to conditions observed inland. This variability may reflect differences between weather conditions at survey sites and conditions that murrelets respond to down drainages and other flight corridors, or at the coast. Timing and duration of activity inland also reflects seasonal variation in environmental conditions. For example, activity is earlier and shorter in winter when days are shorter and environmental conditions more extreme than in summer. This presumably reduces the time available to murrelets for foraging, and may increase the effort required to obtain food. Consequently, less time and energy may be available for inland flights. Differences may also correspond to changes in social behavior or reduced numbers of birds in winter (see Naslund 1993a,b; O'Donnell and others, this volume). The late and reduced duration of activity observed in August corresponds to a time when detections become sporadic and decrease overall (Kuletz and others 1994c, Naslund 1993a, Nelson and Hardin 1993a).

Temporal variation in behavior, group size, and vocalization patterns of murrelets during the morning activity period reflects features of nesting biology. The early timing of single birds and birds flying below canopy coincides with the typical times that murrelets exchange incubation duties and display around nest sites (Naslund 1993a; Nelson and Hamer, this volume a; Nelson and Peck, in press; Singer and others 1991, 1992). Similarly, murrelets make single calls and wing sounds early in the morning. These behaviors have also been associated with incubation exchanges, chick feedings, and possible displays in nesting territories (Naslund 1993a; Naslund and Hamer 1994; Nelson and Hamer, this volume a; Nelson and Hardin 1993a). Conversely, the larger and more vocal groups that are more frequent later in the morning may represent murrelets engaged in social interactions or joining together for flights to sea.

\section{Survey Implications}

Based on the daily activity patterns described here for murrelets, it is clear that current guidelines, which recommend that surveys be conducted during the dawn activity period, will provide the most consistent information on use of inland habitat by nesting murrelets (see Ralph and others 1993, 1994). Evening surveys may furnish additional information useful for interpreting stand-use or furthering our understanding of murrelet biology. It is evident that survey start-times should be shifted earlier as one moves north to compensate for changes in light levels relative to sunrise. Exact timing for some areas (e.g., southwest Alaska) may require further evaluation.

It is difficult to standardize surveys in a manner which eliminates the contribution of weather conditions to daily variation in activity patterns. Variability in activity is further confounded by the effects of weather conditions on the ability to detect murrelets. For example, fog and rain may reduce observers' abilities to see or hear murrelets. However, Rodway and others (1993b) found no evidence that some weather conditions (e.g., cloud cover) affect the proportion of detections that are seen. Avoiding surveys during certain conditions (e.g., heavy rain), as recommended by current guidelines (Ralph and others 1993, 1994), will reduce variation in recorded activity due to differences in visibility. This can be particularly important when evaluating subcanopy behaviors, which relies primarily on the visual detection of murrelets. In Alaska, where inclement weather prevails, surveys may be conducted on all days except those with high winds and extreme rain. Weather effects should be considered accordingly when making temporal and spatial comparisons between surveys.

Collection of data on group size, behaviors, and vocalizations during surveys provides information that is important for interpreting stand-use by murrelets. These data may also prove useful for unraveling various aspects of the ecology of this enigmatic species.

\section{Acknowledgments}

We thank Kathy Kuletz, Peter Walsh, and Michael Westphal for generously allowing us access to their unpublished data. This manuscript was greatly improved by the insightful comments of Jim Baldwin, Alan Burger, Peter Connors, David Fortna, Anne Harfenist, Gary Kaiser, Debbie Kristan, S. Kim Nelson, Peter Paton, John Piatt, Michael Rodway, Jean-Pierre Savard, and Fred Sharpe. 


\section{Chapter 13 \\ Interannual Differences in Detections of Marbled Murrelets in Some Inland California Stands}

\section{John Ralph ${ }^{1}$}

Abstract: I compared the mean level of detections of Marbled Murrelets by month over five years at three inland sites in northern California. These areas all have relatively high levels of detections. There were no significant differences in mean detection levels year to year at any site, and for any month with the exception of April at one site. This lack of evidence for significant interannual variation in the number of detections of birds suggests that data from any one of the years would have been sufficient to detect occupancy of these stands by Marbled Murrelets. Caution must be used in applying this result, as interannual variation in detection rates may be greater at sites with relatively few birds, and only three sites were investigated in this study.

Most species of birds vary in the proportion of birds breeding among years, with profound effects upon the demography of the species. In the case of the Marbled Murrelet, it would be useful to know the proportion of the population breeding. This knowledge would help determine if surveys taken in different years are comparable for purposes of determining the occupancy status of stands proposed for timber harvest. Changes in the number of murrelets detected in a stand during the breeding season are assumed to be related to changes in the number actually breeding in the stand. In this study, I compared the detection rates of murrelets at three sites for evidence of year-to-year variation. Finding a significant difference would indicate that surveys in any one year might not detect birds in a stand that would have had birds in another year, especially a stand with a relatively low detection rate. Although detection rates are not equivalent to numbers of birds actually breeding in a stand (Paton, this volume), I make the assumption that they are analogous.

\section{Methods}

I examined the among-year variations for three areas with moderate and high detection levels (table I) in northern California: Lost Man Creek, in Redwood National Park, Humboldt County; James Irvine Trail, in Prairie Creek Redwoods State Park, Humboldt County; and Redwood Experimental Forest, near Klamath, Del Norte County. These three survey sites all are located within large contiguous stands of old-growth redwood in a natural reserve and parks.

Data used in this analysis were total number of detections (both audio and visual) per survey for each study site for the

${ }^{1}$ Research Wildlife Biologist, Pacific Southwest Research Station, USDA Forest Service, Redwood Sciences Laboratory, 1700 Bayview Drive, Arcata, CA 95521 years 1989-1993. Surveys at these sites were conducted according to Marbled Murrelet survey protocol (Ralph and others 1993). Only data from April through August of each year were used, the recommended murrelet survey period in the protocol.

Data were analyzed using one-way ANOVAs ( $\alpha<$ 0.05 ), for each month and year with surveys (table 1). The number of birds detected in a morning's survey were log $($ count +1$)$ transformed to approximate normality of the distribution of detections.

\section{Results}

The detection rate was highest at Lost Man Creek with monthly means ranging up to 240 detections in July 1990 (table I). James Irvine Trail had fewer detections with a maximum average of 146 in July 1990. Experimental Forest had the lowest rate, with a maximum average detection rate of 111 in July 1993.

I first compared each site separately by month. An inspection of the average number of detections of murrelets (table l) shows that months in a given year, even with only a few samples, were generally very similar to the averages for that month in the other years with more robust samples. Monthly means were not significantly different at any site, with the exception of April at Lost Man Creek $(P=0.004)$. This month had a larger range of mean detections than in other months or at other sites. Comparing among years at Lost Man Creek in April, I found that 1990 and 1991 were similar, but that 1989 and 1992 were both different from each other, as well as from other years (Ryan-Einot-GabrielWelsch multiple comparison test).

\section{Discussion}

Though only one month was significantly different over a five-year period at three sites, it is quite likely that further data would show that detections are lower in certain years at specific sites.

Particularly unseasonable weather during the breeding season could impact numbers of inland detections at specific sites. Fluctuations of prey fish populations may also be a factor in inland murrelet detection levels. Warmer ocean temperatures associated with an El Niño event are responsible for changing local and global weather cycles that affect many species of marine animals, including nesting seabirds and their food (Ainley and Sanger 1979). The ocean temperature events may also affect Marbled Murrelet prey (Burkett, this volume), although this has not been documented. The effects of warmer offshore water 


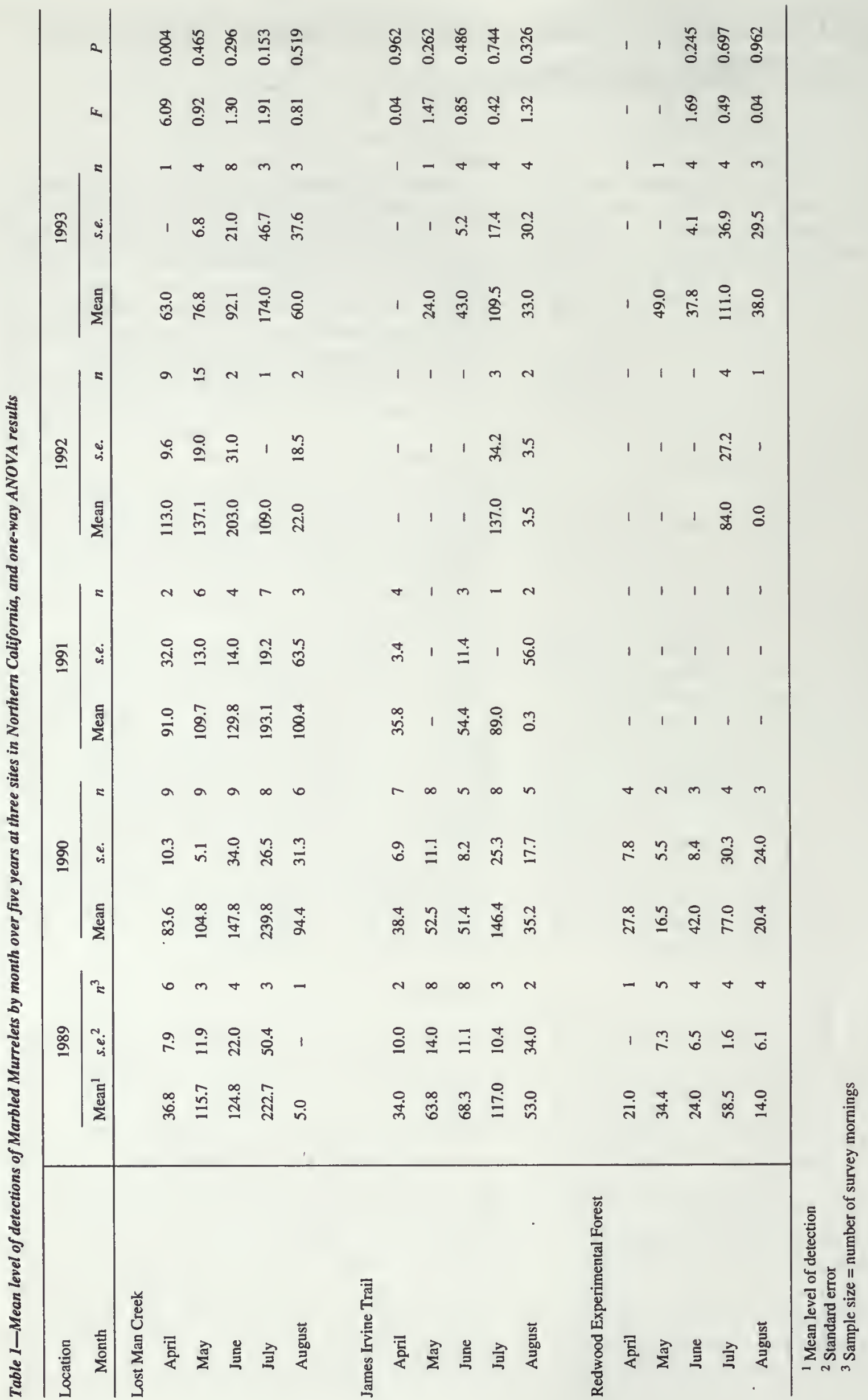


temperatures during an El Niño event may cause a reduction in murrelet breeding effort, and thus influence inland detection levels. The current El Niño has become the longest on record, beginning in early 1991, or perhaps even earlier.

All of the sites studied had relatively high murrelet activity, as compared to many sites elsewhere in the Pacific Northwest. This may have had an effect of moderating differences if social facilitation is a factor in levels of murrelet activity. However, we have no data at present to support such a supposition, although Shaughnessy (pers. comm.) and Nelson (pers. comm.) found differences between years when comparing murrelet use at a site. Also, there is some evidence that detections vary as a function of weather (Naslund and O'Donnell, this volume). For example, there are frequently more detections on foggy mornings. Thus, a year in which low detection rates would have been expected might instead have normal detection rates because of unusually foggy weather in that year. However, the amount of daily variation induced by clouds in our studies has been less than 20 percent (O'Donnell, pers. comm.).

The great variation between mornings at most sites might be the key to the lack of significant difference among years. However, the fact that the monthly average values were quite similar indicates that no differences exist.
I was unable to find any evidence that would suggest that the number of detections of birds was consistently lower or higher in any one of the five years. Therefore, results of inland surveys used to determine presence or absence of Marbled Murrelets in proposed timber harvest stands would likely have been valid in any of these years in this area of California. Caution must be used in applying these data to other sites and regions, however, as only three sites were surveyed, and the variance was large.

I suggest that we need continued monitoring of murrelets at established sites over several years, combined with careful quantification of the many influences on inland detection levels, to fully resolve the indications derived from this study. This effort would greatly increase our understanding of this bird and its use of inland habitats.

\section{Acknowledgments}

I am very grateful to the biologists who have worked in the early dawn over the years to put together this data set. Especially noteworthy are Sherri Miller, Brian O'Donnell, and Linda Long. I thank Robin Wachs for her excellent help in tabulating and analyzing these data. I also thank Jim Baldwin, Ann Buell, George Hunt, Debbie Kristan, Kim Nelson, Peter Paton, and Meg Shaughnessy for helpful comments on the manuscript. 



\title{
A Review of the Effects of Station Placement and Observer Bias in Detections of Marbled Murrelets in Forest Stands
}

\section{Brian O'Donnell'}

\section{Site Characteristics}

\section{Visibility at Survey Station}

A high percentage of murrelets remain unseen to the observer during surveys (Paton and Ralph 1988; Nelson 1989). The numbers of visual sightings of murrelets are strongly influenced by the location of the observer, yet they are critical for determining murrelet use of a stand (Paton, this volume). Nelson (1989) reported the highest percent of visual detections (55 percent) occurred at a survey station with the greatest view of open sky. Rodway and others (1993b) detected murrelets visually in 19 percent and 26 percent of detections at two sites in British Columbia. They speculate that greater visibility accounted for more visual detections at the latter site. Ralph (pers. comm.) examined the effect of canopy cover upon detection and behavior levels to assess the level of survey effort needed to determine occupancy by breeding murrelets in a stand. Detections indicating probable nesting in a stand are of murrelets below or within the canopy, and require visual sightings of the birds (Paton, this volume). At a dense canopy site, only 3 percent of detections indicated occupancy, while at moderate and open canopy sites, these detections were 14 percent and 30 percent, respectively. I (O'Donnell 1993) found that, in general, sites with greater visibility had more detections of murrelets below the canopy (fig. 1). Visibility at each site was quantified by estimation of the percent of clear view to the horizon in all directions. Including only sites in or near old-growth stands, I found that visibility had a significant positive relationship ( $r=$ $0.73, P=0.04, n=8$ ) with the numbers of below canopy behaviors observed.

\section{Environmental Noise}

While there are no studies which examine the effects of extraneous noise (e.g., wind, road, or stream) specifically on murrelet survey results, it seems very likely that any noise impairing an observer's ability to hear murrelets will be detrimental to survey goals. The effects of environmental noise on the audio detection of landbirds are discussed in papers in Ralph and Scott (1981).

\section{Environmental Acoustics}

Acoustical properties in the environment will degrade bird song and calls in a variety of ways (Richards 1981). Attenuation, the decrease in intensity of sound with distance, can be affected by habitat type. Kuletz and others (1994c)

\footnotetext{
1 Wildlife Biologist, Pacific Southwesı Research Station, USDA Forest Service, Redwood Sciences Laboratory, 1700 Bayview Drive, Arcata. CA 95521
}

\begin{abstract}
A variety of factors influence the results of surveys
\end{abstract} Ralph and Scott (1981), there are studies on observer effects on landbird censusing results. Ralph (pers. comm.) compared site in northwestern California to find the area around the observer that is effectively surveyed. Kuletz and others (1994c) found significant observer effects on detection levels at sites in Alaska. 


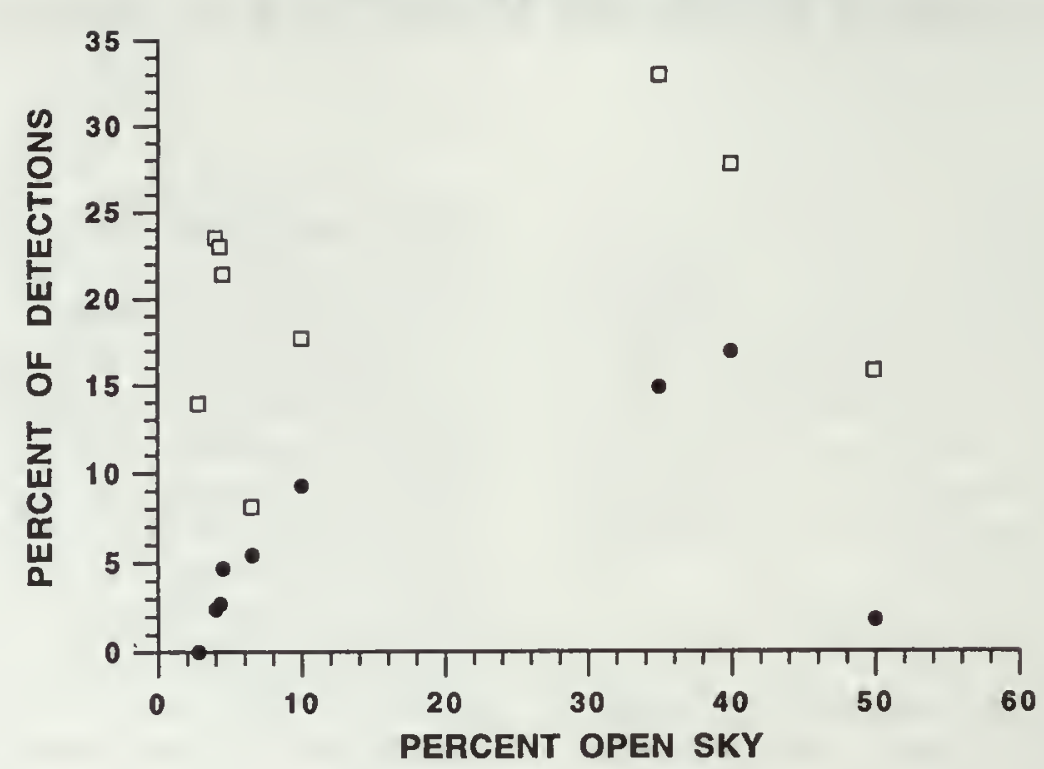

Figure 1-Relationship between percent of open sky at survey stations and observations of marbled murrelets flying above and below the canopy. Data from nine sites in northwestern California.

detected murrelets by sound at greater distances from stations placed in open meadow, than at stations closely surrounded by forest, accounting for difference in numbers of detections between sites. Detection distances for murrelets that were heard and not seen varied considerably between sites in northwestern California (O'Donnell, unpubl. data). The locations of stations ranged from closed canopy forest to large, open prairies. The maximum detection distances at stations in more open areas was generally greater than for stations within the forest.

\section{Discussion}

\section{Observer Variability}

There can be little doubt that variability exists between observers in their ability to see and hear murrelets. While some differences between observers cannot be eliminated, adequate training and evaluation can greatly improve individual abilities and increase comparability between observers. A training and evaluation protocol (Ralph and others 1993) was developed to accomplish this goal. The training program helps trainees to develop their ability to detect murrelets in the forest and to accurately record observations according to protocol. The evaluation, a simultaneous survey conducted by trainees and a qualified evaluator, insures that trainees are able to survey murrelets at acceptable levels of proficiency. In California, Oregon, and Washington, all persons conducting murrelet surveys for management or research purposes must successfully complete an evaluation process. Since inception of the training and evaluation program in 1991, approximately 500 persons have been evaluated in California alone (Burkett, pers. comm.), providing a large pool of qualified observers.

\section{Site Characteristics}

Factors influencing an observer's ability to hear and see murrelets can largely be controlled by sensible placement of survey stations. Because such a high proportion of murrelets are detected by call alone, survey stations should not be placed near sources of loud noise. Similarly, since behaviors suggestive of breeding activity are determined primarily from visual observations of murrelets, it is important to place survey stations in areas that have the greatest view of open sky (Ralph and others 1993).

\section{Acknowledgments}

I thank Steve Courtney, Dave Fortna, Debbie Kristan, S. Kim Nelson, Peter Paton, C. John Ralph, and Sherri Miller for comments on this manuscript. 


\section{Inland Habitat Suitability for the Marbled Murrelet in Southcentral Alaska}

Katherine J. Kuletz

Dennis K. Marks
Nancy L. Naslund

Nike J. Goodson
Mary B. Cody'
Abstract: The majority of Marbled Murrelets (Brachyramphus marmoratus) nest in Alaska, where they sometimes nest on the ground, and their nesting habitat requirements are not well understood. The inland activity of murrelets was surveyed, and habitat features measured, between 1991 and 1993, in Prince William Sound, Kenai Fjords National Park and Afognak Island, Alaska ( $n=262$ sites). We used these data to develop statistical models that explain variation in murrelet activity levels and predict the occurrence of occupied behaviors (indicative of nesting), based on temporal, geographic, topographic, weather, and habitat characteristics. Multiple regression analyses explained 52 percent of the variation in general murrelet activity levels $(P<0.0001)$. The best model included survey date, location relative to the head of a bay, elevation, slope, aspect, percentage of forest cover, tree diameter, and epiphyte cover on tree branches. The highest activity levels were associated with late July surveys at the heads of bays where there was high epiphyte cover on trees. Stepwise logistic regression was used to identify variables that could predict the probability of detecting occupied behaviors at a survey site. The best model included survey method (from a boat, shore, or upland), location relative to the head of a bay, tree diameter, and number of potential nesting platforms on trees. The best predictors for observing occupied behaviors were tree diameter and number of platforms. In a jackknife procedure, the logistic function correctly classified 83 percent of the occupied sites. Overall, the features indicative of murrelet nesting babitat include low elevation locations near the heads of bays, with extensive forest cover of large old-growth trees. Our results were derived from surveys designed to estimate murrelet use of forested habitat and may not accurately reflect use of nonforested habitat. Therefore, caution should be exercised when extrapolating observed trends on a broad scale across the landscape.

The reliance of Marbled Murrelets (Brachyramphus marmoratus) on mature and old-growth forest for nesting has been well established in the southern portion of the species' range (see Carter and Morrison 1992; Hamer and Nelson, this volume b). Yet, the majority of Marbled Murrelets breed in Alaska, where nesting habitat requirements are not clearly understood (Mendenhall 1992). Offshore surveys suggest that about 97 percent of the population within Alaska occurs offshore of lands with at least some old-growth forest cover (Piatt and Ford 1993). These forested areas extend from southeast Alaska, north along the Gulf of Alaska, and throughout southcentral Alaska. However, the extent of forested habitat is variable in this region. "Forested" areas include unforested habitat, and tree line may extend only $200 \mathrm{~m}$ above sea level and a few kilometers inland.

I Wildlife Biologists, Migratory Bird Management, U.S. Fish and Wildlife Service, U.S. Department of Interior, 1011 E. Tudor Road, Anchorage, AK 99503
The choice of nesting habitat for murrelets appears superficially to be broader in Alaska, where murrelets nest both in trees and on the ground, than at lower latitudes. Before the early 1980's, only six Marbled Murrelet ground nests had been found (Day and others 1983). Since then, three tree nests have been documented in southeast Alaska, and one nest was found on a tree root overhanging a cliff (Brown, pers. comm.; Ford and Brown 1994; Quinlan and Hughes 1990). In southcentral Alaska, 15 tree nests and seven additional ground nests were found between 1989 and 1993 (Balogh, pers. comm.; Hughes, pers. comm.; Kuletz and others 1994c; Mickelson, pers. comm.; Naslund and others, in press; Rice, pers. comm.; Youkey, pers. comm.). The apparent importance of ground nesting by murrelets in Alaska is partially an artifact of effort. Ground nests are more easily discovered than tree nests, inflating their relative numbers. Additionally, it is possible that ground nests of the Kittlitz's Murrelet ( $B$. brevirostris) can be mistaken for those of Marbled Murrelets (Day and others 1983). Therefore, it was unclear how important ground nesting was to the Marbled Murrelet population.

Following the 1989 Exxon Valdez Oil spill, the protection of habitat was identified as a means of restoring injured resources such as the Marbled Murrelet. Our goal was to provide information on murrelet nesting habitat in the spill zone to guide protection and land acquisition decisions. Between 1990 and 1993, we examined aspects of murrelet nesting behavior and habitat use in Prince William Sound and Kenai Fjords National Park (Kuletz and others 1994b, c). Concurrently, in 1992, murrelet surveys were conducted on Afognak Island, north of Kodiak Island (Cody and Gerlach 1993, U.S. Fish and Wildlife Service 1993). Although there were differences in study design among the studies, they provided a substantial data base for relating habitat variables to murrelet activity throughout the spill zone. Data from these four studies were combined to develop a broad-based model of murrelet activity in relation to weather, season, and habitat variables that would apply throughout southcentral Alaska. We also developed a statistical model of site characteristics where occupied behavior, indicative of nesting birds, was observed.

\section{Methods}

\section{Study Area}

The study area encompasses the Naked Island group in central Prince William Sound, western Prince William Sound, the Kenai Fjords National Park, and two parcels on Afognak Island (fig. 1). Brachyramphus murrelets comprise a large portion of the avifauna in these areas. The estimated Brachyramphus murrelet population for Prince William 


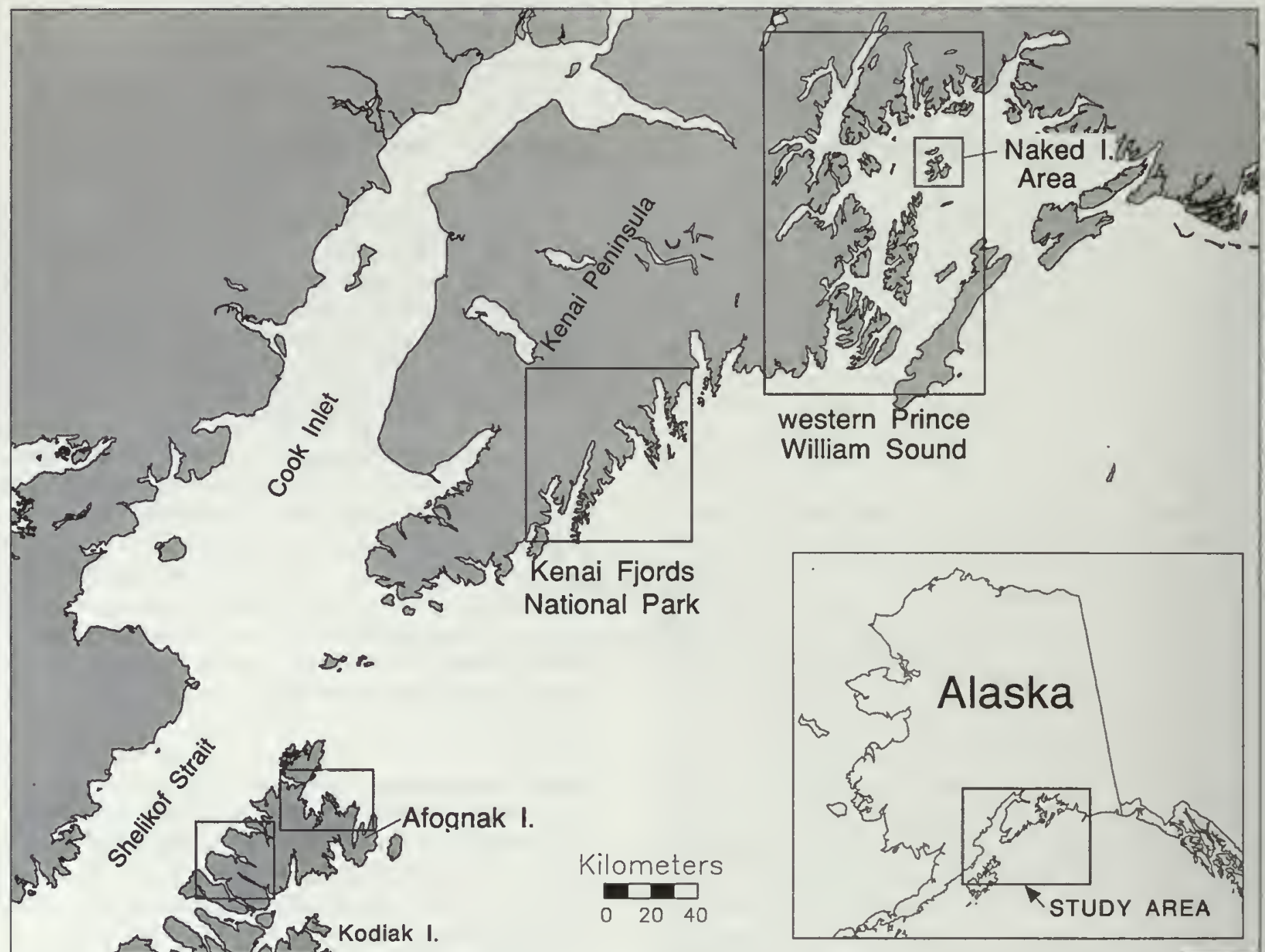

Flgure 1-The four study areas of southcentral Alaska surveyed for inland murrelet activity between 1991 and 1993: Naked Island, western Prince William Sound (PWS), Kenai Fjords National Park (KFNP), and Afognak Island (in two parcels).

Sound is approximately 100,000 birds (Klosiewski and Laing 1994). Within $5 \mathrm{~km}$ of the Naked Island group (Naked, Peak, and Storey islands), there are an estimated 3,000 Marbled Murrelets (Kuletz and others 1994a). At-sea surveys of Kenai Fjords National Park have been restricted to shoreline surveys (within $200 \mathrm{~m}$ of shore) and complete counts in some bays. In 1989 the estimates ranged from 2,000 Brachyramphus murrelets in June to 6,500 in August (Tetreau, pers. comm.). At-sea surveys off Afognak Island in summer 1992 produced estimates of 2200 murrelets off the northern section, and 2000 murrelets off the southwest section (Fadely and others 1993). Brachyramphus murrelet population estimates include a small percentage of Kittlitz's Murrelets in Prince William Sound (approximately 7 percent; Laing, pers. comm.) and Kenai Fjords National Park (between 7 12 percent; Tetreau, pers. comm.).

\section{General Habitat}

Prince William Sound, the northernmost portion of the study area, is characterized by protected waters, numerous islands and bays, and deep-water fjords, including some with tidewater glaciers. Forested areas of mixed hemlockspruce forests (Tsuga mertensiana, T. heterophylla, and Picea sitchensis) are interspersed with muskeg meadows, alpine vegetation, and exposed rocks. Tree line ranges from 30 to $600 \mathrm{~m}$ (see Isleib and Kessel 1973). Naked Island is in the center of Prince William Sound, and vegetation is a mix of forest and muskeg meadow, but lacks other habitat types (Kuletz and others, in press).

The Kenai Fjords National Park, on the southern Kenai Peninsula, is characterized by steep, rugged coastline and numerous islands on the outer coast. There are protected waters and tidewater glaciers at the heads of fjords, and 
exposed coasts near fjord mouths bordering the Gulf of Alaska (Bailey 1976). Glaciers cover more than 50 percent of Kenai Fjords National Park (Selkregg 1974). Because of receding glaciers, forested portions of the coast are primarily in the outer, more exposed headlands and islands. Tree line is typically $300 \mathrm{~m}$, and few areas beyond $500 \mathrm{~m}$ from shore are forested. Tree species are similar to those in Prince William Sound, and alder is the dominant vegetation in unforested areas.

There were two study sites on Afognak Island. The northern parcel faces north into the Gulf of Alaska and is heavily forested. The southwest parcel faces west into Shelikof Strait and is primarily unforested, except along river valleys and around the heads of bays. There are no glaciers. Tree line ranges from 100 to $300 \mathrm{~m}$ and the only conifer is Sitka spruce (Picea sitchensis), which tends to be larger than on the mainland.

\section{Data Collection}

\section{Dawn Watch Surveys}

In Alaska, surveys are limited by logistic considerations due to inaccessibility of coastal habitats, and by the relatively short time available for breeding surveys (mid-May through early August). Therefore, intensive surveys (hereafter referred to as "dawn watches"; Paton and others 1990, Ralph and others 1993) were conducted from land-based ("upland") sites and from boats anchored near shore. The basic unit of measure was the 'detection' which is defined as "the sighting or hearing of a single bird or a flock of birds acting in a similar manner" (Paton and others 1990). We assume that dawn activity (i.e., numbers of detections) is positively related to nesting activity. We recognize, however, that no quantitative relationship between dawn activity and numbers of nesting murrelets has been defined, and conclusions about relative use of different habitats are tentative.

Dawn watches were modified for southcentral Alaska (for more details see Kuletz 1991b, Kuletz and others 1994c). Modifications included: (1) earlier start and finish times relative to sunrise (i.e., usually beginning $105 \mathrm{~min}$ before official sunrise and lasting until 15 min after sunrise, or 15 min after the last murrelet detection) to compensate for greater light levels in Alaska; (2) addition of behavior categories not observed further south; and (3) some watches were conducted from boats and shore to allow sampling of shoreline habitat. Using landmarks, we designated each detection as $<200 \mathrm{~m}$ or $>200 \mathrm{~m}$ from the observer. When the dawn watch was conducted near the water, a bird passing over land at any time during the observation was designated a land detection.

Behaviors indicative of murrelet nesting are referred to as "occupied behaviors." These included flying below canopy, emerging from or flying into trees, landing on or departing from a branch, or calling from a stationary point in the forest (Paton and others 1990). In unforested areas we considered flights into hillsides or brush or $\leq 3 \mathrm{~m}$ above ground cover to be occupied behaviors. Occupied sites were those with at least one recorded occupied behavior. We considered other sites to be of "unknown status" since a single visit was not sufficient to determine whether a site was unoccupied (Ralph and others 1993).

\section{Habitat Variables}

A 50-m vegetation plot was sampled at each dawn watch site. When the dawn watch was conducted from shoreline or from a boat, the vegetation plot center was placed within the habitat most visually representative of the area adjacent to the dawn watch site. Within the plot we measured the diameter at breast height (d.b.h.) of the 10 nearest upper canopy trees, the percentage of epiphyte cover on the branches of each tree, and the number of platforms per tree (horizontal surfaces $\geq 15 \mathrm{~cm}$ diameter and $\geq 10 \mathrm{~m}$ above the ground). Data on epiphyte cover and platforms were not collected for the Naked Island group. We also made visual estimates of overall canopy height, percentage canopy closure, and percentage of forested area. Slope grade, aspect, and elevation were measured on site or from topographic maps. Distance from the ocean was measured from aerial photographs. Each site was classified as either exposed coastline, semi-protected in a bay, or at the head of a bay.

\section{Study Design Sampling and Analyses}

The Naked Island group was surveyed between 10 June and 11 August 1991 ( $n=69$ sites). Sites in western Prince William Sound were surveyed between 15-18 July 1991 ( $n=$ $9)$ and 12 June-3 August $1992(n=68)$. Afognak Island was surveyed from 4 June-5 August $1992(n=76)$. Kenai Fjords National Park was surveyed from 8-29 July $1993(n=40)$. We surveyed Marbled Murrelet activity and recorded weather, survey period, and topographic and vegetation variables at each survey site in the four study areas. Murrelet activity is highly seasonal and generally exhibits a pattern of peak activity during the breeding season (Hamer and Cummins 1991, Nelson 1989, Rodway and others 1993b). Therefore, survey period was categorized as early and late (before or after $10 \mathrm{July,}$, respectively), based on activity patterns previously documented in Prince William Sound (Kuletz and others 1994c). Study designs and survey methods varied among areas (for details see Kuletz and others 1994b, c). At Naked Island, sites were randomly selected equally among four forest types (Kuletz and others, in press), with 69 of the sites having sufficient habitat data to include in this study. In western Prince William Sound, 77 sites were randomly selected from available habitat, although sample sizes among habitat types were not equal. Forty-six surveys were done from an anchored vessel, 23 from shore locations, and eight upland. An additional nine upland sites were surveyed opportunistically in 1991. These sites were located in forested and nonforested habitat, and occurred in areas of western Prince William Sound not previously surveyed. Sampling at Kenai Fjords National Park was randomly stratified by forested versus unforested and bay head versus not bay head. The 38 survey sites were equally distributed among the strata; 21 
sites were surveyed from shore, eight from boats, and nine from upland sites. At Afognak Island, 76 dawn watch sites were arbitrarily selected with efforts to sample equally throughout the north and southwest parcels. Two sites were surveyed from shore and 74 upland.

Sites were not randomly located within the entire spill zone. Therefore, our statistical results apply directly only to the sampled sites, and caution should be used when making inferences about other areas. Application of results to the entire area is based on the assumption (supported by our observations) that the study sites were representative of habitat types throughout the spill zone.

Because epiphyte cover and platforms were not recorded at Naked Island, we used Naked Island data for preliminary analyses, but not for the final multivariate analyses. For analyses, we used detections over land $<200 \mathrm{~m}$ from the observer because it produced stronger relationships with predictor variables in preliminary analysis of portions of the data set. Data from boat- and shore-based surveys were combined with upland survey data because these data are highly correlated (Marks and others, in press). Data from all areas were grouped because preliminary analyses indicated that within-site trends were similar to trends exhibited for all sites combined.

\section{Multiple Regression Analyses of Murrelet Activity Levels}

We used multiple regression analyses to examine the continuum of murrelet activity levels relative to independent variables, to examine the interactive effects of those variables, and to describe the amount of variation explained by the model. Although season and weather affect inland activity level, we incorporated all these variables into the model rather than attempting to develop standardization factors. Our initial set of 19 predictor variables were factors known or suspected to be associated with high levels of activity or nesting of Marbled Murrelets, based on previously conducted analyses (Kuletz and others, in press; Marks and others, in press; Naslund and others, in press), and on univariate statistics across the four study areas. We used Kruskal-Wallis nonparametric analysis of variance to test categorical variables for significant effects on the number of detections. We calculated Pearson correlation coefficients between continuous variables and the number of detections, and between each pair of continuous variables. To control for colinearity, only one of a pair of variables with $r>0.80$, whichever had the strongest correlation with the number of detections, was included in the same regression analysis.

Because categorical and continuous variables were included in the multiple regression model, we used a General Linear Model procedure (SAS Institute 1988) to examine variation in murrelet activity levels. We transformed the number of detections by using natural logarithms and the percent data (canopy cover, forest cover, alder cover, and slope) by using square roots to stabilize residuals. We ran our initial regression model with all sites, and included all significant $(P<0.05)$ categorical variables and those continuous variables which were measured across all four study areas. We ran a second regression model for the three areas for which variables more directly related to Marbled Murrelet nest site selection (epiphyte cover and platforms per tree) were estimated. For this model we included all variables in the initial regression and epiphyte cover, which was highly correlated with platforms per tree. We reduced the model to include $t$ probabilities for parameter estimates where $P<0.25$ in the original model. This criterion was selected because our objective was to include all variables that explained variation in murrelet activity. Standardized parameters (parameter estimates divided by their standard error) were used to determine the relative importance of variables included in the models.

\section{Discriminant Analyses of Murrelet Occupancy}

We used univariate tests and stepwise logistic regression to identify variables that could predict the probability of detecting occupied behavior at a survey site. This analysis included a test of how well the logistic model performed in classifying individual observations. For all four areas combined, we tested frequencies of classes of categorical variables for differences between occupied sites and sites of unknown status by using chi-square; and for differences in rank sums of continuous variables between occupied and unknown status sites by using the Wilcoxon 2-Sample Test (procedure NPARIWAY; SAS Institute 1988). Significant variables $(P<0.05)$ in these tests were entered into a stepwise logistic regression model (procedure LOGISTIC; SAS Institute 1990; Naked Island group excluded). Inclusion and retention of variables in the stepwise logistic analysis were allowed at $P<0.10$. We included platforms per tree in the model because it performed marginally better than one including epiphyte cover. Standardized parameter estimates were estimated by dividing the parameter estimate by the ratio of the standard deviation of the underlying distribution to the sample standard deviation of the explanatory variable (SAS Institute 1990), and were used to determine the relative importance of variables in the model. The classification error rate was calculated using a jackknife approach to reduce the bias of classifying the same data from which the classification criterion was derived (SAS Institute 1990).

\section{Results}

\section{Marbled Murrelet Activity Levels}

Activity of Marbled Murrelets differed by study area $(P=0.018)$, with the greatest level of activity occurring at Afognak Island, the least at Naked Island, and intermediate levels in western Prince William Sound and Kenai Fjords National Park (table 1). Activity was greater during late summer than during spring and early summer (table 1). Activity was greater when the cloud ceiling was low than when there was a high ceiling or clear conditions (table 1). Activity was also greater at survey sites located at the heads 
Table I-The number of detections for categorical variables considered for inclusion in multiple regression analyses relating activity of Marbled Murrelets to survey periad, weather, topographic, and vegetation variables. A Kruskal-Wallis nonparametric analysis of variance tested the null hypotheses that murrelet activity did nor differ between (or among) classes of each variable

\begin{tabular}{|c|c|c|c|c|c|c|}
\hline \multirow[t]{2}{*}{ Variable regression } & \multirow[t]{2}{*}{ Classes $(n)$} & \multicolumn{2}{|c|}{ Number of detections } & \multirow[t]{2}{*}{ Chi-square } & \multirow[t]{2}{*}{ df } & \multirow[t]{2}{*}{$P$} \\
\hline & & Mean & (s.e.) & & & \\
\hline \multirow[t]{4}{*}{ Area } & Naked Island (69) & 15.8 & $(2.27)$ & 10.12 & 3 & 0.0175 \\
\hline & Prince William Sound (77) & 23.8 & (3.11) & & & \\
\hline & Kenai Fjords (38) & 29.9 & $(5.78)$ & & & \\
\hline & Afognak Island (76) & 38.4 & $(5.27)$ & & & \\
\hline \multirow[t]{2}{*}{ Survey period } & Early (May 1-Jul 10)(113) & 18.1 & $(2.84)$ & 11.03 & 1 & 0.0009 \\
\hline & Late (Jul 11-Aug 31)(147) & 33.6 & (296) & & & \\
\hline \multirow[t]{3}{*}{ Survey method } & Boat (54) & 28.0 & $(3.62)$ & 2.48 & 2 & 0.2890 \\
\hline & Shore (67) & 23.6 & $(4.32)$ & & & \\
\hline & Upland (139) & 28.0 & $(3.10)$ & & & \\
\hline \multirow[t]{3}{*}{ Cloud ceiling } & None (26) & 15.4 & $(4.05)$ & 6.44 & 2 & 0.0398 \\
\hline & Above ridge (103) & 35.1 & $(4.09)$ & & & \\
\hline & Below ridge (68) & 18.6 & $(2.90)$ & & & \\
\hline \multirow[t]{4}{*}{ Windspeed } & $0 \mathrm{~km} / \mathrm{h}(123)$ & 31.1 & (3.51) & 6.51 & 3 & 0.0893 \\
\hline & $1.8 \mathrm{~km} / \mathrm{h}(103)$ & 23.6 & $(2.86)$ & & & \\
\hline & $9-16 \mathrm{~km} / \mathrm{h}(15)$ & 11.5 & $(4.14)$ & & & \\
\hline & $>16 \mathrm{~km} / \mathrm{h}(18)$ & 28.6 & $(8.86)$ & & & \\
\hline \multirow[t]{3}{*}{ Headbay } & Exposed shore (59) & 16.6 & (3.45) & 27.75 & 2 & 0.0001 \\
\hline & Bay (106) & 21.1 & $(2.62)$ & & & \\
\hline & Headbay (95) & 39.6 & $(4.28)$ & & & \\
\hline
\end{tabular}

of bays than elsewhere in bays or on exposed shorelines (table 1). Windspeed did not significantly affect murrelet activity and activity did not vary significantly among survey methods (by boat, from shore or upland; table 1).

Correlation coefficients between Marbled Murrelet activity and continuous weather, topographic, and vegetation variables measured in all four areas varied from -0.16 for alder cover to 0.39 for d.b.h. (table 2). The largest correlation coefficients were between murrelet activity and variables directly related to nest site selection (epiphyte cover; platforms per tree; table 2).

Our reduced model explained 52 percent of the total variation in murrelet activity (table 3). Parameters for survey period, location relative to the head of a bay, and epiphyte cover were highly significant. Based on ratios of parameters to their standard errors (table 3), epiphyte cover, survey period, and location relative to the head of a bay were the most important predictors of murrelet activity.

Across all four study areas combined, tree d.b.h. $\left(\chi^{2}=\right.$ $7.58, \mathrm{df}=2, P=0.02$ ), number of potential nesting platforms $\left(\chi^{2}=7.08, \mathrm{df}=2, P=0.03\right)$, and percent epiphyte cover $\left(\chi^{2}\right.$
Table 2-Pearson correlation caefficients between continuous variables considered for inclusion in multiple regression model and murrelet activity (Orerland detections <200 $\mathrm{m}$ from observer)

\begin{tabular}{l|lc}
\hline Variable & Units & $\begin{array}{c}\text { Pearson } \\
\text { correlation } \\
\text { coefficent }\end{array}$ \\
\hline Cloud cover & Percent & 0.14 \\
Elevation & Meters & -0.14 \\
Slope & Percent & 0.08 \\
Degrees from north & Degrees & -0.03 \\
Degrees from east & Degrees & -0.03 \\
Forest & Percent & 0.24 \\
Canopy cover & Percent & 0.12 \\
Canopy height & Meters & 0.24 \\
Diameter at breast beight $_{\text {Alder cover }}^{\text {Epiphyte cover }}{ }^{1}$ & Centimeters & 0.39 \\
Platforms $^{1}$ per tree & Percent & -0.16 \\
& Percent & 0.48 \\
\hline
\end{tabular}

\footnotetext{
${ }^{1}$ Not estimated at Naked Island
} 
Table 3-Multiple regression model relating activity of Marbled Murrelets ${ }^{l}$ to survey period, weather, topographic, and vegetation variables at three study areas: western Prince William Sound, Kenai Fjords National Park, and Afognak Island. Categorical variables were entered into the regression as dummy variables

\begin{tabular}{|c|c|c|c|c|c|c|}
\hline \multirow[b]{2}{*}{ Model } & \multirow[b]{2}{*}{ Variable } & \multirow[b]{2}{*}{$\begin{array}{l}\text { Levels of } \\
\text { categorical variables }\end{array}$} & \multirow[b]{2}{*}{ Estimale (s.e.) } & \multicolumn{2}{|c|}{ Parameter } & \multirow[b]{2}{*}{$\begin{array}{c}\text { Standardized } \\
\text { estimate }\end{array}$} \\
\hline & & & & $t^{2}$ & $P$ & \\
\hline $\begin{array}{c}F=15.21 \\
\mathrm{df}=10,140\end{array}$ & Intercepl & & $2.326(0.421)$ & 5.53 & 0.0001 & \\
\hline$R^{2}=0.52$ & Period & $\begin{array}{l}0 \text { (Early) } \\
1 \text { (Late) }\end{array}$ & $-0.851(0.19)$ & -4.38 & 0.0001 & 4.39 \\
\hline$P=0.0001$ & Headbay & $\begin{array}{l}0 \text { (Exposed) } \\
\text { I (Bay) } \\
2 \text { (Headbay) }\end{array}$ & $\begin{array}{l}-1.028(0.281) \\
-0.820(0.200)\end{array}$ & $\begin{array}{l}-3.66 \\
-4.10\end{array}$ & $\begin{array}{l}0.0004 \\
0.0001\end{array}$ & $\begin{array}{l}3.66 \\
4.10\end{array}$ \\
\hline & Elevation & & $-0.005(0.002)$ & -3.03 & 0.0029 & 2.50 \\
\hline & Slope $^{3}$ & & $0.131(0.053)$ & 2.47 & 0.0148 & 2.47 \\
\hline & Degrees from north & & $-0.003(0.002)$ & -1.86 & 0.0648 & 1.50 \\
\hline & Forest cover ${ }^{3}$ & & $0.121(0.070)$ & 1.72 & 0.0700 & 1.73 \\
\hline & Canopy cover ${ }^{3}$ & & $-0.120(0.072)$ & -1.67 & 0.0964 & 1.70 \\
\hline & D.b.h. & & $0.010(0.006)$ & 1.73 & 0.0863 & 1.67 \\
\hline & Epiphyle cover & & $0.018(0.004)$ & 4.73 & 0.0001 & 4.50 \\
\hline
\end{tabular}

\footnotetext{
1 Variable was natural log transformed

${ }^{2}$ Tesied null hypothesis that coefficient estimate $=0$

${ }^{3}$ Variable was square root transformed
}

$=6.73, \mathrm{df}=2, P=0.03$ ) were greater at sites located at heads of bays, than at more exposed sites.

\section{Identification of Occupied Sites}

The probability of observing occupied behavior was greater: (1) at Afognak Island than at other areas; (2) during upland surveys than during boat or shore surveys; (3) during days with a high percentage of clouds than during clear days; and (4) at bays (especially at heads of bays) than at exposed sites (table 4). The probability of observing occupied behaviors did not vary with survey period or windspeed. Occupied sites had greater levels of cloud cover, forest cover, canopy cover, canopy height, d.b.h., epiphyte cover, and platforms per tree, than other sites (table 5). Alder cover was greater at other sites than at occupied sites.

Tree size (d.b.h.) and location relative to the head of a bay entered the model at the $P<0.10$ level; survey method and platforms per tree were also included. Standardized parameter estimates (lable 6) indicated that d.b.h. and platforms per tree were the most important predictors of occupied sites. The logistic function correctly classified 78.9 percent of observations in a jackknife procedure; 82.7 percent of occupied sites, and 74.6 percent of sites of unknown status were correctly classified.

\section{Discussion}

\section{Habitat Predictors Of Murrelet Use}

\section{Murrelet Activity Levels}

Several variables were consistent predictors of high murrelet activity. Allowing for survey period, activity was highest at the heads of bays, at low elevations, and in areas with a high percentage of forest cover and large diameter trees. The most important habitat variables across all study areas were location relative to heads of bays, tree size (d.b.h.), and epiphyte cover on trees (excluding the Naked Island group for which there was no data on epiphyte cover). The number of platforms per tree was also important because it is highly correlated with epiphyte cover.

The importance of tree size and the number of platforms per tree was consistent with results from other studies and with attributes of nest trees found in southcentral Alaska (Hamer and Cummins 1991; Hamer, this volume; Naslund and others, in press). The importance of location relative to heads of bays was noted in earlier analyses of Prince William Sound data (Kuletz and others, in press; Marks and others, in press) but has not been reported elsewhere. Further, the trend for a bay effect in Kenai Fjords National Park was not significant in prior analyses (Kuletz and others 1994b). It is 
Table 4-Univariate tests for differences in frequencies of classes of categorical variables between occupied sifes (where behaviors indicating nesting were observed) and other sites (where behaviors indicating nesting were not observed

\begin{tabular}{|c|c|c|c|c|c|}
\hline Variable & Class (n) & $\begin{array}{l}\text { Proportion of } \\
\text { occupied sites }\end{array}$ & Chi-square & df & $\boldsymbol{P}$ \\
\hline \multirow[t]{4}{*}{ Area } & Naked Island (69) & 0.22 & 42.08 & 3 & 0.0001 \\
\hline & Prince William Sound (77) & 0.22 & & & \\
\hline & Kenai Fjords (38) & 0.32 & & & \\
\hline & Afognak Island (76) & 0.66 & & & \\
\hline \multirow[t]{2}{*}{ Survey period } & Early (May 1-Jul 10) (113) & 0.34 & 0.23 & 1 & 0.629 \\
\hline & Late (Jul 11-Aug 11) (147) & 0.37 & & & \\
\hline \multirow[t]{3}{*}{ Survey method } & Boat (54) & 0.24 & 14.56 & 2 & 0.001 \\
\hline & Shore (67) & 0.24 & & & \\
\hline & Upland (139) & 0.47 & & & \\
\hline \multirow[t]{3}{*}{ Cloud ceiling } & None (68) & 0.23 & 7.74 & 2 & 0.021 \\
\hline & Above Ridge (103) & 0.44 & & & \\
\hline & Below Ridge (63) & 0.41 & & & \\
\hline \multirow[t]{4}{*}{ Windspeed } & $0 \mathrm{Km} / \mathrm{h}(123)$ & 0.37 & 1.704 & 3 & 0.636 \\
\hline & $1-8 \mathrm{Km} / \mathrm{h}(103)$ & 0.38 & & & \\
\hline & $9-16 \mathrm{Km} / \mathrm{h}(15)$ & 0.33 & & & \\
\hline & $>16 \mathrm{Km} / \mathrm{h}(18)$ & 0.22 & & & \\
\hline \multirow[t]{3}{*}{ Headbay } & Exposed shore (59) & 0.22 & 9.42 & 2 & 0.009 \\
\hline & Bay (106) & 0.35 & & & \\
\hline & Headbay (95) & 0.46 & & & \\
\hline
\end{tabular}

Table 5-Means, standard errors, and univariate tests for differences in rank sums of continuous variables between sites where one or more occupied behaviors (behaviors indicating nesting of marbled murrelets) were observed (occupied sites) and sites where no behaviors indicating nesting of Marbled Murrelets were observed (other sites)

\begin{tabular}{|c|c|c|c|c|c|c|c|c|}
\hline \multirow[t]{2}{*}{ Variable } & \multicolumn{3}{|c|}{ Occupied sites } & \multicolumn{3}{|c|}{ Other sites } & \multirow{2}{*}{$Z^{I}$} & \multirow[t]{2}{*}{$P$} \\
\hline & $n$ & Mean & (s.e.) & $n$ & Mean & (s.e.) & & \\
\hline Cloud cover & 94 & 80.85 & (3.76) & 166 & 68.75 & (3.33) & 2.06 & 0.04 \\
\hline Elevation & 87 & 51.65 & $(4.61)$ & 140 & 71.70 & $(6.81)$ & -0.62 & 0.53 \\
\hline Slope & 88 & 21.25 & $(18.52)$ & 140 & 22.15 & (12.89) & -1.30 & 0.19 \\
\hline Degrees from north & 88 & 91.25 & $(5.53)$ & 140 & 91.29 & $(4.51)$ & -0.05 & 0.96 \\
\hline Degrees from east & 88 & 99.77 & $(6.00)$ & 140 & 99.14 & $(4.61)$ & 0.12 & 0.90 \\
\hline Forest cover & 88 & 74.64 & $(2.64)$ & 136 & 60.34 & $(3.00)$ & 2.69 & 0.008 \\
\hline Canopy cover & 88 & 63.26 & $(2.46)$ & 134 & 49.69 & (2.86) & 2.54 & 0.01 \\
\hline Canopy height & 88 & 26.71 & $(1.25)$ & 135 & 17.31 & (1.19) & 7.94 & 0.0001 \\
\hline D.b.h. & 87 & 57.11 & $(1.98)$ & 140 & 33.70 & (1.77) & 7.94 & 0.0001 \\
\hline Alder cover & 86 & 3.03 & $(0.70)$ & 132 & 10.90 & $(1.86)$ & -3.08 & 0.002 \\
\hline Epiphyte cover & 72 & 54.57 & (3.88) & 82 & 16.78 & (2.18) & 7.06 & 0.0001 \\
\hline Platforms per tree & 72 & 7.36 & $(0.67)$ & 82 & 2.06 & $(0.38)$ & 6.95 & 0.0001 \\
\hline
\end{tabular}

\footnotetext{
'Wilcoxon 2-Sample Test
} 
Table 6-Logistic regression model to predict probability of occupied sites of Marbled Murrelets (sites where one or more behaviars indicating nesting were observed) for the three study sites: western Prince William Sound (1992), Kenai Fjords National Park (1993) and Afognak lsland (1992), Alaska ( $n=152$ sites total)

\begin{tabular}{|c|c|c|c|c|c|c|c|}
\hline \multirow{2}{*}{$\begin{array}{l}-2 \log \mathrm{L} \\
\text { Chi-square }\end{array}$} & \multirow[t]{2}{*}{ df } & \multirow[t]{2}{*}{$P$} & \multirow[t]{2}{*}{ Variable } & \multicolumn{4}{|c|}{ Parameter } \\
\hline & & & & Estimate (s.e.) & Chi-square & $P$ & $\begin{array}{l}\text { Standardized } \\
\text { estimate }\end{array}$ \\
\hline \multirow{5}{*}{73.513} & \multirow[t]{5}{*}{4} & \multirow[t]{5}{*}{0.0001} & Intercept & $4.918(0.903)$ & 29.633 & 0.0001 & \\
\hline & & & Method & $-0.679(0.257)$ & 6.970 & 0.0083 & 0.31 \\
\hline & & & Headbay & $-0.559(0.306)$ & 3.331 & 0.0680 & -0.26 \\
\hline & & & D.b.h. & $-0.040(0.012)$ & $\$ 1.320$ & 0.0008 & -0.56 \\
\hline & & & Platforms & $-0 . t 38(0.057)$ & 5.776 & 0.0162 & -0.41 \\
\hline
\end{tabular}

possible that high detection rates result from murrelets funneling through bay heads and using them as flyways. However, the consistency of high activity at bay heads for the study areas overall, combined with the high proportion of occupied sites at bay heads, suggests otherwise.

Marks and others (in press) found that murrelet activity was positively correlated with stand size in western Prince William Sound. High activity at bay heads may be a result of larger contiguous forests at bay heads, although stand size relative to landform has not been investigated in these areas. Microclimate and minimal exposure to weather at bay heads may foster characteristics associated with known murrelet nesting habitat, including large tree size and mossy platforms on trees. This may explain the larger tree d.b.h., greater number of potential nesting platforms, and higher percentage of epiphyte cover at sites located at heads of bays relative to more exposed sites. However, these trends were not evident at Kenai Fjords National Park in earlier analyses (Kuletz and others 1994b). This is likely due to the recent deglaciation of many of the bay heads.

The importance of tree size and elevation in predicting murrelet activity has been suggested by other studies. Murrelets typically nest in old-growth stands where trees tend to be relatively large (see Hamer and Nelson, this volume b). Hamer and Cummins (1991) and Rodway and others (1991) found that murrelet activity was highest in low elevation forests in Washington and British Columbia. In northern latitudes, larger trees are found at lower elevations (Viereck and Little 1972). Kuletz and others (in press) found a significant negative correlation between tree d.b.h. and elevation on the Naked Island group, even though the highest elevation was $<460 \mathrm{~m}$. Thus, the contribution of elevation to the model is likely due to its effect on patterns of vegetation growth.

Conversely, it is also possible that murrelets are detected more frequently at low elevations, as they move from marine to terrestrial areas, because low elevation habitat tends to be closer to shore. Murrelets must pass over the shoreline to reach sites further inland. However, in some areas, murrelets leave the water and rapidly gain altitude before flying to distant inland sites (Van Vliet, pers. comm.), and would not be detected along the shoreline.
Responses of murrelet activity to variation in slope, aspect, and canopy cover were not consistent, and may have been influenced by local geography. Activity was positively related to northerly aspect in preliminary regression models, similar to findings of earlier analyses for Naked Island data. At Naked Island, there was a non-significant positive trend of higher murrelet activity on northerly slopes, possibly due to more high-volume forests on these slopes or the prevalence of southeast winds, that murrelets may seek to avoid (Kuletz and others, in press).

\section{Occurrence of Occupied Behaviors}

The influence of habitat features on the occurrence of occupied behaviors was similar to their influence on murrelet activity levels. In particular, the size of trees and the number of potential nest platforms were good predictors of murrelet occupied behavior. This is consistent with Alaskan tree nests that have been documented; most were located on large moss-covered platforms, often on the largest trees in an area (Naslund and others, in press). However, our results could be biased in that occupied behaviors in non-forested habitats have not been adequately defined.

Epiphyte cover, number of potential nest platforms, and tree size were clearly related. The importance of these habitat features to nesting murrelets may vary geographically. For example, epiphyte cover may be more important in Alaska than in other areas; moss was not the primary nest substrate of some nests at lower latitudes (Hamer and Nelson, this volume b; Singer and others 1991). Naslund and others (in press) suggested that moss is more important as insulation in Alaska's severe climatic conditions. Additionally, moss increases platform size, which could be important where small trees predominate.

Nesting clearly occurs in non-forested areas (Day and others 1983). However, the extremely low levels of general activity and of occupied behaviors at non-forested sites suggest that nesting activity in non-forested areas is less common than in forested areas. We believe that our results indicate that murrelet nesting density is low in sparsely forested or nonforest areas and that such habitat is of less importance to the population. However, it.is possible that differences in murrelet 
activity levels and behaviors in non-forested and forested habitats may not reflect actual differences in murrelet abundance. For example, murrelets may be more vulnerable to predation in open areas and therefore less active around ground nests.

\section{Effects of Survey Methods}

Levels of murrelet activity did not vary among survey methods. However, significantly more occupied behaviors were observed when surveys were done from upland sites rather than from the shoreline or a boat. Occupied behaviors may be hard to detect during surveys conducted from a boat because the observer is often $50-100 \mathrm{~m}$ from forest habitat. However, occupied behaviors were equally low in frequency when surveys were done from the shoreline. Thus, our results may reflect real differences in habitat use. Although murrelets sometimes nest within a few hundred meters of the shore (Cody, unpubl. data; Kuletz. unpubl. data; Marks, unpubl. data; Naslund and others, in press), they may use areas along the shoreline less frequently than those further inland (Hamer, this volume). The effect of survey method was confounded with effect of survey area, because boat and shore-based surveys predominated at Prince William Sound and Kenai Fjords National Park, whereas upland surveys predominated at Naked Island and Afognak Island. The latter had very high activity levels, large trees and high epiphyte cover (Naslund and others, in press), and the high occupied status rate could have been due to truly higher nesting densities.

\section{Sources of Unexplained Variation}

Our best multiple regression model explained 52 percent of the variation in murrelet activity. There were many potential sources of unexplained variation. Because sites were surveyed only once, day-to-day variation within the same area could have contributed to incorrect estimation of general activity level of a given site. We did not account for observer variability, which can introduce additional bias to murrelet surveys (Kuletz and others 1994c; Ralph, pers. comm.). Because each area was generally surveyed by different observers, area effects could be due partially to observer variability. In addition, differences in sampling design may have contributed to area effects or other variation. For example, all forest was treated equally in our analyses, yet forest characteristics (e.g., age structure, volume, tree species) are quite variable. The Naked Island group was the only area for which specific forest types were stratified and sampled.

Prevailing winds, local topography and vegetation patterns varied throughout the study area. Therefore, the geographic range of study sites likely contributed to the variation in murrelet activity we observed. In addition, murrelet nesting distribution may vary with availability of suitable habitat. For example, murrelets may be more dispersed in Prince William Sound if prime nesting habitat is abundant and widespread, whereas nesting density may be higher in good habitat on the Kenai Peninsula if suitable habitat is sparse. Thus, the lower activity levels in Prince William Sound, relative to the Kenai Peninsula, may reflect differences in habitat availability, rather than habitat suitability, between the two areas.
An important factor not considered in our models was the adjacent marine environment and the availability of foraging habitat. These factors must ultimately determine the use of suitable nesting habitat. Thus, the apparent increase in murrelet activity from Prince William Sound to Afognak Island may also reflect large-scale differences in prey availability.

\section{Conclusions}

These models primarily serve as descriptive tools until they can be tested with independent data. However, we were able to explain 52 percent of the total variation in Marbled Murrelet activity levels based on temporal, topographic, and habitat characteristics. Further, our results suggest an 83 percent success rate of classifying murrelet nesting habitat in the areas examined on the basis of occupied behavior. The features indicative of murrelet nesting habitat include low elevation locations near the heads of bays, with extensive forest cover of large old-growth trees. In some areas, such as the Kenai Fjords, location relative to bay heads may be less important. The best predictors of nesting habitat in forested areas are high epiphyte cover and large numbers of potential nesting platforms on trees.

Our results were derived from surveys designed to estimate murrelet use of forested habitat. Potential variation in murrelet behavior associated with habitat type (i.e., forest or non-forest) has not been adequately examined and could influence accurate interpretation of survey results. Therefore, caution should be exercised when extrapolating observed trends on a broad scale across the landscape.

\section{Acknowledgments}

The contribution of several studies was integral to this paper. We thank the USDA Forest Service (Chugach National Forest), who was a cooperative partner in the studies in Prince William Sound and Naked Island areas, and the U.S. Fish and Wildlife Service, Division of Realty who conducted murrelet surveys on Afognak Island. This research was funded through the U.S. Fish and Wildlife Service, Division of Migratory Bird Management as part of the Exxon Valdez oil spill restoration program and the Division of 'Realty. For assistance on projects we thank G. Esslinger, A. Belleman, I. Manley, S. Anderson, D. Huntwork, K. Rausch, K. Fortier, J. Maniscalco, E. Tischenor, L. Fuller, B. Grey, J. Fadely, B. Fadely, D. Zwiefelhofer, G. Johnson, V. Vanek, M. Nixon, T. Nelson, G. Landua, D. Goley and D. Kaleta. For the GIS support, we also thank T. Gerlach of the Division of Realty and T. Jennings and C. Wilder, all of them with U.S. Fish and Wildlife Service. From the USDA Forest Service we thank C. Hubbard, R. DeVelice, Z. Cornett, and B. Williams. S. Klosiewski provided guidance on study design and data analysis. The comments of R. Barrett, P. Connors, Chris Iverson, Michael McAllister, C. John Ralph, and an anonymous reviewer greatly improved this manuscript. 



\title{
Chapter 16
}

\section{Inland Habitat Associations of Marbled Murrelets in British Columbia}

\author{
Alan E. Burger?
}

\begin{abstract}
Most Marbled Murrelets (Brachyramphus marmoratus) in British Columbia nest in the Coastal Western Hemlock biogeoclimatic zone. In this zone, detection frequencies were highest in the moister ecosections and in low elevation forests. Nests and moderately high levels of activity were also found in some forest patches in the subalpine Mountain Hemlock zone. There was no evidence of nesting in subalpine scrub forest, lowland bog forest, or alpine tundra. Studies on the Queen Charlotte Islands and Vancouver Island reported consistently higher detection frequencies in old-growth than second growth forests (20-120 years old). Defections in second-growth were usually associated with nearby patches of old-growth. Within low elevation old-growth, detection frequencies were sometimes positively correlated with mean tree diameler, but showed weak or no associations with tree species composition and minor variations in forest structure. Sitka spruce (Picea sitchensis) and western hemlock (Tsuga heterophylla) were imporanl components of many high-activity sites. High murrelet activities were associated with well-developed epiphytic mosses, but mistleloe seemed less important. A study on Vancouver Island showed higher predation of artificial nests and eggs at forest edges, which suggests problems for Marbled Murrelets in fragmented forests. The use of detection frequencies in the selection and preservation of potential nesting habitat is discussed and the limitations of single-year studies are exposed.
\end{abstract}

British Columbia supports a significant portion of the North American population of Marbled Murrelets (Brachyramphus marmoratus). Over the past century, evidence accumulated that the birds nested in large trees in British Columbia (Campbell and others 1990), and at least one early biologist made the connection between declining numbers of murrelets and the reduction of oldgrowth forests on eastern Vancouver Island (Pearse 1946). In recent decades the pace of logging of coastal oldgrowth forests has greatly increased. Between 1954 and 1990 about half of the large-tree old-growth forest on Vancouver Island ( 75 percent in the southern island) was logged (Husband and Frampton 1991). Out of 354 forested watersheds larger than 5,000 ha in coastal British Columbia, only 20 percent are pristine and 67 percent have been significantly changed by industrial activity, primarily logging (Moore 1991). Concerns over the effects of logging on Marbled Murrelet populations were raised by Sealy and Carter (1984), but there were no intensive inland studies until the species was listed as threatened in Canada in 1990. Loss of nesting habitat by logging was considered

${ }^{1}$ Associate Professor (Adjuncl), Department of Biology, University of Vicloria, Victoria, British Columbia, V8W 2Y2, Canada the greatest threat (Rodway 1990, Rodway and others 1992). The listing stimulated several inland studies, including reconnaissance surveys in many watersheds of the Queen Charlotte Islands (Rodway and others 1991, 1993a) and Vancouver Island (Savard and Lemon in press) and intensive surveys at several sites.

Identification and mapping of potential nesting habitats was identified as a high priority for research in the National Recovery Plan for the Marbled Murrelet, prepared by the Canadian Marbled Murrelet Recovery Team (Kaiser and others 1994). Detailed 1:50,000 maps of coastal old-growth forests are being prepared (Derocher, pers. comm.). There are still very few data available for either landscape- or stand-level analyses of habitat associations. I review the available data and point out research topics that urgently need to be addressed.

\section{Methods and Sources of Data}

The studies reviewed here followed the Pacific Seabird Group survey protocols for general (road) and intensive (fixed station) surveys (Paton and others 1990, Ralph and others 1994), with the exception of Eisenhawer and Reimchen (1990) and Reimchen (1991).

Rodway and others $(1991 ; 1993 a, b)$ did intensive sampling through the 1990 season in Lagins Creek and Phantom Creek on Graham Island, and less frequent general surveys in 12 other watersheds on the Queen Charlotte Islands. Savard and Lemon (in press) analyzed data from 382 surveys at 151 fixed stations and 88 road surveys in 82 watersheds on Vancouver Island in 1991. Relatively few surveys were made at each station (mean 1.6, range 1-5), and large numbers of observers were used with variable degrees of training. Savard and Lemon (in press) warned that their data could not present an accurate picture of murrelet activity in any of the watersheds surveyed. Nevertheless, some significant patterns emerge at the landscape scale.

The remaining studies focussed on fine-scale temporal and spatial variations within single watersheds during one season (Eisenhawer and Reimchen 1990; MacDuffie and others 1993; Manley and others 1992, 1994) or 3-4 seasons (Burger 1994; Jones 1992, 1993). Only three studies combined repeated intensive surveys with detailed habitat analysis at a variety of sites (Burger 1994, Manley and others 1994, Rodway and others 1993a). These data are insufficient for a thorough examination of habitat patterns at stand and landscape scales in British Columbia, but some trends are apparent and are reviewed here. Figure I shows the location of the study sites. 


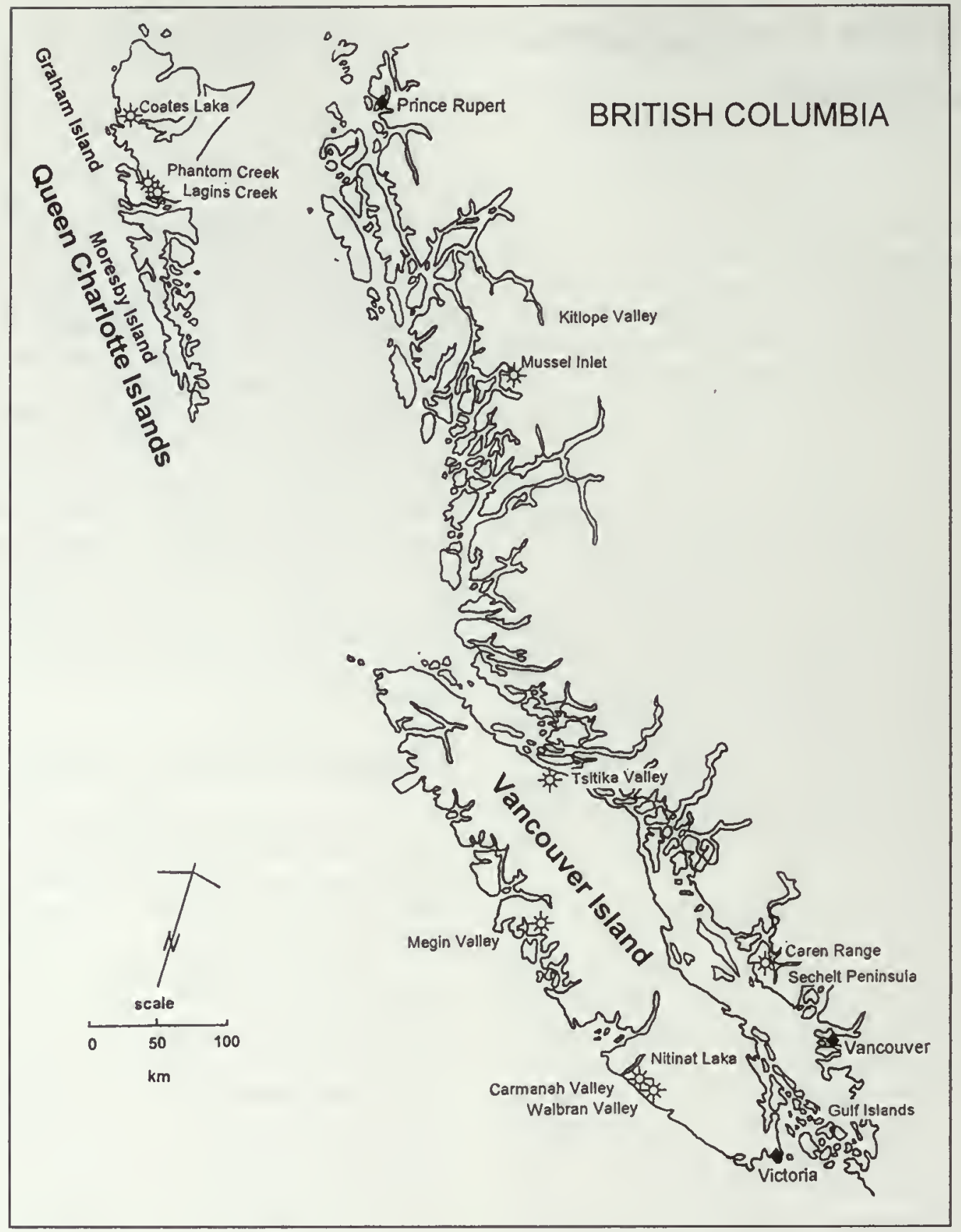

Flgure 1-Coastal British Columbia showing the location of inland studies of Marbled Murrelets (open stars).

\section{Biogeoclimatic Zones}

Marbled Murrelets have access to four biogeoclimatic zones (Meidinger and Pojar 1991). The Coastal Western Hemlock Zone covers most of coastal British Columbia at low to mid elevations $(0-900 \mathrm{~m}$ on windward and $0-1050 \mathrm{~m}$ on leeward slopes on the south and mid-coast; and $0-300 \mathrm{~m}$ on the north coast). Dominant trees are western hemlock (Tsuga heterophylla), western red cedar (Thuja plicata), and Amabilis fir (Abies amabilis), with yellow cedar (Chaemaecyparis nootkatensis) in higher elevations and Douglas-fir (Pseudotsuga menziesii) in drier habitats. Lodgepole pine (Pinus contorta) occurs in dry shoreline areas and bogs. Sitka spruce (Picea sitchensis) is an important component on floodplains in the southern forests, and in many older forests in the Queen Charlotte Islands and the northern mainland, and is an important nest site for Marbled Murrelets. Most Marbled Murrelets in British Columbia appear to nest in this zone (see below).

The Coastal Douglas-fir Zone covers a small area on southeastern Vancouver Island, the Gulf Islands, and a narrow strip of the adjacent southern mainland at elevations below 
$150 \mathrm{~m}$. It characterizes relatively dry forest in the rain shadow of the Vancouver Island and Olympic Mountains. Very little old-growth remains in this heavily populated zone. Douglasfir is the dominant tree, with other conifers and broad-leaved trees sometimes common. There has been no research on Marbled Murrelets in this zone, but nesting is likely, because the birds are often seen nearby on the ocean.

The Mountain Hemlock Zone occurs at $900-1800 \mathrm{~m}$ in southern British Columbia (lower on windward slopes) and $400-1000 \mathrm{~m}$ in the north. It is most common above the Coastal Western Hemlock Zone on the mainland Coast Mountains and the insular mountains of Vancouver Island and the Queen Charlotte Islands. Dominant trees are mountain hemlock (Tsuga mertensiana), amabilis fir, and yellow cedar. Much of this forest occurs as a mosaic among areas of subalpine heath, meadow, and ferns. Nesting has been recorded in these forests on the southern mainland (see below).

The Alpine Tundra Zone occurs on high coastal mountains, above $1650 \mathrm{~m}$ in the south and $1000 \mathrm{~m}$ in the north, and is dominated by shrubs (willows and birch), herbs, bryophytes, and lichens. Marbled Murrelets have been reported flying over such habitats (Rodway and others 1993a), but there is no evidence that they nest there in British Columbia.

\section{Landscape Attributes}

\section{Old-Growth Compared with Second-Growth}

Two studies compared detection frequencies in oldgrowth and second-growth. Rodway and others (1993a) recorded high densities of activity in intensive surveys in old-growth on the Queen Charlotte lslands (details below), but had only one detection in five intensive surveys in secondgrowth stands (60-120 years old). In road surveys, detections were reported at 76 percent $(n=25)$ of old-growth stations, but only at 27 percent $(n=101)$ of second-growth stations (20-120 years old). In 85 percent of the cases where detections were recorded in second-growth forest, there were stands of old-growth within $500 \mathrm{~m}$. Detection frequencies were significantly higher in old-growth than second-growth, and within second-growth they were significantly higher if there was old-growth nearby (fig. 2).

Savard and Lemon (in press) reported significantly fewer detections from stations in watersheds with less than 50 percent remaining old-growth, compared to more intact watersheds (fig. 3). At fixed stations in May and July, fewer detections were recorded when the proportion of old-growth fell below 75 percent of the watershed. In addition, stations

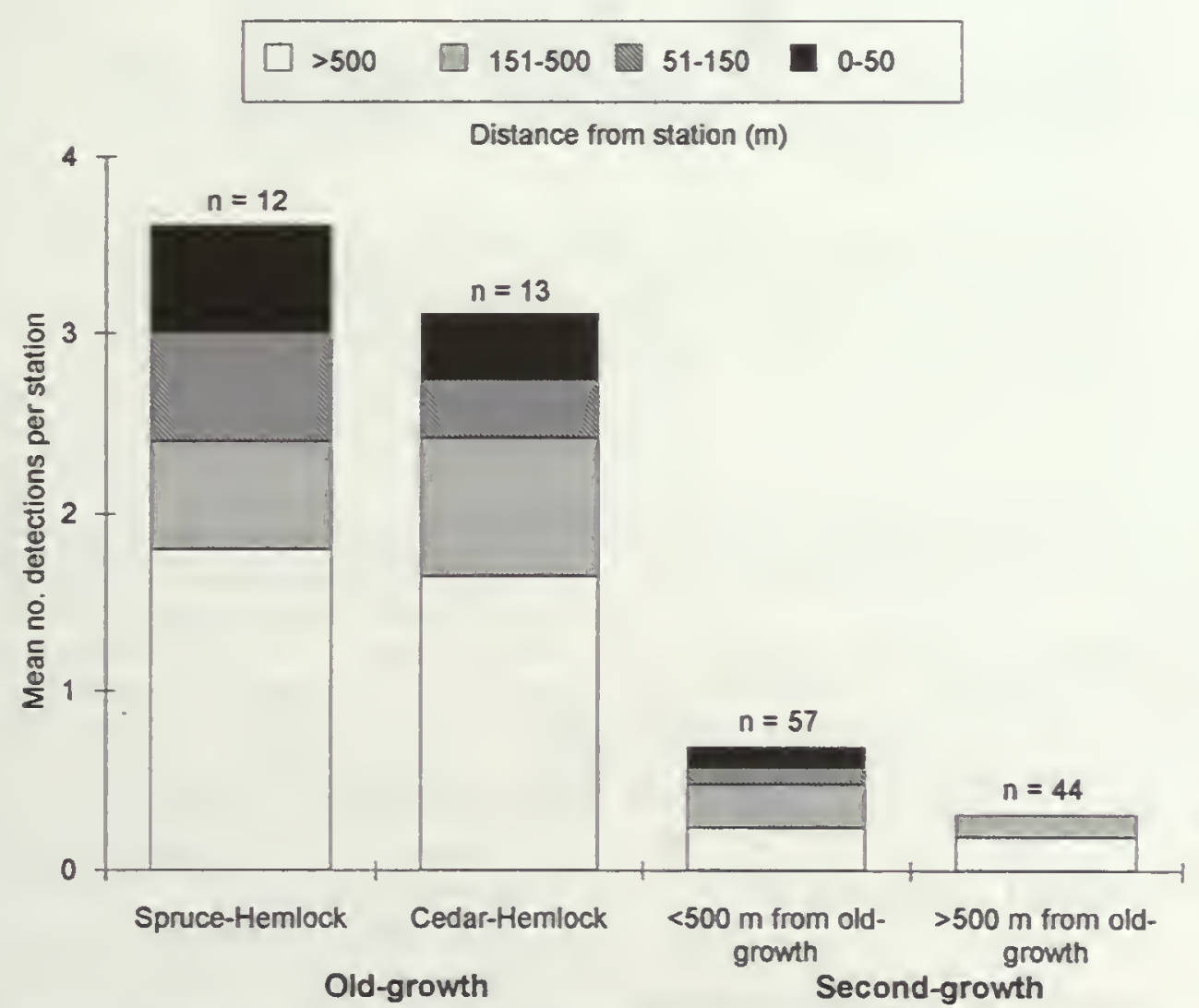

Figure 2-Mean number of Marbled Murrelet detections per road transect station in relation to adjacent habitat type in the Queen Charlotte Islands (from Rodway and others 1993a). The sample size ( $n$ ) is the number of surveys. 


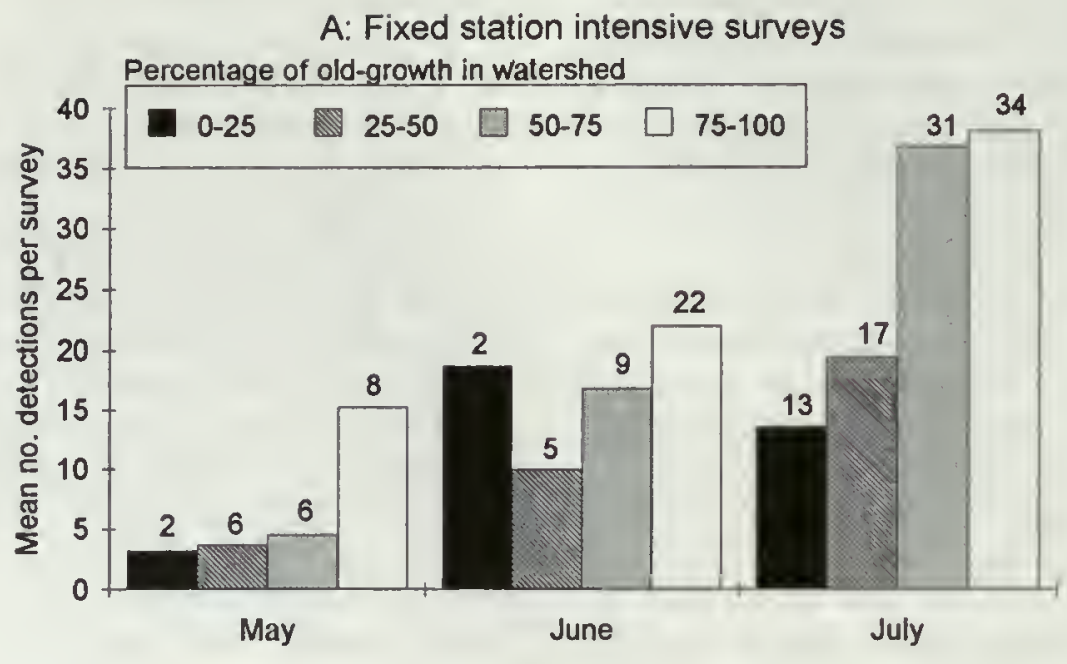

B: Road surveys

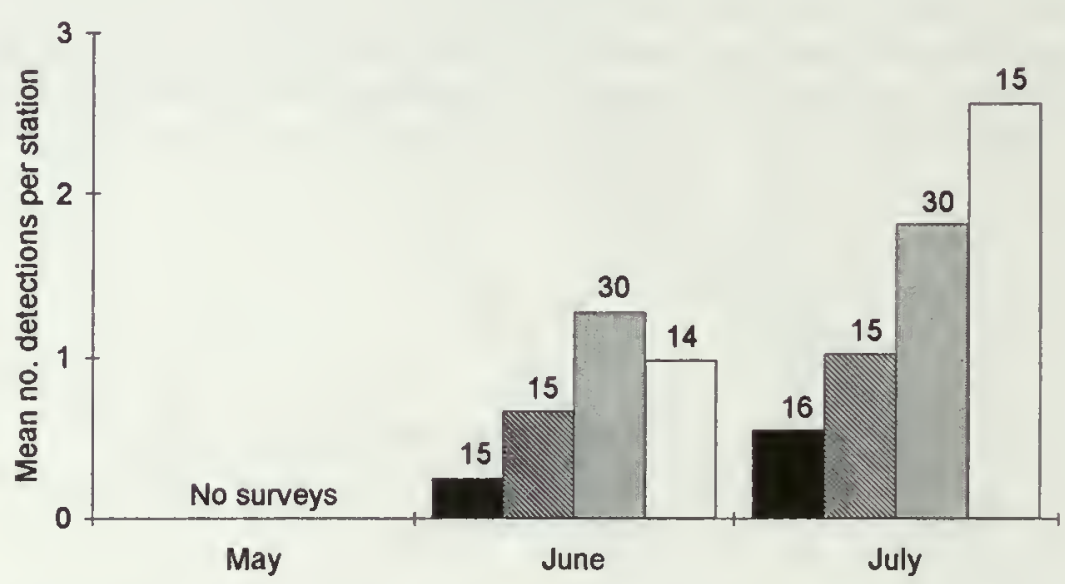

Figure 3-Mean numbers of Marbled Murrelet detections in intensive fixed station (A) and general road surveys $(B)$, in relation to the percentage cover of remaining oldgrowth forest in the sampled watersheds on Vancouver Island (from Savard and Lemon, in press). Sample sizes $(n)$ shown above columns are numbers of surveys.

close to old-growth (within $200 \mathrm{~m}$ in fixed stations and within $500 \mathrm{~m}$ in road transects) had higher detection rates than those further away.

These studies confirm that murrelets avoid second-growth forests, even those 60-120 years old. Furthermore, the Vancouver Island results tentatively suggest that murrelets do not pack into the remaining old-growth with increased density; reduced habitat leads to reduced populations.

\section{Relationship Between Landscape and Stand}

Distance to Salt Water and Location Within the Watershed

Savard and Lemon (in press) found no significant correlation between detection frequency and distance from salt water (using intervals of $0-5,5-15$, and $>15 \mathrm{~km}$ ) at 151 stations on Vancouver Island in May and July, but found a negative correlation in June. They found no effects of distance to open ocean (beyond the inlets) in any month. The location of fixed stations within each watershed did not affect detection rates (each watershed was divided into four zones, from mouth to headwaters), although road surveys showed significantly higher detections in the centers of the watersheds. These data indicate that Marbled Murrelets are able to access all of Vancouver Island, although only a small portion might be suitable nesting habitat.

The effect of distance from the ocean was tested in the Carmanah and Walbran watersheds in which unbroken oldgrowth forest extends from the ocean almost to the headwaters for 21 and $18 \mathrm{~km}$, respectively. Manley and others (1992) reported a significant negative correlation between detection rates and distance from the ocean at six stations in Carmanah- 
Walbran in 1990. A larger data set (11 stations in 1991 and 13 in 1992) produced no significant correlations when occupied detections (Pearson correlation, $r=-0.081$ and -0.271 , respectively) or total detections $(r=-0.140$ and -0.267 , respectively; $P>0.05$ in all cases) were considered (fig. 4; Burger 1994). The highest detection frequencies were found at sites $8-17.5 \mathrm{~km}$ inland. All six nests found in CarmanahWalbran were more than $10 \mathrm{~km}$ from the ocean (Burger 1994).

\section{Precipitation Amount and Form}

Most of the old-growth forests in which high densities of murrelets have been reported receive high rainfall (most in winter) and relatively little snow. On Vancouver Island, detection frequencies were significantly higher in the two moist ecosections (Western Island Mountains and Northern Island Mountains; Demarchi and others 1990) than in the drier Nahwitti Lowland and Nanaimo Lowland ecosections (Savard and Lemon, in press). Overall, detections were significantly higher on the moister western side of Vancouver Island than on the eastern side, but the latter area has also been far more extensively logged and urbanized, which might contribute to this difference.

Rodway and others (1993a) reported no detections at apparently suitable forest with large Sitka spruce at Gray Bay, Queen Charlotte Islands. The spruce trees there had virtually no moss development on their limbs, apparently as a result of sea spray, which might have made them less attractive to murrelets.
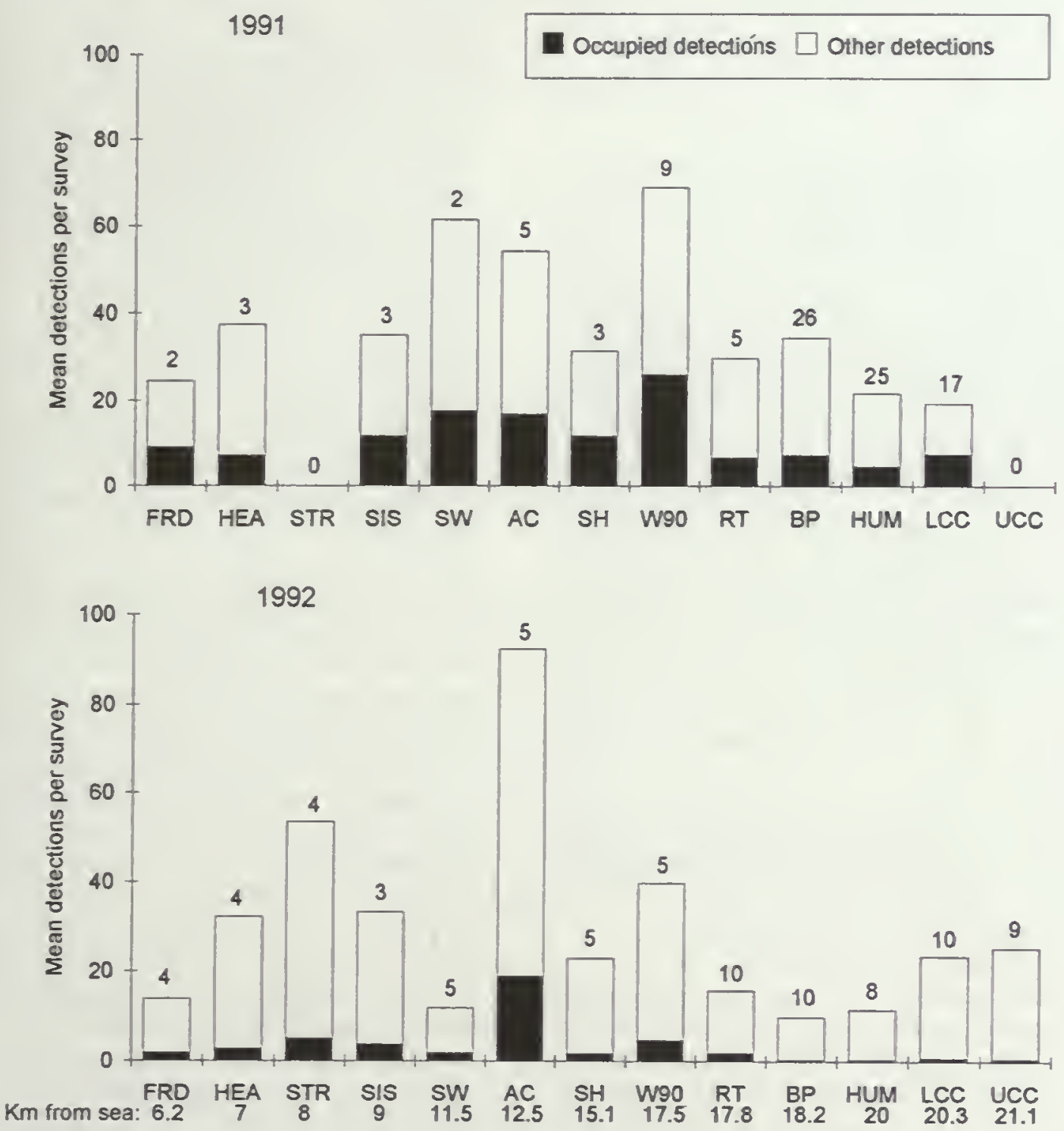

Figure 4-Mean frequencies of occupied and other detections reported from 13 intensive survey stations (arranged in increasing distance from the ocean) in the Camanah-Walbran watersheds, Vancouver Island, in the period 15 May through 16 July in 1991 and 1992 (from Burger 1994). Sample sizes (n) above columns are numbers of surveys. The $x$-axis is labelled with the codes for each station. Codes for each station are: FRD = Ford, HEA = Heaven Canp, STR = Stream Site, SIS = Three Sisters, SW = South Walbran Bridge, AC = August Creek, $\mathrm{SH}=$ Sleepy Hollow, W90 = West Walbran 1990 Nest Site, RT = Research Tree, BP = Bearpaw Camp, HUM = Hummingbird Camp, LCC = Lower Clearcut, UCC = Upper Clearcurt. 


\section{Stand Attributes and Relative Murrelet Densities}

\section{Elevation}

Eisenhawer and Reimchen (1990) found no evidence of Marbled Murrelets in high elevation (to $700 \mathrm{~m}$ ) subalpine scrub forest of lodgepole pine above Coates Lake, Queen Charlotte Islands. At Lagins Creek, Queen Charlotte Islands, Rodway and others (1991, 1993a) found a significant difference in mean detection rates in May through July between low elevation forests $(90-150 \mathrm{~m})$, high forests (230$460 \mathrm{~m}$ ), and alpine areas (720-1000 m): $32.4 \pm 4.1$ (s.e.), $17.5 \pm 3.0$, and $3.0 \pm 0.7$ detections per survey, respectively. About 98 percent of the old-growth forest occurred below $500 \mathrm{~m}$ in this area. A few birds passed over alpine ridges in this area, but 84 percent of the detections in high altitude stations were of birds $500-1500 \mathrm{~m}$ distant, flying in the valleys below. Ground searches in alpine areas yielded no sign of nesting.

Marbled Murrelets do nest in some high altitude forests above fjords on the mainland coast. Murrelets have been reported flying over the steep slopes, mostly covered in scrubby sub-alpine forest with patches of taller trees, which surround fjords (Burns, pers. comm.; Kaiser, pers. comm.; Prestash, pers. comm.). One radio-tagged bird was tracked to a sub-alpine stand of large conifers above Mussel Inlet (Prestash and others 1992b; see details below). Similar habitat appears to support Marbled Murrelets in the Kitlope drainage on the north-central mainland (Kelson, pers. comm.).

Fairly high rates of activity (details below) were reported from sub-alpine forest at $750-1200 \mathrm{~m}$, dominated by mountain hemlock and yellow cedar in the Caren Range, Sechelt Peninsula (Jones 1992; P. Jones, pers. comm.). An active nest was found here in 1993 at $1088 \mathrm{~m}$ (Jones 1993). A fledgling Marbled Murrelet was found alive on the ground by a tree faller at Downing Creek, near Furry Creek on the east side of Howe Sound in 1985. The suspected nest was at the top of a "red cedar" (sic) at an altitude of $1064 \mathrm{~m}$ (Morgan 1993).

Marbled Murrelets nest as high as $1000 \mathrm{~m}$, and these somewhat meager data suggest that vegetation development, specifically the absence of large trees at high altitudes, affects Marbled Murrelets more than altitude per se.

\section{Aspect, Slope and Stand Position on Slope}

The effects of slope and aspect have not been adequately investigated in British Columbia. High elevation stations on side slopes in two watersheds in the Queen Charlotte Islands (see above for altitudes) had lower detection rates than those in the valley bottoms, but this might be a consequence of elevation, rather than slope or aspect (Rodway and others 1991, 1993a). These authors pointed out that if birds circled over narrow valleys, they would probably pass over observers on the valley floor more often than observers on the side slopes, causing differences in detection frequencies.

\section{Vegetation Classification and Tree Size}

Intensive surveys in Lagins Creek, Queen Charlotte Island, by Rodway and others (1993a) yielded the highest densities of detections in stands of large Sitka spruce and western hemlock. These preferred stands included the following site associations: (1) valley bottom, western red cedar/Sitka spruce - foamflower (mean diameter at breast height [d.b.h.] = 162 $\mathrm{cm})$; (2) valley bottom, western red cedar/Sitka spruce Conocephalum (d.b.h. $=104 \mathrm{~cm}$ ); and (3) slope forest, western hemlock/Sitka spruce - lanky moss (d.b.h. $=93 \mathrm{~cm}$ ). Within these associations, vegetation groups with the largest trees (mean d.b.h. $141 \mathrm{~cm}$ vs. $60 \mathrm{~cm}$ for all other plots) had significantly higher rates of murrelet detections. These differences disappeared when only low-altitude sites were considered. Lower detections rates were found in these site associations: (1) valley bottom, western red cedar/Sitka spruce - skunk cabbage (d.b.h. $=40.4 \mathrm{~cm}$ ); (2) higher altitude, western red cedar/western hemlock - blueberry (d.b.h. not measured); and (3) lodgepole pine/yellow cedar - sphagnum (d.b.h. not measured) found in low-elevation bog-forest.

Reimchen (1991) made informal observations of flight activity of Marbled Murrelets (not following the Pacific Seabird Group protocol) at 49 lakes on Graham and Moresby Islands (Queen Charlotte Islands) between 25 May through 25 July over a 12 year period. The birds were absent or rare ( $<2$ calls per 15 minute survey) at 40 lakes, most of which were surrounded by unforested scrubby vegetation or "poorly forested" terrain. The nine lakes at which there was extensive murrelet activity were distributed primarily in old-growth forest with mossy boughs. Sitka spruce appeared to be an important component of the vegetation at active sites. Intensive observations by Eisenhawer and Reimchen (1990) at Coates Lake, Graham Island from 1 June to 3 August 1986 yielded a mean of 12.9 (range $1-50, n=42$ ) detections per dawn survey, as well as records of birds carrying fish, landing on trees, and possibly copulating on a branch. The old-growth forests here were mixtures of western hemlock, Sitka spruce, western red cedar, and yellow cedar, with canopies 40-70 m tall. No detailed habitat plots were made.

Murrelet activity was reported over the steep forested slopes overlooking Mussel Inlet, a northern mainland fjord (Prestash and others 1992b; Prestash, pers. comm.; Burns, pers. comm.). The forests were primarily within the Very Moist Coastal Western Hemlock (CWHvmL and CWHvm2) and Moist Maritime mountain hemlock (MHmml) biogeoclimatic subzones. Two radio-tagged murrelets were repeatedly tracked to forest stands here (the third radiotagged bird reported by Prestash and others [1992b] appeared to have lost its transmitter or died in the forest). Vegetation characteristics of these stands were derived from forest inventory maps. One stand was in sub-alpine hemlock/amabilis fir forest ( $400 \mathrm{~m}$ asl) with large mountain hemlock trees (37$46 \mathrm{~m}$ tall, estimated age $>250$ years), and the second in a low altitude $(80 \mathrm{~m})$ moss-covered bog-forest dominated by western red cedar (28-37 m, estimated 141-250 years old). 
Murrelets were also studied in subalpine forests in the Caren Range, Sechelt Peninsula (Jones 1992). Dominant trees were mountain hemlock and yellow cedar. This is very old forest and one cedar stump was 1717 years old. Detection frequencies from scattered stations in June and July in 1991, 1992 and 1993 averaged $13.9 \pm 13.8$ (s.d.; $n=27$; range 1 $61), 17.6 \pm 16.7$ (17;0-45), and $20.3 \pm 13.7$ (54;0-57), respectively (P. Jones, pers. comm.). Vegetation was not analyzed in detail. A nest was found here in a yellow cedar in 1993 (Jones 1993).

High densities of murrelet detections (mean 24.4 \pm 20.7 s.d., range 9-85, $n=12$ ) were obtained at Tsitika Creek station between 29 June and 15 July 1991 in the lower Tsitika Valley, northeastern Vancouver Island (MacDuffee and others 1993). A second station nearby, affording less visibility, yielded only 1-4 detections in two surveys in this period. Western hemlock (mean d.b.h. $=73 \mathrm{~cm}$ ), western redcedar $(117 \mathrm{~cm})$, amabilis fir $(75 \mathrm{~cm})$ and Sitka spruce $(112 \mathrm{~cm})$ made up 60 percent, 18 percent, 16 percent and 7 percent, respectively, of the trees with d.b.h. $>7.5 \mathrm{~cm}$ in this stand.

Vegetation analysis has been done in Carmanah-Walbran, Vancouver Island in conjunction with murrelet surveys in 1990-1993 (Burger 1994, Manley 1992, Manley and others 1992). This is an area of relatively unfragmented valleybottom old-growth, dominated by western hemlock ( 47 percent of all sampled stems $>10 \mathrm{~cm}$ d.b.h.; 37.7 percent of combined basal area), amabilis fir (41.8 percent; 19.2 percent), Sitka spruce ( 8.4 percent; 33.3 percent), western red cedar (2.6 percent; 9.7 percent) with a few red alder. Six nests have been found in this area, five in large Sitka spruce (d.b.h. range 1.33-3.7 m) and one in a large western hemlock (d.b.h. $2.1 \mathrm{~m}$ ). Manley (1992) found that murrelet detections at six stations were positively correlated with combined basal areas of hemlock and spruce, and negatively correlated with combined fir and cedar. Burger (1994) used a larger sample (11 stations in 1991, 12 in 1992) and considered a wider range of habitat variables, including stem densities and basal areas of all species, combinations of species, snags and trees $>1 \mathrm{~m}$ d.b.h.. He found the same patterns as Manley, but the only significant correlation was a negative relationship between detection rate and stem density of hemlock in 1991 (and not 1992). Burger (1994) concluded that the habitat variables measured were too coarse, and detection rates too variable, to detect subtle variations in suitability in this relatively homogeneous watershed. All of the stations were clearly in suitable nesting habitat, and occupied behaviors had routinely been recorded at all stations (fig. 4).

Manley and others (1994) sampled 14 sites in oldgrowth forest in the Megin Valley, central Vancouver Island. These were grouped into sites dominated by western hemlock (4 sites), western red cedar (4), Sitka spruce (5) and amabilis fir (1), although all sites supported a variety of these large trees. Analysis of detection frequencies in June and July 1993 showed that the spruce sites had significantly lower detection rates than either cedar or hemlock, but cedar and hemlock did not differ significantly (table 1). The differences disappeared when only occupied detections were considered, because spruce sites had higher proportions of occupied detections (14 percent) than hemlock ( 4 percent) and cedar $(3$ percent). Average tree

Table 1-Mean (s.d.) detection frequencies of Marbled Murrelets in three forest types in the Megin Valley, central Vancouver Islands in June and July 1993 (from Manley and others 1994)

\begin{tabular}{|c|c|c|c|c|}
\hline \multirow[b]{2}{*}{ Parameters } & \multicolumn{3}{|c|}{ Mixed forests dominaled by: } & \multirow[b]{2}{*}{ Significant differences* } \\
\hline & Spruce & Cedar & Hemlock & \\
\hline \multicolumn{5}{|c|}{ Total detections } \\
\hline June & $12.75(8.75)$ & $38.0(35.29)$ & $27.56(13.61)$ & $\begin{array}{l}\text { Cedar }>\text { Spruce }(Z=2.28, P<0.02) \\
\text { Hemlocl }>\text { Spruce }(Z=2.65, P<0.01)\end{array}$ \\
\hline July & $13.36(8.3)$ & $27.13(9.08)$ & $19.56($ to.1) & $\begin{array}{l}\text { Cedar }>\text { Spruce }(Z=1.96, P<0.02) \\
\text { Hemlock }>\text { Spruce }(Z=3.33, P<0.01)\end{array}$ \\
\hline \multicolumn{5}{|c|}{ Occupied detections } \\
\hline June & $1.44(2.37)$ & $2.00(4.50)$ & $1.11(1.76)$ & None \\
\hline July & $1.82(2.74)$ & $0.25(0.46)$ & $0.56(1.13)$ & None \\
\hline \multicolumn{5}{|c|}{ No. of stations } \\
\hline & 4 & 4 & 5 & \\
\hline \multicolumn{5}{|c|}{ No. of surveys } \\
\hline June & 16 & 8 & 9 & \\
\hline July & 10 & 8 & 9 & \\
\hline
\end{tabular}

* Multiple Kruskal-Wallace comparisons 
diameter and total basal area of trees ranged from 46 to $123 \mathrm{~cm}$, and 5.9 to $25.3 \mathrm{~m}^{2}$ per 0.9 ha plot, respectively. Frequencies of occupied detections were positively correlated with both mean tree diameter $(r=0.729, n=15$, $P<0.01)$ and basal area $(r=0.585, n=15, P<0.05)$, but frequencies of all detections showed no significant correlations (Manley and others 1994). These data suggest that the murrelets were more sensitive to tree size than to tree species composition in these old-growth forests.

There have been no analyses of the effects of stand size, edge effects or stand isolation on Marbled Murrelets in British Columbia.

\section{Effects of Epiphytic Mosses and Mistletoe}

All nine nests known for British Columbia were on platforms of epiphytic mosses. Dense mosses were associated with the large trees in those vegetation groups in which detection frequencies were highest in the Queen Charlotte Islands (Rodway 1993a). In Carmanah-Walbran watersheds, Burger (1994) found no correlation between murrelet detection frequency and estimated moss cover per site, but the trees in all of the sample plots were well endowed with mosses and this was not a limiting factor for the murrelets here.

None of the nine nests found in British Columbia were associated with mistletoe. Murrelet detection frequencies were not correlated with mistletoe index (Hawksworth 1977) in Carmanah-Walbran in 1991 (11 sites) or 1992 (12 sites), and moss-covered boughs provided many more potential nest sites than mistletoe in these large trees (Burger 1994).

\section{Predator Abundance}

I found no records of predation of Marbled Murrelets from British Columbia, but did not review all the raptor literature. Marbled Murrelets were absent from prey remains of Bald Eagles (Haliaeetus leucocephalus) found beneath 35 nests (which included 145 bird carcasses) in the Gulf Islands (Vermeer and others 1989a) and 17 nests (33 bird carcasses) in Barkley Sound (Vermeer and Morgan 1989). Jones (1992) reported that murrelets fell silent and disappeared for 10 minutes when a large owl (probably Barred Owl [Strix varia]) appeared.

Bryant (1994) tested the effects of egg predators in montane western hemlock-mountain hemlock forest in central Vancouver Island, using 120 artificial nests, each with three quail eggs, placed on the ground or in trees at eye level. He found that 43 percent of nests ( 52 percent of eggs) were damaged or removed in the first week, and 87 percent (91 percent eggs) after two weeks. The survival of both nests and eggs placed in trees was significantly higher with increasing distance from the forest edge, after both 7 and 14 days (fig. 5). Nests of Marbled Murrelets are much higher in trees and better camouflaged than these experimental nests, and so would not necessarily experience the same levels of predation. Nevertheless, these results indicate a strong edge effect of nest predation, suggesting that fragmentation of forests exposes Marbled Murrelet nests to increased predation. Steller's Jays (Cyanocitta stelleri), Gray Jays (Perisoreus canadensis) and Common Ravens (Corvus corax) were likely predators of tree nests in this experiment. These corvids did not appear in Bryant's census transects often enough to determine their distribution (Bryant, pers. comm.).

These results are consistent with the conclusions reached by Paton (1994). In a critical review of 14 studies, he found strong evidence that avian nest success was reduced by predation and parasitism near habitat edges. Increased predation of natural and artificial (experimental) nests was most marked within $50 \mathrm{~m}$ of forest edges. In addition, nest success was consistently correlated with habitat patch size. There were apparently no studies in old-growth forest in the Pacific Northwest, nor did any studies consider nests as high in trees as those of the Marbled Murrelet. Studies on the effects of edges and habitat fragmentation on nest success of Marbled Murrelets are clearly a priority in areas with intensive logging.

\section{Assessing Marbled Murrelet Habitat Quality in British Columbia}

\section{Conservation and Management Requirements}

Marbled Murrelets appear to nest in scattered forest locations over a vast area in coastal British Columbia (Campbell and others 1990, Rodway 1990, Rodway and others 1992). There is a growing need to identify and preserve nesting habitat, particularly in the many areas facing clearcut logging. Unlike the situation to the south in the United States, identification of occupied stands has not guaranteed protection in British Columbia because Canada lacks an Endangered Species Act to enforce strict protection of habitat, and neither federal nor provincial governments are likely to block all commercial logging in occupied stands. Only the most valuable nesting habitat is likely to be preserved outside parks, and measures to identify such habitat are urgently needed. At least two categories of forest need to be considered for immediate preservation: areas supporting many breeding birds which make up a significant proportion of the provincial murrelet population; and forest patches supporting remnant populations in areas severely affected by habitat loss. The first is important for maintaining a large, viable breeding population of murrelets and the second to maintain a wide breeding range and genetic diversity.

Efforts to identify high quality habitat in British Columbia are at a very early stage. The huge areas involved and paucity of resources for surveying murrelets make it unlikely that the intensive multi-year surveys covering 12-30 ha, which are recommended for identifying occupied stands (Ralph and others 1994) will be widely implemented for short term management in British Columbia. As an interim measure, forest and wildlife managers will need general guidelines on the quality of forest stands being considered for logging. Intensive surveys can then be focused on the forest stands with greatest potential as nest sites. 

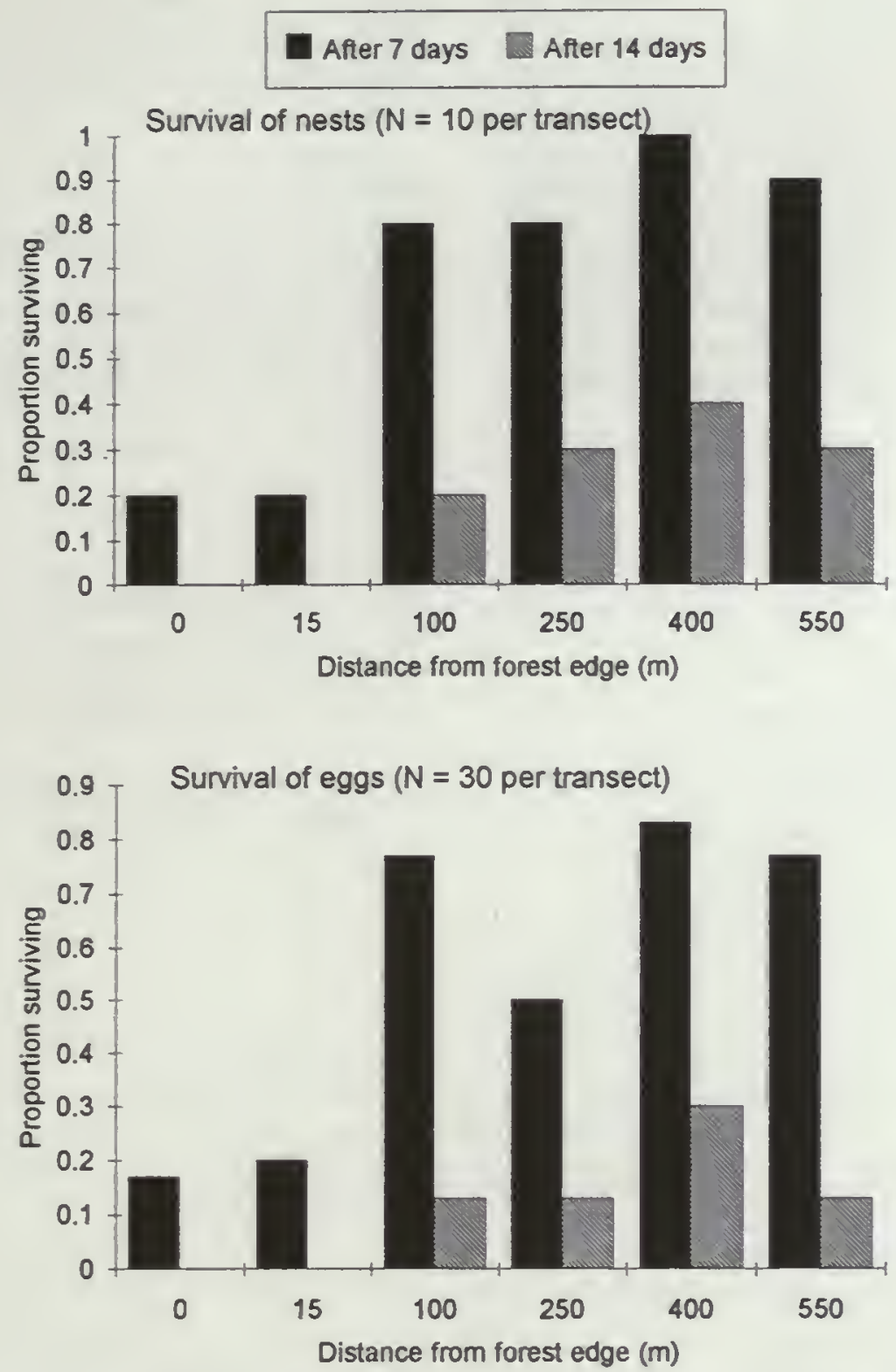

Figure 5-Survival of artificial nests, each containing three quail eggs, placed at eye level in trees in transects laid out at various distances from the forest edge in montane westem hemlock-mountain hemlock forest in central Vancouver Island, 1992 (data from Bryant 1994). Nest "survival" meant the nest was in good condition with at least one undamaged egg, egg survival was the count of undamaged eggs.

\section{Use of Detection Frequency to Delineate Marbled Murrelet Habitat}

Standardized pre-dawn surveys provide indications of relative nesting density (Ralph and others 1994), although the relationship between the number of detections per survey and the density of nesting pairs has not been established and is likely to vary among sites and through the season (Rodway and others 1993a,b). As a first approach I have compared the frequency of detections among a wide range of survey stations from three sources: (1) the Queen Charlotte Islands (158 surveys at 50 sites in 1990; Rodway and others 1991, 1993a)
(2) a large sample of watersheds throughout most of Vancouver Island (471 surveys at 151 sites in 1991; Savard and Lemon in press); and (3) intensive surveys made over four years (1990-1993) at 12 sites in Carmanah Valley, two in the Walbran Valley and one at Nitinat Lake (Burger 1994). At each site (in some of the Queen Charlotte Islands surveys, a site included several stations), the mean frequency of detections per morning survey was calculated for the period 1 May through 31 July. Occupied detections (Ralph and others 1994) could not be analyzed separately since these were not given in all reports. 
The percentage of the sampled sites in which the mean frequency of detections exceeded a given threshold was then plotted (fig. 6). This should facilitate ranking a particular site, relative to other sites, or guide decisions on how important surveyed sites might be on a provincial or regional basis. The trends in the Queen Charlotte Islands and on Vancouver Island were surprisingly similar. These indicate, for example, that about 18 percent of all sites in these areas had mean densities exceeding 40 detections per survey. If a manager decided to preserve all sites above this threshold, then one would expect about 18 percent of the potential sites to be included. These trends should obviously only be used as guides, since some lowdensity sites might be important in places where there are few high quality sites.

These data were derived from relatively few surveys (means for Queen Charlotte Islands and Vancouver Island were 3.2 and 1.6 surveys per site, respectively), made in a single year (1990 and 1991, respectively). By contrast, the surveys made in Carmanah-Walbran-Nitinat used fewer sites, but were much more intensive (mean 31.4 surveys per site) and covered four years. Not surprisingly, the threshold pattern
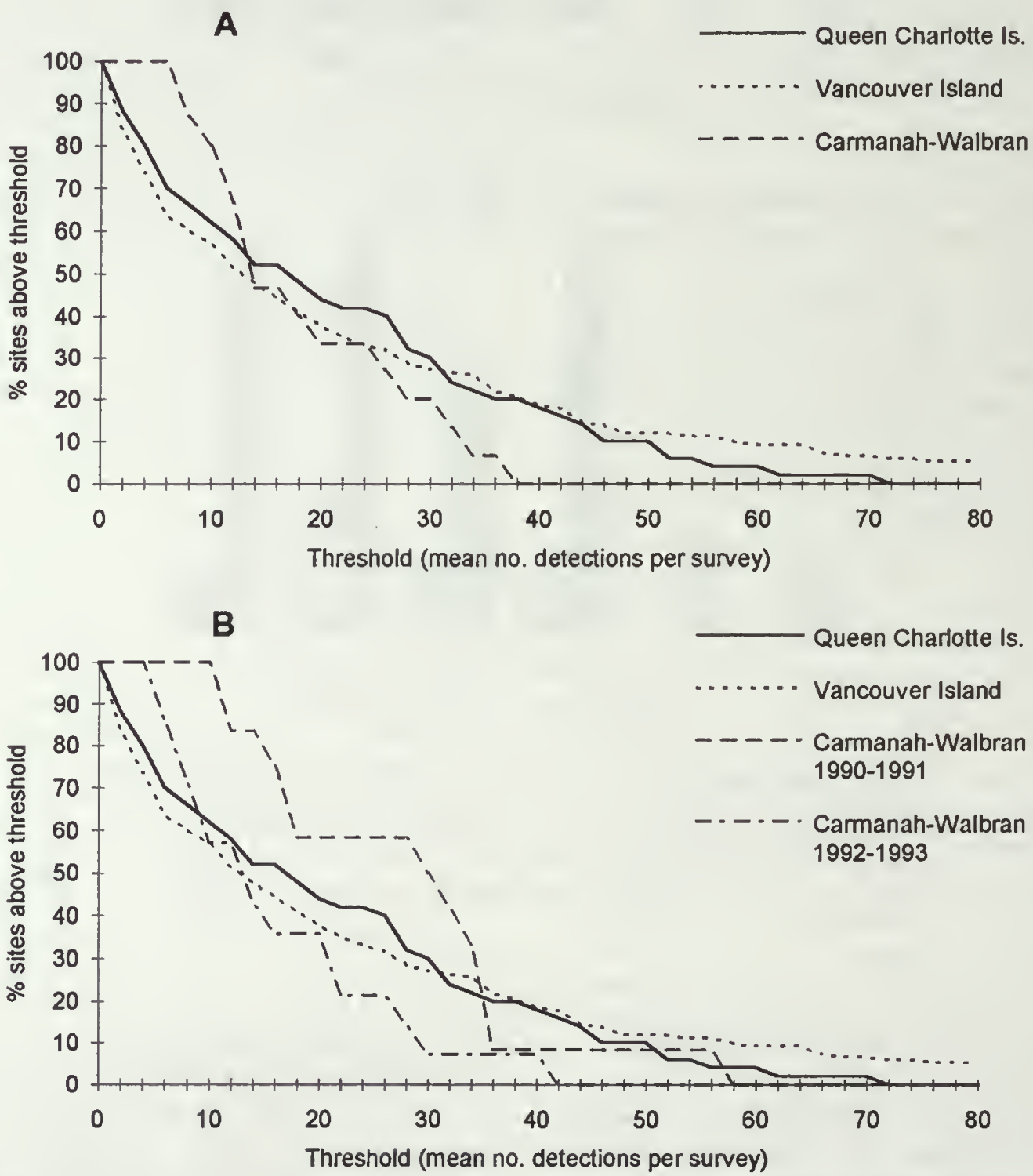

Figure 6-A: plot of the percentage of sites in which the mean frequency of Marbled Murrelet detections exceeded the thresholds on the x-axis. Data from the period 1 May through 31 July in the Queen Charlotte Islands (158 surveys at 50 sites in 1990; Rodway and others 1991), Vancouver Island (209 surveys at 151 sites in 1991; Savard and Lemon in press), and Carmanah-Walbran-Nitinat (471 surveys at 15 sites in 1990 1993; Burger 1994). B: the same plot as A, but with the Carmanah-Walbran-Nitinat data separated into two periods: 1990-1991 (176 surveys at 12 sites) and 1992-1993 (297 surveys at 14 sites). 
differed from the previous studies, showing a smaller proportion of sites at each extreme (fig. $6 a$ ). These results emphasize that the single-year Queen Charlotte Islands and Vancouver Island surveys provide only rough guides to the expected patterns in a specific area.

The effect of year-to-year variability in detection frequency can be clearly seen when the Carmanah-WalbranNitinat data are split into two periods $(f i g$. $6 b$ ). The first (1990-1991) was a period of normal sea temperatures and high murrelet detections in the Carmanah-Walbran-Nitinat forests, whereas the second (1992-1993) covered two years with unusually high inshore sea temperatures and low murrelet activity in parts of the forest (Burger 1994). The resultant threshold patterns are quite different, showing that variable factors affecting murrelets (such as El Niño effects) must be considered when habitats are assessed on the basis of detection frequency. If, for example, forest managers set a threshold of 30 detections per survey to delineate optimal habitat, then this would cover 50 percent of all sites sampled in the good years (1990-1991), but only 7 percent of the same sites in poor years (1992-1993).

In order to avoid such problems, managers would need to be very conservative and use relatively low thresholds (e.g., means of 10 or 20 detections per survey) to delineate high-quality habitat requiring preservation. Comparisons among sites of the mean detection frequencies provides only a crude estimation of the quality of a stand, particularly if only one or two intensive surveys are made in a single season. A more meaningful analysis would use the relative frequency of occupied behaviors recorded over at least two years (Ralph and others 1994), and surveys in British Columbia should be directed towards this goal.

\section{Acknowledgments}

Preparation of this chapter was funded by the British Columbia Ministries of Forests (Research Branch) and Environment, Lands, and Parks (Wildlife Branch); I thank Brian Nyberg and Don Eastman for their support. I thank Rick Burns, Andy Derocher, Andrea Lawrence, Moira Lemon, David Manuwal, Ken Morgan, Lynne Prestash, Martin Raphael for valuable comments. Unpublished material was provided by Andrew Bryant, Rick Burns, Paul Jones (Friends of Caren), Moira Lemon (Canadian Wildlife Service), Irene Manley, Misty MacDuffee (Western Canada Wilderness Committee), and Lynne Prestash. 



\title{
Inland Habitat Associations of Marbled Murrelets in Western Washington
}

\author{
Thomas E. Hamer ${ }^{1}$
}

\begin{abstract}
Little research has been done to quantify and describe the structural characteristics of forest stands that are associated with Marbled Murrelet (Brachyramphus marmorarus) nesting in the Pacific Northwest. Vegetation measurements and murrelet surveys to determine occupancy were conducted in stands located throughout western Washington. 1 used logistic regression to contrast stand attributes between occupied $(n=64)$ and unoccupied ( $n$ $=87$ ) stands. The probability of occupancy of an old-growth stand increased with increasing total number of potential nest platforms, percent moss coverage on the limbs of dominant trees $(\geq 81 \mathrm{~cm}$ d.b.h.), percent slope, the stem density of dominant trees, and the mean d.b.h. of western hemlock. The probability of occupancy of a stand decreased as lichen coverage on the limbs of dominant trees, stand elevation, and canopy closure increased. Mean detection rates and the percent of stands surveyed and verified as occupied declined sharply with an increase in elevation over 1,067 $\mathrm{m}$, and for stands $>63 \mathrm{~km}$ from salt water. The relationship of the number of potential nesi platforms and elevation 10 the probability of occupancy was best explained by comparing the structural characteristics of old-growth trees for the five conifer species available for nesting. Land management activities that reduce or affect the number of potential nest platforms/ha, composition of low elevation conifers, moss cover on tree limbs, stem density of dominant trees $(\geq 81 \mathrm{~cm}$ d.b.h.), or canopy closure, would reduce the quality of a site as nesting habitat for murrelets. Reproductive success should be used as a measure of habitat suitability in future studies by intensively studying occupied stands that have high detection rates of Marbled Murrelets and locating a sample of active nests to observe.
\end{abstract}

The research attempts to quantify and describe the structural characteristics associated with Marbled Murrelet (Brachyramphus marmoratus) nesting habitat have examined the general relationship between murrelet abundance and stand age, stand size, and tree size. A more specific model describing habitat is needed for a variety of reasons. A model would help (1) assess the relative impacts that forest management practices and associated activities will have on the quality of murrelet nesting habitat, (2) evaluate the relative suitability of a forest stand as nesting habitat for murrelets, (3) more accurately map suitable habitat, (4) understand how to speed the development of suitable habitat to meet long-term objectives for maintaining or increasing murrelet populations, (5) attempt to fashion habitat enhancement techniques or mitigation measures, and (6) plan future habitat research studies.

${ }^{1}$ Research Biologish, Hamer Environmental, 2001 Highway 9, ML. Vernon, WA 98273
Studies specifically addressing the forest habitat associations of Marbled Murrelets in Washington were initiated in 1990 and continued through 1993. A 1990 study examined the association of murrelets to four broad habitat categories and recorded the distribution and abundance of murrelets within an entire drainage basin, beginning at the Cascade crest and ending at its terminus with the Puget Sound (Hamer and Cummins 1990). An analysis of murrelet detection rates relative to the percent of old-growth forest available on the landscape was also conducted in this study. Studies from 1991 to 1993 focused on describing and analyzing the structural differences between old-growth stands occupied by murrelets and unoccupied old-growth stands. The results of these structural analysis are presented in this paper. In addition, a landscape analysis examining the attributes associated with stands occupied by Marbled Murrelets was completed in Washington in 1994 (Raphael and others, this volume).

\section{Methods}

\section{Landscape Characteristics}

\section{Detection Rate Comparisons}

For the comparison of Marbled Murrelet detection (murrelet detections/survey morning) and occupancy rates (number of stands surveyed and verified as occupied/number of stands surveyed) with respect to elevation, inland distance, and physiographic province, 262 old-growth stands were used. To investigate the effect of elevation on murrelet detection and occupancy rates, the mean detection rate and the percent of old-growth stands found occupied by murrelets were averaged for each 150 -m interval in elevation ranging from 0 to $1,500 \mathrm{~m}$. To determine the effect of inland distance on habitat use by murrelets, the mean detection rate and percent of old-growth stands verified as occupied were averaged for inland distances using $15-\mathrm{km}$ intervals ranging from 0 to $95 \mathrm{~km}$. The mean detection rate and the percent of stands surveyed and verified as occupied were also used as measures of the use of a region by murrelets. The physiographic provinces we used for data comparisons are those described by Franklin and Dyrness (1973). Of the 262 old-growth stands in this analysis, 132 stands occurred in the North Cascades Province, 32 in the South Cascades, 80 on the Olympic Peninsula, 8 in the Coast Range (southwest Washington), and 10 stands in the Puget Trough Province.

Inland surveys for Marbled Murrelets were conducted using standardized survey techniques developed by the Pacific Seabird Group Marbled Murrelet Technical Committee (Ralph 
and others 1994). Single observers visited each stand three or more times during the breeding season (1 May-5 August) recording observations during a 2 -hour dawn survey period each visit. Mean detection rates for each stand were calculated by dividing the total number of detections by the number of survey visits. To standardize this calculation, stands with $<3$ visits were not used in the analysis. These stands would not have had enough survey effort to determine occupancy with sufficient likelihood. For sites with $>4$ visits, survey visits were removed by selecting those four visits that best represented the seasonal timing of surveys recommended by the Pacific Seabird Group survey protocol. This helped standardize the selection of surveys in order to equalize the survey effort between stands. Therefore, survey effort was standardized by using only three or four visits for each stand used in the analysis.

Occupied sites were defined as those stands with birds observed flying through the canopy, in or out of the canopy, birds observed landing or perched in trees, or stands with murrelets observed circling over the canopy (Ralph and others 1994). Occupied sites also included stands where nest platforms, murrelet egg shells, or juveniles had been found. Unoccupied sites included stands with birds present, but where no occupied or below canopy behaviors were observed, and stands where birds were not detected.

\section{Stand Characteristics}

Old-growth stands were included in the study if they met the definition of old-growth developed by the Washington Department of Wildlife Remote Sensing Program. Old-growth stands were defined as having at least 20 dominant overstory trees per hectare that were $\geq 81 \mathrm{~cm}$ diameter at breast height (d.b.h.). Co-dominant trees were $\geq 40 \mathrm{~cm}$ d.b.h. The presence of at least 2 canopy layers was also required.

\section{Vegetation Quantification}

A total of 38 attributes describing forest characteristics were used in the analysis (table 1 ). Observers were trained during a 3-day period to ensure forest variable measurements and estimates were performed consistently by all crew members. Vegetation data was not obtained from all the stands that were surveyed, therefore the sample size for the vegetation analysis was less than the number of stands used in the comparisons of mean detection and occupancy rates. Vegetation measurements were obtained from 64 occupied and 87 unoccupied old-growth stands located throughout western Washington for a total sample size of 151 stands.

The sample size of stands where vegetation data was collected was variable in each physiographic province (table 2). Old-growth stands in the North Cascades and Puget Trough Physiographic Provinces were selected systematically to represent a range of elevations, forest zones, and geographic areas. One to several stands were selected from each drainage depending on drainage size and access. Old-growth stands in the Olympic, South Cascades, and Coast Range Physiographic Provinces were selected in a opportunistic manner, primarily from a need to conduct surveys for Marbled Murrelets in certain stands because of impending forest harvest plans or other land management projects. The North Cascades and Olympic Peninsula physiographic provinces contained the largest proportion of sites because these provinces were areas where research had been conducted earlier and more intensively.

Because murrelet detection rates were found to decline with increasing inland distance, not all stands that were surveyed were used in the statistical analysis. Some stands may have possessed all the appropriate structural features required to produce suitable nesting habitat, but were unoccupied because the inland distance was too great. To avoid misinterpreting study results, only stands $\leq 61 \mathrm{~km}$ from salt water were used in the vegetation analysis. I arrived at this value by examining the relationship between murrelet abundance and the inland distance of stands.

Sites $<0.8 \mathrm{~km}$ from salt water were not used in any analysis. Over the last three years a total of nine unoccupied sites have been located in Washington $<0.8 \mathrm{~km}$ from salt water, with what appears to be excellent murrelet nesting habitat. This included five sites from southwest Washington and the Puget Trough, and four sites from the San Juan Islands. Murrelets may avoid using these stands because of their exposure to wind and coastal storms, or because of the presence of a higher number of predators such as gulls (Larus spp.), and crows and ravens (Corvus spp.).

Survey stations were located in or adjacent to old-growth stands with a minimum stand size of $50 \mathrm{ha}$. This is an area encompassed by a circle with a $0.4 \mathrm{~km}$ radius and was therefore the sampling unit used for the study. From field experience I felt that this would be the approximate area an observer could detect murrelets on the landscape, and also prevented the surveying of small old-growth stands in heavily fragmented areas. These smaller stands may have a lower abundance of murrelets because they lack a sufficient amount of habitat, rather than a deficiency in any particular structural feature of the forest. Stand size was not included as a variable in the study design. This was due to the large number of observation stations per stand needed to successfully measure this effect, and the large sample of stands required for the statistical design. Although the influence of stand size on murrelet abundance is a vital piece of information required by land managers, more extensive research will be needed to evaluate this variable. The mean stand size or age of the stands sampled was not determined.

The forest vegetation was measured using one $25-\mathrm{m}$ radius plot for each old-growth stand being surveyed. The exact location of the plot was chosen by placing it in an area where flight behaviors below the canopy indicated possible nesting or, in other stands, in an area with the highest murrelet activity. For stands with no activity, the plot was located in an area with the highest stem density and largest basal area of old-growth trees. Therefore, even in areas with no activity, the highest quality old-growth available was selected to represent the stand thus establishing a conservative analysis. 
Table 1-Definitions and units of measurement for each habitat variable used in the statistical comparison of occupied versus unoccupied murrelet stands in western Washington, 1991-92. A dominant tree was $\geq 81 \mathrm{~cm}$ diameter at breast height (d.b.h.)

\begin{tabular}{|c|c|}
\hline Variable & Definition and units of measurement \\
\hline Aspect & Major aspect of the plot in degrees \\
\hline Basal area & Basal area $\left(\mathrm{m}^{2}\right)$ of all dominant trees $(\geq 81 \mathrm{~cm} \mathrm{d.b.h.)} \mathrm{in} \mathrm{a} 25-\mathrm{m}$ radius plot \\
\hline Canopy closure & Percentage of plot occupied by the crowns of live trees over $10 \mathrm{~m}$ in height \\
\hline Canopy height & Mean tree height (m) of 10 trees measured per plot \\
\hline High comp. & Percent composition of silver fir and mountain hemlock \\
\hline Low comp. & Percent composition of Douglas-fir, western bemlock, western red cedar and Sitka spruce \\
\hline Nest comp. & $\begin{array}{l}\text { Percent composition of those tree species selected for nesting by murrelets in Washington and } \\
\text { Oregon including Sitka spruce, Douglas-fir, and western hemlock }\end{array}$ \\
\hline Silver fir comp. & Percent composition of silver fir \\
\hline Sitka spruce comp. & Percent composition of Sitka spruce \\
\hline Douglas-fir comp. & Percent composition of Douglas-fir \\
\hline Western red cedar comp. & Percent composition of western red cedar \\
\hline Western hemlock comp. & Percent composition of westem hernlock \\
\hline High d.b.h. & Mean d.b.h. (cm) of silver fir and mountain bemlock \\
\hline Low d.b.h. & Mean d.b.h. (cm) of of Douglas-fir, western hemlock, western red cedar and Sitka spruce \\
\hline Mean d.b.h. & Mean d.b.h. (cm) of all dominant trees measured per plot \\
\hline Nest d.b.h. & Mean d.b.h. $(\mathrm{cm})$ of tree species selected for nesting by murrelets in Washington and Oregon \\
\hline Silver fir d.b.h. & Mean d.b.h. (cm) of silver fir \\
\hline Sitka spruce d.b.h. & Mean d.b.h. (cm) of Sitka spruce \\
\hline Douglas-fir d.b.b. & Mean d.b.h. (cm) of Douglas-fir \\
\hline Western red cedar d.b.h. & Mean d.b.h. $(\mathrm{cm})$ of western red cedar \\
\hline Westem hemlock d.b.h. & Mean d.b.h. (cm) of western hemlock \\
\hline Mountain hemiock d.b.h. & Mean d.b.h. $(\mathrm{cm})$ of mountain hemlock \\
\hline Distance to saltwater & Closest distance $(\mathrm{km})$ from the plot to salt water \\
\hline Ecozone & Geographical areas of similar environments (Henderson and others 1989,1991 ) \\
\hline Elevation & Plot elevation (m). \\
\hline Forest zone & $\begin{array}{l}\text { A classification method for determining plant association based on vegetation series of tree species } \\
\text { present (Henderson and others } 1989,1991 \text { ) }\end{array}$ \\
\hline Latitude & Latitude of the plot to the nearest minute \\
\hline Mean lichen & $\begin{array}{l}\text { The mean amount of lichen per plot based on an index of lichen coverage on the limbs of all } \\
\text { dominant trees }\end{array}$ \\
\hline Mean mistletoe & $\begin{array}{l}\text { The mean amount of mistletoe per plot based on an index of mistletoe abundance } \\
\text { (Hawksworth 1977) }\end{array}$ \\
\hline Mistletoe number & The total number of trees/hectare infected with mistletoe \\
\hline Mean moss & An index of moss coverage on the platforms of all dominant trees \\
\hline Percent moss & The percent moss coverage on the limbs of all dominant trees in a plot \\
\hline Platforms ha & The total number of potential nest platforms/ha over $15 \mathrm{~m}$ in height and $18 \mathrm{~cm}$ in diameter \\
\hline Platform total & The total number of platforms from all dominant trees measured within and outside the plot \\
\hline Platforms/tree & Mean number of potential nest platforms per tree \\
\hline Percent slope & Percent slope of plot \\
\hline Slope position & Position of stand on slope: (1) lower $1 / 3$; (2) middle $1 / 3$; and (3) upper $1 / 3$ \\
\hline Stem density & The number of dominant trees/hectare \\
\hline
\end{tabular}


Table 2-Sample size of stands used in the stepwise logistic regression analysis, listed by physiographic province and stand status.

\begin{tabular}{|c|c|c|c|c|c|c|c|c|c|}
\hline \multirow[b]{2}{*}{ Physiographic province } & \multirow[b]{2}{*}{ Number of sites } & \multicolumn{6}{|c|}{ Stand status codes ${ }^{1}$} & \multirow[b]{2}{*}{ Total occupied } & \multirow[b]{2}{*}{ Total unoccupied } \\
\hline & & 0 & 1 & 2 & 3 & 4 & 5 & & \\
\hline North Cascades & 84 & 20 & 1 & 3 & 16 & 28 & 16 & 40 & 44 \\
\hline South Cascades & 17 & 1 & 0 & 0 & 1 & 6 & 9 & 2 & 15 \\
\hline Olympic Mountains & 45 & 3 & 1 & 1 & 13 & 20 & 7 & 18 & 27 \\
\hline Southwest Coast & 5 & 0 & 0 & 1 & 3 & 0 & 1 & 4 & 1 \\
\hline Puget Trough & 0 & 0 & 0 & 0 & 0 & 0 & 0 & 0 & 0 \\
\hline Total & 151 & 24 & 2 & 5 & 33 & 54 & 33 & 64 & 87 \\
\hline
\end{tabular}

${ }^{1}$ Stand status codes were: 0 = Marbled Murrelets observed circling the stand; 1 = nest platform was located; $2=$ juveniles, eggs, or eggshell fragments were located; 3 = murrelets were observed flying in the canopy; $4=$ murrelets were detected in the area; and $5=$ no murrelets were detected. Occupied stands included status codes $0-3$

Only dominant trees $\geq 81 \mathrm{~cm}$ in diameter were included in all vegetation measurements except for canopy closure and forest vegetation series. In addition, only conifer trees were included in the measurement for each variable, except canopy closure. To ensure that a large sample of tree measurements for each variable were recorded from each site, at least 20 trees were measured at each plot. If 20 trees were not available within the plot, the nearest dominant trees to plot edge were selected to be measured until 20 trees were recorded. Trees selected outside the plot were included in the calculations for mean tree d.b.h., total number of potential nest platforms, potential nest platforms/tree, lichen coverage, dwarf mistletoe (Arceuthobium spp.) infestation, moss (Isothecium spp.) coverage on potential nest platforms, and all tree species composition variables. Trees within the plot were used to calculate basal area, forest zone, vegetation series, canopy closure, mean canopy height, and all other measurements.

Ecozones, geographical areas of roughly similar environments, were delimited on the basis of the abundance and distribution of plant indicator species and are a general measure of the amount and kind of precipitation an area received. Ecozones were mapped in Washington by the USDA Forest Service (Henderson and others 1989, 1991). Ecozone 0 represented the wettest part of the study area $(457 \mathrm{~cm}$ or more of annual precipitation), whereas ecozone 13 was the driest (less than $203 \mathrm{~cm}$ ). Each plot was given an ecozone classification based on its location. The vegetation series and forest zone were identified for each plot using standard protocol and field guides (Henderson and others 1989, 1991). The latitude and distance to nearest salt water for each site was measured using topographic maps with a scale of 1:250,000. Latitude was measured to the nearest minute and distance to salt water to the nearest $0.4 \mathrm{~km}$.

The number of potential nest platforms (platform total) for each tree was estimated from one point near the tree where the maximum number of limbs could be seen. The observer counted the number of limbs or structures $>15 \mathrm{~m}$ in height and $>18 \mathrm{~cm}$ in diameter directly along the tree bole. All structures were counted; the observers did not make judgments as to the suitability of the platforms for nesting. These measurements were chosen because all of the 18 nests found at the time the index was developed were $>27 \mathrm{~m}$ in height with the majority of nest limbs $>20 \mathrm{~cm}$ in diameter. Therefore, limbs $>18 \mathrm{~cm}$ seemed a reasonable threshold to use for the index. To practice estimating whether tree limbs were $>18 \mathrm{~cm}$, limbs of known diameters were observed from a 30-m distance. A total count of all potential nest platforms in a tree was not possible, so this measurement was treated as an index. Mistletoe blooms located away from the tree bole were not counted as platforms, since their abundance was measured using another index. Mistletoe infestation was rated for each tree following an index developed by Hawksworth (1977). The number of trees infected wilh mistletoe (mistletoe number) were summed for each plot.

The percent cover of all epiphytes (moss and lichens separately) on the surface of the limbs of dominant trees was recorded for each tree by eslimating the average cover for all limbs using five categories, including 0-20 percent, $21-40$ percent, $41-60$ percent, $61-80$ percent, and $81-100$ percent cover. Each tree was placed in a category and an average calculated for all trees in the plot for both lichen and moss coverage. Moss cover (mean moss) was estimated for potential nest platforms only. Lichen cover (mean lichen) on the surface of the limbs of dominant trees was estimated by averaging all the limbs of the tree. The average percent moss coverage (percent moss) on all the limbs of dominant trees in the plot were also estimated to the nearest 5 percent, as an additional measure of moss abundance.

Canopy closure was measured in a smaller $17.8-\mathrm{m}$ plot by physically measuring all gaps in the canopy $>4 \mathrm{~m}^{2}$ in size. 
This was accomplished by estimating the distance between gap edges as if the canopy created vertical shadows on the ground. Trees $<9 \mathrm{~m}$ tall were not considered a part of the canopy. Mean canopy height was calculated from 10 dominant trees in the plot using a clinometer.

The percent composition and mean values for mean d.b.h., height, basal area, number of potential nest platforms, moss cover, lichen cover, and mistletoe abundance were calculated for each tree species present on each plot.

\section{Statistical Model}

Stepwise logistic regression was used to compare the structural characteristics of occupied and unoccupied oldgrowth stands in Washington. A predictive model for the binary dependent variable, defined as occupied and unoccupied stands, was developed to help define those forest characteristics associated with murrelet nesting habitat.

Logistic regression methods (SAS Institute, Inc. 1987) were used to develop a model for the binary dependent variable which was defined as occupied and unoccupied stands (Hosmer and Lemeshow 1989). Candidate independent variables were selected for inclusion in the model using the stepwise selection procedure. The $P$-value chosen for allowing a candidate variable to enter the model was 0.05 . This value was also used as the criteria for retaining an independent variable in the model at the conclusion of each step.

For the statistical analysis, all 38 forest variables were treated as continuous variables except for forest zone. Forest zone was divided into two categories, high-elevation, and low-elevation zones. High-elevation zone included stands located in silver fir (Abies amabilis) and mountain hemlock (Tsuga mertensiana) zones. Low-elevation zone included stands located in the western hemlock (Tsuga heterophylla), western red cedar (Thuja plicata), Douglas-fir (Pseudotsuga menziesii), and Sitka spruce (Picea sitchensis) zones. In addition, the variable ecozone was analyzed as a separate logistic stepwise model, because at a few sites the ecozone value could not be determined.

Principal Components Analysis (PCA) (SAS Institute, Inc. 1987) was used to create a correlation matrix of all variables and to consider more complex interdependencies among the independent variables. The correlation matrix was used to gauge the degree of association and interdependence between pairs of variables. This helped determine if one variable could be used in the logistic regression model as a substitute for another highly correlated variable. The PCA was not definitive in identifying higher order dependencies in these data.

\section{Importance of Independent Variables}

Four methods were used to subjectively evaluate the relative importance of each variable to the model's ability to predict occupancy and the importance of each variable in describing the differences between occupied and unoccupied sites. The first method was to examine the initial chi-square values of each variable before they entered the model. The second technique involved examining the step in which a variable was selected by the model. Variables selected earlier in the stepwise selection procedure had more power in explaining the variation between occupied and unoccupied sites than variables selected later in the procedure or variables not selected at all. The third method involved examining the final chi-square values for each variable used in the model. The last technique examined the stability of a variable as the stepwise selection procedure of the model progressed. Unstable variables experienced large fluctuations in chisquare value as each new variable was selected in the stepwise procedure, because of high colinearity with other variables used in the model.

\section{Tree Characteristics}

The mean structural characteristics of old-growth trees for the six conifer tree species available for nesting by Marbled Murrelets in Washington were calculated by pooling the values for each variable measured for each tree species across all plots. These variables included mean d.b.h., mean tree height, basal area, potential nest platforms/tree, percent moss coverage on limbs, percent lichen cover on limbs, and mistletoe abundance. This analysis was used to subjectively compare the structure and suitability of tree species in providing murrelet nesting habitat.

\section{Results}

\section{Landscape Characteristics}

\section{Distance to Salt Water}

Highest detection rates (5.9-9.5 detections/survey morning) in Washington occurred in intervals between 16 $\mathrm{km}$ and $64 \mathrm{~km}$ inland, but declined to 0.85 detections/ morning at distances $>63 \mathrm{~km}$ from salt water (fig. 1). To date, 98.5 percent of all detections have been recorded $<64$ $\mathrm{km}$ inland, but this is partly due to the extensive survey effort that has occurred in this zone. The maximum distance at which birds were detected inland was at an occupied stand $84.1 \mathrm{~km}$ from salt water, located on Irene Creek near the Cascade River Drainage in 1992 and 1993. The next farthest occupied stands were located $72 \mathrm{~km}$ and $74 \mathrm{~km}$ inland. Of the known occupied stands, 36 percent $(n=31)$ were located more than $47 \mathrm{~km}$ from the ocean. Nests were located an average of $16 \mathrm{~km}$ inland, with a maximum distance of $34 \mathrm{~km}(n=6)$. Of the old-growth stands located between 0 and $63 \mathrm{~km}$ inland, 20-54 percent were occupied (fig. 1). The percentage of occupied stands declined sharply after 63 $\mathrm{km}$, with only 13 percent of stands occupied $>63 \mathrm{~km}$ from the ocean.

\section{Elevation}

In Washington, detection rates declined sharply with an increase in elevation over $1,067 \mathrm{~m}$ (fig. 2). The highest detection rates, which ranged from 4.3 to 9.2 detections/ survey morning, were recorded between sea level and 1,067 $\mathrm{m}$. Stands located above $1,067 \mathrm{~m}$ had mean detection rates 


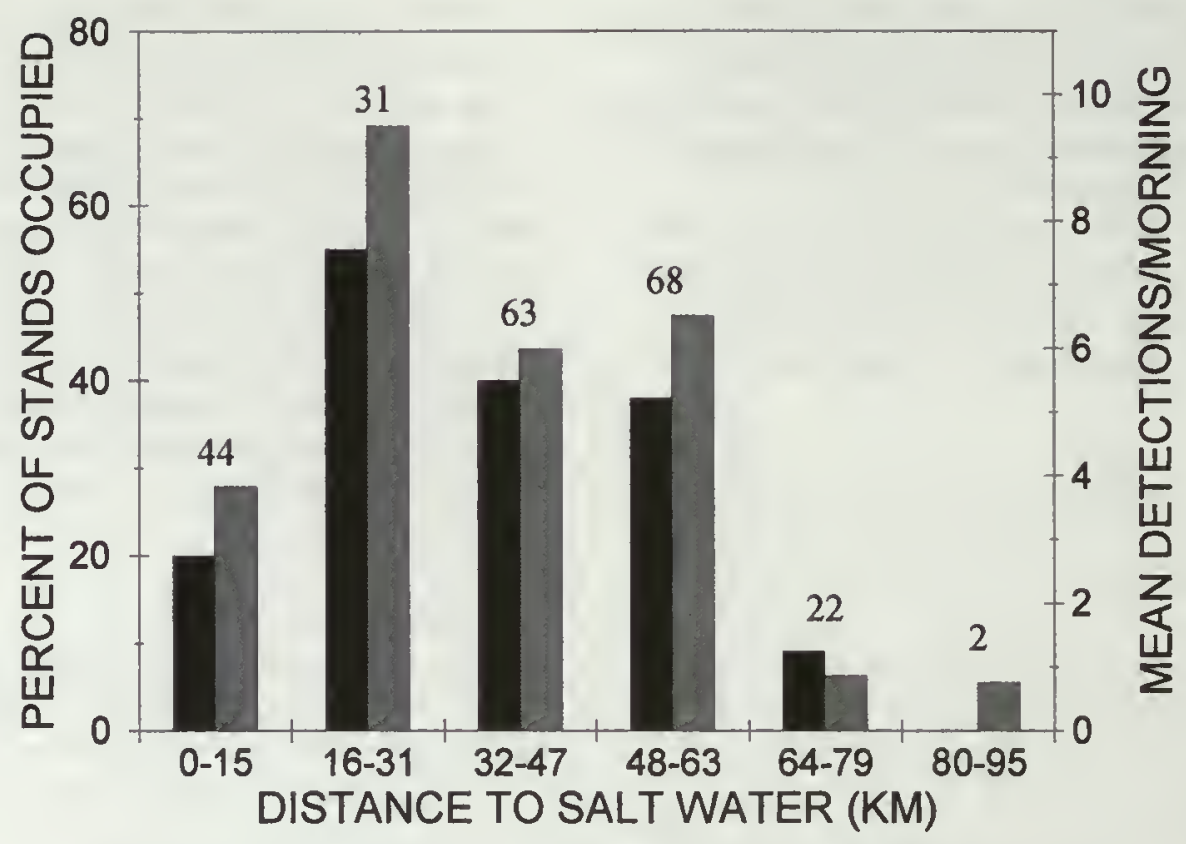

Figure 1-The percent of stands surveyed and verified as occupied, and the mean number of murrelets detected/survey morning, in relation to the distance of the stand from salt water. The sample of stands is from all the physiographic provinces in western Washington, 1991-93. Mean detection rates corresponded closely to occupancy trends.

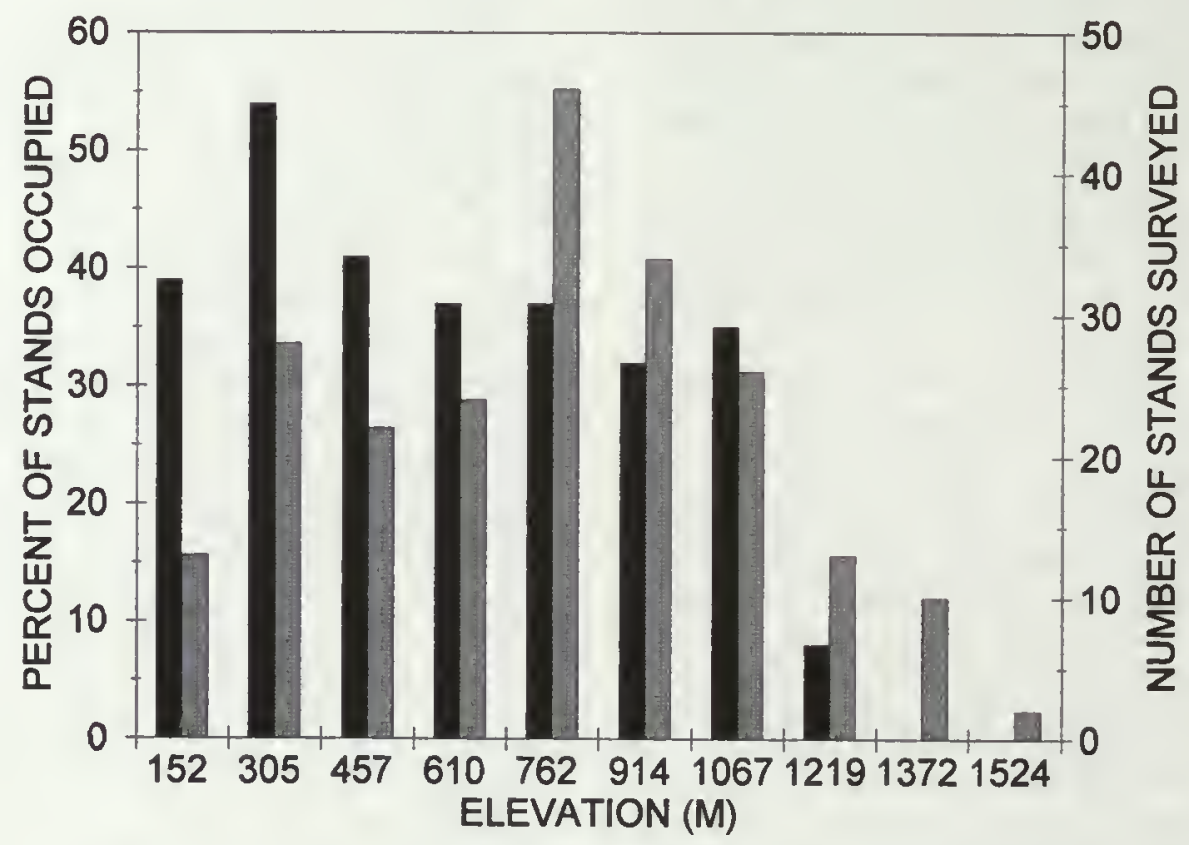

\section{PERCENT STANDS OCCUPIED NUMBER OF STANDS SURVEYED}

Figure 2-The percent of stands surveyed and verified as occupied in relation to stand elevation. The sample of sites is from all the physiographic provinces in western Washington, 1991-93. 
$<1.1$ detections/morning. The highest occupied stand in Washington was located at $1,105 \mathrm{~m}$ in elevation, in the North Cascades Physiographic Province, near the upper headwaters of Crevice Creek. The highest occupied stand in the Olympic Peninsula Physiographic Province was located $1,025 \mathrm{~m}$ in elevation near Spot Lakes on the Hood Canal Ranger District, Olympic National Forest. The South Cascades physiographic province had an occupied stand $1,051 \mathrm{~m}$ in elevation, located $13 \mathrm{~km}$ south of Alder Lake in Lewis County, near the East Fork Little Creek drainage. More than 98 percent of all detections in Washington were recorded below $1,067 \mathrm{~m}$ in elevation.

\section{Forest Type and Physiographic Province}

Forest types surveyed in Washington included stands dominated by western hemlock, Douglas-fir, Sitka spruce, silver fir, and mountain hemlock. These stands commonly had a large component of western red cedar.

The mean detection rates for 229 old-growth stands were compared between the five physiographic provinces in Washington. The North Cascades Province bad a mean detection rate of 23.5 detections/survey morning ( $n=117$ sites, s.d. $=7.9$ ) and 40 percent of the old-growth stands surveyed were verified as occupied. The Olympic Peninsula had a similar rate of 18.3 detections/survey morning ( $n=67$, s.d. $=8.2$ ) and a 37 percent occupancy rate of old-growth stands. The South Cascades had a detection rate of 12.5 detections/survey morning $(n=30, s . d .=15.7)$, and 10 percent of the stands surveyed were occupied. The Puget Trough had the lowest detection rate of any province, with
1.3 detections/survey morning $(n=7, s . d .=0$, and no occupied stands, but the number of stands sampled was small. The Southwest Coast had the highest detection rate (90.1 detections/survey morning; $n=8, s . d .=7.4$ ) and the highest occupancy rate ( 50 percent), but the number of oldgrowth stands surveyed was also small.

\section{Stand Characteristics}

\section{Statistical Model}

The results of the logistic regression model results from the 1994 study gave a total accuracy rate of 74.2 percent for a predicted probability of occupancy for each stand analyzed. The classification accuracy of occupied stands was 67.2 percent. The classification accuracy of unoccupied stands was 79.2 percent. Of the 32 stands with a predicted probability of occupancy $>0.75,74$ percent were occupied. Of the 54 stands with a predicted probability of occupancy of $<0.25$, 93 percent were unoccupied. A total of 65 stands ( 43 percent) had probability values $\geq 0.25$ and $\leq 0.75$.

Eight forest variables were included in the model by the stepwise logistic regression procedure. These variables best predicted occupancy of a stand by murrelets (table 3 ). The stepwise selection procedure was completed in 10 steps.

The probability of occupancy of an old-growth stand increased with increasing percent topographic slope, total number of potential nest platforms/ha, stem density of dominant trees, mean d.b.h. of western hemlock, and the moss coverage (percent moss) on the limbs of dominant trees (table 3). The probability of occupancy of a stand decreased with increasing stand elevation, canopy closure,

\begin{tabular}{|c|c|c|c|c|}
\hline Variable & Regression coefficient & Standard error & Wald Chi-square & Prob. > Chi-square \\
\hline Intercept & -1.31820 & 1.6352 & 0.65 & 0.41 \\
\hline Percent slope & 0.04360 & 0.0123 & 12.47 & $<0.01$ \\
\hline Platform total & 0.04330 & 0.0151 & 8.19 & $<0.01$ \\
\hline Elevation & -0.00083 & 0.0003 & 8.16 & $<0.01$ \\
\hline Stem density & 0.18590 & 0.0668 & 7.75 & $<0.01$ \\
\hline Canopy closure & -0.03340 & 0.0130 & 6.63 & 0.01 \\
\hline Western bemlock d.b.h. & 0.01610 & 0.0065 & 6.18 & 0.01 \\
\hline Percent moss & 0.02220 & 0.0093 & 5.72 & 0.02 \\
\hline Mean lichen & -0.58700 & 0.2726 & 4.64 & 0.03 \\
\hline
\end{tabular}


and lichen coverage (mean lichen) on the limbs of dominant trees. Sites with a high probability of occupancy had a mean canopy closure of 86 percent.

\section{Importance of Independent Variables}

The step in which each variable was selected, the stability of variables through the stepwise procedure, the final chisquare values of variables used in the model, and the relationship between variables were used to subjectively assess the relative contribution of variables in predicting the probability of occupancy (table 3 ). The variables most correlated with occupancy of old-growth stands, included total potential nest platforms/ha, total percent moss cover on tree limbs, percent slope, mean d.b.h. of all dominant trees, mean lichen cover on tree limbs, stem density of dominant trees, elevation, canopy closure, mean d.b.h. of western hemlock, and percent composition of low elevation conifers.

\section{Describing Low- and High-Quality Habitat}

To begin to define what values would be considered to be the lower and upper thresholds for describing murrelet nesting habitat, the minimum, mean, and average values for each forest variable were calculated for occupied and unoccupied stands (table 4). Suitable murrelet nesting habitat was defined as sites with a high probability of occupancy. These stands had a mean topographic slope of 50 percent and were found at a mean elevation of $152 \mathrm{~m}$. Stands with a high probability of occupancy also had a mean of 92 platforms/ ha, a stem density of 50 dominant trees/ha $(>81 \mathrm{~cm} \mathrm{d.b.h.),}$ 83 percent canopy closure, $101 \mathrm{~cm}$ mean d.b.h. of western hemlock, 49 percent moss coverage on tree limbs, and a low index of lichen cover (table 4).

Stands with a high probability of occupancy $(>0.76)$ had minimum values of 10 platforms/ha, 29 dominant trees/ha, 29 percent canopy closure, $85 \mathrm{~cm}$ mean d.b.h. of western hemlock, 5 percent moss cover, and $97 \mathrm{~cm}$ mean tree d.b.h.. These occupied stands were found at a maximum of $288 \mathrm{~m}$ in elevation.

\section{Tree Characteristics}

A comparison of old-growth tree characteristics for different conifer species in Washington indicated that oldgrowth Sitka spruce had most of the characteristics associated with known nest sites (Hamer and Nelson, this volume b). Sitka spruce had a higher mean d.b.h., taller height, higher number of platforms/tree, and higher moss coverage of the limbs than any of the five other conifers (table 5). On average, this species had more than two times as many platforms/tree than any other conifer species except Douglasfir. Douglas-fir was second in having characteristics deemed suitable for murrelet use, with a similar number of platforms/ tree as Sitka spruce, a large height, high mean d.b.h., but a low moss coverage on the limbs. Western red cedar ranked third as a suitable nest tree choice with a large mean d.b.h., high basal area, 1.4 platforms/tree, and one of the highest moss cover indexes. Western hemlock ranked fourth in the comparison but, as expected, has one of the highest mistletoe indexes of any tree species. Mountain hemlock ranked third and silver fir last. Both silver fir and mountain hemlock had a low mean d.b.h., low basal area, low number of platforms/ tree, and a higher lichen index. Silver fir had an average of only 0.81 platforms/tree.

\section{Discussion}

\section{Landscape Characteristics}

\section{Distance to Salt Water}

Because murrelets forage at sea and only carry single prey items to the nest, but can nest at long distances from the coast, the energetic requirements of flying inland to incubate eggs and feed young, places a limit on their inland breeding distribution and use of inland forests. Even with the potential problems of energetic expenditure, Marbled Murrelets displayed a great tolerance for using nesting stands located up to $63 \mathrm{~km}$ inland from the ocean. Almost all the habitat in the North Cascades and South Cascades Physiographic Provinces is located $>42 \mathrm{~km}$ inland because of rural development and intensive forestry practices within the Puget Trough. Even with these long flight distances, some birds were passing occupied stands to fly farther inland.

Breeding records also indicated that nesting is occurring at stands located long distances from salt water. A small downy chick was located on the ground along a trail on the east shore of Baker Lake in 1991, $63 \mathrm{~km}$ from the ocean (pers. obs.). Another downy chick was located $45 \mathrm{~km}$ inland at Helena Creek, in Snohomish County (Reed 1991). Six additional records of eggs, downy young, and fledglings found $29-55 \mathrm{~km}$ inland in Washington were compiled by Leschner and Cummins (1992a), and Carter and Sealy (1986).

\section{Elevation}

In general, stands found at higher elevations had a lower composition of conifer species reported to be used as nest trees. Murrelet nests have not been located in the higher elevation conifers such as silver fir or mountain hemlock in British Columbia, Washington, Oregon, or California, (Hamer and Nelson, this volume b). A negative association of murrelet abundance and stand occupancy to the occurrence of silver fir and mountain hemlock (high elevation tree species) is best explained by these species low mean d.b.h. and low number of platforms/tree (see Tree Characteristics). In addition, silver fir branches generally exit the trunk at sharp downward angles creating few level platforms.

\section{Forest Type and Physiographic Province}

All records of nests, eggs, eggshell fragments, and downy chicks in Washington have been associated with old-growth forests $(n=17)$ (Leschner and Curmmins 1992a). In North America, fledglings have been found in a variety of unusual habitat types such as roads, airports, and rural areas (Carter and Sealy 1987b; Hamer and Nelson, this volume a). These 
Table 4-Mean values for occupied murrela stands in Washington calculated using stands with a predicted probability of occupancy $>76$ percent ( $\mathrm{n}=25$ ). Mean values for unoccupied stands were calculated using sites with a predicted probability of occupancy $<4$ percent $(n=44)$. Variables are listed in order of their initial chi-square score before step 1 of the model, with the eight rariables used to develop the logistic regression model listed firs. Final chisquare scores for the eight variables used by the model are listed in table 3

\begin{tabular}{|c|c|c|c|c|c|}
\hline Variable & $\begin{array}{c}\text { Predicted } \\
\text { probability } \\
\text { of occurrence }\end{array}$ & Mean & Minimum & Maximum & $\begin{array}{c}\text { Probability > } \\
\text { Chi-square }\end{array}$ \\
\hline Percent slope & $\begin{array}{l}>0.76 \\
<0.14\end{array}$ & $\begin{array}{l}49.9 \\
35.1\end{array}$ & $\begin{array}{l}3.0 \\
3.0\end{array}$ & $\begin{array}{l}90.0 \\
75.0\end{array}$ & 0.05 \\
\hline Platform total & $\begin{array}{l}>0.76 \\
<0.14\end{array}$ & $\begin{array}{r}27.2 \\
7.3\end{array}$ & $\begin{array}{l}4.0 \\
0.0\end{array}$ & $\begin{array}{l}65.0 \\
29.0\end{array}$ & $<0.01$ \\
\hline Elevation & $\begin{array}{l}>0.76 \\
<0.14\end{array}$ & $\begin{array}{l}152.4 \\
271.4\end{array}$ & $\begin{array}{l}29.6 \\
27.9\end{array}$ & $\begin{array}{l}288.0 \\
445.8\end{array}$ & $<0.01$ \\
\hline $\begin{array}{l}\text { Stem density } \\
\text { (trees/ha) }\end{array}$ & $\begin{array}{l}>0.76 \\
<0.14\end{array}$ & $\begin{array}{l}50.0 \\
39.0\end{array}$ & $\begin{array}{r}29.0 \\
-\quad 0.0\end{array}$ & $\begin{array}{l}89.0 \\
84.0\end{array}$ & 0.05 \\
\hline Canopy closure & $\begin{array}{l}>0.76 \\
<0.14\end{array}$ & $\begin{array}{l}82.6 \\
81.1\end{array}$ & $\begin{array}{l}29.0 \\
50.0\end{array}$ & $\begin{array}{r}98.0 \\
100.0\end{array}$ & 0.02 \\
\hline $\begin{array}{l}\text { Westem hemlock } \\
\text { d.b.h. }\end{array}$ & $\begin{array}{l}>0.76 \\
<0.14\end{array}$ & $\begin{array}{r}100.8 \\
98.3\end{array}$ & $\begin{array}{l}84.7 \\
56.5\end{array}$ & $\begin{array}{l}136.2 \\
135.2\end{array}$ & 0.02 \\
\hline Percent moss & $\begin{array}{l}>0.76 \\
<0.14\end{array}$ & $\begin{array}{l}49.1 \\
14.1\end{array}$ & $\begin{array}{l}5.0 \\
0.0\end{array}$ & $\begin{array}{l}82.0 \\
75.0\end{array}$ & $<0.01$ \\
\hline Mean db.h. & $\begin{array}{l}>0.76 \\
<0.14\end{array}$ & $\begin{array}{l}131.7 \\
103.3\end{array}$ & $\begin{array}{l}97.3 \\
58.7\end{array}$ & $\begin{array}{l}169.7 \\
183.0\end{array}$ & $<0.01$ \\
\hline Low d.b.h. & $\begin{array}{l}>0.76 \\
<0.14\end{array}$ & $\begin{array}{l}133.0 \\
107.0\end{array}$ & $\begin{array}{l}97.3 \\
58.8\end{array}$ & $\begin{array}{l}169.7 \\
183.0\end{array}$ & $<0.01$ \\
\hline Platforms/ha & $\begin{array}{l}>0.76 \\
<0.14\end{array}$ & $\begin{array}{l}92.0 \\
25.0\end{array}$ & $\begin{array}{r}10.0 \\
0.0\end{array}$ & $\begin{array}{r}183.0 \\
89.0\end{array}$ & $<0.01$ \\
\hline $\begin{array}{l}\text { Western redcedar } \\
\text { d.b.h. }\end{array}$ & $\begin{array}{l}>0.76 \\
<0.14\end{array}$ & $\begin{array}{l}153.9 \\
122.0\end{array}$ & $\begin{array}{l}91.4 \\
98.0\end{array}$ & $\begin{array}{l}247.5 \\
177.3\end{array}$ & $<0.01$ \\
\hline Mean lichen & $\begin{array}{l}>0.76 \\
<0.14\end{array}$ & $\begin{array}{l}1.4 \\
2.5\end{array}$ & $\begin{array}{l}1.0 \\
1.0\end{array}$ & $\begin{array}{l}3.1 \\
4.8\end{array}$ & $<0.01$ \\
\hline $\begin{array}{l}\text { Western red cedar } \\
\text { composition }\end{array}$ & $\begin{array}{l}>0.76 \\
<0.14\end{array}$ & $\begin{array}{l}45.1 \\
20.6\end{array}$ & $\begin{array}{l}5.9 \\
6.7\end{array}$ & $\begin{array}{r}100.0 \\
40.0\end{array}$ & $<0.01$ \\
\hline Slope position & $\begin{array}{l}>0.76 \\
<0.14\end{array}$ & $\begin{array}{l}1.6 \\
2.2\end{array}$ & $\begin{array}{l}1.0 \\
1.0\end{array}$ & $\begin{array}{l}3.0 \\
3.0\end{array}$ & $<0.01$ \\
\hline Basal area & $\begin{array}{l}>0.76 \\
<0.14\end{array}$ & $\begin{array}{r}14.3 \\
8.1\end{array}$ & $\begin{array}{l}4.2 \\
1.4\end{array}$ & $\begin{array}{l}28.4 \\
17.7\end{array}$ & $<0.01$ \\
\hline Platforms/tree & $\begin{array}{l}>0.76 \\
<0.14\end{array}$ & $\begin{array}{l}2.0 \\
0.8\end{array}$ & $\begin{array}{l}0.3 \\
0.0\end{array}$ & $\begin{array}{l}5.7 \\
3.2\end{array}$ & $<0.01$ \\
\hline Canopy height & $\begin{array}{l}>0.76 \\
<0.14\end{array}$ & $\begin{array}{l}53.6 \\
45.8\end{array}$ & $\begin{array}{l}37.2 \\
26.1\end{array}$ & $\begin{array}{l}69.3 \\
71.3\end{array}$ & 0.01 \\
\hline Low composition & $\begin{array}{l}>0.76 \\
<0.14\end{array}$ & $\begin{array}{l}92.4 \\
77.3\end{array}$ & $\begin{array}{r}50.0 \\
6.7\end{array}$ & $\begin{array}{l}100.0 \\
100.0\end{array}$ & 0.01 \\
\hline High composition & $\begin{array}{l}>0.76 \\
<0.14\end{array}$ & $\begin{array}{l}26.7 \\
49.7\end{array}$ & $\begin{array}{l}6.3 \\
7.0\end{array}$ & $\begin{array}{r}50.0 \\
100.0\end{array}$ & 0.02 \\
\hline $\begin{array}{l}\text { Mistletoe number } \\
\text { (trees/ha) }\end{array}$ & $\begin{array}{l}>0.76 \\
<0.14\end{array}$ & $\begin{array}{l}15.0 \\
10.0\end{array}$ & $\begin{array}{l}5.0 \\
5.0\end{array}$ & $\begin{array}{l}39.0 \\
25.0\end{array}$ & 0.03 \\
\hline $\begin{array}{l}\text { Distance to } \\
\text { saltwater } \\
\end{array}$ & $\begin{array}{l}>0.76 \\
<0.14 \\
\end{array}$ & $\begin{array}{l}38.2 \\
38.5 \\
\end{array}$ & $\begin{array}{l}1.5 \\
1.5 \\
\end{array}$ & $\begin{array}{l}62.8 \\
62.5 \\
\end{array}$ & 0.94 \\
\hline
\end{tabular}


Table 5-Summary of seven characteristics measured for six species of conifers available as nest trees by the murrelet in Washington state. Only trees $\geq 81 \mathrm{~cm} \mathrm{d.b.h}$. were measured. The mean, range, and sample size are shown. See text for moss and lichen cover categories

\begin{tabular}{|c|c|c|c|c|c|c|}
\hline \multirow[b]{2}{*}{ Variable } & \multicolumn{6}{|c|}{ Tree Species } \\
\hline & $\begin{array}{l}\text { Sitka } \\
\text { spruce } \\
n=55\end{array}$ & $\begin{array}{c}\text { Douglas- } \\
\quad \text { fir } \\
n=552\end{array}$ & $\begin{array}{l}\text { Western } \\
\text { red cedar } \\
n=347\end{array}$ & $\begin{array}{c}\text { Western } \\
\text { hemlock } \\
n=793\end{array}$ & $\begin{array}{c}\text { Mountain } \\
\text { hemlock } \\
n=54\end{array}$ & $\begin{array}{c}\text { Silver } \\
\text { fir } \\
n=234\end{array}$ \\
\hline D.b.h. (cm) & $\begin{array}{c}163.1 \\
91-326\end{array}$ & $\begin{array}{c}131.7 \\
55-268\end{array}$ & $\begin{array}{c}143.0 \\
81-290\end{array}$ & $\begin{array}{c}106.7 \\
51-268\end{array}$ & $\begin{array}{c}103.0 \\
55-140\end{array}$ & $\begin{array}{c}100.4 \\
52-184\end{array}$ \\
\hline Height (m) & $\begin{array}{c}57.2 \\
27-73\end{array}$ & $\begin{array}{c}58.3 \\
18-85\end{array}$ & $\begin{array}{c}49.3 \\
26-72\end{array}$ & $\begin{array}{c}47.4 \\
15-76\end{array}$ & $\begin{array}{c}40.5 \\
18-73\end{array}$ & $\begin{array}{c}50.8 \\
23-69\end{array}$ \\
\hline Basal area $\left(\mathrm{m}^{2}\right)$ & $\begin{array}{c}2.3 \\
0.6-8.4\end{array}$ & $\begin{array}{c}1.9 \\
0-5.6\end{array}$ & $\begin{array}{c}4.6 \\
0.5-6.6\end{array}$ & $\begin{array}{c}4.3 \\
0.2-4.4\end{array}$ & $\begin{array}{c}2.2 \\
0.2-1.5\end{array}$ & $\begin{array}{c}0.8 \\
0.2-2.7\end{array}$ \\
\hline Platforms/tree & $\begin{array}{c}2.9 \\
0-18\end{array}$ & $\begin{array}{c}2.3 \\
0-13\end{array}$ & $\begin{array}{c}1.4 \\
0-10\end{array}$ & $\begin{array}{c}1.2 \\
0-19\end{array}$ & $\begin{array}{l}1.0 \\
0-6\end{array}$ & $\begin{array}{l}0.8 \\
0-5\end{array}$ \\
\hline Moss index & $\begin{array}{l}2.8 \\
1-5\end{array}$ & $\begin{array}{l}1.5 \\
1-5\end{array}$ & $\begin{array}{l}2.2 \\
1-5\end{array}$ & $\begin{array}{l}2.0 \\
1-5\end{array}$ & $\begin{array}{l}1.1 \\
1-2\end{array}$ & $\begin{array}{l}2.4 \\
1-5\end{array}$ \\
\hline Lichen index & $\begin{array}{l}2.5 \\
1-5\end{array}$ & $\begin{array}{l}2.0 \\
1-5\end{array}$ & $\begin{array}{l}1.2 \\
1-5\end{array}$ & $\begin{array}{l}1.7 \\
1-5\end{array}$ & $\begin{array}{l}2.6 \\
1-5\end{array}$ & $\begin{array}{l}2.2 \\
1-5\end{array}$ \\
\hline Mistletoe index & $\begin{array}{l}0.2 \\
0-5\end{array}$ & $\begin{array}{l}0.1 \\
0-2\end{array}$ & $\begin{array}{l}0.0 \\
0-3\end{array}$ & $\begin{array}{l}1.1 \\
0-6\end{array}$ & $\begin{array}{l}0.1 \\
0-3\end{array}$ & $\begin{array}{l}0.2 \\
0-4\end{array}$ \\
\hline
\end{tabular}

records indicate that fledglings may travel some distance before becoming grounded.

Detection and stand occupancy rates increased with more older forest available on the landscape. For all provinces, the low detection and occupancy rates near the coast were probably due to the presence of large amounts of unsuitable or marginal habitat in the Puget Trough and near coastal lowland areas of the Olympic Peninsula. In a study encompassing the entire South Fork of the Stillaguamish River basin in northern Washington, significantly higher numbers of murrelets were observed in old-growth and mature forests than either rock/talus, clear-cut/meadow, or small saw/pole cover types (Hamer and Cummins 1990). Murrelet detection rates increased rapidly when the percentage of old-growth and mature forest cover types found within a 2,000-m-radius circle around each survey station made up more than 30 percent of the landscape. Mean detection rates for sites located in these areas ranged between 1 and 20 detections/morning ( $\bar{x}=5.7 ; s . d .=5.8$ ). All sites with $<30$ percent old-growth and mature forest cover had $<1.5$ detections/morning $(\bar{x}=0.2 ; s . d .=0.4)$. An analysis of the landscape features associated with occupied and unoccupied stands in Washington found that the amount of old-growth and large sawtimber available best predicted murrelet occupancy at the stand level (Raphael and others, this volume). Sites with a higher proportion of these mature forest classes were more likely to have evidence of nesting or occupancy than unoccupied sites.

\section{Stand Characteristics}

\section{Statistical Model}

Overall the model correctly predicted occupancy on about 74 percent of the sites. However, this success rate may be biased because the same sites that were used to build the model were used to test it. Because the model treats occupancy as a categorical variable, individual sites that scored near 0.5 were difficult to judge. In these cases it was more convenient to think of occupancy as a continuous variable where the higher probability scores indicaled more suitable habitat and a higher probability of being occupied by murrelets. Errors in the classifications of stands could be due to several factors: (1) some stands determined to be unoccupied from field surveys may have actually been occupied; (2) it is possible in some instances that birds may be occupying stands of marginal habitat and; (3) the vegetation sampling for some stands may have been 
inadequate to accurately reflect the true structure of the stand. These potential problems could be avoided by increasing the number of survey visits to a stand used to determine occupancy and increasing the vegetation sampling effort. More vegetation information from a larger number of independent occupied and unoccupied stands needs to be collected to validate the model.

The results of the statistical model suggested that any land management activity that reduced or affected the number of potential nest platforms/ha, composition of low elevation conifers, moss cover on tree limbs, stem density of dominant trees, or canopy closure, would reduce the probability of occupancy of old-growth, and thus the suitability of an oldgrowth stand as nesting habitat for murrelets. Results from studies of murrelet habitat use to date have been derived from comparisons of stands occupied by murrelets to unoccupied stands, comparisons of stands receiving high use versus low use, or comparisons of nest trees and nest plots to random trees and plots. Although these can provide extremely useful descriptions and definitions of suitable habitat, they do not provide information on the habitat characteristics associated with successful nests. Information on the landscape and within-stand habitat characteristics that influence reproductive success is needed to fully understand murrelet nesting ecology and to model optimum habitat suitability for this species. Reproductive success should be used as a measure of habitat suitability in future studies by intensively studying occupied stands that have high detection rates of Marbled Murrelets and locating a sample of active nests to observe. A discussion of each variable used by the model follows.

Total Platforms-Results suggest that if any variable were to be used solely to assess habitat quality, total platforms would be the best indicator. More potential nest platforms within a stand mean more nesting and hiding opportunities and a higher diversity of nest choices for the murrelet. Although the total number of platforms was important, I currently have few measures of platform quality. A examination of the limb diameters of Marbled Murrelet nests indicated higher use and possible selection for platforms $>35 \mathrm{~cm}$ in diameter (Hamer and Nelson, this volume b). Some stands may have an abundance of smaller potential nest platforms that are only $10-20 \mathrm{~cm}$ in diameter. These stands may be marginal nesting habitat because of the limitations of platform size. Future studies should include a measure of mean platform size when quantifying forest vegetation.

The total number of potential nest platforms would be especially important if nest platforms within a stand were limited, the number of nesting stands available on the landscape were limited, or intraspecific competition occurred for nest platforms within a given area. It is unknown whether platforms meeting all the requirements for nesting are limited in availability in a typical old-growth stand. It has been assumed that nest platforms may be unlimited in oldgrowth stands (Sealy 1974), but an understanding of the structural requirements needed for a platform to be used by murrelets is required before an analysis of platform availability is possible.

Total Moss-The presence of moss in the tree canopy was another important indicator of murrelet habitat. Although murrelets do not absolutely require moss as a nest substrate, the majority of nests have been located on moss (Hamer and Nelson, this volume b); the presence of moss may increase the number of potential platforms within a stand. Limbs with little or no moss coverage result in nest locations close to the trunk of a tree, which is usually the only area on a tree where debris such as needles and duff collect in sufficient quantities to form a thick substrate suitable for nesting, or where branches are large enough in diameter to create suitable nest platforms (pers. obs.). Other areas on the tree are usually too exposed to wind and other environmental influences to collect enough substrate to form a platform of suitable size. Thick mistletoe blooms are sometimes the exception to this observation. A high cover of moss creates a multitude of nest platform choices by providing substrate on many locations throughout a single limb, especially where there is suitable overhead cover and the limb is large enough to support a nest. In addition, the presence of a moss carpet essentially thickens the diameter of limbs, transforming limbs of marginal size into suitable nesting platforms. Moss is therefore related to the number of potential nest platforms of a stand. It is not known if one species of moss is preferred over others.

Mean D.b.h.-Although not selected by the final regression model, mean tree d.b.h. had one of the highest initial chi-square values (16.2) and the chi-square values showed high stability through the selection process. The mean number of platforms/tree increased rapidly with an increase in tree diameter from 50 to $200 \mathrm{~cm}$ (fig. 3). No increase in the mean number of platforms was evident for larger trees that ranged from 220 to $300 \mathrm{~cm}$ in diameter. Suitable platforms were most commonly found in stands with larger tree sizes, as evidenced by a correlation of total platforms to mean tree d.b.h. $(r=0.60)$, but the relationship of these two variables was complex. The presence of larger trees alone did not always explain the presence of nest platforms. In Washington, there were abundant examples of large trees $>176 \mathrm{~cm}$ in diameter that contained no platforms. Other factors that can create platforms may include wind and insect damage, mistletoe brooms or other plant parasites, moss or larger quantities of duff, multiple overlapping tree limbs, natural limb deformities, and disease. Examples of 80 -year-old stands of western hemlock that are heavily infested with mistletoe and occupied by murrelets have been found in Oregon (Nelson, pers. comm.). Therefore, total platforms was the best indicator of suitable murrelet nesting habitat because it directly measures the nesting structures required by this alcid, whereas mean tree diameter measures the availability of platforms indirectly and with less accuracy or predictability. Still, most agencies and private timber companies have measures of mean tree diameter available for their stands, but no measures of platforms or structure. In attempts to force the model to use mean tree diameter, the 


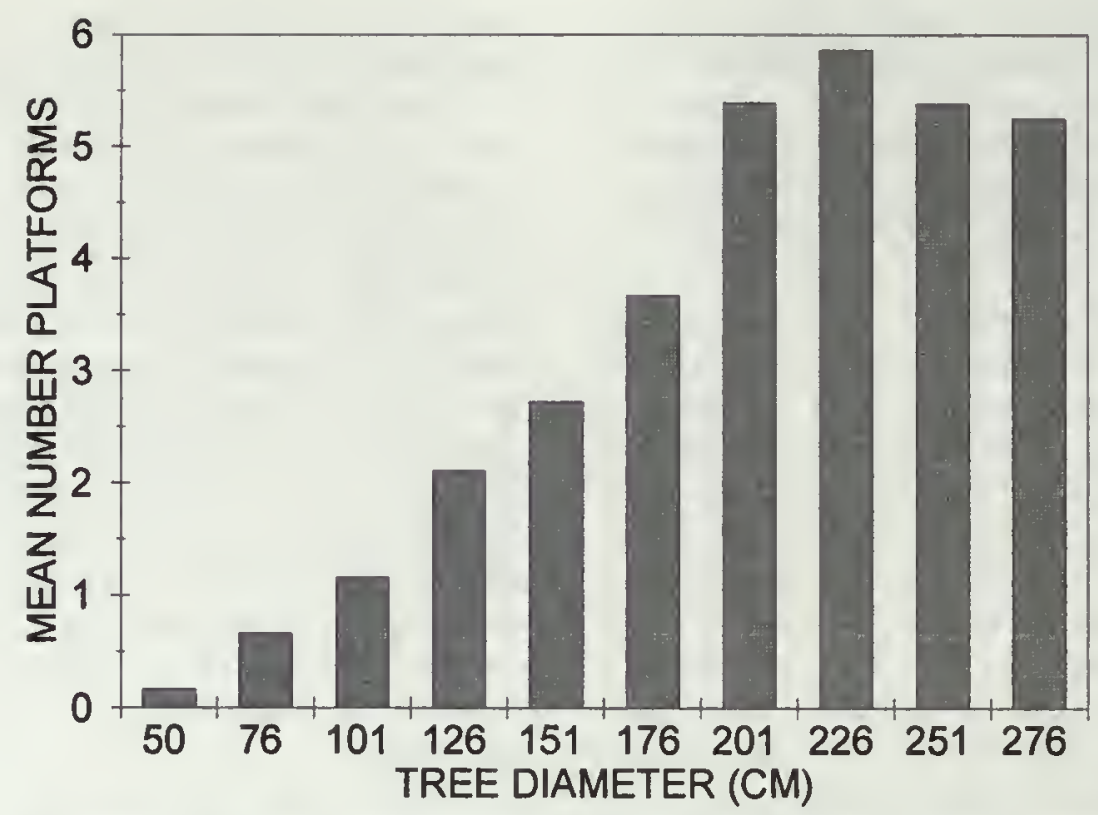

Figure 3-The mean number of potential nest platforms/tree in relation to tree diameter (25-cm intervals) for western hemlock, western red cedar, Douglas-fir, and Sitka spruce trees in western Washington, 1991-93. Trees $(n=1,860)$ were sampled from 151 stands.

model always re-selected a platform variable to replace mean tree diameter. Total platforms accounted for all the variation of mean tree d.b.h., but mean tree d.b.h. could not account for all the variation of total platforms. These results indicate that the structure of a stand is more important in predicting stand occupancy by murrelets than the size of the trees within the stand.

Mean Lichens-The percent cover of lichens on tree limbs was negatively correlated with the percent cover of moss $(r=-0.23)$. Some common moss species such as Isothecium spp. require mild and wet conditions. These conditions are usually found at lower elevations in the Sitka Spruce and Western Hemlock Zones. Lichens such as Alectoria spp. and Bryoria spp. are most abundant at higher elevations where conditions are colder and dryer (Henderson and others 1989). These stands usually have a high percent composition of silver fir and mountain hemlock, which are not known to be used as nest trees by Marbled Murrelets in the Pacific Northwest. Therefore, it was not surprising that lichen cover was negatively related to the probability of occupancy.

Stem Density (trees $\geq 81 \mathrm{~cm} \mathrm{d.b.h.)}$-This variable was not correlated to any other variable to any great degree except basal area (0.63), but it can be assumed that in general, stands with a higher stem density of trees $\geq 81 \mathrm{~cm} \mathrm{d.b.h.} \mathrm{would} \mathrm{have}$ a larger number of potential nest platforms/ha and higher canopy closures. A larger sample of stands in Washington with lower stem densities is needed to fully understand this variable and its effect on the probability of occupancy. Occupied stands with stem densities of only 5 trees/ha have been documented in Oregon (Nelson, pers. comm.)
Canopy Closure-It may be difficult for murrelets to locate and access nest platforms in stands with extremely high canopy closures, and the results of the analysis may reflect this because occupied old-growth stands still had mean canopy closures of 86 percent. A larger sample of stands with lower canopy closures is needed to fully understand this variable and its effect on the probability of occupancy. Nests located in stands with very low canopy closures may be subject to higher predation rates since corvids are the most common nest predator and locate prey almost entirely by sight. Stands with low canopy closures and low tree densities would be expected to have longer sight distances through the canopy. In these cases, murrelet nests would be easier to locate by visual predators.

Mean Diameter of Western Hemlock-Because the majority of trees infected with mistletoe were western hemlock and the mean d.b.h. of low-elevation trees was useful in assessing suitable habitat, the mean d.b.h. of western hemlock appears to combine the variation of these two factors into one variable.

Mistletoe Number-Stands that are infested with mistletoe may provide a higher number of nest platforms for murrelets. Mistletoe infects the branches of living trees, causing swelling, deformation, and brooming, which acts to thicken smaller diameter branches. This process can create suitable nest platforms from otherwise marginally-sized limbs. Thick secondary branching is characteristic of these mistletoe brooms that create dense overhead cover, a characteristic found at many murrelet nest platforms in Washington and Oregon (Hamer and Nelson, this volume b). In addition, mistletoe 
blooms help trap debris falling from the upper canopy, creating additional nesting platforms and platforms of larger size.

\section{Describing Low and High Quality Habitat}

In order to use the model to predict the probability of occupancy of an old-growth stand by murrelets, and thus judge the suitability of a stand as nesting habitat, it is necessary to obtain values for the 8 variables used by the model from the stand needing evaluation. The values for these variables can then be compared to the mean, minimum, and maximum values calculated for stands with a high probability of occupancy and stands with a low probability of occupancy (table 4). Using this comparison, a general sense of the suitability of a stand as nesting habitat can be obtained. In addition, by entering the values for the 8 forest characteristics into the formula shown below, the probability of occupancy can be calculated. Elevation should be entered in feet, stem density as the number of trees $/ 25 \mathrm{~m}$ plot, mean d.b.h. of western hemlock in cm; and lichen, moss and canopy cover as percent total cover. First, the logistic regression model is used to predict $g(x)$ as follows:

$$
g(x)=b_{0}+b_{1} x_{1}+b_{2} x_{2}+\ldots .+b_{8} x_{8}
$$

where,

$b_{0}$ is the intercept and, $b_{1}, \ldots ., b_{8}$ are the logistic regression coefficients for each variable. These values are listed under the Regression Coefficients in table 3.

$x_{1}, \ldots ., x_{8}$ are the values for the independent variables measured at the stand in question and,

$g(x)$ is the predicted value of the logistic transformed probability of occupancy.

Then $g(x)$ is retransformed to estimate the probability of occupancy as follows:

$$
P=\operatorname{EXP}(g(x)) /[1+\operatorname{EXP}(g(x))] \text { where, }
$$

$P$ is the predicted probability of occupancy,

$g(x)$ is as defined in equation (1).

EXP is the exponentiation function, i.e.

$\operatorname{EXP}^{3}=\mathrm{e}^{3}$ where $\mathrm{e}=2.7183 \ldots$, the base of natural logarithms.

It is important to recognize that this model was developed from a sample of old-growth stands and its reliability in other stands has not been evaluated.

\section{Tree Characteristics}

Because western red cedar ranked third in producing potential nest platforms and was indicated by the regression analysis to be helpful in assessing suitable habitat, nestsearch parties should pay closer attention to this conifer.
Western hemlock was rated lower as a suitable nest tree because of a lower platform abundance. Because observers did not count mistletoe brooms on the outer limbs of trees as potential nest platforms, the actual number of potential nest platforms/tree for western hemlock may be much higher.

Because murrelet surveys are often conducted in stands containing a mix of conifer species, it is difficult to use detection trend information from different stand types to confirm a preference for nesting in one type of conifer. In addition, not enough murrelet nests have been located, or located in a random manner, to determine whether birds are selecting particular tree species for nesting, especially since greater nest-search and survey effort have occurred in the Douglas-fir and Western Hemlock zones than in the Sitka Spruce zone. This comparison provides evidence that certain tree species are more likely to be used by murrelets than others.

\section{Acknowledgments}

These studies were funded by the Washington Department of Wildlife Nongame Program and Pacific Northwest Region Office, USDA Forest Service. I am grateful to Eric Cummins and Bill Ritchie of Washington Department of Fish and Wildlife for their considerable contributions of time and energy in developing and carrying out this research. Additional funding and field personnel were obtained from the Washington Department of Natural Resources Forest Land Management Division. The Endangered Species and Migratory Bird Programs of the U.S. Fish and Wildlife Service, U.S. Department of Interior, in Portland, Oregon, also contributed valuable funding. Dick Holthausen and Grant Gunderson (USDA Forest Service) were both instrumental in coordinating the participation of the Forest Service in the project. I thank Lenny Young and Chuck Turley of the Washington Department of Natural Resources for their support of the research and Tara Zimmerman of the U.S. Fish and Wildlife Service for her efforts in providing additional funding. I thank Phyllis Reed and Charlie Vandemoer of the USDA. Forest Service, Mt. Baker-Snoqualmie National Forest for their cooperation and help with logistical needs.

I also acknowledge the large number of field personnel from the Washington Department of Fish and Wildlife, Mt. Baker-Snoqualmie, Olympic, and Gifford Pinchot National Forests, Washington Department of Natural Resources, private biological consulting companies, and the timber industry for their major contributions to data collection and willingness to share information. I thank statisticians Tim Max and Don Bachman of the USDA Forest Service Forestry Sciences Laboratory biometrics group for their help in study design, analysis, and interpretation of a complex habitat model.

Helpful reviews of this manuscript were provided by Alan Burger, Martin Raphael, C. John Ralph, Peter Conners, Dean Stauffer, Bill Block, and Jim Baldwin. 



\section{A Landscape-Level Analysis of Marbled Murrelet Habitat in Western Washington}

\author{
Martin G. Raphael ${ }^{1}$
}

John A. Young ${ }^{2}$
Beth M. Galleher ${ }^{3}$

\begin{abstract}
Relationships between landscape-level patterns of forest cover and occupancy by Marbled Murrelets in the state of Washington where state-wide forest-cover information was available were investigated. Using a geographic information system, a 203-hectare circular area surrounding each of 261 previously surveyed locations was delineated. Within each area, we calculated the amount, distribution, and pattem of various classes of late-seral forest. Proportions of old-growth forest and large sawtimber were greater at sites that were occupied by murrelets than at sites where they were not detected. Mean size of patches (contiguous cover) of old growth and large sawtimber were also greater among occupied sites than among detected and undetected sites. On average, old growth and large sawtimber combined comprised about 36 percent of occupied sites (203-ha areas) vs. 30 percent and 18 percent on detected and undetected sites, respectively. Various indices of landscape pattern were less useful in distinguishing these sites, but in general, occupied sites had more complex patterns with more edge, a greater variety of cover types, and more complex shapes (greater lengths of edge relative 10 area of patches). Broader patterns, evaluated within large river basins, are also described, but lack of consistent survey effort among these basins precluded analyzing rates of occupancy in relation to forest cover at that scale.
\end{abstract}

Studies of murrelet nesting behavior in the Pacific Northwest have shown that breeding birds select stands of old-growth forest or stands that provide platforms for nests and suitable protection from predators in California (Paton and Ralph 1988), Oregon (Grenier and Nelson, this volume), and Washington (Hamer and Cummins 1990, 1991). All murrelet nests found in these states have been located in old-growth conifer forests (Hamer and Nelson, this volume b). Whereas nesting habitat requirements of murrelets at the individual tree or nest platform and the stand level have been examined in some detail, characteristics of murrelet nesting habitat at the landscape level are less understood (Hamer and Cummins 1990).

Recently-completed studies by Hamer and others (1993) have provided much needed information on suitable nesting habitat characteristics within forest stands in Washington that can be used as predictors of murrelet occupancy from ground-based surveys or forest inventories. No studies have

${ }^{1}$ Chief Research Wildlife Biologist, Pacific Northwest Research Station, USDA Forest Service, 3625 93rd Ave., Olympia, WA $98512-9193$

${ }^{2}$ Geographer, Pacific Northwest Research Station, USDA Forest Service, 3625 93rd Ave., Olympia, WA 98512-9193

${ }^{3}$ Program Analyst, Pacific Northwesi Research Station, USDA Foresi Service, 3625 93rd Ave., Olympia, WA $98512-9193$ as yet considered whether landscape-level characteristics of nesting habitat such as shape, size, or configuration among forest stands have predictive capabilities for occupancy by murrelets. To determine if broad-scale patterns of habitat distribution influence murrelet occupancy, we initiated a study of relationships between amount and configuration of habitat and occupancy of murrelets at previously surveyed locations. Information on relationships between habitat characteristics and occupancy by murrelets at broader scales could be of value in planning conservation strategies and guidelines for management at the regional level. Assessments of habitat requirements across all scales - nest, stand, site, and landscape - are necessary to determine the proper mix of management guidelines to assure adequate amounts and configuration of nesting habitat for the murrelet in the Pacific Northwest.

\section{Methods}

Analysis of landscape attributes of Marbled Murrelet habitat selection proceeded at two scales. A broad scale analysis within major river basins considered the distribution of potential habitat among land owners (Federal and nonFederal) over the species' range in Washington. A more sitespecific analysis considered the influence of landscape characteristics immediately adjacent to survey sites on occupancy status of murrelets. We generated statistical measures for both scales of analysis using Geographic Information Systems (GIS) and landscape pattern programs.

\section{Data Sources}

We obtained a database of all murrelet survey locations (through 1992) from the Washington Department of Fish and Wildlife (WDFW). This database was used previously in regional conservation planning efforts for the Northern Spotted Ow1, Marbled Murrelet, and other species associated with late-successional forests (Thomas and Raphael 1993). Murrelet survey locations $(n=708)$ are represented by $x, y$ coordinate locations and associated attributes mapped in GIS form (fig. 1). Survey points were coded by the WDFW into five levels of murrelet detection (table l) following protocols and definitions of the Pacific Seabird Group (Ralph and others 1993). Many of the locations were collected before the currently accepted survey protocol was developed. In addition, some of the database records represent multiple sites clustered around a single survey station. For purposes of this analysis, we analyzed only those surveys conducted following protocol standards, and we eliminated any additional multiple sites around a single station. The number of resulting sites were $n=261$. 


\section{Murrelet Survey Locations}

- Protocol Survey

$\triangle$ Non-Protocol Survey $N$ WRIA Basin fi 50 Mile Buffer

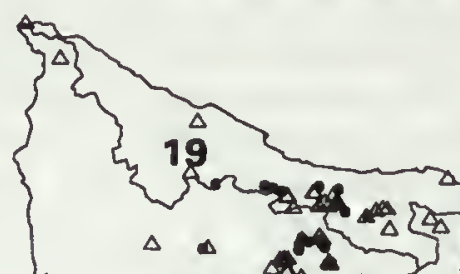

\section{.}

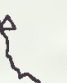

$\Delta$

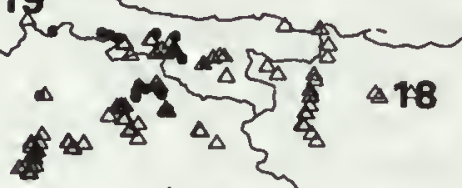

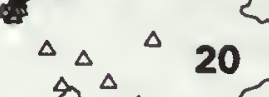

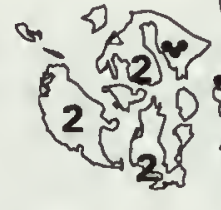

$\Delta \Delta$

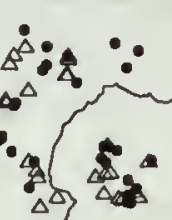

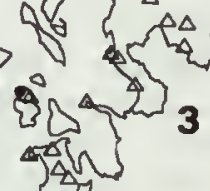

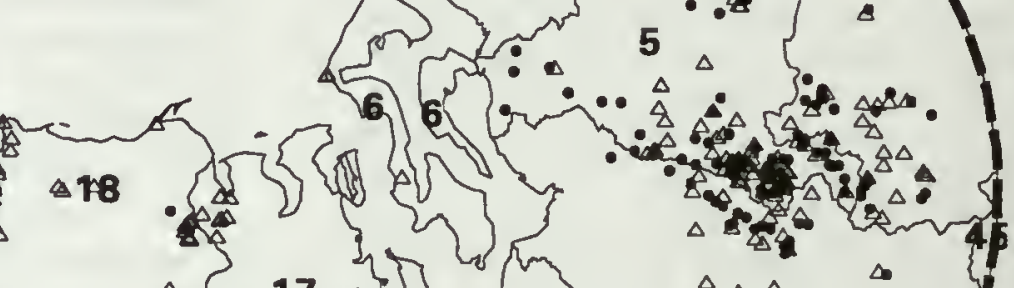<smiles>C1CCC2CCCC2CC1</smiles>
$\Delta \Delta \Delta$ $\Delta \Delta \Delta \Delta$

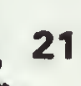

$\Delta \Delta \Delta$
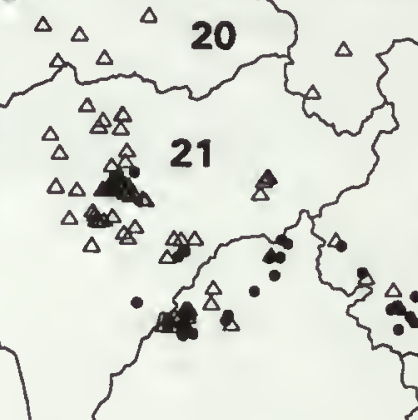<smiles>[Tl]</smiles>

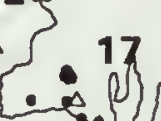<smiles>c1ccc2ccccc2c1</smiles>

\section{2}

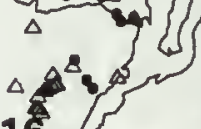

16<smiles>C1CC2CCCC(C1)CC2</smiles>

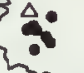<smiles>O=S(=O)(C12CC3CC(CC(C3)C1)C2)C12CC3CC(CC(C3)C1)C2</smiles>

$\Delta$

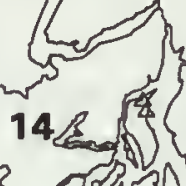
15
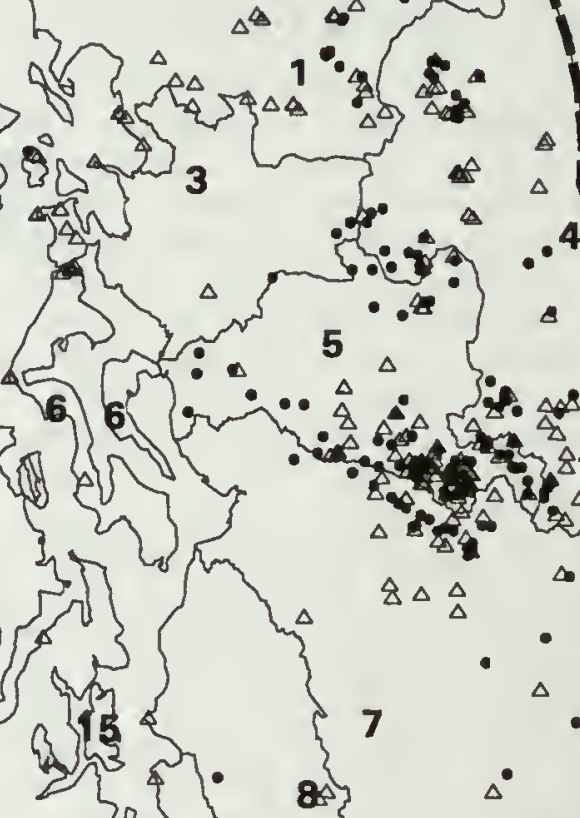
Table 1-Status of inland sites where Marbled Murrelets have been surveyed in Washington', through 1992

\begin{tabular}{l|lcc}
\hline \multirow{2}{*}{ Survey code } & Status & \multicolumn{2}{c}{ Number of surveys } \\
\cline { 3 - 4 } & Active nest & $\begin{array}{c}\text { All } \\
\text { surveys }\end{array}$ & $\begin{array}{c}\text { Surveys following } \\
\text { protocol standands }\end{array}$ \\
\hline 1 & Nest site & 19 & 0 \\
2 & Occupied site & 141 & 3 \\
3 & Presence & 308 & 66 \\
4 & No detection & 235 & 108 \\
5 & & 708 & 84 \\
Total & & & 261 \\
\hline
\end{tabular}

ISource: Washington Department of Fish and Wildlife.

${ }^{2}$ Protocol developed by Pacific Seabird Group (Ralph and others 1993). Multiple records from the same station are also excluded. See this document for definition of status categories.

We obtained two maps of forest vegetation from Washington State natural resource databases for this analysis. These maps represent the only sources of forest cover classified across both Federal and non-Federal lands in Washington. A digital map of old-growth and other cover classes was obtained from the WDFW (Eby and Snyder 1990, Collins 1993). This map was updated by Washington Department of Natural Resources (WDNR), Forest Practices Division, using 1991 Landsat Thematic Mapper (TM) imagery to account for timber cutting since 1988 (Collins 1993). The map displays old-growth and other forest conditions in western
Washington from the Pacific coast to 50 miles inland on lands below 3200' elevation (table 2). The 50-mile limit was defined by WDFW as the inland extent of murrelet activity, even though their database contains three records at greater distances (to 53 miles).

The WDFW forest-cover map was used for both a basinlevel analysis and a site-level analysis. We received the data as $1: 100,000$ vector (polygon) maps. We converted the vector maps into a raster (grid) format using the ARC/INFO GRID software (Environmental Systems Research Institute, Inc., Redlands, CA) at a cell resolution of 50 by 50 meters. We projected the maps from a State Plane coordinate system into a Universal Transverse Mercator (UTM) map projection and joined the individual 1:100,000 scale maps together to form one seamless map that we could use with our existing GIS databases.

We used a second source of vegetation data for basinlevel analysis to compare against the WDFW data. The WDNR, Forest Practices Division provided a map of forest seral stages that was developed for the state from 1988 Landsat TM imagery (Green and others 1993). This map is in a raster (grid) format with a cell resolution of 147 by 147 meters and was classified into six classes (table 3). To match the WDFW map, we created a murrelet zone map by drawing a boundary 50 miles inland from the Washington Pacific and Puget Sound coasts. This map was used as the geographic extent for all subsequent analyses; maps of vegetation, river basins, and elevation were subset to coincide with this zone map.

We used other GIS data sources in conjunction with the above sources of forest vegetation data to analyze murrelet

Table 2-Washington Department of Fish and Wildlife old-growth classifucation'

\begin{tabular}{|c|c|}
\hline Class name & Description \\
\hline Old growth & $\begin{array}{l}\text { Coniferous forest stands, dominant trees }>30^{\circ} \text { d.b.h. }{ }^{2} \text {, co-dominant trees }>16^{\circ} \text { d.b.h., } 8 \\
\text { or more dominant trees per acre, multi-layered canopy, several snags per acre }>20^{\circ} \\
\text { d.b.h., many down logs }>24^{\prime \prime} \text { diameter }\end{array}$ \\
\hline Large sawtimber & $\begin{array}{l}\text { Coniferous forest stands, dominant trees } 20-30^{\prime \prime} \mathrm{d} . \mathrm{b} . \mathrm{h} . \text {, co-dominant trees }>14^{\prime \prime} \mathrm{d} . \mathrm{b} . \mathrm{h} ., 10 \\
\text { or more dominant trees per acre, } 2-3 \text { layer canopy, few snags or downed logs }\end{array}$ \\
\hline Small sawtimber & $\begin{array}{l}\text { Coniferous forest from sapling/pole stands to large sawtimber, }<20^{\circ} \text { d.b.h., closed single } \\
\text { layer canopy, very little dead wood }\end{array}$ \\
\hline Other & Non-forested, or non-vegetated. Also includes closed mature deciduous stands \\
\hline Above 3,200 feet & $\begin{array}{l}\text { All areas above } 3200 \text { feet were masked out of the updated version of Eby and Snyder's } \\
(1990) \text { map }\end{array}$ \\
\hline Cleared & Clear-cut since 1988 \\
\hline Partial harvest & Partial harvest since 1988 \\
\hline Salt water & Ocean, Puget Sound, other marine waters \\
\hline Freshwater & Inland lakes, rivers \\
\hline
\end{tabular}

\footnotetext{
${ }^{1}$ Source: Washington Department of Fish and Wildlife, Eby and Snyder (1990), Collins (1993).
}

2 D.b.h. = diameter at breast height 


\begin{tabular}{|c|c|}
\hline Class & Description \\
\hline Late seral & $\begin{array}{l}\text { Coniferous forest stands, }>10 \text { pet tree crown closure in trees }>21 \text { " d.b.h., with }>70 \\
\text { pct total crown closure, and }<75 \text { percent of the crown in hardwoods or shrubs }\end{array}$ \\
\hline Mid-seral & $\begin{array}{l}\text { Coniferous forest stands, }<10 \text { pct tree crown closure in trees }>21 \text { " d.b.h., with }>70 \\
\text { pct tolal crown closure and }<75 \text { percent of the crown in hardwoods or shrubs }\end{array}$ \\
\hline Early seral & $\begin{array}{l}\text { Coniferous forest stands, } 10-70 \text { pct total crown closure and }<75 \text { pct of the crown in } \\
\text { hardwoods or shrubs }\end{array}$ \\
\hline Cleared/Other & $<10 \mathrm{pct}$ crown closure conifers and/or $>75 \mathrm{pct}$ of the crown in hardwoods or shrubs \\
\hline Water & Open water bodies \\
\hline Non-forested & Non-forest land (agriculture, urban, rock, etc.) \\
\hline
\end{tabular}

occurrence against measures of landscape pattern and composition. A map of major river basins depicting WDNR's Water Resource Inventory Areas (WRIA's) was obtained from WDNR and used to subdivide the vegetation maps into analysis units based on river drainages (fig. 1 ) for the basinlevel analysis (Green and others 1993).

\section{Accuracy of Forest-Cover Maps}

Forest-cover maps used for the Marbled Murrelet landscape analysis were developed by WDFW and WDNR. The WDFW data set was developed from 1984 and 1986 Landsat Multi-Spectral Scanner (MSS) imagery. This imagery has a minimum spatial resolution of approximately $80 \mathrm{~m}^{2}$ and collects information in four spectral bands. Digital elevation models were used by WDFW to compensate for shadowing on north-facing slopes (Eby and Snyder 1990). The stated accuracy of this data source for mapping oldgrowth cover is 80 percent for the Cascades $(20$ percent error of commission and 7 percent error of omission) and 85 percent for the Olympic Peninsula (15 percent error of commission and 7 percent error of omission) (Eby and Snyder 1990). Errors of commission are areas that are mapped as old-growth forest, for example, but are found to be some other type upon field inspection. Errors of omission are areas of old-growth forest that are missed in the mapping but are found to exist on the ground. Accuracy was assessed by WDFW by checking mapped interpretations against field observations (Eby and Snyder 1990). Other potential errors in this data set are large sawtimber stands mapped as oldgrowth forest, wind-throw or fire regenerated stands mapped as old growth, and the omission of small, narrow features and stand edges (Eby and Snyder 1990). In addition, areas of mature deciduous forest and sapling conifer are lumped into the "other forest" class, which causes difficultly in determining actual stand boundaries in areas with little older forest, such as in southwest Washington (Snyder, pers. comm.). In addition, because the focus of the mapping effort was to determine areas of old-growth forest, errors associated with other types of land cover were not distinguished.

The WDNR data set was developed from 1991 TM imagery. This imagery has a minimum spatial resolution of $30 \mathrm{~m}^{2}$ and collects information in seven spectral bands. High altitude aerial photography, field reconnaissance, and WDNR maps were used to guide the classification (Green and others 1993). The stated overall accuracy of this data set within the range of the Marbled Murrelet is 92 percent, with the lowest accuracy in the Puget lowland ( 87 percent) and the highest in the North Cascades (97 percent) (Green and others 1993). No information is given on errors of commission or omission. Potential confusion in this dataset may be caused by the grouping of stands with $>75$ percent crown closure in hardwoods and young conifer in the "other forest" category.

\section{GIS Processing}

We subdivided both habitat maps (WDFW and WDNR) in to WRIA river basins by using ARC/INFO GRID commands for the basin level analysis. Attributes from each basin were then input to the DISPLAY landscape pattern program. DISPLAY is a package of statistical routines that calculates indices of landscape pattern from GIS maps (Flather and MacNeal 1993). Landscape pattern indices calculated by DISPLAY (table 4) are based on pattern indices discussed in O'Neill and others (1988), Milne (1991, 1992), and Krummel and others (1987).

For the site-level analysis, we subsetted the WDFW forest condition map into 0.5 -mile radius circles around survey locations (fig. 2). We calculated indices of pattern on each resulting circular landscape using the FRAGSTATS program (Marks and McGarigal 1993). FRAGSTATS is a set of routines that calculates indices of pattern on landscapes. FRAGSTATS calculates many of the same indices as 
Table 4-Landscape pattern indices output by DISPLAY and used in the basin level analysis

\begin{tabular}{|c|c|c|}
\hline Pattern index & Possible values ${ }^{1}$ & Description \\
\hline Landscape diversity & $0-\infty$ & $\begin{array}{l}\text { Measures proportion of landscape in different types; } 0=\text { lowest } \\
\text { diversity (only } t \text { type); larger value indicates more diverse } \\
\text { landscape }\end{array}$ \\
\hline Landscape dominance & $0-\infty$ & $\begin{array}{l}\text { Extent to which } 1 \text { or few types dominate the landscape; as } \\
\text { value approaches } 0 \text {, all types are present in equal proportions; } \\
\text { max. value depends on number of types in landscape }\end{array}$ \\
\hline Landscape contagion & $0-\infty$ & $\begin{array}{l}\text { Extent to which landscape is aggregated or clumped; as value } \\
\text { approaches } 0 \text {, many small patches exist; max. value depends } \\
\text { on number of types in landscape }\end{array}$ \\
\hline Number of different types & $\begin{array}{l}\mathrm{WDFW}^{2}=9 \\
\mathrm{WDNR}^{3}=6\end{array}$ & $\begin{array}{l}\text { Number of types possible in landscape, also lermed } \\
\text { "patch richness" }\end{array}$ \\
\hline $\begin{array}{l}\text { Proportion of each type } \\
\text { in landscape }\end{array}$ & $0-1$ & Percent of total area \\
\hline $\begin{array}{l}\text { Number of patches of each } \\
\text { type in landscape }\end{array}$ & $0-\infty$ & Count of palches by type \\
\hline Mean palch size by type & $\begin{array}{l}0 \text { - lotal } \\
\text { landscape area }\end{array}$ & Sum of palch area by type divided by total area \\
\hline $\begin{array}{l}\text { Perimeter/area fractal } \\
\text { dimension }\end{array}$ & $1.0-2.0$ & $\begin{array}{l}\text { Index of patch edge complexity, contrasts log (patch } \\
\text { perim.) with log (patch area) }\end{array}$ \\
\hline $\begin{array}{l}\text { Grid based fractal } \\
\text { dimension }\end{array}$ & $1.0-2.0$ & $\begin{array}{l}\text { Index of paich edge complexity, calculated using a } \\
\text { grid-cell counting method }\end{array}$ \\
\hline
\end{tabular}

${ }^{1}$ Values reported are theoretical limits, not actual ranges.

${ }^{2}$ WDFW $=$ Washington Department of Fish and Wildlife

${ }^{3}$ WDNR $=$ Washington Department of Natural Resources

DISPLAY and also calculates additional landscape-level and patch-level indices (table 5). We attempted to use FRAGSTATS for the basin level analysis, but these landscapes were too large to process using this program. We tabulated indices of pattern for each of the 261 circular areas and compared site-level attributes among survey-status attributes (those sites where murrelets were not detected, were detected, or classified as occupied).

We computed additional site-level variables using the GIS to add other environmentally related measures to the multivariate comparison of site-level pattern and occupancy status. Distance to closest coastline (meters) was calculated for each murrelet survey location using the NEAR function in ARC/INFO. This represents a straight-line distance between a survey location and the closest body of salt water.

We identified patch size and type for each survey location by recording the contiguous patch on the overall landscape (whether or not that patch was outside of the 0.5 -mi radius circle) directly underneath each survey point. The definition of patch used here differs significantly from the concept of a stand typically used by foresters. In this case, a patch is defined in terms of the GIS map as each unique set of contiguous cells of the same cover class type. Some of these patches can be quite large (up to 25,000 hectares) and should not be considered equivalent to typically defined stands in forest management. Rather, these are areas defined by pixels sharing the same class value.

We determined survey-site elevations by overlaying the map of survey locations on a digital elevation model and interpolating the ele vation at each point using GIS operations. United States Geological Survey 1:250,000 scale digital elevation models were used to derive an elevation surface for the state of Washington. These elevation models are a regular (grid) sample of elevations and have a vertical accuracy 


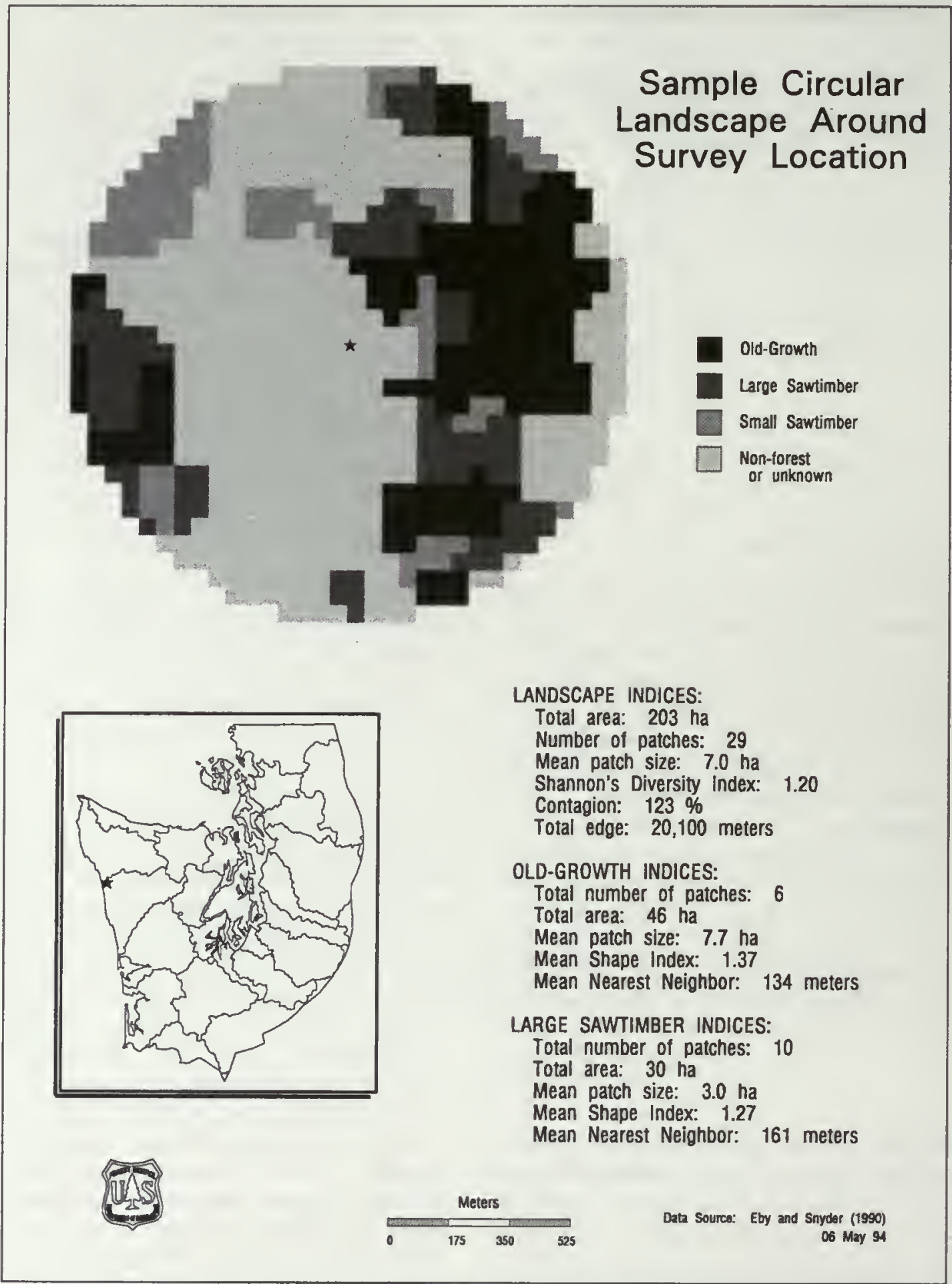

Figure 2-Example of forest cover classification within a 203-ha circular area surrounding a Marbled Murrelet survey location. Forest cover from classification by Washington Department of Fish and Wildlife (Eby and Snyder 1990). See table 5 for explanation of landscape indices. 
Table 5-Landscape pattern statistics output by the FRAGSTATS program and used in the site-level analysis, Washington Department of Fish a nd Wildlife old-growth data set

\begin{tabular}{|c|c|c|}
\hline Pattern index & $\begin{array}{l}\text { Range of values for 203-ha } \\
\text { circles }(n=261)\end{array}$ & Description \\
\hline Number of parches & $1-46$ & Count of number of patches \\
\hline Mean patch size & $44.1-203$ & Average size (ha) of all patches in landscape \\
\hline Patch size std dev & $0-143$ & Standard deviation of patch sizes in landscape (ha) \\
\hline Patch size coeff var & $0-321.81$ & Coefficient of variation of patch sizes in landscape \\
\hline Mean shape index & $1.06-1.98$ & Average shape index (complexity) of all patches in landscape \\
\hline Area weighted mean shape index & $1.12-3.36$ & Average shape of patches standardized by patch area \\
\hline Landscape shape index & $0.98-4.85$ & Overall complexity of landscape \\
\hline Mean patch fractal dimension & $1.0-1.1$ & Fractal edge complexity for all parches in landscape \\
\hline Patch richness & $1-9$ & Maximum number of different types in landscape \\
\hline Shannon's diversity index & $0-1.77$ & An index of patchiness, dependent on proportion of landscapes of different types \\
\hline Simpson's diversity index & $0-0.83$ & $\begin{array}{l}\text { Another index of patchiness, } 1 \text { minus the squared sum of the proportion of the } \\
\text { landscape in different types }\end{array}$ \\
\hline Modified Simpson's diversity index & $0-1.75$ & $\begin{array}{l}\text { The Simpson index modified by taking the negative log of the sum of landscape } \\
\text { proportion of patch types }\end{array}$ \\
\hline Shannon's evenness index & $0-1$ & $\begin{array}{l}\text { Index relating the proportion of landscape in each type to the number of } \\
\text { different types }\end{array}$ \\
\hline Simpson's evenness index & $0-1$ & $\begin{array}{l}\text { Index relating } 1 \text { minus the proportion of landscape in each type to } 1 \text { minus the } \\
\text { inverse of the number of different types }\end{array}$ \\
\hline Modified Simpson's eveaness index & $0-1$ & $\begin{array}{l}\text { Modified evenness index, relates the negative log of squared proportion of } \\
\text { landscape in different types to log of the number of types }\end{array}$ \\
\hline Mean nearest neighbor & $0-1304$ & Average distance $(m)$ to closest patch of similar type \\
\hline Nearest neighbor std dev & $0-721$ & Std. deviation of nearest neighbor distance by type \\
\hline Nearest neighbor coeff var & $0-124$ & Coefficient of variation (m) for nearest neighbor distances \\
\hline Contagion & $0-154$ & $\begin{array}{l}\text { Extent to which landscape is aggregated or clumped; as value approaches } 0 \text {, } \\
\text { many small patches exist; maximum value depends on number of types in } \\
\text { landscape }\end{array}$ \\
\hline Contagion $(2)^{2}$ & $0-80$ & $\begin{array}{l}\text { Extent to which landscape is aggregated or clumped; as value approaches } 0 \text {, } \\
\text { many small patches exist; maximum value depends on number of types in } \\
\text { landscape (excludes landscape border) }\end{array}$ \\
\hline Total edge & $5600-27650$ & Total length of edge $(m)$ between patches of different types \\
\hline
\end{tabular}

Varies from contagion in that landscape border is excluded. 
of ( $+r /-) 30 \mathrm{~m}$ (U.S. Geological Survey 1990). The original cell resolution of $90 \mathrm{~m}$ was resampled to $200 \mathrm{~m}$ to create a sta tewidf: elevation grid. Elevations were recorded as height above sea level in meters.

\section{Results}

\section{Basin-I evel Analysis}

Laindscape characteristics for the WDFW data by major river bisin (table 6 ) show the majority of the basins" area is in the "other forest/unknown" category ( $\bar{x}=84$ percent). Two luasins have 100 percent of their area in this class. Mean proportion of old growth was only 5 percent over all 25 ba sins, although one basin (number 21 ) had 21 percent of its a'rea in old growth (table 6). Pattern statistics calculated on these basins show a low diversity of types $(\bar{x}=0.57)$, a high dominance $(\bar{x}=0.94)$ or influence of one or a few types, and a high contagion ( $\bar{x}=4.55)$ or "clumpiness" in the data (table 6 ).

In contrast, the WDNR seral-stage data (table 7) show a more even distribution of classes. Late-seral classes averaged 15 percent of the basin's area, and had higher mean patch sizes ( $\bar{x}=69 \mathrm{ha}$ ) than the mean patch sizes of old growth from the WDFW data set (10 ha) (table 6). Pattern indices show the WDNR seral stage data by basin as relatively less "clumpy" ( $\bar{x}$ contagion $=5.58$ ), and with a greater diversity ( $\bar{x}=1.40$ ) than the WDFW classification. Basins classified using the WDNR seral stages also have a greater proportion of area in mid-seral ( $\bar{x}=27$ percent) and cleared ( $\bar{x}=32$ percent) classes.

The range outlined in figure 1 encompasses about 5.2 million ha, over half of which is privately managed (2.9 million ha, 56 percent). Another 0.6 million ha ( 12 percent) are managed by the Washington Department of Natural

Table 6-Water Resource Inventory Area (WRIA) basin characteristics: Landscape pattern indices and proportion of basin area in cover classes, Washington Department of Fish and Wildtife cover classification (Eby and Snyder 1990, Collins 1993)'

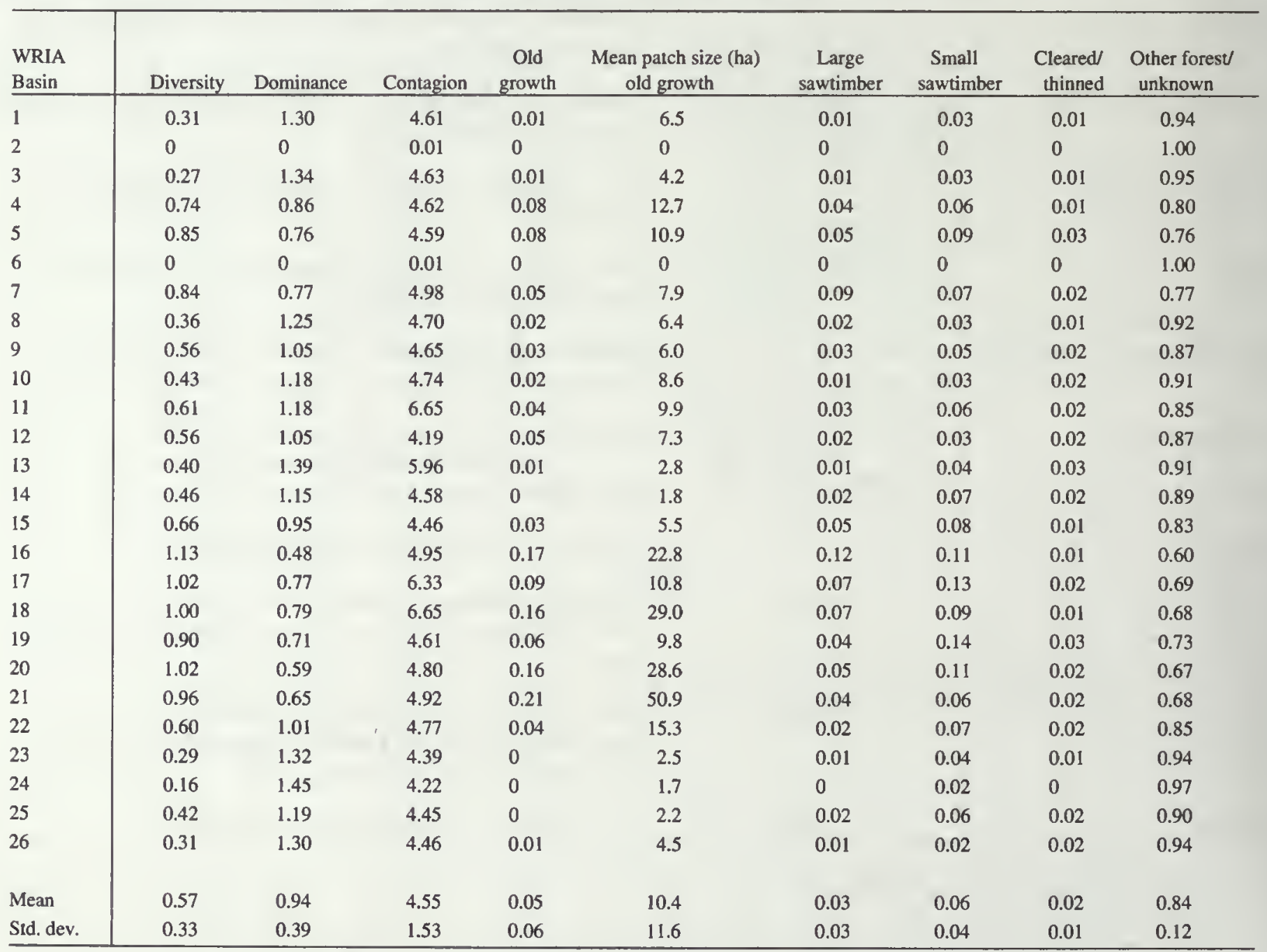

${ }^{1}$ See figure 1 for location of each basin; table excludes fragments of WRIA basins 38, 39, and 45 along western boundary of range. 
Table 7-Water Resource Inventory Area (WRIA) basin characteristics: landscape pattern indices and proportion of basin area in cover classes, Weshington Department of Natural Resources seral stage data (Green and others 1993)"

\begin{tabular}{|c|c|c|c|c|c|c|c|c|c|c|}
\hline $\begin{array}{l}\text { WRIA } \\
\text { Basin }\end{array}$ & Diversity & Dominance & Contagion & $\begin{array}{l}\text { Late } \\
\text { seral }\end{array}$ & $\begin{array}{l}\text { Mean patch } \\
\text { size (ha) LS }\end{array}$ & $\begin{array}{l}\text { Mid- } \\
\text { seral }\end{array}$ & $\begin{array}{l}\text { Early } \\
\text { seral }\end{array}$ & Cleared & Water & $\begin{array}{c}\text { Other/non- } \\
\text { fores1 }\end{array}$ \\
\hline 1 & 1.55 & 0.24 & 6.06 & 0.16 & 88.6 & 0.13 & 0.09 & 0.31 & 0.01 & 0.30 \\
\hline 2 & 1.44 & 0.35 & 4.67 & 0.02 & 10.2 & 0.37 & 0.06 & 0.27 & 0.04 & 0.23 \\
\hline 3 & 1.44 & 0.35 & 6.20 & 0.03 & 41.8 & 0.15 & 0.10 & 0.36 & 0.03 & 0.34 \\
\hline 4 & 1.38 & 0.41 & 6.00 & 0.43 & 149.0 & 0.15 & 0.01 & 0.26 & 0.02 & 0.13 \\
\hline 5 & 1.48 & 0.31 & 5.81 & 0.26 & 117.7 & 0.23 & 0.05 & 0.33 & 0 & 0.11 \\
\hline 6 & 1.29 & 0.50 & 5.27 & 0 & 4.6 & 0.15 & 0.07 & 0.43 & 0.02 & 0.33 \\
\hline 7 & 1.54 & 0.26 & 5.53 & 0.24 & 70.5 & 0.25 & 0.05 & 0.31 & 0.01 & 0.14 \\
\hline 8 & 1.46 & 0.33 & 6.26 & 0.05 & 43.4 & 0.19 & 0.03 & 0.21 & 0.08 & 0.44 \\
\hline 9 & 1.44 & 0.35 & 5.73 & 0.11 & 34.4 & 0.24 & 0.03 & 0.28 & 0.01 & 0.34 \\
\hline 10 & 1.48 & 0.31 & 6.04 & 0.20 & 97.1 & 0.27 & 0.02 & 0.29 & 0.01 & 0.20 \\
\hline 11 & 1.43 & 0.36 & 6.07 & 0.07 & 162.6 & 0.36 & 0.06 & 0.35 & 0.01 & 0.15 \\
\hline 12 & 1.05 & 0.56 & 4.17 & 0 & 0.0 & 0.14 & 0.01 & 0.23 & 0.02 & 0.60 \\
\hline 13 & 1.33 & 0.28 & 3.77 & 0 & 0.0 & 0.29 & 0.08 & 0.36 & 0.01 & 0.26 \\
\hline 14 & 1.41 & 0.38 & 5.36 & 0.05 & 108.5 & 0.40 & 0.09 & 0.35 & 0.03 & 0.09 \\
\hline 15 & 1.33 & 0.28 & 3.35 & 0 & 0.0 & 0.43 & 0.09 & 0.26 & 0.02 & 0.19 \\
\hline 16 & 1.42 & 0.37 & 5.57 & 0.47 & 126.4 & 0.15 & 0.04 & 0.21 & 0.01 & 0.12 \\
\hline 17 & 1.50 & 0.29 & 5.20 & 0.20 & 72.5 & 0.27 & 0.06 & 0.36 & 0.01 & 0.10 \\
\hline 18 & 1.38 & 0.41 & 5.49 & 0.46 & 202.0 & 0.10 & 0.04 & 0.17 & 0 & 0.23 \\
\hline 19 & 1.22 & 0.57 & 5.91 & 0.14 & 38.5 & 0.46 & 0.01 & 0.35 & 0.02 & 0.02 \\
\hline 20 & 1.49 & 0.30 & 5.99 & 0.29 & 84.9 & 0.28 & 0.08 & 0.28 & 0.02 & 0.06 \\
\hline 21 & 1.48 & 0.31 & 5.70 & 0.38 & 150.8 & 0.22 & 0.23 & 0.12 & 0.01 & 0.05 \\
\hline 22 & 1.32 & 0.47 & 5.71 & 0.17 & 34.4 & 0.33 & 0.02 & 0.40 & $0.0 \mathrm{t}$ & 0.07 \\
\hline 23 & 1.28 & 0.51 & 5.92 & 0 & 12.8 & 0.34 & 0.09 & 0.39 & 0 & 0.17 \\
\hline 27 & 1.25 & 0.54 & 5.52 & 0.03 & 10.7 & 0.44 & 0.05 & 0.37 & 0.01 & 0.10 \\
\hline 25 & 1.34 & 0.45 & 6.07 & 0 & 11.4 & 0.34 & 0.12 & 0.41 & 0.03 & 0.10 \\
\hline 26 & 1.38 & 0.41 & 6.33 & 0.02 & 51.0 & 0.27 & 0.10 & 0.45 & 0.02 & 0.13 \\
\hline Mean & 1.40 & 0.37 & 5.58 & 0.15 & 69.0 & 0.27 & 0.0 & 0.32 & 0.02 & 0.18 \\
\hline Std. dev. & 0.09 & 0.09 & 0.72 & 0.16 & 57.8 & 0.10 & 0.05 & 0.08 & 0.02 & 0.11 \\
\hline
\end{tabular}

${ }^{1}$ See figure $I$ for locations of each basin; table excludes fragments of WRIA basins 38, 39, and 45 along western boundary of range.

${ }^{2} \mathrm{LS}=$ late seral

Resources and 0.9 million ha (18 percent) by the National Park Service. Based on the WDNR classification, private and state lands are predominantly mid-seral and other forest, whereas National Forest and Park Service lands are predominantly late-seral (fig. 3). An analysis based on the WDFW classification (fig. 4) shows a similar distribution of forest age classes among land managers. However, the amount of late-seral forest (old growth and large sawtimber) is much lower than that estimated from the WDNR classification. This difference reflects the elevation cutoff ( 3200 feet) used by the WDFW (table 2).

The WRIA basin is too large an area relative to the number of surveys conducted within each basin (fig. I) to detect relationships among landscape pattern variables and detection rate. Analysis of smaller basins with greater sampling intensities may help to clarify what, if any relationship exists between broad landscape pattern and likelihood of murrelet detection. However, the description of amount and config- uration of forest vegetation within river basins given here may help to determine those areas in Washington that are in need of closer examination at finer scales of analysis and with greater surveying effort.

\section{Site-Level Analysis}

\section{Stand Characteristics}

Most (59 percent) of the Marbled Murrelet survey sites were centered within the various other forest categories (WDFW forest-cover map). Most of the remaining sites were located within old-growth stands (table 8). The proportion of sites within the various forest-cover classes differed significantly among detection classes (chi-square $=$ $40.2, P=0.000$ ). Patch area did not differ significantly among occupied, detected or undetected sites, nor did it differ among forest-cover classes (table 9). Survey sites averaged $30.6 \mathrm{~km}$ from nearest saltwater; mean distance did not significantly vary among occupied, detected, and un- 

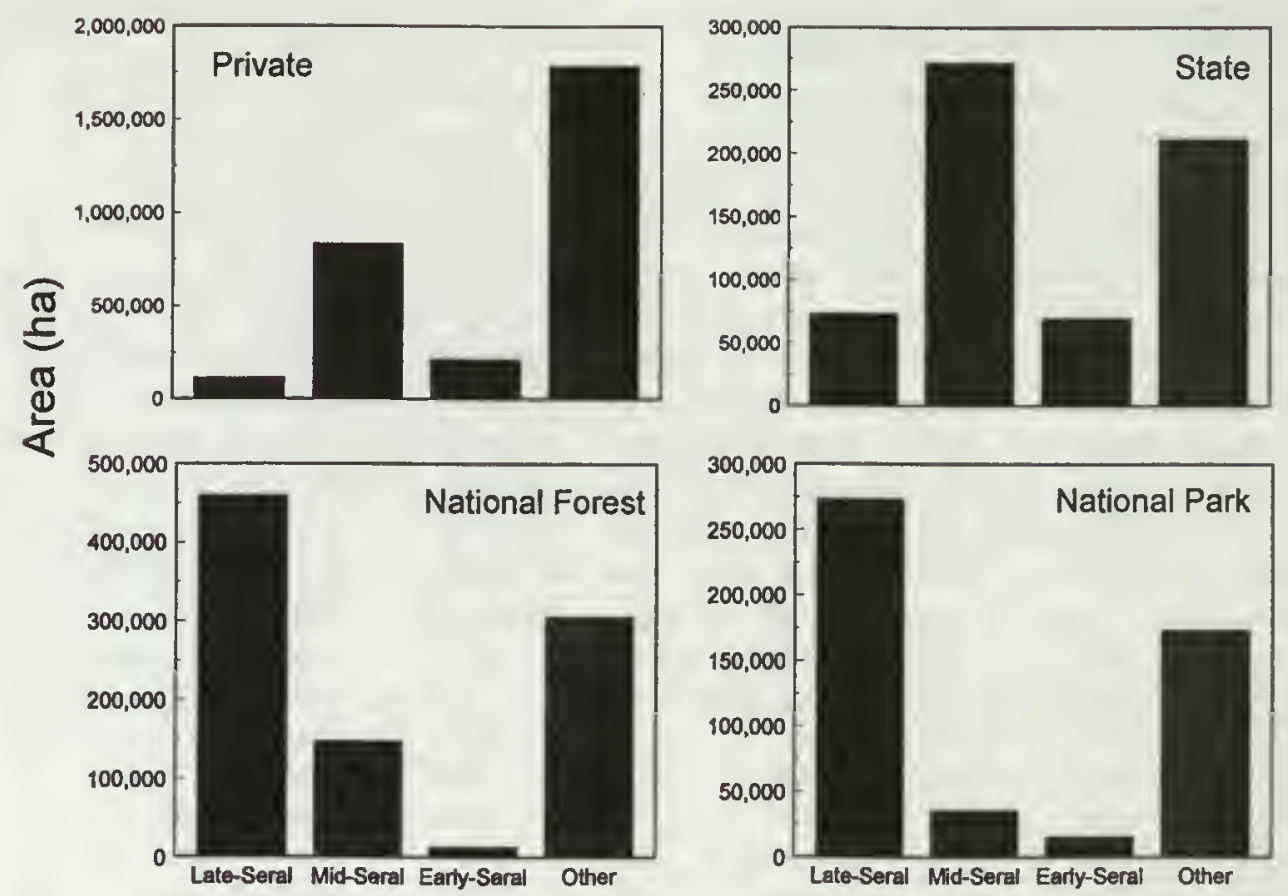

Figure 3 - Classification by Washington Department of Natural Resources of the distribution of forestcover classes among Federal, state, and private lands within the range of the Marbled Murrelet in Washington (Green and others 1993). "Other" includes all remaining cover classes from table 3. See figure 1 for map.
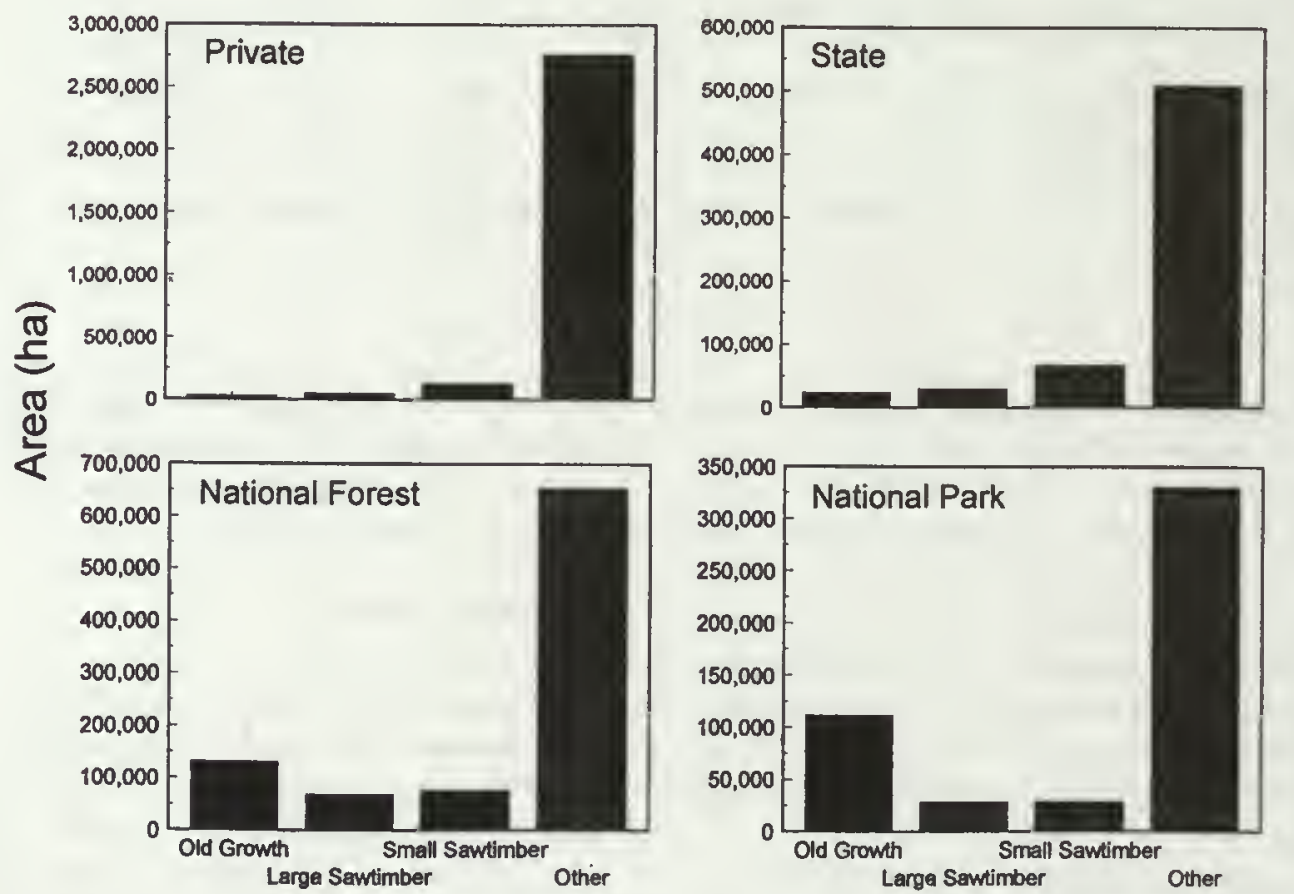

Figure 4-Classification by Washington Department of Fish and Wildlife of the distribution of forestcover classes among Federal, state, and private lands within the range of the Marbled Murrelet in Washington (Eby and Snyder 1990, Collins 1993). "Other" includes all remaining cover classes from table 2. See figure 1 for map. 
Table \& Frequency of Marbled Murrelet survey sites among forest-cover classes by detection class, western Washington

\begin{tabular}{l|cccc}
\hline & \multicolumn{4}{|c}{ Detection class } \\
\cline { 2 - 5 } Forest-cover class ${ }^{1}$ & Occupied & Detected & Undetected & Total \\
\hline Old growth & 27 & 17 & 8 & 52 \\
Large sawtimber & 9 & 17 & 4 & 30 \\
Small sawtimber & 10 & 10 & 5 & 25 \\
All other classes & 23 & 64 & 67 & 154 \\
& & & & \\
Total & 69 & 108 & 84 & 261 \\
\hline
\end{tabular}

'Cover classes from Washington Department of Fish and Wildlife (Eby and Snyder 1990, Collins 1993), updated by Washington Department of Natural Resources (Collins, pers. comm.). See table 2 for cover class descriptions.

detected sites $(31.2,30.3,30.6 \mathrm{~km}$, respectively). Elevation of survey sites averaged 482 meters and mean elevation did not significantly differ among occupied, detected, and undetected sites $(520,467$, and 473 meters, respectively). Maximum elevation for all surveys was 1,455 meters, minimum elevation was sea-level ( 0 meters).

\section{Site Characteristics}

We investigated two general characteristics in describing the 203-ha area surrounding each site-amount and pattern of forest-cover classes (WDFW forest-cover map). The relative amounts of each of four general forest cover classes varied significantly among each of the detection classes (fable 10). Over the entire sample of 261 survey sites, oldgrowth forest averaged 18 percent of the 203-ha landscape surrounding each site. Percentages of large sawtimber, small sawtimber and other averaged 9 percent, 11 percent, and 61 percent, respectively. Percentage of old-growth forest was significantly greater on occupied sites compared to undetected sites (rable 10). Similarly, the proportion of large sawtimber was greater on occupied sites than on undetected sites. Proportion of other forest land was greater on undetected sites than occupied sites.
Table Q Analysis of variance of patch size in relation to survey status (occupied, detected, unoccupied) and cover class (old-growth, lange sawtimber, small sawtimber) of Marbled Murrelet survey sites, western Washington'

\begin{tabular}{l|ccc}
\hline & & & \\
Source of variation & $d f$ & $\boldsymbol{F}$ & Significance \\
\hline Status & 2 & 0.40 & 0.671 \\
Cover class & 2 & 2.35 & 0.100 \\
Interaction & 4 & 0.69 & 0.603
\end{tabular}

\footnotetext{
'Patch area was estimated for contiguous cover surrounding each survey
} site as classified from cover maps of Eby and Snyder (1990). Collins (1993).

Many of the landscape pattern indices are correlated. Rather than report estimates for each of the 21 different indices we computed, we used principal components analysis to produce composite landscape shape index variables. This analysis resulted in four factors that contained about 88 percent of the variation inherent in the original set of variables. The first factor contained about 61 percent of the variation in the original variables and was used in subsequent analyses. This composite factor was highly correlated $(r>0.80)$ with 10 of the original variables. Values of this composite index increased with increasing number. of patches, landscape shape index, Shannon's diversity index, Simpson's diversity index, modified Simpson's density index, Shannon's and Simpson's evenness indices, modified Simpson's evenness index, contagion index, and total edge. Mean values of this composite landscape pattern index (table 11) varied significantly among detection classes $(F=14.88, P=0.000)$, and was significantly greater among occupied sites than in either of the other detection classes (planned contrast, $t=$ 5.17, $P=0.000$ ).

We also investigated the influence of shape and size of old-growth and large sawtimber patches (table 11). These attributes are correlated with the amount of each cover

Table 10-Forest cover (mean percentage) wưhin 203-ha circles centered on Marbled Murrelet survey siles, western Washington"

\begin{tabular}{|c|c|c|c|c|c|c|c|c|c|c|c|c|}
\hline \multirow[b]{3}{*}{ Status } & \multicolumn{12}{|c|}{ Forest-cover class ${ }^{2}$} \\
\hline & \multicolumn{3}{|c|}{ Other forest } & \multicolumn{3}{|c|}{ Small sawtimber } & \multicolumn{3}{|c|}{ Large sawtimber } & \multicolumn{3}{|c|}{ Old growth } \\
\hline & $\bar{x}$ & $\min$ & $\max$ & $\bar{x}$ & $\min$ & $\max$ & $\bar{x}$ & $\min$ & $\max$ & $\bar{x}$ & $\min$ & $\max$ \\
\hline Occupied ${ }^{3}$ & $51.7 \mathrm{~A}$ & 2.5 & 100 & $12.1 \mathrm{~A}$ & 0 & 46.7 & $11.4 \mathrm{~A}$ & $\mathbf{0}$ & 55.4 & $24.7 \mathrm{~A}$ & $\mathbf{0}$ & 76.3 \\
\hline Detected & $57.8 \mathrm{AB}$ & 4.4 & 100 & $12.1 \mathrm{~A}$ & 0 & 51.5 & $10.3 \mathrm{AB}$ & $\mathbf{0}$ & 70.3 & $19.8 \mathrm{AB}$ & 0 & 73.9 \\
\hline Undetected & $72.4 \mathrm{~B}$ & 0 & 100 & $9.6 \mathrm{~A}$ & 0 & 61.7 & $6.4 \mathrm{~B}$ & 0 & 91.8 & $11.6 \mathrm{~B}$ & 0 & 54.2 \\
\hline
\end{tabular}

\footnotetext{
${ }^{1}$ Letters indicate results of pairuise comparisons among means; experiment-wise $P \leq 0.05$, using Tukey's test. Means with same letter (within columns) did not differ significantly.

${ }^{2}$ Forest cover map from Washington Department of Fish and Wildlife (Eby and Snyder 1990, Collins 1993).

3 Includes starus codes I, 2, and 3 from table 1.
} 
Table 11-Attributes of forest cover within 203-ha circles centered on Marbled Murrelet survey sites, western Washington

\begin{tabular}{|c|c|c|c|c|c|}
\hline \multirow[b]{2}{*}{ Site attribute } & \multicolumn{3}{|c|}{ Detection class } & \multirow{2}{*}{$\begin{array}{c}\text { Univariate } \\
\text { significance }^{1}\end{array}$} & \multirow{2}{*}{$\begin{array}{c}\text { Correlation with } \\
\text { discriminant function }\end{array}$} \\
\hline & Occupied & Detected & Undetected & & \\
\hline \multicolumn{6}{|l|}{ Old growth: } \\
\hline Proportion & 0.247 & 0.198 & 0.116 & 0 & 0.90 \\
\hline Mean patch size & 18.600 & 13.900 & 8.500 & 0 & 0.96 \\
\hline Mean shape index & 1.500 & 1.400 & 1.100 & 0 & 0.65 \\
\hline \multicolumn{6}{|l|}{ Large sawtimber: } \\
\hline Proportion & 0.115 & 0.103 & 0.064 & 0 & 0.73 \\
\hline Mean patch size (ha) & 4.100 & 3.800 & 4.100 & 0 & 0.58 \\
\hline Mean shape index & 1.300 & 1.200 & 1.000 & 0 & 0.69 \\
\hline \multicolumn{6}{|l|}{ Small sawtimber: } \\
\hline Proportion & 0.121 & 0.121 & 0.096 & 0 & 0.49 \\
\hline Other forest proportion ${ }^{2}$ & 0.517 & 0.578 & 0.723 & 0 & $-m^{2}$ \\
\hline Landscape pattern index & 0.413 & 0.062 & -0.419 & 0 & 0.76 \\
\hline Sample size & 69 & 108 & 84 & & \\
\hline
\end{tabular}

\footnotetext{
${ }^{1}$ Significance of univariate analysis of variance, based on transformed variables where appropriate.
}

${ }^{2}$ Variable was not included in the discriminant analysis.

type; as the amount increases, the values of the pattern indices increase. Therefore, using planned contrasts we found that mean patch size of old-growth $(t=4.67, P=$ $0.000)$ and large sawtimber $(t=3.03, P=0.003)$ was greater among occupied sites than among detected and undetected sites and that mean shape index was greater as well $(t=3.64, P=0.000$ for old growth; $t=4.24, P=0.000$ for large sawtimber).

To evaluate the relative contributions of the amounts of various forest cover classes and the pattern of those classes over the 203-ha landscapes, we used discriminant analysis to compare attributes among the three detection classes. For this analysis, we used all of the attributes listed in table 11 with the exception of proportion other forest (because all of the proportions sum to 1.00 within any 203-ha area, the proportion of other forest is directly implied by the sum of the remaining proportions). This analysis resulted in a single significant discriminant function (chi-square $=48.8, d f=16$, $P=0.000$ ); each detection class differed significantly from each of the other classes. The variables that best discriminated among the classes were old-growth proportion, landscape pattern index, old-growth patch size, large sawtimber proportion, and large sawtimber shape index (table 11). Although the average differences among the detection classes were significant, there was considerable overlap among the sites; $R^{2}$ was only 17.5 percent and only about 44 percent of the sites could be correctly classified based on the discriminant function (table 12).

\section{Discussion}

Landscape-level analysis of amount and configuration of forest vegetation can be a valuable tool for assessing the nesting habitat requirements of murrelets. However, the scale of analysis influenced our ability to predict occupancy in a given landscape. We found the forest-cover attributes within a 203-ha circular area surrounding each survey location were useful predictors of occupancy by the Marbled Murrelet. Both the amount and the pattern of various forest-cover classes differ among occupied, detected, and undetected 203-ha sites. Given the strong correlations among the forest pattern and amount attributes, the variables describing the amounts of the various cover classes are probably most useful in describing Marbled Murrelet habitat as it occurs in this sample from western Washington. Among the forestcover classes, old-growth cover, and to a lesser extent, large sawtimber, seem best to predict murrelet occupancy. Sites occupied by murrelets, as evidenced by nests or circling behavior, have a higher proportion of these mature forest classes than do non-occupied sites.

More definitive analyses must await completion of additional surveys. The present database is not the result of a survey designed to understand the statewide distribution of the species. Instead, it is heavily influenced by one intensive study (Hamer and Cummins 1990, 1991) and by sites selected at the location of proposed timber sales. Therefore, the set of survey sites we analyzed may be biased. Until more systematic 
Table 12-Predicted and observed classification of detection-status of Marbled Murrelet survey locations based on discriminant analysis using forest-cover attributes within 203-ha acres surrounding each site, western Washington

\begin{tabular}{|c|c|c|c|c|}
\hline \multirow[b]{2}{*}{ Actual status } & \multicolumn{3}{|c|}{ Predicted status (pct) ${ }^{1}$} & \multirow[b]{2}{*}{ Locations } \\
\hline & Occupied $^{2}$ & Detected & Undetected & \\
\hline Occupied ${ }^{2}$ & $7 t$ & 16 & 13 & 69 \\
\hline Detected & 49 & 21 & 30 & 108 \\
\hline Undetected & 29 & 19 & 52 & 44 \\
\hline
\end{tabular}

${ }^{1}$ Predicted from discriminant function (sec table $I I$ ).

${ }^{2}$ Includes status codes 1,2 , and 3 from table $I$.

surveys are completed, it will be difficult to judge the reliability of estimates of habitat selectivity.

Until such surveys are completed, we offer the following tentative guidelines. For purposes of identifying potential habitat, areas composed of at least 35 percent large sawtimber and old-growth forest (as classified by WDFW) are most likely to be occupied. Landscapes on the order of $200-300$ ha should be examined to determine proportion of potential habitat.

In evaluating areas of about $200 \mathrm{ha}$, we conclude that the amount and configuration of old-growth or large sawtimber forest (Eby and Snyder 1990) are important components of murrelet nesting requirements, as has been previously demonstrated in analyses at the stand (Hamer 1993) and the nest level (Hamer and Cummins 1991) in Washington. Quantifying the amount and pattern of late-seral forests in larger landscapes can help to determine areas that may be at risk to loss of suitable nesting habitat for murrelets. Further landscape analysis at a basin level between the small landscapes and broad river basins we used here may help to determine the appropriate configurations and amounts of nesting habitat necessary to support murrelets, assuming adequate surveying has been conducted. This information would be a useful component of local or regional conservation planning for the murrelet and other old-growth associated species.

\section{Acknowledgments}

This study would not have been possible without the full cooperation of the Washington Department of Fish and Wildlife and the Washington Department of Natural Resources. These organizations (and their cooperators) conducted the Marbled Murrelet surveys and developed the rangewide habitat maps that were the basis of our analyses. Tom Hamer, who collected much of this data, helped us assemble the information. Additional help was provided by Eric Cummins, William Ritchie, James Eby, Michelle Snyder, Doretta Collins, Steve Bernath, Randy Kreuziger, and Tom Owens. We thank Kurt Flather for assistance with DISPLAY software. We appreciate the helpful comments from Tom Hamer, Jeffrey Granier, David Hays, Kevin McKelvey, and Gordon Orions. This study was funded in part by the Ecosystem Processes Research Program and by the Ecological Framework for Management Research, Development and Application Program of the Pacific Northwest Research Station. We thank Kevin Peeler for assistance with GIS analysis and Janet Jones for help preparing the manuscript. 



\section{Chapter 19 \\ Marbled Murrelet Habitat Associations in Oregon}

\author{
Jeffrey J. Grenier ${ }^{1,2} \quad$ S. Kim Nelson ${ }^{1}$
}

\section{Study area}

Study sites were located in the Coast Range and Klamath Mountain (Siskiyou Mountains) Provinces in Oregon (Franklin and Dyrness 1973). These areas consisted of rugged, mountainous terrain, with steep slopes and deeply cut river and creek drainages. Elevations ranged from $50 \mathrm{~m}$ along the coast of Oregon, to more than $1200 \mathrm{~m}$ in the central mountains. The climate consists of cool, wet winters and warm, dry summers. Mean temperatures range from $0^{\circ} \mathrm{C}$ in winter to $24^{\circ} \mathrm{C}$ in summer, and annual precipitation varies from 150 to $300 \mathrm{~cm}$ (Franklin and Dymess 1973).

These areas are primarily forested, although they have been intensively managed for timber since the early $1900 \mathrm{~s}$, and many stands are $<200$ years old. In addition, natural and man-caused fires have altered many stands. Relatively small, isolated patches of mature and old-growth tree species remain. Douglas-fir (Pseudotsuga menziesii) was the dominant tree species in the north and mixed-evergreen species, including Douglas-fir and tanoak (Lithocarpus densiflorus), were dominant in the south.

\section{Methods}

Between 1990 and 1993, murrelets were surveyed on state and federal lands throughout the Coast Range and Siskiyou Mountains, primarily within $50 \mathrm{~km}$ of the coast. Surveys included intensive research surveys, and intensive and general surveys for agency monitoring projects. Forest stands were surveyed to existing protocols (Paton and others 1990, Ralph and Nelson 1992, Ralph and others 1993) and were classified as occupied (birds exhibiting nesting or below canopy activity), with murrelets present (presence), or without murrelets (undetected), based on murrelet behavior patterns. In addition, we searched for nests using three methods: watching murrelets land in trees, searching for eggshells on the forest floor, and climbing trees to examine branches for nest cups.

\section{Characteristics of Occupied Sites}

Four databases were examined. The characteristics of occupied sites were summarized using one state lands database from Oregon Department of Forestry (Reagan, pers. comm.), two U.S. Forest Service databases from the Siuslaw National Forest (McCain, pers. comm.; Wettstein, pers. comm.), and one research database from Oregon State University. Habitat variables differed among databases. Similar habitat variables were used in the analyses where possible. We used Spies and Franklin's (1991) definition for stand age (i.e., young stands $=40-80$ years, mature $=80-200$ years, and old growth $=200+$ years). Remnant trees were defined as those

\footnotetext{
${ }^{1}$ Research Wildlife Biologists, Oregon Cooperative Wildlife Research Unit, Oregon State University, Nash 104, Corvallis, OR 97331-3803

${ }_{2}^{2}$ Present address: 1402 Cedar Street, Philomath, OR 97370
} 
that survived recent fires and were $\geq 66 \mathrm{~cm}$ d.b.h., except in one Forest Service database where remnant trees were classified as $\geq 100 \mathrm{~cm}$ d.b.h..

\section{State Lands Database}

Data were compiled from Oregon Department of Forestry's (ODF) OSCUR Inventory System (Ownership, Soils, forest Cover, land $U$ se, and operation Rating). The OSCUR database was comprised of habitat variables collected between the mid-1970s and 1993 (appendix 1). ODF delineated and described habitat characteristics in forest sites through one of the following: (1) photographic interpretation; (2) stand examinations (fixed plot cruising, variable plot inventory, or timber sale appraisal); and (3) reconnaissance (walk-through) (ODF 1991). The OSCUR database included data from 6,409 sites. A site was defined as a uniform, homogeneous tree community that usually was a portion of a larger, contiguous, heterogeneous stand. Sites were characterized by approximately 160 habitat and geographic variables. In addition, comments from original data sheets were included to supplement data for some sites.

We selected 34 key habitat variables (appendix 2) and forest sites $\geq 40$ years old for analyses. Sites of this age were chosen because the youngest occupied site on state lands was classified as 42 years old (although the site included remnant old-growth trees). In addition, we were interested in examining differences of habitat characteristics between occupied and random sites within a sample universe of only suitable habitat i.e., sites containing large trees with adequate branch sizes and moss coverage to accommodate nesting (Grenier and Nelson 1994). Using maps and databases, we found that 72 occupied sites existed on ODF lands (Allen, pers. comm; Goggans, pers. comm.; Nelson 1990b; Nelson and Shaughnessy 1992; Platt and Goggans 1992; Shaughnessy and Nelson 1991). Characteristics of these 72 occupied sites were compared to a random sample of 216 sites of unknown murrelet status.

\section{National Forest Land Databases}

Vegetation Resource and Structure Examination Databases (VSE) - Older-aged forests or those with multiple canopy layers were monitered on the Siuslaw National Forest in 1990. These study sites were located in areas proposed for timber harvest and in Northern Spotted Owl (Strix occidentalis) Habitat Areas. In addition, Vegetation Resource Examinations (VRE) were conducted in 1991 and 1992 to ground truth satellite imagery of old-growth and mature forests with multi-layered canopies. Overlapping data from the two databases (1209 VRE and $1210 \mathrm{VSE}$ plots) were used for analyses. Forty-seven habitat variables were common to both databases (appendix 2). Data from 120 sites (Wettstein, pers. comm.), 30 occupied sites and 90 other sites of unknown murrelet status, were used for analyses.

Ecological Habitat Sampling-Ecologists at the Siuslaw National Forest collected habitat data in intensive and reconnaissance plots throughout the forest from 1981 to 1984 (Hemstrom and Logan 1986; USDA 1983, 1985). The database provided to us included 974 forested sites and 162 habitat variables (McCain, pers. comm.). We used ArcView (1992) to determine that 75 occupied sites overlapped with plots in this database. We selected 13 of the 162 habitat variables for our analyses (appendix 3 ). To be consistent with the ODF database, we used data from sites $\geq 40$ years old. The characteristics of the 75 occupied sites were compared with a random sample of 225 sites of unknown murrelet status.

\section{Research Database}

In 1992, 40 small ( $\leq 12 \mathrm{ha}$ ), isolated, mature and oldgrowth stands were selected (Nelson and Hardin 1993a). Using protocol surveys, we determined that 10 of these stands were occupied. Habitat characteristics were measured in two 25-m-radius circular plots randomly located within each of these stands. Variables included number of trees and snags by species, tree and snag diameter at breast height (d.b.h.), heights ( $m$ ) of five dominant conifers (measured by triangulation with a Suunto optical clinometer), height (m) and decay class of snags (Cline and others 1980), forest zone (Franklin and Dyrness 1973), ecozone (average precipitation levels), plant associations (Hemstrom and Logan 1986), number of canopy layers, canopy cover (visual estimate of percent crown closure), ground cover (percent and species composition), abundance of moss and dwarf-mistletoe (Arceuthobium sp.), number of suitable nest platforms ( $>18$ cm d.b.h., > $15 \mathrm{~m}$ height), slope (percent), aspect (degrees), position on slope (canyon bottom, lower $1 / 3$, middle $1 / 3$, upper $1 / 3$, ridgetop), distance to water $(m)$, and distance to opening ( $\mathrm{m}$; opening defined as road, river, clearcut, or vegetation type without trees but not forest gap). Calculations made from these data included density (number/ha) of trees ( $\geq 46$ and $\leq 80 \mathrm{~cm}$ d.b.h.) and dominant trees ( $\geq 81 \mathrm{~cm} \mathrm{d.b.h.),}$ mean diameter (d.b.h., $\mathrm{cm}$ ) of all trees and dominant trees, mean dominant tree height $(\mathrm{m})$, and tree species composition. Percent cover of epiphytes (moss and lichens) were recorded in four categories: (1) trace, (2) 1-33 percent, (3) 34-66 percent, (4) 67-100 percent. Average mistletoe infestation was calculated for each plot using an index of 0 to 6 developed by Hawksworth (1977). Distance inland $(\mathrm{km})$, latitude, elevation $(\mathrm{m})$, and stand size (ha) were determined from topographic maps $(1: 250,000)$ and aerial photos $(1: 1,000)$.

\section{Nest Site Characteristics}

Nests were located using ground-based and tree climbing techniques, most (15 of 22) in areas where likelihood of finding nests was considered to be high. Ground-based methods consisted of observing the flight of individual birds during dawn and dusk activity periods, and searching for eggshell fragments on the forest floor. Flight behaviors suggesting the presence of nesting birds (e.g., landing in or departing from trees and flying silently below the canopy) were identified at survey stations established in areas where 
potential nest trees were located or where general activity levels were high, and at previously unsurveyed sites. Eggshell searches were conducted around all trees where birds were observed landing or taking off, and around numerous other trees that had potential nest platforms (platforms $\geq 18 \mathrm{~cm}$ in diameter and $\geq 15 \mathrm{~m}$ above ground). When potential nest trees were found, surveys were conducted on 1 to 3 successive mornings to confirm the presence of an active nest and identify its location.

Nests located by tree climbing were found during an intensive tree climbing study at a single site or while reclimbing trees previously known to support nests (Nelson and others 1994a). The tree climbing study consisted of climbing all trees (Perry 1978) within a 40-m-radius plot and examining all platforms for nests. In addition, seven trees containing nests found between 1990 and 1992 were climbed in 1993 to determine if the nests had changed over time and to determine if nests or nest trees were reused.

Characteristics of nests and nest trees were measured at the 22 nest sites. Nest tree measurements included diameter at breast height (d.b.h., $\mathrm{cm}$ ), height (m), diameter at nest limb $(\mathrm{cm})$, and nest branch height $(\mathrm{m})$, diameter at the trunk and at the nest $(\mathrm{cm})$, branch length $(\mathrm{m})$, and position in crown (percent tree height). Nest measurements included distance from the trunk $(\mathrm{cm})$ and cup dimensions (cm). In addition, the moss depth adjacent to the nest $(\mathrm{cm})$, nest platform dimensions $(\mathrm{cm})$, and canopy closure above the nest (percent) were measured.

Micro-site habitat features of nest sites and 2 to 3 adjacent sites were measured at ten of the nests in 0.2-ha $(25-\mathrm{m}$ radius) plots (as described previously). Plots for nest sites were centered on the nest tree. Adjacent plots, centered around a dominant canopy-forming tree, were a minimum of $75 \mathrm{~m}$ from nest trees, and were located the same distance from forest edges as nest trees to minimize any edge biases. Micro-site habitat characteristics were compared between nest sites and adjacent sites within the same stand to determine if the location of nests was associated with specific microsite characteristics.

\section{Data Analyses}

\section{Occupied Sites and Habitat Associations}

We used the two-sample Kruskal-Wallis test (Zar 1984:138) to compare habitat characteristics of occupied sites to a random sample of other sites (with unknown murrelet status). The number of random sites selected equalled three times the number of occupied sites (Breslow and Day 1980:27; Ramsey, pers. comm.; Schafer, pers. comm.). The Chi-square goodness-of-fit test (Zar 1984) and Bonferroni Z-statistic (Byers and others 1984, Neu and others 1974) were used for categorical data.

Logistic regression was used to determine key habitat components of occupied and randóm sites for each database (Manly and others 1993, Ramsey and others 1994). The following two steps were used in our analyses: (1) habitat variables (continuous and categorical) were divided into groups of related variables that described one or two biological aspects of the site. Logistic regressi on was used to test statistical significance of each variab le within the group. (2) habitat variables that were statistica' lly significant within the groups $(P<0.05)$ were then used i1 1 the stepwise procedure to determine the final model. $\mathrm{V}$ ariables were excluded if $P>0.05$.

Logistic regression helps select a set if key habitat variables that represent the probability of $s$ ite occupancy. We chose to use logistic regression as a tool to identify key components of murrelet habitat, rather than ijetermining the predictive probabilities of the occupancy rat es of murrelets. This was due to: (1) the use of retrospective sa mpling (Flamsey and others 1994); (2) the limitations of the: databas,es (i.e., data were collected over many years so sa mpling methods and data collectors may have changed yei urly and. the data were not collected with the murrelet in $\mathrm{m}$ ind); and (3) the murrelet status of random sites was unkno wn.

\section{Nest Sites}

Habitat characteristics within nest pliots we re compared to average values for adjacent plots usirig a V Vilcoxon test (paired-sample signed-rank; Snedecor and Coch.an 1980:140). Each nest site was treated as a block, i and t'ne overall test statistic was based upon the cumulative differences among plots. A Chi-square test using a Bonfestoni، Z-statistic was used to compare snag decay class.

\section{Results}

\section{Occupied Site Characteristics}

\section{State Lands Database}

Tree Species-Douglas-fir was 'the dominant tree species (SPECIES1) in 67 percent of occupied sites ( $n=$ 72 ) and 83 percent of random sites $(n==2.16)$. The codominant trees (SPECIES2) were generally a cc in.bination of Douglasfir, western hemlock (Tsuga heteriophylla), Sitka spruce (Picea sitchensis), and red alder (Aln us oregona) in occupied and random sites.

Age, Tree Diameter, and Tre * Density-Twenty-two percent ( 16 of 72 ) of occupied sit es were $\leq 80$ years of age (AGE1993) whereas 60 percent (1 30 of 216) of random sites were $\leq 80$ years old. Ninety four $F$ sercent $(15$ of 16$)$ of these young occupied sites had remna nt trees (TPH66, $\geq 66 \mathrm{~cm}$ d.b.b.), averaging 19.5 trees/ha (range: $2.5-75.0$ trees/ha; s.e. $=5.0$ ), and 15 of these sit es contained mature trees (TPH46, $\geq 46 \mathrm{~cm}$ d.b.h.; $\bar{x}=73.1$ ) ; s.e. $=11.6$; range $=12.3$ 140.8). Random sites $\leq 80$ year $s$ of age averaged only 10 remnant trees/ha (s.e. $=1.4 ; \mathrm{r}$ ange $=2.5-59.3)($ table 1 , appendix 1). All occupied sites $\geq 81$ years old had remnant trees, averaging 46.9 trees/ha (range $=2.5-116.1$ trees/ha; s.e. $=2.8$ ). Similarly, 97 perce nt $(83$ of 86 ) of random sites $\geq 81$ years old had remnants ave sraging 45.9 trees/ha (range $=$ 2.4-79.0 trees/ha; s.e. $=2.3$ ).

Mistletoe, Platforms, and Moss Abundance-Variables in the database did not include inforrnation on nest platforms. 
Table 1-Habitat characteristics of 72 Marbled Murrelet occupied sites and 216 random sites on State Lands, Oregon. Data are from Oregon Department of Farestry's OSCUR database, 1993. See appendix 1 for variable definitions

\begin{tabular}{|c|c|c|c|c|c|c|c|}
\hline \multirow[b]{2}{*}{ Variable } & \multicolumn{3}{|c|}{ Occupied } & \multicolumn{3}{|c|}{ Random } & \multirow[b]{2}{*}{$P$-value ${ }^{l}$} \\
\hline & $\bar{x}$ & $\begin{array}{c}\text { (s.e.) } \\
\text { Range }\end{array}$ & $n$ & $\bar{x}$ & $\begin{array}{c}\text { (s.e.) } \\
\text { Range }\end{array}$ & $n$ & \\
\hline DBHI & 60.7 & $\begin{array}{r}(3.10) \\
23-142 \\
\end{array}$ & 72 & 44.7 & $\begin{array}{l}(1.30) \\
18-130\end{array}$ & 203 & 0.0001 \\
\hline $\mathrm{BAl}$ & 35.8 & $\begin{array}{c}(1.95) \\
9-91\end{array}$ & 72 & 33.3 & $\begin{array}{c}(0.99) \\
4-84\end{array}$ & 200 & 0.3163 \\
\hline $\mathrm{MBFACl}$ & 237.7 & $\begin{array}{r}(15.56) \\
52-734 \\
\end{array}$ & 72 & 173.1 & $\begin{array}{l}(7.23) \\
6-548\end{array}$ & 200 & 0.0001 \\
\hline DBH2 & 59.2 & $\begin{array}{c}(4.65) \\
18-178\end{array}$ & 62 & 40.4 & $\begin{array}{c}(1.63) \\
15-122\end{array}$ & 153 & 0.0001 \\
\hline$B A 2$ & 10.2 & $\begin{array}{c}(1.04) \\
0-38\end{array}$ & 62 & 8.3 & $\begin{array}{c}(0.46) \\
0-35\end{array}$ & 153 & 0.0554 \\
\hline MBFAC2 & 65.8 & $\begin{array}{l}(7.05) \\
6-274\end{array}$ & 59 & 37.9 & $\begin{array}{l}(2.04) \\
6-122\end{array}$ & 147 & 0.0002 \\
\hline DBH3 & 48.0 & $\begin{array}{l}(2.59) \\
23-97 \\
\end{array}$ & 46 & 46.7 & $\begin{array}{l}(2.06) \\
15-104\end{array}$ & 82 & 0.0448 \\
\hline $13 A 3$ & 6.0 & $\begin{array}{l}(0.76) \\
1-24\end{array}$ & 46 & 5.8 & $\begin{array}{c}(0.54) \\
0-22\end{array}$ & 82 & 0.6478 \\
\hline M 1 BFZC3 & 29.7 & $\begin{array}{c}(3.73) \\
6-99 \\
\end{array}$ & 45 & 26.8 & $\begin{array}{c}(2.68) \\
6-99\end{array}$ & 67 & 0.3677 \\
\hline DI 3 H4 & 38.6 & $\begin{array}{l}(2.34) \\
23-84\end{array}$ & 30 & 35.1 & $\begin{array}{l}(1.78) \\
15-64\end{array}$ & 42 & 0.0351 \\
\hline $\mathrm{BA} 4$ & 7.7 & $\begin{array}{l}(1.21) \\
1-21 \\
\end{array}$ & 30 & 6.4 & $\begin{array}{c}(1.08) \\
0-30\end{array}$ & 42 & 0.1695 \\
\hline MB FAC4 & 38.5 & $\begin{array}{l}(6.29) \\
6-128\end{array}$ & 28 & 26.2 & $\begin{array}{l}(5.42) \\
6-157\end{array}$ & 36 & 0.0980 \\
\hline TPE & 89.0 & $\begin{array}{l}(15.47) \\
17-410\end{array}$ & 29 & 134.4 & $\begin{array}{r}(9.88) \\
12-645 \\
\end{array}$ & 116 & 0.0260 \\
\hline 1 PH 20 & 50.7 & $\begin{array}{c}(5.73) \\
12-153\end{array}$ & 39 & 112.7 & $\begin{array}{l}(6.52) \\
5-432\end{array}$ & 141 & 0.0001 \\
\hline TI'H:S & 44.0 & $\begin{array}{l}(5.76) \\
7.131\end{array}$ & 35 & 68.4 & $\begin{array}{l}(4.55) \\
7-334\end{array}$ & 158 & 0.0044 \\
\hline TPI 130 & 37.8 & $\begin{array}{l}(4.13) \\
5-138\end{array}$ & 52 & 53.3 & $\begin{array}{l}(3.56) \\
5.247\end{array}$ & 164 & 0.0067 \\
\hline TPH 36 & 48.9 & $\begin{array}{r}(5.76) \\
2-220 \\
\end{array}$ & 62 & 67.0 & $\begin{array}{l}(3.53) \\
2-230 \\
\end{array}$ & 177 & 0.0018 \\
\hline TPH4 6 & 56.1 & $\begin{array}{l}(5.04) \\
2-183\end{array}$ & 70 & 48.4 & $\begin{array}{l}(2.84) \\
2-277\end{array}$ & 174 & 0.2189 \\
\hline TPH66 & 41.0 & $\begin{array}{l}(2.79) \\
2-116 \\
\end{array}$ & 71 & 30.1 & $\begin{array}{c}(1.93) \\
2-79 \\
\end{array}$ & 114 & 0.0010 \\
\hline AGE199: 3 & 105.1 & $\begin{array}{c}(3.83) \\
42-213\end{array}$ & 72 & 75.9 & $\begin{array}{c}(1.72) \\
40-140\end{array}$ & 216 & 0.0001 \\
\hline $\mathrm{CDBH}$ & 55.1 & $\begin{array}{c}(2.01) \\
25-112 \\
\end{array}$ & 72 & 44.2 & $\begin{array}{c}(1.09) \\
20-112 \\
\end{array}$ & 210 & 0.0001 \\
\hline HDBH & 37.6 & $\begin{array}{l}(1.37) \\
18-58\end{array}$ & 46 & 33.8 & $\begin{array}{l}(0.71) \\
15-61\end{array}$ & 125 & 0.0005 \\
\hline CTPH & 248.3 & $\begin{array}{l}(21.79) \\
12-961\end{array}$ & 72 & 313.1 & $\begin{array}{l}(16.09) \\
10-1260 \\
\end{array}$ & 210 & 0.0616 \\
\hline HTPH & 99.3 & $\begin{array}{c}(12.31) \\
7-366\end{array}$ & 46 & 163.6 & $\begin{array}{c}(14.08) \\
5-783\end{array}$ & 125 & 0.0208 \\
\hline CBA & 45.7 & $\begin{array}{l}(2.25) \\
12-100\end{array}$ & 72 & 35.6 & $\begin{array}{l}(1.08) \\
1-92\end{array}$ & 210 & 0.0002 \\
\hline HBA & 9.5 & $\begin{array}{c}(1.01) \\
1-24\end{array}$ & 46 & 11.6 & $\begin{array}{c}(0.79) \\
0-54\end{array}$ & 125 & 0.3464 \\
\hline CMBFAC & 297.2 & $\begin{array}{l}(16.96) \\
58-752\end{array}$ & 72 & 188.2 & $\begin{array}{l}(7.87) \\
6-594 \\
\end{array}$ & 196 & 0.0001 \\
\hline HMBF.AC & 46.6 & $\begin{array}{l}(5.36) \\
6-128 \\
\end{array}$ & 44 & 46.6 & $\begin{array}{l}(3.03) \\
6-157\end{array}$ & 113 & 0.9120 \\
\hline
\end{tabular}

${ }^{1}$ Significant , difference between occupied and random sites $(P<0.05$, Kruskal-Wallis test) 
However, data concerning tree damage or abnormalities were collected and may indicate presence of nesting platforms. Sixty-three percent ( 45 of 72 ) of the occupied sites had tree damage or abnormalities, 33 percent (15 of 45) of which included mistletoe infestations. Damage or abnormalities observed in random sites was similar (59 percent; 128 of 216 trees), however mistletoe infestation was less common in random sites (12 percent; 15 of 128 trees).

\section{National Forest Land Databases}

Vegetation Resources and Structure Examination Databases-Douglas-fir was the most common dominant tree in occupied and random sites. However, western red cedar (RC_DBH3, Thuja plicata), which occurred in approximately 33 percent of occupied sites, had the largest mean diameter $(\bar{x}=114.3 \mathrm{~cm}$, s.e. $=6.65, n=10$ ). Occupied sites had an average of 13.4 remnant trees/ha (REM, trees $\geq 100 \mathrm{~cm}$ d.b.h.), and 63.7 percent canopy closure (table 2, appendix 2).

Ecology Databases-Occupied sites were mid-seral stage stands with large tall conifer trees (table 3, appendix 3). Most (75 percent) occupied sites were located in western hemlock climax forest types. The most common (17 percent; 13 of 75) plant association in occupied sites was western hemlock/Oregon oxalis (Oxalis oregona). This plant association only occurred in 5 percent (11 of 225) of random sites, and the frequency of occurrence was significantly less than in occupied sites $\left(\chi^{2}=30.2, d f=9\right.$, $P=0.0004$ ). The most frequently occurring plant association in random sites was western hemlock/vine maple (Acer circinatum)/western swordfern (Polystichum munitum) (12 percent; 27 of 225). The western hemlock/Oregon oxalis sites occur on moist, shaded upper slopes and benches or alluvial terraces and have high conifer basal area $\left(79.7 \mathrm{~m}^{2} /\right.$ ha, s.e. $=4.6, n=9$ compared to $71.0 \mathrm{~m}^{2} /$ ha average for 22 plant associations, s.e. $=2.0, n=178$; Hemstrom and Logan 1986).

\section{Research Database}

Ten occupied sites from this study were located in the western hemlock $(n=6)$ and Sitka spruce $(n=4)$ Zones (Franklin and Dymess 1973), and included one or more of the following plant associations: vine maple $(n=4)$, salal (Gaultheria shallon) $(n=3)$, sword fern $(n=5)$, salmonberry (Rubus spectabilis) $(n=2)$, Pacific rhododendron (Rhododendron macrophyllum) $(n=1)$, and Oregon grape (Berberis aquifolium $)(n=2)$. All sites had two or more canopy layers ( $\bar{x}=2.2$, s.e. $=0.1$ ), were located between middle of the slope and the ridgetop, had $>25$ percent moss $(\bar{x}$ index $=$ 3.8 , s.e. $=0.2$ ), contained some mistletoe or witches brooms ( $\bar{x}$ index $=2.2$, s.e. $=0.3$ ), and had platforms for nesting ( $\bar{x}$ $=1.3$ per plot, s.e. $=0.3$ ) (table 4$)$. The number of suitable platforms was correlated with the number of canopy layers $(r=0.39, P=0.02, n=34)$ and with mistletoe abundance $(r$ $=0.43, P=0.01, n=34$ ).

\section{Habitat Associations}

\section{State Lands}

Twenty-one of 34 habitat variables were significantly different between occupied $(n=72)$ and random $(n=216)$ sites $(P<0.05)$ (table 1$)$. In general, occupied sites were older (AGE1993), contained larger diameter conifers (DBH l4, CDBH, CBA) and hardwoods (HDBH), had more large remnant trees/ha (TPH66), and had fewer small/mediumsized trees (TPH15-36) and hardwoods/ha (HTPH) than random sites (table 1, appendix I).

Stepwise logistic regression suggested a model with only large remnant tree density (TPH66) as a significant predictor of murrelet habitat ( $P=0.0164 ; n=46$ occupied and 80 random sites). It was estimated that the odds of use were 4.9 percent higher for each unit increase in large remnant tree density $(95$ percent Confidence Interval $[\mathrm{CT}]=0.8$ percent to 9.1 percent; s.e. $=0.02$ ).

\section{National Forest Land Databases}

Vegetation Resources and Structure ExaminationsSeven variables differed $(P<0.05)$ between occupied $(n=$ $30)$ and random $(n=90)$ sites. Occupied sites had less slope, less canopy closure (CC), more large Douglas-fir/ha (DF_TPH3), larger midstory western hemlocks (WH_DBH1) and western redcedars (RC_DBH1, RC_DBH2), and fewer shade tolerant trees/ha $\geq 41 \mathrm{~cm}$ (STH_40) than random sites (table 2, appendix 2).

Stepwise logistic regression suggested a model with larger diameters of midstory western redcedar (RC_DBH1) and less canopy closure (CC) as significant predictors of murrelet habitat. It was estimated that the odds of use were 48.3 percent higher for each unit increase in diameter of midstory western red cedar $(95$ percent $\mathrm{CI}=9.1$ percent to 100 percent; s.e. $=0.1565, n=12$ occupied and 28 random sites). Also, it was estimated that the odds of use were 16.5 percent higher for each unit decrease in canopy closure when comparing occupied to random sites $(95$ percent $\mathrm{CI}=$ 2.8 percent to 32.1 percent; s.e. $=0.064$ ) .

Ecology-Four habitat variables were significantly different $(P<0.05)$ between occupied $(n=75)$ and random sites $(n=225)$. Occupied sites were in later seral stage classes (SERAL), and had taller (HT), older (AGE), and larger diameter trees (DIA) than random sites (table 3, appendix 3).

Stepwise logistic regression suggested a model with tree height (HT) and percent cover of understory trees (TREER) as significant predictors of murrelet habitat. It estimated that the odds of use were 2.3 percent higher for every unit increase in tree height $(95$ percent $\mathrm{CI}=0.8$ percent to 3.7 percent; s.e. $=0.0022 ; n=34$ occupied and 86 random). Also the odds of use were 4.3 percent higher for every unit increase in percent cover of understory trees $(95$ percent $\mathrm{CI}=0.3$ percent to 8.5 percent; s.e. $=0.0202$ ). 
Table 2-Habitat characteristics of 30 Marbled Murrelet occupied sites and 90 random sites on the Siuslaw National Forest, Oregon, 1990-1992. Data are from forest stand inventories (Vegetation Structure and Vegetation Resource Examination). See appendix 2 for variable definitions

\begin{tabular}{|c|c|c|c|c|c|c|c|}
\hline \multirow[b]{2}{*}{ Variable } & \multicolumn{3}{|c|}{ Occupied } & \multicolumn{3}{|c|}{ Random } & \multirow[b]{2}{*}{$P$-value } \\
\hline & $\bar{x}$ & $\begin{array}{c}\text { (s.e.) } \\
\text { Range }\end{array}$ & $n$ & $\bar{x}$ & $\begin{array}{c}\text { (s.e.) } \\
\text { Range }\end{array}$ & $n$ & \\
\hline SLOPE & $35.1)$ & $\begin{array}{c}(3.63) \\
7.80\end{array}$ & 30 & 47.2 & $\begin{array}{c}(2.39) \\
5-90\end{array}$ & 90 & 0.0053 \\
\hline ELEV & 255.0 & $\begin{array}{c}(18.68) \\
122-488\end{array}$ & 30 & 268.5 & $\begin{array}{l}(15.79) \\
91-823\end{array}$ & 89 & 0.9606 \\
\hline REM & 13.4 & $\begin{array}{c}(3.87) \\
1-64\end{array}$ & 16 & 10.4 & $\begin{array}{c}(2.42) \\
1-58\end{array}$ & 29 & 0.2626 \\
\hline $\mathrm{CC}$ & 63.7 & $\begin{array}{l}(3.20) \\
16-83\end{array}$ & 30 & 76.1 & $\begin{array}{l}(1.16) \\
36-94\end{array}$ & 90 & 0.0004 \\
\hline C_HT & 55.4 & $\begin{array}{r}(1.53) \\
37-69 \\
\end{array}$ & 30 & 55.7 & $\begin{array}{l}(0.85) \\
35-72\end{array}$ & 90 & 0.9999 \\
\hline DF_DBH3 & 88.4 & $\begin{array}{c}(3.12) \\
41-122\end{array}$ & 29 & 94.7 & $\begin{array}{c}(2.18) \\
64-160\end{array}$ & 84 & 0.3472 \\
\hline DF_DBH2 & 57.7 & $\begin{array}{l}(3.63) \\
33-99\end{array}$ & 23 & 58.2 & $\begin{array}{r}(4.17) \\
25-185\end{array}$ & 49 & 0.4253 \\
\hline DF_DBHI & 27.9 & $\begin{array}{l}(2.46) \\
17-46\end{array}$ & 10 & 30.7 & $\begin{array}{c}(4.01) \\
13-137\end{array}$ & 31 & 0.6054 \\
\hline DF TPH3 & 66.0 & $\begin{array}{c}(8.70) \\
11-224\end{array}$ & 29 & 45.0 & $\begin{array}{l}(3.34) \\
2-128\end{array}$ & 84 & 0.0267 \\
\hline DF_TPH2 & 17.8 & $\begin{array}{c}(4.08) \\
1-69\end{array}$ & 23 & 16.8 & $\begin{array}{c}(1.66) \\
0-43\end{array}$ & 49 & 0.4249 \\
\hline DF_TPHI & 22.2 & $\begin{array}{c}(10.28) \\
5.114\end{array}$ & 10 & 16.3 & $\begin{array}{c}(2.30) \\
2-56\end{array}$ & 31 & 0.8021 \\
\hline WH_DBH3 & 74.9 & $\begin{array}{l}(2.95) \\
61.90\end{array}$ & 14 & 76.2 & $\begin{array}{c}(1.93) \\
51-107\end{array}$ & 53 & 0.7991 \\
\hline WH_DBH2 & 52.6 & $\begin{array}{l}(4.09) \\
26-94\end{array}$ & 19 & 45.0 & $\begin{array}{l}(1.52) \\
25-94\end{array}$ & 55 & 0.1090 \\
\hline WH_DBHI & 31.5 & $\begin{array}{l}(3.25) \\
19-61\end{array}$ & 15 & 23.4 & $\begin{array}{l}(1.14) \\
13-56\end{array}$ & 53 & 0.0021 \\
\hline WH TPH3 & 37.8 & $\begin{array}{c}(11.19) \\
2-115\end{array}$ & 14 & 44.0 & $\begin{array}{l}(5.14) \\
2-162\end{array}$ & 53 & 0.3468 \\
\hline WH_TPH2 & 25.0 & $\begin{array}{c}(4.94) \\
2-79\end{array}$ & 19 & 39.0 & $\begin{array}{l}(4.25) \\
3-136\end{array}$ & 56 & 0.1038 \\
\hline WH_TPHI & 42.7 & $\begin{array}{l}(9.29) \\
4-130\end{array}$ & 15 & 52.4 & $\begin{array}{l}(6.25) \\
3-185\end{array}$ & 53 & 0.5483 \\
\hline RC_DBH3 & 114.3 & $\begin{array}{c}(6.65) \\
82-150\end{array}$ & 10 & 105.2 & $\begin{array}{l}(7.62) \\
5-211\end{array}$ & 34 & 0.2263 \\
\hline RC DBH2 & 72.6 & $\begin{array}{r}(3.99) \\
58-105\end{array}$ & 12 & 59.7 & $\begin{array}{l}(4.80) \\
8-156\end{array}$ & 32 & 0.0081 \\
\hline RC_DBHI & 39.9 & $\begin{array}{l}(4.01) \\
23-71\end{array}$ & 13 & 26.7 & $\begin{array}{c}(1.80) \\
3-56\end{array}$ & 29 & 0.0031 \\
\hline RC_TPH3 & 3.5 & $\begin{array}{c}(1.38) \\
0-15\end{array}$ & 10 & 5.4 & $\begin{array}{c}(1.26) \\
1-28\end{array}$ & 23 & 0.1265 \\
\hline RC_TPH2 & 10.6 & $\begin{array}{c}(1.85) \\
2-27\end{array}$ & 12 & 17.3 & $\begin{array}{c}(1.16) \\
2-69\end{array}$ & 32 & 0.2626 \\
\hline RC_TPH I & 27.4 & $\begin{array}{c}(7.41) \\
2-94\end{array}$ & 13 & 25.0 & $\begin{array}{l}(3.83) \\
4-113\end{array}$ & 31 & 0.9384 \\
\hline DF_81 & 27.9 & $\begin{array}{c}(2.82) \\
3-57\end{array}$ & 30 & 23.0 & $\begin{array}{l}(1.70) \\
1-66\end{array}$ & 82 & 0.1046 \\
\hline STH_40 & 47.4 & $\begin{array}{r}(8.10) \\
1.149 \\
\end{array}$ & 26 & 67.5 & $\begin{array}{l}(5.14) \\
1-194 \\
\end{array}$ & 69 & 0.0270 \\
\hline
\end{tabular}

'Significant difference between occupied and random sites $(P<0.05$, Kruskal-Wallis test $)$ 
Table 3-Habilat characteristics of 75 Marbled Murrelet occupied sises and 225 random sites on the Siuslaw National Forest, Oregon, 1981-1984. Data are from the Ecology Program Intensive and Reconnisance Plots database, 1993. See appendix 3 for variable definitions

\begin{tabular}{|c|c|c|c|c|c|c|c|}
\hline \multirow[b]{2}{*}{ Variable } & \multicolumn{3}{|c|}{ Occupied } & \multicolumn{3}{|c|}{ Random } & \multirow[b]{2}{*}{$P$-value } \\
\hline & $\bar{x}$ & $\begin{array}{l}\text { (s.e.) } \\
\text { Range }\end{array}$ & $n$ & $\bar{x}$ & $\begin{array}{c}\text { (s.e.) } \\
\text { Range }\end{array}$ & $n$ & \\
\hline ELEV & 243.3 & $\begin{array}{c}(15.25) \\
9-604\end{array}$ & 75 & 293.2 & $\begin{array}{l}(11.26) \\
6-1067\end{array}$ & 225 & 0.0650 \\
\hline ASPECT & 198.4 & $\begin{array}{c}(12.06) \\
6-358\end{array}$ & 75 & 194.1 & $\begin{array}{l}(6.86) \\
0-361\end{array}$ & 225 & 0.6602 \\
\hline SLOPE & 125 & $\begin{array}{l}(2.52) \\
3.85\end{array}$ & 73 & 45.8 & $\begin{array}{l}(1.59) \\
2-92\end{array}$ & 224 & 0.2788 \\
\hline TREER & 9.5 & $\begin{array}{c}(2.37) \\
1-75\end{array}$ & 50 & 4.7 & $\begin{array}{c}(0.60) \\
1-35\end{array}$ & 126 & 0.1737 \\
\hline SHRLBH & 41.2 & $\begin{array}{l}13.58 \\
1.95\end{array}$ & 75 & $5: 5$ & $\begin{array}{l}2.07) \\
1.99\end{array}$ & 220 & 00519 \\
\hline HERB & 528 & $\begin{array}{c}(4.02) \\
3-99\end{array}$ & 60 & 45.7 & $\begin{array}{c}(2.28) \\
1-98\end{array}$ & 181 & 0.0972 \\
\hline MOSS & 22.2 & $\begin{array}{l}(286) \\
2-95\end{array}$ & 63 & 19.8 & $\begin{array}{l}|1.67| \\
1.90\end{array}$ & 185 & 0.1121 \\
\hline SERAL & 2.9 & $\begin{array}{c}(0.07) \\
2-4\end{array}$ & 75 & 2.7 & $\begin{array}{c}(0.04) \\
2-5\end{array}$ & 218 & 0.0414 \\
\hline IBAL & 72.6 & $\begin{array}{l}(3.93) \\
9-156\end{array}$ & 57 & 683 & $\begin{array}{l}2.0^{-7} \\
14-134\end{array}$ & 169 & 03299 \\
\hline TBAD & 17.8 & $\begin{array}{c}(1.69) \\
9-46\end{array}$ & 34 & 173 & $\begin{array}{c}(1.10) \\
0-64\end{array}$ & 103 & 0.5677 \\
\hline DLA & 1172 & $\begin{array}{l}1+75 \\
58-208\end{array}$ & 57 & 101.1 & $\begin{array}{l}(2-37) \\
30-216\end{array}$ & 172 & $0.01+6$ \\
\hline HT & 57.5 & $\begin{array}{l}(1.17) \\
3+79\end{array}$ & 56 & 52.4 & $\begin{array}{l}(0.85) \\
18-79\end{array}$ & 172 & 0.0049 \\
\hline $\mathrm{AGE}$ & 147.7 & $\begin{array}{l}(1231) \\
53-486\end{array}$ & 57 & 1125 & $\begin{array}{l}(+23) \\
40-400\end{array}$ & 172 & 00035 \\
\hline
\end{tabular}

${ }^{1}$ Significant difference between occupied and random sites $(P<0.05$, Kruskal-Wallis test)

\section{Nest Sites}

Twenty-two nests were found between 1990 and 1993. Ten nests were located by observing adult Marbled Murrelets landing in or departing from a nest tree, three were found after finding eggshell fragments on the forest floor, six were located during the intensive tree climbing study, and three were found while reclimbing known nest trees. Overall, nine nests were confirmed active when discovered (Nelson and Peck, in press). Of these, four were in the egg stage and five were in the nestling stage. Nestlings were thought to have fledged from three of these nests (see Nelson and Hamer, this volume a; Nelson and Peck, in press).

\section{Nest and Nest Tree Characteristics}

All nests were located in trees $\geq 127 \mathrm{~cm}$ in d.b.h. $(\bar{x}=$ 187.9 , s.e. $=9.4)$ and $\geq 36 \mathrm{~m}$ tall $(\bar{x}=65.5$, s.e. $=2.4$; rable 5). Twenty nests were found in Douglas-fir, one was found in a Sitka spruce, and one was found in a western hemlock. Nests generally consisted of depressions in a moss mat (average moss depth $=5.3 \mathrm{~cm}$ ), but compacted duff (needles, lichen, debris) substrates were also used. Nest cups averaged $12.0 \times 11.1 \mathrm{~cm}$ (length $\mathrm{x}$ width) and were located on platforms considerably larger than the nest $(\bar{x}=42.2 \times 31.7 \mathrm{~cm}$, s.e. $=$ 4.2 and 2.9 , respectively). The placement of nests on nest branches was variable, ranging from 1 to $762 \mathrm{~cm}$ from the trunk of the tree $(\bar{x}=101.3$, s.e. $=35.7)$. The nest in the Sitka spruce was furthest from the tree trunk (at $762 \mathrm{~cm}$ ); all other nests were located $\leq 230 \mathrm{~cm}$ from the trunk. Nest height ranged from 18 to $73 \mathrm{~m}$ above the ground $(\bar{x}=50.3$, s.e. $=2.4$; table 5 ).

\section{Nest Stand Characteristics}

Nest stands generally consisted of 2 to 3 canopy layers $(\bar{x}=2.2$, s.e. $=0.09, n=10$ ). Trees $\leq 45 \mathrm{~cm} \mathrm{d.b.h.} \mathrm{were} \mathrm{most}$ numerous ( 94.3 trees $/ \mathrm{ha}$ ), followed by trees $\geq 81 \mathrm{~cm}$ d.b.h., and trees $46-80 \mathrm{~cm}$ d.b.h. (64.3 and 39.7 trees/ha) (table 6). There were $7.1($ s.e. $=1.7)$ standing snags/ha in nest stands, with a mean height of $15.5 \mathrm{~m}($ s.e. $=2.1)$ and mean d.b.h. of 
Table \&-Overall habitat characteristics of occupied stands, Oregon Coast Range, 1992

\begin{tabular}{|c|c|c|c|c|}
\hline Characteristics & $\bar{x}$ & s.e. & Range & $n$ \\
\hline Stand size (ha) & 6.5 & 1.1 & $2.0-12.1$ & 10 \\
\hline Elevation (m) & 298.8 & 56.6 & $61-610$ & 10 \\
\hline Distance inland $(\mathrm{km})$ & 15.9 & 3.5 & $2.3-33.0$ & 10 \\
\hline Distance to stream (m) & 310.0 & 98.3 & $0-1000$ & 10 \\
\hline Aspect $\left(^{\circ}\right)$ & 194.3 & 15.7 & $65-328$ & 20 \\
\hline Slope (pct) & 53.7 & 7.0 & $3-126$ & 20 \\
\hline Position on slope' & 3.9 & 0.2 & $2-5$ & 20 \\
\hline Canopy closure (pct) & 48.9 & 4.3 & $13-83$ & 20 \\
\hline Canopy height (m) & 56.9 & 3.4 & $32-88$ & 20 \\
\hline Canopy layers (no.) & 2.2 & 0.1 & $2-3$ & 20 \\
\hline Number of platforms & 1.3 & 0.3 & $0-5$ & 20 \\
\hline Moss index ${ }^{2}$ & 3.8 & 0.2 & $3-5$ & 20 \\
\hline Mistletoe index ${ }^{3}$ & 2.2 & 0.3 & $1-5$ & 20 \\
\hline Tree d.b.h. (cm) & 43.8 & 0.9 & $10-206$ & 1374 \\
\hline Tree d.b.h. $\geq 46 \mathrm{~cm}$ & 80.6 & 1.3 & $46-206$ & 518 \\
\hline Tree d.b.h. $\geq 81 \mathrm{~cm}$ & 109.3 & 1.7 & $81-206$ & 208 \\
\hline Tree density (no./ha) & 349.8 & 24.1 & $208.8-565.2$ & 20 \\
\hline Tree density $\geq 46 \mathrm{~cm}$ (no./ha) & 131.9 & 15.0 & $10.2-269.9$ & 20 \\
\hline Tree density $\geq 81 \mathrm{~cm}$ (no./ha) & 55.7 & 6.8 & $15.3-127.3$ & 19 \\
\hline Snag d.b.h. (cm) & 57.8 & 2.7 & $10.5-187.0$ & 212 \\
\hline Snag density (no./ha) & 54.0 & 9.3 & $5.1-142.6$ & 20 \\
\hline Tree basal area $\left(\mathrm{m}^{2} / \mathrm{ha}\right)$ & 56.3 & 5.2 & $12.6-86.3$ & 20 \\
\hline Tree basal area $Z 46 \mathrm{~cm}\left(\mathrm{~m}^{2} / \mathrm{ha}\right)$ & 69.9 & 5.9 & $4.6-111.5$ & 20 \\
\hline Tree basal area $\geq 81 \mathrm{~cm}\left(\mathrm{~m}^{2} / \mathrm{ha}\right)$ & 53.1 & 7.0 & $8.0-101.1$ & 19 \\
\hline Snag basal area $\left(\mathrm{m}^{2} / \mathrm{ha}\right)$ & 16.8 & 4.3 & $0.5-66.8$ & 20 \\
\hline
\end{tabular}

\footnotetext{
1 Position on Slope: $1=$ canyon bottom, $2=$ lower $1 / 3,3=$ middle $1 / 3,4=$ upper $1 / 3,5=$ ridge top.

${ }^{2}$ Moss Index: $0=$ none, 1 = trace, $2=1-24$ percent, $3=25-49$ percent, $4=50-100$ percent.

${ }^{3}$ Mistletoe Abundance: Divide tree into thirds. Rate each section; 0 for no mistletoe, 1 if less than $1 / 3$ of branches are infected, and 2 if more than $1 / 3$ are infected. Score range is $0-6$.
}

$81.4 \mathrm{~cm}($ s.e. $=7.4)$. Mistletoe and witches brooms were found on dominant trees in most stands. Nests were located between 1.6 and $40 \mathrm{~km}$ from the ocean.

Three habitat variables at 10 nest sites differed from adjacent plots (table 6 ). The density of live trees in the largest size class (d.b.h. $\geq 81 \mathrm{~cm}$ ) was greater in adjacent plots than in nest plots (64.3 versus 43.3 trees/ha; $P=0.03$ ). Snag height was greater and snags were less decayed in adjacent plots compared with nest plots $(15.5$ versus $7.5 \mathrm{~m}$; $P=0.03 ; 3.3$ versus $3.7 ; P<0.001$, respectively). In addition, canopy closure was marginally greater in adjacent plots than nest plots (61.3 percent versus 41.2 percent, $P=0.06$ ).

\section{Discussion}

\section{Occupied Sites}

In Oregon, sites occupied by Marbled Murrelets were characterized by large diameter conifers and hardwoods, tall trees, high densities of dominant trees, and low densities for small diameter trees (conifers and hardwoods combined). In addition, these sites were older, located on gentler slopes, and had less percent canopy cover than random sites. Important habitat components for predicting occupancy were height and density of dominant trees, diameter and percent cover of midstory and understory conifers, and canopy cover. 


\begin{tabular}{|c|c|c|c|c|}
\hline Characteristic & $\bar{x}$ & s.e. & Range & $n^{1}$ \\
\hline \multicolumn{5}{|l|}{ Nest tree } \\
\hline D.b.h. $(\mathrm{cm})$ & 187.9 & 9.4 & $127-279$ & 19 \\
\hline Diameter at nest limb $(\mathrm{cm})$ & 80.1 & 6.2 & $36-122$ & 15 \\
\hline Height (m) & 65.5 & 2.4 & $36-85$ & 19 \\
\hline \multicolumn{5}{|l|}{ Nest branch } \\
\hline Height (m) 、 & 50.3 & 2.4 & $18-73$ & 21 \\
\hline Diameter at trunk $(\mathrm{cm})$ & 31.1 & 2.6 & $15-56$ & 19 \\
\hline Diameter at nest (cm) & 29.4 & 2.7 & $10-50$ & 20 \\
\hline $\begin{array}{l}\text { Position in crown (pct.) } \\
\text { (nest ht/tree ht) }\end{array}$ & 74.7 & 2.6 & $50-9221$ & \\
\hline Length $(m)$ & 5.1 & 0.7 & $1-12$ & 17 \\
\hline \multicolumn{5}{|l|}{ Distance from trunk to nesi } \\
\hline & $\begin{array}{l}101.3 \\
(68.2)^{2}\end{array}$ & $\begin{array}{c}35.7 \\
(14.2)\end{array}$ & $\begin{array}{c}1-762 \\
(1-230)\end{array}$ & $\begin{array}{l}21 \\
(20)\end{array}$ \\
\hline \multicolumn{5}{|l|}{ Nest cup } \\
\hline Length $(\mathrm{cm})$ & 12.0 & 1.0 & $6.0-26.0$ & 19 \\
\hline Width $(\mathrm{cm})$ & 11.1 & 0.7 & $7.0-17.8$ & 19 \\
\hline Depth of cup (cm) & 3.1 & 0.3 & $0.5-5.1$ & 17 \\
\hline Depth of moss on branch $(\mathrm{cm})$ & 5.2 & 0.6 & $0.6-12.0$ & 18 \\
\hline \multicolumn{5}{|l|}{ Nest platform } \\
\hline Length $(\mathrm{cm})$ & 42.2 & +2 & $11-66$ & 14 \\
\hline Width $(\mathrm{cm})$ & 31.7 & 2.9 & $10-51$ & 21 \\
\hline Canopy closure above nest (pct.) & 78.6 & 3.5 & $40-100$ & 18 \\
\hline
\end{tabular}

\footnotetext{
' Characteristics were not measured at some nests.

${ }^{2}$ Excludes a nest in a Sitka spruce $7.6 \mathrm{~m}$ from the trunk. This nest was 3.3 times farther than the next most distant nest and 11.2 times farther than the mean.
}

Tree species composition of occupied sites was consistent with composition across the landscape. The western hemlock/ Oregon oxalis plant association, within the western hemlock zone, was especially important. These sites are very fertile and moist and may produce larger trees (Hemstrom and Logan 1986). In addition, moisture in these sites may decrease the likelihood of intense fires, thereby allowing higher densities of remnant trees.

Historically, extensive, and sometimes catastrophic, fires occurred in the Oregon Coast Range (Agee 1994). These fires created diverse forests with attributes of older-aged forests that are not found in intensively managed plantations. For example, natural stands generally have more tree species, less uniform tree sizes, more random spacing of trees, and larger remnant overstory trees, as compared to even-aged stands of the same age (Spies and Franklin 1991). Many of the occupied sites in Oregon were created naturally, and many have not been managed (i.e., thinned or partially harvested). Thus, these sites were uneven-aged forests and they included a variety of tree sizes and ages. Spacing of the dominant trees was not uniform, allowing midstory and understory trees to fill in the gaps in the canopy. The structure of these forests, in most cases, was similar to old-growth forests, although tree density was lower and average tree size smaller than "classic" old-growth (as defined in Franklin and others 1986). It is the structure of these stands, the large trees with nesting platforms, hiding cover (vertical canopy cover), and variable canopy cover, that are important to murrelets. Mean tree age alone and low canopy closure do not indicate the quality of the habitat. For example, some sites on state lands were typed as young ( $\leq 80$ years old), yet all of these sites had remnant trees ( $\geq 66 \mathrm{~cm}$ d.b.h.), except one, and all had other older forest structures that survived or were created by fire (snags, woody debris). The single young site without remnant trees was located adjacent to and contiguous with a stand that contained 42.0 remnant trees per ha. In addition, while low canopy closure may allow murrelets access to nests, most (70 percent) nests near openings or edges have been unsuccessful (Nelson and Hamer, this volume b). Therefore, suitable murrelet habitat likely includes complex structure, high densities of large trees, large nesting platforms, and hiding cover.

The key components of occupied sites in this study were similar to occupied sites throughout the Pacific Northwest and California, and to other studies in Oregon (Nelson 1989, 1990a). Most sites used by murrelets have 
Table 6-Comparison ${ }^{l}$ of vegetation characteristics between 25 -meter plots around nest trees and within three plots ${ }^{2}$ adjacent to 10 nest trees found in Oregon between 1990 and 1992

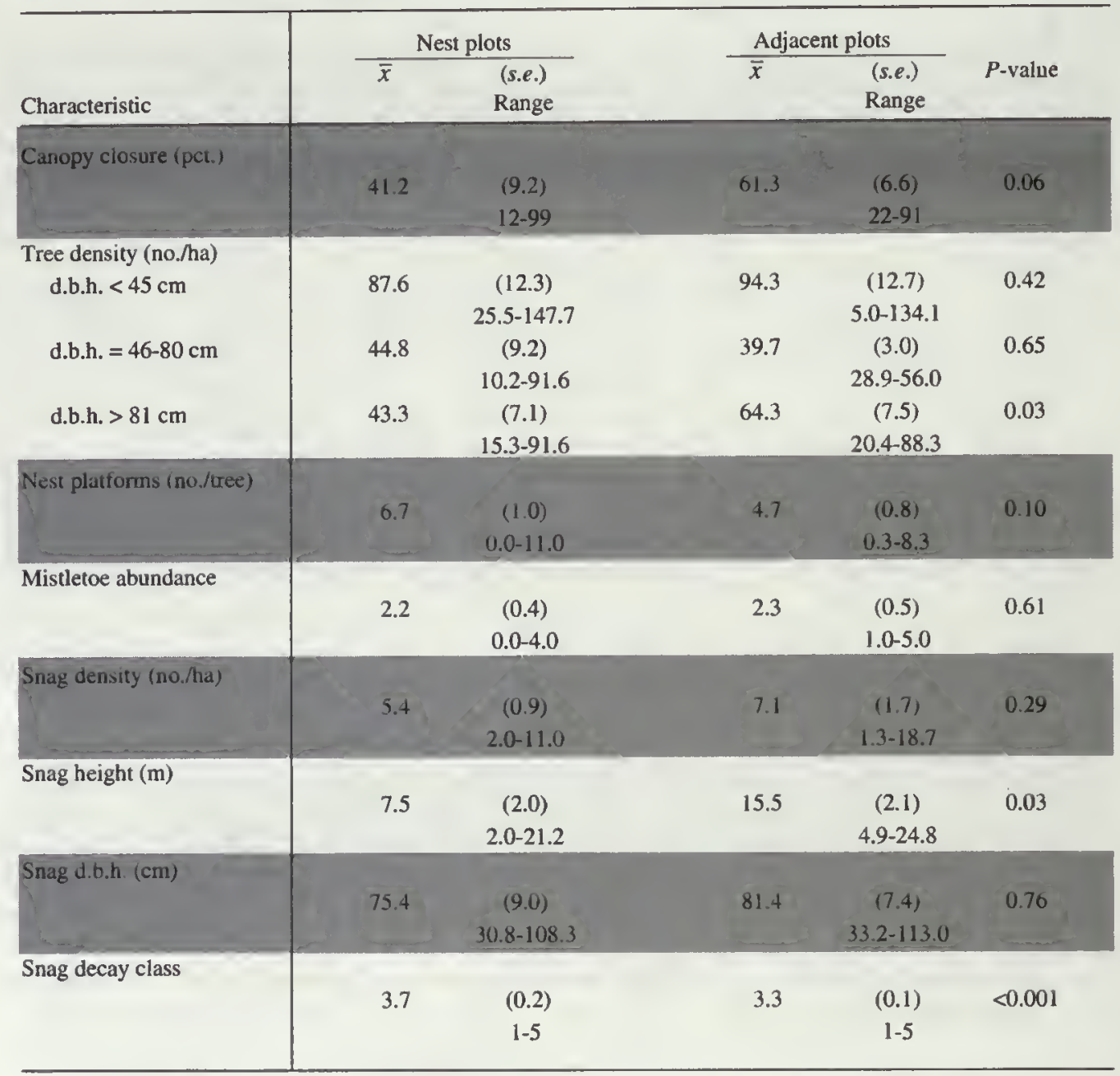

\footnotetext{
${ }^{1}$ Comparisons based upon a Wilcoxon paired-sample test for all characleristics except decay class of snags which is compared using a Chi-square test and a Bonferroni Z-statistic (Neu and others 1974) for the distribution of observations within five decay-class categories.

${ }^{2}$ Characteristics measured within two adjacent plots at one nest site.
}

been in older-aged forests, with high densities of dominant trees (Burger, this volume a; Hamer, this volume; Miller and Ralph, this volume; Nelson 1989, 1990a; Paton and Ralph 1990). In addition, in British Columbia, the presence of murrelets was correlated with the presence of Sitka spruce and western hemlock, low elevations, and large trees which had platforms for nesting (Burger 1994, this volume a; Manley and others 1992; Rodway and others 1991). In Washington, number of platforms and moss abundance were the most important variables for predicting murrelet occupancy (Hamer, this volume). Elevation (low) and canopy closure (moderate) were also key characteristics of occupied sites (Hamer, this volume).

\section{Nest Sites}

Murrelets used mature or old-growth forests and large diameter Douglas-fir, Sitka spruce, and western hemlock trees for nesting. Nests $(n=22)$ were on large limbs $(\bar{x}=29.4 \mathrm{~cm})$ usually $18 \mathrm{~m}$ or more above ground level, and were located in trees $>127 \mathrm{~cm}(\bar{x}=187.9)$ in diameter. Other structures at the nest were also important, including high vertical canopy cover above the nest cup ( $\bar{x}=78.9$ percent). In addition, all nests were located in forests with multi-layered canopies (23 ) with a wide range of both tree densities (121.0-718.8 ha) and canopy cover (12-99 percent).

In general, the forest immediately around the nest trees was open, with fewer dominant trees. The density of dominant trees at nest sites was lower than at adjacent sites. However, occupied sites had a higher density of dominant trees than random sites. Apparently, it is important for murrelets to have numerous dominant trees throughout a stand to provide nesting opportunities, but at the nest site, a lower density of dominant trees may facilitate access to the nest tree for a bird with limited flying maneuverability. 
However, nests may have been easier to find by observers in situations where tree densities were low. In addition, very low canopy cover may allow higher predation rates (see Nelson and Hamer, this volume b). Conclusions about appropriate canopy cover levels for nesting murrelets cannot be made without further research on nesting success and with larger sample sizes.

The characteristics of nests in Oregon were similar to those described by others in Alaska, British Columbia, Washington, and California (Hamer and Nelson, this volume b; Jordan and Hughes, in press; Manley and Kelson, in press; Naslund 1993b; Naslund and others, in press; Nelson and Hamer 1992; Singer and others 1991, in press). Excluding Alaska, all nests have been located in trees $>88 \mathrm{~cm}$ in diameter and $>18 \mathrm{~m}$ in height $(n=47)$ (Hamer and Nelson, this volume $b$ ).

\section{Conclusions}

Our results support previous studies and observations that murrelets use older forests or forests with old-growth characteristics. Key habitat characteristics of occupied sites were tree height, density of dominant (or remnant) trees, diameter and percent cover of midstory and understory trees, and canopy cover. Nests were located in large trees with large platforms and high vertical canopy cover.

Additional detailed information on the characteristics (platform availability, abundance of mistletoe and moss) of Marbled Murrelet habitat are needed to refine the definition of suitable habitat in Oregon. Studies designed to collect habitat data specific to murrelets from plots in the forest (including the key variables listed above) are needed. In addition, further investigations into plant associations are recommended.

There are limitations to describing murrelet habitat on the basis of occupancy, presence, or abundance. We can describe the general features of habitat used by this species; however use of these measures as a means for determining habitat quality, suitability, or preference may not be valid, especially in patchy habitats (Fretwell and Lucas 1969, Hanski 1982, Van Horne 1983). Models developed to measure habitat quality and suitability have included components of density, reproductive rates, genetic contribution of adults to the next generation, and survival of adults and juveniles (Fretwell and Lucas 1969, Van Horne 1983). A more adequate means of evaluating habitat suitability will be to explore the relationship between reproductive success, and habitat and landscape characteristics. This should be an emphasis of future research projects.

In addition, caution is advised in using our description of occupied sites from the state and federal databases. These data were not collected to describe murrelet habitat, and our analysis was retrospective. Occupied sites also were not selected randomly. Therefore, occupied site characteristics may be an artifact of how stands were chosen for timber harvesting and thus murrelet surveying, and which habitat variables were measured. Future research should include collecting data specific to biology of murrelets, e.g., availability of platforms, moss, and mistletoe.

\section{Acknowledgments}

Funding for this project was provided by the Oregon Department of Fish and Wildlife, Nongame Wildlife Research Program; the USDI Bureau of Land Management, Salem and Coos Bay Districts; the U.S. Fish and Wildlife Service, U.S. Department of Interior; and the USDA Forest Service. Special thanks go to G. Gunderson, W. Logan, L. Mangan, M. Nugent, C. Puchy, M. Raphael for their cooperation, support, and advice.

We also thank S. Andrews, C. Bickford, R. Davis, S. Madsen, C. McCain, C. Wettstein of the Siuslaw National Forest, B. Reagan, B. Reich, K. Graham of the Oregon Department of Forestry, and N. Allen, C. Bruce, G. Sieglitz of the Oregon Department of Fish and Wildlife for access to their databases. Data collection and management were conducted by D. Elliott, J. Hardin, A. Hubbard, B. Peck, M. Pope, M. and J. Raisinghani, J. Reams, J. Rosenthal, T. Ross, M. Shaughnessy, and J. Wells. Additional logistical support was provided by D. Crannell, J. Guetterman, J. Heeney, B. Hill, S. Hopkins, K. Kritz, from the U.S. Bureau of Land Management, and D. Gutherie and S. Livingston of the U.S. Forest Service.

F. Ramsey and D. Schafer from Oregon State University, Statistics Department provided assistance with data analyses. We thank J. Baldwin, B. Block, A. Burger, P. Connors, T. De Santo, R. Mannan, C.J. Ralph, M. Raphael, R. Steidl and $\mathrm{J}$. Weeks for reviewing earlier drafts of this manuscript and making numerous suggestions that greatly improved its quality. Support for preparation of this manuscript was provided by the Oregon Department of Fish and Wildlife, USDA Forest Service, USDI Bureau of Land Management, and U.S. Fish and Wildlife Service, U.S. Department of Interior. This is Oregon State University Agricultural Experiment Station Technical Paper Number 10,537. 
Appendix 1-Variables used to describe Marbled Murrelet occupied sites using data from Oregon's Department of Forestry OSCUR database. Note that the 1,2, and 3 assigned to DBH are reversed compared to federal lands database

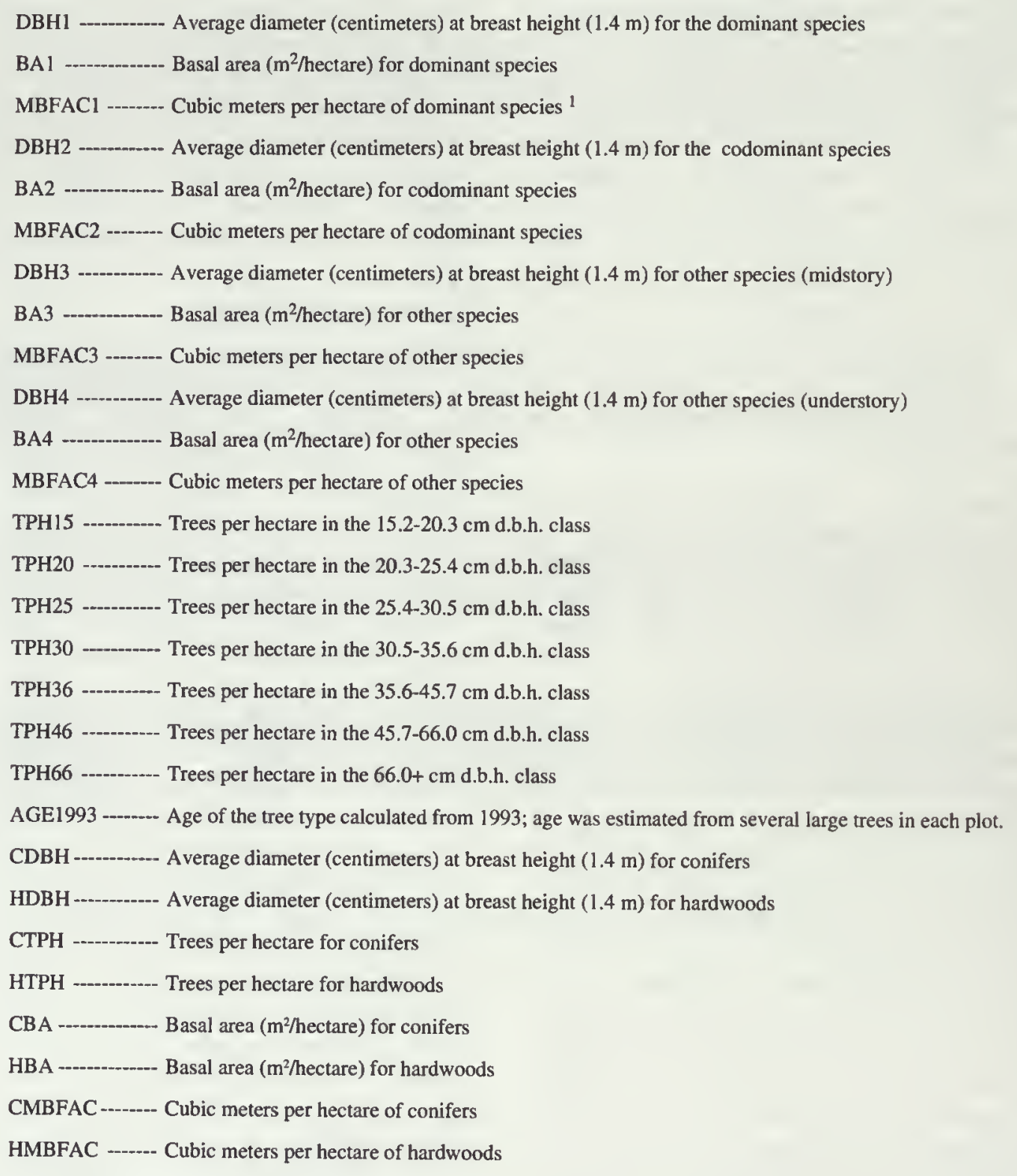

\footnotetext{
${ }^{1} 1,000$ board feet $=5.83 \mathrm{~m}^{3}$ hectare $(\mathrm{ha})$
} 
Appendix 2-Variables used to describe stonds of mature and old-growth forests on the Siuslaw National Forest, Corvallis, Oregon. Data were collected using Vegetation Resource and Structure Examination methods, 1990-1993. Note that the 1,2 , and 3 assigned to $\mathrm{DBH}$ are reversed compared to state lands database.

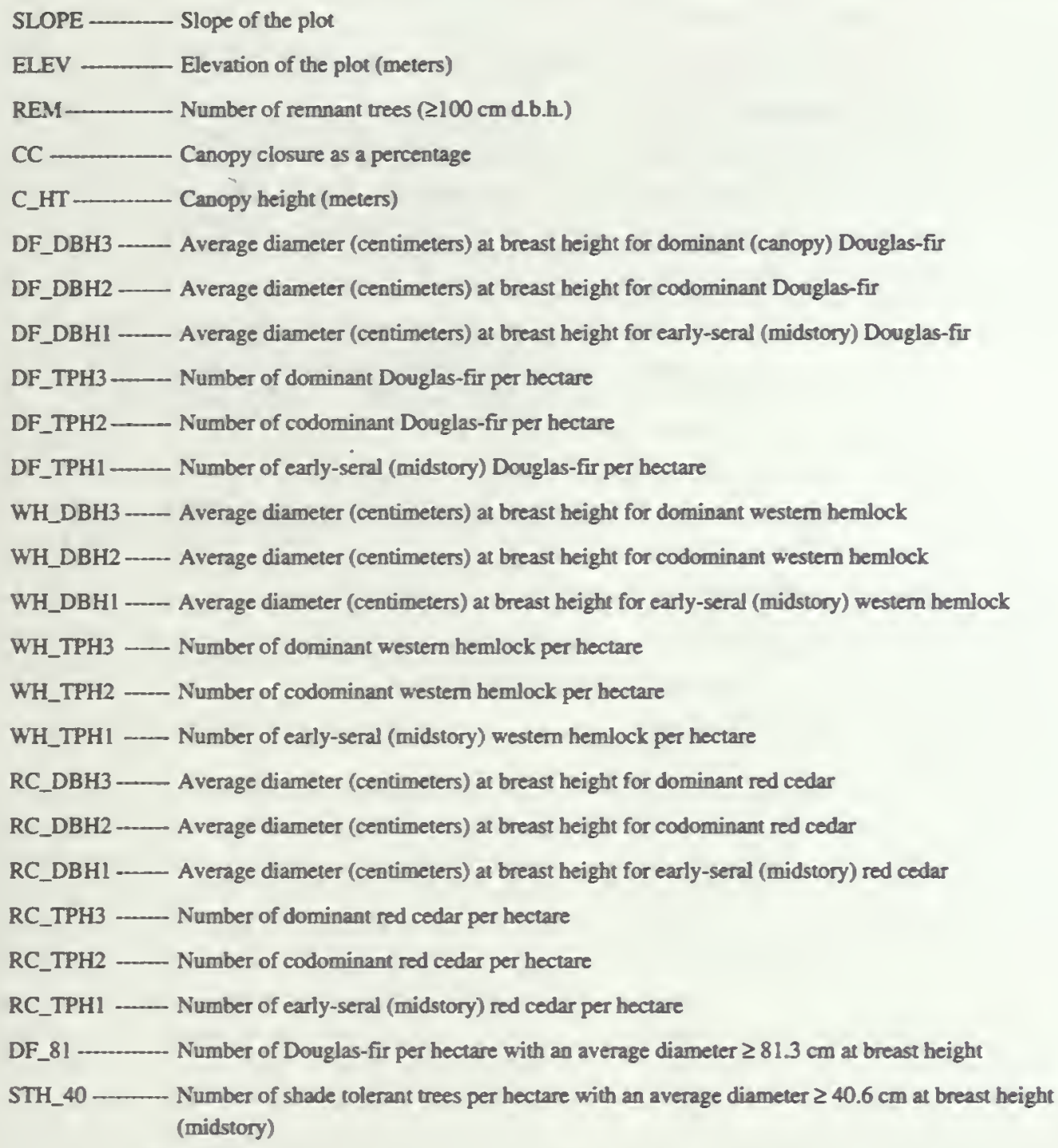


Appendix 3-Variables used to describe forest stands $>75$ years old on the Siuslaw National Forest. Data were collected by the Ecology Program (USDA 1983, USDA 1985), Siuslaw National Forest, Corvallis, Oregan, 1982-1986

ELEV --_.-...- The elevation of the plot (meters)

ASPECT -...-..- The aspect toward which the plot faces recorded as degrees azimuth

SLOPE -------- The slope of the plot in percent

TREER ----------- The percent cover of understory trees ( $<3.7$ meters in height)

SHRUBH ------- The percent cover of high woody perennial plants greater than 0.9 meters in height

HERB --.-- The percent cover of herbaceous plants

MOSS ------- The percentage of the ground area which is covered by moss or lichens

SERAL --------- The seral stage of the site [ $]=$ very early, pioneer ( 1 to 30 years) brush and small trees; $2=$ early seral ( 30 to 100 years) young stand; $3=$ mid-seral ( 100 to 00 years) mature stand; $4=$ late seral, highly stable (200 until late seral species are gone) old growth; 5 = climatic, topographic, or edaphic climax (seral dominants gone)]

TBAL ------ The total basal area in $\mathrm{m}^{2} /$ hectare of living trees

TBAD ---------- The total basal area in $\mathrm{m}^{2} /$ hectare of standing dead trees, including snags in all stages of deacy greater than 3.7 meters in height

DIA -..-.-.-.-.-The diameter of the site dominant trees to the nearest centimeter

HT --_ot The total height measured on the site dominant trees

AGE --------- The breast height age of the site dominant trees from bore count 


\section{Chapter 20 \\ Relationship of Marbled Murrelets with Habitat Characteristics at Inland Sites in California}

Sherrl L. Miller

\author{
C. John Ralph ${ }^{2}$
}

Abstract: We examined the range and the relationships of Marbled Murrelet (Brachyramphus marmoratus) behavior with habitat and landscape characteristics in isolated old-growth and residual forest stands from 2 to 400 ha in California. In large contiguous stands of old-growth forest in parks, we examined relationships of murrelet detections with elevation and topography. In isolated stands we found higher murrelet detection levels in stands with higher dominant and codominant crown cover and $>50$ percent coast redwood (Sequoia sempervirens). Surveys also were more likely to detect occupied behaviors at stands with higher crown cover and a greater proportion of redwoods. Density of old-growth cover and species composition may be the strongest predictors of murrelet presence and occupancy in California. Contrary to previous studies, we did not find that larger stands were more likely to have murrelets present. In the large park stands, we found that mean detection levels and the number of occupied stations were highest in the major drainages and at lower elevations. Major ridges tended to have lower detection levels and fewer occupied behavior stations.

In recent years, much has been learned about the occurrence of Marbled Murrelets (Brachyramphus marmoratus) at inland forest sites. Throughout most of its range, the murrelet nests in old-growth forests within 50-75 miles of the coast (Carter and Morrison 1992). In California, Paton and Ralph (1990) conducted general surveys (Paton, this volume) to determine the distribution of murrelets in coastal old-growth and mature second-growth forests. Concentrations were found in regions containing large, contiguous, unharvested stands of old-growth redwood, mostly within state and federal parks, with the highest detection numbers in stands $>250$ ha. In excess of 200 detections for single-survey mornings have been recorded at some survey stations in remaining unharvested stands within parks in California, including Redwood National Park and Prairie Creek State Park in Humboldt County (Ralph and others 1990); and Big Basin State Park in San Mateo County (Suddjian, pers. comm.).

Federal listing of the Marbled Murrelet as threatened (U.S. Fish and Wildlife Service 1992) has created a need for information about the role of habitat and landscape features for the murrelet.

We conducted two studies to examine the relationships of the murrelet to habitat and landscape characteristics within old-growth forests, as defined by Franklin and others (1986). In isolated stands in fragmented landscapes (the Stand Study), we compared murrelet detections with stand size, structure,

1 Wildlife Biologist and Research Wildlife Biologist, Pacific Southwest Research Station, USDA Forest Service, Redwood Sciences Laboratory, 1700 Bayview Drive, Arcata, CA 95521 and landscape characteristics. In large contiguous stands of old-growth in state and federal parks (the Park Study), we examined murrelet detections with landscape features, such as elevation and topography. We confined our study to oldgrowth forests, because previous studies indicate murrelets nest only in forests with these characteristics.

\section{Methods}

The survey methods followed the intensive survey protocol of Ralph and others (1993). To maximize the number of visual detections, we selected station positions at the edges of the isolated stands or at interior locations with openings in the canopy whenever possible. Observers could move within a $50-\mathrm{m}$ radius of the station.

We estimate that, for an individual forest stand, four surveys are needed to determine with a 95 percent probability that murrelets are present (appendix A). If below canopy behaviors were observed, we categorized the stand as Occupied (see below) for analyses. During 1992 and 1993 for the Stand Study, we attempted to survey each isolated stand at least four times between 15 April and 7 August. Surveys at each stand were distributed throughout the survey period whenever possible. However, due to difficult access for some stands, surveys in some areas were temporally aggregated. To eliminate potential effects from aggregated surveys, detection levels were standardized for seasonal variation (see Analyses below).

For the 1993 Park Study, within the boundaries of the large stands of old-growth forests in national and state parks (fig. 1), stations were placed in a matrix over the landscape, as illustrated in figure 2. We surveyed all sections of park stands with adequate accessibility. We placed stations 400 meters apart on roads and trails, and 400 meters out perpendicular to trails, creating a matrix. Ralph and others (1993) found that observers detect few birds at distances $>200 \mathrm{~m}$, therefore, we assumed each station covered a 200 $\mathrm{m}$ radius circle, approximately 12.5 ha. Due to safety considerations for observers hiking to stations in pre-dawn hours, we limited stations to within 400 meters of a trail or road. Stations were surveyed once during the survey season. We attempted to avoid surveys at adjacent stations on the same morning.

The species' range in northern California was determined by examining the results of inland surveys conducted from 1988 through 1992 by government agencies and private landowners. Murrelet use for each stand or station was determined by the number and type of detections. All survey stations were digitized into a Geographic Information System 


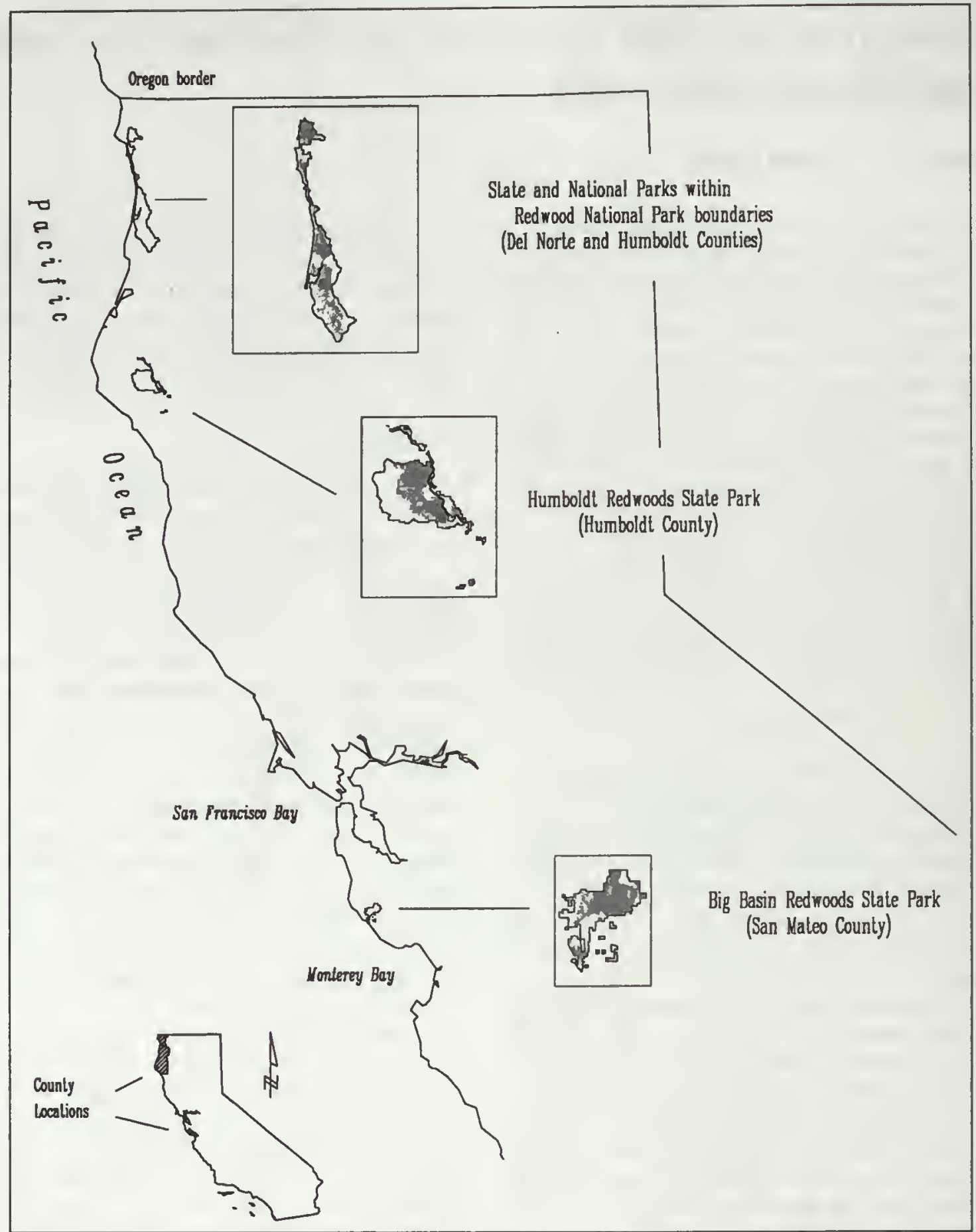

Figure 1-Location of state and national parks surveyed during the summer of 1993. Shaded areas represent distribution of old-growth forests within the parks.

(GIS) database (ARC/INFO 6.1.1) and grouped by distances from the ocean by $10-\mathrm{km}$ bands from 0 to $60 \mathrm{~km}$ (fig. 3).

\section{Definition and Selection of Isolated Study Stands}

Isolated stands were located by examining habitat maps of private lands, state and federal parks, and national forests. The maps were drawn from interpretation of aerial photographs. For the stand selection process, stand size was estimated from measurements on the maps. Stands were randomly selected from size categories of 2 to 20 ha, 21 to 40 ha, 41 to 100 ha, and greater than 100 ha. If the stand was accessible, it was visited and visually inspected. If the stand was old-growth or residual forest, the stand was surveyed, if not, then another stand was selected. Upon completion of field work, station locations and stand perimeters were adjusted on maps according to ground-truthing, then digitized into a GIS database. 


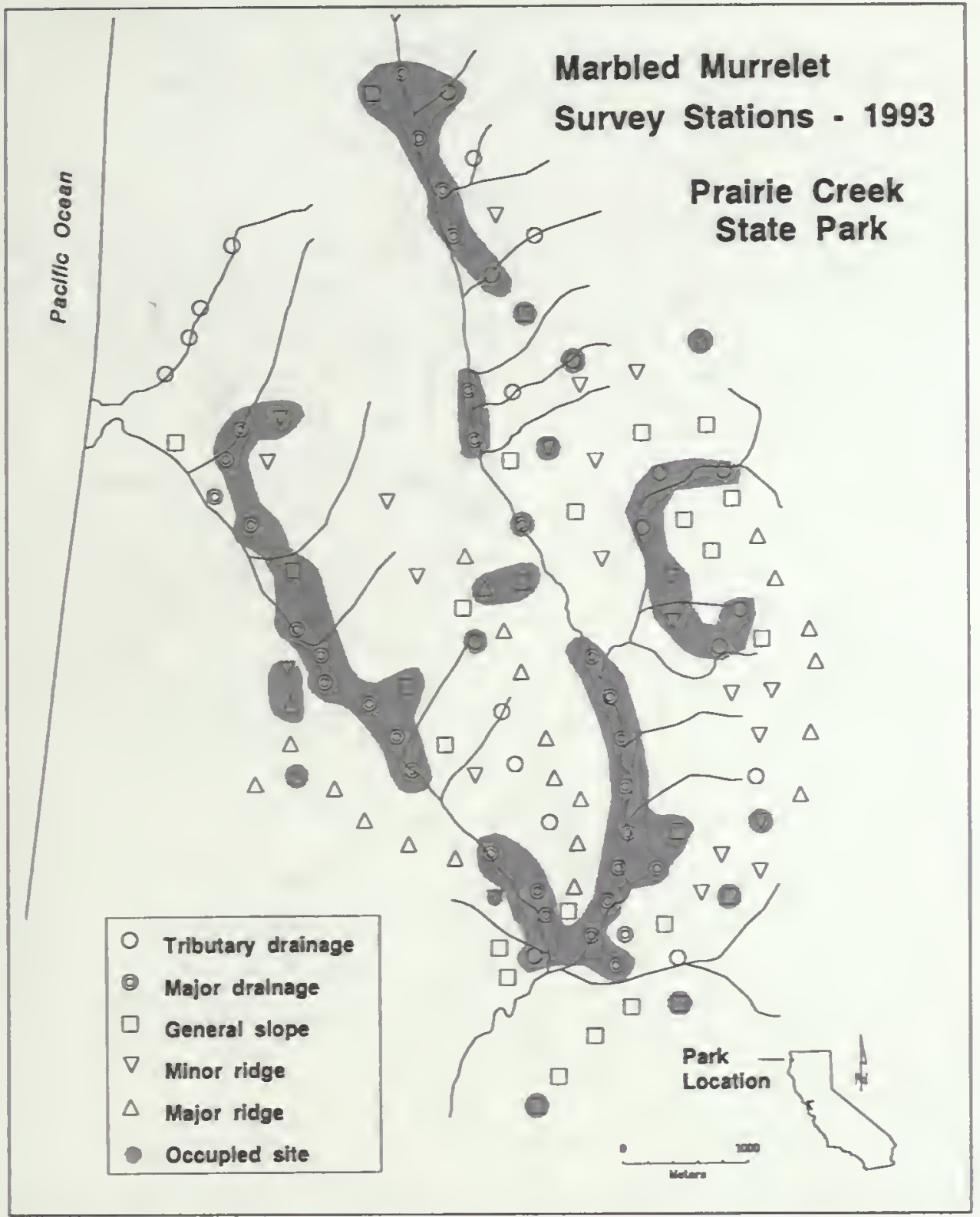

Figure 2-Spatial and topographical distribution of a subset of Marbled Murrelet stations surveyed at Praine Creek Redwoods State Park during the summer of 1993. Occupied sites are shaded in groups to illustrate possible associations with topographical features.

Stand area, perimeter length, and distance from salt water were derived from the GIS database. For stands with inclusions of non-forested area within the stand, we added the length of the lines around the stand and around the inclusions for the total perimeter measurements. Perimeter, therefore, is a measure of the amount of forest edge in and around the stand.

Stand type was characterized as residual or old-growth. This variable is a measure of harvest history for the stand, but is not a direct measure of years since the last disturbance. Old-growth stands contained trees greater than $90 \mathrm{~cm}$ diameter at breast height (d.b.h.) with no history of timber harvest and some evidence of decadence in the canopy. Residual stands had some history of parial removal of large trees with the remaining dominant trees greater than $90 \mathrm{~cm}$ d.b.b.. Some stands with contiguous areas of old-growth and residual were classified as mixed.

Stands also were classified by density as determined by interpretation of aerial photographs. Density was defined as the percent of the old-growth canopy cover (dominant and codominant trees): sparse, $<25$ percent; low, $25-50$ percent; moderate, $51-75$ percent; and dense, $>75$ percent. Species of dominant trees ( $>50$ percent) was determined from aerial photography and verified by vegetation information after visiting the stand. For the purpose of this study, a stand was a single, isolated group of old-growth trees surrounded by 


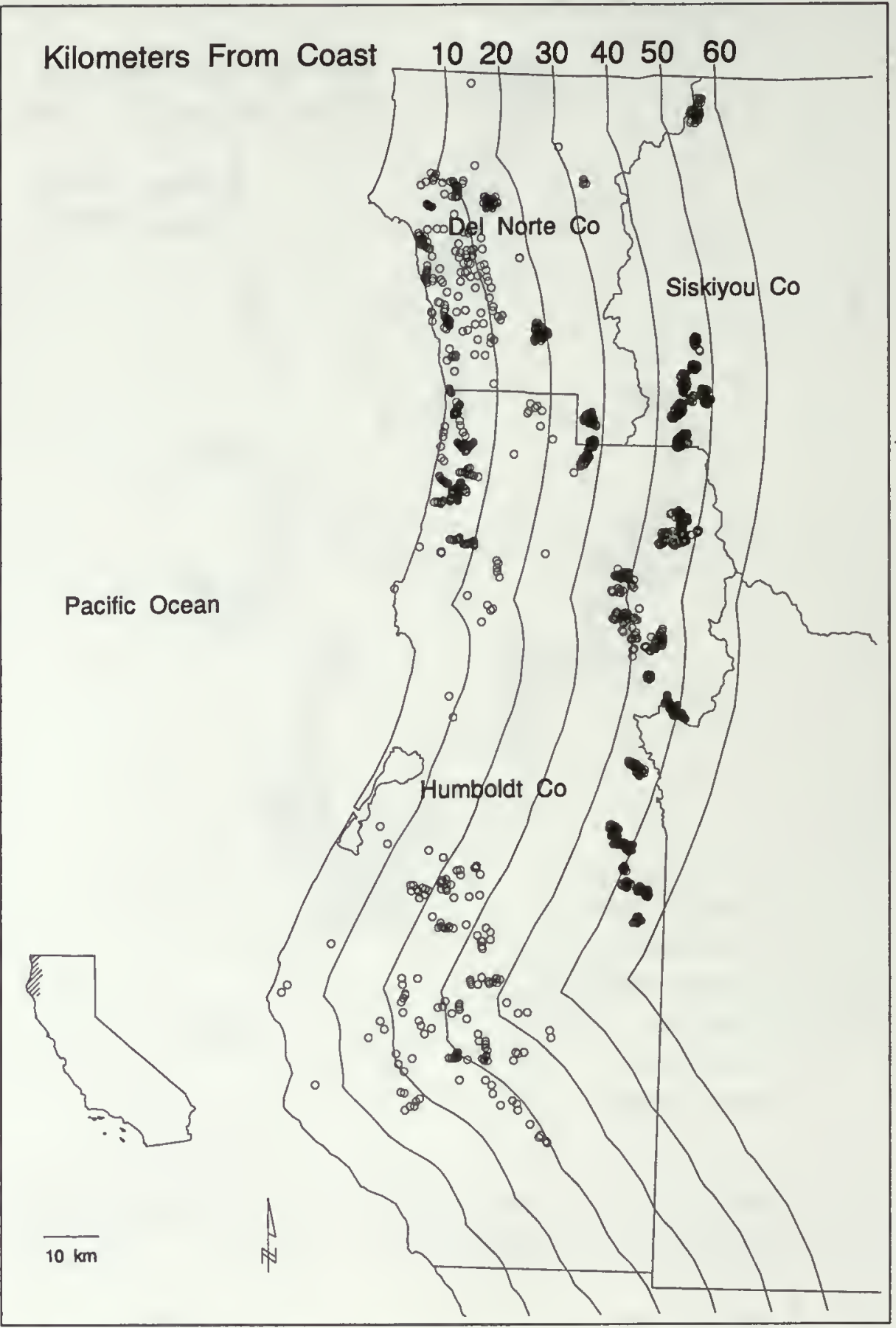

Figure 3-Distribution of Marbled Murrelet survey stations in northern California. Stations are located on private and public lands and surveys were conducted one or more seasons from 1988 to 1994. Open circles represent one survey station or a group of stations in one isolated stand. In areas with high concentrations of stations, open circles appear filled in or shaded.

non-forested or harvested habitat. If groups of trees were less than 160 meters apart they were considered one stand.

Stands that met all of the following criteria were included in the group of potential survey sites: old-growth or residual stands with dominant and codominant trees that comprised at least 20 percent canopy cover; size between 2 ha and $400 \mathrm{ha}$; distance from coast less than $40 \mathrm{~km} \mathrm{(25}$ miles); dominant vegetation type of coast redwood (Sequoia sempervirens) or Douglas-fir (Pseudotsuga menziesii) at elevations of less than $1,000 \mathrm{~m}$; and safely accessible by road or well-defined trail.

\section{Analyses}

\section{Standardization for Seasonal Variation}

Various factors may influence the numbers of detections of murrelets at inland locations, including environmental conditions, time of year (O'Donnell and Naslund, this 
volume), and observer (O'Donnell, this volume). To help eliminate the effects of observer bias, all stands were surveyed by two or more observers. The influence of weather on numbers of detections appears to be highly variable (Naslund and O'Donnell, this volume). The effect of weather is probably stochastic with respect to survey days, and we assumed it did not have an overall impact at a site because surveys were distributed throughout the breeding season. The seasonal variation in detection levels, however, has been well documented and quantified at several sites in California (O'Donnell and Naslund, this volume). To identify differences in murrelet use (detection levels) of stands in our study, we first accounted for the effect of season on detection levels.

Morning surveys were conducted throughout the breeding season in multiple years at three sites in Humboldt County. The sites at Lost Man Creek (Redwood National Park) and James Irvine Trail (Prairie Creek Redwoods State Park) were surveyed from 1989-1993. The Experimental Forest site was surveyed in 1989, 1990, 1992, and 1993. We attempted to monitor each site weekly. Data from these three sites was used to calculate standardization factors.

\section{Standardization}

The following method was used to calculate a factor to standardize the number of detections for seasonal differences.

1. We examined the distribution of detections (fig. 4) over all years for the three sites and used a KruskalWallis test to determine that the distributions by season were similar for the three sites $(P<0.0001)$. Surveys from all sites and years then were pooled.

2. We calculated the mean number of detections per survey for the period 15 April to 12 August, that we refer to as the summer mean.

3. We then calculated the mean numbers of detections per survey for each 10-day interval, the interval mean. Detection levels for periods longer than 10 days began to show the effects of seasonal variation.

4. The ratio of each of the 12 interval means and the summer mean was calculated (interval mean/summer mean $=$ standardization factor).

The 10-day intervals and corresponding standardization factors calculated for the data from the three sites are presented in table 1 .

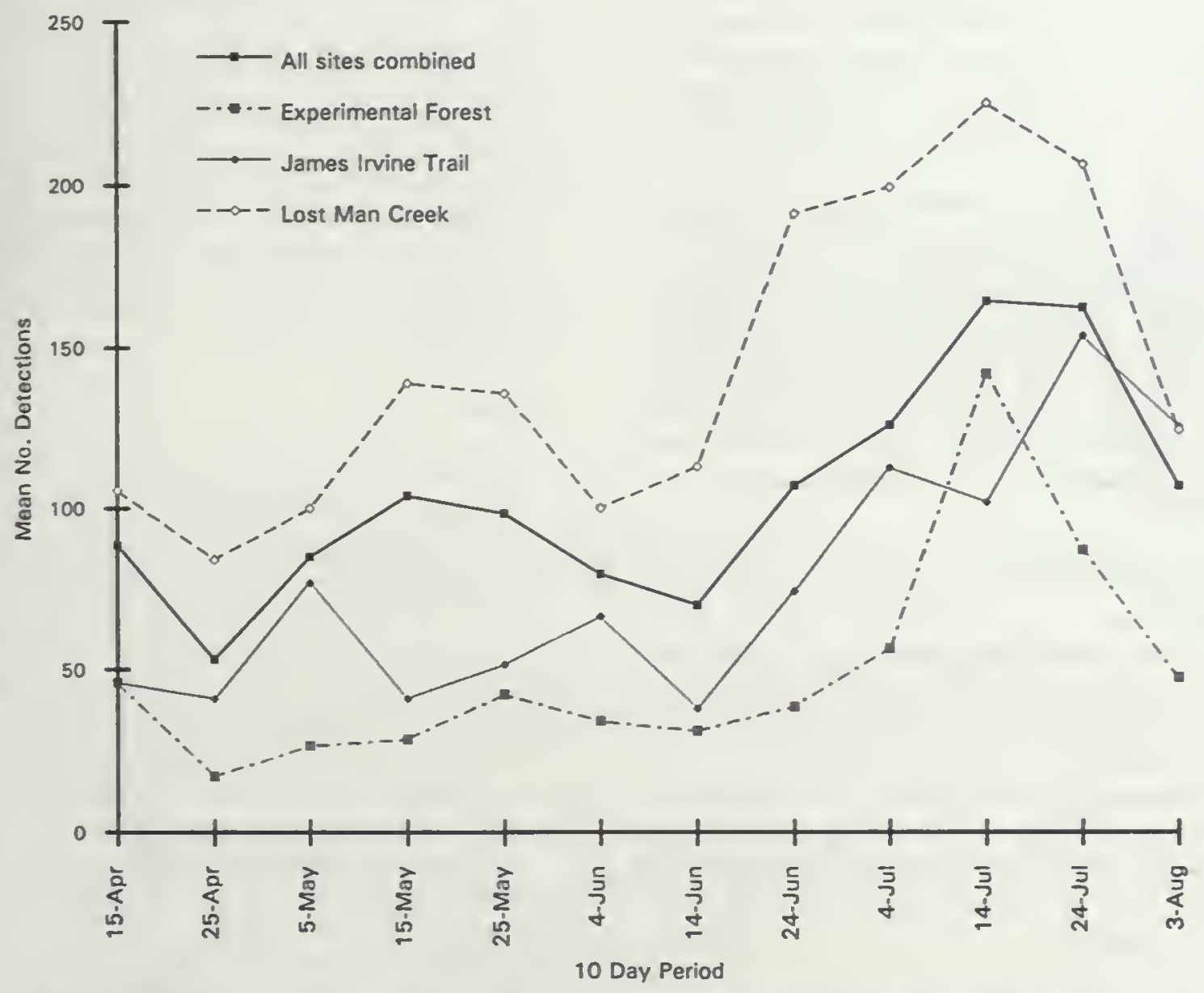

Figure 4 - Mean Marbled Murrelet detections from forest surveys at three sites in northern California: James Irvine Trail, Prairie Creek Redwoods State Park; Lost Man Creek, Redwood National Park; and the USDA Forest Service Experimental Forest, Klamath. Means for the three sites combined by 10 day intervals also are presented. Surveys were conducted 3-4 times per month most years from 1989-1993 and points represent the means for 10-day intervals. 
Table 1-Ten-day intervals and corresponding standardization factors for seasonal variation of mean Marbled Murrelet levels at three sites in northern California

\begin{tabular}{l|c}
\hline Interval & Standardization factor \\
\hline April t5 to April 24 & 0.86 \\
April 25 to May 4 & 0.51 \\
May 5 to May 14 & 0.82 \\
May 15 to May 24 & 1.01 \\
May 25 to June 3 & 0.95 \\
June 4 to June 13 & 0.77 \\
June 14 to June 23 & 0.68 \\
June 24 to July 3 & 1.04 \\
Juty 4 to July 13 & 1.22 \\
July 14 to July 23 & 1.59 \\
July 24 to August 2 & 1.04 \\
August 3 to August 12 & 1.03 \\
\hline
\end{tabular}

Thus for surveys conducted at the three sites from 14 July to $23 \mathrm{July}$, numbers of detections per survey were on average 1.59 times greater than the summer mean; surveys conducted from 15 May through 24 May had numbers of detections which were about equivalent to the summer mean; and numbers of detections for surveys from 25 April to 4 May averaged about half of the summer mean.

In applying the standardization, we made the assumption that the relationship between detections at any site on a given day and the mean detection levels for the summer period at that site would be the same as the relationship we found at the three test sites. We have compared data with one site with very low activity and found the seasonal curves were similar. Standardized mean detection levels were calculated for all stands and stations and this measure used for all analyses.

\section{Stand Study: Isolated Stands}

\section{Multiple Regression}

We examined the relationship between standardized mean detection levels for the stand, referred to as the dependent variable, and the following independent variables: stand size, Patton's index of perimeter to area (Patton 1975) which was used as a measure of the edge or shape, distance from salt water, density of old-growth trees, type of stand, and dominant tree species. As a transformation of the standardized mean detection level, we used the square root of the mean for the multiple regression.

\section{Logistic Regression}

For each stand we summarized the detections and behaviors for all surveys conducted during the study to determine the status of the stand. If no murrelets were detected during any of the surveys, then the status was "Undetected." Stands with murrelet detections were assigned a status of "Present" or, if occupied behaviors (Paton, this volume; Ralph and others 1993) were observed, a status of "Occupied."

Using logistic regression (SAS Institute, Inc. 1991) with maximum likelihood analysis of variance, we examined the relationship between a selection of independent variables, and status. We compared response variables Present (including Occupied stands) and Undetected, and response variables Occupied and Unoccupied (all stands with a status of Undetected or Present). For the stands with murrelets present we compared Occupied stands, with stands with a status of Present.

\section{Park Study: Large Contiguous Stands}

Elevation and position on the landscape were estimated from topographic maps to give a measure of topography for each station. Landscape position was described as one of five categories: (1) in the bottom of a major drainage, a drainage covering a large length of the landscape and isolated by parallel ridges; (2) in the bottom of a tributary (or minor) drainage, a drainage flowing into a major drainage, or a short, steep drainage flowing directly into the ocean; (3) on top of a major ridge, a ridge running parallel to a major drainage; (4) on top of a minor ridge, a ridge line that originated from the major ridge and was generally perpendicular to a major drainage; and (5) on a general slope, a station not on a ridge nor in a drainage.

When stations were located on slopes or ridges, it was possible to detect murrelets calling in the drainages. The topography within $100 \mathrm{~m}$ of the stations was similar to the topography at the station itself. To help isolate the effects of topography, we included only detections within $100 \mathrm{~m}$ of the observer.

\section{Results}

\section{Stand Study: Isolated Stands}

We identified 286 potential study stands in Del Norte, Humboldt, Trinity, San Mateo, and Santa Cruz counties meeting the criteria in the four size categories 2 to 20 ha $(n=$ $184) ; 21$ to 40 ha $(n=39) ; 41$ to 100 ha $(n=35) ;>100$ ha $(n$ $=28$ ). We located few stands $>21$ ha, therefore, we surveyed all accessible stands in those categories. From these potential study stands we selected and surveyed 152 stands as follows: 2 to 20 ha $(n=86) ; 21$ to 40 ha $(n=22) ; 41$ to 100 ha $(n=$ $23) ;>100$ ha $(n=21)$. Due to weather conditions, three stands were surveyed only three times.

Density of the combined dominant and codominant tree cover and presence of redwood trees were positively and significantly $\left(F_{0.05}=2.428, d f_{\text {model }}=10, P=0.0105, R^{2}=\right.$ 0.1625 ) related to mean murrelet detection levels in the multiple regression model. Because only 16 percent of the variation in the system was explained by the model, the predictive ability was limited. Other variables examined were not related to mean detection levels. 
The logistic regression model included density of oldgrowth (dominant and co-dominant) tree cover, tree species, and stand size as variables explaining the differences between sites with no detections and those with murrelets present (table 2). Stands with higher density classifications, and with redwood as the dominant tree species, were more likely to have murrelets present. Results also indicated a very minor effect of smaller stands increasing the likelihood of murrelet presence. We found, however, no significant effect of stand size on the status of murrelets in the stands (Undetected, Present, or Occupied), when tested by Chisquare contingency table $\left(d f=6, \chi^{2}=3.294, P=0.7721\right)$ (rable 4). Using these variables accounts for virtually all of the variability in the model.

For stands with a status of Occupied $(n=37)$, compared with all Unoccupied stands $(n=115)$, old-growth tree density and tree species were significant variables (table 3 ) for predicting observations of occupied behaviors. Stands in higher density classes with redwood as the dominant species were more likely to be classified as Occupied.

Among stands with murrelet detections $(n=62)$, we found no differences in habitat variables between stands with a status of Occupied $(n=37)$ and Present $(n=25)$.

\section{Park Study: Large Contiguous Stands}

\section{Central California}

Big Basin Redwoods State Park was surveyed in a matrix of 37 survey stations. The elevation ranged from $240-500 \mathrm{~m}$ and we divided stations into four equal categories (table 5). We found the mean detection levels and the number of Occupied stations higher for stations in lower elevation categories. The proportion of Occupied stations was not significantly different $(P>0.05)$ among topography categories (table 5). Occupied behaviors were observed in all topography categories, and the only station with a status of Undetected was on a major ridge.
Table 2-Results of logistic regression analysis for stands in California ( $\mathbf{n}=$ 152) with a status of murrelets Present (Present and Occupied) $(\mathrm{n}=62)$ and Undetected $(\mathrm{n}=90)$. Only variables with significant contribution to the model are presented

\begin{tabular}{l|ccc}
\hline Variable & $\begin{array}{l}\text { Regression } \\
\text { coefficient }\end{array}$ & Chi-square & $\begin{array}{l}\text { Chi-square } \\
\text { probability }\end{array}$ \\
\hline Tree species $^{1}$ & 1.8101 & 9.43 & 0.0021 \\
Cover density $^{2}$ & 0.8755 & 5.76 & 0.0164 \\
Stand size & -0.0206 & 5.45 & 0.0195 \\
\hline
\end{tabular}

${ }^{1}$ Coast redwood (Sequoia sempervirens) or Douglas-fir (Pseudotsuga menziesit) $>50$ percent of stand.

${ }^{2}$ Percent dominant and codominant tree cover.

Table 3-Results of logistic regression analysis for stands in California ( $\mathrm{n}=152$ ) with status of Occupied $(\mathrm{n}=37)$ and stands with murrelets Present or Undetected (Unoccupied) $(\mathrm{n}=115)$. Only variables with significant contribution to the model are presented

\begin{tabular}{l|ccc}
\hline Variable & $\begin{array}{l}\text { Regression } \\
\text { coefficient }\end{array}$ & Chi-square & $\begin{array}{l}\text { Chi-square } \\
\text { probability }\end{array}$ \\
\hline Tree species $^{1}$ & 1.9243 & 5.86 & 0.0155 \\
Cover density $^{2}$ & 1.0831 & 6.64 & 0.0100
\end{tabular}

\footnotetext{
${ }^{1}$ Coast redwood (Seguoia sempervirens) or Douglas-fir (Psuedotsuga menziesii) $>50 \%$ of stand.

${ }^{2}$ Percent dominant and codominant tree cover.
}

\section{Northern California}

We surveyed 352 stations in the 8 stands within northern California parks. We found that topography had a major influence on murrelet use $(P<0.0001)$. The mean detection levels were three times higher in major drainages (table 6 ) than on the major ridges.

Table 4-Percent of stands by murrelet use or status in each size category of stands surveyed in California for the Stand Study. Stands with a designation of Present had murrelet detections, but no observations of below canopy, or Occupied behaviors

\begin{tabular}{|c|c|c|c|c|c|c|c|}
\hline \multirow[b]{3}{*}{ Stand size (ha) } & \multirow[b]{3}{*}{$n$} & \multicolumn{6}{|c|}{ Percent of stands by murrelet use (status) } \\
\hline & & \multicolumn{2}{|c|}{ Not detected } & \multicolumn{2}{|c|}{ Present } & \multicolumn{2}{|c|}{ Occupied } \\
\hline & & $n$ & Percent & $n$ & Percent & $n$ & Percent \\
\hline $2-20$ & 86 & 55 & 63.9 & 14 & 16.3 & 17 & 19.8 \\
\hline $21-40$ & 22 & 12 & 54.6 & 3 & 13.6 & 7 & 19.8 \\
\hline $41-100$ & 23 & 12 & 52.2 & 5 & 21.7 & 6 & 26.1 \\
\hline$>100$ & 21 & 11 & 52.4 & 3 & 14.3 & 7 & 33.3 \\
\hline Totals & 152 & 90 & 59.2 & 25 & 16.4 & 37 & 24.3 \\
\hline
\end{tabular}


Table 5-For central California: Summary of detections ${ }^{l}$ and status for Marbled Murrelet stations surveyed in old-growth forests within state and national parks during the summer, 1993

\begin{tabular}{|c|c|c|c|c|c|c|c|}
\hline \multirow[b]{2}{*}{ Landscape variable } & \multirow{2}{*}{$\begin{array}{c}\text { Mean } \\
\text { number of } \\
\text { detections }{ }^{2}\end{array}$} & \multirow[b]{2}{*}{ s.d. } & \multirow[b]{2}{*}{ Range } & \multicolumn{4}{|c|}{ Number of stations $(n)$} \\
\hline & & & & Occupied & Presenl & Absent & Total \\
\hline \multicolumn{8}{|l|}{ Topography } \\
\hline Tributary drainage & 55 & 42 & $30-104$ & 3 & 0 & $\mathbf{0}$ & 3 \\
\hline Major drainage & 74 & 53 & $1-177$ & 10 & 3 & $\mathbf{0}$ & 13 \\
\hline General slope & 58 & 31 & 1.97 & 7 & 1 & 0 & 8 \\
\hline Minor ridge & 34 & 31 & $1-83$ & 5 & 2 & 0 & 7 \\
\hline Major ridge & 11 & 14 & $0-37$ & 3 & 2 & 1 & 6 \\
\hline \multicolumn{8}{|l|}{ Elevation } \\
\hline $240-305 \mathrm{~m}$ & 70 & 53 & $1-177$ & 10 & 2 & 0 & 12 \\
\hline $306-360 \mathrm{~m}$ & 64 & 36 & $13-122$ & 10 & 1 & 0 & 11 \\
\hline $361-420 \mathrm{~m}$ & 35 & 31 & $1-946$ & 4 & 0 & 10 & 10 \\
\hline $421-500 \mathrm{~m}$ & 4 & 6 & $0-122$ & 1 & 1 & 4 & 4 \\
\hline
\end{tabular}

${ }^{1}$ Includes only detections within 100 meters of observer

${ }^{2}$ Standardized detections

Table 6-For northern California: Summary of detections ${ }^{l}$ and status of Marbled Murrelet stations surveyed in old-growth forests within the state and national parks during the summer, 1993

\begin{tabular}{|c|c|c|c|c|c|c|c|}
\hline \multirow[b]{2}{*}{ Landscape variable } & \multirow{2}{*}{$\begin{array}{c}\text { Mean } \\
\text { number of } \\
\text { delections }{ }^{2}\end{array}$} & \multirow[b]{2}{*}{ s.d. } & \multirow[b]{2}{*}{ Range } & \multicolumn{4}{|c|}{ Number of stations $(n)$} \\
\hline & & & & Occupied & Present & Absent & Total \\
\hline \multicolumn{8}{|l|}{ Topography } \\
\hline Tributary drainage & 22 & 33 & $0-134$ & 18 & 19 & 54 & 91 \\
\hline Major drainage & 30 & 28 & $0-160$ & 67 & 25 & 17 & 109 \\
\hline General slope & 14 & 17 & $0-83$ & 40 & 67 & 22 & 129 \\
\hline Minor ridge & 16 & 19 & $0-107$ & 19 & 29 & 18 & 66 \\
\hline Major ridge & 10 & 13 & $0-51$ & 14 & 27 & 6 & 47 \\
\hline \multicolumn{8}{|l|}{ Elevation } \\
\hline $21-100 \mathrm{~m}$ & 28 & 30 & $0-160$ & 83 & 53 & 27 & 163 \\
\hline $10 \mathrm{t}-200 \mathrm{~m}$ & 16 & 18 & $0-83$ & 46 & 66 & 36 & 148 \\
\hline $201-300 \mathrm{~m}$ & 12 & 13 & $0-56$ & 19 & 37 & 19 & 75 \\
\hline $301-500 \mathrm{~m}$ & 4 & 6 & $0-22$ & 10 & 11 & 18 & 39 \\
\hline
\end{tabular}

${ }^{1}$ Includes only detections within 100 melers of observer

${ }^{2}$ Standardized delections

The proportion of Occupied stations was significantly higher at stations of less than 100-m elevation than at stations $>200 \mathrm{~m}(P<0.0001)$ ( (able 6$)$. The proportion of stations with no detections was significantly higher in the $>300 \mathrm{~m}$ category and significantly lower in the $<100 \mathrm{~m}$ category.

\section{Inland Range}

We found highest frequencies of presence ( 89.05 percent) and occupancy (21.9l percent) at stands and stations within $10 \mathrm{~km}$ of the coast (table 7). The proportion of Occupied sites decreased in the $10-$ to $20-\mathrm{km}$ band. The number of stations with detections declined by more than 99 percent from the $30-$ to $40-\mathrm{km}$ to the $40-$ to $50-\mathrm{km}$ band, although four times the number of stations were surveyed in the 40 - to $50-\mathrm{km}$ band. The proportion of Occupied stations declined rapidly beyond $30 \mathrm{~km}$ from the coast.

\section{Discussion}

\section{Stand Study}

The most important factor in indicating Occupied stands was density of the old-growth cover, that is, the percent of the area covered by the crowns of old-growth trees. Occupied stands had a higher percentage of old-growth cover than stands with murrelets only present, or in stands with no detections. These relationships are consistent with those 
Table 7-Marbled Murrelet use of forest stands in northern California. Numbers represent individual stands for isolated stands surveyed surveyed four times during the Stand Study or stations for surieys conducted in each 12.5 ha of a large contiguous stand for the Park Study or in preparation for timber haves!

\begin{tabular}{|c|c|c|c|c|c|}
\hline \multirow{2}{*}{$\begin{array}{l}\text { Distance } \\
\text { band } \mathrm{km} \\
\text { from coast }\end{array}$} & \multirow{2}{*}{$\begin{array}{l}\text { Number of } \\
\text { stations } \\
\text { surveyed }\end{array}$} & \multicolumn{4}{|c|}{ Number of stations by use } \\
\hline & & Detected $^{l}$ & Percent & Occupied & Percent \\
\hline $0-10$ & 283 & 252 & 89.05 & 62 & 21.91 \\
\hline $10-20$ & 133 & 38 & 28.57 & 6 & 4.51 \\
\hline $20-30$ & 144 & 52 & 36.11 & 24 & 16.67 \\
\hline $30-40$ & 100 & 36 & 36.00 & 6 & 6.00 \\
\hline $40-50$ & 428 & 1 & 0.23 & 1 & 0.23 \\
\hline $50-60$ & 95 & 2 & 2.11 & 0 & 0.00 \\
\hline Totals & 1183 & 379 & 32.04 & 98 & 8.28 \\
\hline
\end{tabular}

${ }^{1}$ All stations or stands with murrelet detections, including occupied behaviors

found in Oregon (Grenier and Nelson, this volume) and Washington (Hamer, this volume).

We found the presence of redwood as the dominant tree species to be a factor for predicting higher mean detection levels and stand occupancy. In Washington, Hamer and others (1993) also found tree species composition to be an important factor for murrelet occupancy. Within the range of our study, stands dominated by Douglas-fir often were in drier areas with higher summer temperatures. Sites very close to the coast are usually dominated by Douglas-fir and Sitka spruce (Picea sitchensis) and, for unknown reasons, also lack murrelets.

Contrary to previous studies we did not find larger stands more likely to have murrelets present or to be occupied. Other factors, such as, stand history and juxtaposition to other old-growth stands may mask the effects, if any, of stand size on murrelet presence and use.

Although in the Stand Study we did not find a significant relationship between distance from the ocean and murrelet detections or behaviors, this possibly was related to the limited range of distances for stands surveyed. Our examination of all surveys from 1988 through 1992, however, indicates a strong pattern of declining murrelet presence with distance from the coast (table 7 ). The number of stations more than 40 $\mathrm{km}$ inland with murrelet detections was only about 2 percent. One factor which may have biased the bands $>40 \mathrm{~km}$ inland was the selection of the survey sites. Many of these sites were located in forest habitat selected for timber planning and not considered optimal for murrelets. A lack of murrelet detections would then allow timber harvesting on some of these lands. Further studies inland in California at sites selected by unbiased methods would provide needed information on the murrelet's distribution in these areas.

It is unlikely that one factor alone will best describe murrelet habitat. Density of old-growth cover and species composition are included as important factors in more than one analysis. These variables may be the strongest predictors of murrelet presence in California.

\section{Large Contiguous Stands}

Within the large stands of old-growth in the parks, most stations with observations of occupied behaviors occurred in the major drainages and, correspondingly, at low elevations. Occupied behaviors were observed at 69 ( 73 percent) of the 95 stations in the major drainages. Trees in these drainages tend to be larger, and experience less limb breakage from wind (Tangen, pers. comm.). Both of these factors could contribute to larger diameter branches and more potential nest platforms.

\section{Acknowledgments}

This research was a cooperative effort with private landowners in California who formed the Marbled Murrelet Study Trust including: The Pacific Lumber Company, Arcata Redwood Company, Miller-Rellim Company, Big Creek Lumber Company, Simpson Timber Company, Sierra-Pacific Industries, Barnum Timber Company, Eel River Sawmills, Louisiana-Pacific Corporation and Schmidbauer Lumber Company. We especially would like to thank Lloyd Tangen and Lee Folliard who gave frequent help and encouragement. Jim Brown, Sal Chinnici, Joe Dorman, Steve Kerns, Ray Miller, and Rob Rutland also gave of their assistance and insight. We appreciate the guidance of members of the project's advisory committee, which included members froin all cooperators and agencies, and the U.S. Fish and Wildlife Service, especially Mike Horton. Financial support for the study was provided by the Marbled Murrelet Study Trust of the timber companies, USDA Forest Service, California Department of Fish and Game, California Department of Forestry, California Department of Parks and Recreation, and Redwood National Park. We thank Jennifer Weeks, Brian O'Donnell, Deborah Kirstan, and Ann Buell for their assistance with data preparation, analysis and manuscript reviews and James Baldwin for his statistical advice. We appreciate also the reviews provided Martin Raphael, Alan Burger, Frank Thompson, Mark Huff, Marty Berbach, Valerie Elliot, Sal Chinnici, Lee Folliard, Todd Sloat, and Steve Kerns. We appreciate the efforts of the many field personnel who gathered data for the study.

\section{Appendix A}

Designing a study to examine the relationship of Marbled Murrelets with forest habitats requires first determining if the birds are present or absent from individual forest stands. Here, we outline the methods used to determine the appropriate number of surveys required when the objective is to determine murrelet presence or absence.

For our study, we wished to know how many survey mornings were necessary to determine presence in a stand of murrelets with a 95 percent probability of being correct. We, therefore, set the level of probability of a false negative at 5 
percent. That is, murrelets are present, but we accept a 5 percent probability that they are not detected. Data from previous surveys have been used in the discussion below (table 1). From the data provided by Rob Hewlett, Steve Kerns, Kim Nelson, and our studies, we determined the number of survey mornings needed to meet this level of confidence at sites having various levels of detection rates.

In the following example, we assumed murrelets are present in the relatively homogeneous stand of old-growth timber to be surveyed. Each survey consists of one person observing from a station for one morning.

The method for examining our data was:

$$
P=1-(1-p)^{\mathrm{n}}
$$

where-

$P$ is the probability of at least one detection,

$p$ is the proportion of surveys with at least one detection, that is, the number of surveys with at least one detection, divided by the number of surveys, and

$n$ is the number of surveys required to detect at least one bird.

To determine the number of surveys needed if we want to be 95 percent certain $(P=0.95)$ we are not missing birds which are present, we solve for $n$ :

$$
n \geq \frac{\ln (1-P)}{\ln (1-p)}
$$

where-

In is the natural log.

We tested our survey sample size from 19 sites (table 1) with relatively low average detection rates and a minimum of seven survey mornings. The mean detection rate per morning was divided into four categories, 0.4 to $2.5,2.6$ to 5.0, 5.1 to 7.5 , and 9.4 to 16.6 detections. We used the average percent of surveys with detections within each category to estimate $p$.

In the 0.4 to 2.5 category, the percent of survey mornings with detections varied from 13 percent to 75 percent, with an average of 48 percent of the mornings with detections. The calculation is as follows:

$$
n \geq \frac{\ln (1-0.95)}{\ln (1-0.48)}=4.58 \text {, or } 5 \text { surveys. }
$$

In the 2.6 to 5.0 detection range, the percent of surveys with detections varied over a smaller range, from 63 percent to 91 percent, an average of 81 percent. Using the average number, the calculation is:

$$
n \geq \frac{\ln (1-0.95)}{\ln (1-0.81)}=1.80 \text {, or } 2 \text { surveys. }
$$

In the 5.1 to 7.5 detection range, the percent of surveys with detections varied from 65 percent to 88 percent, an
Table 1-Detection rate at stations with low rates, and the percent of surveys with detections

\begin{tabular}{l|ccc}
\hline Station name & $\begin{array}{c}\text { Number of } \\
\text { surveys }\end{array}$ & $\begin{array}{c}\text { Mean } \\
\text { detection } \\
\text { rate }\end{array}$ & $\begin{array}{c}\text { Percent of } \\
\text { surveys with } \\
\text { detections }\end{array}$ \\
\hline Site F & 8 & 0.4 & 13 \\
ALCR 6 & 8 & 1.0 & 75 \\
FRNO & 7 & 1.3 & 57 \\
Site E & 8 & 2.1 & 25 \\
ALCR 3 & 8 & 2.5 & 75 \\
ALCR 9 & 8 & 2.6 & 63 \\
ALCR 4 & 8 & 3.0 & 88 \\
ALCR 1 & 8 & 3.1 & 75 \\
FRSO & 11 & 4.7 & 91 \\
PATM & 8 & 5.0 & 88 \\
ALCR 10 & 8 & 5.1 & 75 \\
ALCR 12 & 8 & 5.1 & 88 \\
ALCR 13 & 8 & 5.6 & 88 \\
KLMO & 11 & 6.2 & 65 \\
SFYA & 13 & 6.5 & 77 \\
EHSP 10 & 8 & 7.5 & 75 \\
ALCR 11 & 8 & 9.4 & 75 \\
ALCR 8 & 13.0 & 88 \\
CUPE & & 16.6 & 92 \\
\hline & & & \\
\hline
\end{tabular}

average of 78 percent. The calculation as above was 1.98 or a minimum of 2 surveys.

The highest detection range used for this calculation was 9.4 to 16.6 birds per morning, an average of 85 percent of survey mornings with at least 1 detection. The calculation resulted in 1.75 , or 2 surveys.

From these data we can conclude that in areas with mean detection rates as low as 0.4 to 2.5 per survey (and presumably low occupancy rates as well), a minimum of five survey mornings will detect birds if they are present, with a 95 percent probability. In areas of detection rates from 9.4 to 16.6 , the number of surveys necessary to prevent a false negative is about two. Using this formula, 4 surveys would be required to detect birds in areas with a mean of 1.0 to 2.5 detections per survey. We can then conclude that a suggested survey rate of four surveys per stand, will detect birds in excess of 95 percent of the time, and will likely detect all but the smallest populations 99 percent of the time.

\section{Assumptions}

There are several assumptions we have made in using these methods. We list them below and discuss each.

We assume that the amount of canopy cover at a station will have no effect on detection probability $(\mathrm{P})$. 
In most forests, the majority of detections are audio and are not affected by canopy cover. Though the number of visual detections decreases with increased canopy cover, there should be a compensating effect as we have found higher numbers of total detections (e.g., Paton and Ralph 1990 ) as forest age and canopy cover increase.

In calculating $P$, the probability of at least one detection in a stand, we assume that murrelets are present in the stand when the survey is conducted.

The effects of this assumption are discussed in detail in Azuma and others (1990), and the situation with the murrelet is similar. Since there is some probability that murrelets will be present in a stand and not be detected, the result would be an underestimate of the number of stands with murrelets present. Following data collection, bias adjustments presented in Azuma and others (1990) could be used to estimate the number of stands with murrelets in each stand category.
We assume that $\mathrm{P}$ is constant and independent of stand size and habitat type.

It is possible that as stand size increases and habitat matures, the number of birds in a stand will increase. Increased numbers will likely increase $P$ as individuals may call in response to other birds as a result of social facilitation. Therefore, stands with few birds will have fewer detections than stands with many birds. We will be examining this assumption, and it forms the basis of the null hypothesis that stand size and habitat type have no effect on detection rate.

\section{Frequency of surveys}

If the habitat is homogeneous and we assume that the birds are distributed essentially evenly throughout the stand, the stations can be positioned throughout the stand and all stands, regardless of size, would be surveyed four survey mornings. 



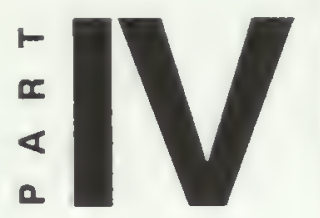

The Marine Environment 


\title{
Chapter 21 \\ Oceanographic Processes and Marine Productivity in Waters Offshore of Marbled Murrelet Breeding Habitat
}

\author{
George L. Hunt, Jr. ${ }^{1}$
}

\begin{abstract}
Marbled Murrelets (Brachyramphus marmoratus) occupy nearshore waters in the eastern North Pacific Ocean from central Califomia to the Aleutian Is]ands. The offshore marine ecology of these waters is dominated by a series of currents roughly parallel to the coast that determine marine productivity of shelf waters by influencing the rate of nutrient flux to the euphotic zone. Immediately adjacent to the exposed outer coasts, wind driven Ekman transport and upwelling in the vicinity of promontories and other features create zones of enhanced primary production in which primary and secondary consumers may aggregate. In the more protected waters of the sounds, bays and inlets of British Columbia and Alaska, tidal processes dominate the physical mechanisms responsible for small-scale variation in primary production and prey aggregations.
\end{abstract}

In North America, Marbled Murrelets (Brachyramphus marmoratus) occupy coastal marine waters from central California to the Aleutian Islands of Alaska. To understand factors controlling marine resources in the habitats occupied by Marbled Murrelets, it is useful to review the coastal oceanography of the region between California and Alaska. For the purposes of this review, I focus on three types of habitat: shelf waters, influenced primarily by the major longshore current systems; inshore waters of the open coasts; and the relatively sheltered waters of sounds, inlets and bays.

This chapter provides an overview for the non-marine specialist of the types of habitats, and the processes that determine the distribution and abundance of marine resources used by Marbled Murrelets.

\section{Determinants of the Shelf Circulation}

The major offshore currents off the west coast of northern North America originate as eastward flowing currents crossing the North Pacific Ocean. One of these, the North Pacific Current, divides into two branches west of the continental shelf off the British Columbia coast (Reed and Schumacher 1987. Thomson 1981). The northern branch curves northeast as the Alaska Current, and forms a counterclockwise rotating gyre in the Gulf of Alaska (fig. 1). The second branch of the North Pacific Current turns southeast as the California Current and flows along the edge of the continental slope off Washington, Oregon and California. The division of the North Pacific Current is seasonally variable; it is most abrupt in winter, and most diffuse and spatially variable in summer (Thomson 1981).

\footnotetext{
${ }^{2}$ Professor, Deparment of Ecology and Evolutionary Biology, University of Califomia. Inine. CA 92717
}

The Alaska Current is relatively wide $(400 \mathrm{~km})$ and slow $(30 \mathrm{~cm} / \mathrm{s})$ as it moves through the eastern Gulf of Alaska (Reed and Schumacher 1987). As the Alaska Current passes Kayak Island in the northern Gulf of Alaska, it forms a strong ( $>50 \mathrm{~cm} / \mathrm{s})$, clockwise rotating gyre in the island's lee (Royer and others 1979). A branch of the Alaska Current, the Alaska Coastal Current, diverges from the gyre and approaches the Kenai Peninsula coast (fig. 1). In fall, the Alaska Coastal Current shows a marked increase in velocity, apparently as a result of both increased freshwater runoff and easterly winds that constrain the current in a narrow coastal stream and produce coastal convergence (movement of water toward the coast, with attendant downwelling) (Royer 1979, 1983; Schumacher and Reed 1980). Much of this flow passes through Kennedy Entrance, south of the Kenai Peninsula, and thence into either Cook Inlet or westward into Shelikof Strait between Kodiak Island and the Alaska Peninsula. The main Alaska Current exits the Alaska Gyre to the west as the Alaska Stream, flowing along the Alaska Peninsula and the south side of the Aleutian Islands. West of Kodiak Island, it becomes narrow $(100 \mathrm{~km})$ and swift ( 100 $\mathrm{cm} / \mathrm{s}$ ) (Reed and Schumacher 1987). Although these currents are for the most part seaward of the distribution of Marbled Murrelets in the Gulf of Alaska (Piatt and Ford 1993), the currents are important to marbled murrelets because they influence the transport of plankton into coastal waters and also because they can play an important role in the transport of oil slicks when spills occur (Piatt and others 1990).

The California Current varies in its intensity, definition, and direction of flow geographically and seasonally (fig. 2) (Mooers and Robinson 1984; Thomson 1981). It is relatively weak off the Washington and Oregon coasts, where it has a southward flow only 20 percent of the time. In contrast, off California, the current is usually well defined and flows southward about 50 percent of each month. The California Current is most often southward and strongest between March and September.

Changes in the direction and intensity of flow of the California Current have important effects on offshore marine production (Chelton 1981, Chelton and others 1982). When the current moves strongly southward, water throughout the water column moves away from the coast (offshore transport) due to the Coriolis Effect. In addition, offshore transport of surface water, also related to the Coriolis Effect (Ekman transport), results when north and northwest winds force increased surface flow to the south. Water transported offshore is replaced by the upwelling of deep, cold, nutrient rich water that supports enhanced productivity. These seasonal and interannual fluctuations in the California Current system and its productivity have been linked to changes in the 


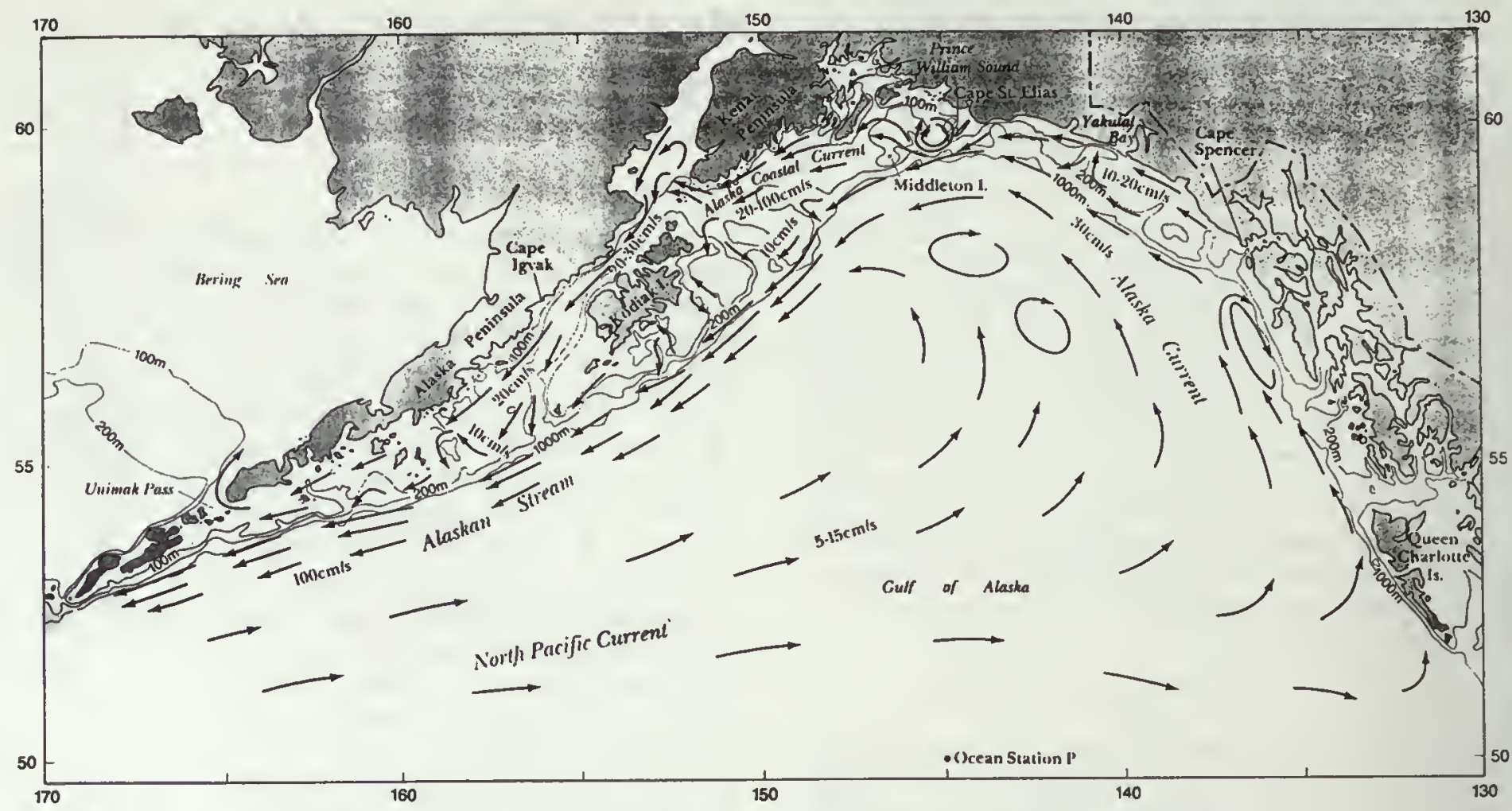

Flgure 1-Major features of ocean circulation in the Gulf of Alaska. From Reed and Schumacher (1987), by permission.

breeding success of seabirds (Ainley and Boekelheide 1990, Ainley and others, in press) and in the numbers and distribution of seabirds at sea (Briggs and others 1987).

Inshore of the California Current, the Davidson current flows northward seasonally from about $32^{\circ}$ to about $50^{\circ} \mathrm{N}$ (fig. 2). The onset of the Davidson Current usually occurs in October, when the overall average movement of water in the California Current system shifts toward the north until March (Thomson 1981). When the northward flowing Davidson Current prevails, upwelling is suppressed because northward flowing water is deflected by the Coriolis Effect toward the shore and downwelling is likely to prevail (McLain and others 1985). The seasonal shifts in the flow of the California Current system are largely the result of changes in the direction of the prevailing winds. In spring and summer, the winds blow from the northwest and move the surface water southward, whereas in winter, prevailing winds are from the southwest and surface water movements are to the north.

Off Vancouver Island, a northwestward coastal current flows inshore of the southeastward flowing southern branch of the North Pacific Current (Thomson 1981). This inshore current originates in the outflow of the Strait of Juan de Fuca and is confined in summer to within $15-20 \mathrm{~km}$ of the coast. The speed of the coastal current is determined by the velocity of the winds. In winter, the coastal flow merges with that of the Davidson Current.

Strong El Niño-Southern Oscillation events cause a reversal of flow in the California Current System, the presence of a surface layer of warm, nutrient-depleted water, and the replacement of coastal upwelling with downwelling (Johnson and O'Brien 1990; Norton and others 1985; Rienecker and Mooers 1986). A consequence of these events is a marked reduction in primary production, followed by a reduction in zooplankton populations and reduced survival of at least some larval fish (Barber and Chavez 1984, MacCall 1986, Pearcy and Schoener 1987). These events result in a marked decrease in seabird reproductive success and in striking changes in the offshore distribution and abundance of seabirds (Ainley and Boekelheide 1990; Ainley and others, in press; Briggs and others 1987).

\section{Inshore Waters of the Open Coasts}

Large oceanic currents determine regional marine habitat types and are responsible for a major portion of the seasonal variation in production on the shelf. However, marine waters within a few kilometers of the shore are where Marbled Murrelets spend most of their time. In these areas, currents interacting with bathymetry can create fronts (boundaries between water masses where convergences or upwelling may occur) and upwellings that either enhance productivity, or cause organisms to accumulate because of behavioral responses to physical gradients. For example, upwelling results when a current passes a promontory and draws away surface water that is then replaced by water from depth (Pingree and others 1978; Thomson 1981). Fronts associated with these processes provide foraging sites for seabirds. 
A
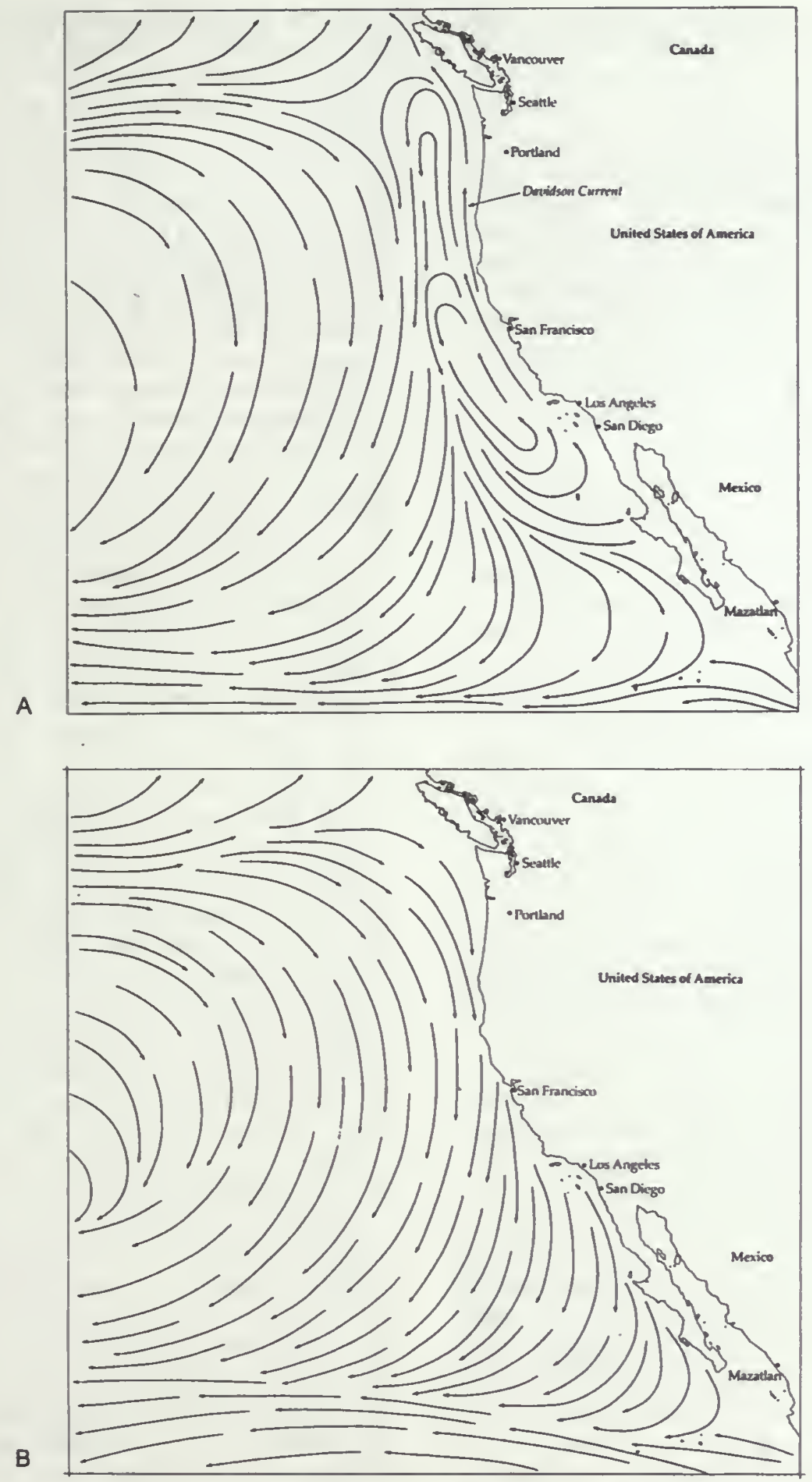

Flgure 2-Schematic of the circulation of the California Current in (a) February and (b) August. From Ingmanson and Wallace (1989), by permission. 
In coastal waters, strong winds cause upwelling by two mechanisms. In the first, water is displaced from near the coast by winds blowing parallel to the coast from the north. In the northern hemisphere, if water depths are sufficient, surface waters will move at approximately 90 degrees to the right of the direction of the surface wind because of the Coriolis Effect (Ekman transport). When this occurs near the coast, the displaced water is replaced by nutrient rich water from depth. In the second, winds blowing from the shore cause inshore upwelling. If the water is sufficiently shallow, the Ekman transport is effectively canceled by friction with the bottom, and surface flows will be in the same direction as the wind. When strong land breezes blow surface water away from a lee shore, inshore surface waters are replaced with water from greater depth.

Along the open coasts of California, Oregon, and Washington, localized nearshore upwelling due to Ekman transport and offshore winds blowing water away from lee shores provides regions of enhanced primary and secondary production. These upwelling processes, and fronts associated with river discharges are expected to be the most important physical features in determining murrelet foraging opportunities. Ainley and others (this volume) provide one of the only examples of the sort of mesoscale studies needed to link murrelet foraging distributions to physical and biological processes that result in exploitable concentrations of prey.

\section{Sheltered Waters of Sounds, Inlets and Bays}

The physical and chemical oceanographic processes controlling primary production in the fjords and estuaries of the Gulf of Alaska and the British Columbia coasts are reviewed by Burrell (1987) and Reeburgh and Kipphut (1987). In these fjords, freshwater input, primary production, and other biogeochemical processes are highly seasonal. Freshwater, less dense than saltwater, forms a surface layer in the fjords and is discharged from these upper layers into the Gulf of Alaska; waters from the Gulf of Alaska circulation episodically penetrate the fjords to replace intermediate and deep resident waters (Burrell 1987). These exchanges influence the availability of nutrients to, and the residence time of, phytoplankton. Both factors also affect the timing and magnitude of primary production in the fjords. Coastal frontal zones associated with shallow areas with increased water flow can be the site of elevated primary production because of enhanced vertical flux of nutrients (Parsons and others 1983, 1984). High tidal ranges present in British Columbia and along the coast of the Gulf of Alaska would promote these enhanced vertical fluxes in the vicinity of sills at the mouths of fjords (Burrell 1987). In late summer and early fall, turbidity from river inflows may progressively limit primary production in the upper ends of fjords (e.g., Goering and others 1973).
Fjords may support one of two generalized trophic pathways (Burrell 1987, Matthews and Heindal 1980). In shallow fjords or those with shallow sills, the pathway may lead from small phytoplankton to small copepods to jellyfish. In deeper fjords, and fjords with deep sills, the trophic pathway may include large net phytoplankton (primarily diatoms), large copepods and finfish. Apparently, the depth of the sill is a critical feature; if it intercepts the pycnocline (the layer in which water density changes rapidly with depth, and which inhibits vertical mixng of water), the upper layer of out-flowing fresh water inhibits the recruitment of large calanoid copepods from outside the fjord. The ontogenetic migration to the upper water column of Neocalanus plumchrus and related oceanic copepod species in the North Pacific occurs at the same time as the coastal convergence mentioned above (Burrell 1987). Their presence in the upper water column at this time allows them to be transported into adjacent fjord environments according to observations by R. T. Cooney, as cited by Burrell (1987). These large copepods are likely to be important prey for the small fish taken by Marbled Murrelets. One might hypothesize, then, that murrelets would be more likely to forage in fjords supporting populations of large copepods than in fjords lacking this component of trophic transfer. Additionally, one might expect that Marbled Murrelets would be more likely to forage at the seaward ends and near the sills of these fjords, rather than at their inner ends.

In the inland waters of the sounds and channels of Washington, British Columbia, and Alaska, tidal processes are likely the most important determinants of localized foraging opportunities for marbled murrelets and other seabirds. Upwellings can be caused by currents impinging on an obstruction and being driven to the surface, such as when strong tidal currents encounter a sill and flow over it. In these circumstances planktonic organisms are driven to the surface (Brown and Gaskin 1988; Vermeer and others 1987), or may be concentrated at depth where their ability to swim against a gradient is matched by an opposing current (e.g., Coyle and others 1992).

Superimposed on the physical mechanisms that enhance primary production and concentrate prey are the seasonal variations in production and the movements of prey of suitable size. We know of few studies of physical processes and fish movements at temporal or spatial scales appropriate for understanding murrelet foraging, and none for which murrelets were a focus of the study. This paucity of data makes it difficult to assess, in oceanographic terms, the characteristics of habitats critical for foraging murrelets.

\section{Acknowledgments}

I thank Dan Anderson, Larry Spear and C. John Ralph for helpful comments on an earlier version of this manuscript. 


\section{Chapter 22 \\ Marbled Murrelet Food Habits and Prey Ecology}

\section{Esther E. Burkett"}

\begin{abstract}
Information on food habits of the Marbled Murrelet (Brachyramphus marmoratus) was compiled from systematic studies and anecdotal reports from Alaska to California. Major differences between the winter and summer diets were apparent, with euphausiids and mysids becoming more dominant during winter and spring. The primary invertebrate prey items were euphausiids, mysids, and amphipods. Small schooling fishes included sand lance, anchovy, herring, osmerids, and seaperch. The fish portion of the diet was most important in the summer and coincided with the nestling and fledgling period. Murrelets are opportunistic feeders, and interannual changes in the marine environment can result in major changes in prey consumption. Site-specific conditions also influence the spectrum and quantity of prey items. More information on food habits south of British Columbia is needed. Studies on the major prey species of the murrelet and relationships between other seabirds and these prey are briefly summarized. Short-term phenomena such as EI Niño events would not be expected to adversely affect murrelet populations over the long term. However, cumulative impacts in localized areas, especially in conjunction with El Niño events, could cause population declines and even extirpation.
\end{abstract}

An understanding of Marbled Murrelet (Brachyramphus marmoratus) food habits is needed for effective conservation of this threatened seabird. Many seabirds are known to be affected by prey availability, though human activities induce and compound impacts (Croxall 1987: 377-378; Furness and Monaghan 1987: 35-45, 98-99; Gaston and Brown 1991; Jones and DeGange 1988; Tyler and others 1993). Ainley and Boekelheide (1990: 373-380) discuss the interplay of factors affecting seabird reproduction and total population size, especially as related to different marine systems.

The dramatic loss of old-growth forest nesting habitat (Marshall 1988b) has resulted in a fragmented distribution of the murrelet at sea, especially during the breeding season (Carter and Erickson 1988, Piatt and Ford 1993). Proximity of nesting habitat to an oceanic prey base is important for energetic reasons (Cody 1973, Sealy 1975c, Carter and Sealy 1990), but the bird's capabilities are not understood, and fluctuations in prey populations and variability in prey distribution have not been studied relative to murrelet nesting success or inland distribution. Nevertheless, much of the work on food habits conducted thus far is useful for management purposes and can be used to direct further research.

Six systematic studies on food habits of the murrelet have been conducted in North America. Two occurred during the breeding season in British Columbia (Carter 1984, Sealy 1975c) and one in the non-breeding season (Vermeer 1992).

'Associale Wildlife Biologist, Califomia Department of Fish and Game, 1416 Ninth Street, Sacramento, CA 95814
In Alaska, two studies have been conducted in the nonbreeding season (Krasnow and Sanger 1982, Sanger 1987b), and one took place during the breeding season (Krasnow and Sanger 1982). These studies form the basis for much of the knowledge of murrelet food habits and are discussed below along with anecdotal information on murrelet diet.

Recent genetic analysis has indicated that the North American Marbled Murrelet warrants full specific status (Friesen and others 1994a). For this reason, and since this chapter was written primarily to aid in management action and recovery planning in North America, information on the diet of the Long-billed Murrelet (Brachyramphus marmoratus perdix) has been omitted.

Overall, murrelet food habits in the Gulf of Alaska and British Columbia have received the most attention. Very little information is available on food habits of murrelets in Washington, Oregon, or California, and systematic stomach analyses have never been conducted in these states.

\section{Methods}

Because so few studies with large sample sizes have been conducted and the geographic scope of the studies to date is limited, an attempt was made to assemble information on food habits from Alaska to California, even though many of the records are anecdotal or represent field studies with small sample sizes. In addition to a literature review, murrelet biologists from Alaska to California were contacted for information.

An attempt was made to separate adult and nestling food items and to distinguish between foods used in the breeding and non-breeding seasons. However, in some cases the researcher's "winter" collection period continued into the early part of the breeding season (March and April), and the data were not analyzed separately. Also, at times the age class of the murrelet specimens was not stated in the literature. Even if such information were known, the small sample sizes, large geographic differences, and separation of time scales would confound the interpretation of results. Prior to this work, four summaries of murrelet diet were produced (Ainley and Sanger 1979, Ewins and others 1993, Sanger 1983, Carter 1984).

\section{Results}

\section{Systematic Studies of Food Habits \\ Sealy (1975c)}

Sealy (1975c) was the first to systematically study murrelet feeding ecology, along with work on the diet of the Ancient Murrelet (Synthliboramphus antiquus) near Langara Island, British Columbia. Langara Island is part of the Queen Charlotte Islands and is approximately 500 kilometers 
northwest of Vancouver Island. The study spanned two breeding seasons ( 1970 and 1971), and 86 adult and subadult Marbled Murrelets were collected between March 25 and August 10 (years combined). The diets were essentially the same for both sexes, and samples from subadults and adults were identical, so the data were pooled for a total sample of 75 individuals. Additionally, six newly fledged murrelets were taken between July 10 and August 4, 1971, and their food habits were analyzed separately. The percentage of murrelets collected that contained prey ranged from 87 to 100 percent.

Sand lance (Ammodytes hexapterus) made up 67 percent of the food items in the diet of the adults and subadults. Euphausiids were the next most important food item and contributed 27 percent of the items. Two species of euphausiids were consumed, Euphausia pacifica and Thysanoessa spinifera, with relative importance values of 2 percent and 25 percent, respectively. The next most important food item was the viviparous seaperch (Cymatogaster aggregata), with a value of 3 percent. Overall, sand lance, euphausiids, seaperch, scorpaenids, and osmerids made up 98 percent of the murrelet diet. Including the less common food items which occurred in very small amounts, at least nine different types of prey were identified (table 1 ).

The six samples of newly fledged young selected different prey than adult/subadult murrelets (table 1 ). Sand lance still dominated the diet at 65 percent (similar to 67 percent for adult/subadult murrelets), but the seaperch was the next most important prey species, rather than euphausiids, with a value of 35 percent. The euphausiid, T. spinifera, and amphipods made up trace amounts of the remainder of the fledgling diet.

The difference in adult and juvenile diets can be partially explained by looking at the difference in abundance of prey items taken by the adult/subadult murrelets over the course of a breeding season. The euphausiid, $T$. spinifera, was found more commonly in the adult/subadult diet during the mid-April to mid-May period and was more important than the sand lance at this time, but euphausiids diminished greatly in the diet after the early part of the breeding season. However, T. spinifera remained important in the diet of adult Ancient Murrelets through mid-July when the study concluded. Sealy attributed this difference in diet to the offshore movement of $E$. pacifica (affinity for deeper water than $T$. spinifera) and, to some extent, offshore movement of $T$. spinifera as the spring progressed and water temperature rose. He also attributed the diet change to reduced abundance of $T$. spinifera due to loss of females after reproduction. Additionally, he noted that adult Ancient Murrelets feed further offshore than Marbled Murrelets or juvenile Ancient Murrelets, and he believed the food supply of the Ancient Murrelet was spotty and unpredictable.

Sealy tested for a measurable change in prey availability mid-summer by examining the stomach contents of 13 individuals of seven species, including the Ancient and Marbled Murrelet, from six mixed-species feeding assemblages. Between 9 May and 26 June 1971 he conducted plankton hauls where collected birds had been foraging. The results indicated that only Thysanoessa was available and taken by those individuals examined in May, and later samples in June found only Ammodytes available and being consumed. He concluded that fishes such as Cymatogaster and Ammodytes tend to spend the winter and early spring in midwater offshore, but migrate to the surface and move inshore in late spring, thus possibly becoming available to murrelets at this time.

Plankton hauls made in 1971 also indicated that the murrelets were more selective in their feeding habits when compared to prey availability (Sealy 1975c). Organisms such as ctenophores, amphipods, and polychaetes were obtained in the plankton hauls, but none of these organisms were found in the food samples analyzed. Zooplankton sampling by Project NorPac (Dodimead 1956) during summer 1955 (primarily in August) resulted in a similar difference in prey availability; copepods were by far the most numerous organisms with a total volume of more than 65 percent, while euphausiids composed less than 10 percent of the total volume (LeBrasseur 1956).

Sealy (1975c) concluded that murrelets seldom feed more than $500 \mathrm{~m}$ from shore, usually in water less than $30 \mathrm{~m}$ deep. His work demonstrated that euphausiids made up only a small part of the overall diet during the breeding season, but were dominant during the early part of the breeding season. He thought the breeding season was possibly ultimately controlled by the cycles of abundance of fishes near shore, especially the sand lance, which were taken by the murrelet in great quantities in the study area.

\section{Krasnow and Sanger (1982)}

Krasnow and Sanger (1982) collected murrelets at sea in the vicinity of Kodiak Island in the winter of $1976 /$ 1977. They collected 18 murrelets (all with food) between December 1976 and April 1977 at Chiniak Bay, a large bay on the northeast end of Kodiak Island; a second sample of 19 murrelets ( 16 with food) was collected from Chiniak in February 1978. Two other sites were sampled during the breeding season of 1978. At Izhut Bay, a small bay north of Chiniak Bay, Krasnow and Sanger collected 34 murrelets ( 25 with food) between April and August 1978 and from Northern Sitkalidak Strait, which is located on the southeast end of Kodiak, they collected 26 murrelets (17 with food) between May and August 1978. The percentage of murrelets collected which contained prey ranged from 65 to 100 percent.

Krasnow and Sanger calculated an Index of Relative Importance (IRI) value for the foods consumed by murrelets according to Pinkas and others (1971). During the 1976/ 1977 winter, fish, primarily of the family osmeridae, were the most important prey, followed by euphausiids of the genus Thysanoessa, and mysids (table 2). A total of 11 different prey items were identified (table 2), compared to nine from Sealy's (1975c) breeding season study (table 1). 


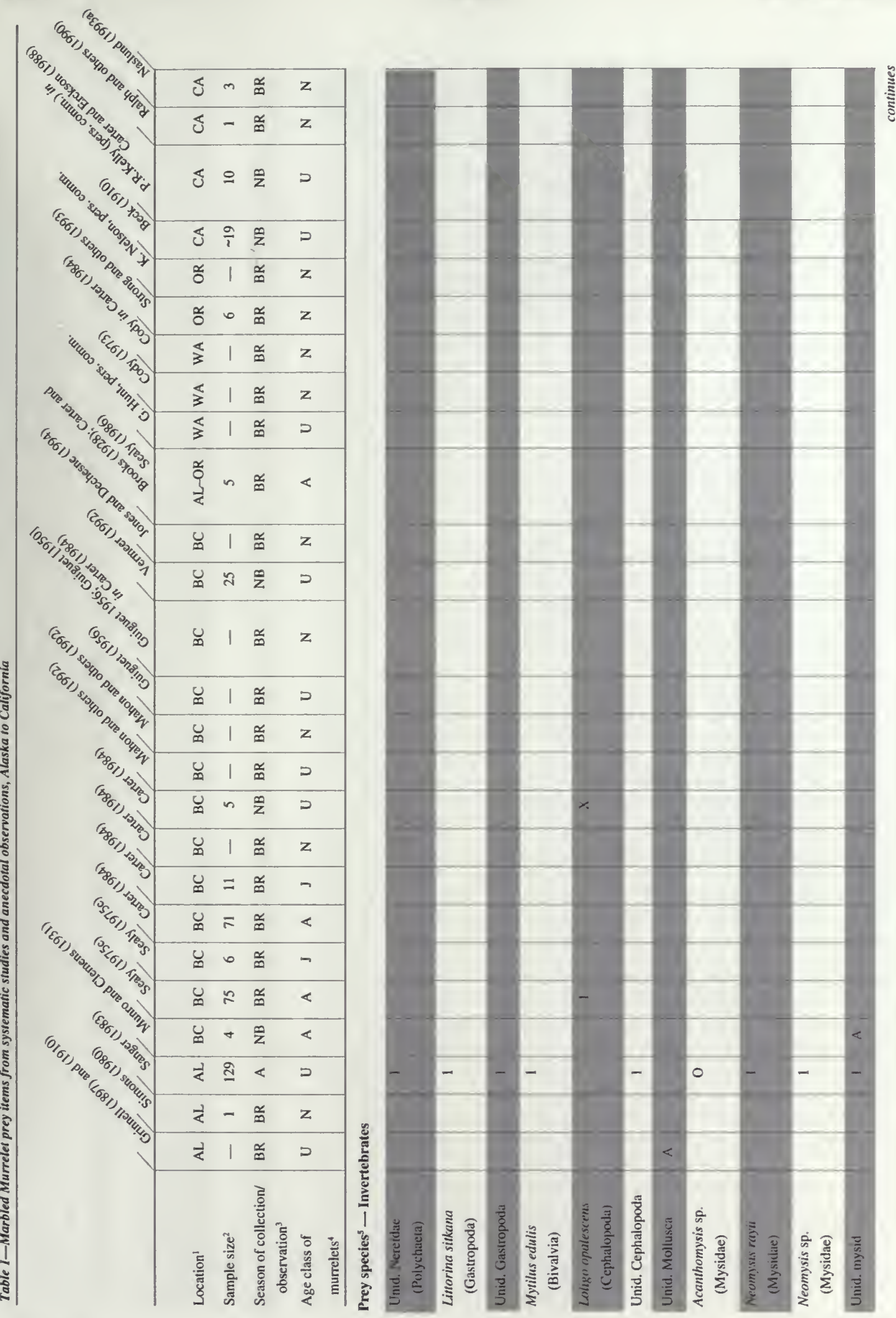




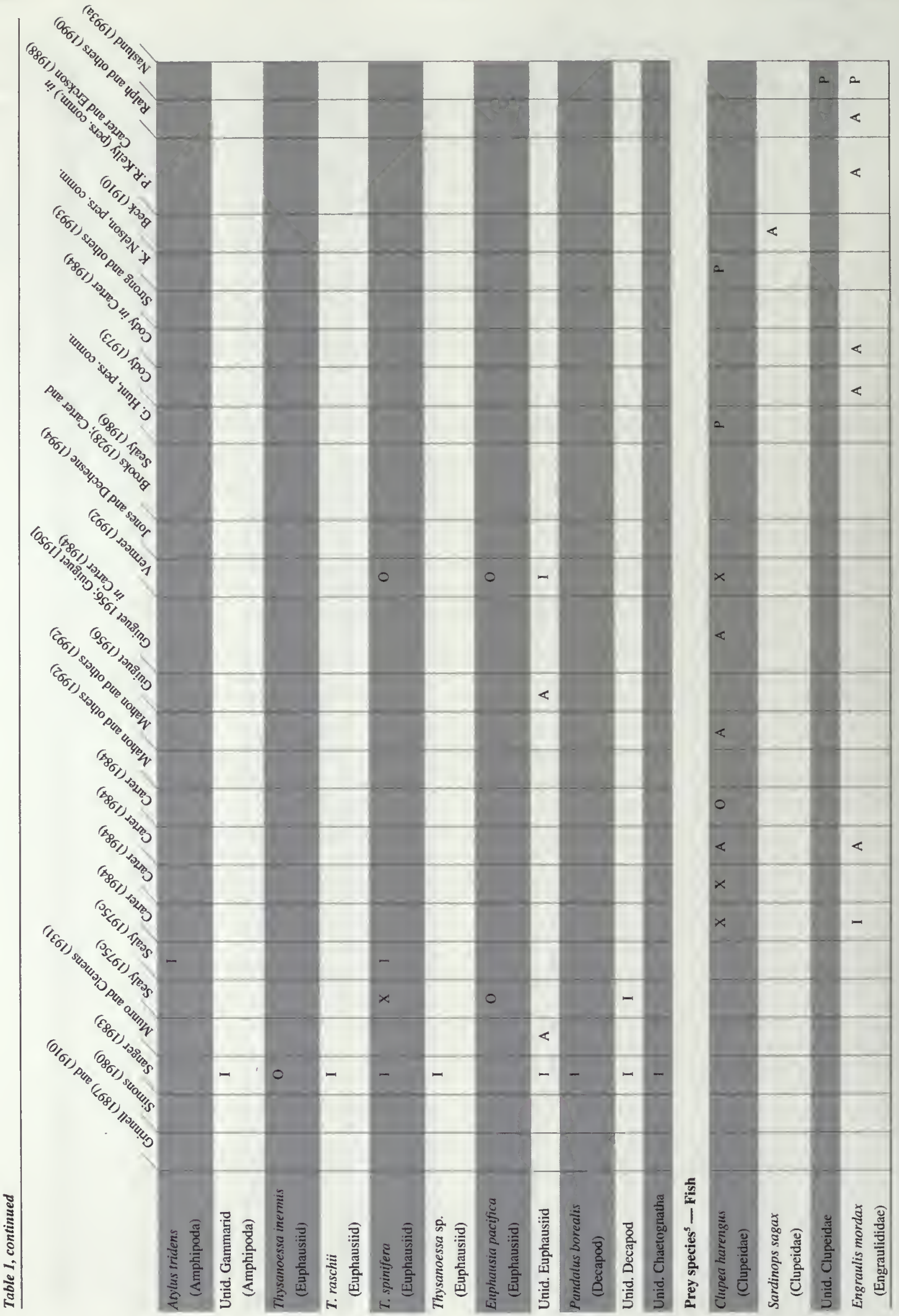




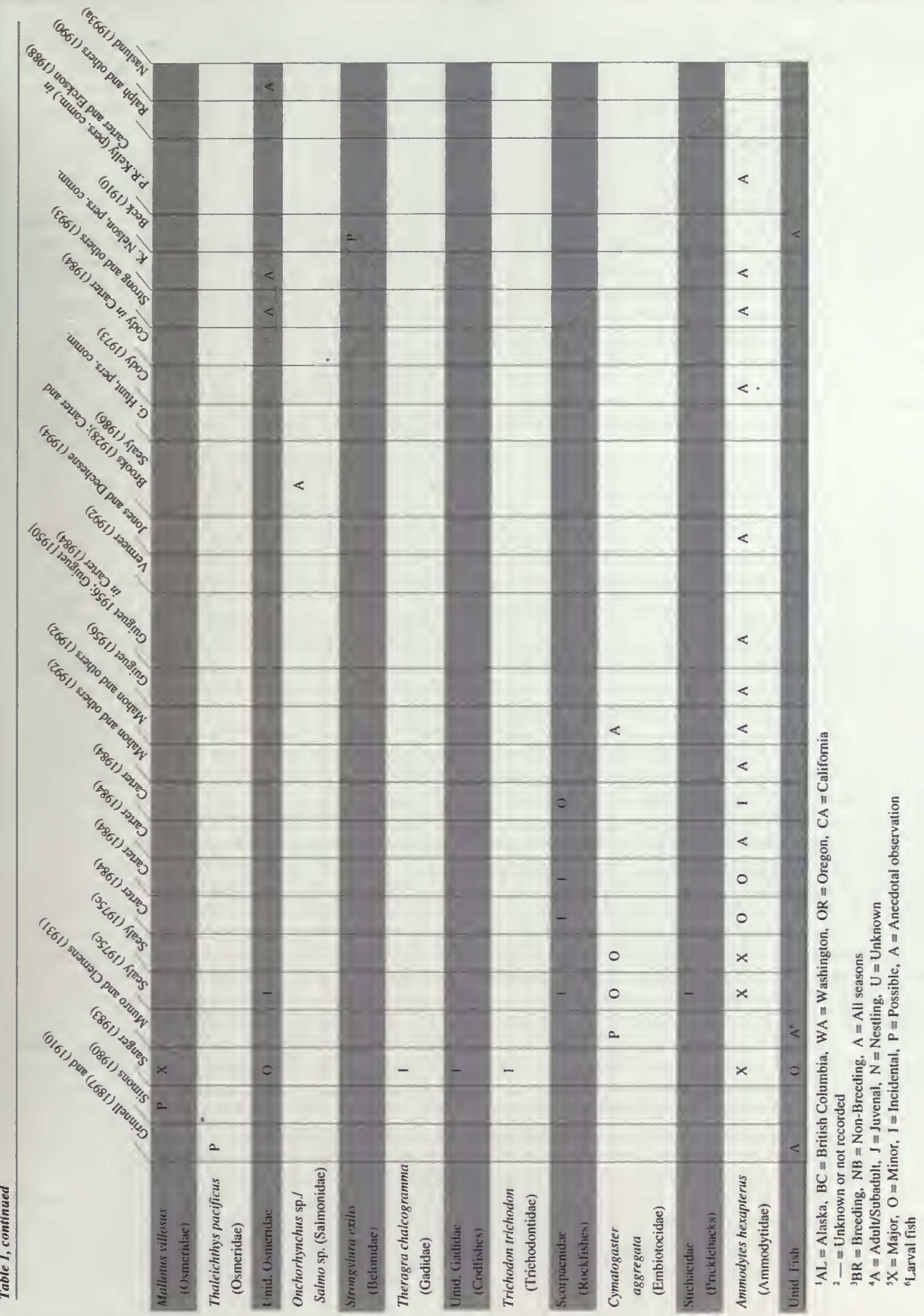


Table 2-Comparison of winter diet af Marbled Murrelets in Chiniak Bay, Alaska, between December 1976-April 1977, and February 1978

\begin{tabular}{|c|c|c|}
\hline \multirow[b]{2}{*}{ Prey } & \multicolumn{2}{|c|}{ Year } \\
\hline & $1976 / 1977$ & 1978 \\
\hline Nereidae & $3^{b}$ & 0 \\
\hline Chaelognatha & 1 & 0 \\
\hline Mysidacea & 23 & 447 \\
\hline Acanthomysis sp. & 4 & 10,548 \\
\hline Neomysis sp. & 0 & 870 \\
\hline N. rayii & 2 & 27 \\
\hline Thysanoessa sp. & 74 & $\quad 0$ \\
\hline T. inermis & 1,169 & 0 \\
\hline$T$. spinifera & 5 & 0 \\
\hline T. raschii & 0 & 4 \\
\hline Gammaridea & 0 & 58 \\
\hline Decapoda & 0 & 8 \\
\hline Pandalidae & 0 & 6 \\
\hline Pandalus goniurus & 0 & 4 \\
\hline Osteichlhyes & 3 & 62 \\
\hline Osmeridae & 1,584 & 33 \\
\hline Mallotus villosus & 526 & 41 \\
\hline \multirow[t]{2}{*}{ Theragra chalcogramma } & 0 & 4 \\
\hline & $n=18$ & $n=16$ \\
\hline
\end{tabular}

${ }^{a}$ Data from Krasnow and Sanger (1982)

b Values are Index of Relative Importance values calculated after Pinkas and others (1971).

In contrast to the results of Sealy (1975c), no Ammodyles were present, but, similar to Sealy's (1975c) study, Thysanoessa was an important prey item.

The results from the February 1978 collections were extremely different from the 1976/1977 winter data. Mysids dominated the prey items with a cumulative IRI value of 11,892 (table 2). Osteichthyes were second, followed by gammarids and capelin (Mallotus villosus). A total of 13 different prey items were identified (table 2). Once again, no Anımodyles were noted, and even Thysanoessa was reduced to an IRI value of 4. Sealy's (1975c) breeding period study did not detect mysids and gammarids, but these prey items appear to be more important in the winter diet of murrelets, at least in the Gulf of Alaska (Sanger 1987b, Sanger and Jones 1982). The lack of Thysanoessa consumption in February 1978 by the murrelets is particularly interesting in light of Sealy's (1975c) work. Krasnow and Sanger (1982) reported that murrelets fed primarily in shallow water but obtained their prey throughout the water column. Sanger (1987b) noted that the ability of murrelets to forage at least part of the time near the bottom assures a broader trophic spectrum than a food supply originating with phytoplankton productivity in the water column alone.
The reduction of capelin in the winter diet of murrelets between the study periods may be due to the dynamic nature of capelin populations. Because capelin live only 3 or 4 years and most spawn only once, poor recruitment of a given year class can lead to cycles of abundance and near absence [Warner and Dick in Krasnow and Sanger (1982)]. Fisheries data indicated that the distribution of capelin was different in the 2 years, with most fish being caught in deep troughs in 1978 [Rogers and others in Krasnow and Sanger (1982)]. Additionally, fewer capelin and more sand lance were fed to Black-legged Kittiwake (Rissa tridactyla) chicks in Northern Sitkalidak Strait during 1978 than in 1977. Productivity of kittiwakes declined from 0.74 young fledged per nest attempt to 0.17 , suggesting that the availability of food was depressed below some "critical level" [Baird and Hatch in Krasnow and Sanger (1982)]. Productivity of kittiwakes in Chiniak Bay also decreased, from 1.23 young fledged per nest attempt in 1977 to 0.77 in 1978 [Nysewander and Barbour in Krasnow and Sanger (1982)]. Food samples were not collected at the breeding colonies of kittiwakes in Chiniak Bay in 1978, and thus the assumption that fewer capelin were brought to chicks than during the previous years could not be substantiated.

If euphausiids were scarce or, for some reason, unavailable to murrelets in early 1978 in Chiniak Bay, then the ability of the murrelet to feed so heavily on detritivores such as mysids and gammarids likely demonstrates preyswitching capability. This adaptive and opportunistic behavior illustrates the result of natural selection pressure due to dynamic prey populations. Alternatively, two factors, small sample size and a difference in the collection period (5 months compared to 1 month), could be complicating the results. However, given the information on kittiwake reproduction and capelin being found in deeper waters cited above, it would appear that changes in the marine food web in Chiniak Bay between years and prey-switching behavior by the murrelet are more plausible explanations.

The results of Krasnow and Sanger's (1982) study of breeding-season diet at Izhut Bay and Northern Sitkalidak Strait in 1978 pointed to the importance of local differences in the relative availability of major prey species within the same year. The diets from the two different study areas included a high proportion of unidentified osteichthyes (table 3 ), with ten different prey items identified in the summer diet, comparing with 9 from Sealy (1975c). Euphausiids were more common in the murrelet diet at northern Sitkalidak Strait. For the murrelets and most other seabird species in the Kodiak area, distinct seasonal trends were apparent from spring through late summer 1978. Marbled Murrelets, Tufted Puffins (Fratercula cirrhata), Sooty Shearwaters (Puffinus griseus), and Black-legged Kittiwakes exploited a similar suite of prey. Sand lance and euphausiids were taken during spring, capelin during early summer, and sand lance during late summer. The authors attributed this chronology to the probable seasonal occurrence and distribution of prey as did Sealy (1975c) and Carter (1984) in their study areas. 
Table 3-Comparison of May 1978 breeding season diet of Marbled Murrelets between Ishut Bay and Northern Sitkalidak Strait, Alaskor

\begin{tabular}{l|rc}
\hline \multirow{2}{*}{ Prey } & \multicolumn{2}{|c}{ Location } \\
\cline { 2 - 3 } Crustacea & Izhut Bay & Northern Sitkalidak Strait \\
Thysanoessa inermis & $60^{\mathrm{b}}$ & 0 \\
Osteichthyes & 0 & 18,910 \\
Osmeridae & 316 & 82 \\
Mallorus villosus & 326 & 0 \\
& 5,957 & 190 \\
& $n=3$ & $n=4$ \\
\hline
\end{tabular}

Dasa from Krasnow and Sanger (1982)

b Values are Index of Relative Importance values calculated after Pinkas and others (1971)

The difference between the two areas in the May diet (table 3) may be due to the small sample sizes or may represent a local difference in prey abundance as discussed above relative to winter diet. The two study areas showed similarity in murrelet diet in June, with fish (primarily capelin) the most important food item. The July samples indicated the importance of sand lance and fish in murrelet diet during that period: three birds collected at Izhut Bay had only sand lance in their stomachs, while four birds collected at Sitkalidak were full of sand lance and other unidentified osteichthyes.

\section{Sanger (1983)}

Sanger's compilation of data from throughout the Gulf of Alaska, and across all seasons, provides an overview of the broad spectrum of the murrelet's diet (table 1). Data were derived from multiple Outer Continental Shelf Environmental Assessment Program (OCSEAP) studies (including Krasnow and Sanger 1982, Sanger and Jones 1982) and from the National Marine Fisheries Service $(n=129)$. At least 16 prey species were identified. This broad spectrum of prey species from different trophic levels is a good indication that the murrelet is an opportunistic feeder, though preferences have been documented (Sealy 1975c). Generally, murrelets seem to prefer euphausiids in spring and fish in summer though prey availability and energetic requirements during these seasons are also important factors in prey selection (Carter and Sealy 1990, Cody 1973, Sealy 1975c).

Additionally, "food-chain pathways that include detritus may result in a more stable food supply than non-detrital food chains. This could be reflected in demersal-benthic feeders like Pelagic Cormorants [Phalacrocorax pelagicus] and Pigeon Guillemots [Cepphus columba] showing stable productivity over the years, compared with midwater and surface feeders. Winter survival of species like Common Murres [Uria aalge] and Marbled Murrelets may be enhanced by their ability to alter their 'normal' diet of pelagic fishes to include demersal crustaceans, thus seasonally linking themselves to a detrital-based food chain" (Sanger 1987a).

\section{Sanger (1987b)}

One last example of the importance of local conditions on murrelet diet from the OCSEAP work in Alaska comes from a summary of work done in Kachemak Bay during the winter of 1978 (Sanger 1987b). Twenty-one murrelets were collected from January to April 1978, and 18 stomachs were used for the analysis. Capelin and osmerids dominated the diet, followed by euphausiids (Thysanoessa sp.), mysids, unidentified gammarid amphipods, and sand lance. Compared to the work of Krasnow and Sanger (1982) in Chiniak Bay, euphausiids were more important, and sand lance were taken. Thus, although the sample sizes are similar, the relative importance of prey species is variable. This disparity is another example of the importance of local and interannual conditions in determining murrelet food habits.

\section{Carter (1984)}

Carter's intensive study occurred in Barkley Sound, on the southwest coast of Vancouver Island. Field work was conducted from 10 May to 7 September 1979, 18-19 December 1979, and 8 June to 13 October 1980. Eightyseven murrelets were obtained during the study and examined for diet information. Carter (1984) noted that small fish larvae $(<31 \mathrm{~mm})$ were apparently digested quickly, and therefore this size class was under-represented in the results. Food samples from both sexes were taken throughout the day in both years and were combined for analysis. Carter also separated the diet of breeding, molting, hatching-year, and winter birds and calculated a relative importance value in the same way of Sealy (1975c), though he referred to this percent value as frequency.

Breeding adults fed primarily on sand lance and Pacific herring (Clupea harengus), including larval and juvenile fish (table 1). Molting and hatching-year birds also fed primarily on herring and sand lance, and four juvenile northern anchovy (Engraulis mordax) were found in the stomach of one molting bird. Carter (1984) noted that molting murrelets consumed more herring ( 90 percent) than sand lance (7 percent), and the same was true for the hatching-year murrelets, with herring consumption at 81 percent and sand lance at 13 percent. By contrast, the breeding murrelets consumed more sand lance ( 63 percent) and less herring ( 36 percent) (table 1).

In contrast to the work of Sealy (1975c), euphausiids were absent in the diet of murrelets in Barkley Sound. Though Carter's (1984) work began approximately one month later than Sealy's (1975c), euphausiids in minor amounts should have occurred at least in May and throughout the summer at least as a minor component of the diet. Additionally, the overall diversity of prey species in the summer diet of murrelets from Barkley Sound was low (4 different prey items) compared to 9 from Sealy's (1975c) study and 10 from Krasnow and Sanger (1982). 
Five murrelets collected in winter had eaten scorpaenid rockfish and squid (Loligo opalescens), as well as large juvenile herring and sand lance (table 1). Scorpaenids and Loligo were also found in the murrelet diet at Langara Island by Sealy (1975c) during the breeding season (table 1).

Carter (1984) also made observations at sea of adults holding fish for nestlings; Ammodytes, Clupea, and Engraulis were documented as nestling food (table 1).

The importance of herring in the diet of the murrelet in Carter's (1984) study correlates with the local abundance and availability of juvenile herring. He suggested that murrelets fed opportunistically on available prey and noted that juvenile herring were abundant only in localized areas near spawning grounds (Hourston in Carter 1984). This conclusion is further strengthened by the work of Vermeer (1992) discussed below.

\section{Vermeer (1992)}

Winter food habits of murrelets from Quatsino Sound, British Columbia, were studied for the period from October 1981 through March 1982 (Vermeer 1992). Quatsino Sound is located approximately 270 kilometers northwesterly of Barkley Sound where Carter's (1984) work was conducted.

Twenty-five murrelets were collected, and all birds ( 100 percent) contained food. Most fish were digested, but Pacific herring were identified in 15 of the 25 murrelets. All invertebrates eaten consisted of euphausiids, of which $T$. spinifera and $E$. pacifica were the main species. The fish portion of the diet constituted 71.2 percent of the wet weight of the prey items, and the invertebrate portion was 28.7 percent; thus, the murrelets ate mostly fish, primarily herring, during the non-breeding season in Quatsino Sound (table 1). Sand lance were not consumed, and the diversity of prey items (at least 3) was low compared to that found in the winter diet work by Krasnow and Sanger (1982) and Sanger (1987b).

Vermeer (1992) did point out that the study location has one of the largest herring spawn areas along the west coast of Vancouver Island and that herring spawn constitutes a major food source for piscivorous as well as nonpiscivorous birds, such as diving ducks. The massive presence of herring in March for spawning and the predictable nature of this occurrence has resulted in annual utilization of this resource by many seabirds and other animals (Vermeer 1992). Therefore, it seems apparent that the high use of herring in Vermeer's (1992) study is another example of the opportunistic foraging behavior of the murrelet and another demonstration of the importance of local differences in availability of prey as noted by Krasnow and Sanger (1982). Of further interest, four male murrelets collected in Departure Bay on the southeast coast of Vancouver Island during February and March (in 1928 and 1929) did not contain any identifiable herring in their stomachs even though the study area was also known as a major spawn location for herring during March (Munro and Clemens 1931). Results and implications of the Munro and Clemens (1931) collection effort are described in more detail below.

\section{Freshwater Feeding}

The studies described previously were conducted to assess murrelet food habits in the marine environment. To assess the importance of freshwater lakes in the feeding ecology of murrelets, Carter and Sealy (1986) summarized records of year-round use of coastal lakes for the period 1909 to 1984 from Alaska to California. No records were found for California. Three of the 67 records included small collections of murrelets at lakes in British Columbia during late April and early May. Five stomachs of adults were examined, and three were found to contain yearling Kokanee salmon (Onchorhynchus nerka kennerlyi), while the fourth contained two fingerling sockeye salmon (O. nerka). The examiner of the fifth murrelet, R.M. Stewart, noted, "The stomach was full of small fish which looked like salmon fry" [Onchorhyncus or Salmo sp.] (Brooks 1928) (table 1). Carter and Sealy's (1986) work contains numerous anecdotal sightings of murrelets feeding at inland lakes and references which document many of the lakes as large nurseries for juvenile salmon. The discussion includes evidence for nocturnal feeding by murrelets and winter-time use of inland lakes. The relative lack of inland lakes near known nesting sites south of British Columbia, along with a lack of census effort for murrelets at inland lakes, could lead to an underestimate of the importance of lakes and freshwater fish species as a food source for the murrelet. The effect of the reduction of salmonid stocks on the use of lakes by murrelets is unknown. This aspect of the murrelet's life history needs further investigation throughout its range.

\section{Isotopic Analysis of Diet}

Stable carbon and nitrogen isotopic analyses were performed on tissues of Marbled Murrelets collected from July to December 1979 (Carter 1984), in Barkley Sound $(n=18)$, and in June 1985 on Johnston Lake, British Columbia $(n=3)$ (Hobson 1990). Most murrelets showed stable carbon isotopic values (pectoral muscle) between -15.5 and -17.5 , and males and females were the same. These values compare favorably to the value of -17.9 for a sample of five Ammodytes sp. taken from coastal British Columbia for comparison. However, three individuals, an adult male from Barkley Sound and two adult males from Johnston Lake, differed significantly from the group. On the basis of a model, Hobson concluded that the three individuals had short-term freshwaterderived protein inputs to their diets ranging from 50 to 100 percent. Hobson (1990) suggested that while some murrelets may feed exclusively on freshwater prey for a short but important period of several weeks, freshwater protein did not appear to be a significant long-term dietary component. However, he concluded that he was unable to ascertain the relative importance of freshwater feeding in different murrelet populations without additional analysis. He suggested that tissues from murrelets found dead or collected for other studies be analyzed by isotopes of stable carbon.

Analysis by isotopes of stable nitrogen cannot be used for separating dietary differences between freshwater and 
marine protein contributions, because nitrogen isotope ratios in the muscles of fish species in coastal lakes may overlap with those of marine fish (Hobson 1990). Lower trophiclevel fish such as fingerling salmonids also overlap with marine invertebrates. Thus, nitrogen isotope analysis may be better suited than carbon to delineating the trophic levels of murrelets and other seabirds. The results of this analysis (Hobson 1990) showed Marbled Murrelets in the middle of a spectrum ( 10 species) from Dovekies (Alle alle) to Pigeon Guillemots; the Marbled Murrelet was between the Ancient Murrelet and the Common Murre. This isotopically intermediate position is consistent with the results of the studies described above which document murrelet consumption of invertebrate prey as well as marine fish. The trophic-level approach also has the value of being less biased against the soft-bodied invertebrates which are not easily detected in conventional studies.

A further analysis of the variability of stable nitrogen isotopes in wildlife showed that tissue can be enriched because of fasting or nutritional stress (Hobson and others 1993). Thus, studies using analysis by stable nitrogen isotopes to infer diet or trophic position must take into account the nutritional history of the individual specimen. Fasting should not be a factor for the murrelet because both sexes incubate the egg and feed the nestling, but nutritional stress could affect the results in a year of severe prey shortage.

\section{Ecological Studies and Anecdotal Information}

Alaska

Food habits of the murrelet were described by Bent (1963), "The food of the marbled murrelet seems to consist largely of fish which it obtains by diving in the tide rips and other places where it can find small fry swimming in schools." It appears he derived this information from observations contained in Grinnell (1897) and Grinnell (1910) (table I). In the summer of 1896 , during a visit to Sitka Bay, Alaska, Grinnell (1897) noted, "Small fish caught by diving seemed to be the standard article of food, but dissection of the stomachs also showed remains of some small mollusks. A shoal of candle-fish [Thaleichthys pacificus] was sure to have among its followers, besides a cloud of Pacific kittiwakes [Rissa sp.], several of the Murrelets" (table 1). Grinnell (1910: 366) noted fish as a prey item in a collected specimen and during an observation by Joseph Dixon of a foraging murrelet, but the species of fish were not recorded (table I).

Observations at the first documented ground nest of a murrelet indicated capelin as a food source for the nestling (Simons 1980) (table 1). An adult murrelet delivered a single fish about $8 \mathrm{~cm}$ long. Simons (1980) noted, "The fish appeared to be a capelin (Mallotus sp.)..." [emphasis added]. This observation would appear valid given the documented importance of capelin in murrelet diet in Alaska (Sanger 1983). Simons (1980) also noted that the pattern of weight gain was variable from days 2 to 12, and he suggested the possibility of multiple feedings. He concluded that predation and the distribution of the food resource were important selective agents acting upon ground-nesting murrelets.

\section{British Columbia}

Food habits of "water fowl" during the spawning season of herring in the vicinity of Departure Bay, British Columbia, were studied between 1928 and 1930 (Munro and Clemens 1931). Four male murrelets were collected in late February to mid-March, and the stomachs contained Cymatogaster, larval fish, mysids, and schizopods (table I). The archaic group schizopoda included euphausiids and mysids because, superficially, the members of these two orders appeared so similar. These two groups are now separated into different tribes based on characteristics of the carapace and the distinguishing luminescent organs of the euphausiids (Hardy 1965: 171-172).

The results from Munro and Clemens (1931) differ from the winter results of Carter (1984) and Vermeer (1992), in that identifiable herring are absent (table 1). This difference could be due to the small sample size. Alternatively, it could result from differences in availability of herring age classes and in herring distribution relative to murrelets, and differences in the magnitude and duration of the herring spawn between the three study areas (McAllister, pers. comm.). A number of herring stocks aggregate close to the spawning area for some time before actually moving on to the grounds to spawn (Lambert 1987).

An anecdotal account of murrelet diet by Guiguet was published in 1956. He spent many summers on zoological exploration in coastal British Columbia and stated that the murrelet "...eats small crustacea such as euphausid [sic] shrimps, and fishes such as the sand launce [sic]...." He also described watching murrelets foraging off the Queen Charlotte Islands in July 1946 and noted, "all were feeding on sand launces [sic]...." When darkness had almost descended that day, the murrelets disappeared inland to the west. Guiguet (1956) noted, "All of them were "packing feed' in their bills, and the silvery sand launce [sic] showed up in the darkness" (table I).

Between 6 June and 8 August 1991, Mahon and others (1992) conducted 27 at-sea surveys to determine the composition and density of mixed feeding flocks. They observed 126 feeding flocks, 100 of which contained only murrelets and Glaucouswinged gulls (Larus glaucescens). Murrelets were seen to feed on schools of sand lance by driving the fish to the surface. First-year sand lances were the only prey identified in feeding flocks (table 1). In the evenings, murrelets were seen holding larger sand lance, Pacific herring, and shiner perch as prey for nestlings (table I). The nestling prey items closely match the juvenile diet reported by Sealy (1975c), and two of the nestling items, herring and sand lance, reported by Carter (1984) and Guiguet (1956), respectively.

Additional anecdotal information on nestling food habits in British Columbia comes from a nest which was monitored in summer 1993 (Jones and Dechesne 1994). Sand lance was noted as a prey item for the nestling (table 1). 


\section{Washington}

During the summers of 1968 and 1969, Cody (1973) collected information on seabird breeding activity, prey species, and foraging patterns off the west coast of the Olympic Peninsula in Washington State. Murrelets holding fish before their evening flights inland were observed at close range from a boat. The birds were seen to carry only anchovy (Engraulis) and sand lance (Ammodytes) in their bills, and it was presumed these fish were for nestlings (Carter and Sealy 1987a) (table 1). The murrelets showed great similarity in chick diet with the Common Murre, Tufted Puffin, and Rhinoceros Auklet (Cerorhinca monocerata), though smelt (Hypomesus) and sea-bass (Sebastoides) were also recovered from 54 fish loads for these latter three species of alcids.

Similar to Sealy's (1975c) study of sympatric Ancient and Marbled Murrelets, Cody (1973) concluded that differences in foraging areas at sea reduced interspecific competition between alcids off the west coast of the Olympic Peninsula, though prey species consumed were similar. Lacking specific knowledge of murrelet nesting areas, neither of these researchers were able to compare foraging areas with nesting habitat distribution, though Cody (1973) concluded that the zonation of alcid feeding areas with respect to distance from the nest was the most important factor affecting coexistence. He contrasted this to other studies which have found differences in diet between similar seabird species to be the isolating mechanism. He also pointed out that foraging zonation which is optimal while adults feed nest-bound young is relaxed and expanded when young leave their nests and accompany the parents. Cody (1973) found that murrelets fed within a few kilometers of the shore. He observed that in the evenings they were often seen carrying food within a half kilometer of the Hoh and Quilleute Rivers and that adults and partiallygrown, non-flying young were observed close to these same river mouths in August.

Cody presumed these rivers provided transportation for the young murrelets from inland nesting sites (Day and others 1983, Nechaev 1986). The discovery of a young murrelet at a freshwater marsh close to the sea in British Columbia is described by Brooks (1926a). The bird appeared unable to fly, and it was noted that the primaries were in sheaths at their bases and there was a good deal of down on the head, back, and flanks. Another similar young was with it. Brooks (1926a) noted another juvenile murrelet, collected off Langara Island, British Columbia: "...the bases of its quills still in the sheath was taken some 200 yards out to sea...". Young fledglings would consume available prey resources in freshwater environments as they gained sustained flight capabilities and made their way to the ocean (Carter and Sealy 1986). It is thought that the majority of murrelets fledge by direct flight to the ocean (Nelson and Hamer, this volume a). Diving behavior is an escape response and does not necessarily indicate an inability to fly (Carter and Sealy 1987b); however, repeated harassment of the juveniles by Cody (1973) resulted in no flight attempts, though adults would take wing when continually harassed by boat (Cody, pers. comm.).

Additional work by Cody in Carter (1984) at the San Juan Islands again revealed anchovy as nestling prey from fish held in the bill by murrelets on the water (table 1).

One other observation on murrelet food habits from Washington was provided by Hunt (pers. comm.). He observed murrelets foraging in August in mixed-species flocks in the San Juan Islands. He dip-netted (approximately $7.5 \mathrm{~cm}$ mesh) for surface fish in this foraging area and captured only herring (table 1 ).

\section{Oregon}

At-sea surveys for murrelets during 1992 off the coast of Oregon resulted in some anecdotal information on nestling food items (Strong and others 1993). A total of six murrelets carrying fish were observed from 15 June to 11 August (table 1). The first two observations occurred on 15 June, and the prey type was judged to be "smelt sp." (osmeridae). The next four observations, on 1 August, 2 August, and 11 August (two observations), were of sand lance. On the basis of additional observations of other seabirds with prey over the same time period, the authors thought a switch in prey occurred from smelt in late July to sand lance thereafter.

Video footage from an active nest site in 1992 documented sand lance as nestling food, and during at-sea surveys, observers noted osmerids, sand lance, and a possible herring as nestling food items being held by murrelets (Nelson, pers. comm.) (table 1).

\section{California}

A report on the population status and conservation problems of the murrelet in California was produced in 1988 as the Department of Fish and Game began gathering information on the species (Carter and Erickson 1988). Field notes from work by R. H. Beck in the vicinity of Point Pinos, Monterey County, were included in Carter and Erickson's (1988) report and are repeated here (Museum of Vertebrate Zoology; see also Beck 1910): “...the Marbled Murrelets yesterday [had in their stomachs] 2, 3, 4, or 5 small sardines [Sardinops sagax] about 3 inches long" (November 24, 1910); four days later, 13 murrelets were collected (November 28, 1910), and Beck noted, "Sardines 2 to 3 inches long in stomachs"; then, on February 16, 1911, Beck reported, "A six [inch] needle fish? [Strongylura exilis] swallowed by Marbled Murrelet inside bill when picked up fish just caught"; and finally, on March 1, 1911, a Marbled Murrelet was collected with a "...6 1/2 [inch] fish in stomach" (table 1).

The reference to the possible needlefish (California needlefish $=$ Strongylura exilis) is interesting because the northern distribution limit for this species is San Francisco (Miller and Lea 1972). Carter and Erickson (1988) thought the fish may have been a sand lance.

Carter and Erickson (1988) also reported on the food habits of 10 murrelets which were collected in early fall from northern Monterey Bay in the late 1970's. The murrelets 
were noted as feeding mainly on anchovy and to a lesser extent on sand lance (table I).

Another instance of anchovy in murrelet diet came from mist netting of murrelets in Redwood National Park for radio-telemetry purposes during summer 1989 (Ralph and others 1990). During this work, on July 3, 1989, one murrelet hit the mist net and bounced out (05:30 p.d.t.), leaving a whole northern anchovy at the base of the net. The anchovy weighed 10.0 grams and was $113 \mathrm{~mm}$ in length. It seems most likely that this prey item was destined for a murrelet nestling (table 1 ).

It is unfortunate that systematic studies of murrelet food habits in this region of California did not occur before and after the great sardine fishery (mid 1930 to mid 1940). The anecdotal information from above mirrors the documented change in prey abundance over time, from sardine to anchovy. The interesting history of sardine and anchovy population fluctuations and their fisheries are briefly summarized below under the prey ecology section of this chapter. The fact that murrelets have persisted in the central California region after a decline in the largest fishery in the Western Hemisphere is probably another indication of the opportunistic feeding behavior of the bird. This flexibility in prey choice has probably helped to sustain the murrelet population in this geographic region in spite of massive loss and deterioration of inland nesting habitat.

Anecdotal information on nestling diet was obtained from video footage recorded during observation of an active nest site in Big Basin State Park in the Santa Cruz Mountains (Naslund 1993a). Three fish carried to the nestling were identified (table 1). Two of the fish appeared to be either northern anchovy or possibly of the clupeidae. The third fish was judged to be a smelt (osmeridae).

Rockfish make up an important component of seabird diet in California, and if more intensive studies of murrelet diet were conducted it is possible that these fish would be found to be eaten by murrelets (Ainley and others, this volume). Both Sealy (1975c) and Carter (1984) documented scorpaenids in the murrelet's diet (table 1).

\section{Food Habits Summary}

The sand lance is the most common food of the murrelet across its range (table 1 ). For the fish species, records of sand lance represent 52 percent of the compiled information (11 occurrences per 21 studies/anecdotal observations) on murrelet food habits. The next most commonly recorded species are anchovy and herring at 29 percent, followed by osmerids at 24 percent, and by Cymatogaster at 14 percent.

Euphausiids as a group represented 24 percent of the compiled information (table 1 ). They were generally not a dominant component of murrelet diet during the breeding season; however, euphausiids were an important prey source for murrelets in the spring (Sealy 1975c) and during the breeding season in some years (Krasnow and Sanger 1982). Euphausiids were also important during the winter in the Gulf of Alaska (Krasnow and Sanger 1982) and in British
Columbia (Vermeer 1992). Mysids and gammarids were another component of murrelet diet, especially in winter (Krasnow and Sanger 1982, Munro and Clemens 1931, Sanger 1987b).

Studies under the OCSEAP program revealed the importance of seasonal and interannual variation in prey abundance (Krasnow and Sanger 1982, Sanger 1983, Sanger 1987b). The OCSEAP compilation (Sanger 1983) revealed a broader prey spectrum compared to systematic studies (Carter 1984, Sealy 1975c, Vermeer 1992), though this may have been partially because of the larger time period and larger geographic extent of collection (table 1). It may also have been a function of the larger sample size compared to these other studies (table 1 ).

Comparison of results from Sealy (1975c), Carter (1984), and Vermeer (1992) reveals the influence of site-specific conditions on prey availability and selection by murrelets (table 1). Differences between adult, nestling, and fledgling diet were also apparent (Carter 1984, Mahon and others 1992, Sealy 1975c) (table 1 ).

Though much work needs to be done on food habits in different geographic regions and seasons, in general it can be said that murrelets feed on invertebrates such as euphausiids, mysids, decapods and amphipods, and small schooling fishes including sand lance, anchovy, herring, smelt, and seaperch. The fish portion of the diet is most important in the summer and coincides with the nestling and fledgling period (Carter 1984, Carter and Sealy 1990, Sealy 1975c).

\section{Prey Ecology}

Because few systematic studies of murrelet food habits have taken place and the murrelet occupies such a large geographic area with a wide variety of fish species potentially available, the rest of this chapter will focus on selected prey species considered most important in murrelet diet at this time. Due to the long-standing commercial value of anchovies, herring, and sardines, there is a large body of information on life history and factors affecting their abundance and distribution. The following overview is not an attempt to compile the rich literature on these or the other known prey species, but instead focuses on interesting aspects of their life history and the interrelationship between prey species, murrelets, humans, and the marine environment. The relationship between other seabirds and these same prey resources, along with the marine environment, will be discussed. Sand lance and euphausiids have been little studied compared to the commercially valuable fish species, but are discussed first because of their position and interaction in the marine food web, and their importance in the murrelet's diet.

\section{Euphausiids}

Euphausiids are a group of small crustaceans which make up part of the zooplankton ("krill") found in the marine environment. Euphausiids are more or less transparent 
and phosphorescent and closely resemble shrimps in form though they are often not more than $25 \mathrm{~mm}$ long. The phosphorescent organs are along the sides of the body. Their purpose is not known. Attached to the thorax are the eight pairs of two-branched legs which give rise to the name "schizopoda," as this order was formerly called (Johnson and Snook 1967: 293-294).

Zooplankton are found in greater abundance during coldwater years in California waters. Many of the zooplankton are predators on fish eggs and larval fish, and their abundance was sometimes twenty times greater during the colder periods (Reid and others 1958). Accordingly, not only would the lowered temperature affect survival of fish eggs and larvae directly, it would also add to the hazards of being eaten by providing conditions for the rapid increase of zooplankton (Ricketts and Calvin 1962: 394).

Komaki (1967) summarized information obtained from fishermen on the phenomenon of surface swarming of euphausiids ( $E$. pacifica) in the Sea of Japan. This phenomenon differs from the usual vertical migratory behavior because it occurs in the daytime, independent of light intensity. The swarming season in the Kinkazan waters ranged between late February and late May. Water temperature was determined to be the most important factor, with swarming starting at a slightly higher temperature than the local minimum ( 7 degrees Celsius), continuing with increasing temperature, and then terminating as the temperature exceeded 16 degrees Celsius. Because swarming did not occur earlier in the year when temperatures were favorable, Komaki (1967) concluded that the swarming was related to reproduction. Also, it appeared that the population was composed of several stocks, and that as stocks reached a certain degree of maturity, they approached the coast in succession.

The daily phenomenon of vertical migration was noted as early as 1872 during the Challenger Expedition. Many plankton animals actively move towards the surface of the ocean at night and sink or swim away to the depths in the daytime. Vertical climbing requires much energy and has been developed so frequently in the animal kingdom that it was thought to clearly be of some significance in the lives of such animals (Hardy 1965: 199-200). The main proximate factor for daily vertical migration appears to be light intensity (Cushing in Raymont 1963: 435).

Both E. pacifica and $T$. spinifera were found to undergo vertical migration off Washington State in summer 1967 (Alton and Blackburn 1972). High catch rates were sustained from near-surface water throughout the late evening and early morning hours, approximately 2200 to 0500 hours.

Hardy (1965: 212-215) advanced a general theory for the value of diurnal vertical migration. Because the uppermost layers of the sea generally move at higher speeds than lower levels and bottom topography results in currents which may differ from surface layers, the regular movement of plankton between these layers allows the animals to be carried over greater distances than would otherwise be the case. Thus, the plankton population can be distributed over a much larger area of the ocean than if continually moved by only one body of water. This large-scale movement has the advantage of putting the animals in contact with more food source patches. Individual variation in the degree of vertical migration and the amount of time spent at any one layer further promote the patchy distribution of plankton.

A genetic theory has also been proposed (David in Raymont 1963: 466). Marine planktonic species may tend to become divided into relatively small, separate populations if continually drifting in one stratum and not normally encountering directional stimuli to encourage horizontal migration. However, the broader distribution caused by vertical migration would help to encourage interchange of zooplankton populations and thus promote gene flow.

There are many other theories regarding vertical migration. The fact that both Raymont (1963) and Hardy (1965) devoted an entire chapter to the subject attests to the complexity of factors which operate in the marine environment. As summarized by Hardy (1965: 217): "There can be no doubt that the patchy distribution of the plankton must be due to a great variety of causes." Raymont (1963: 466) ended his chapter by recognizing the need for more research on the subject: "At this stage no conclusive answer can be given to the question as to the value of diurnal vertical migration, but the tremendously wide occurrence of this phenomenon in the seas is one of the most challenging aspects of marine plankton study."

With the variability in zooplankton distribution and abundance, the way in which murrelets find such prey resources warrants attention. The interannual variability in euphausiid consumption (tables 2 and 3) noted by Krasnow and Sanger (1982) could demonstrate differences in zooplankton distribution (rather than abundance) and the corresponding inability of murrelets to locate and use the resource. However, some of the distribution patterns should be predictable at least between "normal" years, and thus the learning of foraging areas by murrelets would indeed be important for minimizing energy expenditure as suggested by Carter (1984). Komaki (1967) demonstrated that E. pacifica and sand eels ( $A$. personatus) fluctuated in parallel on the basis of data on fishery harvest, and that sand eels were taken in almost the same area as the euphausiid fishery. The traditional euphausiid swarming areas were known to the fishermen, though the density of the swarm varied between years (Komaki 1967). Thus, conservation of the murrelet and its food web will be aided by identification and appropriate management of important euphausiid swarming areas, especially in the vicinity of known murrelet nesting areas.

\section{Pacific Sand Lance}

Sand lance are slim, elongated, usually silver fishes especially abundant in northern seas. They belong to the ammodytidae and are sometimes called sand eels, but they are not true eels even though eel-like in shape and movement. The Pacific sand lance is distributed from southern California to. Alaska and to the Sea of Japan. 
They grow to about 20 centimeters in length (Miller and Lea 1972). There has been much confusion over the taxonomy of the sand lances throughout the world since they are similar in external appearance (Hardy 1965: 209_ 210; McGurk and Warburton 1992). Of this confusion Hardy (1965: 210) wrote, "It all goes to show how elusive...these sand-eels are. They are all very much alike; little silvery eel-like fish which occur in large shoals in sandy parts of the sea and escape from their predators by diving like a flash into the sand ànd becoming completely covered." They are most abundant in the shallow regions around the coast, but may also be found on sand banks far out on the continental shelf (Hardy 1965: 211).

The most interesting characteristic of the sand lances is their ability to burrow into sand or gravel and remain there for long periods. Both burrowing and emergence are extremely rapid, the fish entering and leaving the surface almost vertically at swimming speed. Coastal sand lance may bury themselves above low-water mark and remain buried as the tide recedes and until it covers the area again. This habit demands a loose, porous substrate in which respiratory water maintains sufficient oxygen to support life (Scott 1973).

Food habits of 486 specimens $(15-31 \mathrm{~cm})$ of northern sand lance (A. dubius) taken at various localities and seasons from Nova Scotia Banks revealed copepods as the most frequent food item, followed by crustacean larvae, invertebrate eggs, and polychaete larvae. Volumetric analysis showed copepods to comprise the bulk of the food (65 percent), followed by polychaete larvae ( 15 percent) and euphausiids (14 percent). The latter two food items were selected for in greater volume when compared to availability, since euphausiids made up less than 4 percent of the volume of simultaneous plankton tows (Scott 1973).

McGurk and Warburton (1992) conducted an intensive study of environmental conditions and the effects on sand lance larvae in the Port Moller estuary in Alaska. They found that three waves of spawning sand lance entered the estuary from mid-January to late May. Peak spawning occurred in January, March, and April. Eggs incubated for a period of 45 to 94 days. Slow growth was directly responsible for the reduced number of cohorts and the long time periods between peak hatch dates compared to other demersally-spawning fish such as herring or capelin, because first-feeding sand lance larvae took longer to vacate their feeding niches. The larvae fed primarily during the day on a diet of copepod eggs and nauplii, copepodites, and small adult copepods. This type of prey and its average length and width were similar to that of herring larvae, indicating that the larvae of these two species shared the same food resource.

McGurk and Warburton (1992) concluded that the stock of sand lance that spawns in Port Moller belongs to a class of stocks that have an entirely estuarine or coastal early life history, in contrast to some stocks of sand lance whose larvae disperse offshore from inshore spawning sites. This life history strategy may have evolved in response to the unique physical conditions of the Port Moller estuary-a shallow, well-mixed site with sandy substrate that is suitable for incubation of demersal eggs next to a deep, stable fjord with a rich zooplankton community that is suitable for rearing of larval and juvenile sand lance.

Variation in physical factors, particularly, storm events, local wind-forced surface currents, baroclinic surface currents, and regional downwelling events at the boundary of the estuary cause annual variation in recruitment. Additionally, density-dependent factors such as competition for food between sand lance, between sand lance and other planktivorous fish larvae such as herring, and between sand lance and invertebrate planktivores such as chaetognaths may play as important a role as density-independent physical factors (McGurk and Warburton 1992). McGurk and Warburton noted that the small scale of dispersal in the Port Moller stock also leaves it more vulnerable to industrial development such as dredging or release of toxic chemicals.

Sherman and others (1981) summarized research in the North Sea which documented an increase in sand eel (Ammodytes sp.) as a result of depleted herring and mackerel (Scomber sp.) stocks. In the absence of a sand lance fishery on the east coast of North America from which to estimate population trends, researchers in this area used ichthyoplankton surveys. As in the North Sea, population explosions of small, fast-growing sand eel coincided with depletions of larger tertiary predators, including herring and mackerel. From 1974 to 1979 the percentage of sand eel increased from less than 50 percent of the total mid-winter ichthyoplankton community to more than 85 percent (Sherman and others 1981). This change followed significant fishing stress of the northwest Atlantic ecosystem, where fish biomass in the region was reduced by 50 percent from 1968 to 1975 (Clark and Brown in Sherman and others 1981).

Clark and Brown concluded that reductions in herring and mackerel on both sides of the Atlantic in response to heavy fishing mortality, followed by increases in sand eel and other small, fast-growing fish, made unlikely the hypothesis that the changes were due to environmental factors. They concluded that, when a large biomass of mid-size predators is removed, it can be replaced by smaller, fastergrowing, opportunistic species (Sherman and others 1981).

This relationship was further evaluated by Fogarty and others (1991) with a mathematical model. A significant negative interaction between sand lance recruitment and an integrated measure of herring and mackerel biomass was indicated. However, since both herring and mackerel feed on sand lance, it was impossible to distinguish the relative roles of the two predators. The authors concluded that direct evidence of predation by mackerel and herring was available to support the inference of interactions between sand lance and pelagic predators, though alternative hypotheses could be formulated.

Recent changes in the population of sand eels (Ammodytes marinus) at Shetland were studied in relation to estimates of seabird predation (Bailey and others 1991). Since 1974 there has been a sand eel fishery in inshore waters around Shetland, 
and landings have decreased. Simultaneously, there was a decrease in consumption of sand eels by seabirds. These findings indicate that the switching of seabirds from sand eels to other prey is in approximate proportion to the abundance of sand eels. However, Bailey and others (1991) concluded that more data were needed to significantly refine the analysis. It was noted that different seabirds respond differently to changes in stock. Surface feeders must forage close to the colony and make many fishing trips per day; thus they are especially sensitive to reduction in food availability. This is in agreement with evidence that Arctic Terns (Sterna paradisaea) showed the earliest and most severe breeding failures at Shetland (Heubeck in Bailey and others 1991). By contrast, some of the larger seabirds with generalist feeding abilities took sand eels when these were abundantly available but switched diet as the sand eel stock declined.

The relationship between British [Black-legged] Kittiwake breeding success and the Shetland stock of sand eels (Ammodytes) was studied by Harris and Wanless (1990). The evidence that food shortage was responsible for low breeding success was mostly circumstantial but, taken as a whole, compelling. However, the authors concluded that natural factors could have caused the decline in the sand eels, rather than overfishing (Kunzlik in Harris and Wanless 1990). They also suggested that herring predation was responsible for the fishery decline. As in the other studies of seabirds and sand lance described above, the authors concluded that more comprehensive studies were needed to allow definitive interpretation of the results.

More studies on the Pacific sand lance are needed on the west coast of North America, especially on environmental effects and predator influence on survival and abundance. Spawning areas of sand lance need to be identified and managed. The trophic links between sand lance and two other murrelet prey items, euphausiids and herring, indicate a need for comprehensive, long-term study and management.

\section{Northern Anchovy}

These fish belong to the engraulidae family. They have no adipose fin or lateral line and are closely related to herring.

The following life history information (for anchovies and sardines) was taken from a draft document (Anonymous 1993) which was not completed or published because of a change in Pacific coastal pelagic species management policy between regulatory agencies (Wolf, pers. comm.).

Northern anchovy are distributed from the Queen Charlotte Islands, British Columbia, to Magdalena Bay, Baja California. The population is divided into northern, central, and southern subpopulations, or stocks. The central subpopulation, which supports significant commercial fisheries in the United States and Mexico, ranges from approximately San Francisco, California, to Punta Baja, Baja California. The northern subpopulation supports a small but locally important bait fishery in Oregon and California.
Anchovies are small, short-lived fish typically found in schools near the surface. The fish rarely exceed 4 years of age and $18 \mathrm{~cm}$ in total length. They have a high natural mortality; approximately 45 to 55 percent of the total stock may die each year of natural causes in the absence of fishing. Northern anchovy eat plankton either directly or by filter feeding.

Anchovy spawn during every month of the year, but spawning increases in late winter and early spring and peaks from February to April. The eggs, found near the surface, are typically ovoid and translucent and require two to four days to hatch, depending on water temperature. Anchovy are all sexually mature at age 2 . The fraction of one-year-olds that is sexually mature in a given year depends on water temperature and has been observed to range from 47 to 100 percent (Methot in Anonymous 1993).

Northern anchovy in the central subpopulation are harvested by commercial fisheries in California and Mexico for reduction, human consumption, live bait, dead bait, and other nonreduction commercial uses. Anchovy landed in Mexico are used primarily for reduction although small amounts are probably used as bait. Small quantities of the northern subpopulation are taken off Oregon and Washington for use as dead bait.

Anchovy landed by the reduction fisheries are converted to meal, oil, and soluble protein products sold mainly as protein supplements for poultry food and also as feed for pigs, farmed fish, fur-producing animals, laboratory animals, and household pets. Meal obtained from anchovy is about 65 percent protein.

Anderson and others (1980) compared estimates of anchovy biomass and catch statistics to Brown Pelican (Pelecanus occidentalis californicus) reproductive success. Brown Pelican diet was composed of 92 percent anchovies in the Southern California Bight (SCB) study area. Mean SCB anchovy biomass (square miles of anchovy schools) and mean pelican reproductive rate (number of fledglings per nesting attempt) were highly correlated. It was estimated that a minimum anchovy biomass of 43 square miles was necessary for maintaining the existing pelican reproductive rate, though it was recognized that the rate would have to increase in order to at least maintain the pelicans in the SCB. Secondly, the minimum biomass estimate was almost twice the forage reserve which was recommended at the time in the Anchovy Management Plan. They regarded the information as preliminary and concluded that better estimates of the forage reserve were needed.

A similar relationship between anchovies and Elegant Terns (Sterna elegans) was described by Schaffner (1986). Breeding pairs of Elegant Terns and estimates of anchovy spawning biomass were significantly correlated for the period of 1979 through 1983. Additionally, extensive overlap in age compositions of the tern and fishery samples suggested they were using similar resources and the potential for competition existed. Anchovies constituted more than 86 percent of the chick regurgitations when population size peaked. Schaffner (1986) pointed out the similarities to the Brown Pelican 
study and advised that a close watch of the situation was in order because of declining anchovy populations.

Anderson and others (1980) proposed the establishment of protected foraging zones as critical habitat under the federal Endangered Species Act in order to assure adequate pelican reproduction and conservation. However, they recognized that because of the unpredictable nature of anchovy distribution, such areas could be difficult to define between seasons and between years. Protection of marine habitat as critical habitat for the murrelet has also been recommended by researchers, the Marbled Murrelet Recovery Team, and the California Department of Fish and Game.

\section{Pacific Sardine}

These small pelagic clupeids occur in the California Current system from southern Baja California to southeastern Alaska, and in the Gulf of California. In the northern portion of the range, occurrence is seasonal. It has been generally accepted that the sardine population off the west coast of North America consists of three subpopulations. A northern subpopulation (northern Baja California to Alaska), a southern subpopulation (off Baja California), and a Gulf of California subpopulation were distinguished on the basis of serological techniques (Vrooman in Anonymous 1993).

Historically, the sardines migrated extensively, moving north as far as British Columbia in the summer and returning to southern California and northern Baja California in the fall. The migration was complex, and timing and extent of movement were affected to some degree by oceanographic conditions (Hart in Anonymous 1993).

Sardines reach about $41 \mathrm{~cm}$ in length, but usually are shorter than $30 \mathrm{~cm}$. They live as long as 13 years, although most sardines in the historical and current commercial catch are 5 years and younger. They spawn in loosely aggregated schools in the upper 50 meters of the water column probably year-round, with peaks from April to August. Spawning has been observed off Oregon, and young fish have been seen in waters off British Columbia, but these were probably sporadic occurrences (Ahlstrom in Anonymous 1993). The spatial and seasonal distribution of spawning is influenced by temperature.

Sardines prey on crustaceans, mostly copepods, and consume other phytoplankton, including fish larvae. Larval sardines feed extensively on the eggs, larvae, and juvenile stages of copepods, as well as on other phytoplankton and zooplankton.

The fishery began in central California in the late 1800's and developed in response to a demand for food during World War I (Schaefer and others in Wolf 1992). The Pacific sardine supported the largest fishery in the Western Hemisphere during the 1930's and 1940's, with landings in British Columbia, Washington, Oregon, California, and Mexico. The fishery declined, beginning in the late 1940's and with some short-term reversals, to extremely low levels in the 1970's. There was a southward shift as the fishery decreased, with landings ceasing in the northwest in 1947-
1948, and in San Francisco in 1951-1952. The regulatory history of the sardine fishery might best be described as "too little too late." Regulatory authority for the sardine fishery in California rested with the legislature, which delegated only limited authority to the Fish and Game Commission. State biologists had expressed concern about the size of the fishery as early as 1930 . Industry opposed any regulation of total catch, and an intense debate began over whether the decline of the sardine fishery and population was due to overfishing or environmental factors (Clark and Marr in Wolf 1992).

It was not until 1967, well after the fishery had collapsed, that the California legislature passed an "emergency" bill declaring a 2-year moratorium on fishing sardines, and in 1974 another bill was enacted which established a complete moratorium on directed fishing for sardines, though an incidental catch provision continued. A small directed fishery was first allowed in 1986 and the directed quota has recently been enlarged (Wolf 1992).

Since the early 1980's, sardines have been taken incidentally with Pacific (Scomber japonicus) and jack mackerel (Trachurus symmetricus) in the southern California mackerel fishery and primarily canned for pet food, although some were canned for human consumption. Sardines landed in the directed sardine fisheries off California are primarily canned for human consumption and sold overseas.

Management of the sardine is difficult in the absence of a large fishery since a precise, direct estimate of a relatively small biomass is difficult and expensive to obtain (Wolf 1992). Integrated methods of stock assessment will be necessary to manage this resource (Barnes and others 1992).

Baumgartner and others (1992) presented a composite time series of anchovy and Pacific sardine fish-scaledeposition rates which they developed from sampling the anaerobic layered sediments of the Santa Barbara Basin off southern California. Other researchers (Soutar; and Soutar and Isaacs in Baumgartner and others 1992) had previously collected information on the deposition rates of these species, but their sample sizes were limited and there was uncertainty in the underlying chronology because of imperfect preservation of the annually deposited layers. The new sardine and anchovy series provide significantly more reliable estimates of the scale-deposition rates (SDR's) (Baumgartner and others 1992). An overriding lesson from the Santa Barbara records is that in the past both sardines and anchovies experienced large natural fluctuations which were clearly unrelated to fishing, and that abrupt natural declines, similar to the collapse of the sardines during the 1940 's, are not uncommon.

The scale-deposition record shows nine major recoveries and subsequent collapses of the sardine population over the past 1,700 years. The average time for a recovery of the sardine is 30 years. Sardines and anchovies both tend to vary over a period of approximately 60 years. In addition, the anchovies fluctuate at a period of 100 years. There is a moderate correlation between sardines and anchovies over 
long time scales of several centuries or more, but the correlation of shorter-period components in the time series is virtually nil.

Baumgartner and co-authors say that caution in interpreting the data should be exercised on two fronts: (1) sample size; they acknowledge that additional samples are needed to capture the complete range of variability of the SDR's over the basin. (2) The collapse and recovery demonstrated for the sardine do not necessarily mean that the current cycle of collapse and recovery has no relation to the application/release of fishing pressure or change in ocean climate, or both. They infer that even though the causes may vary (biological interaction, environmental change) for different recoveries or collapses, the sustained reproductive consequences are similar from one event to another (Baumgartner and others 1992).

Analysis of fish scales in sediments of the central Gulf of California resulted in similarities with the Santa Barbara Basin work (Holmgren-Urba and Baumgartner 1993). The reconstructions show a strong negative association between the presence of sardines and anchovies, with anchovies dominating throughout the 19th century, and with only two important peaks of sardine scale deposition. The two episodes of sardine scale deposition occur virtually 180 degrees out of phase with anchovy scale deposition. This suggests an overall coherent pattern in changing ecosystem structure that operates over a period of about 120 to 140 years. The collapse of the sardine population in the Gulf of California was very similar to the collapse in the California Current during the late 1940's and 1950's. Both populations declined under heavy fishing pressure (Barnes and others 1992) superimposed on broad, natural, decadal-to-centennial-scale biomass fluctuations (Soutar and Isaacs in Holmgren-Urba and Baumgartner 1993). Both declines appear to be accompanied by an increasing population of northern anchovy (MacCall and Praeger in Holmgren-Urba and Baumgartner 1993). The relationship to climate was not entirely clear, but suggested a mediating effect on population sizes. However, the process is still subject to strong filtering through biological interaction among species.

Butler and others (1993) modeled anchovy and sardine populations to examine how natural variation of life-history parameters affected per capita growth. The greatest change in growth for both species occurred during larval stages. A number of important life history parameters of marine fish are directly affected by changes in temperature, and temperature and food densities affect growth at all stages. For anchovies, there is some evidence that reproduction is drastically reduced during major El Niño events. Under such conditions, the anchovy stock declined. For the sardine, high fishing mortality reduces the abundance of the oldest age classes, which have the highest reproductive potential because of their larger size and greater number of spawnings. Densitydependent factors such as cannibalism on eggs may also be important (Valdes and others and Valdes Szeinfeld in Butler and others 1993). The results of this modeling exercise parallel the results and conclusions of McGurk and Warburton (1992) described earlier in the section under sand lance.

Structural changes over time in the California Current ecosystem between sardines and anchovies are similar to changes between herring and sand lance described previously for the North Sea and the Atlantic, though different factors were probably operative. Additionally, most researchers have found it difficult to separate the effects of humans from natural influences on the fish stocks. The fact that both mechanisms will continue to operate dictates that managers conduct effective monitoring programs and adaptive management to allow prompt remedial action to be taken where necessary (Wilson and others 1991).

The low occurrence of sardines in the diet of murrelets is interesting given the wide geographic distribution of this fish (table 1). This low occurrence may be due to fewer studies in the southern end of the murrelet's geographic range where sardines are more abundant. Alternatively, it may represent an overall lower abundance due to overfishing, competition, and natural influences. Anderson and Anderson in Anderson and others (1980) suggested that past breeding populations of Brown Pelicans in the Southern California Bight probably had a larger prey base than the existing anchovy-dominated diet, perhaps also importantly involving Pacific sardines and Pacific mackerel. Recent increased abundance of sardines off southern California was followed by increased breeding success and abundance of Brown Pelicans (Ainley and Hunt in Anonymous 1993).

Because of the natural fluctuations in anchovies and sardines as shown from the scale-deposition studies, murrelets probably evolved to use this resource in proportion to availability. Thus, the periodic lows in anchovy and sardine populations would probably not adversely affect the murrelet as long as alternative forage fish remained available. Development of new fisheries (sand lance or euphausiids) and escalation of harvests for rockfish and herring would be expected to affect murrelets, especially in conjunction with a low period of anchovies and sardines, and El Niño events.

\section{Pacific Herring}

Herring belong to the clupeidae as do the Pacific sardine. Adults range up to $45 \mathrm{~cm}$ in length (Miller and Lea 1972: 54). Herring are one of the most abundant species of fishes in the world and prey upon copepods, pteropods, and other planktonic crustaceans, as well as fish larvae. They travel in vast schools, providing food for larger predators.

The Pacific herring ranges from Baja California to Alaska and across the north Pacific to Japan. Within this range, abundance generally increases with latitude and the largest populations are centered off Canada and Alaska (Spratt 1981).

Currently, all herring commercially harvested in California and Oregon are taken as sac-row for Japanese markets. In British Columbia and Alaska, herring are primarily harvested for sac-row, and as longline bait (McAllister, pers. comm.).

Spawning begins during November in California and ends during June in Alaska, becoming progressively later 
from south to north. During the spawning season, herring congregate in dense schools and migrate inshore where they deposit their sticky eggs on vegetation found in intertidal and shallow subtidal areas of bays and estuaries. The eggs hatch in about 2 weeks. After spawning, herring return to the open ocean where their movements are largely unknown (Spratt 1981). The large herring fisheries are subject to great fluctuations in their annual catches because the survival of young herrings varies widely from year to year, with a heavy dependence on copepods (Hardy 1965: 62). The fish mature in about 4 years and may live 20 years.

Information on the age structure of spawning herring was analyzed by Lambert (1987). He noted that it is an underappreciated fact that herring often arrive at spawning grounds in runs or waves. This phenomenon has been reported in both the Atlantic and Pacific Oceans for C.h. harengus and $C . h$. palasii. It is suggested that spawning proceeds consecutively through year classes from oldest to youngest due to differential maturation. Discrete batches of eggs deposited by these waves of spawning herring give rise to a succession of larval cohorts. The more age classes involved in spawning, the longer will be the spawning season and the spawning will be more widespread since different age groups tend to spawn in different areas. Therefore, it would appear that the maintenance of a wide, well-balanced age structure tends to promote a resilient or more stable population (Lambert 1987).

Near the Queen Charlotte Islands in British Columbia, shoals of immature herring occur frequently at the surface, where they often jump clear, making a calm sea suddenly erupt in a tiny "boil." Herring boils are often associated with swarms of euphausiids which provide food for the herrings (Gaston 1992: 74). Many seabird species will be found feeding at such prey concentrations.

In his chapter on the herring, Hardy (1965: 61) wrote: "Early in the year, in March and April, the North Sea herring is feeding very largely on young sand-eels [Ammodytes sp.]; and often at this season you will find the stomach of the herring crammed full of them, lying neatly side by side like sardines in a tin."

McGurk and Warburton (1992) found that herring and sand lance larvae consumed prey of similar lengths and widths. They concluded that herring and sand lance larvae compete for substantially the same prey resource. More than 99 percent of the prey items found in the guts of sand lance larvae were various life history stages of copepods (McGurk and Warburton 1992).

The work of Carter (1984) and Vermeer (1992) indicated the importance of herring in the diet of murrelets (table I). Lid (1981) suggested that the breeding failure of Puffins [Atlantic Puffins] (Fratercula arctica) in Norway was due to over-harvesting of herring and, to some extent, over-fishing of sand eels (Ammodyres sp.). Many puffin chicks died, and adult weights were lower during the study period. Spawning stock size in weight-of the Norwegian spring-spawning herring declined from-approximately 9.5 million tons to less than 0.5 million tons between 1950 and 1980 (Lid 1981).

Commercial fishing harvest of herring should be monitored for effects on murrelet reproductive success. In the absence of a sand lance fishery on the west coast of North America, it may be that sand lance populations will respond positively to reduction in herring as documented elsewhere. However, murrelet use of either of these resources will depend on temporal and spatial distribution of the prey relative to murrelet nesting and foraging habitat. The patchy distribution of prey during different seasons must be considered along with changes in offshore distribution of the murrelet between seasons.

\section{Smelt}

The osmeridae are closely related to salmon and trout, and like trout, have a small, adipose fin. They are confined to arctic and north temperate waters and are best represented in the north Pacific basin. All spawn in fresh water or along the seashore (Hart and McHugh 1944). Among related Pacific species are the surf smelt or silver smelt (Hypomesus pretiosus), capelin, and eulachon or candlefish.

The silversides (atherinidae) and other unrelated fishes are sometimes also called smelts, sand smelt, or whitebait. The atherinidae also include grunion (Leuresthes tenuis) which occurs north only to the San Francisco area.

The eulachon has been called candlefish because the flesh is so oily that the dried fish, when provided with a wick of rush-pith or strip from the inner bark of cedar, burns with a steady flame and was used as a candle by the natives. This fish gave rise to the famous "grease trails" which roughly follow the courses of the great northern rivers (Hart and McHugh 1944). The only record of eulachon in murrelet diet was the anecdote by Grinnell (1897) described previously under the section on Alaska. Eulachon are distributed from northern California to the Bering Sea. They seem to feed primarily on euphausiids. Eulachon are important as an intermediate step in the food chain between the euphausiids and larger fish (Hart and McHugh 1944).

The range of the silver smelt extends from southern Alaska to central California. Some of the smelt may spawn at the end of the first year as has been indicated for Puget Sound fish. They spawn under a great variety of conditions and in most months of the year. Summer spawnings take place both on exposed beaches and at the head of sheltered bays. Usually the fish spawn where there is a certain amount of seepage of fresh water through the fine gravel to which the eggs adhere. Euphausiids seem to be the main food item consumed by silver smelt (Hart and McHugh 1944).

The capelin is an arctic species with its center of abundance in the Bering Sea or Arctic Ocean (Hart and McHugh 1944). In the Pacific, capelin occur from Alaska to Juan de Fuca Strait. Their distribution in the coastal zone varies seasonally but peaks in June and July when beach spawning accurs. At other times of the year, capelin can be found in large concentrations in the offshore waters (Jangaard 
in Carscadden 1984). At spawning time, capelin appear in schools of considerable size along the shores of gravelly beaches. Spawning occurs in the evening at high tide right at the water's edge. Studies of the beach both during and after spawning indicate that a specific type of ground is selected, the fish tending to avoid both rocky and sandy patches. The eggs are extremely adhesive and immediately become firmly cemented to the gravel (Hart and McHugh 1944).

Capelin mature at 3 or 4 years of age with faster growing fish maturing earlier (Winters in Carscadden 1984). In the spawning populations, 3-and 4-year-olds usually predominate. Spawning mortality is high, usually greater than 80 percent (Carscadden and Miller in Carscadden 1984).

Like other pelagic fish species, capelin populations exhibit large variations in abundance of year classes, and natural fluctuations in abundance are often complicated by the presence of fishing mortality. Carscadden (1984) evaluated fluctuations in capelin biomass in the northwest Atlantic and concluded they were the result of natural variation in yearclass strength. The causes of the variation were not well understood, but temperature and onshore wind-induced wave action have been correlated with emergence of larval capelin (Frank and Leggett in Carscadden 1984).

Carscadden (1984) considered the relationship between Atlantic Puffins and capelin as described by Brown and Nettleship (1984) and concluded that a complex of natural environmental and biological factors would probably affect the abundance and behavior of capelin predators, rather than a single one such as abundance of capelin. Brown and Nettleship (1984) concluded that the management of the capelin fishery in the northwest Atlantic should "proceed cautiously" until the relationships between the capelin and its predators were better understood.

Vader and others (1990) evaluated the relationship between Common Murres, Thick-billed Murres (U. lomvia), and capelin in Norway. A complete collapse of the Barents Sea stock of capelin occurred between 1985 and 1987, and in 1987 fishermen noted a near-complete absence of sand lance. The low sand lance population resulted in a complete breeding failure of Shags (Phalacrocorax aristotelis) in West Finnmark, where Shags are normally totally dependent on sand lance during the breeding season. A sudden drop in breeding Common Murres also occurred in 1987. The authors concluded that the capelin and sand lance food shortage caused the large drop in Common Murres and the reduced breeding of Thick-billed Murres. The authors thought the larger prey spectrum utilized by the Thick-billed Murres allowed that population to fare better than the Common Murres in the face of the food shortage. The causes of the decline in capelins probably included overfishing, uncommonly large year-classes of the predatory cod (Gadus morhua), and a reduction in recruitment due to changes in the physical oceanography of the Barents Sea (Hamre; Ushakov and Ozhigin in Vader and others 1990).

The importance of capelin in the diet of the murrelet in the Gulf of Alaska (Sanger 1983) indicates the need to monitor and manage carefully this resource. Other smelt species may be important in murrelet diet; unidentified osmerids have been documented as murrelet prey over a broad geographic range (table 1). Further research is needed on the importance of smelt in the diet of the murrelet, especially in Washington, Oregon, and California.

\section{Prey Ecology Summary}

The marine environment, especially in an eastern boundary current system, is not static (Ainley and Boekelheide 1990: 376). In his book on the Ancient Murrelet, Gaston (1992: 74) wrote of a diagram of the food web of Reef Island: "A complete diagram of the food webs of Hecate Strait would probably cover a baseball field at this scale, and would take several lifetimes of research to construct." Sanger's (1983) compilation contains numerous food web diagrams which depict the complex interactions in the marine environment. A food web and a model of the trophic-level interactions influencing murrelets at any site in North America would be complex indeed, but much information on life history of prey species and the murrelet at sea must be gathered.

From the studies discussed above, some variability in reproductive success of the murrelet can be expected because of the naturally dynamic nature of their prey base and the marine environment. Anthropogenic influences can compound prey fluctuations; thus, marine research and management should be designed to minimize or avoid adverse changes in seabird reproduction and marine trophic-level interactions. Anthropogenic and environmental influences will continue to affect marine ecosystems. Management must therefore entail monitoring and the ability to change course in response to observed effects. Cumulative impacts in localized areas of murrelet abundance should be anticipated and averted.

\section{Size of Prey Items}

A compilation of prey item size in the diet of adult and subadult murrelets from systematic studies indicates the majority of fish taken ranged from 30.1 to $60.0 \mathrm{~mm}$ (table 4). The largest combined sample size was for sand lance, and the distribution indicated a heavy reliance on fish up to $60.0 \mathrm{~mm}$, although fish greater than $90.0 \mathrm{~mm}$ were also taken. Sanger (1987b) calculated a mean value of $45 \mathrm{~mm}$ (total length) for sand lance which correlates well with the distribution of prey size revealed in table 4. Smaller size classes (0.1-30.0 mm) of scorpaenids and Cymatogaster aggregata were taken by murrelets; this could be a function of availability or preference. Larval and juvenile fish (0.1$60.0 \mathrm{~mm}$ ) appear to be the main size classes eaten by adult and subadult murrelets. Larval fish are underrepresented in murrelet diet because they are digested quickly (Carter 1984), therefore, the overall importance of larval fish for murrelets is difficult to assess.

The size of prey items in the diet of hatching-year and nestling murrelets is markedly different (table 5) though a comparison of fish lengths in tables 4 and 5 reveals adult/ subadult and hatching-year murrelet prey size to be similar. 
Table 4-Size of prey ilems for adult and subadult Marbled Murrelets

\begin{tabular}{|c|c|c|c|}
\hline \multirow[b]{2}{*}{ Prey } & Sample size & Mean length & Range or size class \\
\hline & $n$ & $m m$ & $m m$ \\
\hline \multirow{2}{*}{ Lolıģo opalescens } & 5 & - & $0.1-30.0$ \\
\hline & 2 & - & $>240$ \\
\hline Unidentified mysids & $20 \times$ & 18 & $11-38$ \\
\hline Lude ufred gammand amphupod & $6^{\circ}$ & 15 & $12-18$ \\
\hline Thysanoessa inermis & $2^{c}$ & - & $15-21$ \\
\hline Thusenacssa reschi & $38^{\circ}$ & 14 & $11-21$ \\
\hline Thysanoessa spp. & $24^{c}$ & 13 & $11-18$ \\
\hline \multirow[t]{4}{*}{ Th scroessa sp nufero } & 1 & 21 & - \\
\hline & $21^{t}$ & - & f $1-12.0$ \\
\hline & $149^{b}$ & - & $12.1-24.0$ \\
\hline & $23^{-h}$ & - & $>240$ \\
\hline Euphousio pacifica & $34^{b}$ & - & $12.1-24.0$ \\
\hline \multirow[t]{3}{*}{ Cluppea havengus } & $35^{2}$ & - & $01-300$ \\
\hline & $101^{\mathrm{a}}$ & - & $30.1-600$ \\
\hline & $26^{1}$ & - & $601-9 \times 0$ \\
\hline Engraulis mordax & $4^{2}$ & - & $30.1-60.0$ \\
\hline Mal-tur villosws & 5 & 63 & $2-105$ \\
\hline \multirow[t]{2}{*}{ Osmeridae } & $6^{b}$ & - & $0.1-30.0$ \\
\hline & $11^{b}$ & - & $30.1-60.0$ \\
\hline \multirow[t]{2}{*}{ Scorpacudae } & $290^{\circ}$ & - & $0.1-30.0$ \\
\hline & $3^{2}$ & - & $301-60.0$ \\
\hline \multirow[t]{3}{*}{ Cymarogaster aggregara } & $32^{b}$ & - & $0.1-30.0$ \\
\hline & $14^{b}$ & - & $30.1-60.0$ \\
\hline & $1^{b}$ & - & $60.1-90.0$ \\
\hline Suchoreldae & $6^{c}$ & - & $3^{n} 1-6.0$ \\
\hline \multirow[t]{5}{*}{ Ammadyres hexapterus } & $13^{c}$ & 45 & $29-135$ \\
\hline & $528^{\circ b}$ & - & $0.1-30.0$ \\
\hline & $596^{\mathrm{bb}}$ & - & $30.1-60.0$ \\
\hline & $88^{\text {tb }}$ & - & $60.1-90.0$ \\
\hline & $6^{b}$ & - & $>90.0$ \\
\hline
\end{tabular}

"Carter (1984): length for invertebrates is total length, and fork length for fish

bealy (1975c); length same as Carter (1984) except as noted for Loligo opalescens

'Sanger (1987); length for all specimens is total length

As noted by Carter (1984) and Mahon and others (1992), murrelet nestlings are fed much larger fish than the adults consume. Most nestling prey items were $>60.1 \mathrm{~mm}$, and sand lance prey were $>90.1 \mathrm{~mm}$ (table 5 ).

Schweiger and Hourston in Carter (1984) concluded that second-year herring fed to nestlings were much less abundant than the juvenile herring that adult murrelets ate for themselves. Second-year sand lance and anchovy were also not considered very abundant in Carter's (1984) study area, which suggested that murrelets selected larger prey to carry to nestlings, even though such fish were less abundant. This behavior is consistent with optimal foraging theory (Carter and Sealy 1990), and other seabirds have exhibited this same adaptive trait (Gaston and Nettleship; and Slater and Slater in Carter 1984).

The lengths of nestling prey probably represent secondyear fish (Hart in Carter 1984), thus, murrelet adults, subadults, and hatching-year birds feed primarily on larval and juvenile fish, whereas nestlings are most commonly fed second-year fish. Therefore, both of these cohorts of the principal prey species should be monitored and managed to assure maximum productivity of murrelets in any one year.

\section{Energetics and Energy Values of Some Prey Items}

Energy values of prey items also help explain why murrelets select certain prey species for themselves and their 
Table 5-Size of prey items for hatching-year and nestling Marbled Murrelets

\begin{tabular}{|c|c|c|c|c|}
\hline \multirow{3}{*}{ Prey } & \multicolumn{2}{|c|}{ Hatching-year prey size } & \multicolumn{2}{|c|}{ Nestling prey size } \\
\hline & Sample size & Range & Sample size & Length of specimen or range \\
\hline & $n$ & $m m$ & $n$ & $\mathrm{~mm}$ \\
\hline \multirow[t]{3}{*}{ Clupen harengus } & $3^{a}$ & $0.1-30.0$ & $16^{\mathrm{a}}$ & $60.1-120.0^{b}$ \\
\hline & $38^{\mathrm{a}}$ & $30.1-60.0$ & & \\
\hline & $7^{\mathrm{a}}$ & $60.1-90.0$ & & \\
\hline \multirow[t]{2}{*}{ Engraulis mordax } & - & - & $2^{\mathrm{a}}$ & $90.1-120.0^{b}$ \\
\hline & & & $1^{e}$ & 113 \\
\hline Mullotus villosus & - & $=$ & $1^{d}$ & 80 \\
\hline \multirow[t]{5}{*}{ Ammodytes hexapterus } & $2^{\mathrm{e}}$ & $0.1-30.0$ & & \\
\hline & $25^{\mathrm{ae}}$ & $30.1-60.0$ & & \\
\hline & $2^{e}$ & $60.1-90.0$ & & \\
\hline & & & $70^{\mathrm{a}}$ & $90.1-120.0^{b}$ \\
\hline & & & Unknown ${ }^{f}$ & $140-180^{b}$ \\
\hline Cymulogaster aggregata & $12^{c}$ & $0.1-30.0$ & $=$ & - \\
\hline Scorpaenidae & $f^{\mathrm{a}}$ & $30.1-60.0$ & - & - \\
\hline Unidentified fish & $=$ & - & $56^{\mathrm{a}}$ & $60.1-120.0^{b}$ \\
\hline
\end{tabular}

Carter (1984); 16 June - 6 July 1980, $n=144$ fish observed.

b Sizes of prey estimaled while held by murrelets in their bills when on the water

c Ralph and others (1990); observation during mist-netting operation, 3 July 1989.

d Simons (1980); observation of a feeding at a ground nest.

e Sealy (1975c); from 6 newly-fledged murrelets collected between 10 July and 4 August 1971.

f Mahon and others (1992); murrelets observed on the water in the evenings, 6 June - 8 August 1991.

nestlings. Energy values of seabird prey items have been little studied (Hislop and others 1991), but a gross comparison from some closely related species reveals marked differences in food energy, protein, and total lipids (lable 6). Especially when considering the feeding of nestlings at inland sites, optimal foraging theory would predict that the largest and most energy-rich food items would be brought to the nestlings. This would be adaptive by reducing energy demand on the adults, and by increasing the chances of a successful fledging. However, prey availability and competition with other seabirds also affects prey selection. The small size of the murrelet also limits its prey load, and a long flight time inland with a heavy prey load would be energetically costly and would subject the bird to an increased period of vulnerability to inland predation. Prey also loses water during transport by seabirds. Montevecchi and Piatt in Hislop and others (1991) simulated transport of capelin by tying fish to a drying rack mounted on a pick-up truck which was driven at $60 \mathrm{~km} / \mathrm{h}$. After one hour, weight loss averaged 9 percent for male capelin and 11.5 percent for females.

A detailed analysis of variation in the calorific value and total energy content of the lesser sand eel (A. marinus) and other fish preyed on by seabirds was conducted in north Scottish waters by Hislop and others (1991). They found the calorific values and body weights of sand eels larger than 10 $\mathrm{cm}$ showed marked seasonal trends, and thus the total energy content of a sand eel of given length in summer was approximately double the spring value. Calorific values of Atlantic herring also varied from month to month, but seasonal cycles were less obvious. Seasonal cycles in fat content and, consequently, in calorific value are generally associated with the annual reproductive and feeding cycles of the fish, and tend to be greater among the larger, mature members of the population. Since different species of fish spawn at different times, their condition cycles are out of phase to some extent. And, since herring spawn in different waves, their condition is not uniform at any one point in time.

Hislop and others (1991) concluded that because fish demonstrate intraspecific length-related and seasonal changes in calorific value and energy content, it is unwise to generalize about the relative food values of different prey species to predators. They noted that sand eels have maximum calorific values intermediate between those of gadoids and clupeoids. Of interest, Hislop and others also noted that juvenile sand 


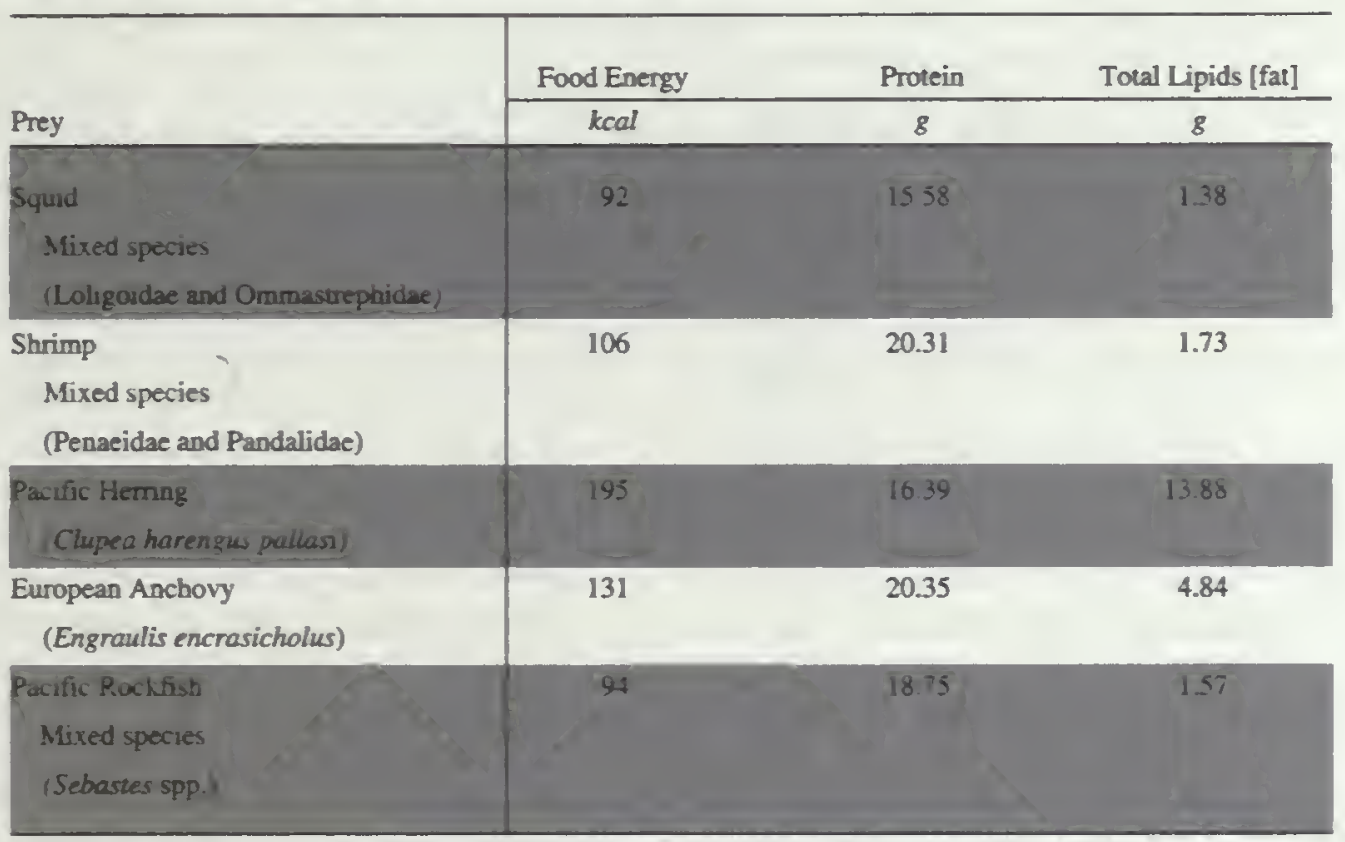

${ }^{1}$ Amounts in 100-g raw samples, edible portion (Exler 1987)

eels $(<10 \mathrm{~cm})$ which have low body weights and high water content seemed, on purely energetic grounds, to be lowquality food. Because many different seabird species use sand lance in their diet, it may be that the overall abundance and availability of these fish compensates for the low energy value. Sand lance may also contain essential nutrients which seabirds have a need for, and the higher water content may also be important physiologically. The estimation of total energy content is complicated by dehydration of fish specimens; thus, Montevecchi and Piatt in Hislop and others (1991) urged seabird biologists to compare dry weight energy densities across studies. Both sets of researchers also noted the value of including wet calorific values as well.

The work of Hislop and others (1991) provides data for comparison of energy values between sand eel and herring which indicates that herring have much higher total energy value than sand eel (table 7). Unfortunately, there is no data available for both herring and sand eel of murrelet nestling prey size (60.1-120.0 mm) in July or August to allow a more relevant comparison.

Roby (1991) studied the diet and postnatal energetics in three species of plankton-feeding seabirds. Lipid-rich diets were associated with shorter brooding periods, higher rates of nestling fat deposition, and larger lipid reserves at fledging. The energy cost of growth was a relatively minor component of nestling energy budgets; most assimilated energy was allocated toward maintenance and fat deposition. Once growth requirements for protein had been mel, any additional assimilated protein was metabolized to meet maintenance costs, and the energy saved was stored as fat. High lipid diets were associated with higher rates of lipid deposition by chicks, but not higher growth rates. Instead, constraints operating at the level of tissues are apparently responsible for most of the variation in growth rate among seabirds. Large lipid reserves at fledging presumably enhance post-fledging survival.

\section{Discussion}

Conservation and recovery of the murrelet will depend in part on a better understanding of the interaction between the factors affecting the species inland and at sea. The studies described in this chapter have shed some light on this relationship and have indicated the need for comprehensive management of marine resources and inland nesting habitat.

There is a need for additional study of murrelet diet, especially in the southern end of its range. Winter diet studies are also needed to help understand why some murrelet populations disperse to other locales during the non-breeding season. Comparison of prey abundance and composition between breeding and non-breeding foraging areas may help explain these movements.

Additionally, more research on the use of inland lakes and estuaries as foraging sites is needed, across all seasons. This aspect of the murrelet's life history has not received adequate attention except by Carter and Sealy (1986) and Hobson (1990). Though there are few large inland lakes in the coastal area of Washington, Oregon, and California, 
Table 7-Calorific values ( $\mathrm{kJ} / \mathrm{g}$ ) and total energy content ( $\mathrm{kJ}$ ) of Lesser sand eel (Ammodytes marinus) and Atlantic herring (Clupea harengus) ${ }^{l}$

\begin{tabular}{l|cccccc}
\hline \multirow{2}{*}{ Fish } & $\begin{array}{c}\text { Mean } \\
\text { length }\end{array}$ & $\begin{array}{c}\text { Collection } \\
\text { month }\end{array}$ & $\begin{array}{c}\text { Dry } \\
\text { calorific } \\
\text { value }\end{array}$ & $\begin{array}{c}\text { Wet } \\
\text { calorific } \\
\text { value }\end{array}$ & $\begin{array}{c}\text { Wet } \\
\text { weight }\end{array}$ & $\begin{array}{c}\text { Tolal } \\
\text { energy } \\
\text { content }\end{array}$ \\
\cline { 2 - 7 } Lesser sand eel & $\mathrm{cm}$ & & $\mathrm{kJ} / \mathrm{g}$ & $\mathrm{kJ} / \mathrm{g}$ & $\mathrm{g}$ & $\mathrm{kJ}$ \\
\hline Atlantic herring & 16.5 & June & 25.8 & 6.9 & 13.5 & 93.2 \\
\hline
\end{tabular}

${ }^{1}$ Data from Hislop and others (1991)

there are numerous coastal lagoons and estuaries which may be important to murrelets.

Intensive studies on factors affecting sand lance distribution and abundance are needed, as well as further exploration of the food web of this species. The importance of this little-studied fish in the diet of murrelets from Alaska to California certainly indicates a need for further investigation of predator-prey interactions. Monitoring of sand lance populations may prove useful for comparisons with murrelet population and productivity estimates from at-sea surveys. Sand lance recruitment could potentially serve as an indicator of murrelet reproductive success. A strong correlation was reported between number of tern chicks available for banding and recruitment of sand lance (Monaghan and others 1989). The effect of pollution and physical disturbance (dredging) on sand lance populations needs management attention (Auster and Stewart 1986, Nakata and others 1991, Pinto and others 1984). Identification of sand lance spawning areas could aid conservation of the murrelet through directed management of these sites.

The threatened and endangered status of the murrelet, coupled with the low productivity estimates, indicates the need for intensive field work in order to determine food habits without sacrificing birds. Long hours of observation of murrelets at sea catching and holding fish will be necessary, and intensive, systematic searches for beached birds could yield specimens for studies of food habits. Plankton hauls along with traditional methods of assessing marine fish can be used in areas where murrelets are actively foraging to at least determine prey abundance and composition. Video footage of prey items along with collections of fish parts from nest sites can contribute to knowledge of murrelet diet. Specimens can also be obtained from gill netting operations and oil spill events. Stomach pumping or emetics could possibly be employed, especially in conjunction with radiotelemetry studies and banding or marking operations.

The identification of important foraging areas near known murrelet nesting sites will help in the conservation of this species (Ainley and others, this volume). Human activities or influences which are detrimental to the murrelets or their prey resources could then be appropriately managed in such areas.
Clark and others (1990) compared habitat structure and the number of active nests for Red-tailed Tropicbirds (Phaethon rubricauda) before and after an El Niño event. An increase in availability of quality habitat post-EI Niño resulted in an increase in the number of active nest sites relative to pre-El Niño breeding seasons. The data of Clark and others supported the hypothesis that suitable nest sites may limit short-term reproductive opportunities of tropicbirds and, hence, influence the rate of population growth and time course of recovery from catastrophic events such as El Niño. This has important management implications for a threatened species such as the murrelet. Inland nesting habitat becomes a very important management consideration even though the murrelet relies on the marine environment for food. A study on the Red-throated Loon (Gavia stellata) indicated that as distance from the ocean to the nest site increased, both density and nesting success of loons decreased (Eberl and Picman 1993). The authors suggested that the higher density of breeding loons in areas near the ocean reflected a preference by these birds for nesting grounds that are closer to their foraging areas.

Since the murrelet is a forest-nesting seabird, it is imperative to consider multiple factors when devising research and management strategies. Because of its secretive nesting habits, it has been difficult to document nest success relative to prey abundance as has been done with other seabirds. Even if adult murrelets can easily choose alternate prey species for their own diet, having abundant forage fish available during the nestling period may significantly reduce the energy demand on the adults by requiring less foraging time and fewer trips inland for feeding nestlings (Carter 1984, Carter and Sealy 1990, Cody 1973, Sealy 1975c). The juxtaposition of nesting areas and foraging areas is probably most critical as one determinant of reproductive success in years of low prey abundance. Increased foraging time of adults, long flights inland, and more numerous trips inland with small prey items would potentially reduce both adult and chick survival. Competition with other seabirds for available food is also an important factor in foraging patterns and prey selection (Ainley and Boekelheide 1990: 380; Cody 1973; Mahon and others 1992). 
Marine communities have been altered by the activities of humans in conjunction with natural influences (Caims 1992a: 39). As early as 1886, declines in fish populations in heavily fished areas seemed apparent. The notes of an expedition to Puget Sound in July 1895 contained the following anecdote regarding herring: "Exceedingly abundant. J.P. Hammand (American Angler, December 18, 1886) states that from 18-25 years ago it was not an uncommon occurrence for a 'gang' of fishermen to catch from 200-300 barrels of herring in a night on Puget Sound. Now the largest night's work is 20 barrels" (Jordan and Starks 1896). The sardine fishery in California which was discussed above is another example. The relatively new fishery went from the "palmiest days" of Cannery Row in the mid-1930's to a catastrophic drop in 1947. In response to this drastic decline, there emerged what is known today as the California Cooperative Oceanic Fisheries Investigations (CalCOFI) program to belp better manage marine resources (Ricketts and Calvin 1962: 382). The observations of Radovich (1961) are helpful: "The mere fact one can demonstrate the environment has a large effect on the catch does not imply man's effect is inconsequential. To understand man's effect, one must study the effect of man. However, a satisfactory understanding may never be achieved so long as one fails to recognize the existence of some of the other factors constantly confusing his data. The effects of environment and man on fish populations are not mutually exclusive." The long history of fishing activity in the North Sea produced steep declines followed by increases when fishing pressure diminished. Such events resulted in Sir Alister Hardy's remark: "Certainly no one can deny that over-fishing exists; we must find the best way to remedy it" (Hardy 1965: 247-248).

The scale-deposition studies described above provide evidence that abundance of coastal pelagic fish species varied considerably before the inception of modern fisheries. Environmental factors and trophic-level interactions contribute to the naturally dynamic state of marine ecosystems. Fishing has, however, probably exacerbated the natural variability in recent decades because reduced stock size and loss of old fish, which is an inescapable result of fishing, increase the speed and magnitude of population decreases during periods of poor reproduction. Approaches to fishery management based on equilibrium or steady-state concepts that ignore variability in abundance have a long history of failure for coastal pelagic species in many regions of the world (Troadec and others in Anonymous 1993). Managers should expect considerable interannual variation in abundance and yields and should curtail fisheries to protect the long-term health of the stock when necessary. Chaotic ecosystems appear to require reliance on management that is beneficially adaptive rather than manipulative. The possibility of detailed predictions is effectively ruled out, and many factors, including socioeconomic ones, must be used when modeling populations, ecosystems, and fishery impacts (Wilson and others 1991).

Throughout its range, the murrelet consumes a very diverse group of prey resources, especially when one considers the limited studies which have been done to date. This indicates great flexibility in prey choice and a high capability for prey-switching behavior. This would make adaptive sense given the multiple factors affecting prey availability each year and the oceanographic differences found offshore from forest nesting habitat throughout the range of the species. It also indicates that El Niño events would not be expected to cause catastrophic population fluctuations or declines, especially in the long term. Given the variability in frequency and intensity of El Niño events, murrelet production could be lower than "normal" in some years as has been demonstrated for many other seabirds. But, like other seabirds, the murrelet has evolved with this phenomenon and can likely change its foraging behavior and food preferences to some degree in order to utilize available resources (Carter 1984, Croll 1990, Krasnow and Sanger 1982, Sanger 1987b, Sealy 1975c). Additionally, the long life span of the species allows for adequate reproduction and dynamic equilibrium of the population, even in the face of low reproduction in some years. However, cumulative impacts in localized areas over a short time period could cause serious population declines or possibly even extirpations.

Research should continue to identify bottlenecks to recovery; "scientifically approachable" and "practically realizable" studies should be done along with attempts at "integrated management of the marine ecosystem as a whole" (Holt 1993). A lack of information on the functioning of "natural systems" (Willers 1993) should not prevent comprehensive research or recovery actions in the future, but instead sbould help guide more unified study efforts. Biologists have long recognized the need to integrate seabird and marine science (Ainley and Sanger 1979, Furness 1984, Munro and Clemens 1931, Sealy 1990, and others) and the excellent treatise on the matter by Caims (1992b) should help guide marine ecosystem research and management in the future.

Managers and researchers today are faced with the listed or sensitive management status of the murrelet and limited financial resources to conduct the necessary studies. It is now more important than ever to pool resources and seek innovative ways to conduct the necessary research. Mitigation banking policies imposed on commercial fishing and timber industries, coupled with damage assessment rewards, could help gather research funds and support the large-scale studies proposed by Nisbet (1979) and Vermeer (1992). Research monies alone are not recognized as adequate mitigation for negative impacts to natural resources, but funds derived from such policies could certainly play a stronger role in the conservation and recovery of the murrelet than has occurred up to this point.

These ideas are not new (Drury 1979, Nisbet 1979), but implementation has yet to occur on a meaningful scale. In the words of Drury (1979: 136): "Experience in Europe and in New England suggests that if reasonable limitations are set on human activities and that if adequate money charge is made against those who profit by economic development to 
defray full social costs, wildlife can continue to do well. In most cases where damage has occurred it is because those who administer the public institutions have failed to include consideration of the common property resources".

\section{Acknowledgments}

I thank my friends and colleagues Jack Fancher and Bob Hoffman for involving me in fish assessment work, and Charlie Collins and Mike Horn for stimulating my interest in seabird feeding ecology during the Bolsa Chica days. Special thanks to Charlie for being such a good teacher and enthusiastic field partner. Thanks also to Dick Zembal for involving me in a project on a coastal wetland food web; that project cemented my interest in predator-prey relationships. Patty
Wolf was especially helpful in providing much needed literature and background information from all the work done on the Pacific Coastal Pelagic Species Fishery Management Plan. I thank C.J. Ralph, Mike McAllister, George Hunt, and an anonymous reviewer for their encouragement and helpful comments on an earlier version of this manuscript. I especially appreciate George's interest in the energetic aspects of seabird ecology. The dedicated work of Harry Carter and Gerry Sanger provided inspiration. They also provided much help and guidance. This project would not have been possible without the capable assistance of Vikki Avara who searched for and obtained the copious and obscure literature upon my sometimes fickle demands. Thanks also to Shannon Sayre and Heather Johnson for assistance with the tables. 


\section{Chapter 23 \\ Marbled Murrelet At-Sea and Foraging Behavior}

\author{
Gary Strachan'
}

Michael McAllister ${ }^{2}$

\section{John Ralph ${ }^{3}$}

\begin{abstract}
The behavior of Marbled Murrelets (Brachyramphus marmoratus) at sea while foraging for small fish and invertebrates is poorly known. This murrelet forages by pursuit diving in relatively shallow waters, usually between 20 and 80 meters in depth. We have also observed it diving in waters less than 1 meter and more than 100 meters deep. The majority of birds are found as pairs or as singles in a band about 300 to 2000 meters from shore. Pairs tend to dive simultaneously when foraging, and we suggest that pairing has some benefit to foraging efficiency. At uimes they are in small flocks and in aggregations. Larger aggregations are found in the northern part of its range, probably due to the denser population. Foraging dive times averaged about 16 seconds. Murrelets generally forage during the day, and are most actively in the morning and late afternoon hours. Some foraging occurs at night Vocalizations during foraging occur after individuals of a pair surface apart from each other. The majority of the birds' surface time is spent loafing, preening, and wing stretching. We feel that adults holding fish are usually about to depart inland to feed a young, and are potentially a very useful measure of reproductive rare. Murrelets are not generally associated with interspecific feeding flocks, except in the northem part of its range.
\end{abstract}

The at-sea behavior of the Marbled Murrelet (Brachyramphus marmoratus) is relatively little known, with the exception of the work of Carter and Sealy (1990). Understanding the relationship between the species, its foraging habitat, and its prey species are important so that appropriate decisions are made concerning future recovery efforts. We have spent many thousands of hours observing murrelets on the ocean and this paper brings together these observations, contributions from colleagues, and the published literature, to give a perspective on the life history of the species in its marine environment.

\section{Foraging Range}

Nearshore feeding-During the breeding season, the Marbled Murrelet tends to forage in well-defined areas along the coast in relatively shallow marine waters (Carter and Sealy 1990). Part of their distribution is related to availability of nesting habitat, as discussed in other chapters in this volume. Murrelets generally forage within $2 \mathrm{~km}$ of the shore in relatively shallow waters in Washington, Oregon, and

\footnotetext{
'Supervising Ranger, Año Nuevo State Reserve, New Year's Creek Road, Pescadero, CA 94060

2 Wildlife Biologist, Wildland Resources Enterprises, 60069 Morgan Lake Road. La Grande, OR 97850

${ }^{3}$ Research Wildlife Biologist, Pacific Southwest Research Station, USDA Forest Service. Redwood Sciences Laboratory, 1700 Bayview Drive, Arcata, CA $9552 \mathrm{t}$
}

California. The species does occur farther offshore than 2 $\mathrm{km}$ (Carter, pers. comm.; Piatt and Naslund, this volume; Ralph and Miller, this volume; Sealy 1975a), but in much reduced numbers. Ainley and others (this volume) reported a few murrelets up to $24 \mathrm{~km}$ offshore in central California. Their offshore occurrence is probably related to current upwelling and plumes during certain times of the year (Hunt, this volume a). Off Alaska and British Columbia. the bird occurs more frequently further offshore; they occur quite regularly out $40 \mathrm{~km}$ in the Gulf of Alaska in the relatively shallow waters of that region (Piatt and Naslund, this volume; McAllister, unpubl. data). During the non-breeding season, murrelets disperse and can be found farther from shore, as is the case with some other alcids.

Murrelet prey species mostly include small inshore fish and invertebrate species such as sand lance (Ammodytes hexapterus), smelt (Hypomesus spp.), Pacific herring (Clupea spp.), capelin (Mallotus spp.), and various other fish (Burkett, this volume). Invertebrates such as Euphausia pacifica and Thysanoessa spinifera are also important prey (Sanger 1987b, Sealy 1975a).

Winter distribution-In some locations, after the breeding season, birds appear to disperse, and are less concentrated in the immediate nearshore coastal waters. This has been observed in Año Nuevo Bay in central California (fig. I), as birds move away from this protected bay from November through April. Similar movements have been observed in Clarence Strait in Southeast Alaska (McAllister, unpubl. data), where the birds are greatly reduced in numbers and probably have moved to the south. In the southern portion of their range, murrelets are reported in winter as far south in central California as San Luis Obispo County, and at times to the southern portion of the state. In many areas, however, individuals maintain an association with the inland nesting habitats during the winter months (Carter and Erickson 1988).

Fresh water lake use-Carter and Sealy (1986) found 67 records of birds on 33 fresh water lakes; 78.6 percent of those recorded were in British Columbia, 12.1 percent in Alaska, 6.1 percent in Washington, and 3 percent in Oregon. Foraging on lakes had been suspected because salmon fry, fingerlings, and yearlings that have been found in birds' stomachs (Carter and Sealy 1986). A few observations of birds presumably feeding in lakes have been recorded (Munro 1924, Carter and Sealy 1986). Carter and Sealy (1986) speculated that murrelets feed at night on these lakes when fish are available closer to the surface. Hobson (1990) found evidence, based on isotope analysis of murrelet muscle tissue, that birds collected on Johnston Lake, British Columbia, may feed in fresh water lakes for several weeks at a time. 


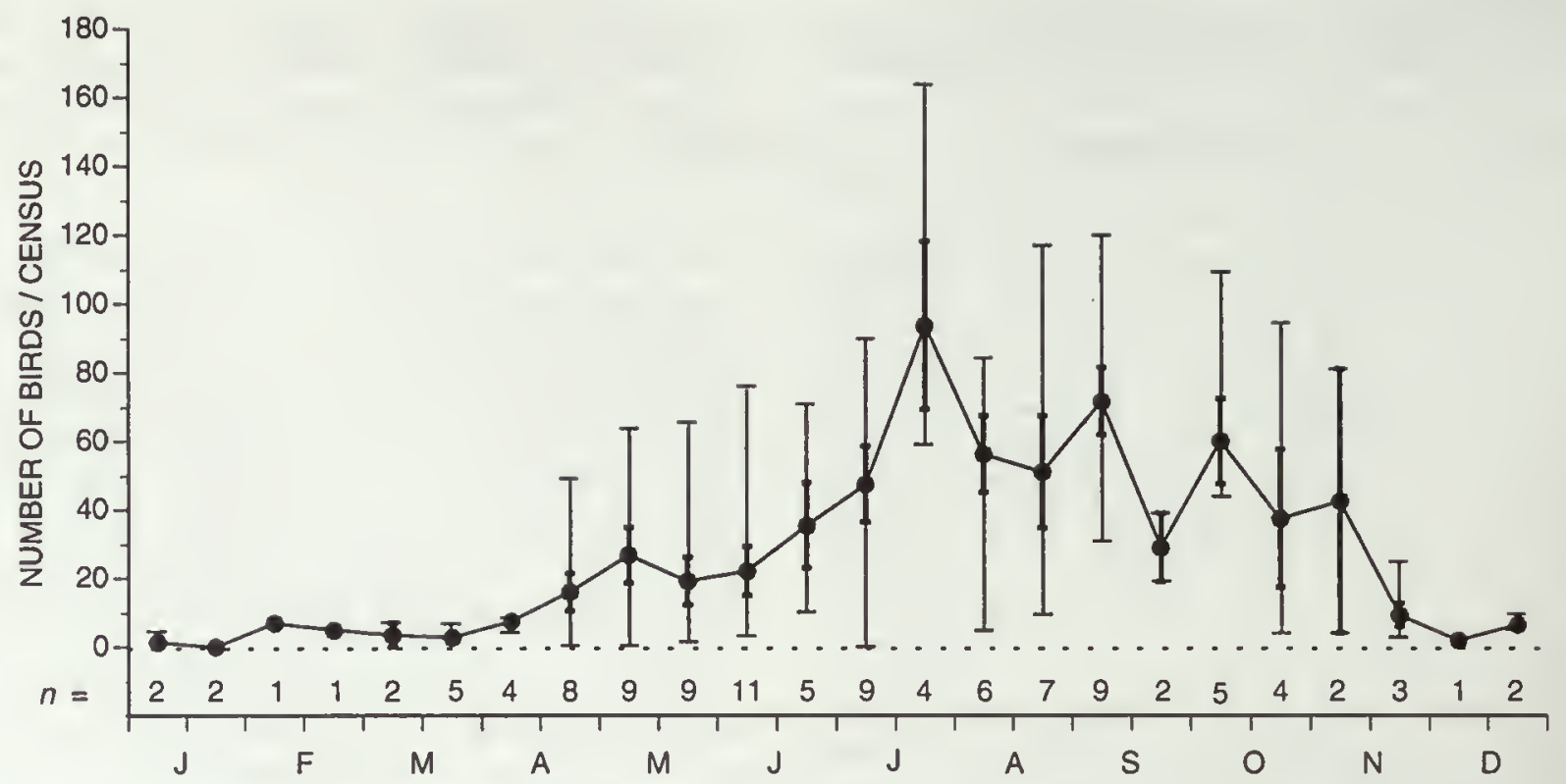

Figure 1-Average number of Marbled Murrelets/census by biweekly periods on Año Nuevo Bay during 1990. Figure shows the mean, standard error, and minimum and maximum values of from-shore censuses. $n=$ number of censuses/time period.

\section{Foraging Behavior}

\section{Pairing and Group Size}

Frequency of pairs-Murrelets forage mostly in pairs throughout the year. This is an important aspect of their life at sea, as we have often observed murrelets vocalizing on the water while foraging, apparently attempting to locate the other member of a pair when coming to the surface, or after a disturbance. The call usually used is the typical "keer" in rapid succession or singly. The percentage of birds in an area that are foraging or loafing in pairs varies, but not greatly. Mean group size from Oregon was 1.8 birds, with about 70 to 80 percent of the birds observed in pairs (Nelson 1990). Along the central Oregon coast, Strong and others (1993) observed that murrelets almost always occurred as single birds or pairs. In Alaska, pairs made up 45 percent of the population (Kuletz, pers. comm.). Carter and Sealy (1990) found in Trevor Channel, Alaska, that pairs were 40 percent of the birds seen. During the summer of 1993, Ralph and Long (this volume) reported 63 percent of groups were pairs and 27 percent were single birds in northern California.

In central California, 75 to 80 percent of birds foraged as pairs during the breeding season (fig. 2). Single birds are more common in the winter, when the populations are low at this location (fig. 2). Sealy (1975c) suggested that, during the incubation period, a daily pairing of birds occurred as birds flew around in the forested nesting area after an incubation exchange. We have observed many single birds circling and calling at inland sites until joined by a second bird, when both headed west to the ocean. We have also observed at times many hundreds of birds arriving at the ocean in the morning from inland nesting sites, usually in pairs, threes, or fours. Observations at the nest would suggest that the birds should arrive singly (Naslund 1993a; Nelson and Hamer, this volume a), as pair members are rarely at the nest simultaneously, which might suggest that the birds pair with non-mates enroute to the sea.

Composition of pairs-In British Columbia, Sealy (1975c) found that 11 out of 13 pairs collected in late April were composed of an adult male and adult female. After egg laying occurred, more single "off duty" birds were encountered at sea. He surmised that both adults stay together during the day and returned to the nest site at night to feed their chick. The subadults (birds one or two years old who have not yet bred, as determined by collecting) also returned in late April, but were encountered only as single individuals until late June and early July when mixed groups of "off duty" adults and subadults, were observed. During late July newly fledged young were frequently seen in these groups.

Reason for foraging in pairs-Sealy (1975c) stated "I believe that the occurrence of these pairs can be adequately explained on the basis of pair bond maintenance and that an advantage to feeding need not be involved." Possible evidence of pair bonding is found in observations of pairs separated by boats. Ralph (unpubl. data) and Miller (pers. comm.) have noted that about two-thirds of these pairs call and attempt to reunite, while the remaining birds simply disperse. However, we feel that foraging plays the major role in pairing, and probably involves some sort of cooperative foraging technique. Evidence of this includes the observation that the vast majority of actively foraging paired murrelets consistently dive together (Carter and Sealy 1990). Laing (1925) stated that the "birds of this genus work in winter and summer in pairs, but not as a defensive measure, for 


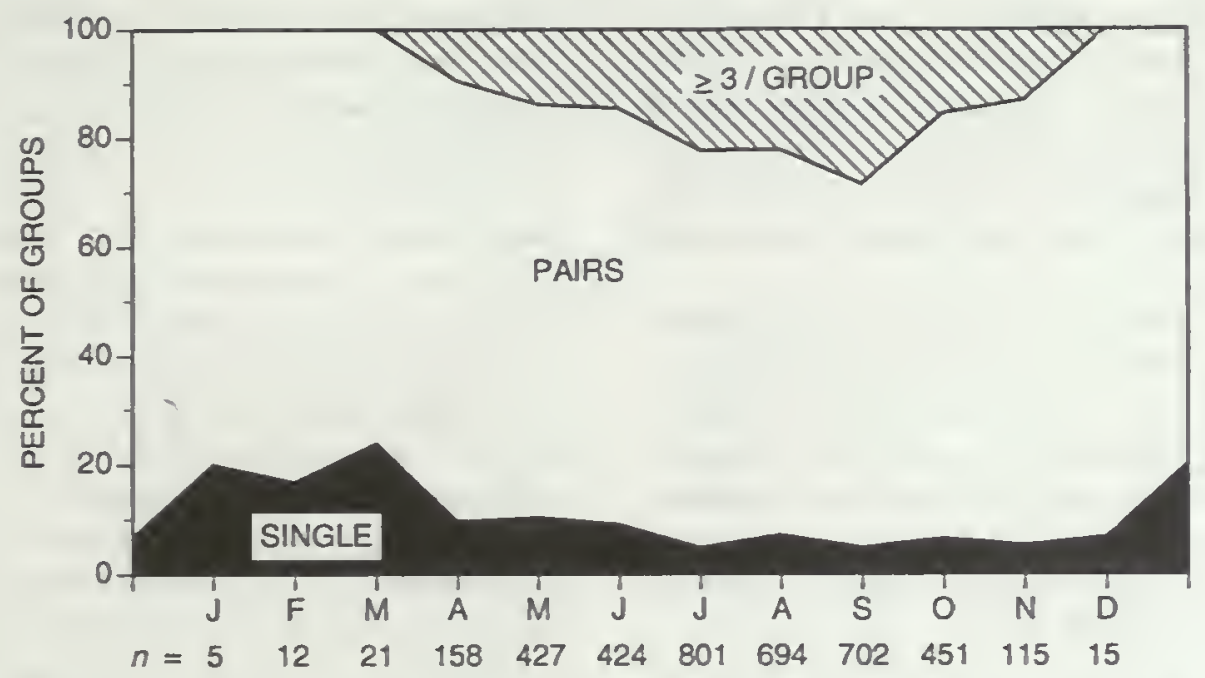

Figure 2-Group size of Marbled Murrelets by month on Ario Nuevo Bay during 1990, detailing percentage of groups observed consisting of single birds, pairs, or groups of $>3$ birds. $n=$ number of groups observed.

they dive almost together". Carter and Sealy (1990) reported that pairs were often seen swimming towards each other before diving, and that three or more birds never dove together in a coordinated fashion. They also stated that foraging by singles and pairs may prevent foraging interference, competition, and kleptoparasitism that would be more likely in foraging flocks.

Flock size and frequency - Carter and Sealy (1990) suggested that murrelets are most aggregated during the nesting period. Aggregations of large numbers have been reported in the northern range (Carter 1984; Carter and Sealy 1990; Hunt, pers. comm.; McAllister, unpubl. data). Foraging aggregations were probably related to concentrations of prey. McAllister (unpubl. data) observed an aggregation of 4,000 to 6,000 individuals at Point Adolphus on Icy Strait, in southeast Alaska, on 3 May 1991.

Observers have noted great variation in size of flocks (defined as three or more birds in close proximity and maintaining that formation when moving). In southeast Alaska, Quinlan and Hughes (1984) reported flock sizes up to 50 birds in Kelp Bay. Kuletz (1991a) found in another Alaskan population that flock sizes greater than three birds made up about 8 percent of the birds, 7 percent of the birds were found in groups of four birds, 3 percent of the birds in groups of five, and 1 percent were found in groups larger than five. The largest number in a concentrated flock was 22 birds. In British Columbia, Carter (1984) found larger, non-feeding flocks of up to 55 birds. The larger flocks usually occur during the later part of the breeding season, and may be made up of juveniles and subadults. Sealy (1975c) found that flocks would feed together at Langara Island, British Columbia, with the mean flock size of eight.

Flock sizes in the southern populations of California, Oregon, and Washington, rarely number more than 10 , according to our and others' observations. Nelson (pers. comm.) recorded groups greater than 3 as very uncommon in Oregon, with a maximum of 10 birds in a flock. Also in Oregon, Strong (pers. comm.), found similar flock sizes during his 1992 study. The largest flock that he observed was 15 birds. In California, Ralph and Long (this volume) found two was the most frequent group size (63 percent), while less than 10 percent of flocks contained more than three birds. The largest flock seen was 12 birds at Santa Cruz. At Año Nuevo Bay, in central California, flocks are similar in size (fig. 2). Here, at the southern end of the species' range, during late summer and early fall, flocks of over three would often contain juvenile birds. Groups of three or more were found during the summer, when the population is highest (fig. I), and may be a function of density, rather than flocking.

Behavior in flocks-Sealy (1975c) observed that the flocks would tend to dive against the current, and soon become spaced in a linear fashion with the main axis of the flocks paralleling the direction of the current. Carter and Sealy (1990) observed that larger flocks do not appear to be foraging. Sealy (1975a) stated that birds foraging during the breeding season "invariably occur in pairs or as single individuals." Early in spring adults feed in pairs while the subadults feed singly, but in early July, when pairs are still feeding young at the nest, mixed flocks of adults and subadults begin to form.

\section{Foraging of Juveniles}

When the first juveniles reach the water during the breeding season, usually by early July (Hamer and Nelson, this volume a), they are distinctive in plumage from adults. making identification of individuals in a small flock possible (Carter and Stein, this volume). From this we can learn 
about the need for foraging in groups. McAllister (unpubl. data) found in Alaska, between mid-July and mid-August, that more than 80 percent of the young were observed without adults present. By contrast, in California, Ralph and Long (this volume) observed that half of the juveniles observed were accompanied by one or more adults, while the remaining juveniles occurred alone.

By mid-August, it becomes difficult to differentiate juvenal plumage from molting adults. In our observations of juveniles on the water, we found that juveniles foraged without the assistance of the adults. They were seen as single birds, in pairs, and in small flocks. The largest flock was one of 12 young seen together in Peril Strait (McAllister, unpubl. data). Juveniles were most common within $100 \mathrm{~m}$ of shorelines, particularly where bull kelp (Nereocystis spp.) is present (McAllister, unpubl. data). At this time of year, adults were generally farther from shore in this area, at the sharp tidal interfaces, e.g. rips. However, in a 1993 study, Ralph and Long (this volume) found no difference between the distribution of adults versus juveniles in California.

Behaviorally, the fledglings are generally less wary, more curious, and much more approachable by boat. In flight, they are weak and slow (McAllister, unpubl. data), as compared to adults.

\section{Interspecific Relations During Foraging}

In the southern part of the range, from Washington south, murrelets rarely forage in mixed seabird flocks. Pairs or small flocks will usually forage away from other species. In California and Oregon, murrelets have been reported foraging close to Pigeon Guillemots (Cepphus columba) and Common Murres (Uria aalge), but seldom within any major mixed species flocks. Murrelets have been observed by Strong and others (1993) to avoid large feeding flocks of murres, cormorants (Phalacrocorax spp.), and other species in Oregon. He presumed that the small size of the murrelet may render them vulnerable to kleptoparasitism or predation in mixed species flocks. In addition, if the murrelets forage in some cooperative effort, the confusion of a large flock of birds might reduce foraging efficiency.

In the northern part of the range of the murrelet, from Puget Sound north, the literature has more records of the bird mixing with other seabirds when foraging (e.g., Hunt, this volume b). In this region, Marbled Murrelets were less common than the other species in the flocks, and rarely initiated the feeding flock (Porter and Sealy 1981; Chilton and Sealy 1987). Porter and Sealy (1981) found in Barkley Sound, British Columbia, that the murrelet had the lowest flocking tendency ( 0.2 percent $)$ of the birds seen participating in multispecies feeding flocks, although there they did appear to initiate feeding flocks. Mahon and others (1992) observed that murrelets participate frequently in mixed species feeding flocks in the Strait of Georgia, British Columbia. They found a correlation between the number of feeding flocks observed in the area and the number of murrelets present. Chilton and Sealy (1987) suspected that murrelets enter small flocks to minimize disturbance from larger, more numerous, and aggressive individuals of other species that would find single birds easy to intimidate. Mixed flocks would occur after murrelets drove a school of sand lance to the surface. Other species participating in these feeding flocks in order of relative occurrence were Glaucous-winged Gulls (Larus glaucescens), Bonaparte's Gulls (Larus philadelphia), Common Mergansers (Mergus merganser), Pigeon Guillemots, Mew Gulls (Larus canus), and Pelagic Cormorants (Phalacrocorax pelagicus). They felt that several factors encouraged a higher level of interspecific flocking behavior by murrelets: (1) larger and more aggressive alcids, such as Common Murres were absent; (2) the area had a high density of Marbled Murrelets; and (3) prey were locally concentrated, as the fish balled up at the surface when attacked, likely facilitating flock formation.

In Alaska, the foraging flock of 4,000-6,000 Marbled Murrelets on 3 May 1991 in Icy Strait contained an equal number of Bonaparte's Gulls (McAllister, unpubl. data). Both species were feeding actively on what was suspected to be the hatch from a recent herring spawn. In southeast Alaska, McAllister (unpubl. data) found that Marbled Murrelets were rare in the areas where Common Murres and Rhinoceros Auklets (Cerorhinca monocerata) from the Forrester Island colony foraged around Prince of Wales Island. This area contains much suitable nesting habitat for murrelets, including large, contiguous stands of old-growth trees, but murrelets apparently avoid the region. He has also observed this at colonies near Saint Lazaria Island, in Sitka Sound, and Hazy Islands group.

In the Gulf of Alaska, where the range of the Kittlitz's Murrelet (Brachyramphus brevirostris) overlaps with that of the Marbled Murrelet, the two species often share common foraging areas (McAllister, unpubl. data). However, the two species were not found to interact as pairs or in flocks.

\section{Diving}

Marbled Murrelet foraging is by pursuit diving (Ashmole 1971). Depth and time of murrelet dives are little known.

Dive times-We have recorded dive times of birds using birds with transmitters that were monitored by an observer on shore. When birds are underwater, the transmitter can no longer be heard. We also present some data from birds observed from shore through telescopes.

Dive times were obtained from six birds fitted with transmitters in studies in 1989 and 1991 in northern California. The birds were followed on 13 occasions by a monitor on shore. The median dive times averaged 14 seconds, with the longest at 69 seconds. The mean length of pauses between dives averaged 17 seconds in each year. Rest times were naturally more variable, with as long as 18 minutes between dives.

From-shore observations at Año Nuevo Bay in Califormia, birds were observed with dive times ranging from 7 to 42 seconds. The depth of water for the 7-second dive was 1-2 
meters, in a rocky substrate, and the longer dives were observed in about 40 meters of water. Over a 4-year observation period, Strachan (unpubl. data), observed dive times in 20 to 50 meters deep water averaging about 31 seconds. Also at Año Nuevo, Strachan (unpubl. data) observed four birds, with a combined average dive time of 17 seconds, ranging from 6-39 seconds. The shortest average time (11.2 seconds) was a pair of possible juveniles in shallow waters of 2 to $5 \mathrm{~m}$ depth, up against the edge of a cliff. Those dives in the deepest water $(40-45 \mathrm{~m})$ were also the longest, and averaged 20.0 seconds.

Pairs of birds resurface together on most dives, suggesting that they likely keep in visual contact underwater. Carter and Sealy (1990) found that dive times of individual birds averaged 27.8 seconds. Thoresen (1989), in a Washington study, observed the mean time for a dive was 44 seconds (range 15-115).

Dive depths - Carter and Sealy (1984) found that murrelets killed in gill nets at night were probably feeding near the surface, as they were caught within 3 to 5 meters of the surface. Sealy (1974) stated that they usually foraged in areas that were sheltered from the prevailing winds and were relatively shallow (<30 $\mathrm{m}$ in depth). In southeast Alaska, Quinlan and Hughes (1984) found them most often in water less than 100 meters in depth and along steep, rocky coastline. In Prince William Sound, Alaska, Kuletz (1991a) found the highest densities of foraging birds in waters less than 80 meters deep. Also in Alaska, Sanger (1987b) collected birds in January and estimated that most birds had been feeding in water of 18 to 45 meters deep. The birds had apparently foraged from the mid depths, to occasionally at or near the bottom, based on the prey species found in their stomachs. In Año Nuevo Bay, California, Strachan (unpubl. data) found the murrelets generally foraged in waters that ranged from 20-30 meters.

\section{Fish Holding}

Few observations have been published of birds on the water holding fish. Carter and Sealy (1990) observed that most murrelets seen holding fish were observed near dusk, just before they fly to their nest to feed nestlings. A few birds were observed holding fish at dawn and later in the moming. They inferred that some individuals may feed chicks during the day because they felt that adults holding fish can not usually capture more fish. Carter and Sealy (1990) felt that increased fish holding by birds toward dusk coincided with the decrease in overall numbers of birds in the foraging area. Larger flocks sometimes included birds holding fish that were not feeding, although most birds that held fish were alone or in pairs. McAllister (unpubl. data) has recorded pre-dusk flyways where hundreds of fish-holding murrelets are counted as they leave foraging areas in Icy Strait, Sumner Strait, and in Frederick Sound in Southeast Alaska, heading towards their presumed nesting areas. At numerous locations, McAllister (unpubl. data) has recorded continuous flyway activity (averaging more than 20 birds per minute), with the majority of birds holding fish.
On a few occasions, birds have been reported holding more than one fish in their bill. Thoresen (1989) observed a bird with two fish and a bird with three fish held crosswise, both on the water's surface and flying. Other observations of multiple fish in the bill include Carter (pers. comm.), Cody (1973), Fortna (pers. comm.), and Savile (1972).

\section{Foraging Influences}

Adjacent inland babitat-Densities of the Marbled Murrelet in specific geographic areas during the breeding season appear to be related to the adjacent nesting habitat (Carter and Sealy 1990; Ralph and Miller, this volume). It is also very probable that foraging locations are dependent upon prey habitat or availability, but no research has been conducted on this subject to date.

Weather-Throughout their range, murrelets have been observed foraging in all weather conditions normal for that habitat. They have also been seen foraging in extreme weather conditions. McAllister (unpubl. data) has recorded foraging at night in sub-freezing conditions, with 40-60 knot easterly winds blowing out from the Taku River Valley. The birds were foraging on the herring schools that were feeding in the interface between marine and fresh water. Due to the topography, nearby waters within $4 \mathrm{~km}$ were relatively calm, yet the birds chose to be active at night in the rough weather and seas.

Times of day-Birds appear to forage at all times of the day, and in some cases during night hours, presumably when there is enough ambient light to capture prey. Some observers have hypothesized that murrelets move from one feeding area to another during the early morning and late afternoon periods (Carter 1984, Carter and Sealy 1984, Prestash and others 1992). On the other hand, they may be staging in an area in the early morning near the nesting area, then moving out into foraging areas. Off the California coast, six birds with radio transmitters did not forage during the night in June or July (Ralph, unpubl. data), rather, the foraging was confined to the daylight hours.

Topography-We have observed consistent densities of birds utilizing the lee of protected headlands in California, as has Kuletz (pers. comm.) in Alaska. We have noticed, but not quantified, that the wind conditions could be a factor for greater bird densities in the lee of headlands. Carter and Sealy (1990) speculated that prey also concentrates in sheltered waters. Certainly concentrations of birds are likely due to the availability of prey at the rip-current lines and in the tidal eddies that are established to the downwind of such features. In Oregon, Strong and others (1993) found that the highest densities of murrelets were found adjacent to beaches or mixed beach and rocky shore areas.

\section{Non-Foraging Behavior}

\section{Coalescence}

An interesting phenomena that has been noted by a few researchers is that during the breeding season, about an hour 
before dusk, birds that are both loafing or foraging will coalesce into loose aggregations with much preening and wing stretching (Carter and Sealy 1990; Nelson, pers. comm.; O'Donnell, pers. comm.). We and Sealy (1975) have noted that specific sites are consistently used for these gatherings. Carter (pers. comm.), Kuletz (pers. comm.), and we have observed many times that a few minutes before dark the birds will begin to take off and fly inland in pairs or singly. In southeast Alaska, McAllister (unpubl. data) has found that these loose aggregations most often occurred offshore of forests, and in waters where foraging is rarely, if ever, observed. He found that birds begin landing at these locations in the late afternoon. The rate of arrival increased steadily until the hour before dusk, as birds were commonly seen flying in and landing, with most holding fish. He observed this commonly along the west shore of Admiralty Island where birds arrive on flyway routes from foraging areas in Icy Strait. The birds holding fish were found in a band between $1-2 \mathrm{~km}$ from the shoreline. At dusk these birds fly from the water, often climbing steeply before heading inland. Simons (1980) and Hirsch and others (1981) also observed murrelets holding fish just before flying inland at dusk.

\section{Loafing Activities}

Loafing in the murrelets involves resting on the water, perhaps sleeping, along with preening and other activities. During loafing, we have observed that birds appear to drift with the currents, or move about without direction. We have also observed vocalizations during loafing periods, especially during the mid-morning and late afternoon. There are no data available on the frequency of wing stretches and flutters during the day, nor the function of the vocalizations.

\section{Flyways}

In regions of high murrelet populations in coastal British Columbia and Alaska, what we refer to as "flyways" of Marbled Murrelets occur. Here, hundreds to thousands of birds commute between foraging and nesting areas. The birds are moving distances up to $60 \mathrm{~km}$ (McAllister, unpubl. data). McAllister has observed throughout the breeding season that birds moving along these routes are most numerous in the two hours following sunrise, as birds returned to foraging areas. During the chick-feeding period, the same flyways are again active in the night just before dawn (taking fish to their young) and just after dusk (returning to foraging areas).

\section{Courtship Behavior}

Courtship behavior at sea has been rarely reported in Marbled Murrelets. Quinlan (1984) described courtship behavior involving both birds of a pair extending their necks vertically and pointing their bills skyward while slowly swimming towards each other. The birds maintained this posture, then swam together for 15 to 30 seconds. McAllister (unpubl. data) has observed courtship behavior in March and April in southeast Alaska, most often in the early morning, soon after birds land following dawn flights. He has recognized two distinct behaviors: heads-up posturing, and pursuit flightdiving. The most common, heads-up posturing, involves two birds taking an erect posture, necks fully extended upwards, and heads tipped back, so that bills are directed upward. Pairs will draw very close to one another and either circle or swim forward rapidly. They may dive and then resurface in the heads-up posture. If separated while diving, the pair will rapidly swim towards each other in the headsup posture. Heads-up posturing may change into pursuit flight-diving behavior, as one bird flies low across the water pursued by the other bird. The lead bird then makes a flying dive, the other following into the water and pursuing the lead bird underwater until they resurface into flight again, without a hesitation in wing beats. The pair may take flight and dive repeatedly, as many as four times consecutively.

Copulation has been observed only rarely on the water, and may primarily occur in forests before egg laying. Quinlan (1984) observed copulation at sea once on 16 May 1984. Prestash (pers. comm.), recorded copulation on May 29, 1990 at Muscle Inlet, British Columbia. In California, copulation on the water has been observed only 3 times in approximately 3,000 hours of observations, mostly during the breeding season (Ralph, unpubl. data).

\section{Disturbances}

The effects of human disturbance on murrelets at sea is not well documented. Strong (in press) felt that birds were very sensitive to his passing vessel. Almost all responses occurred at less than $50 \mathrm{~m}$ from the boat. Of 4721 behaviors recorded, in apparent response to passage of the boat, 1103 birds dived (23.4 percent), and 725 (15.4 percent) flew. McAllister (unpubl. data) observed that in Gastineau Channel, near Juneau, Alaska, murrelets apparently habituate to heavy levels of boat traffic. Ralph (unpubl. data) has noted that birds in the San Juan Islands, Washington, allowed much closer approach in boats, as contrasted to birds in waters of offshore California, where boat traffic is much lighter.

\section{Discussion}

Documentation of the species' at-sea behavior is important to the full understanding of the ecology of the species. Our overview demonstrates how few data have been gathered on the behavior of the bird on the ocean. Knowledge of the timing and extent of different behaviors is also essential to the design and implementation of at-sea monitoring protocols. For instance, the response of birds to boats and airplanes would greatly influence the ability of observers to count birds. Also, knowledge of the percent of time spent underwater is also important in determining the ability of observers to detect birds from boats.

Various observations during the breeding season suggest that the birds may forage in some areas at night, and probably more often at or near dawn and dusk, to procure food for their chicks. Some observations of nocturnal feeding are possibly related to prey tending to be closer to the surface at 
night. Certainly murrelets must be able to locate prey species where or when there is little ambient light.

Many observations of fish holding occur at dusk. At nests, observations of nestlings being fed whole fish have almost always been during first light at dawn (Nelson and Hamer, this volume a). Foraging for nestlings therefore would probably occur during the early morning periods when there is enough light for the murrelets to catch prey. We feel that observations of adults holding fish are strong indicators of a bird about to depart inland to feed a young. As such, this may be a sensitive measure of birds with young on the nest, potentially a very useful measure of reproductive rate in this species.

The majority of birds on the water are in pairs. We do not know what proportion of these are mated birds, or what proportion are birds temporarily paired for foraging. Observations of murrelets in groups of more than four are rarely foraging, and appear to be largely loafing. In most cases, pairs on the water dive simultaneously, strongly suggesting to us an apparent benefit to foraging. We can find no evidence that pairs on the water during the breeding season are actually mates involved in breeding. By the same token, we do not know if single birds belong to a pair of incubating birds. We feel that it is likely that the species has evolved a yet-undescribed feeding strategy that involves cooperative herding of schools of small fish.

Flock size appears to be related to the size of the regional populations, prey availability, and possibly juvenile behavior. The largest flocks are in areas with the largest populations of birds. There are no obvious behaviors related to flocking. other than loafing, that have been reported.

We very much need more work in several areas relating to offshore behavior. Since it is possible to completely census birds on the water, and much of the adult mortality probably takes place here, it is vital that we have a fuller understanding of the factors involving the distribution, abundance, feeding behavior, juvenile behavior and survivorship, at-sea social behavior, as well as many other factors, of these interesting birds.

\section{Acknowledgments}

We thank Alan Burger, George Hunt, Sherri Miller, William Sydeman, and Craig Strong for many helpful comments on this manuscript. We also thank Linda Long for creating the figures. 



\title{
Chapter 24 \\ Monospecific and Mixed Species Foraging Associations of Marbled Murrelets
}

\author{
George L. Hunt, Jr. ${ }^{1}$
}

\begin{abstract}
Marbled Murrelets (Brachyramphus marmoratus) vary in the frequency with which they are associated with mixed species foraging flocks of seabirds. When foraging in the exposed waters of the outer coasts, murrelets are almost invariably found in pairs or small monospecific flocks. In protected waters, they are frequently associated with other species. The reasons for these differences are unknown. An increase in the number of gulls foraging in association with murrelets could be detrimental to the murrelets if it resulted in an increased rate of kleptoparasitism.
\end{abstract}

Marbled Murrelets (Brachyramphus marmoratus) occupy a variety of foraging habitats and vary in their propensity to forage in the company of other seabirds. In this brief review, I contrast two types of habitats used by foraging murrelets, and discuss the likelihood that murrelets will be accompanied by foragers of other seabird species. Because marbled murrelets may be subject to kleptoparasitism in these mixed species flocks, it is possible that changes in the relative abundance of the species in these flocks could impact the foraging success and ability of murrelets to provision young.

\section{Habitats Used}

Marbled Murrelets occur in nearshore (usually less than $2 \mathrm{~km}$ from shore) waters from central California to Alaska. Within this range, murrelets are found in two different habitats: along the open "outer" coasts, and in the protected inshore waters of bays, sounds, and inlets. In California, Oregon, the outer coast of Washington, and parts of the west coast of Vancouver Island, murrelets use coastal waters at the edge of the open ocean. These coasts are occasionally intersected by rivers with their associated offshore plumes, or headlands that may set up eddies or fronts in their vicinity. However, for the most part, these waters are lacking in obvious features that should result in predictable, smallscale concentrations of prey. In contrast, in the more protected bays, sounds and inlets of British Columbia, Alaska, and Puget Sound, there are often strong tidal currents that interact with bathymetric features to create eddies, rips and others features where prey predictably concentrate. In addition, these waters are often nursery areas for young schooling fish that forage in quiet bays as well as in association with tidal features such as rips and eddies.

${ }^{1}$ Professor, Department of Ecology and Evolutionary Biology, University of California, Irvine, CA 92717

\section{Foraging Associations}

The foraging behavior of Marbled Murrelets, particularly the propensity to be associated with mixed species foraging flocks, appears to differ between exposed and sheltered waters. Although quantitative data are lacking, murrelets are usually found in pairs, or occasionally in small monospecific flocks along the exposed ocean coast (Ainley and others, this volume; Strachan and others, this volume); I observed this to be also true of the Xantus' Murrelet (Synthliboramphus hypoleuca) in the waters near the Channel Islands of the Southern California Bight. It is not known why these two species of birds prefer to forage as pairs in the open ocean. Xantus' Murrelets specialize on young-of-the-year northern anchovies (Engraulax mordans) (Hunt, unpublished data) and marbled murrelets take these as well as other species of small, schooling fish (Burkett, this volume). Cooperative foraging may be more efficient when hunting for these fish, but many species of seabirds forage as singletons when taking the same fish species. In central California, murrelets were also occasionally found in small (up to 25 individuals) flocks, with some of these flocks being in the vicinity of river mouths (Ralph and Miller, pers. comm). None was accompanied by other species of seabirds. Likewise, near Barkley Sound on the west coast of Vancouver Island, Porter and Sealy (1981) reported that outside the sound, murrelets did not participate in any of seven mixed species foraging flocks. Sealy (1973b) found marbled murrelets in about 4 percent of mixed species flocks off Langara Island, British Columbia, but most birds along the outside of the west coasts of Vancouver Island and the Queen Charlotte Islands were thought to forage singly or in monospecific pairs (Carter 1984; Carter and Sealy 1990; Sealy 1973b, 1975c). Chilton and Sealy (1987) suggested that the low frequency of murrelet participation in mixed species foraging flocks was a means of avoiding competition with larger, more aggressive species of seabirds.

Despite the potential for competition with other species of seabirds and kleptoparasitism from gulls in protected waters from Washington to Alaska, Marbled Murrelets frequently forage in mixed species flocks (Piatt, pers. comm.; Hunt, pers. obs.; Burger, pers. comm.). For example, in the protected waters within Barkley Sound, Porter and Sealy (1981) found murrelets present in 7 of 27 mixed species feeding flocks. Recently, Mahon and others (1992) documented the role of Marbled Murrelets in foraging flocks in the protected inlets of the Strait of Georgia, British Columbia. They found that the number of feeding flocks observed in an area was positively correlated with the number of murrelets present. They observed that in 100 of 
the 127 mixed species foraging flocks, Marbled Murrelets and Glaucous-winged Gulls (Larus glaucescens) were the only participants. Other species that accompanied murrelets included Bonaparte's Gulls (Larus philadelphia), Common Mergansers (Mergus merganser), Pigeon Guillemots (Ceppus columba), and Pelagic Cormorants (Phalacrocorax pelagicus). Mahon and others (1992) observed the initiation of 27 flocks. In each case, the flocks began after Marbled Murrelets drove a school of sand lance (Ammodytes hexapterus) to the surface, where the fish "thrashed briefly in a tightly packed "boil.", Gulls and, if the boil of small fish jumping from the water's surface lasted sufficient time, other birds were then attracted to this food resource. The feeding flocks observed by Mahon and others (1992) had on average 7.7 murrelets and 5.9 Glaucous-winged Gulls, with a positive correlation between the numbers of murrelets and gulls in the flocks. Flock duration varied between 1 and 79 minutes and was also positively correlated with the number of murrelets present. I have seen Marbled Murrelets in mixed species foraging flocks in the San Juan Islands of Puget Sound. There, murrelets foraged on young of the year herring (Clupea harengus), and started foraging flocks when they forced dense schools (balls) of herring to the surface. Thus, these mixed-species feeding flocks are similar to the Type I feeding flocks described by Hoffmann and others (1981). Within these flocks, the murrelets acted as catalysts, even though their foraging did not appear to be as conspicuous as that of species considered catalysts by Hoffmann and others. In the San Juan Islands, I have seen Marbled Murrelets join mixed species foraging flocks that contained not only gulls (Glaucous-winged, Mew [L. canus], and Heermann's [ $L$. hermanni]) but also harbor seals (Phoca vituillina), Rhinoceros Auklets (Cerorhinca monocerata), and Common Murres (Uria aalge). Both in the cases where murrelets were catalysts, and when they joined flocks, they foraged beneath the surface and probably served to drive small, highly clumped schools of fish to the surface.

The variability in associations between foraging Marbled Murrelets and other seabirds noted above and elsewhere (Carter and Sealy 1987a, Hoffman and others 1981) demonstrates the plasticity in both the behavior of murrelets and in the frequency with which other species take advantage of the foraging behavior of the murrelets. Reasons for the differences in the frequency that foraging murrelets are associated with other bird species on exposed outer coast waters, when compared with more sheltered inside waters, is not known. It may be that interspecific competition with other alcids is more intense along the outer coast of Vancouver Island than in sheltered waters (see Chilton and Sealy 1987; Mahon and others 1992; Piatt 1990), but this cannot explain the lack of mixed species flocking farther south where large alcids are scarce. Alternatively, differences in the roughness, clarity, or depth of water may influence the ability of surface foragers to take advantage of the murrelet foraging. Additionally, the size, distribution or behavior of fish aggregations may differ in the two habitats. It would be useful to explore why these mixed species foraging flocks occur in one habitat, but not in the other, and their importance to murrelet foraging success.

Although it would seem reasonable to assume that murrelets benefit from joining mixed species foraging flocks in those instances when they choose to join, it is not known whether murrelets benefit from being joined by other species. Gulls sometimes attempt to steal fish from murrelets when they surface with a fish in their bill (G. Hunt pers. obs.) and larger alcids may interfere with their foraging (Chilton and Sealy 1987, Piatt 1990). Alternatively, the presence of surfaceforaging gulls may aid the murrelets by driving fish from their protective balls where they may be less vulnerable to underwater predators (Girsa and Danilov 1976, Götmark and others 1986, Grover and Olla 1983). Clearly the gulls benefit from the activities of the murrelets in driving fish to the surface and holding them there (Grover and Olla 1983; Hoffman and others 1981).

From the point of view of murrelet conservation, it would be useful to know the costs and benefits to Marbled Murrelets of being joined by gulls. Gulls apparently forage with murrelets in those areas where murrelet populations are most dense. If gull populations are artificially increased by the wasteful habits of people, and the gulls suppress murrelet capture or retention of fish, then it would be useful to investigate how this indirect anthropogenically caused pressure on murrelets could be relieved. 


\section{Chapter 25 \\ Pollution and Fishing Threats to Marbled Murrelets}

\section{Michael Fry}

Abstract: The principal pollutant threats to Marbled Murrelets are chlorinated organic effluent discharges from chlorine bleach pulp mills located in California, Washington, and British Columbia. The distribution of murrelets away from riverine input of agricultural chemicals reduces the threat from these pollutants. Plastic ingestion does not appear to pose a serious threat to murrelets, as it does for other species of small alcids. Significant threats from oil pollution are present because of heavy oil tanker, commercial shipping, and barge traffic along the Pacific coast. Commercial fishing threats have been significantly reduced in California, Oregon, and Washington because of regulation and banning of gill-net fisheries, but thousands of murrelets are still killed annually in Alaska.

Persistent organochlorine pollutants in the environment are represented by pesticides, herbicides, polychlorinated biphenyls (PCB), and pulp mill discharges containing polychlorinated dibenzo-dioxins (PCDD) and polychlorinated dibenzo-furans (PCDF). Organochlorine pesticide use has been reduced during the past two decades, with the prohibition of use of DDT, dieldrin, kepone, and chlordane in the United States and Canada, although methoxychlor and dicofol continue to be used in selected agricultural areas. The herbicides 2,4-D and 2,4,5-T were used extensively in reforestation projects in the Pacific Northwest, and 2,4-D continues to be used. 2,4-D poses a potential risk because of the presence of PCDD as contaminants of manufacture and incineration product after burning of clearcut slash piles. Within the range of Marbled Murrelets, PCDD and PCDF represent the most prevalent pollutant risk.

\section{Point Sources of Organochlorine Pollutants}

\section{Kraft Pulp Mills}

Bleached paper grade pulp mills using chlorine bleaches have a wide distribution along the Pacific coast of North America (fig. I), with two mills in southeastern Alaska, eleven in coastal British Columbia, seven in Washington State, four in Oregon and three in coastal California (Colodey and Wells 1992). The chlorine bleach process extracts pigmented plant lignins, and produces chlorinated effluents containing dioxins and furans which have been discharged to the environment at levels resulting in significant injury to fisheries, birds (Great Blue Herons [Ardea herodias], cormorants, and grebes), and estuarine environments (Colodey and Wells 1992, Elliott and

\footnotetext{
${ }^{1}$ Research Physiologist, Department of A vian Sciences, University of California, Davis, CA 95616
}

others 1989, Whitehead 1989, Whitehead and others 1991). The PCDD and PCDF bioaccumulate in the sediments, fish populations, and in fish-eating birds, causing reproductive impairments in bird populations with reduced breeding success, as well as malformations and embryo mortality in Great Blue Herons (Bellward and others 1990, Elliott and others 1989, Hart and others 1990). No specific residues or breeding impairment have been identified in Marbled Murrelets, but murrelets feeding locally in the areas of historic effluent discharge would be at risk of exposure through bioaccumulation in forage fish. In a study of coastal aquatic birds in British Columbia, Whitehead and others (1991) found the highest levels of dioxins in Western Grebes, which have a prey base

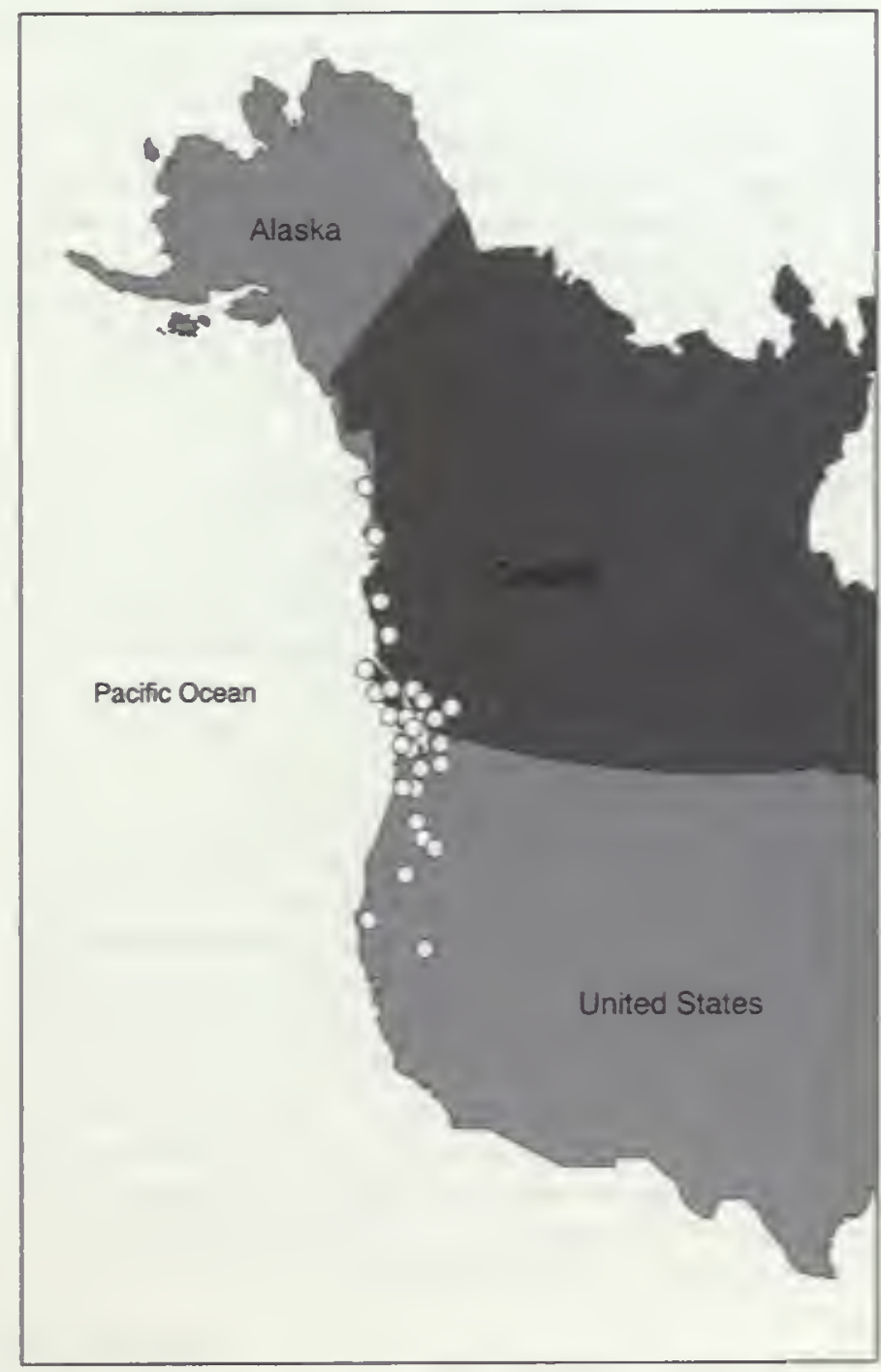

Figure 1-Distribution of paper grade pulp mills active or recently closed which discharge chlorinated organics into estuarine environments on the Pacific Coast of North America. 
similar to that of murrelets, indicating that murrelets could be at risk from pulp mill effluents.

The discharges from the mills have generally been localized to the vicinity of less than $25 \mathrm{~km}$ from the mill (Colodey and Wells 1992), with variable local impact on wildlife populations. Since pulp mills and Marbled Murrelets are both distributed all along the Pacific coast, the discharges from these mills is of concern.

The mills most probably affecting murrelets would be those in southeast Alaska, British Columbia, Washington (Port Angeles, Bellingham, Everett and Grays Harbor), and California (Eureka). The distribution of murrelets in Washington is primarily in the Straits of Juan de Fuca and in the San Juan Islands (Speich and others 1992), with fewer birds in the more polluted areas of southern Puget Sound.

The high toxicity and very long environmental persistence of dioxins and furans has resulted in regulatory action reducing pulp mill effluent discharges, and is also resulting in changes in the bleaching processes used by paper-grade pulp mills to eliminate chlorine bleaches. Most mills in the United States and Canada continue to use chlorine bleaches, but effluent discharges in British Columbia were reduced by 75 percent between 1989 and 1991 (from 81.5 to 20.5 metric tons of chlorinated organics per day). It had been determined that most mills will retool to convert to oxygen bleaches or close down (Colodey and Wells 1992). The Ocean Falls mill in British Columbia closed in 1981 , but persistent residues may still affect the population of murrelets using adjacent fjords (Burns and Prestash 1993, Manley and Kelson 1992).

\section{Industrial Pollutant Discharges}

Industrial discharges from the population centers of San Francisco Bay, California, Puget Sound, Washington, and Vancouver, British Columbia, have contaminated estuarine sediments with heavy metals, petroleum hydrocarbons, and PCB in addition to PCDD and PCDF (Henny and others 1990, Hoffman and others 1986, Ohlendorf and Marois 1991, Phillips and Spies 1988, Riley and others 1983, Speich and others 1988). Marbled Murrelets may be only peripherally at risk, however. Their range is primarily in coastal areas, largely remote from populated areas, because historic logging near population centers has reduced nesting habitats. Pollutant monitoring of Pigeon Guillemots (Cepphus columba) in Washington indicated that birds resident in the Straits of Juan de Fuca were less contaminated than those resident near Seattle, presumably because contaminated forage fish do not move widely throughout Puget Sound (Calambokidis and others 1985). Murrelet risk would be expected to be broadly similar to the risk to guillemots.

\section{Non-Point Discharges}

\section{Discharges from Rivers}

The major rivers with historic pollutant discharges in the murrelet range are the Sacramento-San Joaquin
(California), Columbia (Oregon, Washington), and Fraser (British Columbia). The Copper River, in Alaska, was a source of mining discharge, but probably not currently a risk factor for murrelets. Most other rivers within the murrelet range have little agriculture, or mining pollutant inputs which would affect murrelets.

The current distribution of murrelets at the mouths of these rivers is generally low, probably because they are human population centers where there has been a historic reduction of murrelet nesting habitat.

\section{Global Bioaccumulation of Organochlorines in the Food Web}

Murrelets are probably at low risk from global food web bioaccumulation of pollutants because of their foraging habits, prey size and the distribution of prey in coastal habitats. Most fish eaten by murrelets are juveniles of commercial species, or ground fish without a wide pelagic distribution. The background global organochlorine input into the seabirds of the North Pacific has resulted in a modest increase in organochlorine pollutants in seabird eggs over the past two decades (Elliott and others 1989), but the levels remain below those generally considered to be of threshold biological significance.

\section{Plastics and Small Floating Marine Debris}

Ingestion of floating bits of plastic, rubber filaments, and fishing line has been documented in many seabirds, most commonly in species preying on plankton. Day and others $(1982,1985)$ documented plastic ingestion by 50 species, including eight species of alcids: Cassin's (Ptychoramphus aleuticus), Least (Aethia pusilla), Parakeet (Cyclorrhynchus psittacula), and Rhinoceros (Cerorhinca monocerata) auklets; Dovekie (Alle alle); Common Murre (Uria aalge); and Tufted (Fratercula cirrhata) and Horned (Fratercula corniculata) puffins. Day (1980) also examined 61 Marbled Murrelets, 16 Ancient Murrelets (Synthliboramphus antiquus), 5 Kittlitz's Murrelets (Brachyramphus brevirostris) and 18 Pigeon Guillemots and found no plastic or other foreign objects present in their upper digestive tracts. The lower risk to murrelets and guillemots is probably due to a combination of their coastal foraging and a diet restricted to fish, thereby reducing the likelihood of inadvertent ingestion of foreign objects.

\section{Oil Pollution Threats}

Documentation of oil spills along the Pacific coast since 1968 have demonstrated significant threats to seabirds in California, Oregon, Washington, British Columbia, and Alaska (see also Carter and Kuletz, this volume). Small numbers of murrelets (fewer than 10 birds) were recovered oiled after spills from the tankers Blue Magpie, Oregon, 1983; Puerto 
Rican, California, 1984; ARCO Anchorage, Washington, 1985; and Apex Housion, California, 1986 (Bayer 1988, Burger and Fry 1993, Kittle and others 1987; Page and others 1990, Point Reyes Bird Observatory 1985). Mortality estimates of larger numbers have been made for recent spills, extrapolating from recovery experiments which demonstrate that fewer than 10 percent of oiled murrelets are likely to be recovered after spills, because of their small size, likelihood of scavenging by predators, and other factors (ECI 1991). About 170-200 murrelets were estimated to have been oiled following the Nestucca spill, Washington, 1989 (Burger 1990; Rodway and others 1989, 1992), and approximately 8.400 killed after the Exxon Valdez, Alaska, 1989 (Piatt and Naslund, this volume), representing approximately 3.4 percent of the Alaska population. About 45 Marbled Murrelet carcasses were recovered following the Tenyo Maru spill, Washington 1992 (U.S. Fish and Wildlife Service, Ecological Services, Olympia, Washington).

Continuing threats to murrelets from oil pollution vary among different areas of the Pacific coast, in direct proportion to the probability of an oil spill and the local murrelet population vulnerability.

Three areas of Alaska have significant vulnerability: Lower Cook Inlet, Prince William Sound, and the Alexander Archipelago. Lower Cook Inlet receives the majority of cargo shipping traffic within the state. Offshore oil deposits within Cook Inlet have recently been discovered which could be developed within 10 years. Prince William Sound has a very high density of murrelets and transits up to $700,000,000$ bbl of crude oil annually from the pipeline terminal at Valdez. The Alexander Archipelago in Southeast Alaska supports the largest population of murrelets in the state $(>180,000 ; 57$ percent of total population)(Piatt and Naslund, this volume), and has a large number of ship transits, including fishing, cargo, and passenger vessels.

Threats from oil pollution in British Columbia appear to be highest around Vancouver Island, because of the coincidence of tanker and barge traffic through the Strait of Juan de Fuca and high populations of murrelets on the west side of the island. Murrelets in lower densities also breed in the Queen Charlotte Islands, but ship traffic and tanker traffic are less. The very large volume of crude oil traffic from Alaska to California occurs more than $100 \mathrm{~km}$ offshore, reducing the threat from tanker spills.

The smaller populations of murrelets in Washington in the Strait of Juan de Fuca remain at considerable risk because of both tanker traffic and large volumes of commercial shipping (cargo and fishing) into Seattle, Tacoma, and Vancouver. The local, inshore distribution of murrelets makes them particularly vulnerable to spills in coastal areas.

Tanker and barge traffic in coastal waters of California, Oregon, and Washington pose significant threats to murrelets. Barges are used to enter smaller ports, and are often towed in near-shore waters. While the tonnage of oil transported by barge is much less than that conveyed by tanker, the Apex Houston (approximately 10,000 dead birds) and Nestucca
( $>50,000$ dead birds) spills have demonstrated barge traffic to be of high risk to murrelets along the Pacific coast. A potential threat to the small northern California murrelet population may emerge if the offshore oil reserves present off Mendocino and Humboldt counties are developed following the possible end to a federal moratorium on drilling after year 2002.

\section{Commercial Fishing Threats}

Relatively large numbers of Marbled Murrelets have been recorded killed in gill-nets in British Columbia and Alaska (Carter and others, this volume; Carter and Sealy 1984; DeGange and others 1993; Mendenhall 1992; Piatt and Naslund, this volume; Wynne and others 1991, 1992), with smaller numbers caught in Washington (Speich and Wahl 1989), and California (Carter and others, this volume). Recent fishing closures and regulations have reduced the threats in California, but significant threats continue to exist for murrelet populations in Alaska, British Columbia, and Washington.

\section{Alaska}

Salmon gill-net bycatch of murrelets in Alaska is estimated at 3,300 birds annually by Piatt and Naslund (this volume), based upon observer program data of Wynne and others (1991, 1992), and extrapolations using current fishing permit and fishing effort data. The approximate distribution of murrelet mortality is: Lower Cook Inlet, 1,100 birds; Prince William Sound, 1,000; Alaska Peninsula, 300; and Southeast Alaska 900; these were primarily Marbled Murrelets, and the vast majority being adults. This total of 3,300 birds represents approximately 1.7 percent of the Alaska population killed on an annual basis in the drift-net fishery. The set-net, pound-net, and seine-net fisheries may also contribute to mortality, but no quantitative data are available on these fisheries.

\section{British Columbia}

Carter and Sealy (1984) reported a large bycatch of murrelets in the Barkley Sound salmon fishery in 19791980 , with approximately 4 percent ( 360 birds) of the local Marbled Murrelet population killed that season, plus loss of chicks in nests from loss of adults. The potential for a large continued bycatch exists, but data are lacking, as there is not a current seabird observer program. High densities of murrelets and high fishing effort do not always coincide, possibly minimizing the risk in some areas, but alcids and salmon frequently take the same prey species (Burger, this volume b). The highest population densities of murrelets occur along the west coast of Vancouver Island, with lower densities along the mainland coast and Queen Charlotte Islands.

\section{Washington}

With current information, it is not possible to determine the extent of mortality on Marbled Murrelets in Washington. The salmon fishery in Washington has declined in recent years, and may pose much less risk to murrelets than in 
British Columbia or Alaska. Plenert (U.S. Fish and Wildlife Service 1993b) indicated that U.S. Fish and Wildlife Service anticipated an incidental take of five murrelets from the 1993 all-citizens fishery, and another five murrelets from the tribal fishery, levels not thought to be injurious to the murrelet population. The greatest threat from fisheries bycatch is in the eastern Strait of Juan de Fuca and the San Juan Islands, where the largest murrelet population is located.

\section{Oregon}

Gill-net fishing has been prohibited along the outer coast of Oregon and in estuaries and bays since 1942 (Nelson and others 1992). A gill-net fishery exists in the Columbia River, but no murrelet bycatch has been recorded during observer programs in 1991-1993 (Jefferies and Brown 1993).

\section{California}

Gill-net fishing is prohibited north of Point Reyes, Marin County, and prohibited in waters less than 40 fathoms from Point Reyes south to Santa Cruz County, and in waters less than 30 fathoms south to Point Conception, largely to prevent bycatch of birds and sea otters. If these restrictions are maintained, the threat to murrelets from net fisheries is largely eliminated.

\section{Acknowledgments}

The author would like to thank Nancy Ottum and Denise Chakorian for help in preparation of the manuscript, and Dan Anderson, Robert Risebrough, and Harry Carter, for reviewing drafts. 


\section{Chapter 26 \\ Mortality of Marbled Murrelets Due to Oil Pollution in North America}

\section{Harry R. Carter ${ }^{1} \quad$ Katherine J. Kuletz ${ }^{2}$}

\begin{abstract}
Mortality of Marbled Murrelets (Brachyramphus marmoratus) due to oil pollution is one of the major threats to murrelet populations. Mortality from-large spills and chronic oil pollution has been occurring for several decades but has been documented poorly throughout their range; it probably has contributed to declines in populations, in conjunction with loss of nesting habilat and mortality in gill nets. The 1989 Exxon Valdez oil spill in Alaska caused the largest single mortality of murrelets (about 8,400 birds) in the world and contributed to decline in murrelet populations in Prince William Sound. Due to inadequate baseline data, low recovery of oiled carcasses, and other factors, the full impacts of this extensive mortality have not been determined. Restoration activities have included acquisition of murrelet nesting areas in old-growth forests in southcentral Alaska. Similar acquisition of old-growth forests will occur as restoration for mortality from the 1986 Apex Houston oil spill in California. Future oil spills will continue to threaten the viability of small, declining populations, especially in California, Oregon and Washington where a single large spill could extirpate an entire population. Efforts must be expanded to: better document mortalities during large and small spills, develop better baseline data to assess impacts, identify old-growth forests for acquisition for restoration, and reduce oil pollution.
\end{abstract}

Large oil spills have killed millions of seabirds around the world in this century, as recently demonstrated during the 1989 Exxon Valdez spill in Alaska (Ford and others 1991 a, Piatt and Lensink 1989, Piatt and others 1990a). In particular, oil pollution poses a significant threat to Marbled Murrelets (Brachyramphus marmoratus) in Alaska, British Columbia, Washington, and California (Carter and Morrison 1992, King and Sanger 1979, Marshall 1988a, Sealy and Carter 1984, Wahl and others 1981). Large numbers of Marbled Murrelets were killed during the Exxon Valdez spill, and this has increased concerns. Large oil spills result periodically from: oil tanker and barge mishaps (groundings, collisions, explosions, accidental spillages); similar mishaps by other large ocean-going vessels; offshore oil wells (well blow-outs, accidental spillages); unloading and loading cargo from onshore and offshore facilities; and onshore facility spills that enter the ocean. In addition, small oil spills occur frequently in many populated areas due to cleaning of tanks at sea, bilge pumping and smaller accidental spills. All types of boats and marine transportation vessels may be involved.

\footnotetext{
"Wildlife Biologist, National Biological Service, U.S. Department of the Interior, Califomia Pacific Science Center, 6924 Tremont Road, Dixon, CA 95620

2 Wildlife Biologist, U.S. Fish and Wildlife Service, Migralory Bird Management, 1011 EasI Tudor Road, Anchorage, AK 99503
}

Other forms of marine pollution that may affect seabirds are considered by Fry (this volume).

Impacts of large oil spills on seabirds in California, Oregon, and Washington have been well-documented during the last 25 years, and sporadically in earlier years. Widespread concern about the effects of oil spills on seabirds along the west coast developed after the 1969 Santa Barbara and 1971 San Francisco oil spills in California and smaller spills in Washington. These spills followed similar events in Europe such as the 1967 Torrey Canyon spill in the western English Channel (Bourne and others 1967). Since the 1970s, the documentation of oil spills and their impact on seabirds has been much improved.

Impact assessment is now formalized within Natural Resource Damage Assessment (NRDA) legislation. When possible, the numbers of birds affected are enumerated and impacts at the population level are determined. Impacts include: the direct deaths of birds found dead on shore; deaths of birds found alive on shore and taken to rehabilitation centers; deaths of birds at sea and on shore that are not directly enumerated; reductions in numbers of breeding birds; reductions in breeding range; reduced breeding success; and the sublethal effects of oiling for birds that survived initial oil contamination whether rehabilitated or not.

When the full impacts of oil pollution are considered, lethal and sublethal impacts may have profound effects on local populations, especially when oil mortality acts in concert with other anthropogenic and/or natural factors affecting populations (Piatt and others 1991, Swartzman and Carter 1991, Takekawa and others 1990). However, population impacts are often difficult to demonstrate because they usually require detailed pre-event baseline data, careful injury determination, and detailed follow-up data after the event.

In this paper, we review documentation of mortality of Marbled Murrelets due to oil pollution throughout their range in North America. In particular, we have focused on providing a summary of mortality and restoration efforts after the 1989 Exxon Valdez spill in Alaska and details of mortality for several smaller spills in California, Oregon, Washington, and British Columbia, where the species in now listed as threatened. Information for the three southern states was collated for the Marbled Murrelet Recovery Plan (U.S. Fish and Wildlife Service, in press).

\section{Exxon Valdez Oil Spill}

The largest single event of Marbled Murrelet mortality from oil pollution in North America was the Exxon Valdez oil spill in Prince William Sound, Alaska. On 24 March 
1989, the oil supertanker Exxon Valdez spilled 11 million gallons of crude oil, that eventually travelled $750 \mathrm{~km}$ to the southwest and covered approximately $30,000 \mathrm{~km}^{2}$ of coastal and offshore waters in southcentral Alaska (see fig. 1; Piatt and others 1990a).

\section{Immediate Mortality}

Alcids had the highest rate of mortality, as compared to the population at risk. Of six species of small alcids, Marbled Murrelets suffered the highest mortality (Ford and others 1991a, Piatt and others 1990a). An estimated 75 percent of Marbled Murrelets in U.S. waters breed in Alaska (Ralph and others, this volume a). Other than southeast Alaska, the primary population areas are Prince William Sound, the southern Kenai Peninsula, and the Kodiak archipelago (Piatt and Ford 1993; Piatt and Naslund, this volume). Therefore, a large portion of the U.S. murrelet population was at risk from the Exxon Valdez spill.

Immediate impacts of the Exxon Valdez oil spill on seabirds were attempted through two main approaches: (1)

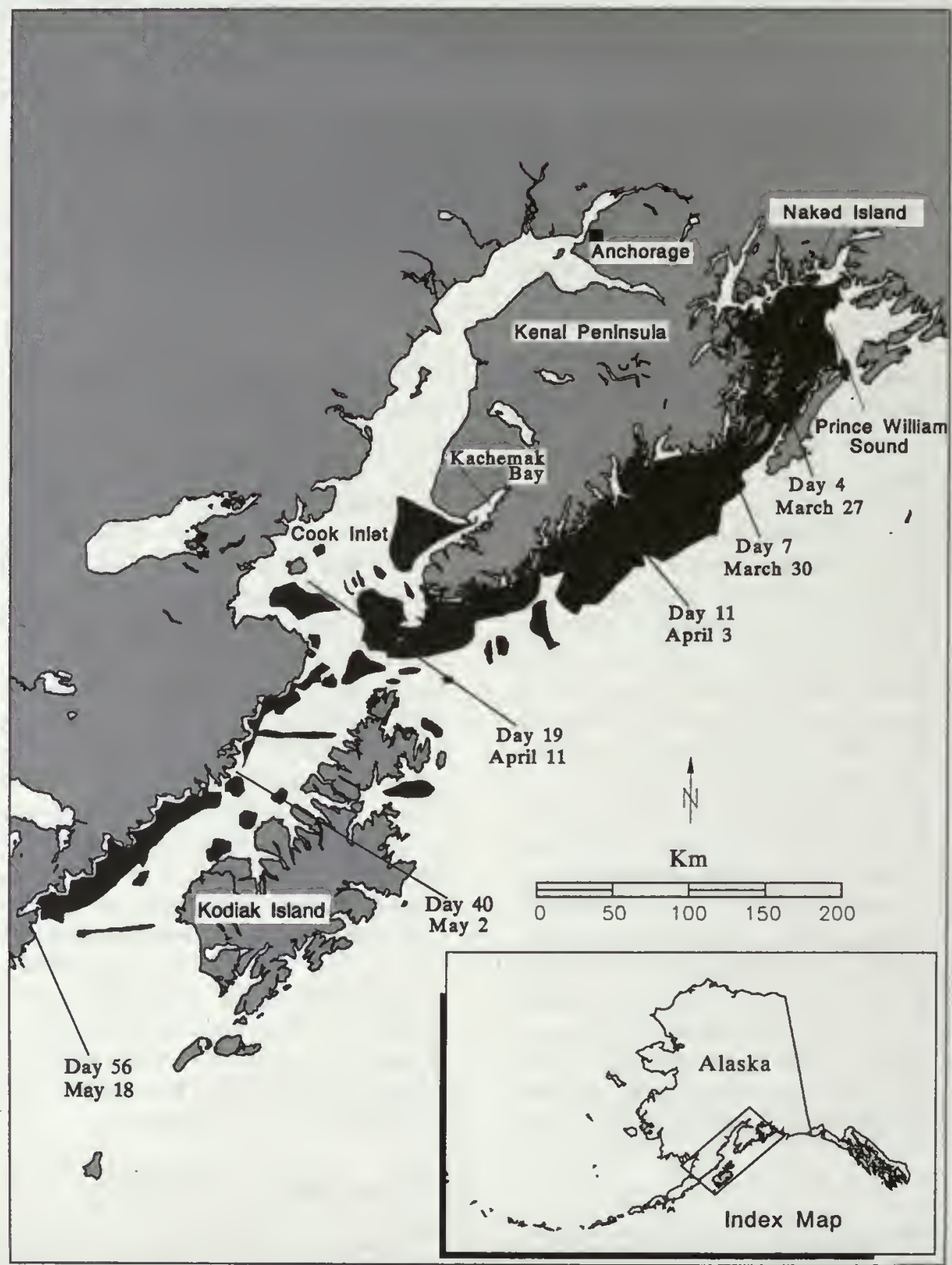

Flgure 1-Extent of surface oiling (dark shading) from the Exxon Valdez oil spill as it spread from Prince William Sound in late March 1989 to the Alaska peninsula by late June 1989. 
an estimate of the total numbers of seabirds killed was constructed, based on numbers of carcasses recovered from beaches and complex extrapolations to account for times and shoreline areas not covered, and the loss of carcasses at sea and on land (Ford and others 1991a); and (2) other NRDA studies were conducted to measure population impacts at breeding colonies and at sea for specific species and areas. All NRDA studies were initiated under the federal Comprehensive Environmental Response, Compensation and Liability Act (CERCLA) and the Clean Water Act. Population estimates for Marbled Murrelets in Prince William Sound were obtained from NRDA Bird Study No. 2 (Klosiewski and Laing 1994). These population estimates were compared with those derived from similar surveys in 1972-1973 (Dwyer and others 1976) and 1984-1985 (Irons and others 1985). NRDA Bird Study No. 6 examined indices of changes in murrelet numbers and productivity at two locations in the spill zone and collected tissue samples for contaminant studies (Kuletz, in press; Oakley and others 1994).

Approximately 30,000 seabird carcasses were recovered in the spill zone throughout the spring and summer of 1989 through a large-scale effort coordinated by Exxon. Carcasses were processed and identified by U.S. Fish and Wildlife Service personnel. A variety of estimates suggest that at least 240,000 seabirds were killed (Ford and others 1991a; Piatt and Anderson, in press; Piatt and others 1990a). Murrelet carcasses were identified to species (i.e. Marbled, Kittlitz's or Ancient murrelets [B. marmoratus, $B$. brevirostris, Synthliboramphus antiquus]) whenever possible. However, many carcasses could only be classified as unidentified murrelets. Using U.S. Fish and Wildlife Service data files on identified carcass recoveries, recovery location and estimated carcass recovery rates for each region (Ford and others 1991a), the total mortality estimate was about 8,400 Brachyramphus murrelets (table 1). Most Brachyramphus murrelets were Marbled Murrelets. The estimate included only about 255 Kittlitz's Murrelets. Additional work is required to refine such estimates based on a reexamination of sample carcasses held in freezer vans after the spill (Ford and others 1991a). However, based on preliminary analyses, it is unlikely that estimates will change dramatically (Carter, unpubl. data; Ford and others 199la; Page, pers. comm.).

The Exxon Valdez spill zone may support roughly half of the estimated 280,000 Marbled Murrelets in Alaska (Mendenhall 1992; Piatt and Ford 1993; Piatt and Naslund, this volume). If so, then approximately 6 percent of the murrelets in the spill zone were killed directly by oil. The carcass recovery rate for murrelets was probably lower than for other seabirds due to their small body size (Ford and others 1991a). Thus, the mortality estimate should be considered a minimum number.

Despite the high mortality of murrelets, U.S. Fish and Wildlife Service at-sea surveys of murrelet abundance in Prince William Sound were unable to demonstrate an effect of oiling on the marine population, although the total population had declines 67 percent since 1972. Murrelet populations were compared after the spill between oiled and unoiled areas, as well as to 1972 estimates (Klosiewski and Laing 1994). Kuletz (in press) suggested that significant oiling impacts were masked in this comparison. First, individual murrelets can forage over wide areas that may be up to $75 \mathrm{~km}$ apart (Burns and others 1994), making the assignment of birds to "oiled" or "unoiled" areas an uncertain exercise. Second, murrelets dispersed to widely scattered breeding sites up to a month after the initial oiling event. Part of the breeding population in Prince William Sound was exposed to oil prior to entering the Sound. Only about 25 percent of the summer population is present in the Sound in March (Klosiewski and Laing 1994). In nearshore southcentral Alaska, murrelet numbers increase throughout April, and do not reach summer peak numbers until May (Kuletz, unpubl. data; Vequist and Nishimoto 1990). The majority of murrelet carcasses were retrieved in April (Ford and others 1991a, Piatt and others 1990a) and most murrelets may have been killed outside Prince William Sound as they migrated northward and inshore in April. Large numbers are known to winter in the vicinity of Kodiak Island, southwest of the initial spill area in Prince

Table 1-Estimates of direct mortality of Brachyramphus murrelets from the Exxon Valdec oil spill in Alaska in 1989. Carcasses were identified as Marbled Murrelets (MAMU), Kinlit's Murrelets (KIMU), or unidentified murrelet which includes Ancient Murrelets (see tert)

\begin{tabular}{|c|c|c|c|c|c|c|c|c|}
\hline Region & $\begin{array}{l}\text { Estimated } \\
\text { recovery } \\
\text { rate }\end{array}$ & $\begin{array}{l}\text { Number } \\
\text { MAMU } \\
\text { carcasses }\end{array}$ & $\begin{array}{l}\text { Estimated } \\
\text { MAMU } \\
\text { mortality }\end{array}$ & $\begin{array}{l}\text { Number } \\
\text { KMTU } \\
\text { carcasses }\end{array}$ & $\begin{array}{l}\text { Estimated } \\
\text { KMIU } \\
\text { mortality }\end{array}$ & $\begin{array}{l}\text { Number } \\
\text { unidentified } \\
\text { murrelet } \\
\text { carcasses }\end{array}$ & $\begin{array}{l}\text { Estimated } \\
\text { unidentified } \\
\text { murrelet } \\
\text { mortality }\end{array}$ & $\begin{array}{l}\text { Estimated' } \\
\text { total } \\
\text { mortality }\end{array}$ \\
\hline Prince William Sound & 0.35 & 289 & 826 & 23 & 66 & 21 & 60 & 952 \\
\hline Kenai Peninsula & 0.14 & 113 & 807 & 23 & 164 & 73 & 521 & 1,492 \\
\hline Barren Islands & 0.49 & 17 & 35 & 4 & 8 & 14 & 29 & 72 \\
\hline Kodiak Island & 0.06 & 64 & 1,066 & 1 & 17 & 71 & 1,183 & 2,266 \\
\hline Alaska Peninsula & 0.02 & 45 & 2,250 & 0 & 0 & 27 & 1,350 & 3,600 \\
\hline Total & & 528 & 4,984 & 51 & 255 & 206 & 3,143 & 8,382 \\
\hline
\end{tabular}

'Excludes Ancient Murrelets, based on carcasses identified to species (see text). 
William Sound (Forsell and Gould 1981). This scenario is supported by the relatively high proportion of carcasses estimated as killed outside Prince William Sound (table l), compared to the relatively low numbers of murrelets which breed in other areas (Piatt and Ford 1993).

\section{Other Impacts}

A variety of other impacts to murrelets occurred as a result of the Exxon Valdez oil spill. Some murrelets were sublethally oiled and probably were affected physiologically after the immediate oiling event. Oakley and others (1994) found evidence of compounds indicative of oil ingestion in murrelets collected in 1989 in heavily-oiled areas, but not in lightly-oiled or unoiled areas of Prince William Sound. Murrelets also were affected in foraging areas by increased human activity, associated with clean-up and monitoring programs. In the summer of 1989 in Prince William Sound, Exxon mobilized over 600 marine vessels and 85 aircraft which logged 6,000 flight hours (Carpenter and others 1991). A reduced operation was conducted in 1990 , followed by minimal operations in 1991 and 1992. In 1989, repeated surveys at Naked Island (in central Prince William Sound) and in Kachemak Bay (in lower Cook Inlet) showed a decrease in the number of murrelets with an increase in boat traffic over the course of the summer (Kuletz, in press). Similarly, land-based counts showed a similar relationship between murrelet numbers and boat and low-flying aircraft counts per hour. The Exxon Valdez was anchored at Naked Island until late June 1989. This area was a staging ground for clean-up and monitoring activities. Kuletz (in press) found significantly fewer murrelets there in 1989 , compared to three pre-spill years. In 1990-1992, murrelet numbers returned to pre-spill levels.

The oil spill may have impacted on forage fish populations. Prey species for murrelets in south central Alaska include Pacific sand lance (Ammodytes hexapterus), capelin (Mallotus villosus), cod (Gadidae spp.) and juvenile Pacific herring (Clupea harengus) (Kuletz, unpubl. data; Sanger 1983, 1987). Seabird diet studies in Prince William Sound indicated that sand lance and herring were less available in 1989 and 1990 than in pre-spill years (Irons 1992; Oakley and Kuletz 1994; Piatt and Anderson, in press). Many prey species are intertidal spawners, and are more susceptible to oil pollution than pelagic spawners (Trasky and others 1977). At Naked Island, herring had high levels of sublethal damage and larval malformations after the spill; herring did not spawn there in 1991 (Hose and others 1993). Herring returns were drastically reduced between 1992-1994 and adult fish have had high rates of viral infections. On the other hand, there is evidence that the composition and abundance of forage fish populations throughout the Gulf of Alaska have changed markedly during the last 20 years (Piatt and Anderson, in press).

Marbled Murrelets may have experienced lower reproductive success at Naked Island after the spill, as evidenced by lower numbers of juveniles in relation to adults on the water (Kuletz, in press). In contrast, the adult:juvenile ratio at Kachemak Bay did not change after the spill. Kachemak Bay was further removed temporally and spatially from the spill epicenter. The potential for disruption of breeding activities in Prince William Sound was great due to the potential combination of direct mortality of adults, direct mortality of mates affecting surviving mates, displacement from foraging areas due to human activity, sub-lethal oil ingestion, and possible impacts on the prey base.

\section{Restoration}

Planning for restoration activities, mandated under CERCLA, began in late 1989. In October 1989, under a civil consent decree between Exxon and the state and federal governments, Exxon agreed to make ten annual payments totaling $\$ 900$ million for injuries to natural resources, agency service costs, and for restoration and replacement of natural resources. A portion of these funds were used to lay the groundwork for restoration of the injured resources. Under a Memorandum of Agreement between state and federal governments, the restoration funds were to be used "...for the purposes of restoring, replacing, enhancing, or acquiring the equivalent of natural resources injured as a result of the Oil Spill...", and further, that the funds had to be spent on resources in Alaska if possible. Six appointed Trustees have overseen public meetings, authorization of projects, and implementation of restoration programs (Exxon Valdez Oil Spill Trustee Council [EVOSTC] 1994).

Public input has been an important part of the restoration process. Overwhelming public support was indicated for acquisition of land to protect natural resources and promote recovery. For aesthetic and recreational reasons, as well as to protect commercially-important salmon resources, the acquisition of forested lands has remained a high priority. Few other options could be agreed upon to restore injured resources within a landscape of the size and complexity of the Exxon Valdez oil spill zone. By 1994, 42 percent of the $\$ 100$ million committed to annual work has been allocated to habitat protection (EVOSTC 1994). Marbled Murrelets were known to depend on old-growth forests, were impacted heavily by the spill, and have become a focal species for ranking lands for potential acquisition. Therefore, the Marbled Murrelet Restoration Project attempted to describe their nesting habitat in the spill zone (see Kuletz and others, in press; Kuletz and others, this volume; Marks and others, in press; Naslund and others, in press).

Although protection of nesting habitat in old-growth forests removes one future threat to murrelets, partial or full recovery may not be possible until other threats are addressed. For example, mortality in commercial gill-net fisheries (Carter and others, this volume) and apparently high predation levels also impact murrelet populations in the spill zone.

\section{Summary}

The Exxon Valdez oil spill made it abundantly clear that oil spill prevention, response preparation, and habitat protection are the best means to reduce the impact of oil pollution on 
Marbled Murrelets in Alaska. Large oil spills cannot be effectively contained, and rehabilitation efforts can be costly and of limited value to affected populations. Brachyramphus murrelets comprised only 2.4 percent of the total number of birds brought to rehabilitation centers during the spill (Wood and Heaphy 1991). Murrelets did not respond well to rehabilitation efforts. Only 3 of 33 Marbled and 2 of 6 Kittlitz's murrelets survived to be released (Wood, pers. comm.), compared to 51 percent released of all 1,630 treated birds. Wood and Heaphy (1991) concluded that murrelets had a low tolerance for capture and rehabilitation. Necropsies revealed enlarged adrenal glands, indicating stress-induced mortality.

The Exxon Valdez oil spill affected regions of Alaska with some of the highest recorded murrelet densities in the world. Prince William Sound is the northernmost extension of the coniferous rainforest on the west coast of North America. There is no doubt that the spill has been a contributing factor to population decline in Prince William Sound over the past 20 years, along with other factors (Carter and others, this volume; Klosiewski and Laing 1994; Piatt and Naslund, this volume). The threat from future oil spills remains. Since 1989, several near catastrophes already have occurred in Prince William Sound. A spill similar to the Exxon Valdez during the peak breeding season has the potential to risk three to four times the number of murrelets that were present in Prince William Sound in late March 1989.

\section{Large Oil Spills in California, Oregon, Washington, and British Columbia}

Between the late 1800 s and 1968 , medium and large oil spills occurred frequently, but were rarely documented with respect to seabird mortality in California, Oregon, Washington, and British Columbia. In most cases, the source of the spilled oil was not determined. Few reports of murrelet mortality during this period are available. In spring 1929, 15 oiled murrelets were found dead on a $0.4 \mathrm{~km}$ section of beach at Crescent Beach, British Columbia, after a fuel oil spill that occurred weeks earlier and extended from Vancouver to at least Crescent Beach on the CanadaU.S. border (Racey 1930, Rodway and others 1992). In March 1937, 14 Marbled Murrelets (as well as five other unidentified murrelets) were found dead on beaches after the tanker Frank H. Buck oil spill near San Francisco, California (Aldrich 1938, Moffitt and Orr 1938). In September 1956, one Marbled Murrelet was found dead on beaches searched after a spill from the freighter Seagate on the outer coast of Washington, near Point Grenville (Richardson 1956). There is no way to quantify historical losses or fully assess the impact of these losses on murrelet populations based on available data. They serve to demonstrate that oil pollution has been affecting murrelet populations for many decades.

Since 1968, several large and medium oil spills have occurred for which seabird mortality was estimated. These spills are discussed below (see figure 2 for general locations).
1969 Santa Barbara: In January 1969, a large spill (3-5 million gallons) of crude oil resulted from an offshore well blow-out off Santa Barbara, California. Oil spread throughout the Santa Barbara Channel area between January and August (Nash and others 1972, Steinhart and Steinhart 1972). No oiled murrelets were recorded dead on beaches but large numbers of other birds were reported (Straughan 1971). Murrelets occur only in small numbers in this area at all times of year.

1971 Anacortes: In April 1971, a large spill $(204,600$ gallons [gals]; 4,870 barrels [bbls]) of diesel oil resulted from an accident at a Texaco onshore facility while loading a barge near Anacortes, Washington (Chia 1971). Although at least 460 dead and live seabirds were recovered, mortality to marine birds was not properly assessed and no oiled murrelets were recorded.

1971 San Francisco: A large spill (810,000 gals; 19,300 bbls) of bunker oil occurred in the entrance to the Golden Gate near San Francisco when a Chevron oil tanker struck another vessel in January 1971. No murrelets were reported from this winter spill, but efforts were focused on rehabilitating live oiled birds recovered on beaches (Smail and others 1972). The lack of recovery of murrelets in January 1971 may also reflect a population decline in this area since the March 1937 Frank H. Buck oil spill (Carter and Erickson 1988). The latter spill occurred in the same area and at the same general time of year, and yet several murrelet carcasses were recovered in the earlier spill.

1978 Toyota Maru: In 1978, a fuel oil spill of 30,00058,000 gals (715-1380 bbls) occurred from the vessel Toyota Maru just east of Portland along the Columbia River, Oregon (Nelson and others 1992). No documentation of impacts to birds was undertaken.

1983 Blue Magpie: A medium spill of 69,000 gals (1,643 bbls) from the vessel Blue Magpie occurred in Yaquina Bay, Oregon, in November 1983 (Bayer 1988, Burger and Fry 1993, Nelson and others 1992). At least two (and possibly four) oiled murrelets were recovered on beaches over a wide stretch of coast in Clatsop, Tillamook, and Lincoln counties.

1984 Mobiloil: In March 1984, a medium spill of about 200,000 gals $(4,700 \mathrm{bbls})$ of mixed oils occurred from the tanker Mobiloil about 88 miles inland along the Columbia River, Oregon, near St. Helens (Burger and Fry 1993, Nelson and others 1992, Speich and Thompson 1987). The oil travelled to the ocean and extended north to Grays Harbor. A total of 450 birds were recovered although a complete damage assessment was not conducted. No oiled murrelets were reported. However, one dead oiled murrelet was found during monthly beached bird surveys on 20 June 1984 on Ocean Park Beach, Washington according to Lippert (Speich, pers. comm.). This beach was well within the spill zone and oiled birds were noted from March to August in this vicinity. This murrelet was probably killed by the Mobiloil spill and, if so, we suspect that more murrelets could have been affected.

1984 Whidbey Island: In December 1984, a spill $(5,000$ gals; 120 bbls) of fuel oil at the south end of Whidbey Island, 


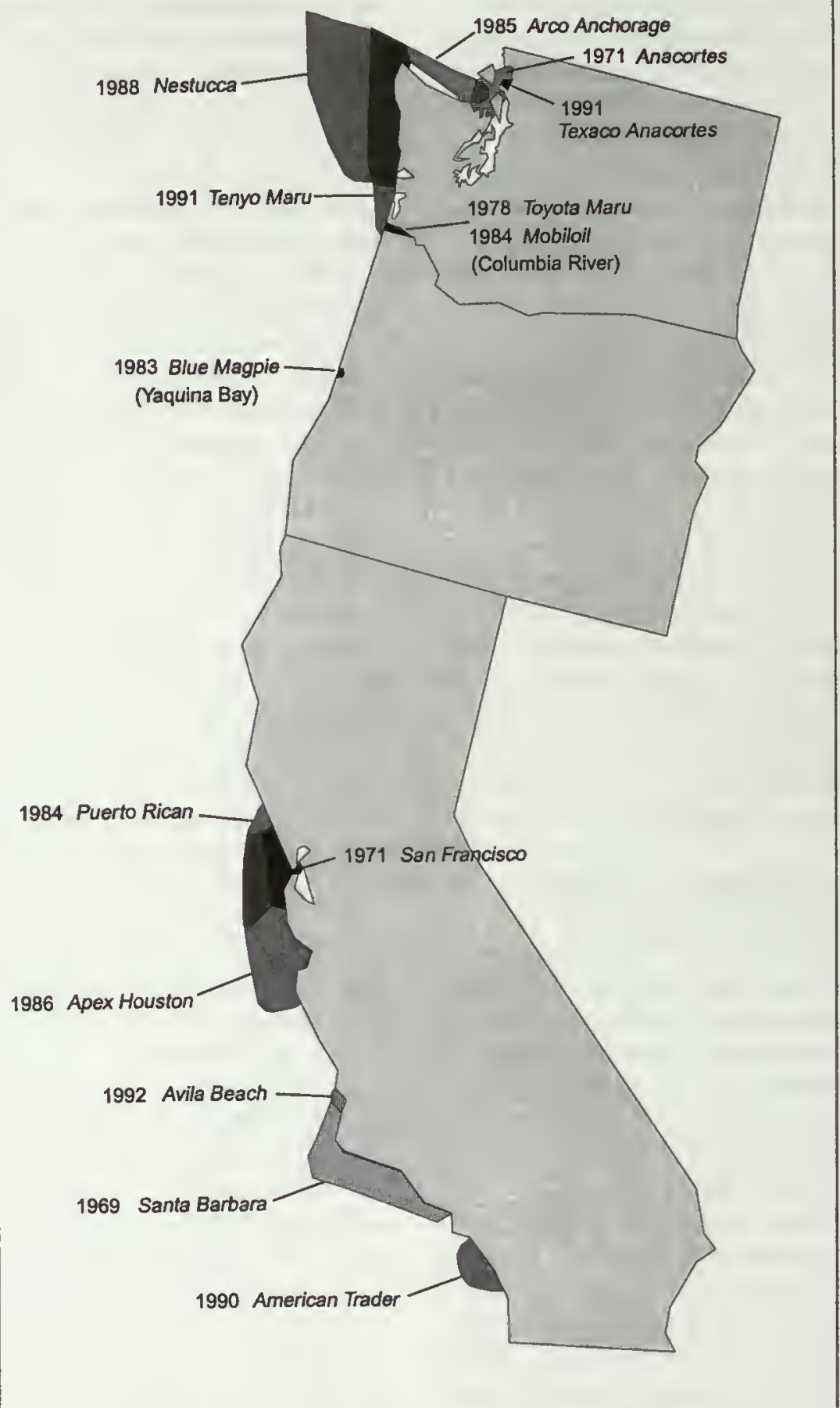

Figure 2-West Coast Oil Spills (1969-1993). The approximate locations of large and medium oil spills in Washington, Oregon and California where seabird mortality was assessed are indicated.

near Seattle, Washington (Speich and Thompson 1987). About 450 dead birds were recovered and about 650 live oiled birds were observed off shore. No oiled murrelets were recovered or observed.

1984 Puerto Rican: In November 1984, a large spill (1,470,000 gals; 35,000 bbls) of mixed oils occurred when the tanker Puerto Rican exploded off San Francisco (Herz and Kopec 1985). About 1,300 birds were recovered on beaches and a minimum of 4,800 birds were estimated to have been killed (Dobbin and others 1986, Ford and others 1987, Point Reyes Bird Observatory 1985). One dead oiled Marbled Murrelet was found on a beach.

1985 Arco Anchorage: In December 1985, the oil tanker Arco Anchorage spilled 240,000 gals (5,700 bbls) of crude oil off Port Angeles, Washington (Kittle and others 1987; Speich and others 1991; Speich, pers. comm.). Totals of 1,562 live and 355 dead oiled birds were recovered on shore after the spill. About 4,000 birds total were estimated to 
have been killed. One dead oiled Marbled Murrelet was recovered. On 1 July 1986, 62 murrelets were counted in the Striped Peak Headland area near the spill location (Kittle and others 1987), indicating that local breeding birds probably were affected.

1986 Apex Houston: In February 1986, the tank barge Apex Housion spilled 26,100 gals (616 bbls) of crude oil between San Francisco and Monterey (Ford and others 1987, Page and Carter 1986, Page and others 1990). A total of 4,198 birds were recovered and about 10,600 birds were estimated to have been killed, based on carcass and live bird counts from searched and unsearched coastal areas, as well as birds lost at sea. A total of 11 Marbled Murrelets were estimated to have been killed: three were found dead on beaches, two live birds were turned into rehabilitation centers, and another six birds were estimated to have died and washed ashore in coastal areas not searched (Carter and Erickson 1988, 1992; Page and others 1990; Siskin and others 1991). This mortality probably was significant for the small, declining local breeding population in central California (Singer and Carter 1992). Acquisition of old-growth forest nesting habitat in central California with restoration funds obtained through recent litigation is indicated in the Consent Decree signed in 1994.

1988 Barge MCN5: In January 1988, this barge spilled 72,000 gals (1,700 bbls) of gasoline and oil near Anacortes, Washington (Burger and Fry 1993). No bird mortalities were reported.

1988 Nestucca: In December 1988, the Nestucca spilled 231,000 gals $(5,500$ bbls) of bunker oil off Grays Harbor, Washington, with oil extending as far north as Vancouver Island, British Columbia (Burger 1990, 1992; Ford and others 1991b). A total of 12,535 live and dead birds were recorded and an estimated 56,000 birds were killed. Only two Marbled Murrelets were recovered along the outer Washington coast (Ford and others 1991b) although about 50 murrelet deaths could be extrapolated from the sample of dead birds recovered on Vancouver Island beaches; $120-150$ were estimated to have been killed there (Burger 1990, 1992; Rodway and others 1989, 1992). Oiled carcasses recovered on Vancouver Island may have included some local birds and some carcasses that were passively transported across the border from Washington.

1990 American Trader. In February 1990, the oil tanker American Trader ran onto its own anchor and spilled 400,000 gals (7,000 bbls) of crude oil off Huntingdon Beach, in southern California (Oceanor 1990). Hundreds of birds were recovered on shore. No murrelets were found, possibly because few occur along the southern California coast during winter.

1991 Texaco Anacortes: In February 1991, a small spill (200,000 gals; 4,760 bbls) of crude oil occurred from an onshore facility at Fidalgo Bay near Anacortes, Washington. No murrelets were found dead in the immediate vicinity of the facility (Momot, pers. comm.).

1991 Tenyo Maru: In July 1991, the Tenyo Maru fish packer struck another vessel off the Olympic Peninsula, Washington, spilling 99,000 gals (2,360 bbls) of bunker and diesel oil. About 45 Marbled Murrelet carcasses were recovered on beaches (Benkert, pers. comm.), representing the largest recovery of oiled murrelets after a spill, excepting the Exxon Valdez spill. Total estimates of 200-400 birds have been derived (Warheit, pers. comm.). This mortality represents a significant proportion of local breeding populations. These murrelets probably belonged to western Washington populations, which also have been heavily impacted by loss of old-growth forest nesting habitat (Hamer, this volume). This oil spill is in the process of litigation, so a full assessment of population impacts to murrelets is not currently available.

1992 Avila Beach: In August 1992, a spill of about 16,800 gals ( $400 \mathrm{bbls}$ ) of crude oil occurred while loading a tanker at Avila Beach in southcentral California. No murrelets were found during NRDA work (Kelly, pers. comm.), possibly because few birds occur along this part of the coast throughout the year.

A great variety of other medium and large spills have occurred off the Alaska, California, and Washington coasts since 1968 (especially prior to 1980) without adequate documentation of their impacts on seabirds. At least 7 significant spills (between 300-300,000 gals) have occurred on the west coast of Vancouver Island between 1972 and 1984 without documentation of mortalities (Burger 1992, Kay 1989).

\section{Chronic Oil Pollution in California, Oregon, Washington, and British Columbia}

Chronic oil pollution, which includes small oil spills, bilge dumping, seeps, etc., have occurred continuously throughout this century. Chronic oil pollution has been documented very poorly in California, Oregon, Washington, and British Columbia, making an assessment of impacts difficult. There are sporadic reports of oiled murrelets separate from known large and medium spills in the literature, especially in California. Streator (1947) noted "many dead on the beach, oil soaked" in Santa Cruz County. Munro (1957) noted single dead oiled murrelets on 21 December 1953, 31 January 1954, and 9 January 1957 at Morro Bay in San Luis Obispo county. One dead oiled murrelet was found at Las Varas Ranch Beach in Santa Barbara County on 21 September 1976 (Stenzel and others 1988). Two murrelets were found on 26 April 1986 on Hope Ranch Beach, Santa Barbara County (Carter and Erickson 1988).

The only direct means to assess potential impacts of chronic oiling is through beached bird surveys. In California, the Point Reyes Bird Observatory coordinated an extensive beached bird survey program throughout much of the state from 1971-1985 (Stenzel and others 1988). Only 23 dead Marbled Murrelets were identified on beaches throughout this period. Marbled Murrelets were probably underrepresented because: (1) low sampling effort occurred in northern California where most murrelets occur; (2) counts usually were conducted monthly and small alcid carcasses may not have persisted long enough to be counted on beaches; 
and (3) some observers may not have been able to identify Marbled Murrelet carcasses (especially decomposed carcasses) (Stenzel, pers. comm.). Only one of the 23 murrelets found during this program was determined to be oiled. However, the degree of oiling may be underestimated, due to the advanced state of decomposition of some carcasses (Stenzel, pers. comm.). In Washington, beached bird surveys were conducted between 1978-1979 for inland marine areas (Speich and Wahl 1986). Only one unoiled Marbled Murrelet was recovered dead on beaches out of a total 110 birds examined. Between January 1982 and December 1986, outer Washington coast areas (especially in the vicinity of Grays Harbor) also were surveyed by Lippert (Speich, pers. comm.). A total of five murrelets (two adults and three unknown age) were found. Only one oiled adult was found on Ocean Park Beach, Washington (see 1984 Mobiloil above). Both of these beached bird programs were conducted between the early 1970s and mid 1980s when large and medium oil spills occurred less frequently (Burger and Fry 1993). Thus, the low occurrence of oiled murrelets on these surveys may reflect low incidence of oil pollution as well as low recovery of oiled and unoiled murrelet carcasses. Burger (1992) conducted beached bird surveys between 1987-1991 on the southwest coast of Vancouver Island, British Columbia. Marbled Murrelets were not reported specifically. Small alcids were lumped into one category (of which few were recovered in any case).

\section{Summary and Recommendations}

It is difficult to assess the impacts of oil spills and other marine pollution on Marbled Murrelets because of inadequate baseline data, and poor documentation of post-spill damages. For example, even though reasonable population estimates were available in Prince William Sound, 17 years separated pre-spill and post-spill surveys. Klosiewski and Laing (1994) determined that, given the low number of baseline survey years, their tests only had a $20-40$ percent probability (based on Monte Carlo runs) of detecting a 50 percent decline in population size of Marbled Murrelets in Prince William Sound. In particular, low recovery rates of murrelets after pollution events must result in part from: (1) improper identification of murrelet carcasses that resemble other small alcids; (2) undercounting of carcasses on beaches due to small carcass size, incomplete coastal coverage, and burial in beach substrates; (3) high rates of carcass removal by predators on shore and at sea; and (4) carcass loss due to sinking at sea. Efforts are underway to improve the rate of recovery of murrelet carcasses during large oil spills, especially by the California Department of Fish and Game (Kelly, pers. comm.) and Washington Department of Fish and Wildlife (Warheit, pers. comm.).

However, seabird mortality from small spills is often not assessed. Greater efforts should be expended to investigate all spills for their impacts on Marbled Murrelets. In addition, greater coordination is required between wildlife care centers and government agencies for documenting live and dead murrelets sporadically found on shore in small numbers. In Washington, the Adopt A Beach program may recover such oiled carcasses during regular beach surveys although none have been found from 1988-1993 (Silver, pers. comm.). In California, a group such as the International Wildlife Rehabilitation Council could coordinate better documentation and reporting of oiled murrelets turned into wildlife care centers of various affiliations (e.g., Society for the Prevention of Cruelty to Animals, International Bird Rescue, etc.). In addition, the Beach Watch program may encounter oiled murrelets through regular beach surveys within the Gulf of the Farallones and Monterey Bay National Marine Sanctuaries which encompass the central California population of Marbled Murrelets (Rolleto, pers. comm.). Birds found on beach surveys or interned in centers should be preserved for later examination or to have their identification confirmed. Oil samples from such birds also may link mortality to specific sources. Also, rehabilitation efforts for oiled murrelets must be improved by conducting physiological, wildlife health, and captive care research on oiled murrelets.

Better baseline data and monitoring (before, during and after the pollution event) is needed for at-sea population size and distribution during the non-breeding and breeding seasons. This task is immense, especially in Alaska and British Columbia, but is critical to documenting injury and devising restoration activities. As populations dwindle in size, it will be important to attempt to prevent all mortality possible, even if this process is costly and has only moderate success.

We feel that a detailed assessment of the threat of oil pollution to Marbled Murrelets throughout their range in North America is required by analyzing data on: (1) the location, size and frequency of oil spills; (2) the distribution and abundance of Marbled Murrelets at sea; (3) the routes of tanker and other shipping traffic along the coast; and (4) the amount of oil transported along the coast by various means (Burger 1992; USDI Fish and Wildlife Service, in press). Databases with some of the above spill and NRDA information are being developed from California to Alaska (Kelly, pers. comm.; Oman, pers. comm.). With these databases, future in-depth analyses should be conducted to indicate the overall threat of oil pollution to Marbled Murrelets over the long term and to devise methods to reduce oil mortality.

Oil pollution has had significant impacts on murrelet populations in Prince William Sound, central California, and western Washington. However, these effects have probably been felt only sporadically by local populations. If murrelet populations were in better health, oiling mortality might be naturally recoverable within several years to decades, depending on the size and nature of the mortality. However, when oiling mortality is considered as a cumulative effect with other anthropogenic factors and affects small, declining populations of murrelets, the relative effects of oil pollution will become greater and recovery may not be possible (Piatt 
and others 1991, Singer and Carter 1992). Management efforts to reduce or stop oil spills should be undertaken. Industry and government efforts are underway to examine how tanker traffic could be routed away from sensitive coastal areas in California, Oregon, and Washington (Kelly, pers. comm.; Oman, pers. comm.). However, oil traffic into and out of major oil ports at Valdez (Alaska), Anacortes (Washington), San Francisco, and Los Angeles (California) will continue to threaten murrelet populations in adjacent areas throughout the 21 st century'and beyond.

\section{Acknowledgments}

Information of various oil spills and other aspects of marine pollution on the west coast were provided by: K. Benkert, R.G. Ford, P.R. Kelly, G.S. Miller, J. Momot, S.K. Nelson, L. Oman, G.W. Page, J.F. Piatt, E. Silver, S.M. Speich, L.E. Stenzel, and K. Warheit. Tom Jennings and Debora Flint provided figure 1 and Gerard McChesney helped prepare figure 2. This summary has benefitted from reviews and editing by L.L. Long, J.F. Piatt, C.J. Ralph, and M.G. Raphael. 



\section{Chapter 27 \\ Mortality of Marbled Murrelets in Gill Nets in North America}

\author{
Harry R. Carter ${ }^{1}$ \\ Michael L.C. McAllister ${ }^{2}$
}

\begin{abstract}
Mortality of Marbled Murrelets (Brachyramphus marmoratus) due to accidental capture in gill nets is one of the major threats to murrelet populations. Gill-net mortality of murrelets throughout their range has been occurring for several decades and probably has contributed to declines in populations, in conjunction with loss of nesting habitat and mortality from oil spills. Gill-net mortality has been best studied in Prince William Sound, Alaska, and in Barkley Sound, British Columbia. However, gill-net fishing occurs widely and it is likely that: (1) several thousand to tens of thousands of murrelets are killed annually in Alaska; (2) hundreds to thousands are probably killed annually in British Columbia; and (3) tens to hundreds may be killed annually in Washington. In the 1980's, hundreds also were killed in central California al though recent regulations have markedly reduced this mortality. Despite the potential impacts of gill-net mortality on murrelet populations, little has been done to examine the degree of mortality or to develop long-term solutions to reduce or eliminate net mortality. Gill-net mortality should be assessed by management agencies through the establishment of more observer programs, especially in Alaska, British Columbia, and Washington.
\end{abstract}

Gill-net fisheries have occurred off the Pacific coast of western North America throughout this century. Following World War II, these fisheries expanded to cover large geographic areas, including most nearshore and offshore waters. Concern has been expressed repeatedly over the last 3 decades about the excessive mortality of seabirds and marine mammals in gill nets in many areas of the North Pacific Ocean (see reviews in DeGange and others 1993; Jones and DeGange 1988; King 1984; King and others 1979). Most attention has been paid to offshore international fisheries where hundreds of thousands of seabirds are killed annually. Less attention has been directed towards lower levels of mortality in nearshore gill-net fisheries, even though this mortality can have serious impacts to local seabird populations (Atkins and Heneman 1987; Carter and Sealy 1984; DeGange and others 1993; Piatt and Gould, in press; Piatt and others 1984; Takekawa and others 1990).

There has been mounting concern about the impacts of gill-net mortality on the Marbled Murrelet (Brachyramphus marmoratus) (Carter and Morrison 1992, Carter and Sealy 1984, DeGange and others 1993, Marshall 1988a, Sealy and Carter 1984). Murrelets become tangled and drown in gill nets while swimming under water. Gill-net fishing is conducted with either drift or set nets. Drift nets are operated

1 Wildlife Biologist, National Biological Service, U.S. Department of the Interior, California Pacific Science Center, 6924 Tremont Road, Dixon, CA 95620

${ }^{2}$ Wildlife Biologist, Wildland Resources Enterprises, 60069 Morgan Lake Road, La Grande, OR 97850

3 Commercial Fisherman, 9229 Emily Way, Juneau, AK 99801 (Deceased June 1993)

\section{M.E. "Pete" Islelb"}

from a boat and are free to move with the currents, whereas set nets are anchored at both ends and can be set at any depth. Other forms of net fishing tend to be much less destructive to birds. Seine fishing is known at times to cause mortality.

At-sea mortality from gill nets and oil spills has been identified as a significant conservation problem for the Marbled Murrelet (Carter and Morrison 1992; U.S. Fish and Wildlife Service, in press). Gill-net mortality may act separately or in concert with the loss of nesting habitat and mortality from oil pollution to threaten survival of several populations. In this paper, we: (1) review factors that lead to mortality of murrelets in gill nets; (2) discuss known and suspected levels of mortality of Marbled Murrelets in gill and seine nets throughout their range in North America; and (3) indicate management actions that have been considered to stop or reduce the impacts of gillnet mortality. Information is presented by state and province from north to south. Information for the three southern states was collated for the Marbled Murrelet Recovery Plan (U.S. Fish and Wildlife Service, in press.)

\section{Alaska}

Large net fisheries have existed in many areas of Alaska for decades. These fisheries target mainly salmon (Onchorynchus sp.), although other fish also are taken (e.g., herring Clupea harengus). Salmon fisheries are broken down into 12 statistical areas with many districts and subdistricts in each area. The salmon gill-net fishery targets specific stocks of fish as they return to rivers to spawn, and can occur within 3 miles of land in a river, river delta, embayment, or fjord. Open fishing periods vary between a half day and 7 days per week, depending on run strength of fish stocks, harvest levels, and numbers of fish reaching spawning areas. Some districts are opened for only one year out of five.

\section{Types of Nets}

Drift nets are about $900-1200$ feet (275-365 m) long and are fished as a single unit. Set nets are about 300-900 feet $(90-275 \mathrm{~m})$ long, but are usually broken down into subunits as short as 60 feet $(18 \mathrm{~m})$ long. Gill nets in most areas are restricted to 60 meshes deep. In Bristol Bay, there is a 28-meshes deep maximum for both set and drift nets. Stretched mesh sizes vary from 4.5-9.0 inches (11.4-22.9 $\mathrm{cm})$ although restrictions apply in certain districts and at certain times. Thus, a net with a mesh size of 5.5 inches (14 $\mathrm{cm})$, with 60 meshes, would be about 30 feet $(9 \mathrm{~m})$ deep. When restrictions do not apply, nets are often set at 120-150 meshes deep. Further discussion of various aspects relating 
to how murrelets become tangled in gill nets can be found in Carter and Sealy (1984).

\section{Behavior Near Nets}

Isleib (1982) observed Marbled Murrelets feeding close to nets, as well as elsewhere, but birds appeared to be displaced by a vessel or activity aboard a vessel. Young of the year showed little fear of vessels. Isleib usually observed murrelets swimming along the nets in singles or pairs, frequently diving, often surfacing on one side and then the other of the net. This occurs with nets 60 feet $(18 \mathrm{~m})$ deep, with mesh sizes of 5.5 inches $(14 \mathrm{~cm})$. Isleib suggested that they may actually be going through these nets, but more than 80 percent of the birds were caught at night. Isleib felt murrelets are likely caught while pursuing small feed fishes, including juvenile herring, sand lance (Ammodytes hexapterus), capelin (Mallotus villosus), needlefish (Strongylura exilis), and various salmon fry. This may not be the case for some of the juvenile murrelet mortalities where juveniles tend to dive from suspected danger on the surface while adults tend to fly. Murrelets are caught at varying depths in the nets, from the surface to 10 meters, mostly 3 to 5 meters down. Beyond 60 meshes deep, murrelets do not appear to be caught.

\section{Historical Records of Mortality: 1950s to $1980 \mathrm{~s}$}

Historical documentation of gill-net mortality of murrelets (and other seabirds) in Alaska before the 1970s is poor. An observer program for determining incidental mortality of seabirds in offshore net fisheries in Alaska began in 1974 (King and others 1979), but a similar observer program for nearshore waters, where murrelets primarily occur and are killed, was not instigated by the National Marine Fisheries Service until 1990 in Prince William Sound (DeGange and others 1993, Mendenhall 1992, Wynne and others 1991). At least 3 scraps of information indicate that gill-net mortality occurred in the 1950s and 1960s: (1) Sealy and Carter (1984) reported an adult murrelet in breeding plumage was killed at a depth of 25-30 feet in a gill net near Little Port Walter on Baranof Island in southeastern Alaska between 29 July and 6 August 1958 (Sealy, pers. comm.); (2) a molting murrelet was reported killed in a fishing net at Coho Beach, in the northern Gulf of Alaska, in August 1959 (Smith 1959); and (3) two adults in breeding plumage were killed in gill nets near Cordova, in the northern Gulf of Alaska, in 1969 (Carter, unpubl. data in Mendenhall 1992).

In the 1970s, the only documentation of mortality of murrelets in gill nets in Alaska was obtained by one of us (Isleib). Below we summarize the information and observations, taken largely from a letter to the senior author (Isleib 1982). Most of Isleib's observations are from Statistical Area E, the Prince William Sound/Copper-Bering River Districts. Specific districts have different opening periods by gear type.

The number of murrelets that are killed is difficult to determine. Isleib estimated that the degree of magnitude for all the districts of Area E was "several hundreds" annually.
He felt that the numbers had increased in the past 20 years due to several factors: the vessels are continuously fishing around the clock; the use of finer web; and more boats are actively fishing (Isleib 1982). He observed that murrelets are killed throughout the fishing season, with most $(80+$ percent) killed at night.

He felt that the major locations of kills were as follows. In the Copper and Bering River Districts, murrelets are not numerous, except during brief migration periods in early September, and most birds occur offshore. These districts front the open Gulf of Alaska. Here, most murrelets are caught between 0.5 and 3 miles $(0.3-1.9 \mathrm{~km})$ offshore, where water depth is about 10 fathoms $(18 \mathrm{~m})$. His best estimate of murrelet mortality in these districts is from 100 to 300 annually. A similar number, or slightly higher mortality of Common Murres (Uria aalge) also occurs here.

In the Coghill-Unakwik and Eshamy districts, murrelets were numerous in the 1970s: 10,000+ Kittlitz's Murrelets (Brachyramphus brevirostris) and 100,000+ Marbled Murrelets. These districts are either within or at the mouths of fjords. Isleib estimated the annual kill at about 500 birds. In the Bristol Bay area, murrelets are very rare. Isleib fished Bristol Bay for 3 years and only 3 Common Murres were killed in 1981.

While the above observations apply mainly to the 1970 s, more recent comments by Isleib reflected similar or greater amounts of mortality continuing throughout the 1980s (see DeGange and others 1993). For southeastern Alaska, Isleib had estimated in DeGange and others (1993) up to 1,000 Marbled Murrelets were taken annually, but it is unclear if this estimate is based on more data than available in 1982. At this time, he had "no first hand knowledge", but suspected mortality at similar levels as found in Prince William Sound (Isleib 1982). His suspicion was based on fishing effort, fishing locations near murrelet aggregations, and types of fishing gear (Isleib, pers. comm.). For the same reasons, he suspected similar mortality along the Alaska peninsula during the 1970s and 1980s (Isleib, pers. comm.).

Isleib observed that murrelets are captured in the same locations year after year throughout the season. Young of the year, first noted in mid-July, are killed in a higher proportion to their respective numbers than adults.

\section{Historical Records of Mortality: 1980s and 1990s}

From 1983-1993, one of us (McAllister, unpubl. data) conducted surveys of murrelets throughout most coastal regions in the Gulf of Alaska. Preliminary population estimates for the Gulf of Alaska are similar to estimates generated more recently from the Outer Continental Shelf Environmental Assessment Program (OCSEAP)(Piatt and Ford 1993; Piatt and Naslund, this volume). The sub-area found to support the greatest populations $(45,000-70,000$ birds [McAllister, unpubl. data]) is Southeast Alaska. Three major nesting areas (each containing approximately 5,000-10,000 birds) occur in southeastern Alaska: the west slopes of Admiralty Island; the mainland slopes of Stephens Passage (Juneau south to Tracy 
Arm); and the mainland slopes near Wrangell (Stikine River south to Emest Sound). At-sea foraging areas occur near these and other nesting areas, resulting in a complex pattern of aggregations throughout much of southeastern Alaska (figs. $I$ and 2). There are three fishing subdistricts where intensive gill-net fishing overlap with at-sea foraging aggregations of Marbled Murrelets: (1) Area 1B, located at the south end of Revillagigedo Channel near the Canadian border; (2) Area 6A, located near Point Baker in Sumner Strait; and (3) Area $11 \mathrm{~B}$, located south of Juneau in the central part of Stevens Passage. Gill-net fisheries in subdistricts $6 \mathrm{~A}$ and $11 \mathrm{~B}$ are targeted on fish stocks returning to the Stikine and Taku rivers, respectively. Area $\mathrm{lB}$ receives the most fishing pressure and is open for the longest period each year (June-October).

Although murrelets are not found to aggregate in large numbers in Area $1 \mathrm{~B}$ at present, it is possible that large numbers formally occurred in Boca de Quadra, Behm Canal, and Carol
Inlet before being reduced by gill-net mortality and logging of nesting habitats in old-growth forests. Area $1 \mathrm{~F}$ is an offshore area where murrelets are not found in aggregations. In Areas $6 \mathrm{~A}$ and $11 \mathrm{~B}$, large numbers of gill-net boats congregate from June through August, and these could have decimated local populations. In Area $6 \mathrm{~A}$, dense murrelet foraging aggregations occur at Point Baker and along the north shores of Zarembo Island during gill-net openings. This would be a prime area in southeastern Alaska to monitor the ongoing impacts of gill-net fishing on the Marbled Murrelet. In Area 11B, McAllister (unpubl. data) retrieved two floating dead Marbled Murrelets in the vicinity of gill-net boats fishing at Taku Harbor. A former gill-net fisherman reported to McAllister that Marbled Murrelets were killed regularly in area $11 \mathrm{~B}$ in the late 1970s, stating that up to 12 Marbled Murrelets were found in nets upon retrieving gear at dawn near Taku Harbor in Area 11B. Murrelet mortality does not

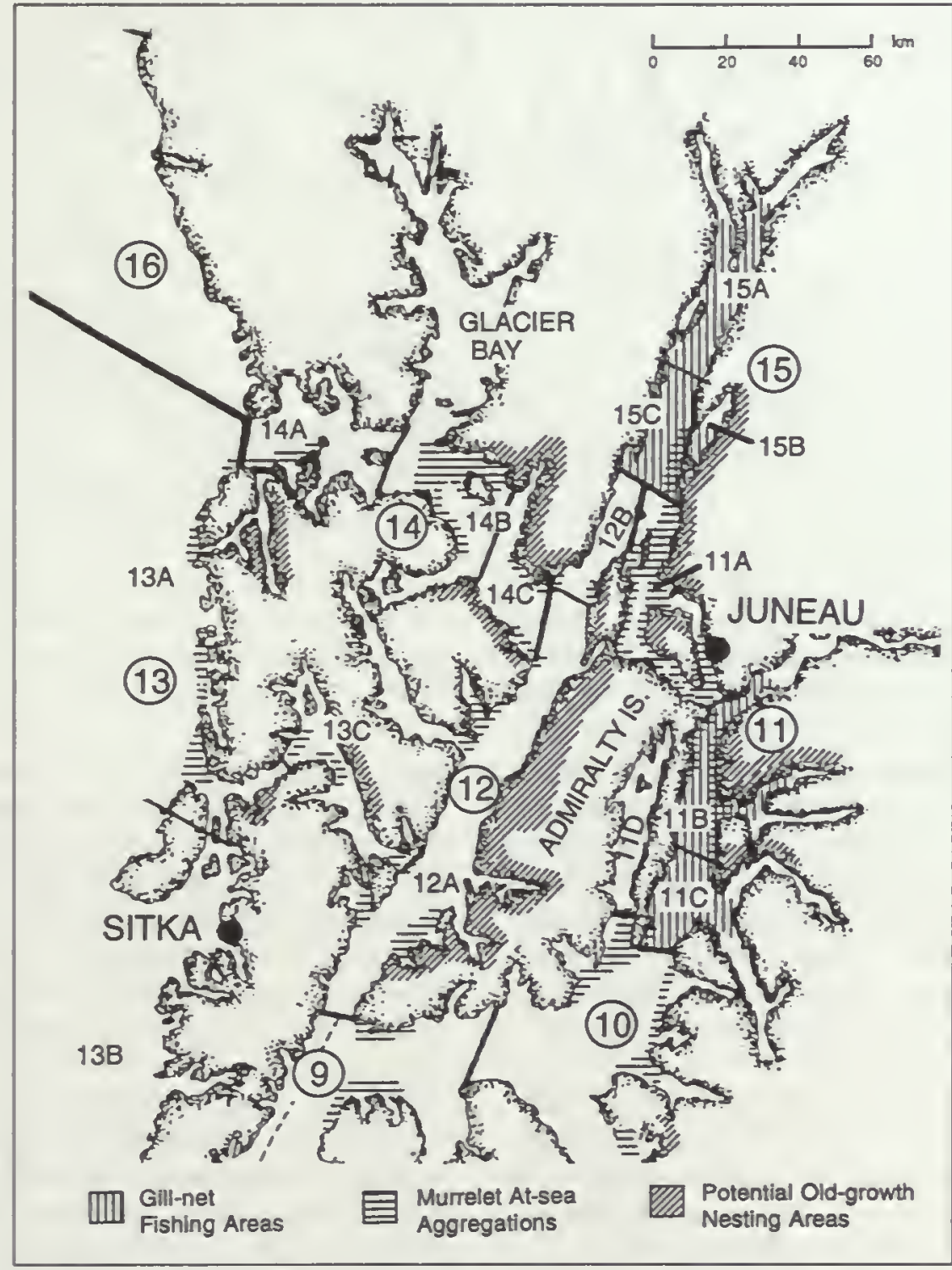

Figure 1-North portion of Southeastem Alaska indicating 1988 fishing districts (numbered) with locations of Marbled Murrelet at-sea aggregations, potential old-growth forest nesting areas, and gill-net fishing areas (McAllister, unpubl. data). Murrelet information for Glacier Bay is not included. 


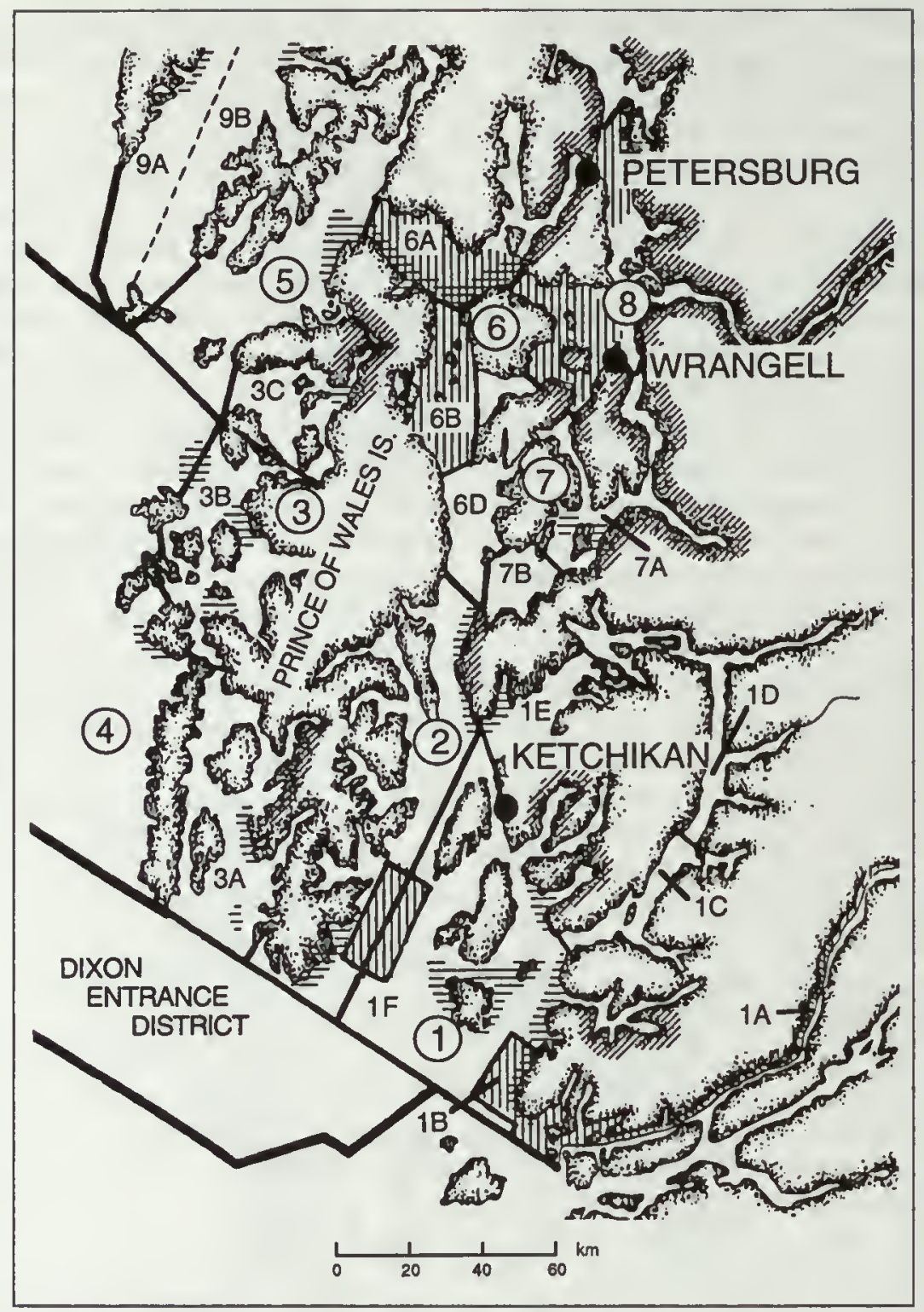

Figure 2-South portion of Southeastern Alaska indicating 1988 fishing districts (numbered). Other symbols and sources as in fig. 1.

occur to a significant degree in subdistricts $15 \mathrm{~A}$ and $15 \mathrm{C}$ in southern Lynn Canal, because birds in this region forage to the south in northern Steven's Passage and in Icy Straits. Also, gill-net fishing tends to occur in this subdistrict mainly in July to October, after most birds have left the area. It is difficult to estimate the true magnitude of impact, but when actively foraging aggregations of murrelets overlap with gill-net gear, the potential for mortality is high (Carter and Sealy 1984).

Purse seine fishing occurs more extensively than gillnet fishing throughout most of Southeast Alaska. McAllister (unpubl. data) has observed no mortalities of Marbled Murrelets in 10 years of fishing in the area, although fishermen have reported "dozens" of Common Murres and Rhinoceros Auklets (Cerorhinca monocerata) per net and smaller numbers of Cassin's Auklets (Ptychoramphus aleuticus) being killed in seine nets in a year, especially in fishing district 4 (fig. 2). This mortality could amount to many thousands of dead birds. Murrelets are frequently trapped inside encircled nets, but almost always escape by swimming and hopping over or through spaces between the floats that line the top of nets. On five occasions in late summer, McAllister retrieved and released live murrelets from encircled nets near Cape Chacon in district 2 (fig. 2) that were not able to escape over the floats, including juveniles and adults undergoing prebasic molt. A seine fisherman has reported to McAllister similar entrapment of murrelets in seine nets in August at Stepovak Bay on the Alaska Peninsula.

In Prince William Sound and Cook Inlet, Isleib (pers. comm.) indicated continued mortality of Marbled Murrelets in the 1980s and 1990s, at levels similar to or greater than that reported in the 1970s (DeGange and others 1993). In addition, Kuletz (pers. comm.) reported catching a few murrelets per year from 1982-1988 during set-net fishing on the east side of the middle of Cook Inlet. This mortality occurred while fishing with nine nets, set a few days per 
week during the summer. Fishermen have reported further (DeGange, pers. comm.) that murrelets have been killed occasionally near Raspberry Island at the northwest end of Kupreanof Strait, involving mostly juveniles. In other areas near Kodiak Island (e.g., Cape Uganik and the south side of Kupreanof Strait), none were known to be killed. A few murrelets per year also were reported killed in nets on the east side of Cook Inlet near Clam Gulch (between Kenai and Homer). This mortality occurred during nine net sets over the fishing season, whereas about 150 net sets occur in this area throughout the year. Puffins (Fratercula sp.) and other seabirds (possibly including murrelets) are taken occasionally in nets set near Chisdik Island on the west side of Cook Inlet. However, no seabirds were reported killed in nets while fishing north of Chisdik Island.

Since 1990, official observers were placed on fishing boats in Prince William Sound and near the Copper River delta by the National Marine Fisheries Service (Mendenhall 1992). Observers reported mortalities of 36 and 25 Brachyramphus murrelets (84 percent Marbled Murrelets) in 1990 and 1991 (Wynne and others 1991, 1992). Extrapolating from observed fishing effort ( 3.9 percent and 3.5 percent nets observed in 1990 and 1991, respectively), then, as many as 923 and 714 murrelets may have been killed in gill nets in Prince William Sound in 1990 and 1991, respectively (Piatt and Naslund, this volume; Wynne and others 1991, 1992). Extrapolating 1990 data from mean catch per week data, Wynne and others (1991) estimated that 1,468 seabirds (95 percent confidence limits: 836-2,100) were killed in Prince William Sound in 1990, 97 percent of which were murrelets. Using this level of observed mortality in Prince William Sound, Piatt and Naslund (this volume) estimated annual mortality of 900,1100 , and 300 murrelets in Southeast Alaska, lower Cook Inlet, and along the Alaska Peninsula, respectively. Thus, the Alaska total may approach about 3,300 birds annually. However, it is likely that gill-net mortality rates differ in other areas, and it may be inappropriate to apply mortality rates from Prince William Sound elsewhere.

\section{Offshore Mortality}

Only one bird was reported killed in offshore high-seas drift-net fishery near the western Aleutian Islands through 1988 (DeGange 1978, DeGange and others 1985, Mendenhall 1992, Sealy and Carter 1984). However, murrelets do not usually occur far offshore, and there does not appear to be a significant problem in offshore fisheries.

\section{Outlook}

Additional observer programs are required to estimate total mortality of Marbled Murrelets and other seabirds throughout Alaska (see DeGange and others 1993). Effort should focus on American nearshore fisheries. In 1992, a United Nations resolution was passed which ended largescale pelagic driftnet fisheries, and this problem appears to be resolved for the time being. On the other hand, declining populations of Marbled Murrelets in Alaska cannot sustain the apparent levels of mortality in fishing nets. Great efforts should be made to reduce this mortality to much lower levels. Carter and Sealy (1984) pointed out two main methods of reducing gill-net mortality: (1) exclude fishing from areas with high murrelet densities at sea; and (2) allow daylight fishing only, since most murrelets are caught in nets at night. These solutions often may not apply to other seabird species. Another factor affecting levels of mortality is the future of these fisheries themselves, if fish stocks decline. However, gill-net fishing is likely to continue at high levels due to climbing value of salmon, limited entry of fishermen, and constant fishing pressure during openings. It is clear that gillnet mortality has the potential to be the greatest conservation problem for Marbled Murrelets in Alaska since it occurs annually throughout almost all at-sea foraging areas during the breeding season when murrelets are aggregated.

\section{British Columbia}

Large salmon gill-net fisheries have existed off the mouth of the Fraser River and in the Skeena River area since the turn of the century. In the 1950s, other large fisheries developed in other parts of British Columbia as the Fraser fishery declined, due to severe landslides and other problems upriver (Larkin and Ricker 1964). Small coastal fisheries expanded with the development of a mobile fleet of gill-net boats that travelled widely in relation to regulated openings. The British Columbia gill-net and seine fishery is broken down into 32 statistical areas and subdistricts (figs. 3 and 4). Certain portions of these areas are closed to net fishing. Like Alaska, open fishing periods vary considerably within areas and districts. Gill nets used have a $115-\mathrm{mm}$ minimum mesh size and vary from 100-500-m length maximum (Department of Fisheries and Oceans Canada 1978).

Historical documentation of gill-net mortality of murrelets and other seabirds in British Columbia is lacking. In 1979 , Marbled Murrelets were first reported in gill nets in Barkley Sound on the west coast of Vancouver Island in Statistical Area 23 (Carter and Sealy 1984, see below). It is likely that gill-net mortality has occurred widely and for many decades in British Columbia. Carter (unpubl. data) travelled widely around the coast of British Columbia while conducting seabird surveys in 1974-1977 (e.g., Campbell and others 1990, Vermeer and others 1983). From 4-7 July 1976, he noted two areas in the inside passage from Prince Rupert to Campbell River where many gill-net fishing boats and Marbled Murrelets co-occurred: (1) between Namu and Fairmile Inlet in Fitz Hugh Sound in Statistical Area 8 (fig. 3; see brief reference in DeGange and others 1993); and (2) in Johnstone Strait, west of Port Neville, in Statistical Area 12 (fig. 4). Mortality of murrelets probably has occurred in many areas of British Columbia, but has not been properly documented, except in Barkley Sound (below).

In 1979 and 1980, Carter and Sealy (1984) documented mortality of Marbled Murrelets in gill nets in Barkley Sound. A total of 28 dead Marbled Murrelets (including 26 breeding adults, 1 nonbreeder and 1 juvenile), 10 Common Murres and 1 Rhinoceros Auklet were recovered from 5 fishermen, a 


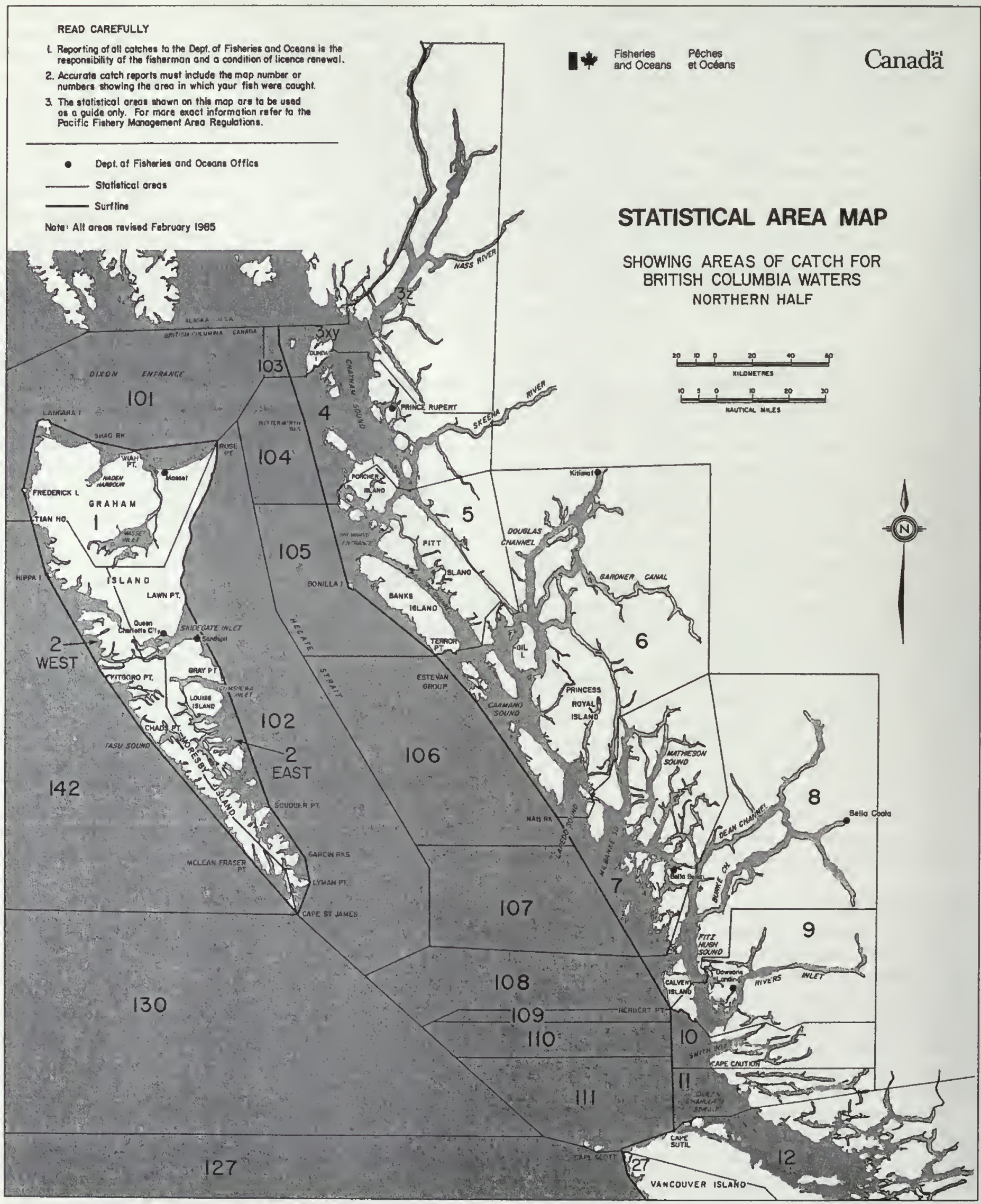

Figure 3-Fishing statistical areas in northern British Columbia (Source: Department of Fisheries and Oceans Canada). 


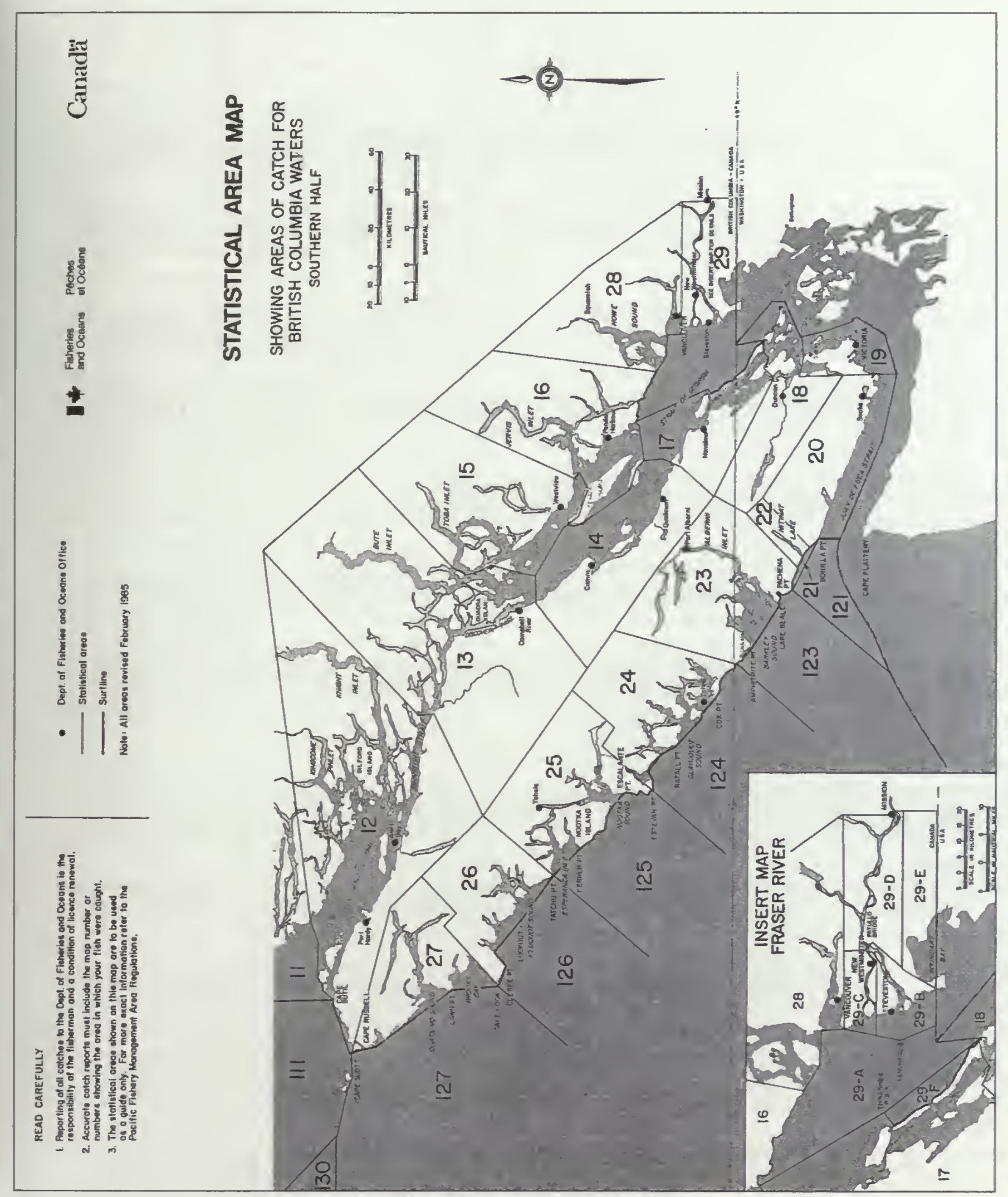

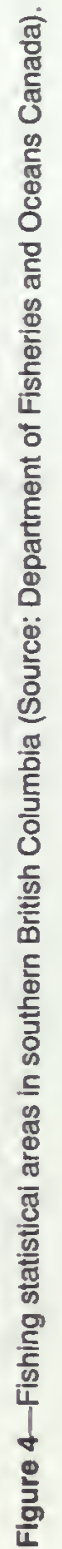


fisheries patrol boat, or were found floating in the water. All birds were killed between 11 June and 17 July in multifilament nylon nets, $135-375 \mathrm{~m}$ in length, less than $10 \mathrm{~m}$ in depth, with mesh sizes of $10-13 \mathrm{~cm}$. Most murrelets were killed at night off Cape Beale and south Trevor Channel near Bamfield where large numbers of boats (average about 70/census) fished in densities of $1-4$ boats $/ \mathrm{km}^{2}$. In the same area, Marbled Murrelets also occurred in large numbers (average about $266 /$ census) and in high densities (average $11.3 \mathrm{birds} / \mathrm{km}^{2}$ ). Murrelets also were observed in small flocks sitting and diving near nets during the day and may have been attracted to nets to feed on small fish. Other details on gill-net mortality in Barkley Sound can be found in Carter and Sealy (1984).

Carter and Sealy (1984) estimated a minimum of 175 250 murrelets were killed in 1980, representing 6.2 percent of the breeding population or 7.8 percent of the potential fall population. They pointed out that the long-term impacts of such mortality could be great, but the degree of impact depended upon continued high fishing effort in Barkley Sound. In August 1987 and December 1989, local people in Bamfield indicated that gill-net fishing had not occurred every year since 1980 (Carter, unpubl. data; see brief reference in DeGange and others 1993). Nonetheless, gill-net mortality. may have contributed to the decline ( $>50$ percent) of Marbled Murrelets that has been estimated in Trevor Channel and Barkley Sound between 1979-1980 and 1992-1994 (Burger, this volume b; Kelson, pers. comm.). However, a large decline (about 40 percent) also has occurred in Clayoquot Sound, further west on the west coast of Vancouver Island, where gill-net fishing does not occur (Kelson and others, in press). This decline in Barkley Sound probably reflects losses of old-growth forest habitat and mortality from the Nestucca oil spill, in addition to gill-net mortality (Burger, this volume b; Carter and Kuletz, this volume; Rodway and others 1992). The decline in Clayoquot Sound has been attributed mainly to the loss of nesting habitats in old-growth forests (Kelson and others, in press).

Marbled Murrelets were not recovered from purse seines in Barkley Sound in 1979-1982, although hundreds of Common Murres were recovered (Carter, unpubl. data in DeGange and others 1993). Similarly, murrelets were not observed among floating carcasses of Common Murres off Carmanah Point north of Cape Flattery on the west coast of Vancouver Island in Statistical Areas 20, 21, and 121 in August 1979 (Carter, unpubl. data in Vermeer and Sealy 1984; DeGange and others 1993). Marbled Murrelets were not reported among Ancient Murrelets (Synthliboramphus antiquus) and Rhinoceros Auklets killed in gill nets in July 1970-1971 and 1978 near Langara Island in the Queen Charlotte Islands (Statistical Area 1)(Vermeer and Sealy 1984). However, Marbled Murrelets were caught frequently on sports fishing lures near Campbell River in the 1960 s (Campbell 1967). In 1979-1980, sports fishermen in Barkley Sound also reported catching murrelets on sports fishing lures (Carter, unpubl. data).

To examine the potential for gill-net mortality of Marbled Murrelets in British Columbia, we have summarized recent data on gill-net and seine fishing effort for all Statistical
Areas in 1992 (table 1). Gill-net fishing occurred in almost all areas, but the largest gill-net fisheries ( $>2,000$ days fished) occurred in Statistical Areas 3, 4, 9, 10, 12, 14, 21, and 23 in the general vicinity of the Southeast Alaska border, Prince Rupert, Rivers Inlet, Smith Inlet, Queen Charlotte/Johnstone straits, Comox/Qualicum, Pachena Point to Bonilla Point, and Barkley Sound, respectively (see figs. 3 and 4). Marbled Murrelets occur throughout the coasts of British Columbia, including almost all fishing Statistical Areas (Campbell and others 1990, Rodway and others 1992, Vermeer and others 1983). At present, it is difficult to assess the overall degree of gill-net mortality in British Columbia, given incomplete knowledge of the at-sea distribution and population sizes. However, hundreds to thousands of murrelets may be killed annually due to the extensive nature of these fisheries throughout the province.

In five statistical areas $(3,4,9,10$, and 23$)$, extensive fishing effort occurred in July when large numbers of murrelets are feeding chicks at the nest, aggregate in high densities, and may be more susceptible to mortality (Carter and Sealy $1984,1990)$. Notably, Barkley Sound is among these earlier fisheries. Heavy gill-net fishing effort occurs mainly in the fall (August to November) in many Statistical Areas (table 1) which may avert high levels of mortality. Murrelets are undergoing a flightless pre-basic molt during this period and tend to occur in lower densities and closer to shore in many areas (Carter and Stein, this volume).

In 1992, extensive seine fishing effort tended to occur in conjunction with high gill-net fishing effort in most statistical areas (table 1). However, in Barkley Sound in 1979-1980, seine fishing occurred in a different area (with low densities of murrelets) than where gill-net fishing occurred, apparently to prevent interference. Seabird mortality (primarily Common Murres) in seine nets did occur in the fall in Trevor Channel when gill-net fishing had moved farther up the Alberni Canal and seine fishing occurred in central Trevor Channel (Carter and Sealy 1984).

Gill-net and seine fisheries should be examined throughout British Columbia for bycatch of Marbled Murrelets and other seabirds. Extensive mortality may be occurring annually in many areas. Efforts should be taken to reduce or stop such mortality immediately.

\section{Washington}

In Puget Sound and the Columbia River area (fig. 5), large gill-net and purse seine fisheries, which target several species of salmon, have existed since at least the 1940s. These fisheries peaked in the 1970s and 1980s and have recently declined because of reduced catch, increasing regulation, and declining salmon populations. These fisheries involve both native and non-native fishermen and are managed by state (Washington Department of Fish and Wildlife [WDFW]) and federal (National Marine Fisheries Service [NMFS]) agencies, native nations, and tribal (Northwest Tribal Fish Commission) and non-tribal (Bureau of Indian Affairs [BIA]) fishing groups. 
Table 1-Fishing effort in boat-days fished for gill-nets (G) and seine-nets (S) in various fishery statistical areas on the Northern and Southern coasts of British Columbia by month in 1992 (Source: Department of Fisheries and Oceans Canada 1992). No gill-or seinenet fishing occurred from Jonuary to March 1992

\begin{tabular}{|c|c|c|c|c|c|c|c|c|c|c|c|}
\hline \multirow[b]{2}{*}{ Statistical area $^{1}$} & \multirow[b]{2}{*}{ Fishing gear } & \multicolumn{9}{|c|}{ Month } & \multirow[b]{2}{*}{ Total effort } \\
\hline & & Apr & May & Jun & Jul & Aug & Sep & Oct & Nov & Dec & \\
\hline \multicolumn{12}{|l|}{$\begin{array}{l}\text { Northern } \\
\text { British Columbia }\end{array}$} \\
\hline \multirow[t]{2}{*}{1} & $\mathrm{G}$ & & & & 36 & 63 & 22 & & & & 121 \\
\hline & $s$ & & & & 76 & 123 & 40 & & & & 239 \\
\hline \multirow[t]{2}{*}{$2 E$} & G & & & & & & 762 & 2 & & & 764 \\
\hline & $S$ & & & & & & 259 & & & & 259 \\
\hline \multirow[t]{2}{*}{$2 W$} & G & & & & & 3 & 29 & & & & 32 \\
\hline & S & & & & 43 & 38 & & & & & 81. \\
\hline \multirow[t]{2}{*}{3} & G & & & 10 & 3,168 & 808 & 157 & & & & 4,143 \\
\hline & $S$ & & & & 738 & 563 & & & & & 1,301 \\
\hline \multirow[t]{2}{*}{4} & G & & & 5 & 8.681 & 3.700 & 211 & & & & 12.597 \\
\hline & S & & & & 145 & 251 & & & & & 396 \\
\hline \multirow[t]{2}{*}{5} & G & & & & 249 & 151 & & & & & 400 \\
\hline & $S$ & & & & 68 & 63 & & & & & 131 \\
\hline \multirow[t]{2}{*}{6} & G & & & & 5 & 19 & & & & & 24 \\
\hline & S & & & & 133 & 69 & & & & & 202 \\
\hline \multirow[t]{2}{*}{7} & G & & & & 32 & 46 & 178 & & & & 256 \\
\hline & S & & & & 5 & 10 & 109 & & & & 124 \\
\hline \multirow[t]{2}{*}{8} & G & & & 156 & $8+40$ & 175 & 21 & & & & 1,192 \\
\hline & S & & & & 737 & 127 & & & & & 864 \\
\hline \multirow[t]{2}{*}{9} & G & & & & 3,412 & 322 & & & & & 3,734 \\
\hline & $S$ & & & & & & & & & & 0 \\
\hline \multirow[t]{2}{*}{10} & G & & & & 5,676 & 365 & & & & & 6.041 \\
\hline & S & & & & & & & & & & 0 \\
\hline 30 & G & & & & & & & & & & 0 \\
\hline & $S$ & & & & 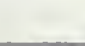 & _. & 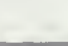 & 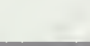 & & & 0 \\
\hline Taku River ${ }^{2}$ & G & & & & 25 & 180 & 121 & 1 & & & 327 \\
\hline & $\mathrm{s}$ & & & & & & & & & & 0 \\
\hline Stikine River ${ }^{2}$ & G & & & & 150 & 80 & 30 & & & & 260 \\
\hline & $S$ & & & & & & & & & & 0 \\
\hline $\begin{array}{l}\text { Southern } \\
\text { British Columbia }\end{array}$ & & & & & & & & & & & \\
\hline 11 & G & & & & 1 & 1.884 & & & & & 1.885 \\
\hline & $\mathrm{S}$ & & & & & & & & & & 0 \\
\hline 12 & $\mathbf{G}$ & & & 5 & 32 & 3,695 & 923 & 2,279 & 7 & & 6,941 \\
\hline & $\mathbf{S}$ & & & & & 866 & 294 & 306 & 39 & & 1,505 \\
\hline 13 & G & & & & & 285 & 228 & 951 & & & $1 .+64$ \\
\hline & s & & & & & 281 & 154. & 369 & & & 804 \\
\hline 14 & G & & & & & & & 980 & 1,378 & & 2,358 \\
\hline & $\mathbf{S}$ & & & & & & & & 186 & & 186 \\
\hline 15 & G & & & & & & & & & & 0 \\
\hline & s. & & & & & & & & & & 0 \\
\hline 16 & G & & & & & 900 & & 68 & 43 & & 1,011 \\
\hline & $S$ & & - & & & 70 & & 1 & & & 71 \\
\hline 17 & G & & & & & & 301 & 41 & & & $3+2$ \\
\hline & S & & & & & & & & & & 0 \\
\hline 18 & G & & & & & & & 2 & 954 & 65 & 1,021 \\
\hline 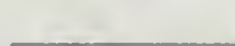 & $S$ & & & & & & & & & & 0 \\
\hline 19 & G & & & & & & & & & & 0 \\
\hline & $s$ & & & & & & & & & & 0 \\
\hline 20 & G & & & 8 & 70 & 1,607 & & 4 & & & 1,689 \\
\hline & $S$ & & & & & 1,185 & & & & & 1,185 \\
\hline 21 & G & & & & & 3 & 2 & 2,620 & & & 3.625 \\
\hline- & S & & & & & & & 1,475 & & & 1,475 \\
\hline
\end{tabular}


Table 1-continued

\begin{tabular}{|c|c|c|c|c|c|c|c|c|c|c|c|}
\hline \multirow[b]{2}{*}{ Statistical area ${ }^{1}$} & \multirow[b]{2}{*}{ Fishing gear } & \multicolumn{9}{|c|}{ Month } & \multirow[b]{2}{*}{ Total effort } \\
\hline & & Apr & May & Jun & Jul & Aug & Sep & Oct & Nov & $\overline{D e c}$ & \\
\hline 22 & G & & & & & & & & & & 0 \\
\hline \multirow[t]{2}{*}{23} & G & & & & 2,560 & 79 & 3 & & & & 2,625 \\
\hline & $s$ & & & & 21 & $18 \mathrm{t}$ & & & & & 202 \\
\hline \multirow[t]{2}{*}{24} & G & & & & & & & & & & 0 \\
\hline & $S$ & & & & & & & & & & 0 \\
\hline \multirow[t]{2}{*}{25} & G & & & & 2 & 4 & 523 & 683 & & & 1,212 \\
\hline & 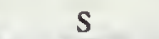 & & & & & & & & & & 0 \\
\hline \multirow[t]{2}{*}{26} & G & & & & & & & & & & 0 \\
\hline & s & & & & & & & & & & 0 \\
\hline \multirow[t]{2}{*}{27} & G & & & & & 1 & & & & & 1 \\
\hline & $s$ & & & & & & & & & & 0 \\
\hline \multirow[t]{2}{*}{ Fraser River ${ }^{3}$} & G & 14 & 20 & 31 & 104 & 2,446 & 56 & 526 & 53 & 7 & 3.257 \\
\hline & s & & & & & & & & & & 0 \\
\hline \multirow[t]{2}{*}{ Total } & G & 14 & 20 & 240 & 25,198 & 16,757 & 3,146 & 8,416 & 2,476 & 72 & 56,339 \\
\hline & $s$ & 0 & 0 & 0 & 1,966 & 3,827 & 856 & 2,151 & 225 & 0 & 9,025 \\
\hline
\end{tabular}

'See figs. 3 and 4 for locations of statistical areas

${ }^{2}$ These rivers reach the ocean in southeastern Alaska

${ }^{3}$ Includes areas 28, 29A-E in fig. 4

Seabirds have been known to die in these fisheries for some time, although there has been little documentation of the degree of mortality (DeGange and others 1993, Speich and Wahl 1989, Wahl 1981). Observer programs for marine mammal bycatch in certain fisheries have been in place since the 1970s, but there was little focus on seabirds. Speich and Wahl (1989) reported that Western Grebes (Aechmophorus occidentalis), Common Murres, and Marbled Murrelets were frequently killed, based on reports by local fishermen (Speich, pers. comm.; Wahl, pers. comm.). Because significant mortality of murrelets was recorded in nearby Barkley Sound, British Columbia (see above), it is reasonable to assume that murrelet mortality occurs in Washington waters also.

Marbled Murrelets occur throughout most of northern Puget Sound and the San Juan Islands where the bulk of the Washington breeding population occurs (Speich and others 1992; Speich and Wahl, this volume; Wahl and others 1981). Recent concern about the potential impacts of net fisheries on Marbled Murrelets in Washington prompted the U.S. Fish and Wildlife Service, U.S. Department of Interior, NMFS, and BLA to develop additional tribal and non-tribal fishery observer programs in 1993 to better assess impacts to seabirds, especially Marbled Murrelets (see U.S. Fish and Wildlife Service $1993 \mathrm{~b}, \mathrm{c}$ ). Information on seabird mortality from non-native fisheries in 1993 is just now becoming available, whereas some 1993 data from tribal fisheries have not been released. Below, we summarize what information is available to date, as collated for the Marbled Murrelet Recovery PIan (U.S. Fish and Wildlife Service, in press):
Pacific Salmon Commission - In 1993, a test fishery using monofilament gill nets was conducted at the south entrance to the San Juan Islands (off San Juan and Lopez islands) by the Pacific Salmon Commission, a Canadianbased fisheries group (Craig and Cave 1994). Fishing occurred between dusk and dawn from 23 June to 7 August. One murrelet was caught on 4 July 1993 off Iceberg Point, Lopez Island. Another murrelet was caught in a gill net during test fishing in this area in 1990, but no other details were provided. Most test fishing occurred further offshore than where most murrelets were observed foraging. Thus, more murrelets may be killed than indicated by this sample. A total of 64 Common Murres and 9 Rhinoceros Auklets also were killed in 1993. A similar program will occur in 1994.

Washington Department of Fish and Wildlife - In 1993, a limited gill-net monitoring program for non-tribal fisheries was conducted by WDFW in certain parts of Puget Sound where high concentrations of seabirds occur but few murrelets. A preliminary report is presented in a Biological Assessment (WDFW 1994). No murrelets were encountered, but 42 dead birds, mainly Common Murres, were recorded. A more extensive program is planned for 1994.

Purse Seine Vessel Owners Association - In 1993, two Marbled Murrelets among about 50 seabirds were noted caught during the Seabird Observer Program for the Non-Tribal Purse Seine Fishery (Natural Resources Consultants 1993). A total of 702 net sets were observed (about 3.9 percent of all non-tribal purse seine effort) in many areas from the Canadian border, through the San Juan Islands, to southern Puget Sound 
and Hood Canal. Common Murres and Rhinoceros Auklets were the most frequently caught species. On 25 August 1993, two murrelets were captured at $0657 \mathrm{hrs}$ in the same purse seine set about $500 \mathrm{~m}$ off Village Point, Lummi Island, in the San Juan Islands. Both birds were captured alive and released within 10-15 minutes. Almost all seabirds captured during this program also were released shortly after capture. A similar program is envisioned for 1994.

Point Roberts Tribal Fishery - In February and March 1993, a small tribal fishery (involving 10 boats) for herring occurred in the Point Roberts/Semiahmoo Bay area. Observers reported no entanglements or mortalities of murrelets (BIA 1993).

Beached Birds - Kaiser (1993) reported two dead juvenile murrelets and hundreds of other seabirds, especially Common Murres and Rhinoceros Auklets, washed ashore in Boundary Bay, British Columbia, in August 1993. Boundary Bay is located just across the border from areas where high numbers of murrelets and gill-net fishing areas co-occur.

Grays Harbor - No Marbled Murrelets have been recorded as killed in gill nets in Grays Harbor during observer programs in summer and fall 1991, 1992, and 1993 for non-tribal fisheries (Jefferies and Brown 1993, WDFW 1994). Between 4 and 10 percent of nets were monitored each season and year. Bycatch included Common Murres, Rhinoceros Auklets, and loons. Some unidentified alcids and birds were recorded which may have included murrelets.

Willapa Bay - No Marbled Murrelet bycatch was observed in Willapa Bay during observer programs in summer and fall 1991, 1992, and 1993 for non-tribal fisheries (Jefferies and Brown 1993, WDFW 1994). Between 1 and 13 percent of nets were monitored each season and year. Bycatch included Common Murres, cormorants, loons, grebes, and other alcids. Some unidentified alcids and birds were recorded which may have included murrelets.

Columbia River - No Marbled Murrelets have been recorded as killed in gill nets in the Columbia River during observer programs in winter 1991, 1992 and 1993 (Jefferies and Brown 1993). Bycatch included Common Murres, cormorants, Western and unidentified grebes, and Surf Scoters (Melanitra perspicillata). Some unidentified alcids and birds were reported which may have included murrelets.

With available information, it is not yet possible to accurately determine the extent of mortality on Marbled Murrelets in Washington. U.S. Fish and Wildlife Service (1993b,c) stated in a biological opinion that a mortality of less than ten murrelets recovered from nets during the observer programs would not jeopardize the continued existence of the Marbled Murrelet in Washington. Additional information on mortality must be derived from tribal and non-tribal fisheries, especially within and north of the San Juan Islands, northern Puget Sound, along the northern side of the Olympic Peninsula, and in the Cape Flattery area.

It is likely that significant mortality of murrelets is occurring and has occurred in northern Puget Sound and around the San Juan Islands. The large amount of fishing effort that occurs throughout this area is likely to cause mortality on the scale of tens to hundreds of murrelets at a minimum. Mortality extrapolations using 1979-1980 mortality rates in relation to fishing effort and murrelet densities from Trevor Channel in Barkley Sound, British Columbia (Carter, unpubl. data; Carter and Sealy 1984), in association with murrelet densities and fishing effort in various fishing areas in northern Puget Sound and around the San Juan Islands (Speich and others 1992; Speich and Wahl, this volume; Wahl and others 1981), yielded potential annual mortality estimates in the high hundreds (Wilson, pers. comm.). However, fishing effort is more intensive and murrelet densities are lower in northem Puget Sound which may act to produce different mortality rates than observed in Barkley Sound. Observer programs should be continued and augmented to better describe gill-net mortality in northern Washington.

\section{Oregon}

Gill-net fishing has been prohibited in estuaries, bays and along the outer coast of Oregon since 1942 (Nelson and others 1992). No net-caused mortalities of murrelets are known in Oregon.

\section{California}

Nearshore gill- and trammel-net fisheries have existed in Central and Southern California since the early 1900s, and increased dramatically in size during the 1970s and 1980s. These fisheries have targeted a wide array of fish, including halibut and flounder (Bothidae and Pleuronectidae), croaker (Sciaenidae), shark, rockfish (Scorpaenidae), and others. The catch from these fisheries peaked during the 1980 s and early 1990s, but has since declined because of regulations aimed at reducing mortality of marine birds and mammals. These fisheries are managed primarily by the California Department of Fish and Game (CDFG) which operated a bycatch monitoring program from 1983 to 1989. This observer program has been continued by NMFS from 1990 to 1994. These fisheries are managed through a series of CDFG fishing regions (fig. 5).

Northem California - Gill-net fishing is prohibited north of Point Reyes, Marin County.

Central California - Small numbers of birds were killed in gill nets before the late 1970's (Sowls and others 1980). From 1979 to 1987, more than 70,000 Common Murres were killed in regions 3 and 4 (fig. 5), mainly in the summer and fall, which contributed to a severe decline in the local breeding population (Carter and others 1992, DeGange and others 1993, Takekawa and others 1990). Thousands of other seabirds including Marbled Murrelets, and marine mammals also were killed. Carter and Erickson (1988, 1992; also see Sealy and Carter 1984) summarized known evidence of mortality of murrelets from this fishery. Three birds were noted in the monitoring program: (1) two birds in Monterey Bay on 3 


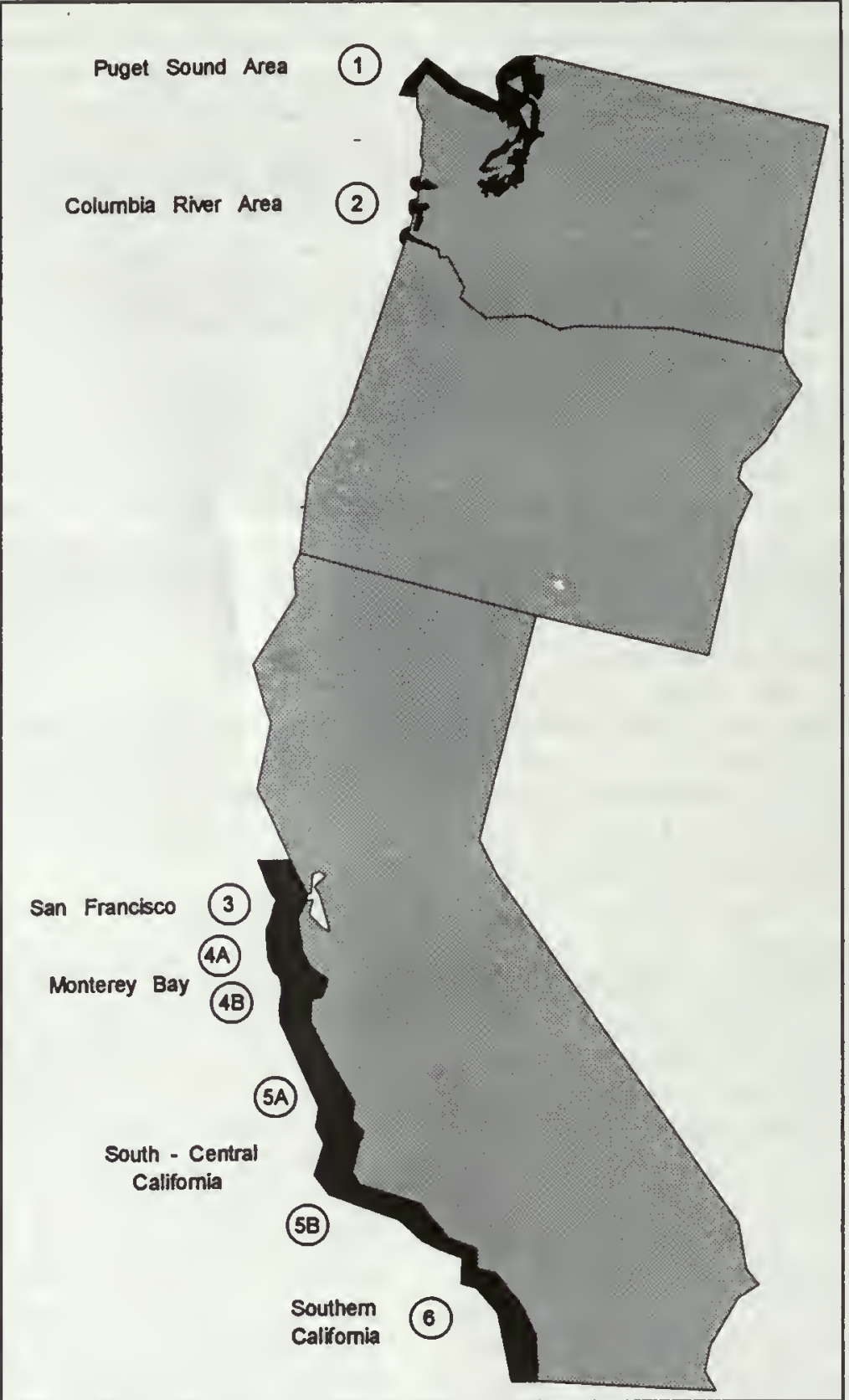

Figure 5-Locations of gill-net fisheries along the coasts of California, Oregon and Washington. Numbers refer to fishing areas referred to in the text. In central and southern California, numbers $3,4,5$, and 6 refer to California Department of Fish and Game fishing districts D10, D17, D18, and D19/D20, respectively.

December 1981; and (2) one bird off San Gregorio Creek, San Mateo County, on 21 November 1986. More than 100 dead murrelets also were found on beaches in the Monterey Bay area (regions $4 \mathrm{~A}$ and $4 \mathrm{~B})($ fig. 5) during the winter of 1980-1981. Carter and Erickson $(1988,1992)$ estimated that at least 150 to 300 birds were killed from 1979 to 1987.

A series of small, patchwork fishing closures were implemented by CDFG from 1982 to 1984 in an attempt to reduce seabird mortality. These efforts proved to be ineffective. Following consideration of the problem for several years (Atkins and Heneman 1987, Salzman 1989), severe restrictions were implemented by CDFG in 1987 which closed waters less than 40 fathoms $(80 \mathrm{~m})$ in regions 3 and 4A (fig. 5) to gill-net fishing. These regulations eliminated most fishing in these areas, although a small gill-net fishery for rockfish still exists outside of the Farallon Islands. Fishing was further restricted in the Monterey Bay and south-central coast area in 1990 to further reduce mortality of marine mammals (especially sea otters Enhydra lutra) and seabirds. Fishing was prevented in waters shallower than 30 fathoms $(60 \mathrm{~m})$, as well as in much of inner Monterey Bay, in regions 4B and 5A (fig. 5).

Most murrelets from the Central California population (that nest in San Mateo and Santa Cruz counties) forage 
throughout the year in waters less than $80 \mathrm{~m}$ in depth in regions 3 and $4 A$, or in waters less than $60 \mathrm{~m}$ in region $4 B$ (fig. 5). Thus, 1987 and 1990 CDFG regulations should protect most birds from future gill-net mortality. No mortalities of Marbled Murrelets that could be related to gill-net fishing have been recorded since 1987 . However, murre mortality has continued in winter in northem Monterey Bay, especially south of Año Nuevo State Reserve between Waddell Creek and Santa Cruz (near the border of regions $4 A$ and $4 B$ ). Westfall (pers. comm.) also reported mortality of several Marbled Murrelets on sports fishing lines near Santa Cruz. This mortality is important because of the small size and poor health of the central California population (Carter and Erickson 1992).

Southern California - From 1983 to 1989, several thousand cormorants (mainly Brandt's Cormorants, Phalacrocorax penicillatus) probably were killed in gill-net fisheries in Southern California (Carter, unpubl. data). Mortalities were recorded both near the northern Channel Islands, as well as along the mainland coast, in regions $5 \mathrm{~B}$ and 6 . Because of concerns by several interest groups, gill-net fishing was prohibited in state waters within 3 miles of shore in these regions by CDFG regulations in January 1994, except for some areas near the northem Channel Islands, where fishing is still allowed outside of 1-2 miles from islands.

No mortality of Marbled Murrelets that could be attributed to gill-net and trammel-net fishing has been recorded south of Monterey Bay. Small numbers of murrelets occur in nearshore waters in this area during winter. These birds probably represent some limited southward dispersal of birds in the non-breeding season from the Central California breeding population. Marbled Murrelets have not been recorded at the Channel Islands.

\section{Discussion}

Mortality in gill nets may be one of the greatest conservation problems facing the Marbled Murrelet. In Alaska and British Columbia, levels of mortality need to be better established, but available evidence indicates that several thousands are killed annually. The large numbers of murrelets killed in nets in Alaska and British Columbia has not been fully appreciated in previous reviews (DeGange and others 1993, Mendenhall 1992, Rodway and others 1992, Sealy and Carter 1984). Since these levels of mortality probably have been focused on certain populations over the past few decades, gill-net mortality alone may have already been an important factor of the decline in Alaska and British Columbia populations. Coupled with the loss of old-growth forest nesting habitats and mortality from oil spills which may affect the same populations, it is clear that survival of populations in many areas in the center of its range may be difficult if such problems continue. Lower numbers of birds killed in central California and Washington also have had relatively large impacts on these small populations and may have contributed significantly to their potential future extirpation (see Carter and Erickson 1992).
Even the very few dead murrelets reported anecdotally or from observer programs probably are significant because few people (aside from fishermen) could report mortalities, carcasses are discarded shortly after death and either sink or are taken by predators soon thereafter, fishermen typically do not divulge knowledge of such mortality due to fear of affecting their livelihoods, and only a small fraction of nets are examined in certain localities during monitoring programs. For example, in Monterey Bay, California, only two birds were noted in the observer program, whereas more than 100 were found on nearby beaches and 150-300 birds were estimated killed over several years in the early 1980s (Carter and Erickson 1992). Similarly, Carter and Sealy (1984) recovered only 28 dead murrelets, but fishermen reported catching larger numbers and a minimum of 175-250 murrelets were estimated to have been killed in 1980 in Barkley Sound, British Columbia. We feel that the large size of gill-net fisheries, and their extensive coverage of almost all coastal areas throughout the range of the Marbled Murrelet, places gill-net mortality among the most significant problems for the species.

We suggest that a detailed examination of Marbled Murrelet and other seabird mortality in all coastal gill-net and seine fisheries is required throughout the range of the murrelet, especially in Alaska, British Columbia, and Washington. It is likely that relatively minor modifications can be made to gill-net fisheries to vastly reduce mortality quickly without significant impact to fisheries, by either stopping fishing in small at-sea areas where murrelets are aggregated, preventing night fishing in certain areas, or both. Similarly, mortality or injury in seine nets probably can be greatly reduced by ensuring that spaces occur between floats along the top of the nets which allow murrelets and other seabirds to escape from encircled nets. If populations become (or are) too small, even low levels of gill-net and seine-net mortality or injury will have or has a greater relative effect. Under these conditions, it may be necessary to stop all mortality by considering more drastic changes, including stopping gill-net fishing in much larger areas, changing fishing methods altogether, or both. To avoid severe confrontation in the future, it is clear that this issue should be addressed immediately.

\section{Acknowledgments}

J. Engbring (U.S. Fish and Wildlife Service), C. Haugen, M. Vojkovich, and P. Wild (California Department of Fish and Game), and D. McMullin, S. Benoit, and K. Lorette (Department of Fisheries and Oceans Canada) provided many valuable reports and comments. Additional information was provided by R. Brown, T. Clockson, A.R. DeGange, C. Haugen, S. Jefferies, K. Kuletz, G.S. Miller, J.F. Piatt, J. Scordino, S.G. Sealy, S. Speich, T. Wahl, P. Wild, and J. Wilson. G. McChesney and L.L. Long assisted figure preparations. This summary has benefitted from reviews and editing by A.R. DeGange, L.L. Long, J.F. Piatt, C.J. Ralph, and M.G. Raphael. 



\section{Abundance, Distribution, and Population Status of Marbled Murrelets in Alaska}

\author{
John F. Piatt' Nancy L. Naslund ${ }^{2}$
}

Abstract: Ship-based surveys conducted throughout Alaska during the 1970's and 1980's, and more recent small boat surveys conducted in the northern Gulf of Alaska, suggest that about 280,000 murrelets reside in Alaska during summer. Most Marbled Murrelets are concentrated offshore of large tracts of coastal coniferous forests in southeast Alaska, Prince William Sound, and the Kodiak Archipelago. About 1-3 percent of murrelets breed wholly outside of forested areas in Alaska, and these presumably all nest on the ground. At sea, murrelets tend to occupy sheltered waters of bays, fiords, and island straits, and often aggregate near large river outflow's or tide rips. Small boat surveys of Prince William Sound and Christmas Bird Count trends suggest that Marbled Murrelet populations in Alaska declined by about 50 percent between 1972 and 1992. Population declines may have resulted from cumulative effects of oil pollution, gill netting, logging of old-growth breeding habitat, and natural changes in the marine environment. The Exxon Valdez oil spill killed an estimated 8,400 murrelets in 1989 , or about 3 percent of the Alaska population. The toll from chronic pollution is unknown. About 3300 murrelets ( 89 percent adult) die annually in fishing nets in Alaska - a sustained adult mortality rate of 1.5 percent per annum. The extent or effect on murrelets of logging in Alaska are unknown. While only 7 percent of the old-growth has been harvested in the Tongass National Forest, about 40 percent of the highly productive old-growth in the forest has already been logged. A decline in forage fish populations in the Gulf of Alaska during the last 20 years may account for reduced breeding success and population size of several seabird species, including murrelets. Murrelet populations should be sensitive to small increases in adult mortality from the above factors because production by murrelets is low and must therefore be balanced by a low annual adult mortality rate.

The North American subspecies of the Marbled Murrelet (Brachyramphus marmoratus marmoratus) breeds primarily in old-growth coniferous rainforests along the west coast from California to Alaska. Populations of this subspecies range as far west as the Aleutian Islands and north into the Bering Sea. The Asian subspecies B. m. perdix occurs from the Commander Islands and west throughout the Sea of Okhotsk (Ewins and others 1993). However, this subspecies is sufficiently distinct morphologically and genetically from the North American subspecies to be considered a separate species (the "Long-billed Murrelet"; Friesen and others 1994a; Piatt and others 1994). Thus, Alaska contains the extreme western and northern range of the Marbled Murrelet in North America.

${ }^{1}$ Research Biologist, Alaska Science Center, National Biological Service, U.S. Department of Interior 1011 East Tudor Road, Anchorage, AK 99503

¿Wildlife Biologist, Migratory Bird Management, U.S. Fish and Wildlife Service, U.S. Deparment of the Interior, 1011 East Tudor Road, Anchorage, AK 99503
The bulk of the North American population of Marbled Murrelet resides in Alaska. Population estimates have ranged from hundreds of thousands to millions (Ewins and others 1993), but recent estimates suggest that about 250,000 murrelets reside in Alaska (Mendenhall 1992; Piatt and Ford 1993). In this chapter we review information on the abundance and distribution of Marbled Murrelets in Alaska, and the status of populations. Except for the congeneric Kittlitz's Murrelet ( $B$. brevirostris), all other auks breed in colonies and nest on the ground-mostly on predator-free islands. In Alaska, a small proportion of Marbled Murrelets also breed on the ground, usually on rocky or sparsely vegetated inland slopes (Day and others 1983; Marks, pers. comm.; Mendenhall 1992).

\section{Abundance and Distribution}

\section{Survey Methods}

Whereas most surface-nesting seabirds may be censused conveniently at their colonies, population $\mathrm{f}$ : imates of burrownesting, nocturnal, and forest-nesting eabirds are more difficult to obtain. Murrelet population estimates are based solely on counts of birds at sea (Carter and Ericksen 1992; Klosiewski and Laing 1994; Mendenhall 1992; Nelson and others 1992; Piatt and Ford 1993; Rodway and others 1992, in press; Sealy and Carter 1984; Speich and others 1992). A wide variety of observation platforms and sampling methods have been used to collect data and extrapolate abundancewhich makes it difficult to pool or compare data from adjacent geographic areas.

No method for censusing murrelets at sea has ever been ground-truthed for accuracy. Studies of at-sea behavior of murrelets in British Columbia (Carter and Sealy 1990; Rodway and others, in press; Sealy and Carter 1984), southeast Alaska (Speckman and others 1993), and Oregon (Varoujean and Williams, this volume; Strong and others, this volume) reveal that time of day and season, tide state, and weather conditions are all important variables influencing murrelet aggregation behavior, distribution, and detectability. High temporal variability in murrelet abundance at sea undermines the confidence we may have in the accuracy of absolute population estimates-although statistically precise $( \pm 15-30$ percent) measures of abundance are available in some areas (e.g., Barkley Sound, Carter and Sealy 1990, Sealy and Carter 1984; Prince William Sound, Klosiewski and Laing 1994).

Surveys conducted at smaller spatial or temporal scales than those over which movements of birds occur may underestimate populations (Rodway and others, in press). The detectability of murrelets declines with distance from the observer and rough sea conditions (Kuletz 1994), and 
these factors may also lead to underestimates of at-sea densities (Ralph and Miller, this volume). Larger scale boat-based surveys may overestimate populations as birds move within the survey area and are recounted (Rodway and others, in press). Continuous counting of flying birds during boatbased surveys may significantly overestimate densities (Gaston and others 1987; Varoujean and Williams, this volume; Strong and others, this volume). Aerial surveys provide a good synoptic picture of distribution, but may underestimate densities at sea (Strong and others, this volume).

\section{Murrelet Distribution}

Piatt and Ford (1993) used ship-based census data collected under the Outer Continental Shelf Environmental Assessment Program (OCSEAP) to assess the abundance and distribution of regional murrelet populations (figs. 1 and
2 , table 1). The relative distribution of important murrelet habitat revealed by OCSEAP data is supported by fine-scale surveys conducted in different areas of Alaska (Agler and others 1994, Forsell and Gould 1981, Klosiewski and Laing 1994, Kuletz 1994, Piatt 1993).

Although murrelets range widely in Alaska, they are concentrated during the breeding season in three main areas: the Kodiak Archipelago, Prince William Sound, and the Alexander Archipelago (figs. 1 and 2, table 1). At a smaller scale, areas of concentration (fig. 2) include in the Alexander Archipelago: Stephens Passage, Lynn Canal, Sumner Strait, Chatham Strait, Icy Strait, and Glacier Bay; on the outer coast: Yakutat Bay, Icy Bay; all of western Prince William Sound; along the south Kenai Peninsula; in lower Cook Inlet: Kachemak Bay and Kamishak Bay; in the Kodiak Archipelago: around Afognak Island, in Chiniak Bay and

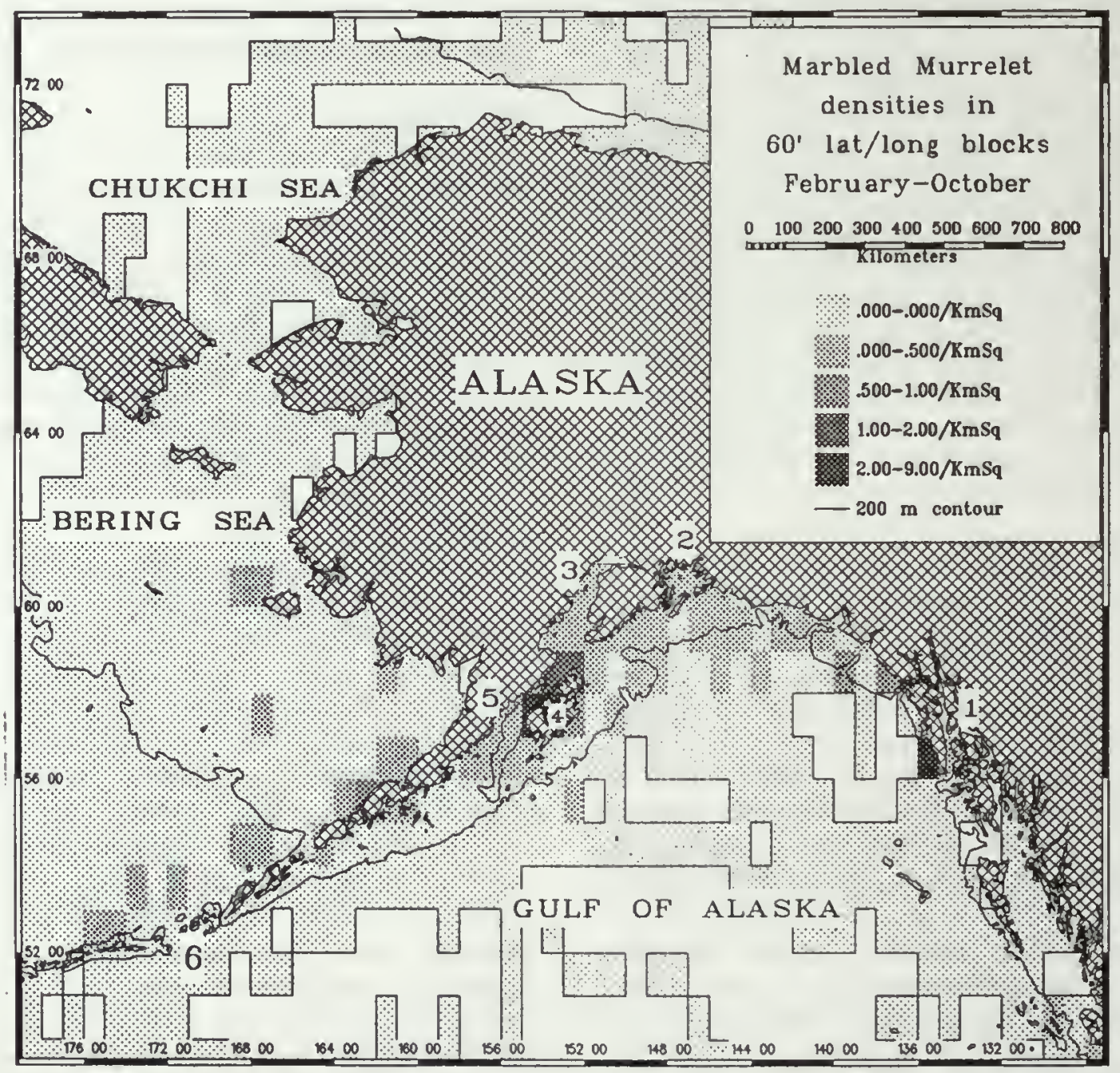

Figure 1-Distribution of Marbled Murrelets and survey coverage in 60' latitude-longitude blocks in Alaska (from Piatt and Ford 1993). Data compiled for the months of February - October. Murrelet densities are scaled geometrically. Similar analyses for breeding and non-breeding seasons were used for estimating population sizes (table 1). Numbered areas are: 1-Southeast Alaska (Alexander Archipelago), 2- Prince William Sound, 3- Cook Inlet, 4- Kodiak Archipelago, 5- Alaska Peninsula, 6- Aleutian Islands. 


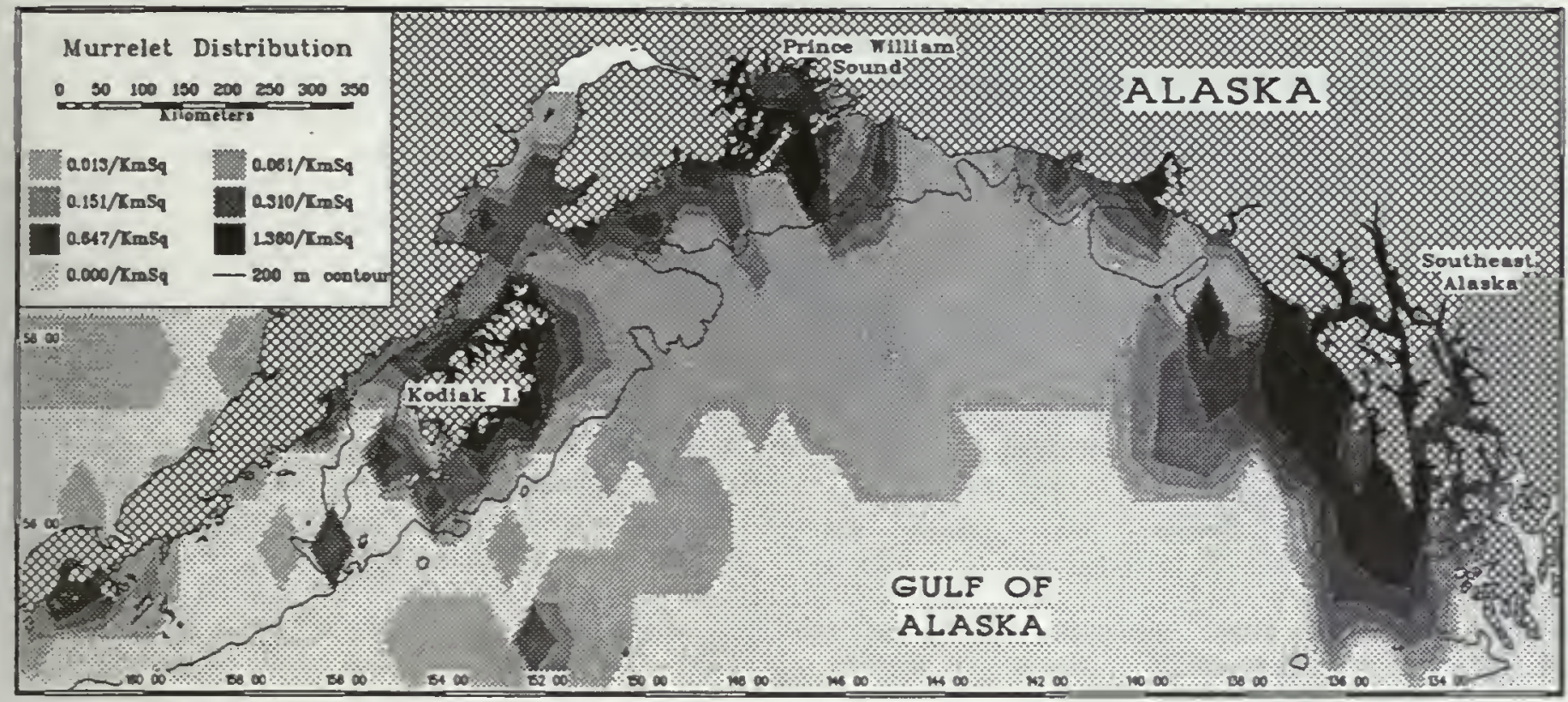

Flgure 2-Distribution of Marbled Murrelets in the northem Gulf of Alaska (from Piatt and Ford 1993). Density contour polygons calculated from data grouped in $30^{\prime}$ latitude-longitude blocks and scaled arithmetically.

Table I-Abundance of Marbled Murrelets in different marine areas of Alaska during breeding (May-July) and nonbreeding (February-April and August-October) periods as estimated by extrapolation from OCSEAP data. From Piats and Ford (1993)

\begin{tabular}{|c|c|c|c|c|c|}
\hline \multirow[t]{3}{*}{ Marine area } & \multirow[t]{3}{*}{$\mathrm{Km}^{2}$} & \multicolumn{4}{|c|}{ Estimated number of murrelets } \\
\hline & & \multicolumn{2}{|c|}{ Breeding } & \multicolumn{2}{|c|}{ Non-breeding } \\
\hline & & $n$ & pet. & $n$ & pet. \\
\hline \multicolumn{6}{|l|}{ Gulf of Alaska" } \\
\hline Offshore $(50-300 \mathrm{~km})$ & 488,000 & 9.820 & 6.4 & 30,000 & 18.0 \\
\hline Alexander Archipelago & 48,200 & 96,200 & 62.9 & 87,100 & 52.3 \\
\hline Northern Gulf Coast" & 83,000 & 21,200 & 13.9 & 12,800 & 7.7 \\
\hline Kodiak Archipelago & 30,300 & 21,900 & 14.3 & 27,800 & 16.7 \\
\hline Alaska Peninsula & 40,500 & 1,580 & 1.0 & 2,420 & 1.5 \\
\hline Aleutian Islands ( $<100 \mathrm{~km})$ & 95,000 & 370 & 0.2 & 1,840 & 1.1 \\
\hline \multicolumn{6}{|l|}{ Bering Sea } \\
\hline Alaska Penninsula ( $50 \mathrm{~km}$ ) & 27,700 & 1,300 & 0.8 & 3,380 & 2.0 \\
\hline Bering Shelf & 570,000 & 660 & 0.4 & 1,130 & 0.7 \\
\hline Chukchi, Beaufort Sea & 685.000 & $\ldots$ & 0.0 & -0 & 0.0 \\
\hline TOTAL & $2,067,700$ & 153,030 & & 166,470 & \\
\hline \multicolumn{6}{|l|}{ Survey Effort } \\
\hline 60 blocks sampled & & 510 & & 533 & \\
\hline Transect distance $(\mathrm{km})$ & & 18,224 & & 22,400 & \\
\hline
\end{tabular}

- Area within ca. $50 \mathrm{~km}$ of coast unless otherwise stated.

" Population size underestimated, see texL. 
Sitkadilak Strait; along the Alaska Peninsula: Halo Bay, Kukak Bay, Wide Bay, and the Shumagin Islands. In the Aleutians, small numbers are found at Unalaska, Adak, and Attu islands, and other large islands in the chain.

Murrelets are most abundant in sheltered "inside waters", which includes bays, fiords, and island passes located in coastal areas of the northern Gulf of Alaska (fig. 2). The distribution of the majority of murrelets surveyed at sea coincides spatially with the terrestrial distribution in Alaska of coastal old-growth coniferous forests - especially Sitka spruce (Picea sitchensis) and hemlock (Tsuga spp.) (USDA Forest Service Alaska Region 1991, 1992; Viereck and Little 1972), which are used for nesting by murrelets (Naslund and others 1993, Quinlan and Hughes 1990). Ship-based studies of lower Cook Inlet conducted in 1992 (Piatt 1993) suggest that waters subject to strong tidal mixing provide poor foraging habitat for murrelets compared to stratified coastal waters (fig. 3). Marbled Murrelet distribution in summer may be determined largely by the spatial co-occurrence of terrestrial breeding habitat and suitable marine foraging areas.

During the breeding season, low densities of murrelets (possibly nonbreeders) may be found in outside waters ( $>50$ $\mathrm{km}$ from shore). Excluding these offshore birds during the breeding season, Piatt and Ford (1993) found that only 3.1 percent of all murrelets were distributed outside the range of coastal coniferous forests in Alaska (i.e., west of and including the Alaska Peninsula). It appears that murrelets disperse to the south and west in winter, as numbers decline in sheltered northern Gulf waters, but increase offshore, along the Alaska Peninsula, and in the Aleutians (table 1). Murrelet populations in Prince William Sound diminish by about 75 percent in winter (Klosiewski and Laing 1994).

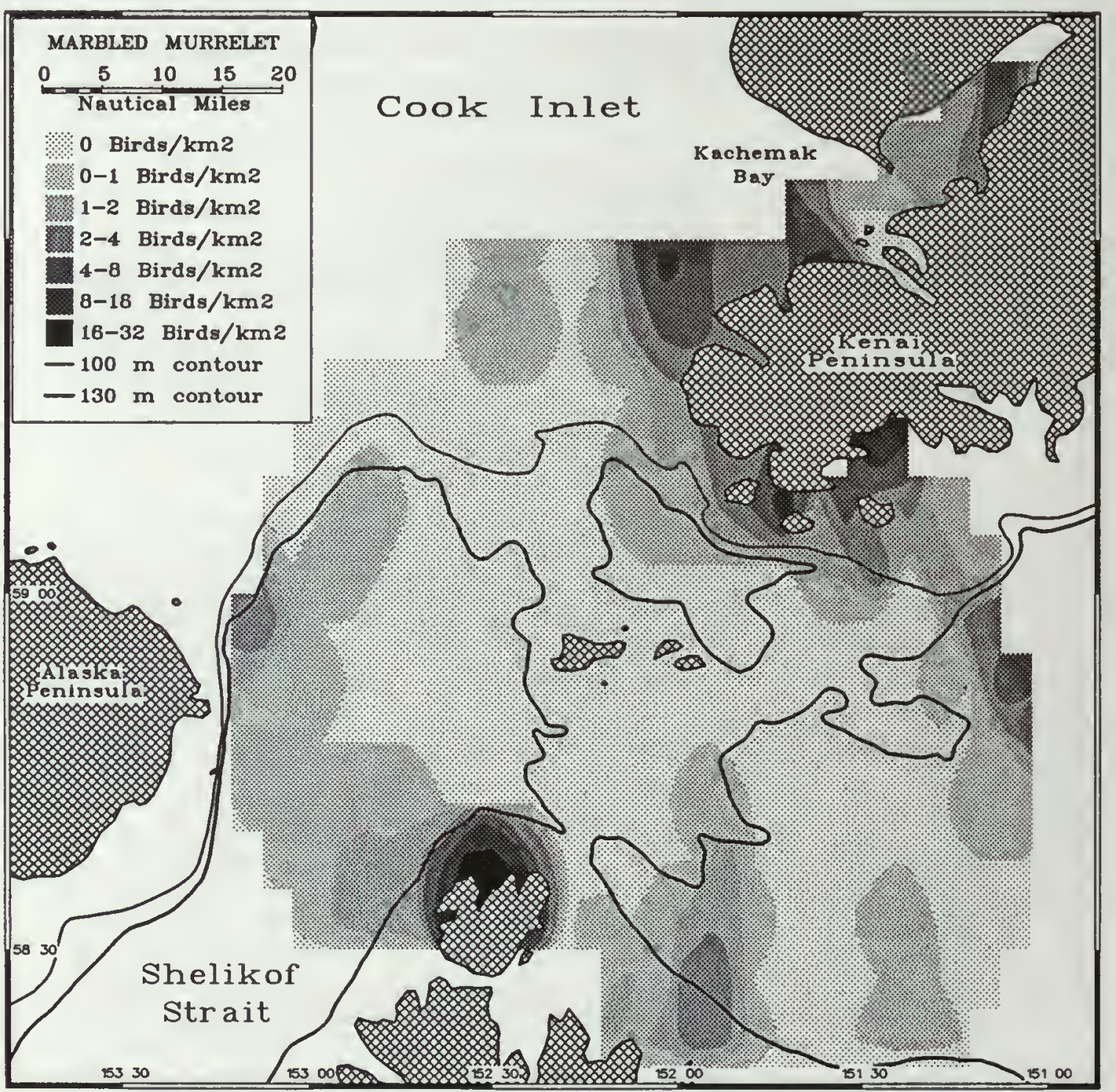

Figure 3-Distribution of Marbled Murrelets in lower Cook Inlet during July, 1992 (from Piatt 1993). 


\section{Murrelet Abundance}

Piatt and Ford (1993) estimated the abundance of regional murrelet populations (table 1) by extrapolating from coarsescaled OCSEAP data. The population estimate for the Northern Gulf of Alaska (table 1) is undoubtedly an underestimate because of poor sampling of Prince William Sound and Cook Inlet. Repetitive small-boat surveys conducted in Prince William Sound after the Exxon Valdez oil spill yielded summer (July) population estimates ( \pm 20 percent) of $107,000,81,000$, and 106,000 Brachyramphus murrelets in 1989, 1990, and 1991, respectively (Klosiewski and Laing 1994). Averaging these estimates, and subtracting the proportion that were Kittlitz's Murrelets (ca. 10 percent), suggests that about 89,000 Marbled Murrelets use Prince William Sound in summer. Ship-based surveys conducted in lower Cook Inlet in summer, 1992, suggest that about 18,000 Brachyramphus murrelets may be found in a $50 \mathrm{~km}$ radius of the Barren Islands; with high concentrations along the Kenai Peninsula and near Shuyak Island in the Kodiak Archipelago (Piatt
1993; fig. 3). Small-boat surveys in 1993 of a larger area in lower Cook Inlet (fig. 4) suggest that about 60,000 Brachyramphus murrelets use this area during summer (Agler and others 1994).

The OCSEAP estimate for murrelet populations throughout the entire Kodiak Archipelago in winter (table 1) is similar to the estimate $(15,000-20,000)$ given by Forsell and Gould (1981) for wintering populations of Brachyramphus murrelets in selected bays of Kodiak and Afognak islands. Reflecting an influx of post-breeding birds, winter populations are higher (table l) and birds appear to move into more sheltered bays and fiords. Summer and winter populations concentrate in different areas (figs. 5 and 6).

No other published regional estimates are available for comparison with the OCSEAP data. Mike McAllister conducted hundreds of surveys throughout much of the northern Gulf of Alaska between 1983 and 1991. Based on a preliminary examination of his data (McAllister, pers. comm.), he made the following summer population estimates:

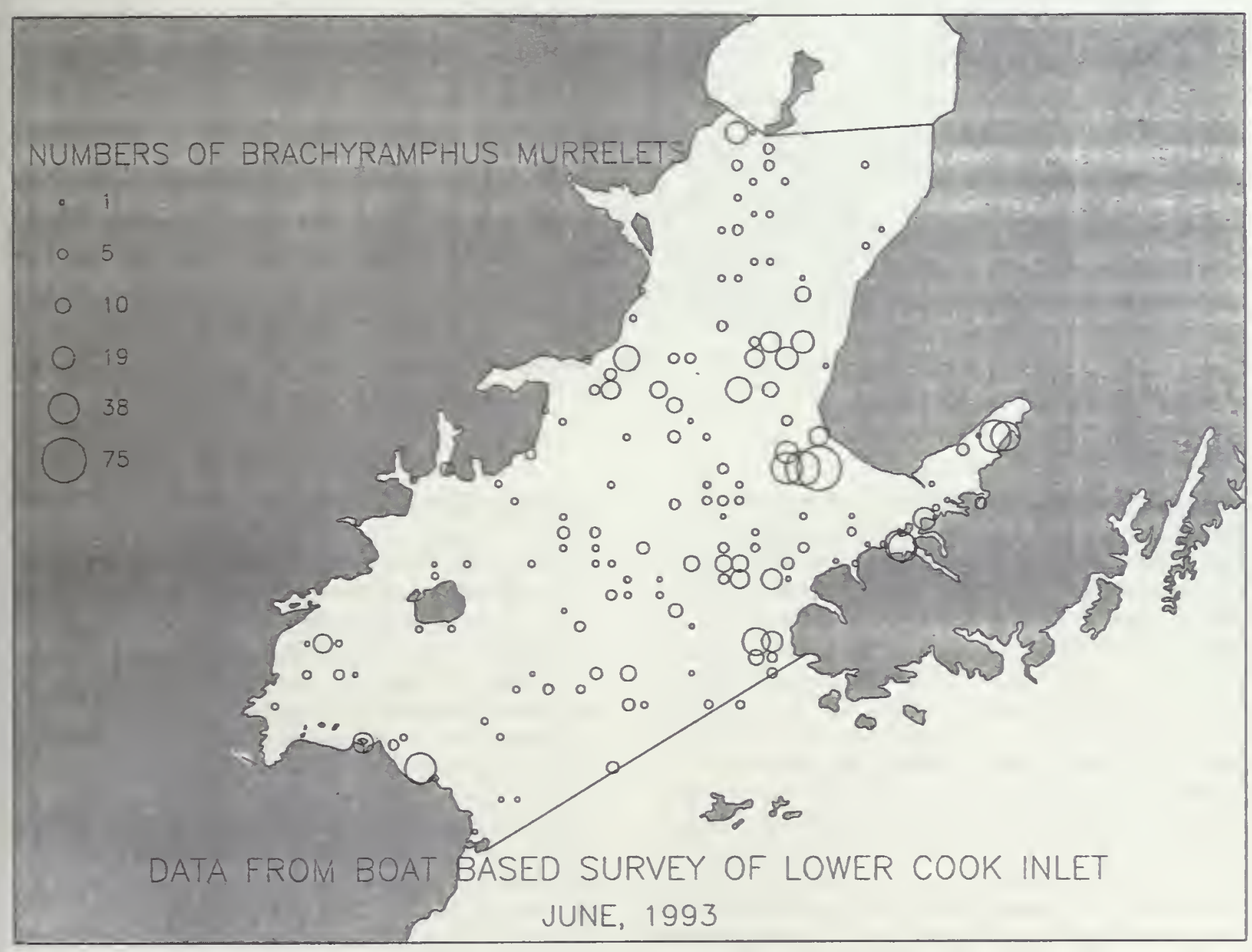

Figure 4-Distribution of Marbled Murrelets in lower Cook Inlet during June, 1993 (from Agler and others 1994). 


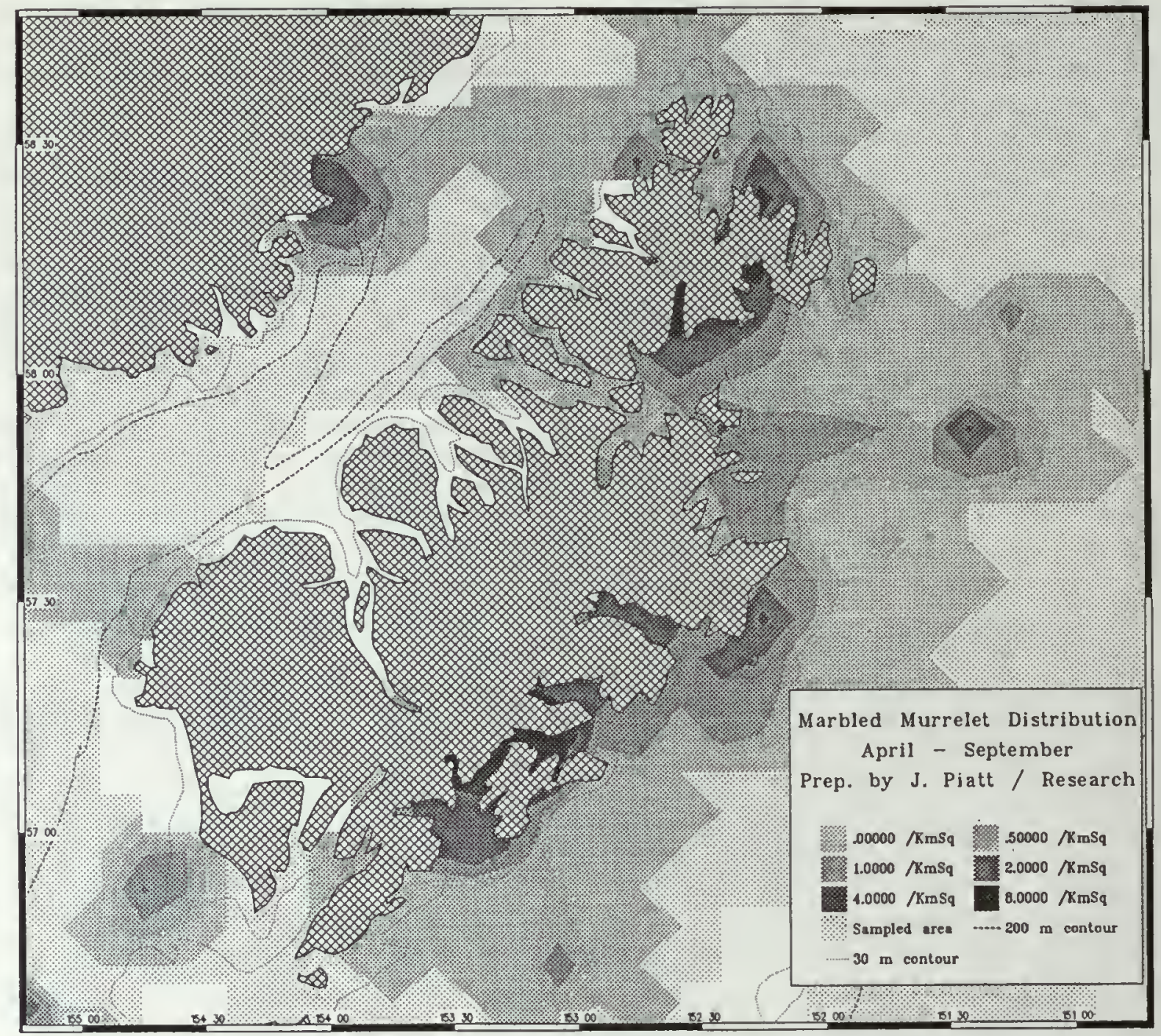

Figure 5-Distribution of Marbled Murrelets around the Kodiak Archipelago in summer (April-September). Density contour polygons calculated from data grouped in $5^{\prime}$ latitude-longitude blocks and scaled geometrically.

Southeast Alaska: 45,000-70,000; Northern Gulf Coast (including Prince William Sound): 32,000-60,500; Kodiak Archipelago: 7,000-13,000; Alaska Peninsula: 4,000-10,000.

Combining results of the Alaska-wide OCSEAP surveys, and the more recent fine-scale surveys of Prince William Sound and Cook Inlet, we conclude that Marbled Murrelet populations in Alaska are in the low $10^{5}$ category, possibly around 280,000 individuals. One important implication of the OCSEAP data is that only about 3 percent of the Alaskan Marbled Murrelet population resides in wholly nonforested regions during the breeding season. If we factor in the finescale survey results, then the proportion of murrelets residing in non-forested regions is further reduced to only 1.4 percent of the total Alaskan population. Presumably at least this fraction of the population nests on the ground. Some murrelets also nest on the ground in alpine habitat of forested areas and, rarely, on the ground in forests (Ford and Brown 1994; Kuletz, pers. comm.; Mendenhall 1992).

\section{Human Threats to Populations}

\section{Logging of Old-Growth Nesting Habitat}

Aside from a small fraction that nest on the ground (see above), most Marbled Murrelets in Alaska nest in old-growth forests (Kuletz and others, this volume; Naslund and others 1993), and populations are therefore affected directly by logging of these forests. Unlike factors leading to direct mortality, such as oil spills and gill-nets, it is difficult to quantify the impact of logging on murrelet populations. However, it is obvious that logging of breeding habitat must lead to an immediate reduction in murrelet production. If murrelets do not, or can not, breed elsewhere in subsequent years, then removal of habitat must eventually lead to reduced population size as adults are culled over time from breeding populations, but are not replaced by new recruits. The massive (85-90 percent) reduction in old-growth nesting habitat in California, Oregon, Washington, and British Columbia because 


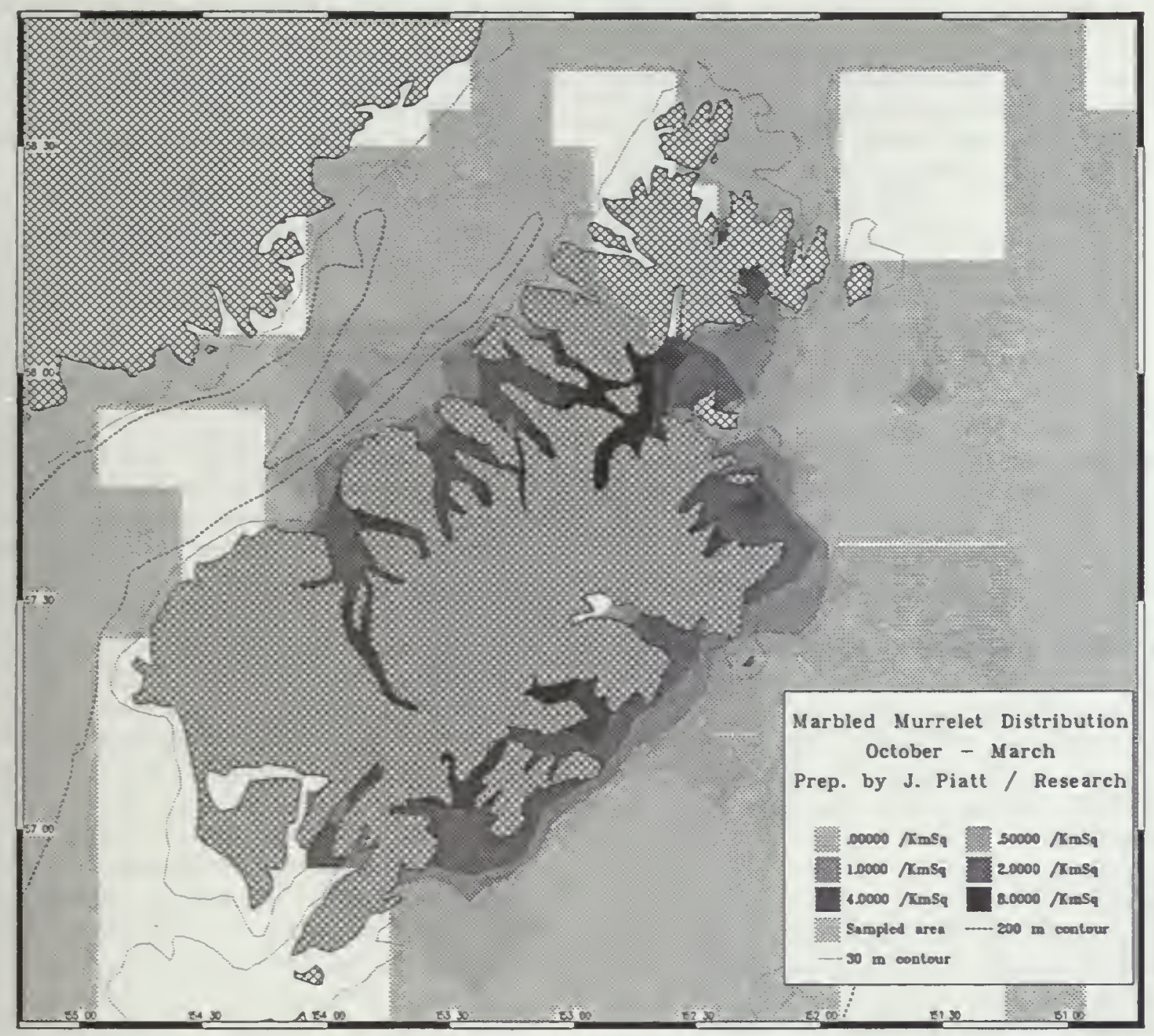

Figure 6-Distribution of Marbled Murrelets around the Kodiak Archipelago in winter (October-March). Density contour polygons calculated from data grouped in $5^{\prime}$ latitude-longitude blocks and scaled geometrically.

of logging is credited for the decline and fragmentation of murrelet populations in these regions (Rodway and others 1992: Sealy and Carter 1984; Stein and Miller 1992). Despite the relatively large present-day population of murrelets in Alaska, there is no reason to expect that populations here will fare any better without habitat conservation.

Despite Alaska's image as a pristine wilderness, much oId-growth habitat here has already been logged. Exact figures on timber harvest and the proportion of old-growth remaining are largely unpublished or undocumented (Mendenhall 1992). While only 7 percent of the old-growth has been harvested in the Tongass National Forest, a significant portion (about 40 percent) of the highly productive old-growth in the forest has already been eliminated, and remaining habitat continues to be logged (USDA Forest Service Alaska Region 1991; Perry, this volume). Substantial areas of potential nesting habitat have also been logged on state and private lands elsewhere in Alaska, principally in Prince William Sound and the Kodiak Archipelago, and logging pressure continues, as we and others (Mendenhall 1992; Forsell, pers. comm.) have observed. Privately-owned forests, much of which were selected or granted because of their old-growth holdings, are found in all areas of known importance to murrelets. Clearcutting is planned or underway on all privately-owned forests (Mendenhall 1992).

\section{Gill Nets}

The impact of gill-net mortality on Marbled Murrelets in Alaska is poorly known. Anecdotal evidence from the past suggested that 100 's to 1000 's of murrelets were caught in gill-net fisheries in coastal areas of Alaska during the 1970's (Mendenhall 1992; Carter and Sealy 1984). Quantitative data on seabird bycatch from Prince William Sound in 1990 and 1991 (Wynne and others 1991,1992$)$ reveal that these earlier estimates were probably of the right order of magnitude. Extrapolating from observed bird bycatch rates and the 
proportion of total salmon catch observed, it appears that 923 and 714 Brachyramphus murrelets ( 84 percent Marbled) were killed in Prince William Sound gill net fisheries in 1990 and 1991, respectively. A more careful analysis of 1990 data, using mean bycatch rates per week and gill net effort, indicates that 1,468 (95 percent confidence limits 813-2043) seabirds (97 percent murrelets) were killed in nets in 1990 (Wynne and others 1991). Of 18 murrelet specimens examined, 16 ( 89 percent) were in adult breeding plumage and 2 were juveniles. Most murrelets were caught in late July-just prior to the post-breeding period for murrelets.

In 1989, there were 1,972 salmon drift net permits and 4,947 set net permits issued for the Gulf of Alaska (DeGange, pers. comm.; DeGange and others 1993). Extrapolating from Prince William Sound with 598 drift net permits, and assuming that 1000 murrelets die there in nets annually, then as many as 900,1100 , and 300 murrelets may drown in gill nets in Southeast Alaska, lower Cook Inlet, and along the Alaska Peninsula, respectively. In total, some 3300 (2940 adult) murrelets may drown in fish nets annually throughout their range in Alaska. Assuming a population size of 280,000 individuals, of which 70 percent are adult breeders, then as much as 1.5 percent of adult mortality may derive from drowning in nets. This estimate does not include mortality in set nets, pound nets or seine nets, which anecdotal evidence suggests also kill a number of murrelets each year.

\section{Oil Pollution}

Chronic low-volume oil pollution is a significant source of seabird mortality in many parts of the world (Burger and Fry 1993, Piatt and others 1991), but effects on murrelets in Alaska are largely unknown, owing to the remoteness of bird populations in Alaska and the sparse human population. Two oil spills in 1970 may have each killed about 100,000 seabirds, mostly murres (McKnight and Knoder 1979). Limited beach survey data suggests that low-level mortality occurs throughout the year. In 1988 and 1989 alone, 43 oil spills involving 14 million gallons of oil were reported in Alaskan waters (including 11 million from the Exxon Valdez). Several of these spills were in the vicinity of major seabird colonies, but damages were not documented. Chronic oil pollution is likely to get worse as fishing fleets expand and more oil, and gas development occurs in offshore environments (Lensink 1984).

Following the Exxon Valdez oil spill in Prince William Sound during March 1989, about 30,000 seabirds were recovered and the actual kill toll ranged between 100,000 300,000 birds (Piatt and others 1990). Both Marbled and Kittlitz's murrelets were affected by the spill, as were many other alcids. A total of 612 Marbled Murrelets were retrieved from beaches. Another 413 unidentified murrelets were recovered and, if we prorate these birds by the proportion that were Marbled Murrelets in each area of recovery, then the total number of Marbled Murrelets retrieved was 808 . Only a fraction of birds killed at sea made it to shore (ca. 10 percent), and if we apply recovery rates estimated by Ecological Consulting, Inc. (1991) and Piatt and others (1990) for each region affected, then about 8400 Marbled Murrelets were killed by the Exxon Valdez oil spill (see also Kuletz 1994). This represents a one-time loss of 3 percent of the total Alaska population, and about 7 percent of the population in the spill zone (Kuletz 1994). Similarly, about 530 Kittlitz's Murrelets were killed, or about 3 percent of their total Alaska population (van Vliet 1993).

\section{Boat Traffic}

Owing to their coastal distribution and use of relatively sheltered marine habitats, murrelets are more exposed to vessel activities than most other seabirds in Alaska. Disturbance can disrupt feeding birds and persistent boat traffic may prevent murrelets from using important foraging areas (Speckman, pers. comm.). Even in areas where murrelets may habituate to existing boat traffic, changes in boat activity may influence murrelet foraging activity. Following the Exxon Valdez oil spill in Alaska, boat activity increased greatly in Prince William Sound and Kachemak Bay because of rescue and clean-up efforts. There, Kuletz (1994) found that murrelet numbers were negatively correlated with numbers of boats and low-flying aircraft. Evidence also suggested that breeding may have been disrupted (Kuletz 1994). Increasing activity by fishing, commercial, tourist and private boats in areas known to be important for murrelets (e.g., Glacier Bay National Park, Prince William Sound, Kenai Fiords National Park, and Kachemak Bay) may have important long-term implications for murrelet populations in Alaska. The potential impact of vessel disturbance on murrelet foraging and breeding success requires more study.

\section{Other Factors Influencing Population Dynamics}

\section{Natural Changes in the Environment}

A variety of independent data indicate that a marked "change of state" in the marine ecosystem of the Gulf of Alaska occurred during the last 20 years (Piatt and Anderson, in press). This shift has been manifested by marked changes in sea water temperatures, composition of marine fish communities, reduced overall fish biomass, and dramatic changes in the diet and population ecology of higher vertebrates that depend on those fish populations (Piatt and Anderson, in press). In particular, productivity and populations of Common Murres (Uria aalge), Black-legged Kittiwakes (Rissa tridactyla), Stellar sea lions (Eumetopias jubatus), and harbor seals (Phoca vitulina) declined dramatically in - various areas of the Gulf of Alaska during the 1980's. Declines in Marbled Murrelet populations in Alaska (see below) also coincided with these changes in the marine ecosystem, and may be related to changes in forage fish availability during this time. Between the late 1970's to the late 1980's, high quality capelin (Mallotus villosus) were replaced largely by lower quality pollock (Theragra chalcogramma) in the diets 
of Marbled Murrelets (Piatt and Anderson, in press). Unlike short-term phenomenon such as El Niño events, this longterm shift represents a more pervasive and persistent change in the ecosystem and can potentially have long-term effects on Alaskan murrelet populations. In the short term, evidence suggests that murrelets and other seabirds will have difficulty recovering from impacts of the 1989 Exxon Valdez oil spill and other sources of adult mortality until conditions favorable for seabirds are re-established in the Gulf of Alaska (Piatt and Anderson, in press).

\section{Life History}

As a group, the Alcidae exhibit life history characteristics typical of other seabirds. Laying only $1-2$ eggs per breeding season, they have a low capacity for production but this is balanced by low adult mortality and long life (see review by De Santo and Nelson, this volume). Compared to other fish-feeding members (e.g., murres, puffins, auks) within the family, however, it is clear that murrelets are extreme in their adaptation for very low production (see below), which must be balanced by very high adult survival rates. This is important to consider when evaluating the longterm impacts of anthropogenic and natural mortality factors on populations in Alaska. Whereas murres (Uria spp.), with natural adult mortality rates of 8-12 percent per annum and annual chick production rates of $0.5-0.9$ chicks per pair, may be able to compensate relatively quickly for acute or chronic mortality losses of adults, increases in mortality of adult murrelets may have more serious demographic consequences. Thus, losses of 1-3 percent of adult murrelets resulting from oil spills and gill nets (see above) are cause for serious concern.

No data are available on adult survivorship in murrelets, but much evidence suggests that production is extremely low and regulated largely by predation. Indeed, predation pressure appears to have been a major ecological factor influencing the evolution of murrelet life history strategies. Excepting its close relative, the Kittlitz's Murrelet, Marbled Murrelets are the only alcid with cryptic plumage and nesting behavior. Breeding Marbled Murrelets fly silently to their woodland nest-sites for incubation exchange or chick-feeding, and like the even smaller Synthliboramphus murrelets, fly mostly at dawn, dusk, or in darkness (Gaston 1992; Naslund 1993a: Nelson and Hamer, this volume a). Selection for breeding in old growth forest by Marbled Murrelets may have arisen because of the scarcity of predators relative to second growth or disturbed habitat.

Despite their best efforts to avoid predation, Marbled Murrelets suffer the highest nesting failure known for any alcid, largely due to predation. Only 28 percent of 32 nests with known outcomes have ever fledged young successfully (Nelson and Hamer, this volume b). In southcentral Alaska, all nests $(n=8)$ failed where breeding success was know'n (Marks, pers. comm.; Naslund and others, in press). Abandonment and predation were implicated as factors causing nesting failure. Adults also suffer from predation by raptors and possibly corvids (Marks and Naslund 1994, Singer and others 1991). Being only slightly smaller and larger, respectively, than Marbled Murrelets, Synthliboramphus murrelets and Cepphus guillemots also suffer from high levels of chick and adult predation. However, these species have compensated through the evolution of 2-egg clutchesunique among the Alcidae. Thus, Marbled Murrelets stand out among the Alcidae for having extremely low levels of production, and a limited capacity for dealing with increased predation pressure or unnatural sources of mortality.

\section{Population Trends}

There are few quantitative data to assess population trends of murrelets in Alaska. We analyzed 20 years (19721991) of Christmas Bird Count (CBC) data in the northern Gulf of Alaska (fig. 7). Totals for each year were calculated as the sum of all murrelets seen on CBC's in Sitka, Juneau, Glacier Bay, Cordova, and Kodiak Island. We could not take the average of counts among sites $(n=5)$ because of missing data (see below). There was considerable inter-annual variation in total numbers, which we smoothed by taking 5year running averages of the annual data (fig. 7). Unsmoothed data were extremely variable, and did not reveal a statistically significant trend. However, the smoothed data suggest a steady decline in abundance of about $\mathbf{5 0}$ percent from the early 1970's to the early 1990 's. This analysis is biased because some years of $\mathrm{CBC}$ data are missing (16 out of a possible 100 counts). As most (11) missing CBC counts were from the first decade (1972-1980) of study, the downward trend is greater than indicated in figure 7.

Interpretation of CBC's is confounded by several effects including survey conditions and observer effort (Arbib 1981, Bock and Root 1981). CBC data may be most suitable for monitoring long-term trends in species (such as the Marbled Murrelet) that occur regularly, are widely distributed, and occupy easily-censused, discrete habitats (Bock and Root 1981, Trapp 1984). We chose not to standardize the $\mathrm{CBC}$ data by dividing murrelet numbers by some measure of census effort (e.g., party-hours) because this approach may not be appropriate for some species likely to be well censused, regardless of how many people participate in the census (Bock and Root 1981). If we had standardized the data for effort, which increased by more than 50 percent over the period of study (fig. 7), the apparent decline in Marbled Murrelets would have been even more pronounced.

Compelling evidence for a major decline in murrelet abundance is also provided by comparing results of surveys that were conducted in Prince William Sound during 19721973 with those conducted after (1989-1991) the Exxon Valdez oil spill (Klosiewski and Laing 1994). Based on randomly-selected transects censused throughout the entire Sound, and on surveys conducted in both winter and summer, populations of Brachyramphus murrelets apparently declined by $67-73$ percent between the early 1970 's and late 1980 's. 


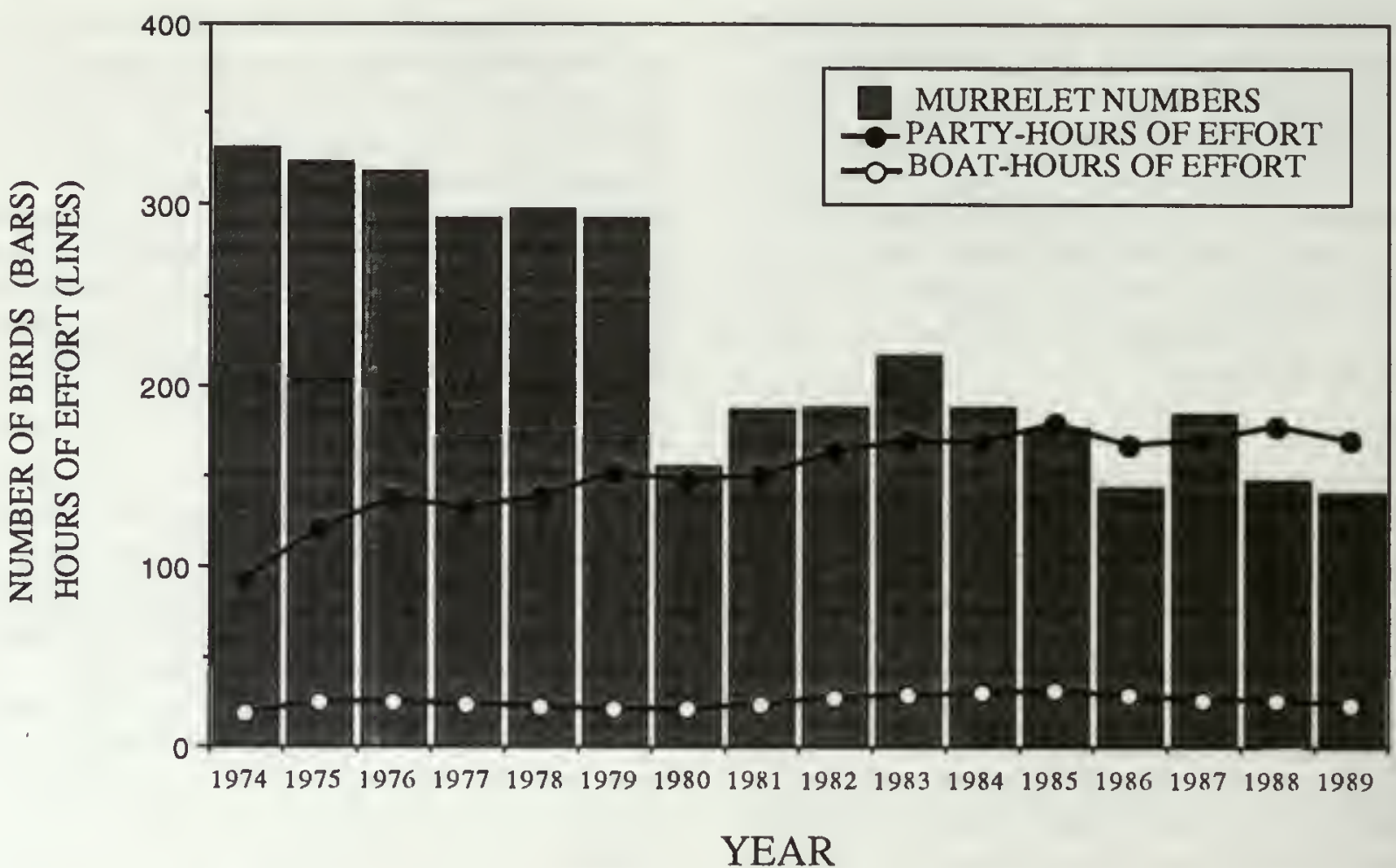

Figure 7 - Numbers of Marbled Murrelets observed on Christmas Bird Counts (CBC) at five coastal sites in Alaska (see text). Numbers are 5-year running means of CBC data collected from 1972-1991. Survey effort (lines) also presented as 5-year running means.

Surveys in all years were conducted using similar protocols, population estimates were relatively precise $( \pm 37-47$ percent in winter, $\pm 16-32$ percent in summer), and declines observed on surveys conducted in summer were highly significant $(P$ $<0.01$; Klosiewski and Laing 1994). Declines observed for murrelets were paralleled by population declines in 15 other marine bird species as well. These declines could not be accounted for by losses from the Exxon Valdez oil spill, and suggest that other large-scale factors have influenced marine bird populations in Prince William Sound during the 20-year interval between surveys (Klosiewski and Laing 1994). This is consistent with observations on other marine animals in the Gulf of Alaska (above).

In summary, the bulk of Marbled Murrelet populations in North America reside in Alaska. Most murrelets are concentrated in areas containing large tracts of coastal oldgrowth forests. Populations in Alaska have apparently declined by more than 50 percent over the last 20 years. This decline has presumably occurred in response to the cumulative effects of habitat loss (logging), gill-net mortality, oil pollution, and natural changes in the marine environment. Life history characteristics of the Marbled Murrelet predispose the species to slow recovery from natural and anthropogenic perturbations, and make it particularly vulnerable to factors which increase adult mortality.

\section{Acknowledgments}

We thank Patrick Gould, Kate Wynne, and Chris Wood (and the Burke Museum, University of Washington) for access to unpublished data on murrelet bycatch in gill-nets. We thank Peter Connors, Anthony DeGange, Douglas Forsell, George Hunt Jr., David Irons, Karen Laing, Mike McAllister, C. John Ralph, Larry Spear, and Steven Speich for thoughtful reviews and discussions on the paper, and Mary Cody, Scott Hatch, Kathy Kuletz, John Lindell, Dennis Marks, Suzann Speckman, Alan Springer, and Gus van Vliet, for sharing their insights about murrelets in Alaska. 


\section{Chapter 29 \\ Marine Distribution, Abundance, and Habitats of Marbled Murrelets in British Columbia}

\section{Alan E. Burger ${ }^{1}$}

Abstract: About 45,000-50,000 Marbled Murrelets (Brachyramphus marmoratus) breed in British Columbia, with some birds found in most parts of the inshore coastline. A review of at-sea surveys at 84 sites revealed major concentrations in summer in six areas. Murrelets tend to leave these breeding areas in winter. Many murrelets overwinter in the Strait of Georgia and Puget Sound, but the winlering distribution is poorly known. Aggregations in summer were associated with nearshore waters $(<1 \mathrm{~km}$ from shore in exposed sites, but $<3 \mathrm{~km}$ in sheltered waters), and tidal rapids and narrows. Murrelets avoided deep fjord water. Several surveys showed considerable daily and seasonal variation in densities, sometimes linked with variable prey availability or local water temperatures. Anecdotal evidence suggests significant population declines in the Strait of Georgia, associated with heavy onshore logging in the early 1900s. Surveys made between 1979 and 1993 in Barkley and Clayoquot sounds suggest 20-60 percent declines in densities. These changes are correlated with intensive onshore logging, although El Niño effects are probably also involved.

British Columbia is second only to Alaska in the population size of Marbled Murrelets and also in complexity of marine habitats used by these birds. There have been many marine studies of this species in British Columbia, beginning with the pioneering work of Sealy in the Queen Charlotte Islands (Sealy 1973b, 1974, 1975a,c), and the work of Carter and Sealy in southwestern Vancouver Island (Carter 1984, Carter and Sealy 1984, Sealy and Carter 1984). Most studies have been short term (one season or less) and highly localized. Previous province-wide reviews of marine distributions and habitats relied primarily on data from sight record cards, along with a few standardized censuses (Campbell and others 1990, Rodway 1990, Rodway and others 1992). The sight records are not reanalyzed here. This chapter summarizes data on populations, distribution, habitats, and basic biology of the Marbled Murrelet obtained largely from boat surveys.

\section{Abundance and Distribution}

\section{Regional and Range-Wide Population Densities}

Marbled Murrelets have been recorded from most of the coastal waters of British Columbia (Campbell and others 1990, Rodway 1990, Rodway and others 1992). Current estimates of the provincial population $(45,000-50,000$ breeding

\footnotetext{
${ }^{1}$ Associate Professor (Adjunct), Department of Biology, University of Vicloria, Vicloria, British Columbia, V8W 2Y2, Canada
}

birds) are extrapolations from relatively few data from 1972 to 1982 , mainly counts in high-density areas and transects covering a small portion of coastline (Rodway and others 1992). Between 1985 and 1993 many parts of the British Columbia coast were censused, usually by shoreline transects, although methods and dates varied, making comparisons and extrapolation difficult. Much of the $27,000 \mathrm{~km}$ of coastline remains uncensused (fig. 1).

Appendix 1 summarizes censuses for the core of the breeding season (1 May through 31 July). Murrelet densities are given as birds per linear kilometer of transect. It was necessary to convert density estimates from other units in several cases, and this was done in consultation with the original authors, using charts to determine distances travelled. Several authors used strip counts, ranging in width from 300 $\mathrm{m}$ (e.g., $150 \mathrm{~m}$ on either side of the boat) to $1 \mathrm{~km}$, whereas others reported all birds visible from the boat. Relatively few murrelets are likely to be detected at distances $>200 \mathrm{~m}$, even in the sheltered inner waters of British Columbia (Burger, unpubl. data; Kaiser, pers. comm.), and so these differences in technique, while adding to the variability of the data, were not considered to be a major source of error.

\section{Gaps in Distribution}

There are no obvious gaps in the marine distribution in British Columbia, although low densities are associated with several large areas (e.g., eastern Graham Island, eastern Vancouver Island, and many of the large mainland fjords), and this is discussed below. Many areas have not been adequately sampled in the breeding season (much of NW and NE Vancouver Island, the Strait of Georgia, Strait of Juan de Fuca).

\section{Movements and Seasonal Variations in Density}

Rodway and others (1992) used an extensive data base of sight record cards in the Royal British Columbia Museum to demonstrate a post-breeding emigration from areas which support large breeding concentrations on the west coast of Vancouver Island and the Queen Charlotte Islands. Habitat shifts were associated with these changes. Apparent densities (mean numbers of birds per sighting record) were higher in spring and summer than in fall and winter in both exposed inshore waters (1-5 km from shore) and nearshore waters $(<1 \mathrm{~km}$ of shore) of the Strait of Georgia, but the opposite was true for most fjords. This suggests that murrelets leave the exposed outer coast and more exposed areas of large straits in late summer and fall to move into more sheltered waters, including some of the many large fjords on the mainland. 
Langara Island

\section{BRITISH COLUMBIA}

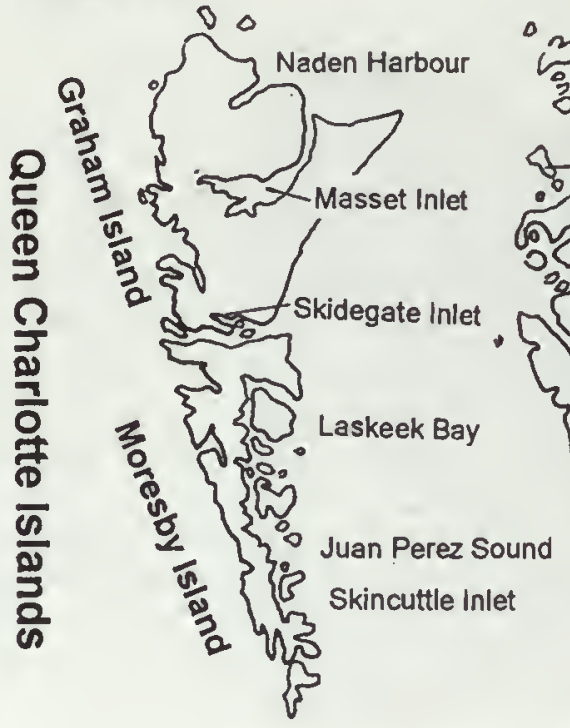

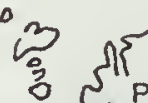

0 Prince Rupert

Of Stevensisland

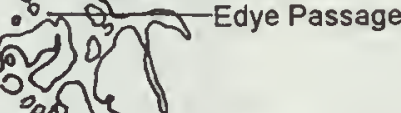

क्ष $\}$

(2)

$\int$

20 2 Kitlope inlet

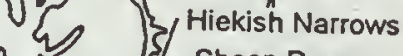

of Sheep Pass

3 1 Mussel Inlet

Kynoch Inlet

Milbanke Sound

0

Queen's Sound
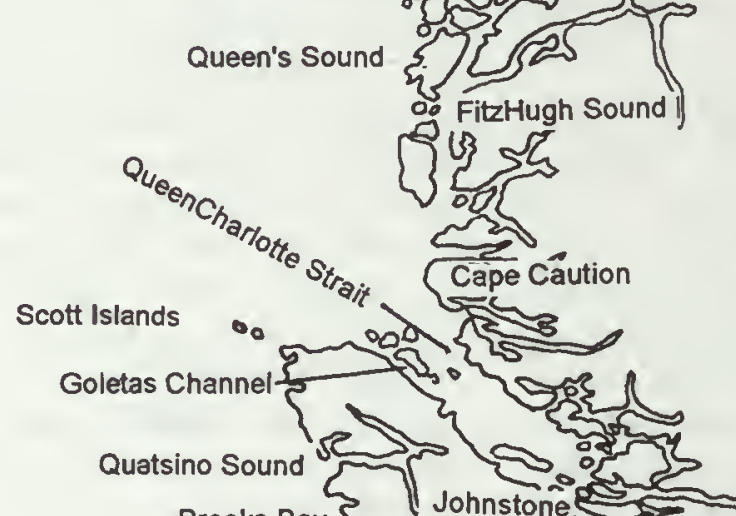

Brooks Bay S Johnstone
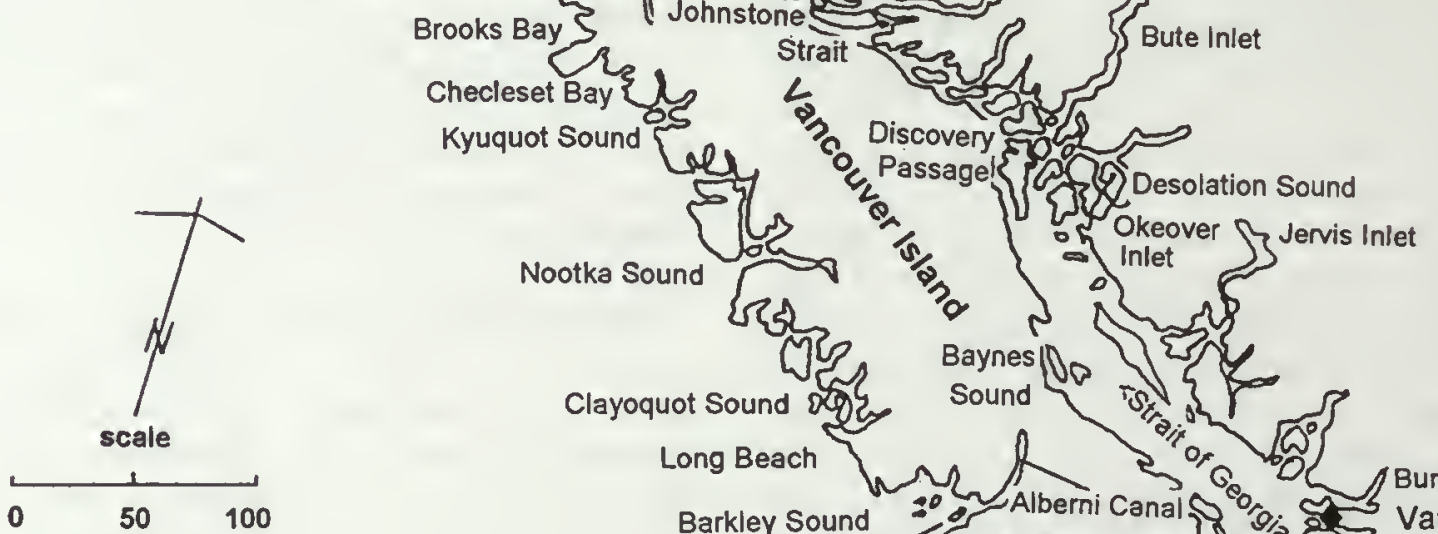

Clayoquot Sound o

Sound

Long Beach

Barkley Sound

Trevor Channel Fape Beale

Pachena Point

Owen Point

Port

or

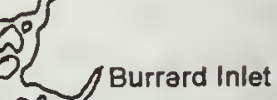
Vancouver

Port San Juan

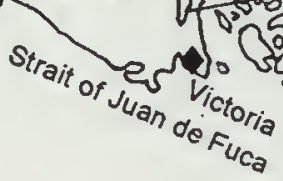

Sidney - Mandarte I.

I Saanich Inlet

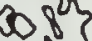

$\mathrm{DO}^{\circ}$

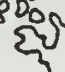


Shoreline surveys in 1976 and 1977 by Vermeer and others (1983) show similar trends: low densities were found in October and November in most areas in the Queen Charlotte Islands and nearshore waters of the Strait of Georgia (table 1). Robertson (1974) reported higher densities of Marbled Murrelets in protected waters off southwest Vancouver Island in summer $\left(11.19 \mathrm{~km}^{2}\right)$ and found low densities in sheltered inlets during winter (range 0.13-1.17/ $\mathrm{km}^{2}$ ). More recently, high densities were found among islands on the northern edge of the Strait of Georgia (Harfenist, pers. comm.) and at some inlets off the strait (Burns, pers. comm.; Prestash, pers. comm.).

Year-round surveys have been made at few sites. Those in Barkley Sound and adjacent waters show that murrelet densities rise in April and decline in late July and August (fig. 2). Some of these birds appear to move into Alberni Canal in winter, but the relatively low densities there cannot account for all the Barkley Sound murrelets. In the Strait of Georgia, murrelets were more common between Sidney and Mandarte Island between May and October than in winter, whereas densities were higher in winter in the sheltered fjords of Jervis and Saanich Inlets (fig. 3) and also in Puget Sound in Washington (Speich and others 1992; Speich and Wahl, this volume). The winter counts might include birds from exposed western and northern parts of British Columbia.
There is no evidence of a major move into pelagic waters in fall or winter (Burger, unpubl. data; Morgan and others 1991; Vermeer and others 1983, 1989b). Low to moderate densities ( 0.01 to 1.00 birds per $\mathrm{km}$ ) were reported from only two areas of open water in winter (in central Hecate Strait, between the Queen Charlotte Islands and Banks Island, and over La Perouse Bank off SW Vancouver 1sland) (Morgan and others 1991).

Overall, it seems that selected parts of the Strait of Georgia and Puget Sound are the primary wintering areas of murrelets breeding in British Columbia. Small numbers overwinter in most of the coastal waters and more open ocean. Winter samples are, however, very inadequate and other important wintering areas will undoubtedly be discovered.

\section{Habitats Used}

\section{Coarse-Scale Comparisons}

Marbled Murrelets in British Columbia tend to aggregate within $500 \mathrm{~m}$ of land on exposed shores and within $1-5 \mathrm{~km}$ in more sheltered waters (Morgan and others 1991; Sealy and Carter 1984; Vermeer and others 1983, 1987). They are relatively rare in more open pelagic water or in the centers of broad straits; consequently these waters were not considered in the following analysis.

Table 1-Seasonal changes in densities of Marbled Murrelets recorded during boat surveys in 1976 and 1977 (Vermeer and others 1983)

\begin{tabular}{|c|c|c|c|}
\hline \multirow[b]{2}{*}{$\begin{array}{l}\text { Region } \\
\text { Census area } \\
\end{array}$} & \multicolumn{3}{|c|}{ Density (birds per km) } \\
\hline & $\begin{array}{l}\text { Pre-breeding } \\
\text { (Mar-Apr) }\end{array}$ & $\begin{array}{l}\text { Breeding } \\
\text { (May-Jul) }\end{array}$ & $\begin{array}{c}\text { Fall } \\
\text { (Oct-Nov) }\end{array}$ \\
\hline \multicolumn{4}{|l|}{ Strait of Georgia } \\
\hline Howe Sound & 0.74 & - & 0.09 \\
\hline Mainland coast & 3.38 & - & 0.43 \\
\hline Jervis Inlet & 11.02 & - & 1.46 \\
\hline Bute Inlet & 0.63 & - & 0.00 \\
\hline Northern strait islands & 2.60 & - & 11.82 \\
\hline Neck Point - Campbell River & 0.28 & - & 0.07 \\
\hline Vhisria - Neck Point & 0.38 & - & 0.10 \\
\hline \multicolumn{4}{|l|}{ E. Queen Charlotte Islands } \\
\hline Houston - Stewart Channel & - & 2.15 & 0.10 \\
\hline Skincuttle Inlet & - & 7.40 & 0.50 \\
\hline Juan Perez Sound & - & 4.72 & 0.10 \\
\hline Logan Inlet - Darwin Sound & - & 1.78 & 0.04 \\
\hline Cumshewa Inlet - Selwyn Sound & - & 0.33 & 0.08 \\
\hline Skidegate Inlet & - & 0.46 & 0.03 \\
\hline East Graham Island coast & - & - & 0.00 \\
\hline \multicolumn{4}{|l|}{ N. and W. Queen Charlotte Islands } \\
\hline N. Graham Island coast & - & 0.00 & 0.02 \\
\hline Masset Inlet & - & 0.00 & 0.10 \\
\hline Naden Harbour & - & 0.00 & 0.04 \\
\hline W. Graham Island coast & - & 3.00 & - \\
\hline W. Graham Island inlets & - & 0.09 & - \\
\hline W. Moresby Island coast & - & 5.16 & - \\
\hline W. Moresby Island inlets & - & 0.15 & - \\
\hline
\end{tabular}




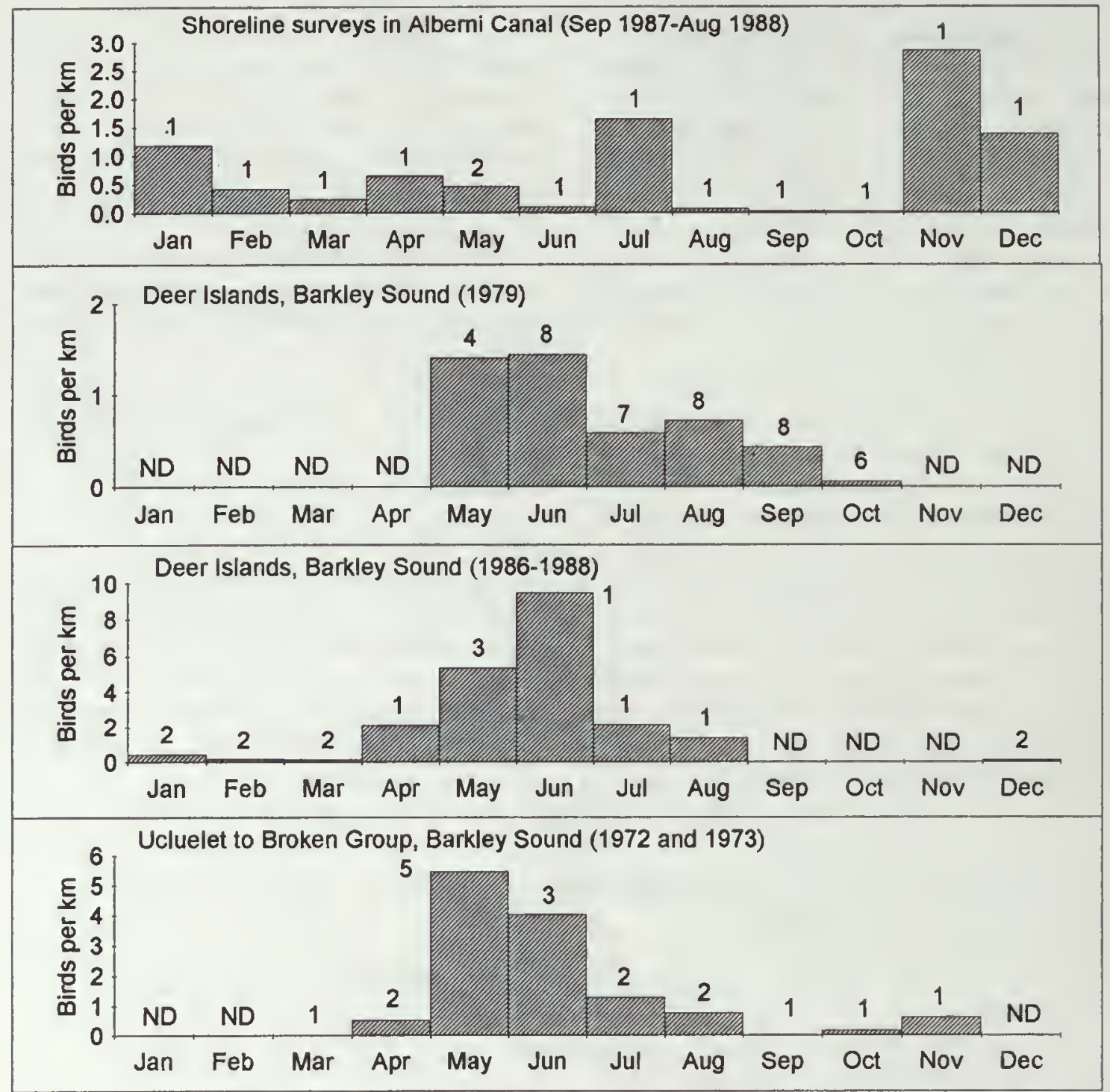

Figure 2-Monthly variations in densities of Marbled Murrelets measured in boat surveys in and near Barkley Sound. Data are from shoreline surveys in the Alberni Canal (Vermeer and Morgan 1992), along fixed routes through the Deer Islands in 1979 (Porter 1981) and 1986-1988 (Burger 1994), and along a fixed route between Ucluelet and the Broken Group islands (Hatler and others 1978). Numbers above columns show numbers of surveys; ND = no data.

Data from the breeding season (generally 1 May through 31 July) in 82 sample areas (some overlapping) show marked variations in density (fig. 4; appendix 1 ). At a very coarse spatial scale $(10-100 \mathrm{~km})$, trends include: higher densities on the more sheltered eastern shores of Moresby Island than in the rest of the Queen Charlotte Islands; higher densities off SW Vancouver Island than NW or NE Vancouver Island; and, surprisingly, higher densities along the exposed nearshore coast of western Graham, Moresby, and Vancouver Islands than in the inlets off these coasts. Major concentrations ( $>5$ birds per linear kilometer on average) were found in six regions: the outer west coast of Moresby Island (1976 census); several inlets and bays with many islands on the sheltered coast of Moresby Island
(Long Inlet, Laskeek Bay, Skincuttle Inlet, Poole Inlet and Collison Bay); Okeover Inlet in Desolation Sound on the southern mainland; SE Clayoquot Sound and exposed shores off Long Beach, SW Vancouver Island; several parts of Barkley Sound, SW Vancouver Island; and exposed nearshore water between Barkley Sound and Port San Juan, SW Vancouver Island. This last area supported the highest densities (average $>12$ birds $/ \mathrm{km}$ in both 1991 and 1993) for a large stretch of coast $(65 \mathrm{~km})$ in British Columbia.

The fjords and sheltered waters of the central mainland coast supported relatively low summer densities overall (average $1.65 / \mathrm{km}$ in a $640-\mathrm{km}$ traverse between 15 and 30 May 1990; Kaiser and others 1991), but there were some dense patches (Sheep Passage, and Mussel and Kynoch inlets). 


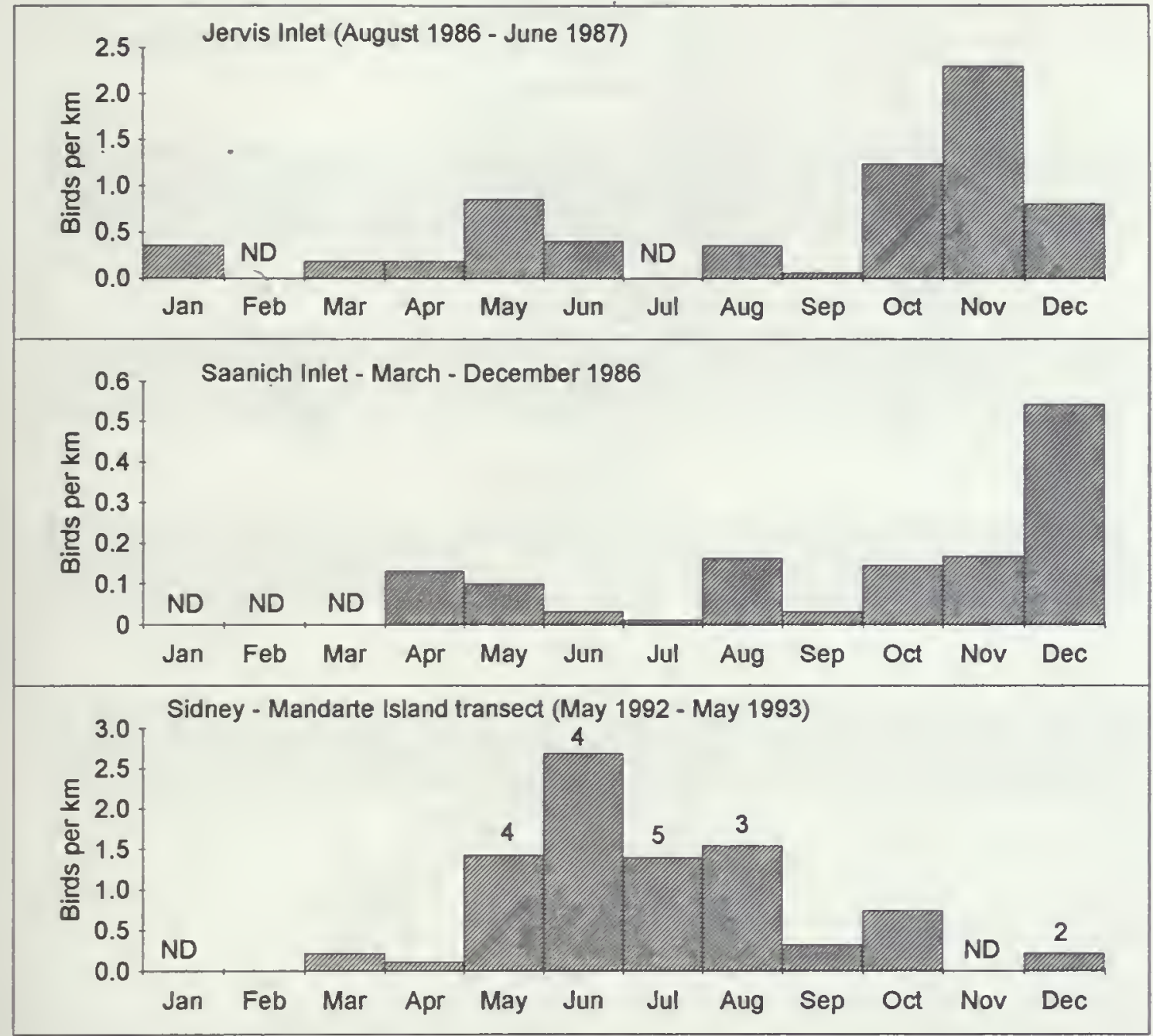

Figure 3-Mean monthly densities of Marbled Murrelets in the Strait of Georgia. Data are from fixed shoreline transects in the fjords of Jervis Inlet Nermeer 1989), and Saanich Inlet (Morgan 1989), and from a fixed transect among the southern Gulf Islands, between Sidney and Mandarte Island (Clowater, pers. comm.). One survey was done per month, except as otherwise noted. ND = no data.

Stationary counts of Marbled Murrelets at the mouth of Mussel Inlet were high in 1991 (>500 on several days) but lower in 1992 and 1993 (Prestash and others 1992a; Prestash, pers. comm.). These appear to be commuting birds, drawn from an undetermined area, which are channeled through narrow fjords en route to feeding areas in more open ocean.

I analyzed coarse-scale habitat use by using the material in appendix 1. Habitats were classified as:

- E: exposed ocean (facing the open Pacific or exposed parts of large straits);

- S: sheltered water in large strait or sound;

- I: smaller inlet; or

- F: steep-sided fjord.

Within these categories were subcategories:

- OW: open water ( $>1 \mathrm{~km}$ from shore);

- NW: nearshore water (<l km from shore);
-IS: among islands offering relatively sheltered water;

- OC: outer coast (for fjords or inlets);

- IC: inner coast (for fjords or inlets).

Each survey was assigned to one or more combinations of categories (see appendix 1).

Exceptionally high mean densities in May and June ( $>5$ birds $/ \mathrm{km}$ ) were associated with few habitats: sheltered waters on the east of the Queen Charlotte Islands, SW Vancouver Island, and Desolation Sound; and exposed nearshore waters off SW Vancouver Island (table 2). Exceptionally low summer densities $(<\mathrm{l}$ bird $/ \mathrm{km})$ were found in sheltered nearshore waters of NW Vancouver Island and fjords of the southern mainland, southern Strait of Georgia and SW Vancouver Island. This analysis is not entirely satisfactory, because some transects covered large areas of diverse habitat, and the habitat classification was not based on detailed field data. 


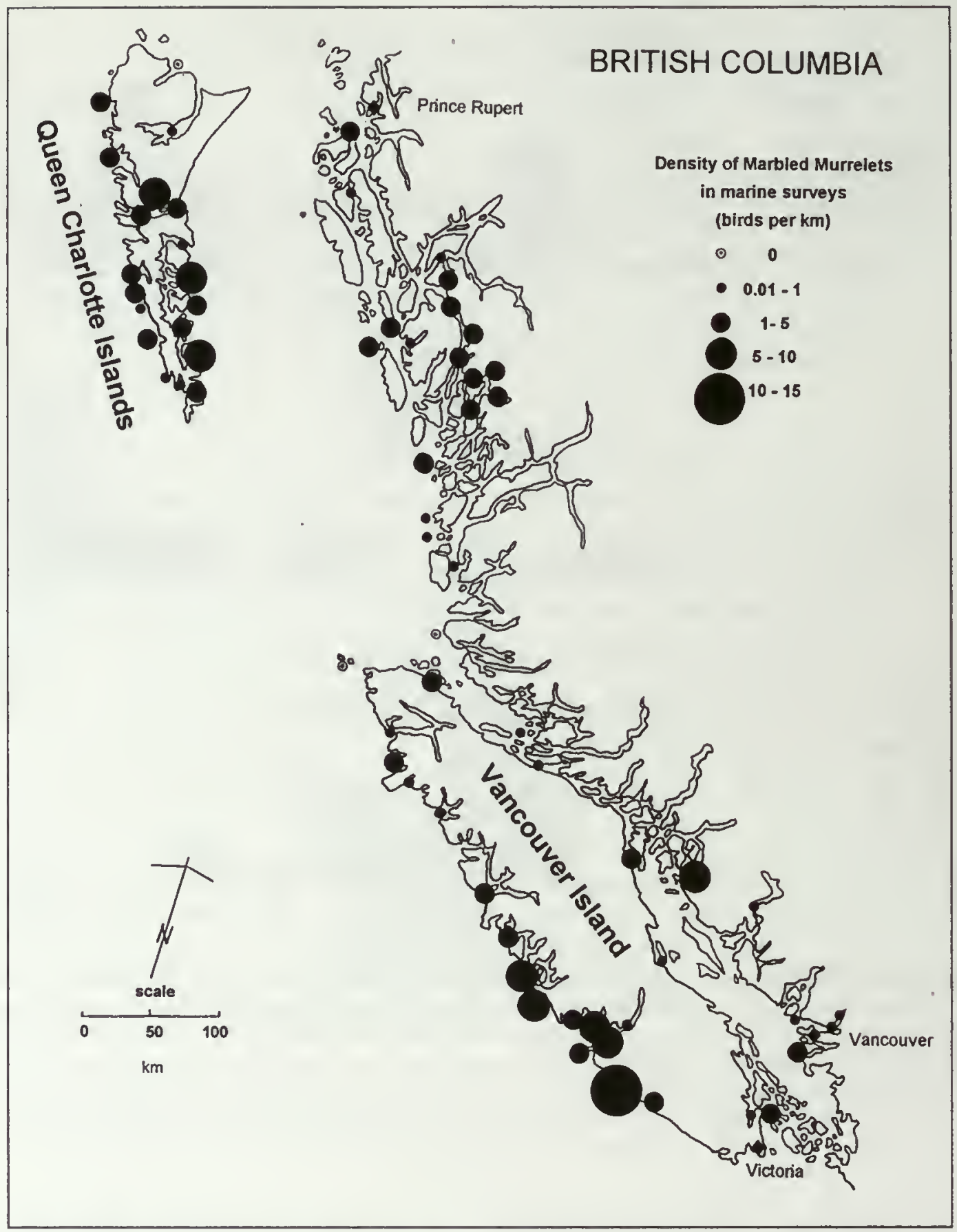

Figure 4-Mean estimates of the densities of Marbled Murrelets during the breeding season (May through July) from marine surveys in British Columbla. The data are shown as birds per $\mathrm{km}$ of transect, which was the most compatible measure among the variable studies (see appendix 1 for details). Most of these data were collected in the 1980 s and early 1990 s.

\section{Fine-Scale Comparisons}

\section{Habitats}

Several studies reported murrelet habitat use on a finer spatial scale (0.1-1.0 km). In deep fjords, higher densities were associated with estuaries, shallow bays, and waters off beaches (Morgan 1989, Vermeer 1989, Vermeer and Morgan 1992). This might be linked with the habitat supporting prey species such as sand lance (Ammodytes hexapterus), which bury themselves in sand for parts of the day (Field 1988).
Off NW Vancouver Island, murrelets avoided deep open water in fjords, but in shallower, sheltered bays and exposed nearshore seas densities were higher in open water $(5.58 /$ $\mathrm{km})$ than in inlets $(0.16 / \mathrm{km})$ or channels $(0.56 / \mathrm{km}$; Savard and Lemon 1992).

Sealy and Carter (1984) reviewed the distribution of 9955 sightings of murrelets in a grid census of Barkley and Clayoquot Sounds. Murrelet densities were highest in inshore 
Table 2-Mean densities of Marbled Murrelets (birds per km) in marine habitats in British Columbia. Data fram appendix 1 (see text for selection criteria). Mean $\pm \mathrm{s.d.}$ shown, and (in parentheses) range and sample size

\begin{tabular}{|c|c|c|c|c|}
\hline Region & $\begin{array}{l}\text { Exposed } \\
\text { nearshore }\end{array}$ & $\begin{array}{c}\text { Sheltered } \\
\text { nearshore and } \\
\text { open / islands }\end{array}$ & Inlets & Fjords \\
\hline N. and W. Queen Charlotte Islands & $\begin{array}{l}2.7 \pm 2.6 \\
(0-5.2: 3)\end{array}$ & - & $\begin{array}{c}1.1 \pm 1.2 \\
(0-4.0 ; 12)\end{array}$ & - \\
\hline E. Queen Charlotte Islands & - & $\begin{array}{c}5.4 \pm 4.4 \\
(0.9-16.0 ; 11)\end{array}$ & $\begin{array}{c}2.6 \pm 0.2 \\
(2.3-2.9 ; 6)\end{array}$ & - \\
\hline Noruhem and Central Mainland & $\begin{array}{l}1.4 \pm 1.9 \\
(0-4.2: 5)\end{array}$ & $\begin{array}{l}1.1 \pm 1.6 \\
(0-3.2,6)\end{array}$ & $\begin{array}{c}2.1 \pm 1.8 \\
(0.6-4.1 ; 3)\end{array}$ & $\begin{array}{c}2.7 \pm 1.7 \\
(0.4-4.9 ; 8)\end{array}$ \\
\hline Southern Mainland & - & $\begin{array}{l}5.11 \\
(-; t)\end{array}$ & - & $\begin{array}{l}0.63 \\
(-; 1)\end{array}$ \\
\hline Gulf Islands and S. Siratt of Georgia & - & $\begin{array}{l}2.08 \\
(-: 1)\end{array}$ & - & $\begin{array}{l}0.05 \\
(-; 1)\end{array}$ \\
\hline NE. Vancouver Island & - & $\begin{array}{c}1.2 \pm 0.6 \\
(0.8-2.2 ; 5)\end{array}$ & - & - \\
\hline NW. Vancouver Island & $\begin{array}{c}3.0 \\
(-i 1)\end{array}$ & $\begin{array}{c}0.6 \pm 0.6 \\
(0.03-1.3 ; 4)\end{array}$ & - & - \\
\hline SW. Vancouver Island & $\begin{array}{c}8.5 \pm 5.1 \\
(4.1-14.2 ; 5)\end{array}$ & $\begin{array}{c}4.5 \pm 1.3 \\
(2.8-6.0 ; 6)\end{array}$ & $\begin{array}{c}t .9 \pm 1.4 \\
(0.9-2.9 ; 2)\end{array}$ & $\begin{array}{c}0.7 \\
(-; 1)\end{array}$ \\
\hline
\end{tabular}

areas ( 12.9 birds $\left./ \mathrm{km}^{2}\right)$, relative to more nearshore channel and fjord habitats (6.3 and 0.2 birds $/ \mathrm{km}^{2}$, respectively). Carter and Sealy (1990) reported lower densities of murrelets in mid-channel, than in shallower, sheltered nearshore waters in Trevor Channel, Barkley Sound. High densities were associated with sheltered, shallow nearshore water and at a sill at the mouth of the channel, where a thermal front was frequently found (Carter 1984).

I summarized data from Carter's (1984) grid and transect surveys in and near Barkley Sound to show the distribution of Marbled Murrelets relative to distance from the shore ( $f i g$. 5). The distances to shore were estimated from the midpoints of each of 12 sample blocks in Trevor Channel and from the midpoints of each of 16 transect segments in Trevor Channel, Imperial Eagle Channel, and the open sea off Cape Beale (collectively referred to here as the Cape Beale transects). The transect densities were converted from birds $/ \mathrm{km}$ as given by Carter (1984) to birds $/ \mathrm{km}^{2}$ by assuming a 250 -m transect width on each side of the boat (the same as used in the grid surveys). Murrelets in this area were strongly aggregated within $1 \mathrm{~km}$ of the shore, with highest densities $100-600 \mathrm{~m}$ offshore (fig. 5). Similar results were found in grid surveys in 1992 and 1993 (fig. 5 inset). Overall, the 1980 data fitted a negative logarithmic curve:

density $\left[\right.$ birds $\left./ \mathrm{km}^{2}\right]=2.438 d^{-1.356}$

$\left(r^{2}=0.735, n=28, P<0.001\right)$ where $d$ is distance from shore in kilometers. This curve is plotted in figure 6 for values of $d \geq 100 \mathrm{~m}$. The density for $d<100 \mathrm{~m}$ was assumed to be $7 \mathrm{birds} / \mathrm{km}^{2}$ from the data in figure 5 . This model probably applies only to more exposed shores of western Vancouver Island.

A strikingly different distribution pattern emerges from surveys made in Laskeek Bay, Queen Charlotte Islands, from 1989 through 1993 (see appendix 1 for references). Two types of transects were sampled repeatedly: shoreline transects within $400 \mathrm{~m}$ of the surfline and linear transects in open water and among islands, up to $3 \mathrm{~km}$ from land. The open water transects often had similar or higher densities than the nearshore ones, and there was considerable variation within and between seasons (fig. 7). The variability in these data emphasizes the need for caution in interpreting distribution and census data based on only one or a few seasons.

In 1992 the positions of all Marbled Murrelets in open water at Laskeek Bay were plotted on a chart to the nearest $200 \mathrm{~m}$ and, at this fine scale, show the widespread and variable distribution of murrelets relative to the nearest land (fig. 6). The pattern in these sheltered waters is quite different from that of the more exposed outer Barkley Sound area shown by the logarithmic model (fig. 6). These data clearly illustrate the problems in estimating total densities for any marine area from extrapolations of one or more shoreline transects. The distribution pattern for open and exposed water is quite 
Trevor Channel and Cape Beale surveys (1980)

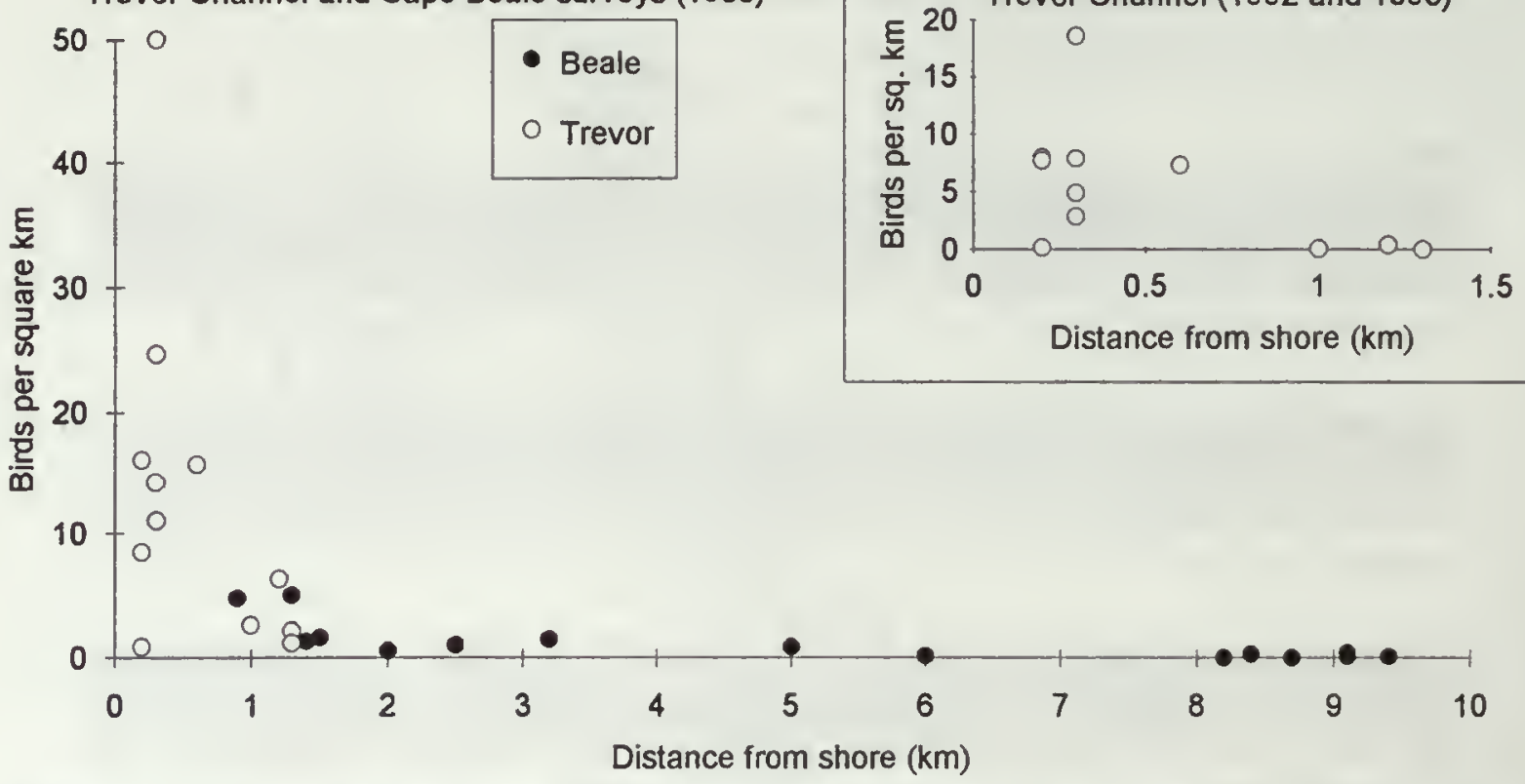

Figure 5-Densities of Marbled Murrelets in and near southern Barkley Sound between 1 May and 31 July in 1980, 1992, and 1993. The main graph shows densities from grid surveys in Trevor Channel and strip transects near Cape Beale in 1980 (Carter 1984). The inset shows densities from grid surveys in Trevor Channel in 1992-1993 (Burger 1994).

different, and the presence of islands and reefs adds further complications (see also Sealy 1975c, Sealy and Carter 1984).

\section{Temporal Patterns}

Using repeated grid surveys in Trevor Channel, Barkley Sound, Carter and Sealy (1990) showed that local densities of Marbled Murrelets declined, but clumping increased through the day. Consistent high densities in some quadrats and direct flights by murrelets into these areas at dawn indicated that the birds were returning to predictable feeding sites. Nitinat Lake, a large semi-saline lake adjacent to important forest and marine habitats appears to be used as a staging area for murrelets which leave the forests at dawn and later move to the ocean (Burger 1994).

\section{Effects of Temperature and Salinity}

In fjords and channels in Desolation Sound, Kaiser and others (1991) found no correlation between murrelet density and sea surface temperature, and a weak positive correlation with salinity $\left(r^{2}=0.256, n=20, P<0.05\right)$. Between 6 June and 8 August 1990, the murrelets were often concentrated in areas with strong currents, and densities were negatively but weakly correlated with sea temperature $\left(r^{2}=0.185, n=15, P\right.$ $<0.05$ ). Warm water was associated with algal blooms, creating surface turbidity, which might have affected prey densities and the birds' hunting efficiency. The murrelet's primary prey, sand lance, was usually found in clear water. These fish are likely to move to deeper water or become dormant in their burrows in unusually warm water (Field
1988). Murrelet densities declined rapidly in late July as the surface water heated up to near $20^{\circ} \mathrm{C}$. Large-scale effects of warm water influxes are described below.

\section{Tidal Patterns and Presence of Rips}

The relationship between tides and feeding patterns of Marbled Murrelets in British Columbia is not consistent. Repeated surveys in Barkley Sound (Carter 1984, Carter and Sealy 1990) and Desolation Sound (Kaiser and others 1991) reported no significant changes in murrelet densities with tidal state or tidal flow rate. Aggregations of murrelets at sites with strong tidal flow were reported from Edye Passage and north of Stevens Island, both on the northern mainland (Fuhr, pers. comm.), Hiekish Narrows (central mainland), and Desolation Sound (Kaiser and others 1991), Sechelt Rapids in Jervis Inlet (Vermeer 1989), and Yuculta Rapids between Sonora Island and the mainland (Prestash, pers. comm.). Marbled Murrelets were sparse or absent, however, at strong tidal rips at Malibu Rapids (Jervis Inlet), and Active Pass (Gulf Islands) where many gulls and other birds were feeding (Vermeer 1989, Vermeer and others 1987).

\section{Abundance Related to Feeding and Nesting Habitats}

\section{Effects of Prey Availability}

There have been no detailed comparisons of murrelet distribution relative to. independent measures of prey 


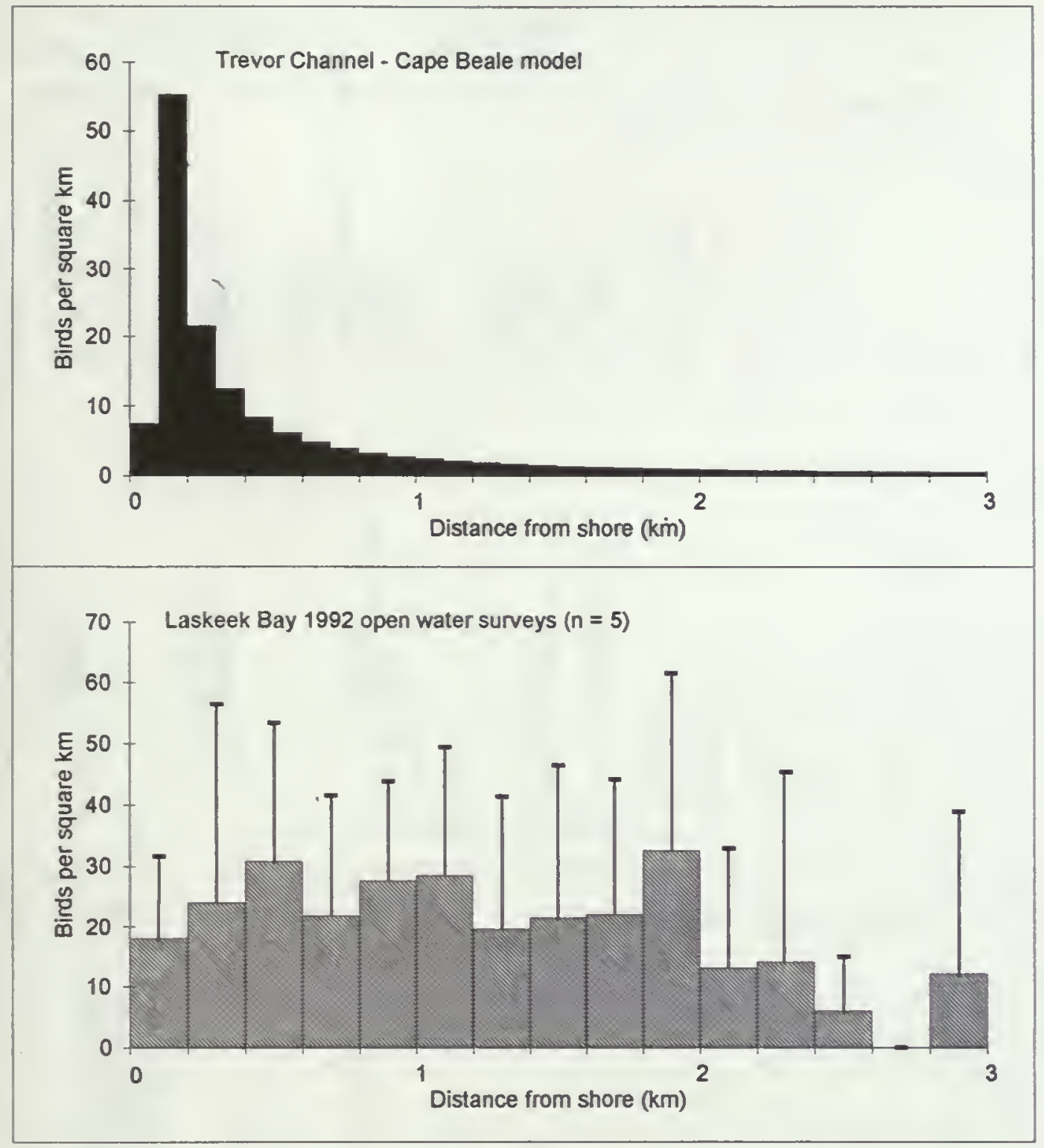

Figure 6-Variations of the density of Marbled Murrelets with distance from shore, in exposed (upper) and sheltered (lower) inshore waters in British Columbia. Upper. densities predicted by the logarithmic model derived from Carter's (1984) counts made in 1980 in Trevor Channel and the Cape Beale area (see fig. 5). Lower: mean densities in 200-m segments of open water surveys made in Laskeek Bay in 1992 (Lawrence, pers. comm.). Error bars show standard deviation.

abundance, such as estimates using echosounders. Carter (1984) explained the influx and aggregations of murrelets in Trevor Channel, Barkley Sound, as a consequence of aggregations of juvenile herring (Clupea harengus) and sand lance. Murrelet distribution in this area was highly clumped and was associated with features such as gravel or sand substrates, where sand lance might burrow, or thermal fronts and small channels, where juvenile herring and other prey aggregate (Carter 1984, Carter and Sealy 1990). Carter (1984) found that murrelets in Trevor Channel were more likely to have food in their guts in the morning than in the afternoon or at night, and linked this with the availability of sand lance and juvenile herring in surface waters. Off Langara Island, where murrelets concentrated on euphausiids and sand lance, the birds appeared to feed throughout the day (Sealy 1975c). Availability of sand lance appeared to affect both the spatial distribution and the seasonal densities of murrelets in Okeover Inlet, Desolation Sound during the breeding season (Kaiser and others 1991, Mahon and others 1992).

The effects of El Niño and other oceanographic events on murrelets in British Columbia are poorly known. Exceptionally warm water persisted off southwestern Vancouver Island from January through August 1992 and again from April through mid-June 1993 (data from $\mathrm{H}$. Freeland, in Burger 1994). In Barkley Sound this warm water was associated with an influx of mackerel (Scomber japonicus) 

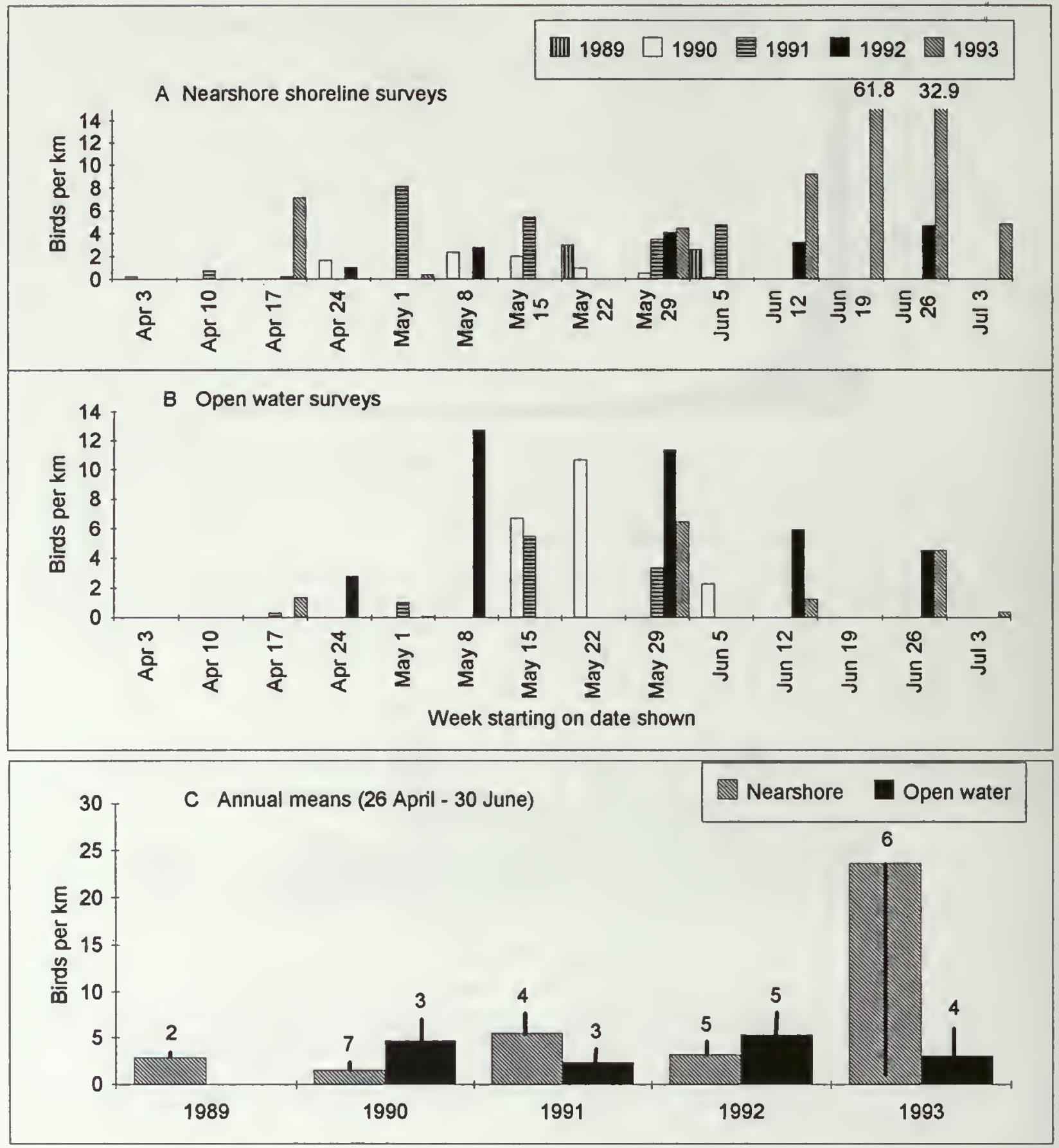

Flgure 7-Densities of Marbled Murrelets in Laskeek Bay, Queen Charlotte Islands, showing seasonal patterns in nearshore surveys (A) and those in open water (B); and inter-year variations in mean densities (C). No open water surveys were made in 1989. Sample sizes show numbers of surveys used to calculate the mean values for the period 26 April through 30 June. Error bars show standard deviations (inverted for 1993 nearshore). Transect widths were $400 \mathrm{~m}$ throughout (Lawrence, pers. comm.).

and jack-mackerel (Trachurus symmetricus), which eat prey similar to that taken by murrelets, and significantly low densities of euphausiids and juvenile herring (Hargraves, pers. comm.; Tanasichuk, pers. comm.). Murrelet surveys in the Broken Islands showed no effects of these changes in 1992, relative to 1991 , but in 1993 many murrelets appeared to leave the Broken Islands and the Deer Island-Trevor Channel area in June, at least a month before their usual departure (fig. 8).

\section{Abundance and Distribution Relative to Distribution of Forest Stands}

There are insufficient data for coarse-scale comparisons between murrelet densities at sea and rates of detections in adjacent forests. Murrelet detection frequencies in forest surveys on the east coast of Vancouver Island, which has been extensively logged, were much lower than on the west coast (Savard and Lemon in press), and this corresponds to 


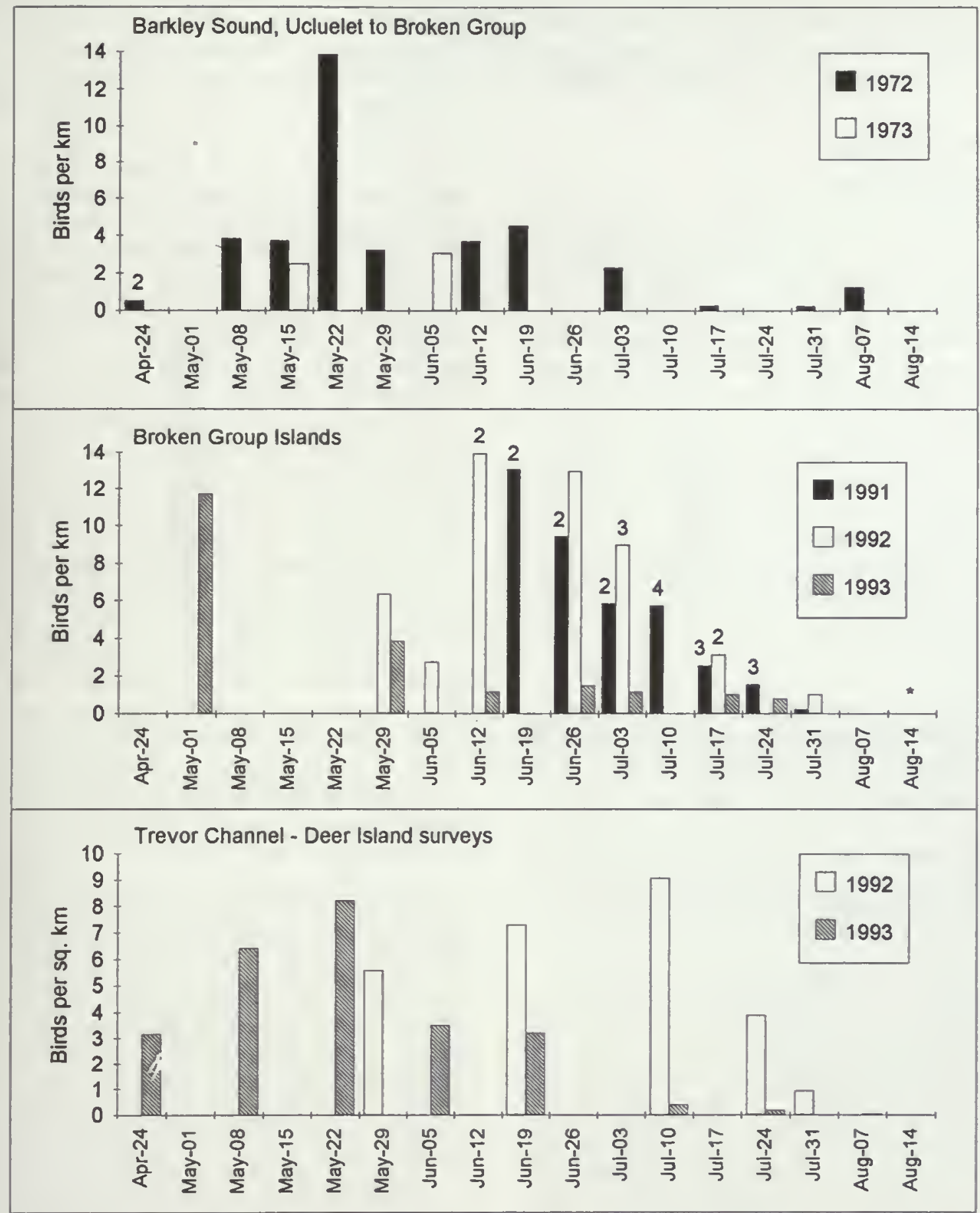

Flgure 8-Densities of Marbled Murrelets in Barkley Sound, plotted in weekly intervals through the breeding season. One survey was made per week, except where indicated by numbers above the columns. The asterisk indicates a survey with no murrelets seen. Note that the units of density are not the same in all studies. Data from Hatler and others (1978) and Burger (1994).

a general pattern of low densities at sea in summer off the east coast (appendix 1).

On a finer scale, Burger (1994) examined murrelet densities in 19 segments of coast between Pachena Bay and Port San Juan off southwestern Vancouver Island. This $65-\mathrm{km}$ stretch of coast has one of the highest known densities of murrelets in British Columbia (appendix I) and is relatively straight and unbroken, and hence more easily censused than along the highly indented coastline found in most of British Columbia. Adjacent to this area are some of the largest tracts of oldgrowth forest remaining on southern Vancouver Island, specifically the Nitinat-Tsusiat-Klanawa and CarmanahWalbran watersheds. The highest at-sea densities in both 1991 and 1993 were consistently found in four segments immediately 
adjacent to these two tracts of forest, while most of the very low-density areas were adjacent to heavily logged watersheds (Burger 1994). The relative importance of marine versus forest habitat in explaining this distribution has not been determined.

\section{Population Changes}

\section{Historical Numbers and Distribution}

Rodway (1990) and Rodway and others (1992) reviewed the scanty evidence of long-term population changes in British Columbia. There is anecdotal evidence of population declines in the Strait of Georgia. Brooks (1926b) commented on the scarcity of murrelets on the east coast of Vancouver Island in 1925-1926, compared to numbers seen in 1920 and earlier, and speculated that disease or crude oil might have been responsible. Pearse (1946) reported a decline in murrelet numbers in the Comox district, eastern Vancouver Island, between 1917 and 1944 and attributed this to the removal of coniferous forests. Rodway and others (1992) found no significant trends in numbers of murrelets observed in Christmas Bird Counts made at 22 sites, some extending back as far as 1957 , but relatively few counts were from regularly used wintering areas.

\section{Recent Trends}

I assessed changes in densities of Marbled Murrelets in the past 15-20 years by comparing surveys made from 1976 through 1982 with more recent surveys. Relatively few areas can be compared, and the precise routes and methods of some of the earlier surveys could not always be replicated. The paucity of annually repeated surveys makes it difficult to rule out inter-year fluctuations (perhaps related to oceanic effects) as the cause of some of the changes reported here.

\section{Clayoquot Sound and Barkley Sound}

In June 1992 and 1993, Kelson and others (in press; Kelson, pers. comm.) repeated the grid census made in southeastern Clayoquot Sound in June 1982 by Sealy and Carter (1984). In each year the entire area $\left(294 \mathrm{~km}^{2}\right.$; Tofino Sound excluded) was surveyed once, over periods of several days, by counting all murrelets seen within $250 \mathrm{~m}$ of a boat traversing a u-shaped path through each $1-\mathrm{km}$ by $1-\mathrm{km}$ block. The spatial distributions of the birds were broadly similar in each count, but the total numbers declined from 4,522 in 1982 to 2,701 (60 percent of the 1982 total) in 1992 and 2,622 (58 percent) in 1993. Kelson and others (in press) attributed the decline to significant reductions in old-growth forests adjacent to Clayoquot Sound.

Carter (1984) used a similar grid technique in June and July 1980 in outer Trevor Channel and the adjacent Deer Islands, one of the areas with consistently high densities in Barkley Sound (Carter and Sealy 1984). In 10 morning surveys he recorded a mean of 351.6 birds (on the water and flying; range 74-518) Repeating these censuses for the morning periods in 1992 and 1993, Burger (1994) recorded averages of only 153.0 (range 92-215; four surveys) from 2
June to 26 July 1992 and 86.0 (4-194; six surveys) from 1 May to 25 July 1993 . These means represent 44 percent and 25 percent of the 1980 mean, respectively. The low 1993 numbers were partly due to an early departure from this area of murrelets in June, which was associated with persistent warm water and possible low prey densities.

In 1979, Carter (1984) counted murrelets in a 17.2-km linear transect running through outer Trevor Channel and along the open coast to Seabird Rocks. Burger (1994) counted seabirds along a virtually identical $19.5-\mathrm{km}$ route in 1987 , 1989,1991 , and 1993 and found significantly lower murrelet densities, with the mean values consistently less than 50 percent of the 1979 value (fig. 9; 1979 data versus pooled data 1987-1993: Mann-Whitney test, $\mathrm{U}_{7,13}=79.5, \mathrm{P}<0.01$ ). Other censuses suggest that 1979 was not an unusual year in this area for the study period 1979-1982 (Carter 1984, Sealy and Carter 1984a). These three replicated studies are consistent in showing a significant decline in the densities of Marbled Murrelets in Clayoquot and Barkley sounds. The changes might be partly due to coarse-scale shifts in distribution, but the Clayoquot Sound surveys covered a large area in which distribution shifts of 1-10 km should have been detected. It is likely that the 1992 and 1993 El Niño conditions caused many murrelets to leave Clayoquot and Barkley Sound temporarily. Support for this hypothesis came in spring 1994 when densities of murrelets in Trevor Channel, Barkley Sound, were 2-3 times higher than they had been in 1992 and 1993 (Burger, unpubl. data). There is no simple correlation between murrelet numbers and local sea temperatures, however, because summer temperatures were also above normal in early counts in 1979 and 1980 (but not 1982) and in later counts in 1987 and 1989 (data from H. Freeland, in Burger 1994). The effects of local ocean temperatures, upwelling events, and El Niño conditions on the distribution of Marbled Murrelets and their prey clearly need to be investigated in detail to help explain the apparent declines.

One likely cause of decline is the widespread loss of valley-bottom old-growth forests in the surrounding areas (Kelson and others in press, Sealy and Carter 1984). Between 1954 and 1990, an estimated 75 percent of the ancient rainforest of southern Vancouver Island was logged, including extensive tracts adjacent to Clayoquot and Barkley Sounds (Husband and Frampton 1991), and much of this occurred in the past decade. Gill-net fishing also killed appreciable numbers of murrelets in Barkley Sound (Carter and Sealy 1984), but does not occur here every year (Burger, pers. obs.) and is not a factor in Clayoquot Sound (Kelson and others, in press). Increased disturbances from sports fishing and recreational boating might have displaced murrelets at a few localities.

\section{Queen Charlotte Islands}

Nearshore surveys made in May and June in 1977 (Vermeer and others 1983) provide comparative data for some areas in which similar surveys were undertaken in 1990-1992 (table 3). The trends were not consistent; there were increases in two areas with relatively low densities, but 


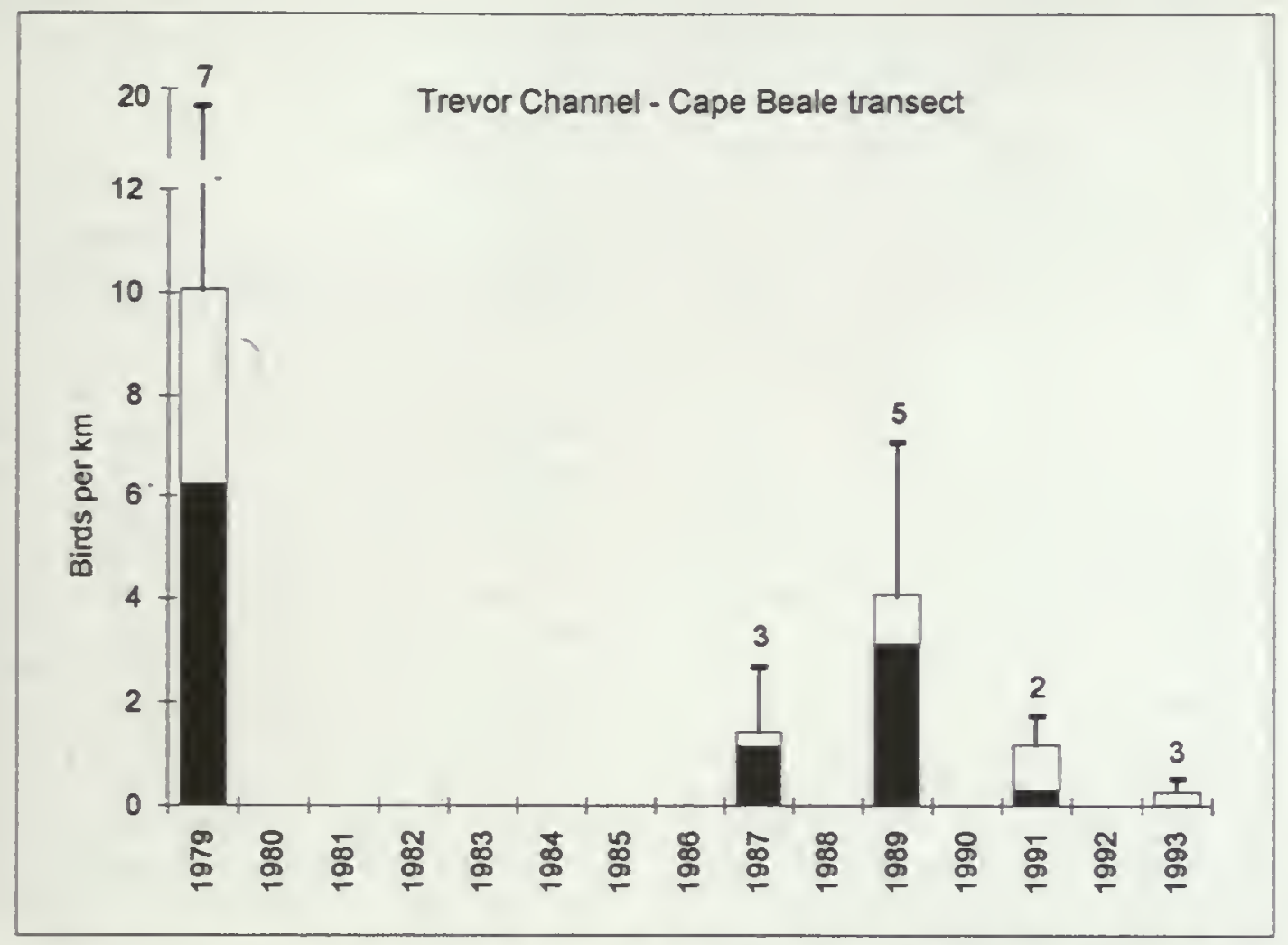

Figure 9-Mean (ts.d.) densities of Marbled Murrelets on transects of 17.2-19.5 km in Trevor Channel, past Cape Beale and south to Seabird Rocks in June and July of 1979, 1987, 1989, 1991, and 1993 (Burger 1994, Carter 1984). The sample sizes are numbers of transects. Birds seen on the water and flying are shown in shaded and open columns, respectively.

slight declines in two areas in which many murrelets occurred. The changes were well within the year-to-year variations reported for this coast. Considerable logging of old-growth forests has occurred around Skidegate Inlet and to the north of Juan Perez Sound, but the forests adjacent to Skincuttle Inlet have not been logged. Oil spills and gill-net fisheries do not appear to have been problems for murrelets in any of these areas. The low densities in Massett Inlet shown contrast with records of flocks of 200 or more in the summers of 1946 and 1947 (Carter 1984), but large flocks were also present in May 1990 (Rodway and others 1991). There were thus no indications of significant population declines in these parts of the Queen Charlotte Islands, but the data were insufficient to reliably detect any real changes.

\section{Threats to Marbled Murrelets at Sea in British Columbia}

\section{Oil Pollution}

There is a moratorium on offshore exploration and development of oil fields in British Columbia, and this seems likely to continue. Threats to murrelets come from catastrophic spills from large vessels as well as chronic small-volume spills (Burger 1992, Vermeer and Vermeer 1975). The Canadian Coast Guard (1991) reported annual transits of 7,000 freighters and tankers off British Columbia, including at least 1,500 tankers. Each year at least 300 loaded tankers enter the Strait of Juan de Fuca (Shaffer and others 1990). Overall, the annual shipments of crude oil and refined petroleum products average 26.0 and 15.0 million $\mathrm{m}^{3}$, respectively, in southern British Columbia and northern Washington (Shaffer and others 1990). Vessel traffic was estimated to increase by $6-11$ percent between 1989 and 1991 (Canadian Coast Guard 1991). A probability model predicted that spills exceeding 1,000 barrels are expected in southern British Columbia and northern Washington every 2.5 years for crude oil, and every 1.3 years for all petroleum products (Cohen and Aylesworth 1990), and this prediction was close to the actual pattern of spills between 1974 and 1991 (Burger 1992). These studies indicate a high risk from oiling for Marbled Murrelets. This is particularly pertinent in inshore areas off southwestern Vancouver Island in summer and southern Strait of Georgia and Puget Sound in winter, when high murrelet densities coincide with the greatest volumes of tanker traffic and other shipping (Burger 1992).

The Nestucca spill in December 1988 killed an estimated 143 Marbled Murrelets off Vancouver Island (Burger 1993a), which represents about 0.9 percent of the 16,000 birds thought to occur off Vancouver Island (Rodway 1990). Marbled 
Table 3-Density estimates (birds perlinear $\mathrm{km}$ ) of Marbled Murrelets at four nearshare sites in the Queen Charlatte 1slands surveyed in May-June 1977 and again in spring or summer 1990,1991 ar 1992. See appendix 1 for details

\begin{tabular}{l|cccc}
\hline Sample area & 1977 & 1990 & 1991 & 1992 \\
\hline Massett Inlet & 0.0 & 0.3 & - & - \\
Skidegate Inlet & 0.5 & 1.0 & - & - \\
Juan Perez Sound & 4.7 & - & 3.2 & 3.6 \\
Skincuttle Inlet & 7.4 & - & 3.5 & - \\
\hline
\end{tabular}

Murrelet carcasses were rarely found in surveys of beached birds in southern British Columbia, and were not among the small sample of birds killed by chronic oiling but could easily have been overlooked (Burger 1993b).

\section{Other Toxic Chemicals}

High levels of polychlorinated biphenyls (PCBs), dioxins, and furans have been found in some piscivorous birds in inshore waters of British Columbia, although Marbled Murrelets were not sampled (Elliott and Noble 1993). Levels of these contaminants and of organochlorides appear to be declining in water birds sampled in British Columbia (Elliott and Noble 1993, Elliott and others 1992).

\section{Gill Nets}

Little is known about the effects of gill nets on seabirds in British Columbia. In 1988, the gill-net effort totaled 54,770 net-days, concentrated in summer and fall in inshore areas (Barlow and others 1990). Anecdotal evidence from fishermen suggests that Marbled Murrelets are among the bird species most often killed. Carter and Sealy (1984) estimated that the bycatch of 200 Marbled Murrelets caught in gill nets in Barkley Sound in 1980 represented a loss of 7.8 percent of the expected fall population (including loss of fledglings caused by deaths of parent birds). There have been no other studies of this problem in British Columbia, but it clearly needs to be examined in detail.

\section{Other Effects of Fishing and Aquaculture}

Competition with the fishing industry for prey species does not appear to be a significant issue for murrelets in British Columbia. The herring stocks appear to have recovered after periods of overfishing in the 1960's and are now strictly regulated. Sand lance, zooplankton, and other prey species are not fished in appreciable amounts. Sport fishing continues to increase, and disturbance from the hundreds of small boats, plus occasional bycatch of murrelets on lures is possibly a localized problem.

Habitat degradation and disturbance at fish and shellfish pens can affect Marbled Murrelets, and many aquaculture farms exist or are planned in sheltered inshore waters favored by murrelets (e.g., Clayoquot, Barkley, and Desolation sounds). Marbled Murrelets were not among the species considered to be most affected by aquaculture in British Columbia (Rueggeberg and Booth 1989).

\section{Conclusions}

Proper management of the Marbled Murrelet in British Columbia requires an improved estimate of the provincial population and better understanding of its distribution and relative abundance in the breeding and nonbreeding seasons (Kaiser and others 1992). The census coverage of marine areas has greatly increased over the past decade, but quantitative surveys are still lacking for large tracts of the convoluted $27,000-\mathrm{km}$ coastline (fig. 4). The differences in distribution between exposed and sheltered waters (e.g., fig. 6) and the variability within and among seasons (e.g. fig. 7 and 8 ) make it very difficult to estimate regional populations from single-season shoreline transects. We need to know a lot more about the factors which affect the murrelet's marine distribution, such as prey distribution and effects of tides, sea temperature, salinity, and seafloor topography, before we can plan and interpret census transects and monitor population dynamics. Regularly repeated surveys made over many years, such as those performed in Laskeek Bay and Barkley Sound, will be very valuable in showing both shortand long-term patterns.

Most of the urgent gaps in our knowledge can be filled by relatively simple, inexpensive studies of fine-scale distribution and foraging ecology if they are carefully planned to collect the most pertinent data. There are also opportunities to tap the expertise of the burgeoning number of birders and naturalists who visit remote coastal areas of British Columbia. The establishment of a long-term data base, meshed with a Geographic Information System, would facilitate the accumulation of data from both dedicated and opportunistic censuses. Other priority problems, such as making a provincewide marine census, measuring population demographics, or investigating the effects of gill nets or logging, require more dedicated, expensive studies.

\section{Acknowledgments}

Preparation of this chapter was funded by the British Columbia Ministries of Forests (Research Branch) and Environment, Lands and Parks (Wildlife Branch), and I thank Brian Nyberg and Don Eastman for their support. I thank Dick Brown, Rick Burns, Tony Gaston, Gary Kaiser, Anne Harfenist, Moira Lemon, Ken Morgan, and Lynne Prestash for valuable comments. Unpublished material was provided by Rick Burns, James Clowater, Brian Fuhr (Wildlife Branch), Bob Hanson (Pacific Rim National Park), John Kelson (Conservation International), the Laskeek Bay Conservation Society, Andrea Lawrence, Lynne Prestash, Anne Stewart (Bamfield Marine Station), and Anne Harfensit, Gary Kaiser, and Moira Lemon of the Canadian Wildlife Service. A special thanks to Andrea Lawrence for assistance in analyzing the Laskeek Bay data and with many other parts of the chapter. 


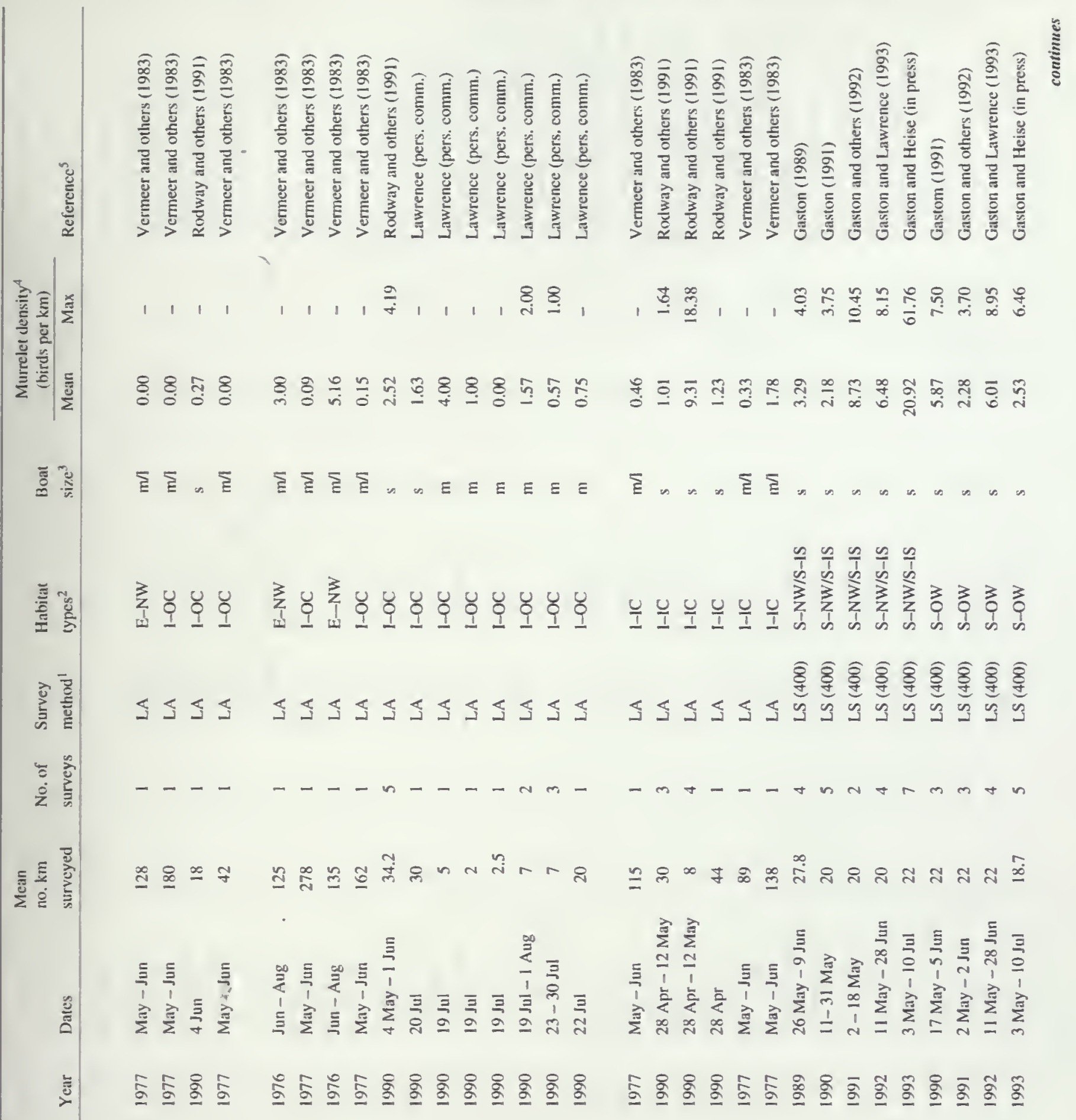




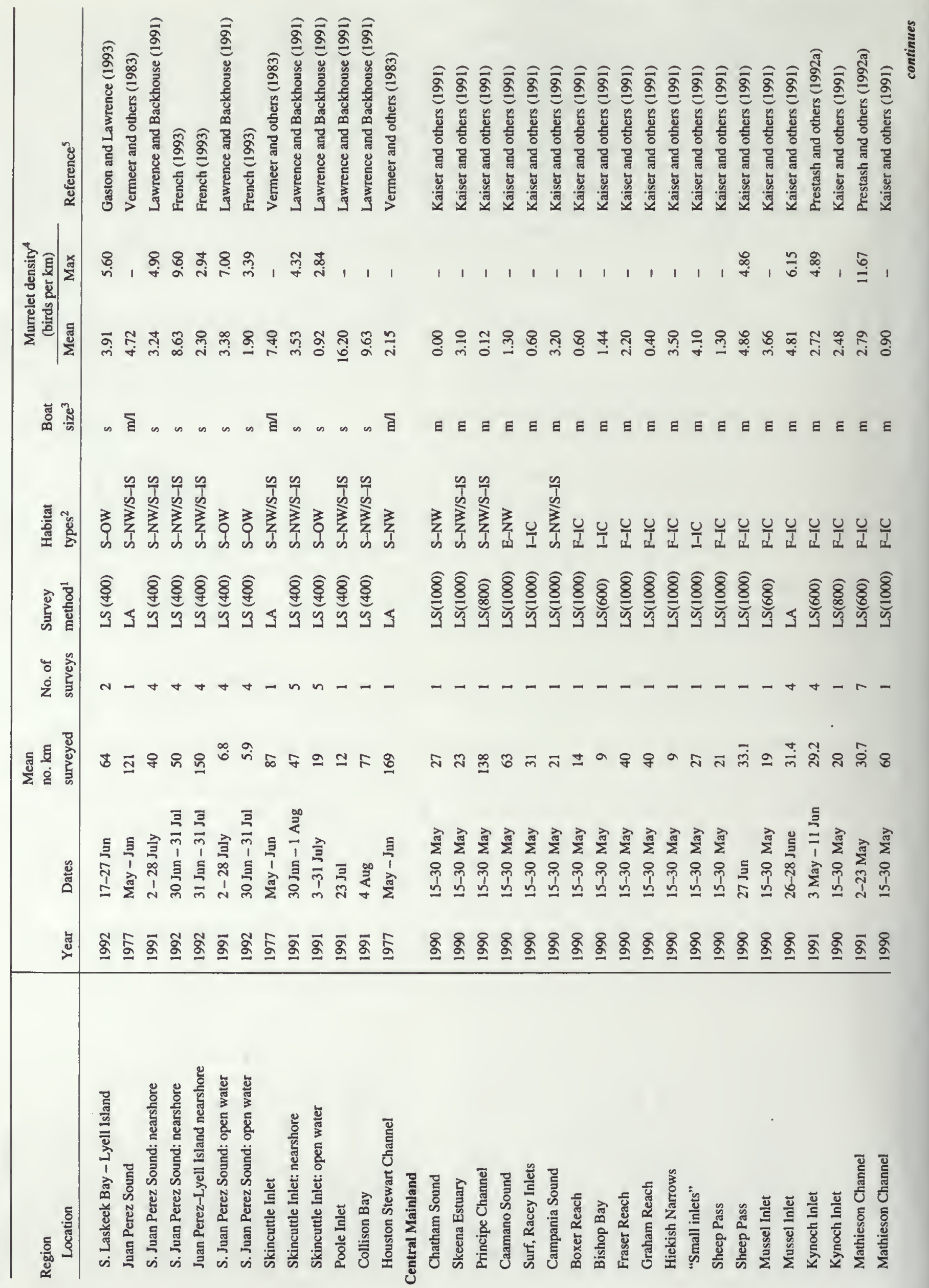




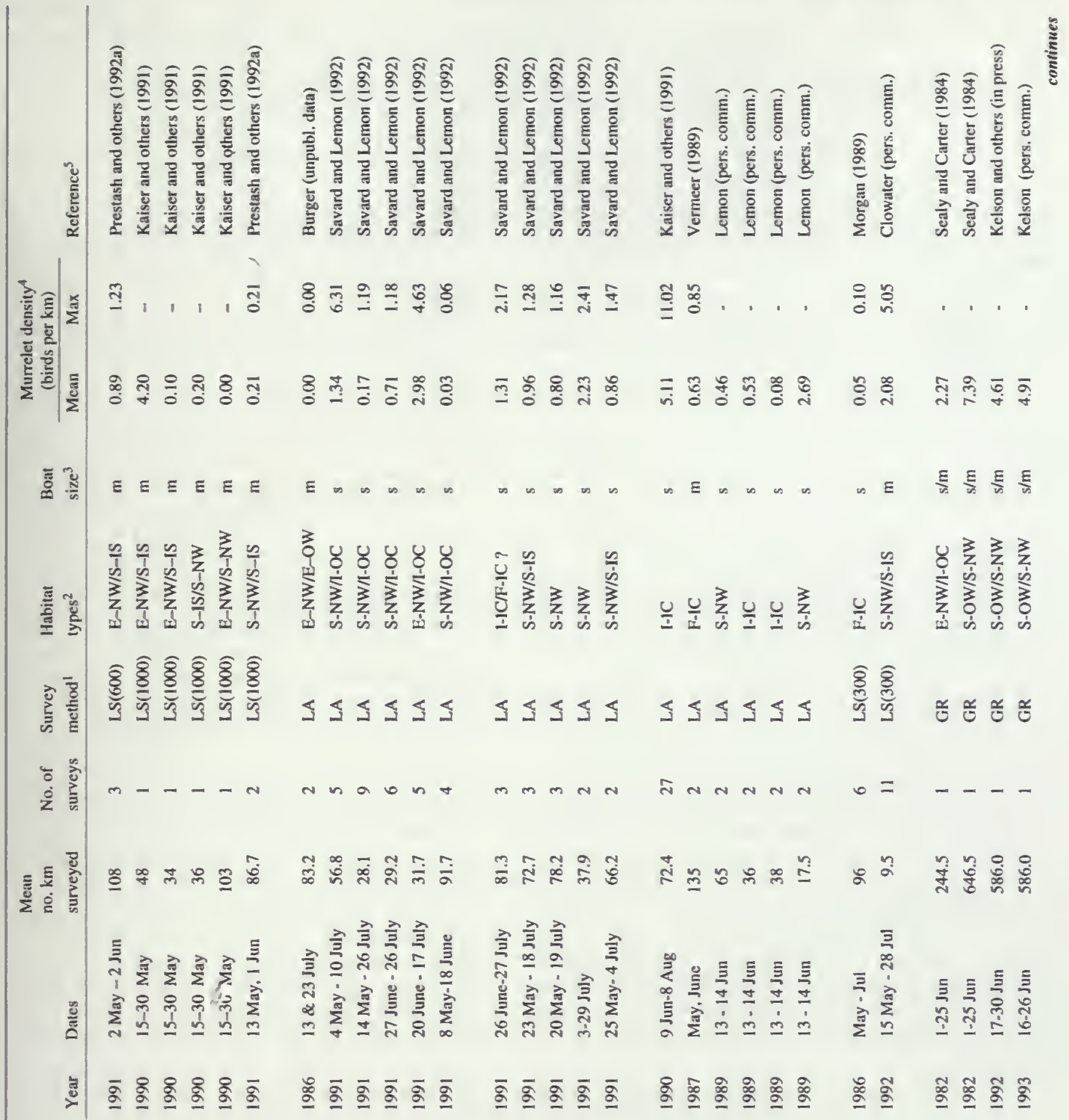

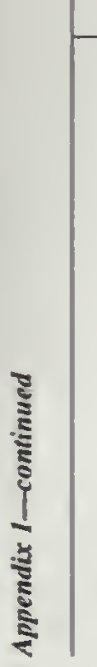

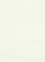




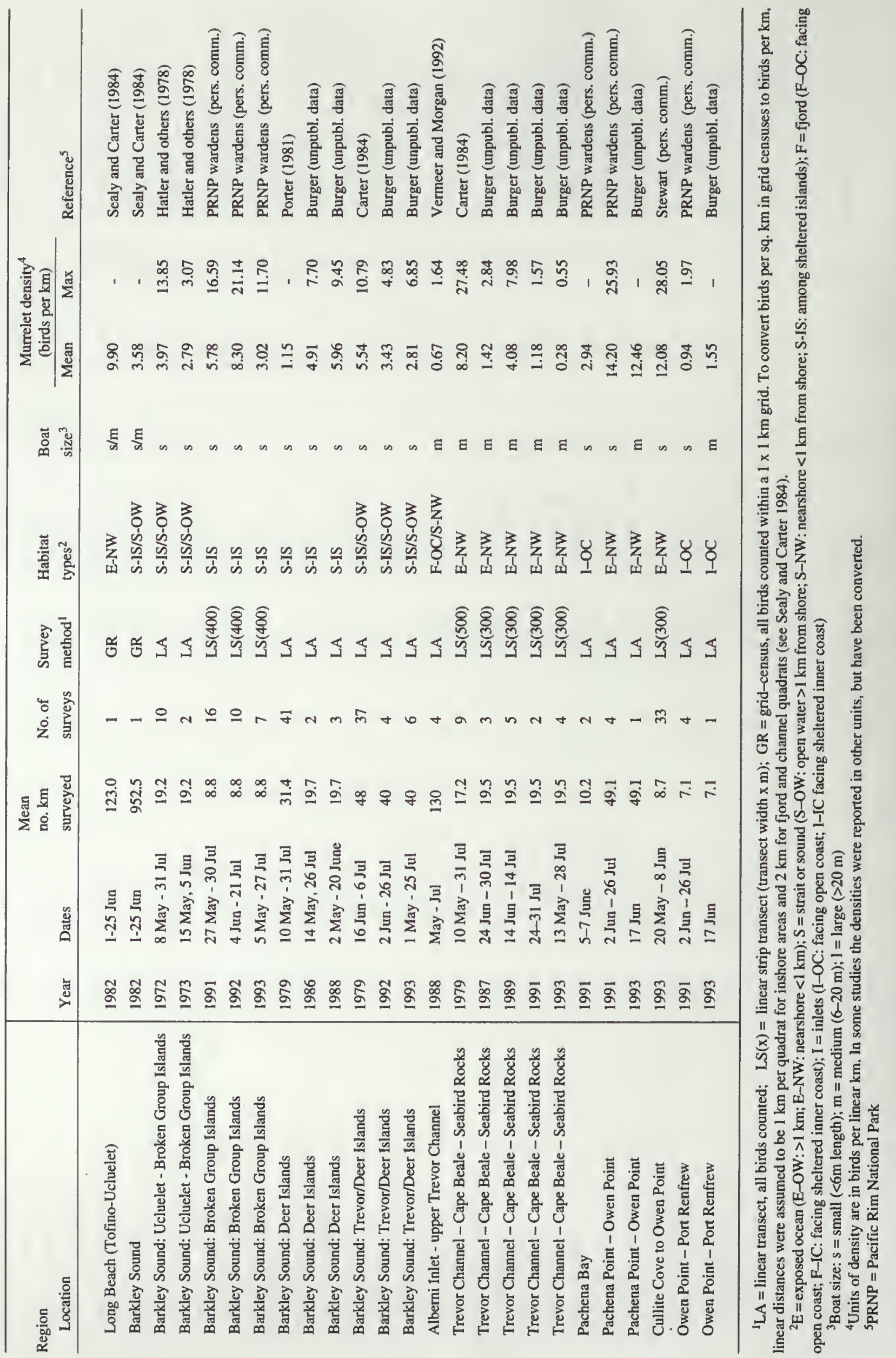




\title{
Marbled Murrelet Populations of Washington- Marine Habitat Preferences and Variability of Occurrence
}

\author{
Steven M. Speich' Tersence R. Wahl ${ }^{2}$
}

\begin{abstract}
Marbled Murrelets occur in Puget Sound marine habitats in relatively low numbers. The rates of occurrence of murrelets on censuses within marine habitats is generally low. Further analysis is required to determine if low occurrence rates are a general function of the movement of birds, or their consistent occurrence on particular censuses and not on others. Qualitative data indicate that Marbled Murrelet abundance in Puget Sound is now lower than earlier this century. Such long-term information is unavailable for Marbled Murrelets along the Pacific Ocean coast of Washington. Census data from nearshore waters of the Pacific Ocean off Grays Harbor indicate that Marbled Murrelet abundance is reduced there since 1989 and especially in 1993. This pattern is also reflected in several other more oceanic species suggesting basic and widespread changes in marine carrying capacity.
\end{abstract}

Early reports on the birds of Washington (Dawson and Bowles 1909, Jewett and others 1953) consisted primarily of interesting general accounts, whereas several recently published reports have focused specifically on marine birds in Washington (Briggs and others 1992; Cody 1973; Grover and Olla 1983; Manuwal and Campbell 1979; Manuwal and others 1979; Paine and others 1990; Speich and Wahl 1989; Wahl 1984; Wahl and Speich 1984; Wahl and Speich, in press; Wahl and others 1981; Wilson 1991). Despite these reported activities of researchers, including ourselves, little has been written of the habitat preferences of marine birds, including Marbled Murrelets, in Washington. Lately, a few general descriptions and quantifications of the abundance of marine birds based on marine habitats have appeared. While only the reports of Wahl and others (1981) and Long (1983) are pertinent to Puget Sound, and of Wahl (1984,, Speich and others (1987), and Briggs and others (1992) to the Pacific Ocean coast, they only marginally included the Marbled Murrelet. The same paucity of information pertains to the foods of marine birds in Washington marine areas, with the exception of a few species specific studies (e.g., Rhinoceros Auklet [Cerorhinca monocerata] [Wilson and Manuwal 1986]). Little has been written that specifically deals with Marbled Murrelets in Washington marine waters (Speich and others 1992; Thoresen 1989; Varoujean and Williams, this volume).

Marbled Murrelets are found throughout the Puget Sound region, although their distribution varies spatially and temporally (Speich and others 1992; Wahl and others 1981; Wahl and Speich 1983, 1984). Speich and others (1992)

\footnotetext{
${ }^{1}$ Research Ecologisl, Dames \& Moore, Inc., 1790 E. River Road, Suite E-300, Tucson, Arizona 85718

${ }^{2}$ Naturalist, 3041 Eldridge, Bellingham, Washinglon 98225
}

attempted to establish the size of populations in each of the major marine areas of Washington, to determine if a seasonal change in numbers occurred, and to evaluate historical marine evidence for changes in the numbers of breeding birds. The results were a breeding population estimated at near 5,000 Marbled Murrelets, evidence of an influx of birds into at least Puget Sound during the winter, and an indirect conclusion that the breeding population in Puget Sound had declined from early periods, although the magnitude of the change is unknown and cannot be quantified. Our impression is that murrelets are variable in their occurrence, moving from one area to another, often in short time periods, although birds are often found in specific areas.

In this paper we quantify and discuss the seasonal geographic and marine habitat distribution, abundance and variability of Marbled Murrelets in Washington marine waters. Changes in abundance over the past 23 years of censusing continental shelf waters near Grays Harbor are explored.

\section{Methods}

The inland marine areas of Washington, better known as Puget Sound, are a complex of bays and passages, supporting a large variety of marine habitats and associated organisms (Long 1983, Simenstad and others 1979). They are connected by larger deep water areas such as the Strait of Juan de Fuca, Admiralty Inlet, Haro Strait, Rosario Strait and Georgia Strait, all distinct habitats. During the 1978 and 1979 National Oceanic and Atmospheric Administration (NOAA) Marine Ecosystem Analysis Program (MESA), marine bird surveys of northern Puget Sound (Wahl and others 1981) censuses were established and conducted. These quantified distribution and abundance of the marine birds found in all the major marine habitat types and geographic areas of northern Puget Sound. During the MESA program, northern Puget Sound was divided into 11 major regions and 72 subregions, largely based upon marine and terrestrial geography and water depth. Each subregion, and certainly each region, contained one or more distinct marine habitat types, based on water depth, marine substrate type, slope and, in part, geography. Each region, subregion and habitat type was overlain with one or more distinct marine census transects. These transects were fixed in location and were censused by one or more standardized census methods. Census methods included small aircraft, small boats, Washington State Ferries, and fixed locations at points, about bays, and along beaches. Census data were lumped by location, marine habitat, subregion and region, and time period, as appropriate. In the habitat analysis for this paper, censuses were combined by habitat type and 
time period. Densities were calculated by dividing the total numbers of Marbled Murrelets observed by the total area censused on all censuses within each habitat types for the specific time period. Data from 1978 and 1979 were combined.

Surveys similar to the MESA bird program, partially funded by NOAA and the Washington Department of Wildlife, were later established for southern Puget Sound (Wahl and Speich 1983, 1984). These surveys were designed to allow the quantification and appraisal of the general, seasonal distribution and abundance of all marine waterbird species in southern Puget Sound. This program consisted of one complete summer survey of the area and extensive winter surveys (as yet unpublished) over several years. All winter surveys were from light aircraft and summer surveys were from small boats and light aircraft following the methods set forth in Wahl and others (1981, see above). Results are expressed as birds per square kilometer and are summarized by geographic area, inshore or offshore, and time period.

There are only limited data from the Pacific Ocean coast of Washington that quantify the occurrence of Marbled Murrelets in marine habitats. The best data are for the southern outer coast, the coast south of Point Grenville, including the Grays Harbor Channel and habitats in the shelf waters off the mouth of Grays Harbor channel to the continental shelf break (Wahl 1984), and the onshore area in the vicinity of Point Grenville (Speich and others 1987, 1992). Along the north portion of the coast, the area north of Point Grenville, only limited data are available for the nearshore and offshore waters of the continental shelf (Speich and others 1992). Censuses of birds over the continental shelf, to the shelf break, off of Grays Harbor, were made from chartered fishing boats, from 1971 to the present. Census frequency, especially during the winter storm period, was often limited for access to the ocean due to rough bar and sea conditions. All birds observed were counted and summarized for transects of varying length within specific water depth intervals, and results are expressed as birds observed per linear kilometer, as described in specific detail by Wahl (1984). Observations of birds of specified nearshore water areas from three land locations near Point Grenville were accomplished with the aid of binoculars and telescopes during the spring-summer periods of 1984 and 1985 (Speich and others 1987). Observations were expressed as Marbled Murrelets observed per square kilometer for consecutive week periods. North of the Point Grenville study area, observations were made from boats (Zodiacs) while moving up and down the coast over nearshore waters of the continental shelf (Speich and others 1992). All birds observed in moving zones about the vessel were recorded, with results expressed as birds per square kilometer.

\section{Results}

\section{Abundance and Occurrence by Habitat Types - Puget Sound}

For northern Puget Sound, the seasonal densities and percent occurrence of Marbled Murrelets were determined for censuses within five broad habitat groups, each in turn subdivided into several more specific habitat types (table 1 , figs. 1-10).

\section{Open Water Greater than $20 \mathrm{~m}$ Depth}

In Sequim and Discovery bays, the large sheltered bays at the eastern end of the Strait of Juan de Fuca, Marbled Murrelets reach peak abundance during the fall period (table 1, fig. 1). No other habitat within this habitat group had as high a density, $2.5 \mathrm{birds} / \mathrm{km}^{2}$. The maximum density obtained during the winter period, $0.92 \mathrm{birds} / \mathrm{km}^{2}$, was also from Sequim and Discovery bays. Concentrations of Marbled Murrelets were also reported from this area on Audubon Christmas Counts, according to summary statements by Speich and others (1992).

Within this habitat group, the proportion of individual censuses with Marbled Murrelets was generally near, and often less than, 20 percent $(0.2)$ (table 1, fig. 2). The exception was the summer period for Sequim and Discovery bays where Marbled Murrelets were observed on 50 percent of all censuses in the area, but the sample size $(n=2)$ is very small. Within this habitat group, the deep open waters within the San Juan Islands showed peak numbers (density) and occurrence rate during the summer and fall periods (table 1 , figs. 1 and 2).

\section{Bays with Steep and Gradual Slopes}

Habitat types within the group, "bays-steep and gradual slopes", are described by location and type (table 1, figs. 3 and 4). These habitat types generally are characterized by low densities of Marbled Murrelets. High densities of four and five murrelets per square kilometer, were found in habitats on steep slope and sand substrate within Whatcom and Skagit counties (Chuckanut Bay) and within the San Juan Islands, during the winter period.

Although the densities of Marbled Murrelets in the habitat types of this group are low, the rate of occurrence of censuses with birds is nonetheless relative high. While the density of birds was relatively high during the winter in steep slope habitats with sand substrate within the San Juan Islands, birds were only observed on about half of censuses (table 1, fig. 4). This suggests that relatively large numbers of birds were present during the winter in this habitat type, but birds move about and were not always encountered on censuses. A similar pattern was observed in this habitat type in Whatcom and Skagit Counties, except in winter when birds were detected on a greater portion of censuses, about 80 percent. Similarly, during the spring period, birds were detected on about 90 percent of censuses, even though average density ( 1.42 birds/ $\mathrm{km}^{2}$ ) (table 1) was lower than the winter period density (3.92 birds $\left./ \mathrm{km}^{2}\right)$.

\section{Areas of Tidal Activity}

The occurrence of Marbled Murrelets in areas of tidal mixing is not unexpected, as these are generally thought of as productive areas where prey concentrate in nutrient and food- 


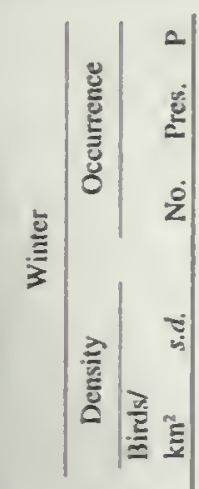

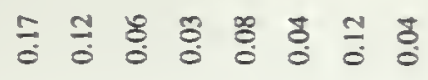

送

$m=a-\infty+a+=$

Ð

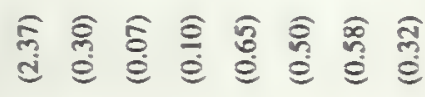

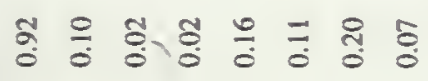

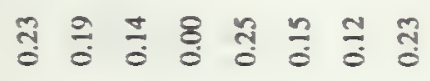

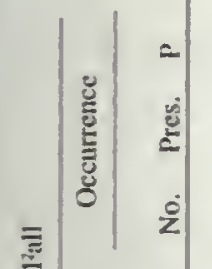

$m \simeq 0 \underline{0} \mathrm{~m} \mathrm{~m}$

I

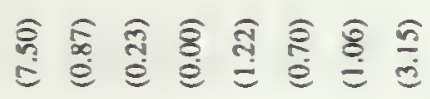

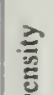

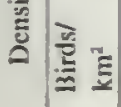

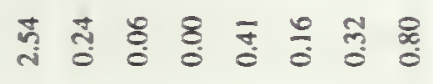

ํํㅇ สํㅇ

- n-o-0 = r

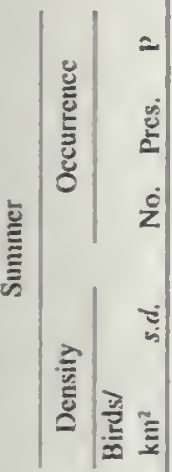

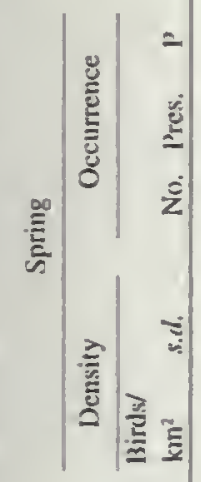

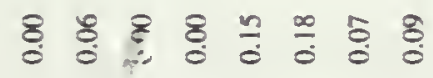

om o or $r a$

$=\tilde{n} \underline{ \pm \infty} \frac{\infty}{\alpha} \underline{8}$

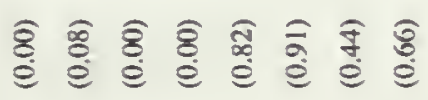

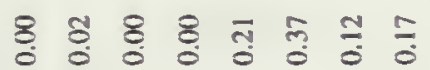

$\simeq \simeq$

ह

융 สำ

๙ั่

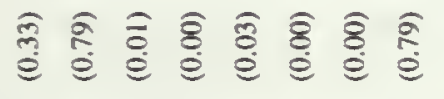

$\stackrel{\infty}{\circ} \overline{\overline{0}}$

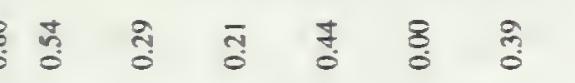

ง $\simeq$

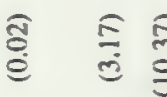

$\frac{8}{0} 3_{0}^{\circ} \frac{m}{0}$ ส $\frac{m}{0} \overline{\frac{0}{0}}$

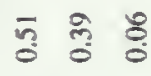

$\bar{m}-$

$\infty \propto \infty$

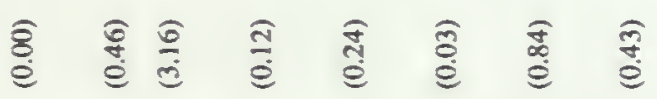

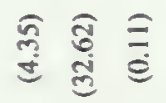

$\stackrel{8}{\circ}$

சै

$\stackrel{8}{-0}$

$\stackrel{\overbrace{}}{\stackrel{0}{0}}$

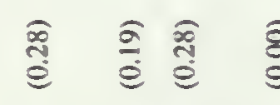

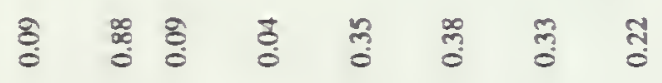

$\stackrel{\infty}{3} \frac{n}{0}=$

$=a-$

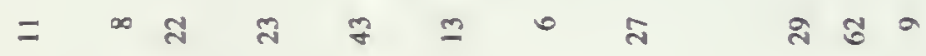

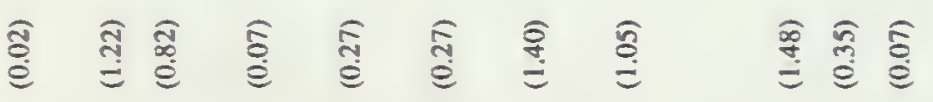

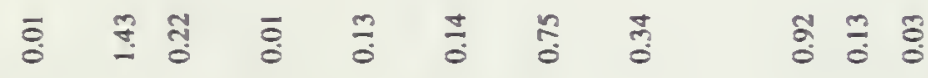

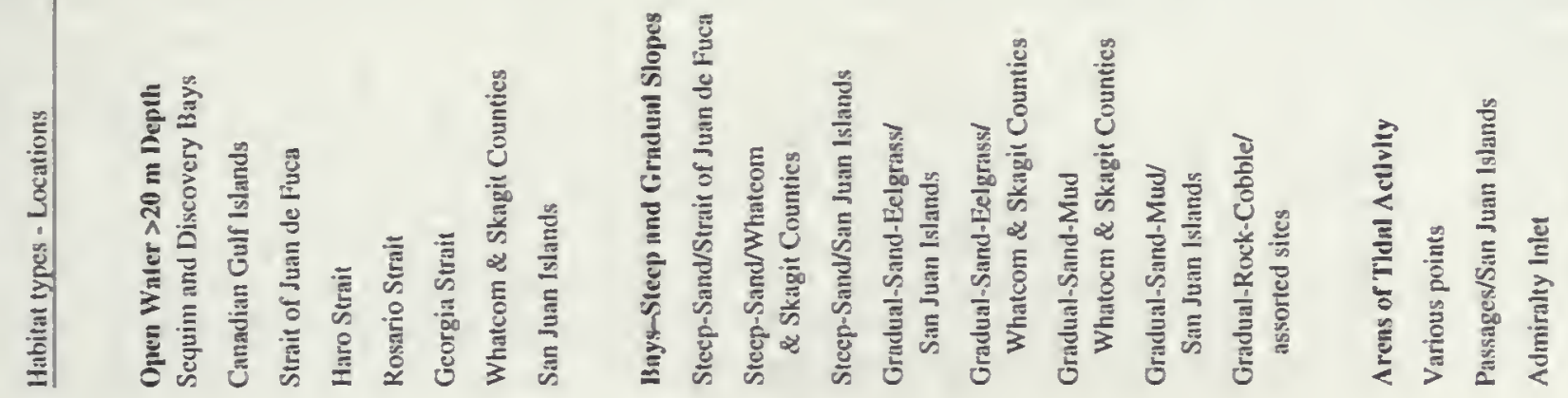




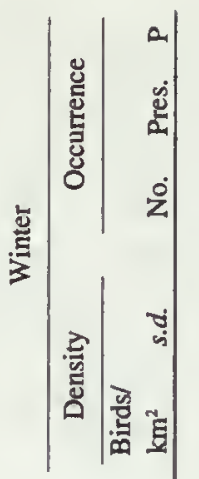

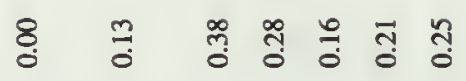

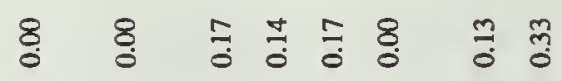

- $\rightarrow \cong$

ล $\infty \pi$ ก

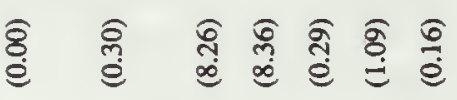

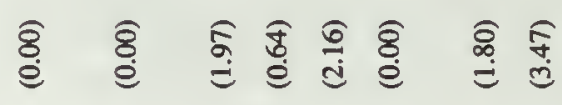

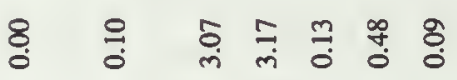

8) 8 व

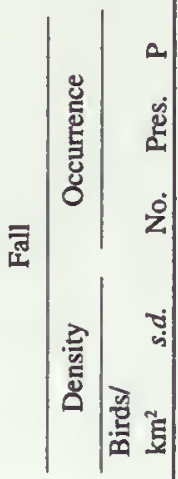

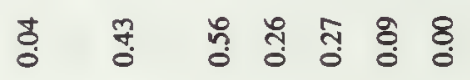

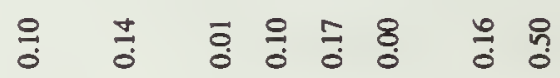

- $\infty \quad \infty=\infty m 0$

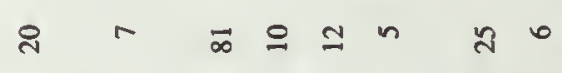

ก ฉ

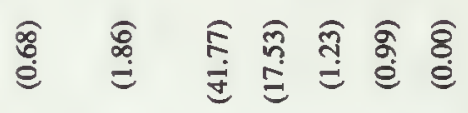

悉 旁

†

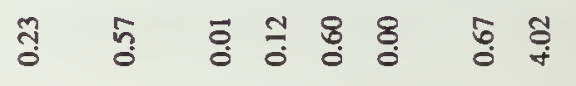

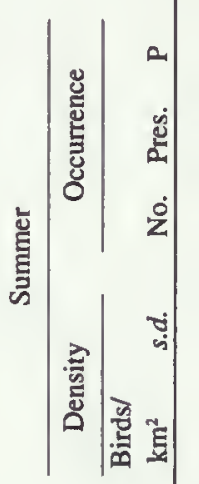

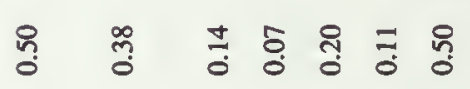

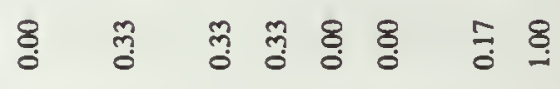

4 4 - h - - -

- $\rightarrow n-0$ - - -

$+\simeq r \cong n a r$

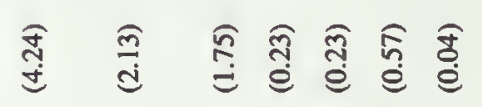

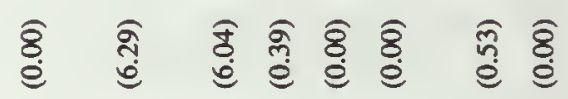

\& $\stackrel{-}{\circ}$ 형 \&

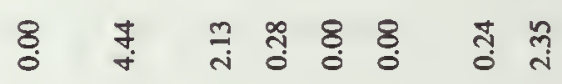

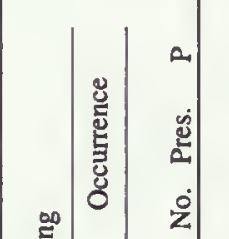

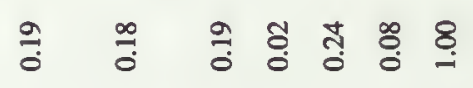

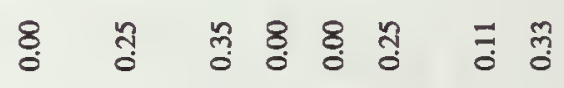

言

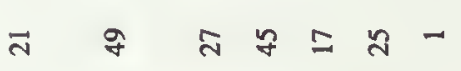

$\pm \therefore g+a+g m$

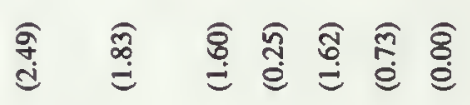

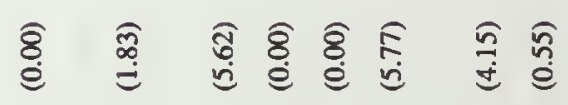
\& पั

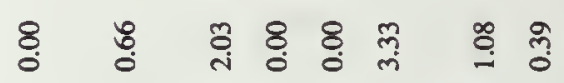

放

हึ

\& \&

竎

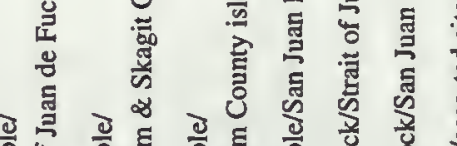

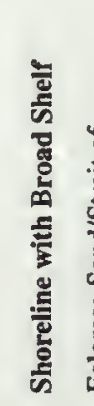

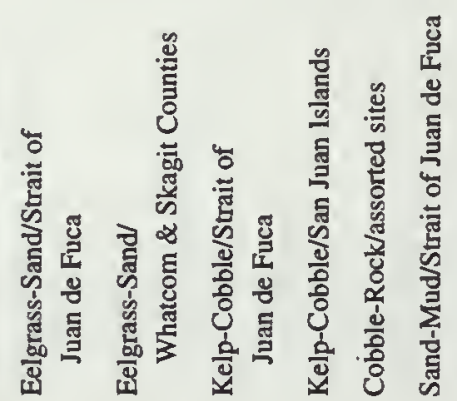

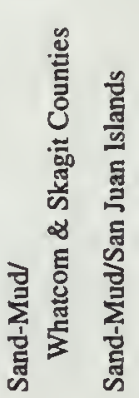

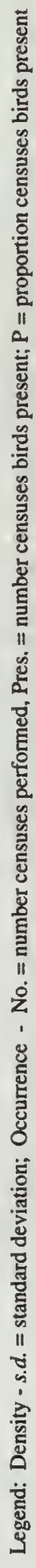




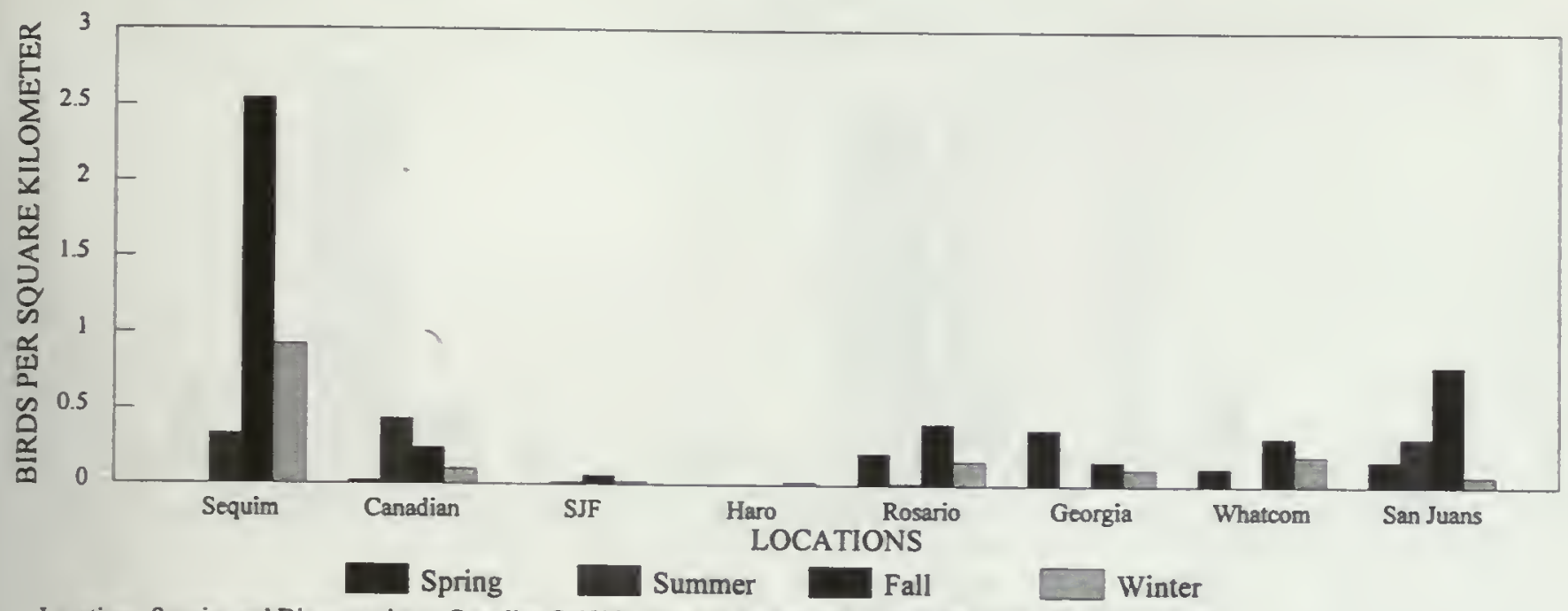

Locations: Sequim and Discovery bays; Canadian Gulf Ids.; Strait of Juan de Fuca; Haro St; Rosario St; Georgia St; Whatcom and Skagit counties; San Juan Islands.

Figure 1-Seasonal abundance of Marbled Murrelets, open water greater than $20 \mathrm{~m}$ depth.

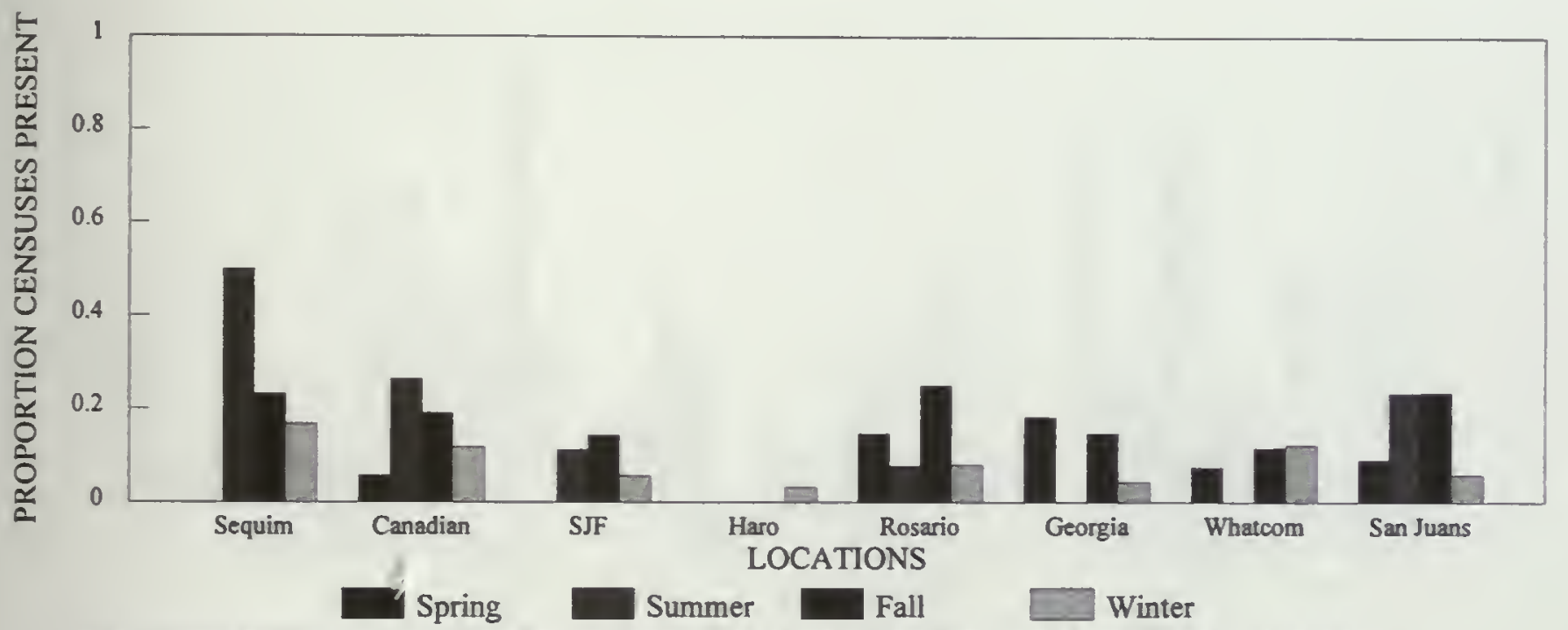

Locations: Sequim and Discovery bays; Canadian Gulf Islands; Strait of Juan de Fuca; Haro Strait; Rosario Strait; Georgia Strait; Whatcom and Skagit counties; San Juan Islands.

Figure 2-Seasonal presence of Marbled Murrelets, open water greater than $20 \mathrm{~m}$ depth.

rich upwelled or mixed waters. Within Puget Sound, such areas are normally associated with narrow passages or points where currents, and mixing, are intensified. The habitat types presented here reflect those conditions (table 1, figs. 5 and 6).

Highest densities were calculated from observations during the summer period from "Various Points" (figs. 5 and 6) where Marbled Murrelets were recorded on over 70 percent of all censuses. Densities of birds at these points were lower during the spring and fall, and the percent occurrence on censuses was lower, but on average, Marbled Murrelets were observed on about half of all censuses during this period. Only during winter did both the density and occurrence rate drop below values from other periods.
In Passages-San Juan Islands, the highest seasonal density was obtained for the fall period, $5.05 \mathrm{birds} / \mathrm{km}^{2}$ (table 1 , fig. 5), when birds were observed on about 40 percent of all censuses (rable 1, fig. 0 ). There, numbers observed and percent occurrence of censuses were much lower during the spring and summer periods. During the winter period, the density ( 1.69 birds $/ \mathrm{km}^{2}$ ) was considerably lower, while birds were recorded on over 50 percent of all censuses.

Murrelets occurred at much lower rates on censuses in Admiralty Inlet, (table 1, fig. 5), compared to other tidal areas. However, more birds were likely present as the area of this tidal passage is larger than the other tidal habitat areas discussed. Similar to the other areas of tidal activity 


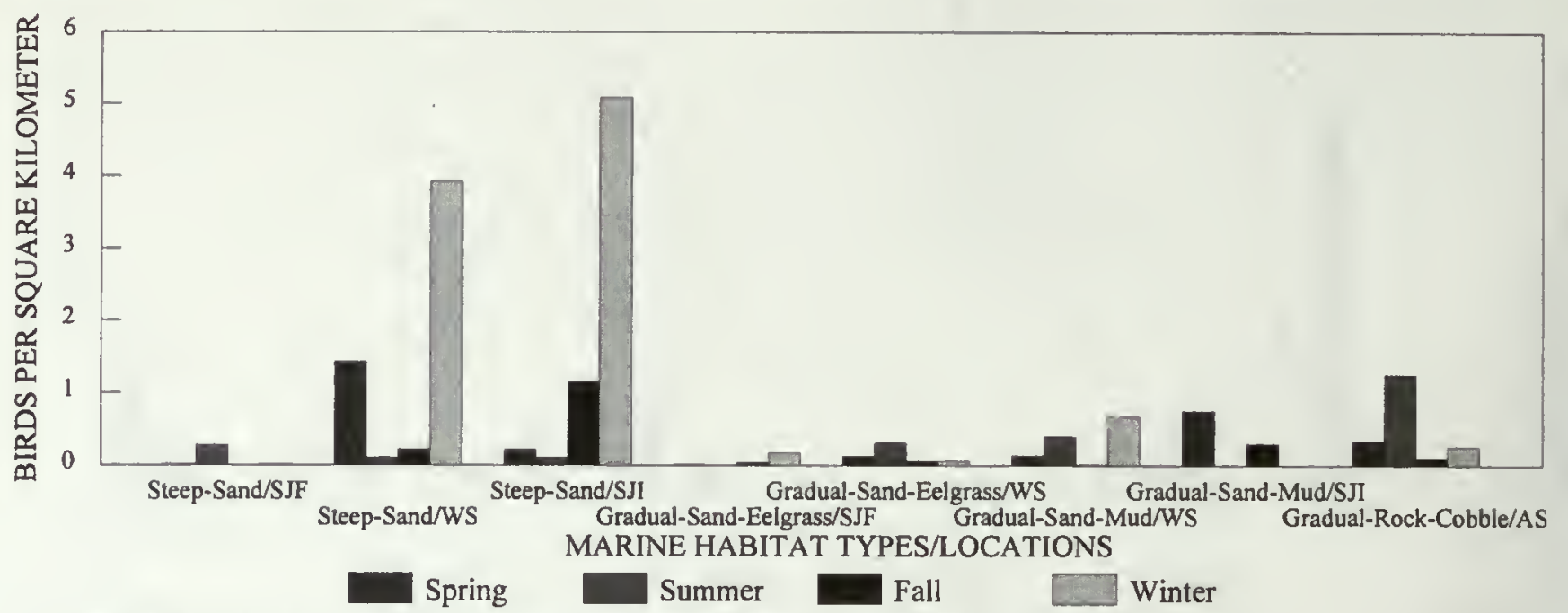

Habitats: Steep Slope-Sand; Steep Slope-Sand, Eelgrass; Gradual Slope-Sand, Mud; Gradual Slope-Rock, Cobble. Locations: Strait of Juan de Fuca; Whatcom and Skagit counties; San Juan Islands; Assorted locations.

Figure 3-Seasonal abundance of Marbled Murrelets, bays - steep and gradual slopes.

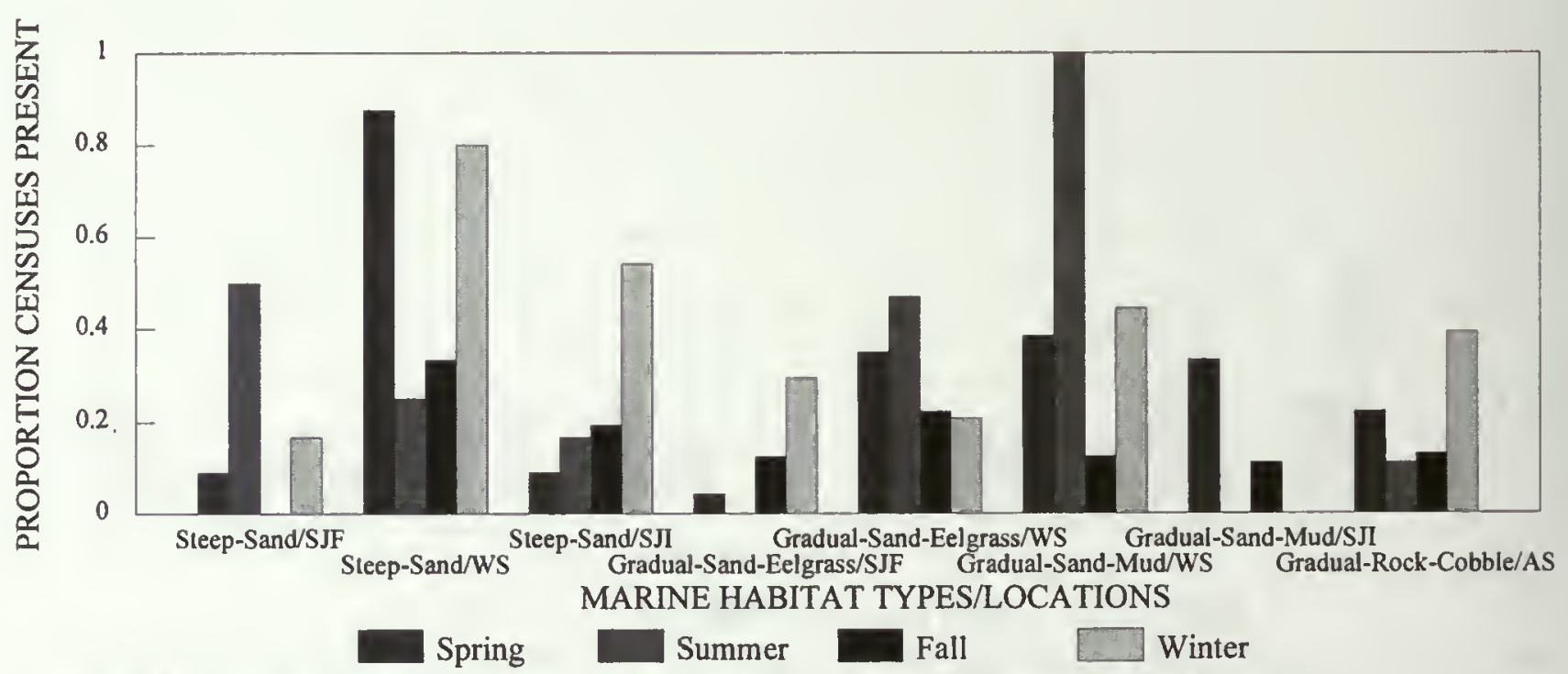

Habitats: Steep Slope-Sand; Gradual Slope-Sand, Eelgrass; Gradual Slope-Sand, Mud; Gradual Slope-Rock, Cobble. Locations: Strait of Juan de Fuca; San Juan Islands; Whatcom and Skagit counties; Assorted locations.

Figure 4-Seasonal presence of Marbled Murrelets, bays - steep and gradual slopes.

in Puget Sound, occurrence on censuses is quite variable (table 1, fig. 6).

\section{Shorelines with Narrow Shelf}

This group is represented by three specific habitat types, Kelp and Cobble, Cobble and Rock, and Sand and Mud. Within this general habitat group, there is considerable variation in densities (table 1, fig. 7) and in the proportion of censuses on which they are recorded (table 1, fig. 8). The highest density ( $19.98 \mathrm{birds} / \mathrm{km}^{2}$ ) determined for any habitat in Puget Sound occurred in the fall in the Kelp and Cobble substrate in the Whatcom County islands area, where birds were also recorded on half of all surveys. A relatively high density $\left(5.05 \mathrm{birds} / \mathrm{km}^{2}\right)$ was also determined for the fall period for Kelp and Cobble substrate in the San Juan Islands. Otherwise, with a couple of additional exceptions, densities of murrelets in this habitat group were generally low (table 1, fig. 7).

\section{Shorelines with Broad Shelf}

This group is represented by four habitat types, Eelgrass and Sand, Kelp and Cobble, Cobble and Rock, and Sand and Mud. Here again the variation in densities of Marbled Murrelets between and within habitat types is apparent (table 1, fig. 9), although sample sizes in some cases are small 


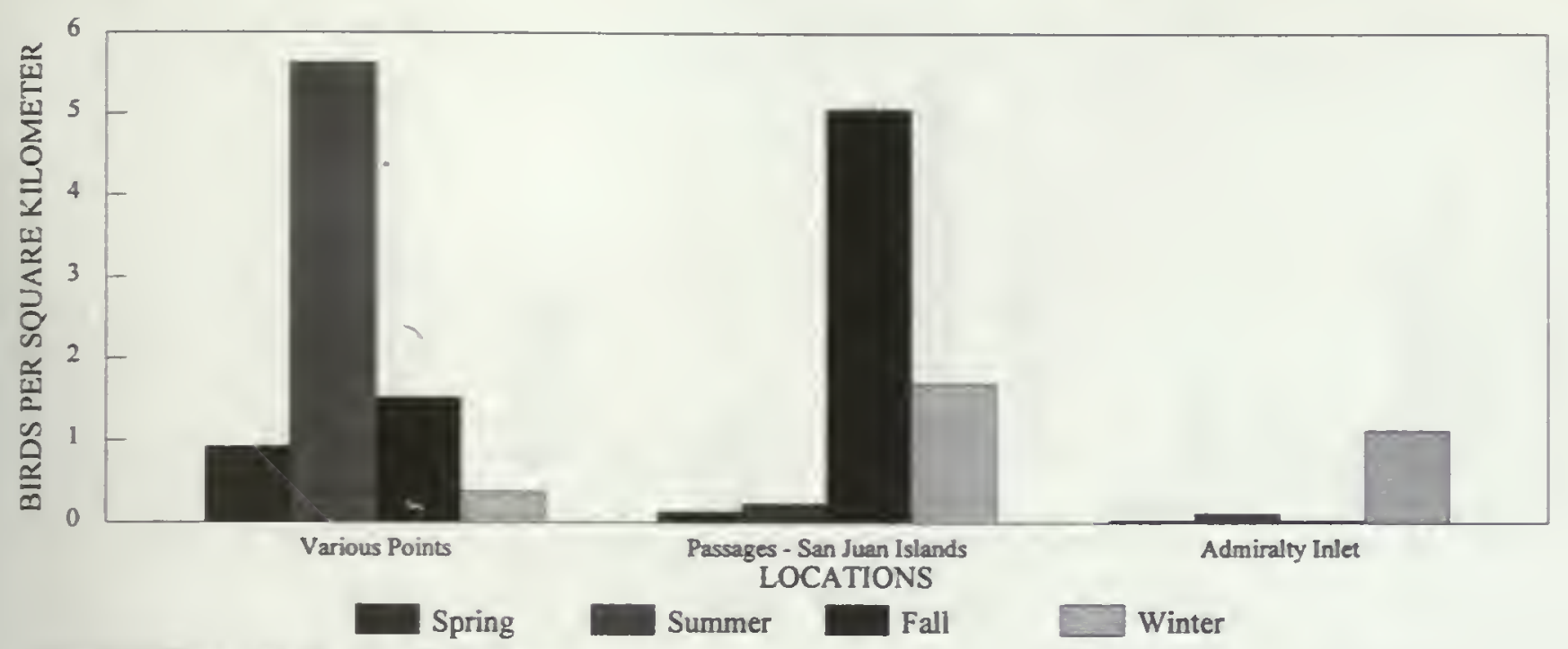

Points: Pt. Wilson, Cattle PL, Green PL, PL. Roberts.

Flgure 5-Seasonal abundance of Marbled Murrelets, areas of tidal activity.

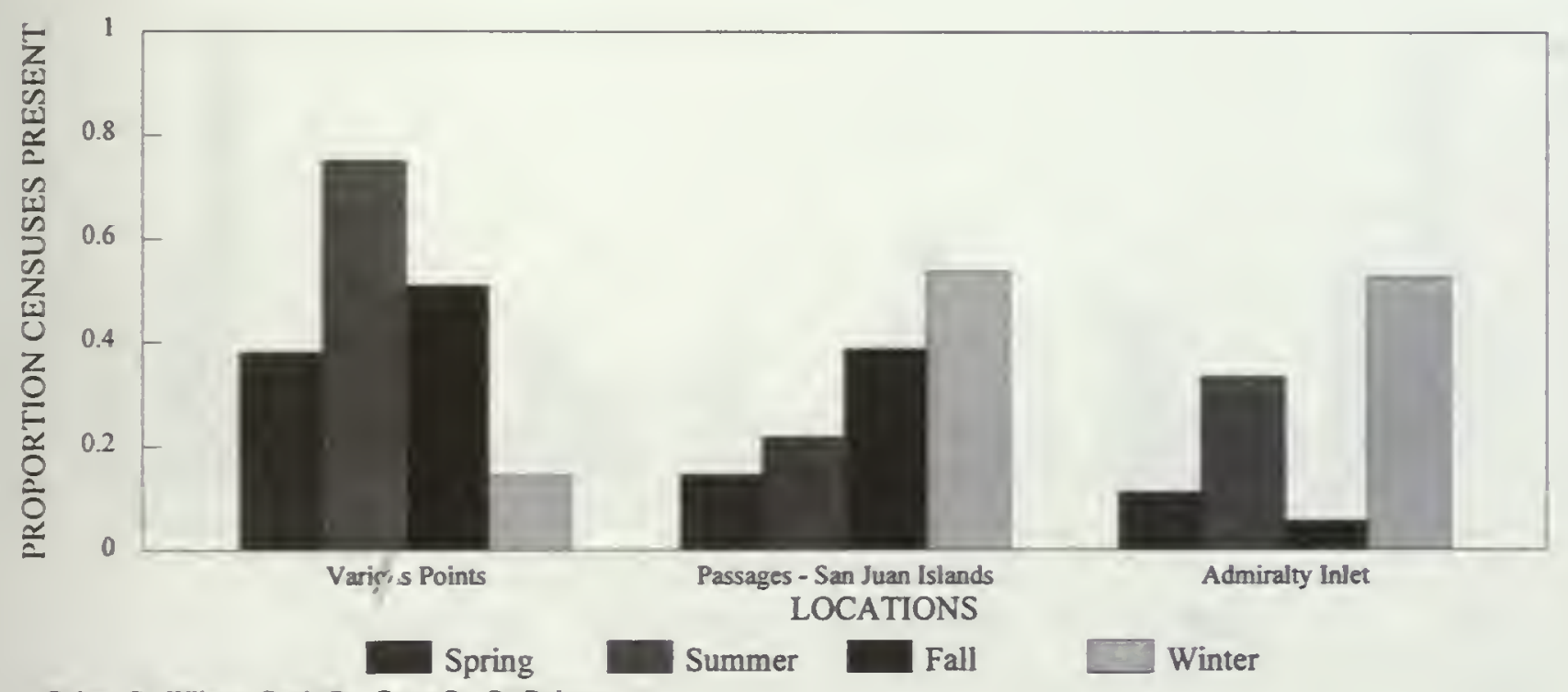

Points: Pt. Wilson, Cattle PL, Green Pt., Pt. Roberts.

Figure 6-Seasonal presence of Marbled Murrelets, areas of tidal activity.

(table 1). The highest calculated densities occurred in Eelgrass and Sand substrate in Whatcom and Skagit Counties during the summer, Cobble and Rock substrate of "Assorted Areas" during the winter, and in the Sand and Mud substrate in the San Juan Islands during the fall. The last habitat type had overall the highest determined seasonal densities.

Overall within this habitat group, the proportion of censuses with murrelets was below 40 percent (table 1, fig. 10). The only exceptions were the spring and summer periods of the Sand and Mud substrate in the San Juan Islands, however small sample sizes (table 1) suggest caution in interpreting those values. As elsewhere, there is considerable seasonal within and between habitat variation.

\section{Abundance and Occurrence by Habitat Types - Pacific Coast}

\section{Grays Harbor Channel and Shelf Waters}

Over a 23-year period, Marbled Murrelets were recorded in Grays Harbor channel in every month. The general pattern of occurrence was one of high average densities during the spring, fall, and winter months (table 2, fig. 11), and higher densities in habitats closer to shore. Overall, the highest densities occurred in Grays Harbor Channel, followed by Grays Harbor Channel to $20 \mathrm{~m}$ depth, and 20 to $50 \mathrm{~m}$ depth. Only rarely were they recorded in deeper habitat areas. The highest densities occurred during the spring months and highest average density occurred in Grays Harbor Channel in March. 


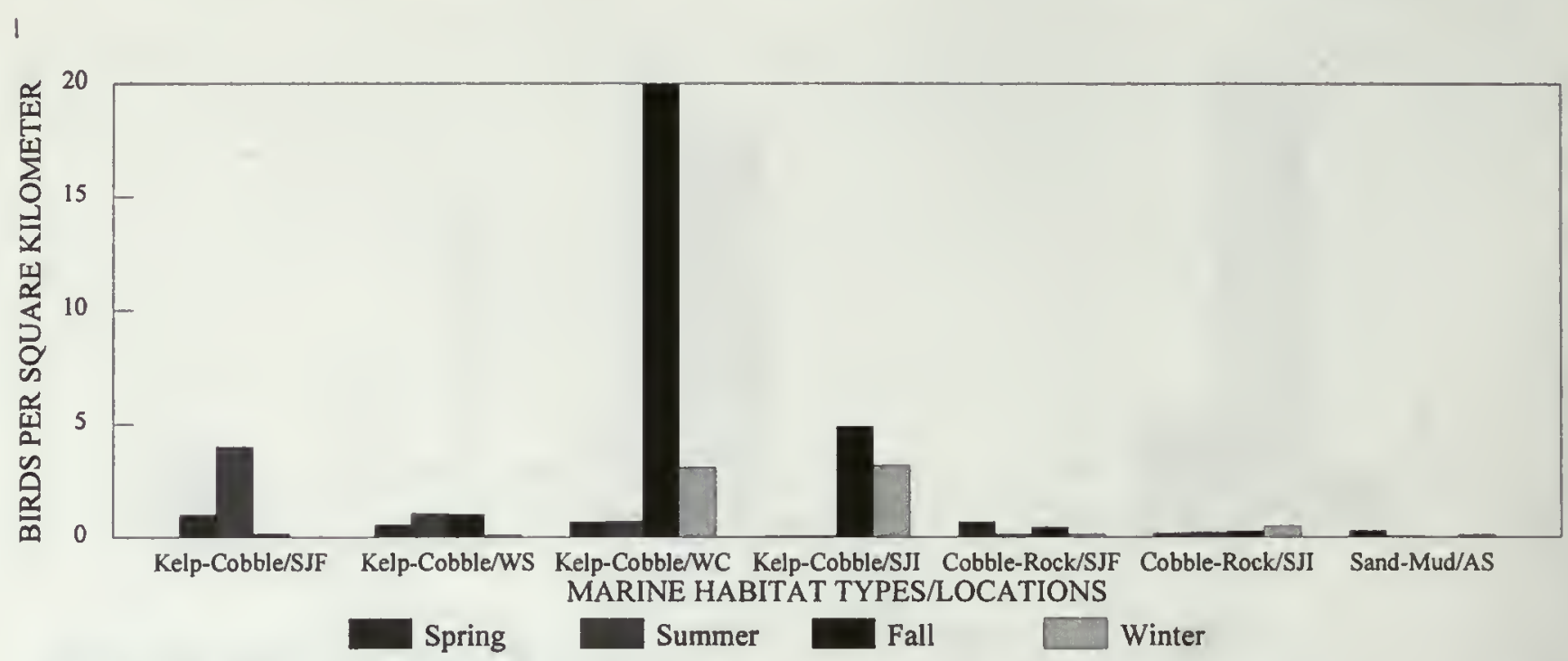

Habitats: Kelp and Cobble; Cobble and Rock; Sand and Mud.

Locations: Strait of Juan de Fuca; Whatcom and Skagit counties; Whatcom County islands; San Juan Islands; Assorted locations.

Figure 7-Seasonal abundance of Marbled Murrelets, shorelines with narrow shelf.

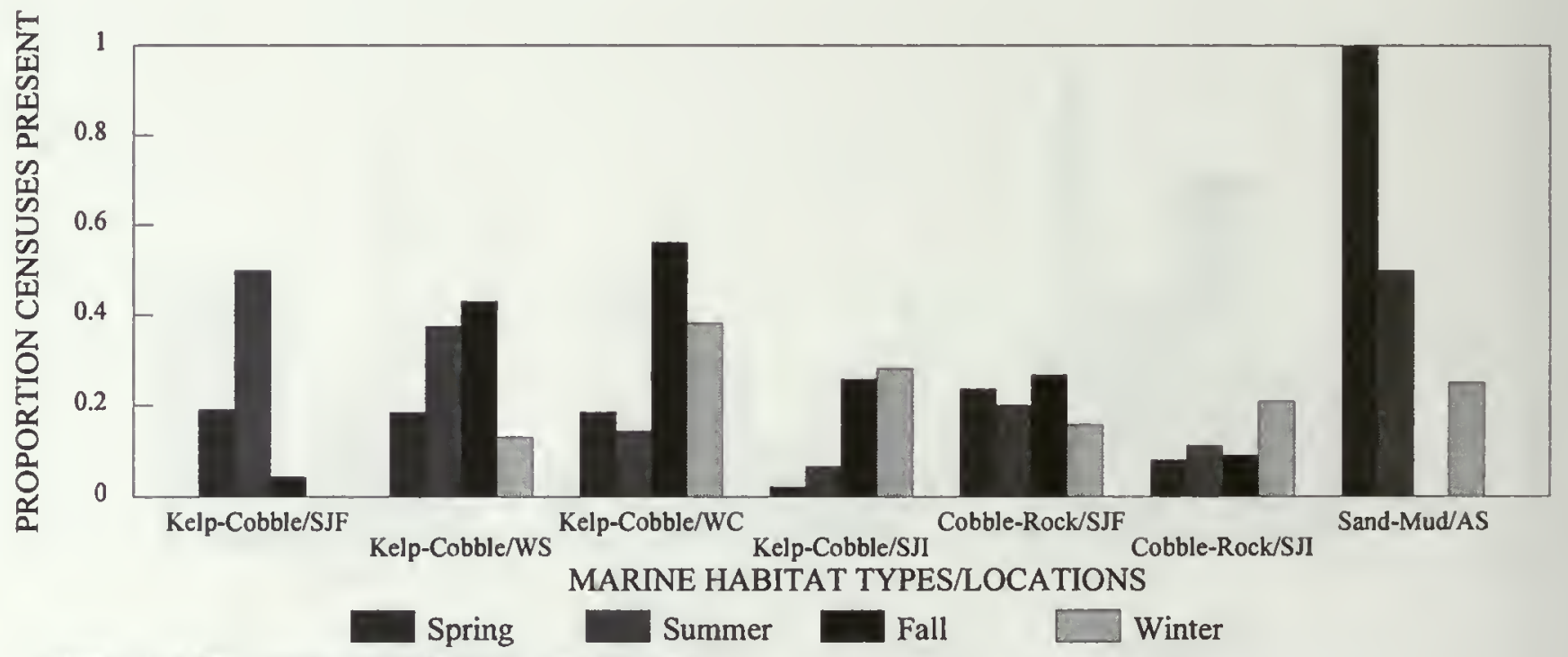

Habitats: Kelp and Cobble; Cobble and Rock; Sand and Mud.

Locations: Strait of Juan de Fuca; Whatcom and Skagit counties; Whatcom County islands; San Juan Islands; Assorted locations.

Figure 8-Seasonal presence of Marbled Murrelets, shorelines with narrow shelf.

The percent of censuses that Marbled Murrelets were recorded in each of the habitat types, by month, followed the same pattern as shown by densities according to Wahl's unpublished observations. Overall, though, sample size is small, with highest occurrence recorded during the winter, spring, and summer periods. Interestingly, over a period of 23 years, murrelets were recorded on every census in Grays Harbor Channel in February, March, November, and December. They were also recorded in the habitat area from Grays Harbor Channel to $20 \mathrm{~m}$ depth in February, March, and November. Even though the proportion of censuses on which murrelets were recorded was often high, densities were often low (e.g., February).

\section{Point Grenville Inshore Waters}

During the spring and summer periods of 1984 and 1985 Marbled Murrelets were irregularly observed in the inshore waters near Point Grenville (Speich and others 1987). These data, previously reported in Speich and others (1992), showed that they were absent from about 25 to 30 percent of all censuses, mainly in April. In both years peak densities were recorded in July, and in August 1985.

\section{Continental Shelf Waters}

Earlier, Speich and others (1992) suggested that the Marbled Murrelet population on the Pacific Ocean Coast of Washington was largely found north of Point Grenville with 


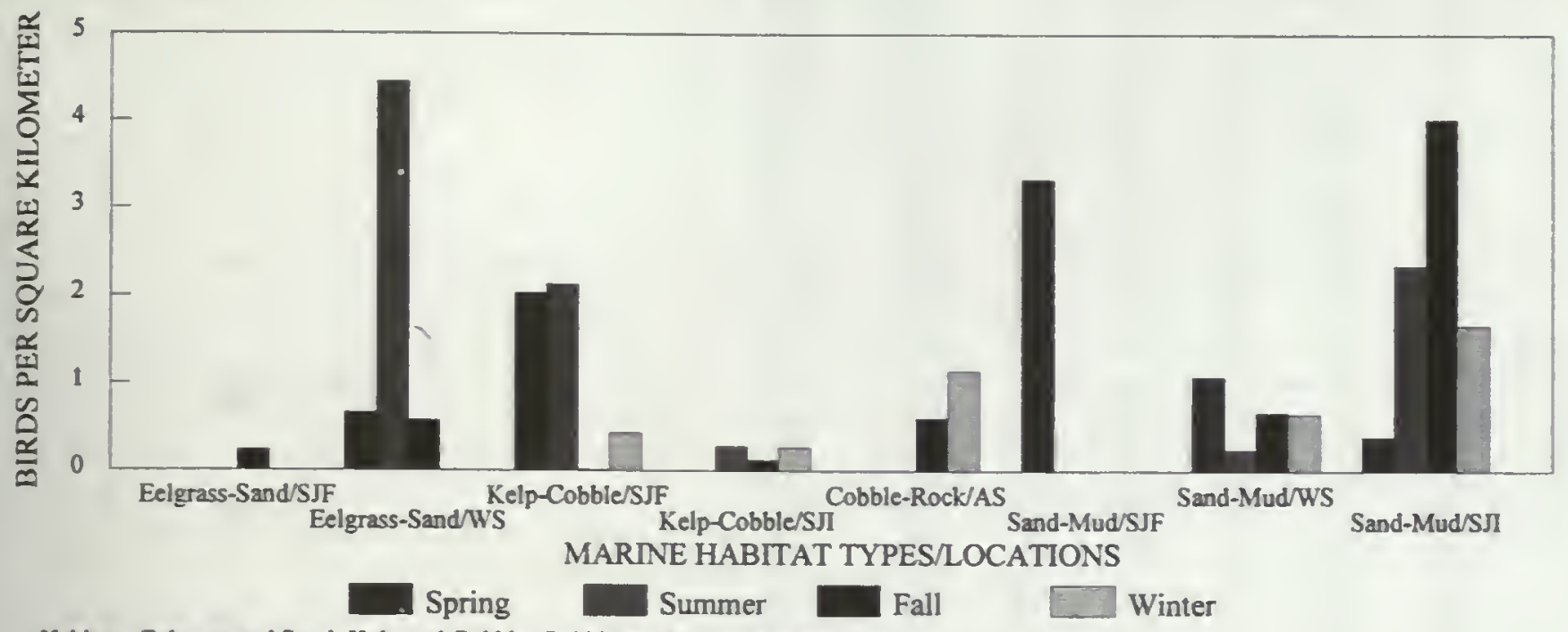

Habitats: Eelgrass and Sand; Kelp and Cobble; Cobble and Rock; Sand and Mud.

Locations: Strait of Juan de Fuca; Whatcom and Skagit counties; San Juan Islands; Assorted locations.

Figure 9 Seasonal abundance of Marbled Murrelets, shorelines with broad shelf.

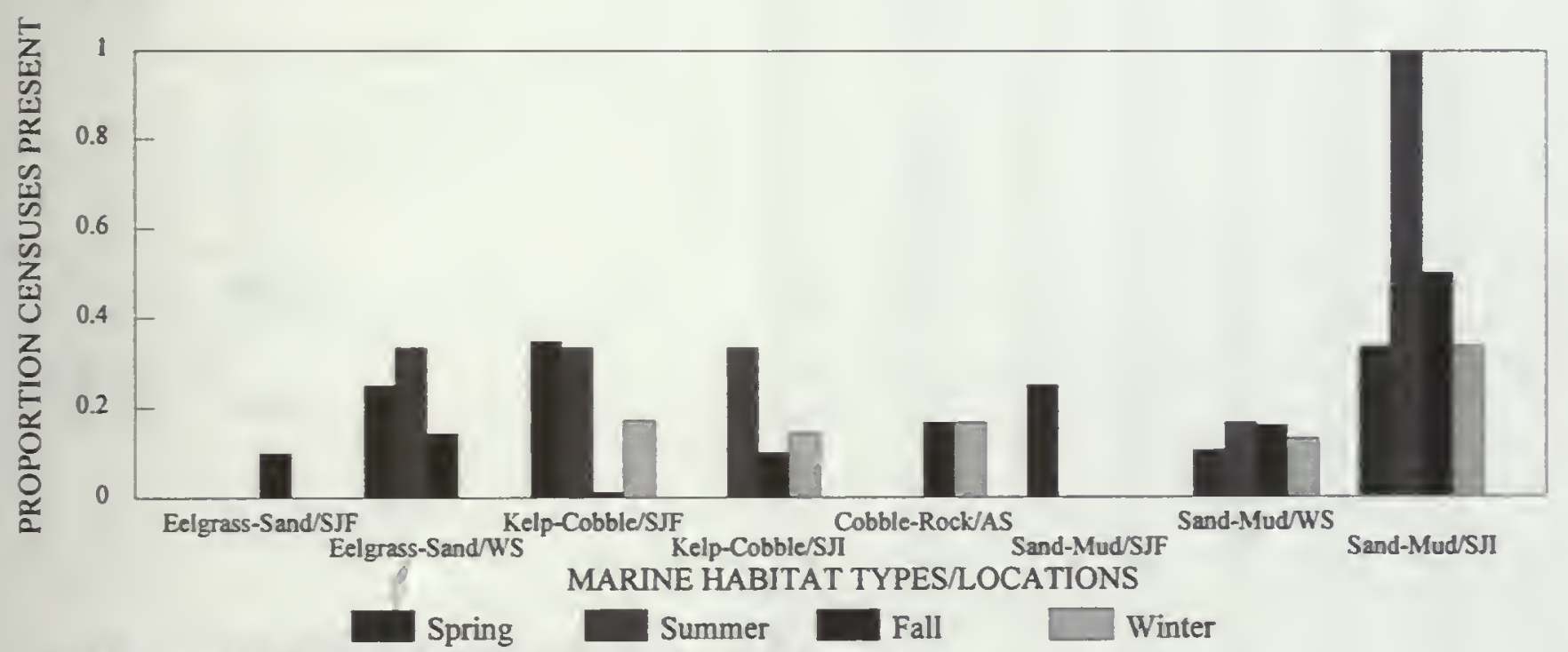

Habitats: Eelgrass and Sand; Kelp and Cobble; Cobble and Rock; Sand and Mud.

Locations: Strait of Juan de Fuca; Whatcom and Skagit counties; San Juan Islands; Assorted locations.

Figure 10 Seasonal presence of Marbled Murrelets, shorelines with broad shelf.

an uncertain number found in the waters off the southern coast. However, the numbers there were thought to be low. This pattern was confirmed by the August 1993 aerial survey of the coast (Varoujean and Williams, this volume).

\section{Regional Distribution and Variability - Puget Sound}

During the 1978 and 1979 survey of northern Puget Sound (Wahl and others 1981), Marbled Murrelets were found differentially distributed temporally and spatially through the study area. Overall, the results of surveys during the spring-summer and winter periods showed on average that the obtained densities and the proportion of surveys with murrelets were higher during the winter, compared with the spring-summer period (see appendices 1 and 2, and fig. 3 in Speich and others [1992]). Indeed, the calculated total for northern Puget Sound was higher in winter than the spring-summer period.

Not only were changes at the region level apparent, but changes within each region, at the subregion level were also found (see appendices in Speich and others [1992]). For example, along the Strait of Juan de Fuca, at the north end of the Olympic Peninsula, the densities (and calculated totals) of murrelets decreased during the winter period in seven of the 20 subregions ( 35 percent), remained the same in nine of the 20 (45 percent) and increased in three ( 15 percent). There were no increases of densities in subregions west of 


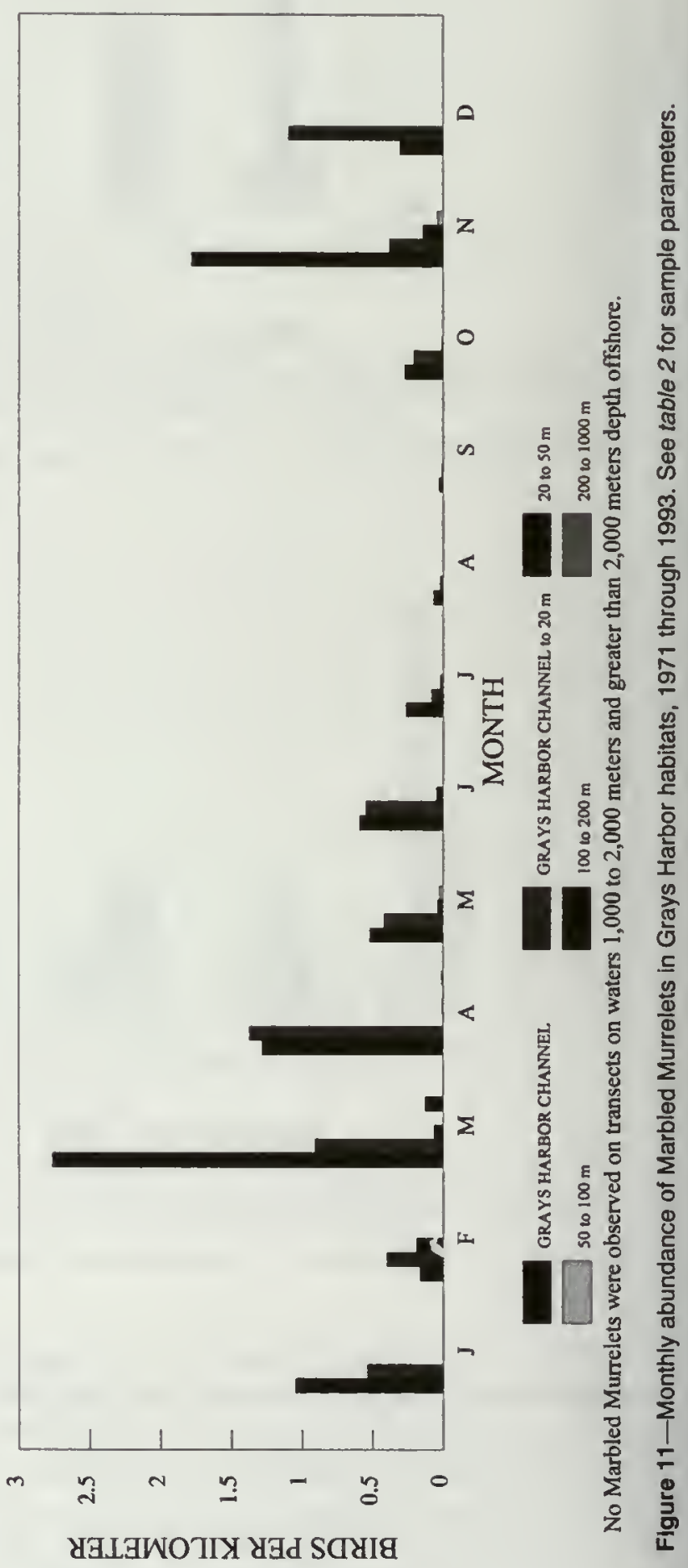


Dungeness Spit: six showed decreases and six showed no change. East of Dungeness Spit, four subregions showed increases, one showed a decrease and four showed no change. The Dungeness Spit subregion showed no change in density or projected total of birds.

A different pattern was observed when spring-summer densities and calculated totals were compared with those of winter in more northern and eastern areas of northern Puget Sound. Within the eastern bays and passages of Whatcom and Skagit counties, the area to the east of Rosario Strait, including Bellingham, Padilla, Samish, Fidalgo and Lummi bays, murrelets were more plentiful during the winter period in five of the seven ( 71 percent) subregions and there was no change in the other two subregions (29 percent).

This pattern was also observed in the bays and passages of the San Juan Islands. There, Marbled Murrelet densities and projected totals were greater in 11 ( 52 percent) of the 21 subregions of this geographic area. Values decreased in only five subregions ( 24 percent) and remained the same in five others ( 24 percent).

\section{Long-Term Trends in Abundance and Occurrence - Puget Sound}

As reported earlier (Speich and others 1992), there are no data that will allow for the quantification of long term changes in the abundance of Marbled Murrelets in Washington marine waters. Qualitative statements in early accounts suggest that the species was once more abundant than present in Puget Sound waters.

\section{Long-Term Trends in Abundance and Occurrence . Pacific Ocean Coast}

There are no data that we are aware of that allow a direct appraisal of the long term stability, or instability, of populations along the Pacific Ocean coast of Washington, over the last century, or even over the last several decades. The only quantified information available is the data set collected by Wahl from offshore birding trips irom Grays Harbor to over the continental shelf break, covering the years 1971 through 1993 (rable 3, fig. 12). Therein, no long term trend in the abundance of Marbled Murrelets is evident, except that since 1989, yearly abundance is visibly diminished. The lowest level of murrelet abundance over the entire study period occurred in 1993.

We are unable to directly predict if the pattern of abundance observed in nearshore waters near Grays Harbor are indicative of abundance patterns along the entire outer coast of Washington. However, some insight is obtained by considering the yearly patterns of relative abundance of other marine bird species occurring in nearshore and continental shelf waters off of Grays Harbor. Several marine species, consisting of four families of birds, and comprising local breeders, migrants, and winter visitors, were less abundant in recent years in the Grays Harbor study area. Wahl's unpublished observations are summarized below. The lowest abundances since 1971 were recorded during the past two years for eight species (Sooty Shearwater [Puffinus griseus], Red-necked Phalarope [Phalaropus lobatus], Sabine's Gull [Xema sabini], Arctic Tern [Sterna paradisaea], Common Murre [Uria aalge], Cassin's Auklet [Ptychoramphus aleuticus], Rhinoceros Auklet, Tufted Puffin [Fratercula cirrhata]), and during one of the last two years for two species (Fork-tailed Storm-Petrel [Oceanodroma furcata], Red Phalarope [Phalaropus fulicaria]). Of interest, Common Murre abundance decreased noticeably in 1989, and has remained low, after several years (1980-1988) of relative high abundance. The abundance pattern of the last species corresponds to that observed for the Marbled Murrelet, relative low abundance since 1989 (fig. 12).

\section{Discussion}

The overall pattern of abundance (density) and occurrence of Marbled Murrelets observed in the marine habitats of Puget Sound is one of variability. Our impression of Marbled Murrelets in Puget Sound before this limited analysis was of a species that moves about a great deal on several temporal scales: seasons, daily, and hourly. Indeed, we have often observed Marbled Murrelets foraging in a particular area then departing that area in a short period of time, and flying out of our sight to another unknown location. Such movements may account for the generally low probability of encountering murrelets on censuses within habitat types. Thus, the observed occurrence patterns are not surprising. However, there are sources of noise in the original census program that could give a partially false impression of this species' patterns of occurrence. Specifically, not discounting our general impression of variability, we have noticed that they are often found in specific areas, while other areas are less likely to contain them. Thus, since any specific habitat type presented is usually represented by several spatially distinct censuses and the mixing of censuses, some often with and without detecting murrelets, leads to lowered occurrence rates. We predict that this will be the case, and that the habitat spatial scale we presented here for Puget Sound will turn out to be too coarse.

Our field observations of Marbled Murrelets in Puget Sound, during the course of formal censuses and otherwise, suggest that the foraging distribution is closely linked to tidal patterns, in particular to specific locations when tidal flows are clearly evident. The locations of tidal activity covered by data that are presented here (figs. 5 and 6 ) are well known and particularly prominent places of tidal activity. However, tidal activity is observable throughout Puget Sound and is likely the single dominant and persistent physical process there. We suggest that analysis of our data at the level of individual censuses may give insight into the relative importance of tidal activity in determining the movements and foraging areas of Marbled Murrelets.

As recognized previously, there are seasonal regional patterns in the distribution and abundance of murrelets in 
Table 3-Yearly rates of occurrence of Marbled Murrelets in nearshore habitats off Grays Harbor, Washington

\begin{tabular}{|c|c|c|c|c|c|c|c|c|c|}
\hline \multirow[t]{2}{*}{ Year } & \multicolumn{3}{|c|}{ Grays Harbor Channel } & \multicolumn{3}{|c|}{ Grays Harbor Channel to $20 \mathrm{~m}$} & \multicolumn{3}{|c|}{20 to $50 \mathrm{~m}$ depth } \\
\hline & $\begin{array}{l}\text { No. } \\
\text { birds }\end{array}$ & $\begin{array}{l}\text { No. } \\
\text { km }\end{array}$ & $\begin{array}{r}\text { Birds/ } \\
\mathrm{km}\end{array}$ & $\begin{array}{l}\text { No. } \\
\text { birds }\end{array}$ & $\begin{array}{l}\text { No. } \\
\mathrm{km}\end{array}$ & $\begin{array}{r}\text { Birds/ } \\
\mathrm{km}\end{array}$ & $\begin{array}{l}\text { No. } \\
\text { birds }\end{array}$ & $\begin{array}{l}\text { No. } \\
\mathrm{km}\end{array}$ & $\begin{array}{r}\text { Birds/ } \\
\mathrm{km}\end{array}$ \\
\hline 1971 & 6 & 27.7 & 0.22 & 0 & 20.3 & 0 & 0 & 53.4 & 0 \\
\hline 1972 & 51 & 98.6 & 0.52 & 0 & 66.3 & 0 & 0 & 108.0 & 0 \\
\hline 1973 & 15 & 109.4 & 0.14 & 0 & 39.6 & 0 & 0 & 93.8 & 0 \\
\hline 1974 & 7 & 40.0 & 0.18 & 0 & 51.2 & 0 & 0 & 88.7 & 0 \\
\hline 1975 & 16 & 69.8 & 0.23 & 9 & 56.0 & 0.16 & 0 & 81.1 & 0 \\
\hline 1976 & 11 & 36.8 & 0.30 & 7 & 88.6 & 0.08 & 0 & 117.1 & 0 \\
\hline 1977 & 35 & 76.9 & 0.46 & 15 & 148.9 & 0.10 & 1 & 206.9 & 0 \\
\hline 1978 & 10 & 90.2 & 0.11 & 10 & 81.8 & 0.12 & 0 & 150.7 & 0 \\
\hline 1979 & 26 & 88.4 & 0.29 & 0 & 54.7 & 0 & 0 & 155.9 & 0 \\
\hline 1980 & 7 & 75.6 & 0.09 & 51 & 77.7 & 0.66 & 0 & 100.1 & 0 \\
\hline 1981 & 24 & 60.8 & 0.39 & 20 & 125.1 & 0.16 & 18 & 168.8 & 0.11 \\
\hline 1982 & 88 & 111.1 & 0.79 & 16 & 128.2 & 0.12 & 2 & 202.5 & 0.01 \\
\hline 1983 & 23 & 101.2 & 0.23 & 16 & 75.4 & 0.21 & 4 & 158.8 & 0.03 \\
\hline 1984 & 24 & 128.4 & 0.19 & 7 & 100.8 & 0.07 & 11 & 213.4 & 0.05 \\
\hline 1985 & 74 & 137.9 & 0.54 & 102 & 140.5 & 0.73 & 0 & 227.2 & 0 \\
\hline 1986 & 24 & 81.8 & 0.29 & 7 & 73.5 & 0.10 & 0 & 136.1 & 0 \\
\hline 1987. & 27 & 129.3 & 0.21 & 16 & 115.2 & 0.14 & 3 & 191.0 & 0.02 \\
\hline 1988 & 69 & 112.6 & 0.61 & 50 & 104.6 & 0.48 & 2 & 179.5 & 0.01 \\
\hline 1989 & 8 & 104.0 & 0.08 & 2 & 86.0 & 0.02 & 0 & 120.0 & 0 \\
\hline 1990 & 11 & 111.5 & 0.10 & 13 & 140.0 & 0.09 & 2 & 173.0 & 0.01 \\
\hline 1991 & 25 & 131.5 & 0.19 & 21 & 148.5 & 0.14 & 0 & 172.0 & 0 \\
\hline 1992 & 13 & 141.5 & 0.09 & 22 & 126.5 & 0.17 & 2 & 165.5 & 0.01 \\
\hline \multirow[t]{2}{*}{1993} & 5 & 125.0 & 0.04 & 2 & 142.5 & 0.01 & 0 & 172.5 & 0 \\
\hline & - & 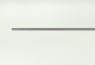 & & - & $\longrightarrow$ & & - & $\longrightarrow$ & \\
\hline Total & 599 & 2190 & & 386 & 2191.9 & & 45 & 3436 & \\
\hline
\end{tabular}

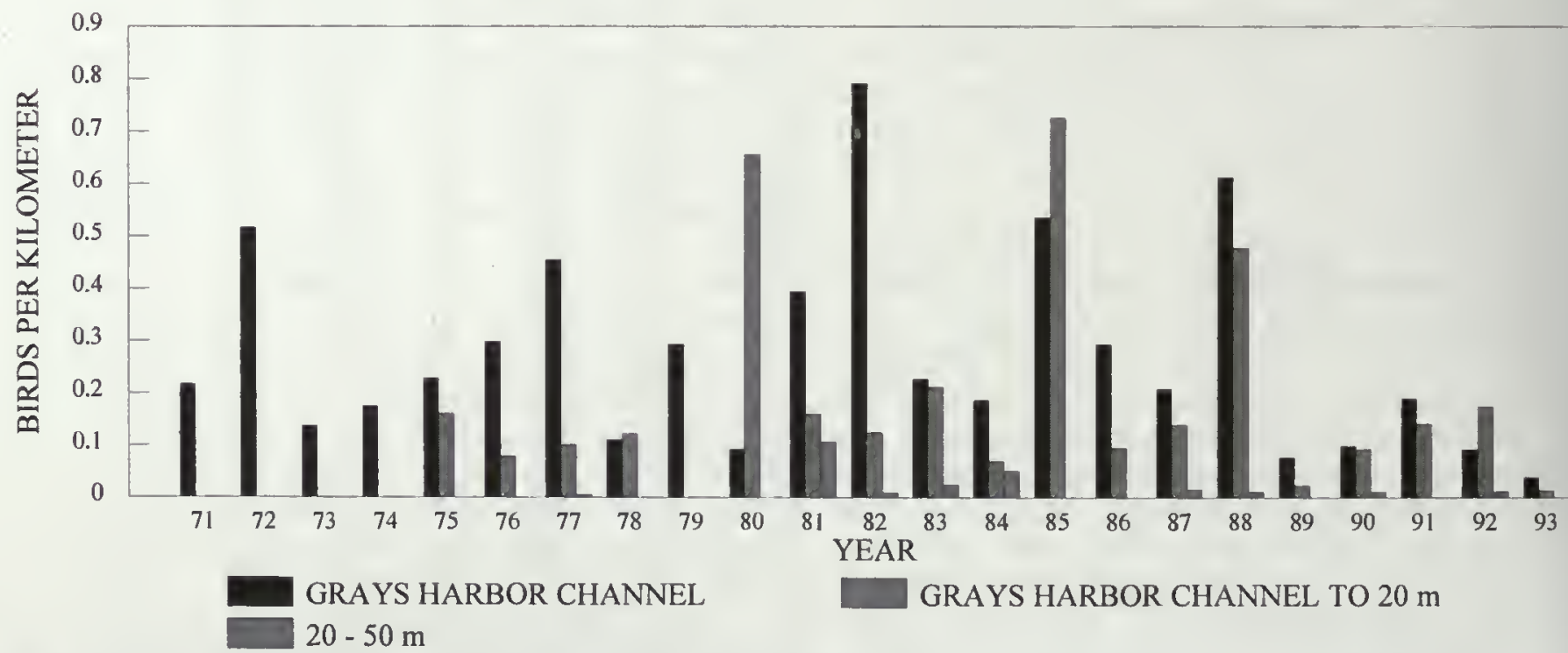

Figure 12-Yearly abundance of Marbled Murrelets in Grays Harbor habitats, 1971 through 1993. See table 3 for sample parameters. 
Puget Sound. Of particular note, are the nearshore subregions along western portion of the Strait of Juan de Fuca where they are found less often during the winter period. This area, particular in Puget Sound, is exposed to winter storm activity, as it opens directly to the Pacific Ocean, while those Strait of Juan de Fuca subregions to the east of Dungeness Spit are relatively protected from western approaching winter storms. The densities in these subregions also suggest a shift of birds from the Strait of Juan de Fuca during the spring and summer periods, to areas in the San Juan Islands and the eastern bays during the fall and winter periods. In addition, as demonstrated in Speich and others (1992), there is apparently an additional influx of Marbled Murrelets into the latter areas from the north, presumably British Columbia. A shift in Marbled Murrelets from the Strait of Juan de Fuca alone cannot account for the increases in numbers in these areas. Similar patterns, though on a lesser scale, are likely present in other areas of Puget Sound.

An estimate of the size of the Marbled Murrelet population found in the marine waters of Washington during the springsummer breeding period has been made by Speich and others (1992), calculated at approximately 5,000 birds. Estimates were made for each of four marine regions: southern outer coast, <500 birds; northern outer coast, 1,900; southern Puget Sound, 480; and northern Puget Sound, 2,100. Except for the southern outer coast figure, in reality an educated guess, estimates of breeding populations were based on data from censuses that sampled specific areas, calculated projected numbers for sub-regions (see Wahl and others 1981), then adjusted for the proportions of non-breeding birds and those not present on the water during censuses but incubating and brooding at inland nest sites (Speich and others 1992). We consider these only approximations of the numbers of breeding Marbled Murrelets, requiring a better defined baseline for detecting and appraising potential changes in the future.

There may be several factors that could explain the observed apparent decrease in murrelet abundance in the Grays Harbor study area in the inearshore continental shelf waters. Some may suggest that the population has been reduced by the accumulative removal of terrestrial nesting habitat areas. Such action has the potential to affect Marbled Murrelet populations and may have in particular locations. However, such an evaluation is beyond this paper (see Ralph 1994). In our paper, in the time period presented (19711993), there are recent indications of changes in the marine carrying capacity of waters over the continental shelf and slope, off Grays Harbor and beyond. This is reflected in the recent record low abundances reported for several species of marine birds, birds representing several different foraging techniques and positions in marine food changes, and of various geographic affinity. On a slightly larger scale, the reduced abundance of Common Murres in the study areas since 1989 suggests that marine food chains have been reduced, or have otherwise become unavailable to Common Murres for several years, because breeding colonies as far south as Oregon have experienced depressed reproduction rates (Varoujean, pers. comm.). The study area numbers in part reflect the abundance of murres moving north from Oregon breeding colonies after the breeding period. Additionally, the Common Murre breeding population in Washington has declined over the past decade (Ainley and others 1994; Wilson 1991). Although the Marbled Murrelet is not as oceanic a species as other species reported on here, the documented declines in abundance and local breeding success suggest that fundamental changes in marine systems have occurred, likely expressed by the reduced availability of prey. Considering the temporal and geographic scale of reported effects it is perhaps not surprising that Marbled Murrelet abundance in the Grays Harbor study area was lower the past two years in particular, or even for the past several years.

The patterns of abundance and occurrence presented herein are descriptive in nature, and represent the "what" stage of the continuing investigation of the Marbled Murrelet in the marine waters of Washington, in this case, Puget Sound. There is certainly the need to advance our understanding of the marine biology of the Marbled Murrelet beyond the descriptive phases of investigation. We need to address, as we have started to do here, "why" Marbled Murrelets are found distributed as they are. However, such post priori explanations are limited by their nature in their potential to allow understanding of the causes of Marbled Murrelet distribution and abundance patterns. Clearly, the development and testing of a priori questions, hypotheses, and the development of models are appropriate and necessary steps for meaningful advancement of our understanding of Marbled Murrelet biology. However, as necessary and desirable as these last steps are, a sound and basic knowledge of the natural history of the species is necessary for the interpretation and evaluation of study and test results and for our understanding of the factors influencing and controlling Marbled Murrelets (see interesting discussion in Oreskes and others [1994]).

Puget Sound is by its very nature a complex system of bays, estuaries, channels, passages and straits, greatly influenced by tidal and wind patterns, by the influx of fresh water and nutrients from several river systems, and by its connections to the Pacific Ocean. Perhaps a better understanding of, and precision in predicting, the temporal and spatial variable distribution and abundance of the Marbled Murrelet in Puget Sound and along the Pacific Ocean coast would result from an increased understanding of marine physical and biological processes and how they link with Marbled Murrelets.

\section{Acknowledgments}

This paper is the result of combining the data from several different projects. Consequently, the list of persons and organizations who contributed in many different ways is long. Specific acknowledgments are found in documents cited herein as are the many sources of support (see also 
Speich and others 1992). Data from the Grays Harbor area were made largely possible through the long interest and efforts of bird watchers and other naturalists that supported vessel time. William Tweit and Dennis Paulson, by their interest and participation, contributed in no small way to the success of the Grays Harbor effort. We especially appreciate the professionalism of Deborah Kristan, as reflected in her review, and her manipulating and editing of the Puget Sound data set. The review and comments of C. John Ralph and S. Kim Nelson were particularly helpful, as was the technical assistance of Linda Long.

The participation of S. Speich in the Conservation Assessment process was made possible by unconditional support from the California Forestry Association, the National Council of the Paper Industry for Air and Stream Improvement, and the Pacific Lumber Company. 


\section{Abundance and Distribution of Marbled Murrelets in Oregon and Washington Based on Aerial Surveys}

\author{
Daniel H. Varoujean II Wendy A. Willlams'
}

\begin{abstract}
To determine the abundance and distribution of Marbled Murrelets, aerial surveys of the Oregon coast, Washington outer coast, and shores of the western Strait of Juan de Fuca were conducted in August/September 1993. Based on these marine surveys, abundance estimates are established for Oregon (6,400-6,800 birds) and the waters surveyed in Washington (3,400-3,600 birds). A comparison of these estimates to those established by other surveys indicates that boat-based surveys may give higher estimates of murrelet abundance, and that population size has probably not decidedly changed over the last 10 years in either Oregon or Washington. On the Pacific Ocean coast of both states, murrelets were found to be unevenly distributed with birds being most abundant in central Oregon and northern Washington, and present in lower abundance in southern Oregon and from northern Oregon through southern and central Washington. This distribution appears to be related to shore type, and proximity to the entrances to major river mouths and embayments, at least in Oregon, and to available inland nesting habitat in both states. The ratio of hatch-year birds to the total number of murrelets seen during the surveys was estimated to be 5 percent. As a measure of production, this estimate is too low for population maintenance, but we conclude that murrelets in Oregon and Washington may not be in a long-term population decline.
\end{abstract}

Determination of abundance and distribution is an important element in the conservation management of the Marbled Murrelet (Brachyramphus marmoratus). Because of the secretive habits of murrelets frequenting inland areas, marine surveys are the most effective means for documenting population size. Only recently have systematic marine surveys for murrelets been conducted over the entire length of the Oregon coast, and no such sur eys have been conducted over the extent of the Washington outer coast. Consequently, even though the opportunity to do so arose late in the nesting season, we carried out aerial surveys of the Oregon and Washington coasts during late August and early September 1993. This chapter reviews the results of these surveys, which are examined in more detail in two unpublished reports (Varoujean and Williams 1994a, b). In addition, we compare our findings to those of boat-based surveys conducted in both Oregon and Washington.

\section{Methods}

\section{Survey Schedule}

Various segments of the Oregon study area, which extended from Pt. Saint George/Crescent City, California, north to Tillamook Head, Oregon, were surveyed over the

1 Executive Director and Research Associale, Marzet, Marine and Estuarine Research Co., 2269 Broadway SL, North Bend, OR 97459 period 22-23 August 1993. Because of poor weather conditions and restricted visibility, only a small portion of the southcentral Oregon coast was surveyed on 22 August 1993. The remainder of the south coast, and all of the coast north of Coos Bay were surveyed on 23 August. From the airport at Grays Harbor, various segments of the Washington study area, which extended from Tillamook Head, Oregon, north to Cape Flattery, Washington, were surveyed over the period 45 September. Because of a low cloud ceiling from Cape Elizabeth north, only the southern two-thirds of the outer Washington coast was surveyed on 4 September 1993. On 5 September the survey of the southern two-thirds of the outer Washington coast was completed, as was the survey of the coast from Cape Elizabeth north to Cape Flattery. Portions of the western Strait of Juan de Fuca extending from Neah Bay east to Port Angeles (on the Washington side), and from Port San Juan, east to Becher Bay (on the British Columbia side), were surveyed on 6 September. In general, survey viewing conditions in both Oregon and Washington were good to excellent with sea states of Beaufort 3 (occasional white caps) or less, and long, ocean swell heights of $1 \mathrm{~m}$ or less.

\section{Survey Methods}

In both studies the survey platform was a Partenavia, a high-wing, twin engine aircraft, that was flown at a ground speed of $145 \mathrm{~km} / \mathrm{h}(90 \mathrm{mph})$, and at an altitude of $60 \mathrm{~m}$ (200 $\mathrm{ft}$ ) above sea level. Position data were recorded from an onboard Loran-C instrument, to the nearest $\mathbf{0 . 1}$ ' of latitude and longitude by an investigator stationed in the co-pilot's seat. Position data were recorded approximately every minute of time to the nearest second. The data recorder's watch was synchronized to the nearest second with the watches used by the two observers. The two observers, one located on each side of the aircraft, recorded on audio tapes all seabirds and marine mammals seen on their respective survey transects. Additionally, observers recorded information pertaining to sea conditions, cloud cover and the amount of surface glare in their field of view. Each observer's transect was $50 \mathrm{~m}$ wide (i.e., the survey transect is $100 \mathrm{~m}$ wide when both observers are surveying) as established with a clinometer that was rotated up $50^{\circ}$ from a line extending at an angle of $5^{\circ}$ from the lower edge of the observation window to the surface of the water. Even though the observers were looking approximately straight down out of their respective windows, at times the surface glare from sunlight off the water would hamper or preclude surveying off one side of the aircraft. The analysis of sighting data, any time an observer noted that $>20$ percent of their field was obscured by glare, was limited to 
determinations of presence/absence of a species. Data on species abundance were not used.

Aerial surveys, because of the speed of the aircraft, may underestimate bird abundance through sighting error, i.e., observers not seeing birds that are present on transect. In an attempt to document how many birds observers miss seeing at these speeds, tests of aerial observer sighting abilities were conducted over fields of Marbled Murrelet decoys laid out along three $50 \mathrm{~m}$ wide by $2 \mathrm{~km}$ long courses in Humboldt Bay in February 1992. During the tests, a single engine Cessna was flown at a speed of $175 \mathrm{~km} / \mathrm{h}(110 \mathrm{mph})$ and an altitude of $60 \mathrm{~m}$ ASL over the courses, while a single observer recorded the number of sighted murrelet decoys. On each course, six overflights were made, three with the observer on the glare side of the aircraft, and three with the observer on the non-glare side of the aircraft. The sighting error on the non-glare side of the aircraft resulted in 9-30 percent of the decoys being missed, but there were problems associated with the layout of the courses (some were not straight, which resulted in the plane flying over decoys), and with the density of decoys in the courses. This density was ten times higher than murrelet densities commonly encountered in coastal waters, resulting in an unknown bias. Regardless of the test shortcomings, it was felt that using a slower moving survey aircraft would further reduce sighting error. For this reason, the Partenavia, which is capable of flying at a speed of 145 $\mathrm{km} / \mathrm{h}(90 \mathrm{mph})$ was used for the 1993 survey. Unfortunately, decoy tests at this ground speed were not conducted. We feel that sighting error was low ( $<10$ percent), however, based on the excellent viewing conditions that prevailed during the survey period. Accordingly, the population estimates are not increased because of sighting error.

Potentially murrelets are also missed because they dive in response to the approach of the survey aircraft. Our experience indicates that murrelets were not avoidance diving in response to the approach of the Partenavia. When surveying in Oregon and Washington, the calmness of the sea's surface and the water clarity allowed us to see birds below the water's surface that had dived as, or just before, the plane passed over them. Additionally, we noted the presence of a concentric pattern of wavelets and, frequently, white excrement at the point where the bird dove. Most of these sightings were determined to be of Red-throated Loons (Gavia stellata) and Western/Clark's Grebes (Aechmophorus occidentalis/clarkii). No diving murrelets or murrelet-sized alcids, and no concentric patterns of wavelets on a scale of a diving murrelet-sized seabird were observed during either survey. Therefore, the aerial survey population estimates are not adjusted for bird avoidance-diving.

An onshore and an offshore survey line, each running approximately parallel to the coastline were flown in each segment of the Oregon study area. The onshore line was positioned so that the inboard observer was looking at water just offshore of the breaking wave zone. This placed the onshore survey line approximately $100 \mathrm{~m}$ from the shoreline. At times, however, in both Oregon and Washington the plane was flown farther offshore (typically $300 \mathrm{~m}$ from shore) to avoid disturbing seabirds on nesting colonies, and pinnipeds on hauling-out areas. The pilot, who used a map catalog of these sensitive areas as a reference, was made aware of his approach to these areas by the position-data recorder. Since the pilot would fly the plane in a half-circle arc around these areas, portions of the habitat along the onshore survey line lying just offshore of the wave zone, were undersampled. The offshore survey line was located $1,000-1,200 \mathrm{~m}$ from shore, far enough offshore to include the 18-m (10-fathom) bathymetric contour line. Given this survey coverage, it was appropriate to consider the study area for the Oregon coast to be a 1,000-m-wide band of coastal water. This area extended from Point Saint George/ Crescent City California north to Tillamook Head, an area of approximately $500 \mathrm{~km}^{2}$. When reflected sun glare covered 20 percent or more of the field of view, only data from the non-glare side was used (reducing the survey track from $100-\mathrm{m}$ to a 50 -m-wide band). Even with this restriction, approximately $65 \mathrm{~km}^{2}$ (13 percent) of the $500 \mathrm{~km}^{2}$ study area was surveyed.

On the outer Washington coast, three sets of survey lines running approximately parallel to the coastline, were flown in each segment of the study area. As in Oregon, the onshore line was positioned so that the inboard observer was looking at water just offshore of the breaking wave zone. The nearshore (i.e. middle) line was located 1,600-2,000 m from the shoreline. As compared to the Oregon coast, the continental shelf on the Washington coast is relatively broad; hence, the offshore survey line had to be flown farther offshore than in Oregon to include the 18-m (10-fathom) bathymetric contour line. Consequently, the offshore line was located 3,500-4,500 m from shore. Given this survey coverage, it is appropriate to consider the study area for the outer Washington coast to be a $4,000 \mathrm{~m}$ wide band of coastal water extending from Tillamook Head north to Cape Flattery, an area of approximately $1,065 \mathrm{~km}^{2}$. With sun glare at times precluding surveying on one side of the aircraft, approximately $80 \mathrm{~km}^{2}$ (7.5 percent) of the $1,065 \mathrm{~km}^{2}$ outer Washington coast study area was surveyed.

Aerial surveys were also flown inside Grays Harbor, Willapa Bay and the Columbia River during the Washington study. The study area for each of the embayments was based on the size of an irregular-shaped polygonal area as defined by the survey flight track. Only one complete survey was flown inside each embayment. With such poor temporal coverage of these tidally dominated waters, we feel it is inappropriate to project population estimates for these specific areas. Instead, the murrelets seen in and the survey effort for these embayments are applied to the offshore coastal segment adjacent to each embayment.

Due to restrictions on the availability of the survey aircraft, there was time to survey only one onshore line along the British Columbia shore, and one onshore and one offshore line on the Washington shore of the western Strait of Juan de Fuca. The study area for the Strait was considered 
to be a $1,000 \mathrm{~m}$ wide band of coastal water off both the Washington and British Columbia shorelines (areal estimates of $93 \mathrm{~km}^{2}$ and $65 \mathrm{~km}^{2}$, respectively).

During aerial surveys, Marbled Murrelet location is referenced to the time of sighting, and recorded to the nearest second by the observers. To obtain the location of murrelets, a sighting database file created from the transcribed audio tapes was later merged with the position database file, using interpolation and mapping software. Specifically, CAMRIS (Computer Aided Mapping and Resource Inventory System) was used. The interpolated murrelet database was then used to determine bird density (number of observed murrelets divided by the area of the survey transect). Population estimates are based on projections of the density estimates for 20' latitudinal blocks on the outer coast (except $12^{\prime}$ near Pt. Saint George, and 24' near Cape Flattery). The projection of density is over the areal extent of a block, which is the length of a block times the width of the study area (1,000 $\mathrm{m}$ in Oregon, 4,000 $\mathrm{m}$ in Washington). Similarly, abundance data for the Strait of Juan de Fuca are shown in longitudinal blocks of varying length. This broad-scale approach was used to minimize the error of overestimating density, which can occur when block size is small enough to result in the counting of birds more than once as they move between adjacent blocks.

In 1993, steps were taken to insure that observers maximized the time they actually were looking out the window. The location of all other seabird species was referenced to 5 -minute blocks of time as reported by the data recorder over the aircraft's intercom system. This freed the observers from having to look at their watches for every seabird sighting. Before this change, observers could spend 20-30 percent of the survey time being spent with an observer looking at their watch, not out the window, when in areas of high seabird abundance.

When possible, observers noted the number, group size, plumage and age of all seabirds'seen, including Marbled Murrelets. When two murrelets were seen $<5 \mathrm{~m}$ apart they were designated as a pair. Lone birds and birds seen to be $>5$ $\mathrm{m}$ apart were designated as singles. Groups larger than 2 birds were designated as such, regardless of the distance between individual birds in the group.

During the 1993 aerial survey, we noted that a number of adult Marbled Murrelets appeared to be in a transitional molt from alternate plumage to basic plumage (these birds appear mottled gray in color instead of mottled brown). By late August and early September 1993, Ralph and Long [this volume] noted that a number of adult murrelets in northern California had molted into basic (winter) plumage. Similarly, a number of adults in Puget Sound had by early September molted into basic plumage (Stein, pers. comm.). Given these findings, we classified Marbled Murrelets seen during the aerial survey as being in either alternate plumage (presumed to be adults) or black-andwhite plumage, a category that comprises adults in basic plumage and hatch-year birds.

\section{Results}

\section{Abundance}

On-transect observations along the various segments of the Oregon coast resulted in the sighting of 882 Marbled Murrelets, and a projected population estimate of 6,138 birds (table 1). Observations along the various segments of the outer Washington coast resulted in the sighting of 226 murrelets, and a projected population estimate of 2,907 birds (table 2). Flights off the shores of the western Strait of Juan de Fuca resulted in the sighting of 36 Marbled Murrelets on the Washington side, and 18 murrelets on the British Columbia side, with projected population estimates for these two areas of 340 and 306 birds, respectively (tables 3 and 4). The combined population estimate for the Washington outer coast and western Strait on the Washington side is 3,250 birds.

These projected population estimates are probably underestimates in that, while surveying in aircraft, because foraging murrelets can be readily missed when they are diving. An analysis of dive data obtained from the tracking of radiotagged Marbled Murrelets (table 5) indicates that aerial surveys underestimate abundance by approximately 5-10 percent. Adjusting the projected population estimates for this source of underestimation yields adjusted population estimates of approximately $6,400-6,800$ birds in Oregon and $3,400-3,600$ birds in Washington.

\section{Group Size and Plumage}

In both Oregon and Washington (including birds from the British Columbia side of the Strait) approximately onequarter of the Marbled Murrelets seen were recorded as being in black-and-white plumage (tables 1 and 2). Groups classified as pairs made up an higher proportion of groups seen in Oregon ( 45 percent) than in Washington ( 25 percent). But, if you examine each state separately, the proportional distribution of group size was similar regardless of plumage category (tables 6 and 7). It is unlikely that hatch-year birds would have a group-size distribution similar to those of adults, since many nesting and just post-nesting adults would still be paired in late August and early September. Further, with black-and-white birds making up one-quarter of the murrelets seen, and given our observations of some adults appearing to be in molt from alternate to basic plumage, it is likely that a substantial number of the black-and-white birds seen were adults in basic plumage.

\section{Distribution}

In Oregon, Marbled Murrelets were found to be most abundant off the central part of the state from Coos Bay north to Cascade Head (table I). In contrast, murrelets were in general less abundant in the southern and northern thirds of the state. Based on distribution maps presented in Varoujean and Williams (1994a), murrelets appeared to be more abundant near the entrances to major rivers and embayments. Birds also appeared to be more abundant close 
Table 1-Marbled Murrelet abundance based on an aerial survey canducted on 22-23 August 1993. The study area extended from Pt. Saint George, California, narth to Tillamook Head, Oregon. Except for the survey track off narthern California, the study area is broken into 20' latitudinal blocks. The projected population estimate for each latitudinal block is the density estimate (derived from the number of observed murrelets divided by the actual area surveyed) times the total study area in each block, assuming a study area width of $1,000 \mathrm{~m}$

\begin{tabular}{|c|c|c|c|c|}
\hline Location* & Birds $^{+}$ & $\begin{array}{c}\text { Area surveyed } \\
\left(\mathrm{km}^{2}\right)\end{array}$ & $\begin{array}{c}\text { Density } \\
\text { (birds } / \mathrm{km}^{2} \text { ) }\end{array}$ & $\begin{array}{c}\text { Population } \\
\text { estimate }\end{array}$ \\
\hline $\begin{array}{l}41^{\circ} 48^{\prime} \text { Point St. George } \\
42^{\circ} 00^{\prime} \text { Brookings }\end{array}$ & $\begin{array}{l}17 \mathrm{AD} \\
1 \mathrm{BW}\end{array}$ & 1.48 & 12.1 & 268 \\
\hline $\begin{array}{l}42^{\circ} 00^{\prime} \text { Brookings } \\
42^{\circ} 20^{\prime} \text { Cape Sebastian }\end{array}$ & $\begin{array}{r}19 \mathrm{AD} \\
1 \mathrm{BW}\end{array}$ & 3.70 & 5.4 & 200 \\
\hline $\begin{array}{l}42^{\circ} 20^{\prime} \text { Cape Sebastian } \\
42^{\circ} 40^{\prime} \text { Humbug Mountain }\end{array}$ & $\begin{array}{r}32 \mathrm{AD} \\
4 \mathrm{BW}\end{array}$ & 5.55 & 6.5 & 240 \\
\hline $\begin{array}{l}42^{\circ} 40^{\prime} \text { Humbug Mountain } \\
43^{\circ} 00^{\prime} \text { Croft Lake }\end{array}$ & $\begin{array}{l}21 \mathrm{AD} \\
17 \mathrm{BW}\end{array}$ & 3.91 & 9.7 & 359 \\
\hline $\begin{array}{l}43^{\circ} 00^{\prime} \text { Croft Lake } \\
43^{\circ} 20^{\prime} \text { Coos Bay }\end{array}$ & $\begin{array}{r}39 \mathrm{AD} \\
5 \mathrm{BW}\end{array}$ & 4.53 & 9.7 & 359 \\
\hline $\begin{array}{l}43^{\circ} 20^{\prime} \text { Coos Bay } \\
43^{\circ} 40^{\prime} \text { Umpqua River }\end{array}$ & $\begin{array}{l}87 \mathrm{AD} \\
15 \mathrm{BW}\end{array}$ & 7.13 & 14.3 & 529 \\
\hline $\begin{array}{l}43^{\circ} 40^{\prime} \text { Umpqua River } \\
44^{\circ} 00^{\prime} \text { Siuslaw River }\end{array}$ & $\begin{array}{r}26 \mathrm{AD} \\
8 \mathrm{BW}\end{array}$ & 5.55 & 6.1 & 225 \\
\hline $\begin{array}{l}44^{\circ} 00^{\prime} \text { Siuslaw River } \\
44^{\circ} 20^{\prime} \text { Yachats }\end{array}$ & $\begin{array}{r}109 \mathrm{AD} \\
49 \mathrm{BW}\end{array}$ & 5.55 & 28.5 & 1,055 \\
\hline $\begin{array}{l}44^{\circ} 20^{\prime} \text { Yachats } \\
44^{\circ} 40^{\prime} \text { Yaquina Head }\end{array}$ & $\begin{array}{r}215 \mathrm{AD} \\
56 \mathrm{BW}\end{array}$ & 5.55 & 48.8 & 1,805 \\
\hline $\begin{array}{l}44^{\circ} 40^{\prime} \text { Yaquina Head } \\
45^{\circ} 00^{\prime} \text { Cascade Head }\end{array}$ & $\begin{array}{l}54 \mathrm{AD} \\
16 \mathrm{BW}\end{array}$ & 5.55 & 12.6 & 466 \\
\hline $\begin{array}{l}45^{\circ} 00^{\prime} \text { Cascade Head } \\
45^{\circ} 20^{\prime} \text { Cape Lookout }\end{array}$ & $\begin{array}{l}29 \mathrm{AD} \\
16 \mathrm{BW}\end{array}$ & 5.04 & 8.9 & 329 \\
\hline $\begin{array}{l}45^{\circ} 20^{\prime} \text { Cape Lookout } \\
45^{\circ} 40^{\prime} \text { Nehalem Bay }\end{array}$ & $\begin{array}{l}18 \mathrm{AD} \\
10 \mathrm{BW}\end{array}$ & 5.55 & 5.0 & 185 \\
\hline $\begin{array}{l}45^{\circ} 40^{\prime} \text { Nehalem Bay } \\
46^{\circ} 00^{\prime} \text { Tillamook Head }\end{array}$ & $\begin{array}{r}13 \mathrm{AD} \\
5 \mathrm{BW}\end{array}$ & 5.55 & 3.2 & 118 \\
\hline Total birds observed: & $\begin{array}{l}679 \mathrm{AD} \\
203 \mathrm{BW} \\
882\end{array}$ & & opulation estimate: & 6,138 \\
\hline
\end{tabular}

* Location is represented as the extent of coastline between the latitudinal listings

${ }^{+} \mathrm{AD}=$ Adults in altemate plumage; $\mathrm{BW}=\mathrm{Black} /$ White plumage, which includes adults in basic plumage and hatch-year birds 
Table 2-Marbled Murrelet population estimate based on an aerial survey conducted on the Washington outer coast on 4 5 September 1993. The study area extended from Tillamook Head, Oregon north to Cape Flattery, Washington. The projected population estimate for each latitudinal block is the density estimate (derived from the number of observed murrelets divided by the actual area surveyed) times the total study area in each block, assuming a study area width of $4,000 \mathrm{~m}$

\begin{tabular}{|c|c|c|c|c|}
\hline Location & Binds ${ }^{+}$ & $\begin{array}{c}\text { Area surveyed } \\
\left(\mathrm{km}^{2}\right)\end{array}$ & $\begin{array}{c}\text { Density } \\
(\text { birds//m² })\end{array}$ & $\begin{array}{c}\text { Population } \\
\text { estimate }\end{array}$ \\
\hline $\begin{array}{l}46^{\circ} 00^{\circ} \text { Tillamook Head } \\
46^{\circ} 20^{\circ} \text { North Head }\end{array}$ & $\begin{array}{l}3 \mathrm{AD} \\
1 \mathrm{BW}\end{array}$ & 12.30 & 0.3 & 44 \\
\hline $\begin{array}{l}46^{\circ} 20^{\circ} \text { North Head } \\
46^{\circ} 40^{\circ} \text { Willapa Bay }\end{array}$ & $\begin{array}{l}14 \mathrm{AD} \\
2 \mathrm{BW}\end{array}$ & 18.60 & 0.9 & 134 \\
\hline $\begin{array}{l}46^{\circ} 40^{\circ} \text { Willapa Bay } \\
47^{\circ} 00^{\prime} \text { Ocean Shores }\end{array}$ & $\begin{array}{l}7 \mathrm{AD} \\
2 \mathrm{BW}\end{array}$ & 14.73 & 0.7 & 104 \\
\hline $\begin{array}{l}47^{\circ} 00^{\prime} \text { Ocean Shores } \\
47^{\circ} 20^{\prime} \text { Cape Elizabeth }\end{array}$ & $\begin{array}{l}9 \mathrm{AD} \\
2 \mathrm{BW}\end{array}$ & 12.95 & 0.8 & 118 \\
\hline $\begin{array}{l}47^{\circ} 20^{\circ} \text { Cape Elizabeth } \\
47^{\circ} 40^{\circ} \text { Destruction Island }\end{array}$ & $\begin{array}{l}6 \mathrm{AD} \\
4 \mathrm{BW}\end{array}$ & 11.10 & 0.9 & 133 \\
\hline $\begin{array}{l}47^{\circ} 40^{\circ} \text { Destruction Island } \\
48^{\circ} 00^{\circ} \text { Carroll Island }\end{array}$ & $\begin{array}{l}35 \mathrm{AD} \\
20 \mathrm{BW}\end{array}$ & 10.70 & 5.1 & 755 \\
\hline $\begin{array}{l}48^{\circ} 00^{\prime} \text { Carroll Island } \\
48^{\circ} 24^{\prime} \text { Cape Flattery }\end{array}$ & $\begin{array}{l}89 \mathrm{AD} \\
32 \mathrm{BW}\end{array}$ & 13.20 & 9.2 & 1,619 \\
\hline Total birds observed: & $\begin{array}{l}163 \mathrm{AD} \\
63 \mathrm{BW} \\
226\end{array}$ & Pro & opulation estimate: & 2,907 \\
\hline
\end{tabular}

* Location is represented as the extent of coastline between latitudinal listings

$+A D=$ Adults in alternate plumage; $B W=B$ lack/White plumage, which includes adults in basic plumage and hatch-year birds.

to shore, with approximately 75 percent of the sightings occurring on the onshore survey line.

By early September, which is late in the nesting season (Hamer and Nelson, this volume a), Marbled Murrelets were found to be most abundant off the rocky shores in the north part of the Washington outer coast from Destruction Island to Cape Flattery (table 2). In contrast, murrelets were present in densities of $<1.0 \mathrm{bird} / \mathrm{km}^{2}$ south of Destruction Island. Distribution maps presented in Varoujean and Williams (1994b) indicate that murrelets are not present in abundance off the entrances to the Columbia River, Willapa Bay and Grays Harbor. These areas, however, may play a role as murrelet habitat. Even though fewer than ten Marbled Murrelets were seen inside these embayments, a more thorough temporal coverage of these tidally dominated waters may find them to be important foraging areas in the summer months.

Overall only 10 percent of the murrelet sightings occurred beyond $2,000 \mathrm{~m}$ from shore (table 8 ). The continental shelf in southern Washington, relative to the northern one-third, is broad and exhibits a gradual bathymetric gradient from shore out to sea. Marbled Murrelets along the southern two-thirds of the state appear to be distributed evenly out to $4,000 \mathrm{~m}$ from shore. In this region waters are typically $<10 \mathrm{~m}$ deep within $2,000 \mathrm{~m}$ of shore, and 10-20 m deep in the area between $2,000-4,000 \mathrm{~m}$. From Cape Elizabeth north, the offshore bathymetric gradient is steeper, so that within 2,000 $\mathrm{m}$ from shore the water is up to $20 \mathrm{~m}$ deep. The depth ranges between 20 and $30 \mathrm{~m}$ from 2,000-4,000 m offshore. Murrelet abundance in this part of the study area is not evenly distributed, with an estimated density of $0.9 \mathrm{birds} / \mathrm{km}^{2}$ in the outer half. This is approximately one-eighth of the density reported for waters $<20 \mathrm{~m}$ deep in the inner half. Such low density, however, does correspond to the low densities of murrelets reported in the southern two-thirds of the state.

Based on distribution maps presented in Varoujean and Williams (1994a, b), the distribution of single birds, pairs of birds and larger groups, whether adults in alternate 
Table 3-Marbled Murrelet population estimates based on an aerial survey conducted an the Washington coast of the western Strait of Juan de Fuca on 6 September 1993. The projected population estimate for each longitudinal block is the density estimate (derived from the number of abserved murrelets divided by the actual area surveyed) times the study area in each block, assuming a study area width of $1,000 \mathrm{~m}$

\begin{tabular}{|c|c|c|c|c|c|}
\hline Location* & Birds $^{+}$ & $\begin{array}{c}\text { Area surveyed } \\
\left(\mathrm{km}^{2}\right)\end{array}$ & $\begin{array}{c}\text { Density } \\
\left(\text { birds } / \mathrm{km}^{2}\right)\end{array}$ & $\begin{array}{c}\text { Study area } \\
\left(\mathrm{km}^{2}\right)\end{array}$ & $\begin{array}{c}\text { Population } \\
\text { estimate }\end{array}$ \\
\hline $\begin{array}{l}124^{\circ} 38^{\prime} \text { Koitlah Point } \\
124^{\circ} 18^{\prime} \text { Sekiu Point }\end{array}$ & $\begin{array}{r}10 \mathrm{AD} \\
2 \mathrm{BW}\end{array}$ & 2.76 & 4.3 & 27.78 & 119 \\
\hline $\begin{array}{l}124^{\circ} 18^{\prime} \text { Sekiu Point } \\
123^{\circ} 57^{\prime} \text { Twin River }\end{array}$ & $\begin{array}{l}4 \mathrm{AD} \\
0 \mathrm{BW}\end{array}$ & 4.65 & 0.9 & 27.78 & 25 \\
\hline $\begin{array}{l}123^{\circ} 57^{\prime} \text { Twin River } \\
123^{\circ} 43^{\prime} \text { Tongue Point }\end{array}$ & $\begin{array}{l}4 \mathrm{AD} \\
1 \mathrm{BW}\end{array}$ & 2.04 & 2.5 & 18.52 & 46 \\
\hline $\begin{array}{l}123^{\circ} 43^{\prime} \text { Tongue Point } \\
123^{\circ} 27^{\prime} \text { Port Angeles }\end{array}$ & $\begin{array}{r}14 \mathrm{AD} \\
1 \mathrm{BW}\end{array}$ & 1.86 & 8.1 & 18.52 & 150 \\
\hline Total birds observed: & $\begin{array}{r}32 \mathrm{AD} \\
4 \mathrm{BW} \\
36\end{array}$ & & Project & pulation esti & 340 \\
\hline
\end{tabular}

* Location is represented as the extent of coastline between longitudinal listings

$+\mathrm{AD}=\mathrm{Adults}$ in alternate plumage; $\mathrm{BW}=\mathrm{Black} / \mathrm{White}$ plumage, which includes adults in basic plumage and hatch-year birds.

Table 4-Marbled Murrelet population estimates based on an aerial survey conducted an the British Columbia coast of the western Strait of Juan de Fuca on 6 September 1993. The projected population estimate for each longitudinal block is the density estimate (derived from the number of observed murrelets divided by the actual area surveyed) times the study area in each block, assuming a study area width of $1,000 \mathrm{~m}$

\begin{tabular}{|c|c|c|c|c|c|}
\hline Location* & Birds $^{+}$ & $\begin{array}{c}\text { Area surveyed } \\
\left(\mathrm{km}^{2}\right)\end{array}$ & $\begin{array}{c}\text { Density } \\
\left(\text { birds/ } \mathbf{k m}^{2}\right)\end{array}$ & $\begin{array}{c}\text { Study area } \\
\left(\mathrm{km}^{2}\right)\end{array}$ & $\begin{array}{c}\text { Population } \\
\text { estimate }\end{array}$ \\
\hline $\begin{array}{l}124^{\circ} 28^{\prime} \text { Port San Juan } \\
124^{\circ} 12^{\prime} \text { Magdalena Bay }\end{array}$ & $\begin{array}{l}9 \mathrm{AD} \\
0 \mathrm{BW}\end{array}$ & 1.33 & 6.8 & 18.52 & 126 \\
\hline $\begin{array}{l}124^{\circ} 12^{\prime} \text { Magdalena Bay } \\
123^{\circ} 59^{\prime} \text { Glacier Point }\end{array}$ & $\begin{array}{l}6 \mathrm{AD} \\
3 \mathrm{BW}\end{array}$ & 0.93 & 9.7 & 18.52 & 180 \\
\hline $\begin{array}{l}123^{\circ} 59^{\prime} \text { Glacier Point } \\
123^{\circ} 45^{\prime} \text { Sooke Inlet }\end{array}$ & $\begin{array}{l}0 \mathrm{AD} \\
0 \mathrm{BW}\end{array}$ & 0.93 & 0.0 & 18.52 & 0 \\
\hline $\begin{array}{l}123^{\circ} 45^{\prime} \text { Sooke Inlet } \\
123^{\circ} 38^{\prime} \text { Becher Bay }\end{array}$ & $\begin{array}{l}0 \mathrm{AD} \\
0 \mathrm{BW}\end{array}$ & 0.46 & 0.0 & 9.26 & 0 \\
\hline Total birds observed: & $\begin{array}{r}15 \mathrm{AD} \\
\frac{3 \mathrm{BW}}{18}\end{array}$ & . & Projec & opulation esti & te: 306 \\
\hline
\end{tabular}

* Location is represented as the extent of coastline between longitudinal listings

${ }^{+} \mathrm{AD}=$ Adults in alternate plumage; $\mathrm{BW}=$ Black/White plumage, which includes adults in basic. plumage and hatch-year birds . 
Table 5-Diving data for radiolagged Marbled Murrelets tracked during the 1988 field season in Oregon, and the 1991 field season in northern California (Varoujean and others 1989; Varoujean, unpubl data).

Mean ( \pm s.e.) duration of dive episode:

$X_{D}=0.30$ hours $( \pm 0.04), n=13$ days

Mean ( \pm s.e.) percentage of time during dive episode spent submerged below the surface: $\mathrm{X}_{\mathrm{S}}=67.6$ percent $( \pm 1.0 \mathrm{pct}$ ), $n=20$ dive episodes

Percent time spent diving during daylight hours:

Dive episodes occur 6 times/day from $0530-2130 \mathrm{~h}$ ( $16 \mathrm{~h}$ period):

$6\left(X_{D}\right)=1.80 \mathrm{~h}( \pm 0.24)$, which is 11.3 percent $( \pm 1.5)$ of a $16 \mathrm{~h}$ day, or a range with \pm 2 s.e. of $8.3-14.3$ percent

Percent time spent actually below the surface during daylight hours:

Ranges from $\left(\mathrm{X}_{\mathrm{S}}-2\right.$ s.e. $)(8.3 \mathrm{pct})$ to $\left(\mathrm{X}_{\mathrm{S}}+2\right.$ s.e. $)(14.3 \mathrm{pct})$, or 5.4 to 9.9 percent

Table 6-Number (and percent) of Marbled Murrelets seen as singles, binds in pairs and in groups of $>2$ binds for birds in alternate, and black and white plumage. Data includes all sightings made during aerial surveys of the Oregon coast over the period 22-23 August 1993

\begin{tabular}{l|cccc}
\hline & \multicolumn{4}{|c}{ Group size } \\
\cline { 2 - 4 } & 1 & 2 & $>2^{*}$ & Category \\
Plumage category & No.(pct) & No.(pct) & No.(pct) & total \\
\hline Alternate & $144(41)$ & $170(48)$ & $41(11)$ & 355 \\
Black/white & $62(48)$ & $55(43)$ & $12(9)$ & 129 \\
& & & \\
Group total & $206(43)$ & $225(46)$ & $53(11)$ \\
\hline
\end{tabular}

*Groups ranged in size from 3-12 birds (alternate), and 3-5 birds (black/white)

Table 7-Number (and percent) of Marbled Murrelets seen as singles, birds in pairs and in groups of $>2$ birds for binds in alternate, and black and white plumage. Data includes all sightings made during aerial surveys of the outer coast of Washingtion, and the western Strait of Juan de Fuca over the period 46 September 1993.

\begin{tabular}{l|cccc}
\hline & \multicolumn{4}{|c}{ Group size } \\
\cline { 2 - 4 } & 1 & 2 & $>2^{*}$ & Category \\
Plumage category & No.(pct) & No.(pct) & No.(pct) & total \\
\hline Alternate & $84(66)$ & $32(25)$ & $11(9)$ & 127 \\
Black/white & $40(71)$ & $14(25)$ & $2(4)$ & 56 \\
Group total & $124(68)$ & $46(25)$ & $13(7)$ \\
\hline
\end{tabular}

*Groups ranged in size from 3-18 birds (alternate), and 3-4 birds (black/white) 


\begin{abstract}
Table 8-Distribution of Marbled Murrelets on the outer coast of Washington based on aerial survey results, 4-5 September 1993. From north to south the study area is divided into two sections, with the southern section, from Tillamook Head to Cape Elizabeth, located off sandy shores, and the northern section, from Cape Elizabeth to Cape Flattery located off predominately rocky shores. Within each section the study area is delineated by distance from shore into an inner $(<2,000$ m) and outer (2,000-4,000 m) half
\end{abstract}

\begin{tabular}{|c|c|c|c|c|}
\hline \multirow[b]{2}{*}{ Location* } & \multicolumn{2}{|c|}{$\begin{array}{c}\text { Inner half } \\
(<2,000 \mathrm{~m})\end{array}$} & \multicolumn{2}{|c|}{$\begin{array}{c}\text { Outer half } \\
(2,000-4,000 \mathrm{~m})\end{array}$} \\
\hline & Birds $^{+}$ & $\begin{array}{c}\text { Density } \\
\text { (birds/ } / \mathrm{km}^{2} \text { ) }\end{array}$ & Birds $^{+}$ & $\begin{array}{c}\text { Density } \\
\left(\text { birds } / \mathrm{km}^{2} \text { ) }\right.\end{array}$ \\
\hline $\begin{array}{l}46^{\circ} 00^{\prime} \text { Tillamook Head } \\
47^{\circ} 20^{\prime} \text { Cape Elizabeth }\end{array}$ & $\begin{array}{r}27 \mathrm{AD} \\
4 \mathrm{BW}\end{array}$ & 1.0 & $\begin{array}{l}6 \mathrm{AD} \\
3 \mathrm{BW}\end{array}$ & 0.6 \\
\hline $\begin{array}{l}47^{\circ} 20^{\prime} \text { Cape Elizabeth } \\
48^{\circ} 24^{\prime} \text { Cape Flattery }\end{array}$ & $\begin{array}{r}124 \mathrm{AD} \\
51 \mathrm{BW}\end{array}$ & 7.5 & $\begin{array}{l}6 \mathrm{AD} \\
5 \mathrm{BW}\end{array}$ & 0.9 \\
\hline
\end{tabular}

* Location is represented as the extent of coastline between latitudinal listings

$+\mathrm{AD}=$ Adults in alternate plumage; $\mathrm{BW}=\mathrm{Black} / \mathrm{White}$ plumage, which includes adults in basic plumage and hatch-year birds.

plumage or birds in black-and-white plumage, was similar, indicating no preferred use of a particular section of coast in either Oregon or Washington by any one group size or plumage category.

\section{Production}

The ratio of hatch-year birds to the total number of murrelets seen during the surveys is a potential estimator of production. Of the 882 murrelets seen in Oregon, 203 birds were recorded as being in black-and-white plumage, i.e., adults in basic plumage and hatch-year birds. To obtain an estimate of production requires ascertaining the number of hatch-year birds in the black-and-white plumage category. This was done by using figures obtained by Ralph and Long (this volume) from northern California on the proportion of hatch year birds to the total number of black-and-white birds identified to age. During the period 20-30 August they documented that 21 percent of the black-and-white birds identified to age were hatch years. Therefore, if you assume 21 percent of the 203 black-and-white birds seen during the aerial surveys ( 43 birds) are hatch years, the proportion of hatch-year birds to the total of 882 murrelets seen in Oregon is 4.9 percent.

As there is about a one week delay in the onset of murrelet nesting in Washington as compared to northern California (Hamer and Nelson, this volume a), it is more appropriate, even with the Washington survey occurring in early September, to again use the hatch-year ratio for the period 20-30 August, rather than the ratio of 11 percent documented by Ralph and Long (this volume) for the period 30 August -9 September. Twenty-one percent of the 70 blackand-white birds seen during the aerial surveys is 15 birds, so the proportion of hatch-years to the total of 280 murrelets seen in Washington and British Columbia is 5.4 percent.

\section{Discussion}

\section{Abundance}

In general, the population estimate of $6,400-6,800$ birds corresponds to estimates previously reported for Oregon. Several spatially limited surveys were conducted in Oregon prior to 1992 (Nelson and others 1992), including boatbased surveys carried out during the summers of 1986-1988 by Varoujean and Williams (1987) and Varoujean and others (1989). These surveys, conducted while searching for murrelets to capture for radio tagging, established a mean density estimate of $23.2 \mathrm{birds} / \mathrm{km}^{2}(n=63$, s.e. $=3.7)$. It was felt, however, that murrelet density was overestimated, in part, because the surveys were conducted off only central Oregon, where murrelets are more abundant. Furthermore, because murrelets were found to be episodically concentrating near the tidal plumes of river mouths and harbor entrances, density estimates derived from transects carried out solely within $3 \mathrm{~km}$ of these areas were significantly higher $(t$-test, $P<0.01)$, and more variable than on transects that extended to and beyond $3 \mathrm{~km}$ from these entrances (out to $3 \mathrm{~km}: \bar{x}=54.1$ birds $/ \mathrm{km}^{2}, n=14$, s.e. $=13.7$, range $=$ 6.7-190.0; out to/beyond $3 \mathrm{~km}: \bar{x}=13.5 \mathrm{birds} / \mathrm{km}^{2}, n=49$, s.e. $=1.6$, range $=3.5-32.0)$. Varoujean and Williams $(1987)$ also noted variability in abundance in the same location offshore of sandy beaches over periods of 2-4 days, which they attributed to daily changes in the location and extent of rip-current plumes. Murrelets were observed aligning themselves on or near the boundaries of these plumes, presumably for the purpose of foraging. The presence, persistence, size and shape of these plumes depends on shoreline morphology, tidal state, tidal range, and the magnitude and direction of wind driven waves and long ocean swells (Brown and McLachlan, 1990). With tidal ebb 
and flow periods each lasting 6-7 hours, and with the hourly/ daily variations in sea state that occur during the summer months along the Oregon coast, rip-current plume configuration on the scale of hours changes quickly. Additionally, plume development occurs in a sequential manner along various stretches of shore, because of the consistent differences between areas in the timing of the tide cycle. For example, between Coos Bay and the Siuslaw River, a distance of about $80 \mathrm{~km}$, the onset of tidal ebb or flow consistently occurs 20 minutes earlier off Coos Bay. Given the various factors that can contribute to spatial and temporal variability in murrelet abundance near tidal and rip-current plumes, Varoujean and Williams (1987) felt that they could have been counting the same birds in more than one location on different days. For the same reasons, we presently feel that there is also the possibility that birds can be counted more than once on any one day when boat surveys are conducted over extensive $(>40 \mathrm{~km})$ stretches of coastline, especially if both an onshore and offshore line are being surveyed on the same day. For example, to carry out a boat survey on both an onshore and offshore line over a $45 \mathrm{~km}$ length of coast would require about 6 hours at $15 \mathrm{~km} / \mathrm{hr}$, over which time tidal conditions and sea state would change decidedly. It would be reasonable to assume that during this period every murrelet encountered on transect would be expected to take flight at least once, and, if they landed on a yet to be surveyed segment of a transect, counted again. At $80 \mathrm{~km} / \mathrm{hr}$ (Varoujean and others 1989) a murrelet can take flight, and overtake a vessel that has passed it, or fly offshore into the path of a returning survey vessel in a matter of minutes. The probability of again encountering birds behaving in this manner are high. For example, onshore and offshore survey lines are typically located within $500 \mathrm{~m}$ and between $5 \mathrm{M} \mathrm{m}$ and $1,000 \mathrm{~m}$ from shore, respectively. A transect width of $200 \mathrm{~m}$ (i.e., $100 \mathrm{~m}$ on each side of the vessel) samples 70 percent of the zone out to $500 \mathrm{~m}$, given that the first $100 \mathrm{~m}$ from shore, the surf zone off a sandy beach is infrequently inhabited by murrelets. Similarly, a $200 \mathrm{~m}$ wide transect located between $500 \mathrm{~m}$ and $1,000 \mathrm{~m}$ would sample 50 percent of this zone. Consequently, the probability of counting any one bird, including birds that have already been counted elsewhere and moved into the path of the boat again, is 0.7 in the onshore zone, and 0.5 in the offshore zone.

Two adjustments were made to compensate for the potential sources of overestimation in calculating a population estimate based on the 1980 's boat survey data. First, only the mean density estimate for transects out to and beyond $3 \mathrm{~km}$ of river mouths ( $13.5 \mathrm{birds} / \mathrm{km}^{2}$ ) was used in the calculation. Second, a conservative estimate of $470 \mathrm{~km}^{2}$ was used as the areal extent of suitable nearshore habitat over which it was applicable to apply the density estimate. This area was calculated using a study area width of $1 \mathrm{~km}$, even though one-quarter of the survey transects were located 1.0-1.5 km from shore, and a north-south, straight line distance of 470 $\mathrm{km}$ as a measure of the length of the Oregon coastline. A population estimate based on the product of mean density
( \pm 2 s.e.) and $470 \mathrm{~km}^{2}$ of habitat is $4,850-7,850$ birds. Note that the 1993 aerial survey estimate of $6,400-6,600$ birds falls within this range.

In sharp contrast to the concordance between the population estimates of the 1980's boat surveys and 1993 aerial survey, is the disparity between these estimates and the nearly three-fold higher population estimate of 15,000 20,000 murrelets by Strong and others (this volume). This estimate is based on the results of boat surveys conducted in Oregon during the summers of 1992 and 1993, and is subject to the same overestimation errors just discussed in reference to the 1980 's boat survey data. Interestingly, if we do not use a conservative approach in calculating a population estimate for the 1980's boat survey data, but rather apply the unadjusted density estimate of $23.2 \mathrm{birds} / \mathrm{km}^{2}$ to a $750 \mathrm{~km}^{2}$ study area ( $500 \mathrm{~km}$ of actual coastline times a $1.5-\mathrm{km}$-wide study area), we get an estimate of 17,400 birds.

Our aerial survey population estimates do not take into account the possibility that murrelets may have been distributed farther offshore than our offshore survey lines. Both Strong and others (1993) and Ralph and Miller (this volume) have shown that 20 percent of the murrelet population may be located beyond $1,000 \mathrm{~m}$ from shore, i.e., in waters deeper than $18 \mathrm{~m}$. Our data, however, indicate that murrelet abundance declined sharply out to $1,000 \mathrm{~m}$ from shore in Oregon and out to $2,000 \mathrm{~m}$ from shore in Washington. But even if the 1993 aerial survey estimate for Oregon was adjusted for the possibility that 20 percent of the murrelet population was located offshore of our study area, the resultant estimate of 8,200 birds would still be only about one-half the estimate of $15,000-20,000$ birds. So, in summary, we suggest that $15,000-20,000$ birds is an overestimate of Marbled Murrelet abundance in Oregon. With reservations associated with comparing the 1980's boat to 1993 aerial survey results, we tentatively conclude that murrelet population size has remained relatively stable in Oregon over the last 10 years.

Between 1978 and 1985, several censuses of Marbled Murrelets were conducted along various routes along the outer coast of Washington and the Strait of Juan de Fuca (Speich and others 1992, Wahl and others 1981). Survey platforms included the use of aircraft on flights "of opportunity", and small boats. Even with differences in sampling methodology, the density estimates $(0.2-8.3 \mathrm{birds} /$ $\mathrm{km}^{2}$ ) reported by Speich and others (1992) for spring and summer on the Washington outer coast do correspond to those reported for the September 1993 aerial survey. But their combined population estimate for the outer coast and western Strait was no more than 2,600 birds, about 1,000 fewer birds than our September 1993 estimate of 3,4003,600 birds. This difference is likely attributable to the conservative approach taken by Speich and others (1992) in delineating the areal estimates over which they extrapolated their density estimates. But it is also possible that the higher 1993 estimate is due to differences in the timing of the respective studies. None of the surveys conducted by Speich 
and others (1992) took place later than August, whereas our survey was carried out in early September. It is possible that by early September, murrelets from British Columbia and Puget Sound have dispersed to the northern Washington outer coast. But the overall patterns of population shifts are unknown for this region (Rodway and others 1992), so there is no direct evidence indicating that the September 1993 estimates include birds from outside the study area. Therefore, at present we must conclude that the higher population estimate of the 1993 aerial survey does not represent a real increase in murrelet numbers due to either intrinsic population growth or the immigration of birds from outside the study area. If this is so, then there has been no marked change in the population size of Marbled Murrelets inhabiting the outer coast and western Strait of Washington in the last 10 years.

\section{Distribution}

Marbled Murrelet abundances as documented by the 1993 aerial surveys and the 1992-1993 boat surveys (Strong and others 1993; Strong, pers. comm.) were highest in the central portion of the state and lowest at the south and north ends of the study area. Additionally, this distribution corresponds to that described by Nelson and others (1992), and to the distribution of the remaining older-aged forest stands in Oregon, with the exception of the area between the Umpqua River and Coos Bay. This area exhibits high murrelet abundance even though there are only small, scattered stands of older-aged conifers located within $30-70 \mathrm{~km}$ inland of this section of Oregon's coast.

Ralph and Miller (pers. comm.) recorded a density estimate of 4.0 birds $/ \mathrm{km}^{2}$ based on a boat survey of an onshore and offshore line out to $1,400 \mathrm{~m}$ from shore conducted on 28 September 1992. This survey extended from Cape Sebastian south to the Smith River in California. But from the border south $6 \mathrm{~km}$ to the mouth of the Smith River, they documented a density of $37.2 \mathrm{birds} / \mathrm{km}^{2}$. Potentially then, the numbers of murrelets frequenting waters near the border may be variable, and most likely at times represent birds from the northern California breeding population, which may account for our relatively high density estimate of $12.1 \mathrm{birds} / \mathrm{km}^{2}$ for the area between Pt. Saint George and the border (table I).

There is an indication from the aerial survey data that murrelets were present in greater numbers off the mouths of rivers and entrances to embayments in Oregon, as shown in Figures 1 and 2 of the report by Varoujean and Williams (1994a), and that murrelet numbers were variable off sandy shores. As regards Marbled Murrelet distribution and shore type in Oregon, Strong and others (1993) reported that bird densities were highest off sandy beach and mixed (sandy/ rock) shores. In contrast, Varoujean and Williams (1987) noted that murrelet densities were significantly higher off (and within $3 \mathrm{~km}$ ) of the mouths of major rivers and embayments as compared to either sandy beaches or rocky shores. Part of this disparity, however, may be attributed to the different areas surveyed and differences in survey effort. The survey by Strong and others (1993) occurred over the entire length of coast between Yaquina Bay and Coos Bay, whereas Varoujean and Williams (1987), in general, surveyed up to only $10 \mathrm{~km}$ north and south of the entrances to Yaquina and Coos Bay, and the mouths of the Siuslaw and Umpqua River. Strong and others (1993), Varoujean and Williams (1987) and Varoujean and others (1989) each documented that murrelet abundance is most variable off sandy shores.

Speich and others (1992) suggested that the Marbled Murrelet population on the Pacific Ocean coast of Washington was largely found north of Pt. Grenville with an uncertain number found in the waters off the southern coast, although the numbers there were thought to be low. This pattern was confirmed by the September 1993 aerial survey of the coast.

The southern portion of the state does not seem to be as important to murrelets during the breeding season as does the northern part of the Washington outer coast. It may however play an important role as a wintering area, based on 22 years of records collected off Grays Harbor (Speich and Wahl, this volume). Seabird surveys out of Grays Harbor were conducted on charter boats, and occurred during various seasons from 1971 to 1991 . Although not specifically designed to do so, these surveys do provide information pertaining to the distribution and abundance of Marbled Murrelets. The general pattern of murrelet occurrence was one of high average abundances during the spring, fall and winter months, and higher abundances in habitats closer to shore (numbers encountered ranged from 0.4-2.8 birds/km travelled). Overall, the highest abundances occurred in Grays Harbor channel out to the $50 \mathrm{~m}$ depth contour; only rarely were Marbled Murrelets recorded in deeper habitat areas. Furthermore, murrelets were rarely seen during August and September surveys, a pattern that corresponds to the low abundance figures obtained during the September 1993 aerial surveys for this section of the Washington coast.

\section{Production}

Based on analyses conducted by Beissinger (this volume), the hatch-year proportion estimates of 4.9 percent in Oregon and 5.4 percent in Washington are too low for population maintenance, if these figures are used as measures of productivity in a population growth model. However, to conclude that the murrelet populations in Oregon and Washington are in general decline may be premature. There is an indication that other seabird species nesting in the area experienced low production rates during the 1993 nesting season (Varoujean and Williams 1994a, b). Western Gulls (Larus occidentalis), Glaucous-winged Gulls (L.glaucescens) and their intergrades, and California Gulls ( $L$. californicus) had hatch-year proportions that ranged from 5-7 percent of the total population, and the proportion of Common Murre (Uria aalge) hatch-years was 1.6 percent. Preliminarily, these low measures of production are most likely attributable 
to low food availability that may have been caused by El Niño-like, warm water conditions prevalent in the study area through the summer. Even though the life histories of these seabird species differ from the Marbled Murrelet, it is possible that what caused low gull and murre production also caused reduced production in the murrelet during the 1993 nesting season.

\section{Acknowledgments}

The 1993 aerial survey of the Oregon coast was funded by Menasha Corporation, and administered by Steven $P$. Courtney of the Sustainable Ecosystems Institute. We also greatly appreciate Steve Courtney's participation in the Oregon survey as the position-data recorder and project liaison. The aerial survey of the Washington outer coast and western
Strait of Juan de Fuca was jointly funded by ITT Rayonier, Port Blakely Tree Farms, and Weyerhaueser Co. Funding was administered by the National Council for Air and Stream Improvement with the able assistance of Larry L. Irwin. We thank Daniel Varland (ITT), Neal Wilkins (Port Blakely) and Bob Anderson (Weyco) for understanding and supporting the need for Marbled Murrelet surveys in Washington waters; in addition, each provided comments on an earlier preliminary report. We greatly appreciate Daniel Varland's participation in the Washington survey as the position-data recorder and project liaison. Glen Ford and Janet Casey aided us in getting our data into the proper format for use in the computer mapping software they provided. We would also like to thank the pilot Paul Etchemendy of the Eagle Flight Center, Hillsboro, Oregon for making the survey aircraft available for the project with such short notice. 



\section{Distribution and Population Estimates of Marbled Murrelets at Sea in Oregon During the Summers of 1992 and 1993}

\author{
Craig S. Strong
}

Abstract: We used standardized transect techniques to count Marbled Murrelets and other seabird species al sea from a boat and from a low-flying light aircraft along the length of the Oregon coast. The focus of effort was on vessel surveys of the central Oregon coast. In both years, Marbled Murrelets were most abundant in central Oregon, between Cascade Head and Cape Arago. They were concentrated much closer to sbore in 1992 than in 1993. Different distribution patterns in the two years was likely a consequence of El Niño oceanographic conditions which severely impacted Oregon's seabirds in 1993. New population estimates for the state ranged from 2,500 (shore-based) to 22,250 birds (boat). Estimates generated from vessel surveys were considered far more reliable than estimates from air or from shore counts due to more thorough coverage, proximity to birds, more observers, and longer scanning time. Vessel estimates using both strip and line transect analyses for two years with very different distribution characteristics each produced state population totals between 15,000 and 20,000 birds, after accounting for some assumptions. There is a strong possibility that a large proportion of these birds may not be nesting successfully due to limitations of nesting habitat and other factors.

In the past 6 years, research effort on the Marbled Murrelet (Brachyramphus marmoratus) has increased in response to an apparent dramatic decline in their numbers on the west coast south of British Columbia (Carter and Erickson 1992; Marshall 1988; Nelson and others 1992; Ralph, this volume). Their recent listing as a federally threatened species (U.S. Fish and Wildlife Service, 1992) adds a further imperative to learn more of this bird's nesting and at-sea biology, population size, and reproductive parameters so that meaningful management and recovery plans may be developed.

Historically, Marbled Murrelets were described as 'common' and 'abundant' in the vicinity of the Columbia River and in Tillamook county, and near the Yaquina River mouth in central Oregon (Gabielson and Jewett 1940, Taylor 1921). Currently, sightings from shore are infrequent in these areas (Nelson and others 1992, Strong and others 1993), indicating a decline in the northern half of the state. Presently Marbled Murrelets are seen regularly from shore only between Seal Rock, Lincoln County, and Cape Arago, Coos County (Strong, unpubl. data). Unfortunately, there are no quantified historical data to compare with recent shore counts or vessel surveys in order to determine to what extent the population has declined in central Oregon. There are no records to indicate the historic abundance of murrelets south of Cape Arago. Even current shore observations are few and inconclusive (Nelson and others 1992, Strong and others 1993).

1 Wildlife Biologists, Crescent Coastal Research, 7700 Bailey Rd., Crescent City, CA 95531
Clifford J. Palmer

lan Gaffney'

This project was initiated to fill a gap in knowledge about the abundance, distribution, and at-sea biology of Marbled Murrelets along the Oregon coast. Previous murrelet research at sea in Oregon consisted of observations from shore and limited vessel surveys, summarized in Nelson and others (1992), though more recently aerial surveys have been undertaken (Burketh, pers. comm.; Varoujean and Williams, this volume).

We surveyed Marbled Murrelets and other seabird species in the Oregon coastal waters from Washington to California during the summers of 1992 and 1993 to address the following objectives of this report:

(1) Compare behavior, distribution, and abundance patterns of murrelets between the two years in each of four regions.

(2) Compare and evaluate population estimates between the three survey methods (aerial, vessel, and shore-based) and between line and strip transects.

(3) Qualitatively assess the feasibility and reliability of the three methods for monitoring distribution and abundance of murrelets.

\section{Methods}

The Oregon coast was divided into three regions with distinctly different characteristics of murrelet abundance (Nelson and others 1992, Strong and others 1993). The northern region extended from the Columbia River to the north end of Cascade Head (155 km of coastline). The central region extended from Cascade Head to Coos Bay ( $209 \mathrm{~km})$, though the southern $75 \mathrm{~km}$ of this region, from Florence to Coos Bay, was analyzed separately as a fourth region because of ambiguity of survey results. The southern region went from Coos Bay, south to the California border (195 km).

\section{Vessel Surveys}

A 20 foot Boston Whaler powered by two 70 hp outboard motors was used for all surveys. It was operated from a console in the middle of the boat. A driver and two observers manned the boat. Each observer scanned a $90^{\circ}$ arc between the bow and the beam continuously, only using binoculars to confirm identification or to observe plumage or behavior of murrelets. All species of birds within $50 \mathrm{~m}$ of the boat and on the water were recorded, and plunge divers (terns, pelicans) were also recorded when flying. Marbled Murrelets sighted at any distance were recorded along with the time of sighting, distance from the vessel, group size (defined as birds within $2 \mathrm{~m}$ of each other), side of vessel, behavior and plumage notes. Distance was not reported until murrelets had either responded to the boat by flying or diving, or had been passed by the boat. A bright float was deployed periodically at $50 \mathrm{~m}$ behind the vessel to aid in distance estimation. 
Location was determined by distance travelled through the water between known landmarks on shore, using the speedometer and trip log functions on a sonar fish finder. Speed was maintained at approximately 8 knots at all times. Other variables monitored included water temperature and depth, presence of sonar scattering layers, rip currents, type of shoreline (rocky, sandy beach, adjacent to river mouths, or a combination of the above), association of murrelets with other species, and weather conditions. Observation conditions, as they affected the detectability of murrelets, were categorized as excellent, very good, good, fair, and poor. Observation conditions were classified based on Beaufort sea state, swell, reflections, and fog. Surveys were not initiated at Beaufort state 3 (fair observing conditions), and surveys were terminated at Beaufort state 4 (poor observing conditions). The driver alternated with observers periodically to reduce observer fatigue, and a rest stop was taken at least every 3 hours.

To quantify distribution along the length of the Oregon coast ("coastline transects"), transect lines parallel to the shore between 250 and $500 \mathrm{~m}$ from shore were run, typically covering from 25 to $100 \mathrm{~km}$ in a day.

To quantify distribution in relation to distance from shore ("offshore transects"), repeated transect lines along the same $4 \mathrm{~km}$ section of coast were run, each one $300 \mathrm{~m}$ to $600 \mathrm{~m}$ farther out to sea than the previous one (all 1993 increments were of $300 \mathrm{~m}$; in 1992 the distance increment was variable). Transects lines were repeated progressively farther offshore until no murrelets were seen on the water for a full $4 \mathrm{~km}$ line. In 1992 the outer limit of surveys was 2.5 $\mathrm{km}$ offshore, in 1993 the outer limit was $6 \mathrm{~km}$. offshore. The sample $4 \mathrm{~km}$ coastal sections were selected at various locations between Gleneden Beach and Seal Rocks (except for one survey south of Heceta Head in 1992) in central Oregon. The sample locations were all off sand or mixed sandy and rocky shorelines where murrelets were consistently present.

All information was spoken into a tape recorder via an external microphone, held by one of the observers.

\section{Aerial Surveys}

A single engine high-wing Cessna 187 or 206 aircraft was used for aerial surveys. An observer on each side of the plane used a tape recorder with remote microphone to record observations.

In 1993, the inboard observer (nearest the shoreline) noted when landmark locations were passed. In 1992, a third person recorded time and location on maps. The pilot maintained an altitude of approximately $60 \mathrm{~m}$ and a speed of 90 knots. Distance from shore was held at between 300 and $500 \mathrm{~m}$ (the same as for coastline vessel transects), except when passing seabird nesting islands, where a wide berth was given $(>800 \mathrm{~m})$ to avoid disturbance. Each observer continuously scanned a $50 \mathrm{~m}$ wide corridor of ocean surface which was calculated as an angle between $32^{\circ}$ and $57^{\circ}$ off horizontal, as measured with a clinometer. While maintaining their scan of the water surface, observers recited the number and species of birds seen and time to the nearest 10 seconds, and reported on observing conditions. We found that at the altitude we flew, we were able to identify most birds to species. The $60 \mathrm{~m}$ level was recommended in Briggs and others (1985) and by Varoujean and Williams (this volume) as optimal for surveys of small marine birds. Since our aircraft had only a pressure altimeter, our recorded altitude was only approximated.

\section{Shore-Based Observations}

Additional shore observations were made opportunistically. A 20-45 power telescope was used to carefully scan the sea beyond the surf line to a distance of approximately $1.2 \mathrm{~km}$ (using marks on topographic maps a known distance offshore for reference). Information recorded included location, time of beginning and end of survey, weather and observation conditions, number of all seabird species (except in a few instances when time limitations allowed only Marbled Murrelets to be counted), group size of murrelets, and other notes on murrelet behavior or distribution (e.g. fish holding, concentrated in surf line, etc.).

\section{Data Management and Analyses}

To describe distribution along the Oregon coast, Marbled Murrelets counted from coastline vessel transects were summed in $10 \mathrm{~km}$ blocks as measured by landmarks on shore and time elapsed when traveling at known speed $(8$ knots). Currents and variation in speed resulted in location errors of up to $3 \mathrm{~km}$ on some long transects without landmarks, but error was usually less than $1 \mathrm{~km}$. The $10 \mathrm{~km}$ sums were averaged where counts were repeated on the same section of coast.

\section{Population Estimates}

We used both line and strip transect analyses to develop population estimates from the vessel coastline transects. This allowed for a more robust conclusion and assessment of the different assumptions underlying each method. For both analyses, the complete transect of each day was treated as a sampling unit, which avoided statistical dependence of adjacent transect legs. Birds flying through the transect area were not included in any calculations.

\section{Line Transects}

Because distance from the vessel to each murrelet sighting were recorded, these data were amenable to line transect analyses. Data were processed by the program DISTANCE (Laake and others, 1993) which fits a model to the distances at which birds were detected (a detection probability curve) and then includes data on encounter rate (number of detections/ length of transect) and average group size to derive a density of birds per $\mathrm{km}^{2}$. This is then multiplied by the length of the region to achieve an abundance estimate for a given area. The resulting models (half-normal or cosine, with polynomial adjustments to the fit) all had their peak detection probability on the transect line, whereas, due to avoidance behavior, peak reported detection distance was typically $20-40 \mathrm{~m}$ from the line. To resolve this, we divided the reported distance by 2 or 3 for birds seen on the forward quarters and divided by 4 
for birds sighted off the bow. We also truncated observations to within $160 \mathrm{~m}$ from the vessel, which eliminated very few observations and improved modeling capability

This approximated the undisturbed distribution of birds and allowed satisfactory fit of the models. Transect data for each day were fitted to a model and an independent population estimate was derived for each day. Daily estimates were averaged within a region for population estimates in each year, and variance of daily estimates was used to construct confidence intervals using a normal approximation (Zar 1984: 103). Where lower confidence intervals approached zero (due to few sample days), the lower limit was taken as the actual count times 2 .

\section{Strip Transects}

For strip transects, we summed all Marbled Murrelets occurring within the designated strip (excluding flying birds) for each day's transect, and divided that sum by the length of the transect (in $\mathrm{km}$ ) for a density within the strip. This was multiplied by the appropriate factor to obtain a density measure in $\mathrm{km}^{2}$ and by the length of the region to obtain a population estimate for the day. These estimates were averaged the same way as for line transects to obtain regional population estimates and confidence intervals. Strip width was selected at $50 \mathrm{~m}$ out from the vessel (100 m total) after study of frequency histograms of reported distances and iterations of density calculations at different strip widths (figs. 1 and 2).

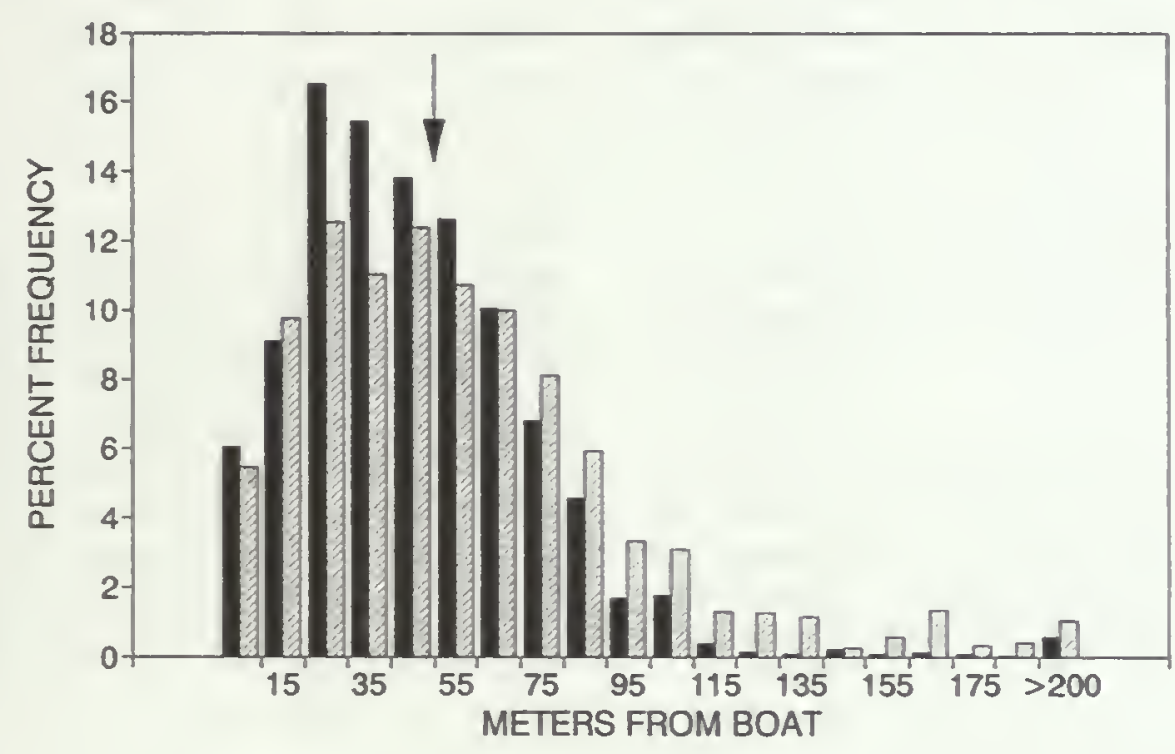

$\square 1992(n=4882) \quad \square 1993(n=3346)$

Figure 1-Distances at which murrelets were reported from observing vessel. Arrow at $50 \mathrm{~m}$ indicates distance from vessel within which all birds were assumed to be detected for strip transects.

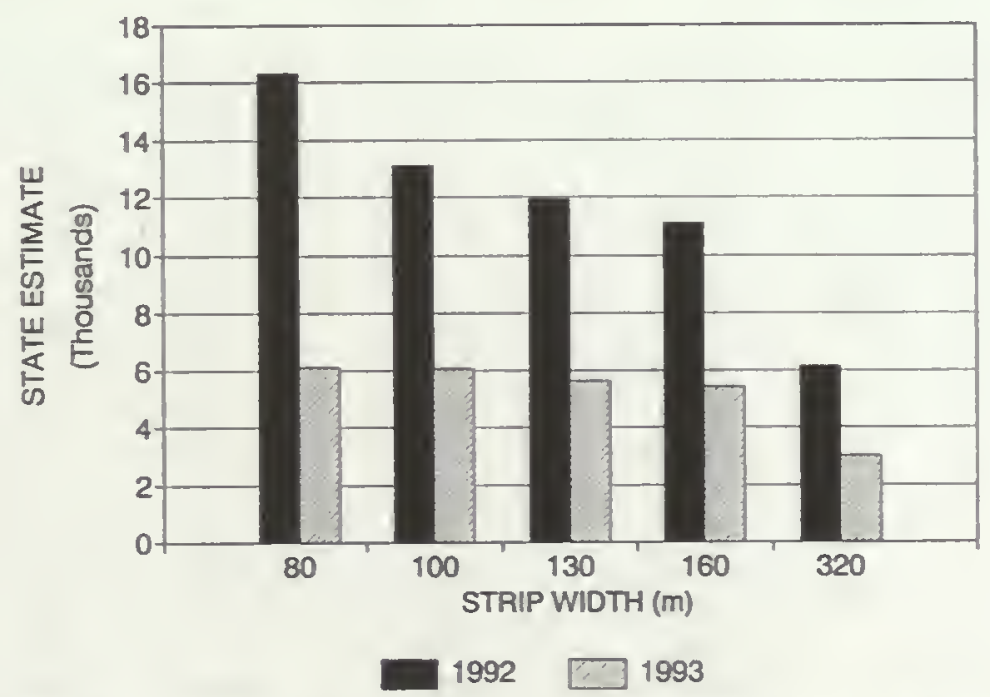

Figure 2-Abundance estimates for the state extrapolating for five different strip widths, without addition of birds $>500$ m offshore (central region) or birds $1000 \mathrm{~m}$ offshore (north and south regions, see text). 
Table 1-Marbled Murrelet unweighted population estimates, estimates weighted by $\mathbf{k m}$ of transect/day (number of observation points for shore surveys), and 95 percent confidence intervals (C1) around unweighted estimates for Marbled Murrelets in Oregon using four methods of estimation

\begin{tabular}{|c|c|c|c|c|c|c|}
\hline Method & Year & Region & $\begin{array}{l}\text { Unweighted } \\
\text { Estimate }\end{array}$ & $\begin{array}{l}\text { Weighted } \\
\text { Estimate }\end{array}$ & Lower CI & Upper CI \\
\hline \multirow[t]{12}{*}{ Vessel Line } & \multirow[t]{6}{*}{1992} & North & 1,115 & 1,090 & 557 & 1,671 \\
\hline & & Central & 6,928 & 7,092 & 4,936 & 8,920 \\
\hline & & Central offshore & 4,056 & 4,056 & 1,865 & 6,273 \\
\hline & & Center-south & 4,898 & 4,898 & 1.71 & 4,898 \\
\hline & & South & 5,255 & 6,137 & 1,912 & 9,784 \\
\hline & & State total & 22,252 & 23,273 & 10,980 & 31,546 \\
\hline & \multirow[t]{6}{*}{1993} & North & 915 & 827 & 184 & 2,360 \\
\hline & & Central & 2,277 & 2,427 & 1,404 & 3,150 \\
\hline & & Central offshore & 9,911 & 9,911 & 1,932 & 18,558 \\
\hline & & Center-south & 1,170 & 1,395 & 458 & 2,471 \\
\hline & & South & 3,061 & 2,868 & 284 & 9,147 \\
\hline & & State total & 17,334 & 17,428 & 4,262 & 35,686 \\
\hline \multirow[t]{12}{*}{ Vessel Strip } & \multirow[t]{6}{*}{1992} & North & 945 & 936 & 665 & 1,219 \\
\hline & & Central & 4,543 & 4,828 & 3,240 & 5,846 \\
\hline & & Central offshore & 3,768 & 3,768 & 1,228 & 6,308 \\
\hline & & Center-south & 3.675 & 3,675 & 1,470 & 3,675 \\
\hline & & South & 3,970 & 4,660 & 944 & 7,407 \\
\hline & & State total & 16,909 & 17,867 & 7,547 & 24,455 \\
\hline & \multirow[t]{6}{*}{1993} & North & 697 & 624 & 126 & 1,548 \\
\hline & & Center & 1,895 & 2,131 & 1,031 & 2,758 \\
\hline & & Central offshore & 8,777 & 8,777 & 1,760 & 15,794 \\
\hline & & Center-south & 938 & 1,126 & 350 & 2,011 \\
\hline & & South & 2,535 & 2,350 & 184 & 5,698 \\
\hline & & State total & 14,842 & 15,008 & 3,451 & 27,809 \\
\hline \multirow[t]{12}{*}{ Aerial Strip } & \multirow[t]{6}{*}{1992} & North & 852 & 929 & 321 & 1,373 \\
\hline & & Central & 1,836 & 1,919 & 1,222 & 4,265 \\
\hline & & Central offshore & 1,522 & 1,522 & 495 & 2,549 \\
\hline & & Center-south & 915 & 847 & 265 & 1,638 \\
\hline & & South & 468 & 426 & 242 & 680 \\
\hline & & State total & 5,593 & 5,643 & 2,545 & 10,505 \\
\hline & \multirow[t]{6}{*}{1993} & North & 155 & 160 & 44 & 312 \\
\hline & & Central & 249 & 249 & 288 & 2,450 \\
\hline & & Central offshore & 1,153 & 1,153 & 231 & 2,075 \\
\hline & & Center-south & 638 & 635 & 170 & 1,740 \\
\hline & & South & 215 & 219 & 36 & 597 \\
\hline & & State total & 2,410 & 2,416 & 769 & 7,174 \\
\hline \multirow[t]{10}{*}{ Shore Point ${ }^{1}$} & \multirow[t]{5}{*}{1992} & North & 47 & 43 & 6 & 73 \\
\hline & & Central & 2,185 & 1,770 & 1,510 & 3,300 \\
\hline & & Central offshore & 143 & 143 & 93 & 193 \\
\hline & & South & 585 & 579 & 73 & 1,248 \\
\hline & & State total & 2,677 & 2,535 & 1,679 & 4,814 \\
\hline & \multirow[t]{5}{*}{1993} & North & 124 & 145 & 13 & 323 \\
\hline & & Central & 1,136 & 1,036 & 480 & 3,440 \\
\hline & & Central offshore & 1,148 & 1,148 & 591 & 3,843 \\
\hline & & South & 1,209 & 866 & 48 & 2,311 \\
\hline & & State total & 4,566 & 3,195 & 1,132 & 9,817 \\
\hline
\end{tabular}

${ }^{1}$ The offshore proportion for shore observations was calculated for birds over $1 \mathrm{~km}$ offshore, rather than $500 \mathrm{~m}$ as in other cases. The center-south region was combined with center for shore estimates. 


\section{Offshore Transecls}

Transects sampling offshore waters were grouped in 500 -m increments of distance from shore, and each sampling day was treated as a replicate within the groups. The data within each $500-\mathrm{m}$ group were then modeled with a detection curve for line transect and a density calculated using the DISTANCE program, or summed and divided by transect length for strip transects as described above. In this way, a separate density estimate was calculated for each $500-\mathrm{m}$ increment offshore for both line and strip transect methods in $500-\mathrm{m}$ by $1000-\mathrm{m}$ blocks. These densities were then multiplied by the length of the central region for independent abundance estimates within each 500 - $\mathrm{m}$ increment offshore. The sum of these abundance estimates were added to the central region when incorporating birds offshore in overall population estimates (this offshore component is shown separately in table 1 ).

\section{Aerial Estimates}

Similar strip transect methods as were used on the vessel were used in aerial surveys. Each observer's results were treated as a separate transect (sometimes only one observer could conduct transects due to glare on one side, for example), so toral strip width was $50 \mathrm{~m}$ and the number of transect samples was greater. Densities were calculated by dividing the total number of murrelets seen by each observer in a region on a transect by the length of that region. Densities were multiplied to measure square kilometers, and then multiplied by the length of each region for population estimates as with vessel surveys. For the central region the proportion of birds occurring over $500 \mathrm{~m}$ from shore, based on vessel offshore transect data, were added to the region's estimate.

An independent estimate was calculated for each day, and these data were then averaged for the regional estimate, as with vessel estimates.

\section{Shore-Based Estimates}

To summarize shore-based observations, we assumed a $145^{\circ}$ angle of view (given a $150 \mathrm{~m}$ wide surf zone and setback from the shoreline) and measured an approximate viewing limit of $1.2 \mathrm{~km}$ out to sea, which gave a scanning area of roughly $2 \mathrm{~km}^{2}$. To compensate for low viewing angle over surf, we halved the scanning area to $1 \mathrm{~km}^{2}$ as an actual survey area when computing densities. The average number of murrelets counted from all points in each day was multiplied by the length of the regions coastline for an independent daily estimate, as was done for air and vessel transects. These values were then averaged for a regional population estimate. The proportion of birds greater than $1 \mathrm{~km}$ offshore from the vessel offshore strip transect data were added to central region estimates as with aerial estimates.

\section{Field Effort}

Field work was carried out from 1 June to 15 August in 1992 and from 10 May to 1 August in 1993. Our research effort was primarily devoted to vessel surveys, and most of the vessel transects took place in the central region, between the Siletz and Siuslaw rivers (table 2).

\begin{tabular}{|c|c|c|c|c|c|c|c|c|c|}
\hline \multirow{3}{*}{$\begin{array}{l}\text { Coastal } \\
\text { Region }\end{array}$} & \multirow{3}{*}{ Year } & \multicolumn{4}{|c|}{ Kilometers surveyed } & \multicolumn{4}{|c|}{ Days of surveys } \\
\hline & & \multirow[t]{2}{*}{$A i^{t}$} & \multicolumn{2}{|c|}{ Vessel } & \multirow[t]{2}{*}{ Sbore } & \multirow[t]{2}{*}{ Air } & \multicolumn{2}{|c|}{ Vessel } & \multirow[t]{2}{*}{ Shore } \\
\hline & & & Coast & Offshore & & & Coast & Offshore & \\
\hline \multirow[t]{2}{*}{ North } & 1992 & 767 & 329 & - & 18 & 2 & 4 & - & 4 \\
\hline & 1993 & 450 & 274 & - & 14 & 2 & 4 & - & 4 \\
\hline \multirow[t]{2}{*}{ Central } & 1992 & 824 & 743 & 90 & 136 & 4 & 19 & 9 & 29 \\
\hline & 1993 & 532 & 856 & 292 & 82 & 2 & 20 & 11 & 23 \\
\hline \multirow[t]{2}{*}{ Center-south } & 1992 & 600 & 75 & - & 3 & 4 & 1 & - & 1 \\
\hline & 1993 & 300 & 225 & - & 8 & 2 & 5 & - & 4 \\
\hline \multirow[t]{2}{*}{ South } & 1992 & 672 & 208 & - & 21 & 2 & 3 & - & 6 \\
\hline & 1993 & 585 & 167 & - & 11 & 1 & 4 & - & 4 \\
\hline Combined & & 4,730 & 2,877 & 382 & 293 & 6 & 54 & 20 & 70 \\
\hline
\end{tabular}

\footnotetext{
${ }^{1}$ Air survey strip width was only $50 \mathrm{~m}$ wide as each observer's data was considered an independent survey (flights actually covered half the listed $\mathrm{km}$ ).
} 


\section{Results and Discussion}

\section{Distribution and Behavior}

\section{Distribution Along Oregon's Coastline}

Marbled Murrelets were distributed irregularly along the length of the state, with peak number occurring in the central region for all survey methods and years of surveys (fig. 3 and 4). In 1993 it appeared as if the population was distributed somewhat farther north (fig. 3). The area from Cascade Head to Florence almost always held high numbers of birds. High densities were recorded between Florence and Coos Bay on the one survey of that area in 1992, but this was not seen again on repeated surveys in 1993. Because of the continuing ambiguity of results for this area, it was treated as a separate region in population estimates. In both years there was evidence of a shift to the north late in the season, though it was slight in 1993.

\section{Distribution in Relation to Shore}

Distribution in relation to distance from shore was dramatically different in the two years (fig. 5). Marbled Murrelets were very concentrated within $1 \mathrm{~km}$ of shore for much of the 1992 season, and broadly scattered within 5 $\mathrm{km}$ of shore in 1993. In most cases this resulted in lower densities on coastline transects in 1993 (table 3). In 1992 there was a late-season shift to farther offshore which coincided with the shift farther north described earlier (fig. 6 and Strong and others 1993). Offshore distribution was more variable in 1993 but no seasonal shift away from shore was apparent.

\section{Behavior}

In contrast to distribution offshore, recorded behaviors of murrelets were essentially the same in the two years (fig. 7). Although we did not see any murrelet groups as large as

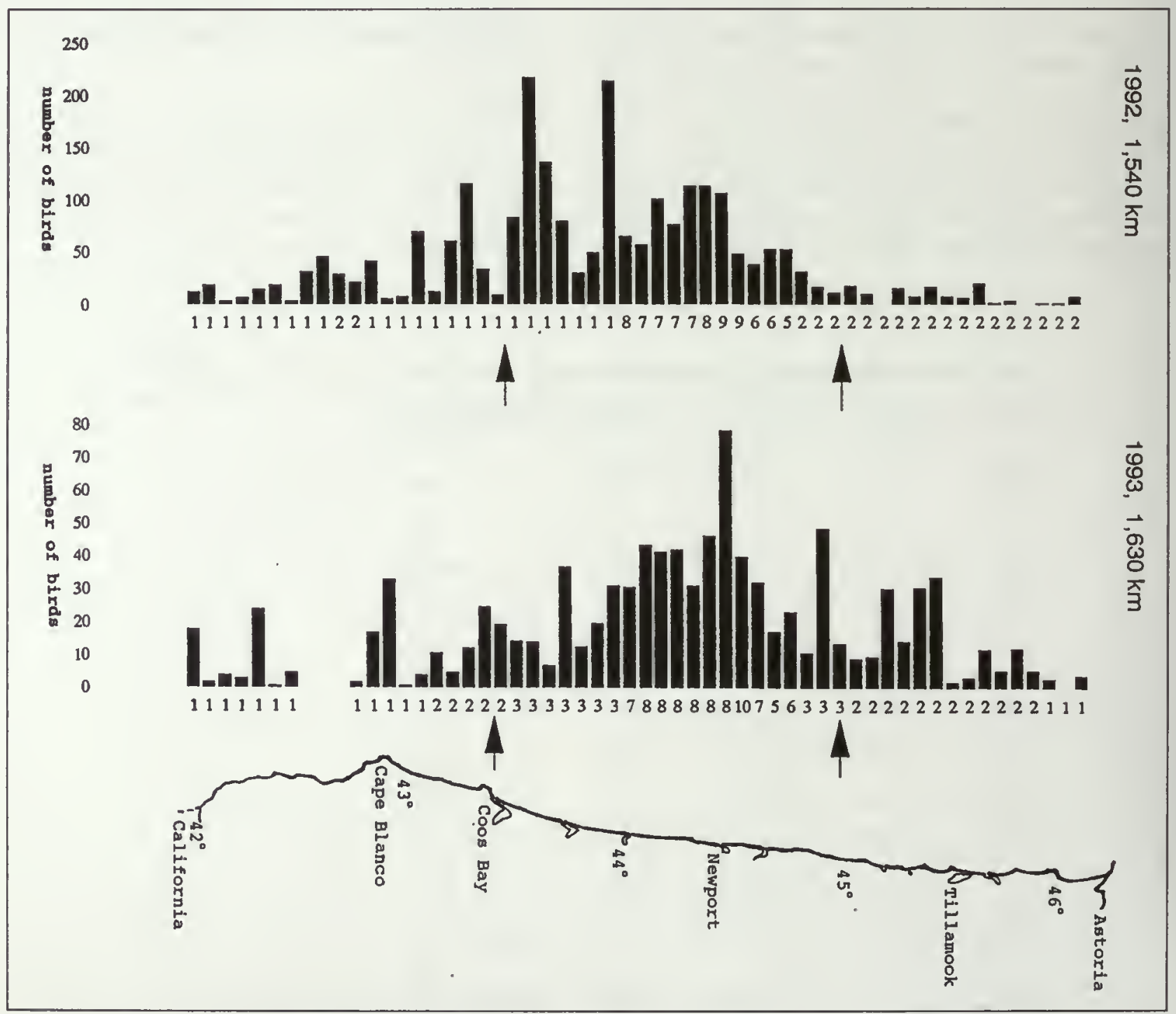

Figure 3-Average numbers of Marbled Murrelets from $100 \mathrm{~m}$ boat transect strips in $10 \mathrm{~km}$ segments off the Oregon coast. Numbers on $x$ axis represent the number of times each segment was surveyed. Arrows indicate divisions between north, center, and south regions. 


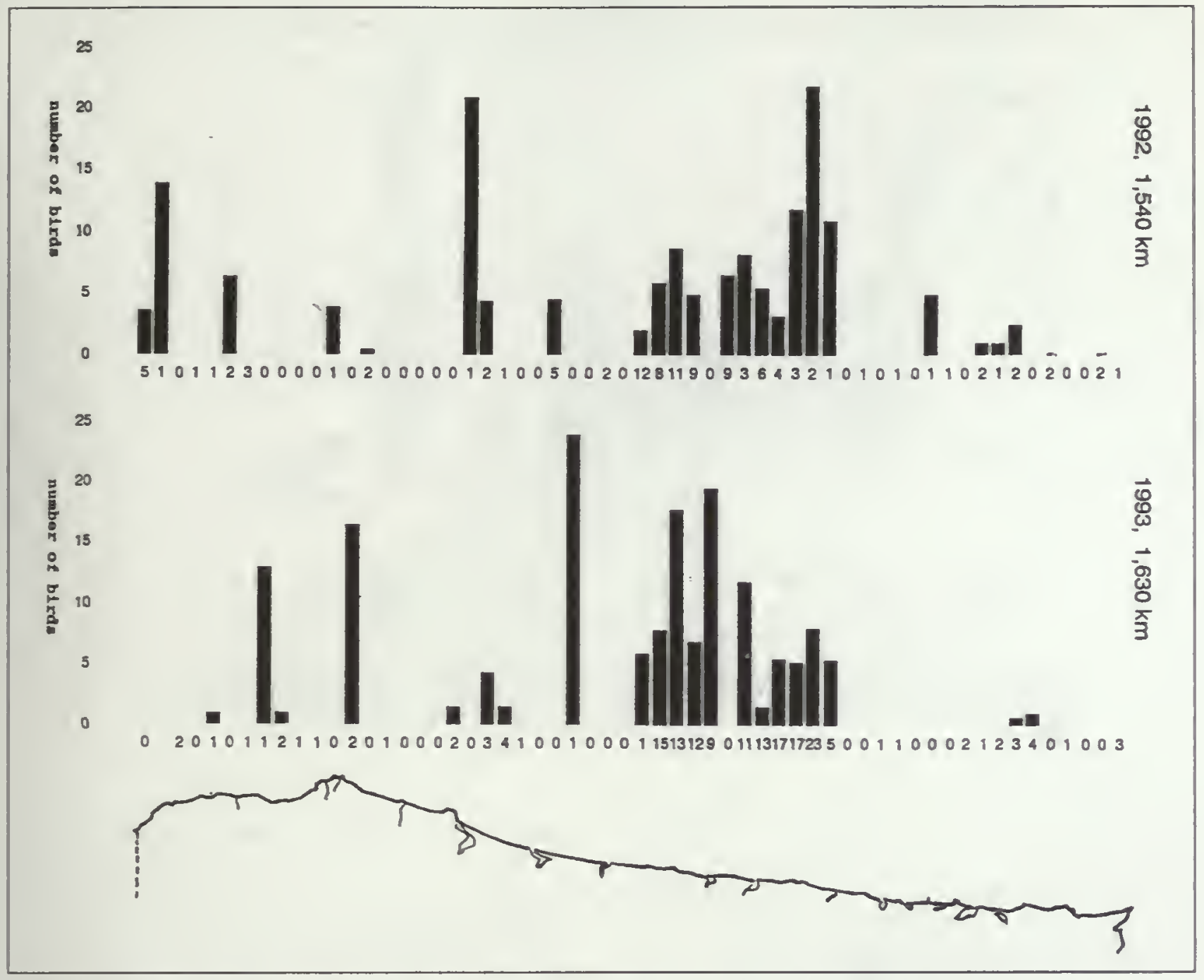

Flgure 4-Average numbers of Marbled Murrelets at sea counted from shore in Oregon. Numbers on $x$ axis represent the number of counts within a 10-km section of coast. Arrows indicate division between regions. Refer to fig. 3 for locations along the Oregon coast.

the largest in 1992, groupings of murrelets was also very similar in 1992 and 1993 (fig. 8).

Distance from the boat at which murrelets were reported was similar among years, except in the 20 to $50 \mathrm{~m}$ range ( $f$ ig. 1). It is likely that this resulted from bias in reporting distances in 1992 when we had predetermined our strip width to be 50 m for density estimates. In 1993 there was no such presupposition and we took care to visually calibrate our estimates with a $50 \mathrm{~m}$ measured buoy line and among ourselves. Based on the curve in Figure 1 and on density computations for various strip widths (fig. 2) we selected a strip width of 50 $m$ on either side of the boat $(100 \mathrm{~m})$. This strip width included 74 percent of all birds seen in 1992 and 64.2 percent in 1993 , not including flying birds. Fewer birds were reported closer than $20 \mathrm{~m}$ since they usually took evasive action at greater distances. Marbled Murrelets dove in avoidance of the boat at a mean distance of $26.5 \mathrm{~m}($ s.d. $=18.6 \mathrm{~m})$, and they flew in avoidance at $42.6 \mathrm{~m}(s . d .=36.1 \mathrm{~m})$.

\section{Population Estimates}

Comparison of Aerial, Vessel, and Shore-Based Estimates

Vessel estimates using line or strip transect analyses produced far higher estimates than air or shore-based surveys (table 1). All methods used densities calculated for $1 \mathrm{~km}^{2}$ in the estimates (table 3) except for the central region, where there was information on offshore distribution (fig. 5). For the central region, $1 \mathrm{~km}^{2}$ densities were halved to estimate only the number out to $500 \mathrm{~m}$, and estimates from offshore sample densities, in 500-m blocks, were summed and added to the estimate (the offshore component is shown separately in Table 1). We added the same proportionate number of birds to air and shore-based estimates in the central region as were added to vessel estimates in accounting for offshore distribution. Differences between estimates, then, were due to differences in mean densities of birds detected with each method and year (table 3). Of the three survey methods, vessel transect data had the highest 


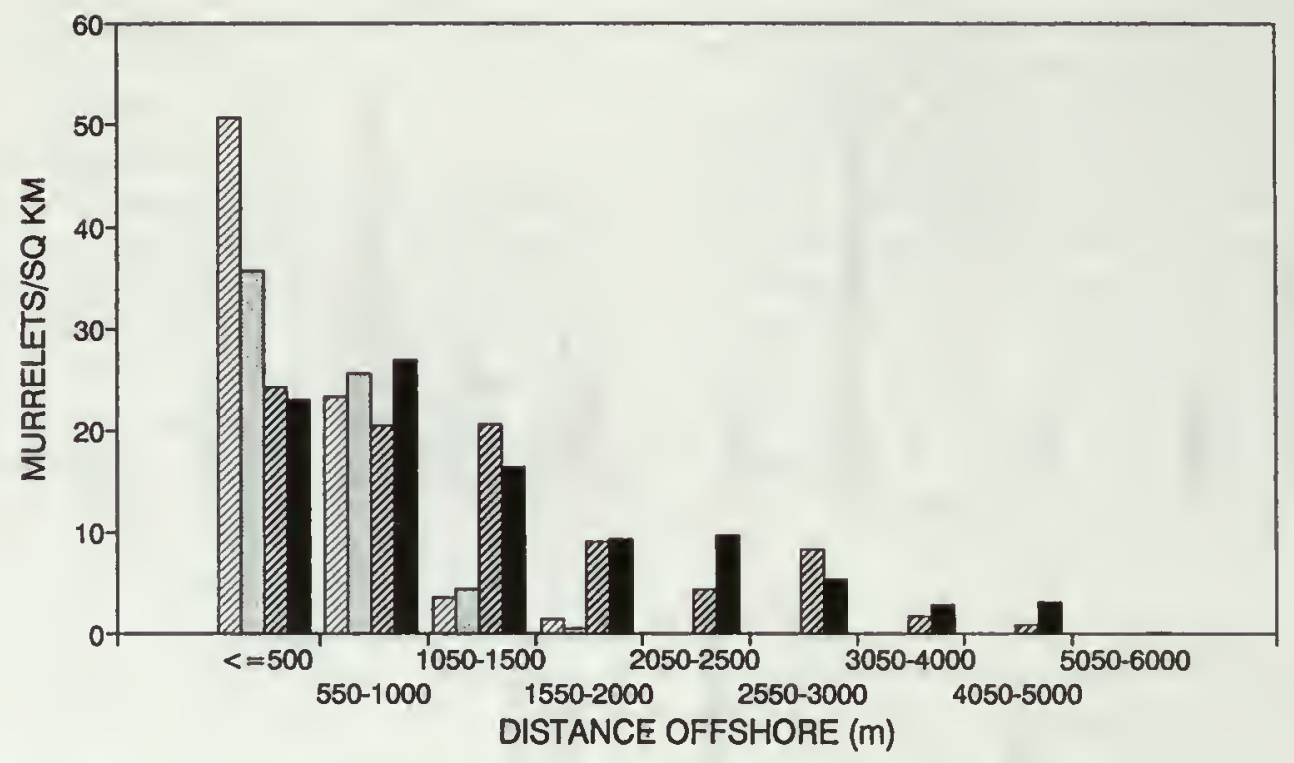

Method: VIIS STRIP $\square$ LINE VIIIA STRIP $\square$ LINE

$1992 \quad 1993$

Flgure 5-Average densities of Marbled Murrelets in $1 \mathrm{~km}^{2}$ based on line and $100 \mathrm{~m}$ strip boat transects for nine categories of distance from shore. The 1992 transects were conducted to a maximum of $2.5 \mathrm{~km}$ offshore.

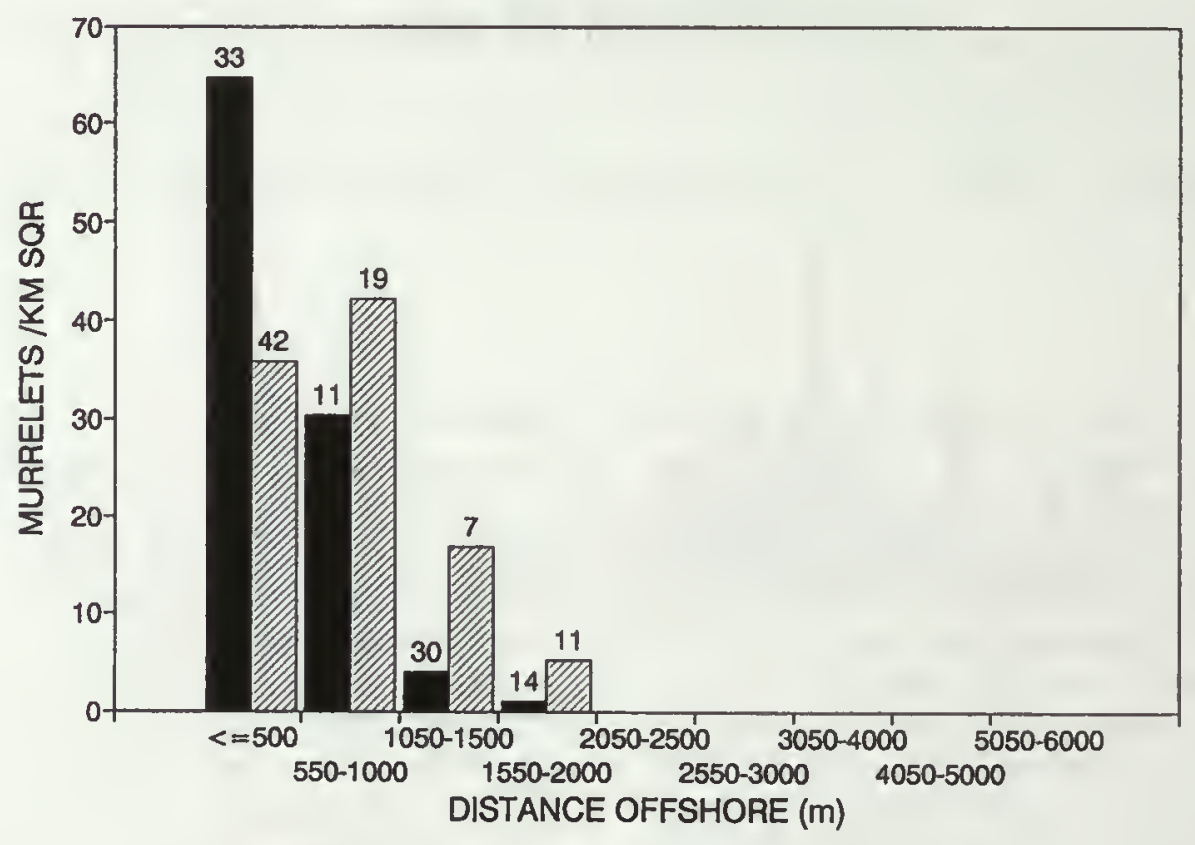

June 1 - July 23 TIIS July 24 - August 15

Figure 6-Number of Marbled Murrelets per km of vessel transect in nine categories of distance from shore in 1992, before and after 24 July. Figures at top of bars represent number of kilometers surveyed within each distance category. 


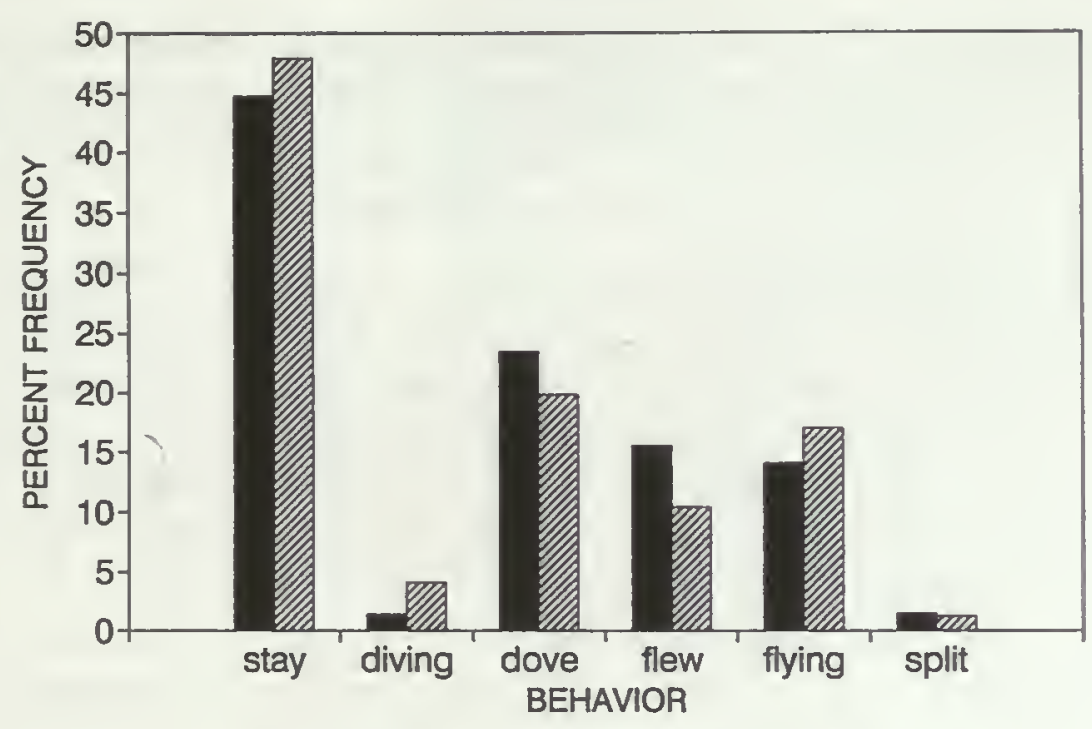

$1992(n=4721)$ WIIA $1993(n=3291)$

Figure 7-Behavior of murrelet groups observed while on transect: stay, remained on the water surface; diving, engaged in diving activity; dove, dove in apparent avoidance of boat; flew, flew in apparent response to the boat; flying, flying past when detected; split, group separated in apparent avoidance of the boat (in all other instances group members behaved the same).

reliability of detection due to proximity, duration of observation, and number of observers.

The average density of birds seen from air was 33.1 percent (1992) and 16.3 percent (1993) of that seen by boat strip transects (table 2), even though they transected the same offshore zone at a similar time of year. The brief scanning time when flying over the transect strip at 90 knots may be the greatest factor affecting detection rates by air. Slight variations in plane altitude and speed, banking on turns, observers checking time and location, and distraction from other species all contributed to further reduce scanning time for murrelets. In addition, on the 1 July 1993 flights, the senior author scanned an area in advance of the plane and noted Marbled Murrelets diving in response to the plane's approach. The extent of this behavior cannot be quantified absolutely, and probably varies with type of plane. On the 1 July 1993 north bound survey, at least nine birds dove in front of the plane ( 8 percent).

Estimates using counts from shore were in the same general range of those based on aerial surveys, though there was no consistency across years (table 1 ). Shore counts had the highest variability in numbers with coefficients of variation averaging over 100 (table 3, fig. 4). The high variability resulted from Marbled Murrelets' locally patchy and shifting distribution (Nelson and Hardin 1993b, Strong and others 1993). Low average numbers seen could also be due to their patchy distribution. Difficulty in detecting birds from a low, distant vantage point under variable conditions may also have reduced the number of detections in some cases. Even though we compensated for difficulty in detection by halving the calculated area scanned when computing densities, values were still far lower than from the vessel. These results may have occurred because the smallest effort was invested in shore surveys. Increased effort may have reduced variability and improved results. Weighting of high counts in proportion with the patchiness of high density areas could possibly generate average densities more representative of the population.

\section{Strip and Line Transect Vessel Estimates}

Line transects generated the highest estimates, and they were consistently higher than strip transect estimates using the same data. Strip transect estimates were between 60 percent and 88 percent of line estimates, but the difference was only marginally significant in one case (center region, $1992, t$-test, $P=0.023$ ) and not significant in others where sample size was sufficient.

Strip transects may be conservative if the assumption that all birds within the strip are detected is not met. This was apparently the case when the strip was $130 \mathrm{~m}$ and greater distances from the vessel (fig. 2). Estimates using a $130 \mathrm{~m}$ strip width were 90.6 and 92.8 percent of those for a $100 \mathrm{~m}$ strip for 1992 and 1993, respectively. We interpreted this as indicating that 7 to 10 percent of the birds were not detected with the larger strip width. The strip width of $80 \mathrm{~m}$ resulted in even higher estimates, but 11.5 percent and 8.7 percent of the birds had avoided the vessel beyond this strip width in 1992 and 1993, respectively (compared with 6.9 percent and 5.2 percent for a $100 \mathrm{~m}$ strip). The selection of a $100-\mathrm{m}$ strip, then, 
Table 3-Mean density of Marbled Murrelets per $\mathrm{km}^{2}$ from air, vessel, and shore-based surveys in the summers of 1992 and 1993. $\mathrm{Km}=\mathrm{km}$ of coastline travelled by vessel, used in extrapolating density to population estimates. Sample size $\mathrm{n}$ refers to number of days surveying (vessel, shore) or number of overflights by each observer (aerial, see methods). C.V. = coefficient of variation $(\mathrm{s} / \bar{x} \cdot 100$, where $\mathrm{s}=$ standard deviation and $\bar{x}=$ mean)

\begin{tabular}{|c|c|c|c|c|c|c|c|}
\hline Method & Year & Region & $\mathrm{Km}$ & $n$ & Density & Range & C.V. \\
\hline \multirow[t]{8}{*}{ Vessel Line } & 1992 & North & 155 & 4 & 7.2 & $4.3-9.8$ & 31.4 \\
\hline & & Central & 134 & 14 & 103.4 & $18.0-160.9$ & 49.8 \\
\hline & & Center-south & 75 & 1 & 130.5 & - & - \\
\hline & & South & 195 & 3 & 26.9 & $11.3-40.7$ & 54.7 \\
\hline & 1993 & North ${ }^{1}$ & 155 & 4 & 5.9 & $3.5-9.1$ & 49.5 \\
\hline & & Central & 134 & 16 & 34.0 & $9.2-89.8$ & 66.3 \\
\hline & & Center-south & 75 & 4 & 15.6 & $6.3-28.9$ & 69.9 \\
\hline & & South & 195 & 4 & 15.7 & $8.8-35.5$ & 83.9 \\
\hline \multirow[t]{8}{*}{ Vessel Strip } & 1992 & North & 155 & 4 & 6.1 & $5.0-7.4$ & 18.5 \\
\hline & & Central & 134 & 14 & 67.8 & $11.5-120.0$ & 49.7 \\
\hline & & Center-south & 75 & 1 & 98.0 & - & - \\
\hline & & South & 195 & 3 & 20.4 & $8.3-22.9$ & 54.2 \\
\hline & 1993 & North $^{1}$ & 155 & 4 & 4.5 & $3.6-7.0$ & 49.6 \\
\hline & & Central & 134 & 16 & 28.3 & $6.0-81.1$ & 62.9 \\
\hline & & Center-south & 75 & 4 & 12.5 & $4.9-23.3$ & 72.1 \\
\hline & & South & 195 & 4 & 13.0 & $7.5-28.3$ & 78.6 \\
\hline \multirow[t]{8}{*}{ Aerial Strip } & 1992 & North & 195 & 6 & 5.5 & $1.8-11.2$ & 58.8 \\
\hline & & Central & 134 & 12 & 13.7 & $4.2-34.4$ & 68.7 \\
\hline & & Center-south & 75 & 9 & 12.2 & $4.7-32.5$ & 103.3 \\
\hline & & South & 195 & 5 & 2.4 & $1.7-5.5$ & 38.4 \\
\hline & 1993 & North & 155 & 3 & 1.0 & $0.3-1.4$ & 61.2 \\
\hline & & Central & 134 & 4 & 3.7 & $2.4-4.8$ & 26.8 \\
\hline & & Center-south & 75 & 4 & 8.5 & $4.0-22.7$ & 112.3 \\
\hline & & South & 195 & 3 & 1.1 & $0.3-2.7$ & 71.4 \\
\hline \multirow[t]{6}{*}{ Shore Point } & 1992 & North & 155 & 4 & 0.3 & $0.0-0.6$ & 106.7 \\
\hline & & Central & 209 & 30 & 10.7 & $0.8-31.0$ & 130.0 \\
\hline & & South & 195 & 6 & 3.0 & $0.2-6.0$ & 85.0 \\
\hline & 1993 & North & 155 & 4 & 0.8 & $0.0-1.7$ & 93.8 \\
\hline & & Central & 209 & 23 & 5.5 & $0.0-21.7$ & 106.3 \\
\hline & & South & 195 & 5 & 6.2 & $0.0-14.0$ & 97.3 \\
\hline
\end{tabular}

${ }^{1}$ The 21 July transect density of $29.4 / \mathrm{km}^{2}$ (line) or $24.2 / \mathrm{km}^{2}$ (strip) was not included here, see text. Vessel offshore densities varied with distance from shore and are shown in figures 5 and 6. 
was a compromise between losing birds to avoidance at narrower strips and not detecting birds in wider strips. Both of these effects are present with a $100 \mathrm{~m}$ strip and, combined, could result in as much as 10 percent under estimation. This may explain some of the difference between strip and line method results.

Line transects may err either high or low, depending on how well the detection curve model represents the true detection distribution. Because birds avoided the vessel and we adjusted for this in the data to model detection curves, fits to any model are necessarily approximations. In spite of these factors, the general agreement between the two methods suggests we are in range of an accurate population estimate.

\section{Averages Versus Weighted Averages}

Because transect length and number of shore observations varied by day, we were able to compare estimates weighted by effort with direct averages of each day (table 1). Estimates weighted by transect length were quite consistently higher for vessel transects, slightly higher for aerial transects, and lower for shore counts (table 1). There was no significant correlation of transect length to densities, however, and no significant differences between regional estimates were found ( $t$-tests). Some vessel transects in each region were aborted when fair conditions degraded to poor, resulting in shorter transects under worse conditions, which may have resulted in lower densities (see 'observation conditions'). In the central region, the two most frequently taken transects were $72 \mathrm{~km}$ (Newport to Florence) and $27 \mathrm{~km}$ (Depoe Bay to Newport) in length; approximately $10 \mathrm{~km}$ of the shorter route was off rocky shore (Boiler Bay to Otter Crest) which always had very low murrelet densities and would make a smaller contribution in weighted data. This probably explains the consistency of higher estimates for weighted vessel data.

\section{Year Comparisons}

Densities averaged far higher in 1992 for all methods and regions except shore counts (table 3). This was due to extremely high concentrations of birds very close to shore in 1992 (fig. 5). The inshore concentration was most pronounced before mid - July 1992 (fig. O), but data for the whole year were averaged for analyses here.

Overall population estimates were significantly different between the two years for aerial and both line and strip vessel estimates ( $t$-tests, $P<0.01$ ). Differences between years likely reflects their different distribution offshore and some error in the assumption of equal densities within 500$\mathrm{m}$ (central region) and 1,000-m (north and south regions) increments of distance from shore. For example, due to the scarcity of birds offshore in 1992, the assumption of equal density in 1-km squares and truncation beyond this may have caused over estimation in that year. From the offshore transect data, only 45 percent of the birds occurred over 500 m from shore in 1992, compared with 82 percent in 1993 (fig. 5, table 1). Using the same logic, the 1993 estimates in other than the central region may have been under estimates, since well over half of the observations occurred beyond 500 $\mathrm{m}$ and many birds were present beyond $1 \mathrm{~km}$. This consideration would bring the overall state totals closer together in the two years.

Murrelets and other seabird species were concentrated close to shore in 1992 because of an apparent high availability

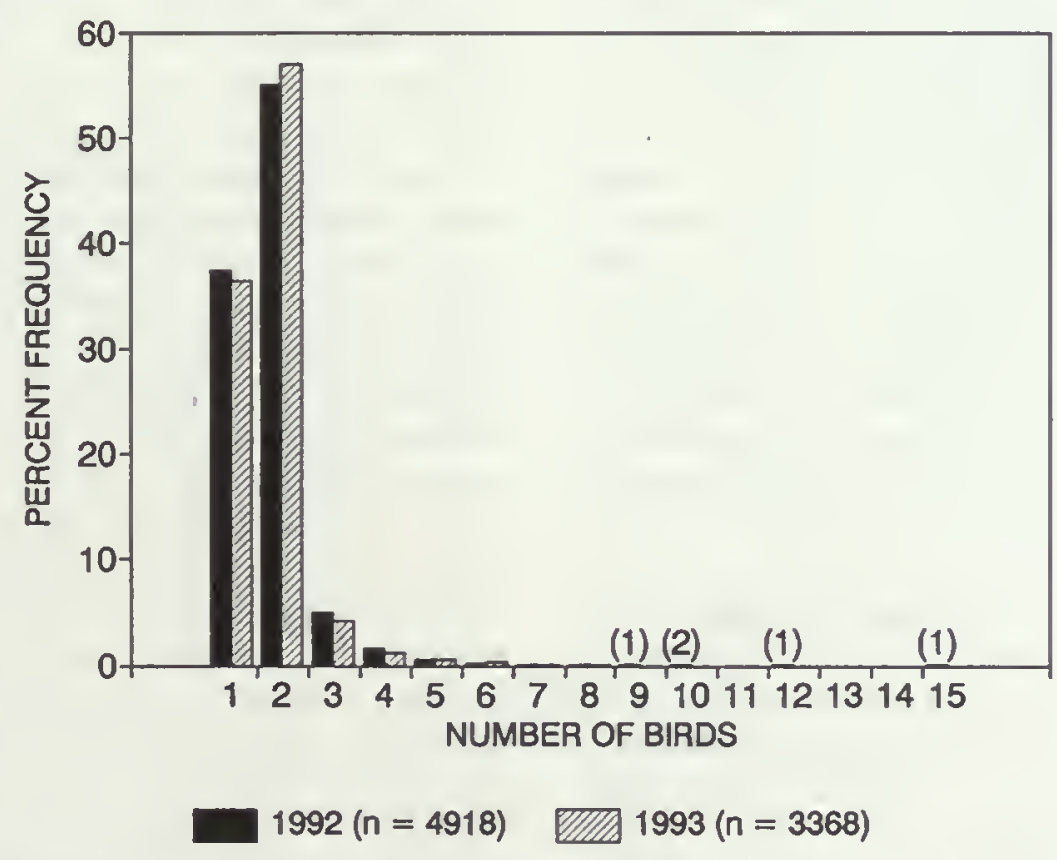

Flgure 8-Group size of Marbled Murrelets seen during vessel surveys. Groups of over 8 birds were not recorded in 1993. The numbers in parenthesis indicate number of groups that were too few to show up on a bar graph. 
of prey there, such as smelt species (Strong and others 1993). With the exception of Surf Scoters (Melanitta perspicallata), other seabirds were more scattered and farther offshore as well in 1993. In 1993, Common Murres (Uria aalge) and Pigeon Guillemots (Cepphus columba) largely abandoned nest sites in June, and very few (murres) or no (guillemots) fledglings were seen at the end of the nesting period. It is probable that very low prey availability caused the reproductive failure for these alcid species, and likely that Marbled Murrelets were also impacted. Both 1992 and 1993 were cited as 'El Niño years', but waters off Oregon were warmer and upwelling weaker in 1993 (NOAA Coastal Ocean Programs 1992-1993).

\section{Regional Characteristics}

We did not attempt to extrapolate from the central region's offshore distribution where we lacked data on offshore distribution for the north and south regions. In the northern region, inshore densities were much lower. Assumption of a proportionate dispersal offshore as for the central region would probably be invalid as it would result in extremely scattered birds. Other data show Marbled Murrelets to have a very clumped distribution (Nelson and Hardin 1993a, Strong and others 1993). Low overall densities on the north coast was characteristic of all survey methods and years, with the exception of one vessel transect on 21 July 1993. On that day, Murrelets were concentrated in the vicinity of Netarts Bay, and the average density ( 24.2 birds/ $\mathrm{km}^{2}$ ) was far higher than any other records for the region. This 'outlier' was interpreted as a movement of non-nesting birds from the central region. It is possible these birds failed or did not attempt to nest due to low prey availability in that year (see above).

The southern region has very different physical characteristics than the rest of the state, with many offshore rocks, rocky shorelines, and variable bathymetry. Coastline densities here were most variable (C.V., table 3), though our survey effort was small and, in 1993, took place under largely fair to poor conditions (Beaufort state 3 to 4 ). Because of these considerations, we have lower confidence in our density estimates for this region. It may be appropriate to further divide the region north and south of Cape Blanco, based on physical characteristics and recorded murrelet densities. Near the California border (south of Goat Island), murrelets from nesting areas in California's protected redwood parks may forage in Oregon waters, thereby confusing measures of the state population.

Interpreting results was problematic in the center-south subregion. The single survey of the region in 1992 generated the highest daily average densities recorded, but four surveys of the area in 1993 each recorded densities well below the rest of the central region (table 3). Aerial surveys in 1993, however, again produced relatively high densities, although this may have resulted from vagaries in aerial surveying. To account for the different offshore distribution between years in this area, and bring the estimates into closer agreement, we only extrapolated to a $500-\mathrm{m}$ wide block of area in computing the 1992 density estimate.

\section{Other Adjustments to the Estimate}

While not including a factor for birds beyond $1 \mathrm{~km}$ in northern and southern Oregon may be seen to cause underestimation, other considerations of distribution and sampling may compensate for this. The surf zone off Oregon's beaches typically ranges from 100 to $400 \mathrm{~m}$ out to sea, depending on swell size. While we did observe Marbled Murrelets within the surf zone, particularly in 1992, they occurred at lower densities than beyond the breakers. If we were to assume, as an approximation, that the inshore $100 \mathrm{~m}$ was without murrelets, the effect would be to reduce the estimate by 10 percent.

A proportion of the birds that flew in response to the vessel went in the direction of vessel travel where they could have been double-counted if they landed in the transect's path. In 1993, we quantified this and found that 21.9 percent of the birds which flew went in the vessel's direction of travel. This was far less than 50 percent since murrelets usually flew against the wind, and we usually ran transects with the wind (birds rarely departed east or west). Of 10.7 percent of birds which flew in avoidance (fig. 7), 22 percent flew in direction of travel. If each were double-counted once, the adjustment would be $0.107 \times 0.22=2.3$ percent of the estimate. This, for example, would amount to 350 birds doublecounted in the 1993 strip transect state estimate, a relatively minor difference. It is possible that many birds may relocate independently of vessel movement during the course of our transects, which last 2-9 hours. But because there is equal probability of birds either relocating into our path or moving out of it, no error was anticipated from this behavior.

Offshore sampling in central Oregon accounted for a relatively small proportion of the total survey effort, but the contribution to the total estimate from those data was large, particularly in 1993 (table 2). Selection of offshore sampling locations took place prior to each day's sampling, and were where murrelets were found to be consistently present during coastline transects. This has the potential for bias to areas of higher density within the whole region, although the effect is probably slight. Specific areas of abundance were virtually impossible to predict, since the clumped distribution of birds shifted daily on a scale of 10's of kilometers (Strong and others 1993).

In 1992 there was a significant correlation between observation conditions and number of birds sighted $(r=$ $0.112, P<0.001$ ), but not in 1993 . We did not detect a difference in the average distance at which birds were seen between excellent and good conditions; it only decreased at fair or poor conditions (ANOVA, $P<0.001$ ). This suggests that our observations had consistency of detections with respect to weather at Beaufort states less than 3.

In addition to the above considerations, other aspects of Marbled Murrelet biology and behavior may affect the results of marine transects for population estimation. Birds tending 
nest sites are not included in the above estimates. Marbled Murrelet chicks are left on their own soon after hatching (Marshall 1988), so the largest period of absence from the water is during incubation. Information on breeding chronology and breeding status were not adequate to adjust for this factor.

The above estimates provide no information on the size of the breeding population in Oregon. A relatively large proportion of some alcid populations do not breed for lack of a nest site or other reasons, constituting a 'floater population' (Ainley and others 1990a, 1990b; Divoky and others 1974; Manuwal 1974). The proportion of non-breeding adults probably varies somewhat by year, as it does for other alcids, depending on such variables as oceanographic conditions (affecting prey availability) and weather. The proportion of non breeding adult murrelets may be considerable for the Oregon population if loss of nesting habitat has left many pairs without nest sites.

We have no data to account for Marbled Murrelets which may occur at greater than $6 \mathrm{~km}$ from shore. However, other researchers have recorded Marbled Murrelets in offshore waters of the west coast as very scarce (Ainley and others, this volume; Wahl 1984) or entirely absent (Briggs and others 1989, 1992; Nelson and others 1992). For lack of better data, we assumed that an insignificant number of murrelets occurred beyond $6 \mathrm{~km}$ and that birds in that area were unlikely to be part of the breeding population.

\section{Conclusions}

\section{Distribution}

The different offshore distribution pattern between 1992 and 1993 was likely due to differences in prey species and/ or prey availability in the two years, although data to support this assertion is sparse and indirect. In 1992, when Marbled Murrelets were so concentrated inshore, they and other seabird species were only seen to eat smelt. When they dispersed farther offshore late in 1992, all prey seen were sand lance (Strong and others 1993). In 1993 murrelets and other species were all farther offshore than in 1992, and the few prey items seen appeared to be sand lance. Murres suffered a dismal nesting failure on the Oregon coast in 1993 (unpubl. data; Lowe, pers. comm.). Pigeon Guillemots also fared poorly, as indicated by the complete lack of guillemot fledglings seen on the water in 1993. Although both years were reported as El Niño years, water temperatures in Oregon were higher in the summer of 1993 (NOAA Coastal Ocean Program 1992-1993), and the effects of the ongoing El Niño event on seabirds were much more apparent in that year.

The higher numbers of birds encountered in northern Oregon in 1993 (table 3) and the more northerly distribution within the central region in 1993 (fig. 3) cannot be easily interpreted. In 1992 when birds moved farther offshore late in the season, they also moved farther north (Strong and others 1993). The very high densities of birds recorded on the July 21, 1993 survey, relative to all other data for the region (Nelson and others 1992) were interpreted as post breeding or non-breeding birds which may reflect fewer nesting attempts in that more severe El Niño year. Additional years of data are needed to characterize distribution along the coastline of both northern and southern Oregon.

\section{Population Measures}

These are the first estimates of the Oregon Marbled Murrelet population which used extensive, repeated, and standardized vessel transect data to quantify abundance patterns parallel and perpendicular to the coast. Given this, it is not surprising that estimates presented here are far higher than previously given for Oregon (Nelson and others 1992, using shore-based observations; Varoujean and Williams 1987 , using a small sample of vessel observations; and Varoujean and Williams [this volume] using aerial surveys). The consistency of our estimated totals in the 15,000 to 20,000 range using different analyses and between very different years, is supportive of their general validity. Individual daily estimates of the central and north coast regions were also consistent around the mean values (see coefficient of variation (C.V.) in table 3), with the exception of the July 1993 north coast transect mentioned above. The few surveys of the south coast took place in conditions and locations too variable to characterize a central tendency. Greater survey effort of the southern Oregon coast and offshore sampling of the northern and southern coasts, are urgently needed to strengthen these estimates.

Aerial transects have systematic problems (high flight speed, missed scanning time, diving avoidance behavior) and great sensitivity to conditions (glare, wind, banking on turns, density of other species) which make estimation results weak and certainly conservative (every factor listed has the effect of potentially reducing detections). Improved data recording methods can increase scanning time, which is probably the greatest factor affecting detections (Varoujean and Williams, this volume), but estimates still may only provide an index of abundance, rather than an absolute measure. It may be possible to develop a correction factor between aerial and vessel detections if the difference is consistent. Aerial surveys do provide an instantaneous 'snapshot' measure of distribution over large areas of coastline not obtainable by other methods.

Shore-based surveys appear inadequate to measure population, and even presence-absence information for a given location could require repeated surveys through a season. An intensive, daily shore survey effort could possibly produce useful population assessments, probably by weighting high count surveys and otherwise statistically accounting for their patchy distribution. The main strength of shore-based surveys may be in studying behavior, since there is minimal possibility of interfering or disturbing the bird. Information on grouping, foraging, dive times, diurnal activity patterns, and social interaction are some areas of research that are easily accomplished from shore. Shore based observation is also likely to be the least expensive and logistically easiest means of studying Marbled Murrelets at sea. 


\section{Population Versus Breeding Population}

Correcting estimates to account for birds tending the nest, or those not part of the breeding population, is valid. Our knowledge of nest-tending behavior and breeding status, however, is so limited that applying factors from other studies or species may only be misleading at present. Nesting site limitations have been shown to also limit breeding populations of other alcids (Ainley 1990, Divoky and others 1974, Manuwal 1974, Nelson 1987, Preston 1968). If loss of old-growth and ancient forest nesting habitat is the major factor affecting populations of Marbled Murrelets from California to Washington (Carter and Erickson 1992, Leschner and Cummins 1992a, Marshall 1988a), then we would expect the 'floating' proportion of non-breeding adults to be very high, probably over 50 percent. Members of the alcid family are long lived, in the range of 20 - 40 years (Ainley 1990, Sealy 1975a), so the possibility of a 'remnant' population is realistic. If only a small proportion of the measured population is nesting then the low number of fledglings observed on the water may be explained. Given this, we would expect total populations, as estimated from vessel survey data, to decline in coming years due to lack of recruitment. Population monitoring and measurements of productivity are crucial to evaluating this concern. Information on the life history and longevity of the bird will also be important in interpreting results of population and productivity monitoring.

\section{Future Research}

This report establishes the feasibility and preferences of using vessel surveys for population assessment on the
Oregon coast. Population monitoring and more refined population estimates are attainable objectives using methods outlined in this paper. Other areas of at-sea research which may be essential to developing effective management and protection strategies for Marbled Murrelets are relating atsea habitat use and distribution to forest nesting habitats, finding a means of assessing yearly productivity and population demographics, and more developing knowledge of prey species' composition and availability in relation to oceanographic parameters and location of nesting habitat.

\section{Acknowledgments}

We are grateful to S. Kim Nelson for setting this project in motion. This work would not have been possible without the logistical support of the U.S. Fish and Wildlife Cooperative Research Unit at Corvallis, and Robin Brown, region coordinator of the Wildlife Diversity Program, Oregon Department of Fish and Wildlife.

John G. Gilardi and Janice M. Cruz were invaluable field observers in 1992. W. Breck Tyler assisted during initial aerial surveys. Dr. Christine Ribic (U.S. Environmental Protection Agency), Dr. Nadav Nur (Point Reyes Bird Observatory), and Dr. Steven Beissinger (Yale University) each provided important comments on statistical treatment of data. We thank Dr. Jeffrey Laake and the other authors of the program DISTANCE for providing the program and manual. C. John Ralph and Dan Varoujean provided helpful comments on methodology. MacKenzie Flight services and Craig Johnson (Gasquet Aviation) provided excellent piloting and reliable aircraft. 


\section{Offshore Population Estimates of Marbled Murrelets in California}

\section{John Ralph Sherri L. Miller}

\begin{abstract}
We devised a method of estimating population size of Marbled Murrelets (Brachyramphus marmoratus) found in California's offshore waters. The method involves determining the distribution of birds from the shore outward to $6,000 \mathrm{~m}$ offshore. Applying this distribution to data from boat surveys, we derived population estimates and estimates of sampling error. We estimate a total California population of approximately 6,500 birds $(+450)$. Lower previous estimates of the Marbled Murrelet population in California were derived from surveys conducted for different purposes. Possible sources of error in our estimates are birds occurring farther offshore than our surveys, incubating birds missed while on nests, birds foraging underwater when the boat passed, double counting flushed birds, and observer error in estimating distance to birds. We feel that these sources of error compensated each other or were minimal.
\end{abstract}

The widespread Marbled Murrelet (Brachyramphus marmoratus) breeds inland along coasts of the North Pacific and is fairly abundant in many portions of its range. In California, the murrelet forages for small fish and invertebrates (Burkett, this volume) in nearshore waters, primarily within five $\mathrm{km}$ of the coast.

Because of the murrelets' secretive nesting habits at inland conifer forests, and the unknown relationship between the number of detections at inland sites and the number of birds present, population estimates must be based on censuses of birds at sea. Previous estimates of the population in California have been derived from incidental data collected during surveys of seabird colonies. Sowls and others (1980) recorded observations of murrelets opportunistically while travelling by boat between colonies. Birds were counted in narrow strips at variable distances, within $1 \mathrm{~km}$ of shore. They speculated that the breeding population in California could be about 2,000 birds. In 1989, Carter and others (1990b) systematically recorded murrelets along certain coastal sections. Boat transects were parallel to and between $200 \mathrm{~m}$ and $600 \mathrm{~m}$ out from shore. They estimated a population of 1,821 breeding birds. Few birds were seen south of Humboldt Bay and only 5 birds between Cape Mendocino (just south of Eureka) and Half Moon Bay, in Central California.

To effectively use offshore survey data to estimate a population of murrelets, we first needed to determine how the birds are distributed in relation to the shoreline. Are they

${ }^{1}$ Research Wildlife Biologist and Wildlife Biologist, respectively, Pacific Southwest Research Station, USDA Foresi Service, Redwood Sciences Laboratory, 1700 Bayview Drive, Arcata, CA 95521 found in pelagic or nearshore waters, and at what depth or distance from the shoreline do they most often forage? From this information, appropriate survey techniques can be developed which optimally survey murrelet populations in the marine environment.

The objectives of our work were to (1) determine the distribution of murrelets from the shore outward in these waters; (2) determine the distribution of birds in the varied marine habitat along the coastline of the state; and (3) from these data, estimate the population for California.

\section{Methods}

For each bird(s) detected during the surveys described below, we recorded the number of individuals, their perpendicular distance from the transect line, and characteristics of plumage or behavior. A $40-\mathrm{cm}$ fishing buoy attached to a $100-\mathrm{m}$ line was towed behind the boat and used by observers as a reference for distance estimates. All birds detected by the observer were recorded, including flying birds. The crew of observers changed from year to year, but some observers surveyed in all years. During each season observers usually participated in surveys in all areas, thereby reducing the bias of observer variability.

\section{Detection Distance}

We assumed that all birds on the transect line were detected, but that some birds were missed as the distance from the transect increased (Dixon 1977, Gould and Forsell 1989, Weins and others 1978). We calculated the "effective area surveyed" (EAS), which allows an unbiased estimate from all detected birds. Using this distance and transect width, it is then possible to calculate the density of birds on the water. The EAS of murrelets varied little from about $100 \mathrm{~m}$, probably because of the limited range of sea conditions under which surveys were conducted. We discontinued surveys when seas reached $25-35 \mathrm{~cm}$ and frequent whitecaps appeared (Beaufort scale 3 or 4 ). The transect width also appeared to remain relatively constant regardless of the observer platform heights on boats we used: $7 \mathrm{~m}$ and 1-2 m. A 100-m transect width was used for calculations below. The area surveyed on each $2-\mathrm{km}$ survey segment described below is therefore $200 \mathrm{~m}$ wide by 2,000 $\mathrm{m}$ long or $0.4 \mathrm{~km}^{2}$ (fig. 1 ).

\section{Intensive Surveys}

In order to determine the distribution of birds outward from the shoreline, we conducted intensive surveys from 


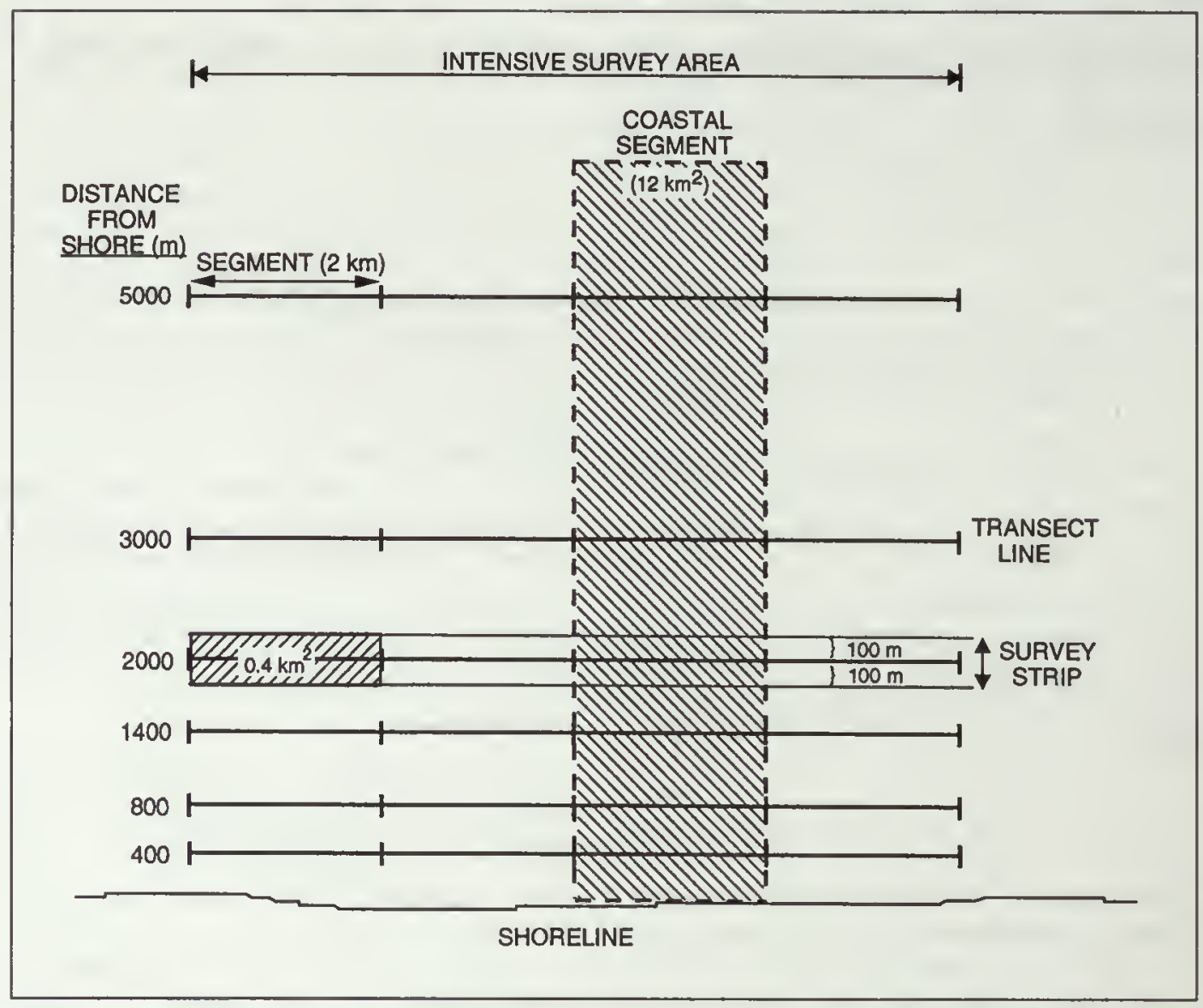

Figure 1-Diagram of intensive survey areas used to determine distribution of Marbled Murrelets from the shoreline outward to $6,000 \mathrm{~m}$.

1989 through 1993 at three survey areas: two in Del Norte County (Pebble Beach and Crescent Beach) and one in Humboldt County (South Jetty) (fig. 2). We chose areas that were accessible from nearby harbors and based on previous Marbled Murrelet sightings consistently had murrelets present. We used two open-decked boats with center consoles and without visual obstructions (Boston Whalers, $5.5 \mathrm{~m}$ and $7 \mathrm{~m}$ lengths). Boat speeds ranged from 8 to 12 knots, depending upon sea conditions, with slower speeds in higher seas. Surveys began in the morning, as soon after sunrise as sea and fog conditions allowed. Surveys ended usually by mid-day, as sea conditions deteriorated.

Surveys consisted of travelling along a series of $6-8 \mathrm{~km}$ long transect lines parallel to shore and, in general, following the depth contours of the ocean floor. The transect lines were positioned offshore from the shoreline at $400 \mathrm{~m}, 800$ $\mathrm{m}, 1400 \mathrm{~m}, 2000 \mathrm{~m}, 3000 \mathrm{~m}$, and $5000 \mathrm{~m}$ (fig. 1). Due to inshore rocks or surf, the $400 \mathrm{~m}$ distance was only possible at the protected Crescent Beach site.

Each year we completed one to four surveys per month at each intensive survey area, as weather and sea conditions permitted. On each survey day we attempted to complete all transects; however, a change in conditions sometimes resulted in partial surveys. Subsequent surveys would begin with those transects not completed on the previous survey.

\section{Extensive Surveys}

We surveyed the coastline of northern and central California from the Oregon border to Point Lobos, south of Monterey Bay (fig. 2). The sampled area was divided into 26 coastal sections with varying numbers of $2-\mathrm{km}$ segments, totalling 393 segments or $786 \mathrm{~km}$ (table 1, fig. 2). The length of each coastal section, and therefore the number of 2-km segments, was determined by topography and access from harbors. Depending on availability of boats and harbors, the different sections of coast were sampled with different intensity. Areas with easy access to harbors were sampled most frequently.

Each coastal section was surveyed at two distances from the shoreline, $800 \mathrm{~m}$ and $1,400 \mathrm{~m}$. The transects were parallel to the shoreline and observations were recorded in $2-\mathrm{km}$ segments. As with the intensive surveys, the area surveyed by each $2-\mathrm{km}$ segment was $200 \mathrm{~m}$ wide by 2,000 m long, or $0.4 \mathrm{~km}^{2}$. 


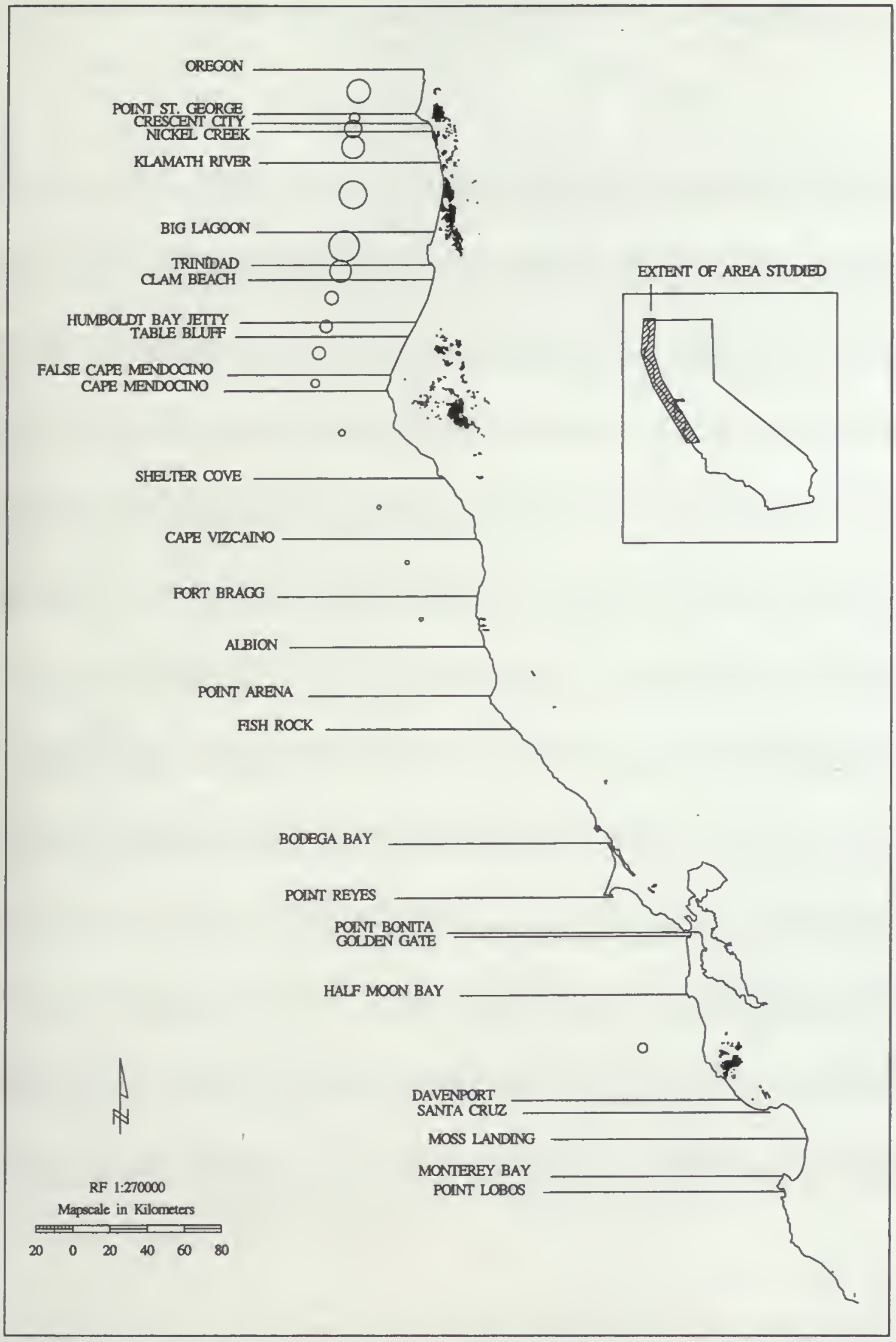

Flgure 2-Densities of Marbled Murrelets along California coast by coastal sections. Proportional circles indicate densities per 2-km coastal segment (12 km²). The largest circle (Big Lagoon to Trinidad) equals a density of 8.81 birds/ $\mathrm{km}^{2}$ (see table 1). Areas of old-growth forests are shown inland as shaded areas, from several sources. 
Table I-Survey effort, densities, and numbers of Marbled Murrelets in coastal waters of California , 1989-1993

\begin{tabular}{|c|c|c|c|c|c|c|c|c|c|c|}
\hline \multirow{2}{*}{$\begin{array}{l}\text { Northern boundary } \\
\text { of coastal section } \\
\text { (see fig. 2) }\end{array}$} & \multirow{2}{*}{$\begin{array}{l}\text { No. 2-km } \\
\text { coastal } \\
\text { segments }\end{array}$} & \multicolumn{2}{|c|}{$1400 \mathrm{~m}$} & \multicolumn{2}{|c|}{$800 \mathrm{~m}$} & \multirow{2}{*}{$\begin{array}{c}\text { No. birds } \\
\text { per km² }\end{array}$} & \multirow{2}{*}{$\begin{array}{c}\text { No. birds } \\
\text { per } \\
\text { segment } \\
\left(12 \mathrm{~km}^{2}\right)\end{array}$} & \multirow{2}{*}{$\begin{array}{c}\text { Total } \\
\text { birds } \\
\text { (estimate) }\end{array}$} & \multirow[t]{2}{*}{ s.e. } & \multirow{2}{*}{$\begin{array}{l}\text { s.e. } \\
\text { (pct. } \\
\text { total) }\end{array}$} \\
\hline & & $\begin{array}{c}\text { No. } \\
\text { segments } \\
\text { surveyed }\end{array}$ & $\begin{array}{c}\text { No. } \\
\text { survey } \\
\text { days }\end{array}$ & $\begin{array}{c}\text { No. } \\
\text { segments } \\
\text { surveyed } \\
\end{array}$ & $\begin{array}{c}\text { No. } \\
\text { survey } \\
\text { days }\end{array}$ & & & & & \\
\hline Oregon & 12 & 48 & 5 & 48 & 5 & 4.47 & 53.67 & 644 & 192.5 & 29.9 \\
\hline Point St. George & 4 & 156 & 42 & 172 & 46 & 1.98 & 23.75 & 95 & 12.7 & 13.3 \\
\hline Crescent Beach & 2 & 110 & 55 & 164 & 57 & 3.71 & 44.50 & 89 & 9.3 & 10.5 \\
\hline Nickel Creek & 9 & 210 & 24 & 227 & 23 & 4.60 & 55.22 & 497 & 39.9 & 8.0 \\
\hline Klamath River & 20 & 159 & 12 & 108 & 11 & 5.43 & 65.15 & 1303 & 132.0 & 10.1 \\
\hline Big Lagoon & 9 & 92 & 13 & 97 & 14 & 8.81 & 105.67 & 951 & 159.7 & 16.8 \\
\hline Trninidad & 8 & 30 & 10 & 29 & 10 & 4.35 & 52.25 & 418 & 72.8 & 17.4 \\
\hline Mad River & 13 & 265 & 26 & 272 & 28 & 2.17 & 26.07 & 339 & 19.3 & 5.7 \\
\hline Humboldt Bay & 4 & 177 & 46 & 170 & 47 & 2.48 & 29.75 & 119 & 14.9 & 12.5 \\
\hline Table Bluff & 11 & 275 & 16 & 282 & 15 & 2.59 & 31.09 & 342 & 21.9 & 6.4 \\
\hline False Cape Mendocino & 4 & 12 & 4 & 12 & 4 & 1.50 & 18.00 & 72 & 16.2 & 22.6 \\
\hline Cape Mendocino & 29 & 197 & 7 & 90 & 6 & 1.16 & 13.93 & 404 & 50.4 & 12.5 \\
\hline Shelter Cove & 20 & 36 & 5 & 50 & 5 & 0.72 & 8.60 & 172 & 15.7 & 9.2 \\
\hline Cape Vizcaino & 16 & 17 & 2 & 30 & 2 & 0.72 & 8.69 & 139 & 16.6 & 11.9 \\
\hline Fort Bragg & 15 & 18 & 2 & 22 & 2 & 0.67 & 8.00 & 120 & 13.8 & 11.5 \\
\hline Albion & 14 & 13 & 2 & 3 & 1 & 0 & 0 & 0 & 0 & 0 \\
\hline Point Arena & 10 & 10 & 1 & 0 & 0 & 0 & 0 & 0 & 0 & 0 \\
\hline Fish Rock & 41 & 33 & 2 & 42 & 2 & 0 & 0 & 0 & 0 & 0 \\
\hline Bodega Bay & 20 & 9 & 1 & 11 & 1 & 0 & 0 & 0 & 0 & 0 \\
\hline Point Reyes & 29 & 17 & 1 & 8 & 1 & 0 & 0 & 0 & 0 & 0 \\
\hline Golden Gate & 17 & 9 & 1 & 14 & 1 & 0 & 0 & 0 & 0 & 0 \\
\hline Half Moon Bay & 35 & 57 & 3 & 33 & 3 & 1.82 & 21.80 & 763 & 125.5 & 16.5 \\
\hline Davenport & 11 & 11 & 1 & 5 & 2 & 0 & 0 & 0 & 0 & 0 \\
\hline Santa Cruz & 17 & 14 & 2 & 18 & 2 & 0 & 0 & 0 & 0 & 0 \\
\hline Moss Landing & 11 & 11 & 1 & 11 & 1 & 0 & 0 & 0 & 0 & 0 \\
\hline Monterey Bay & 12 & 12 & 1 & 12 & 1 & 0 & 0 & 0 & 0 & 0 \\
\hline Totals for California & 393 & 1998 & 285 & 1930 & 290 & & & 6467 & 452.3 & 5.1 \\
\hline
\end{tabular}

'No surveys were conducted from Point Bonita to Golden Gate. 


\section{Analyses}

\section{Murrelet Distribution From the Shoreline}

We used the following method to determine the relationship between the number of birds at varying distances from shore and the total number of birds at the three intensive survey areas. We assumed the relationship was similar for the three areas. Differences in coastal habitat types (sandy beach, rocky shoreline, and offshore rocks) and relative numbers of birds (low, medium, and high densities) at the three areas did not affect the distribution of birds out from the shoreline, as determined by plots of the residuals from a regression analysis.

The following four steps were used to establish the relationship between the distribution of murrelets from shore and the total population in an area.

\section{Monthly Mean Counts}

The datum used for analyses was derived from the total number of birds detected in each $2-\mathrm{km}$ segment on each survey day at each distance from shore. Surveys from April through October for all years were included in the data set. Monthly mean counts were calculated for each transect distance $(400,800,1400,2000,3000$, and $5000 \mathrm{~m})$. An example would be the following: during April, at Crescent Beach in the two 1400-m 2-km segments combined, a total of 235 birds were seen over all years. We surveyed a total of 133 of the $2-\mathrm{km}$ segments at that distance during April. The average was then 235 birds/133 2-km segments or 1.77 birds per $2-\mathrm{km}$ segment for all years.

Not all distances were sampled in all years during each month at each survey area. For example, surveys were not conducted at $400 \mathrm{~m}$ at Pebble Beach because of the unsafe rocky shoreline, nor at $5,000 \mathrm{~m}$ at any survey area prior to 1990 .

Where possible, the missing monthly mean counts were estimated with regression equations constructed with the non-missing monthly mean counts. We assumed that nearby distances would provide the best predictive ability for missing mean counts, and only those models were examined for each distance. For example, when estimating the 400 -m count, we looked only at two models: one with the $800 \mathrm{~m}$ monthly mean and another with both the $800 \mathrm{~m}$ and the $1,400 \mathrm{~m}$ monthly means. The mean monthly count from October 1990 at $800 \mathrm{~m}$ offshore did not fit the distinct pattern found with all other sample points and was excluded from the analysis. The regression equations were chosen to have up to two independent variables and the results were as follows:

$$
\bar{x}_{400}=0.228+0.6824 \cdot \bar{x}_{800}
$$

std. err. of estimate $=2.775$

$r^{2}=0.414 ; n=20$

$\bar{x}_{2000}=0.2605+0.23003 \cdot \bar{x}_{1400}+1.6631 \cdot \bar{x}_{3000}$

std. err. of estimate $=1.205$

$r^{2}=0.738 ; n=36$

$$
\bar{x}_{3000}=0.1205+0.20603 \cdot \bar{x}_{2000}
$$

std. err. of estimate $=.5375$

$r^{2}=0.441 ; n=36$

$\bar{x}_{5000}=0.009026+0.942065 \cdot \bar{x}_{3000}-0.121016 \cdot \bar{x}_{2000}$

std. err. of estimate $=0.2290$

$r^{2}=0.668 ; n=12$

The missing values were estimated with the regression equations, and any negative estimates were replaced with zero. Because some counts could not be predicted because not all of the independent variables were available, repeated use of the equations was performed until no more missing values could be estimated. Months with remaining missing values were excluded from the next step of the analysis.

\section{Murrelets Per 2-km Intensive Coastal Segment}

The total mean numbers of murrelets per $2-\mathrm{km}$ coastal segment (fig. 1) of intensive survey area were then calculated from the actual and estimated mean monthly counts for all survey distances $(400,800,1400,2000$, 3000 , and $5000 \mathrm{~m}$ ). Counts associated with $200-\mathrm{m}$ wide and 2-km long survey strips (fig. 1) starting (and centered) at $200 \mathrm{~m}$ from shore, and ending with a $200-\mathrm{m}$ wide strip centered at $6,000 \mathrm{~m}$ from shore, were interpolated or extrapolated using the surrounding or closest observed counts. For example, the $200-\mathrm{m}$ estimate was found with a linear extrapolation of the $400-\mathrm{m}$ and the $800-\mathrm{m}$ count (fig. 3). This extrapolated distribution closely resembled results of surveys conducted from shore-based stations (Ralph and others 1990), where we found the peak numbers of birds occurred beyond $400 \mathrm{~m}$ from the shoreline. The 3,200 - $m$ strip count was estimated with linear interpolation of the $3,000-\mathrm{m}$ and $5,000-\mathrm{m}$ count. If any linear interpolation resulted in a negative number, then zero was used instead. The total number of murrelets between 100 $\mathrm{m}$ from shore and $6,100 \mathrm{~m}$ from shore was then found by summing the contribution of the $200-, 400-, 600-, \ldots, 6000-$ m strips (fig. 3).

\section{The Total Birds From 800- and 1,400-m Counts}

The total number of murrelets from the intensive surveys was then regressed against the mean counts at $800 \mathrm{~m}$ and $1,400 \mathrm{~m}$. The resulting equation:

$$
\begin{aligned}
& \text { Coastal segment total }= \\
& \qquad 6.758+4.6102 \cdot \bar{x}_{800}+4.6241 \cdot \bar{x}_{1400}
\end{aligned}
$$

represents the relationship between the counts at these two distances and the total number of birds in a $2-\mathrm{km}$ coastal segment of coastline, from $100 \mathrm{~m}$ to $6100 \mathrm{~m}$ offshore.

\section{Estimates of Murrelet Numbers for Each Coastal Section}

The extrapolated distribution of birds, from $100 \mathrm{~m}$ to $6,100 \mathrm{~m}$ out from the shoreline at our intensively surveyed areas, was used to estimate the numbers of birds in the 


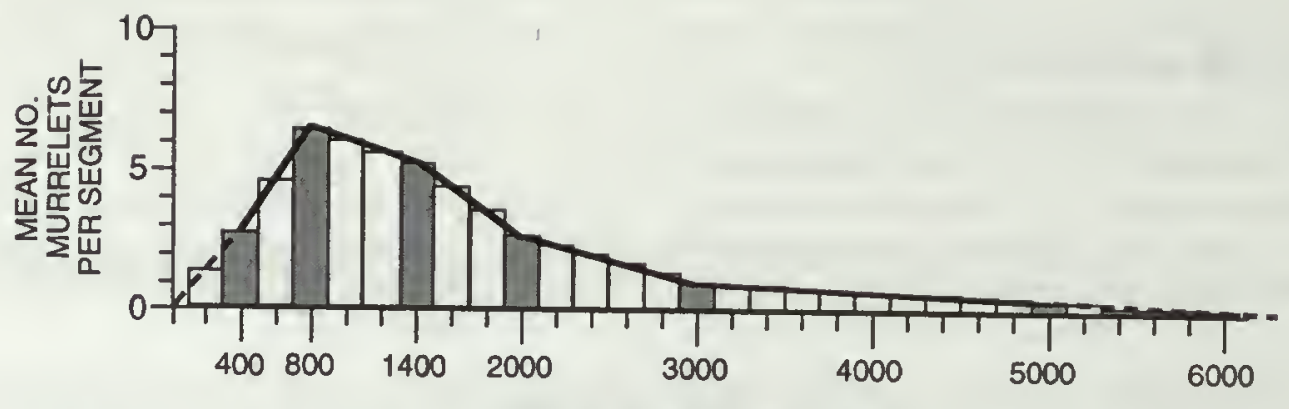

DISTANCE FROM SHORE (m)

Figure 3-Distribution of Marbled Murrelets at distances from $100 \mathrm{~m}$ to $6,000 \mathrm{~m}$ from the shoreline. Extrapolation and interpolation of population estimates for survey strips based on known counts (shaded bars) of the 400-, 800-, 1400-, 2000-, 3000-, and 5000-m transect distances.

extensive survey of coastal sections where only two offshore distances $(800 \mathrm{~m}$ and $1,400 \mathrm{~m})$ were surveyed.

For the $800 \mathrm{~m}$ and $1,400 \mathrm{~m}$ distances of each coastal section (fig. 2), we calculated the mean count, the standard deviation of the count, and the correlation coefficient of the two distances for all paired counts (2-km segments with counts at both distances on the same day). These summary statistics were used with the regression equation from the intensive distribution to estimate the total number of murrelets in each section (table 1 ) and the standard error of that estimate.

Summary Statistics:

$n_{800}=$ number of counts in a section at $800 \mathrm{~m}$

$\bar{x}_{800}=$ mean count at $800 \mathrm{~m}$

$s_{800}=$ standard deviation of counts at $800 \mathrm{~m}$

$n_{1400}=$ number of counts in a section at $1400 \mathrm{~m}$

$\bar{x}_{1400}=$ mean count at $1400 \mathrm{~m}$

$s_{1400}=$ standard deviation of counts at $1400 \mathrm{~m}$

$r=$ correlation coefficient for pairs of $800-m$ and 1400-m counts

$n=$ number of pairs of counts at $800 \mathrm{~m}$ and $1400 \mathrm{~m}$

$L=$ number of $2-\mathrm{km}$ coastal segments

The total numbers for all the sections are then summed to obtain an estimate of murrelets in California and the standard error of the total estimated.

Section total $=$

$L \cdot\left(6.758+4.610 \cdot \bar{x}_{800}+4.624 \cdot \bar{x}_{1400}\right)$

Std. err. $=$

$L \sqrt{4.610^{2} \cdot \frac{s_{800}^{2}}{n_{800}}+4.624^{2} \cdot \frac{s_{1400}^{2}}{n_{1400}}+2 \cdot \frac{21.318 \cdot r \cdot s_{800} \cdot s_{1400}}{n}}$

\section{Results}

\section{Coastal Distribution}

We estimate the total state population to be approximately 6,500 birds (table 1). The distribution of birds in the north and central parts of the state were disjunct (fig. 2). The highest densities of birds were found in the northernmost part of the state, from the Oregon border to Trinidad in Humboldt County. In most of this area, there was a density of more than 4 birds $/ \mathrm{km}^{2}$ ( 48 birds per 2-km coastal segment, $12 \mathrm{~km}^{2}$ ). This population includes approximately 4,000 birds. Most of these birds were adjacent to, and contiguous with, the old-growth forests in Del Norte and northern Humboldt counties. These forests are largely on state and federal parks, and composed primarily of coast redwood (Sequoia sempervirens). From Trinidad south to False Cape Mendocino, murrelet densities were generally less than 2.5 birds $/ \mathrm{km}^{2}$. This population was adjacent to the old-growth forests of Humboldt Redwoods State Park and the private lands of Pacific Lumber Company, all in Humboldt County. South of False Cape Mendocino, the densities of birds again declined from 1.5 to 0.67 birds $/ \mathrm{km}^{2}$ in the area of Fort Bragg and Albion. No birds were observed during surveys between Albion and Half Moon Bay, several hundred kilometers to the south.

The central California population, comprising about 12 percent of the state's population, was estimated at 763 individuals and was located between Half Moon Bay in San Mateo County and Davenport in Santa Cruz County. This population was found primarily between Pigeon Point and the mouth of Waddell Creek and was also offshore of oldgrowth redwood forests, mainly in state parks.

\section{Discussion}

Censusing murrelets from boats is preferable to censusing from the shoreline. During 2 years of surveys conducted from observation points on the shoreline with $30 \mathrm{x}$ telescopes, 
we found the highest numbers of birds were seen between $400 \mathrm{~m}$ and $800 \mathrm{~m}$ from shore, depending on the height of the observer above the water. On surveys conducted from boats at the same locations, we found that most birds were $800 \mathrm{~m}$ or farther from shore, apparently beyond the effective range of the shore-based observers.

\section{Factors Which Might Affect the Estimate}

There are five factors which might cause over- or under-estimate of the population: (1) a small number of birds occur at distances greater than $6,000 \mathrm{~m}$ from shore, beyond our surveys; (2) during incubation a portion of the birds are on nests and, therefore, not counted at sea; (3) a fraction of the birds are foraging underwater when the boat passes and are, therefore, missed by observers. (4) some birds would be flushed and fly ahead of the boat and be repeatedly counted, thus resulting in an overestimate, and (5) observer error in estimating distances to the birds. We feel that these sources of error, detailed below, in part compensate for each other, and would account for only perhaps as much as 10 percent error.

\section{Birds Outside Our Sampled Area}

The density of birds declined rapidly beyond $2,000 \mathrm{~m}$ (fig. 3), but even at $5,000 \mathrm{~m}$, the density of birds is appreciable. About 10 percent of the total are estimated to occur between $3,500-6,000 \mathrm{~m}$ from shore. In extensive surveys off the central California coast murrelets have only very rarely been detected beyond 7,000 $\mathrm{m}$ (Ainley and others, this volume). If we extrapolate our distribution to $7,000 \mathrm{~m}$, approximately 4 percent of the population might occur beyond our sampled area. A $\log -\log$ plot of the data shows that birds could theoretically be detected out to $20 \mathrm{~km}$ from shore, albeit in extremely low densities. While birds regularly occur out to $60 \mathrm{~km}$ from shore off British Columbia and Alaska, there is no evidence of this in California.

\section{Birds Missed During Incubation}

During the approximately 90 -day breeding season (Hamer and Nelson, this volume a), incubation extends over about 30 days for each breeding pair. As the sexes alternate incubation duties, half of the breeding population would be on the nest during the incubation period. Estimates of the proportion of the population breeding in any one year range between 30 and 85 percent (Carter and Sealy 1987b; Beissinger, this volume). Thus, at-sea censuses during incubation would result in an underestimate of 5 to 14 percent of the population. This is calculated by determining the percent of birds that would be on the nest at any one time during the breeding season:

0.85 breeding $\times 0.33$ breeding season $\times 0.50$ birds $=$ 14 percent underestimate.

0.30 breeding $\times 0.33$ breeding season $\times 0.50$ birds $=$ 5 percent underestimate.
Since the potential incubation period represents 43 percent of our survey period from April through November, the error estimates of 5 to 14 percent should be multiplied by 0.43 , suggesting an underestimate of approximately 2 to 6 percent. Based on the proportion of young birds observed offshore in recent years (see Beissinger, this volume; Ralph and Long, this volume), the proportion actually breeding could be substantially lower than 30 percent.

\section{Birds Missed While Diving}

We assume in this study that no birds were missed by being underwater as the observers passed. Our data show that the average dive time of murrelets is less than 17 seconds (Strachan and others, this volume), and the distance traveled in that time at 12 knots is less than $100 \mathrm{~m}$. Since we can detect birds out to $100 \mathrm{~m}$ in front of the boat, most birds that dive while foraging would resurface before the boat passed. While we are certain that some birds are missed due to this factor, we feel that the effect is minimal, and probably much less than 5 percent of the total population.

\section{Repeated Counting of the Same Individuals}

Double counting by more than one observer might result in an overestimate with some survey methods, but we used only a single observer, aided by the driver. It is possible that some birds would fly ahead of the boat and be repeatedly counted, thus also resulting in an overestimate. Strong and others (this volume), however, discount this, and present data indicating a relatively small number of birds fly out ahead of the boat.

\section{Distance Estimates}

One factor which could affect population estimates using EAS for calculations is observer variation, or error in distance estimates. Underestimation of the distance to birds would reduce the transect width and would result in an overestimate of the total population. Overestimating the distance would have the opposite effect and the population would be underestimated. Our use of a reference buoy towed at a known distance from the boat helped decrease the variation and error in distance estimates.

\section{Comparison with Previous Population Estimates}

The numbers of birds derived from the pioneering work of Sowls and others (1980) and Carter and others (1990b) were based on more limited data. Sowls and others (1980) speculated that the population was about 2,000 birds, but their murrelet data was collected opportunistically and did not provide sufficient data for a population estimate. Carter and others (1990b) assumed that birds could be detected out to $250 \mathrm{~m}$, and conducted a limited number of surveys during one breeding season. Furthermore, they often surveyed inshore of the area where we found the highest numbers of murrelets (Carter, pers. comm.). Our surveys were more extensive, sampled most of the offshore areas used by murrelets, and 
were repeated over several years, under usually optimal conditions. Thus, we are confident that our population estimates are more accurate than those derived from past, preliminary survey work.

\section{Comparison of Coastal and Inland Habitat Distribution}

Murrelets are found at sea in California offshore of oldgrowth redwood forests. The only minor exception is the population in the vicinity of Trinidad. This population is about $30 \mathrm{~km}$ to the south and west of the major concentration of old-growth in Redwood National Park. The waters in this area are felt to be unusually productive by knowledgeable fisheries biologists (Roelofs, pers. comm.), perhaps explaining the abundance of murrelets in the area. A 20- to 30-km flight from nesting to foraging areas is well within the capabilities of murrelets. In British Columbia murrelets with radio transmitters were regularly tracked 40 to $60 \mathrm{~km}$ on daily flights from feeding areas to presumed inland nesting sites (Varoujean, pers. comm.).

The coincidence of the fragmentation of the offshore population and the fragmentation of the remaining large stands of old-growth forests adds weight to the argument that the species is dependent for nesting habitat on these stands.

\section{Risk Factors}

Our documentation of two population centers in the state with a decline of numbers from north to south, make it important to ensure that offshore populations are protected from mortality from oil spills and gill nets. Both these risks are present today, and the concentration of birds in local areas, especially the southern population, make them especially vulnerable to extirpation.

\section{Recommendations}

The data on the offshore populations of the murrelet we have gathered over the past five years can provide a basis for determining future population changes. We suggest that these surveys continue annually to monitor this threatened species, as well as the other species frequenting the nearshore waters. Any monitoring program should also include collection of data on the production of young by determining the presence of newly-fledged birds while they are distinguishable from winter-plumaged adults. With such a plan and a regular monitoring program in place, we can determine the health and trend of the population of this unique species.

\section{Acknowledgments}

We thank California Department of Fish and Game, California Department of Forestry, California Department of Transportation, U.S. Minerals Management Service, Redwood National Park, the USDA Forest Service, and the timber industry's Marbled Murrelet Trust that includes The Pacific Lumber Company, Arcata Redwood Company, MillerRellim Company, Barnum Timber, and Eel River Sawmills for financial support. We are grateful to our many brave, hearty, and capable observers for their many hours on the ocean, especially: Brian O'Donnell, Linda Long, Kim Hollinger, Brian Cannon, Dave Forty, Jennifer Weeks, David Craig and Greg Heidinger. We thank Ann Buell, Esther Burkett, George Hunt, Deborah Kristan, Linda Long, Nadav Nur, John Piatt, Larry Spears, Steven Speich, Bill Sydeman, and Jennifer Weeks for their comprehensive and helpful manuscript reviews, and James Baldwin and Kevin McKelvey for their statistical advice. We appreciate the efforts of the many field personnel who gathered data for the study. 


\title{
Chapter 34 \\ Offshore Occurrence Patterns of Marbled Murrelets in Central California
}

\author{
David G. Ainley ${ }^{1} \quad$ Sarah G. Allen ${ }^{2} \quad$ Larry B. Spear ${ }^{3}$
}

Abstract: We assessed the occurrence patterns of Marbled Murrelets (Brachyramphus marmoratus) offshore of Waddell Creek, in central Califomia. Data were derived primarily from cruises during the height of the murrelet breeding season, in June, between 1986 and 1994, as well as some cruises during the prebreeding period, February to early April. The large majority of sightings occurred within $10 \mathrm{~km}$ of Point Año Nuevo, directly offshore the species' breeding area. Only three sightings occurred farther offshore (12-24 km). The physical factors that explained a small but significant portion of variability in murrelet occurrence were: (1) inverse relationships related to distance to breeding area (including ocean depth); and (2) relationships to recently upwelled water. Murrelets were least abundant during periods of El Niño-Southern Oscillation. An analysis of the availability of potential prey species indicated that murrelets were most abundant when more euphausiids were found from the coast to well offshore. Murrelets were absent in years when a large prey concentration occurred only close to shore, indicating that the birds were too close to shore for us to census. We suggest that the critical habitat of this population should include the nearshore marine waters within $10 \mathrm{~km}$ of Año Nuevo Island.

The Marbled Murrelet (Brachyramphus marmoratus) nests in old-growth forests along the Pacific Coast of North America from central California to southem Alaska and the Aleutian Islands. In this region, the birds are unevenly distributed at sea, occurring in distinct clumps, often in bays at the mouths of coastal rivers (Carter and Erickson 1992, Nelson and others 1992, Rodway and others 1992, Speich and others 1992, Strong and others 1993). These concentrations may be associated with the river valleys in which the birds nest, or they may represent areas of good foraging. Both staging and foraging areas comprise "critical habitat," the designation of which is defined and required under the Endangered Species Act (U.S. Fish and Wildlife Service, 1993b).

Other than surveys to estimate abundance, little work at sea on the biology of Marbled Murrelets has been undertaken since the studies of Sealy $(1972,1975$ c), Carter (1984), and Carter and Sealy (1990), who investigated the species in the inside passage waters of British Columbia. Information on factors affecting distribution or clumping remains largely at the broadest scales (Briggs and others 1987, Piatt and Ford 1993). Repetitive at-sea surveys designed to understand at-

\footnotetext{
${ }^{1}$ Marine Program Director, Poinl Reyes Bird Observatory, 4990 Shoreline Highway, Stinson Beach, CA 94970

${ }^{2}$ Ecologist, Western Regional Office, National Park Service, U.S. Deparment of the Interior, San Francisco, CA 94107

${ }^{3}$ Research Biologist, Poinl Reyes Bird Observatory, 4990 Shoreline Highway, Stinson Beach, CA 94970
}

sea biology and marine factors as they affect murrelet distribution from a mesoscale perspective, i.e. $30-50 \mathrm{~km}$, remain non-existent. The smaller scale surveys would be more pertinent to localized populations.

The most disjunct population of Marbled Murrelets is in central California, the southern limit of the species' breeding range. Murrelets aggregate along the coast of northern Santa Cruz and southern San Mateo counties, in the vicinity of Point Año Nuevo and Año Nuevo Island (hereafter referred to collectively as Año Nuevo), about 350 $\mathrm{km}$ south of the next closest murrelet nesting area; see figure 1A (Briggs and others 1987). This aggregation is associated with Waddell Creek, the last remaining near-topristine coastal watershed in the lower two-thirds of California (see, for example, Shapovalov and Taft 1954, an analysis still pertinent to recent times). The watershed drains Big Basin Redwoods State Park and adjacent, private, forested lands. About 250 birds are thought to breed here (Carter and Erickson 1992).

We collected information on Marbled Murrelets in the vicinity of Año Nuevo on ship-based surveys designed to elucidate the physical and biological factors that organize seabird communities off central California during the years 1986-1994. Overall our work was not directed specifically at Marbled Murrelets. Moreover, our large vessel was usually not able to cruise in waters shallower than $20 \mathrm{~m}$, where Marbled Murrelets often occur (Ralph and others 1990, Sealy and Carter 1984, Strong and others 1993). We were able to direct the ship's course at times, however, and whenever in the vicinity of Año Nuevo, we pointedly surveyed for murrelets. We collected data on sea-surface temperature and salinity, thermocline depth, bottorn depth, distance-to-shelf break, distance-to-shore, and distance-to-nesting area, which we recorded at frequent, regular intervals while we surveyed continuously for birds. We also obtained information on availability of potential prey in the study area.

\section{Methods}

Our research extended from Bodega Bay to Carmel, California, in waters from 20 to $2,000 \mathrm{~m}$ deep. For purposes of this report, our study area includes the middle third of this region, specifically, from Half Moon Bay to Santa Cruz (fig. 1). We censused seabirds from the flying bridge of the NOAA Ship David Starr Jordan during the 9 cruises in the first two weeks of June 1986-1994 (referred to hereafter as late spring), and in 5 cruises during 7-27 April 1987, 16-22 April 1988, 21 February-6 March 1992, 2-15 March 1993, and 1-14 March 1994 (early spring). Two observers simultaneously counted 

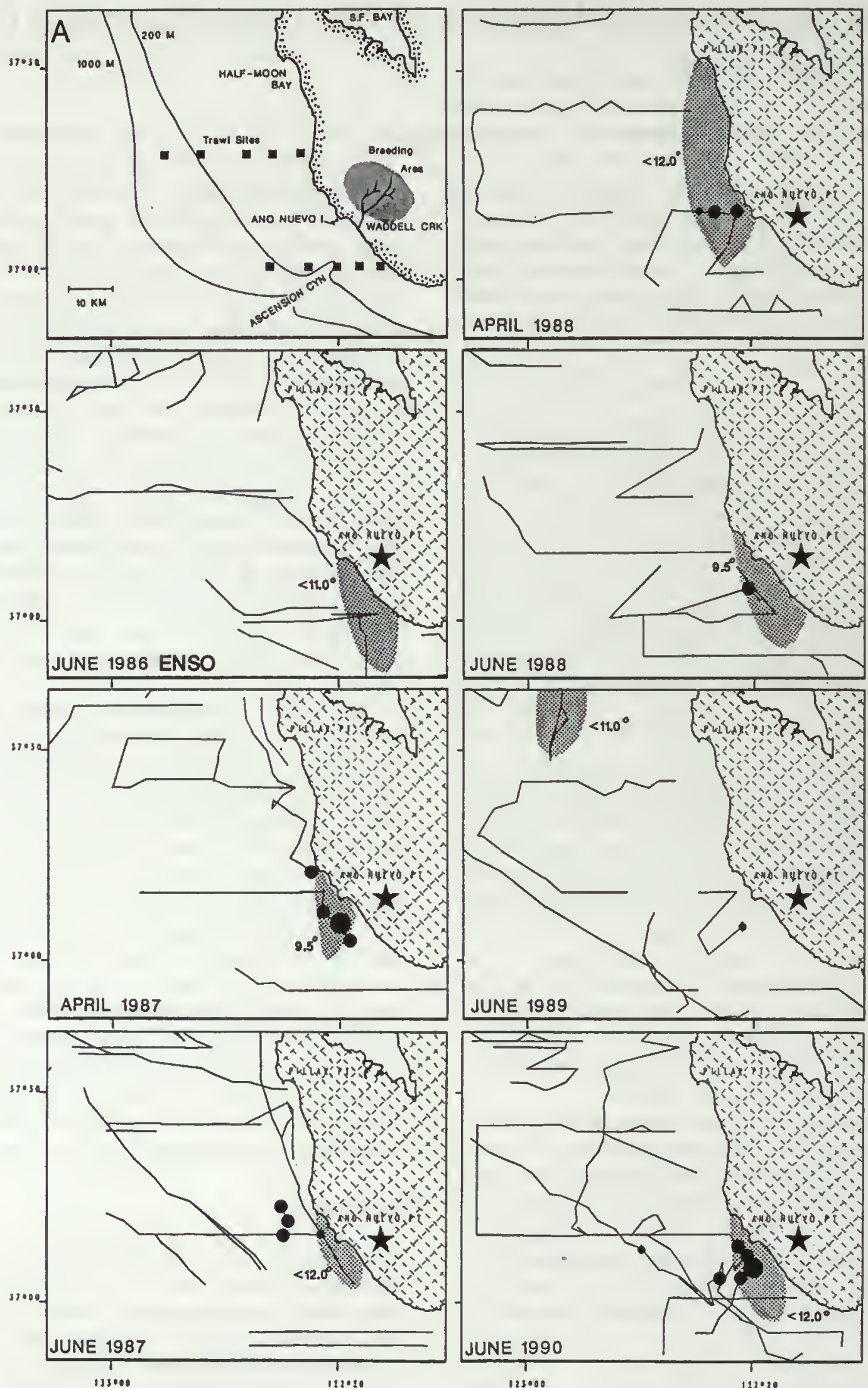

Flgure $1 \mathrm{~A}$ and B-The coast of San Mateo and Santa Cruz counties showing transect lines and number of murrelets seen within $300 \mathrm{~m}$ of the vessel during surveys, 1986-1994. A small circle $=1$ bird, medium circle $=2$ 5 birds, and large circle $=>5$ birds; the star designates the breeding area. The upper panel of $1 \mathrm{~A}$ gives localities mentioned in the text; shaded ocean areas in other panels indicate where sea-surface temperature is the lowest in the region as indicated in degrees centigrade. ENSO indicates an EI Niño-Southern Oscillation condition. 

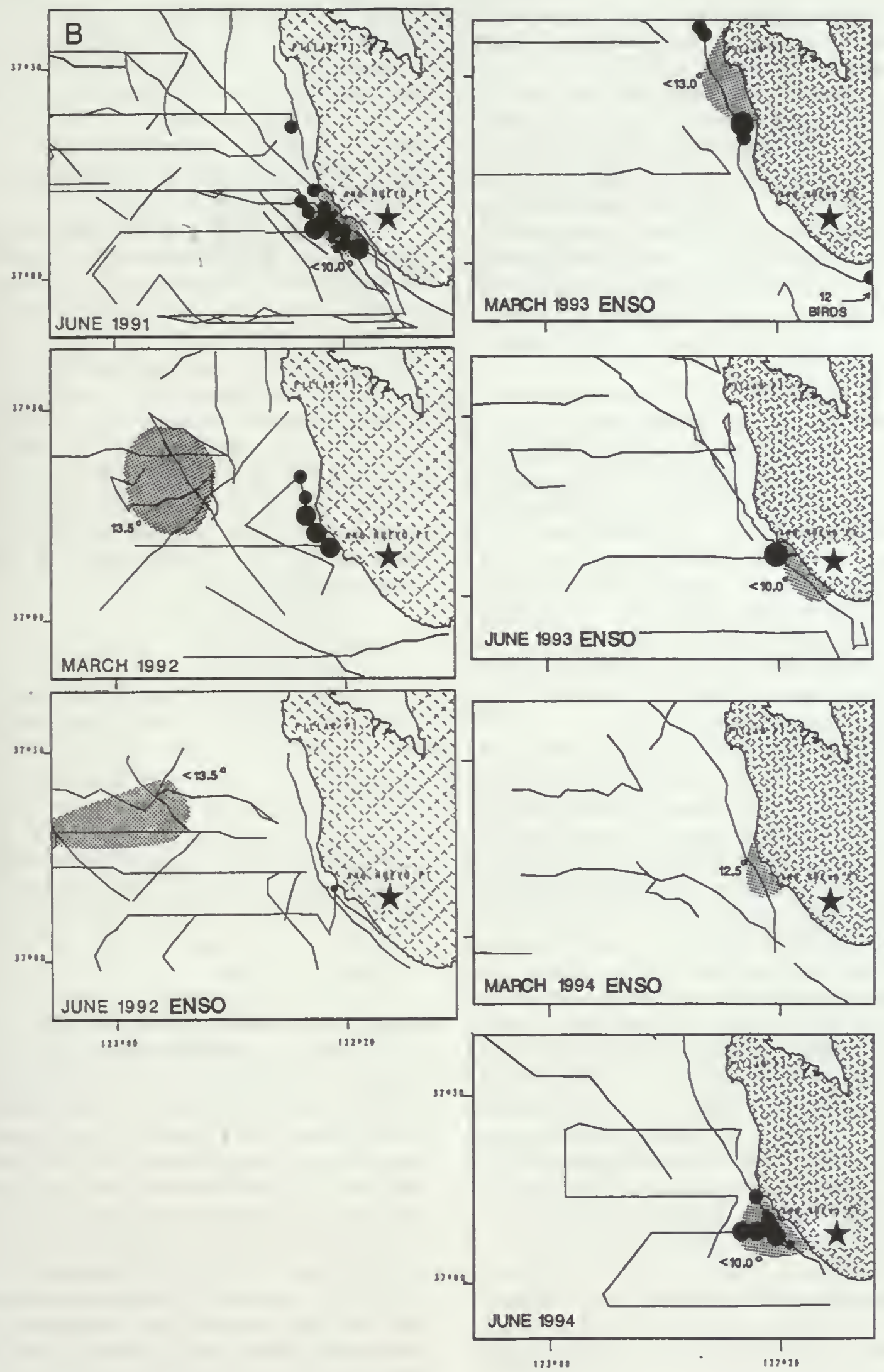
all birds within $300 \mathrm{~m}$ of one fore-quarter, i.e., that side of the bow on which glare was least, but did not include birds following or attracted to the ship (see Tasker and others 1984; not a problem in the case of murrelets). Almost all murrelets were detected on the water, thus, we did not correct for bird flight speed or direction (Spear and others 1992). We looked forward of the 300-m transect boundary to ensure that murrelets were detected before the ship caused them to dive or take flight. Our counts were not affected by ocean turbulence, as wind speeds were generally less than $15 \mathrm{knots}$ and the 10 -m above water vantage point of the flying bridge precluded birds from being obscured by waves. The average ( \pm s.d.) wind speed was $9.0 \pm 6$ knots. Similarly, counts were not affected by poor visibility as we experienced no fog.

Two observers censused the $300-\mathrm{m}$ band continuously whenever the ship was under way (cruising speed $14-15 \mathrm{~km} /$ h). We divided censuses into 15 -minute (ca. $3.5 \mathrm{~km}$ ) segments; at the start of each segment, we recorded position, distanceto-shore, water depth, weather (wind speed and direction, cloud cover) and, using the ship's electronic systems, seasurface temperature, and salinity. We determined thermocline depth and slope from "CTD"'s conducted by ship's personnel at 8-km intervals along our cruise track (CTD is "conductivity and temperature with depth" and refers to the probe used to measure these factors.) Within the region bounded by the coast, $26 \mathrm{~km}$ offshore and at latitudes $37^{\circ} 02^{\prime} \mathrm{N}$ and $37^{\circ} 20^{\prime}$ $\mathrm{N}$ (fig. 1), we logged 1863 15-min transects.

National Marine Fisheries Service personnel conducted trawls at night to estimate the concentrations of micronektonic (i.e., ones $<10 \mathrm{~cm}$ in length) crustaceans and fish. The trawl surveys, done in the May-June period, were designed to assess prevalence of juvenile rockfish (Sebastes spp.). These and similar sized organisms, all of which the nets targeted, all would include suitable murrelet prey. One track of five trawl stations at increasing bottom depth $(25-480 \mathrm{~m})$ occurred in the southern part of the study area, off Davenport, and another occurred in the northern part, off Pescadero (see fig. IA). In most years, two sweeps of the trawl stations were made during the murrelet census period, but in a few years only one was made. For a given year, we averaged trawl results combining all sweeps and both station lines by depth stratum in 5 intervals. Herein, we present average percent composition of the 5 trawl intervals among the four most prevalent species groups: euphausiids (mostly Thysanoessa spinifera), anchovies (Engraulis mordax), juvenile rockfish, and myctophiids (mostly Tarletonbaena crenularis).

We mapped murrelet sightings using an Arc-Info Geographic Information System (ESRI, Inc., Redlands, California). We analyzed the physical habitat features listed above in an attempt to explain murrelet occurrence patterns by both multiple regression on murrelet density and logistic regression on presence/absence of murrelets on census segments. Data were log-transformed before analysis. Our initial model also included the following interaction terms as independent variables: distance-to-shore $\mathrm{x}$ distance-to-nesting- area; distance-to-shore $\mathrm{x}$ depth; and distance-to-shore $\mathrm{x}$ distance-to-shelf-break. Besides the physical habitat features, we calculated distance-to-nesting-area for each transect segment using the southern boundary of the region where most nests or grounded fledglings have been found (see fig. $1 A$; see Carter and Erickson 1992). We conducted the backwards stepwise analysis first for all years and all seasons, and then for early and late spring separately. We considered results to be significant at $P<0.05$.

We could not use prey abundance as a factor in the regressions owing to the statistically inappropriate spacing of the trawl stations relative to the bird censuses. We made qualitative comparisons between murrelet and prey distributions, considering both the species composition of trawls and the number of organisms caught per trawl by depth stratum.

Finally, we investigated the distribution of murrelets relative to distance-to-shore, as this parameter is integral to assessment of murrelet numbers by other researchers in many regions to the north. Besides determining the proportion of murrelets seen at 1000-m intervals from shore, we also normalized the data by using search effort (number of murrelets seen divided by the number of transects at each distance interval x 100).

\section{Results}

Although our June surveys were conducted in the middle of the murrelet nesting season (Carter and Erickson 1992), we saw no fledglings. Our surveys earlier in the spring coincided with the early courtship period.

Most murrelet sightings were within $7 \mathrm{~km}$ of shore (fig. 2) (median $<5 \mathrm{~km}, \bar{x} \pm s . d .5 .5 \pm 5.4 \mathrm{~km}$ ). The largest number of sightings occurred 3-5 km offshore; normalizing the data by search effort revealed no change in this pattern. We saw one Marbled Murrelet $24 \mathrm{~km}$ offshore, the farthest from shore that one was seen. This was near to the edge of the continental shelf break.

In spite of the wide area of our search, almost all murrelet sightings were within $10 \mathrm{~km}$ of Año Nuevo. Only once did we see Marbled Murrelets anywhere else in the region, Bodega Bay to Carmel, in any of the years (see below). On a smaller scale-within $10 \mathrm{~km}$ of Año Nuevo-substantial annual variation was apparent (compare cells of fig. 1). On some cruises, we saw few murrelets: during early spring, only 5 in April 1988 and none in March 1994; and during late spring, none in June 1986, two in 1989, and one in 1992, even though sampling was adequate. In spite of even more sampling tracks, we saw only 5 murrelets in June 1988 and 6 in June 1993. Murrelets were much more numerous during other cruises: 18 in April 1987; 19 in March 1992; and 16 in March 1993. Highest numbers occurred in late spring (June): 27 in 1987, 16 in 1990, 45 in 1991, and 28 in 1994. The March 1993 census was the only one in which we saw substantial numbers of murrelets farther than $10 \mathrm{~km}$ from Año Nuevo; 12 more were recorded off Santa Cruz, a point located just to the right of the margin in figure 1 . 

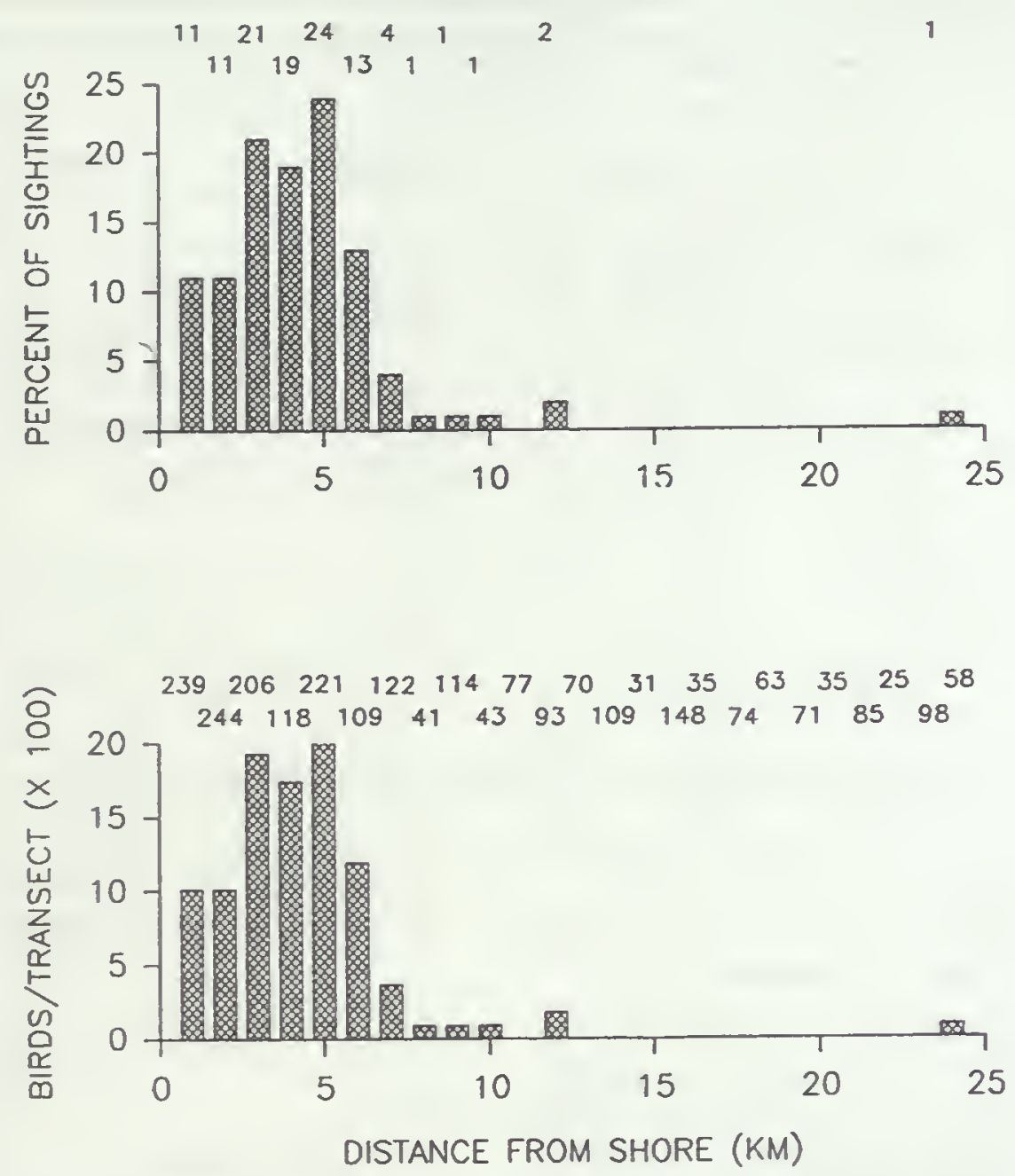

Figure 2-Frequency distribution of murrelet sightings by distance to shore by $1000-\mathrm{m}$ (1$\mathrm{km}$ ) intervals: (A) percent of sightings in the raw data (number of murrelet sightings along the top); and (B) sightings normalized by search effort (sightings divided by number of 15min transects in the distance intervals and the number of transects along the top).

Results of multiple regression analyses, using data from all seasons and only census segments on which murrelets were seen (hence, sample size is low), show distance-toland to be the most important explanatory physical factor, in this case a negative one (higher dersities occur closer to land; table 1 ). Using data from early spring, distance-toland remains important (and becomes statistically significant), but depth and distance-to-nesting-area are important as well. This is logical: a correlation analysis (table 2) shows that distance-to-land, distance-to-nest, and depth are all closely correlated: a point moving closer to land also moves closer to nesting sites (to some degree) and to shallower water. Analyses using only late spring data show that densities are affected most strongly by waters influenced directly by upwelling, i.e. those of low temperature and high salinity (see below; table I).

In the logistic analysis, which considers only presenceabsence on each 15-minute transect and therefore uses all transects, the same factors, but more of them together, explained murrelet distribution (table 3). In addition, more of the variance was explained. Considering both seasons, temperature, salinity, distance-to-land, distance-to-nestingarea, and distance-to-shelf-break were all important (and statistically significant). These distance parameters were related to one another as was temperature to salinity (table 2). Murrelets were found in waters of low salinity during early spring. At this time, freshwater runoff is at maximum extent and enters the study area from the fresh water plume that passes south from the Golden Gate (just to the north of figure 1 boundaries), as well as from Pescadero and Waddell creeks. Thus, lowest salinities at this time of year occur close to shore but in a broad band. During early spring, distance-to-shelf-break was not a significant variable. Considering only late spring data, depth, distance-to-shelfbreak and -to-nesting-area, as well as salinity, became the explanatory variables. The role of salinity was reversed from 
Table I-Results of multiple regression analysis to explain variation in murrelet density: dependent variable $=$ murrelet density; independent variables = water depth, sea-surface temperature and salinity, wind speed, distance-to-land, distance-toshelf-break, and distance-to-nesting-area, as well as interaction terms presented in the Methods

\begin{tabular}{|c|c|c|c|c|}
\hline Variable & Coefficient & Standard error & $T$ & $P$ (2-Tail) \\
\hline \multicolumn{5}{|c|}{ All seasons $\left(r^{2}=0.056, n=53\right)$} \\
\hline Constant & 1.318 & 0.106 & 12.463 & $<0.001$ \\
\hline Land & -0.033 & 0.019 & -1.735 & 0.089 \\
\hline \multicolumn{5}{|c|}{ Early spring $\left(r^{2}=0.381, n=20\right)$} \\
\hline Constant & 1.684 & 0.346 & 4.870 & $<0.001$ \\
\hline Depth & 0.011 & 0.005 & 2.088 & 0.053 \\
\hline Land & -0.154 & 0.058 & -2.670 & 0.017 \\
\hline Nest & -0.014 & 0.008 & -1.783 & 0.094 \\
\hline \multicolumn{5}{|c|}{ Late spring $\left(r^{2}=0.124, n=33\right)$} \\
\hline Constant & 8.159 & 2.795 & 2.920 & 0.006 \\
\hline Sea-surface temperature & -0.481 & 0.230 & -2.093 & 0.045 \\
\hline
\end{tabular}

Table 2-A matrix showing correlation caefficients among independent variables used in the regression analyses

\begin{tabular}{|c|c|c|c|c|c|}
\hline Variable & Depth & Land & Nest & Shelf & $\begin{array}{c}\text { Sea-surface } \\
\text { temperature }\end{array}$ \\
\hline \multicolumn{6}{|c|}{ Early spring ( $n=496$ transects) } \\
\hline \multicolumn{6}{|l|}{ Distance to: } \\
\hline Land & 0.717 & & & & \\
\hline Nest & 0.641 & 0.638 & & & \\
\hline Shelf & 0.613 & 0.465 & 0.482 & & \\
\hline Sea-surface temperature & 0.229 & 0.279 & -0.023 & -0.040 & \\
\hline Sea-surface salinity & 0.006 & -0.048 & 0.176 & -0.149 & -0.415 \\
\hline \multicolumn{6}{|l|}{ Late spring $(n=1367)$} \\
\hline \multicolumn{6}{|l|}{ Distance to: } \\
\hline Land & 0.696 & & & & \\
\hline Nest & 0.468 & 0.651 & & & \\
\hline Shelf & 0.520 & 0.431 & 0.364 & & \\
\hline Sea-surface temperature & -0.124 & -0.217 & -0.149 & -0.193 & \\
\hline Sea-surface salinity & 0.153 & 0.179 & -0.025 & 0.175 & -0.755 \\
\hline
\end{tabular}

the early spring, however; murrelets were found where salinily was highest, which at this time also happened to be close to shore. This was consistent with the onset of coastal upwelling, which reaches maximum in May and June and which brings cold, high salinity water to the surface adjacent to the beach especially 10 the south of Point Año Nuevo (fig. I).

The relationship of murrelet occurrence to prey availability during late spring (fig. 3) could be analyzed only qualitatively because of an inconsistency of scale belween the trawls and the censuses. Palterns were apparent, however, and high inshore prey abundance appeared to result in fewer birds offshore. When murrelets were scarce in June surveys (1986, 1988, 1989, 1992, and 1993), prey abundance was disproportionately high ( $>1000$ prey per trawl) on the shallowest (and next shallowest in the case of 1993) trawl station, as compared to the adjacent trawls in deeper waters oul to the shelf break (i.e., waters $<280 \mathrm{~m}$ ). In contrast, during cruises when murrelets were abundant, particularly 1990,1991 , and 1994, polential prey were also abundant, and equally so among all or almost all the trawls throughout the shelf waters. The exception was 1987, when trawl catches were low, but murrelets were abundant. In 
Table 3-Results of logistic analysis to explain presence and absence of Marbled Mfurrelets on transect segments

\begin{tabular}{l|cccc}
\hline Variable & Coefficient & $\begin{array}{c}\text { Standard } \\
\text { error }\end{array}$ & $T$ & $\begin{array}{c}P \\
\text { (2-Tail) }\end{array}$ \\
\hline All seasons (McFadden's $\left.p^{2}=0.529, n=1863\right)$ & & & & \\
Constant & 22.949 & 5.966 & 3.847 & 0.001 \\
Land & -0.145 & 0.071 & -2.032 & 0.042 \\
Nest & -0.060 & 0.013 & -4.563 & $<0.001$ \\
Shelf & -0.058 & 0.027 & -2.184 & 0.029 \\
Sea-surface temperature & -0.422 & 0.172 & -2.459 & 0.014 \\
Sea-surface salinity & -0.460 & 0.143 & -3.219 & 0.001 \\
Early spring (McFadden's $\left.\rho^{2}=0.569, n=496\right)$ & & & & \\
Constant & 36.752 & 13.542 & 2.714 & 0.007 \\
Land & -0.154 & 0.058 & -2.670 & 0.017 \\
Nest & -0.014 & 0.008 & -1.783 & 0.094 \\
Sea-surface lemperature & -0.966 & 0.386 & -2.501 & 0.012 \\
Sea-surface salinity & -0.671 & 0.268 & -2.502 & 0.012 \\
Late spring (McFadden's $\rho^{2}=0.553, n=1367$ & & & & \\
Constant & -75.56 & 41.000 & -1.843 & 0.065 \\
Depth & -0.026 & 0.010 & -2.501 & 0.012 \\
Nest & -0.088 & 0.026 & -3.372 & 0.001 \\
Shelf & -0.092 & 0.036 & -2.584 & 0.010 \\
Sea-surface salinity & 2.342 & 1.213 & 1.930 & 0.054 \\
\hline
\end{tabular}

most years of high prey abundance, euphausiids dominated most of the trawl catches.

\section{Discussion}

Our results indicate that in the designation of "critical habitat," at least for Marbled Murrelets of the Waddell Creek nesting population, the coastal waters within $10 \mathrm{~km}$ of Point Año Nuevo should be included. It is not surprising to us that during the nesting season, murrelets in this population do not travel far from the nesting area because, as explained below, food availability is predictably high. The juxtaposition of nesting and feeding areas should also be studied among vulnerable, i.e. isolated, murrelet populations to the north.

The small percentage of variation in murrelet distribution explained by physical habitat variables is partly due to the small regional scale of our study and the fact that certain oceanographic features are quite ephemeral (see below). Within the mesoscale perspective that our study area provided, the availability of prey was likely the factor that best explains murrelet occurrence (see below).

The specific prey of this population are unknown, but the three most likely candidates are euphausiids, juvenile rockfish, and young-of-the-year anchovies, the three most important prey to all other coastal seabirds in the vicinity (Ainley and Boekelheide 1990). Euphausiids, shown to be important to murrelets in British Columbia (Sealy 1972, 1975c), probably also comprise a significant proportion of the diet among adults in the Waddell Creek population. The effect of euphausiid abundance on murrelet distribution, as indicated in the analysis above, is circumstantial evidence for this. Euphausiids are especially abundant in this region (see below) and are easily caught by diving seabirds.

Similar to many other alcids (see Bradstreet and Brown 1985), while the adults eat euphausiids, only fish are fed to the nestlings. It is much more efficient for the parents to carry fish to their young, because a single fish represents much more food value than a single euphausiid. In this region, juvenile rockfish and anchovies are likely candidates as dominant species in the chick diet. The undersea Ascension Canyon, extending out from Waddell Creek (see fig. 1), is an area where the high prevalence of juvenile rockfish, specifically Sebastes jordani, is more consistent than anywhere else along this coast (Woodbury, pers. comm.). The principal prey species of central California's seabirds during the nesting season is S. jordani (Ainley and Boekelheide 1990). Anchovies are also consistently abundant in the Año Nuevo area and northern Monterey Bay during late spring and summer (Woodbury, pers. comm.). Euphausiids, too, are consistently abundant in the Ascension Canyon region at this time of year and more so than in adjacent ocean areas.

When euphausiids are abundant throughout shelf waters in the vicinity of Año Nuevo, adult murrelets need not forage far from Waddell Creek, but can remain within $3-5 \mathrm{~km}$ of the nesting area throughout the day. This was the pattern revealed in our analysis. Not inconsistent with this pattern is the fact that we saw few murrelets when potential prey were only abundant at the shallowest trawl station and sparse farther 

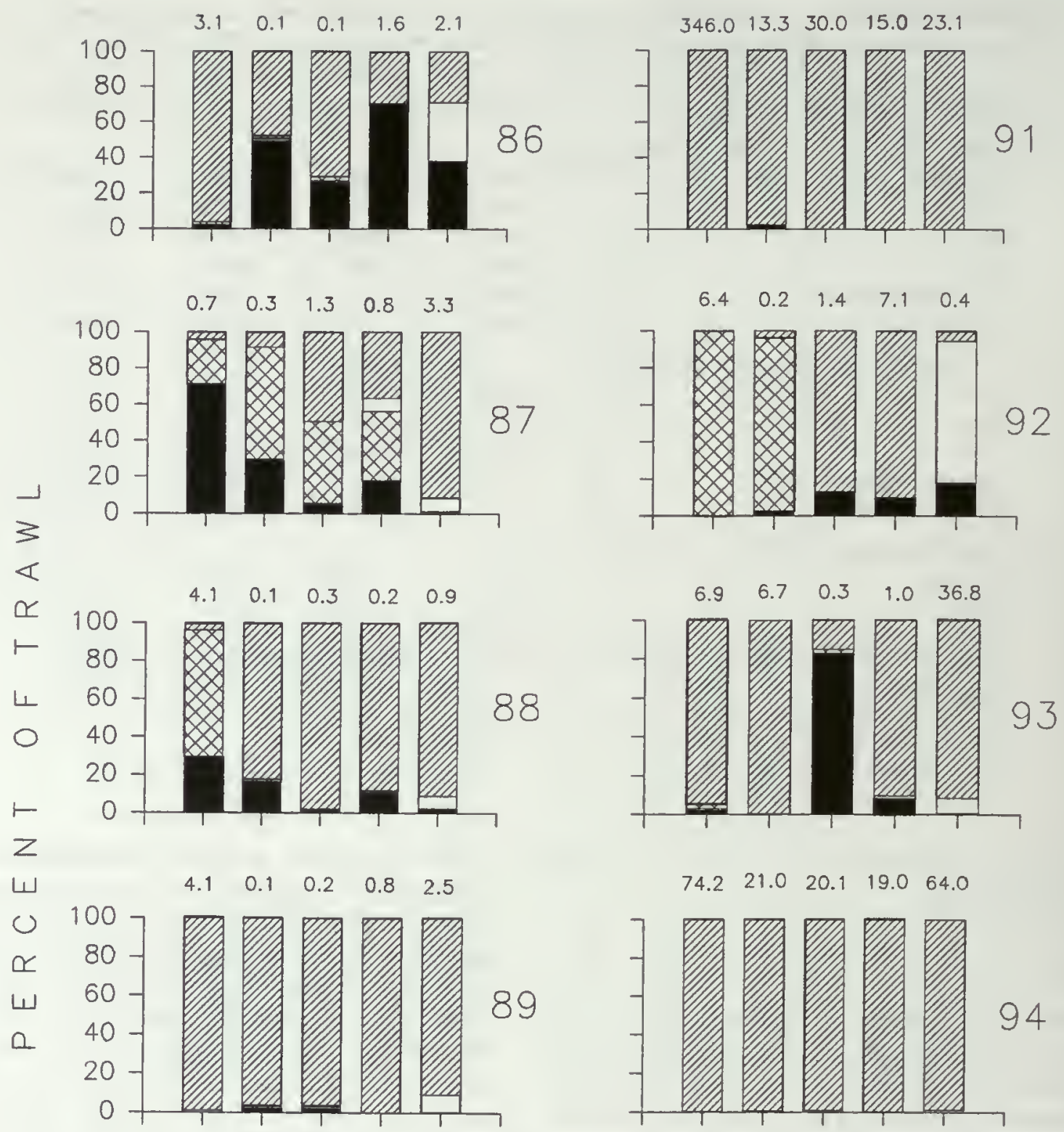

$\begin{array}{lllll}74.2 & 21.0 & 20.1 & 19.0 & 64.0\end{array}$
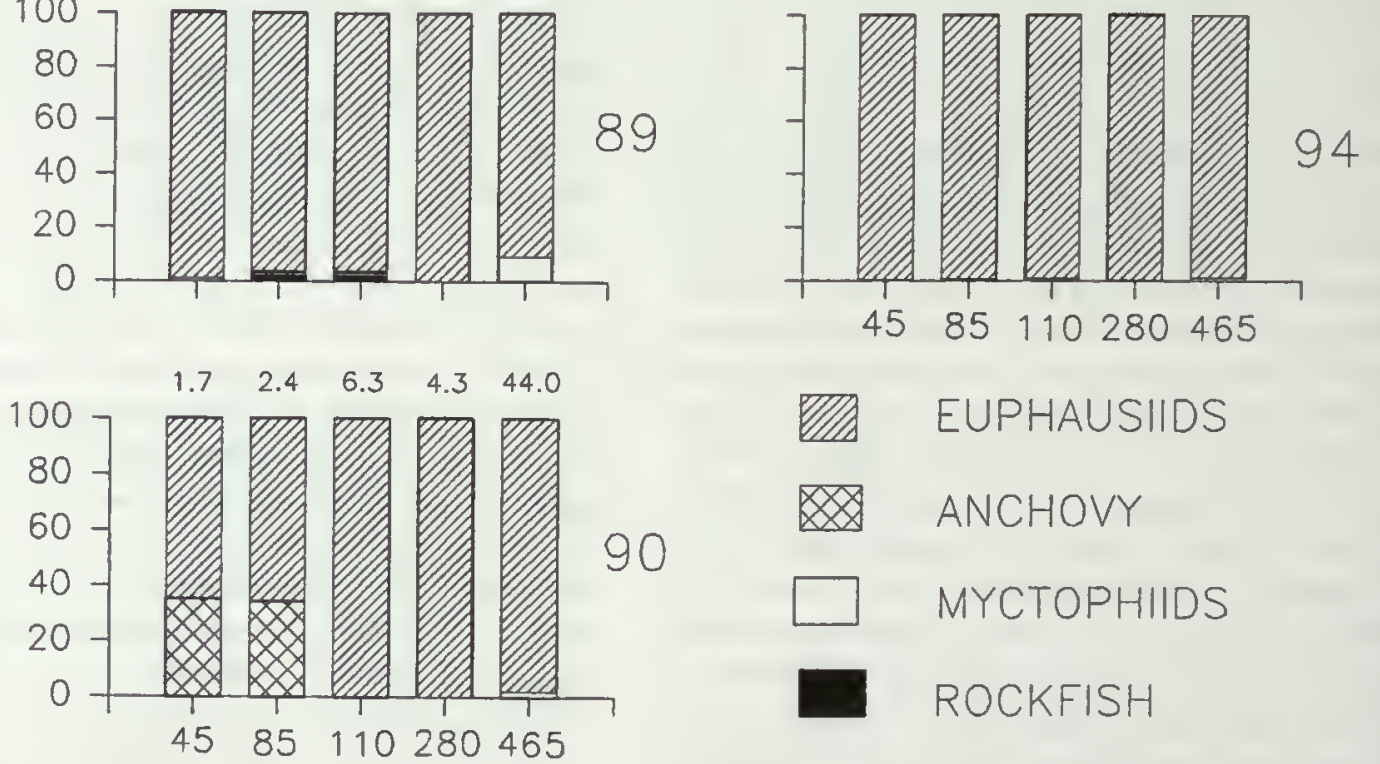

VIIA EUPHAUSIIDS

ANCHOVY

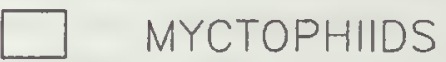

ROCKFISH

\section{EP TH}

Flgure 3-The percent composition among potential prey species collected in trawls off Pescadero (10 km north of Point Año Nuevo) and Davenport (10 km south) during early June 1986-1994 (see fig. 1A for locations of trawl sites); results of the two trawl lines were averaged by depth stratum in meters. Average number of prey items $(x 1,000)$ per trawl is listed above each depth bar. 
offshore. We believe that under these conditions, the murrelets were distributed linearly along the shore within a few hundred meters of the beach, a pattern often displayed by murrelets in some regions to the north (Briggs and others 1987; Strong and others, this volume). We would have been unable to detect these birds because the ship could not venture close enough to shore. Under these conditions, in a distributional pattern likely similar to that of March 1993, some parents would have to fly farther than others to bring food to their chicks. This explanation for the variation in murrelet numbers and distribution is hypothetical, of course. An adequately designed regional study could easily test its validity.

Among years when we saw few murrelets, ocean anomalies may have limited food supply. In particular, El Niño-Southern Oscillation conditions (deep thermocline, warm water, low ocean productivity; see review in Ainley and Boekelheide 1990) occurred during 1986 and from late spring 1992 to early spring 1994 (see fig. 1 ). The response of cther coastal alcid species to these conditions, and to winter conditions when food is also sparse, is to spread out linearly along shore where feeding opportunities are more diverse than in the open ocean (Ainley and Boekelheide 1990; Ainley, unpubl. data). At the least, the frequency of ocean anomaly in the California Current region dictates that any investigation of seabird natural history in this region should span at least a 5 -year period (Ainley and others, in press).

The negative effect of cooler sea-surface temperature (or a positive one of salinity) on murrelet distribution during late spring is consistent with the oceanography of this area and the high availability of prey. A plume of cool, salty water frequently upwells southward from Point Año Nuevo (see fig. 1), moves offshore and then curls back to the north in an anti-cyclonic eddy (Schwing and others 1991). Besides providing nutrients to this region centered on Ascension Canyon, the eddy may concentrate and maintain prey in place as alluded to above. The plume was often indicated by surface measurements of temperature, salinity, and thermocline characteristics revealed by the CTD ("conductivity and temperature with depth" probe). However, as shown by Schwing and others (1991), surface manifestations of this plume and eddy disappear rapidly, i.e. within a day, following cessation of upwelling-favorable winds. Such a rapid change in ocean characteristics in this region precludes further analysis in our study; a more directed investigation including oceanographic measurements is required.

It is possible that other murrelet populations along the West Coast also occupy small at-sea ranges in proximity to nesting areas during spring and summer. Repetitive, regional surveys are needed to identify these habitats. On the other hand, some populations apparently vary much more in the choice of waters to frequent, as indicated by temporal variation in numbers within Puget Sound (Speich and others 1992). Strong and others (1993) noted late spring and summer shifts off Oregon in murrelet clumping and hypothesized that it may be a response to the appearance of Ammodytes hexapterus, an important prey species there but rarely found in central
California. In these broader scale investigations in regions of more closely spaced nesting populations, the movements of non-breeders and adjacent breeding populations may confuse interpretation of factors affecting distribution patterns.

Many studies have found that Marbled Murrelets occur very close to shore, usually within a few hundred meters and in depths $<15 \mathrm{~m}$. Our results indirectly confirm this pattern, but also indicate that under certain circumstances, the species can occur much farther offshore. Analysis of the alongbeach surveys of the USDA Forest Service in the Año Nuevo area during the past few years (Ralph and Miller, this volume) will be helpful in further interpretation of our results. The timing of our surveys and those of the Forest Service, however, did not correspond closely (their surveys were later in the summer). On the other hand, consistent with the finding of Strachan and others (this volume), we too detected highest numbers in the vicinity of Año Nuevo during the late spring, as compared to earlier in the year.

The fact that we did see significant numbers of murrelets well offshore in some years indicates that surveys near the coast to estimate murrelet populations (Carter and others 1990a), especially in the Año Nuevo region, need to account for the possibility that significant numbers of birds may be far offshore. Either the surveys, as recommended above, need to be repeated for several years to assess spatial variability (and then choose the survey in which the murrelets are distributed most linearly alongshore), or the surveys need to include closely spaced, inshore-offshore segments that extend well off the coast (at least to $12 \mathrm{~km}$ ).

\section{Acknowledgments}

We thank the officers and crew of NOAA Ship David Starr Jordan for logistic support. Chief Scientists W. Lenarz, S. Ralston, and D. Woodbury provided substantial ship time when the prime business of the ship was finished each day. We also benefitted from their insights into fish distribution and thank them for the use of their trawl data, the derivation of which was no small task. D. Roberts crunched much of the trawl data. We also appreciate discussions with $\mathrm{C}$. Strong on murrelet biology. Several persons assisted on the cruises: C. Alexander, R. Ferris, I. Gaffney, M. LaBarr, P. Pyle, C. Strong, P. Ryan, and J. Tweedy. Our time was supported by the Point Reyes Bird Observatory, and in some years by the Gulf of the Farallons National Marine Sanctuary, National Marine Fisheries Service (Southwest Fisheries Center-Marine Mammal Division), the U.S. Fish and Wildlife Service, U.S. Department of the Interior and the Environmental Protection Agency. Data analysis was funded by EPA (a by-product of an analysis to locate a dredged material disposal site offshore of central California), and the USDA Forest Service. R. Barrett, University of Califomia, Berkeley, kindly provided GIS facilities, C.A. Ribic provided statistical consultation, and K. Briggs, G. Hunt, B. Tyler, and J. Baldwin provided helpful comments on the manuscript. This paper is contribution number 613 of Point Reyes Bird Observatory. 



\title{
Productivity of Marbled Murrelets in California from Observations of Young at Sea
}

\author{
C. John Ralph Linda L. Long'
}

Abstract: We designed and tested an intensive survey method in 1993 to identify juvenile Marbled Murrelets (Brachyramphus marmoratus) at sea. From this, we used the percent of juveniles seen in the sample as an index of productivity of murrelets along the California coast. We found 2.2 percent of the population sampled were juveniles, similar to our estimates in 1989-1992 of 3 percent from less stringent survey methods in this area. Percent of juveniles in the 1993 sample ranged from almost 6 percent in late June to none in mid-August and September. Juveniles were as often alone as in a group with 1 or 2 adults, and showed a similar distribution in distance from shore as adults. We found that some adults were molting into basic plumage as early as 21 June, with three-fourths in molt by mid-August. Therefore, during September, most birds were unidentifiable to age since most appeared to be in basic plumage unless they flapped their wings to expose molting primaries or markings on the lower breast or belly.

One of the vital components of making a demographic model of any species is a measure of that species' productivity. In the case of the Marbled Murrelet (Brachyramphus marmoratus), virtually all measures that would go into a demographic model (Beissinger, this volume) are conjecture, based upon studies of other species. Many of these species have only fleeting similarities to the life history of the Marbled Murrelet. The percent of young birds found at sea in the summer is one of many potential estimators of productivity, and is the one part of the demographic life history that could be based on actual numbers. Since murrelets are often difficult to observe closely, this quantity has previously only been estimated. We describe our efforts to put this vital parameter on a firm, quantitative foundation.

We have conducted offshore population surveys during 1989-1992 in California. During these surveys, we determined the proportion of murrelets in juvenal plumage as they occurred in late July and early August. However, the proportion of birds in juvenal plumage was exceedingly small, usually less than 3 percent. During these offshore surveys (Ralph and Miller, this volume), we made a concerted attempt to determine the age of all birds not in obvious breeding plumage.

Other investigators have found similar low proportions in recent years. During the 1992 offshore Oregon surveys, Strong and others (1993) found the proportion of juveniles to be 2.7 percent. At three points on the Oregon coast over a four

${ }^{1}$ Research Wildlife Biologist and Wildlife Biologist, respectively, Pacific Southwest Research Station, USDA Forest Service, Redwood Sciences Laboratory, 1700 Bayview Drive, Arcata, CA 95521 year span (1988-91), Nelson and Hardin (in Beissinger, this volume) found that juveniles made up 2, 4, 2, and 5 percent of the population, respectively. If these estimates of reproduction are accurate, this low rate of recruitment indicates one of three possibilities: a markedly declining population, one whose low reproduction must be offset by years of much higher production; or the species has to be extremely long-lived.

These low figures prompted a reevaluation of our methods for the 1993 breeding season. We felt that it was possible that our measure of productivity might be misidentifying some juveniles. Therefore, we designed an intensive survey method to identify juvenile birds at sea and report here on the surveys used to test the new method and to assess its accuracy.

\section{Molt Sequence}

The molt sequence has been investigated by Carter and Stein (this volume), and the information below is largely taken from their paper. The breeding plumage is dark overall, with the entire breast, belly, and sides covered with blotches of dark color, each blotch taking up about half of each feather. During the fall pre-basic molt, the back color changes from the rich brownish black to a duller grey black, but this is difficult to see in the field. Mated pairs may often stay together and molt fairly synchronously. In adults, the timing of the change into winter plumage is poorly documented. It seems generally to be underway by late July, and probably takes 6 to 8 weeks. Failed or non-breeders may molt much earlier. The pre-basic molt begins in the throat area, as the dark feathers are replaced by white, then spreads to the breast, belly, sides, and lower belly. At approximately midmolt, the first six primaries are lost almost simultaneously. This leaves the bird flightless, with a conspicuous gap in the wings, and thus distinguishable from young when the birds flap their wings. The remaining primaries are lost shortly thereafter. As the bird molts to winter plumage, the dark blotches gradually become fewer in number, but generally remain as identifiable blotches until the breast and belly become white.

Fledglings are seen on the water as early as the second week in June, but the majority will not appear until July. Fledging of young from North American nests begins in early June, reaching a plateau from early July through late August (Hamer and Nelson, this volume a). When first fledged, they resemble winter adults, dark above, and light below. However, in contrast to the clean, white breast and belly of the winter-plumaged adult, the neck and breast of the young will have a highly variable pattern of fine markings or tiny dots on the outer edge of some of the feathers. This 
forms a vermiculation pattern, in contrast to the larger blotches of the adult. As the season progresses, the markings on the edges of the feathers are lost, apparently by wear or molt. Another character for identifying young is the egg tooth, which sometimes can be seen into the fall. While this is rarely seen in the field (Carter and Stein, this volume), it has been seen from shore (Strachan, pers. comm.). Finally, fledglings can often be separated from adults by size. When first on the water, young are about 70 percent the size of an adult.

\section{Methods}

\section{Survey Method}

We conducted productivity surveys in various areas of California during 1993, near Crescent City, Trinidad, Eureka, and Santa Cruz, both at sea and from shore. Surveys began 21 June and continued until 1 October. This was the period when young were leaving the nest, continuing until large numbers of adult birds were molting into winter plumage.

Surveys at sea followed the general survey methods contained in Ralph and others (1990) for offshore surveys. We conducted both intensive and extensive surveys (Ralph and others 1992; Ralph and Miller, this volume), with additional surveys conducted at $200-\mathrm{m}$ intervals from the coastline out to $2000 \mathrm{~m}$. The boat moved as close as possible to each bird seen, giving the observer an opportunity to record data on the plumage and behavior. The time for each observation varied, depending on the ability of the observer to get an adequate view of the bird to assess the plumage, or until the bird left the area. Consideration was also given to minimizing the disturbance to the birds. For example, if a bird was observed to continually dive, apparently to avoid the boat, the observation was terminated. We often found that many of the birds were easily flushed by the boats, making it difficult to get close enough to see identifying criteria such as fine plumage markings and egg tooth of the juveniles. The driver aided in observations when possible.

Several surveys were conducted from shore using a 40power spotting scope in a few areas where murrelets occur close to shore, mostly in the Santa Cruz area. Observers scanned the ocean from sites located within $50 \mathrm{~m}$ of the water's edge and recorded the plumage of each murrelet seen. Data were recorded on all birds seen within $400 \mathrm{~m}$ of the observers.

\section{Data Taken}

The location of the bird was recorded, including the depth of the water and the distance to shore.

The information recorded for each bird enabled determination of age by both an assessment of the quality of the observation and then by close examination of the plumage information. The quality of the observation was a subjective evaluation of the ability of the observer to see the plumage of the bird, based on the light level and direction, closest distance to the bird, and what feather tracts were seen. We also recorded the length of time over which what we termed the "best view" of the bird was obtained. For example, a bird might be in view for several minutes, but the best view might only be the 20 seconds when the observer could see the breast area of the bird while it was facing into the light. The quality of the observation could well be marginal, despite a long view. Specific information used to determine the observation quality was:

(1) Total time of best viewing.-Time for the best view as determined by the information below.

(2) Light on the bird.-Determination if light from the sky was on the front, back, or side of the bird, from the observer's view.

(3) Light level on the bird.-We estimated three categories of light, relatively high, medium, or low levels. A high level would be a sunny day, while a medium level would be high overcast or bright fog. Low levels would include a dense, low overcast, very dense fog, or just at dawn or dusk.

(4) View of bird, as to either the front, side, and/or back.

(5) Distance to bird at the best view.

A description of the bird and its plumage was recorded for the entire observation, and was not limited to information gained from the time of best view. The description of the bird included:

(1) Bill details.-Bill color, and presence or absence of an egg tooth.

(2) Size of bird.-As compared to others in the group.

(3) Type of plumage.-The feather tracts of principal concern were the breast, belly, and sides. We recorded the percent area of dark color, seen as dark blotches or fine markings, versus the area that was white. The total for a feather tract would always be 100 percent. If birds stretched their wings, we noted any missing flight feathers.

Behavior was also recorded to evaluate the possibility of juvenile behavior, with an indication of numbers of birds involved in a group. Behaviors recorded were position of birds in a group, begging, feeding of another bird, and vocalizations. Other information, such as condition of primaries, was included as notes.

\section{Evaluation of Productivity Data}

We separated observations into five categories to designate the age of the birds as: definite adult, probable adult, unknown, probable juvenile, and definite juvenile. In determining the category, we subjectively considered the quality of the observation from data given by the observer during the best view of the bird, as described above, to determine if the bird should be rated as a definite, probable, or unknown plumage. For example, the bird was assigned to the category of 'probable' if the observation was of poor quality due to low light levels, distance, or view. The combination of length of best view and light levels was a critical factor. We felt that at least 15 seconds were required for a good quality observation under good light conditions, longer if the lighting was poor (e.g., low levels or back-lighting). Distance to the bird was also a 
major factor, with under 40 meters considered good under most conditions. Distances as far as $50 \mathrm{~m}$, with a longer viewing time and high light levels, were also considered good observations. Beyond $50 \mathrm{~m}$, observations were usually of poorer quality and were usually qualified as probable or unknown. Observalions from shore with a telescope were used if the bird was less than $400 \mathrm{~m}$ from the observer and other criteria above were met.

Plumage was the primary criterion used for determining the age category, since no egg teeth were seen. Any bird in breeding plumage or in the process of molting out of breeding plumage was a definite adult. Black-and-white birds with missing flight feathers were also categorized as adult. Blackand-white birds with no information on flight feathers were categorized in part by the date of observation, as during the molt period it was difficult to distinguish adults in winter plumage from juveniles. In this regard, Carter found all birds to be in alternate plumage from early May to late July (Carter and Stein, this volume). However, by late July, some adults might begin to molt if they were failed breeders, and lake possibly as little as 6 weeks to complete enough of the molt to appear black and white. Therefore, we considered any black-and-white birds seen before 15 August as juveniles. After that date, birds were not considered juveniles unless other criteria were noted. Other potential criteria for identifying juveniles were the presence of the fine breast markings, relative size, and behavior. Black-and-white birds accompanied by an adult and less than 90 percent of the size of the adult were also categorized as juveniles. There were no observations of what we would have considered juvenile behaviors, such as begging from an adult. After 15 August, all winter-plumaged birds were categorized as unknown in the absence of other identifying criteria.

\section{Results}

We attempted to determine the age of 1,174 murrelets (table 1). We successfully aged by the above criteria 1,084 birds and had only 103 birds of unknown age. Only 23 birds (2.2 percent overall) were juveniles, when the probable and definite categories were combined. If we excluded the probable observations, then the estimate of juveniles was much smaller at only 0.6 percent.

We found that juveniles occurred equally as often alone $(n=12)$ as in groups with 1 or 2 other murrelets of either adult or unknown plumages $(n=11)$ (table 2$)$. We did not find juveniles in groups with other known juveniles.

We analyzed the distribution of adults versus juveniles relative to the distance from shore, based on boat surveys alone to eliminate the bias from on-shore surveys. We found no significant difference $\left(\chi^{2}, P>0.05\right)$ in distribution out to $1600 \mathrm{~m}$ (table 3).

The percentage of juveniles by area was: Crescent City 0.6 percent ( $n=2$ juveniles), Trinidad 4.0 percent $(n=12)$, Eureka 1.1 percent $(n=3)$, and Santa Cruz 3.4 percent $(n=$ 6 ). With so few birds in juvenal plumage, we did not consider the differences between areas to be biologically significant.

We divided the 1993 study period into 10-day periods (table I). In June and early July, nearly 6 percent of the known-aged birds observed were juveniles. This percent varied through early September with 2.9 percent juveniles recorded. No juveniles were identified after mid-September. If only the data before 9 September were included (which excluded the time when juveniles were difficult to identify), the overall proportion of juveniles did not change.

The first juvenile was seen on the second survey of the study on 26 June in Crescent City. The first juveniles for

Table 1-Classification of plumages of Marbled Murrelets seen off the California coast by 10-day periods in 1993. All birds with identifiable plumages are categorized os definite or probable adult, definite or probable juvenile, or unknown age bird in basic plumage. Percentage of adults and juveniles are colculated based on the total number of known ages, while percentage of unknown ages is calculated as a percentage of all birds with identified plumages

\begin{tabular}{|c|c|c|c|c|c|c|c|c|c|c|c|c|}
\hline \multirow[b]{2}{*}{ Period } & \multicolumn{4}{|c|}{ Adult } & \multicolumn{4}{|c|}{ Juvenite } & \multirow{2}{*}{$\begin{array}{c}\text { Known age } \\
\text { total }\end{array}$} & \multicolumn{2}{|c|}{ Unknown age } & \multirow[t]{2}{*}{ Total } \\
\hline & Definite & Probable & Total & Percent & Definite & Probable & Total & Percent & & Total & Percent & \\
\hline $6 / 21-7 / 30$ & 14 & 2 & 16 & 94.1 & 0 & 1 & 1 & 5.9 & 17 & 0 & 0 & 17 \\
\hline $7 / 1-7 / 10$ & 60 & 24 & 84 & 94.4 & 1 & 4 & 5 & 5.6 & 89 & 0 & 0 & 89 \\
\hline $7 / 11-7 / 20$ & 157 & 16 & 173 & 98.3 & 2 & 1 & 3 & 1.6 & 176 & 0 & 0 & 176 \\
\hline $7 / 21-7 / 30$ & 186 & 35 & 221 & 98.3 & 1 & 3 & 4 & 1.7 & 225 & 0 & 0 & 225 \\
\hline $7 / 3 t-8 / 9$ & 4 & 7. & 51 & 96.2 & 0 & 2 & 2 & 3.8 & 53 & 0 & 0 & 53 \\
\hline $8 / 10-8 / 19$ & 150 & 6 & 156 & 100.0 & 0 & 0 & 0 & 0 & 156 & 2 & 1.3 & 158 \\
\hline $8 / 20-8 / 29$ & 55 & 11 & 66 & 98.5 & 1 & 0 & 1 & 1.5 & 67. & 3. & 4.3 & 70 \\
\hline $8 / 30-9 / 8$ & 221 & 14 & 235 & 97.5 & 1 & 6 & 7 & 2.5 & 241 & 28 & 10.4 & 269 \\
\hline $9 / 9-9 / 18$ & 42 & 13 & 55 & 100.0 & 0 & 0 & 0 & 0 & 55 & 19 & 25.7 & 74 \\
\hline $9 / 19-9 / 28$ & 2 & 0 & 2 & 100.0 & 0 & 0 & 0 & 0 & 2 & 21 & 91.3 & 23 \\
\hline $9 / 29-10 / 8$ & 0 & 2 & 2 & 100.0 & 0 & 0 & 0 & 0 & 2 & 17 & 89.5 & 19 \\
\hline Total & 931 & 130 & 1,061 & 7.8 & 6 & 17 & 23 & 2.2 & 1,084 & 90 & 7.7 & 1,174 \\
\hline
\end{tabular}


Table 2-Grouping of juveniles and adults off the coast of California in four areas. Both defininte and probable categories of age are included. Groups are broken down by number of birds in group of each age, and number of each group type ${ }^{l}$. For groups containing more than three birds, the range of group size is also shown

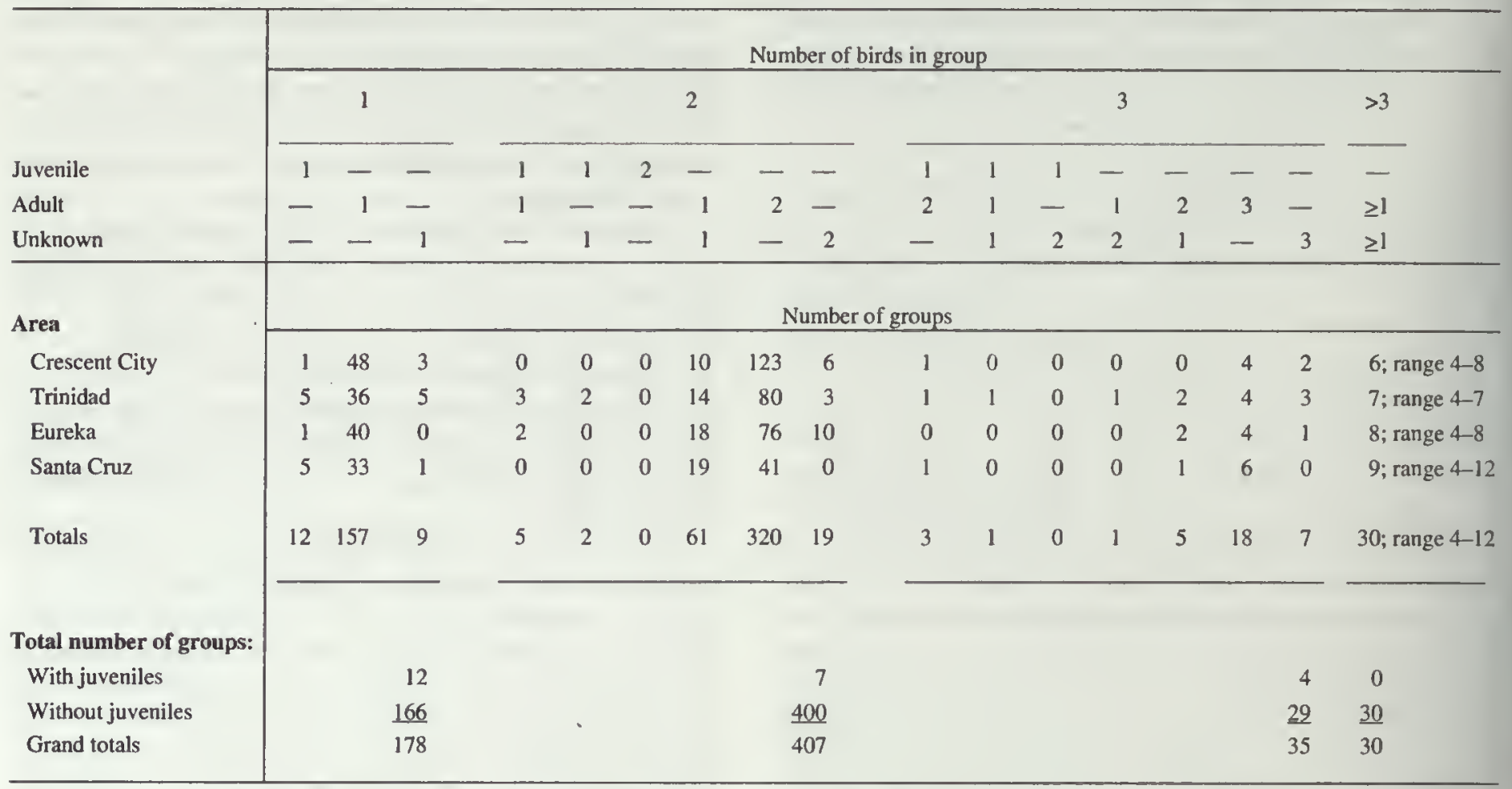

${ }^{1}$ For example, in Trinidad there were 14 groups of 2 birds, consisting of 1 adult and 1 unknown age individual, 80 groups of 2 birds consisting of 2 adults, etc.

Table 3-Distribution of adult and juvenile Marbled Murrelets according to distance from shore off the coast of California, from boat surveys only

\begin{tabular}{|c|c|c|c|c|c|}
\hline \multirow{2}{*}{$\begin{array}{l}\text { Distance } \\
\text { from shore (m) }\end{array}$} & \multicolumn{2}{|c|}{ Adults } & \multicolumn{2}{|c|}{ Juveniles } & \multirow{2}{*}{$\begin{array}{l}\text { Total } \\
\text { Number }\end{array}$} \\
\hline & Number & Percent $^{\top}$ & Number & Percent ${ }^{2}$ & \\
\hline $0-200$ & 52 & 5.7 & 3 & 15.0 & 55 \\
\hline $201-400$ & 161 & 17.7 & 4 & 20.0 & 165 \\
\hline $401-600$ & 103 & 11.3 & 2 & 10.0 & 105 \\
\hline $601-800$ & 339 & 37.2 & 5 & 25.0 & 344 \\
\hline $801-1000$ & 102 & 11.2 & 3 & 15.0 & 105 \\
\hline $1001-1200$ & 32 & 3.5 & 1 & 5.0 & 33 \\
\hline $1201-1400$ & 105 & 11.5 & 2 & 10.0 & 107 \\
\hline $1401-1600$ & 17 & 1.9 & 0 & 0.0 & 17 \\
\hline Total & 911 & & 20 & & 931 \\
\hline
\end{tabular}

'Percent of total adults

${ }^{2}$ Percent of total juveniles 
other areas were: Trinidad $18 \mathrm{July}$; Eureka $17 \mathrm{July}$; and Santa Cruz 8 July. The last two juveniles that were identifiable to age were observed on 8 September near Trinidad.

The percent of the adult population in molt, including both definite and probable categories, was fairly constant from late June until mid-August (fig. 1). A bird was considered to be in molt if there was a patch of basic plumage on its breast, side, or belly. Even at the beginning of the study period in late June, 25 percent of the 16 birds observed were molting, though in the larger sample $(n=84)$ for the next period had only 10 percent molting. However, from 11 July onward, we found no appreciable change in the proportion of molting birds until 20-29 August, when a sharp increase to 75 percent was recorded. By 9 September, 95 percent of the birds were molting.

There was also a marked increase of birds with the appearance of basic plumage (while sitting on the water), including both juveniles and molting adults, during the 9-18 September period (fig. 2). Along with the birds of unknown age in basic plumage, we included those molting adults in

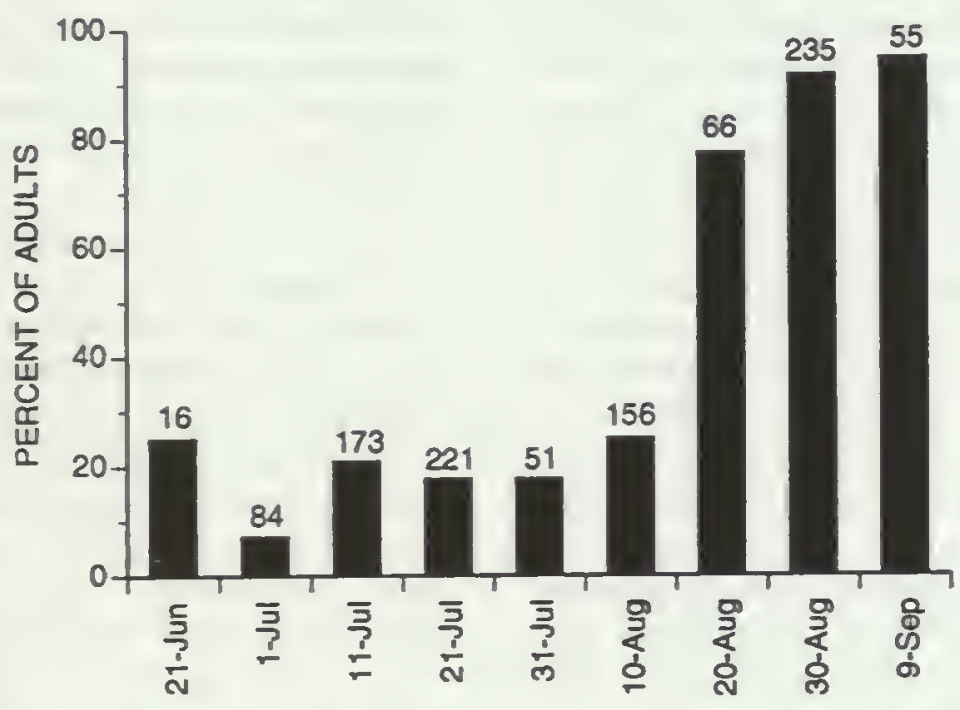

Figure 1-Percent of known adults in molt by 10-day periods. Date indicates the first day of each period. Total number of birds identified as adults (definite and probable) for each period is indicated on the top of each bar.

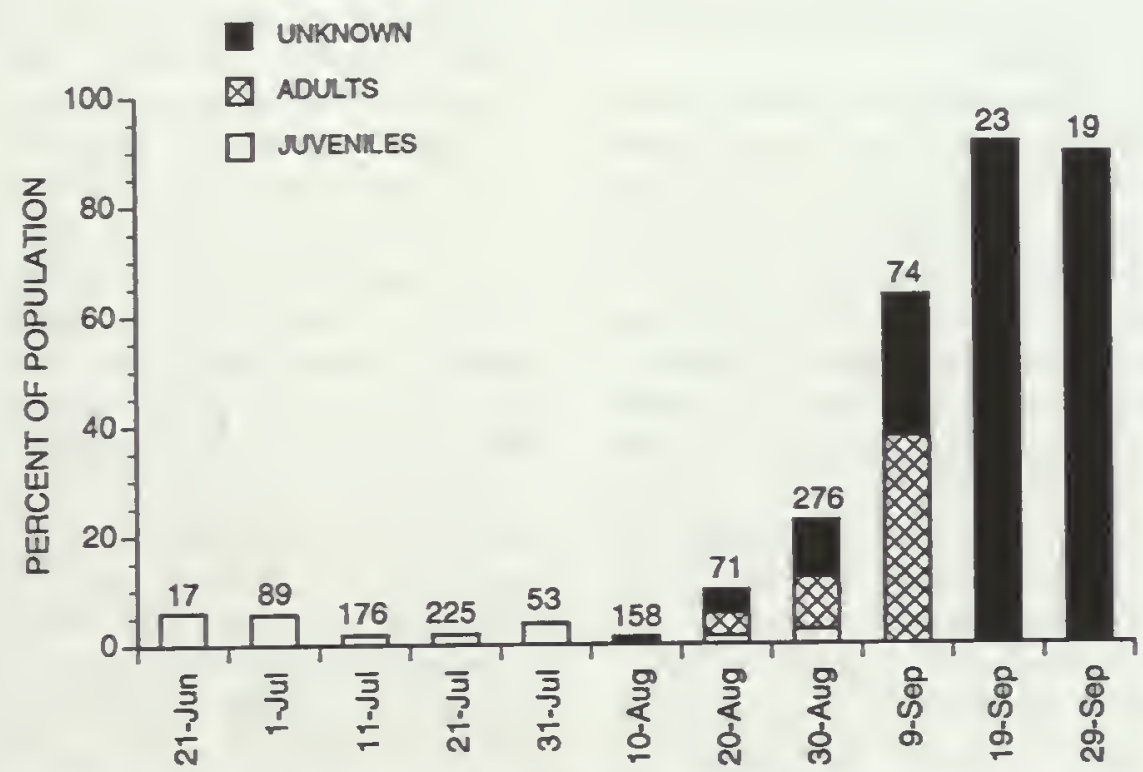

Figure 2-Percent of the total population with black-and-white plumage (both adults and juveniles) by 10 -day periods. Remaining birds are adults in altemate (breeding) plumage. Columns show percent of black-and-white birds which were juveniles, adults, and of unknown age. Definite and probable categories for juveniles and adults were combined. Date indicates the first day of each period. Total number of murrelets observed for each period is indicated on the top of each bar. 
basic-like plumage that we aged by missing primaries or molting areas on the belly, neither of which would be seen unless the bird flapped its wings. A substantial number of adults were classified as birds of unknown age during this period. Obviously, most of these were actually adults. By 19 September, 90 percent of the population was in basic or near-basic plumage.

\section{Discussion}

Our results, using more rigorous methods than previously employed, confirmed productivity estimates from California over the previous five years of under 3 percent. Such a low productivity may indicate a population with a very low reproductive rate. However, we may also be missing some of the juveniles in our surveys if they are distributed differently on the ocean than the adults. In our experience, single birds are usually more difficult to detect from boats. Varoujean (pers. comm.) found during aerial surveys that many juveniles were alone. In British Columbia, Sealy (1974) found about 64 percent of juveniles were seen alone, 20 percent were seen with adults, 14 percent were with another juvenile, and 4 percent were in a group of three or more juveniles. We also found as many juveniles alone as in groups, similar to that found by Sealy, though none were with other known juveniles as in his study. Therefore, we may have missed single juveniles.

There may also be a difference in habitat use by each age group. There is evidence that murrelets as well as other seabirds tend to be distributed in clumps at sea (Harrison 1982, Sealy 1973b). Strong and others (1993) found adult murrelets tended to switch foraging areas between July and August, perhaps in response to prey resources. They also found a patchy distribution of juveniles, with concentrations in three areas on the Oregon coast, which may have been similar to the distribution of adults.

Another aspect of habitat selection is distance from shore. Sealy (1975a) and McAllister (pers. comm.) both found juveniles congregated in nearshore kelp beds in British Columbia and Alaska, while more adults were offshore. Kaiser and others (1991) in Malaspina Inlet and Desolation Sound, British Columbia also found a similar distribution between the young and adults in early August. If there is a difference in distribution between ages in respect to distance from shore, then the use of telescopes from land for determining age ratios may skew the data towards more juveniles. In our study, we did find 35 percent of the juveniles seen from boats were within $400 \mathrm{~m}$ of the coast where they would be easily seen from shore (table 3). However, we found no difference in the distribution of juveniles versus adults relative to distance from shore, so this would not likely skew the results, at least in our data. More research on the behavioral differences of adults versus juveniles will be an integral part of estimating murrelet productivity.

The highest percentages of juveniles were found in the earliest periods of the study in June and July (6 percent). This estimate may be the most accurate, as compared to late
August, since juveniles were difficult to identify when some adults were well into the molt (Carter and Stein, this volume). By early August, about 75 percent of the birds have probably fledged (Hamer and Nelson, this volume a). Unless the primaries were seen, many black-and-white birds were classified as unknown. Thus, the decline in the percent of juveniles in late August may reflect this. The slight increase in juveniles in early September may be a result of the small sample, or indicate a second breeding attempt, as suggested by Hamer and Nelson (this volume a).

We found that some adults on the California coast started molt at least as early as 21 June (fig. 1), and by mid-August, three-fourths of the adults were in molt. This is earlier than previously reported (e.g., 20 July in British Columbia [Sealy 1975a]). If it takes about 2-3 months for the entire molt to be completed (see Carter and Stein, this volume), these birds might have been in basic plumage by late August. Indeed, about 10 percent of the sample of adults had a substantial basic plumage in the 20-29 August period (fig. 2). The remainder of the adults still retained much of their breeding plumage and were distinguishable from juveniles. Therefore, it appears that August 15 is a conservative date for considering a black-and-white plumaged bird as a juvenile. We are thus relatively confident that our identification prior to this date is accurate. This date will lead to some underestimate of juveniles, since approximately 15 percent of the juveniles have not fledged until after mid-August (Hamer and Nelson, this volume a). By late August, this has decreased to less than 5 percent.

These estimates of production, however, do not take into account the numbers of non-breeders in the population. Since there are no good estimates of proportions of nonbreeders for this bird, we must look to other species. Other small alcids do not breed until about 3 years of age. Examples are Ancient Murrelets (Synthliboramphus antiquus), and Crested (Aethia cristatella), Least (Aethia pusilla), and Cassin's (Ptychoramphus aleuticus) auklets (De Santo and Nelson, this volume; Gaston 1992) which live about 5-10 years. Thus, if we assume that they breed at 3 years, and the average life span is 7.5 years, then 2 years out of an average of 6.5 years (or $2 / 6.5=30.7$ percent) of an adult's life are spent as a non-breeder. So, almost one-third of the 1,061 adults in our sample, or 326 birds, may not be breeding, leaving only 735 breeders sampled. Also, we may assume that early in the season when the first fledglings are coming off the nest, a breeding pair that is still feeding young may sometimes not be on the water at the same time, therefore only one of a breeding pair is counted. If we make a conservative estimate that a fourth of the birds seen on the water represent one member of a nesting pair, we would add another 185 birds for a total of 920 potential adult breeding adults, or 460 pairs, of the 1,061 adults. Consequently, a revised estimate of production would be 26 chicks $/ 460$ pairs or 5.0 percent, which is still quite low.

There is a difference in the method of evaluation of plumages between our field study and Carter and Stein's (this volume) analysis of study skins. In their method, they 
used a grid placed over the skin to derive an average ratio of dark:light overall coloration. In adults, for example, this resulted in an overall ratio of 90:10 dark:light. We feel that it is more informative to break the data down by areas of the body, since different feather tracts molt at different rates (Carter and Stein, this volume).

Characterization of plumage is a very valuable tool for the murrelet biologist, and, given the limitations we discuss, a fairly accurate measure of productivity. Since it is also the only measure we have at present of productivity, we would suggest that investigators take ample data to enable them to evaluate, as we did, the quality of their observations.

Also, we would suggest that some additional data be taken, such as percentage of molt on the back of the neck (the only area of early molt possible to see if the bird is swimming away), the wing shape as pointed versus rounded or "stubby" (see Carter and Stein, this volume), and black versus rusty color on the back.

\section{Acknowledgments}

We thank Brian Cannon, David Forty, Greg Heidinger, Kimberly Hollinger, Brian O'Donnell, and Jennifer Weeks for their efforts in surveying murrelets. David Forty and John Shaw were instrumental in keeping the two boats running. Brian Cannon helped us evaluate the observations and Robin Wachs helped with analysis. We also thank Jim Baldwin, Ann Buell, George Divoky, Dave Fortna, Deborah Kristan, John Piatt, Dan Roby, Michael Rodway, Steve Speich, and Jennifer Weeks for helpful comments on this manuscript. 



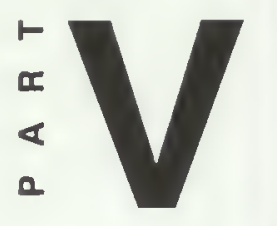

Trends and Status of Population 


\title{
Chapter 36 \\ Status of Forest Habitat of the Marbled Murrelet
}

\author{
David A. Perry'
}

Abstract: Marbled Murrelets (Brachyramphus marmoratus) have been shown to be dependant upon old-growth forests for nesting habitat. These forests have declined over the last century as they are cut for human use. This paper reviews the current status of old-growth forests along the west coast, in both the United States and Canada.

Marbled Murrelets (Brachyramphus marmoratus) are dependant upon forests for nesting habitat, particularly oldgrowth forests, as seen in several studies of murrelets along the west coasts of Washington, Oregon, and California (Grenier and Nelson, this volume; Hamer, this volume; Raphael and others, this volume; Miller and Ralph, this volume). Over the last century, the acreage of old-growth forests has declined as they are cut for human use. The impact of the loss of this habitat is discussed elsewhere in this volume (Divoky and Horton, this volume). In this paper, 1 gathered together the most current information on the acreage of old-growth forests remaining along the west coast of North America from various sources to indicate the current status of the nesting grounds of the Marbled Murrelet.

\section{Washington, Oregon, California}

Presently, the best information on area and distribution of forests that might provide suitable murrelet habitat in these states is provided by two sources: the Final Supplemental Environmental Impact Statement (FSEIS, USDA and USDI 1994) that updates the report of the Forest Ecosystem Assessment Management Team (FEMAT) (Thomas and Raphael 1993), which covers Federal lands in the three states; and unpublished data of Fox (pers. comm.), which covers the coastal redwood zone in California. Both studies used remote imagery to classify forests.

FEMAT, as updated in the FSEIS, documented the following amounts of murrelet nesting habitat on Federal lands, within the range of the species:

$\begin{array}{lr}\text { Physiographic Province } & \text { Hectares } \\ \text { Washington } & \\ \text { Olympic Peninsula: } & 246,260 \\ \text { Western lowlands: } & 0 \\ \text { Western Cascades: } & 146,945 \\ \text { Eastern Cascades: } & 2,670 \\ \text { Washington total: } & \mathbf{3 9 5 , 8 7 5}\end{array}$

${ }^{1}$ Professor of Ecosystem Studies, Forest Sciences Department, Oregon State University, Corvallis, OR 97331
Of the Washington total, 97 percent is in Late Successional Reserves, Adaptive Management Areas (AMA's), and Riparian Reserves.

$\begin{array}{lr}\begin{array}{l}\text { Physiographic Province } \\ \text { Oregon }\end{array} & \text { Hectares } \\ \text { Coast Range: } & 16,600 \\ \text { Klamath: } & 211,530 \\ \text { Western Cascades: } & 450 \\ \text { Willamette Valley: } & 240\end{array}$

Oregon total:

228,820

Of the Oregon total, 88 percent is in Late Successional Reserves, AMA's, and Riparian Reserves.

Physiographic Province Hectares
California

FEMAT amounts

Klamath: $\quad 238,800$

Cascades: $\quad C$

Coast Range: (included in Fox's estimates below)

California Coast Range (Fox, pers. comm.)

Redwood National Park: $\quad \quad 7,930$

State Parks (within the boundaries of Redwood NP): $\quad 10,100$

Other Ownerships: $\quad \quad 74,940$

Total:

92,970

\section{California total:}

331,770

Of the habitat in the Klamath province, 89 percent is in Late Successional Reserves, AMA's, and Riparian Reserves. Fox's unpublished data (pers. comm.) include both public and private lands. He classified old-growth as areas with at least 10 percent cover of trees greater than 24 in. $(60 \mathrm{~cm})$ d.b.h. This comprised 10.6 percent of total forest cover within Fox's study area. Of the area recorded by Fox, 18,030 ha are located in Redwood NP and State Parks (Hofstra, pers. comm.).

Three State Total

Federal Lands:

$1,036,625$

State Parks in California Coast Range: $\quad 10,120$

Private Lands in California Coast Range: $\quad \mathbf{7 4 , 9 2 0}$

If Alternative 9 is implemented as described in the Final Supplemental EIS (USDA and others 1994), about 89 percent of current murrelet habitat on federal lands will be protected within Late Successional Reserves, Riparian Reserves, and Congressionally Reserved Areas. Of the remaining habitat 
with the matrix and AMA's (116,100 hectares), all suitable habitat contiguous with occupied sites will be protected from timber cutting, at least until final recommendations of the Marbled Murrelet Recovery Plan are in place. The FSEIS shows the extent of protection within each physiographic province in these three states.

At least two caveats go with these estimates. First, estimates are largely based on interpretations of satellite imagery that have not been thoroughly ground-truthed. Second, the estimates refer to quantity of habitat, not quality. Depending on proximity to the coast, landscape context, and size, a given stand may or may not provide quality murrelet habitat ("quality" habitat, as defined here, meets basic nesting requirements, provides refuge from predators, and is relatively stable against catastrophic disturbances). At this time, it is not possible to estimate the proportion of remaining habitat that could be considered of high enough quality to allow long-term nesting success.

FEMAT documents only Marbled Murrelet habitat on Federal lands. Very little murrelet habitat remains on private lands in Washington and Oregon. Some habitat exists on State lands, particularly on the Tillamook and Elliot State Forests in Oregon, which comprise areas burned over by wildfires in the early part of the century (see Raphael and others [this volume] for estimates of habitat on state lands in Washington). Murrelets are using these areas to some degree, however it is not possible at present to quantify amounts of suitable murrelet habitat on Oregon State Forest lands. The greatest value of these lands for murrelet conservation may be in providing habitat over the next several decades, while the large areas of young forests within Late Successional Old-Growth reserves delineated in Alternative 9 of the U.S. Administration plan for Spotted Owl habitat are maturing.

Significant amounts of habitat remain on private lands along the California coast. Unlike FEMAT estimates, however, Fox's estimates for the California Coast Range include all land ownerships.

\section{Historic Habitat}

The area of potential murrelet habitat has been significantly reduced in Washington, Oregon, and California during the 20th century. The first comprehensive survey of forests in western Oregon and Washington was conducted in the mid-1930s (Andrews and Cowlin 1940). At that time, old-growth Douglas-fir (Pseudotsuga menziesii), Sitka spruce (Picea sitchensis), and western hemlock (Tsuga heterophylla) covered 459,700 hectares in the Oregon Coast Range, and $1,314,650$ hectares on the Olympic Peninsula and the Puget Sound region of Washington (generally within 60 miles [about $100 \mathrm{~km}$ ] of Puget Sound). Old-growth Douglas-fir had been heavily logged prior to that inventory, especially in western Washington. Andrews and Cowlin (1940) report that "Puget Sound... was formerly surrounded by magnificent forests of old-growth Douglas-fir and western red cedar (Thuja plicata). Ease of logging and transportation attracted lumbermen to lands bordering the sound as early as the middle of the nineteenth century. Grays Harbor and Willapa Bay, on the coast of western Washington, offered almost equally attractive opportunities for forest exploitation. Practically all the old-growth Douglas-fir forests of western Washington were within 30 to 40 miles $(50-65 \mathrm{~km})$ of navigable waterways. Now western Washington, particularly in the vicinity of Puget Sound and Grays Harbor, is characterized by vast expanses of cut-over land largely barren of conifer growth".

Old-growth harvest continued at a high rate following the 1930s survey, especially on private lands, but increasingly on public lands as well. In 1958, a period of relatively low production, 2 billion board feet (International 1/4 in. rule) $\left(4.7\right.$ million $\left.\mathrm{m}^{3}\right)$ were harvested from private lands in western Washington, two-thirds of which was old-growth (Wall 1972). By 1970 , annual harvest from private lands had nearly doubled to 3.8 billion board feet $\left(9.0\right.$ million $\left.\mathrm{m}^{3}\right), 80$ percent of which was old-growth. At the same time, harvest from public lands in western Washington was accelerating, increasing from about 0.5 billion board feet $\left(1.2\right.$ million $\left.\mathrm{m}^{3}\right)$ in 1949 to 2 billion board feet $\left(4.7\right.$ million $\left.\mathrm{m}^{3}\right)$ in 1970 . Most or all of this was probably old-growth, although I do not have data to give exact figures.

While the situation in Oregon was somewhat different than in Washington, the basic results were the same--the amount of old-growth has been reduced. Large wildfires burned in the Oregon Coast Range in the mid-1800s and early 1900 s; consequently historic old-growth in that region was less extensive than in western Washington. Teensma and others (1991) estimate that 200-year and older stands comprised from 40 to 50 percent of Coast Range forests between 1850 and 1920, and declined to 20 percent in 1940 , following large fires in the Tillamook area. If we include stands between 100 and 200 years old, some of which are likely to provide suitable murrelet habitat, stands that are potential murrelet habitat increases the proportion to between 50 percent (1940) and 70 percent (1920) of total forest area in the Oregon Coast Range. The 1930s survey documented 581,950 hectares of old-growth Douglas-fir, western hemlock and Sitka spruce in the Coast Range, and an additional 307,550 hectares of "large second growth"90 - to 160 -year-old stands growing on old burns, with trees approaching the size of old-growth. At the time of the 1930 s survey between 228,600 and 364,000 hectares had been cut over in the Oregon Coast Range, most or all from old-growth. These values indicate that, prior to logging, 1 to 1.5 million hectares of suitable murrelet habitat existed in the Oregon Coast Range. This may be compared to the current 178,500 hectares identified by FEMAT and the FSEIS on Federal lands in the Coast Range. Except for uncertain amounts of habitat on the two State forests mentioned above, virtually all remaining habitat in the Oregon Coast Range is on Federal lands.

In California, a large proportion of forests within nesting radius of the coast are privately owned. Once dominated by old-growth redwood, these forests have been heavily cut over. 


\section{Alaska}

Approximately $50-60$ percent of forests suitable for murrelet nesting occurs on two National Forests (Tongass and Chugach), with the balance on State lands and lands held by various Native Corporations (Iverson, pers. comm.). At this time I have data only for the National Forests.

\section{Tongass National Forest}

It is estimated that on the Tongass National Forest the original old-growth, classified as "productive" stands (i.e., stands with volumes estimated to be greater than 8,000 board feet per acre), was approximately 5,600,000 acres. These stands were composed primarily of western bemlock, Sitka spruce, and mountain hemlock (USDA Forest Service, Alaska Region, 1991). A subset of the productive stands has been classified as "highly productive", with volumes greater than 30,000 board feet per acre. On the Tongass National Forest, the original acreage of this subset consisted of about 933,000 acres. These stands have larger diameter trees, and thus probably more and larger lateral branches. More of these attributes would provide proportionally more high-quality murrelet nesting sites (Hamer and Nelson, this volume b). However, very few data are available on murrelet abundances and nesting habitat characteristics in southeast Alaska. At this time there is no direct evidence that highly productive stands are used to greater degree than those classified as productive in southeast Alaska. The results of Kuletz and others (in press, this volume) in Prince William Sound, Alaska, and Burger (this volume) in British Columbia do, however, indicate that high-density old-growth has characteristics associated with high murrelet use.
Since large scale commercial timber harvest began in the mid-1950's, harvest has largely occurred within the highly productive component. Approximately 350,000 acres of old-growth forest have been harvested through 1990 (USDA Forest Service, Alaska Region, 1991). Additional harvest from 1990 through 1994 has totaled 41,800 acres (M. Wilson, pers. comm.). Thus, an estimated 93 percent of the productive old-growth forests on the Tongass National Forest remains. However, only an estimated 58 percent of the highly productive forest remains. Indications are that forests in southeast Alaska held by Native corporations have and will continue to be extensively logged (C. Iverson, pers. comm.).

\section{Chugach National Forest}

Although a high proportion of productive forest lands on the Chugach National Forest is probably suitable nesting habitat (classed as mature and overmature timber), this represents a total area of only 101,200 hectares (USFS undated).

\section{British Columbia}

Data for British Columbia is being compiled and is not yet available. According to Beebe (1990), "preliminary estimates are that only 17 of the 124 coastal temperate rainforests of more than 20,000 hectares remain unlogged. On Vancouver Island, just six of 89 coastal watersheds of more than 5000 hectares remain unlogged." Though illustrative, these estimates are minimally useful as they give no information on watershed size or the extent of logging within logged watersheds. Beebe (1990) goes on to estimate that "perhaps 30 percent" of the original coastal forest remains in British Columbia. 



\section{Population Trends of the Marbled Murrelet Projected From Demographic Analyses}

\section{Steven R. Beissinger ${ }^{1}$}

Abstract: A demograpbic model of the Marbled Murrelet is developed to explore likely population trends and factors influencing them. The model was structured to use field data on juvenile ratios, collected near the end of the breeding season and corrected for date of census, to estimate fecundity. Survivorship was estimated for the murrelet based on comparative analyses of allometric relationships from 10 species of alcids. Juvenile ratios were generally low, and were higher for counts made from shore or in kelp beds (typically 10 percent) than conducted offshore ( $<5$ percent). Annual survivorship was strongly related to body size in alcids. Survival for the Marbled Murrelet was predicted to be 0.845 and range to 0.90. Lambda, the expected annual growth rate of the population, was estimated for likely combinations of fecundity and survival, and indicated that under all combinations murrelet populations are expected to be declining. Based on the best data, rates of decline are predicted to be 4-6 percent per year, but the rate of decline could conceivably be twice as large. Studies in Alaska and British Columbia suggest population declines at 3-5 percent per year, supporting model predictions. Results are discussed in relation to the factors affecting murrelet population growth, and the use of juvenile ratios for monitoring murrelet populations.

Recovering a threatened or endangered species depends on determining its rate of population change and correcting the factors that limit population growth. Despite the important information on the biology and life history of the Marbled Murrelet (Brachyramphus marmoratus) that has been brought together in this volume, population trends for the murrelet remain elusive because little long term data are available. Christmas bird counts from five sites in Alaska found a 50 percent decline in the population over a 20 year period (Piatt and Naslund, this volume). Murrelet censuses conducted in Clayoquot Sound, British Columbia 10 years apart found a 40 percent decline in the population (Kelson and others, in press). Comparison of historic and current data suggests that the murrelet has disappeared or become very rare in large portions of its nesting range in California, Oregon, and Washington (Carter and Morrison 1992). But current population trends in the Pacific Northwest remain unknown.

Demographic modeling can give indications of likely population trends and play an important role in the conservation of the Marbled Murrelet. Simple demographic models based on estimates of annual survival and fecundity can be used to determine the rate of decline or increase of a species. They can also help focus attention on critical demographic information that needs to be gathered for future studies. Sensitivity analyses, where demographic values are altered to see the effect on

${ }^{1}$ Associate Professor of Ecology and Conservalion, School of Forestry and Environmental Studies, Yale Universily, New Haven, CT 06511 population growth, can indicate which components of the life history are most likely to affect population growth and where the potential for management may be greatest.

Unfortunately, only a little is known about the demography of the murrelet. There are no estimates of survivorship for birds of any age. Reproduction is slightly better understood. Clutch size is known to be one egg, and a substantial proportion of nests are known to fail (Nelson and Hamer, this volume b). However, neither the age of first breeding nor the proportion of adults that breed is known. The ratio of young-of-the-year (hereafter juveniles) to after-hatch-year birds (subadults and adults) has been monitored at-sea and is often very low (e.g., Ralph and Long, this volume).

This paper represents an initial attempt to model the demography of the Marbled Murrelet to explore likely population trends. Although few data are available, there is enough reproductive information from murrelets to use, in conjunction with predictions of survivorship derived from analyses of past studies of alcids, to yield crude estimates of the rate and direction of change of the murrelet population.

\section{Model Structure}

The model was structured to take advantage of the one population parameter that could be best estimated from field data - fecundity. In the absence of detailed data, the simplest way to model the murrelet population is based on three life stages: adults (birds that are breeding age or older), subadults (birds that are greater than one year old but younger than the age of first breeding) and juveniles (fledged young that have reached the ocean but have not yet survived their first year of life). The latter stage takes particular advantage of one of two estimates of productivity available from field data namely the ratio of young to after-hatch-year birds surveyed at sea. The virtue of this scheme - simplicity - is also its weakness. Undoubtedly there may be age variation among the demographic rates of murrelets, as there is with other seabirds (Hudson 1985, Nur 1993, Wooller and others 1992). But without any speciftc information on the age structure of vital rates, assigning age structure to them would be arbitrary. For the moment, simplicity has its virtue.

The simplified population life cycle given in figure 1 is based on post-breeding season censuses with a projection interval of one year (Caswell 1989, Noon and Sauer 1992) and is typical for long-lived monogamous birds (McDonald and Caswell 1993). The flow of events is (1) censuses are conducted at the end of the breeding season, (2) birds must then survive to the next breeding season, (3) all individuals are aged one year, (4) surviving adults then breed, and (5) post-breeding censuses are conducted again. Circles or nodes 


\section{Simplified Marbled Murrelet Demographic Stage Life Cycle}

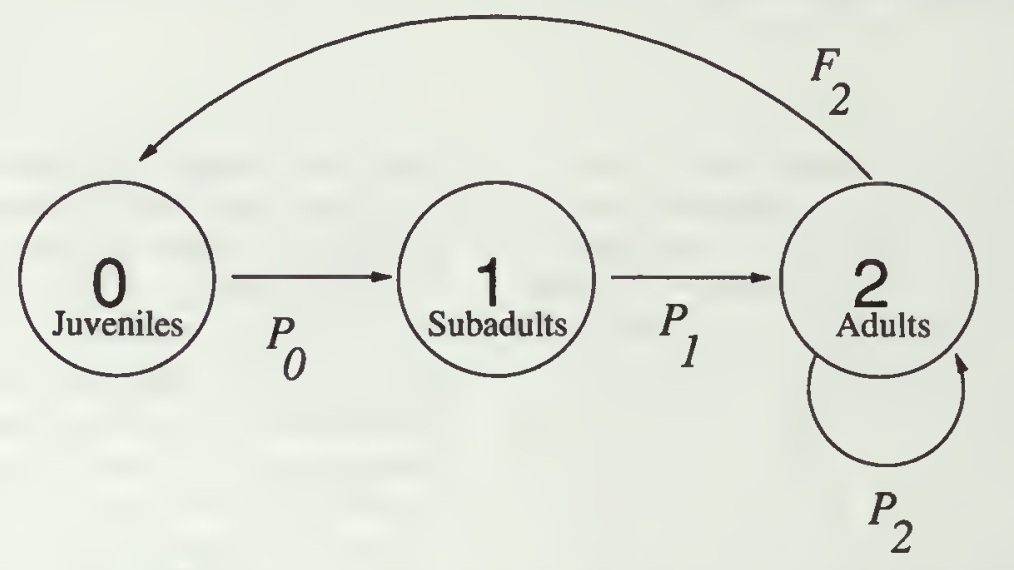

Figure 1-A simplified life cycle diagram for the Marbled Murrelet used in developing predictions of demographic trends: $P_{0}=$ Probablity of annual survival for fledglings that have reached the oceans; $P_{1}=$ Probablity of annual survival for subadults; $P_{2}=$ Probablity of annual survival for adults; and $F_{2}=$ annual fecundity, i.e., the number of young reaching the ocean per pair.

(Caswell 1989, McDonald and Caswell 1993) represent the stage classes: juveniles ( 0 ), subadults (1), and adults (2). $P_{0}$ is the probability of annual survival for fledglings that have reached the ocean. $P_{1}$ is the annual survivorship of subadults. Note that this stage may take several years for birds to mature and additional nodes would need to be added for each year that the age of first breeding exceeded 2 years old. The annual rate of adult survival is given by $\mathrm{P}_{2}$. By definition, only adults breed and their average annual fecundity (i.e., the number of young reaching the ocean per pair) is given by $F_{2}$.

I explored only the simplest deterministic version of the model because no data yet exist on the magnitude of fluctuations of demographic characteristics from year to year. The model assumed: (1) survivorship and fecundity would change little from year to year; (2) populations were near a stable age structure; (3) a 1:1 sex ratio, supported by Sealy (1975a); (4) no density dependence; and (5) no senescence occurs and adult birds have no maximum life span. Such assumptions, although sometimes violated to varying extents in real populations, are typical for models of this nature (Lande 1988, Noon and Biles 1990). Usually such models are constructed only for females, since it is often difficult to know much about male fecundity. Thus, all rates needed for figure 1 were expressed on a per female basis. Since there are little data available for murrelets, the model was evaluated for a range of feasible demographic values.

\section{Methods}

Survivorship estimates were derived from the literature, because there have been no studies of individually-marked murrelets. A comparative analysis of survivorship of auks was conducted by Nadav Nur (1993). Allometric relationships and multiple regression models between body size (32-8000 $\mathrm{g})$, reproductive rate (which is clutch size [1-2 eggs] times brood number [ $1-2$ broods per year]), and annual survival were developed for 10 species of Alcidae. Estimates of annual survival for adult murrelets were then made assuming an adult body size of $222 \mathrm{~g}$ (Sealy 1975a) and a clutch size of 1 egg. Estimates of annual survival for juveniles and subadults were assumed to be proportional to adult survival as revealed from the literature survey of other seabird species.

Fecundity values indicate the average number of female young produced annually by a female that has reached or exceeded the age of first breeding. The only murrelet demographic data that I have found pertains to the reproductive potential of the species: ratios of juveniles to after-hatch-year birds (adults and subadults) in the ocean (hereafter called the "juvenile ratio"), and an estimate of nesting success (the number of young produced per nesting pair). Information on nesting success was derived from Nelson and Hamer (this volume b).

Arguably the best data on reproductive potential are ratios of juveniles from at-sea surveys. If measured at the end of the breeding season, these ratios act like a "snapshot" census of recruitment rates because they implicitly incorporate all of the parameters needed to estimate fecundity: clutch size, the proportion of nests fledging young, the proportion of birds nesting, the number of nesting attempts per year, and the survivorship of fledglings to the sea until the time of census. Because this "snapshot" is taken immediately near the end of the breeding season, a 
post-breeding population model was used. Similar ratios have been used to examine population trends in a variety of other wildlife studies (Hanson 1963, Lambeck 1990, Paulik and Robson 1969, Roseberry 1974).

At-sea surveys should be conducted before subadults and adults begin to molt into winter plumage and become difficult to distinguish from young-of-the-year (Carter and Stein, this volume). In most years, molting adults and subadults are first detected in mid- to late August (Carter and Stein, this volume; Ralph and Long, this volume). Therefore, I used survey data collected on or before 16 August, and pooled results for two week periods to yield reliable sample sizes. However, fledging of young can occasionally occur until late September (Hamer and Nelson, this volume a). When the atsea surveys were conducted, it is likely that some young had not yet fledged (and thus would not be detected), but most adults were censused since they were in the ocean gathering fnod to feed young. Therefore, this ratio will tend to underestimate recruitment. To correct for this problem, I used the cumulative frequency distribution for estimates of "known" fledging dates for all nests or young found throughout the range (Hamer and Nelson, this volume a). From this distribution, 1 determined what proportion of young would have fledged by the end-point of the census date and then adjusted the juvenile ratio upwards by this factor.

There is one problem with using juvenile ratios to estimate fecundity. Fecundity is the number of female young per adult female produced annually. But during the censuses, subadults can not be distinguished from adults that are capable of breeding. Therefore, just using the ratio of juveniles to afterhatch-year birds from the censuses will tend to underestimate fecundity because the proportion of adults will be overestimated. This can be seen by conducting a deterministic projection of a population for 25 years and looking at the proportion of the population that fledglings comprise. Just using the value from the ratio usually results in a lower ratio of young-of-the-year birds to older birds than expected. Fortunately, the ratio can be corrected by increasing it incrementally until the population projection yields the proper starting ratio of juveniles to older birds.

Alcids typically exhibit delayed ages of first breeding (Croxall and Gaston 1988, Hudson 1985). One of the earliest recorded ages of first breeding is for Cassin's Auklet (Ptychoramphus aleuticus) where some birds begin at 2 years but most start at 3 years of age (Croxall and Gaston 1988). Hudson (1985) estimated 5 years in general for Atlantic alcids. The age of first breeding of individuals, however, ranged between 3 and 15 years (Harris and others 1994). Given its small body size, it is unlikely that the murrelet would require 5 years to reach sexual maturity, although it could require longer to obtain a nest site if sites were limiting. On the other hand, nest sites were probably much more abundant historically than they are today as a result of deforestation. Thus, in comparison to most other seabirds, which nest colonially on islands where obtaining a breeding site can sometimes be difficult (Hudson 1985), it seems likely that the Marbled Murrelet would bave a young, rather than old, age of first breeding. I suspect that an age of first breeding would be 3 years, but explored ages from 2 to 5 in the model.

Once demographic traits were selected, values were used to calculate lambda (the expected annual growth rate of the population) and the stable stage distribution. Populations decline when lambda is less than 1 and increase when lambda exceeds 1 . The stable stage distribution is the proportion of the total population that is comprised of each stage class and can be used to yield an expected juvenile ratio. Lambda and the proportion of juveniles in the stable age distribution were calculated: (1) analytically by constructing Leslie matrices and solving for the dominant eigenvalue and right eigenvector (Caswell 1989) using MATLAB (1992); and (2) numerically using spreadsheets to project population changes over 25 years (Burgman and others 1993). I used these same methods to explore what levels of adult survival and fecundity are required to yield estimates of lambda equal to 1 for different ages of first breeding and the juvenile ratios that these combinations would produce. A sensitivity analysis was conducted by determining the partial derivative of lambda with respect to each element in the Leslie matrix (Caswell 1989, McDonald and Caswell 1993).

\section{Results}

\section{Estimating Fecundity}

Reproduction in the marbled murrelet appears to be highly asynchronous. The cumulative frequency distribution for estimated dates of fledging throughout the range of the murrelet shows a regular increase during the breeding season (fig. 2). Fledging has occurred as early as the first week in June and very rarely as late as September, although 94 percent of the nests had fledged by the end of August. Fledging finished by the end of August in Alaska, British Columbia, and Washington, but in Oregon and California, it extended into September (see fig. 3 in Hamer and Nelson, this volume a). A linear model fit the data well, especially through the middle portions of the range of fledging dates (fig. 2). This model was used to estimate the cumulative proportion of nests that had fledged to adjust juvenile ratios for differences in the date of surveys.

Table 1 summarizes the ratio of juveniles for different localities, survey periods, and years for surveys made from shore or from a boat cruising only through kelp beds, which juveniles appear to frequent preferentially (Sealy 1975a). Similar data are shown for the juvenile ratio from boat surveys at sea (table 2). Several trends are evident. First, the proportion of juveniles encountered was much greater near shore ( $<800 \mathrm{~m}$ from shore) and on kelp bed surveys (iable 1 ), than on boat surveys (table 2 ) of near shore (500-800 m) and distant waters (from $1400 \mathrm{~m}$ up to $5 \mathrm{~km}$ off shore in some cases). All at-sea surveys had adjusted ratios of juveniles of less than 5 percent, while onshore surveys typically had adjusted ratios of 9-16 percent juveniles. Juveniles were 


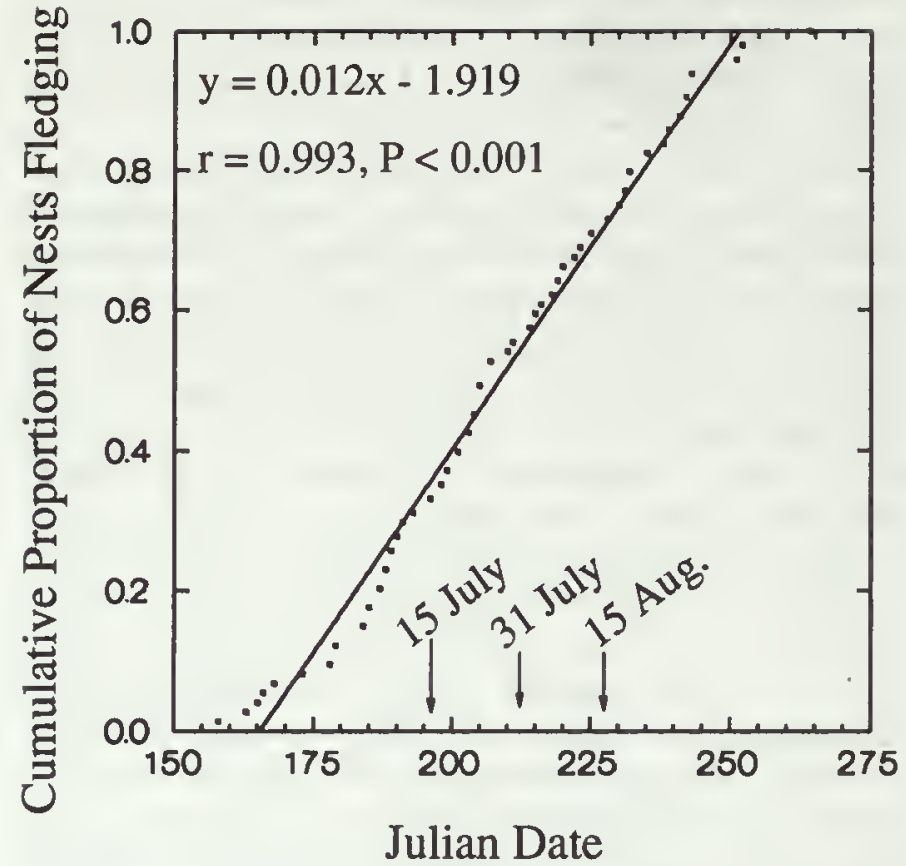

Figure 2-The cumulative probability distribution function for fledging dates of 74 Marbled Murrelel nests. Results of a linear regression of Julian dale $(x)$ on the cumulative proportion of nesis that fledged $(y)$ was fit to data and are given. No probability value can be calculated for the regression because cumulative fledging values are not independent. Data are from Hamer and Nelson (this volume a). Dates shown refer to the end point of censuses used to adjust the juvenile ratio. rarely seen beyond $1 \mathrm{~km}$ offshore, whereas adults have frequently been seen up $3 \mathrm{~km}$ off shore and were still encountered up to $5 \mathrm{~km}$ (Ralph and Miller, this volume; Strong, pers. comm.). A good example of this effect is from studies in Clayoquot Sound, British Columbia (tables $I$ and 2 ). Surveys through kelp beds where juveniles were known to forage found juvenile ratios 3-4 times greater than total area counts (surveys of all individuals in the sound). Thus, it seems likely that onshore surveys will overestimate the juvenile ratio, and at-sea surveys will underestimate them unless the at-sea surveys include some transects close to shore or through kelp beds.

Second, the juvenile ratio increased during the breeding season in every case at locations with repeated surveys (tables 1 and 2). This would be expected if nests in a population were asynchronously fledging young (fig. 2), and juveniles, subadults and adults remained in the general vicinity so that populations were being surveyed. The universal increase in juvenile ralios during the breeding season indicales that juvenile ratios may be useful tools for tracking productivity of a population. Third, sequential surveys often yielded similar juvenile ratios after the percentage of juveniles observed was adjusted for different survey dates using the linear model in figure 2. The closest values generally occurred for surveys conducted in late July and early August (tables 1 and 2). These adjusted ralios differed by about 3 percent or less, in 6 out of 7 instances. Thus, juvenile ratios appear to be sensitive to seasonal change, yet provide repeatable measures for fecundity estimates.

Table 1-Surveys of the ratios of juveniles to after-hatch-year birds (adults and subadults) for Marbled Murrelets conducted during the breeding season along shorelines or from boats cruising only along kelp beds. The percentage of juveniles (Pct. juv.) was adjusted for the timing of the survey (survey period) by using the cumulative frequency of fledging dates (fig. 2) to estimate an adjusted percentage of juveniles (Adj. pct. juv.) for the end of the nesting season

\begin{tabular}{|c|c|c|c|c|c|c|}
\hline \multirow[t]{2}{*}{ Region } & \multirow[t]{2}{*}{ Year } & \multirow{2}{*}{$\begin{array}{l}\text { Survey } \\
\text { period }\end{array}$} & \multirow[t]{2}{*}{$n$} & \multicolumn{2}{|c|}{ Survey results } & \multirow[b]{2}{*}{ Source } \\
\hline & & & & Pct. juv. & Adj.pct. juv. & \\
\hline \multirow[t]{2}{*}{ British Columbia } & \multirow[t]{2}{*}{1993} & 1-15 July & 206 & 7.3 & 16.9 & \multirow{2}{*}{$\begin{array}{l}\text { Manley and Kelson } \\
\text { (pers. comm.) }\end{array}$} \\
\hline & & 16-31 July & 157 & 8.9 & 14.2 & \\
\hline \multirow[t]{10}{*}{ Central Oregon } & 1988 & 16-31 July & 107 & 2.8 & 4.5 & \multirow{10}{*}{$\begin{array}{l}\text { Nelson } \\
\text { (pers. comm.). }\end{array}$} \\
\hline & & 1-15 Aug. & 90 & 7.8 & 9.7 & \\
\hline & \multirow[t]{2}{*}{1989} & 16-31 July & 112 & 5.4 & 8.6 & \\
\hline & & 1-15 Aug. & 101 & 7.9 & 9.8 & \\
\hline & \multirow[t]{3}{*}{1990} & 1-15 July & 555 & 0.4 & 0.9 & \\
\hline & & 16-31 July & 200 & 7.0 & 11.2 & \\
\hline & & 1-15 Aug. & 58 & 8.6 & 10.6 & \\
\hline & \multirow[t]{3}{*}{1991} & 1-15 July & 391 & 1.3 & 3.0 & \\
\hline & & 16-31 July & 486 & 9.9 & 15.8 & \\
\hline & & 1-15 Aug. & 319 & 11.6 & 14.4 & \\
\hline
\end{tabular}


Table 2-Surveys of the ratios of juveniles to after-hatch-year birds (adults and subadults) for Marbled Murrelets during the breeding season conducted from boats cruising at a variety of distances from shore. The percentage of juveniles (Pct. juv.) was adjusted for the timing of the survey (survey period) by using the cumulative frequency of fledging dates (fig. 2) to estimate an adjusted percentage of juveniles (Adj. pct. juv.) for the end of the nesting season

\begin{tabular}{|c|c|c|c|c|c|c|}
\hline \multirow[t]{2}{*}{ Region } & \multirow[t]{2}{*}{ Year } & \multirow{2}{*}{$\begin{array}{l}\text { Survey } \\
\text { period }\end{array}$} & \multirow[t]{2}{*}{$n$} & \multicolumn{2}{|c|}{ Survey results } & \multirow[b]{2}{*}{ Source } \\
\hline & & & & Pct. juv. & Adj. pct. juv. & \\
\hline British Columbia & 1993 & 16 Aug. & 2732 & 4.0 & 4.9 & $\begin{array}{l}\text { Manley and Kelson } \\
\text { (pers. comm.) }\end{array}$ \\
\hline \multirow[t]{3}{*}{ Central Oregon } & 1992 & 1-15 July & 1609 & 0.1 & 0.2 & Strong (pers. comm.) \\
\hline & 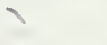 & 16-31 July & 902 & 0.6 & 1.0 & \\
\hline & & 1-15 Aug. & 1032 & 3.3 & 4.1 & \\
\hline \multirow[t]{2}{*}{ Northern California } & 1993 & 15-31 July & 355 & 1.4 & 2.2 & Ralph (pers. comm.) \\
\hline & & 15-30 Aug. & 192 & 2.1 & 2.1 & \\
\hline
\end{tabular}

The adjusted ratios of young-of-the-year murrelets to after-hatch-year birds were generally low, although there was considerable variation among juvenile ratios (tables 1 and 2). The most reliable ratios for estimating murrelet fecundity would come from at-sea surveys which covered long distances $(>20 \mathrm{~km})$ or large areas and surveyed close to shore $(\leq 500 \mathrm{~m})$ as well as farther away in order to have a betler chance of encountering clumps or groups of juveniles. To the best of my knowledge, only two data sets fulfill both requirements - total area counts in Clayoquot Sound, British Columbia and surveys off the coast of central Oregon (table 2). Both studies had seasonally adjusted juvenile ratios around 4-5 percent, so I chose to use 5 percent as a realistic estimate of fecundity. Although Ralph and Long's (this volume) surveys indicate that juvenile ratios may be as low as 2 percent, their transects did not consistently extend closer than $800 \mathrm{~m}$ from shore and may have underestimated the true ratio. Likewise, the 15 percent ratios from onshore counts appear to greatly overestimate the proportion of juveniles because the vast majority of adults would have been too far from shore to be detected (Ralph and Miller, this volume). However, onshore counts do suggest that the 5 percent estimate of fecundity could be too low if at-sea surveys had missed many juveniles. Thus, I also evaluated optimistic estimates of adjusted juivenile ratios of 10 percent, twice the realistic value and similar to corrected nesting success derived below.

Fecundity might also be estimated from studies of nesting success, but this is more difficult to do for the murrelet. A total of 22 nests have been found in the Pacific Northwestsee table 2 of the study by Nelson and Hamer (this volume b). Only 36 percent of the murrelets successfully fledged young. This would yield an estimate of 0.36 young produced per nesting pair (since murrelets can fledge only 1 young), or 0.18 female young per nesting female, assuming half of the young fledging would be males based on the sex ratio found by Sealy (1975a).

This value overestimates fecundity for iwo reasons. First, many nests were found after the young had hatched. This would greatly overestimate overall nesting success because murrelet nests often fail ( $>50$ percent) in the egg or early stages of chick-rearing before they are likely to be detectedsee table 3 of the study by Nelson and Hamer (this volume b). The true number of female chicks fledging per female may be closer to 0.15 . Second, it is unlikely that all females would attempt to nest every year and a significant proportion of the population (5-16 percent) may be nonbreeders (Hudson 1985). Third, the estimate of fecundity for the post-breeding model assumes that the young have safely reached the ocean. The long flight from the nest to the ocean can be expected to be hazardous for nestlings as exemplified by grounded young birds that have been found (Carter and Erickson 1992, Rodway and others 1992). Thus, to arrive at a fecundity value, the true number of female young per nesting female $(0.15)$ would have to be corrected by multiplying it by: (1) the estimated proportion of adult birds nesting (averaged from the estimates of Hudson cited above to yield 0.9 ); (2) the proportion of young that survive from fledging to until the time of census (anybody's guess, but 0.9 might be a reasonable estimate); and (3) the number of nesting attempts per pair per year which is assumed to be 1 (Hamer and Nelson, this volume a). This would result in a fecundity value around 0.12 , similar to average estimates from onshore juvenile ratios (table 1).

\section{Estimating Survivorship}

Nur (1993) found that the annual probability of survival for adults $\left(P_{2}\right)$ was positively related to body size for 10 species of alcids. Similar data are presented in figure 1 of De Santo and Nelson (this volume). Adult survivorship ranged from about $0.75-0.77$ for small-bodied Least Auklets (Aethia pusilla) and Ancient Murrelets (Synthliboramphus antiquus) to $0.91-0.94$ for large-bodied Atlantic Puffins (Fratercula arctica), and Common and Thick-billed murres (Uria aalge and $U$. lomuia). Nur also found that adult survivorship was negatively related to annual reproductive effort (clutch size times broods per year) after controlling for the effects of body size. Together these two variables accounted for 72 percent of the variation in annual survivorship among the 10 species. Nur then derived a multiple regression model to 
estimate an annual survival rate of alcids on the basis of body mass and clutch size. This resulted in an estimate of 0.845 for the Marbled Murrelet. Two standard errors of the estimate for the prediction, encompassing $95 \%$ of the likely values for typical murrelet survivorship (Steel and Torrie 1960), fell between 0.811 and 0.880 . I used 0.85 for adult survival and also explored the possibility that the annual probability of survival might be as high as 0.90 , a value typical for larger Atlantic alcids (Hudson 1985). Values of survivorship as low as 0.81 were not considered because they would have required extremely high fecundity values for populations to persist.

Annual survival for juveniles and subadults of most bird species is usually less than adult survival. Survival for juvenile and subadult alcids is not as well known as adult survival. These values are hard to estimate and can often be underestimated due to emigration. Frequently these values are simply given as the probability of surviving to the age of first breeding. Hudson (1985) gives a range for the probability of surviving to first breeding of 13-53 percent, with a mean close to 30 percent, but this is for large-bodied birds with late ages of first breeding. Nur (1993) suggested that survival of juveniles and subadults could be considered to be proportional to adult survival. Using data from Hudson (1985) for five populations of murres, Nur calculated that juveniles survive their first year of life at about 70 percent the rate of adult survival, first year subadults survived slightly less well than adults (0.888), and that after 2 years of age survivorship was approximately equal to adult survivorship. I used these proportions for juvenile and subadult survival estimates in the model.

\section{Predicted Murrelet Population Trends}

Figure 3 shows the possible combinations of adult survival and fecundity for populations experiencing no growth (lambda equal to 1) for different possible ages of first breeding. Combinations above the lambda isobar result in increasing populations and combinations below the lambda isobar result in declining populations. For the Marbled Murrelet, fecundity may not exceed 0.5 because females are thought to lay only 1 egg per year and, on average, only half of the young that fledge would be females. Note that the lambda isobars for different ages of first breeding converge as survivorship increases and fecundity declines. As fecundity values drop below 0.20 and survivorship rises above 0.90 , our assumption of the age of first breeding will have little effect on the predicted population trends.

Likely combinations of adult survivorship and fecundity are shown for the murrelet in the box on figure 3 . These estimates are well below the lambda isobars, and indicate that murrelet populations are likely to be declining. Given an annual survivorship of $0.85-0.90$, murrelet fecundity would have to range from 0.20 to 0.46 to result in stable populations for different ages of first breeding. Such values would result in adjusted juvenile ratios of 15 percent to 22 percent, well below the values currently observed. Fecundity at these levels

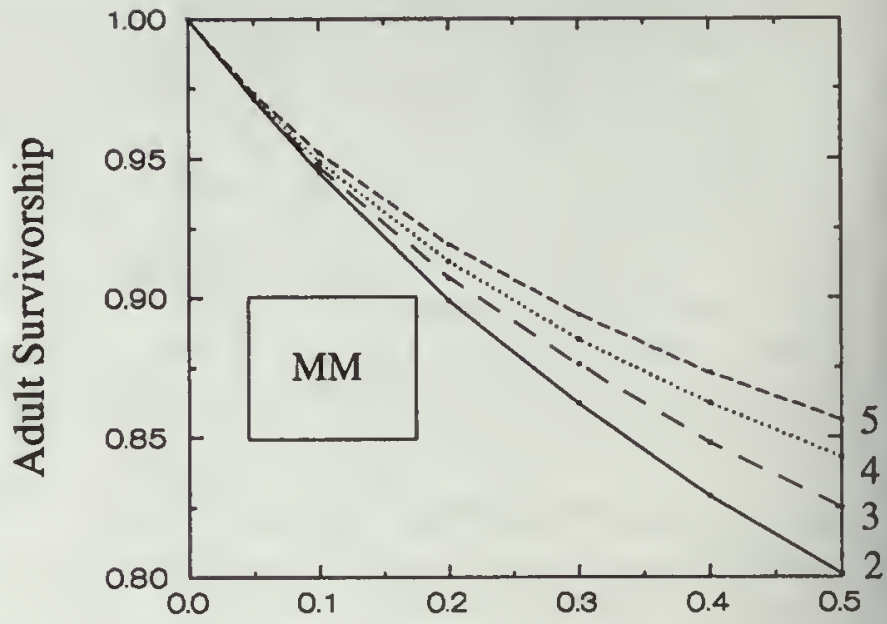

\section{Fecundity}

Figure 3-Sels of isobars where lambda equals 1 (i.e. populations are neither increasing or decreasing) for different combinations of fecundity and annual survivorship. Above the isobars populations should increase and below the isobars populations should decline. Isobars are shown for ages of first breeding from 2 to 5 years. Survivorship of juveniles and subadults was set at 0.700 and 0.888 times adult survivorship, respectively. Likely Marbled Murrelet values for survivorship and fecundity are delimited within the box. See text for details.

is typical for other auks, which generally experience nesting success in excess of 70-80 percent (Hudson 1985, Nur 1993). For example, if murrelets experienced nesting success similar to other seabirds ( 75 percent), nests were attempted by 90 percent of the potential breeding population each year, and 90 percent of the young survived to reach the ocean (i.e., fecundity $=0.30$ ), then murrelet populations would grow when adult survivorship exceeded $0.862-0.894$. These values fall well within the expected range of survivorship values. Unfortunately, even the most favorable estimate of fecundity, conceivable from current field data for the Marbled Murrelet (i.e., uncorrected nesting success $=36$ percent), would require survivorship values to exceed $0.908-0.924$ for populations to grow. Such survivorship values may occur during some years, but seem likely to be higher than the long term average expected for this species (Nur 1993).

The above analyses suggest a predicted rate of decline for the murrelet population that is substantial. Using the estimates of survival and fecundity obtained above, likely combinations of demographic rates and their resulting annual change in population size are compiled (table 3 ). It appears that murrelet populations are likely to be declining 2-4 percent per year and it is conceivable that the decline may even be 2 3 times larger.

A sensitivity analysis (table 4) indicated that estimates of lambda were most strongly affected by adult survivorship. Changes in fecundity had about half the effect on lambda that changes in adult survivorship had. Neither juvenile survivorship nor adult survivorship had strong effects on lambda. 
Table 3-Predicted rates of annual change for Marbled Murrelet populations based on likely combinations of demographic rates based on three different scenarios of juvenile recruitment and nesting success measured in the field, and two levels of adult survival from comparative analysis. Lambda, the expected growth rate of the population, was virtually unaffected by changes in age of first breeding

\begin{tabular}{l|cccc}
\hline Fecundity scenario & $\begin{array}{c}\text { Resulting } \\
\text { fecundity }\end{array}$ & $\begin{array}{c}\text { Adult } \\
\text { survival }\end{array}$ & $\begin{array}{c}\text { Lambda } \\
\text { Al-sea juvenile ratio (5 pct) }\end{array}$ Annual $^{\text {pct change }}$ \\
\hline On-shore juvenile ratio (10 pct) or & 0.06 & 0.85 & 0.88 & -12 \\
corrected nesting success (24 pct) & 0.06 & 0.90 & 0.93 & -7 \\
Uncorrected nesting success (36 pct) & 0.12 & 0.85 & 0.91 & -9 \\
& 0.18 & 0.90 & 0.96 & -4 \\
\hline
\end{tabular}

Table 4 Sensitivity of lambda to changes in the Leslie matrix elements for the Marbled Murrelet based on the three different fecundity scenarios for an age of first breeding of 3 years. See Table 3 for values used in each of the fecundity scenarios

\begin{tabular}{l|ccc}
\hline & $\begin{array}{c}\text { At-sea } \\
\text { juvenile ratio }\end{array}$ & $\begin{array}{c}\text { On-shore } \\
\text { juvenile ratio }\end{array}$ & $\begin{array}{c}\text { Uncorrected } \\
\text { nesting success }\end{array}$ \\
\hline Fecundity & 0.487 & 0.544 & 0.444 \\
Juvenile survival & 0.084 & 0.047 & 0.114 \\
Subadult survival & 0.066 & 0.037 & 0.090 \\
Adult survival & 0.890 & 0.937 & 0.854 \\
\hline
\end{tabular}

\section{Discussion}

\section{Model Parameter Estimates}

There are a number of sources of uncertainty in the parameter estimates that may have affected model outcomes. Lambda was most sensitive to changes in adult survivorship (table 4), which is typical for potentially long-lived birds like the murrelet. Estimates of survival have the greatest uncertainty, since they were not derived from field data but instead were based on comparative analyses of allometric models. Nevertheless, there are reasons for confidence in the estimates evaluated. Survivorship is often strongly related to both body size and reproductive effort in birds (e.g., Gaillard and others 1989, Saether 1988), and this trend was also strong in the Alcidae (Nur 1993). The range of annual survivorship values for adults evaluated in the model $(0.85$ 0.90 ) included more than two standard errors for the upper bound of the prediction from the regression, which should encompass $>95$ percent of the variation in potential mean estimates. Higher annual survival rates (0.90-0.94) are typical only for three species of auks with body masses exceeding $600 \mathrm{~g}$ (Nur 1993; De Santo and Nelson, this volume), three times the size of the murrelet. Survivorship ranges from 0.75-0.88 for seven alcid species with medium and small body sizes $(<600 \mathrm{~g})$; only the Atlantic Puffin had annual survival rates routinely above 0.90 .
It is likely that annual survivorship for Marbled Murrelets will be among the upper range of values evaluated in this model (e.g., 0.87-0.90), because the murrelet's inherently low reproductive rate ( 1 egg per nesting attempt) requires high survivorship for populations to grow. On the other hand, because the murrelet's unusual life history strategy of nesting in old growth forests often far from the sea, it probably faces higher mortality risks than other seabirds. Field studies to determine survival rates are needed, and are becoming more feasible as marking and telemetry techniques are perfected for this bird (Quinlan and Hughes 1992; Priest and Burns, pers. comm.).

All measures of fecundity from field data for the Marbled Murrelet appear to be low. Arguably the most complete measures of fecundity were derived from juvenile ratios based on extensive at-sea censuses corrected for the date of census in relation to the timing of fledging (table 2, fig. 2). Extensive at-sea censuses conducted recently have universally produced low percentages of juvenile birds (table 2). Such low ratios indicate poor reproductive success that could be due to high nest failure rates from predation (Nelson and Hamer, this volume b), or a low proportion of adults attempting to breed, perhaps because they are unable to find suitable nest sites. Some portion of the low reproductive success could have been due to El Niño effects on food supplies. Although there is ample evidence that El Niño affects nesting success of 
seabirds that nest and forage offshore (Ainley and Boekelheide 1990), there is no evidence that fish populations within $2 \mathrm{~km}$ of shore, which murrelets mostly utilize, are affected.

Some uncertainty in the measure of fecundity derived from juvenile ratios is associated with the timing of censuses. To convert juvenile ratios to a fecundity estimate, ratios had to be increased to account for young fledging after the date of census by using the cumulative frequency distribution for fledged nests with known dates (fig. 2). This distribution was comprised of nests from Alaska to California, because sample size was not large enough to partition nests among portions of the murrelet's range. Variation in the fledging dates exists between Alaska, British Columbia, and the Pacific Northwest (Hamer and Nelson, this volume a), although there is much overlap. Future research might employ bootstrapping techniques (Crowley 1992) to calculate an error estimate for the cumulative frequency by date, as one way to determine the inherent variability of the correction factor.

Other approaches to estimating fecundity also yielded low values, but are likely to have too many biases to be useful yet. Juvenile ratios measured only using on-shore counts tended to be higher than off-shore counts (table 2). But fecundity will be overestimated by using only on-shore counts because they undersample adults. Estimates of fecundity from nesting success are likely to be less useful than juvenile ratios because they must be corrected for many factors that are difficult to measure (such as the proportion of adults nesting, fledgling survival to the ocean, and renesting frequencies). Furthermore, for the foreseeable future, fecundity estimates based on nesting success are likely to depend on small sample sizes because of the difficulty in finding nests.

\section{Predicted Rates of Decline of Murrelet Populations}

All scenarios of the demographic model predicted that murrelet populations are likely to be declining (table 3 ). The estimated rate of decline varied from 2-12 percent per year, depending on the parameter estimates used. Based on the discussion of the parameters above, the most likely rate of decline would be based on fecundity values from juvenile ratios intermediate between offshore juvenile ratios (which may underestimate reproductive success) and nesting success (which certainly overestimates fecundity), used with an estimate of survival close to 0.90 . These intermediate fecundity values would suggest a rate of decline around 4 percent per year.

A predicted decline of 4 percent per year is in close agreement with population declines documented in two field studies of murrelets. A 50 percent decline in murrelets detected over 20 years of Christmas Bird Counts in Alaska (Piatt and Naslund, this volume), despite an increase in observer effort during this period, would represent a 3.4 percent average annual decline. Similarly, the 40 percent decline in the Clayoquot Sound murrelet population in British Columbia over 10 years (Kelson and others, in press) would average to a 5 percent annual decline. These studies are based on either periodic but intensive sampling during few annual periods (British Columbia), or low intensity but extensive sampling every year (Alaska). Despite, the sampling shortcomings inherent in these two studies, the population trends that they have documented are in good agreement with trends predicted by the model in this paper.

Model results suggest that murrelet populations may even be declining at greater rates (table 3). A 7 percent annual decline would be predicted from juvenile ratios based on offshore counts in conjunction with high survival estimates. This value is certainly a possibility for Pacific Northwest populations of murrelets, which exhibit low offshore juvenile ratios. It is even conceivable that murrelet populations could be declining at 9-12 percent per year (table 3 ). However, this rate of decline is so high that it seems unlikely to go unnoticed by field researchers. Furthermore, it is based on the most pessimistic combinations of fecundity and survivorship. I interpret the model predictions, in conjunction with the field evidence, to suggest that murrelet populations are likely to be declining at least 4 percent per year and perhaps as much as 7 percent per year.

\section{Use of Juvenile Ratios for Murrelet Conservation}

Conservation efforts for Marbled Murrelets have been hampered in part because of a lack of reliable biological information. Demographic characteristics have been especially difficult to measure because nests are very hard to find and monitor, murrelets fly long distances both over the ocean and across land, and the birds are difficult to capture, mark, and telemeter (Quinlan and Hughes 1992). Juvenile ratios provide one estimator of murrelet population health that may be reasonably measured in the field.

Juvenile ratios have great potential as estimators of productivity. It is easy to obtain large sample sizes of juvenile ratios compared to the difficulty of finding and monitoring nests. It will be many years before enough nests are found to yield sample sizes sufficient for accurate estimates of nesting success. Additional information needed to convert nesting success into annual fecundity (the proportion of birds that nest and the number of attempts per year) will perhaps be even more difficult to obtain. Juvenile ratios implicitly incorporate these factors. Research will need to determine optimal protocols for sampling juvenile ratios at-sea that take into account apparent differences in habitat use by juveniles and adults (tables $I$ and 2 ) as well as other factors that could bias these ratios.

Changes in juvenile ratios could be a useful tool to understand factors limiting murrelet population growth. Juvenile ratios could be monitored in a regional areas (e.g., over $30-50 \mathrm{kms}$ of shoreline) and compared to landscape characteristics to determine the effects of forest management and other land use practices. Juvenile ratios may also be useful for monitoring murrelet population trends. However, changes in juvenile ratios can be caused either by changes in recruitment (increased nesting success results in greater proportions of juveniles) or changes in adult survivorship (decreased survivorship results in greater proportions of juveniles). Whether juvenile ratios change due to improved 
recruitment or decreased adult survivorship should be apparent by examining year-to-year changes in population size. Increases in juvenile ratios coupled with increased population size should indicate increased productivity. However, if coupled with decreased population size, increased juvenile ratios would indicate decreased adult survivorship.

For making sound conservation decisions based on population trends and demography, there is no substitute for good field data based on direct estimates of population change, survival and fecundity. For the Marbled Murrelet, such information is likely to remain scarce. Future research should explore the strengths and weakness of using the ratio of juveniles to after-hatch-year birds as a proxy for direct demographic measurements.

\section{Acknowledgments}

I am grateful to John Kelson, Irene Manley, S. Kim Nelson, C. J. Ralph, and Craig Strong for permitting me to include their data on juvenile ratios. Tom Hamer provided me with the murrelet fledging dates, and Nadav Nur graciously permitted me to use his analyses of auk survival rates in this paper. I benefited from many discussions of these ideas and of murrelet biology with Esther Burkett, Harry Carter, Blair Csuti, James Gibbs, Tom Hamer, Mike Horton, Gary Miller, S. Kim Nelson, Nadav Nur, David Perry, C. J. Ralph, and Scott Stoleson. Reviews by Jon Bart, Kevin McKelvey, Martin Raphael, E. Rexstad, and Robert Taylor helped to improve this paper. 



\section{References}

\section{Linda L. Long, Compiler}

Agee, James K. 1994. Fire ecology of Pacific Northwest forests. Washington, DC: Island Press; 493 p.

Agler, Beverly A.; Kendall, Stephen J.; Seiser, Pam E.; Irons, David B. 1994. Population estimates of marine birds and sea otter populations in Lower Cook Inlet, Alaska, during June 1993. Anchorage, AK: U.S Fish and Wildlife Service; 79 p.

Ainley, David G. 1990. Farallon seabirds: patterns at the community level. In: Ainley, David G.: Boeketheide, Robert J., eds. Seabirds of the Farallon Islands. Stanford, CA: Stanford University Press; 349-380.

Ainley, David G. Point Reyes Bird Observatory, 4990 Shoreline Highway, Stinson Beach, CA 94970 . [Personal communication].

Ainley, David G.; Allen, Sarah G.; Spear, Larry B. Offshore occurrence patterns of Marbled Murrelets in central Califomia. [This volume].

Ainley, David G.; Boeketheide, Robert J. 1990. Seabirds of the Farallon Islands: ecology, dynamics, and structure of an upwelling-system community. Stanford, CA: Stanford University Press; 450 p.

Ainley, David G.; Boeketheide, Robert J.; Morrel], Stephen H.; Strong, Craig S. 1990a. Cassin's Auklet. In: Ainley, David G.; Boekelheide, Robert J., eds. Seabirds of the Farallon Islands. Stanford, CA: Stanford University Press; 306-338.

Ainley, David G.; Boekelheide, Robert J.; Morrell, Stephen H.; Strong, Craig S. 1990b. Pigeon Guillemot. In: Ainley, David G.; Boekelheide, Robert J., eds. Seabirds of the Farallon Islands. Stanford, CA: Stanford University Press; 276-305.

Ainley, David G., Morrell, Stephen H.; Boekelheide, Robert J. 1990c. Rhinoceros Auklet and Tufted Puffin. In: Ainley, David G.; Boekelheide, Robert J., eds. Seabirds of the Farallon Islands. Stanford, CA: Stanford University Press; 338-348.

Ainley, David G.; Norton, J.; Sydeman, William J. Apex predators indicate interannual negative and positive anomalies in the Califomia Current food web. Marine Ecology Progress Series. [In press].

Ainley, David G.; Sanger, Gerald A. 1979. Trophic relations of Seabirds in the Northeastern Pacific Ocean and Bering Sea. In: Bartonek, James C.; Nettleship, David N., eds. Conservation of marine birds of northern North America. Wildlife Research Report 11. Washington, DC: U.S. Fish and Wildlife Service; 95-122.

Ainley, David G.; Sydeman, William J.; Hatch, Scott A.; Wilson, Ulric W. 1994. Seabird population trends along the coast of North America: causes and the extent of regional concordance. In: Jehl, J.R., Jr.; Johnson, N.K., eds. A century of avifaunal changes in western North America. Studies in Avian Biology 15: 119-133.

Ainley, David G.; Sydeman, William J.; Norton, J. Upper-trophic level predators indicate interannual negative and positive anomalies in the California Current food web. Marine Ecology Progressive Series. [In press].

Aldrich, E.C. 1938. A recent oil pollution and its effects on the waterbirds of the San Francisco Bay area. Bird Lore 40: 110-114.

Allen, Nancy. Experimental Biology Aid, Oregon Department of Fisb and Wildlife, Corvallis. [Personal communication].

Alton, M.S.; Blackburn, C.J. 1972. Diel changes in the vertical distribution of the cuphausiids. Thysanoessa spinifera [Holmes] and Euphausia pacifica [Hansen], in coastal waters of Washington. California Fisb and Game 58: 179-190.

American Ornithologists' Union. 1983. Check-list of North American birds. 6th ed. Lawrence, KS: Allen Press; 877 p.

Anderson, Daniel W.; Franklin, Grefs; Mais, Kenneth F; Kelly, Paul R. 1980. Brown Pelicans as anchovy stock indicators and their relationships to commercial fishing. California Cooperative Oceanic Fisheries Investigations Report, Vol. XXI: 54-61.
Anderson, Daniel W.; Jehl, Joseph R., Jr.; Risebrough, R.W.: Woods, L.A.; DeWeese, L.R.; Edgecomb, W.G. 1975. Brown Pelicans: improved reproduction off the southern California coast. Science 190: 806-808.

Anderson, V.L. 1972. The murrelet's secret. Pacific Discovery 25: 25-26.

Andren, H.; Angelstam, P.; Lindstrom, E.; Widen, P. 1985. Differences in predation pressure in relation to habitat fragmentation: an experiment. Oikos 45: 273-277.

Andrews, H.J.; Cowlin, R.W. 1940. Forest resources of the Douglas-fir region. Misc. Pub. No. 389. U.S. Department of Agriculture, Forest Service.

Anonymous. 1993. Draft fishery description for the Pacific coastal pelagic species fisbery management plan. Draft report. Coastal pelagic species fishery management plan development team and contributing experts. July 12, 1993.

Arbib, Robert S., Jr. 1981. The Christmas bird count: constructing an "ideal model." In: Ralph, C. John; Scott, J. Michael, eds. Estimating numbers of terrestrial birds. Studies in Avian Biology 6: 30-33.

ArcView. 1992. Geographic exploration system. 2nd ed. Redlands, CA: Environmental Systems Resources Institute, Inc.

Artyukhin, Dr. Yurii B. Insitute of Ecology and Resources Management, Partisanskaya Street, 6, Petropavlovsk-Kamchatsky, Russia. [Personal communication].

Asbirk, S. 1979. The adaptive significance of the reproductive pattern in the Black Guillemor Cepphus grylle. Videnskabelige Meddelelser Dansk Naturhistorisk Forening 141: 29-80.

Ashcroft, R.E. 1979. Survival rates and breeding biology of puffins on Skomer Island, Wales. Omis Scandinavica 10: 100-110.

Ashmole, N.P. 1962. The Black Noddy Anous tenuirostris on Asceosion Island. Part 1. Ibis 103b:235-273.

Ashmole, N.P. 1971. Avian Biology. Vol. 1. London: Academic Press.

Atkins, Natasha; Heneman, Burr. 1987. The dangers of gill netting to seabirds. American Birds 41: 1395-1403.

Atkinson, Jim. Biologist, U.S. Fish and Wildlife Service, Illwaco, WA. [Personal communication].

Auster, P.J.; Stewart, L.L. 1986. Species profiles: life histories and environmental requirements of coastal fisbes and invertebrates (North Allantic) - sand lance. U.S. Fish and Wildlife Service Biol. Rep. 82 (11.66). TR EL-82-4. U.S. Army Corps of Engineers; 11 p.

Azuma, David L.; Baldwin, James A.; Noon, Barry R. 1990. Estimating the occupancy of spotted owl habitat areas by sampling and adjusting for bias. Gen. Tech. Rep. PSW-124. Berkley, CA: Pacific Southwest Research Station, Forest Service, U.S. Department of Agiculture; 9 p.

Babenko, V.G.; Poyarkov, N.D. 1987. Stort data on rare species. Marbled Murrelets on the south-east coast of the Sea of Okhotsk. In: Il'yashenko, V.Y., ed. Problems of rare animals protecture; 149-151. (in Russian).

Bailey, Edgar P. 1976. Breeding seabird distribution and abuodance along the south side of the Kenai Peninsula, Alaska. Anchorage, AK: U.S. Fish and Wildlife Service. Unpublished report supplied by the author.

Bailey, Edgar P.; Kaiser, Gary W. 1993. Impacts of introduced predators on nesting seabirds in the northeast Pacific. In: Vermeer, Kees; Briggs, Kenneth T.; Morgan, Ken H.; Siegel-Causey, Douglas, eds. The status, ecology and conservation of marine birds of the North Pacific. Special Publication. Ottawa, ON: Canadian Wildlife Service, Environment Canada; 218-226.

Bailey, R.O. 1980. The post-breeding ecology of the Redhead Duck (Aythya americana) on Long Island Bay, Lake Winnipegosis, Manitoba. Montreal, Quebec: MacDonald College. Pb.D. Thesis.

Bailey, R.S.; Fumess, R.W.; Gauld, J.A.; Kunzlik, P.A. 1991. Recent changes in the population of the sand eel (Ammodytes marinus Raitt) at Shetland in relation to estimates of seabird predation. ICES Marine Science Symposium 193: 209-216.

Balat, F. 1970. On the wing moult of the mallard (Anas plaryrynchos) in Czechoslovakia. Zool. Listy 19: 135-144.

Balogh, Gregory R. Migratory Bird Management, U.S. Fish and Wildlife Service, 101] E. Tudor Road, Anchorage, AK 99503. [Personal communication].

Barber, Robert T.; Chavez, Francisco G. 1984. Biological consequences of El Niño. Science 222: 1203-1210. 
Barlow, J.; Baird, R.W.; Heyning, J.E.; Wynne, K.; Manville, A.M.; Lowry, L.F.; Hanan, D.; Sease, J. 1990. A review of cetacean mortality in coastal fisheries of the eastern North Pacific and USSR Far East. International Whaling Commission Meeting Doc. SC/090/G28; 48 p.

Barnes, J.T.; MacCall, A.D.; Jacobson, L.D.; Wolf, P. 1992. Recent population trends and abundance estimates for the Pacific sardine (Sardinops sagax). California Cooperative Oceanic Fisheries Investigations Report 33: 60-75.

Barrett, R.T.; Rikardsen, F. 1992. Chick growth, fledging periods and adult mass loss of Atlantic Puffins Fratercula arctica during years of prolonged food stress. Colonial Waterbirds 15(1): 24-32.

Baumgartner, T.R.; Soutar, A.; Ferreira-Bartrina, V. 1992. Reconstruction of the history of Pacific sardine and northern anchovy populations over the past two millennia from sediments of the Santa Barbara Basin, California. California Cooperative Oceanic Fisheries Investigations Report 33: 24-40.

Bayer, Range D. 1988. Changes in waterbird numbers after the 1983 oil spill at Yaquina estuary. Oregon Birds 14: 157-161.

Bayer, Range D.; Lowe, Roy W.; Loeffel, Robert E. 1991. Persistent summer mortalities of Common Murres along the Oregon central coast. Condor 93: 516-525.

Beck, R.H. 1910. Water birds of the vicinity of Point Pinos, California. Proceedings of California Academy of Sciences (4th series) 3: 57-72.

Becking, Rudolf W. 1991. Eggshell fragments of the Marbled Murrelet (Brachyramphus marmoratus) in San Mateo County, California. Northwestern Naturalist 72: 74-76.

Becking, Rudolf W. Wildlife Biologist, Arcata, California [Personal Communications].

Bédard, Jean. 1969a. Adaptive radiation in Alcidae. Ibis 111: 189-198.

Bédard, Jean. 1969b. The nesting of the Crested, Least, and Parakeet auklets on St. Lawrence Island, Alaska. Condor 71: 386-398.

Bédard, Jean; Sealy, Spencer G. 1984. Moults and feather generations in the Least, Crested and Parakeet auklets. Journal of Zoology 202: 461-488.

Beebe, S.B. 1990. Ecosystem conservation in the temperate rainforest. Wings 15: 1-6.

Beissinger, Steven. Population trends of the Marbled Murrelet projected from demographic analyses. [This volume].

Bellward, G.D.; Norstrom, R.J.; Whitehead, P.E.; Elliott, J.E.; Bandeira, S.M.; Dworschak, C.; Chang, T.; Forbes, S.; Cadario, B.; Hart, L.E.; Cheng, K.M. 1990. Comparison of polychlorinated dibenzodioxin levels with hepatic mixed-function oxidase induction in Great Blue Herons. Journal of Toxicology and Environmental Health 30: 33-52.

Benkert, Katherine. U.S. Fish and Wildlife Service, Ecological Services, Olympia, WA. [Telephone conversation with Harry R. Carter]. May 1994.

Bent, A.C. 1963. Life histories of North American diving birds. (Reprint of U.S. National Museum Bulletin 107). New York: Dover Publications, Inc.; $239 \mathrm{p}$.

Bergman, G. 1971. Gryllteisten Cepphus grylle in einen Randgebiet: Nährung, Brutresultat, Tagesrhythmus und Ansiedlung. Commentationes Biologicae 42: 1-26.

Bertram, Douglas F. 1988. The provisioning of nestlings by parent Rhinoceros Auklets (Cerorhinca monocerata). Burnaby, BC: Simon Fraser University; 100 p. M.Sc. Thesis.

Bertram, Douglas F.; Kaiser, Gary W. 1988. Monitoring growth and diet of nestling Rhinoceros Auklets to gauge prey availability. Technical Report Series No. 48. Delta, BC: Pacific and Yukon Region, Canadian Wildlife Service.

Binford, Laurence C.; Elliot, Bruce G.; Singer, Steven W. 1975. Discovery of a nest and the downy young of the Marbled Murrelet. Wilson Bulletin 87(3): 303-319.

Birkhead, Tim R. 1976. Breeding biology and survival of guillemots (Uria aalge). Oxford, England: Oxford University; 204 p.; Ph.D. Thesis.

Birkhead, Tim R. 1977. The effect of habitat and density on breeding success in the Common Guillemot Uria aalge. Journal of Animal Ecology 46:751-764.

Birkhead, Tim R. 1985. Coloniality and social behaviour in the Atlantic alcidae. In: Nettleship, David N.; Birkhead, Tim R., eds. The Atlantic Alcidae. London: Academic Press; 355-383.
Birkhead, Tim R.; Harris, Michael P. 1985. Ecological adaptations for breeding in the Atlantic Alcidae. In: Nettleship, David N.; Birkhead, Tim R., eds. The Atlantic Alcidae. London: Academic Press; 205-232.

Birkhead, Tim R.; Nettleship, David N. 1981. Reproductive biology of Thick-billed Murres (Uria lomvia): an inter-colony comparison. Auk 98(2): 258-269.

Birkhead, Tim R.; Taylor, A.M. 1977. Moult of the Guillemot Uria aalge. Ibis 119: 80-85.

Blosinger, Charles L.; Waddell, Karen. 1993. Area of old-growth forest in California, Oregon, and Washington. Resource Bulletin PNW-RB-197. Portland, OR: USDA Forest Service, Pacific Northwest Research Station.

Bock, Carl E.; Root, Terry L. 1981. The Christmas bird count and avian ecology. In: Ralph, C. John; Scott, J. Michael, eds. Estimating numbers of terrestrial birds. Studies in Avian Biology 6: 17-23.

Bockelheide, Robert J.; Ainley, David G.; Morrell, Stephen S.; Huber, Harriet R.; Lewis, T. James. 1990. Common Murre. In: Ainley, David G.; Boekelheide, Robert J., eds. Seabirds of the Farallon lslands. Stanford, CA: Stanford University Press; 245-275.

Boersma, P. Dee; Wheelwright, Nathanial T. 1979. Egg neglect in the Procellariiformes: reproductive adaptations in the Fork-tailed Storm Petrel. Condor 81: 157-165.

Boone, Daniel L. 1986. Breeding biology and early life history of the Tufted Puffin (Fratercula cirrhata). Corvallis, OR: Oregon State University; 46 p. M.Sc. Thesis.

Bourne, W.R.P.; Parrack, J.D.; Potts, G.R. 1967. Birds killed in the "Torrey Canyon" disaster. Nature 215: 1123-1125.

Bradstreet, Michael S.W.; Brown, Richard G.B. 1985. Feeding ecology of the Atlantic Alcidae. In: Nettleship, David N.; Birkhead, Tim R., eds. The Atlantic Alcidae. Orlando, FL: Academic Press; 264-318.

Brazil, Mark A. 1991. The birds of Japan. Washington, DC: Smithsonian Institution Press. 466 p.

Breslow, N.E.; Day, N.E. 1980. Statistical methods in cancer research. Volume 1 - the analysis of case-control studies. Scientific Publications No. 32. International Agency for Research on Cancer. Lyon, France: World Health Organization. 360 p.

Briggs, Kenneth T.; Tyler, William B.; Lewis, David B. 1985. Aerial surveys for seabirds: methodological experiments. Journal of Wildlife Management 49(2):412-417.

Briggs, Kenneth T.; Tyler, William B.; Lewis, David B.; Carlson, D.R. 1987. Bird communities at sea off California: 1975-1983. Studies in Avian Biology 11; 74 p.

Briggs, Kenneth T.; Varoujean, Daniel H.; Heinemann, D.; Ford, R. Glenn 1989. Synthesis of information on seabirds of the eastern North Pacific, with emphasis on the Oregon and Washington OCS area. In: Brueggeman, J.J., ed. 1989. Oregon and Washington marine mammal and seabird surveys: information synthesis and hypothesis formulation. OCS Study MMS 89-0030. Los Angeles, CA: Minerals Management Service Pacific Outer Continental Shelf region; $374 \mathrm{p}$.

Briggs, Kenneth T.; Varoujean, Daniel H.; Williams, Wendy W.; Ford, R. Glenn; Bonnell, M.L.; Casey, J.L. 1992. Seabirds of the Oregon and Washington OCWS, 1989-1990. In: Brueggeman, J.J., ed. Oregon and Washington marine mammal and seabird surveys. Final Report. OCS Study MMS 91-0093. Contract no. 14-12-0001-30426. Los Angeles, CA: United States Department of Interior, Minerals Management Service, Pacific Outer Continental Shelf Region; 162 p + appendices.

Brooks, A. 1926a. The mystery of the Marbled Murrelet. Murrelet 7: 1-2. Brooks, A. 1926b. Scarcity of the Marbled Murrelet. Murrelet 7: 39.

Brooks, A. 1928. Does the Marbled Murrelet nest inland? Murrelet 9: 68.

Brown, A.C.; McLachlan, A. 1990. Ecology of sandy shores. New York: Elsevier Publications; $328 \mathrm{p}$.

Brown, Mike. Biologist, USDA Forest Service, Tongass National Forest, Federal Building, Ketchikan, AK. [Personal communication].

Brown, Richard G.B.; Gaskin, D.E. 1988. The pelagic ecology of the Grey and Red-necked phalaropes Phalaropus fulicarius and $P$. lobatus in the Bay of Fundy, eastern Canada. Ibis 130: 234-250.

Brown, Richard G.B.; Nettleship, David N. 1984. Capelin and seabirds in the Northwest Atlantic. In: Nettleship, David N.; Sanger, Gerald A.; Springer, Paul F., eds. Marine birds: their feeding ecology and commercial fisheries relationships. Special Publication. Ottawa, 
Canada: Canadian Wildlife Service, Minister of Supply and Services; 184-194.

Bryant, Andrew A. 1994. Montane alternative silvicultural systems (MASS): pre-treatment breeding bird communities. FRDA report No. 216. CanadaBritish Columbia Partnership Agreement on Forest Resourses Development: FROA II. Victoria, BC: Canadian Forest Service and British Columbia Ministry of Forests, 21 p.

Bryant, Andrew A. Department of Biology, University of Victoria, Victoria, B.C. V8W 2Y2. [Personal communication].

Buchholz, David. Biologist, Oregon Department of Forestry, Tillamook, OR. [Personal communication with S. Kim Nelson].

Buckland, S.T.; Anderson, D.R.; Bumham, K.P.; Laake, J.L. 1993. Distance sampling: estimating abundance of biological populations. New York: Chapman \& Hall; $446 \mathrm{p}$.

Bureau of Indian Affairs. 1993. Biological assessment for the Coastal and Puget Sound Net Fisheries conducted by the Treaty Tribes of Western Washington. Report on file. Bureau of Indian Affairs, Portland, OR.

Burger, Alan E. 1990. Effects of the Nestucca oil spill on seabirds along the coast of Vancouver lsland in 1989. Report on file. Environmental Protection Service, Environment Canada, Vancouver, BC.

Burger, Alan E. 1992. The effects of oil pollution on seabirds off the west coast of Vancouver Island. In: Vermeer, Kees; Butler, Robert W.; Morgan, Ken H., eds. The ecology, status and conservation of marine and storeline birds on the west coast of Vancouver Island. Occasional Paper No. 75. Ottawa, ON: Canadian Wildlife Service; 120-128.

Burger, Alan E. 1993a. Effects of the 'Nestucca' oil spill on seabirds along the southwest coast of Vancouver Island in 1989. Technical Report Series 179. Delta, B.C.: Canadian Wildlife Service, Pacific and Yukon Region.

Burger, Alan E. 1993b. Mortality of seabirds assessed from beached bird surveys in Southem British Columbia. Canadian Field-Naturalist 107: 169-176.

Burger, Alan E. 1994. Analysis of terrestrial and marine activities of Marbled Murrelets breeding on southwest Vancouver Island. Report on file. University of Victoria, Victoria, British Columbia.

Burger, Alan E. Inland habitat associations of Marbled Murrelets in British Columbia. [This volume a].

Burger, Alan E. Marine distribution, abundance, and habitats of Marbled Murrelets in Britist Columbia. [This volume b].

Burger. Alan E. Department of Biology, University of Victoria, Victoria, British Columbia, Canada V8W 2Y2. [Personal communication].

Burger, Alan E: Dechesne, Sharon B.C. 1994. Radar tracking of Marbled Murrelets on Vancouver lsland, Britisb Columbia. (Abstract). Pacific Seabirds 21(1): 35 .

Burger, Alan E.; Fry, D. Michael. 1993. Effects of oil pollution on seabirds in the northeast Pacific. In: Vermeer, Kees; Briggs, Kenneth T.; Morgan, Ken H.; Siegel-Causey, Douglas, eds. The status, ecology and conservation of marine birds of the North Pacific. Special Publication. Ottawa, ON: Canadian Wildlife Service, Environment Canada; 254 263.

Burgman, M.A.; Ferson, S.; Akcakaya, H.R. 1993. Risk assessment in conservation biology. London: Chapman \& Hall.

Burkett, Esther A. Marbled Murrelet food habits and prey ecology. [This volume].

Burkett, Esther A. California Department of Fish and Game, 1416 Ninth Street, Sacramento, CA 95814 . [Personal communication].

Burns, Rick A. 12136 New McLellan Road, Surrey, BC. V3X 2X9. [Personal communication].

Burns, Rick A.; Prestash, Lynn M. 1993. Activity and nesting habitat of Marbled Murrelets on the central coast of British Columbia. Pacific Seabird Group Bulletin 20(1): 41.

Burns, Rick A.; Prestash, Lynn M.; Kuletz, Katherine J. 1994. Pilot study on the capture and radio tagging of murrelets in Prince William Sound, Alaska, July and August, 1993. Final report. Anchorage, AK: U.S. Fish and Wildlife Service.

Burrell, D.C. 1987. Interaction between silled fjords and coastal regions. ln: Hood, Donald W.; Zimmerman, Stephen T. eds. The Gulf of Alaska: Physical environment and biological resources. Publication number:
OCS study, MMS 86-0095. Washington, DC: U.S. Department Commerce and U.S. Department Interior, Mineral Management Services, 187-216.

Butler, J.L.; Smith, P.E.; Lo, N.C.H. 1993. The effect of natural variability of life-history parameters on anchovy and sardine population growth. Califormia Cooperative Oceanic Fisheries Investigations Report 34: 104-111.

Byers, C. Randall; Steinhorst, R.; Krausman, P. 1984. Clarification of a technique for analysis of utilization-availability data. Journal of Wildlife Management 48: 1050-1053.

Byrd, G. Vernon; Divoky, George J.; Bailey, E.P. 1980. Changes in marine bird and mammal populations on an active volcano in Alaska. Murrelet 61:50-62.

Byrd, G. Vernon; Gibson, Daniel D. 1980. Distribution and population status of Whiskered Auklet in the Aleutian lslands, Alaska. Western Birds 11: 135-140.

Byrd, G. Vernon; Johnson, David J.; Gibson, Daniel D. 1974. The birds of Adak Island, Alaska. Condor 76: 288-300.

Byrd, G. Vernon; Murphy, Edward C.; Kaiser, Gary W.; Kondratyev, Alexander Y.; Shibaev, Yurij V. 1993. Status and ecology of offshore fish-feeding alcids (murres and puffins) in the North Pacific. In: Vermeer, Kees; Briggs, Kenneth T.; Morgan, Ken H.; Siegel-Causey, Douglas, eds. The status, ecology and conservation of marine birds of the North Pacific. Special Publication. Ottawa, ON: Canadian Wildlife Service, Environment Canada; 176-186.

Byrd, G. Vernon; Williams, Jeff C. 1993. Whiskered Auklet (Aethia pygmaea). In: Poole, Alan; Gill, Frank, eds. The birds of North America, No. 76. Philadelphia, PA: The Academy of Natural Sciences; and Washington, DC: The American Ornithologists' Union.

Caims, David K. 1981. Breeding, feeding, and chick growth of the Black Guillemot (Cepphus grylle) in southern Quebec. Canadian Field Naturalist 95: 312-318.

Cairns, David K. 1987. The ecology and energetics of chick provisioning by Black Guillemots. Condor 89(3): 627-635.

Caims, David K. 1992a. Population regulation of seabird colonies. In: Power, D.M., ed. Current omithology. Vol. 9. New York: Plenom Press; 37-61.

Cairns, David K. 1992b. Bridging the gap between omithology and fisheries science: use of seabird data in stock assessment models. Condor 94: 811-824.

Calambokidis, J.; Speich, Steven M.; Peard, J.; Steiger, G.H.; Cubbage, J.C.; Fry, D.M.; Lowenstine, Linda J. 1985. Biology of Puget Sound marine mammals and marine birds: population health and evidence of pollution effects. NOAA Technical Memorandum NOS OMA 18. Rockville, MD: U.S. Dept. of Commerce, National Oceanic and Atmospheric Administration, National Ocean Service; 159 p.

Campbell, R. Wayne. 1967. Fishing lures, a hazard to sea birds. Blue Jay 25: 71-72.

Campbell, R. Wayne; Dawe, N.K.; McTaggant-Cowan, 1.; Cooper, J.M.; Kaiser, G.W.; McNall, M.C.E. 1990. The birds of British Columbia. Vols. 1, 2. Victoria, BC: Royal British Columbia Museum and Canadian Wildlife Service.

CAMRIS [Computer Program]. Ford, R. Glenn. 1992. Computer Aided Mapping and Resource Inventory System. Available from: Ecological Consulting Inc., 2735 N.E. Weidler St, Portland, OR.

Canadian Coast Guand. 1991. 1991 Vessel Traffic Services (VTS) update study. Ottawa, ON: Canadian Coast Guard, Marine Navigation Services; $159 \mathrm{p}$.

Carpenter, A.D; Dragnich, R.G.; Smith, M.T. 1991. Marine operations and logistics during the Exxon Valdez spill cleanup. 1n: Proceedings for 1991 International Oil Spill Conference, March, 1991; 205-211.

Carscadden, J.E. 1984. Capelin in the northwest Atlantic. In: Netuleship, David N.; Sanger, Gerald A.; Springer, Paul F., eds. Marine birds: their feeding ecology and commercial fisheries relationships. Special Publication. Ontawa, Canada: Canadian Wildlife Service, Minister of Supply and Services; 170-183.

Carter, Harry R. 1984. At-sea biology of the Marbled Murrelet (Brachyramphus marmorarus) in Barkley Sound, British Columbia. Winnipeg: University of Manitoba; 143 p. M.Sc. Thesis. 
Carter, Harry R. Wildlife Biologist, National Biologica] Service, Northern Prairie Research Center, Dixon, CA. [Personal communication].

Carter, Harry R.; Erickson Richard A. 1988. Population status and conservation problems of the Marbled Murrelet in California, 18921987. Report on file. California Department Fish and Game, Sacramento, CA; 68 p.

Carter, Harry R.; Erickson, Richard A. 1992. Status and conservation of the Marbled Murrelet in California, 1892-1987. In: Carter, Harry R.; Morrison, Michael L., eds. Status and conservation of the Marbled Murrelet in North America. Proceedings of the Western Foundation of Vertebrate Zoology 5(1): 92-108.

Carter, Harry R.; Jaques, Deborah L.; McChesney, Gerald J.; Strong, Craig S.; Parker, Michael W.; Takekawa, Jean E.; Point Reyes Bird Observatory and Channel lslands National Park. 1990a. Breeding populations of seabirds on the northern and central California coasts in 1989 and 1990. Los Angeles, CA: U.S. Department Interior, Minerals Management Service.

Carter, Harry R.; Jaques, Deborah L.; Strong, Craig S.; McChesney, Gerald J.; Parker, Michael W.; Takekawa, Jean E. 1990b. Survey of seabird colonies of northern and central California in 1989. Draft report on file. California Pacific Sciences Center, National Biological Service, 6924 Tremont Road, Dixon, CA.

Carter, Harry R.; Kuletz, Katherine J. Mortality of Marbled Murrelets due to oil pollution in North America. [This volume].

Carter, Harry R.; McChesney, Gerald J. 1994. Breeding population size and distribution of Xantus' Murselets (Synthliboramphus hypaleucus) in southern California (abstract only). Pacific Seabirds 21(1): 36.

Carter, Harry R.; McChesney, Gerald J.; Jaques, Deborah L.; Strong, Craig S.; Parker, Michael W.; Takekawa, Jean E.; Jory, Deborah L.; Whitworth, Darrell L. 1994. Breeding populations of seabirds in California, 19891991. Final report on file. National Biological Service and U.S. Fish and Wildlife Service, Dixon, CA.

Carter, Harry R.; Morrison, Michael L., eds. 1992. Status and conservation of the Marbled Murrelet in North America. Proceedings of the Western Foundation of Vertebrate Zoology 5(1).

Carter, Harry R.; Sealy, Spencer G. 1984. Marbled Murrelet (Brachyramphus marmoratus) Mortality due to gill-net fishing in Barkley Sound, British Columbia. In: Nettleship, David N.; Sanger, Gerald A.; Springer, Paul F., eds. Marine birds: their feeding ecology and commercial fisheries relationships. Special Publication. Ottawa, Canada: Canadian Wildlife Service, Minister of Supply and Services; 212-220.

Carter, Harry R.; Sealy, Spencer G. 1986. Year-round use of coastal lakes by Marbled Murrelets. Condor 88: 473-477.

Carter, Harry R.; Sealy, Spencer G. 1987a. Fish-holding behavior of Marbled Murrelets. Wilson Bulletin 99: 289-291.

Carter, Harry R.; Sealy, Spencer G. 1987b. Inland records of downy young and fledgling marbled murrelets in North America. Murrelet 68: 58-63.

Carter, Harry R.; Sealy, Spencer G. 1990. Daily foraging behavior of Marbled Murrelets. In: Sealy, Spencer G., ed. Auks at sea. Studies in Avian Biology 14: 93-102.

Carter, Harry R.; Stein, Janet L. Molts and plumages in the annual cycle of the Marbled Murrelet. [This volume].

Caswell, H. 1989. Matrix population models. Sunderland, MA: Sinaeur Associates, Inc.

Chambers, Carol. Oregon State University, Department of Forest Sciences, Corvallis, OR 97331. [Personal communication]

Chasko, Gregory G.; Gates, J. Edward. 1982. Avian habitat suitability along a transmission-line corridor in an oak-hickory forest region. Wildlife Monographs 82; 41 p.

Chelton, D.B. 1981. Interannual variability in the California Current: physical factors. California Cooperative Ocean Fisheries Investigations, Reports 22: 34-48.

Chelton, D.B.; Bernal, P.A.; McGowan, John A. 1982. Large-scale interannual physical and biological interaction in the California Current. Journal of Marine Research 40: 1095-1125.

Chia, F.-S. 1971. Diesel oil spill at Anacortes. Marine Pollution Bulletin 2: 105-106.
Chilton, G.; Sealy, Spencer G. 1987. Species roles in mixed-species feeding flocks of seabirds. Journal of Field Ornithology 58: 456-463.

Chinnici, Sal. Wildlife Biologist, Pacific Lumber Company, Scotia, CA. [Personal communication].

Clapp, R.B.; Klimkiewicz, M.K.; Kennard, J.H. 1982. Longevity records of North American Birds: Gaviidae through Alcidae. Journal of Field Ornithology 53(2): 181-208.

Clark, L.; Schreiber, R.W.; Schreiber, E.A. 1990. Pre- and post-El Niño southern oscillation comparison of nest sites for Red-tailed Tropicbirds breeding in the central Pacific Ocean. Condor 92: 886-896.

Cline, Steven; Berg, A.; Wight, Howard. 1980. Snag characteristics and dynamics in Douglas-fir forests, western Oregon. Journal of Wildlife Management 44: 773-786.

Clowater, J.S. Department of Biological Sciences, Simon Frasier University, Burnaby, BC, Canada V5A 1S6. [Personal communication]

Cody, Martin L. 1971. Ecological aspects of reproduction. In: Farner, D.S.; King, J.R., eds. Avian biology. London: Academic Press, Inc.; 46] -512.

Cody, Martin L. 1973. Coexistence, coevolution, and convergent evolution in seabird communities. Ecology 54:31-44.

Cody, Martin L. Professor, Department of Biology, University of California, Los Angeles, CA. [Personal communication].

Cody, Mary B.; Gerlach, Thomas P. 1993. Distribution and activity levels of Marbled Murrelets at coastal and inland sites on Afognak Island, Alaska. Biological report. Anchorage, AK: U.S. Fish and Wildlife Service, Division of Realty; $15 \mathrm{p}$.

Cohen, P.; Aylèsworth, R. 1990. Oil spill risk for southern B.C./northern Washington coast marine area. Final report of the States/British Columbia oil spill task force, Appendix Vll. Publ. Province of British Columbia and the States of Washington, Oregon, Alaska and California. Available from Librarian, Ministry of the Environment, Land and Parks, Victoria, BC, Canada V8XIX5. 105 p.

Collins, Doretta C. 1993. Rate of harvest for 1988-1991: preliminary report and summary statistics for state and privately owned land. Internal document. Washington Department of Natural Resources, Forest Practices Division; 40 p.

Collins, Doretta C. Washington Department of Natural Resources, Division of Forest Practices, Olympia, WA. [Conversation with Martin G. Raphael]. 3 March 1994.

Colodey, A.G.; Wells, P.G. 1992. Effects of pulp and paper mill effluents on estuarine and marine ecosystems in Canada: a review. Journal of Aquatic Ecosystem Health 1: 201-226.

Confer, Cindi. Biologist, Harza Northwest, Bellevue, WA. [Personal communication].

Coyle, Kenneth O.; Hunt, George L., Jr.; Decker, Mary Beth; Weingartner, Thomas J. 1992. Murre foraging, epibenthic sound scattering and tidal advection over a schoal near St. George Island, Bering Sea. Marine Ecology Progress Series 83: 1-14.

Craig, B. Wildlife Biologist, USDA Forest Service, Six Rivers National Forest, Gasquet Ranger District, Gasquet, CA. [Personal communication].

Craig, V.; Cave, J. 1994. Report on the impacts of the Gillnet Test Fishery operated at Salmon Banks (Area 7) on the Marbled Murrelet (Brachyramphus marmaratus marmoratus) and other alcids. Report on file. Pacific Salmon Commision, Vancouver, British Columbia, Canada.

Croll, D.A. 1990. Physical and biological determinants of the abundance, distribution, and diet of the Common Murre in Monterey Bay, California. In: Sealy, Spencer G., ed. Auks at sea. Studies in Avian Biology 14: 139-148.

Crowley, P.H. 1992. Resampling methods in computation-intensive data analysis in ecology and evolution. Annual Review of Ecological Systems 23: 405-448.

Croxall, John P. 1987. Conclusions. In: Croxall, John P., ed. Seabirds: feeding ecology and role in marine ecosystems. Cambridge, England: Cambridge University Press; 369-381.

Croxall, John P.; Gaston, Anthony J. 1988. Patterns of reproduction in high-latitude Northern- and Southern-hemisphere seabirds. Acta XiX Congressus Internationalis Ornithologici (Ottawa). Ottawa, ON: University of Otawa Press; 1176-] 194. 
Croze, HJ. 1970. Searcbing images in carrion crows. Zeitscbrift Tierpsychologie Beiheft. 85 p. Cited in: Kilham, L. 1989. The American Crow and the Common Raven. College Station, TX: Texas A \& M University Press.

Cummins, Eric. Non-game Program Manager, Washington Department of Fish and Wildlife, Olympia, WA. [Personal communication].

Dawson, W.L. 1923. The birds of California. San Diego, CA: South Moulton Company: 997 p.

Dawson, W.L.; Bowles, J.H. 1909. The birds of Washington. Seattle, WA: Occidental Publishing Company.

Day, Robert H. 1980. The occurrence of characteristics of plastic pollution in Alaska's marine birds. Fairbanks, AK- University of Alaska; 111 p. M.S. Thesis.

Day, Robert H.; Oakley, Karen L.; Barnard, Douglas R. 1983. Nest sites and eggs of Kittlitz's and Marbled Murrelets. Condor 85(3): 265-273.

Day, Robert H.; Wehle, D.H.S.; Coleman, Felicia C. 1982. Ingestion of plastic by marine birds: a global phenomenon. Pacific Seabird Group Bulletin 9(2): 77.

Day, Roben H.; Wehle, D.H.S.; Coleman, Felicia C. 1985. Ingestion of Plastic Pollutants by Marine Birds. In: Shomura, R.S.; Yoshida, H.O. eds. Proceedings of the workshop on the fate and impact of marine debris. Tech. Memorandum NOAA-TM-NMFS-SWFC-54. Honolulu, HI: U.S. Deparment of Commerce, National Oceanographic and Atmospheric Administration, National Marine Fisheries Service; 344-386.

DeBenedictis, Paul; Chase, T. 1963. Middle Pacific coast region. American Birds 17: 480-483.

Docker, Mary Beth; Hunt, George L., Jr, Byrd, G. Vernon, Jr. The relationship between sea-surface temperature, the abundance of juvenile wall-eyed pollock (Theragra chalcograma) and the reproductive performance and diets of seabirds at the Pribolof Island, southeast Bering Sea. Occasional Paper. Canadian Fisheries and Aquatic Sciences. [In press].

DeGange, Anthony R. 1978. Observations on the mortality of seabirds in Japanese salmon gillnets made from the Oshoro Maru and Hokusei Maru, summer 1978. Unpublished reporr on file. U.S. Fish and Wildlife Service, Anchorage, AK.

DeGange, Anthony R. Wildlife Biologish, U.S. Fish and Wildlife Service, Anchorage, AK. [Personal communication].

DeGange, Anthony R.; Day, Robert H.; Takekawa, Jean E.; Mendenhall, Vivian M. 1993. Losses of seabirds in gill nets in the North Pacific. In: Vermeer, Kees; Briggs, Kenneth T.; Morgan, Ken H.; Siegel-Causey, Douglas, eds. The status, ecology and conservation of marine birds of the Nonth Pacific. Special Publication. Ottawa, ON: Canadian Wildlife Service, Environment Canada; 204-211.

DeGange, Anthony R.; Forsell, Douglas J.; Jones, Linda L. 1985. Mortality of seabirds in the high-seas Japanese salmon mothership fishery, 19811984. Unpublished report on file. U.S. Fish and Wildlife Service, Anchorage, AK.

Demarchi, D.A.; Marsh, R.D.; Harcombe, A.P.; Lea, E.C. 1990. The evvironment. In: Campbell, R.W.; Dawe, N.K.; McTaggart-Cowan, I.; Cooper, J.M.; Kaiser, G.W.; McNall, M.C.E, eds. The birds of British Columbia, Vol. 1. Victoria, BC: Royal British Columbia Museum and Canadian Wildlife Service; 55-142.

Dementiev, G.P.; Gladkov, N.A. 1951. Birds of the Soviet Union. Vol. 2. Moscow; 169-240. (in Russian).Translated by Program for Scientific Translations, Jerusalem, Israel. Available from the National Technical Information Services, Springfield, VA.

Department of Fisheries and Oceans Canada. 1978. British Columbia fishery (general regulations made under the Fisheries Act (and amendments). Unpublished report on file. Department of Fisberies and Oceans Canada, Otawa, ON.

Department of Fisheries and Oceans Canada. 1992. British Columbia commercial catcb statistics by species, gear, month and area -1992 Pacific Region. Unpublished report. Department of Fisheries and Oceans Canada, Pacific Region, Vancouver, BC.

Derocher, A.B.C. Ministuy of Forests, 4595 Canada Way, Burnaby, B.C. V5G 4L9. [Personal communication].

Desante, David; LeValley, Ron. 1971. The nesting season: middle Pacific Coast region. American Birds 25: 899-904.
De Santo, Toni L.; Nelson, S. Kim. Comparative reprodactive ecology of the Auks (family Alcidae) with emphasis on the Marbled Murrelet. [This volume].

DeWeese, Lawrence R; Anderson, Daniel W. 1976. Distribution and breeding biology of Craveri's Murrelet. Transactions of the San Diego Society of Natural History 18: 155-168.

Dickens Associates Limited. 1990. Marine oil transportation systems: evaluations of environmental risk and alternatives for risk reduction. Vol 1. Report on file. Vancouver, BC: D.F. Dickens Associates.

Divoky, George J. 1982. The occurrence and behavior of pon-breeding Horned Puffins at Black Guillemot colonies in northem Alaska. Wilson Bulletin 94: 356-358.

Divoky, George J. 1994. Decreased survival and reduced colony size in Black Guillemots in northern Alaska (abstract). Pacific Seabirds 21(1): 37 .

Divoky, George J. Biologist, Seattle, WA. [Personal communication]

Divoky, George J.; Horton, Michael. Breeding and natal dispersal, nest habitat loss, and implications for the Marbled Murrelet. [This volume].

Divoky, George J.; Watson, George E.; Bantonek, James C. 1974. Breeding of the Black Guillemot in northern Alaska. Condor 76(3): 339-343.

Dixon, TJ. 1977. The distance at which sitting birds can be seen at sea. Ibis 119: 372-375.

DNA Associates. 1993. Tanker and barge movements along the California coast - 1992. Report on file. Sacramento, CA: DNA Associates.

Dobbin, J.A.; Robernson, H.E.; Ford, R. Glenn; Briggs, Kenneth T.; Clark, E.H. II. 1986. Resource damage assessment of the T/N Puerto Rican oil spill incident. Report on file. Alexandria, VA: James Robbin Assoc., Inc.

Dodimead, A J. 1956. Project Norpac. Progress Report Pacific Coast Stations. Technical Report 105. Nanaimo, BC: Fisheries Resources Board of Canada; 16-18.

Doer, J.G. USDA Forest Service, Tongass-Stikine Area, Box 309. Petersburg, AK 99833. [Personal communication].

Drent, R.H. 1965. Breeding biology of the Pigeon Guillemot Cepphus columba. Ardea 53: 99-160.

Dreat, R.H.; Guiguet, C.J. 1961. A catalogue of British Columbia sea-bird colonies. Occasional Papers of the British Columbia Provincial Museurn Number 12.

Drent, R.H.; Van Tets, G.F.; Tompa, F.; Vermeer, Kees. 1964. The breeding birds of Mandarte Island, Britisb Columbia. Canadian Field-Naturalist 78: 208-263.

Drost, Charles A. 1994. Breeding ecology of Xantus' Murrelet on Santa Barbara Island, California (abstract). Pacific Seabirds 21(1): 37-38.

Drury, William H. 1979. Population dynamics in northern marine birds. In: Bartonek, James C.; Nettleship, David N., eds. Conservation of marine birds of northern North America. Wildlife Research Report 11. Washington, DC: U.S. Fisb and Wildlife Service; 123-139.

Dunning, John B. 1992. CRC Handbook of avian body masses. Boca Raton, FL: CRC Press; 371 p.

Dwyer, Thomas, J.; Isleib, M. "Pete": Davenport, David A.; Haddock, J.L. 1976. Marine bird populations in Prince William Sound, Alaska. Unpublished report on file. U.S. Fish and Wildlife Service, Anchorage, $A K ; 21 p$.

Eberl, C.; Picman, J. 1993. Effect of nest-site location on reproductive success of Red-throated Loons (Gavia stellara). Auk 110: 436-444.

Eby, J.R.; Snyder, M.C. 1990. The status of old growth in western Washington: A Landsat perspective. Report on file. Washington Department of Wildlife, Wildlife Management Division, Remote Sensing Program; 34 p.

Ecological Consulting. Inc. 1991. Assessment of direct seabird mortality in Prince William Sound and the western Gulf of Alaska resulting from the Exxon Valdez oil spill. Report on file. Ecological Consulting, Inc., 2735 N.E. Weidler Street, Portland, OR. 221 p.

Eisenhawer, A.E.; Reimcben, T.E. 1990. Inland flight patterns of Marbled Murrelets, Brachrramphus marmorarus, on the Queen Charlotte Islands, Britisb Columbia. Canadian Field-Naturalist 104(3): 439-444.

Ellioth, John E.; Butler, R.W.; Norstrom, R.J.; Whitehead, P.E. 1989. Environmental contaminants and reproductive success of Great Blue 
Herons (Ardea herdia) in British Columbia 1986-87. Environmental Pollution 59: 91-114.

Elliott, John E.; Noble, David G. 1993. Chlorinated hydrocarbon contaminants in marine birds of the temperate North Pacific. In: Vermeer, Kees; Briggs, Kenneth T.; Morgan, Ken H.; Siegel-Causey, Douglas, eds. The status, ecology and conservation of marine birds of the North Pacific. Special Publication. Ottawa, ON: Canadian Wildlife Service, Environment Canada; 241-253.

Elliott, John E.; Noble, David G.; Norstrom, R.J.; Whitehead, P.E. 1989. Organochlorine contaminants in seabird eggs from the Pacific coast of Canada, 1971-1986. Environmental Monitoring and Assessment 12: $67-82$.

Elliott, John E.; Noble, David G.; Norstrom, R.J.; Whitehead, P.E.; Simon, M.; Pearce, P.A.; Peakall, D.B. 1992. Patterns and trends of organic contaminants in Canadian seabird eggs, 1968-1990. In: Walker, C.R.; Livingstone, D., eds. Persistent pollutants in marine ecosystems. UK: Pergamon Press.

Elsukov, S.V. 1984. On sea coast avifauna of North Primorye territory. In: Kostenko, V.A.; Nazarenko, A.A., eds. Faunistics and biology of birds in the South Far East. Vladivostok. (in Russian).

Emms, S.K.; Verbeek, N.A.M. 1989. Significance of the pattern of nest distribution in the Pigeon Guillemot (Cepphus columba). Auk 106(2): 193-202.

Emslie, Steven D.; Henderson, R. Philip; Ainley, David G. 1990. Annual variation of primary molt with age and sex in Cassin's Auklet. Auk 107(4): 689-695.

Emslie, Steven D.; Sydeman, William J.; Pyle, Peter. 1992. The importance of mate retention and experience on breeding success in Cassin's Auklet (Ptychoramphus aleuticus). Behavioral Ecology 3(3): 189-195.

Erickson, D.; Morlan, J. 1978. The autumn migration: middle Pacific coast region. American Birds 32: 250-255.

Erickson, Richard A.; Hamilton, Robert A.; Howell, Steven N.G.; Patten, Michael A.; Pyle, Peter. 1994. First record of Marbled Murrelet and third record of Ancient Murrelet for Mexico. Unpublished manuscript supplied by author.

Evans, Peter G.H. 1981. Ecology and behaviour of the Little Auk Alle alle in west Greenland. lbis 123(1): 1-18.

Evans, Peter G.H.; Nettleship, David N. 1985. Conservation of the Atlantic Alcidae. In: Nettleship, David N.; Birkhead, Tim R., eds. The Allantic Alcidae. London: Academic Press; 427-488.

Ewins, Peter J. 1988. The timing of moult in Black Guillemots Cepphus grylle in Shetland. Ringing and Migration 9: 5-10.

Ewins, Peter J. 1993. Pigeon Guillemot (Cepphus columba). In: Poole, Alan; Gill, Frank, eds. The birds of North America, No. 49. Philadelphia, PA: The Academy of Natural Sciences; Washington, DC: The American Ornithologists' Union.

Ewins, Peter J.; Carter, Harry R.; Shibaev, Yurij V. 1993. The status, distribution, and ecology of inshore fish-feeding alcids (Cepphus guillemots and Brachyramphus murrelets) in the North Pacific. In: Vermeer, Kees; Briggs, Kenneth T.; Morgan, Ken H.; Siegel-Causey, Douglas, eds. The starus, ecology and conservation of marine birds of the North Pacific. Special Publication. Ottawa, ON: Canadian Wildlife Service, Environment Canada; 164-175.

Exler, J. 1987. Composition of foods: finfish and shellfish products. Agric. Handb. No. 8-15. Wahington, DC: U.S. Department of Agriculture.

Exxon Valdez Oil Spill Trustee Council. 1994. Status report on the Exxon Valdez oil spill-five years later. Unpublished report on file. Oil Spill Information Center, Anchorage, AK.

Fadely, Janey; Gerlach, Thomas P.; Cody, Mary B. 1993. Distribution and population estimates of marine birds in the near-shore and pelagic waters of Afognak lsland, Alaska. Biological report. Anchorage, AK: U.S. Fish and Wildlife Service, Division of Realty; 18 p.

Field, L.J. 1988. Pacific sand lance, Ammodytes hexapterus, with notes on related Ammodytes species. In: Wilimovsky, N.J.; Incze, L.C.; Westerheim, S.J., eds. Species synopses: life histories of selected fish and shellfish of the Northeast Pacific and Bering Sea. Seattle, WA: University of Washington; 15-33.
Fimreite, N.; Holsworth, W.N.; Keith, J.A.; Perce, P.A.; Gruchy, 1.M. 1971. Mercury in fish and fish-eating birds near sites of industrial contamination in Canada. Canadian Field-Naturalist 85: 211-220.

Flather, C.H.; Macneal, R. 1993. DISPLAY Spatial analysis computer program. Fort Collins, CO: U.S. Department of Agriculture, Forest Service, Rocky Mountain Forest and Range Experiment Station.

Fogarty, M.J.; Cohen, E.B.; Michaels, W.L.; Morse, W.W. 1991. Predation and the regulation of sand lance populations: an exploratory analysis. ICES Marine Science Symposium 193: 120-124.

Folliard, Lee. Wildlife Biologist, Simpson Timber Company, Arcata, CA. [Personal communication].

Ford, Cheri. USDA Forest Service, Tongass National Forest, Thorne Bay Ranger District, Thorne Bay, AK 99919. [Personal communication].

Ford, Cheri; Brown, Mike. 1994. Unusual Marbled Murrelet nest discovered in southeast Alaska (abstract). Pacific Seabirds 21(1): 38-39.

Ford, R. Glenn; Bonnell, M.L.; Varoujean, Daniel H.; Page, G.W.; Sharp, B.E.; Heinemann, D.; Casey, J.L. 1991a. Assessment of direct mortality in Prince William Sound and the western Gulf of Alaska resulting from the Exxon Valdez oil spill. Report on file; Ecological Consulting, Portland, $O R$.

Ford, R. Glenn; Casey, J.L.; Hewitı, D.B.; Varoujean, Daniel H.; Warrick, D.R.; Williams, W.A. 1991 b. Seabird mortality resulting from the Nestucca oil spill incident, winter 1988-1989. Report on file. Ecological Consulting, Portland, OR.

Ford, R. Glenn; Page, Gary W.; Carter, Harry R. 1987. Estimating mortality of seabirds from oil spills. In: Proceedings of the 1987 oil spill conference. Washington, D.C.: American Petroleum Institute; 747-751.

Forsell, Douglas J. Refuge Biologist, 6 Arlie Drive, Annapolis, MD 21401. [Personal communication].

Forsell, Douglas J.; Gould, Patrick J. 1981. Distribution and abundance of marine birds and mammals wintering in the Kodiak area of Alaska. FWS/OBS 81/13. Washington, DC: U.S. Fish and Wildlife Service.

Fortna, David. Biologist, P.O. Box 371, Orick, California. [Personal communication].

Fox, Lawrence. Professor, Department of Forestry, Humboldt State University, Arcata, CA 95521. [Personal communication].

Franklin, Jerry F.; Dymess, C.T. 1973. Natural vegetation of Oregon and Washington. Gen. Tech. Rep. PNW-8. Portland, OR: Pacific Northwest Experiment Station, Forest Service, U.S. Department of Agriculture; 417 p.

Franklin, Jerry F.; Hall, F.; Laudenslayer, W; Maser, C.; Nunan, J.; Poppino, J.; Ralph, C. John; Spies, Thomas. 1986. Interim definitions for oldgrowth Douglas-fir and mixed-conifer forests in the Pacific Northwest and California. Research Note PNW-447. Portland, OR: Pacific Northwest Experiment Station, Forest Service, U.S. Department of Agriculture; $7 \mathrm{p}$.

Freeland, H. Institute of Ocean Sciences, Box 600, Sidney, BC, Canada V8L 4B2. [Personal communication].

Freethy, Ron. 1987. Auks. New York: Facts on File Publications; 208 p.

French, C. 1993. Population levels and seasonal movements of Marbled Murrelets in the Juan Perez Sound area of Gwaii Haanas/South Moresby National Park Reserve. 1992. Report on file. Canadian Parks Service, Queen Charlotte City, British Columbia. 22 p. + appendices.

Fretwell, S.D.; Lucas, H., Jr. 1969. On territorial behavior and other factors influencing habitat distribution in birds. 1. Theoretical development. Acta Biothcoretica 19:16-36.

Friesen, Vicki L.; Baker, Allan J.; Piatt, John F. 1994a. A molecular investigation of evolutionary relationships within the Alcidae (abstract). Pacific Seabirds 21(1): 39.

Friesen, Vicki L.; Baker, Allen J.; Piatt, John F. 1994b. Population genetics and the conservation of rare seabirds (abstract). Pacific Seabirds 21(1): 39 .

Fuhr, B. Regional Habitat Biologist, Ministry of Environment, Lands and Parks, Smithers, BC, Canada V0J 2N1. [Personal communication].

Furness, R.W. 1984. Modelling relationships among fisheries, seabirds, and marine mammals. In: Nettleship, David N.; Sanger, Gerald A.; Springer, Paul F., eds. Marine birds: their feeding ecology and 
commercial fisheries relationships. Special Publication. Ottawa, Canada: Canadian Wildlife Service, Minister of Supply and Services; 117-126.

Furness, R.W.; Monaghan, P. 1987. Seabird ecology. London: Blackie and Son Lid. 164 p.

Gaillard, J.-M.; Pontier, D.; Allaine, D.; Lebreton, J.-D. 1989. An analysis of demographic tactics in birds and mammals. Oikos 56:59-76.

Gaston, Anthony J. 1985. Development of the young in the Atlantic alcidae. In: Nettleship, David N.; Birkhead, Tim R, eds. The Atlantic Alcidae. London: Academic Press; 319-354.

Gaston, Anthony J. 1989. Notes on Marbled Murrelet surveys carried out around Louise Island, 26 May - 9 June 1989. Unpublished notes on file. Canadian Wildlife Service, Ottawa.

Gasion, Anthony J. 1990. Population parameters of the Ancient Murrelet. Condor 92(4): 998-1011.

Gaston, Anthony J. 1991. Laskeek Bay Conservation Society report on scientific activities in 1990. Report on file. Queen Charlotte City, BC: Laskeek Bay Conservation Society.

Gaston, Anthony J. 1992. The Ancient Murrelet: a natural history in the Queen Charlotte 1slands. London: T \& AD Poyser; 249 p.

Gaston, Anthony J. 1994. Impact of predation by raccoons on seabirds breeding in Haida Gwaii (Queen Charlotte Islands), British Columbia (abstract). Pacific Seabirds 2](1): 40.

Gaston, Anthony J.; Brown, R.G.B. 1991. Dynamics of seabird distributions in relation to variations in the availability of food on a landscape scale. In: Bell, B.D.; Cossee, R.O.; Flux, J.E.C.; Heather, B.D.; Hitchmough, R.A.: Robertson, C.J.R.; Williams, M.J., eds. Bird conservation at a landscape scale. ACTA XX Congressus Internationalis Ornithologici (New Zealand) 4: 2306-2312.

Gasion, Anthony J.; Carter, Harry R.; Sealy, Spencer, G. 1993. Winter ecology and diet of Ancient Murrelets off Victoria, British Columbia. Canadian Journal of Zoology 71(1): 64-70.

Gaston, Anthony J.; Collins, Bruce T.; Diamond, Anthony W. 1987. Estimating densities of birds at sea and the proportion in fligbt from counts made on transects of indefinite width. Occasional Paper No. 59. Ottawa, ON: Canadian Wildlife Service; 16 p.

Gaston, Anthony J.; Heise, K. Laskeek Bay Conservation Society repon on scientific activities No. 4: 1993. Queen Charlotte City, B.C.: Laskeek Bay Conservation Society. [In press].

Gaston, Anthony J.; Jones, lan L. 1989. The relative importance of stress and programmed anorexia in determining mass loss by incubating Ancient Murrelets. Auk 106(4): 653-658.

Gaston, Anthony J.; Lawrence, A. 1993. Laskeek Bay Conservation Society report on scientific activities No. 3: 1992. Report on file. Queen Charlotte City, BC: Laskeek Bay Conservation Society.

Gaston, Anthony J.; Lawrence, A.; French, C. 1992. Laskeek Bay Conservation Society report on scientific activities in 1991. Report on file. Queen Charlotte City, BC: Laskeek Bay Conservation Society.

Gaston, Anthony J.; Nettleship, David N. 1981. The Thick-billed Murres of Prince Leopold Island-a study of the breeding ecoiogy of a colonial high Arctic sea bird. Monograph series No. 6. Ottawa, ON: Canadian Wildlife Service; 350 p.

Gaston, Anthony J.; Powell, David W. 1989. Natural incubation, egg neglect, and hatchability in the Ancient Murrelet. Auk 106(3): 433-438.

Gates, J.E.; Gysel, L.W. 1978. Avian nest dispersion and fledgling success in field-forest ecotones. Ecology 59(5): 871-883.

Gilchrist, Grant. 1994. Effects of gull predation at a declining Thick-billed Murre colony (abstract). Pacific Seabirds 21(1): 40.

Gill, Robert E.; Petersen, Margaret R.; Jorgensen, P.D. 1981. Birds of the north central Alaska peninsula, 1976-1980. Arctic 34: 286-306.

Girsa, I.I.; Danilov, A.N. 1976. The defensive behavior of the White Sea sand lance Ammodytes hexapterus. Journal of Icbthyology 16: 862-865.

Gizenko, A.G. 1955. Birds of Sakhalin Oblast. Moscow. (in Russian).

Gluscbenko, Y.N. 1988. Notes on the avifauna of the South Sakhalin oblast. In: Litvinenko, N.M., ed. Rare birds of the Far East and their protecture; Vladivostok: Akademia Nauk SSSR 62-63. (in Russian).

Gluschenko, Y.N.; Stibaev, Yurij V.; Medvedev, V.N. 1986. Notes on new birds for Primorye and rare birds. In: Neufeidt, 1.A., ed. The distribution and biology of birds of the Altai and the Far East. Proceedings of the Zoological Institute 150; 83-84. (in Russian).

Goering, John J.; Shiels, W.E.; Patton, C.J. 1973. Primary Production. In: Hood, Donald W.; Sheils, W.E.; Kelly, EJ., eds. Occasional Publication No. 3. Fairbanks, AK: Institute of Marine Science, University of Alaska; 251-278.

Goggans, Rebecca. Wildlife Diversity Biologist, Oregon Department of Fish and Wildife, Corvallis, OR. [Personal communicatioo].

Goldwasser, L.; Roughgarden, J. 1993. Construction and analysis of a large Caribbean food web. Ecology 74: 1216-1233.

Goodwin, D. 1976. Crows of the world. Ithaca, NY: Cornell University Press; 354 p.

Götmark, Frank. 1992. The effects of investigator disturbance on nesting birds. Current Ornithology 9: 63-104.

Götmark, Frank; Winster, D.W.; Andersson, Mälte. 1986. Flock-feeding on fisb schools increases individual success in gulls. Nature (London) 319:589-591.

Gould, Patrick J.; Forsell, Douglas J. 1989. Techniques for shipboard surveys of marine birds. Fish and Wildlife Technical Report 25. Washington, DC: U.S. Fish and Wildlife Service.

Green, K.; Bernath, Stephen; Lackey, L.; Brunengo, M.; Smith, S. 1993. Analyzing the cumulative effects of forest practices: where do we start? Geolnfo Systems 3: 31-41.

Greenwood, J.G. 1987. Winter visits by Black Guillemots, Cepphus grolle, to an Irish breeding site. Bird Study 34: 135-136.

Greenwood, P.J.; Harvey, P.H. 1982. The natal and breeding dispersal of birds. Annual Review of Ecology and Systematics 13: 1-21.

Grenier, Jeffrey J.; Nelson, S. Kim. 1994. Habitat characteristics of Marbled Murrelet occupied sites on state lands in Oregon. Publication no. 93-9. 01. Portland, OR. Nongame Program, Oregon Department of Fish and Wildlife.

Grenier, Jeffrey: Nelson, S. Kim. Marbled Murrelet habitat associations in Oregon. [This volume].

Gress, F.; Risebrough, R.W.; Anderson, D.W.; Kiff, L.F.; Jehl, J.R., Jr. 1973. Reproductive failures of Double-crested Cormorants in southern California and Baja California. Wilson Bulletin 85: 197-208.

Grinnell, Joseph. 1897. Notes on the Marbled Murrelet. Osprey 1: 115-117.

Grinnell, Joseph. 1910. Birds of the 1908 Alexander Alaska Expedition. University of California Publications in Zoology 5: 361-428.

Grover, J.J.; Olla, B.L. 1983. The mole of Rhinoceros Auklet (Cerorhinca monocerata) in mixed-species feeding assemblages in the Strait of Juan de Fuca, Washington. Auk 100: 979-982.

Guggisberg, C.A.W. 1970. Man and wildlife. New York: ARCO Publishing Company, Inc.; 224 p.

Guiguet, Charles J. 1956. Enigma of the Pacific. Audubon 58: 164-167, 174.

Guiguet, Charles J. 1971. A list of seabird nesting sites in Barkley Sound. British Columbia. Syesis 4: 253-259.

The Habitat Restoration Group. 1992. Marbled Murrelet Monitoring Program. Report on file. Big Creek Lumber Company, Davenport, CA.

Hagan, John M. III; Johnson, David W., eds. 1992. Ecology and conservation of neotropical migrant landbirds. Washington, DC: Smithsonian Press; 609 p.

Halley, D.J.; Harris, M.P. 1992. Intercolony movement and behavior of immature guillemots Uria aalge. Ibis 135: 264-270.

Hamer, Thomas E. 1993. Guidelines for collecting data at Marbled Murrelet nest trees or landing trees. Available from: Pacific Seabird Group Marbled Murrelet Technical Committee, U.S. Fish and Wildlife Service, 1011 E. Tudor Rd. Anchorage, AK 95503-6199.

Hamer, Thomas E. Inland babitat associations of Marbled Murrelets in western Washington. [This volume].

Hamer, Thomas E. Hamer Environmental, 615 State Street, Sedro Wooley, WA 98284 [Personal communication].

Hamer, Thomas E; Cummins, Eric B. 1990. Forest habitat relationships of Marbled Murrelets in northwestern Washington. Report on file. Washington Dept. of Wildlife, Nongame program, Olympia, WA; 51 p.

Hamer, Thomas E.; Cummins, Eric B. 1991. Relationships between forest characteristics and use of inland sites by Marbled Murrelets in nonhern 
Washington. Report on file; Washington Dept. of Wildlife, Nongame program, Olympia, WA; $47 \mathrm{p}$.

Hamer, Thomas E.; Nelson, S. Kim. Nesting chronology and behavior of the Marbled Murrelet. [This volume a].

Hamer, Thomas E.; Nelson, S. Kim. Characteristics of Marbled Murrelet nest trees and nesting stands. [This volume b].

Hamer, Thomas E.; Ritchie, William P.; Cummins, Eric B.; Turley, Charles W. 1993. Forest habitat relationships of Marbled Murrelets in northwestern Washington. Report on file. Washington Department of Wildlife, Nongame program, Olympia, WA.

Hansen, Andrew J.; Spies, Thomas A.; Swanson, Frederick J.; Ohmann, J.L. 1991. Conserving biodiversity in managed forests. BioScience. 41:382-392.

Hanski, 1. 1982. Dynamics of regional distribution: the core and satellite species hypothesis. Oikos 38:210-221.

Hanson, W.R. 1963. Calculation of productivity, survival, and abundance of selected vertebrates from sex and age ratios. Wildlife Monographs 9.

Hardin, Janet. Data on file: Cooperative Wildlife Research Unit; Oregon State University, Corvallis, OR 97331. [Personal communication].

Hardy, A. 1965. The open sea: Its natural history. Boston, MA: Houghton Mifflin Company. 657 p.

Harfenist, Anne. 1994. Impact of introduced rats on the breeding Ancient Murrelets (Synthliboramphus antiquus) of Langara Island and the feasibility of rat eradication (abstract). Pacific Seabirds 21(1): 41 .

Harfenist, Anne. Canadian Wildlife Service, Box 340, Delta, BC, Canada V4K 3Y3. [Personal communication].

Hargreaves, B. Pacific Biological Station, Nanaimo, BC, Canada V9R 5K6. [Personal communication].

Harris, Larry D. 1984. The fragmented forest: island biogeography theory and the preservation of biotic diversity. Chicago, IL: University of Chicago Press; 211 p.

Harris, Michael P. 1983. Biology and survival of the immature Puffin, Fratercula arctic. Ibis 125:56-73.

Harris, Michael P. 1985. Morphology and breeding of puffins at Isle of May and St. Kilda, Scotland. Biological Conservation 32: 81-97.

Harris, Michael P.; Birkhead, Tim R. 1985. Breeding ecology of the Atlantic alcidae. In: Nettleship, David N.; Birkhead, Tim R., eds. The Atlantic Alcidae. London: Academic Press; 156-204.

Harris, Michael P.; Halley, D.J.; Swann, R.L. 1994. Age of first breeding in Common Murres. Auk 111: 207-209.

Harris, Michael P.; Hislop, J.R.G. 1978. The food of young puffins Fratercula arctica. Journal of Zoology (London) 185(1978): 213-236.

Harris, Michael P.; Wanless S. 1989. Fall colony attendance and breeding success in the Common Murre. Condor 91: 139-146.

Harris, Michael P.; Wanless, S. 1990. Breeding success of British Kittiwakes (Rissa tridactyla) in 1986-88: evidence for changing conditions in the northern North Sea. Journal of Applied Ecology 27: 172-187.

Harris, Michael P.; Wanless, S. 1991. Population studies and conservation of Puffins Fratercula arctica. In: Perrins, C.M.; Lebreton, J.D.; Hirons, G., eds. Bird population studies: relevance to conservation and management. Oxford, UK: Oxford University Press; 230-248.

Harris, R.D. 1971. Further evidence of tree nesting in the Marbled Murrelet. Canadian Field-Naturalist 85: 67-68.

Harrison, Craig S. 1982. Spring distribution of marine birds in the Gulf of Alaska. Condor 84(3): 245-254.

Harrison, Peter. 1983. Seabirds: an identification guide. Boston, MA: Houghton Mifflin Company.

Hart, J.L.; McHugh, J.L. 1944. The smelts (Osmeridae) of British Columbia. Bulletin Fisheries Research Board Canada LXIV: 1-27.

Hart, L.E.; Cheng, K.M.; Whitehead, P.E.; Shah, R.M.; Lewis, R.J.; Ruschkowski, S.R.; Blair, R.W.; Bennett, D.C.; Bellward, G.D.; Bandiera, S.M. 1990. Effects of dioxin contamination on the growth and development of great blue heron embryos. Unpublished manuscript supplied by author.

Hatch, Scott A.; Hatch, Martha A. 1983. Populations and habitat use of marine birds in the Semidi Islands, Alaska. Murrelet 64: 39-46.

Hatch, Scott A.; Hatch, Martha A. 1990a. Breeding seasons of oceanic birds in a subarctic colony. Canadias Journal of Zoology 68: 1664-1679.
Hatch, Scott A.; Hatch, Martha A. 1990b. Components of breeding productivity in a marine bird community: key factors and concordance. Canadian Journal of Zoology. 68: 1680-1690.

Hatler, D.F.; Campbell, R.W.; Dorst, A. 1978. Birds of the Pacific Rim National Park. Occasional Paper No. 20. Vancouver, BC: British Columbia Provincial Museum; 194 p.

Hawksworth, F.G. 1977. The 6-class dwarf mistletoe rating system. Gen. Tech. Rep. RM-48. Fort Collins, CO: Rocky Mountain Research Station, Forest Service, U.S. Department of Agriculture; 7 p.

Heinl, S. 1988. Field notes: western Oregon, August-November 1987. Oregon Birds 14: 291.

Hejl, Sally J. 1992. The importance of landscape patterns to bird diversity: a perspective from the northern Rocky Mountains. Northwest Environmental Journal 8:119-137.

Hemstrom, Miles A.; Logan, Sheila E. 1986. Plant association and management guide: Siuslaw National Forest. Publication R6-Ecol 220 1986a. Corvallis, OR: Pacific Northwest Region, Forest Service, U.S. Department of Agriculture; $121 \mathrm{p}$.

Henderson, J.A.; Lesher, R.D.; Peter, D.H.; Shaw, D.C. 1991. Field guide to the forested plant associations of the Mt. Baker-Snoqualmic National Forest. Technical Paper \#028-91. Portland, OR: Pacific Northwest Region, Forest Service, U.S. Dept. Agriculture; 189 p.

Henderson, J.A.; Peter, D.H.; Lesher, R.D.; Shaw, D.C. 1989. Forested plant associations of the Olympic National Forest. Technical Paper \#001-88. Portland, OR: Pacific Northwest Region, Forest Service, U.S. Dept. Agriculture; 502 p.

Henny, Charles J.; Blus, Lawrence J.; Grove, Robert A. 1990. Western Grebe, Aechmophorus occidentalis, wintering biology and contaminant accumulation in Commencement Bay, Puget Sound, Washington. Canadian Field Naturalist 104(3): 460-472.

Herz, M.J.; Kopec, D. 1985. Analysis of the Puerto Rican tanker incident, recommendations for future oil spill response capability. Report on file. Tiburon Center for Environmental Studies, Tiburon, CA.

Hirsch, Katherine V.; Woodby, Douglas A.; Astheimer, Lee B. 1981. Growth of a nestling Marbled Murrelet. Condor 83(3):264-265.

Hislop, J.R.G.; Harris, M.P.; Smith, J.G.M. 1991. Variation in the calorific value and total energy content of the lesser sandeel (Ammadytes marinus) and other fish preyed on by seabirds. Journal of Zoology (London) 224: 501-517.

Hobson, K.A. 1990. Stable isotope analysis of Marbled Murrelets: evidence for freshwater feeding and determination of trophic level. Condor 92: 897-903.

Hobson, K.A.; Alisauskas, R.T.; Clark, R.G. 1993. Stable-nitrogen isotope enrichment in avian tissues due to fasting and nutritional stress: implications for isotopic analyses of diet. Condor 95: 388-394.

Hodder, Jan; Greybill, Michael R. 1985. Reproduction and survival of seabirds in Oregon during the 1982-83 El Niño. Condor 87: 535-541.

Hoffman, David J.; Ratıner, Barnett A.; Bunck, Christine M.; Krynitsky, Alex; Ohlendorf, Harry M.; Lowe, Roy W. 1986. Association between PCBs and lower embryonic weight in Black-Crowned Night Herons in San Francisco Bay. Journal of Toxicology and Environmental Health 19: 383-391.

Hoffman, Wayne; Heinemann, Dennis; Wiens, John A. 1981. The ecology of seabird feeding flocks in Alaska. Auk 98: 437-456.

Hofstra, Terry. Redwood National Park, 1125 16th St., Arcata, CA 95521. [Personal communication].

Holmgren-Urba, D.; Baumgartner, T.R. 1993. A 250-year history of pelagic fish abundances from the anaerobic sediments of the central Gulf of California. California Cooperative Oceanic Fisheries Investigations Report, Vol. 34; 60-68.

Holt, S. 1993. On loving whales, krill, and marine ecosystems. Conservation Biology 7: 451-452.

Holtrop, Karen. Wildlife Biologist, USDA Forest Service, Olympic National Forest, Quilcene Ranger District, Quilcene, WA. [Personal communication].

Hose, J.E.; Biggs, E.; Baker, T. 1993. Effects of the Exxon Valdez oil spill on herring embryos and larvae: sublethal assessments, 1989-1991. Exxon 
Valde: oil spill symposium abstract book. Anchorage, AK: Exxon Valdez Oil Spill Trustee Council, Oil Spill Public Information Center.

Hosmer, D.W.; Lemeshow, S. 1989. Applied logistic regression. New York: John Wiley and Sons; 307 p.

Hudson, P.J. 1985. Population parameters for the Atlantic Alcidae. In: Netuleship, David N.; Birkhead, Tim R, eds. The Atlantic Alcidae. New York: Academic Press; 233-261.

Hughes, Jeff H. Nongame Wildlife Program, Alaska Department of Fish and Game, 333 Raspberry Road, Anchorage, AK 99503. [Personal communication].

Hughes, Stephanie K. Biologish, Tofino, British Columbia. [Personal communication].

Hunt, George L., Jr. Oceanographic processes and marine productivity in waters offshore of Marbled Murrelet breeding habitat. [This volume a].

Hunt, George L., Jr. Monospecific and mixed species foraging associations of Marbled Murrelets. [This volume b].

Hunt, George L.. Jr. Professor, University of California, Irvine, CA. [Personal communication].

Hunter, John. USDA Forest Service, Six Rivers National Forest, Eureka, Californai. [Personal communication].

Husband, V.; Frampton, G.T., Jr. 1991. Ancient rainforests at risk: an interim report by the Vancouver Island Mapping Project. Victoria, B.C.: Sierra Club of Western Canada; and Seanle, WA: The Wilderness Society.

Ingmanson, D.E.; Wallace, WJ. 1989. Introduction to oceanography. 4th ed. Belmont, CA: Wadworth Publishing.

Irons, David B. 1992. Aspects of foraging behavior and reproductive biology of the black-legged kittiwake. Irvine, CA: University of California. Ph.D. Dissertation

lrons, David; Nysewander, David; Trapp, John L. 1985. Prince William Sound waterbird distributions in relation to habitat type. Unpublished report on file. U.S. Fish and Wildlife Service, Anchorage, AK. 24 p.

lsleib, M.E. "Pete". [Letter to Harry R. Carter]. 1982. February 25. Located at: U.S. Deparment of the Interior, National Biological Service, Dixon, CA.

Isleib, M.E. "Pete". 9229 Emily Way, Juneau, AK 99801 (deceased). [telephone conversation with Katherine J. Kuletz]. December 1992.

Iverson, Chris. USDA Forest Service, Region 10 Regional Office, P.O. Box 21628, Juneau, AK 99801. [Personal communication].

Jackson, J.A. 1977. Alleviating problems of competition, predation, parasitism, and disease in endangered birds, a review. In: Temple, Stanley A., ed. Endangered birds, management techniques for preserving threatened species. Madison, WI: University of Wisconsin Press; 466 p.

Jefferies, Steven J.; Brown, Robin F. 1993. Observations of seabird entanglements in the Columbia River, Willapa Bay, and Grays Harbor Salmon Driftnet Fisheries, 1991-1993. Report on file. Tacoma, WA: Washington Deparment of Wildlife; and Newport, OR: Oregon Department of Fish and Wildlife.

Jehl, D.R; Jehl, Joseph R., Jr. 1981. A North American record of the Asiatic Marbled Murrelet (Brachyramphus marmoratus perdix). American Birds 35: 911-912.

Jewett, S.G. 1930. Notes on the Dowell bird collection. Condor 32:123-124.

Jeweth, S.G.; Taylor, W.P.; Shaw, W.T.; Aldrich, J.W. 1953. Binds of Washington State. Searle, WA: University of Washington Press; 767 p.

Johnsgard, P.A. 1987. Diving birds of North America. Lincoln, NE: University of Nebraska Press.

Johnson, David J. 1992. Spotted owls, great homed owls, and forest fragmentation in the central Oregon Cascades. Corvallis: Oregon State University: 125 p. M.S. Thesis.

Johnson, M.A.; O'Brien, JJ. 1990. The northeast Pacific Ocean response to the 1982-83 El Niño. Journal of Geophysical Research 95(C5): 7155-7166

Johnson, M.E.; Snook, H.J. 1967. Seashore animals of the Pacific Coast. New York: Dover Publications, Inc. 659 p.

Johnson, S.R.; West, G.C. 1975. Growth and development of heat regulation in nestlings, and metabolism of adult Common and Thick-billed murres. Ornis Scandinavica 6: 109-115.
Johnston, S.; Carter, Harry R. 1985. Cavity-nesting Marbled Murrelets. Wilson Bulletin 97: 1-3.

Jones, Ian L. 1990. Plumage variability functions for status signalling in Least Auklets. Animal Behaviour 39: 967-975.

Jones, lan L. 1992. Factors affecting survival of adult Least Auklets (Aethia pusilla) at St. Paul lsland, Alaska. Auk 109(3): 576-584.

Jones, Ian L. 1993a. Crested Auklet (Aethia cristatella). In: Poole, Alan; Gill, Frank, eds. The birds of North America, No. 70. Philadelphia, PA: The Academy of Natural Sciences; and Washington, DC: The American Ornithologists" Union.

Jones, Ian L. 1993b. Least Auklet (Aethia pusilla). In: Poole, Alan; Gill, Frank, eds. The Birds of North America, No. 69. Philadelphia, PA: The Academy of Natural Sciences; and Washington, DC: The American Ornithologists' Union.

Jones, Ian L. 1994. Mass changes of Least Auklets Aerhia pusilla during the breeding season: evidence for programmed loss of mass. Journal of Animal Ecology 63: 71-78.

Jones, Ian L. Simon Frasier University, Burnaby, British Columbia, Canada. [Personal communication].

Jones, lan L.; Falls, J. Bruce. 1987. Colony departure of family groups of Ancient Murrelets. Condor 89(4): 940-943.

Jones, Ian L.; Montgomerie, R.D. 1991. Mating patterns of Least Auklets Aethia pusilla in relation to plumage and ornamentation. Behavioral Ecology 2: 249-257.

Jones, Linda L.; DeGange, Anthony R. 1988. Interactions between seabirds and fisheries in the Northern Pacific Ocean. In: Burger, Joanna, ed. Seabirds and other marine vertebrates: competition, predation and other interactions. New York: Columbia University Press; 261-290.

Jones, Paul H. 1992. Marbled Murrelet flight behaviour at a presumed nesting area in the Caren Range, near Sechelt, British Columbia. British Columbia Birds 2: 14-18.

Jones, Paul H. 1993. Canada's first active Marbled Murrelet nest discovered and observations. British Columbia Naturalist 31(6): 8.

Jones, Paul H. Friends of Caren. Box 272, Madeira Park, BC, Canada VON 2H0. [Personal communication].

Jones, Paul H.; Dechesne, Sharon. 1994. Canada's first active Marbled Murrelet nest (abstract). Pacific Seabirds 21(1): 42-43.

Jordan, D.S.; Starks, E.C. 1896. The fishes of Puget Sound. Proceedings California Academy Sciences (2nd series) 5: 785-855.

Jordan, Kevin M.; Hughes, Stephanie K. Discovery of three Marbeld Murrelet tree nests, British Columbia 1992. In: Nelson, S. Kim; Sealy, Spencer G., eds. Biology of Marbled Murrelets: inland and at sea-a symposium of the Pacific Seabind Group 1993. Northwestern Naturalist. [In press].

Kaiser, Gary W. 1993. Seabind wreck in Boundary Bay. Pacific Seahird Group Bulletin 20(2): 18-20.

Kaiser, Gary W. Canadian Wildlife Service, P.O. Box 340, Delta, B.C. V4K 3Y3. [Personal communication].

Kaiser, Gary W.; Barclay, HJ.; Burger, Alan E; Kangasnierni, D.; Lindsay, D.J.; Munro, W.T.; Pollard, W.R.; Redhead, R.; Rice, J.; Seip, D. 1992. National Recovery Plan for the Marbled Murrelet. Report No. 8. Ottawa, ON: Recovery of Nationally Endangered Wildlife Committee, Canadian Wildlife Service; 36 p.

Kaiser, Gary W.; Mahon, T.E;; Fawceth, Michael D. 1991. Studies of Marbled Murrelets in marine habitats, during 1990. Technical Report Series No. 131. Delta, BC: Canadian Wildlife Service, Pacific and Yukon Region; 52 p.

Kartashev, N.N. 1979. Materials on biology of Alcidae at Komandorskie Islands. Ornitologiya 14:144-149. (in Russian).

Kay, B.H. 1989. Pollutants in British Columbia's marine environment: a status report. Unpublished report, SOE Rep. No. 89-1. Vancouver, BC: Environment Canada, Environmental Protection Directorate.

Keitt, B.S. 1991. A survey of the behavior of the Marbled Murrelet along flight corridors and at nesting areas. Santa Cruz, CA: University of California; 18 p. B.Arts Thesis.

Kelly, Paul R. California Department of Fish and Game, Office of Oil Spill Prevention and Response, Sacramento, CA. [Telephone conversation with Harry R. Carter]. May 1994. 
Kelson, John D. Wildlife Biologist, Conservation Intemational, Tucker Bay Road, Lasqueti Island, BC, Canada VOR 2J0. [Personal communication].

Kelson, John D.; Manley, Irene. 1993. Assessment of change in population size for Marbled Murrelets in Clayoquot Sound, British Columbia: 1982 to 1992 (Abstract). Pacific Seabird Group Bulletin 20(1): 43.

Kelson, John D.; Manley, Irene A.; Carter, Harry R. Decline of Marbled Murrelets in Clayoquot Sound, British Columbia: 1982-1993. In: Nelson, S. Kim; Sealy, Spencer G., eds. Biology of Marbled Murrelets: inland and at sea-a symposium of the Pacific Seabird Group 1993. Northwestern Naturalist. [In press].

Kems, Steven J. Biologist, Wildland Resource Managers, Round Mountain, CA. [Personal communication].

Kiff, Lloyd F. 1981. Eggs of the Marbled Murrelet. Wilson Bulletin 93: 400-403.

King, J.R.; Sanger, Gerald A. 1979. Oil vulnerability index for marine oriented birds. In: Bartonek, James C.; Nettleship, David N., eds. Conservation of marine birds of northern North America. Wildlife Research Report 11. Washington, DC: U.S. Fish and Wildlife Service; 227-239.

King, Warren B. 1984. Incidental mortality of seabirds in gillnets in the north Pacific. In: Croxall, John P.; Evans, Peter G.H.; Schreiber, Ralph W., eds. Status and conservation of the world's seabirds. Intemational Council for Bird Preservation (ICBP) Technical Publication No. 2; Norwich, UK: Page Bros.; 709-715.

King, Warren B.; Brown, R.G.B.; Sanger, Gerald A. 1979. Mortality to marine birds through commercial fishing. In: Bartonek, James C.; Nettleship, David N., eds. Conservation of marine birds of northern North America. Wildlife Research Report 11. Washington, DC: U.S. Fish and Wildlife Service; 195-199.

Kistchinsky, A.A. 1968a. Birds of the Kolymskogo Nagoria. Moscow, USSR: Nauka Publishing House.

Kistchinsky, A.A. 1968b. On the biology of Brachyramphus marmoratus and B. brevirostris). Ornitologiya 9: 208-213. (in Russian).

Kitaysky, Alexander S. 1994. Breeding biology, feeding ecology and growth energetics of the Spectacled Guillemot (abstract). Pacific Seabirds 21(1): 43.

Kittle, Lewey J.; Burge, Richard; Butler, Randy; Cook, Walter; Fresh, Kurt; Kyte, Micahel; Lowell, Richard; Pease, Richard; Pentilla, Dan; Scholz, Al; Speich, Steven; Steelquist, Robert; Walton, Jim. 1987. The Washington State Department of Ecology marine resource damage assessment report for the ARCO Anchorage oil spill, December 21, 1985 into Port Angeles harbor and the Strait of Juan de Fuca. Report on file. Washington Department of Ecology, Olympia, WA.

Klimkiewicz, M.K.; Futcher, A.G. 1989. Longevity records of North American Birds, Supplement 1. Joumal of Field Omithology 60(4): 469-494.

Klosiewski, Steven P.; Laing, Karen K. 1994. Marine bird populations of Prince William Sound, Alaska, before and after the Exxon Valdez Oil Spill. Report on file. Migratory Bird Management, U.S. Fish and Wildlife Service, Anchorage, AK; 88 p.

Knudtson, Eric P.; Byrd, G. Vernon. 1982. Breeding biology of Crested, Least, and Whiskered auklets on Buldir Island, Alaska. Condor 84(2):197-202.

Komaki, Y. 1967. On the surface swarming of euphausiid crustaceans. Pacific Science 21: 433-448.

Konarzewski, Marek; Taylor, Jan R.E.; Gabrielsen, Geir W. 1993. Chick energy requirements and adult energy expenditures of Dovekies (Alle alle). Auk 110(2): 343-353.

Kondratyev, Alexander Y. 1994. Population status and breeding biology of the Spectacled Guillemot (abstract). Pacific Seabirds 21(1): 43-44.

Kondratyev, Alexander Y. Institute for Biological Problems of the North, Russian Academy of Sciences, Magadan, Russia. [Personal communication].

Kondratyev, Alexander Y.; Nechaev, V.A. 1989. Marbled Murrelet. In: Kostenko, V.A.; Ler, P.A.; Nechaev, V.A.; Shibaev, Yurij V., eds. Rare vertebrates of the Soviet Far East and their protection; 142-143. (in Russian).
Kondratyev, Alexander Y.; Zubakin, V.A.; Golubova, E.Y.; Kondratyev, L.F.; Kharitonov, S.P.; Kitaysky, Alexander S. 1992. The fauna of mammals and birds of Talan Island. In: Tschemyavsky, F.B.; Kondratyev, Alexander Y, eds. Coastal ecosystems in the northern part of the Sea of Okhotsk. Talan Island; 72-115. (in Russian).

Konyukhov, Nicolai B. 1990a. Crested Auklet. In: Flint, V.E.; Golovkin, A.N., eds. Ptitsy SSSR: Chistikovyye [Birds of the USSR: Auks (Alcidae)]. Moscow, USSR: Nauka Publishing House; 112-121.

Konyukhov, Nicolai B. 1990b. Is it really an Ancient Murrelet? In: Kondratyev, Alexander Y., ed. Investigations of seabirds in the USSR; 44-45. (in Russian).

Konyukhov, Nicolai B.; Kitaysky, Alexander S. The Asiatic race of the Marbled Murrelet. [This volume].

Kostenko, V.A.; Ler, P.A.; Nechaev, V.A.; Shibaev, Yurij V. 1989. Rare vertebrates of the Soviet Far East and their protection. Leningrad, USSR: Nauka Publishing House, Leningrad branch.

Kozlova, E.V. 1957. Charadriiformes, Suborder Alcae. In: Fauna of the USSR. Birds 2(3): 1-140. Moscow, Leningrad. (In Russian; English translation by R. Ettinger, Israel Program for Scientific Translations, 1961).

Krasnow, L.D.; Sanger, Gerald A. 1982. Feeding ecology of marine birds in the nearshore waters of Kodiak Island. OCSEAP Final Rep. 45 (1986). Anchorage, AK: U.S. Department Commerce, National Oceanic and Atmospheric Administration; 505-630.

Kress, S.W.; Nettleship, David N. 1988. Re-establishment of Atlantic puffins (Fratercula arctica) at a former breeding site in the Gulf of Maine. Journal of Field Omithology 59(2): 161-170.

Kristan, Deborah. USDA Forest Service, Redwood Sciences Laboratory, 1700 Bayview Drive, Arcata, CA 95521. [Personal communication].

Krummel, J.R.; Gardner, R.H.; Sugihara, G.; O'Neill, R.V.; Coleman, P.R. 1987. Landscape pattems in disturbed environments. Oikos 48:321-324.

Kuletz, Katherine J. 1983. Mechanisms and consequences of foraging behavior in a population of breeding Pigeon Guillemots. Irvine, CA: University of Califomia; 79 p.; M.Sc. Thesis.

Kuletz, Katherine J. 1991 a. Summary of the Exxon Valdez damage assessment studies on the Marbled Murrelet. Unpublished report, U.S. Fish and Wildlife Service, Anchorage, AK.

Kuletz, Katherine J, 199lb. Restoration feasibility study number 4 identification of upland habitats used by wildlife affected by the EVOS: Marbled Murrelets. Anchorage, AK: U.S. Fish and Wildlife Service, Migratory Bird Management; 34 p.

Kuletz, Katherine J. 1994. Marbled Murrelet abundance and breeding activity at Naked lsland, Prince William Sound, and Kachemak Bay, Alaska, before and after the Exxon Valdez oil spill. Bird Study no. 6. Anchorage, AK: U.S. Fish and Wildlife Service; 46 p.

Kuletz, Katherine J. Marbled Murrelet abundance and breeding activity at Naked Island, Prince William Sound, and Kachemak Bay, Alaska, before and after the Exxon Valdez oil spill. In: Rice, Jeep; Wright, Bruce, eds. Proceedings of the Exoron Valdez oil spill symposium. American Fisheries Society. [In press].

Kuletz, Katherine J. Wildlife Biologist, Migratory Bird Management, U.S. Fish and Wildlife Service, 1011 E. Tudor Road, Anchorage, AK 99516. [Personal communication].

Kuletz, Katherine J.; Marks, Dennis K.; Naslund, Nancy L. 1994a. At-sea abundance and distribution of Marbled Murrelets in the Naked Island area in summer, 1991 and 1992. Anchorage, AK: U.S. Fish and Wildlife Service, Migratory Bird Management; 40 p.

Kuletz, Katherine J.; Marks, Dennis K.; Naslund, Nancy L.; Stevens, Niki G.; Cody, Mary B. 1994b. Information needs for habitat protection: Marbled Murrelet habitat identification. Final Report, Restoration Project 93051B. Anchorage, AK: U.S. Fish and Wildlife Service, Migratory Bird Management; 54 p.

Kuletz, Katherine J.; Naslund, Nancy L.; Marks, Dennis K. 1994c. Identification of Marbled Murrelet nesting habitat in the Exxon Valdez oil spill zone. Restoration Project R15 Final Report. Report on file. U.S. Fish and Wildlife Service, Migratory Bird Management, Anchorage, AK; $67 \mathrm{p}$. 
Kuletz, Katherine J.; Marks, Dennis K.; Naslund, Nancy L.; Cody, Mary B. Marbled Murrelet activity relative to forest characteristics in the Naked Island area, Prince William Sound, Alaska. In: Nelson, S. Kim; Sealy, Spencer G., eds. Biology of Marbled Murrelets: inland and at sea-a symposium of the Pacific Seabird Group 1993. Northwestem Naturalist. [In press].

Kuletz, Katherine J.; Maris, Deanis K.; Naslund, Nancy L.; Goodson, Nike J.; Cody, Mary. Inland habitat suitability for the Marbled Murreler in southcentral Alaska. [This volume].

Kuroda. N. 1967. Morpho-anatomical analysis of parallel evolution between Diving Petrel and Ancient Auk, with comparative osteological data of other species. Yamashina Institute for Omithology Misc. Repons 5: 111-137.

Kuzyakin, A.P. 1963. On the biology of the Marbled Murrelet. Ornitolgiya 6:315-320. (In Russian; English Translation in Van Tyne Memorial Library, University of Michigan, Ann Arbor, Michigan).

Laake, J.L.; Buckland, S.T.; Anderson, D.R.; Burnham, K.P. 1993. DISTANCE program and user's guide, v. 2.0. Fort Collins, CO: Colorado Cooperative Fish and Wildlife Research Unit, Colorado State University; 72 p.

Labzyuk, V.I. 1975. Summer avifauna of the sea coast in the vicinity of the Gulf of Olga. In: Nechaev, V.A., ed. Ornithological studies in the Soviet Far East; 279-284. (in Russian).

Labzyuk. V.I. 1987. A sudden occurrence of the nest of Brachyramphus mamoranus in Southern Primorye. In: Litvinenko, N.M., ed. Distribution and biology of seabinds of the Far East. Vladivostok, USSR: Akademiya Nauk SSSR; 85-86. (In Russian; English translation by P.T. Gilbert).

Lack, David. 1968. Ecological adaptations for breeding birds. Loodon: Methuen; 409 p.

Ladygin, Alexander. Kronotsky Reserve, Ryabihova Street, 48, Elizovo, Kamchatka Region, Russia. [Personal communication].

Laing, H.M. 1925. Birds collected and observed during the cruise of the Thiepval in the North Pacific, 1924. Victoria Memorial Museum Bulletin Number 40 . Biological Series, Number 9.

Laing, Karen K. Migratory Bird Management. U.S. Fish and Wildlife Service, 1011 E. Tudor Road, Anchorage, AK 99503. [Personal communication].

Lambeck. R.H.D. 1990. The applicability of age ratio and brood size counts in population dynamic studies of the Brent Goose Brania $b$. bernicla. Ardea 78: 414-425.

Lambert, T.C. 1987. Duration and intensity of spawning in berring (Clupea harengus) as related to the age structure of the mature population. Marine Ecological Progress Series 39: 209-220.

Lande, R. 1988. Demographic models of the torthern Spotted Ow] (Strix occidentalis caurina). Oecologia 75: 601-607.

Larkin, Peter A; Ricker, William E 1964. Canada's Pacific marine fisheries: past performance and future prospects. In: Inventory of the natural resources of British Columbia. British Columbia Natural Resources Conference Transactions. Victoria, BC; 194-268.

Lawrence, A.D. 5012 Old W'est Saanich Road, Victoria, BC, Canada V8W 3X1. [Personal communication]

Lawrence, A.; Baclhouse, F. 1991. Sea surveys of Marbled Murrelets in Skincuttel Inlet and Juan Perez Sound, Queen Charlotte Islands, BC., 1991. Report on file. Canadian Park Service, Queen Charlotte City, BC.

LeBrasseur, R.J. 1956. Zooplankton distribution in the Northeast Pacific Ocean. Tech. Rep. 107. Progress Report Pacific Coast Stations, Nanaimo, BC: Fisheries Research Board of Canada; 3-5.

Lehmkuhl, John F.; Ruggerio, Leonard F. 1991. Forest fragmentation in the Pacific Northwest and its potential effects on wildlife. In: Ruggerio, Leonard F.: Aubry, Keith B.; Carey, Andrew B.; Huff, Mark H., eds. Wildlife and vegetation of unmanaged Douglas-fir forests. Geo. Tech. Rep. PNW-285. Portland, OR: Pacific Northwest Research Station, Forest Service, U.S. Department of Agriculture; 35-46.

Leito, A.; Man, R.; Oja, T; Paal, J.; Talvi, T. 1991. Ecosystem studies on the Koni Peninsula (Magadan Nature Reserve). Tallinn. (in Russian).

Lemon, Moira J.F. Senior Technician, Canadian Wildlife Service, P.O. Box 340, Delta, BC. Canada. [Personal communication].
Lensink. Calvin J. 1984. The status and conservation of seabirds in Alaska. In: Croxall, John P.; Evans, Peter G.H.; Schreiber, Ralph W. Status and conservation of the world's seabirds. Technical Publication No. 2. International Council for Bird Preservation. Norwich, UK: Page Bros.; 13-27.

Leschner, Laura L. 1976. The breeding biology of the Rhinoceros Aulket on Destruction Island. Seattle, WA: University of Washington. M.Sc. Thesis.

Leschner, Laura L.; Burrell, G. 1977. Populations and ecology of marine birds on the Semidi Islands. In: Environmental assessment of the Alaskan continental shelf, annual reports, Vol. 4. Anchorage, AK: U.S. Department of Commerce, National Oceanic and Atmospheric Administration; 13-109.

Leschner, Laura L.; Cummins, Eric B. 1992a. Breeding records, inland distribution, and threats of the Marbled Murrelet in Washington from 1905 to 1987. Iv: Carter, Harry R.; Morrison, Michael L., eds. Status and conservation of the Marbled Murrelet in North America. Proceedings of the Westem Foundation of Vertebrate Zoology 5(1): 42-47.

Leschner, Laura L.; Cummins, Eric B. 1992b. Distribution of Marbled Murrelets at sea compared to occurrence of old-growth forests in the San Juan Islands. Pacific Seabird Group Bulletin 19(1): 51.

Lid, G. 1981. Reproduction of the Puffin on Rost in the Lofoten Island in 1964-1980. Cinclus 4: 30-39.

Lloyd, Clare S. 1976. The breeding biology and survival of the Razorbill Alca torda L. Oxford, England: Oxford University; Ph.D. Thesis.

Lloyd, Clare S. 1979. Factors affecting breeding of Razorbills Alca torda on Skokholm. Ibis 121(2): 165-176.

Lloyd, Clare S.; Perrins, C.M. 1977. Survival and age at first breeding in the Razorbill (Alca torda). Bird-Banding 48: 239-252.

Loblov, E.G. 1986. Breeding birds of Kamchatka. Vladivostok, (in Russian).

Long, E.R. 1983. A synthesis of biological data from the Strait of Juan de Fuca and northern Puget Sound. Interagency Energy/Environment R\&D Program Repor, EPA-600/7-82-004. Washington, DC: United States Department of Commerce, National Oceanic and Atmospheric Administration and Environmental Protection Agency; 295 p.

Lowe, Roy. U.S. Fish and Wildlife Service, Newport, OR 97365. [Personal communication].

MacCall, Alec. 1986. Changes in the biomass of the California Current ecosystem. In: Sherman, K.; Alexander, L.M., eds. Variability and management of large ecosystems. Washington, DC: American Association for the Advancement of Science; 33-54

MacDuffee, M. Western Canada Wilderness Committee, Bastion Square, Victoria, British Columbia V8W 1J1. [Personal communication].

MacDuffee, M.; Henderson, C; Truman, K. 1993. The activity patterns of Marbled Murrelets Brachyramphus mamoratus in old-growth forests of the Lower Tsitika Valley, 1991. Report on file: Western Canada Wildemess Committee, Victoria, BC.

Mahon, T.E.; Kaiser, Gary W.; Burger, Alan E. 1992. The role of Marbled Murrelets in mixed-species feeding flocks in British Columbia. Wilson Bulletin 104: 738-743.

Manly, Bryan; McDonald, Lyman; Thomas, Dana. 1993. Resource selection by animals. London: Chapman and Hall; 177 p.

Manley, Irene A. 1992. Marbled Murrelet (Brachyramphus marmorarus) activity and behavior patterns at forest nesting sites in the Camanab and Walbran valleys, B.C. Victoria, BC: University of Victoria; 46 p. Unpublished B.Sc. Honors Thesis.

Manley, Irene A. Wildlife Biologist, Lasquets Island, British Columbia. [Personal communication].

Manley, Irene A.; Kelson, John D. 1992. Marbled Murrelets in the Walbran Valley; inland behavior and discovery of Canada's second nest. Pacific Seabird Group Bulletin 19(1): 51.

Manley, Irene A.; Kelson, John D. The discovery of two Marbled Murrelet tree nests in the Walbran Valley, Britisb Columbia. In: Nelson, S. Kim; Sealy, Spencer G., eds. Biology of Marbled Murrelets: inland and at sea-a symposium of the Pacific Seabird Group 1993. Northwestern Naturalist. [In press].

Manley, Irene A.; Kelson, John D.; Hughes, S.; Jordan, K. 1994. Marbled Murrelet forest and at-sea studies in Clayoquor Sound, BC, 1993. 
Unpublished report on file. Irene Manley, Tucker Bay Road, Lasqueti Island, BC, VOR $2 \mathrm{~J} 0$.

Manley, Irene A.; Shortt, R.; Burger, Alan E. 1992. Marbled Murrelet activity patterns in the Carmanah Valley on the southwest coast of Vancouver Island. In: Vermeer, Kees; Butler, Robert W.; Morgan, Ken H., eds. The ecology, status and conservation of marine and shoreline birds on the west coast of Vancouver Island. Occasional Paper No. 75. Ottawa, ON: Canadian Wildlife Service, Environment Canada; 71-75.

Manuwal, David A. 1974. The natural history of Cassin's Auklet (Ptychoramphus aleuticus). Condor 76(4): 421-431.

Manuwal, David A. 1979. Reproductive commitment and success of Cassin's Auklet. Condor 81(2): 111-121.

Manuwal, David A.; Campbell, R.W. 1979. Status and distribution of breeding seabirds of southeastern Alaska, British Columbia, and Washington. In: Bartonek, James C.; Nettleship, David N., eds. Conservation of marine birds of northern North America. Wildlife Research Report 11. Washington, DC: U.S. Fish and Wildlife Service; 73-91.

Manuwal, David A.; Thorensen, Asa C. 1993. Cassin's Auklet (Ptycharamphus aleuticus). In: Poole, Alan; Gill, Frank, eds. The birds of North America, No. 50. Philadelphia, PA: The Academy of Natural Sciences; and Washington, DC: The American Ornithologists' Union.

Manuwal, David A.; Wahl, Terrance R.; Speich, Steve M. 1979. The seasonal distribution and abundance of marine bird populations in the Strait of Juan de Fuca and northern Puget Sound in 1978. Technical Memorandum, Environmental Research Laboratory Marine Ecosystem Analysis Program-44. Washington, DC: U.S. Department of Commerce, National Oceanic and Atmospheric Administration; 391 p.

Marks, B.; McGarigal, K. 1993. FRAGSTATS spatial analysis computer program. Unpublished manuscript on file. Corvallis, OR: Oregon State University, Forest Science Department.

Marks, Dennis K. Wildlife Biologist, Migratory Bird Management, U.S. Fish and Wildlife Service, 1011 E. Tudor Road, Anchorage, AK. [Personal communication].

Marks, Dennis K.; Kuletz, Katherine J.; Naslund, Nancy L. Boat-based survey methods and Marbled Murrelet habital use in Prince William Sound, Alaska. In: Nelson, S. Kim; Sealy, Spencer G., eds. Biology of Marbled Murrelets: inland and at sea-a symposium of the Pacific Seabird Group 1993. Northwestern Naturalist. [In press].

Marks, Dennis K.; Naslund, Nancy L. Predation by a Sharp-shinned Hawk on a Marbled Murrelet at its nest. Wilson Bulletin 106: 565-567.

Marshall, D.B. 1988a. Status of the Marbled Murrelet in North America: with special emphasis on populations in California, Oregon and Washington. Biological Rept. No. 88(30). U.S. Fish and Wildlife Service.

Marshall, D.B. 1988b. The Marbled Murrelet joins the old-growth forest conflict. American Birds 42: 202-212.

Martin, Thomas E. 1992. Breeding productivity considerations: what are the appropriate habitat features for management. In: Hagan, John M. III; Johnson, David W., eds. Ecology and conservation of neotropical migrant landbirds. Washington, DC: Smithsonian Institute Press; 455-473.

Martin, Thomas E.; Geupel, Geoffrey R. 1993. Nest-monitoring plots: methods for locating and monitoring success. Journal of Field Ornithology 64: 507-519.

Martin, Thomas E.; Roper, James J. 1988. Nest predation and nest site selection for a western population of the Hermit Thrush. Condor 90:51-59.

Marzluff, John M. 1994. Historical Changes of Populations and Perceptions of Native Pest Bird Species in the West. In: Jehl, Joseph R., Jr.; Johnson, Ned K., eds. A Century of avifaunal change in North America. Studies in Avian Biology 15: 202-220.

Marzluff, John M.; Balda, R.P. 1992. The Pinyon Jay: behavioral ecology of a colonial and cooperative corvid. London: T \& AD Poyser; 317 p.

MATLAB. 1992. The student edition of MATLAB. Englewood Cliffs, NJ: Prentice Hall.

Matthews, J.B.I.; Heimdal, B.R. 1980. Pelagic productivity and food chains in fjord systems. In: Freeland, H.J.; Farmer, D.M.; Levings, C.D., eds. Fjord oceanography. New York: Plenum Press; 377-398.
McAllister, Michael L. Wildlife Biologist, Wildland Resources Enterprises, 60069 Morgan Lake Road, La Grande, OR 97850. [Personal communication].

McCain, C. Ecologist, Siuslaw National Forest, Corvallis, OR. [Personal communication].

McDonald, D.B.; Caswell, H. 1993. Matrix methods for avian demography. Current Ornithology 10: 139-185.

McGurk, M.D.; Warburton, H.D. 1992. Fisheries oceanography of the southeast Bering Sea: Relationships of growth, dispersion, and mortality of sand lance larvae to environmental conditions in the Port Moller Estuary. Report 92-0019. U.S. Department Interior, Minerals Management Service; $43 \mathrm{p}$.

McKnight, Donald E.; Knoder, C. Eugene. 1979. Resource development along coasts and on the ocean floor: potential conflicts with marine bird conservation. In: Bartonek, James C.; Nettleship, David N., eds. Conservation of marine birds of northern North America. Wildlife Research Report 11. Washington, DC: U.S. Fish and Wildlife Service; 183-194.

McLain, D.R.; Brainard, R.E.; Norton, J.G. 1985. Anomalous warm events in eastern boundary current systems. California Cooperative Oceanographic and Fisheries Investigations, Report 26: 51-64.

McLain, D.R.; Thomas, D.H. 1983. Year-to-year fuctuations of the California Countercurrent and effects on marine organisms. California Cooperative Oceanographic and Fisheries Investigations, Report 24: 165-180.

Meidinger, D.; Pojar, J., eds. 1991. Ecosystems of British Columbia. Special Report Series No. 6. Victoria, BC: British Columbia Ministry of Forests.

Mendenhall, Vivian M. 1992. Distribution, breeding records and conservation problems of the Marbled Murrelet in Alaska. In: Carter, Harry R.; Morrison, Michael L., eds. Status and conservation of the Marbled Murrelet in North America. Proceedings of the Western Foundation of Vertebrate Zoology 5(1): 5-16.

Mickelson, Pete. Box 525, Cordova, AK 99574. [Personal communication].

Miller, Daniel J.; Lea, Robert N. 1972. Guide to the coastal marine fishes of California. Fish Bulletin 157. Sacramento, CA: California Department Fish and Game.

Miller, Sherri L. USDA Forest Service, Redwood Sciences Laboratory, 1700 Bayview Drive, Arcata, CA 95521 [Personal communication].

Miller, Sherri L.; Ralph, C. John. Relationship of Marbled Murrelets with habitat characteristics at inland sites in California. [This volume].

Milne, B.T. 1991. Lessons from applying fractal models to landscape patterns. In: Turner, M.G.; Gardner, R.H., eds. Quantitative methods in landscape ecology. New York: Springer Verlag; 199-235.

Milne, B.T. 1992. Spatial aggregation and neutral models in fractal landscapes. The American Naturalist 139:32-57.

Moffitt, J.; Orr, R. T. 1938. Recent disasterous effects of oil pollution on birds in the San Francisco Bay region. California Fish and Game 24: 239-244.

Momot, Jeffrey. U.S. Fish and Wildlife Service, Ecological Services, Olympia, WA. [Telephone conversation with Harry R. Carter]. January 1994.

Monaghan, P.; Uttley, J.D.; Okill, J.D. 1989. Terns and sandeels: seabirds as indicators of changes in marine fish populations. Journal of Fish Biology 35: 339-340.

Mooers, Christopher N.K.; Robinson, A.R. 1984. Turbulent jets and eddies in the California Current and inferred cross-shelf transport. Science 223: 51-53.

Moore, K. 1991. Coastal watersheds: an inventory of watersheds in the coastal temperate forests of British Columbia. Available from: Earthlife Canada Foundation, P.O. Box 47105 , Vancouver, BC, Canada V5Z 4L6; 54 p. and maps.

Morgan, J. [Letter to Dr. Jeanne-Pierre L. Savard]. 1993 September 21. 1 leaf + map. Located at Canadian Wildlife Service, P.O. Box 340, Delta, BC, Canada V4K 3 Y3.

Morgan, Ken H. 1989. Marine birds of Saanich Inlet, a Vancouver Island fjord entering the Strait of Georgia. In: Vermeer, Kees; Butler, Robert W., eds. The ecology and status of marine and shoreline birds in the Strait of Georgia, British Columbia. Special Publication. Ottawa, ON: Canadian Wildlife Service; 158-165. 
Morgan, Ken H.; Vermeer, Kees; McKelvey, Richard W. 1991. Atlas of pelagic birds of Western Canada. Occasional Paper 72. Ottawa, ON: Canadian Wildlife Service.

Morrison, Michael L.; Mareot, Bruce G.; Mannan, R. William. 1992. Wildlife-habitat relationships: concepts and applications. Madison, W1: University of Wisconsin Press: 343 p.

Morrison, Peter H. 1988. Old-growth forests in the Pacific Northwest: a status report. Washington, DC: The Wilderness Society; 46 p.

Munro, J.A. 1924. Miscellaneous bird notes from southern Vancouver Island, 1923. Canadian Field-Naturalist 38: 147-150, 175-177.

Munro, J.A. 1957. Observations of the winter waterfowl population at Morro Bay, California. Murrelet 38: 9-25.

Munro, J.A.; Clemens, W.A. 1931. Water fowl in relation to the spawning of herring in British Columbia. Bulletin 17. Toronto, ON: Fisheries Resources Board of Canada.

Murphy, Edward C. 1994. Population status and reproductive success of Common Murres at Bluff, Alaska (abstract). Pacific Seabirds 21(1): $45-46$.

Murray, K.G.; Winnett-Murray, K.; Eppley, Z.A.; Hunt, George L., Jr.; Schwartz, D.B. 1983. Breeding biology of the Xantus' murrelet. Condor 85: 12-21.

Nakata, H.; Kimura, S.; Kishi, M.J.; Fujiwara, T. 1991. Environmental constraints on the sand lance population in the Eastern Seto Inland Sea. Marine Pollution Bulletin 23: 195-199.

Nash, A.E.K.; Mann, D.E.; Olsen, P.G. 1972. Oil pollution and the public interest: a study of the Santa Barbara oil spill. Berkeley, CA: Institute of Governmental Studies, University of California.

Naslund, Nancy L. 1993a. Breeding biology and seasonal activity patterns of Marbled Murrelets (Brachyramphus marmoratus) nesting in an old-growth forest. Santa Cruz, CA: University of California; 146 p. M.Sc. Thesis.

Naslund, Nancy L. 1993b. Why do Marbled Murrelets attend old-growth forest nesting areas year-round? Auk 110(3): 594-602.

Naslund, Nancy L. U.S. Fish and Wildlife Service, 1011 E. Tudor Road, Anchorage, AK 99503. [Personal communication].

Naslund, Nancy L.; Hamer, Thomas E. 1994. Techniques for finding tree nests of the Marbled Murrelet. Unpublished report available from: Pacific Seabird Group Marbled Murrelet Technical Commintee, U.S. Fish and Wildlife Service, 1011 E. Tudor Rd., Anchorage, AK 99503-6199.

Naslund. Nancy L.; Kuletz, Katherine J.; Cody, Mary B.; Marks, Dennis. 1993. Tree and habitat characteristics and status of 14 Marbled Murrelet tree nests in Alaska (abstract). Pacific Seabird Group Bulletin 20(1): 41.

Naslund, Nancy L.; Kuletz, Katherine J.; Cody, Mary B.; Marks, Dennis $\mathrm{K}$. Tree and babitat characteristics and status of Marbled Murrelet tree nests in Alaska. In: Nelson, S. Kim; Sealy, Spencer G., eds. Biology of Marbled Murrelets: inland and at sea-a symposium of the Pacific Seabird Group 1993. Northwestern Naturalist. [In press].

Naslund, Nancy L; O'Donnell, Brian P. Daily patterns of Marbled Murrelet activity at inland sites. [This volume].

Naslund, Nancy L.; Piatt, John F.; Van Pelt. Thomas. 1994. Breeding behavior and nest site fidelity of Kittlitz's Murrelet (abstract). Pacific Seabirds 21(1): 46 .

National Geographic Society. 1983. Field guide to the binds of North America. Washington, DC: National Geographic Society. 464 p.

Natural Resources Consultants, Inc. 1993. Seabird observer program, non-Tribal purse seine fishery. Final report, 1993 Washington State Salmon Fisheries. Report on file. Natural Resources Consultants, Inc., Seatzle, WA.

Nechaev, V.A. 1969. Birds of southern Kuril Islands. Leningrad: Izdatelstvo Nauka Leningradskoe. (in Russian).

Nechaev, V.A. 1977. Breeding of the Ruff and Marbled Murrelet on the Sakchalin 1sland. In: VII USSR Omithological Conference. Part 1. p. 90. Kiev.

Nechaev, V.A. 1986. New data on the seabirds of Sakhalin Island. In: Litvinenko, N.M., ed. Seabirds of the Far East. Vladivostok, USSR: Akademia Nauk SSSR; 71-81. (In Russian; English translation by Douglas Siegel-Causey).
Necbaev, V.A. 1987. Rare birds of Sakhalin and Kuril lslands. In: Il'yashenko. V.Y., ed. Problems of rare animals protection; 124-129. (in Russian).

Nechaev, V.A.; Kurenkov, V.D. 1986. New data on birds of Kunashir Island. In: Neufeidt, 1.A., ed. The distribution and biology of birds of the Altai and the Far East. Proceedings of the Zoological Institute 150: 86-88. (in Russian).

Nelson, Douglas A. 1987. Factors in fuencing colony attendance by Pigeon Guillemots on southeast Farallon Island, Califomia. Condor 89(2): 340-348.

Nelson, S. Kim. 1989. Development of inventory techniques for surveying Marbled Murrelets (Brachyramphus marmoratus) in the central Oregon coast range. Publ. No. 88-6-01. Portland, OR: Oregon Department of Fish and Wildlife, Nongame Program; 104 p.

Nelson, S. Kim. 1990a. Distribution of the Marbled Murrelet in western Oregon. Publication Number 89-9-02. Portland, OR: Oregon Department of Fish and Wildlife, Nongame Program.

Nelson. S. Kim. 1990b. Marbled Murrelet surveys in 1991 and 1992 timber sales, Siuslaw National Forest, 21 May-17 August 1990. Unpublished report on file. Siuslaw National Forest, Forest Service, U.S. Department of Agriculture, Corvallis, OR.

Nelson, S. Kim. 1991. Nest-site characteristics and behavior of Marbled Murrelets in western Oregon. Publication Number 90-6-01. Final Report to the Nongame Program. Portland, OR: Oregon Department of Fish and Wildife.

Nelson, S. Kim. 1992. Intensive searches for nests of Marbled Murrelets through the use of visual observations and sophisticated audio equipment. Publication Number 91-9-07. Final Report to the Nongame Program. Portand, OR: Oregon Deparment of Fish and Wildlife.

Nelson, S. Kim. Oregon Cooperative Wildlife Research Unit, Oregon State University, Nash 104, Corvallis, OR 97331-3803 [Personal communication].

Nelson, S. Kim; Hamer, Thomas. 1992. Nest-site characteristics of Marbled Murrelets in the Pacific Northwest. Pacific Seabird Group Bulletin 19(1): 52.

Nelson, S. Kim; Hamer, Thomas E. Nesting biology and behavior of the Marbled Murrelet. [This volume a].

Nelson, S. Kim: Hamer. Thomas E. Nest success and the effects of predation on Marbled Murrelets. [This volume b].

Nelson, S. Kim; Hamer, Thomas E.; Holtrop, Karen K. Nest site characteristics of Marbled Murrelets in the Pacific Northwest. In: Sealy, Spencer G.; Nelson, S. Kim, eds. Proceedings of the Pacific Seabird Group's Marbled Murrelet symposium, 1993. Northwestern Naturalist. [In press].

Nelson, S. Kim; Hardin, Janet G. 1993a. Landscape patterns and Marbled Murrelet occupancy: a pilot study. Publication Number 92-9-04. Porland, OR: Oregon Department of Fish and Wildlife; 76 p.

Nelson, S. Kim; Hardin, Janet G. 1993b. Shore-based surveys of Marbled Murrelets along the Oregon coast, 1988-1992 (abstract). Pacific Seabird Group Bulletin 20(1): 59.

Nelson, S. Kim; McAllister, Michael L.C.; Stern, Mark A.; Varoujean, Daniel H.; Scott, J. Michael. 1992. The Marbled Murrelet in Oregon, 1899-1987. In: Carter, Harry R.; Morrison, Michael L., eds. Status and conservation of the Marbled Murrelet in North America. Proceedings of the Western Foundation of Vertebrate Zoology 5(1): 61-91.

Nelson, S. Kim; Peck, Rober W. Behavior of Marbled Murrelets at nine nest sites in Oregon. ln: Nelson, S. Kim; Sealy, Spencer G., eds. Biology of Marbled Murrelets: inland and at sea-a symposium of the Pacific Seabird Group 1993. Northwestern Naturalist. [ln press].

Nelson, S. Kim; Peck, Robert W.; De Santo, Toni L. 1994. Searches for Marbled Murrelet Nests using ground-based and tree climbing techniques. Publication No. 93-9-01. Portland, OR: Nongame Program, Oregon Department of Fish and Wildlife.

Nelson, S. Kim; Shaughnessy, Margaret M. 1992. Marbled Murrelet surveys in areas proposed for timber harvest on Oregon Deparument of Forestry Lands, Lane District, 1 May-14 August 1992. Report on file. Siuslaw National Forest, Forest Service, U.S. Department of Agriculture. Corvallis, OR. 
Nettleship, David N. 1972. Breeding success of the Common Puffin (Fratercula arctica L.) on different habitats at Great Island, Newfoundland. Ecological Monographs 42(2): 239-268.

Nettleship, David N.; Birkhead, Tim R., eds. 1985. The Atlantic Alcidae. London: Academic Press. 574 p.

Nettleship, David N.; Evans, Peter G.H. 1985. Distribution and status of the Atlantic Alcidae. In: Nettleship, David N.; Birkhead, Tim R., eds. The Atlantic Alcidae. London: Academic Press; 54-155.

Neu, C.W.; Byers, C. Randall; Peek, J.M. 1974. A technique for analysis of utilization-availability data. Journal of Wildlife Management 38: 541-545.

Nilsson, Greta. 1986. The endangered species handbook. Washington, DC: Animal Welfare Institute; $261 \mathrm{p}$.

Nisbet, Ian C.T. 1979. Conservation of marine birds of northern North America - a summary. In: Bartonek, James C.; Nettleship, David N., eds. Conservation of marine birds of northern North America. Wildlife Research Report 11. Washington, DC: U.S. Fish and Wildlife Service; 305-315.

NOAA Coastal Ocean Program. 1992-1993 (monthly). El Niño watch, advisory nos. 92-4 through 93-8. Coastwatch, Southwest Regional Node, National Marine Fisheries Service, La Jolla, CA 92038.

Noon, Barry R.; Biles, C.M. 1990. Mathematical demography of Spotted Owls in the Pacific Northwest. Journal of Wildlife Management 54: 18-27.

Noon, Barry R.; Sauer, John R. 1992. Population models for passerine birds: structure, parameterization, and analysis. In: McCullough, D.R.; Barrett, R.H., eds. Wildlife 2001: populations. London: Elsevier Applied Science; 441-464.

Norderhaug, M. 1968. Trekkforhold, stedstrohet og pardannelse hos alkekonge pa Svalbard. Norsk Polarinstitutt Medd. 96: 236-244.

Norderhaug, M. 1980. Breeding biology of the Little Auk (Plautus alle) in Svalbard. Norsk Polarinstitutt Skrifter 173: 1-45.

Norton, J.; McLain, D.; Brainard, R.; Husby, D. 1985. The 1982-83 E] Niño event off Baja and Alta California and its ocean climate context. In: Wooster, W.S.; Fluharty, D.L., eds. El Niño North: Niño effects in the eastern subarctic Pacific Ocean. Washington Sea Grant. Seattle, WA: University of Washington; 44-72.

Nur, Nadav. 1993. Establishing the demographic parameters of the Marbled Murrelet. Report on file. Portland, OR: U.S. Fish and Wildlife Service.

Nysewander, David. Washington Department of Wildlife, 24120 19th N.E., Arlington, WA 98223. [Personal communication].

Oakley, Karen L.; Kuletz, Katherine J. 1994. Population, reproduction and foraging of Pigeon Guillemots at Naked Island, Prince William Sound, Alaska, before and after the Exxon Valdez oil spill. Unpublished final report on file, NRDA Bird Study No. 9., U.S. Fish and Wildlife Service, Anchorage, AK.

Oakley, Karen L.; Wade, Terry L.; Kuletz, Katherine J. 1994. Aliphatic and polycyclic aromatic hydrocarbons in livers of Marbled Murrelets in Prince William Sound, Alaska, after the Exxon Valdez Oil Spill. Exxon Valdez Oil Spill State/Federal Natural Resources Damage Assessment Final Reports: Bird Study 6, U.S. Fish and Wildlife Service, Anchorage, AK. Unpublished manuscript supplied by authors.

Oceanor. 1990. The "American Trader" incjdent assessment of oil spill response. Report on file. Oceanor Inc., Trondheim, Norway.

O'Donnell, Brian P. 1993. Patterns of activity and vocalizations of the Marbled Murrelet, Brachyramphus marmoratus, within old-growth redwood stands in northwestern California. Arcata, CA: Humboldt State University; 84 p. M.Sc. Thesis.

O'Donnell, Brian P. A review of the effects of station placement and observer bias in detections of Marbled Murrelets in forest stands. [This volume].

O'Donnell, Brian P.; Naslund, Nancy L.; Ralph, C. John. Patterns of seasonal variation of activity of Marbled Murrelets in forested stands. [This volume].

Odum, E.P. 1971. Fundamentals of ecology. 3rd ed. Pennsylvania, PA: W.B. Saunders Company; 574 p.

Ohlendorf, Harry M. 1993. Marine birds and trace elements in the temperate north Pacific. In: Vermeer, Kees; Briggs, Kenneth T.; Morgan, Ken H.;
Siegel-Causey, Douglas, eds. The status, ecology and conservation of marine birds of the North Pacific. Special Publication. Ottawa, ON: Canadian Wildlife Service, Environment Canada; 232-240.

Ohlendorf, Harry M.; Marois, Katherine C. 1991. Trace elements and organochlorines in Surf Scoters from San Francisco Bay, 1985. Environmental Monitoring and Assessment 18: 105-122.

Oman, L. U.S. Fish and Wildlife Service, Olympia, WA. [Telephone conversation with Harry R. Carter]. May 1994.

O'Neill, R.V.; Krummel, J.R.; Gardner, R.H.; Sugihara, G.; Jackson, B.; De Angelis, D.L.; Milne, B.T.; Turner, M.G.; Zygmunt, B.; Christensen, S.W.; Dale, V.H.; Graham, R.L. 1988. Indices of landscape pattern. Landscape Ecology 1(3): 153-162.

Ono, Koji. 1993. The biology of nesting Japanese Murrelets on Kojine reef (Hachijo Island). In: Ono, Koji, ed. Symposium on the Japanese Murrelet: its status and conservation; Annual Meeting of Japanese Ornithological Society; October 11, 1993; Ehine University.

Ono, Koji; Nakamura, Yutaka. 1993. The biology of nesting Japanese Murrelets on Biroto Island (Kadokawa-cho, Miyazaki pref.). In: Ono, Koji, ed. Symposium on the Japanese Murrelet: its status and conservation; Annual Meeting of Japanese Ornithological Society; October 11, 1993; Ehine University.

Ono, Koji; Nakamura, Yutaka. 1994. Current status and breeding ecology of Japanese Murrelets (abstract). Pacific Seabirds 21(1): 47.

Oregon Department of Forestry. 1991, revised. Personal Service Inventory Contract, Training Contract, Exhibit A, District Timber Inventory Project. Unpublished report on file. Oregon Department of Forestry, Salem, OR.

Oreskes, N.; Shrader-Frechette, K.; Belitz, K. 1994. Verification, validation, and confirmation of numerical models in the earth sciences. Science 263: 641-646.

Page, Gary W. Point Reyes Bird Observatory, Stinson Beach, CA. [Personal communication].

Page, Gary W.; Carter, Harry R., eds. 1986. Impacts of the 1986 San Joaquin Valley Crude oil spill on marine birds in central California. Report on file. Point Reyes Bird Observatory, Stinson Beach, CA.

Page, Gary W.; Carter, Harry R.; Ford, R. Glenn. 1990. Numbers of seabirds killed or debilitated in the 1986 Apex Houston oil spill in central California. In: Sealy, Spencer G., ed. Auks at sea. Studies in Avian Biology 14: 164-174.

Paine, R.T.; Wootton, J.T.; Boersma, P. Dee. 1990. Direct and indirect effects of Peregrine Falcon predation on seabird abundance. Auk 107:1-9.

Paradox. [computer program]. 1990. Version 3.5. Scotts Valley, CA: Borland International.

Parsons, T.R.; Dovey, H.M.; Cochlan, W.P.; Perry, R.L.; Crean, P.B. 1984. Frontal zone analysis at the mouth of a fjord-Jervis Inlet, British Columbia. Sarsia 69: 133-137.

Parsons, T.R.; Perry, R.1.; Nutbrown, E.D.; Hseieh, W.; Lalli, C.M. 1983. Frontal zone analysis at the mouth of Saanich Inlet, British Columbia. Marine Biology 73: 1-5.

Paton, Peter W.C. 1994. The effect of edge on avian nesting success: how strong is the evidence? Conservation Biology 8: 17-26.

Paton, Peter W.C. Marbled Murrelet inland patterns of activity: defining detections and behavior. [This volume].

Paton, Peter W.C.; Ralph, C. John. 1988. Geographic distribution of the Marbled Murrelet in California at inland sites during the 1988 breeding season. Report on file. California Department Fish and Game, Sacramento, CA; 35 p.

Paton, Peter W.C.; Ralph, C. John. 1990. Distribution of the Marbled Murrelet at inland sites in California. Northwestern Naturalist 71: 72-84.

Paton, Peter W.C.; Ralph, C. John; Carter, Harry R.; Nelson, S. Kim. 1990. Surveying Marbled Murrelets at inland forested sites: a guide. Gen. Tech. Rep. PSW-120. Berkeley, CA: Pacific Southwest Research Station, Forest Service, U.S. Department of Agriculture; 9 p.

Patton, D.R. 1975. A diversity index for quantifying habitat "edge." Wildlife Society Bulletin 3(4): 171-173.

Paulik, G.J.; Robson, D.S. 1969. Statistical calculations for change-inratio estimators of population parameters. Journal of Wildlife Management 33: 1-27. 
Payne, Robert B. 1965 . The molt of breeding Cassin's Auklets. Condor 67: 220-228.

Pearcy, W.G.; Schoener, Amy. 1987. Changes in the marine biota coincident with the 1982-83 El Niño in the northeastern subarctic Pacific Ocean. Journal of Geophysical Research 92(C13): 14417-14428.

Pearse, T. 1946. Notes on changes in bird populations in the vicinity of Comox, Vancouver 1sland - 1917 to 1944. Murrelet 27: 4-9.

Perry, David A. Status of forest habitat of the Marbled Murrelet. [This volume].

Perry, D.R. 1978. A method of access into the crowns of emergent and canopy trees. Biotropica 10: 155-157.

Petersen, A. 1981. Breeding biology and feeding ecology of Black Guillemots. Oxford, England: Oxford University; 378 p. Dissertation.

Phillips, David J.H.; Spies, R.B. 1988. Chlorinated hydrocarbons in the San Francisco estuarine ecosystem. Marine Pollution Bulletin 19(9): 445-453.

Piatt, John F. 1990. The aggregative response of Common Murres and Atlantic Puffins to schools of capelin. In: Sealy, Spencer G., ed. Auks at sea. Studies in Avian Biology 14: 36-51.

Piatt, John F. 1993. Oceanic, shelf, and coastal seabird assemblages at the mouth of a tidally-mixed estuary (Cook Inlet, Alaska). Unpublished report. Minerals Management Service, Anchorage, AK; 52 p. Available from: National Biological Service, Anchorage, AK.

Piatt, John F.: Anderson, Paul J. Response of murres (Uria spp.) to the Excon Valder oil spill and changes in the Gulf of Alaska marine ecosystem. In: Rice, Jeep; Wright, Bruce, eds. Proceedings of the Exxon Valdez oil spill symposium. American Fisheries Society. [Io press].

Piat, John F. National Biological Service, Anchorage, AK. [Personal communication].

Piatt, John F.; Carter, Harry R.; Nettleship, David N. 1991. Effects of oil pollution on marine bird populations. In: White, Jan, ed. The effects of oil on wildlife. Proceedings of the oil symposium, Herndon, Virginia, October 16-18, 1990. Hanover, PA: Sheridan Press; 125-141.

Piatt, John F.; Ford, R. Glenn. 1993. Distribution and abundance of Marbled Murrelets in Alaska. Condor 95(3): 662-669.

Piatt, John F.; Friesen, Vicki; van Vliet, Gus. 1994. Status of a "new" rare alcid, the Long-billed Murrelet (abstract). Pacific Seabirds 21(1): 47.

Piart, John F.; Gould, Patrick J. Endangered Japanese Murrelets: incidental catch in high seas drift nets and post-breeding dispersal. Auk. [In press].

Piatt, John F.; Lensink, Calvin J. 1989. Exxon Valdez bird toll. Nature 342: 865-866.

Piatt, John F.; Lensink, Calvin J.; Butler, William; Kendziorek, M.; Nysewander, David R. 1990. Immediate impact of the Exxon Valdez oil spill on marine birds. Auk 107(2): 387-397.

Piatt, John F.; Naslund, Nancy. Abundance, distribution, and population status of Marbled Murrelets in Alaska. [This volume].

Piatt, John F.; Nettleship, David N.; Threlfall, William. 1984. Net-mortality of Common Murres and Allantic Puffins in Newfoundland, 1951-81. In: Nettleship, David N.; Sanger, Gerald A.; Springer, Paul F., eds. Marine birds: their feeding ecology and commercial fisheries relationships. Special Publication. Ottawa, Canada: Canadian Wildlife Service, Minister of Supply and Services; 196-206.

Piatt, John F.; Roberts, Bay D.; Lidster, Wayne W.; Wells, John L.; Hatch, Scott A. 1990. Effects of human disturbance on breeding Least and Crested auklets at St. Lawrence Island, Alaska. Auk 107(2): 342-350.

Pimm, S. 1976. Estimation of duration of bird molt. Condor 78: 550.

Pingree, R.D.; Bowman, MJ.; Esaias, W.E. 1978. Headland fronts. In: Bowman, M.J.; Esaias, W.E., eds. Oceanic fronts in coastal processes. New York: Springer-Verlag; 78-86.

Pinkas, L.; Oliphant, M.S.; Iverson, I.K. 1971. Food habits of albacore, bluefin tuna and bonito in California waters. Fish Balletin 152. Sacramento, CA: California Department of Fish and Game; 1-105.

Pinto, J.M.; Pearson, W.H.; Anderson, J.W. 1984. Sediment preferences and oil contamination in the Pacific sand lance (Ammodytes hexapterus). Marine Biology 83: 193-204.

Pitochelli, F. Jay. Biology Department, St. Anselm College, Manchester, New Hampshire. [Personal communication].
Platt, Melissa; Goggans, Rebecca. 1992. 1992 survey for the Marbled Murrelet on lands managed by Oregon Department of Forestry. Report on file. Oregon Department of Fish and Wildlife, Corvallis, OR.

Podkovyrkin, B.A. 1955. The list of birds of the northern part of the Kurils. Zoologia zh. 34: 1379-1385.

Point Reyes Bird Observatory. 1985. The impacts of the T/V Puerto Rican oil spill on marine bird and mammal populations in the Gulf of the Farallones, 6-19 November 1984. Report on file. Point Reyes Bird Observatory, Stinson Beach, CA.

Porter, Julia M. 1981. The dynamics of seabird multispecies flocks in Barkley Sound, BC. Winnipeg, Manitoba: University of Manitoba. M. Sc. Thesis.

Porter, Julia M.; Sealy, Spencer G. 1981. Dynamics of seabird multispecies feeding flocks: chronology of flocking in Barkley Sound, British Columbia in 1979. Colonial Waterbinds 4: 104-113.

Poyarkov, Dr. Nikolai D. Zoology of Vertebrates and General Ecology, Biological Department, Moscow State University, Moscow, Russia. [Personal communication].

Poyarkov, N.D.; Budris, R.R. 1991. Notes on birds of the Mukhtel Lake, western coast of the Sea of Okhotsk. Ornitologiya 25: 172-174. (in Russian).

Prestash, Lynn M. 12136 New McLellan Road, Surrey, BC, Canada V3X 2X9. [Personal communication]

Prestash, Lynn M.; Burns, Rick A.; Kaiser, Gary W. 1992a. Surveys of Marbled Murrelets during the breeding season on the central coast of BC, 1991. Tech. Rep. Ser. No. 160. Delta, BC: Canadian Wildlife Service, Pacific and Yukon Region.

Prestash, Lyoo M.; Burns, Rick A.; Seip, D. 1992b. Mussel Inlet Marbled Murrelet research project: research summary, June 1992. Report oo file. Ministry of Forests, Vancouver District, Burnaby, BC; 3 p.

Preston, W. 1968. Breeding ecology and social behavior of the Black Guillemot, Cepphus grolle. Ann Arbor, Ml: University of Michigan. Unpublished $\mathrm{Ph}$.D. Thesis.

Priest, L.; Burns, Rick A. 12136 New McLellan Road, Surrey, British Columbia. [Personal communication].

PRNP (Pacific Rim National Park) Wardens. Att: Bob Redhead, Chief Warden, Pacific Rim National Park, Heritage Canada, P.O. Box 280, Ucluet, BC, Canada VOR 3A0. [Personal communication].

Pyle, Peter. Point Reyes Bird Observatory, Stinson Beach, CA. [Personal communication].

Quinlan, Susan E.; Hughes, Jeff H. 1984. Use of radiotagging to locate Marbled Murrelet nest sites. Repont on file. Alaska Deparment of Fish and Game, Juneau, AK.

Quinlan, Susan E.; Hughes, Jeff H. 1990. Location and description of a Marbled Murrelet tree nest site in Alaska. Condor 92(4): 1068-1073.

Quinlan, Susan E.; Hnghes, Jeff H. 1992. Techniques for capture and radio tagging of Marbled Murrelets. In: Carter, Harry R.; Morrison, Michael L., eds. Status and conservation of the Marbled Murrelet in North America. Proceedings of the Western Foundation of Vertebrate Zoology 5(1): 117-121.

Racey, K. 1930. Effect of fuel oil on sea birds. Murrelet 11: 22.

Radovich, J. 1961. Relationships of some marine organisms of the Northeast Pacific to water temperatures_particularly during 1957 through 1959. Fish Bulletin 112. Sacramento, CA: California Department Fish and Game; $1-62$.

Ralph, C. John. 1994. Evidence of changes in populations of the Marbled Murrelet in the Pacific Northwest. In: Jehl, Joseph R., Jr.; Johnson, Ned $\mathrm{K}$., eds. A century of avifaunal changes in western North America. Studies in Avian Biology 15: 286-292.

Ralph, C. John. Interannual differences in detections of Marbled Murrelets in some inland California stands. [This volume].

Ralph, C. John. Pacific Southwest Research Station, Forest Service, U.S. Department of Agriculture, 1700 Bayview Drive, Arcata, CA. [Personal communication].

Ralph, C. John; Hunt, George L. Jr.; Raphael, Martin G.; Piatt, John F. Overview of the ecology and conservation of the Marbled Murrelet in North America. [This volume]. 
Ralph, C. John; Long, Linda L. Productivity of Marbled Murrelets in Califomia from observations of young at sea. [This volume].

Ralph, C. John; Miller, Sherri L. Offshore population estimates of Marbled Murrelets in California. [This volume].

Ralph, C. John; Miller, Sherri L.; Naslund, Nancy L.; O'Donnell, Brian P.; Paton, Peter W.C.; Seay, Jeff; Singer, Steven W. 1990. Marbled Murrelet research during 1989 in Northern and Central Califormia. Technical Report 1990-8. Report on file. Nongame Bird and Mammal Section, Department of Fish and Game, Sacramento, CA.

Ralph, C. John; Miller, Sherri L.; O'Donnell, Brian P. 1992. Marbled Murrelet research in northem Califomia during 1991 and 1992; an interim report. Job II.B.2. Report on file. Nongame Bird and Mammal Section, Department of Fish and Game, Sacramento, CA; 13 p.

Ralph, C. John; Nelson, S. Kim, compilers. 1992. Methods of surveying Marbled Murrelets at inland forested sites. Report on file. Pacific Seabird Group, Oregon Cooperative Wildlife Research Unit, Oregon State University, Corvallis, OR; 21 p.

Ralph, C. John; Nelson, S. Kim; Shaughnessy, Margaret M.; Miller, Sherri L., Pacific Seabird Group, Marbled Murrelet Technical Committee. 1993. Methods for surveying Marbled Murrelets in forests. Technical paper \#1. Corvallis, OR: Oregon Cooperative Wildlife Research Unit, Oregon State University; $48 \mathrm{p}$

Ralph, C. John; Nelson, S. Kim; Shaughnessy, Margaret M.; Miller, Sherri L.; Hamer, Thomas E.; Pacific Seabird Group, Marbled Murrelet Technical Committee. 1994. Methods for surveying Marbled Murrelets in forests. Technical paper \#1, revision. Available from: Oregon Cooperative Wildlife Research Unit, Oregon State University, Corvallis, OR; $48 \mathrm{p}$.

Ralph, C. John; Scott, J. Michael. 1981. Estimating number of terrestrial birds. Studies in Avian Biology 6;630 p.

Ralston, S., ed. 1993. Progress in rockfish recruitment studies. Admin. Rept. T-93-01. Tiburon CA: Tiburon Laboratory, National Marine Fisheries Service.

Ramsey, Fredrick L. Professor of Statistics, Oregon State University, Corvallis, OR. [Personal communication].

Ramsey, Fredrick L.; McCraken, Marti; Crawford, John A; Drut, Martin; Ripple William J. 1994. Case-control habitat association studies. In: Lange, Nicholas; Ryan, Louise; Billard, Lynne; Brillinger, David; Conquest, Loveday; Greenhouse, Joel, eds. Case studies in biometry. New York: John Wiley \& Sons, Inc.; Chapter 10.

Ramsey, Fredrick L.; Scott, J. Michael. 1981. Analysis of bird survey data using a modification of Emlen's method. In: Ralph, C. John; Scott, J. Michael, eds. Estimating the numbers of terrestrial birds. Studies in Avian Biology 6: 483-487.

Raphael, Martin G.; Young, John A.; Galleher, Beth M. A landscapelevel analysis of marbled murrelet habitat in western Washington. [This volume].

Ray, G.C. 1988. Ecological diversity in coastal zones and oceans. In: Wilson, E.O.; Peter, F.M., eds. Biodiversity. Washington, DC: National Academy Press; $36-49$

Raymont, J.E. 1963. Plankton and productivity in the oceans. Oxford, England: Pergamon Press. 660 p.

Reagan, Bonnie, J. Inventory and Geographic Information Service Planning Assistant, Oregon Department of Forestry, Salem, OR. [Personal communicaton].

Reeburgh, William S.; Kipphut, G.W. 1987. Chemical distributions and signals in the Gulf of Alaska, its coastal margins and estuaries. In: Hood, D.W.; Zimmerman, S.T., eds. The Gulf of Alaska: physical environment and biological resources. Publication number: OCS study, MMS 86-0095. Washington, DC: U.S. Department Commerce, and U.S. Department Interior, Mineral Management Services; 77-91.

Reed, P.; Wood, C. 1991. Marbled Murrelet chick and eggshell fragments from inland Washington. Northwestern Naturalist 72: 77-78.

Reed, R.J.; Schumacher, James D. 1987. Physical oceanography. In: Hood, D.W.; Zimmerman, S.T., eds. The Gulf of Alaska: physical environment and biological resources. Publication number: OCS study, MMS 860095, Washington, DC: U.S. Department Commerce, and U.S. Department Interior, Mineral Management Services; 57-75.
Reese, Kerry P.; Ratti, John T. 1988. Edge effects: a concept under scrutiny. Transactions North American Wildlife and Natural Resources Conference 53: 127-136.

Reid, J.L., Jr.; Roden, G.I.; Wyllie, J.G. 1958. Studies of the California current system. California Cooperative Oceanic Fisheries Investigations, Report Vol. 6; 28-57.

Reimchen, T.E. 1991. Marbled Murrelet habitat use near lakes in the Queen Charlotie lslands. In: Rodway, Michael S.; Savard, Jean-Pierre L.; Regehr, Heidi M., eds. Habitat and activity pattems of Marbled Murrelets at inland and at-sea sites in the Queen Charlotte lslands, British Columbia. Tech. Rep. Ser. No. 122. Delta, BC: Canadian Wildlife Service; 101107.

Reville, Barry J.; Tranter, Jeff D.; Yorkston, Hugh D. 1990. Impact of forest clearing on the endangered seabird Sula abbotti. Biological Conservation 51: 23-38.

Rice, Bud. National Park Service, Anchorage, AK. [Personal communication].

Richards, D.G. 1981. Environmental acoustics and censuses of singing birds. In: Ralph, C. John; Scott, J. Michael, eds. Estimating numbers of terrestrial birds. Studies in Avian Biology 6: 297-300.

Richardson, F. 1956. Sea birds affected by oil from the freighter Seagate. Murrelet 37: 20-22.

Ricketts, E.F.; Calvin, J. 1962. Between Pacific Tides. Stanford, CA: Stanford University Press; 516 p.

Rienecker, M.M.; Mooers, Christopher N.K. 1986. The 1982-1983 El Niño signal off northern California. Joumal of Geophysical Research 91(C5): 6597-6608.

Riley, R.G.; Crecelius, E.A.; Fitzner, R.E.; Thomas, B.L.; Gurtisen, J.M.; Bloom, N.S. 1983. Organic and Inorganic Toxicants in Sediment and Marine Birds from Puget Sound. NOAA Technical Memorandum NOS OMS 1. Rockville, MD: U.S. Dept. of Commerce, National Oceanic and Atmospheric Administration, National Ocean Service; 123 p.

Ritchie, B. Wildlife Biologist, Washington Department of Fish and Wildlife, Nongame Program, Olympia, WA. [Personal communication]

Robbins, Chandler S.; Bruun, Bertel; Zim, Herbert S. 1983. A guide to field identification of birds of North America. New York: Golden Press.

Robbins, Chandler S.; Bystrak, Danny; Geissler, Paul H. 1986. The breeding bird survey: its first fifteen years, 1965-1979. Resource Publication 157. Washington, DC: U.S. Fish and Wildlife Service.

Robertson, I. 1974. An inventory of seabirds occurring along the west coast of Canada. Part II: The shoreline and inlet zone. Report on file. Canadian Wildlife Service, Vancouver, BC.

Robertson, 1. 1977. Low seabird densities in the pelagic environment of the Strait of Georgia, BC. Pacific Science 31: 279-283.

Roby, Daniel D. 1991. Diet and postnatal energetics in convergent taxa of plankton-feeding seabirds. Auk 108: 131-146.

Roby, Daniel D.; Brink, Karen L. 1986. Breeding biology of Least Auklets on the Pribilof Islands, Alaska. Condor 88(3): 336-346.

Rodway, Michael S. 1989. Distribution and abundance of waterbirds in Barkley Sound and the Long Beach/Tofino/Grice Bay area in spring 1989 following the Nestucca oil spill. Tech. Rep. Ser. 76. Delta, BC: Canadian Wildlife Service.

Rodway, Michael S. 1990. Status report on the Marbled Murrelet in Canada. Ottawa: Committee on the Status of Endangered Wildlife in Canada.

Rodway, Michael S.; Carter, Harry R.; Sealy, Spencer G.; Campbell, R. Wayne. 1992. Status of the Marbled Murrelet in British Columbia. In: Carter, Harry R.; Morrison, Michael L., eds. Status and conservation of the Marbled Murrelet in North America. Proceedings of the Westem Foundation of Vertebrate Zoology 5(1): 17-41.

Rodway, Michael S.; Lemon, Moira J.F.; Kaiser, Gary W. 1988. Canadian Wildlife Service seabird inventory report \#1: East coast of Moresby Island. Tech. Rep. Ser. No. 50. Delta, BC: Canadian Wildlife Service, Pacific and Yukon Region.

Rodway, Michael S.; Lemon, Moira J.F.; Savard, Jean-Pierre L.; McKelvey, R. 1989. Nestucca oil spill: impact assessment on avian populations and habitat. Tech. Rep. Ser. No. 68; Delta, BC: Canadian Wildlife Service, Pacific and Yukon Region.

Rodway, Michael S.; Regehr, Heidi M.; Savard, Jean-Pierre L. 1993a. Activity levels of Marbled Murrelets in different inland habitats in the 
Queen Charlotte Islands, British Columbia. Canadian Journal of Zoology 71: 977-984.

Rodway, Michael S.; Regehr, Heidi M.; Savard, Jean-Pierre L. 1993 b. Activity patterns of Marbled Murrelets in old-growth forest in the Queen Charlotte Islands, British Columbia. Condor 95: 831-848.

Rodway, Michael S.; Savard, Jean-Pierre L.; Garner, Donald C.; Lemon, Moira J.F. At-sea activity patterns of Marbled Murrelets adjacent to probable inland nesting areas in the Queen Charlotte Islands, British Columbia. In: Nelson, S. Kim; Sealy, Spencer G., eds. Biology of Marbled Murrelets: inland and at sea-a symposium of the Pacific Seabird Group 1993. Northwestern Naturalist. [In press].

Rodway, Michael S.; Savard, Jean-Pierre L.; Regehr, Heidi M. 1991. Habitat use and activity pattems of marbled murrelets at inland and atsea sites in the Queen Charlotte Islands, British Columbia. Tech. Rep. Ser. No. 122. Delta, BC: Canadian Wildlife Service, Pacific and Yukon Region; 152 p.

Roeloffs, Terrance. Fisheries Department, Humboldı State University, Arcata, CA 95521. [Personal communication].

Roletto, Jan. National Oceanic and Atmospheric Administration, Gulf of the Farallones National Marine Sanctuary, San Francisco, CA. [Telephone conversation with Hany R. Carter]. April 1994.

Roseberry, J.L. 1974. Relationsbips between selected population phenomena and annual bobwhite age ratios. Journal of Wildlife Management 38: 665-673.

Rosenberg, Kenneth V.; Raphael, Martin G. 1986. Effect of forest fragmentation on vertebrates in Douglas-fir forests. In: Vemer, Jared; Morrison, Michael L.; Ralph, C. John, eds. Wildlife 2000. Madison, WI: Unjversity of Wisconsin; 263-272.

Royer, Thomas C. 1979. On the effect of precipitation and runoff on coastal circulation in the Gulf of Alaska. Journal of Pbysical Oceanography 9: 555-563.

Royer, Thomas C. 1983. Northern Gulf of Alaska. Review of Geophysical and Space Physics 21: 1153-1155.

Royer, Thomas C.; Hansen, D.V.; Pashinski, D.J. 1979. Coastal flow in the northern Gulf of Alaska as observed by dynamic topography and satellite-tracked drouged drift buoys. Journal of Physical Oceanography 9: 785-801.

Rudnicky, Tamia C.; Hunter, Malcolm L. 1993. Avian nest predation in clearcuts, forests, and edges in a forest dominated landscape. Journal of Wildlife Management 57: 358-364.

Rueggeberg, H.; Booth, J. 1989. Marine birds and aquaculture in British Columbia: assessment and management of interactions. Final report: Summary and conclusions. Repont to Environment Canada (Canadian Wildlife Service), Vancouver, BC; 17 p.

Saether, B.-E. 1988. Pattem of covariation between life-history traits of European binds. Nature 331: 616-617.

Salzman, J.E. 1989. Scientists as advocates: the Point Reyes Bird Observatory and gill netting in central Califomia. Conservation Biology 3: 170-180.

Sander, T. G. 1987. Inland activity pattems of Marbled Murrelets, Brachyramphus mamoratus, in old-growth forests in northern California. Report on file. Department of Biology, Evergreen State College, Olympia, WA.

Sanger, Gerald A. 1983. Diets and food web relationships of seabirds in the Gulf of Alaska and adjacent marine regions. OCSEAP Final Rep. 45 (1986). Anchorage, AK: U.S. Dept. Commerce, National Oceanic and Atmospheric Administration; 631-771.

Sanger, Gerald A. 1987a. Trophic levels and trophic relationships of seabirds in the Gulf of Alaska. 1n: Croxall, John P., ed. Seabirds: Feeding ecology and role in marise ecosystems. Cambridge, England: Cambridge University Press; 229-257.

Sanger, Gerald A. 1987b. Winter diets of Common Murres and Marbled Murrelets in Kachemak Bay, Alaska. Condor 89: 426-430.

Sanger, Gerald A.; Jones, R.D., Jr. 1982. The winter feeding ecology and trophic relationships of marine birds in Kachemak Bay, Alaska. OCSEAP Final Rep. 16 (1982). Anchorage, AK: U.S. Dept. Commerce, National Oceanic and Atmospheric Administration; 161-294.

SAS Institute, Jnc. 1987. SAS/STAT gujde for personal computers. 6th ed. Cary, NC: SAS Institute, Ine.; 1,028 p.
SAS Institute, Inc. 1988. SAS/STAT user's guide, Release $6.03 \mathrm{ed.} \mathrm{Cary,}$ NC: SAS Institute Inc.; 1,028 p.

SAS Institute, Inc. 1990. SAS Technical Report P-200, SAS/STAT Software: CALIS and LOGISTIC Procedures, Release 6.04. Cary, NC: SAS Institute lnc.; 1,028 p.

SAS Institute, Inc. 1991. SAS/STAT Users Guide, Version 6, 4th ed. Cary, NC: SAS Institute Inc; 1,739 p.

Savard, Jean-Pierre L.; Lemon, Moira J.F. 1992. Summer distribution and abundance of Marbled Murrelets on the west and east coasts of Vancouver Island. In: Vermeer, Kees; Butler, Robert W.; Morgan, Ken H., eds. The ecology, status and conservation of marine and shoreline birds on the west coast of Vancouver Island. Occasional Paper No. 75. Ottawa, ON: Canadian Wildlife Service, Environment Canada; 114-119.

Savard, Jean-Pierre L.; Lemon, Moira J.F. Geographic distribution of the Marbled Murrelet on Vancouver lsland at inland sites and at sea during the 1991 breeding season. Tech. Rep. Ser. No. 189. Delta, B.C.: Canadian Wildlife Service. [In press].

Savile, D.B.O. 1957. Adaptive evolution in the avian wing. Evolution 11: 212-224.

Savile, D.B.O. 1972. Evidence of tree nesting by the Marbled Murrelet in the Queen Charlotte Islands. Canadian Field-Naturalist 86: 839-930.

Schafer, Daniel. Associate Professor of Statistics, Oregon State University, Corvallis, OR. [Personal communication].

Schaffner, F.G. 1986. Trends in Elegant Tern and northern anchovy populations in California. Condor 88: 347-354.

Schönwetter, M. 1963. Handbuch der Oologie, Part VIII. In: Meise, W., ed. Berlin: Alademie-Verlag; 458-472.

Schumacber, James D.; Reed, R.K. 1980. Coastal flow in the northwest Gulf of Alaska: the Kenai Current. Journal of Geophysical Research 85: $6680-6688$.

Schwing, F.B.; Husby, D.M.; Garfield, N.; Tracy, D.E. 1991. Mesoscale oceanic responses to wind events off central California in spring 1989: CTD surveys and AVHRR imagery. California Cooperative Oceanographic and Fisheries Investigations, Report 32:47-64.

Scotr, J. Michael.; Hoffman, W.; Ainley, David G.; Zeillemaker, C. Fred. 1974. Range expansion and activity patterns in Rhinoceros Auklet. Western Binds 5: 13-20.

Scoth, J.S. 1973. Food and inferred feeding behavior of northern sand lance (Ammodyres dubius). Joumal Fisheries Resource Board of Canada 30: $451-454$.

Sealy, Spencer G. 1968. A comparative study of breeding ecology and timing in plankion-feeding alcids (Cyclorrhynchus and Aethia spp.) on St. Lawrence Island, Alaska. Vancouver, B.C.: University of British Columbia; 193 p. M.Sc. Thesis.

Sealy, Spencer G. 1970. Egg teeth and batching methods in some alcids. Wilson Bulletin 82: 289-293.

Sealy, Spencer G. 1972. Adaptive differences in breeding biology in the marine family Alcidae. Ann Arbor. University of Michigan; 283 p. Ph.D. Thesis.

Sealy, Spencer G. 1973a. Adaptive significance of post-batcbing developmental patterns and growth rates in the Alcidae. Ornis Scandinavica 4: 113-121.

Sealy. Spencer G. 1973b. Interspecific feeding assemblages of marine birds off B.C. Auk 90: 796-802.

Sealy, Spencer G. 1973c. Breeding biology of the Horned Puffin on St. Lawrence Island, Bering Sea, with zoogeographical notes on the North Pacific puffins. Pacific Science 27(2): 99-119.

Sealy, Spencer G. 1974. Breeding pbenology and clutch size in the Marbled Murrelet. Auk 91(1): 10-23.

Sealy, Spencer G. 1975a. Aspects of the breeding bjology of the Marbled Murrelet in B.C.. Bird-Banding 46: 141-154.

Sealy, Spencer G. 1975b. Egg size of murrelets. Condor 77(4): 500-501.

Sealy, Spencer G. 1975c. Feeding ecology of Ancient and Marbled Murrelets near Langara Island, B.C. Canadian Journal of Zoology 53: 418-433.

Sealy, Spencer G. 1976. Biology of nesting Ancient Murrelets. Condor 78(3): 294-306.

Sealy, Spencer G. 1977. Wing molt of the Kittlitz's Murrelet. Wilson Bulletin 89: 467-469. 
Sealy, Spencer G. 1982. Voles as a source of egg and nestling loss among nesting auklets. Murrelet 63: 9-14.

Sealy, Spencer G. 1984. Interruptions extend incubation by Ancient Murrelets, Crested Auklets, and Least Auklets. Murrelet 65: 53-56.

Sealy, Spencer G. 1990. Auks at sea: prospects for future research. In: Sealy, Spencer G., ed. Auks at sea. Studies in Avian Biology 14: 1-6.

Sealy, Spencer G. Department of Zoology, University of Manitoba, Winnipeg, Manitoba R3T 2N2. [Personal communication].

Sealy, Spencer G.; Bédard, Jean. 1973. Breeding biology of the Parakeet Auklet (Cyclorrhynchus psittacula) on St. Lawrence Island, Alaska. Astarte 6: 59-68.

Sealy, Spencer G.; Carter, Harry R. 1984. At-sea distribution and nesting habitat of the Marbled Murrelet in B.C.: problems in the conservation of a solitary nesting seabird. In: Croxall, John P.; Evans, Peter G.H.; Schreiber, Ralph W., eds. Status and conservation of the world's seabirds. Tech. Publ. No. 2. International Council for Bird Preservation. Norwich, UK: Page Bros. 737-756.

Sealy, Spencer G.; Carter, Harry R.; Alison, D. 1982. Occurrences of the Asiatic Marbled Murrelet [Brachyramphus marmoratus perdix (Pallas)] in North America. Auk 99: 778-781.

Sealy, Spencer G.; Carter, Harry R.; Shuford, W. David; Powers, Kevin D.; Chase, Charles A., 111. 1991. Long-distance vagrancy of the Asiatic Marbled Murrelet in North America, 1979-1989. Western Birds 22: 145-155.

Selkregg, Lidia L. 1974. Alaska regional profiles, state of Alaska. Vol. 1. Southcentral. Anchorage, AK: University of Alaska, Arctic Environmental Information and Data Center.

Shaffer, M. and Associates Ltd. 1990. Crude oil and petroleum product traffic in British Columbia and Puget Sound. Final Report of the States/ British Columbia oil spill task force, Appendix 1V. Publication Province of British Columbia and the States of Washington, Oregon, Alaska and California; 51 p.

Shapovalov, L.; Taft, A.C. 1954. The life histories of the steelhead rainbow trout (Salmo gairdneri gairdneri) and silver salmon (Onchorhynchus kisutch) with special reference to Waddell Creek, California, and recommendations regarding their management. Fish Bulletin 98. Sacramento, CA: California Fish and Game.

Shaughnessy, Margaret. Oregon Cooperative Wildlife Research Unit, Oregon State University, Nash 104, Corvallis, OR 9733 1-3803 [Personal communication].

Shaughnessy, Margaret M.; Nelson, S. Kim. 1991. Marbled Murrelet surveys in timber sales of the Siuslaw National Forest, 13 May-15 August 1991. Report on file. USDA Forest Service, Siuslaw National Forest, Corvallis, OR.

Shaughnessy, Margaret M.; Nelson, S. Kim. Temporal variation in presence and behavior of Marbled Murrelets in forests during the breeding season. Draft manuscript supplied by authors.

Sherman, K.; Jones, C.; Sullivan, L.; Smith, W.; Berrien, P.; Ejsymont, L. 1981. Congruent shifts in sand eel abundance in western and eastern North Atlantic ecosystems. Nature 291: 486-489.

Shibaev, Yurij V. 1990. Marbled Murrelet. In: Flint, V.E.; Golovkin, A.N., eds. Birds of the USSR: Auks (Alcidae); 82-88. (in Russian).

Shields, W.M. 1983. Optimal inbreeding and the evolution of philopatry. In: Swingland, I.R., Greenwood, P.J., eds. The ecology of animal movement. Oxford, England: Clarendon Press; 132-159.

Sibley, David. 1993. An Asiatic Marbled, Murrelet in Ontario. Birders Journal 2: 276-277.

Silver, Emily. Adopt A Beach, Seattle, WA. [Telephone conversation with Harry R. Carter]. August 1994.

Simenstad, C.A.; Miller, B.S.; Nyblade, C.F.; Thornburgh, K.; Bledsoe, L.J. 1979. Food web relationships of northern Puget Sound and the Strait of Juan de Fuca. Interagency Energy/Environment R\&D Program Report EPA-600/7-79-259. Washington, DC: U.S. Department of Commerce/Environmental Protection Agency; 334 p.

Simons, Theodore R. 1980. Discovery of a ground-nesting Marbled Murrelet. Condor 82(1): 1-9.

Singer, Stephanie A. Biologist, 218 Nevada St. Santa Cruz, CA 95060. [Personal communication].
Singer, Steven W. Environmental and Ecological Services, 218 Nevada Street, Santa Cruz, CA 95060. [Personal communication].

Singer, Steven W.; Carter, Harry R. 1992. Restoration of the centra] California population of the Marbled Murrelet after injuries from the Apex Houston oil spill. Report on file. U.S. Department of Justice, Washington, DC.

Singer, Steven W.; Naslund, Nancy L.; Singer, Stephanie A.; Ralph, C. John. 1991. Discovery and observation of two tree nests of the Marbled Murrelet. Condor 93(2): 330-339.

Singer, Steven W.; Suddjian, David L.; Singer, Stephanie A. 1992. Discovery, observations and fledging of a Marbled Murrelet from a redwood tree nest. Santa Cruz, CA: Santa Cruz Museum of Natural History Report; 10 p.

Singer, Steven W.; Suddjian, David L.; Singer, Stephanie A. Fledging of Marbled Murrelets from two tree nests in California. In: Nelson, S. Kim; Sealy, Spencer G., eds. Biology of Marbled Murrelets: inland and at sea-a symposium of the Pacific Seabird Group 1993. Northwestern Naturalist. [In press].

Singer, Steven W.; Verardo, D.R. 1975. The inurrelet's nest discovered. Pacific Discovery 28: 18-21.

Siskin, B.R.; Page, Gary W.; Carter, Harry R. 1991. Impacts of the 1986 Apex Houston oil spill on marine birds in central California. Report on file. U.S. Department of Justice, Washington, DC.

Smail, John; Ainley, David G.; Strong, Helen. 1972. Notes on birds killed in the 1971 San Francisco oil spill. California Birds 3: 25-32.

Small, M.F.; Hunter, M.L. 1988. Forest fragmentation and avian nest predation in forested landscapes. Oecologia 76: 62-64.

Smith, M.A. 1959. Cohoe, Alaska. American Birds 13: 55-57.

Snedecor, George W.; Cochran, William G. 1980. Statistical methods. 7th ed. Ames, IA: lowa State University Press; 507 p.

Snyder, Shelly. Washington Department of Fish and Wildlife, 600 Capitol Way N., Olympia WA 98501-1091 [Personal communication].

Sowls, Arthur L.; Hatch, Scott A.; Lensink, C.J. 1978. Catalog of Alaskan seabird colonies. FWS/OBS 78-78. USDI Fish and Wildlife Service, Biological Services; 252 p.

Sowls, Arthur L.; DeGange, Anthony R.; Nelson, Jay W.; Lester, Gary S. 1980. Catalog of California seabird colonies. FWS/OBS-37/80. Washington, DC: U.S. Fish and Wildlife Service, Biological Services Program; $371 \mathrm{p}$.

Spear, Larry B.; Nur, Nadav; Ainley, David G. 1992. Estimating absolute densities of flying seabirds using analyses of relative movement. Auk 109: 385-389.

Speckman, Suzann G. Wildlife Biologist, University of Alaska, Fairbanks, AK. [Personal communication].

Speckman, Suzann G.; Springer, Alan M.; Piatt, John F. 1993. Marbled Murrelet abundance patterns at sea in relation to the marine environment (abstract). Pacific Seabird Group Bulletin 20(1): 42.

Speich, Steven M. Dames \& Moore, 1790 E. River Road, Suite E300, Tucson, AZ 85718. [Personal communication].

Speich, Steven M.; Calambokidis, J.; Peard, R.J.; Fry, D.M.; Witter, M. 1988. Puget Sound Glaucous-winged Gulls: biology and contaminants. Puget Sound Research. Olympia, WA: Puget Sound Water Quality Authority.

Speich, Steven M.; Manuwal, David A. 1974. Gular pouch development and population structure in Cassin's Auklet. Auk 91(2): 291-306.

Speich, Steven M.; Thompson, S.P. 1987. Impacts on waterbirds from the 1984 Columbia River and Whidbey Island, Washington, oil spills. Western Birds 18: 109-116.

Speich, Steven M.; Troutman, B.L.; Geiger, A.C.; Meehan-Martin, P.J.; Jeffries, S.J. 1987. Evaluation of military flight operations on wildlife of the Copalis National Wildlife Refuge, 1984-1985. Final Report. Western Division, Naval Facilities Engineering Command, Department of the Navy, San Bruno, CA.

Speich, Steven M.; Wahl, Terrence R. 1986. Rates of occurrence of dead birds in Washington's inland marine waters, 1978 and 1979. Murrelet 67: 51-59.

Speich, Steven M.; Wahl, Terrence R. 1989. Catalog of Washington seabird colonies. Biological Report 88(6). Washington, DC: U.S. Fish and Wildlife Service; $510 \mathrm{p}$. 
Speich, Steven M.; Wahl, Terrence R. Marbled Murrelet populations of Washington - marine habitat preferences and variability of occurrence. [This volume].

Speich, Steven M.; Wahl, Terrence R.; Manuwal, David A. 1992. The numbers of Marbled Murnelets in Washington marine waters. In: Carter, Harry R.; Morrison, Michael L., eds. Status and conservation of the Marbled Murrelet in North America. Proceedings of the Western Foundation of Vertebrate Zoology 5(1): 48-60.

Speich, Steven M.; Wahl, Terrence R.; Steelquist, Roben U. I991. The Arco Anchorage oil spill-an evaluation of avian impact assessment methods. In: Ransom, ed. Puget Sound research 1991 proceedings. Volume 1. Olympia, WA: Puget Sound Water Quality Authority; 383-392.

Spies, Thomas A.; Franklin, Jerry F. 1991. The strucrure of natural young, mature, and old-growth Douglas-fir forests in Oregon and Washington. In: Ruggiero, Lenny F.; Aubry, Keith B.; Carey. Andrew B.; Huff, Mark A., tech. eds. Wildlife and vegetation of unmanaged Douglas-fir forests. Gen. Tech. Rep. PNW-GTR-285. Portland, OR: Pacific Northwest Research Station, Forest Service, U.S. Department of Agriculture: 91-110.

Spratt, J.D. 1981. Status of the Pacific herring, Clupea harengus pallasii, resource in California 1972 to 1980 . Fish Bulletin 171. Sacramento, CA: California Department Fish and Game.

Springer, Alan M.; Kondratyev, Alexander Y.; Ogi, Haruo; Shibaev, Yurij V.; van Vliet, Gus B. 1993. Status, ecology, and conservation of Synthliboramphus murrelets and auklets. In: Vermeer, Kees; Briggs, Kenneth T.; Morgan, Ken H.; Siegel-Causey, Douglas, eds. The status, ecology and conservation of marine birds of the north Pacific. Special Publication. Ottawa, ON: Canadian Wildlife Service, Environment Canada; 187-203.

Steel, R.G.D.; Torrie, J.H. 1960. Principles and procedures of statistics. New York: McGraw-Hill.

Stein, Janet L. Washington Department of Fish and Wildlife, Olympia, WA. [Personal communication].

Stein, Janet L.; Carter, Harry R. 1994. Criteria for separating juveniles from after-batching-year Marbled Murrelets in late summer and early fall (abstract). Pacific Seabirds 21(1): 68.

Steinhart, C.E.; Steinhart, J.S. 1972. Blowout: a case study of the Santa Barbara oil spill. Belmont, CA: Wadsworth Publication Co.

Stempniewicz, L. 1981. Breeding biology of the Little Auk, Plaurus alle, in the Hornsund region, Spitsbergen. Acta Omithologica 18: 1-26.

Stenzel, Lynne E. Point Reyes Bird Observatory, Stinson Beach, CA. [Telephone conversation with Harry R. Carter]. May 1994.

Stenzel, Lynne E.; Page, Gary W.; Carter, Harry R.; Ainley, David G. 1988. Seabird mortality in California as witnessed througb 14 years of beached bird censuses. Report on file. Point Reyes Bird Observatory, Stinson Beacb, CA.

Stewart, A. Field Trip Coordinator, Bamfield Marine Station, Bamfield, BC. Canada VOR IBO. [Personal communication].

Storer, Roben W. 1952. Variation in the resident Sharp-shinned Hawks of Mexico. Condor 54: 283-289.

Storer, Robert W. 1971. Adaptive radiation in birds. In: Farner, Donald S.; King, James R., eds. Avian biology. Vol. 1. New York: Academic Press. 149-188.

Strachan, Gary. Director, Año Nuevo State Reserve, New Years Creek Road, Pescadero, CA. [Personal communication].

Strachan, Gary; McAllister, Michael L.; Ralph, C. John. Marbled Murrelet at-sea and foraging behavior. [This volume].

Straughan, D. 1971. Oil pollution and seabirds. In: Straughan, D., ed. Biological and oceanographical survey of the Santa Barbara oil spill 1969-1970. Vol. J. Biology and bacteriology. Los Angeles, CA: Allan Hancock Foundation, University of Southern California; 307-324.

Streator, C.P. 1947. Birds of Santa Cruz County, California. Report on file. Santa Cruz Public Library, Santa Cruz, CA.

Stresemann, E.; Stresemann, V. 1966. Die Mäuser der Vogel. Journal für Ornithologie 107 (Supplemert): 1-445.

Strong, Craig S. Distribution of Marbled Murrelets along the Oregon coast in 1992. In: Nelson, S. Kim; Sealy, Spencer G., eds. Biology of
Marbled Murrelets: inland and at sea-a symposium of the Pacific Seabird Group 1993. Northwestern Naturalist. [In press].

Strong, Craig S. Wildlife Biologist, Crescent Coastal Research, 7700 Bailey Road, Crescent City, CA 95531. [Personal communication].

Strong. Craig S.; Gilardi, John R.; Gaffney, lan; Cruz, Janice M. 1993. Distribution and abundance of Marbled Murrelets at sea on the Oregon coast in 1992. Grant Agreement No. 92-06-01. Report on file. Nongame Program, Oregon Department of Fish and Wildlife, Portland, OR; 29 p.

Strong, Craig S; Keitt, Bradford S.; Mclver, William R.; Palmer, Clifford J.; Gaffney, lan. Distribution and population estimates of Marbled Murrelets at sea in Oregon during the summers of 1992 and 1993. [This volume].

Suddjian, David L. Wildlife Biologist, Habitat Restoration Group, 6001 Butler Lane, Suite 1, Scott's Valley, CA. [Personal communication].

Swartzman, G.; Carter, Harry R. 1991. Long-term injuries to the central California population of Common Murres (Uria aalge) due to mortality from the 1986 Apex Houston oil spill. Report on file. U.S. Department of Justice, Washington, DC.

Sydeman, William J. 1993. Survivorship of Common Murres on Southeast Farallon Island, California. Ornis Scandinavia 24: 135-141.

Takekawa, Jean E.; Carter, Harry R.; Harvey, Thomas E. 1990. Decline of the Common Murre in central California, 1980-1986. In: Sealy, Spencer G., ed. Auks at sea. Studies in Avian Biology 14: 149-163.

Tanasichuk, R. Pacific Biological Station, Nanaimo, BC, Canada V9R 5K6. [Personal communication].

Tangen, Lloyd. Arcata Redwood Company, P.O. Box 1089, Arcata, CA 95521 [Personal communication].

Tasker, M.L.; Jones, Hope P.; Dixon, T.; Blake, B.F. 1984. Counting seabirds at sea from ships: a review of methods employed and a suggestion for a standardized approach. Auk 101: 567-577.

Taylor, K.; Reid J.B. 1981. Earlier colony attendance by guillemots and razorbills. Scottish Birds 11: 173-180.

Taylor, W.P. 192J. The Marbled Murrelet mystery. Murrelet 2: 8.

Teensma, P.D.A: Rienstra; J.T.; Yeiter, M.A. 1991. Preliminary reconstruction and analysis of change in forest stand age classes of the Oregon coast range from 1850 to 1940. USDl Bureau of Land Management Tech. Note T/NOR-9. Portiand, OR: Bureau of Land Management; 9 p.

Thomas, Dana L.; Taylor, Eric J. 1990. Study designs and tests for comparing resource use and availability. Journal of Wildlife Management 54: 322-330.

Tetreau, Mike. Kenai Fjords National Park, U.S. Department of the Interior, National Park Service, Seward, AK. [Personal communication].

Thomas, Jack Ward; Raphael, Martin G., eds. 1993. Forest ecosystem management: an ecological, economic, and social assessment: report of the Forest Ecosystem Management Team. Portland, OR: U.S. Department of Agriculture; U.S. Department of Commerce; U.S. Department of Interior, Environmental Protection Agency; [irregular pagination].

Thomson, A.L. 1953. The migration of British auks (Alcidae) as shown by the results of marking. British Birds 46: 3-15.

Thomson, R.E. 1981. Oceanography of the British Columbia coast. Canadian Special Publication of Fisheries and Aquatic Sciences 56.

Thorensen, Asa C. 1964. The breeding behavior of the Cassin Auklet. Condor 66: 456-476.

Thorensen, Asa C. 1984. Breeding phenology and mid-seasonal social bebavior of the Sooty Guillemot on Teuri lsland, Japan. Western Birds 15(4): 145-160.

Thorensen, Asa C. 1989. Diving times and behavior of Pigeon Guillemots and Marbled Murrelets off Rosario Head, Washington. Western Birds 20: 33-37.

Tinbergen, L. 1960. The natural control of insects in pinewoods, 1. Factors influencing the intensity of predation by song birds. Archives Neerlandaises de Zoologie 13: 265-343.

Trapp, John L. 1984. Winter population trends of waterbirds in Alaska: Christmas bird count analysis-1980. Anchorage, AK: U.S. Fish and Wildlife Service; 48 p.

Trasky, Lance L.; Flagg, Loren B.; Burbank, David C. 1977. Environmental Studies of Kachemak Bay and Lower Cook Inlet. Vol. I: Impact of oil 
on the Kachemak Bay Environment. Unpublished report. Alaska Department of Fish and Game, Marine Coastal Habitat Management, Anchorage, AK.

Tuck, L.M. 1960. The murres: their distribution, populations, and biology. Rept. Ser. No. 1. Ottawa, ON: Canadian Wildlife Service.

Tuck, L.M. 1961. The Murres. Their distibution, populations and biology, a study of the genus Uria. Ottawa, ON: Canadian Wildlife Service; 206 p.

Tyler, W. Breck; Briggs, Kenneth T.; Lewis, David B.; Ford, R. Glenn 1993. Seabird distribution and abundance in relation to oceanographic processes in the California Current system. In: Vermeer, Kees; Briggs, Kenneth T.; Morgan, Ken H.; Siegel-Causey, Douglas, eds. The status, ecology and conservation of marine birds of the North Pacific. Special Publication. Ottawa, ON: Canadian Wildlife Service, Environment Canada; 48-60.

Udvardy, M.D.F. 1963. Zoogeographical study of the Pacific Alcidae. In: Gressit, J.L., ed. Pacific Basin biogeography: a symposium. Honolulu, HI: Bishop Museum Press; 85-111.

USDA Forest Service. 1983. Area ecology plot cards. Report on file. USDA Forest Service, Siuslaw National Forest, Corvallis, OR.

USDA Forest Service. 1985. Intensive plot instructions. Report on file. USDA Forest Service, Siuslaw National Forest, Corvallis, OR.

USDA Forest Service, Alaska Region. 1991. Tongass National Forest land management plan revision. Supplement to the draft environmental impact statement. R10-MB-149. Anchorage, AK; 755 p.

USDA Forest Service, Alaska Region. 1992. Ecological definitions for old-growth forest types in southcentral Alaska. Tech. Rep. R10-TP-28. Anchorage, AK; 85 p.

USDA Forest Service. undated. Final environmental impact statement. Chugach National Forest. Administrative Document 127A.

U.S. Department of Agriculture / U.S. Department of the Interior. 1994. Supplemental environmental impact statement on management of habitat for late-successional and old-growth forest related species within the range of the Northern Spotted Owl. Portland, OR.

U.S. Fish and Wildlife Service. 1992. Final rule listing the Marbled Murrelet as threatened in Washington, Oregon, and California. United States Federal Register, October 1, 1992.

U.S. Fish and Wildlife Service. 1993a. Afognak Island biological assessment and land acquisition plan. Anchorage: U.S. Fish and Wildlife Service, Division of Realty. Draft report supplied by the authors.

U.S. Fish and Wildlife Service. 1993b. Letter from Marvin L. Plenert, Regional Director, U.S. Fish and Wildlife Service, to R. A. Schmitten, Regional Director, National Marine Fisheries Service, dated 1993 July 27. (Subject: USFWS Biological Opinion with regard to effects of the proposed commercial net fisheries in Washington State for 1993 (allcitizens net fisheries) on the threatened Marbled Murrelet)

U.S. Fish and Wildlife Service. 1993c. Letter from Marvin L. Plenert, Regional Director, U.S. Fish and Wildlife Service, to Area Director, Bureau of Indian Affairs, dated 27 July 1993. (Subject: Formal consultation on Tribal, Coastal and Puget Sound Net Fisheries)

U.S. Fish and Wildlife Service. Draft Marbled Murrelet (Brachyramphus marmoratus marmoratus) (Washington, Oregon and California) recovery plan. Portland, OR: [In press].

U.S. Geological Survey. 1990. Digital elevation models, data users guide 5. Reston, VA; 51 p.

Vader, W.; Barrett, R.T.; Erikstad, K.E.; Strann, K.B. 1990. Differential responses of Common and Thick-billed Murres to a crash in the capelin stock in the southern Barents Sea. In: Sealy, Spencer G., ed. Auks at sea. Studies in Avian Biology 14: 175-180.

Van Horne, S. 1983. Density as a misleading indicator of habitat quality. Journal of Wildlife Management 47: 893-901.

Van Vliet, Gus. 1993. Status concerns for the "global" population of Kittlitz's Murrelet: is the "glacier murrelet" receding? Pacific Seabird Group Bulletin 20(1): 15-16.

Van Vliet, Gus. Seabird Biologist, P.O. Box 210442, Auke Bay, AK. [Personal communication].

Varoujean, Daniel H. Executive Director, Marine and Estuarine Research Company, 2269 Broadway, North Bend, OR 97459 [Persona] communication].
Varoujean, Daniel H.; Williams, Wendy A. 1987. Nest locations and nesting habitat of the Marbled Murrelet (Brachyramphus marmoratus) in coastal Oregon. Report on file; Portland, OR: Oregon Department of Fish and Wildlife; $49 \mathrm{p}$.

Varoujean, Daniel H.; Williams, Wendy A. 1994a. Abundance and distribution of Marbled Murrelets in Oregon based on aerial surveys. Unpublished draft supplied by author; $56 \mathrm{p}$.

Varoujean, Daniel H.; Williams, Wendy A. 1994b. Distribution and abundance of Marbled Murrelets on the outer coast of Washington and in the Strait of Juan de Fuca. Unpublished draft suppled by author; 51p.

Varoujean, Daniel H.; Williams, Wendy A. Abundance and distribution of Marbled Murrelets in Oregon and Washington based on aerial surveys. [This volume].

Varoujean, Daniel H.; Williams, Wendy A.; Warrick, D.R. 1989. Nest locations and nesting habitat of the Marbled Murrelet (Brachyramphus marmoratus) in coastal Oregon. Tech. Rept. \#88-6-02. Portland, OR: Oregon Department of Fish and Wildlife.

Vega, Robyn S. 1994. Bird communities in managed conifer stands in the Oregon Cascades: habitat associations and nest predation. Corvallis, OR: Oregon State University. M.S. Thesis.

Velizhanin, A.G. 1977. Some rare and lesser known birds of the Kuril Islands. Ornitologiya 13: 25-32. (in Russian).

Vequist, G.W.; Nishimoto, Michael. 1990. Seabird survey on the coast of Kenai Fiords during the Exxon Valdez oil spill. Unpublished final report. National Park Service, Alaska Region, Anchorage, AK.

Vermeer, Kees. 1980. The importance of timing and type of prey to reproductive success of Rhinoceros Auklets Cerorhinca monocerala. Ibis 122(3): 343-350.

Vermeer, Kees. 1981. The importance of plankton to breeding Cassin's Auklets. Journal Planktonic Research 3: 315-329.

Vermeer, Kees. 1989. Marine birds of Jervis Inlet, a mainland fjord entering the Strait of Georgia. In: Vermeer, Kees; Butler, Robert W., eds. The ecology and status of marine and shoreline birds in the Strait of Georgia, British Columbia. Special Publication. Ottawa, ON: Canadian Wildlife Service; 148-157.

Vermeer, Kees. 1992. The diet of birds as a tool for monitoring the biological environment. In: Vermeer, Kees; Butler, Robert W.; Morgan, Ken H., eds. The ecology, status, and conservation of marine and shoreline birds on the west coast of Vancouver Island. Occasional Paper No. 75. Delta, BC: Canadian Wildlife Service; 41-50.

Vermeer, Kees; Briggs, Kenneth T.; Morgan, Ken H.; Siegel-Causey, Douglas, eds. 1993. The status, ecology, and conservation of marine birds of the North Pacific. Special Publication. Ottawa, ON: Canadian Wildlife Service, Environment Canada; 263 p.

Vermeer, Kees; Cullen, Leo. 1979. Growth of Rhinoceros Auklet and Tufted Puffin, Triangle Jsland, British Columbia. Ardea 67(1979): 22-27.

Vermeer, Kees; Cullen, Leo. 1982. Growth comparison of a plankton- and a fish-feeding alcid. Murrelet 63: 34-39.

Vermeer, Kees; Cullen, Leo; Porter, Marian. 1979. A provisional explanation of the reproductive failure of Tufted Puffins Lunda cirrhata on Triangle Island, British Columbia. Ibis 121(3): 348-354.

Vermeer, Kees; Hay, R.; Rankin, L. 1987. Pelagic seabird populations off southwestern Vancouver Island. Canadian Tech. Rep. Hydrog. Ocean Sci. No. 87; Sidney, BC, Canada: Department of Fisheries and Oceans, Institute of Ocean Science; $\mathrm{iii}+26 \mathrm{p}$.

Vermeer, Kees; Lemon, Moira J.F. 1986. Nesting habits and habitats of Ancient Murrelets and Cassin's Auklets in the Queen Charlotte Jslands, British Columbia. Murrelet 67: 33-44.

Vermeer, Kees; Morgan, Kenneth H. 1989. Nesting population, nest sites, and prey remains of Bald Eagles in Barkley Sound, British Columbia. Northwestern Naturalist 70: 21-26.

Vermeer, Kees; Morgan, Kenneth H. 1992. Marine bird populations and habitat use in a fjord on the west coast of Vancouver Island. In: Vermeer, Kees; Butler, Robert W.; Morgan, Ken H., eds. The ecology, status and conservation of marine and shoreline birds on the west coast of Vancouver Island. Occasional Paper No. 75. Ottawa, ON: Canadian Wildlife Service; 86-95. 
Vermeer, Kees; Morgan, Ken H.; Butler, Robert W.; Smith, G.E. John. 1989a. Population, nesting habitat and food of Bald Eagles in the Gulf lslands. In: Vermeer, Kees; Butler, Robert W., eds. The ecology and status of marine and shoreline birds in the Strait of Georgia, British Columbia. Special Publication. Ottawa, ON: Canadian Wildlife Service; 123-1 30.

Vermeer, Kees; Morgan, Ken H.; Smith, G.E. John; Hay, R. 1989b. Fal] distribution of pelagic birds over the shelf off SW Vancouver Island. Colonial Waterbirds 12: 207-214.

Vermeer, Kees; Robertson, lan; Campbell, R. Wayne; Kaiser, Gary; Lemon, Moira J.F. 1983. Distribution and densities of marine birds on the Canadian west coast. Unpublished report. Delta, BC: Canadian Wildlife Service.

Vermeer, Kees; Sealy, Spencer G. 1984. Status of nesting seabirds of British Columbia. In: Croxall, John P.; Evans, Peter G.H.; Schreiber, Ralph W., eds. Status and conservation of the world's seabirds. International Conservation of Bird Populations Technical Publication No. 2. Norwich UK: Page Bros.; 29-40.

Vermeer, Kees; Sealy, Spencer G.; Sanger, Gerald A. 1987a. Feeding ecology of alcidae in the eastern north Pacific Ocean. In: Croxall, John P., ed. Seabirds: feeding biology and role in marine ecosystems. Cambridge, England: Cambridge University Press; 189-227.

Vermeer, Kees; Szabo, 1.; Greisman, P. 1987b. The relationship between plankton-feeding Bonaparte's and Mew Gulls and tidal upwelling at Active Pass, British Columbia. Journal of Plankton Research 9: 483-501.

Vermeer, Kees; Vermeer, R. 1975. Oil threat to birds on the Canadian West Coast. Canadian Field Naturalist 89: 278-298.

Viereck, Leslie A.; Little, Elbert L. 1972. Alaska trees and shrubs. Agric. Handb. No. 410. Washington, DC: Forest Service, U.S. Department of Agriculture; $265 \mathrm{p}$.

Vyatkin, P.S. 1981. New data on the distribution of sea birds on the shore of Kamchatka. Bulletin of the Moscow Society of Naturalists. 86: 1418. (in Russian).

Wahl, Terrence R. 1981. Distribution of Western Grebes in Washington's inland waters with reference to commercial fishing operations (abstract). Pacific Seabird Group Bulletin 8(2): 102.

Wahl, Terrence R. 1984. Distribution and abundance of seabirds over the continental shelf off Washington. Report on file. Washington Department of Ecology, Olympia, WA.

Wahl, Terrence R. 3041 Eldridge, Bellingham, WA 98225. [Personal communication].

Wahl, Terrence R.; Speich, Steven M. 1983. First winter survey of marine birds in Puget Sound and Hood Canal December, 1982 and February, 1983. Report on file. Washington Department of Game, Nongame Wildlife Program, Olympia, WA.

Wahl, Terrence R.; Speich, Steven M. 1984. Survey of marine birds in Puget Sound, Hood Canal and waters east of Whidbey Island, Washington, in summer 1982. Western Birds 15: 1-14.

Wahl, Terrence R.; Speich, Steven M. Foraging distribution of Rhinoceros Auklets from colonies in the Strait of Juan de Fuca, Washington. 1n: Sealy, Spencer G.; Nelson, S. Kim, eds. Proceedings of the Pacific Seabird Group's Marbled Murrelet symposium, 1993. Northwestern Naturalist. [In press].

Wahl, Terrence R.; Speich, Steven. M.; Manuwal, David A.; Hirsch, K.V.; Miller, C. 1981. Marine bird populations of the Strait of Juan de Fuca, Strait of Georgia, and adjacent waters in 1978 and 1979. Interagency Energy-Environmental Research Development Program Rept., EPA600/7-81-156. Seattle, WA: National Oceanic and Atmospheric Administration, Marine Ecology Anal. Prog.; 788 p.

Wall, B. 1972. Log production in Washington and Oregon: an historical perspective. Resource Bulletin PNW-42. Portland, OR: Forest Service, Pacific Northwest Experiment Station, U.S. Department of Agriculture.

Walsh, Peter. USDA Forest Service, Petersburg Ranger District, Petersburg, AK. [Personal communication].

Warbeit, K.1. 1992. A review of the fossil seabirds from the Tertiary of the North Pacific: plate tectonics, paleoceanography, and faunal change. Paleobiology 18: 401-424.
Warheit, Kenneth. Washington Department of Fish and Wildlife, Olympia, WA. [Telephone conversation with Harry R. Carter]. May 1994.

Washington Department of Fish and Wildlife. 1994. Biological assessment of the effects of the Puget Sound area all-citizens commercial salmon gillnet and purse seine mixed-stock (preterminal) fisheries on Marbled Murrelets. Report on file. Washington Department of Fish and Wildlife, Olympia, WA.

Watanuki, Y. 1987. Breeding biology and foods of Rhinoceros Auklets on Teuri Island, Japan. National Institute of Polar Research (NIPR) Symposium Polar Biological Proceedings 1: 175-183.

Watson, George E. 1968. Synchronous wing and tail molt in diving petrels. Condor 70: 182-183.

Wehle, D.H.S. 1980. The breeding biology of the puffins: Tufted Puffin (Lunda cirrhata), Horned Puffin (Fratercula carniculata), and Rhinoceros Auklet (Cerorhinca monocerata). Fairbanks, AK: University of Alaska. Ph.D. Thesis.

Wehle, D.H.S. 1983. The food, feeding, and development of young Tufted and Horned puffins in Alaska. Condor 85(4): 427-442.

Weins, J.S.; Heinemann, D.; Hoffman, W. 1978. Community structure, distribution and inter-relationships of marine birds in the Gulf of Alaska. Final reports of Principal lnvestigators. Vol. 3. Boulder, CO: National Oceanographic and Atmospheric Administration.

Welty, J.C.; Baptista, Luis. 1988. The life of birds. 4th ed. New York: Saunders College Publishing; 581 p.+ appendices.

Westfall, Michael S. Naturalist, Butano State Park, Pescadero, CA. [Personal communication].

Wettstein, Cal. Forester, Siuslaw National Forest, Corvallis, OR. [Personal communication].

Whitehead, P. 1989. Toxic chemicals in Great Blue Heron (Ardea herodius) eggs in the Strait of Georgia. In: Vermeer, Kees; Butler, Robert W., eds. The ecology and status of marine and shoreline birds in the Strait of Georgia, British Columbia. Special Publication. Ottawa, ON: Canadian Wildlife Service; 177-183.

Wilcove, D.S. 1985. Nest predation in forest tracts and the decline of migratory songbirds. Ecology 66(4): 1211-1214.

Wild Bird Society of Japan. 1982. Birds of Japan.

Willers, B. 1993. Ecocentrism versus management: a reply to Blumstein. Conservation Biology 7: 452-453.

Williams, Jeff C.; Byrd, G. Vernon; Zubakin, Victor. 1994. Status and ecology of Whiskered Auklets (abstract). Pacific Seabirds 21(1): 51-53.

Wilson, J.A.; Kleban, P.; McKay, S.R.; Townsend, R.E. 1991. Management of multispecies fisheries with chaotic population dynamics. International Council for the Exploration of the Sea (ICES) Marine Science Symposium 193: 287-300.

Wilson, John. U.S. Fish and Wildlife Service, Ecological Services, 3704 Griffin Lane SE, Suite 102, Olympia, WA 98501. [Persona] communication].

Wilson, Ulrich W. 1991. Responses of three seabird species to El Niño events and other warm water episodes on the Washington coast, 19791990. Condor 93: 853-858.

Wilson, Ulrich W.; Manuwal, David A. 1986. Breeding biology of the Rhinoceros Auklet in Washington. Condor 88(2): 143-155.

Wilson, William. USDA Forest Service, Alaska Region, P.O. Box 21628, Juneau, AK 99802. [Personal communication].

Wolf, P. 1992. Recovery of the Pacific sardine and the California sardine fishery. California Cooperative Oceanic Fisheries Investigations Report 33; 76-86.

Wolf, P. 1993. Deputy Regional Manager-Region 5. California Department of Fish and Game, Long Beach, CA. [Memorandum to Esther Burkett] December 8, 1993.

Wood, Millicent A. Unpublished data on file at: International Bird Rescue, Berkeley, CA [Personal communication].

Wood, Millicent A.; Heaphy, Nicolette. 1991. Rehabilitation of oiled seabirds and Bald Eagles following the Exron Valdez oil spill. In: Ludwigson, John, ed. 1991 international oil spill conference (prevention, behavior, control, cleanup). Publication no. 4529; Washington, DC: American Petroleum Institute; 235-239. 
Woodbury, D., Chief Scientist; NOAA Ship David Starr Jordan, National Marine Fisheries Service. [Personal communication].

Woolfenden, Glenn. 1967. Selection for delayed simultaneous wing molt in loons (Gaviidae). Wilson Bulletin 79: 416-420.

Wooller, R.D.; Bradley, J.S.; Croxall, John P. 1992. Long-term population studies of seabirds. Trends in Ecology and Evolution 7: 111-114.

Wynne, Kate; Hicks, D.; Munro, N. 1991. 1990 salmon gillnet fisheries observer programs in Prince William Sound and south Unimak Alaska. Report on file. Saltwater Inc., 540 L Street, Anchorage, AK; 69 p.

Wynne, Kate; Hicks, D.; Munro, N. 1992. 1991 marine mammal observer program for the salmon driftnet fishery of Prince William Sound Alaska. Report on file. Saltwater Inc., Anchorage, AK. Available from National Marine Fisheries Service, Alaska Region Office of Marine Mammals, P.O. Box 21668, Juneau, AK; 53 p.

Yahner, Richard N. 1988. Changes in wildlife communities near edges. Conservation Biology 2: 333-339.

Yahner, Richard N.; Cypher, Brian L. 1987. Effects of nest location and depredation of artificial arboreal nests. Journal of Wildlife Management 51: 178-181.

Yahner, Richard N.; Morrell, Thomas E.; Rachael, Jon S. 1989. Effects of edge contrast on depredation of artificial avian nests. Journal of Wildlife Management 54: 1135-1138.
Yahner, Richard H.; Scott, D.P. 1988. Effects of forest fragmentation on depredation of artificial nests. Journal of Wildlife Management 52(1): 158-161.

Yahner, Richard N.; Wright, Anthony L. 1985. Depredation of artificial ground nests: effects of edge and plot age. Joumal of Wildlife Management 49:508-513.

Yakhontov, V.D. 1979. A new place of Marbled Murrelet Brachyramphus marmoratus perdix Pall. nesting. Birds of northeastern Asia; 163 p. (in Russian).

Ydenberg, Ron C. 1989. Growth-mortality trade-offs and the evolution of juvenile life histories in the Alcidae. Ecology 70(5): 1494-1506.

Youkey, Don. Cordova Ranger District, Chugach National Forest, USDA Forest Service, P.O. Box 280, Cordova, AK 99574. [Personal communication].

Zach, R. 1979. Shell droppings: decision-making and optimal foraging in northwestern crows. Behaviour 68: 106-117.

Zar, Jerrold H. 1984. Biostatistical analysis. 2nd ed. Englewood Cliffs, NJ: Prentice-Hall, lnc.; 718 p.

Ziswiler, V. 1967. Extinct and vanishing animals. New York: SpringerVerlag, Inc.; $133 \mathrm{p}$. 


\section{Appendix A-Conservation Assessment Coordinating Group, Core Team and Technical Working Group}

Linda L. Long, compller

\section{Coordinating Group}

Hugh Black, Jr., Pacific Northwest Region, USDA Forest Service, Portland, Oregon

Garland N. Mason, Pacific Southwest Research Station, USDA Forest Service, Albany, California

\section{Core Team}

C. John Ralph, Pacific Southwest Research Station, USDA Forest Service, Arcata, California (Team Leader) George L. Hunt, Jr., Department of Ecology and Evolutionary Biology, University of California, Irvine, California Martin G. Raphael, Pacific Northwest Research Station, USDA Forest Service, Olympia, Washington John F. Piatt, Alaska Science Center, U.S. Department of the Interior, National Biological Service, Anchorage, Alaska

\section{Internal Support Group}

Deborah Kristan, Pacific Southwest Research Station, USDA Forest Service, Arcata, California Linda L. Long, Pacific Southwest Research Station, USDA Forest Service, Arcata, California

\section{Technical Working Group}

\section{USDA Forest Service}

James A. Baldwin, Pacific Southwest Research Station, Albany, California

Bruce Bingham, Pacific Southwest Research Station, Arcata, Califomia

Grant Gunderson, Pacific Northwest Region, Portland, Oregon

Chris Irerson, Alaska Region, Juneau, Alaska

Sarah Madsen, Siuslaw National Forest, Corvallis, Oregon

Kevin McKelvey, Pacific Southwest Research Station, Arcata, Califomia

Sherri L. Miller, Pacific Southwest Research Station, Arcata, California

Barry Noon, Pacific Southwest Research Station, Arcata, California

Linda Parker, Pacific Southwest Region, San Francisco, Califomia

Lynn Roberts, Six Rivers National Forest, Eureka, California

U.S. Department of the Interior, U.S. Fish and Wildlife Service

Blair Csuti, Portland Regional Office, Portland, Oregon

Michael Horton, Endangered Species Office, Sacramento, California

Katherine J. Kuletz, Migratory Bird Management, Anchorage, Alaska

John Lindell, Juneau Office, Juneau, Alaska

Gary Miller, Portland Regional Office, Portland, Oregon

Nancy L. Naslund, Anchorage, Alaska

Alison Willy, Sacramento Field Office, Sacramento, California

U.S. Department of the Interior, Bureau of Land Management

Mike Collopy, Cooperative Unit, Corvallis, Oregon

Barb Hill, Portland Regional Office, Portland, Oregon

Joe Lint, Roseburg, Oregon

Wayne Logan, Salem Office, Salem, Oregon 
Other Federal Agencies

Harry R. Carter, California Pacific Science Center, USDI National Biological Service, Dixon, California

Ken Lathrop, USDI Bureau of Indian Affairs, Portland, Oregon

Carolyn Meyer, Redwood National Park, USDI National Park Service, Orick, California

\section{State Agencies}

Marty Berbach, California Department of Forestry and Fire Protection, Sacramento, California

Esther E. Burkett, California Department of Fish and Game, Sacramento, California

Paula Burgess, Governor's Forest Planning Team, Salem, Oregon

Eric B. Cummins, Washington Department of Fish and Wildlife, Olympia, Washington

Paul Kelly, Oil Spill Assessment, California Department of Fish and Wildlife, Sacramento, California

Martin Nugent, Oregon Department of Fish and Wildlife, Portland, Oregon

Marilyn Sigman, Alaska Department of Fish and Game, Douglas, Alaska

Janet L. Stein, Washington Department of Fish and Wildlife, Mill Creek, Washington

Gary Strachan, Año Nuevo State Reserve, Pescadero, California

\section{Canadian Agencies}

Alan E. Burger, Canadian Wildlife Service; also Department of Biology, University of Victoria, Victoria, British Columbia Anne Harfenist, Canadian Wildlife Service, Delta, British Columbia

\section{Universities}

Dan Anderson, Department of Wildlife and Fisheries, University of California, Davis, California

Steven B. Beissinger, School of Forestry and Environmental Studies, Yale University, New Haven, Connecticut

Toni L. De Santo, Oregon Cooperative Wildlife Research Unit, Oregon State University, Corvallis, Oregon

George J. Divoky, Institute of Arctic Biology, University of Alaska, Fairbanks, Alaska

D. Michael Fry, Department of Avian Sciences, University of California, Davis, California

Jeffrey J. Grenier, Oregon Cooperative Wildlife Research Unit, Oregon State University, Corvallis, Oregon

S. Kim Nelson, Oregon Cooperative Wildlife Research Unit, Oregon State University, Corvallis, Oregon

Peter W.C. Paton, Utah Cooperative Fish and Wildlife Research Unit, Utah State University, Logan, Utah

David A. Perry, Forest Sciences Department, Oregon State University, Corvallis, Oregon

Margaret M. Shaughnessy, Oregon Cooperative Wildlife Research Unit, Oregon State University, Corvallis, Oregon

\section{Timber Industry Representatives}

Sal Chinnici, Pacific Lumber Company, Scotia, California

Lowell Diller, Simpson Timber Company, Arcata, California

Lee Folliard, Arcata Redwood Company, Orick, California

Ross Mickey, Northwest Forest Resource Council - Wildlife Committee, Eugene, Oregon

\section{Environmental Research Groups}

David G. Ainley, Point Reyes Bird Observatory, Stinson Beach, California

Rick Burns, Surrey, British Columbia, Canada

Steve Courtney, Eugene, Oregon; supported by the National Council of the Paper Industry for Air and Stream Improvement

Thomas E. Hamer, Hamer Environmental, Mt. Vernon, Washington

Michael L.C. McAllister, Wildland Resources Enterprises, La Grande, Oregon

Steven W. Singer, Environmental and Ecological Services, Santa Cruz, California

Steven M. Speich, Dames and Moore, Tucson, Arizona; supported by California Forestry Association, the National Council of the Paper Industry for Air and Stream Improvement, and Pacific Lumber Company

Craig S. Strong, Crescent Coastal Research, Crescent City, Oregon

David Suddjian, Habitat Restoration Group, Scotts Valley, California

Daniel H.Varoujean II, Marine and Estuarine Research Company, North Bend, Oregon

Terrence R. Wahl, Bellingham, Washington

Gus van Vliet, Auke Bay, Alaska 


\section{Appendix B-Author Index}

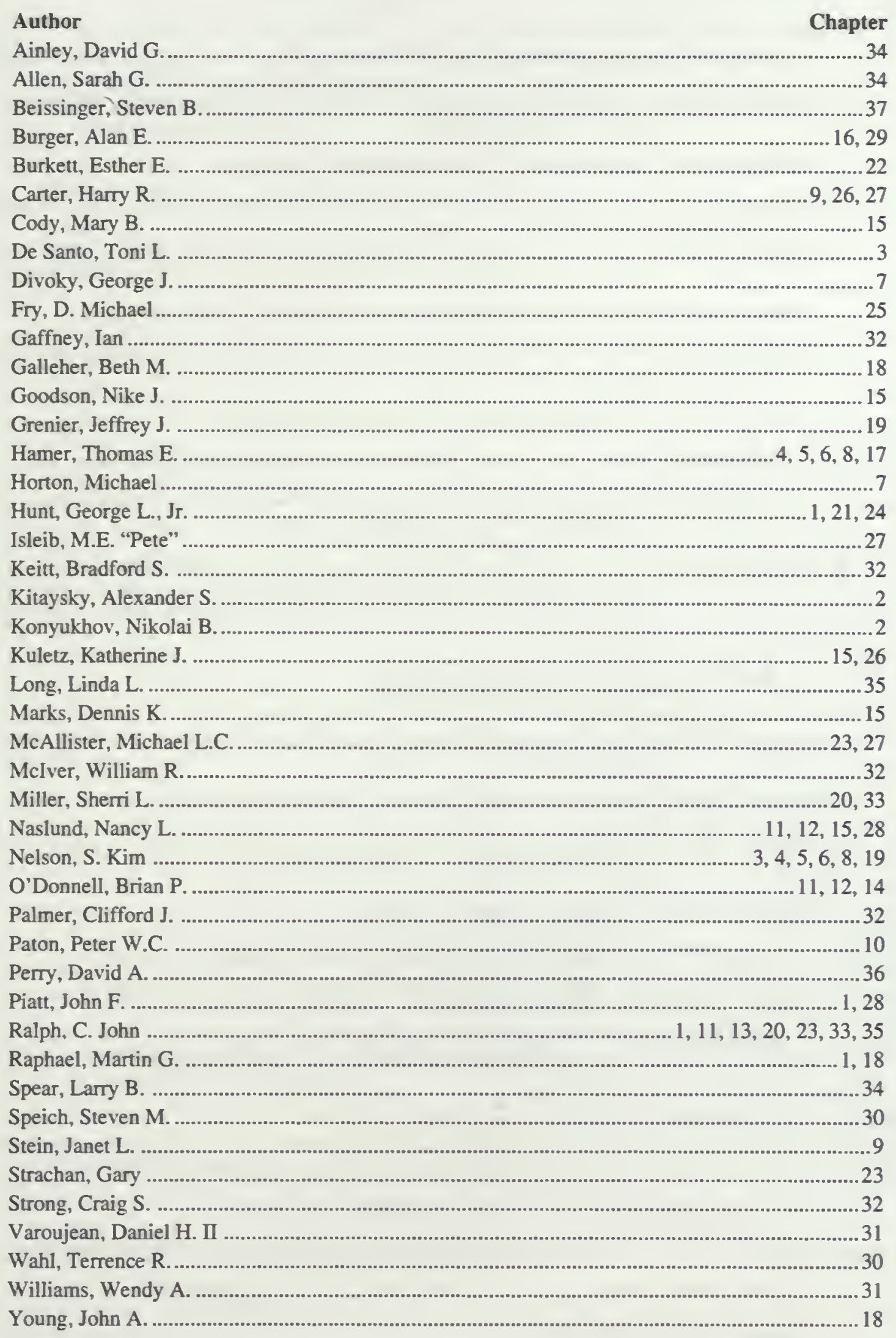




\section{Appendix C-Chronology of Events in Marbled Murrelet Conservation Assessment}

August 1992

September 1992

October 1992

November 1992

December 1992

January 1993

February 1993

March 1993

April 1993

May 1993

May-August 1993

June 1993

July-November 1993

December 1993

January 1994

February 1994

March 1994

March-April 1994

April 1994

May 1994

June 1994

August-September 1994

October 1994

February 1995
- Appointment of Team Leader and working outline of Conservation Assessment prepared.

- Species is listed as 'Threatened' by the U.S. Fish and Wildlife Service for Washington, Oregon, and California.

- Recruitment of Technical Working Group

- Naming of Core Team to compile a draft report and prepare a final report.

- Funding for Conservation Assessment approved by USDA Forest Service

- Workshop of Technical Working Group held in Arcata, California.

- Establishment of Conservation Assessment Center in Arcata.

- Meeting of Technical Working Group during Pacific Seabird Group Meeting in Seattle, Washington.

- Meeting of Technical Working Group in Arcata

- Core team meets in Arcata to determine any general analyses.

- All data pertinent to the Assessment was collated in Arcata where a group of technicians assembled and dispersed data to authors.

- This period was used to direct existing, previously-funded programs in augmenting their data sets, in analysis of existing data, and compilation of incoming data at Arcata. The second working session considered reviews of the first draft and, as appropriate, suggested revisions and reanalysis.

- Charter drafted and approved.

- Chapters assigned to authors.

- Chapters undergo extensive internal and peer review by core team and reviewers selected by authors.

- Draft of complete Assessment sent out for outside review

- Meeting of Technical Working Group to discuss chapters and possible additions at Pacific Seabird Meeting in Sacramento, California.

- Revisions received from authors

- Review by outside, scientific societies begun.

- Continued review from peers of each chapter, and revisions received from authors.

- Reviews from scientific societies received.

- The comments from outside reviewers, selected by the Core Team, received and distributed to authors.

- Final drafts received from authors.

- Core Team meets and reviews all manuscripts and drafts overview chapter.

- Core Team's comments to authors for preparation of final, electronic document.

- Manuscripts submitted to Station editors.

- Final typescripts from Station editors to authors for approval of editorial changes.

- Final typescripts to Station for layout and production.

- Publication. 


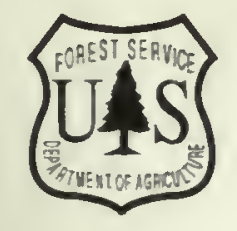

The Forest Service, U.S. Department of Agriculture, is responsible for Federal leadership in forestry. It carries out this role through four main activities:

- Protection and management of resources on 191 million acres of National Forest System lands

- Cooperation with State and local governments, forest industries, and private landowners to help protect and manage non-Federal forest and associated range and watershed lands

- Participation with other agencies in human resource and community assistance programs to improve living conditions in rural areas

- Research on all aspects of forestry, rangeland management, and forest resources utilization.

\section{The Pacific Southwest Research Station}

- -Represents the research branch of the Forest Service in California, Hawaii, American Samoa and the western Pacific.

The policy of the United States Department of Agriculture Forest Service prohibits discrimination on the basis of race, color, national origin, age, religion, sex, or disability, familial status, or political affiliation. Persons believing they have been discriminated against in any Forest Service related activity should write to: Chief, Forest Service, USDA, P.O. Box 96090, Washington, DC 20090-6090. 
